DER TOTENKULT DER NGADJU DAJAK

IN SÜD-BORNEO 
Hans Schärer - 978-90-04-28681-8 Downloaded from Brill.come4/26/2023 11:12:05AM via free access 


\title{
VERHANDELINGEI
}

VAN HET KONINKLIJK INSTITUUT VOOR TAAL-, LAND- EN VOLKENKUNDE

\author{
DEEL 51,1
}

HANS SCH ̈̈RER

\section{DER TOTENKULT DER NGADJU DAJAK IN SÜD-BORNEO}

MYTHEN ZUM TOTENKULT

UND DIE TEXTE ZUM TANTOLAK MATEI

ERSTER TEIL MYTHEN ZUM TOTENKULT

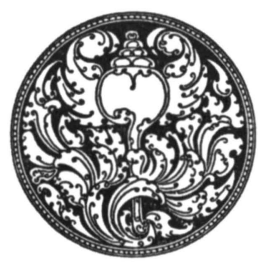

'S.GRAVENHAGE-MARTINUS N IJ H OFF-1966 
Hans Schärer - 978-90-04-28681-8 Downloaded from Brill.come4/26/2023 11:12:05AM via free access 


\section{VORWORT}

Das jetzt veröffentlichte Buch über den Totenkult der Ngadju Dajak ist der erste von einem in vier Bänden geplanten Werk, worin der Autor das vollständige von ihm in Borneo gesammelte Material herausgeben wollte. Dieser erste Band, umfänglich wie er ist, enthält nur noch das allgemein mythische Material und die Texte, die zu kleineren Zeremonien gehören, die dem eigentlichen Totenfest, dem die darauf folgenden Bände gewidmet wären, vorangehen. In der hiernach folgenden Einleitung gibt der Autor eine kurze übersichtliche Darstellung vom Inhalt des 2., 3. und 4. Bandes, wie er sich diese gedacht hatte. Augenscheinlich hatte er die Absicht, danach in einem 5. Band eine zusammenfassende Darstellung des Totenkults erscheinen zu lassen: an einigen Stellen verweist er schon auf dieses Buch, das aber nie geschrieben wurde. Statt dessen schrieb er seine „Gottesidee der Ngadju Dajak", womit er 1940 an der philosophischen Fakultät der Universität Leiden promovierte, und worin er auch mehrere Male etwas aus dem Manuskript seines jetzt veröffentlichten ersten Bandes des „Totenkult” übernahm (vgl. hierunten die Mythe von Silai (Seite 124-138) und Seite 435). Auch die Ausarbeitung des Materials für den 2. bis 4. Band wurde vermutlich nicht zur Ausführung gebracht, wie sich aus dem Lebenslauf des Autors herausstellen wird.

Hans Schärer wurde 1904 in Wädenswil, bei Zürich in der Schweiz, geboren. Er ging als Missionär nach Borneo, wo er von 1932-1939 unter den Ngadju Dajaks von Süd-Borneo lebte und arbeitete, anfangs in der Gegend längs des Katingan Flusses, danach, während einer kürzeren zeit längs des Barito. Im Jahre 1939, als er auf Urlaub nach Europa gekommen war, studierte er bis 1944 Ethnologie an der Universität Leiden unter Prof. Dr. J. P. B. de Josselin de Jong. Seine obengenannte Dissertation war die Frucht dieses Studiums. Kurz nach seiner Promotion ging er wieder nach Borneo. Doch am 10. Dezember 1947 starb er dort plötzlich an Blutvergiftung. 
Das Manuskript des ersten Bandes des „Totenkult”, das von Schärer vermutlich in den ersten Jahren nach seiner Rückkehr nach Europa im Jahre 1939 verfasst worden ist, und das sich jetzt in der Universitätsbibliothek in Leiden befindet, war zwar völlig ausgearbeitet, aber andererseits nie endgültig druckfertig gemacht. Kleine Tipp- und Schreibfehler, kleine Inkongruenzen wären unzweifelhaft vom Autor korrigiert, wenn er selbst die letzte Hand an sein Werk hätte legen können. Jetzt ist das Manuskript, ehe es zur Presse ging, mit Berücksichtigung der einem Nachgelassenen Werk angemessenen Sorgfalt, gewissenhaft betrachtet und wo notwendig und möglich korrigiert worden. In den verschiedenen Stufen dieser Arbeit haben sich hierum die Damen: Frau C. J. L. Verbraeck-Stibbe, Fräulein C. Slotemaker de Bruine und Frau W.E.Haver Droeze-Hulswit verdient gemacht, zunächst unter Aufsicht Dr. P. Voorhoeves und später Dr. J. Noorduyns. Dabei hat sich herausgestellt, dass in bestimmten Fällen nur die unvergleichlichen Kenntnisse von Schärer selbst, vor allem hinsichtlich der dajakischen Priestersprache, die Lösung einiger Inkongruenzen hätten geben können. Um jede willkürliche Entscheidung zu vermeiden, haben die Herausgeber in diesen Fällen das Prinzip des in dubiis abstine vertreten.

Wie sich aus dem Manuskript-Inhaltsverzeichnis und aus einigen Verweisungen im Texte des Buches selbst herausstellt, hatte Schärer den Plan, diesem ersten Band ein ausführliches Register und überdies zwei Beilagen, die vermutlich Stammbäume enthielten, beizufügen. Diese fehlen jetzt. Durch die Beifügung eines kurzen Verzeichnisses der dajakischen Wörter, die in die Erklärungen aufgenommen sind, ist der Versuch gemacht, den Mangel an einem eigentlichen Register einigermassen $z \mathfrak{u}$ ersetzen.

Es ist erfreulich, dass kurz nach der aufs neue erschienenen Ausgabe von Schärers Dissertation in Englischer Ubersetzung (Ngaju Religion: The Conception of God among a South Borneo People, The Hague 1963) jetzt dieses nachgelassene Werk Schärers veröffentlicht werden kann, das noch eimal seine Kenntnisse, Einsichten und seine grosse Energie wie auch den Reichtum und die literarischen Leistungen der dajakischen Kultur bekundet.

Die Bedeutung dieser Ausgabe für die enthnologischen und linguistischen Kenntnisse von den Ngadju kann wahrscheinlich am besten danach beurteilt werden, wenn wir sie im Zusammenhang mit früheren Veröffentlichungen auf diesem Gebiet sehen. 
Das einzige andere grosse Werk von Schärer selbst, das in Druck erschienen ist, ist Die Gottesidee der Ngadju Dajak in Süd-Borneo (E. J. Brill, Leiden 1946), ins Englische übersetzt mit dem Titel Ngaju Religion (Koninklijk Instituut voor Taal-, Land- en Volkenkunde, Translation Series no. 6; Martinus Nijhoff, The Hague 1963). Die Qualitäten dieses Werkes werden allgemein anerkannt: Tom Harrisson z. B. schreibt: „In 1906 there were not more than two accounts of Borneo death rituals ...; in 1961 there are still less than six available; of these only Schärer on the Ngadju... has tried to give a real insight into the native meaning of the whole". Zugleich aber haben öfters zuständige Anthropologen eine Kritik geäussert, die Waldemar Stöhr folgendermassen in Worte fasst: „Seine Darstellungsweise hat aber zur Folge, dass man zwischen direkter Beobachtung, Aussage und Erklärung des Eingeborenen einerseits und einer eigenen Deutung andererseits nicht mehr klar unterscheiden kann. Es ergibt sich die Frage, ob die Arbeiten Schärers dieser Anforderung an eine Quelle von Wissenschaftlichem Wert, die sein Vorbild Malinozeski einmal formulierte, noch entsprechen. Sie kann erst noch beantwortet werden, wenn das ganze ethnographische Material von Schärer vorliegt".

Wenn mit dieser Veröffentlichung auch das ,ganze ethnographische Material" Schärers noch nicht zur Verfügung steht (schon die Lektüre von Seite VII des „Preface” in Ngaju Religion genügt, um zu sehen, wieviel von diesem Material in den verschiedenen Stufen der Bearbeitung noch immer nicht veröffentlicht wurde), aber gewiss ist jetzt eine grössere Anzahl von „Beilagen” zugänglich gemacht, die den Ethnologen instand setzen, Schärers grossartige synthetische Darstellung des religiösen Systems der Nadju-Dajak an Hand von Originaltexten zu prüfen.

Nur wenige in Südost-Asien tätige Ethnologen haben so folgerichtig wie Schärer, nach dem Vorbild Boas' und seines eigenen Lehrmeisters, J. P. B. de Josselin de Jong, ihre ethnologische Forschung via das Medium der einheimischen (oralen) Literatur verrichtet. Eine Folge ist, dass sein Werk auch linguistischen Wert hat. Dies um so mehr als zwar „Ngaju has become widely spread, developing into a kind of lingua franca for nearly the whole of South Borneo", aber andererseits „Up to the present not many Ngaju texts have been published" (A. A. Cense \& E. M. Uhlenbeck, Critical Survey of Studies on the languages of Borneo). Hardeland und Mallinckrodt verdanken wir die wichtigsten religiösen Texte, aber die „Einleitung” zu dem Werk, das jetzt herausgegeben wird, macht es deutlich, wie hoch wir, auch in dieser Hinsicht, 
zowohl in bezug auf die Qualität, wie die Quantität des gesammelten Materials bei Schärer selbst in der Kreide stehen.

Es ist uns eine angenehme Pflicht hier Prof. Dr. C. Hooykaas, London, und der Niederländischen Organisation für Reinwissenschaftlichte Forschung, Haag, den Dank für ihre finanzielle Unterstützung auszusprechen, welche diese Ausgabe ermöglicht hat.

Leiden.

HET KONINKLIJK INSTITUUT

VOOR TAAL-, LAND- EN VOLKENKUNDE. 


\section{N H A L T}

VORWORT

EINLEITUNG

\section{Erster Teil \\ MYTHEN ZUM TOTENKULT}

I. HANDWERK (HEILBRINGER-MYTHEN) . . . . . . 30
A. Der Ursprung der Nutzpflanzen . . . . . . . . . . . 30
B. Der Ursprung des Eisenholzes . . . . . . . . . . . . . 32
C. Wie die Menschen die Handarbeiten lernten . . . . . . . . 35
D. Der Ursprung des Eisens . . . . . . . . . . . . . . . . 40
E. Der Ursprung der Edelsteine und des Goldes . . . . . . . . 42

II. REISBAU-MYTHEN . . . . . . . . . . . . . . . 45
A. Der Ursprung des Reises
B. Wie der Reis befruchtet wird
C. Panjat besucht Djangkarang Matanandau . . . . . . . . . 48

III. DER URSPRUNG DER STÄNDE . . . . . . . . . . 53
A. Der Ursprung der Freien
B. Der Ursprung der Sklaven
C. Die Geschichte des Antang Taui

IV. DIE RELIGION . . . . . . . . . . . . . . . . . 62

A. Die Welt- und Menschwerdung . . . . . . . . . . . 62

a. Der Ursprung der Sangiang nach der katinganischen Version 62

b. Der Ursprung der Sangiang nach Hardeland . . . . . . 64

c. Der Ursprung der Sangiang nach Schwaner . . . . . . 66

d. Der Ursprung der Sangiang nach C. Hupe . . . . . . 71

e. Der Ursprung von Himmel und Erde nach Sundermann . . 73

f. Der Ursprung der Sangiang nach Mallinckrodt . . . . . 74

g. Djata und ihr Anteil an der Weltwerdung, nach Hardeland 79

h. Weltwerdung und Ursprung der Sangiang nach Bapa Haastert . . . . . . . . . . . . . . . . 
B. Der Ursprung der Bewohner fremder Welten . . . . . . . 106

a. Der Ursprung der Olon Tamuan . . . . . . . . . 107

b. Der Ursprung der Olon Sembuluh . . . . . . . . . 108

C. Die Mächte . . . . . . . . . . . . . . . . . . 109

a. Die Entstehung der Hantuen (Hexen) . . . . . . . . 109

Der Ursprung der Hantuen im Oberland . . . . . . 109

Der Ursprung der Hantuen am unteren Katingan . . . 114

Radja Haramaung Batolang Buno, Balikur Talawang . . . 123

b. Die Ursache der Sonnen- und Mondfinsternis . . . . . 124

c. Der Verkehr mit der übersinnlichen Welt . . . . . . . 139

Wie die Vorzeichen entstanden: Die Mythe von Umang und dem Hirsch . . . . . . . . . . . . . . . . . 139

Tunggol Samali . . . . . . . . . . . . . . . . 140

Der Ursprung des Antang nach Missionar Becker . . . 142

Der Ursprung des Antang nach Missionar Hupe . . . 144

D. Mythen zum Totenkult der Ngadju-Dajak . . . . . . . . 144

1. Weshalb der Mensch sterblich ist . . . . . . . . . . 144

a. Die Geschichte von Ranjing Pahatara (Die Mythe stammt vom Katingan) . . . . . . . . . . . . 144

b. Weshalb das Lebenswasser verloren ging . . . . . . 146

2. Die Abwendung des vorausgewussten Todes (Mythen zum stellvertretenden Opfer) . . . . . . . . . . . . . 149

a. Mangapatong Liau oder Taloh . . . . . . . . . 149

Die Geschichte von Patih Teteh und Akah Ihang Iho . . 151

Die Geschichte des Panetang Nupi . . . . . . . . 158

Die Handlungen nach der Rezitation der Mythe . . . 166

b. Das Mantumbal . . . . . . . . . . . . . 167

Mantumbal Lunok . . . . . . . . . . . . . 167

Die Mythe von Karawambang Rawajan Kupang . . . 172

Die Mythe des Anak Luting . . . . . . . . . . 179

Mantumbal Kalue . . . . . . . . . . . . . 182

Mantumbal Patis . . . . . . . . . . . . . . 183

c. Manolak Peres (Verabschiedung des Krankheitsgeistes) 183

Die Mythe vom Ursprung des Peres . . . . . . . 184

d. Manolak Puru (Verabschiedung der Pocken) . . . . 190

Pulang Gana und Putir Seri Bunge . . . . . . . 190

e. Das stellvertretende Opfer bei der Schwangerschaft . 197

Das stellvertretende Opfer in Penda-Hara . . . . . 197

Das stellvertretende Opfer in Tumbang-Lahang . . . 198

Benang Kanjangan Tewang und Tipung Kandajun

Tandjong . . . . . . . . . . . . . . . . 199

Das aussergewöhnliche Opfer für die Schwangere . . 205

Die Mythe von Budjang Badara . . . . . . . . . 206

3. Basaloh-Mythen . . . . . . . . . . . . . . 210

a. Basaloh durch Sarok . . . . . . . . . . 210 
Der Ursprung des Kalanaman . . . . . . . . . 212

Der Ursprung des Nasenaffen . . . . . . . . . 213

b. Basaloh durch Tulah . . . . . . . . . . . . . 215

Wie der Samanja entstand . . . . . . . . . . . 216

4. Gaip-Mythen . . . . . . . . . . . . . . . . 218

Das Geisterdorf bei Tumbang Danum . . . . . . . 220

Wie das Geisterdorf von Pang Gajau entstand . . . . 221

5. Die Erscheinung von Toten (liau) . . . . . . . . . . 222

Wie eine Liau ihrer Mutter erscheint . . . . . . . 223

6. Liau aus dem Sandong besuchen ihre Angehörigen . . . 226

Die Erzählung von Kanjok . . . . . . . . . . 226

7. Warum die Leichen bewacht werden . . . . . . . . 228

8. Die Feier des ersten Tiwah in Batu Nindan Tarong . . . 230

E. Anhang: Aus der Mythologie eines Dajakdorfes . . . . . . 233

1. Der Ursprung der Bevölkerung . . . . . . . . . . 234

2. Die Mythe von der Naga Andoh . . . . . . . . . . 234

3. Der Tod der Naga Andoh . . . . . . . . . . . . 237

4. $\mathrm{Pa}$ Tanggoi und seine Brüder werden verwandelt (basaloh) 239

5. Der Ursprung der Insel Torah . . . . . . . . . . . 245

Das Batapa . . . . . . . . . . . . . . . . . 246

a. Batapa mandoi (das Batapa durch Baden) . . . . . 247

b. Batapa danum (Batapa im Wasser) . . . . . . . 247

c. Batapa hong pulau (Batapa auf einer Insel) . . . . 247

d. Batapa hong tadjahan . . . . . . . . . . . . 248

e. Batapa hong pataho . . . . . . . . . . . . . 249

f. Batapa intu lunok (Das Batapa beim Lunok) . . . . 249

g. Batapa intu panganen (Batapa durch die Python) . . 249

h. Batohon . . . . . . . . . . . . . . . . 249

6. Karik und der heilige Speer . . . . . . . . . . . 250

7. Der Speer des Maharadja . . . . . . . . . . . 255

\section{Zweiter Teil}

\section{HANDLUNGEN UND TEXTE ZUM TOTENKULT}

\section{HANDLUNGEN UND TEXTE BEIM PLÖTZLICHEN TOD 261}

\section{A. Der Tod durch Verbrennung . . . . . . . . . . . . 262}

1. Mampakanan gana,n apui (Das Opfer an das Feuer nachdem ein Haus verbrannt ist ohne dass dabei Menschen das Leben verloren haben) . . . . . . . . . . . . 262

a. Die Ankunft der Reisseelen bei Darahen Radja,n Antang 264

b. Der Ursprung des Feuers . . . . . . . . . . . 271

c. Die Bitte um neues Feuer . . . . . . . . . . . 302

d. Schluss . . . . . . . . . . . . . . 305 
2. Manolak Sial Apui (Die Verabschiedung des Feuer-Sial) . 308

a. Vorbereitungen . . . . . . . . . . . . . . 308

b. Das Lied der Priesterinnen reist in die Oberwelt um den Njarang Tingang Hatuen Apui herabzuholen . . . . 311

c. Der Prozess zwischen den Besitzern des verbrannten Hauses und Njarang Tingang Hatuen Apui . . . . . 314

d. Schluss . . . . . . . . . . . . . . . . . 329

3. Handlungen beim Tod durch Verbrennung . . . . . . 330

a. Dohong Mama Tandang holt den Toten zurück . . . 333

b. Dohong Mama Tandang rächt den Toten . . . . . 338

B. Der Tod durch Ertrinken (matei buseng) . . . . . . . . 340

a. Das Aufsuchen der Leiche . . . . . . . . . . . 340

b. Manganjau danum (Die Kopfjagd nach dem Geist des Wassers) . . . . . . . . . . . . . . . . 343

C. Der Tod durch einen fallenden Baum (Matei penjet kaju) . . 349

a. Der Tote wird zurückgeholt und sein Tod wird gerächt 349

b. Die Kopfjagd nach dem Pantoh Ganan Kaju Hai . . . 381

D. Die Palivorschriften bei Tod, Bestattung und Tiwah . . . . 383

a. Pali,n hantu (Leichenpali) . . . . . . . . . . 385

b. Pali,n raung (Die Sargpali) . . . . . . . . . . 387

c. Pali,n hinau (Die Pali des Hinau) . . . . . . . . 394

d. Pali,n tolang (Die Pali betreffend der Knochen) . . . 397

e. Pali,n sandong (Die Pali des Knochenhäuschens) . . . 400

f. Pali,n Tiwah (Die Pali beim Tiwah) . . . . . . . 401

g. Pali limbah Tiwah (Die Pali nach dem Tiwah) . . . 402

h. Pali,n balo atawa buju (Die Pali der Witwe oder des Witwers) . . . . . . . . . . . . . . . 404

i. Pali,n Rutas (Die Rutaspali) . . . . . . . . . . 409

II. DAS TANTOLAK MATEI (Das Wegschieben des Toten) . . 414

1. Einleitung . . . . . . . . . . . . . . . . . . . 414

a. Die Behandlung des Tantolak Matei in der Literatur . . 414

b. Die Bedeutung des Tantolak Matei . . . . . . . . 416

c. Die Oberwelt . . . . . . . . . . . . . . . . 417

d. Die Balian und Basir . . . . . . . . . . . . 435

2. Vorbereitungen für das Tantolak matei . . . . . . . . 443

A. Vor dem Haus . . . . . . . . . . . . . . . 443

B. Im Hause . . . . . . . . . . . . . . . . . 445

3. Räucherung und Oelung des Streureises die Besingung seines Ursprunges und die Aufweckung der Reisseelen . . . . . . 450 
A. Räucherung, Oelung und rituelle Bestreichung des Streureises . . . . . . . . . . . . . . . . . . . 451

B. Die Besingung des Ursprunges des Streureises . . . . . 452

C. Die Aufweckung der Reisseele . . . . . . . . . . 481

4. Die Reise der Reisseelen nach der Oberwelt . . . . . . . . 482

A. Die Hervorrufung der Reisseelen und der Auftrag des Priesters . . . . . . . . . . . . . . . . . 483

B. Die Verwandlung des Streureises in Dolchregen . . . . 490

C. Der Streureis erhält ein Boot für seine Reise . . . . . 491

D. Die Vertreibung der Liau vom Wege, den die Frauen des Streureises zurückzulegen haben . . . . . . . . . 493

E. Die Reise der Reisseelen nach der Oberwelt . . . . . . 504

F. Das Dorf Danum Djalajan wird durch die Reisseelen in Finsternis gehüllt . . . . . . . . . . . . .

G. Die Beregnung des Balai und die Beratung zwischen dem Streureis und den Sangiang im Balai . . . . . . . . 529

H. Dohong Mama Tandang ruft den Winden die die Segel blähen sollen . . . . . . . . . . . . . . . .

5. Das Schildbrett reist nach dem Dorfe am Ufer des Flusses der Welt

6. Die Sangiang holen die Seelen der Getragenen zurück . . . 558

A. Vorbereitungen im Schildbrett . . . . . . . . . . 558

B. Die Sangiang ziehen aus um die Seelen der Getragenen zurückzuholen . . . . . . . . . . . . . . . . 563

7. Die Vertreibung der Ambon Barutas Matei . . . . . . . 578

A. Die Vorbereitungen für die Führung des Toten und die Vertreibung der Ambon Barutas Matei . . . . . . . 580

B. Die Aufweckung der Sangiang . . . . . . . . . . 584

C. Die Sangiang kommen im Hause an . . . . . . . . 594

D. Die Sangiang fahren in die Balian ein . . . . . . . 597

E. Die Sangiang werden bewirtet . . . . . . . . . . 612

F. Die rituelle Reinigung der Gebrauchsgegenstände für die Handlungen . . . . . . . . . . . . . . . . 615

G. Die Reinigung der Verwandten des Toten . . . . . . 619

a. Die Reinigung der Männer mit Hühnerblut . . . . 619

b. Das Beissen auf das Eisen . . . . . . . . . . 627

c. Die Reinigung der Frauen mit Hühnerblut . . . . . 627

d. Das Schwingen des Besens über den Köpfen der Verwandten . . . . . . . . . . . . . 628

e. Die Balian bringen die Bambusse zum Knallen . . . 632

f. Die Balian berühren mit dem Schnitzbild die Köpfe der Verwandten . . . . . . . . . . . . 634

H. Die Ventreibung der Ambon Barutas Matei aus dem Haus . 635

a. Die Durchschneidung der Ambon Barutas Matei . . . 635 
b. Die Wegjagung der Ambon Barutas Matei aus dem Haus . . . . . . . . . . . . . . . . . 638

I. Die Sangiang vertreiben die Ambon Barutas Matei . . . 640

a. Die Autweckung der Sangiang und ihre Tätigkeit . . 640

$\mathrm{K}$. Die Beladung der Lanting Buno mit den Ambon Barutas Matei

a. Die Balian durchschneiden mit den Sangiang die Ambon Barutas Matei im Haus und im Dorf . . . . . . . 647

b. Die Sangiang bauen das Lanzenfloss . . . . . . . 659

c. Das Lanzenfloss wird mit den Ambon Barutas Matei beladen . . . . . . . . . . . . . . . 661

d. Das Lanzenfloss wird nach der Oberwelt gebracht . 665

e. Das Lanzenfloss ist am Ziele angekommen . . . . 669

f. Das Schildbrett kehrt nach der Welt zurück . . . . 671

g. Die Seelen werden mit den Körpern vereinigt . . . . 673

h. Die Bestreichung mit Erde und die Begiessung mit Wasser . . . . . . . . . . . . . 676

i. Die Festmachung der Seelen . . . . . . . . . . 677

k. Die Umbindung von Tambaranschnüren um die Handgelenke . . . . . . . . . . . . . . . . 677

8. Die Leitung der Liau nach dem Ort der Balo Indu Rangkang Penjang

A. Der dualistische Aspekt des Lebenden und Toten .

B. Die Vorbereitungen für die Leitung der Liau Balawang Pandjang

C. Die rituelle Bestreichung der Gebrauchsgegenstände . . .

D. Die Sangiang werden herbeigerufen um das Schildbrett zu beladen

E. Das Schildbrett wird beladen

F. Das Schildbrett vor seiner Abfahrt zum Bukit Pasahan Raung

G. Die Abreise des Schildbrettes . . . . . . . . . . . 695

H. Die Aufweckung der Liau . . . . . . . . . . . . 700

I. Das Schildbrett reist mit der Liau nach dem Bukit Kanjaloh Lanting

K. Die Liau nimmt weinend Abschied von der Welt und sie ermahnt die zurückgebliebenen Angehörigen . . . . . 731

L. Das Schildbrett setzt die Reise fort . . . . . . . . . 752

M. Die Ankunft der Liau im Dorfe Bukit Kanjaloh Lanting . 756

N. Das Schildbrett reist vom Dorfe Bukit Kanjaloh Lanting weg und fährt zum Sangiang Saloh Simpei .

O. Das Schildbrett setzt seine Reise fort und kommt wieder in der Welt an . . . . . . . . . . . . . . . 774

P. Die Befestigung der Seelen der Getragenen . . . . . . 777

Q. Die Sangiang verlassen nach beendeter Arbeit die Körper der Balian . . . . . . . . . . . . . . 
9. Abschliessende Handlungen

A. Die Aufweckung der Sangiang am Morgen des angebrochenen Tages . . . . . . . . . . . . . . . 788

B. Die Sangiang fahren in die Balian ein . . . . . . . . 795

C. Die Kenterung der Boote . . . . . . . . . . . . 797

a. Die Vorbereitungen . . . . . . . . . . . . . . . . . . 797

b. Das Schildbrett fährt zum Fluss . . . . . . . . 799

c. Die Handlungen der Sangiang beim Fluss . . . . . 801

d. Ranjing Mahatala Langit und Djata schenken neues Wasser . . . . . . . . . . . . . . . . . 803

e. Das Knallen mit den Bambusstöcken und die $\mathrm{Ab}$ wischung mit dem Besen . . . . . . . . . . . 805

f. Die Kenterung der Boote in der Richtung nach Sonnenuntergang . . . . . . . . . . . . . . . . 807

g. Die Kenterung der Boote in der Richtung nach Sonnenaufgang . . . . . . . . . . . . . . . . 808

D. Die Rückkehr der Seelen der Getragenen . . . . . . 810

E. Auf die Brust wird mit Mehl ein Kreuz gezeichnet . . . 815

F. Ausgiessung von Oel über den Köpfen und Kämmung . . 815

G. Ueber einem Huhn wird Oel ausgegossen und darnach wird es gekämmt .

H. Das Streuen von Reis auf die Köpfe und das Aufpicken des Reises durch das gekämmte Huhn . . . . . . . . . 819

I. Die Reinigung der Verwandten mit dem gekämmten Huhn a. In der Richtung nach Sonnenuntergang . . . .

b. In der Richtung nach flussabwärts . . . . . . .

c. In der Richtung nach flussaufwärts . . . . . . .

d. In der Richtung nach Sonnenaufgang . . . . . .

e. Das Huhn wird in der Richtung der aufgehenden Sonne weggeworfen

K. Die Seelen werden ihren Besitzern wieder zurückgegeben

a. Die Verwandten des Toten begeben sich ins Haus. . .

b. Der Seelenreis wird mit Oel bestrichen und die Seelen werden in den Körper zunückgebracht . . . . . .

c. Die Berührung der Köpfe mit dem Schnitzbild . . .

d. Die Handgelenke werden mit Bändern von Glasperlen umbunden

L. Die Sangiang kehren wieder in ihr Dorf zurück und empfangen für ihre Hülfe den Lohn .

a. Die Vorbereitungen und die Ueberreichung des Lohnes

b. Die Sangiang kehren in ihr Dorf zurück.

M. Die Balian empfangen ihren Lchn und kehren nach Hause zurück 
Hans Schärer - 978-90-04-28681-8 Downloaded from Brill.come4/26/2023 11:12:05AM via free access 


\section{EINLEITUNG}

Als mir die Leitung der Basler Mission, zu Anfang des Jahres 1939 die Erlaubnis gab den Totenkult der Ngadju Dajak von Süd-Borneo $\mathbf{z u}$ untersuchen standen wir vor unserem ersten Europaurlaub. Wir hatten bereits eine Arbeitsperiode von mehr als sechs Jahren hinter uns, die wir am Katingan (ein Fluss in der Onderafdeeling Sampit der Z.O. Afdeeling van Borneo), im Dienste der Classicalen Zendingscommissie Amsterdam und der Basler Mission verbracht hatten. Auf unseren vielen Reisen und durch den freundschaftlichen Verkehr mit der ganzen Bevölkerung, vor allem aber während unseres Aufenthaltes in dem angesehenen Heidendorf Tumbang-Lahang (1937-1939), hatten wir die Gelegenheit gehabt die geistige und materielle Kultur der Katinganer etwas näher kennen zu lernen.

Kommt man als junger Missionar, und in ethnologischen Fragen als Laie auf das Missionsfeld dann lebt man noch in der Vorstellung, dass jeder Dajak ein Kenner seines Volkes und seiner Kultur sei und dass man nur zu fragen brauche und dann von selbst die richtigen Antworten erhalte. Das ist nicht so. Wir dachten auch an unseren Lehrern und Mitarbeitern eine sehr gute Hilfe zu haben. Abgesehen von ganz wenigen Ausnahmen wussten sie erschreckend wenig von ihrer eigenen Kultur. Das hing z.T. damit zusammen, dass sie sie als eine überwundene Stufe betrachteten und sich deshalb auch nicht die Mühe nahmen von ihr etwas kennen zu lernen. Wie irrig diese Auffassung ist zeigt uns die ganze Entwicklung in andern Gebieten wo die Berührung mit der westlichen Kultur und ihren Einflüssen schon seit Generationen datiert.

Mit der Zeit sahen wir, dass kein einziger Dajak mehr das ganze kulturelle Leben beherrscht und ich zweifle ob dies überhaupt je der Fall gewesen sei. Wie überall, so gibt es auch bei ihnen Spezialisten die alle ein besonderes Gebiet des kulturellen Lebens und Denkens beherrschen. Unter diesen Spezialisten finden wir Männer und Frauen analog der kulturellen und materiellen Aufgabenverteilung der beiden Sexen. So beherrscht z.B. auch nicht mehr jeder Priester das ganze religiöse Denken. Es ist zu umfangreich. Wir müssen aber wissen 
welches Gebiet er aber dann wirklich beherrscht. Die Literatur wird von den Männern und Frauen von Generation auf Generation mündlich überliefert. Auch sie ist äusserst umfangreich. Die Stammesmythologie der Katinganer, die in einigen wenigen angesehenen Familien von den Frauen auch heute noch gepflegt wird, und die ja nur ein kleiner Ausschnitt aus der Gesamtliteratur bildet, füllt ungefähr 12000-15000 Druckseiten! Wir müssen genau wissen wer die einzelnen Literaturgattungen oder die wichtigen Mythen kennt. Oft war es nötig tageweit zu reisen um den Kenner einer Mythe, die wir nötig hatten, ausfindig machen zu können. Das gleiche gilt auch für das Recht und die verschiedenen Rechtsgebiete und dann natürlich auch für alle andern Gebiete der geistigen und materiellen Kultur.

Die gleiche umfangreiche geistige Kultur finden wir bei allen andern Stämmen und wenn man einmal das weiss, dann fragt man sich bei dem einen Stamme, mit dem man sich beschäftigt: wie soll man hier überhaupt durchkommen, wenn sich die Untersuchung nicht in jahrelanger und intensiver Arbeit ausschliesslich auf dieses Gebiet konzentrieren kann.

Der Dajak ist sehr schweigsam und es hat lange gedauert bis wir endlich einen Einblick erhalten konnten in verschiedene Gebiete der geistigen Kultur. Einem Fremden gegenüber schweigt man, oder man gibt ihm eine unbefriedigende Antwort weil man auf das unermüdliche Fragen anstandshalber doch etwas entgegnen muss. Die Katinganer, und mit ihnen auch die andern Dajak die ich kennen lernte, haben Angst lächerlich gemacht zu werden. Sie wissen wie man so ungefähr über sie denkt, denn manche sind heute selbst in der Lage zu lesen wie man über sie schrieb, oder sie wissen aus persönlicher Berührung mit dem Europäer, dass dieser sich als der Höherstehende beschaut. Dem Missionar gegenüber sind sie anfänglich vorsichtig weil sie in der religiösen Auseinandersetzung nicht mit eigenen Waffen geschlagen werden wollen. Erst als sie sahen, dass es uns nicht darum zu tun war, sie haben uns gründlich und jahrelang geprüft! wurden sie mitteilsamer.

Fragen ist nicht immer ganz einfach und der Dajak versteht auch nicht immer wo wir eigentlich mit unserer Frage hinauswollen. Erst eine längere Zusammenarbeit fördert das gegenseitige Verstehen. Eine Frage darf auch nie die zu erwartende Antwort enthalten. $\mathrm{Zu}$ lange darf man auch nicht fragen. Arbeitet man einige Stunden mit einem Dajak zusammen, dann wird er müde und seine Antworten werden verwirrt. Manche Antwort, die er gibt, darf man nicht einfach so 
hinnehmen und sich mit ihr zufrieden geben, weil viele Handlungen im Laufe der Jahre eine andere Interpretation erfahren haben. Um weiter zu kommen ist es dann wünschenswert sich die Texte, die z.B. der Priester bei der Handlung spricht, oder die Mythe die ihr zugrunde liegt, sagen zu lassen. Erst durch die erfährt man dann, dass die Handlung einen tieferen Sinn hat als die profane, rationelle und auch populäre Erklärung aussagt. Von einer Frage kommt man natürlich auf die andere und mit der Zeit sieht man ein, dass man nicht in ein paar Jahren alles erreichen kann, sondern dass man sich vorerst einmal auf irgend ein Gebiet konzentrieren muss wenn man etwas erreichen will. Wir haben am Katingan verschiedene Gebiete „durchgearbeitet", aber das Hauptgebiet wurde für uns aus verschiedenen Gründen der Totenkult. Der Hauptgrund war anfänglich ein äusserlicher. Wir sahen in allen Dörfern, in die wir kamen, so manches was mit ihm zusammenhing und wofür wir keine oder eine nur unbefriedigende Erklärung fanden. Wir sahen auch, dass wir, wollten wir die Religion der Dajak etwas näher kennen lernen, vor allem den Totenkult kennen mussten, der eine der wichtigsten Erscheinungen des religiösen, oekonomischen und sozialen Lebens der Dajak ist. Wir nahmen zuerst den Totenkult der Bevölkerung von Tumbang-Lahang auf. Für die verhältnismässig kleine Arbeit hatten wir einige Monate nötig weil er in verschiedene Gebiete des kulturellen Lebens hineingreift die wieder für sich selbst untersucht werden mussten. Viele Fragen sind offen geblieben. Ihre Beantwortung wird erst dann möglich sein, wenn wir einmal einen Einblick in die ebenfalls noch durchaus unbekannte und sehr umfangreiche Stammesmythologie der Ot Danum, die sogenannten Auch Tatom Tambon Bungai haben, die bei jedem, der sie singen hört einen tiefen und unvergesslichen Eindruck ihrer poetischen Schönheit hinterlassen.

Nachdem diese Arbeit abgeschlossen war schien es mir wünschenswert zu sein den grössten und umfangreichsten Totenkult der sich in unserem Missionsgebiet findet, nämlich den der Ngadju Dajak, noch kennen zu lernen. Die Ngadju-Dajak, am Barito von den umliegenden andern Stämmen auch Biadju genannt, sind die kräftigste Bevölkerungsgruppe von Süd-Borneo. Sie bewohnen die Gebiete des unteren Barito, des Kapuas und Kahaian und wir finden sie gegenwärtig in kleineren und grösseren Gruppen zusammenwohnend über die ganze Zuider- en Oosterafdeeling van Borneo verbreitet. Ihre Sprache wird in diesem ganzen Gebiet verstanden und z.T. auch gesprochen. (Ich verweise auf die beigefügte Karte und die ausführliche Einleitung in meinem Werk: 
Der Totenkult der Ngadju Dajak von Südborneo.) Von der ebenfalls sehr umfangreichen Literatur der Ngadju, die etwa 40000 Druckseiten füllen wird, ist bis heute ebenfalls noch nichts bekannt, ausser einigen wenigen Mythen und Erzählungen die $\mathrm{H}$. Sundermann veröffentlicht hat 1 und einigen wenigen Fragmenten die wir in Hardeland's Wörterbuch und bei Schwaner finden.

Für diese Untersuchung liess ich mich während einigen Monaten in Kuala-Kapuas nieder, und zwar deshalb weil im dortigen Spital der Basler Mission Johannes Salilah, ein junger sehr begabter Priester, der seit einigen Jahren Christ geworden war, als Krankenpfleger arbeitete. Von ihm hoffte ich die nötigen Informationen erhalten $\mathrm{zu}$ können. Kuala-Kapuas liegt aber auch im Zentrum des Wohngebietes der Ngadju Dajak und ist ihre grösste Niederlassung. Wir besprachen zuerst die ganze Arbeit und begannen dann mit der Niederschrift des Materials. Da es erwünscht war das gesamte Textmaterial aufzunehmen, eine Arbeit die etwa drei Monate erforderte, zogen wir noch einen Lehrer herzu. Johannes Salilah sang und diktierte die Texte, der Lehrer schrieb sie auf und darnach wurden sie von Johannes noch einmal durchgesehen. Jeden Abend kam er mit einem Heft von 36 Seiten zu mir und es blieb mir noch genügend Zeit mich in die Texte einzulesen und sie mit Johannes zu besprechen. Notwendige Erklärungen brachte er im Texte selbst an und versah das Ganze auch mit zahlreichen erläuternden Erklärungen. Anhand einer Priesterkarte von der Oberwelt, die Johannes Salilah im Jahre 1929 für Missionar J. H. Göttin gezeichnet hatte konnte ich mich über die angegebenen Orte inund die zurückzulegenden Wege nach- und von der Oberwelt orientieren, aber ich sah auch bald ein, dass gerade die Oberwelt später einer gründlichen Untersuchung und Bearbeitung bedarf, die wahrscheinlich einige Jahre erfordern wird, weil ihre Kenntnis ohne die gute Einsicht in die so umfangreiche Mythologie der Ngadju Dajak nicht möglich ist. Erst wenn das einmal geschehen ist wird die Darstellung der geistigen Kultur möglich sein. Ich war bereits in der Schweiz als ich die letzten Hefte dieses treuen und fleissigen Gewährmannes in meinen Besitz bekam. Anhand dieser Texte ist nun auch die Darstellung des Totenkultes möglich, wenn auch wiederum einschränkend gesagt werden muss, dass nicht alle Einzelheiten in ihren Finessen aufgenommen werden konnten, weil auch der Totenkult in

1 H. Sundermann: Dajakkische Fabeln und Erzählungen. In : Bijdragen,66, 1912. 
alle Gebiete der Kultur eingreift und deshalb auch die Kenntnis der ganzen Kultur in ihren verschiedenen Aspekten voraussetzt.

Die mitgeteilten Texte, ebenso auch die ganze Stammesmythologie, Priester oder die Priesterin lernt sie von einem Hauptpriester(-in), zu dem er(sie) sich in die Lehre begeben hat. Diesen Hauptpriester nennt man Upon Balian. Der Lehrling begleitet ihn als Hülfspriester oder Beantworter (Panggapit oder Panombah) zu allen Festen. Der Upon Balian singt einen kurzen Satz vor der durch die Beantworter wiederholt wird. Beherrscht er die Texte vollständig und ist er mit allen Handlungen bekannt, dann hat er seine Lehre beendet und kann selbst als Hauptpriester auftreten und wieder eine Schar von Schülern um sich sammeln.

Was Hardeland 2 über die Texte sagt, gilt aber auch heute noch, nämlich :

„Dies augh olo balian ist einer es singenden Balian nachgeschrieben; natürlich musste sie es oft singen, bis der Text zu Papier stand. Darauf nahm ich mit mehreren andern Balian die Probe darauf, und fand, dass wie es bei bloss mündlicher Ueberlieferung von einer Balian auf die andre nicht anders zu erwarten ist, die Gesänge im Munde der verschiedenen Balian ziemlich stark differieren."

Das ist auch heute noch so und wir können natürlich nicht alle Versionen sammeln und dann einen sauberen Text herstellen. Das ist weder möglich noch notwendig. Trotz mancher Verschiedenheiten bleiben die prinzipiellen Teile, um die es geht, unangetastet, weil jede willkürliche Antastung oder Veränderung dieser wichtigsten Teile die Gesänge, und damit die ganze Handlung, nicht nur unwirksam machen würde, sondern auch für die Priester und Priesterinnen (Basir und Balian) sehr schwere Folgen hätte, sei es plötzliche Erkrankung oder rasch eintretender Tod.

Die mitgeteiiten Texte, ebenso auch die ganze Stammesmythologie, und natürlich auch alle andern Priestertexte, also ein grosser Teil der Literatur der Ngadju Dajak, werden in der sogenannten Basa Sangiang (Sangiangsprache) überliefert und sie werden in meiner Textausgabe auch in dieser Sprache mitgeteilt. August Hardel.and, Missionar und Sprachgelehrter, ist der erste, und er ist auch der einzige geblieben, der im Jahre 1858 in seinem Versuch der Grammatik darüber geschrieben hat und der im Anhang zu diesem Versuch in der Basa Sangiang auch

2 Versuch einer Grammatik der Dajackschen Sprache. S. 210. 
eine Anzahl Texte zum Tiwah (Totenfest) der Ngadju vorgelegt hat. 3 In seinem Wörterbuch 4 finden sich auch etwa 900 Wörter zu dieser eigenartigen Kultsprache. Damit ist ihr Wortschatz natürlich noch lange nicht erschöpft. Für den ersten Teil dieses Werkes wurde die Wörterliste um etwa 1500 neue Wörter vermehrt. Die Uebersetzung des Materials und die Herstellung der Wörterliste kostete viel Mühe weil für diese Arbeit so gut wie keine Hülfsmittel bestanden und weil ich vor meiner Rückkehr nach Europa die Basa Sangiang auch nicht gelernt habe. Der Europäer weiss um ihr Bestehen, aber er hat sie nicht nötig (heute denke ich darüber etwas anders), lernt sie deshalb auch nicht und darum ist sie wahrscheinlich auch keinem von ihnen näher bekannt. Für etwa fünf Wörter gelang mir die Uebersetzung nicht. Es war auch möglich ganze Sätze zu übersetzen ohne ihren Sinn zu verstehen, sei es, weil es sich um poetische Umschreibungen handelte, oder weil ihnen irgend eine mir noch unbekannte Mythe $z u$ Grunde lag. Bei der Durcharbeitung des ganzen Materials wurden die meisten dieser Schwierigkeiten behoben weil die gleichen Ausdrücke immer wieder in anderem Zusammenhange vorkamen. Die Uebersetzung wurde auch dadurch einigermassen erleichtert, dass die Gesänge aus zweigliederigen, parallelen, synonymen Redeabschnitten bestehen, die denselben Gedanken mit andern, gewöhnlich im zweiten Abschnitt mehr aus der Sangiangsprache entnommenen Wörtern wiederholen, während im ersten Gliede sich mehr gewöhnliche Ngadjuwörter finden. Durch diese Wiederholungen war es möglich den Sinn mancher Wörter $\mathrm{zu}$ verstehen und eine Uebersetzung $z \mathrm{u}$ geben, die bei den oftmaligen Wiederholungen nachgeprüft und auch verbessent werden konnte. Aber schon Hardeland klagt (Versuch einer Grammatik, pag. 210) :

„Die Uebersetzung und Erklärung kostete viel Mühe, da die Dajacken die Bedeutung vieler Wörter und ganzer Sätze selbst nicht mehr verstehen, und keine oder die oft widersprechendsten Erklärungen gaben, so dass ich oft auf blosse Conjecturen gewiesen war; - weiss nicht ob ich immer das Rechte traf."

Ohne das grosse Verdienst von Hardeland irgendwie schmälern zu wollen, so muss doch gesagt werden, dass er nicht immer das Rechte traf, aber es ist mehr als wahrscheinlich, dass es mir in einzelnen Fällen auch so ging, trotzdem ich für die Vergleichung ein grösseres Material zur Verfügung hatte. Ich nenne nur ein Beispiel aus dem

3 Das Augh olo balian hapa tiwah. Anhang zum Versuch einer Grammatik.

4 Dajacksch-Deutsches Wörterbuch. Amsterdam 1859. 
Texte von Hardeland. Auf Seite 218 des Versuches einer Grammatik gibt er von einer wichtigen Stelle folgende Schreibweise und Uebersetzung :

Tawor hataburangku halawo petak sintel habalambang timpong, etan bulau hapapajang$\mathrm{ku}$ harende liang deret, habangkalan garantong.
Gestreutes, du wirst durch mich ausgestreut, falle nieder auf die Erde, die dichte, dicht wie Kante habendes Zeug (wie die Kante des Zeugs,) Korn des Goldes, du wirst gestreut durch mich, fall nieder bis zur Erde, der dichten, dicht wie hat den Stoff die Gong (kupfern, kesselförmig Musikinstrument).

Schreibweise und Uebersetzung müssen aber folgendermassen lauten:

Tawor hataburangku halawo petak sintel, habalambang tambon, etan bulau hapapajangku harende liang deret, habangkalan garantong.
Streureis, ich streue dich aus, dass du herniederfallest auf die Erde, die feste, die als Schwelle besitzt die Wasserschlange, goldenes Korn, ich streue dich aus, dass du herunterfallest auf die Erde, die harte, die als Schwelle hat die Gong.

Die Basa Sangiang (Sangiangsprache ${ }^{5}$ ) wird von den Ngadju Dajak als die ursprüngliche Sprache bezeichnet, die heute durch Fremdeinflüsse, sei es aus umliegenden Dialekten oder aus dem Malaiischen, eine starke Veränderung erfahren habe. Die Ursprache wäre dann die Basa Sangiang, die heute nur noch im Kultus gebraucht wird, und das heutige Ngadju wäre ihre degenerierte Form. Eine der Forderungen des dajakischen, stark religiös gefärbten Nationalismus, die immer wieder aufgestellt wird, sei es in Vorträgen oder in der Presse, lautet: „Zurück zur alten Sprache der Ahnen, zurück zur Basa Sangiang!" Dieser Ruf schliesst natürlich eine ganze Ideologie und ein ganzes Programm in sich, auf das wir hier nicht näher eingehen können. Wir finden diese heilige Sprache natürlich bei allen Stämmen und überall wird die Stammesmythologie in ihr überliefert und rezitiert. Bei vielen Stämmen heisst sie, so z.B. bei den Katinganern, die basa helo (die Sprache der früheren Zeiten. Gemeint ist

s Hardeland nennt die Sangiang „gute, hülfreiche Wesen“ und sagt von ihnen ferner noch: „Sie leben über dem Nebelmeer irgendwo in dem Himmel, im Lewu Sangiang (Sangiangland), welches durch 160 Flüsse durchströmt wird". Wörterbuch, pag. 505. Wer die Sangiang sind haben wir später nachzuweisen. 
damit die mythische Vorzeit in der die Ahnen und Kulturheroen lebten). Sie wird auch bei den Ngadju oft so genannt und das kann auch der Grund sein, dass bei vielen die Meinung herrscht, als handle es sich tatsächlich um eine alte, nur noch im Kultus gebrauchte Sprache. Das ist nicht so. Es ist nicht die Sprache der Vorfahren und auch nicht die Ursprache der Ngadju Dajak, die, wenn man sie heute wieder allgemein sprechen würde, die mythische Vorzeit mit ihrem Heil und ihren schöpferischen Kräften aufleben liesse. Es handelt sich um eine Kultsprache in der noch alte Sprachelemente bewahrt geblieben sind, die heute nicht mehr gebraucht werden. Das ist eine Erscheinung die sich durch die Art und Weise der Ueberlieferung der Texte leicht erklären lässt. Vergleichen wir das heute gesprochene Ngadju mit dem das zur Zeit von Aug. Hardeland gesprochen wurde, dann sehen wir, dass die heutige Sprache manche Elemente ausgeschieden hat die tatsächlich in der Basa Sangiang noch fortleben. Neben diesen alten Sprachelementen, die noch nicht einmal so häufig vorkommen als man erwarten würde, finden sich Wörter aus andern dajakischen Sprachgruppen, vor allem aber auch aus dem Malaiischen. Die meisten Wörter in der Basa Sangiang entstehen aber durch Wortumformungen oder durch Anfügung von Vor- oder Nachsilben. Eine philologische Untersuchung aber, so nötig sie auch einmal wäre, wird uns den Sinn dieser Sprache nicht zu deuten vermögen. Ihre Erklärung wird eine ethnologische sein müssen. Ich hoffe in der Lage zu sein einen Versuch $z u$ geben und einige Linien, die aus den Texten abgelesen werden, ziehen zu können. Ferner hoffe ich auch in der Lage zu sein, den Beweis zu erbringen, dass die von Dr. Adriani gegebene Erklärung der Priestersprache als magische Sprache 6 für die Basa Sangiang nicht zutrifft, sondern dass ihr Sinn gesucht werden muss in der streng durchgeführten soziologisch und kosmologisch klassifizierenden $Z$ weiteilung. Die Basa Sangiang wäre dann zu sehen als die Sprache der mit dem matrilinealen Aspekt der Gemeinschaft assoziierten Stammhälfte. In der Tat sind die Sangiang nicht nur „gute, hülfreiche Wesen“ sondern sie repräsentierten in der mythischen Urzeit die Stammhälfte, die mit dem matrilinealen Aspekt der Gemeinschaft assoziiert ist. Sie werden auch heute noch so gesehen und sie haben in der Religion der Ngadju auch heute noch die Funktion der Stammhälfte, die mit dem matrilinealen Aspekt der Gemeinschaft verbunden ist. In der mythischen Urzeit ist diese Stammhälfte, als es nach einem Streit zu einer Schei-

B In: Verzamelde Geschriften. Deel III. Seiten 167 - 175. 
dung kam, in den Dörfern der Sangiang, die über den Wolken liegen, zurückgeblieben während sich die andere Stammhälfte an den Ufern des Flusses der Welt niedergelassen hat. Damit ist die Verbindung zwischen diesen beiden Gebieten nicht verbrochen, denn sie bilden zusammen eine Welt und liegen in der gleichen Welt, die, kosmologisch gesehen und klassifiziert zwischen Unterwelt (Tambon oder Bawin Djata Balawang Bulau) und der Oberwelt (Ranjing Mahatala Langit) liegt und beiden angehört. Im sozialen und religiösen Leben der Ngadju ist es so, dass eine Stammhälfte immer auf die andere angewiesen ist. Sie kann allein nichts tun und kann sich vor allem nicht von Unheil befreien. Das Heil kommt immer von der andern Stammhälfte. Und so sehen wir dann auch, dass bei wichtigen Handlungen und Arbeiten die beiden Stammhälften, die als solche mit Unterwelt und Oberwelt assoziiert sind, sich vereinigen um das Heil und den Frieden der Welt aufrecht zu erhalten, zu fördern, und wenn sie verbrochen worden sind, auch wieder herzustellen. Dieses ganze Geschehen wird in die mythische Vorzeit zurückverlegt und es sind also dann nicht nur die beiden Stammhälften der jetzigen Stammesorganisation, die sich vereinigen, sondern es sind auch die beiden Stammhälften, die sich in der mythischen Vorzeit getrennt haben, aber die doch immer wieder zusammenkommen müssen weil sie ohne einander nicht auskommen können und weil sie ohne die Vereinigung den Frieden und das Heil gänzlich verlieren müssten. Tritt nun die Stammhälfte, die die Ufer des Flusses der Welt bewohnt in Verkehr mit der Stammhälfte, die die Dörfer der Sangiang bewohnt (die Menschen sind auch Sangiang, und die Freien müssen von den Unfreien auch so genannt werden, sie bilden also eine Einheit, trotz der sozial und religiös klassifizierten kosmologischen Zweiteilung), dann spricht diese Stammhälfte nun auch die Sprache der Sangiang, die sie um Hülfe ruft. Wir sehen, dass diese kosmologisch klassifizierende $Z$ weiteilung auch auf die Sprache angewandt wird, was weiter nicht verwunderlich ist, weil sie sich überall findet. Das gewöhnliche Ngadju ist dann die „Erdsprache“, die Basa Sangiang ist die „Himmelssprache“. Wir wissen, dass diese Namen auch vorkommen. Heute wird aber, zurückgehend auf die mythische Urzeit die Unterscheidung zwischen Basa Ngadju und Basa Sangiang gemacht. Die Basa Sangiang spricht man nur dann wenn man mit den Sangiang in Verkehr tritt und wenn sie sich in der sie sprechenden Person inkorporiert haben. Das ist auch durchaus der Fall bei der Rezitation der Stammesmythologie, die eigentlich nur dann möglich ist wenn der Rezitator durch einen Sangiang besessen wurde, denn die Stammythen 
greifen zurück in die mythische Vorzeit und erzählen den Ursprung und das Los der beiden Stammhälften und ihrer Unterteile, und ihr gemeinsames Auftreten zum Heil und Frieden des ganzen Stammes und des Kosmos. Das gemeinsame Auftreten der beiden Stammhälften, oder auch heute der Gruppen die diese repräsentieren, bei wichtigen Handlungen und Arbeiten erklärt auch den Gebrauch der beiden Sprachen bei dieser Vereinigung. Dass die Gesänge in zweigliederige, synonyme Redeabschnitte auseinanderfallen, haben wir nicht gleichzustellen mit Text und Auslegung, sondern als das Auftreten der beiden Stammhälften, die beide ihre eigene Sprache sprechen analog der sozialen und kosmologischen Klassifizierung.

Diese Interpretation der Basa Sangiang als die Sprache der mit dem matrilinealen Aspekt der Gemeinschaft assoziierten Stammhälfte, eine Erklärung die sich aus den Texten und Mythen ergibt, werde ich noch näher auszuführen und zu begründen haben in meinem Werk: Der Totenkult der Ngadju Dajak in Süd-Borneo.

Texte zum Totenkult der Ngadju Dajak sind, wie schon gesagt, zum ersten $\mathrm{Mal}$ in der Basa Sangiang veröffentlicht worden von August Hardeland. 7 Es handelt sich aber bei diesen Gesängen nicht um eine vollständige Wiedergabe aller Texte, die beim Totenfest der Ngadju gesungen werden, sondern nur um eine kleine Auswahl. Die wichtigsten Gesänge, die uns die ganze Handlung besser verstehen lassen, fehlen leider. In der Einleitung zur Publikation der Texte zum Tiwah (Totenfest) soll eine Uebersicht gegeben werden über die von Hardeland publizierten Gesänge und es soll auch gezeigt werden mit welchen Gesängen des Gesamtmaterials sie übereinstimmen (Siehe den II. Band dieses Werkes).

M. T. H. Perelaer ${ }^{8}$ gibt eine kurze Textprobe eines Gesanges, der beim Tiwah gesungen wird. Es ist nicht nötig näher auf ihn einzugehen weil er für unsere Untersuchung und Vergleichung wertlos ist.

Auch der von J. Mallinckrodt und L. Mallinckrodt-Djata veröffentlichte Text 9 ist mit grösster Vorsicht zu gebrauchen. Schon seine Einleitung enthält manche Unrichtigkeiten und Undeutlichkeiten. Er sagt z.B.:

„De hieronder volgende priesterzang wordt door de priesters

7 Versuch einer Grammatik, Anhang, Seiten 209 - 374.

8 In: Ethnographische beschrijving der Dajaks. Zaltbommel 1870.

9 Het magah liau, een Dajaksche priesterzang. In: T. B. G. Deel LXVIII. Batavia, 1928. 
voorgedragen bij het doodenfeest, wanneer de ziel naar het hier. namaals geleid wordt.

De hier gegeven tekst wordt gebruikt in de benedenstreken van de onderafdeeling beneden-Dajak, bij de Bara Dia-stam van de Ngadjoe-stammengroep. De gebruikte taal is de spreektaal, hier en daar met woorden uit de priestertaal (basa Sangiang) doorspekt. De tekst wijkt geheel af van die welke door Hardeland gegeven wordt achter zijn spraakkunst. Tegenwoordig hoort men die slechts bij zeer groote doodenfeesten, aangezien het gebruiken van die uitvoerige tekst zeer kostbaar is, in normale gevallen wordt de hier gepubliceerde gebezigd. Het voordragen van dergelijke zangen noemt men bahanteran, dat alleen gebruikelijk is voor doodenzangen en die verhalen waarin de doodenschipper, Tempon Telon, een rol speelt."

$\mathrm{Zu}$ dieser Einleitung von Mallinckrodt haben wir folgendes $\mathrm{zu}$ bemerken : Der Priester, von dem er diesen Text erhalten hat aber dessen Name er in seiner Publikation nicht nennt, wohnt in Kuala-Kapuas. Bei der Niederschrift unseres Textmaterials hat er uns manchmal mit seinem wertvollen Rat geholfen. Zur Vergleichung der Texte gebrauchten wir bei unserer Arbeit auch diesen Text von Mallinckrodt. Der Priester war sich von der Unzulänglichkeit dieses Textes, den er, aus weiss ich welchen Gründen, Mallinckrodt so mitgeteilt hat, sehr wohl bewusst. Die gebrauchte Sprache ist nicht nur das gebräuchliche und gewöhnliche Ngadju, sondern z.T. ein sehr vulgäres Ngadju. Manche Worte, die er gebraucht, dürfen einfach nicht gebraucht werden (z.B. kongan für biti), auch in der gewöhnlichen Sprechweise nicht. Und Priestergesänge dürfen nun einfach einmal nicht in der gewöhnlichen Sprache vorgetragen werden, der Vortrag muss immer und ausschliesslich in der Basa Sangiang geschehen. Ich vermute, dass der Priester bei seiner Mitteilung das gewöhnliche Ngadju gewählt hat um den Text für Mallinckrodt verständlicher zu machen. Daran ändert auch die Mitarbeit von Frau Mallinckrodt-Djata nichts, sondern erklärt noch eher die Fassung des Textes in dem gewöhnlichen Ngadju, denn auch Frau Mallinckrodt war mit der Basa Sangiang nicht vertraut. Es ist auch unrichtig, dass dieser Text in den normalen Fällen gebraucht wird. Erstens würden bei seinem ausschliesslichen Gebrauch keine Sangiang erscheinen, und zweitens würde der Tote das Totendorf wahrscheinlich nie erreichen. Es ist auch unrichtig zu sagen, dass der Text vollständig abweiche von dem der durch Hardeland mitgeteilt 
wurde. Er weicht davon nicht ab. Er findet sich einfach nicht in den Gesängen von Hardeland weil diese unvollständig sind. Der von Mallinckrodt mitgeteilte Text ist aus dem ganzen Zusammenhang herausgelöst und wird deshalb unverständlich bleiben. In meinem Material findet er sich im zweiten Bande, mitgeteilt in der Basa Sangiang und im ganzen Textzusammenhang, aus dem er herausgelöst wurde. Bei der Darstellung dieses Gesanges wird auf Mallinckrodt verwiesen werden. $\mathrm{Zu}$ meiner Uebersetzung, die in diesem Werke vorgelegt werden soll, ist $z u$ bemerken, dass ich mich an den Text gehalten habe, wodurch natürlich manche poetischen Schönheiten verloren gingen. Auch eine poetische Bearbeitung, insofern mir die überhaupt möglich gewesen wäre, könnte die Schönheit mancher Stellen doch nicht zum Ausdruck bringen, denn um ihre Schönheit und Innigkeit ganz $z u$ verstehen und auf sich wirken zu lassen, muss man in Borneo selbst sein und man muss die Gedankenwelt der Ngadju und die Umwelt, die sie bewohnen genau kennen und liebhaben.

Mit der Textausgabe wird beabsichtigt das Gesamtmaterial zum Totenkult der Ngadju Dajak vorzulegen. Wir können uns fragen ob die Veröffentlichung eines so umfangreichen Materials einen Sinn habe. Ich glaube diese Frage aus verschiedenen Gründen mit Ja beantworten zu müssen. Ich glaube auch, dass sie nicht nur einen Sinn hat sondern einem Bedürfnis und einer Notwendigkeit entspricht. Wir besitzen manche ausgezeichnete Beschreibungen über verschiedene Gebiete aus dem kulturellen Leben der archaischen Völker, wir besitzen aber noch lange nicht genug Textmaterial das dem Ethnologen oder auch dem Religionshistoriker die Möglichkeit geben würde die Aussagen zu prüfen und sich ein selbstständiges Urteil bilden zu können. Handelt es sich um Gebiete aus der Religion, dann scheint mir die Publikation der Quellen, und diese sind die Mythen, Gesänge und anderen Texte, unmissbar zu sein. Bei der Darstellung der sogenannten Hochreligionen steht diese Frage überhaupt nicht zur Diskussion, die Kenntnis der Quellen wird einfach vorausgesetzt, warum aber nicht auch für die sogenannten archaischen Religionen? Es ist mir unbegreiflich, dass manche Aussagen über die Religion der Dajak, um hier nur diese zu nennen, einfach auf grund mangelhafter ethnographischer Beschreibungen gemacht werden ohne dass man auch nur etwas von der Mythologie kennt, und von der Mythologie und dem Textmaterial der Ngadju kennen wir ausser einigen wenigen und unzureichenden Fragmenten nichts. Das gleiche gilt ja noch für manche archaische Religion. Wenn 
J. M. van Veen in seinem Werke über Nathan Söderblom 10 mit Recht sagt und fragt:

„De wereld der primitieven is een moeilijk te benaderen complex van zeer variërende voorstellingen en gewoonten, zodat $\mathrm{zij}$ zich maar al te gemakkelijk leent voor de meest uiteenlopende bewerkingen en waarderingen. Zeker, lang niet meer zo willekeurig als in vroeger eeuwen, toen men afwisselend de natuurvolken hemelhoog prees en fel verafschuwde. Maar toch nog wel in die mate, dat een streng wetenschappelijk en empirisch onderzoek naar de mentaliteit en religie der primitieven uitermate noodzakelijk is en dat het tevens gewenst is om met het opstellen van algemene theorieën en hypothesen zo lang mogelijk te wachten.

Hij (Söderblom) vergelijkt zelf de primitieve religie met een oerwoud. De vraag komt bij ons op: hoe kan men dit oerwoud het beste leren kennen? Door er èèn groote weg doorheen aan te leggen? Dan is men wel spoedig aan het andere eind en men denkt misschien, dat men het oerwoud nu kent. Maar in werkelijkheid heeft men bitter weinig gezien. Verschillende wegen en paden zijn nodig om ons de rijkdom van het oerwoud te ontsluiten. Geen sleutel opent alle sloten. Söderblom wordt niet moede, ons dat voortdurend in te prenten. Animisten als Tylor hebben ons een blik in de schoonheid van het oerwoud vergund. Maar praeanimisten als Marett ook. En Lang met de zijnen niet minder. De een ziet, wat den ander ontging. Hun waarnemingen vullen elkaar aan. En wanneer Söderblom die dan samenvat en aanvult met eigen observaties, dan kan een aantrekkelijk beeld van het oerwoud ontstaan"

dann haben wir, um im Bilde zu bleiben, dazu zu sagen, dass man von dem Urwald Baum für Baum kennen muss und auch seine geographische Lage und seine Bodenbeschaffenheit nicht aus dem Auge verlieren darf. Und um es nun ohne Bild zu sagen: um eine archaische Religion kennen zu lernen ist es unmissbar ihre Quellen zu kennen und sie im Rahmen der ganzen Kultur zu sehen und zu deuten. Erst daraus wird sich uns ihr Wesen und ihr Sinn erschliessen. Und erst dann werden wir auch die Möglichkeit besitzen sachlichere und richtigere Schlüsse ziehen zu können. Erst die Publikation eines umfangreichen Textmaterials wird uns auch die Möglichkeit geben, die interessante und wertvolle und oft auch sehr innige religiöse Terminologie, über die

10 J. M. van Veen: Nathan Söderblom. Amsterdam, 1940. 
wir für die Dajak auch so gut wie nichts wissen, in ihrem Zusammenhange kennen zu lernen, aber nicht nur sie, sondern auch die religiösen Handlungen selbst.

Es scheint mir auch, nicht nur erwünscht, sondern auch wichtig zu sein, dass die Priestersprache einmal eine gründliche philologische Untersuchung und Beschreibung erfährt, und auch das wird ja nur möglich sein anhand eines umfangreichen Textmaterials.

Für unsere missionarische Arbeit und unser missionarisches Sprechen wird die Kenntnis der Texte ebenfalls notwendig sein und nebst ihr auch die Kenntnis der Priestersprache selbst. Schon Dr. Adriani hat gesagt 11 :

„Die Kenntnis dieser zur literarischen Kunstsprache gewordenen magischen Sprache ist also nicht zu gebrauchen für die Verkündigung des Evangeliums, aber das Studium dieser Sprache ist doch von grossem Werte für die Arbeit der Mission, weil sie Einsicht gibt in eine Erscheinung des Geisteslebens eines Volkes, auf dessen geistliche Entwicklung das ganze Missionswerk gerichtet ist."

Das gilt auch heute noch. Was aber hier gesagt wird über die Mission, von der vorausgesetzt wird, dass sie die geistige Kultur des Volkes, unter dem sie arbeitet, auch kennen soll, gilt für alle die sich mit ihr beschäftigen oder $z \mathfrak{u}$ beschäftigen haben und wenn die Texte, und eigentlich nur sie, zusammen mit den Handlungen, uns Einsicht geben in die Erscheinung des Lebens- und Denksystemes einer Volksgemeinschaft, dann ist es beinahe überflüssig zu sagen, dass wir sie auch besitzen und kennen müssen.

Das Werk, in dem diese Texte vorgelegt werden sollen, wird vier Bände mit zusammen etwa 2400 Druckseiten umfassen. Am Ende des letzten Bandes soll, nebst der Wörterliste zur Basa Sangiang, auch ein Gesamtregister beigefügt werden, das den Gebrauch des ganzen Werkes erleichtern wird. In einem abschliessenden fünften Bande soll der Totenkult der Ngadju Dajak von Süd-Borneo zusammenhängend dargestellt werden, versehen mit dem nötigen Bildmaterial.

Anlage und Inhalt des ganzen Werkes wird folgendermassen sein:

\section{Band:}

Er enthält die Mythen, die für die Einleitung und die Darstellung des Totenkultes notwendig sind. Ferner: verschiedene Texte die die

11 Verzamelde Geschriften. Deel III. Seite 175. 
Handlungen beim gewaltsamen Tod begleiten. In zweiten Teile dieses Bandes wird das Wegschieben des Toten (Tantolak Matei) dargestellt.

Die weiteren Bände behandeln das grosse Tiwah (Totenfest), das mit allen Vorbereitungen und Schlusshandlungen 33 Tage dauert. Die Behandlung und Publikation geschieht folgendermassen:

\section{Band:}

A. Die Vorbereitungen für das Tiwah.

a. Die Leiter des Tiwah

b. Die Kopfjagd

c. Ankauf von Opfersklaven und Opfertieren

d. Bau der Festhütte

e. Das erste Schlagen der Trommeln und Gong nach den vier Richtungen des Dorfes

f. Die Aufrichtung des Sangkaraja (Schädelgestell)

g. Der Schädel

h. Die Opfer für den Schädel

i. Die Umtanzung des Schädelgestelles

k. Die Bedeutung des Schädels

1. Die Aufrichtung der Opferhütte für die Paligeister

m. Die Opfer für die Pali

n. Die Aufrichtung des Sandong (Knochenhäuschen)

o. Die verschiedenen Sandong und ihre Bedeutung

p. Die Herstellung und Bedeutung der Sapundu (Opferpfähle)

q. Die Herstellung und Bedeutung der Pantar (Eisenholzmaste)

r. Die Herstellung und Bedeutung der Sanggaran

s. Die Aufrichtung des Bara-Bara

t. Die Aufrichtung der Fahnenstangen.

B. Versammlung der Verwandten und Wahl des Tukang Hanteran (Totenführer) und der Balian und Basir.

C. Einleitung zum Beginn des grossen Tiwah. Das Fest dauert 33 Tage und 32 Nächte.

Die Tagesordnung des ganzen Festes und die Folgeordnung der Gesänge und Handlungen ist die folgende: 


\section{Tag:}

Tukang Hanteran, Balian und Basir werden berufen und sie begeben sich mit ihren Helfern auf den Weg nach dem Dorf in dem das Tiwah stattfinden soll. Im Boot besingen sie die Reise und das Geschehen, das sie dazu veranlasst hat.

\section{Nacht:}

Rituelle Reinigung des Hauses. Herbeirufung der Sangiang und der Diener des Dohong Mama Tandang zur Mitarbeit beim Fest.

\section{Tag:}

Die Familie trifft weitere Vorbereitungen für das Tiwah.

\section{Nacht:}

Die Sangiang reinigen das ganze Dorf auf rituelle Weise.

$$
\text { 3. Tag: }
$$

Vorbereitungen für die Herbeirufung der Sangiang, die beim Tiwah mithelfen sollen.

\section{Nacht:}

Die Sangiang sammeln und verarbeiten Material, das für die Feier des Tiwah gebraucht wird.

\section{Tag:}

Weitere Vorbereitungen. Anfertigungen von Zeichnungen (Banama Tingang und Lewu: Nashornvogelboot und das Dorf, das dem Toten mitgegeben wird) für das Tiwah.

\section{Nacht:}

Die Sangiang verzieren den Eingang zu den Häusern und richten die Fahnenstangen auf.

\section{Tag:}

Die Vereinbarung der Entschädigung, die dem Tukang Hanteran und den Balian und Basir ausbezahlt werden muss. Der Tukang 
Hanteran und seine Helfer rufen die Sahor auf, die für die Dauer des Tiwah die Seelen der Teilnehmer in ihre Obhut nehmen sollen. Weitere Vorbereitungen für das Tiwah.

\section{Nacht:}

Die Sangiang stellen den Sandong her, sowie die Pantar und Sapundu und noch andere Gebrauchsgegenstände für das Tiwah.

\section{Tag:}

Herstellung der Sapapalak und Aufrichtung derselben beim Beisetzungsplatz der Leichen als Zeichen des beginnenden Tiwah.

\section{Nacht:}

Der Tukang Hanteran teilt durch die Sangiang den Toten mit, dass für sie nun das Tiwah veranstaltet werden soll, und er nennt ihnen die Speisen, die ihnen auf den Weg mitgegeben werden und die Sklaven, Wasserbüffel und Kühe, die sie begleiten sollen. Die Familie bringt auf dem Platze der Beisetzung den Toten Opfer dar.

$$
\text { 7. Tag: }
$$

Weitere Vorbereitungen.

\section{Nacht:}

Die Priester setzen mit den Sangiang zusammen die Arbeiten am Sandong, den Sapundu und Pantar fort und bauen den Balai Kanihi (die Hütte für den Opferreis).

\section{Tag:}

Die Verwandten bauen neben der Festhütte den Balai Kanihi und treffen weitere Vorbereitungen.

\section{Nacht:}

Die Priester und Priesterinnen suchen mit den Sangiang zusammen Bambusköcher und Itikblätter für die Zubereitung der Opferspeisen. Sie vollenden in dieser Nacht die Pantar, Sapundu und den Sandong.

$$
\text { 9. Tag: }
$$

Die Verwandten suchen Bambusköcher und Itikblätter und bringen 
sie in den Balai Kanihi wo sie zuerst rituell gereinigt und geweiht werden. Weitere Arbeiten für die Vorbereitung des Tiwah. Vorbereitungen zum Empfang der Gäste (lalohan). Bau der Versperrung (pantan), die das Dorf abschliesst. Diese Versperrung muss durch die ankommenden Gäste, unter Hersagung verschiedener Texte, niedergerissen werden (miap pantan), wobei sich zwischen Dorfbewohnern und Gästen ein Scheinkampf abspielt. Opfertiere und Opfersklaven werden für das Tiwah vorbereitet, aber noch nicht getötet.

\section{Nacht:}

Die Priester, Priesterinnen und Sangiang überbringen die Seelen der Verstorbenen aus dem Dorfe der Balo Indu Rangkang Penjang nach dem Balai Entai (Wartehütte) auf dem Bukit Pasahan Raung (dem Berg der Hütten der Särge). Sie stellen das danum henda (Wasser von Curcuma) für den Empfang der Lalohan her. In dieser Nacht dürfen die Liau (die Toten), die die ankommenden Lalohan begleiten (die Lalohan aus andern Dörfer werden begleitet von ihren Liau) die Liau im zu besuchenden Dorfe besuchen. Den Liau, für die man das Tiwah veranstaltet, wird mitgeteilt, dass sie den Liau, die die Lalohan begleiten, Opfer schuldig seien weil auch diese für sie Opfertiere, evtl. auch Sklaven mitbringen werden.

\section{Tag:}

Am Vormittag werden die Boote für die Masken des Dorfes bereit gemacht. Man erwartet die Gäste. Bevor sie in die Nähe des Dorfes gekommen sind wird ein Wasserbüffel geschlachtet. Vollendung der Pasah Pali und des Balai Sanggaran. Opfer an die Pali. Inzwischen nähern sich die Lalohan dem Dorfe. Die Masken des Dorfes rudern ihnen entgegen und auf dem Flusse entspinnt sich ein Scheinkampi zwischen ihnen und den Masken der Lalohan. Ankunft beim Dorf. Das Niederreissen der Versperrung. Kochen des Opferreises (kanihi).

D. Bedeutung der Versperrung und Bedeutung ihrer Niederreissung.

E. Die Bedeutung der Lalohan und der Masken.

F. Die Bedeutung des Menschenopfers.

G. Die Bedeutung der Pantar und Sanggaran. 
10. Nacht:

Priester, Priesterinnen und Sangiang reisen in das Totendorf und fordern die Ahnen auf ihre neuankommenden Verwandten zu erwarten und sich für den Empfang vorzubereiten. Aufrichtung einer Versperrung im Totendorf. Die Masken im Totendorf treffen die Vorbereitungen zum Empfang der Neuankommenden. Sie bereiten sich auch vor für den Empfang der Seelen der Opfertiere, die die Lalohan mitgebracht haben, sowie für den Empfang der Seele (gana) des Flosses, auf dem sie angereist kamen.

In dieser Nacht bereiten sich die Toten im Balai Entai auf dem Bukit Pasahan Raung auf ihre Reise nach dem Totendorf vor. In der gleichen Nacht wird in den Bambusköchern auch Opferreis gekocht.

\section{Tag:}

Der Tukang Hanteran öffnet die Itikblätterbündel im Balai Kanihi. Er reinigt und besingt sie. Die Frauen kochen neuen Opferreis. Am Vormittag wird ein Wasserbüffel getötet. Opfer an die Pali. Die Knochen der Toten werden in die Festhütte gebracht.

\section{Nacht:}

Die Verwandten kochen Opferreis. Der Tukang Hanteran führt die Salumpok Liau nach dem Totendorf.

H. Die Bedeutung der Salumpok Liau.

\section{Tag:}

Der Tukang Hanteran öffnet wiederum die Itikblätterbündel in dem Balai Kanihi. Die Frauen kochen neuen Opferreis. Die Männer richten weitere Sapundu auf und schaffen die Opfer herbei.

\section{Nacht:}

Priester, Priesterinnen und Sangiang reisen nach dem Totendorf und fordern die Ahnen auf die Liau Bereng (den Körper des Toten) zu erwarten, die in der nächsten Nacht hinübergeführt werden soll. Sie bitten sie sich auch für den Empfang der Gäste vorzubereiten. In der gleichen Nacht wird auch wieder Opferreis gekocht. 


\section{Band:}

\section{Tag:}

Der Tukang Hanteran öffnet in dem Balai Kanihi wiederum die Itikblätterbündel. Die Frauen kochen neuen Opferreis. Die Männer richten die letzten Sapundu auf und töten die letzten Opfer (Wasserbüffel und früher Sklaven). Am frühen Nachmittag beginnt der Upon Balian (Hauptbalian) mit seinen Helfern, bezw. Helferinnen, die Liau Bereng oder auch die Liau Balawang Pandjang (den Körper des Toten) nach dem Totendorf $z \mathfrak{u}$ führen.

\section{Nacht:}

Die Verwandten kochen Opferreis. Der Upon Balian führt mit seinen Helfern, bezw. Helferinnen, die Liau Bereng nach dem Totendorf. Schluss der Führung.

I. Die Bedeutung der Liau Bereng oder Liau Balawang Pandjang.

\section{Tag:}

Genannt: Andau Tabuh (der Tag des Höhepunktes des Festes). Spiele, Gesänge, Tänze. Opfer an die Pali und Sangkalan Pali. Menschenopfer und rituelle Reinigung der ganzen Verwandtschaft. Das Opfer für das Menschenopfer. Dem Menschenopfer werden Aufträge übergeben für den Toten. Die vollständige Verstümmelung der Leiche des Opfersklaven durch die Teilnehmer am Tiwah. Die Bestattung des Menschenopfers (kabalik) und die Pflanzung des Sawang Kabalik durch die ganze Verwandtschaft. Rituelle Reinigung. Einstampfen der Erde um den gepflanzten Sawang Kabalik. Die Bedeutung dieser Handlung. Die Oeffnung der heiligen Töpfe, die mit Bier gefüllt sind. Das Zeremoniell und die Person, die diese Handlung ausführen darf. Die Seelen der Verwandten und aller Teilnehmer am Tiwah werden vom Sangiang Sahor, der sie aufgeborgen hat, zurückgeholt. Der Anführer der Lalohan wird besungen und mit Opferblut bestrichen.

\section{Nacht:}

Verabschiedung der evtl. ausgesprochenen Flüche der Opfersklaven. Verabschiedung der Seelen der Bambusköcher und der Itikblätterbündel. Besingung und Bestreichung der Frauen der Anführer der Lalohan und die Zurückgabe ihrer Seelen. 


\section{Tag:}

Am frühen Morgen wird durch den Priester, zusammen mit allen Verwandten der Sawang Sandong gepflanzt. Die Priester teilen sich in zwei Parteien. Die eine Partei bereitet die Verbrennung der Särge mit den Knochen vor, die andere Partei durchschneidet die Ambon Barutas Matei (die Wolken, die vernichtenden des Todes), wofür ein menschlicher Schädel notwendig ist. Den Geistern der Pali wird geopfert. Verabschiedung der Pali durch die Sangiang und den Antang Darahen. Wegstossung der Seelen der Opferhütten. Die Rotanseile, mit denen das Dorf abgeschlossen wurde, werden nach diesen abschliessenden Reinigungshandlungen durchschnitten. Das Gehirn des geopferten Sklaven wird aus dem Schädel genommen. Nach diesen Handlungen findet das heilige Bad statt.

Am Nachmittag: Verbrennung der Knochen und Wiederbelebung der Liau Tolang (Knochenseele). Dohong Mama Tandang wird aufgefordert in der kommenden Nacht die Liau Tolang auf dem Bukit Pasahan Raung zu beleben.

\section{Nacht:}

Der Dohong Mama Tandang belebt zusammen mit den Priestern und Priesterinnen die Liau Tolang. Sie wird in das Ei eines Nashornvogels verwandelt und nach dem Totendorf gebracht wo sie mit der Salumpok Liau Haring Kaharingan vereinigt wird. Gleichzeitig werden auch alle übrigen Seelen (die der Fingernägel, Zehennägel, Haare usw., also alle Bestandteile, die zum Körper gehören) gesammelt und nach dem Totendorf geführt.

\section{Tag:}

Die nicht verbrannten Knochen und die Asche werden in den Sandong überbracht. Beim Sandong findet eine Mahlzeit statt. Die ganze Verwandtschaft naht sich den Knochen. Die Knochen werden mit Opferblut bestrichen und darnach mit Oel übergossen. Die Mitarbeit des Witwers oder der Witwe, sowie der Jünglinge und Jungfrauen. Die Besingung der Knochen. Witwer oder Witwe führen die Knochen in den Sandong ein. Abschliessende Handlungen und Reinigungszeremonien.

\section{Nacht:}

Die Liau Tolang wird nach dem Totendorf geführt. Abschluss. Mitgabe von Reichtümern an die Toten. Zeichnungen und ihre Bedeutung. 


\section{Tag:}

Abschliessende Reinigungszeremonien für die Verwandten und das ganze Dorf. Befreiung des Witwers oder der Witwe von allen Pali. Der Wechsel ihrer Kleider. Teilweiser Abbruch der Opferhütten als Zeichen der Beendigung des Tiwah. Besingung der Sangiang, die beim Tiwah mitgeholfen haben.

\section{Nacht:}

Herbeirufung der Sangiang, damit sie am nächsten Tag die Witwe oder den Witwer besingen und sie aus dem Palizustand lösen können.

\section{Tag:}

Der Sangiang Tempon Telon kehrt mit seinen Begleitern in die Dörfer der Sangiang zurück. Besingung des Witwers oder der Witwe.

\section{Nacht:}

Priester und Sangiang ruhen aus und kauen Betel.

$$
\text { 19. Tag: }
$$

Die Sangiang Bawi Pekas reinigt das ganze Haus und seine Bewohner.

$$
\text { 19. Nacht: }
$$

Priester und Sangiang ruhen aus und kauen Betel.

$$
\text { 20. Tag: }
$$

Besingung der Veranstalter des Tiwah. Die Sangiang Bawi Pekas Penjang fährt fort mit der Reinigung des ganzen Hauses.

$$
\text { 20. Nacht: }
$$

Priester und Sangiang ruhen aus und kauen Betel.

$$
\text { 21. Tag: }
$$

Die weiblichen Familienglieder werden besungen.

$$
\text { 21. Nacht: }
$$

Priester und Sangiang ruhen aus und kauen Betel. 
22. Tag:

Fortsetzung der Besingung der weiblichen Familienglieder.

\section{Nacht:}

Priester und Sangiang ruhen aus und kauen Betel.

$$
\text { 23. Tag: }
$$

Fortsetzung der Besingung der weiblichen Familienglieder.

\section{Nacht:}

Priester und Sangiang ruhen aus und kauen Betel.

$$
\text { 24. Tag: }
$$

Besingung der männlichen Familienglieder.

\section{Nacht:}

Priester und Sangiang ruhen aus und kauen Betel.

25. Tag:

Abschluss der Besingung der Familienglieder.

\section{Nacht:}

Priester und Sangiang ruhen aus und kauen Betel.

$$
\text { 26. Tag: }
$$

Alle Sangiang kehren nach den vollbrachten Arbeiten wieder in ihre Dörfer zurück.

\section{Nacht:}

Keine Tätigkeit. Vollständige Ruhe.

$$
\text { 27. Tag: }
$$

Die Darbringung der Opfer für den Sangiang Sahor, der die Seelen der ganzen Verwandtschaft und aller Teilnehmer am Tiwah, während der Zeit der Dauer desselben, in seinen Schutz genommen hat. 


\section{Nacht:}

Keine Tätigkeit. Vollständige Ruhe.

\section{Band:}

28. Tag:

Vorbereitungen für die Wegstossung der ungünstigen Vorzeichenvögel. Die Zeichnungen. Beginn der Wegstossung der Vorzeichenvögel.

\section{Nacht:}

Abschluss der Wegstossung der Vorzeichenvögel. Die Vorbereitungen für das Balaku Ontong. Man richtet den Lebensbaum auf und wiederholt damit die Welt- und Menschwerdung. Die Bitte um Heil für das neue Leben in der neuen Welt.

K. Die Bedeutung des Balaku Ontong.

\section{Tag:}

Vorbereitungen für das Balaku Ontong (Bitte um Heil) und die Herstellung der Opfergestelle.

\section{Nacht:}

Allen Sangiang in den Dörfern der Sangiang wird mitgeteilt, dass in der Nacht des nächsten Tages Mantir Mama Luhing Bungai zu ihnen kommen werde um für die Verwandten, die nun das Tiwah gefeiert haben, Glück und Heil zu erbitten. Sie werden gebeten, sich für den Empfang vorzubereiten und die Heilsgüter nicht zu weigern.

$$
\text { 30. Tag: }
$$

Fortsetzung des Balaku Ontong. Bereitmachung der Opfergestelle.

$$
\text { 30. Nacht: }
$$

Fortsetzung des Balaku Ontong.

$$
\text { 31. Tag: }
$$

Abschlusshandlungen nach dem vollendeten Balaku Ontong. Fest- 
stellung ob die Glücksgüter gewährt oder verweigert worden sind. Pflanzung des Sawang Ontong und Feststampfung der Erde durch die ganze Verwandtschaft.

\section{Nacht:}

Radja Darong Bawan. Die Sangiang stampfen die Erde um den Sawang Ontong fest.

\section{Tag:}

Mantir Mama Luhing Bungai kehrt nach vollendeter Arbeit wieder an den Fluss Djalajan zurück.

\section{Nacht:}

Zusammenkunft der ganzen Verwandtschaft zur Feststellung der Bezahlung der Entschädigung an den Tukang Hanteran, die Balian und Basir.

\section{Tag:}

Tukang Hanteran, Priester und Priesterinnen empfangen die Entschädigung für ihre geleisteten Dienste und kehren darnach wieder nach Hause zurück. Schluss des Tiwah und des Balaku Ontong.

L. Schlussbemerkungen.

M. Wörterliste der Basa Sangiang.

N. Gesamtregister.

Zum Schlusse habe ich noch allen denen meinen herzlichen Dank auszusprechen, die mir bei den Vorarbeiten, bei der Aufnahme des Totenkultes und bei der Publikation des Textmaterials mit Rat und Tat geholfen haben. Es ist mir unmöglich alle Namen zu nennen. Von den dajakischen Freunden, die mich mit viel Geduld und unermüdlichem Eifer in die geistige und materielle Kultur der Katinganer und Ngadju eingeführt haben nenne ich die Namen folgender Freunde und Mitarbeiter: Pandita Ison Birim, Tumbang-Lahang, die Lehrer Antel Pahu, Frederik Ontong, Alexander Suling, Esliter Uda und Albert Menggang. Sie standen mit mir in der gleichen Arbeit und haben mir für den Kontakt mit der Bevölkerung die Wege geebnet und sie haben für mich in jahrelanger Arbeit auch wertvolles Material versammelt. 
Ich denke auch an unsere zahlreichen Freunde in Pende Hara am mittleren Katingan. Hier war es, wo ich 1935 während eines mehrwöchigen Aufenthaltes zum ersten Male bewusst mit der geistigen Kultur der Katinganer in Berührung kam. Grosse Dienste hat mir dabei mein Freund Katjong, der Sohn des alten und weisen Singa Talawang, erwiesen. Von seinem Vater, der Priester und Dorfshaupt war, hat er für mich zahlreiche Texte, Mythen und Erzählungen aufgeschrieben. Auch meinem hier wohnhaften Freunde Nawa Sampiti danke ich für die jahrelange Bereitwilligkeit zur Zusammenarbeit. Ihm war es zu verdanken, dass wir von seiner Schwiegermutter die Stammesmythologie aufnehmen konnten. Sie war eine ihrer besten Kennerinnen. In mehr als 600 Heften sammelten wir die umfangreichen Stammythen, die sogenannten Sansana Kajau Pulang.

Viel zu danken habe ich auch Pambakal Djambang in Buntut Bali, von dem ich sehr viel lernen konnte. Als ich ihn kennen lernte war er noch Priester und Dorfshaupt und trat 1936 als einer der ersten Katinganer der christlichen Gemeinde bei. Von seinem stets besonnenen und gediegenen Urteil habe ich für meine Arbeit und für den Verkehr mit den Katinganern sehr viel gelernt.

Während unseres Aufenthaltes in Tumbang-Lahang war mein Freund Galam Sindi, der Sohn aus einem der angesehensten Häuser und Geschlechter am oberen Katingan, mein unermüdlicher Helfer. Es verging beinahe kein Tag an dem wir nicht zusammen über die Kultur der Dajak nachdachten. Er hat mir den Zugang zu manchen unbekannten Kennern einzelner Gebiete der Kultur geöffnet, und er hat auch dafür gesorgt, dass ich alle Informationen, die ich nötig hatte, erhalten konnte. In mühsamer Arbeit hat er für mich auch den Totenkult der Bewohner von Tumbang-Lahang und noch anderes wertvolles Material aufgeschrieben. Auch unserem Freund Numan Kunom, dem Lehrer dieses Ortes, danke ich für seine Mitarbeit. Er hat für mich das Material aufgenommen über den Tod im Rechtsleben der Katinganer. Daneben schrieb er auch noch eine grosse Arbeit über den Fischfang, die er mit vielen und guten Zeichnungen versehen hat. Mit Damang Felix Asong durfte ich ein Jahr zusammenarbeiten. Ich habe viel von diesem „Adathoofd“ gelernt. Wir schrieben zusammen auf: Jugendzeit und Kindererziehung bei den Katinganern, und: die Frau im Rechtsleben der Katinganer. Auch über die rechtliche Seite des Totenkultes stellte er wertvolles Material zusammen. Mein Dank gilt auch unserem greisen Freunde Ambil, der täglich unser gerngesehener Gast war. Er hat noch viel von der alten Zeit gesehen und mitgemacht 
und er war immer bereit unsere Fragen $z \mathfrak{u}$ beantworten. Ihm verdanke ich vor allem das Material zu den beiden Aufsätzen: Das Menschenopfer bei den Katinganern 12 und: Die Bedeutung des Menschenopfers im dajakischen Totenkult.13 Von den dajakischen Freunden schulde ich aber den grössten Dank Johannes Salilah, der mir in fleissiger Arbeit und auf genaue und gewissenhafte Weise das gesamte Material zum Totenkult der Ngadju Dajak aufschrieb, das in dieser Arbeit nun vorgelegt werden soll. Den Wert einer solchen Arbeit für die Beurteilung der geistigen Kultur seines Volkes, die noch so manchen Missverständnissen und schiefen Urteilen ausgesetzt ist, hat er eingesehen und er hat sich deshalb auch gerne bereit erklärt sich dieser mühsamen Arbeit zu unterziehen. Die kurze Zusammenarbeit mit diesem stets freundlichen- und für alle Fragen aufgeschlossenen Freund, gehören zu meinen schönsten Erinnerungen an Borneo.

Von den europäischen Freunden, die mir bei dieser Arbeit geholfen haben, schulde ich den grössten Dank Herrn und Frau Dr. Vischer in Kuala-Kapuas. Sie haben mir meine Arbeit auf alle mögliche Weise erleichtert. Während der Aufnahme des Materials durfte ich ihr Gast sein und Herr Dr. Vischer enthob Johannes Salilah von seiner Arbeit Im Missionsspital bis er die Arbeiten für mich beendet hatte. Sie stellten mir wertvolle photographische Aufnahmen zum Totenkult der Ngadju zur Verfügung. Frau Dr. Vischer danke ich für eine nicht veröffentlichte Arbeit über das Tiwah, in der sie ihre persönlichen Eindrücke beschreibt. Herr Dr. Vischer hat, nebst andern wertvollen Sammlungen, eine Sammlung aller Gegenstände, die beim Tiwah der Ngadju Dajak gebraucht werden, zusammengestellt. Sie ist gegenwärtig im Museum der Basler Mission in Basel ausgestellt. Die Erklärungen dazu schrieb Frau R. Kühnle-Degeler. Von beiden durfte ich für meine Arbeit Gebrauch machen. $\mathrm{Zu}$ danken habe ich Herrn und Frau Dr. Vischer auch für die materielle Hülfe bei der Sammlung und Zusammenstellung der wertvollen Zeichnungen zum Totenkult, die in meinem Werke: Der Totenkult der Ngadju Dajak, teilweise veröffentlicht werden sollen.

Von den Missionaren der Basler Mission habe ich den folgenden Herren für die Ueberlassung von Material und die Erteilung von Ratschlägen zu danken: H. Göttin, W. Zimmer, L. Walter, W. H. van den Berg und G. Flach. Herr Pfarrer Schmid in Willisau (Schweiz),

12 Erschienen in: T. B. G. Deel LXXVIII. Batavia, 1938.

13 Erschienen in: M. D. G. V. Nr. 10, Hamburg, 1940. 
früher Missionar in Borneo, hat mir seine wertvollen Zeichnungen und Beschreibungen zur Verfügung gestellt. Herrn K. Epple, Fellbach (Deutschland), dem langjährigen Missionar und Präses der Basler Mission in Borneo, dem Kenner von Volk, Sitte und Sprache der Ngadju und Ot Danum, dem Freund der Dajak und verdienstvollen Revisor der Bibel, danke ich für manchen wertvollen Rat und auch für die freundliche Ueberlassung seines Materials zum Totenkult der Ot Danum am oberen Kahaian.

Schliesslich danke ich aber auch meiner Frau für ihre Mitarbeit und ihre Geduld. Ohne sie wäre mir die Arbeit am Katingan nicht in dieser Weise möglich gewesen. Dass sie sich auf einsamen Posten zu Hause fühlte, sich in rastlosem Eifer der Arbeit hingab und mich auf allen beschwerlichen Reisen nach Zentral Borneo hinein begleitete, hat uns die Möglichkeit gegeben den Kontakt mit der Bevölkerung rasch $z u$ finden und auch den weiblichen Teil der Bevölkerung zu erreichen, die einem einzeln reisenden Manne verschlossen bleibt. Aber ohne ihre Mitarbeit wäre auch die ethnologische Arbeit nicht möglich gewesen, denn was ich von den Frauen nicht erfahren konnte, das hat sie erfahren.

Den Herren des Basler Missionskomitee, vor allem Herrn Inspektor H. Witschi, habe ich herzlich zu danken für die Art und Weise mit welcher sie meine Arbeiten unterstützt und gefördert haben. Auch habe ich ihnen zu danken für die Möglichkeit des Weiterstudiums in Leiden und für den besonderen Auftrag Ethnologie und Religionswissenschaft zu studieren.

Der Missionsleitung von Oegstgeest danke ich für die Gastfreundschaft, die mir und meiner Familie während unseres Aufenthaltes in Holland, in ihrem schönen Missionshaus erwiesen wurde. Vor allem danke ich auch Herrn Dr. F. J. Fokkema, Rektor des Missionsseminares, und seiner Familie für ihre Freundschaft und für Rat und Tat. Herrn Dr. A. C. Kruyt danke ich für den anregenden Unterricht und für manchen wertvollen persönlichen Rat. Herrn Dr. Rassers, Direktor des Reichsmuseum für Völkerkunde in Leiden, habe ich sehr viel zu danken für den anregenden persönlichen Verkehr, für seinen wertvollen Rat bei der Ausarbeitung des Manuskriptes, für Ueberlassung von Photographien, für die Herstellung von Zeichnungen und für die Benützung der Sammlungen und der Bibliothek des Museums.

Meinem Lehrer, Herrn Prof. Dr. H. Kraemer, Leiden, danke ich für manchen direkten und indirekten Rat den ich schon in Borneo empfangen durfte. Seine Ausführungen auf der Missionarskonferenz, die 
1935 in Bandjermasin (Borneo) stattfand waren für mich eine kräftige Anregung die dajakische Kultur noch intensiver zu untersuchen. Auch für seinen Unterricht an der Universität Leiden und im Missionsseminar Oegstgeest habe ich ihm hier zu danken.

Den grössten Dank schulde ich aber meinem verehrten Lehrer, Herrn Prof. Dr. J. P. B. de Josselin de Jong, Leiden. Ohne seinen wertvollen Unterricht, sein Interesse und seine Mitarbeit bei der Ausarbeitung des Manuskriptes wäre mir die Publikation des Textmateriales nicht möglich gewesen. 


\section{MYTHEN ZUM TOTENKULT}

\section{HANDWERK (HEILBRINGER-MYTHEN)}

\section{A. Der Ursprung der Nutzpflanzen}

Am Fluss Djalajan (der Djalajan befindet sich in der Oberwelt. Siehe den zweiten Teil dieses Werkes) lebte in früheren Zeiten ein Ehepaar. Der Mann hiess Mangko Amat, die Frau Njai Djaja. ${ }^{1}$ Njai Djaja war eine berühmte Priesterin. Wenn sie zu Kranken gerufen wurde um für sie die priesterlichen Handlungen auszuführen, dann wurden sie unfehlbar wieder gesund. Eines Tages erhielten sie und ihr Mann den Besuch eines Sklaven des Apang Dohong Bulau der ihnen den Bericht brachte, dass sein Besitzer sehr krank sei und sie bitte $\mathbf{z u}$ ihm zu kommen und ihm zu helfen. Er hätte bereits viele Medizinen angewandt, Gelübde abgelegt und den Geistern grosse Opfer versprochen, aber nichts hätte geholfen, die Krankheit sei statt besser nur noch ärger geworden. Nun bitte er, dass Njai Djaja ihm helfen möchte.

Die ganze Nacht hindurch befragten Mangko Amat und Njai Djaja die Geister durch das Los um von ihnen zu vernehmen aus welchem Grunde Apang Dohong Bulau krank geworden sei und welche Krankheit ihn befallen hätte. Die Geister antworteten ihnen, dass er pahuni: geworden sei weil er nicht von einer Frucht gegessen hätte die ihm Banjawei angeboten hatte. Sie teilten ihnen auch mit auf welche Weise die Krankheit wieder zu heilen sei.

Am andern Morgen machten sich Mangko Amat und Njai Djaja mit dem Sklaven des Apang Dohong Bulau auf den Weg. Bald erreichten sie sein Dorf und Haus. Sie traten in das Haus ein und begrüssten den Kranken und seine Angehörigen und man fragte sie wie es wohl mit Apang Dohong Bulau stehe. Sie antworteten: „Der Kranke leidet schon sehr lange und deshalb müssen wir eine grosse Arbeit veranstalten". ${ }^{3}$ Man machte alles bereit. Man schlachtete Tiere, kochte Reis und braute Bier. Apang Dohong Bulau fühlte sich zusehends besser werden. 
Die Kinder des Apang Dohong Bulau waren sehr schlecht. Sie kamen zusammen und beratschlagten was sie wohl zu unternehmen hätten damit sie die Alten töten könnten und auf diese Weise nicht gezwungen wären ihnen den Lohn für ihre Arbeit zu bezahlen. Da sprachen einige: „Lasst uns ihnen Fische und Pflanzenschösslinge vorsetzen die für sie während ihrer Arbeit pali ${ }^{4}$ sind, essen sie davon, dann müssen sie sterben". Dieser Rat wurde gut geheissen. Sie machten sich sofort an die Arbeit. Einige suchten Schösslinge und andere fingen Fische und davon bereiteten sie für Mangko Amat und Njai Djaja das Essen, dass diese ahnungslos und ohne an eine heimtückische Schlechtigkeit $z \mathfrak{u}$ denken, verzehrten.

Die Arbeit war beendet. Apang Dohong Bulau war gesund geworden und Mangko Amat wollte mit seiner Frau Njai Djaja wieder rasch nach Hause zurückkehren, denn beide fühlten sich nicht recht wohl. Sie baten, dass die Sklaven sie begleiten möchten und mit ihnen zusammen traten sie den Rückweg an. Immer unwohler fühlten sie sich. Die genossenen Speisen, die für sie pali gewesen waren, taten ihre fürchterliche Wirkung. Sie kamen am Fuss des Berges Palangka Langit an. Mühsam schleppten sie sich den Berg hinauf. Auf seiner andern Seite lag ihr Dorf. Als sie auf der Höhe des Berges angekommen waren konnten sie nicht mehr weitergehen. Sie wussten nun dass sie sterben mussten, zugrunde gerichtet durch die schlechten Kinder des Apang Dohong Bulau die ihnen, ohne dass sie davon etwas ahnten, verbotene Speisen zu essen gegeben hatten. Sie sandten die Sklaven wieder heim und dann legten sei sich auf die Erde nieder um zu sterben.

Kurze Zeit darauf flog der Vogel Pahararu Rawei über den Berg Palangka Langit und sah unter sich die beiden Leichen. Er näherte sich ihnen und erkannte zu seinem grossen Schrecken Mangko Amat und Njai Djaja. Er schrie auf vor Schmerz und Leid: „Akui, 5 was sehen meine Augen! Ich will sofort zu Kameloh Bawin Riwut (der weibliche Windgeist) und ihren sieben Brüdern fliegen. Ich will ihnen mitteilen was meine Augen gesehen haben und ich will sie bitten, dass sie doch sofort kommen und dass sie versuchen den Leichen Wind einzublasen 6 damit sie wieder lebend werden können". Rasch flog er zu ihr hin und brachte ihr seine Bitte vor. „Nein“, sagte Kameloh Bawin Riwut, ,ich kann das nicht tun, fliege lieber sofort zu meinem Bruder, $z \mathfrak{u}$ dem wehenden und brausenden Tingang, dem Hüter der vier Windrichtungen, und bitte ihn um Hülfe". Darauf flog der Vogel Pahararu Rawei weiter bis zum Haus des wehenden und brausenden 
Tingang, des Hüters der vier Windrichtungen. „Woher kommst du so rasch geflogen?" fragte ihn dieser. Er antwortete: „Auf dem Berg Palangka Langit liegen die Leichen des Mangko Amat und der Njai Djaja. Ich gewahrte sie auf meinem Fluge. Sie sind getötet worden durch die schlechten Kinder des Apang Dohong Bulau. Ich bitte dich, komm sofort mit mir und belebe sie wieder".

„Has", 7 sprach der wehende, brausende Tingang, der Hüter der vier Windrichtungen, „ich fliege mit dir". Auf seinem Flug brach er die Aeste der Bäume und entblätterte ihre Kronen. Bald kamen sie auf dem Berg Palangka Langit an. Der wehende, brausende Tingang, der Hüter der vier Windrichtungen blies den Leichen keinen Wind ein aber er verwandelte ihre Körper in folgende Nutzpflanzen: Das Haar der beiden wurde zu Rotan, aus den Köpfen entstanden die Kokospalmen mit ihren runden Früchten, aus den Augen die Pinang, aus den Ohren Blätter, aus den Zähnen das Mantikeieisen, aus den Zungen Gambirblätter, aus den Knochen entstand das Eisenholz, aus dem Gehirn der Kalk, aus dem Blut Wasser, aus dem Fleisch Erde, aus den Füssen Betong (eine Art Bambus), auch aus den Fersen und den Händen entstand eine Art Bambus, aus der Haut entstand die Sirenpflanze (eine sehr stark wirkende Giftpflanze), aus den Fingern entstanden Katiting und Kandalisträucher (man verbrennt ihr $\mathrm{Holz}$ und färbt mit dem Saft den man daraus gewinnt die Zähne schwarz). ${ }^{8}$

\section{B. Der Ursprung des Eisenholzes}

Neben der Mythe von Mangko Amat und Njai Djaja die uns den Ursprung der Nutzpflanzen erzählt und uns berichtet dass aus ihren Knochen das Eisenholz entstanden sei, besitzen wir auch diese Mythe die uns erzählt wie Umang (auch Sangumang), einer der Ahnen der Menschen, in den Besitz des Eisenholzes gekommen ist. Diese Mythe muss rezitiert werden bevor man zum ersten Mal Eisenholz sammelt und bearbeitet, sie muss auch bei allen wichtigen Handlungen, wie z.B. beim Hausbau oder bei der Verwendung von Eisenholz für Gegenstände des Totenfestes, wiederholt werden. Damit wiederholt man das Urgeschehen und macht es für die Gegenwart wirksam. Die Mythe lautet:

Maharadja 9 besass zwei junge Hunde. Eines Tages besuchte ihn Umang. Er sah die schönen Tiere und bat seinen Onkel sie ihm zu schenken. Maharadja gab ihm aber nur einen Hund. Mit diesem ging Umang auf die Jagd. Witterte oder sah er ein Wild, dann wollte er 
nicht bellen. Als Umang das gewahrte wurde er in seinem Herzen sehr zornig. Er griff zum Schwert und tötete den Hund und teilte darauf seinen Körper in zwei Hälften. Er nahm die eine Hälfte und ergänzte sie mit Erde. Alsobald lebte der Hund wieder. Umang nannte ihn Petak Pontonge, Langit Silae (Der angefügte Teil ist von Erde, die andere Hälfte ist Himmel). Wieder ging er mit ihm auf die Jagd. Witterte nun der Hund Wild, oder sah er ein Schwein oder einen Hirsch, dann bellte er, aber er bellte auch wenn er nur Reisbehälter, Körbe und dergleichen Dinge mehr sah.

Als eines Tages Umang wieder mit ihm auf die Jagd ging schlug er plötzlich an, denn er hatte eine Frucht gesehen die sich auf der Erde von selbst fortbewegte. Umang verfolgte mit seinem Hund die Frucht über drei Hügel hinweg, endlich konnte er sie einholen. Zum zweiten Mal schlug der Hund an, denn er hatte wieder eine Frucht entdeckt die sich von selbst auf der Erde fortbewegte. Wieder verfolgten sie sie bis sie Umang endlich nach vieler Mühe erhaschen konnte. Ein drittes Mal schlug der Hund an und wieder war es eine eigentümliche Frucht die vor ihnen davonrollte. Auch diese konnte Umang einfangen. Sehr erstaunt betrachtete er diese eigenartigen Früchte die er zuvor noch nie gesehen hatte, aber seine Leber (Herz) schmerzte ihn weil er weder ihren Namen noch ihren Nutzen kannte.

Eines Tages begab er sich mit den drei Früchten zu seinem Grossvater Sakarana um ihn um Rat zu fragen. Schon von weitem sah ihn sein Grossvater, aber der Besuch seines vorwitzigen Enkels, der immer alles besser wissen wollte, war ihm unerwünscht. Er zog sich deshalb rasch in sein Haus zurück, legte sich auf sein Lager und tat als ob er schlafen würde. Inzwischen war nun auch Umang beim Haus angekommen. Er fragte seine Verwandten: „Ist mein Grossvater wohl daheim?" "Ja", antworteten sie ihm, „er ist wohl daheim, aber er schläft nun“. „Wie steht es“, fragte Umang, „dürfen wir ihn wohl aufwecken?" „Nein, auf keinen Fall!" antworteten seine Verwandten, „denn wenn wir ihn aufweckten würde er zornig werden und uns ausschelten". Umang erzählte ihnen nun weshalb er gekommen sei und was er mit seinem Besuch beabsichtigte, und er sprach: „Ich will meinen Grossvater besuchen weil ich ihn gerne in einer Sache um Rat fragen möchte. Vor einigen Tagen ging ich auf die Jagd. Mein Hund schlug an. Dreimal bellte er und bei jedem Bellen fand ich eine dieser Früchte die ich hier mitgebracht habe. Ich habe sie noch nie zuvor gesehen. Ich weiss nicht woher sie sind und ich weiss auch nicht wozu man sie gebrauchen kann. Sie haben eine merkwürdige Eigenschaft, 
sie können sich selbst fortbewegen. Ich bin jeder von ihnen über drei Hügel hinweg nachgefolgt und erst dann konnte ich sie einholen und zu mir nehmen".

Grossvater Sakarana hatte ein ganz klein wenig seine Augen geöffnet und nach den Früchten geschaut von denen Umang erzählte, aber er tat weiterhin als ob er schliefe, denn er wollte seinen Enkel nicht empfangen und wollte ihm auf seine Fragen auch keine Antwort geben. Nachdem Umang seine Erzählung beendet hatte und sah, dass sein Grossvater immer noch schlief und nicht erwachen wollte nahm er Abschied von seinen Verwandten und verliess das Haus. Aber er hatte seinen Grossvater durchschaut und wusste wohl, dass er sich nur schlafend gestellt hatte um seine Fragen nicht beantworten zu müssen. Auf einem Umweg kehrte er rasch wieder nach dem Haus zurück und versteckte sich so in dessen Nähe, dass er jedes Wort verstehen konnte das in ihm gesprochen wurde. Nicht lange dauerte es bis er die Stimme seines Grossvaters vernahm der sich erkundigte: „Wo ist mein Enkel Umang?" „Er ist nach Hause zurückgekehrt", wurde ihm geantwortet. Darauf sprach er weiter: „Die Frucht, die Umang zuerst fand, ist eine Eisenholzfrucht, die zweite ist eine Tengang-10 und die dritte eine Rotanfrucht. Diese Früchte stammen ab von Mangko Amat und seiner Frau Njai Djaja die auf dem Berg Palangka Langit gestorben sind und deren Körper in Pflanzen verwandelt wurden. Von dort ist die Eisenholzfrucht mit den andern Früchten auf die Erde gerollt. Würde sie Umang auf dem Berg Pali oder am Fuss des Berges Tundjong Njaho (beide Berge befinden sich in der Oberwelt) anpflanzen, dann hätte er grossen Gewinn und er würde ein reicher und angesehener Mann werden. Denn das Eisenholz hat grossen Nutzen. Man kann es für alles mögliche gebrauchen. Man kann es verwenden für dauerhafte Hauspfähle, man kann es verarbeiten zu Booten, man kann mit ihm Sandong und Pambak bauen und Sapundu und Pantar aufrichten. 11 Die zweite Frucht, die Umang fand ist eine Tengangfrucht. Auch sie ist sehr nützlich, denn vom Baste des Tengang kann man Schnüre und Stricke drehen. Aus ihnen lassen sich leicht Netze machen mit denen man ganze Flüsse abschliessen, und auf diese Weise die Fische leicht fangen kann. Die dritte Frucht war die des Rotan. Der Rotan kann zu den verschiedensten Flechtarbeiten gebraucht und auch teuer verhandelt werden".

Dieses alles hatte Umang in seinem Versteck ganz genau gehört und befriedigt kehrte er wieder nach Hause zurück und pflanzte die Früchte, so wie er es von seinem Grossvater vernommen hatte. Die 
Pflanzen wuchsen und wurden gross und trugen wiederum Früchte. Eines Tages schweifte Indu Pahararu Rawei, der weibliche Windgeist, durch die Gärten des Umang und wehte die Früchte von den Bäumen. Sie rollten aus der Oberwelt hinunter bis zum Dorf das am Ufer des Flusses der Welt gebaut war und wurden dort zuerst von Radja Peres gefunden und gepflanzt. Von ihm gelangten sie, wieder durch den Windgeist, zu den Menschen und durch List erfuhr ein Mensch der sich ins Dorf des Radja Peres verirrt hatte und dort gefangen genommen wurde aber wieder fliehen konnte, den Nutzen dieser Früchte.

\section{Wie die Menschen die Handarbeiten lernten}

Diese Mythe schliesst an die obige an und erzählt uns wie die Menschen von Radja Peres die Handarbeiten gelernt haben. Auch sie muss bei manchen wichtigen, vor allem erstmalig ausgeführten, Arbeiten und Handlungen rezitiert werden um das Urgeschehen das in der Vorzeit stattfand $z \mathfrak{u}$ wiederholen und für die Gegenwart wirksam zu machen. Die Mythe lautet:

In früheren Zeiten lebte ein berühmter Ahne namens Kundja. Er verliess eines Tages sein Dorf und begab sich nach seiner Feldhütte um von dort aus die nötigen Arbeiten auf dem Reisfeld zu verrichten. Vorrat an Lebensmitteln hatte er nicht viel mit sich genommen. Seine Trockenfische und sein Fleisch gingen bald aus und zu seinem Reis ass er als Zuspeise gekochte Baumblätter die er in der Umgebung gepflückt hatte. Er entschloss sich auf die Jagd zu gehen und hoffte ein Wildschwein, oder einen Hirsch oder auch nur einen Affen zu erlegen. Er band seinen Pfeilköcher um, ergriff das Blaserohr und rief mit lauter Stimme seinen Hunden und machte sich dann auf den Weg in den Wald hinein. Er lief immer zu. Er schaute nicht sehr um sich und achtete nicht auf den Weg, und so kam es, dass er plötzlich vor Häusern stand. Er erschrak heftig als er sah wo er sich plötzlich befand. Das Dorf war das des Radja Peres. 12 Zurück konnte er nicht mehr, denn die im Dorfe herumsitzenden und arbeitenden Leute hatten ihn bereits erblickt. Mutig schritt er vorwärts. Er ging bis zu dem grossen Haus des Radja Peres und bei der Treppe angekommen rief er mit lauter Stimme: „Ooooo, Grossvater, bist du zu Hause?" „Komm nur herein“, ertönte die Antwort.

Er stieg die Treppe hinauf und trat ins Haus ein. Radja Peres schaute den Besucher genau und sehr verwundert an und sprach zu ihm: „Setze dich, mein Enkel, ich muss zuerst geschwind zum Fluss 
hinuntersteigen um meine Notdurft $z \mathfrak{u}$ verrichten, aber ich werde sogleich wieder zurückkommen". Er verliess das Haus, aber er stieg nicht zum Fluss hinunter sondern begab sich zu seinen Sklaven die mit der Bearbeitung von Eisenholz beschäftigt waren. Er sagte zu ihnen: „O meine Sklaven, in meinem Hause befindet sich ein Mensch aus dem Dorf am Rande des Flusses der Welt. Er heisst Kundja. Ergreift ihn und bringt ihn vorerst in den Balai. ${ }^{13}$ Wir wollen für ihn einen dichten Käfig machen der gut verschliesst damit er euch ja nicht bei eurer Arbeit beobachten kann. Er darf auf keinen Fall sehen was und wie ihr arbeitet, denn sollte es ihm durch List gelingen zu flüchten, dann würde er dieses Wissen in sein Dorf zurückbringen und die Menschen unsere Arbeiten lehren. Das darf nicht geschehen. Wir wollen ihn nun gefangennehmen und später umbringen".

Die Sklaven begaben sich sofort ins Haus wo Kundja immer noch auf dem Fussboden sass und auf die Rückkehr des Radja Peres wartete. Sie ergriffen ihn und schleppten ihn zum Balai, begleitet von Radja Peres, der seine Sklaven nochmals ermahnte: „Solange Kundja noch nicht in einem guten Käfig geborgen ist dürft ihr keine Arbeiten verrichten. Ihr dürft kein Eisenholz bearbeiten, kein Flechtwerk herstellen, keine Schnüre drehen, kein Eisen schmieden und bearbeiten und kein Feuer drehen, denn würde Kundja euch zuschauen, dann würde er von euerem Wissen und Können angesteckt und gelänge ihm auf irgendeine Weise später die Flucht, dann würde er dieses Wissen in sein Dorf am Flusse der Welt bringen und darin seine Verwandten unterrichten“. „Sei unbesorgt", riefen die Sklaven, „,wir befolgen dein Wort". Nun holten sie Holz und machten, wie Radja Peres es befohlen hatte, einen dicht verschlossenen Käfig und sperrten Kundja hinein. Radja Peres war überzeugt, dass Kundja nichts zu sehen vermochte und er befahl den Sklaven die Arbeit wieder aufzunehmen. Aber um ganz sicher zu sein rief er nach einer Weile: „O Kundja, kannst du sehen was meine Sklaven arbeiten oder siehst du nun gar nichts mehr?" "Ja", rief Kundja, ,ich sehe alles was sie ausführen“. „Kaja-kajah!" 14 schrie Radja Peres, ,wir haben dich nun absichtlich in diesen dichten Käfig eingeschlossen damit du meine Sklaven nicht bei ihrer Arbeit beobachten kannst und nun schaust du ihnen schon die ganze Zeit zu“. Dann rief er seinen Sklaven: „O meine Sklaven, holt Kundja aus seinem Käfig heraus und steckt ihn in einen hohen Topf. Verschliesst gut seine Oeffnung dann kann er uns gewiss nicht mehr bei unserer Arbeit zusehen". Sie taten wie der Besitzer sie geheissen hatte und setzten darauf ihre Arbeit wieder fort. 
Nach einiger Zeit rief Radja Peres wiederum: „O Kundja, kannst du uns immer noch bei unserer Arbeit beobachten?" „Ja, ich sehe immer noch alles“, rief Kundja zurück. „Kaja-kajah", schrie Radja Peres wild auf und rief seinen Sklaven $z \mathfrak{u}$ : „Holt sofort Kundja aus dem Topf heraus denn er beobachtet uns beständig, wickelt ihn in ein Tuch dann wird er uns gewiss nicht mehr sehen". Die Sklaven befolgten den Befehl ihres Besitzers und setzten darauf ihre Arbeit wieder fort. Schon einige Zeit hatten sie weitergearbeitet als Radja Peres Kundja wieder fragte: „Siehst du jetzt immer noch was wir tun?" „Gewiss“, sagte Kundja, „,ich kann euch ganz gut beobachten“. Wiederum schrie Radja Peres vor Zorn und Schmerz auf und befahl seinen Sklaven: „Wickelt Kundja sofort aus dem Tuch heraus und steckt ihn in eine Fischreuse, vielleicht kann er uns dann nicht mehr sehen". Die Sklaven taten wie sie geheissen worden waren und steckten Kundja in eine grosse Fischreuse. Nun hatte er sein Ziel erreicht. Vorher hatte er nichts gesehen, aber sein heimlicher Wunsch war, die Arbeiten der Geister kennen zu lernen, sich dann heimlich zu flüchten und dieses neue Wissen in sein Dorf am Flusse der Welt 15 zurückzubringen. Als Radja Peres ihn nach einiger Zeit wieder fragte: „Kannst du uns immer noch sehen, Kundja?" da antwortete er : „Nein, nun sehe ich nichts mehr". Aufmerksam schaute er aber durch das weite Geflecht der Reuse den Geistern bei ihren Arbeiten und merkwürdigen Verrichtungen zu. Er sah wie die Männer das Eisenholz bearbeiteten, wie sie aus ihm die Sandong und Pambak schnitzten um beim Totenfest die Knochenüberreste der Verstorbenen beizusetzen. Er sah wie sie die Pantar und Sapundu machten. Er sah wie sie Ruderboote bauten, Feuer drehten, das Eisen schmolzen und schmiedeten. Er sah wie sie den Tengangbast bearbeiteten und ihn zu Schnüren und Seilen drehten und er sah auch wie sie das Reisbier brauten. Er sah wie die Sklavinnen aus gesplisstem Rotan feine Flechtereien herstellten, wie sie Körbe, Fischereigeräte und Hüte flochten, wie sie auch in besonderen Gefässen das Wasser aus dem Fluss aufschöpften, er sah wie sie den Reis trockneten und stampften und noch vieles andere mehr sahen seine Augen, Dinge die er zuvor nie gesehen oder gekannt hatte. Aufmerksam schaute er zu, nichts entging seinen Augen. Plötzlich hörte er aber dass Peres seinen Namen nannte. Er lauschte angestrengt und vernahm zu seinem grossen Schrecken folgende Worte: „In drei Tagen wollen wir hier das Totenfest feiern. Nun hat sich Kundja aus dem Dorf am Ufer des Flusses der Welt zu uns verirrt. Beim Totenfest schmücken wir seinen Hals, seine Lenden und 
seine Gelenke mit feinen Flechtereien und binden ihn dann an einen Sapundu fest. Wir besingen und umtanzen ihn und stechen ihn darauf mit unseren Speeren langsam tot. Bewacht ihn nun gut. Er darf nicht frei werden und darf nicht mehr entkommen um wieder an den Fluss der Welt zurückzukehren. Gewiss hat er manches von unseren Arbeiten gesehen, er hat es ja auch selbst zugegeben. Gelänge ihm die Flucht dann würde er dieses Wissen in sein Dorf mitbringen. Er würde dort die Menschen lehren und sie würden durch dieses neue Wissen und Können reich und könnten ein angenehmes Leben führen. Das darf nicht geschehen und deshalb wollen wir ihn auch am Totenfest umbringen".

Kundja entflieht. Kundja hatte in seiner Fischreuse alle diese Worte vernommen. Er erschrak und das Herzeleid 16 kam über ihn. Er überlegte wie er wohl der Gefahr und dem sicheren Tod entrinnen könnte und er sagte zu sich selbst: „Ich will nun zuwarten bis es Nacht geworden ist und alles im Dorfe schläft, dann will ich mich aus der Reuse befreien, leise aus dem Dorfe wegschleichen und zu meinen Verwandten zurückkehren". Darauf verhielt er sich ganz ruhig und tat wie wenn er von diesem Gespräch gar nichts gehört hätte.

Als die Nacht hereingebrochen war und alles in den Häusern schlief kroch er leise und vorsichtig aus der Reuse heraus, ergriff seinen Pfeilköcher und sein Blaserohr, stahl sich aus dem Balai heraus und verliess das Dorf. Niemand hatte seine Flucht bemerkt.

Als am andern Morgen die Geister erwachten und als Radja Peres aus seinem Haus trat und sich dem Balai näherte, rief er mit lauter Stimme seinem Gefangenen : „O Kundja, o Kundja!“ Er erhielt keine Antwort. Nochmals rief er, aber alles blieb still. „Hau-hau!" 17 sagte er, „was ist wohl mit Kundja geschehen, dass er mir keine Antwort gibt?" Er betrat das Rasthaus. Er sah die leere Fischreuse aber von seinem Gefangenen gewahrte er keine Spur. Auch sein Pfeilköcher und sein Blaserohr waren verschwunden. „Leha-lehan!"18 schrie Radja Peres zornig auf und rief seinen erstaunt herumstehenden und verwundert zuschauenden Sklaven: „Ooo meine Sklaven, Kundja ist nicht mehr hier, auch von seinen Waffen sehe ich keine Spur mehr. Gewiss hat er sich diese Nacht heimlich weggestohlen und ist entflohen. Macht euch rasch bereit, wir wollen ihn sofort verfolgen, vielleicht gelingt es uns ihn auf seiner Flucht wieder gefangen $z \mathfrak{u}$ nehmen oder zu töten". Sie eilten in die Häuser um ihre Waffen zu holen und begaben sich dann mit ihrem Besitzer in den Wald wo sie sich in einzelne Gruppen 
verteilten die das ganze Gebiet genau absuchen sollten. Von Zeit $\mathbf{z u}$ Zeit riefen sie sich gegenseitig $z u$ um sich $z u$ erkundigen ob schon Spuren des Flüchtlings gefunden worden seien oder nicht.

Kundja war noch nicht weit vom Dorf entfernt. Er hörte das Rufen und er merkte, dass die Stimmen immer näher kamen. Er erschrak sehr in seinem Herzen und beeilte sich noch mehr als vorher aus dem Bereiche seiner Verfolger wegzukommen und sein Dorf $z \mathfrak{u}$ erreichen. Plötzlich kam er an einen Fluss der breit und tief war und den er, da er keine Brücke fand, nicht überqueren konnte. Am Fluss stand aber ein hoher Baum mit weiten Aesten. Kundja war erfreut als er ihn sah und er erkletterte ihn rasch um sich vor seinen nahenden Verfolgern zu verstecken. Es dauerte auch nicht lange bis diese ebenfalls am Fluss eintrafen und dort eifrig nach den Spuren des Flüchtlings $\mathbf{z} \mathfrak{u}$ forschen begannen. Sie sahen um sich, sie untersuchten die Erde, sie schauten über den Fluss, aber sie fanden nichts. Als aber Radja Peres auf den Fluss blickte, sah er plötzlich das Schattenbild des Kundja auf dessen Oberfläche und vermeinend, dass er sich im Wasser versteckt hielt, rief er seinen Sklaven: „Hau-hau, meine Sklaven, was sehen meine Augen! Seht ihr nicht auch auf dem Fluss den Schatten des Kundja. Gewiss hat er sich ins Wasser gestürzt und ist untergetaucht und glaubte sich auf diese Weise vor uns verbergen und sich retten zu können. Geschwind, wir wollen ihn fangen". „Ajo!" 19 riefen die Sklaven, ,wir wollen uns ins Wasser stürzen und nach Kundja tauchen, gewiss gelingt es uns ihn gefangen zu nehmen". Die ganze Schar stürzte sich ins Wasser und tauchte unter, aber als sie nach einiger Zeit wieder an die Oberfläche kamen und immer noch das Schattenbild auf dem Wasser sahen, da schrieen sie laut auf: „Kaja-kajah! überall haben wir nach Kundja gesucht und ihn doch nicht gefunden und doch hält er sich immer noch im Wasser versteckt". Wiederum tauchten sie unter. Einige der Sklaven ertranken in dem tiefen und reissenden Fluss. Als sie aber wieder an die Oberfläche kamen hatte noch immer keiner von ihnen Kundja gesehen und doch lag immer noch sein Schattenbild deutlich auf dem Wasser.

„Es ist genug“, schrie Radja Peres, „es hat keinen Wert, dass wir noch länger tauchen, wir wollen ihn auf andere Weise aus seinem Versteck heraustreiben oder ihn darin töten. Wir wollen rasch turwe bereiten und es über das Wasser ausstreuen. 20 Has! gehen wir rasch in den Wald um turee tindjok zu suchen". Die ganze Schar verliess den Platz und begab sich mit ihrem Besitzer in den Wald hinein.

Als Kundja seine Verfolger nicht mehr erblickte kletterte er rasch 
und leise von dem Baum herunter und machte sich unbemerkt davon. Er sah nicht mehr um sich, sondern er lief so rasch er konnte. Schon sah er sein Dorf vor sich und sein Herz wurde froh, dass er sich nun in Sicherheit wusste, denn die Geister wagten das Dorf nicht zu betreten, der Tag war ja bereits angebrochen.

Nach einiger Zeit kehrte Radja Peres mit seinen Sklaven wieder an den Fluss zurück, beladen mit tuwe mit dem sie Kundja aus seinem Versteck $\mathbf{z u}$ verjagen, oder $\mathbf{z u}$ töten gedachten. Sie streuten das betäubende Gift über dem Wasser aus und warteten geduldig seine Wirkung ab, aber kein Kundja tauchte auf. Plötzlich sahen sie auch, dass sein Schattenbild von der Wasseroberfläche verschwunden war. Laut schrieen sie auf vor Zorn und Schmerz und unverrichteter Dinge mussten sie wieder in ihr Dorf zurückkehren, überlistet von einem Sterblichen, von einem Menschen aus dem Dorf am Ufer des Flusses der Welt.

Kundja's Angehörige waren sehr erstaunt als er plötzlich, wie ein gehetztes Wild, ins Dorf hereingelaufen kam, denn sie hatten bereits geglaubt, dass er im Walde umgekommen sei. Sie fragten ihn: „Wo hast du dich denn so lange aufgehalten? Wir suchten dich und konnten dich nicht finden, wir riefen deinen Namen, aber du gabst keine Antwort. Wir glaubten, dass du im Walde dein Leben verloren hättest. Weshalb läufst $d u$ in unser Dorf herein wie einer der von Feinden verfolgt wird?" Kundja erzählte ihnen ausführlich was ihm zugestossen sei und was er im Dorf des Radja Peres gesehen und gelernt hatte. Er zeigte seinen Verwandten das Eisenholz, den Tengang und Rotan und lehrte sie ihre Bearbeitung. Alles was er bei den Sklaven und Sklavinnen gesehen hatte lehrte er nun auch die Männer und Frauen seines Dorfes. Seit dieser Zeit kehrte in den Dörfern an den Ufern des Flusses der Welt Wohlfahrt ein und das Leben begann sich angenehm zu gestalten, dies alles durch Kundja unseren Ahnen der sich in das Dorf des Radja Peres verirrt hatte und von dort reiches Wissen an den Fluss der Welt zurückbrachte.

\section{Der Ursprung des Eisens 21}

Als Tiong Maliana, die Frau des Dandan Kahaian und die Stammmutter des Menschengeschlechtes 22 sich zum zweiten Male schwanger fühlte kam ein grosses Verlangen über sie nach der Leber eines Wildschweines. Sie teilte ihren Wunsch ihrem Manne mit und dieser versprach ihn gerne erfüllen zu wollen. 
Eines Morgens schnallte Dandan Kahaian seinen Pfeilköcher um und rief seinen Hunden. Er ergriff das Blaserohr, verliess sein Haus und begab sich auf die Jagd. Als er am Rande des Feldes angekommen war schlugen die Hunde an denn sie hatten ein Wild gewittert. Dandan Kahaian folgte seinen Hunden und bald sah er ein Wildschwein das sich durch den Busch und Wald flüchtete. Es war ein grosses Tier wie er noch keines gesehen hatte. Es war nicht ein gewöhnliches Wildschwein das vor seinen Hunden wegfloh, nein, es war der König aller Schweine der aus seinem Reiche Katungau ausgezogen war und nun die Wälder durchschweifte. Katungau liegt tief im Innern Borneo's. Die wilden Schweine leben dort unter einem König. Sie haben dort nicht die Gestalt von Schweinen sondern sie sind den Menschen gleich, nur haben sie, im Unterschied zu diesen, einen langen Bart und eine Schweinebrust. In diesem Reiche liegen drei Teiche. Will ein Bewohner von Katungau die Gestalt eines Schweines annehmen, dann badet er sich in ihnen. Entsteigt er dem ersten Teich dann haben seine Füsse die Gestalt von Schweinsfüssen angenommen. Entsteigt er dem zweiten, dann hat sich seine Haut in Schweinshaut verwandelt, kommt er aus dem dritten Teich heraus, dann besitzt er einen Schweinskopf. Menschen, die sich hierher verirren und ahnungslos in einem dieser Teiche baden, werden in Schweine verwandelt. Ist ein wildes Schwein erlegt und getötet worden, dann kehrte seine liau 23 (Totenseele) nach Katungau zurück und erhält dort wieder einen menschlichen Leib.

Dandan Kahaian folgt dem Schweine das sich vor seiner Nachstellung immer weiter flüchtete. Schliesslich war er ihm aber so nahe gekommen, dass er seinen Speer schleudern konnte. Er zielte gut und der Speer verfehlte sein Ziel nicht. Verwundet und stark blutend flüchtete das Tier weiter. Tag und Nacht flüchtete es durch den Wald und durch die Flüsse, unaufhörlich verfolgt von Dandan Kahaian und seinen Hunden. Es flüchtete nach dem Oberlauf des Kahaian, wandte sich von dort an den Malahoi, flüchtete nach dem Katingan und von dort an den Mambaroh, vom Mambaroh wandte es sich an den Serujan und von dort an den Mentaja. Vom Mentaja flüchtete es zurück an den Katingan, wandte sich an seinen Nebenfluss, den Samba und eilte erschöpft weiter nach dessen Nebenflüsslein, dem Mantikei, und bog von dort in den Koro ein. Es gelang ihm noch am Oberlauf dieses Bergbaches den Hügel Kereng Gambir zu erreichen wo es tot niederfiel. 24

Ueberall da wo sein Blut auf die Erde getropft war verwandelte es sich in Eisen. Auch sein grosser Körper wurde in Eisen verwandelt. 
Aber dieses Eisen ist sehr gefährlich, viel gefährlicher als das Eisen das aus dem Blute entstanden war, denn es ist giftig. Eine Wunde die mit diesem Eisen geschlagen wird heilt nicht mehr, sie frisst um sich und sie tötet den Menschen und keine Medizin und kein Opfer und kein Gelübde vermag das Unheil abzuwenden. Die ganze Umgebung des Flüssleins Koro und des Kereng Gambir ist giftig. Wer dort von einer Mücke gestochen oder einem Blutegel angefallen wird muss sterben, denn alle Tiere haben den Giftstoff des verendeten Schweines in sich aufgenommen. Von den frühesten Zeiten an bis jetzt fürchten die Menschen diesen Platz und wagen sich nicht in seine Nähe.

Nur ein Mensch war im Besitz dieses giftigen Eisens, Sempong, der Onkel des Bungai, einer der Stammväter der Ot Danum. 25 Auf seinen vielen Streifzügen kam er auch an den Koro und zum Kereng Gambir. Er war begleitet von zahlreichen Sklaven. Sie fühlten bald am eigenen Leib, dass diese Gegend lebensgefährlich war. Sieben Sklaven starben dahin, gestochen durch Mücken und angefallen durch Blutegel. Sempong fand das Eisen. Er wollte aus ihm eine Speerspitze schmieden, aber so oft er auch die Arbeit versuchte, sie gelang ihm nicht. Er rief deshalb die beiden Geister Njaring und Kalue 26 und bat sie um ihre Hilfe. Ihnen gelang das Werk und sie übergaben Sempong den geschmiedeten Speer. Wen dieser Speer trifft der stirbt, hinweggerafft durch das Gift des Eisens.

Bungai erbte von seinem Onkel Sempong diesen giftigen Speer. Wenn er ihn in die Höhe hob um einen Menschen niederzustechen, oder ihn nach einem Feind zu schleudern, dann sprach er zuerst die verderblichen Fluchworte, die Ursprungsgeschichte des Speeres aus:

„Gefunden wurde das Eisen von meinem Onkel Sempong, Am Flüsslein Djakang wurde herausgemeisselt das Eisen, Das vergiftet ist wie die Haare der Raupe.

Kalue, die einbrüstige, bediente den Blasebalg,

Njaring, der schiefmäulige, schmiedete es.

Sieben Mal in Gift getränkt ist es, in dem feurigen

Und untergetaucht im Teiche verfaulter Knochen.

Heilt eine Wunde, dann entsteht eine neue.

Heilt eine Wunde, immer wieder fliesst doch das Blut."

\section{E. Der Ursprung der Edelsteine und des Goldes 27}

Eines Tages sassen Maharadja Sangen, Maharadja Bunu und 
Maharadja Sangiang zusammen und unterhielten sich über dies und jenes. Und während sie plauderten, so wie die Hühner gackern, entdeckten sie plötzlich einen Elephanten und ein Nashorn. Die Augen des Elephanten waren von Edelstein, seine Haare waren von Edelstein und in seinen Adern floss statt Blut Edelstein. Das Nashorn hatte goldene Augen, goldene Haare und in seinen Adern floss Gold. Sie entschlossen sich sofort die beiden Tiere $z \mathfrak{u}$ fangen. Aber nun erhob sich unter ihnen ein Streit weil jeder von den dreien die Tiere für sich besitzen wollte. Maharadja Sangiang sagte: „Die Tiere gehören mir". „Nein“, rief Maharadja Sangen, „mir gehören sie, denn ich bin der Aelteste“. „Nein”, schrie Maharadja Bunu, ,die Tiere gehören mir, ich bin der Mittlere“. „Nein“, entgegnete Maharadja Sangiang wieder, „sie gehören mir, denn ich bin der Jüngste“. So stritten sie hin und her bis Maharadja Sangen entschied: „Hören wir doch mit unserem Streite auf denn auf diese Weise kommen wir zu keinem Ziel und schliesslich wird dann keiner von uns dreien die Tiere besitzen. Wir werfen nun unsere Speere nach dem Elephanten und Nashorn. Wer von uns dreien dann die geschlagenen Wunden wieder heilen kann, die wir den Tieren beibringen, der hat den Streit gewonnen". Seine beiden Brüder stimmten diesem Rate bei. Sie hiessen zuerst Maharadja Sangiang seinen Speer werfen, aber er antwortete: „Nein, das will ich nicht tun denn ich bin der Jüngste, werft ihr zuerst eure Speere“. „Recht so", sagte Maharadja Sangen, und er warf seinen Speer nach dem Elephanten der getroffen wurde, aber die Wunde heilte sofort wieder denn der Speer war von schwimmendem Eisen, 28 das nur verwunden konnte. Jede Wunde die mit ihm geschlagen wurde heilte aber sofort wieder. Nun warf Maharadja Bunu seinen Speer, aber mit dem gleichen Resultat, denn auch er besass schwimmendes Eisen. Schliesslich warf Maharadja Sangian seinen Speer. Auch er traf sein Ziel und verwundete den Elephanten und das Nashorn. Die Wunden die er aber geschlagen hatte schlossen sich nicht mehr, denn sein Speer war von sinkendem Eisen geschmiedet. 29

Als sich die Tiere verwundet fühlten flüchteten sie sich. Das Nashorn enteilte in den Wald, der Elephant rannte dem Meere zu. Die drei Brüder nahmen die Verfolgung auf. Jeder von ihnen schlug einen andern Weg ein und nach langer Zeit fanden sie sich wieder zusammen. Im Hause des Utan und Rohan, zwei alte Leute am Ufer des Flusses der Welt, kamen auch die Tiere wieder zusammen. Die beiden Alten sahen, dass die verwundeten Tiere nur mühsam weiterkamen. Sie nahmen sie auf, denn sie hatten Mitleid mit ihnen. Sie verpflegten sie 
und versorgten ihre Wunden. Aber es war ihnen nicht möglich die immer weiter um sich fressenden und eiternden Wunden $\mathrm{zu}$ heilen, obgleich sie viele Heilmittel anwandten, denn das Eisen war wie vergiftet. Die Tiere fühlten sich hier aber wohl und vor der Nachstellung ihrer Verfolger sicher.

„Tjeh",30 sprach das jüngste Kind des Ranjing Mahatala Langit kopfschüttelnd, „wo sind wohl meine Spielzeuge hingekommen, weshalb kehren mein Nashorn und mein Elephant solange Zeit nicht zurück, gewiss haben sie sich irgendwo verirrt". Er rief ihnen einmal, er rief ihnen siebenmal, aber sie kamen nicht und er hörte auch keinen Laut von ihnen. Da ergriff Darin Dara (so war der Name dieses jüngsten Sohnes) das Herzeleid, denn er hing sehr an diesen beiden Tieren. Er entschloss sich sie zu suchen. Er durchzog die ganze Oberwelt. Er kam von Fluss zu Fluss und von Dorf zu Dorf und fragte überall nach seinen vermissten Tieren aber nirgends konnte man ihm Auskunft geben und unverrichteter Dinge kehrte er wieder nach Hause zurück. Da entschloss er sich an die Ufer des Flusses der Welt hinunterzusteigen um auch dort seine Tiere zu suchen. Auf seinen Wanderungen kam er auch zum Haus des Utan und Rohan und sah bei ihnen seine beiden Tiere. Zornig wandte er sich gegen die Beiden und sagte zu ihnen: „Endlich finde ich hier meine beiden Tiere die ich schon so lange suche und wegen denen ich bereits die ganze Oberwelt durchzogen habe. Es ist schlecht von euch, dass ihr sie mir gestohlen habt". Sie antworteten ihm: „Wir haben dir diese Tiere nicht gestohlen, sondern sie haben sich ganz allein und schwer verwundet $z \mathfrak{u}$ uns geflüchtet und wir haben alles versucht um ihre Wunden zu heilen, aber kein Heilmittel hat geholfen". Und sie erzählten ihm weiter was sich ereignet hatte. Sie berichteten ihm von dem Streit zwischen den drei Brüdern und von dem verderblichen sinkenden Eisen aus dem der Speer des Marahadja Sangiang geschmiedet worden war und mit dem Wunden geschlagen werden können die nicht mehr heilen. Sie gaben ihm den Rat Maharadja Sangiang aufzusuchen weil er im Besitze wirksamer Heilmittel sei und ihn zu bitten um den Stiller des Blutes und den Heiler der Wunden, denn die Tiere würden zusehends magerer und wollten keine Speisen mehr zu sich nehmen. Nachdem er die Rede der beiden Alten gehört hatte machte er sich auf den Weg. Vor dem Hause des Maharadja Sangiang angekommen räusperte er sich laut: „Hm, hm, hm“. „Nur herein“, rief Maharadja Sangiang, „obgleich du mich von meinem Begehren abbringen willst, bist du mir dennoch willkommen, woher kommst du Darin Dara?" 
„Frage mich nicht", antwortete ihm dieser, „du hast mir schweres Herzeleid zugefügt. Du hast mit deinem Speer vom sinkenden Eisen mein Nashorn und meinen Elephanten schwer verwundet. Ihre Wunden heilen nicht mehr. Die Tiere magern ab und nehmen keine Speisen mehr zu sich. Du allein kannst sie wieder heilen, denn du hast die Heilmittel in deinem Besitz und Utan und Rohan, die meine Tiere pflegen, haben mich zu dir gewiesen um dich zu bitten um den Stiller des Blutes und den Heiler der Wunden“. „Ia“, antwortete Maharadja Sangiang, ,ich besitze diese Heilmittel und ich will sie dir auch geben, obgleich ich die Tiere für mich besitzen wollte". Mit diesen Worten übergab er Darin Dara die beiden Heilmittel und dieser kehrte mit ihnen erfreut zum Hause des Utan und Rohan zurück. Er bestrich die Wunden seiner Tiere mit dem Stiller des Blutes und dem Heiler der Wunden und alsobald wurden sie wieder gesund.

$\mathrm{Da}$ wo die Tiere auf ihrer Flucht aber durchgekommen waren und wo ihr Blut auf die Erde und ins Wasser geträufelt war finden die Menschen seit jener Zeit Gold und Edelsteine.

\section{REISBAU-MYTHEN}

\section{A. Der Ursprung des Reises}

Die Mythen über den Ursprung des Reises scheinen dürftig zu sein. Sie sind es nicht, nur ist das was wir bis jetzt darüber wissen ziemlich dürftig. Eine genaue Untersuchung der Oberwelt und aller mit ihr, ihren Bewohnern, Flüssen und Dörfern verbundenen Mythen, wird das vollständige, jetzt für die Ethnologie von Süd-Ost-Borneo immer noch fehlende, Material liefern. Die Arbeit ist zu umfangreich als dass sie in kurzer Zeit getan werden könnte (siehe Einleitung), erst später, und wahrscheinlich erst nach jahrelanger Untersuchung, wird es möglich sein das Mythenmaterial zu diesem und auch andern Gebieten lückenlos aufzunehmen und zu untersuchen. Ausser einer kurzen Erzählung die ich hier mitteile verweise ich auf die Besingung des Streureises die sich in den Texten zum Tantolak matei findet (siehe unten). In ihr teilt der Priester mehr mit, doch ist auch dieses Material noch nicht vollständig, es setzt wiederum die Kenntnis der Oberwelt voraus. Ich verweise auch auf die Mythe vom Ursprung des Radja Peres (siehe unten, Abschnitt IV. D).

Eine kurze viel gehörte und mir bekannte Erzählung berichtet folgendes: Eines Tages floss aus der Brust der Schwester 31 des Ranjing 
Mahatala Langit ein Tropfen Milch und fiel auf die Erde am Ufer des Flusses der Welt hinunter. Diese Milch verwandelte sich in Reiskörner die von den Menschen gefunden, zum Teil gegessen und, weil sie sehr schmackhaft waren, später wieder angepflanzt wurden. Seit dieser Zeit pflanzen und essen die Menschen Reis.

\section{B. Wie der Reis befruchtet wird 32}

Der Vogel Ganggang Ganggok Tampa Bua 33 ist nicht ein gewöhnlicher Vogel. Er besitzt Macht, denn er schafft die Früchte der Bäume und der Pflanzen. Er ist der König aller Vögel, denn er bereitet ihnen die Speise.

Eines Tages kam der Vogel Bronio zu ihm auf Besuch und im Laufe des Gespräches sagte er: „Ich bin der König aller Vögel“. „Nein“, entgegnete Ganggang Ganggok, „ich bin der König, denn ich besitze die Macht die Früchte der Bäume und aller Pflanzen zu erschaffen". "Nein“, schrie der Bronio, ,ich bin der König“. Lange und heftig stritten sie hin und her. Schliesslich sagte Ganggang Ganggok: „Ich will dir nun beweisen wer von uns beiden wirklich der König ist".

Nachdem er so gesprochen hatte flog er von der Insel Borneo weg und liess sich auf der Insel Java nieder.

Die Bäume auf Borneo liessen ihre Blätter fallen und trugen keine Früchte mehr und die Pflanzen vertrockneten. Ueber die Vögel auf Borneo brach eine furchtbare Hungersnot herein. Unruhig flogen sie umher, viele von ihnen fielen erschöpft und tot auf die Erde, denn nirgends vermochten sie mehr Nahrung zu finden. Schliesslich versammelten sie sich und beratschlagten was zu tun sei um diese Not abzuwenden, die über sie hereingebrochen war weil Ganggang Ganggok, beleidigt durch den Bronio, die Insel Borneo verlassen hatte. Sie entschlossen sich ihm eine Botschaft zu senden und ihn zu bitten doch wieder nach Borneo zurückzukehren weil sonst alles sterben müsse. Sie beauftragten den Vogel Karawambang Burai sich zu Ganggang Ganggok zu begeben, ihm ihre grosse Not zu erzählen und ihn $z \mathfrak{u}$ bitten doch wieder heimzukehren. Karawambang Burai flog sofort weg und kam nach einiger Zeit auf der Insel Java an wo er Ganggang Ganggok fand. Er brachte ihm die Rede und die Bitte aller Vögel auf Borneo vor und erzählte ihm von der grossen Not die hereingebrochen sei und durch die sie ausgerottet würden. Ganggang Ganggok hörte die Rede und vernahm die Bitten und er sprach schliesslich zu Karawambang Burai: „Ich kann mich nicht entschliessen wieder nach Borneo 
zurückzukehren, denn ich habe nun hier eine neue Heimat gefunden, aber ich will euch helfen und eure Not wenden. Ich habe in Borneo meine Kinder zurückgelassen. Sucht sie! Wenn ihr einen lebenden Baum findet, dann untersucht ihn genau. Ihr werdet ein Nest finden. In diesem Nest liegen zwei Eier. Schaut gut zu diesen Eiern bis sie ausgebrütet sind. Durch meine Kinder wird eure Not gewendet werden". Mit diesem Bericht kehrte Karawambang Burai wieder nach Borneo zurück. Er rief alle Vögel zusammen und lud auch die vierfüssigen Tiere zur Versammlung ein und er teilte ihnen mit was ihm Ganggang Ganggok gesagt hatte.

Die Vögel und Tiere machten sich sofort auf um den lebenden Baum zu suchen. Sie durchstreiften die Wälder und kamen plötzlich zu einem mit reichem Blätterschmuck überladenen und blühenden Padjundjungbaum. In seinen Aesten fanden sie ein Nest in dem zwei Eier lagen. Sie beratschlagten was mit ihnen zu tun sei und sie entschlossen sich die Schalen zu reiben bis sie springen würden. So taten sie. Die Eier wurden warm und nach einiger Zeit sprangen die Schalen und die jungen Ganggang Ganggok krochen aus ihrer Umhüllung heraus. Aber sie waren noch hülflos und sie mussten gut bewacht und gefüttert werden. Die Vögel beratschlagten wem von allen Tieren diese Aufgabe anvertraut werden sollte.

Die Bewachung übertrugen sie dem Orang Utan weil er ein tapferes und starkes Tier war. Aber der Orang Utan verrichtete sein Amt sehr nachlässig. Er passte wenig auf seine Schützlinge auf und so konnte es geschehen, dass sie eines Tages aus ihrem Nest in die dichten Dornen fielen. Unter den Vögeln und Tieren entstand grosse Bestürzung. Sie versammelten sich um diesen schwierigen Fall, der sie in Not brachte, gemeinsam zu besprechen. Alle Vögel und Tiere verfluchten den Orang Utan und sprachen: „Wir verfluchen dich weil du deine Pflicht nicht erfüllt hast. Hinfort sollst du sterben wenn du eine Frucht ganz verschluckst. Sie bleibe dir im Mastdarm stecken". Von dieser Zeit an wagt der Orang Utan nicht mehr die Früchte ganz zu verschlucken, er isst nur noch sorgfältig das Fruchtfleisch. Vergisst er sich aber einmal und isst er eine Frucht gar zu hastig, dann erfüllt sich der Fluch der Tiere an ihm und er muss sterben.

Darnach beschlossen alle Tiere dem Eichhorn den Auftrag zu geben die aus dem Neste gefallenen Vögel aus den Dornen zu befreien und in ihr Nest zurückzubringen. Sie brachten ihm ihren Beschluss als Bitte vor. "Ja“, sprach das Eichhorn, „ich erfülle euren Wunsch gern aber ich stelle die Bedingung, dass ihr nicht vor mir die reifen Früchte esst. 
Ich will unter allen Tieren das erste sein, das dies tun darf". Die Tiere nahmen seine Bedingung an. Das Eichhorn begab sich in die Dornen und holte die jungen Vögel heraus und brachte sie in ihr sicheres Nest zurück. Seit dieser Zeit aber isst es immer zuerst die reifen Früchte.

Die Vögel gaben dem Goldvogel den Auftrag die beiden jungen Vögel in seine Obhut $\mathbf{z u}$ nehmen und seine Pflichten besser $\mathbf{z u}$ erfüllen als der Orang Utan. Die beiden Ganggang Ganggok gediehen prächtig unter der guten Pflege des Goldvogels. Sie wurden älter und grösser und als sie erwachsen waren übernahmen sie die Arbeit ihrer Mutter und wurden die Schöpfer der Früchte aller Bäume, aller Pflanzen und auch des Reises. Seit dieser Zeit sind nun alle Vögel dem Ganggang Ganggok untertan und bezahlen ihm ihren Tribut.

Seit dieser Zeit richten die Menschen, bevor sie den Saatreis ausstreuen, auf dem Felde ein Opfergestell auf und hängen es an die abgebrochenen Aeste eines Padjundjungbaumes und füllen es beim Pflanzen des Reises und bei der Ernte mit drei Klumpen gekochtem Reis als Opfer für den Schaffer der Früchte und den Füller der Reisscheuern.

Wie die Vögel und Tiere ist auch der Mensch von seinen Gaben abhängig.

\section{Panjat besucht Djangkarang Matanandau 34}

In früheren Zeiten lebte ein Mann namens Panjat. Bei seinen Feldarbeiten hatte er kein Glück sondern erlebte immer wieder Missernten. Legte er seine Felder auf den Hügeln an, dann zerstörte die brennende Sonne seinen Reis. Legte er sie aber in der Nähe des Flusses an, dann wurden sie vom Hochwasser vernichtet. So hatte er immer Reismangel und litt Hunger. Eines Tages gab ihm seine Mutter den Auftrag den Reis auf der Matte zum Trocknen ins Freie zu tragen. Er brachte ihn auf das Landungsfloss hinunter und setzte sich dann in den Balai um von dort aus auf den Fluss herunterzuschauen und seinen Reis zu bewachen damit er von den Hühnern nicht weggepickt würde. Um seine Zeit nützlich zu vertreiben flocht er ein wenig, aber weil es ein heisser Mittag war wurde er bald schläferig und legte sich auf den Boden. Er schlief bald ein. Während er aber schlief erhob sich ein heftiger Wind und der Regen begann in schweren Tropfen zu fallen. Panjat erwachte und schaute enschrocken um sich. Sofort eilte er zum Landungsfloss um seinen Reis in Sicherheit zu bringen, aber als er zur Treppe 
trat die an den Fluss und zum Floss herunterführte konnte er gerade noch zuschauen wie ein heftiger Windstoss den Reis mit der Matte in den Fluss hinauswehte. Alles war verloren. Kein Korn fand sich mehr.

Betrübt kehrte Panjat in den Balai zurück und setzte sich weinend auf den Fussboden und dachte seinem Unglück nach. Wieviele Jahre hatte er nun doch schon gearbeitet. Nie war ihm etwas gelungen. Nicht nur seine Felder wurden zerstört, auch der wenige Reis den er noch besass und den er trocknen wollte verfiel dem Unglück. Wer war Schuld an dem allem? Wohl kein anderer als Djangkarang Matanandau der sich ihm immer nur feindlich zeigte, ihm die Felder zerstörte und auch jetzt dem Wind und Regen erlaubt hatte den Reis in den Fluss hinauszuwehen. Immer zorniger wurde er in seinem Herzen über den gewalttätigen Djangkarang Matanandau und er beschloss ihn $\mathbf{z u}$ besuchen und ihn wegen seiner feindseligen Haltung zur Verantwortung zu ziehen. Lieber umkommen als Jahr für Jahr immer wieder aufs neue diese willkürliche Handlungsweise des Djangkarang Matanandau zu ertragen!

Inzwischen war seine Mutter zitternd und zähneklappernd vor Kälte $z u$ ihm herausgetreten und er erzählte ihr was mit dem Reis geschehen war und was er sich soeben in seinem Herzen vorgenommen hatte zu tun.

Sie bat ihn mit ihr ins Haus zurückzukehren und dort nahmen sie das einfache Mahl zu sich das nur aus einigen Knollengewächsen und Farnblättern bestand, denn Reis hatten sie keinen mehr. Panjat rührte die Speise nicht an, finster brütete er vor sich hin.

Am andern Morgen früh schnallte er seinen Pfeilköcher um und ergriff das Blaserohr und verliess das Haus. Hinter dem Dorf schritt er in den Wald hinein um sich Gift zu suchen mit dem er die Spitzen der Blaserohrpfeile vergiften wollte. Er schritt über sieben Hügel hinweg und schliesslich erblickte er einen Sirenbaum dessen Saft sehr giftig ist und der von den Menschen gebraucht wird um die Pfeilspitzen zu vergiften. Der Baum fragte ihn: „Woher kommst du und wohin willst du, Panjat?" „Zu dir komme ich“, antwortete Panjat, „denn ich möchte dich bitten, dass du mir von deinem Saft gibst damit ich meine Pfeilspitzen vergiften kann, doch sage mir vorher, ist dein Gift rasch wirksam?"“

Der Sirenbaum antwortete ihm: „Wenn der Pfeil am Morgen trifft, dann tötet das Gift am Nachmittag“. „Ich danke dir,“ sagte Panjat, „zürne mir nicht, ich kann leider dein Gift nicht gebrauchen denn es tötet zu wenig rasch". Dann wanderte er weiter. Wieder schritt er 
über sechs Hügel hinweg und als er beim siebenten ankam sah er auf seiner Höhe einen andern Sirenbaum der ihm durch seine Grösse und seine weitausladenden Aeste auffiel. Als er näher herzutrat sah er, dass die Erde um den Baum herum mit Knochen von Tieren und Vögeln besät war und dass, soweit der Schatten des Baumes reichen mochte, keine Pflanze gedeihen konnte. Der Baum fragte ihn: „Woher kommst du Panjat und wohin willst du?" Er antwortete: „Zu dir komme ich, denn ich möchte dich bitten, dass du mir etwas von deinem Safte gibst damit ich meine Pfeilspitzen vergiften kann, doch sage mir vorher wie rasch dein Gift wirkt.“ Der Baum entgegnete: „Sobald mein Gift in den Körper eingedrungen ist tötet es sofort, du kannst dich selbst davon überzeugen, dass in meiner Nähe keine Pflanze gedeihen kann, dass die Vögel, die sich auf meinen Zweigen niedersetzen, leblos zu Boden fallen und die Tiere, die sich meinem Stamme nähern tot umsinken. Nimm dir nur soviel Gift als du nötig hast, ich gebe dir gerne die Erlaubnis dazu und werde dir keinen Schaden zufügen". Panjat dankte dem Baum und begab sich in den Wald um Bambusköcher zu schneiden als Gefässe für den giftigen Saft. Dann ritzte er den Baum ein wenig in seine Rinde und stellte das Gefäss darunter und begab sich wieder in den Wald und suchte Blätter um den Köcher damit einzuwickeln und er schnitt weiches Holz um aus ihm Pfeiltrichterchen anzufertigen. Dann kehrte er zum Sirenbaum zurück, nahm das mit giftigem Saft gefüllte Gefäss, dankte dem Baum für seine Gabe und kehrte nach Hause zuruck.

Am andern Morgen schnitzte er Pfeile, bestrich sie mit dem Gift und legte sie zum Trocknen nieder.

Tags darauf band er sich den Pfeilköcher um und ergriff das Blaserohr und verliess das Haus. Er begab sich hinter das Dorf. Dort angekommen blies er sieben Pfeile in die Höhe. Sie bildeten sofort eine Kette. Dann sprach er: „Wenn ich wirklich göttlichen Geschlechtes bin (d. h. wenn ich aus der Oberwelt stamme und dort meine Ahnen habe), dann geschehe alles nach meinem Wunsch und Wort". Er berührte die Pfeilkette und sprach: „Werde zu einer starken Schlingpflanze an der ich zum Himmel hinaufklettern kann und bringe mich vor das Dorf des Djangkarang Matanandau". Es geschah wie er gesprochen hatte. Nun kletterte er an der Schlingpflanze empor und kam an die Türe des Himmelsgewölbes. Er trat durch sie ein und fand einen Weg der zu einem grossen Dorf hinführte. Er wanderte auf dem Wege dahin und es dauerte nicht lange bis er das Dorf erreicht hatte. Wie erstaunt war er über alles was seine Augen sahen. Alle Menschen denen er be- 
gegnete trugen schwarze Kleider. Junge und Alte, Männer und Frauen, sie alle waren eigentümlich schwarz gekleidet.

Er sprach die Leute an und fragte sie: „Wem gehört dieses Dorf?“ Sie antworteten ihm: „Es ist das Dorf des Djangkarang, des Königs der Sonne.“ „So, wohnt er hier", erwiderte Panjat, ,,ist er heute wohl zu Hause?" "Ja“, antwortete ein Sklave des Djangkarang Matanandau, „er befindet sich in seinem Haus“. „Gut“, sagte Panjat, „aber was für eine eigenartige Sitte habt ihr hier eigentlich in euerem Dorf? Warum trägt alles schwarze Kleider? Habt ihr keine andern?" „Natürlich haben wir auch andere Kleider", antwortete der Sklave, ,aber wir tragen immer die gleichen Kleider wie unser Herr. Trägt er weisse Kleider, dann tragen wir auch weisse. Trägt er rote Kleider, dann tragen wir alle auch rote. Trägt er aber schwarze Kleider, wie zum Beispiel heute, dann tragen wir alle auch schwarze“. „Hau, ist das so“, versetzte Panjat und ging weiter seines Weges bis er in der Mitte des Dorfes ankam. Dort setzte er sich in den Balai wie es sich Fremden ziemt und von hier aus sah er, dass in dem Dorf alles ganz schwarz war.

Nicht lange darnach kam Djangkarang Matanandau der ihn bereits im Balai erblickt hatte und fragte ihn: „Woher kommst du Panjat und was willst du hier?" Er antwortete ihm: „Ich komme nur so von ungefähr in dein Dorf, ich möchte dich gerne einmal besuchen und ich möchte auch mit dir sprechen. Du weisst, dass ich ein armer Mensch bin der drunten im Dorf am Ufer des Flusses der Welt zu Hause ist. $\mathrm{Du}$ bist ein reicher König und hast grosse Macht und nichts ist dir verborgen. Ich komme heute $z \mathfrak{u}$ dir um dich zu bitten das Wetter etwas zu ändern und zu verbessern, denn siehst du, mit meiner Mutter zusammen baue ich Reis. Haben wir unsere Felder auf den Hügeln angelegt, dann verbrennst du uns unseren Reis und vernichtest unsere Ernte, legen wir sie aber beim Fluss an dann lässt du es regnen bis der Fluss hoch anschwillt und das Hochwasser unsere ganze Ernte wiederum zerstört. Schon seit Jahren arbeiten wir immer vergeblich. Immer hast du uns unsere Ernten zerstört und deshalb leiden wir Mangel und haben nie genug Reis um unseren Hunger zu stillen".

Wütend schrie Djangkarang Matanandau auf: „Was fällt dir denn auch ein Panjat, was unterstehst du dich mir so gegenüber zu treten! Willst du mich etwa belehren was ich $z \mathfrak{u}$ tun und $z \mathfrak{u}$ lassen habe! Bin ich nicht ein reicher König! Habe ich nicht die Macht um zu tun und $z \mathfrak{u}$ lassen was ich will! Unterstehen mir nicht alle Dinge! Was habe ich mich um dich zu bekümmern?" "Ja“, sagte Panjat, „dein Rede ist wahr, aber ich bitte dich nochmals, dass du nicht so willkürlich sein 
mögest. Lasse es nicht regnen und dann wieder die Sonne scheinen wie es dir gerade einfällt und wie es dich gut dünkt. Schenke uns Monate die trocken sind und gib uns andere in denen der Regen fällt damit wir unseren Reis bauen und ernten können und nicht Mangel zu leiden brauchen".

Laut schrie Djangkarang Matanandau auf vor Zorn und rief wütend: „Was fällt dir denn auch ein! Was du von mir bittest kann ich dir nicht gewähren. Was verstehst du denn von diesen Dingen? Eure Jahresund Monatseinteilung gehen mich nichts an. Ich kenne sie nicht und will sie auch nicht kennen. Ich habe eine eigene und andere Zeiteinteilung für mich. Trage ich schwarze Kleider, dann ist alles schwarz (Regenzeit). Trage ich rote Kleider, dann ist alles rot (Trockenzeit). Trage ich aber weisse Kleider, dann ist alles weiss (die Zwischenzeit zwischen Ernte und Neubeginn der Feldarbeiten in der die Feste gefeiert werden). Kein Mensch hat mir da darein zu reden und mir zu raten wie ich es machen solle oder nicht. Ich lasse mir von niemandem befehlen, ich bin mein eigener Herr und Meister. Willst du aber meine Kraft und Tapferkeit versuchen, dann wohlan. Nähere dich, damit wir miteinander kämpfen“. „Das kann geschehen“, sprach Panjat. „Ich habe mich nicht gefürchtet $z u$ dir in dein Dorf zu kommen und dir meine Bitte vorzubringen, wie sollte ich mich nun fürchten zu kämpfen und vielleicht zu sterben". Nach diesen beiden Worten sprangen die beiden Gegner vom Balai auf die Erde. Während Djangkarang Matanandau in sein Haus zurückkehrte um seine Waffen zu holen blies Panjat durch sein Blaserohr einen vergifteten Pfeil um den andern nach den Wasserbüffeln, Kühen, Schweinen, Hühnern und Sklaven des Djangkarang Matanandau und was er traf fiel tot zur Erde. Dann zielte er auf Djangkarang Matanandau der inzwischen wieder bewaffnet aus dem Hause getreten war. Als er aber die vielen Tier- und Menschenleichen sah, da entfiel ihm der Mut und er befürchtete durch Panjat ebenfalls getötet zu werden. Er sprach deshalb zu ihm: „Verzeihe mir meine Worte, o mein Bruder. Ich verspreche dir deine Wünsche anzunehmen und mich nach ihnen zu richten. Ich will tun wie du mir gesagt hast. Fortan sollen Monate des Regens und solche des Sonnenscheins sein. Deine Ernten werden dir in Zukunft gelingen und du wirst keinen Mangel mehr leiden müssen. Wir wollen heute diesen Bund miteinander schliessen. Erzähle diese Geschichte später deinen Kindern und Enkeln und diese sollen sie wieder ihren Kindern erzählen. Wer von ihnen diese Geschichte weiss der soll heilvoll sein (salamat) und in Frieden leben (sanang pambelome). In den günstigen Monaten wird er 
sein Feld anlegen und in den günstigen Monaten wird er auch ernten. So wird es ihm möglich sein einen genügenden Reisvorrat anzulegen und hinfort wird an den Ufern des Flusses der Welt kein Mangel mehr herrschen und kein Hunger die Menschen überfallen".

Panjat freute sich sehr über diese Worte und über den Bund den er für sich und seine Nachkommen mit Djangkarang Matanandau geschlossen hatte. Er dankte ihm und kehrte auf dem gleichen Wege, auf dem er gekommen war, wieder in sein Dorf am Ufer des Flusses der Welt zurück.

Seit dieser Zeit aber ist die Sonne fern von den Menschen, denn Djangkarang Matanandau fürchtet sich vor der Wiederholung eines solchen Besuches und den Menschen ist es auch nicht mehr möglich in die Oberwelt und zum König der Sonne hinaufzusteigen. Djangkarang Matanandau aber hielt seinen Bund und alle die diese Geschichte kennen und sie vor dem Beginn der Feldarbeiten rezitieren haben Heil und Frieden. Sie erzielen immer reiche Ernten und haben volle Speicher und brauchen keinen Mangel und keinen Hunger zu leiden.

\section{DER URSPRUNG DER STAENDE}

Der Dajak von Süd-Ost-Borneo unterscheidet zwei Stände, den der Freien und den der Sklaven. Sie sind mit der Weltwerdung gegeben oder gehen in einzelnen Fällen zurück auf eine neue Menschwerdung durch die die Sklaven entstehen. Das zeigen die beiden letzten Mythen dieses Abschnittes. Diese beiden Stände heissen utus bangsarean und utus djipen. Utus = Stand, Volk, d.h. ein Stand oder ein Volk das von den gleichen Ahnen abstammt. Bangsarwan (mal. = edel), bedeutet die gleiche Abstammung habend von den überweltlichen Ahnen. Statt utus bangsawan hört man auch oft den Ausdruck utus bahalap, der ebenfalls den Stand der Freien bezeichnet. Bahalap heisst gut oder schön, wird aber hier weder im ethischen noch ästhetischen Sinne gebraucht sondern dient als Bezeichnung des Blutes (daha bahalap), das deshalb gut ist, d.h. in Uebereinstimmung mit der Welt- und Menschwerdung und ihren bindenden Ordnungen (hadat), weil es von den gleichen Ahnen herkommt und damit die Gemeinschaft des Blutes, das man den gleichen, deifizierten, Ahnen zu verdanken hat, begründet und zum Ausdruck bringt. Neben dem Stand der Freien besteht, von der Weltwerdung her, der Stand der Sklaven (utus djipen). Im Gegensatz zum 
Ausdruck utus bahalap gebraucht man für diesen Stand auch die Bezeichnung utus papa. Papa bedeutet schlecht oder hässlich und wird hier ebenfalls nicht im ethischen oder ästhetischen Sinne gebraucht sondern ebenfalls zur Andeutung der Blutsgemeinschaft, die insofern papa ist als man mit ihr nicht die gleichen Ahnen besitzt und es gegen alle religiösen und sozialen Ordnungen und Lebensgesetze (hadat) wäre, wenn man sich durch Heiraten mit ihr vermengen würde.

Im Heiratsrecht der Freien finden wir diesen Sprachgebrauch von bahalap und $p a p a$ nicht obgleich man hier auch Gruppen unterscheidet deren Angehörige nicht miteinander heiraten dürfen weil es gegen die Ordnungen wäre. Diese Gruppen werden nicht mit den Ausdrücken bahalap und papa bezeichnet und unterschieden, sondern mit den Benennungen gantong (hoch) und randah (nieder).

Die Ausdrücke bahalap und papa haben mit der Zeit, in ihrer Anwendung auf die beiden Stände der Freien und Sklaven, auch eine ethisch/ästhetische Färbung bekommen, wenn diese ihnen ursprünglich vielleicht auch nicht eigen war. Für diesen besonderen Fall würde man die Ausdrücke besser übersetzen mit vollkommen und unvollkommen .35 Der Freie kann ein vollkommener Mensch werden, der Sklave aber nicht, ausser er werde ein Freier.

Die Unterscheidung von drei Ständen, die u.a. auch von Mallinckrodt gemacht wird ${ }^{36}$, scheint mir unrichtig zu sein. Trotz aller Argumente die dafür scheinbar ins Feld geführt werden können, haben wir in erster Linie auf die einheimische Terminologie $z u$ achten und wir dürfen nie die Unterscheidung von gantong und randah und ihre wirkliche Bedeutung aus dem Auge verlieren. Das unrichtige Verständnis dieser Ausdrücke und die unrichtige Unterscheidung die man gemacht hat, haben dann auch dazu geführt, dass man die Freien in zwei Stände, einen hohen, nämlich den sogenannten Adel, und einen niederen, nämlich die gewöhnlichen Freien, einteilte. Das ist unrichtig. Gantong und randah bezeichnen keine Stände sondern Gruppen.

Gerade diese Terminologie, die zu so vielen Missverständnissen Anlass gegeben hat, beweist uns auch heute, zusammen mit den Funktionen von verschiedenen Gruppen bei wichtigen Handlungen und Arbeiten, dass wir nur von zwei Ständen zu sprechen haben und die übrige Einteilung, die man heute oft vornimmt, nicht in der ursprünglichen Ständeordnung zu suchen haben, sondern in der Stammesorganisation und Claneinteilung die heute aufgelöst ist aber in so manchen Handlungen noch zäh fortlebt. Wir begegnen ihnen ausführlich im II. Band dieses Werkes. 


\section{A. Der Ursprung der Freien 37}

Nach einer Erzählung, die man vor allem unter den Ngadju-Dajak, aber auch unter den andern Stämmen, findet, wurden die Menschen aus der Oberwelt an die Ufer des Flusses der Welt heruntergelassen. Die Freien kletterten an goldenen Seilen herunter, aber die Sklaven benützten dazu nur Holzstangen. Dem goldenen Seil begegnen wir später noch, denn er wird immer dann verwendet wenn Freie aus der Oberwelt an den Fluss der Welt heruntersteigen um sich an ihm niederzulassen.

\section{B. Der Ursprung der Sklaven 38}

Obgleich mit der Weltwerdung der Stand der Sklaven gegeben ist finden wir doch zahlreiche Mythen die uns erzählen, dass auch später, durch Verwandlung von Gegenständen und Tieren, Sklaven entstanden sind. Diese Mythen sind überaus zahlreich. Von ihnen vermelde ich zwei. So berichtet eine dieser Mythen:

In früheren Zeiten lebte ein Mann der mit seiner Familie eine kleine Hütte auf dem Felde bewohnte. Nach zwei oder drei Jahren legte er sich an einer andern Stelle des Waldes sein Reisfeld an (der Reis wird nur zwei, höchstens drei Jahre auf dem gleichen Felde gepflanzt). Er baute sich dort eine neue kleine Hütte. Vor der Ernte bezog er sie mit seiner Familie und brachte auch seine ganze Habe dorthin. Da erinnerte er sich plötzlich, dass er in seiner alter Hütte sein Salzsäcklein liegen gelassen hatte. Er kehrte am andern Morgen zuruck um es zu holen. Als er die Hütte betrat sah er zu seinem grossen Erstaunen, dass dort wo das Salzsäcklein zu liegen pflegte ein kleines Mädchen stand das er noch nie gesehen hatte und das er auch nicht kannte. Das Salzsäcklein aber war und blieb verschwunden. Da wusste er, dass es sich in dieses kleine Mädchen verwandelt hatte. Er nahm es mit sich und gab ihm den Namen Balasai Kahing (Salzsäcklein) und behielt es fortan als Sklavin in seinem Haus.

\section{Die Geschichte des Antang Taui 39}

Ein Mann von Tangkahen mit Namen Antang Taui, der sich in Baras Manjang 40 verheiratet hatte, war eines Tages mit seinen Sklaven damit beschäftigt, einen Weg durch den Urwald hindurch anzulegen der die 
beiden Dörfer miteinander verbinden sollte. Im Walde errichteten sie ein kleines Hüttlein, wo sie zu Mittag essen wollten, und sie stellten inzwischen den mitgebrachten Reistopf dort hinein. Während sie aber an der Arbeit waren kam ein kleines Kind. Es stieg in das Hüttlein hinein und ass von dem Reis und von der Zuspeise. Um die Mittagszeit kehrte Antang Taui mit seinen Sklaven hungrig von der anstrengenden Arbeit zum Hüttlein zurück. Aber siehe da, von der Mahlzeit war nur noch ein kleiner Rest vorhanden. „Wer hat den Reis gegessen ?” fragte Antang Taui seine Sklaven. Niemand wusste es zu sagen. Missmutig kehrten die Männer ins Dorf zurück um dort ihre Mahlzeit einzunehmen. In der Frühe des andern Tages machten sie sich, ausgerüstet mit einem grossen gefüllten Reiskessel, wieder auf den Weg um die Arbeit fortzusetzen. Wieder stellten sie den Kessel in das erstellte Hüttlein. Aber als sie um die Mittagszeit essen wollten, war wiederum fast alles verschwunden, und sie waren nochmals gezwungen ins Dorf zurückzukehren.

In der Frühe des dritten Tages stellten sie wiederum den mitgebrachten Reis und die dazugehörende Zuspeise in das kleine Hüttlein um die Arbeit der beiden vergangenen Vormittage fortzusetzen. Vor der Mittagszeit schlich sich Antang Taui leise und behutsam an das kleine Hüttlein heran, um dem frechen Reisdieb aufzulauern. Kaum lag er auf der Lauer, siehe da kam ein kleiner Knabe herbeigesprungen, erstieg die Leiter zu dem kleinen Hüttlein, setzte sich vor dem Reistopf auf den Boden, nahm den Deckel vom Topf und begann zu essen. Während sich das Kind über das reichliche Essen hergemacht hatte, sprang Antang Taui voller Entrüstung in das Hüttlein und packte den kleinen Reisdieb an Händen und Füssen und hielt ihn fest.

„Du darfst mich nicht töten!“ bat der Knabe. „Ich will euch zeigen, in welcher Richtung ihr den Weg nach Tangkahen anlegen müsst. Der von euch begonnene Weg ist nämlich falsch. Wenn ihr bereit seid meinem Rat und meiner Weisung zu folgen, bekommt ihr einen Weg, auf dem ihr Tangkahen in einem Tag erreichen könnt. Wollt ihr aber den von euch geplanten und begonnenen Weg zu Ende führen, so benötigt ihr zum Gehen von Baras Manjang nach Tangkahen mindestens zwei oder drei Tage".

„Sind deine Worte wirklich wahr?" entgegnete Antang Taui und liess den Knaben wieder los, ,dann geh mit mir ins Dorf zurück”. „Gut", antwortete das Kind, „morgen wollen wir dann mit der Arbeit beginnen".

Daheim fragte Antang Taui's Frau Tapih: „Woher kommt denn 
dieser Knabe?" „Ich weiss es nicht“, antwortete Antang Taui. „Seine Herkunft und seine Abstammung sind mir unbekannt. Dieses Kind ist der Reisdieb, der uns gestern und vorgestern unseren Reis weggegessen hat. Heute schlich ich mich aber, bevor Essenszeit war, an das Hüttlein heran und habe dort den Reisdieb beim Essen erwischt. Sofort packte ich den Dieb und hielt ihn fest. Der Knabe aber bat mich : „Töte mich nicht, ich will euch den richtigen und kürzesten Weg nach Tangkahen zeigen. Morgen wollen wir mit der Arbeit beginnen. Darum habe ich nun den Knaben mit heimgebracht". Tapih gab sich mit der von ihrem Manne erhaltenen Auskunft nicht zufrieden. Immer wieder fragte sie: „Woher kommt denn das Kind? Wer sind seine Eltern und Voreltern?" Schliesslich gab sich der Knabe zu erkennen: „Ich will euch nicht belügen und euch die Wahrheit sagen. Ich bin kein Mensch, sondern ein Waldtier und heisse Ake. Weil ich mich über euch erbarme und euch bei der Anlegung des Weges behilflich sein will, habe ich Menschengestalt angenommen."

In der Frühe des andern Tages liess Antang Taui sich und seine fünfzehn Sklaven von Ake in den Wald führen. Ake, der den Wald aufs genaueste kannte, ging voran und brach in der Richtung in der die Sklaven des Antang Taui den Weg zu lichten hatten, Zweiglein von den Bäumen. Antang Taui und seine fünfzehn Sklaven folgten dem Knaben.

Bald war das Werk vollbracht. Der dichte Wald war von Baras Manjang nach Tangkahen durchbrochen. In der Morgenfrühe traten sie von Tangkahen aus den Rückweg an. Und siehe, mit dem sinkenden Abend waren sie wieder daheim in Baras Manjang angelangt.

Antang Taui war erfreut über den gut gelungenen Weg und er bat Ake: „Bleibe bei uns. Ich will für dich sorgen und dich erhalten. Du darfst dich nicht mehr in ein Waldtier verwandeln". Ake war es zufrieden und er blieb bei Antang Taui.

Eines Abends wollte Antang Taui mit seinen Sklaven mit Hilfe des grossen Wurfnetzes Fische fangen. Als sie nach dem ersten Wurf das Netz aus dem Wasser zogen, hatten sie nur einen kleinen Tahumanfisch gefangen. Ein Sklave des Antang Taui nahm den Fisch aus dem Netz und legte ihn unter den Bretterboden des Nachens. Wiederholt warfen sie das Netz aus und fingen noch viele andere Fische. Plötzlich überzog sich der Himmel mit finsteren Wolken. Ein jäher Sturm und ein furchtbares Gewitter brach los. Der Regen floss in Strömen hernieder.

Eilends ruderte Antang Taui mit seinen Sklaven an den heimatlichen Landungssteg. Dort angekommen, befahl er seinen Sklaven: 
„Holt die gefangenen Fische aus dem Nachen, nehmt sie aus und richtet sie zu".

Die Sklaven taten, wie ihnen ihr Herr befohlen hatte. Sie holten die gefangenen Fische unter dem Holzboden des Nachens hervor, töteten sie und nahmen sie aus. Doch den Tahumanfisch vergassen sie. Als Antang Taui die von seinen Sklaven zum Kochen zubereiteten Fische sah, sagte er verwundert: „Boh 41, wo habt ihr denn den Tahumanfisch?" „Vergessen“, antworteten die Sklaven. „Er ist noch im Boot”. „Dann wollen wir ihn bis morgen früh im Nachen liegen lassen und ihn dann als Zuspeise zum Morgenreis verzehren", entschied Antang Taui. Als der Sklave am nächsten Morgen den Holzboden des Nachens in die Höhe hob, siehe, da sass ein kleines Mädchen darunter. Aber den gesuchten Tahumanfisch konnte der Sklave nirgends finden. Da nahm er das Mädchen mit ins Haus. „Wo hast du den am gestrigen Abend gefangenen Tahumanfisch?" empfing Antang Taui seinen vom Landungsfloss zurückkehrenden Sklaven. Er antwortete: „Er ist nirgends zu finden. Als ich den losen Holzboden des Nachens in die Höhe hob, um den Tahumanfisch herauszuholen, sass dieses Mädchen unter dem Schiffboden." Antang Taui und Tapih fragten das Mädchen: „Wo kommst du her?" Und ohne Umschweif bekannte es: „Ich bin der Tahumanfisch, den ihr gestern mit dem Wurfnetz gefangen habt". Tapih und Antang Taui behielten das Mädchen im Hause und zogen es mit Ake zusammen auf.

Als Ake und Tahuman erwachsen waren, wurden sie von Antang Taui und Tapih zusammen verheiratet. Uebers Jahr gebaren die Frauen zu gleicher Zeit ein Kind, Tapih ein Mädchen, Tahuman einen Knaben. Doch schon nach drei Monaten starben beide Kinder. An demselben Tage wurden sie, jedes in einem besonderen Särglein, nebeneinander begraben.

Als die vielen Vorbereitungen zum grossen Totenfest getroffen waren, grub Antang Taui, die Sitte seiner Väter befolgend, die Särglein wieder aus der Erde heraus, um die sterblichen Ueberreste der beiden Kinder zu verbrennen. Zuerst öffnete er den Sarg seines Kindes. Das Fleisch war bereits verwest. In dem Sarge befanden sich nur noch die Knochen. Dann öffnete er das zweite Kindersärglein. Aber wie sehr erschrak Antang Taui, als darin keine menschlichen Knochen waren, sondern Fischgräten und Tierstacheln. Ins Haus zurückgekehrt rief Antang Taui seine Frau beiseite und sagte ihr unter vier Augen, was er gesehen und in dem Särglein gefunden hatte. „Mir ist's nicht wohl, wenn Ake und Tahuman fernerhin noch bei uns bleiben. Nach 
dem Totenfest wollen wir sie fortschicken". Tapih bekräftigte die Worte ihres Mannes. Und Antang Taui bekannte: „Ich erschrak nicht wenig, als ich in dem einen Sarg nur Fischknochen und Tierstacheln fand".

Nach dem Totenfest redeten Antang Taui und Tapih mit Ake und Tahuman: „Wir haben sicher nichts gegen euch. Aber wir meinen, es sei gut, wenn wir uns voneinander trennen. Wir wollen euch den Rasenfluss ${ }^{42}$, an dem noch keine Menschen wohnen, als Eigentum geben. Von seinem Ursprung bis zur Mündung soll euch der Rasenfluss gehören". Und Antang Taui und Tapih gaben Ake und Tahuman Reiskessel, Bratpfannen, Rotankörbe und alles was sie benötigten, um einen eigenen Haushalt zu führen. Alle diese Güter trugen sie in einen am Landungssteg liegenden Nachen hinunter. Und Ake ruderte mit Tahuman den Rasenfluss hinauf. An den Ufern des Rasen suchten sie sich einen geeigneten Bauplatz. Ake, der als einstiges Waldtier die Erde auf ihre Fruchtbarkeit hin genau kannte, suchte die beste Erde zur Anlegung von Feldern aus. Tahuman, die sich als einstiger Fisch im Wasser auskannte, wusste an welchen Stellen sie das meiste Gold finden konnte. Ake pflanzte Reis, Tahuman wusch Gold. Sie konnten viel Reis und Goldsand verkaufen. Bald konnten sie sich ein schönes Holzhaus erstellen. Von Jahr zu Jahr mehrte sich ihr Reichtum. Wiederum schenkten Tapih und Tahuman gleichzeitig einem Kinde das Leben. Tapih gebar einen Sohn, den sie Rason nannte, Tahuman ein Mädchen mit Namen Rusuh.

Als Rason erwachsen war, verbot ihm sein Vater, jemals an den Rasenfluss zu fahren, da er jede Begegnung mit Ake und Tahuman vermeiden wollte. Rason aber übertrat während einer längeren Abwesenheit seines Vaters dessen Gebot und befuhr trotzdem den Rasen, kam ins Haus Ake's und Tahuman's, die ihn als Verwandten aufnahmen, und er nahm deren Tochter Rusuh zur Frau.

Als Antang Taui nach Hause zurückgekehrt war, liess er seinen Sohn heimrufen. „Oooo, mein Sohn“, klagte der Vater, „was hast du getan! Ake ist nicht mein Bruder und Tahuman ist nicht die Schwester deiner Mutter. Sie beiden gehören nicht einmal dem Menschengeschlechte an, sondern sind Tiere, die Menschengestalt angenommen haben". Und Antang Taui erzählte seinem Sohn Rason die Geschichte der beiden. Und er schloss seine Erzählung mit den Worten: „Sie haben dich betrogen, mein Sohn. Sie sind nicht mit uns verwandt". Die Augen Rasons wurden grösser und grösser, als er die Worte seines Vaters hörte. Im tiefsten Herzen erschrak er und sagte : „Was, so 
sehr haben sie mich betrogen! Hätte ich das gewusst, dann hätte ich nie und nimmer Rusuh geheiratet, trotz ihrer grossen Schönheit".

$Z_{w e i}$, drei Wochen lang blieb Rason zu Hause bei seinen Eltern. Schliesslich konnte er es vor übergrossem Herzweh nicht mehr aushalten und ging auf Reisen. Er reiste an den Kahaian, von dort ging er an den Katingan hinüber, reiste flussaufwärts und wandte sich an den Serujan. Hier verheiratete er sich mit der einzigen Tochter reicher, angesehener Leute. Seine Frau war sehr schön und ihr Reichtum war so gross wie sein eigener.

Als Rusuh, seine verlassene Frau am Rasen, merkte, dass ihr Mann nicht mehr zu ihr zurückkehrte, sagte sie in ihrem Jammer: „Ich will Rason, meinen Mann suchen". Ihr Kopf mit den daranhängenden Eingeweiden löste sich von ihrem Körper, und als Hantuen, als Hexe flog sie davon um Rason zu suchen. 43 Sie flog nach Baras Manjang, aber Rason war nicht dort. Sie suchte ihn in Tangkahen. Vergeblich! Sie flog den Kahaian hinauf. Aber nirgends konnte sie ihn finden. Sie flog an den Samba, hinab an den Katingan. Umsonst! Sie flog den Katingan hinauf, den Mahop hinauf. Aber nirgends konnte sie Rason finden. Endlich flog sie an den Serujan und den Serujan hinauf.

Hier fand sie ihn nun. Am Ende des Dorfes fand ein grosses Totenfest statt. Rason und seine ihm angetraute Frau wollten die Seelen der verstorbenen Grosseltern ins Seelendorf führen. Sämtliche Dorfleute waren auf dem Festplatz versammelt. Rusuh setzte sich in der Nähe der Haustreppe in einen Hühnerkorb und lauerte auf ihren Mann. Als Rason mit seiner jungen Frau und seinen Schwiegereltern am Morgen das Haus verlassen wollte, um mit den vielen Festgästen den Sangkaraja (Schädelpfahl) zu umtanzen, hüpfte Rusuh, die Hantuen, die Hexe, auf die Schulter ihres Mannes und stellte ihn zur Rede: „Wie lange schon hast du mich verlassen! Sogar eine andere Frau hast du dir genommen"! Rason konnte sich der Hantuen nicht erwehren, denn sie sass fest auf seiner Schulter. Er sprang, so schnell ihn seine Füsse tragen konnten, in den Wald hinter dem Dorf. Vom frühen Morgen bis um die Mittagszeit eilte und sprang er, so schnell er konnte.

Um die Mittagszeit kam er an einen mit Früchten überladenen Sauergoldbaum. Rason hielt im Laufen inne und sagte: „Sieh, wie viele Früchte der Sauergoldbaum trägt! Ich habe Hunger und möchte von den Früchten für uns holen. Wir wollen hier ein wenig rasten". „O nein," entgegnete ihm Rusuh, „,vielleicht willst du mich betrügen“. „Nein“, versprach Rason, ,ich will nur den Fruchtbaum erklettern und Früchte herabholen". In der Nähe des Sauergoldbaumes befand sich 
ein Baumstrunk. Rusuh löste sich von der Schulter ihres Mannes los und setzte sich auf den Baumstrunk.

Rason erkletterte den Sauergoldbaum, pflückte eine Frucht und wollte sie seiner auf dem Baumstrunk sitzenden Frau an den Kopf werfen. Aus Furcht, Rason könnte sie treffen, neigte Rusuh ihren Kopf hin und her, und die Frucht fiel auf die Erde. „Schlecht gezielt, schlecht gezielt!" rief Rusuh zu Rason hinauf, immerfort den Kopf hin und her neigend. Hunderte, Tausende dieser Früchte warf Rason hinunter, mit jeder Frucht auf den Kopf seiner Frau zielend, ohne ihn treffen zu können. Zuletzt waren nur noch drei davon übrig. Er nahm die erste dieser drei Früchte, zielte, so gut er konnte, auf den Kopf Rusuhs und traf ihn. Der Kopf fiel von dem Baumstrunk herunter. Mit den beiden letzten Früchten zielte Rason auf den am Boden liegenden Kopf und zerschmetterte ihn ganz und gar.

„Du willst mich töten!“ rief Rusuh, „,ich sterbe“. Und im Sterben befahl sie Rason: „Komm herunter und umzäune den Platz, auf dem mein Kopf liegt". Rason tat wie er geheissen war. Und die sterbende Rusuh befahl weiter: „Nach drei Tagen komm wieder hieher! Aus meinem Kopf werden nebeneinanider zwei Sprosse herauswachsen. Der Spross zur Rechten ist Gift, der Spross zur Linken ist Gegengift.44 Hole sie dir und lege jeden Sprossen in eine leere Flasche. Wenn dich jemand vergiftet, darfst du nur das Gegengift essen und das genossene Gift kann dir nichts schaden, die Giftwirkung ist aufgehoben".

Rason ging darauf wieder zu seiner Frau ins Dorf zurück. Die Festversammlung sass gerade beim grossen Festmahle. Rasons Frau schöpfte ihrem Manne Reis und Zuspeise heraus, und er ass.

Nach Ablauf dreier Tage ging Rason, dem Geheisse Rusuhs gemäss, zum Sauergoldbaum, um zu sehen, was aus Rusuhs Kopf geworden war. In dem umzäunten Platze wuchsen nebeneinander zwei Sprosse. Den Worten Rusuhs folgend, legte Rason den rechten Spross als Gift in eine mitgebrachte leere Flasche, und den linken Spross legte er als Gegengift in eine zweite leere Flasche. Dieses aus dem Kopf Rusuhs entsprossene Gift ist die Mutter alles Giftes.

Rason brachte die beiden Flaschen ins Dorf. Die Rusuhs Kopf entwachsenen Gift- und Gegengiftsprosse vermehrten sich zusehends. Sie töteten sämtliche Pflanzen und Gewächse, die sich in ihrer Nähe befanden. Die Erde im Umkreis dieser beiden Sprosse wurde kahl und leer wie die hartgetretene Erde eines Gehweges, auf dem nichts gedeihen kann.

Wenn die Dorfleute in den Wald gingen, um essbare Pflanzentriebe 
und Blätter für ihre Gemüsesuppe als Zuspeise zum Reis zu holen und unwissenderweise dem Giftpflanzenplatz $z \mathfrak{u}$ nahe kamen, wurden sie von der Ausdünstung des Giftes schwer krank, so, als ob sie Gift gegessen hätten. Wer sich zu spät nach Gegengift umsah, war unrettbar dem Tode verfallen.

Die Dorfleute waren verwundent, ratlos und hilflos und ahnten nicht, woher die Vergiftungen kamen. Nachdem Dutzende von Menschen an dem Gift gestorben waren, weihte Rason seinen Schwiegervater in das Geheimnis ein. Dieser riet ihm: „Teil dein Gegengift mit den Dorfleuten, damit das Gift sie nicht tötet".

Rason befolgte diesen Rat. Sein Schwiegervater lud sämtliche Dorfbewohner in sein Haus ein, und Rason gab ihnen von seinem sicher wirkenden Gegengift. Das Gift selbst aber behielt er für sich. Von jenem Tage an starb niemand mehr im Dorfe an Gift. Bald kamen von überall her Leute, um von Rason das starke Gift und das sicher wirkende Gegengift zu kaufen. Vom Kahaian, vom Katingan und vom Samba kamen sie. ${ }^{45}$

\section{DIE RELIGION}

\section{A. Die Welt- und Menschwerdung 46}

\section{a. Der Ursprung der Sangiang nach der katinganischen Version}

In den frühesten Zeiten hatte Ranjing Mahatala Langit Himmel und Erde geschaffen. Aber die Erde war nur klein. Darnach schuf er einen Menschen, einen Mann. Dieser hatte nichts zu tun und wusste nicht womit er sich die Zeit vertreiben sollte. Tag und Nacht schaute er herum, mehr hatte er nicht zu tun und weil es ihm sehr langweilig wurde und er sich einsam fühlte, weinte er unaufhörlich. Da versenkte ihn Mahatala in tiefen Schlaf. Er wusste nichts mehr von sich und wusste auch nicht was um ihn herum vorging und was mit ihm geschah. Mahatala nahm einen Knochen aus seiner Seite heraus und schuf aus ihm eine Frau die er neben dem Manne niederlegte. Als er erwachte sah er die Frau zu seiner Seite sitzen. Er fragte sie nach ihrem Namen und sie sagte ihm, dass sie Tunggol Garing heisse. Der Mann war sehr erstaunt diese Frau zu sehen aber sein Herz wurde wieder froh und er weinte nicht mehr wie früher. Die beiden verheirateten sich und wohnten nun fortan beisammen. Schon nach kurzer Zeit fühlte sich die Frau schwanger. Im siebenten Monat gebar sie einen Hund. 
Bald darauf fühlte sie sich wieder schwanger und gebar nach sieben Monaten eine Katze. Nach einiger Zeit fühlte sie sich wieder schwanger und gebar nach sieben Monaten ein Schwein. Das nächste Mal, das sie schwanger wurde gebar sie nach sieben Monaten ein Huhn. Nach einiger Zeit fühlte sie sich wieder schwanger und nun gebar sie nach neun Monaten einen sehr schönen Knaben, den sie mit ihrem Manne zusammen Maharadja Sangen nannte. Er wuchs und entwickelte sich sehr rasch. Schon nacht drei Monaten glich er in jeder Hinsicht einem dreijährigen Kind. Er konnte selbst an den Fluss hinuntersteigen, er konnte sich selbst baden und er begab sich da- und dorthin.

Bald fühlte sich die Mutter wieder schwanger und wieder gebar sie einen sehr schönen Knaben den sie Maharadja Bunu nannten. Auch er entwickelte sich wie sein Bruder. Und bald darauf war die Mutter wieder schwanger und sie gebar ihren dritten Sohn den sie Maharadja Sangiang nannten. Die drei Brüder wuchsen rasch und entwickelten sich merkwürdig schnell. Bald konnte Maharadja Sangen mit seinen Brüdern allein auf den Fischfang und die Jagd ausgehen. Eines Tages hatten sie verabredet mit dem Netze zu fischen. Maharadja Sangiang fragte seine Brüder: „Welcher von uns dreien soll nun zuerst das Netz auswerfen?" „Ich“, antwortete Maharadja Sangen, „denn ich bin der älteste von uns dreien". Sie ruderten eine Flussbiegung weit, sie ruderten eine zweite, aber überall wo sie das Netz auswarfen fingen sie nichts. In der dritten Flussbiegung warf Maharadja Sangen wieder sein Netz aus und als er es herauszog war es voll und schwer, aber nicht von Fischen sondern von einem schwimmenden Eisen das sich in ihm verfangen hatte. „Das ist Eisen“, sagte Maharadja Bunu, „wir wollen uns aus ihm unsere Waffen schmieden". Sie warfen wiederum das Netz aus, aber ohne jeglichen Erfolg und so kehrten sie schliesslich mit ihrem merkwürdigen Fang wieder nach Hause zurück. Die beiden ältesten Brüder schmiedeten sich Waffen und jeder von ihnen erhielt ein Schwert und einen Panzer, nur der jüngste Bruder, Maharadja Sangiang, ging leer aus. Mit Herzeleid sah er den anderen Brüdern zu. Seine Arbeit bestand weiterhin im Fischfang, aber er hatte wenig Glück dabei. Als er aber eines Tages wiederum sein Netz auswarf konnte er es nur mit grosser Mühe aus dem Wasser ziehen und als er nachschaute, da sah er, dass sich in ihm ein Stück sinkendes Eisen verfangen hatte. Erfreut über diesen seltenen Fang kehrte er nach Hause zurück und schmiedete sich wie seine Brüder einen Panzer und ein Schwert.

Die Nachkommen des Maharadja Sangen sind (u.a.m.): 
Umang, Sakanak, Paka Hatu, Pang Paloi, Sahawong, Tingang Kamandai, Aring. Sie wohnen alle in der Oberwelt.

Die Nachkommen des Maharadja Bunu sind (u.a.m.):

Djin, Njaring, Pampahilep, Kudjut Kariu, Nabi epat puluh, Kudjuh Apang Pandjong (Radjan Pali). Auch sie wohnen in der Oberwelt.

Die Nachkommen des Maharadja Sangiang sind die Menschen an den Ufern des Flusses der Welt.

\section{b. Der Ursprung der Sangiang nach Hardeland $\mathbf{4 7}$}

Die Sangiang sind gute, hülfreiche Wesen. Sie leben über dem Nebelmeere irgendwo in dem Himmel, im Lewu Sangiang, Sangianglande, welches durch 160 Flüsse durchströmt wird. Die Verhältnisse und das Leben dort kommen übrigens mit dem auf dieser Unterwelt ziemlich überein, nur dass dort alles prächtiger, schöner und lustiger ist. Es wachsen dort z.B. nur Fruchtbäume, Bäume akan manontong tahaseng (um den Atem aneinander zu setzen, zu verlängern); Bäume akan panarang atei (die das Herz hell, weiss machen). Es wachsen dort die Batang garing (Garingbäume) die feine Tücher als Blätter tragen, deren Blüten Gold und Ringe (Arm-, Bein- und Fingerringe), und deren Früchte Lamiang (schön bearbeitete Achate) sind, und welche als Saft danum kaharingan (lebendig machendes Lebenswasser) ausströmen.

Vor alten Zeiten lebten die Sangiang mit auf dieser Welt.48 Sie sind auch mit den Menschen verwandt, konnten sich aber nicht gut mit ihnen vertragen. Obwohl sie nun viel stärker und mächtiger als die Menschen sind, waren sie doch dadurch gegen die Menschen im Nachteil, dass sie nur Sanaman lampang (schwimmendes Eisen) hatten, d.h. solches, welches nur für eine Zeitlang tötet, sodass die dadurch Getöteten nach einiger Zeit wieder lebendig werden. Die Menschen aber hatten Sanaman leteng (sinkendes Eisen), welches wirklich und für immer tötet. Dies bewog den Sabuaja, den Stammvater der Sangiang, um mit den Seinigen nach dem Lewu Sangiang (dem Lande der Sangiang) zu verziehen.

Jener Sabuaja zeugte den Tantulang. Tantulang zeugte zwei Söhne, den Panjarawan Katingan, und den Pampulu Hawon. Diese beiden wurden die Stammväter von zwei Geschlechtern der Sangiang. Jeder von ihnen zeugte vierzehn Kinder, sieben Söhne und sieben Töchter.

Der Panjarawan Katingan gründete ein Reich im Sangianglande am 
Batang danum Barirai (Bariraifluss); der Pampulu Hawon am Batang danum Djalajan (Djalajanfluss). Später haben sich noch mehrere kleinere Geschlechter von jenen beiden Sangiangstämmen abgezweigt, doch werden nur jene beiden Stämme von den Dajak verehrt und um Hülfe angerufen.

Man ruft die Sangiang um Hülfe und Vermittlung an, sobald man irgend etwas von einem andern der Geister wünscht. Hat z.B. der Radja Sial (der Herr des Unglücks), jemanden dadurch krank gemacht, dass er dessen Hambaruan (Seele) entführte (dadurch entstehen die meisten Krankheiten), dann bittet man einen Sangiang dorthin zu gehen, und die Seele wieder zu holen. Will man den Radja Ontong (Herr des Glückes) um Glück anflehen, dann muss ein Sangiang die Bitte überbringen, und den Radja Ontong herbeiholen. Glück verschaffen die Sangiang nicht selbst, das kommt vom Radja Ontong, vom Djata, Pampahilep etc., wohl aber bewahren die Sangiang vor Unglück und Gefahren, weshalb z.B. Reisende sich ihnen anbefehlen, und bamiat intu Sangiang (den Sangiang ein Gelübde tun) d.h. dass sie ihnen Opfer darbringen wollen, wenn sie die Reise wohlbehalten beendet haben. Unglück bringen die Sangiang nur zur Strafe denen, welche ihnen die getanen Gelübde nicht halten. In solchen Fällen strafen sie durch Krankheit, oder lassen den Uebertreter unklug werden. Die den Sangiang gebrachten Opfer bestehen hauptsächlich aus Hühnern, drei, fünf oder sieben Stück, zusammen mit Backwerk und Früchten.

Die oben genannten Stammväter der Sangiang leben noch immer, aber sie sind emeritiert, 49 man wendet sich nicht mehr an sie. Man nimmt jetzt seine Zuflucht hauptsächlich zu vier Sangiang, den beiden ältesten und jüngsten Söhnen des Panjarawan Katingan und Pampulu Hawon. Der älteste Sohn des Panjarawan Katingan heisst Radja Ngalang, der jüngste Tempon Kanarean. Die älteste Tochter heisst Rampan, die jüngste Tempon Tiawon. Der älteste Sohn des Pampulu Hawon heisst Radja Dohong (König des Dolches), der jüngste Tempon Telon (Besitzer des Telon). Die älteste Tochter heisst Sarin Bunge, die jüngste Tempon Hendan.

An welchen dieser Sangiang man sich halten will steht in jedes Belieben. Gewöhnlich hält sich jede Familie an den Sangiang, an welchen schon die Vorfahren sich gehalten haben, wenn nicht etwa dieser Familiensangiang sich gar zu unhülfreich erweist und ein anderer Sangiang dagegen in Ruf als hülfreich gekommen ist. Bei wichtigen Fällen ruft man auch alle Sangiang zu Hülfe. Am meisten von allen 
Sangiang wird der Tempon Telon (Telon ist sein Sklave) um Hülfe angerufen. Er ist der stärkste und tapferste aller Sangiang. Er allein auch kann magah liau (die abgeschiedene Seele führen) in die Lezen liau (Seelendorf). Dieser Tempon Telon, um von diesem Hauptsangiang doch noch etwas Näheres zu sagen, war eine unzeitige Geburt und kam nur als Blutklumpen zur Welt und wurde von seiner Mutter ins Wasser geworfen. Er trieb beim Bukit Lengkong (Lengkongberg) im Sangiangland ans Ufer, wo ihn eine weibliche Sangiang, die Puson Baluso, welche gerade am Baden war, fand, aus dem Wasser zog und aus dem Blutklumpen ein lebendes Wesen machte dem sie den Namen gab Kumpang Bulau Panarusan Langit (die goldene Schwertscheide welche dahintrieb unter dem Himmel). Als der Findling gross geworden war kam seine Base (Nichte) Tempon Tiawon dahin. Sie war auf der Flucht vor einem gewissen Manjamei, einem mächtigen Sangiang, welcher sie heiraten wollte, von ihr aber verschmäht wurde. Manjamei verfolgte sie, wollte sie greifen, da nahm Kumpang Bulau Panarusan Langit sich ihrer an, kämpfte mit dem Manjamei und überwand und tötete ihn, worauf die Tempon Tiawon ihn dann heiratete unter der Bedingung, dass er mit ihr in ihr Land zurückkehren müsse. Bei dieser Gelegenheit offenbarte ihm seine Pflegemutter wer er sei. Zurückkehrend wurde er, der Ueberwinder des Manjamei, welchem alle andern Sangiang nicht zu widerstehen vermochten, mit Freude aufgenommen. Der mächtige Telon unterwarf sich ihm als Sklave, weshalb er nun den Namen Tempon Telon annahm. Er heiratete dann seine Base (Nichte), zugleich heirateten am gleichen Tag seine sechs Brüder ihre sechs Basen, die Schwestern von Tempon Telons Frau, und deren sieben Brüder heirateten die sieben Schwestern des Tempon Telon. Seit der Zeit nun ist Tempon Telon der angesehenste unter den Sangiang geblieben.

Ausser den bereits genannten Sangiang steht unter den Dajak noch ein mächtiger Sangiang, der Sangumang und seine Genossen Papaloi und Sakanak, in grossem Ansehen.

\section{c. Der Ursprung der Sangiang nach Schwaner 50}

Es ist schwierig eine gute Beschreibung zu geben von den religiösen Vorstellungen der Eingeborenen. Sie sind $z u$ sehr zusammengestellt und werden durch eine grosse Menge abergläubischer Begriffe noch komplizierter. Soviel steht fest, dass sie an ein Höchstes Wesen glauben das den ersten Anstoss gab zur Schöpfung alles dessen was 
geschaffen ist und dessen unaufhörlichem Einfluss zu danken ist, dass die Ordnung des Weltalls aufrecht erhalten bleibt.

Ihr Gott, namens Hatala, wird umgeben von einer Menge von Engeln welche mit ihm den höchsten Himmel am Meer Tasik Tabanteram Bulan Laut Lumbung Mattan Andan bewohnen (muss heissen: Tasik Kabanteran Bulan, Laut Lumpong Matanandau). Auf den ersten Himmel folgt der zweite am Meer Tasik Malambang Bulan Laut Babandan Intan (muss heissen: Tasik Malambong Bulau, Laut Bapan$\tan$ Intan), der, nebst einigen Halbgöttern, auch von Engeln einer mehr untergeordneten Klasse bewohnt wird. Darauf folgt der dritte Himmel am Labeho Rambang Mattan Andan Tasik Kalumbang Bulan (muss heissen: Tasik Rampang Matanandau). Dieser wird ebenfalls durch sehr mächtige Engel bewohnt, von denen der wichtigste Tempon Tellon genannt wird. Hier haben auch die Seelen der Verstorbenen ihren Aufenthaltsort. Der vierte Himmel erstreckt sich um das Meer Laut Bohawang (muss heissen: Tasik Ambon Bagantong, Laut Enon Batujang). Hier wohnt, unter andern hohen Wesen, auch der Sangsang (Sangiang) der Balian. Der fünfte Himmel liegt am Meer Tasik Bulan und wird durch den Njaring Dumpang Enjeng (?) bewohnt. Darauf folgt die Erde. Unter der Erde befindet sich der Aufenthaltsort der Kalue Tungal Tussoh (muss heissen: Kalue Tonggal Tusu = die Kalue mit der einzigen Brust), die über die Pflanzen wacht. Diese Himmel sind alle bevölkert mit einer grossen Anzahl von Sangsangs (Sangiang), Engel, welche zum Teil an der Schöpfung der Erde und dem was sie hervorbringt mitgearbeitet haben und die zum Teil auch ständig mit den Menschen in Verbindung bleiben, weil sie ihren Einfluss ausüben auf ihr Los und ihnen Glück oder Unglück zufügen.

Die Luft ist erfüllt von zahlreichen Hantu (Spukgeister). Jedes Ding hat einen solchen Hantu, der es bewacht und gegen Gefahren verteidigt. Die Hantu sind es hauptsächlich die über die Menschen Krankheit und Unheil hereinbringen und aus diesem Grunde werden ihnen, und auch den mächtigen Sangsangs (Sangiang), oft Opfer dargebracht, während der höchste Gott, der die Quelle alles Guten ist, vernachlässigt wird. Während sie sich die Sangsangs (Sangiang) vorstellen als schöne und vollkommene Menschen, gezient mit prächtigen Kleidern und mit glänzenden Schmuckstücken, beschreiben sie die Hantu als riesige Wesen deren Augen Flammen und Funken schiessen, und mit langen, mit Klauen versehenen Fingern. Sie sind mit rauhen Haaren bedeckt.

Die Vorstellungen über die Schöpfung der Erde sind in den verschiedenen Teilen des Stromgebietes (gemeint ist das Stromgebiet des 
Barito) nicht die gleichen. Da, wo die Eingeborenen mit den Mohammedanern in Berührung gekommen sind, finden wir sie vermengt mit islamitischen Begriffen. Tiefer im Inland lassen sich die verschiedenen Vorstellungen auf zwei zurückbringen.

Nach der ersten bestand am Anfang aller Dinge das Wasser, das von der Naga Bussai bewohnt wurde. Es war eine merkwürdig geformte Schlange, prunkend in glänzenden Kleidern und geschmückt mit einer Krone und Diamanten. Ihr Kopf war so gross wie die Erde. Hatala warf Erde auf sie herunter und diese erhob sich als ein fester Wall der wie eine Insel aus dem Wasser emporragte.

Ranjing Atalla (muss heissen: Ranjing Mahatala Langit) stieg herab auf die junge Erde und fand auf ihr sieben, von Erde geformte Eier von denen er zwei aufhob. In dem einen entdeckte er einen Mann, in dem andern eine Frau. Beide sahen wie Tote aus. Ranjing Atalla (Ranjing Mahatala Langit) kehrte zurück zum Schöpfer um von ihm den noch fehlenden Atem $z \mathfrak{u}$ erbitten. Währenddessen stieg der Sangsang Angai (muss heissen: Sangiang Angoi) auf die Erde herab und blies den Menschengestalten Atem ein wodurch sie lebend wurden aber gleichzeitig auch den Keim des Todes in sich aufgenommen hatten.

Ranjing Atalla (Ranjing Mahatala Langit) der den Menschen den Atem der Unsterblichkeit holen wollte, fand bei seiner Rückkehr die durch Angai (Angoi) vollbrachte Arbeit. Traurig kehrte er zurück in den Himmel. Er nahm nicht nur die Unsterblichkeit der Menschen mit sich, er nahm von ihnen auch die göttlichen Geschenke die für das Menschengeschlecht bestimmt waren : die ewige Jugend, das allgemeine und ungestörte Glück, den überfliessenden Genuss des Lebens ohne Arbeit, in einem Wort: die ganze Seligkeit des Paradieses.

Die Verhältnisse der menschlichen Gesellschaft, so wie diese nun ist, werden geregelt durch Angai (Angoi). Erst durch Arbeit verdient man den Genuss, auf das Unrecht folgt die Strafe, Schmerz und Krankheit haben den Tod zur Folge, Krieg und Blutvergiessen zerstören mit Gewalt einen Teil des Menschengeschlechtes.

Die andern Erdeier enthielten die Keime von allen Pflanzen und allen Tieren.

Nach einer andern Vorstellung befanden sich im Reiche der Götter zwei Bäume, nämlich der Bungking Sangalang und der Limut Garing Tinga. Der erste hatte einen kugelförmigen Auswuchs, Bungking genannt, und in seiner Krone lebte der Vogel Sinang (muss heissen: Tingang) zusammen mit dem geflügelten Engel Tambarirang. Die Aeste, in Bewegung gebracht durch das Schwanken ihrer beiden Be- 
wohner, stiessen den Bungking vom Stamme ab und dieser fiel in das Wasser des Batang Danom Sangsang (Sangiangfluss), das durch die Naga Tumbang (die Naga an der Mündung, meist der Aufenthaltsort von Naga) bewohnt war. Diese versuchte den Bungking $z u$ fangen und zu verschlingen, aber er erreichte, ihr entfliehend, das Ufer und verwandelte sich dort in die Jungfrau Budak Bulan Handjuren Karangan, welche ein Blatt von dem Baume Kunuk (muss heissen: Lunok) vom Boden aufhob und es in das Boot Lassang Daun Lunok (muss heissen: Lasang Dawen Lunok = das Boot vom Blatt des Lunok) verwandelte. In diesem Boot fuhr sie flussabwärts bis zur Mündung des Batang Danum Sangiang am Meer Labeho Rampang Mattan Andan Tasik Kalumbang Bulan (muss heissen: Tasik Rampang Matanandau). Hier trieb auf dem Wasser der Baumstamm Garing Tjenjahunan Laut, der sich, durch die Wellen berührt, in die Gestalt eines Mannes verwandelte und deshalb auch genannt wird Garing Banjang (wahrscheinlicher Budjang) Tjenjahunan Laut. Auf einer Felseninsel des himmlischen Meeres vereinigte er sich mit der Jungfrau und die Frucht ihrer Vereinigung waren Blutflüsse (Fehlgeburten) die von Zeit zu Zeit aus der Göttin hervorströmten und sich in Wesen verwandelten, die einen grossen Einfluss ausüben auf die Menschen und ihr Los. Sie alle zusammen bilden die Hantu.

Unter andern mehr erlitt Budak Bulan Handjuren Karangan einen Blutfluss beim Baden. Sie sammelte das Blut und legte es auf einen Baumstamm der bei der Insel Pulan Tellopulu (muss heissen: Pulau Telo pulu $=$ die dreissig Inseln) ans Land getrieben wurde. Hier verwandelte sich das Blut in die Jungfrau Putir Rewo Bawin Tellopulu, die, nachdem sie sich mit dem dort wohnenden Djangong Hadoen Peres (muss heissen: Djangan Hatuen Peres) vereinigt hatte, alles Unglück und alle Krankheiten die zum Unheil der Menschen dienen, zur Welt brachte.

Aus einem andern Blutfluss, ebenfalls beim Baden, entstand die Indu Reman Lawang. Sie verband sich mit dem im Wasser lebenden Angan Bijai Mamasawang Bungei Peneng Basallo Mamarandang Lagang und beide wurden die Stammeltern der Krokodile.

Ein dritter Blutfluss strömte aus der Göttin als sie am Ufer beschäftigt war um mit einem kleinen Sieb Fische zu fangen. Daraus entstand eine Jungfrau die sich mit der Naga Dambang (muss heissen: Naga Dambong) vereinigte und sechs Kindern des Leben schenkte. Sie alle gehen darauf aus den schwangeren Frauen Unheil und Schaden 
zuzufügen. Diese bringen ihnen deshalb ihre Opfer in kleinen Gefässen dar die sie an den Flussufern an den Aesten der Bäume aufhängen.

Ein vierter Blutstrom ergiesst sich auf die Erde des Himmels und verwandelt sich in die Jungfrau Kamello Lellak Lawang (muss heissen: Kameloh Lelak Lawang) die sich mit dem Batu Mambon (muss heissen: Batu Mamben) vereinigt. Sie schenkt sieben Kindern das Leben, die alle zu tapferen und kriegsfreudigen Männern heranwachsen. Diese ruft man an wenn man sich auf den Krieg vorbereitet oder einen Mord ausführen will. Man bringt ihnen Speisen zum Opfer die auf einem Gong ausgebreitet werden. Ihr Beistand wird auch angerufen bei der Feier von Totenfesten und bei der Ablegung von Gelübden für die gute Ausführung einer Reise.

Aus einem fünften Blutfluss entsteht die Jungfrau Indu Mellang Sangar, mit der Tarahem Radja Nandang (muss heissen: Darahen Radja Antang) viele Kinder zeugt die alle die Gestalt von Adler (Falken, Haliastur intermedius) haben. Ruft man sie an und bringt man ihnen Speisopfer dar dann verleihen sie ihre Hülfe bei mordsüchtigen Raubzügen (d.h. bei der Kopfjagd), bei Handelsreisen und bei Erkrankungen.

Einem sechsten Blutfluss verdankt Kamello Bumbong Lunok ihr Entstehen. Aus ihrer Umarmung mit Njaring Gilahanjie Dumbang Enjen Tingang entstehen viele Kinder die die Aufgabe haben die verlassenen Wohnungen und die um sie herum gepflanzten Fruchtbäume $\mathbf{z u}$ bewachen. Wer sich wagt diese $z \mathfrak{u}$ entheiligen oder $\mathbf{z u}$ vernichten wird durch sie mit Geistesstörung bestraft.

Die siebente Schwangerschaft hatte einen normalen Verlauf und endigte mit der Geburt von zwei Söhnen, Mahadara Sangen und Mahadara Singsang (muss heissen: Mahadara, oder auch Maharadja Sangen und Mahadara Sangiang).

Sangen wird ausgerüstet mit allen Keimen der Pflanzen und Tiere und auf die Erde heruntergelassen die noch wüst und tot war. Hier angekommen findet er die Wunderbäume Limut Garing und Limut Gohong, die sich zusammen paaren. Als Frucht dieser Paarung entsteht ein Ei aus dem das leblose Schattenbild eines Mädchens zum Vorschein kommt.

Sangen kehrt zurück in den Himmel um von dort alle Mittel und Kräfte $z u$ holen die nötig sind um der Form, die aus dem Ei geboren wurde, ihre Vollendung zu geben und ihr das Leben zu schenken. Von seiner Abwesenheit machte Angoi, ein Bander Atallas (?), Gebrauch um mit eigener Kraft dieses Werk auszuführen. Er sammelte Wind 
für den Atem, Regen für das Blut, Bading Sangalong (wahrscheinlich Bambus) für die Knochen und Erde für das Fleisch. Diese Elemente vereinigte er mit dem Schattenbild und formte daraus eine irdische Schönheit.

Als Sangen mit dem Danom Kaharingan Belom Bohong Baninting Asseng (muss heissen: Danum Kaharingan Belom, Dohong Kapaninting Aseng = Wasser des Lebens, das lebenschaffende, Wasser, der Reiniger des Atems) wieder zurïckkam und sah was Angoi getan hatte zerschmetterte er vor Zorn das Gefäss in dem er das Lebenswasser mitgebracht hatte, sodass es nach allen Seiten spritzte, den Samen aller Pflanzen aber nicht den Mensch benetzte. Weil der Mensch mit dem himmlischen Wasser nicht befeuchtet wurde ist er ein Opfer des Todes geworden, während die Pflanzen, auch wenn sie abgeschnitten werden, doch immer wieder neu ausspriessen und dem Tod nicht unterworfen sind.

Die Zwietracht der beiden Götter entwickelt sich zu einem Kampf worin Angoi sein Leben verliert. Sein Körper wird in Stücke zerhackt und diese werden überall ausgestreut. Sie verwandeln sich in Schlangen und Tiger und alle andern, dem Menschen feindlich gesinnten Geschöpfe.

Sangen vereinigt sich mit dem ersten menschlichen Wesen, mit Budak Bulan und sie werden die Stammeltern des Menschengeschlechtes. Mahadara Singsang (Sangiang) wird der Stammvater vieler Götter, unter andern auch vom Sangsang Tempon Tellon (Sangiang Tempon Telon), dem Mittler zwischen den Göttern und den Menschen. Er wird in allen Gefahren und Nöten angerufen und bringt auch die Seelen der Verstorbenen nach ihrem Aufenthaltsort in der Seligkeit.

\section{d. Der Ursprung der Sangiang nach C. Hupe 51}

Was hier folgt bildet den kurzen Inhalt einer sangen (Mythe; Hupe : zangen, Holl. = Lieder) der Ngadju-Dajak. Sie lautet :

Am anfang gab es nur Wasser. Da schuf Gott den Nagapusai (Naga kann mit Erdschlange übersetzt werden. Er ist ein erdichtetes Wasserungetüm. Man findet von ihm gewöhnlich ein aus $\mathrm{Holz}$ geschnittenes Bild auf den Gräbern oder vor den Wohnungen der Dajak) in der Mitte des Wassers. Sein Kopf, auf einem sehr kleinen Rumpf ruhend, war so gross wie eine Insel. Diese Unregelmässigkeit im Körperbau verursachte, dass der Kopf, der nicht gut verankert war, durch alle Winde hin und her gedreht wurde. Das verdross den Naga und er weinte. Als Hatala das sah sandte er seinen Sklaven Praman zu ihm 
um nach der Ursache zu fragen und die Klagen des Naga ihm mitzuteilen. Nachdem das geschehen war liess er sich hernieder und gab dem Kopf des Naga einen besseren Rumpf. Er bedeckte ihn mit Erde um ihn so vor der brennenden Sonne zu beschützen. Batu-Djampa (muss heissen: Ratu Tjampa), der Sohn von Hatala sah herunter aus dem Himmel und er entdeckte zwei grosse Erdeier (tanteloh petak) auf dem Naga.

Er stieg zu ihnen herunter und zerbrach sie. Aus ihnen traten ein Mann und eine Frau hervor. Er verheiratete die Beiden. Nachdem sie sieben Knaben und sieben Mädchen das Leben geschenkt hatten, die alle noch leblos waren, als sie geboren wurden, kam der Sohn Gottes wieder zu ihnen und gab dem Mann einen supu (ein kleines Porzellangefäss) und befahl ihm darin bei dem Naga die Seelen der vierzehn Kinder zu holen. Bevor er sich auf den Weg begab gebot er seiner Frau streng, sich während seiner Abwesenheit sorgfältig hinter den Gardinen ihres Bettes verborgen $z u$ halten. Es wurde ihr dort aber zu warm und sie wünschte sich durch ein Bad zu erfrischen. Aber als sie die Gardinen öffnete überfiel sie und ihre Kinder ein Windstoss sodass diese begannen zu leben und zu weinen. Das ist der Grund, dass die Seelen der Menschen nur aus Wind bestehen und deshalb sterblich sind. Der Zorn des Vaters wandte sich gegen die unschuldig unglücklich gemachten Kinder und er schleuderte diese paarweise von sich weg. Ein Paar fiel in das Wasser. Von ihm entstand der Wassergott Djata. Zwei Paare fielen auf Felder und in Wälder und von ihnen stammen ab die Kambe, Pampahilep, Njaring und Kariau (böse Geister). Die noch übrigen flogen im Himmel nach drei verschiedenen Flussreichen.

Der Stammvater des Reiches am Flusse Djalajan ist der Radja Sangin (muss wohl heissen: Maharadja Sangen). Sein Sohn heisst Tantulang bulan. Dieser hatte wieder einen Sohn namens Pampulu hawon. Dieser zeugte sieben Söhne und sieben Töchter. Die Söhne heissen: Radja duhun bulan, Budjang Barinding, Rahin Tingang, Panjulilanka, Babu Kansuling, Tempon Telon und Sahawong Bulan. Die Töchter heissen: Sarinbunge, Bawi sara gantin bulan, Bawi turun bulan, Bawi hilang bulan, Bawi njawang bulan, Pati und Tempon hendan bulan.

Am Flusse Marirai (muss heissen: Barirai) werden als Stammeltern genannt: Panjarawan mit sieben Söhnen und sieben Töchtern. Die Söhne heissen: Radja njalang bulan, Sari kampung duhung, Landa lindang lin, Prakahan Singang, Iring salungan, Talinting bulan, 
Tempon Kanarean. Die Töchter heissen: Rampan, Mandilan, Mandilan bulan, Bawin mandilan dari, Bawi mandilan lamiang, Bungen bulan und Tempon Tijawan bulan.

Im dritten Dorf regierte Sangumang mit seinem Vater Radja Tangku bato, seiner Mutter Batun, seiner Schwester Putir Silo und seinen Söhnen Papaloi und Maharadja. Der letzte hatte sieben Putirs (putris oder Prinzessinnen), welche mit ihrem Bruder Putri Sandang oder Omban Bulan die Brautpaare einsegnen. Alle diese genannten Personen sind unsterblich.

Der erste Mann behielt nur ein Paar von seinen Kindern bei sich und dieses war fruchtbar und bevölkerte die Erde, Hatala sandte ihnen Fische und Vögel als Nahrung, aber er enthielt ihnen den Reis, den grössten Segen der Menschheit, trotz aller flehentlichen Bitten seines Sohnes. Schliesslich entschloss sich der Sohn Gottes den Reis für die Menschen zu stehlen, ebenso das Eisen, er verbot ihnen aber den feindschaftlichen Gebrauch desselben. Auch das Feuer warf er aus dem Himmel, welches auf seinem Wege die Sonne entzündete und schliesslich auf Felsen herunterfiel. Das ist auch der Grund, dass man bis heute aus Stein Feuer schlagen kann.

\section{e. Der Ursprung von Himmel und Erde nach Sundermann 52}

Vor alter Zeit wohnten Menschen auf dem Kopf der Naga (grosse Schlange) welche die Grundlage der Erde ist. Da kamen einmal acht Fremde dort zum Besuch. Man bewirtete sie mit Reis, doch sie wollten gar nicht essen. Sie sagten: „Wir werden nur essen, wenn ihr uns Keang und Mahangstämme (zwei Holzarten) gebt". Da gaben Sangkarewang und Sangkarepang ihnen Keang und Mahangstämme und sofort assen sie davon. Als sie acht Tage und acht Nächte da gewesen waren, reisten sie wieder ab. Sie sagten: „Wir reisen wieder $a b$, da liegen zwei Haufen, die Excremente von dem, was wir gegessen haben. Stampft die beiden Haufen und macht aus dem zur rechten Seite des Weges den Himmel und aus dem zur linken die Erde". Darauf reisten sie ab. Nun stampften Sangkarewang und Sangkarepang die zwei Haufen und in acht Tagen waren Himmel und Erde fertig. Aber wer sollte nun den Himmel aufheben? Sie befahlen dem Kakang Ajus es zu tun. Der begann dann auch zu heben, aber der Himmel war noch immer zu niedrig. Da sagte die Grossmutter des Barurong: „Du musst noch achtmal heben“. Er hob noch achtmal. „O weh!“ sagte die Grossmutter des Barurong, „nun ist er zu hoch“. „Ich kann 
ihn nicht wieder herunterlassen“, sagte Kakang Ajus, „er muss nun so bleiben". Es war aber sowohl vom Himmel als von der Erde ein Häufchen zurückgeblieben. Da stampften Sangkarewang und Sangkarepang von dem Ueberbleibsel des Himmels den Grossvater des Djalu Orai und von den Ueberbleibseln der Erde die Grossmutter des Djalu Orai. Die beiden wurden Ngorai genannt. Es waren Menschen und sind es geblieben bis heute.

\section{f. Der Ursprung der Sangiang nach Mallinckrodt $\mathbf{5 3}$}

Zuerst muss das Höchste Wesen, der Gott der Dajak, genannt werden. Sein Name ist Mahatara, oder wie er in Kota Waringin genannt wird, Sangiang Dewata. Er ist nur wenig bekannt und erfreut sich nicht sehr der Aufmerksamkeit der Gläubigen. Man sieht ihn nur noch zum Vorschein kommen in den alten Erzählungen und nur bei grossen Ausnahmen ruft man ihn noch an. Er ist der Schöpfer der Welt, wobei ihm aber durch verschiedene andere Götter geholfen wurde, vor allem durch seinen sanger (so nennen sich zwei Männer deren Kinder zusammen verheiratet sind) Djata. $Z u$ jener $Z$ eit gab es bereits zahlreiche andere Götter. Wir werden sie noch kennen lernen als die Fürsten des Glücks und Heils, des Unglücks, des Goldes usw. In welchem Verhältnis sie zu Gott standen ist nicht mit Sicherheit zu sagen. Wahrscheinlich sind sie nur als Kräfte zu beschauen. Nur einige von ihnen (nämlich vierzehn) werden angerufen.

Mahatara wohnt im höchsten Himmel von denen es sieben gibt. Djatas Reich besteht aus drei Abteilungen. Die Zugänge zu ihnen liegen bei tiefen Flussbuchten (labeho). Bestand anfänglich nur ein Djata, so sind es nun unzählbare geworden und jeder von ihnen hat wieder einen eigenen labeho (Tiefe im Fluss) als Zugang zu seinem Aufenthaltsort. Von der grössten Bedeutung sind aber die Sangiang oder Luftgeister (nach Hardeland übersetzt) die in dem Orte lewenn Sangiang (Dorf der Sangiang) wohnen. Dieses ist eine der untersten Schichten des Himmels, ein grosses Flussland in dem jeder Sangiang sein eigenes Stromgebiet besitzt.

Sie sind dem Menschen behülflich und werden oft angerufen. An den verschiedenen Flüssen (d.h. unter den verschiedenen Stämmen) findet man verschiedene Himmelsbeschreibungen und auch verschiedene Namen für diese Mächte.

Dem Ursprung der Sangiang kann man am besten nachgehen anhand der Ngadju-Legende (Mythe) die darüber berichtet und die uns auch einen Einblick gibt in das Entstehen dieser höheren Mächte. 
Nachdem Mahatara die Erde erschaffen hatte wünschte er auch dass sie bewohnt würde. An einem Ast des Garingbaumes machte er, an jedem Ende, ein Menschenbild fest. Auf der einen Seite einen Mann, auf der andern Seite eine Frau. Diesen Stock warf er auf die Erde herunter. Das Bild des Mannes kam ins Wasser zu liegen, das Bild der Frau aufs Land. In der Mitte war der Ast durchgebrochen und das Bild des Mannes trieb auf dem Wasser weg. Nachdem es in der Nähe der Flussmündung auf einer Insel angespült worden war, wurde es lebendig. Sein Name war Tonggal Garing Djandjahunan Laut (der einzige Garing der aus dem Meer aufgestiegen ist). Inzwischen war auch das Frauenbild lebendig geworden. Sie hiess Putri Bulau Djulah Karangan (die goldene Prinzessin die hervorkommt aus den Steinbänken). Sie nahm eine Pinangscheide und ruderte in ihr flussaufwärts. Inzwischen war auch der Mann auf einem Stück Holz flussaufwärts gerudert.

Die beiden lebten nun zusammen, zuerst im Boot der Frau. Nach einiger Zeit begann sie $z \mathfrak{u}$ menstruieren, was sie als ein Unglückszeichen ansah.

Dat Blut warf sie ins Wasser und aus ihm entstanden alle bösen Wassergeister. Darauf begaben sie sich aufs Land um dort zu wohnen. Wieder verlor sie Blut und das Blut fiel diesmal auf die Erde. Es verwandelte sich in alle bösen Erdgeister. Sie bauten sich nun ein Haus und sie taten wie sie zuvor getan hatten, aber keine Veränderung stellte sich ein. Bei dieser dritten Gelegenheit wurde das menschliche Bild (d.h. die Frühgeburt, um solche hat es sich auch oben gehandelt) in ein Pinangblatt eingewickelt und in einen Baum geworfen. Es verwandelte sich in alle Baumgeister.

Aber nun kam Mahatara zu ihnen und er teilte ihnen mit, dass sie verkehrt gehandelt hatten weil sie sich einfach ohne weiteres vereinigt hatten. Dies durfte nur geschehen auf eine Weise die er ihnen nun mitteilte. Und was er ihnen sagte hatten sie allen Wesen (d.h. allen Nachkommen) mitzuteilen und sie mussten mit Blut bestrichen werden (manjaki mamalas).

So gab ihnen Mahatara alle Vorschriften die man auch jetzt noch bei der Heiratsfeier befolgt.

Nachdem alle diese Vorschriften durch sie befolgt worden waren, geschah, dass, nachdem Putri Bulau's Zeit wieder gekommen war, sie drei Söhnen das Leben schenkte, nämlich Maharadja Sangiang, Maharadja Sangen und Maharadja Bunu.

In diesen Tagen war noch das Paradies auf Erden, Himmel und Erde 
waren noch beisammen und der Himmelsstoff diente den Menschen als Speise. Bei ihrer Geburt hatten alle drei Kinder ein Geschenk bekommen von Gott. Maharadja Sangen erhielt allerlei nützliche Sämereien und er beschäftigte sich damit sie zu pflanzen zum Nutzen der Menschheit die später entstehen sollte. Maharadja Sangiang hatte zum Geschenk Eisen bekommen, allerdings nur Eisen, dass den Menschen zeitlich kampfunfähig machen konnte, aber ihn nicht zu töten vermochte. Es war das sogenannte sanaman lampang (schwimmendes Eisen). Maharadja Bunu aber bekam ein äusserst gefährliches Spielzeug, nämlich ein Stück Eisen das zu töten vermochte. Es war das sanaman leteng (das sinkende Eisen). Und weil diese Brüder nun fortwährend stritten, sehen wir, dass Mahatara sozusagen jeden Tag mit dem danum kaharingan belom (dem Lebenswasser, dem Leben schaffenden) sich hin und her begab zwischen seinem Wohnplatz und dem der Erdbewohner um einen Erschlagenen wieder zu beleben. Schliesslich aber verdrossen ihn und die Eltern diese ständigen Streitigkeiten und es geschah, dass Himmel und Erde voneinander geschieden wurden und Maharadja Bunu allein zurückblieb. Arm und verlassen irrte er herum und überall suchte er etwas. Wohl standen ihm die durch Maharadja Sangen gepflanzten Fruchtbäume zur Verfügung, aber er wünschte sich eine Frau. Und als er nirgends andern Menschen begegnete beschloss er eine Puppe von Lehm zu machen.

Als er die Puppe gemacht hatte bat er Mahatara sie lebend zu machen, was dieser ihm zusagte. Als er aber wartete, dass das geschehen sollte kam ein Tier $\mathrm{zu}$ ihm, nämlich ein angoi (Chameleon). Dieses spottete ihn aus weil er, um die Puppe lebend zu machen, Mahatara um Hülfe gefragt hatte und es sagte ihm, dass es das auch tun könne. Maharadja Bunu gab seine Zustimmung, dass es die Puppe belebte. Die Puppe wurde lebendig und erhielt den Namen Hantelo Petak (dreimal Erde). Aber in diesem Augenblick kam Mahatara mit dem Danum Kaharingan (Lebenswasser) an und war sehr entrüstet über das was geschehen war. Weil die Puppe durch ein sterbliches Wesen, den Angoi, das Leben erhalten hatte sollte sie nun fortan auch sterblich sein, was nach dem Gebrauch des Danum Kaharingan nicht der Fall gewesen wäre. Alle Menschen stammen nun von diesem Ehepaar $a b$ und deshalb müssen sie auch sterben.

Maharadja Sangiang und Maharadja Sangen hatten sich inzwischen auch verheiratet mit Putri Kambang Ambon Hatantali und Putri Kambang Garing und sie wurden die Stammeltern der beiden Geschlechter der Luftgeister, der Sangiang und Sangen. Die letzteren 
spielen im gewöhnlichen Leben keine Rolle. Der Stamm der Sangiang ist aber sehr wichtig. Nach diesen Sangen nennt man auch die Heldengedichte (Mythen), die man abends zu singen pflegt, sangen.

Wir sehen dann weiter, dass acht Geschlechter aufeinander folgen die aber hier nun weniger wichtig sind. Der achte aber sollte der eigentliche Stammvater werden der Götter die den Menschen ihre Dienste beweisen. Dies war Tantolang Bulan (muss heissen: Tantaolang Bulau, die Uebersetzung von Mallinckrodt: er, der die goldenen Knochen hat, stimmt nicht). Er schenkte zwei Kindern das Leben, nämlich dem Radja Pampulau Hawon und der Kamilau Panjulau Bintang (muss heissen: Kameloh Panjulen Bintang). Die letzte verheiratete sich mit ihrem Vetter Radja Pendjarawan Ketingan (muss heissen: Radja Panjarawan Katingan). Beide schenkten vierzehn Kindern das Leben, sieben Söhnen und sieben Töchtern.

Die Söhne des ersten hiessen : 1. Radja Dohong Bulau, 2. Pandjundai Langka Mamat Tempong Baron, 3. Rahon Tingang Njampulau Bahandang, 4. Talantang Sawang Buang Tolang, 5. Budjang Barendeng dia baka impon lawa, 6. Sahawong Bulau tempon penja, 7. Rawing Tempon Telon Lumba Baharun Bulau.

Seine Töchter hiessen : 1. Saring Bunge Mina djalembang tinggaring, 2. Udjan Bulau kangkalingan andau, 3. Pergantian Bulau, 4. Perahimok Tatawa, 5. Riwut Garantong Manambeleng Sambang, 6. Bawi Turon bulau menjamben Njahau, 7. Tempon Hendan Bulau.

Das andere Ehepaar (Radja Panjarawan Katingan und Kameloh Panjulen Bintang) schenkte ebenfalls sieben Töchtern und sieben Söhnen das Leben. Die Namen der Töchter sind: 1. Rampan bawi hai mengawang Ngambulong Lomba, 2. Balon tambok pandak indu bulau kambahan, 3. Loang Tandang Maheirai bunge, 4. Garing balemo sangkabilang Runtun, 5. Bawi Balang Babilem mina asok kasanparong, 6. Bunge Bulau Bawi Randan, 7. Kameloh Tempon Tiawon.

Die Namen der sieben Söhne sind: 1. Radja Ngambang Bulau, 2. Lalenda Lio, 3. Marakahan Tingang, 4. Sari Kambang Bunge, 5. Tanteloh Tingang, 6. Tawon Babukan Suling Nangai Andang Ngababilai Langit, 7. Tempon Kenarian Sawang.

Von den Erzählungen die über diese Götter in Umlauf sind, sind vor allem die über Tempon Telon sehr beliebt. Wir sehen, dass er zuerst als ein Blutklumpen geboren wurde. Seine Mutter warf ihn weg und er trieb flussabwärts. Eine andere Sangiangfrau (Pusun Baluso) fand ihn beim Bukit Lengkong und machte ihn zu einem Sangiang und gab ihm den Namen Kumpang Bulau Panarusan Langit (die goldene Schwert- 
scheide, die unter dem Himmel davontreibt). Wir hören von vielen Kriegen die durch ihn geführt wurden gegen böse Geister die er beendete mit dem Sieg über Manjamei, einen gefürchteten Sangiang, der Tempon Tiawon belästigte.

Beide, Tempon Telon und Tempon Tiawon, kehren nun nach dem Wohnplatz der Frau zurück und dort verheiraten sie sich miteinander. Zur gleichen Zeit verheiraten sich auch die Brüder und Schwestern. Die Männer lassen sich dann im Gebiet der Frauen nieder, so wie die Hadat das vorschreibt. Die Töchter von Papulan Hawon am Batang Danum Djalajan, die andern am Batang Danum Barirai.

Das Land der Sangiang ist nämlich ein grosses Flussgebiet wo jeder Stamm sein eigenes Wohngebiet besitzt. Zeichnungen dieser Gegenden sind nicht selten zu sehen.

Nicht alle diese Sangiang sind gleich wichtig. Der berühmteste von ihnen ist Tempon Telon, der seinen Namen einem gewissen Telon zu danken hat der sich nach seinem Sieg über Manjamei als sein Sklave unterwarf. Telon ist dann auch in der Sangiangsprache der Name für Sklave (darin irrt sich Mallinckrodt). Ein anderer Sangiang der ihm ebenfalls seine Dienste anboit war Asai Menteng (Asai, der Mutige). Wenn Tempon Telon seine Arbeiten verrichtetet, $d$. $h$. wenn er die Seelen der Verstorbenen in seinem eisernen Schiff (banama sanaman) nach dem Seelenland (lewu liau) bringt, tritt Asai Menteng als Djuru batu (der Mann, der auf dem Schiff mit dem auswerfen des Ankers beauftragt ist) auf.

Tempon Telon wird von den Menschen sehr oft angerufen, ebenso sein ältester Bruder und sein jüngster Schwager.

Sind nun die Götter, die diesen Namen tragen (die Sangiang) vor allem den Ngadju zugehörig, so gibt es unter ihnen doch ein Geschlecht das in ganz Süd-Borneo bekannt ist und angerufen wird. Es ist Sangumang mit seinem Helfer Papaloi und Maharadja Hadji, der Schwiegervater des Sangumang der stets von seinem Schwiegersohn betrogen wird. Die Erzählungen, die über diese drei Personen in Umlauf sind, sind mehr als fröhlich.

Wenn Sangumang jeweils für eine Zeit lang seine Streiche einstellt, dann ist er einer der meist geliebten, wenn nicht überhaupt der angesehenste Sangiang. Er wird sehr viel um Hülfe angerufen, man bringt ihm zahlreiche Gelübde dar und manche Wäldchen (heilige Haine) sind ihm geweiht.

In den verschiedenen Orten wählt man meistens einen gewissen Sangiang den man zum Schutzpatron der Familie oder des Ortes erhebt. 
Nebst den Erdgeistern wird bei verschiedenen Gelegenheiten auch dieser angerufen um seinen Verehrern hülfreich beizustehen. Das nimmt aber nicht weg, dass man nicht auch andere Geister um Hülfe anrufen kann, was meistens bei sehr wichtigen Angelegenheiten der Fall ist, oder auch dann wenn der Schutzheilige seine Pflichten nachlässig erfüllt.

Im gebiet von Kota Waringin nennt man alle diese Gottheiten mit dem Sammelnamen Sangiang Dewata. Es ist also der gleiche Name den auch der Schöpfer der Welt und der Stammvater der Menschheit trägt. Aber auch dort haben die verschiedenen Gebiete ihren eigenen, speziellen Sangiang Dewata und ebenso hat auch jede Familie ihren Schutzheiligen der ebenfalls diesen gleichen Namen trägt.

Der Ursprung der Menschen wird uns im Gebiet von Kota Waringin folgendermassen dargestellt: Nachdem Sangiang Dewata die Erde geschaffen hatte sandte er seinen Sohn und seine Tochter (Bagalah und Batara) auf die Erde um sie zu bevölkern. Batara liess sich mit ihrer Sklavin Baromas auf den Baum Kansurai hernieder, während Bagalah mit seinem Sklaven Suri Bujang aus dem Wasser auftauchte. Nachdem er sich am Ufer niedergesetzt hatte sah er im Wasser das Spiegelbild einer Frau, aber wie er auch nach ihr suchte, es gelang ihm nicht sie unter dem Wasser zu finden. Unzufrieden setzte er sich wieder ans Ufer und hörte plötzlich die Stimme eines Maniboi (ein Vogel) von einem Baum herab. Er schaute nach dem Vogel und auf diese Weise sah er die beiden Frauen die sich auf dem Baum aufhielten.

Er verheiratete sich mit der Frau. Auch der Sklave und die Sklavin heirateten zusammen. Sie wurden die Stammeltern der orang suka und hulun (der Freien und Sklaven). Von den mitgebrachten Früchten pflanzten sie verschiedene Sorten an, nämlich die Sawang, Durian, Sangkawang, Pinang und Kokospalmen.

\section{g. Djata und ihr Anteil an der Weltwerdung, nach Hardeland 54}

Djata nennt man die Götter des Wassers. Jeder grosse Fluss hat verschiedene Djata, von welchen jeder seinen eigenen Bezirk beherrscht. Die mächtigsten derselben residieren nahe der Mündung der Flüsse. Ausser diesen verschiedenen Distrikten der Flüsse, von welchen jeder von seinem Djata beherrscht wird, gibt es in jedem Fluss noch eine Menge einzelner Plätze, wo man meint, dass Djata sind, verschieden in Macht, Ansehen etc. Es sind aber solche Plätze nicht die eigentlichen Wohnplätze der Djata, sondern es ist dont nur der Eingang zu ihrem unter dem Wasser in der hohlen Erde liegenden Reiche, wo 
es ziemlich wie in unserer Oberwelt aussieht, nur alles schöner, prächtiger.

Die badjai (Krokodile) sind die Knechte der Djata, welche eigentlich menschliche Gestalt habend ihre Krokodilgestalt nur als klambi (Kleid), überziehen, wenn sie auf der Oberwelt einen Besuch machen. Deshalb wagt auch kein Dajak ein Krokodil zu töten, ausser wenn dasselbe einen seiner Verwandten gefressen hatte und die Blutrache es also fordert. Auch die tambon (Seeschlange), und viele Krankheiten (z.B. die Cholera, alle solche Krankheiten personifizieren die Dajak), sind Knechte der Djata.

Ursprünglich bestand nur ein Djata, der sanger (so nennen sich zwei Männer deren Kinder miteinander verheiratet sind) des Mahatara, welcher mit dem Mahatara zusammen alle Dinge geschaffen hat. Dieser eine, höchste Djata wird jetzt aber nicht mehr verehrt.

Die Djata sind mächtiger als die Sangiang (Luftgötter). Will man die Djata um etwas bitten, so geschieht das durch Intercession der Sangiang. Man erbittet von den Djata Kinder (besonders ganz unfruchrbare Männer und Frauen). Sie können während der Schwangerschaft vor den vielen bösen Geistern bewahren, welche den Schwangeren nachstellen, und können leichtes und glückliches Gebären verschaffen. Sie geben auch gute Ernten. Wenn man einen Djata um etwas bittet, bringt man entweder gleich Opfer, oder verspricht Opfer zu bringen, wenn die Bitte erfüllt sein wird. Oft bringt man ihnen auch Opfer ohne einen bestimmten $Z$ weck, nur um sich im Allgemeinen ihrer Gunst zu empfehlen. Viele Kinder werden durch mampandoi (taufen) dem Schutze der Djata übergeben.

\section{h. Weltwerdung und Ursprung der Sangiang nach Bapa Haastert 55}

Dieser wichtige Text erzählt uns, dass die Reisseelen, die beim Totenfest ausgesandt werden um Tempon Telon als Helfer abzuholen, in der Oberwelt angekommen sind. Bevor sie ihre Reise aber fortsetzen können haben sie sich zu legitimieren, dass sie wirklich das Recht haben in die Oberwelt zu reisen und Tempon Telon um Hülfe zu bitten. Ihre Reise wird durch Balo Lunok sawan Sangalang Ronggon Andau aufgehalten. Sie haben sich ihr gegenüber auszuweisen und müssen zu diesem $Z$ weck den Ursprung der Welt und der Sangiang erzählen um durch ihr Wissen zu beweisen, dass auch sie zum gleichen Geschlecht gehören. Man vergleiche diesen wichtigen und zentralen Text mit dem der im zweiten Band dieses Werkes mitgeteilt wird.

Die Erzählung lautet:56 
Tawur hajak Bahing Timang palus mahalau lewun Sangiang, lewu pulu ngambo tumbang lawang langit, ie te:
Die Reiskörner (d.h. die Reisseelen) und das Spruchwort (d.h. das personifiziert gedachte Spruchwort des Priesters das die Reisseelen auf ihrer Reise nach der Oberwelt begleitet) gehen vorbei an den Dörfern der Sangiang, an den Orten, den zehn, die sich oberhalb des Zugangs zur Türe des Himmels befinden. An diesen nämlich gehen sie vorbei :
Tawur tuntang 57 Bahing Timang sampai Lunok Hai Ganggahepan Pulu, Baringen Datoh Manindan djalatien.

Lunok hai te pupoh tumbang batang danum 160 .

Bara hete tawur hapisah namuei akan laut, akan batang danum Djalajan, akan hulu danum mangumbang Rawing Tempon Telon, mikeh ie manamuei.

Bahing Timang melai intu
Der Streureis und das Spruchwort kamen an beim Lunok, dem grossen, den zehn Menschen erst umspannen können, beim Waringin, dem umfangreichen, für den neun Männer nötig sind um ihn zu umfassen.

Dieser hohe Lunok ist das Wahrzeichen der Mündungen der 160 Flüsse (in der Oberwelt gibt es 160 Flüsse an denen die Sangiang wohnen).

Von dort trennt sich der Streureis und reist über die See nach dem Fluss Djalajan, nach dem Oberlauf des Flusses um zu suchen den Rawing Tempon Telon, denn es könnte sein, dass er sich auf der Reise befinden würde.

Das Spruchwort bleibt zurück auf dem 
Lunok Hai Ganggahepan Pulu, Baringen Datoh Manindan Djalatien, manunggo sampai Tawur karamahan.

Aton intu hete oloh bawi bagare Balo Lunok sawan Sangalang Ronggon Andau, balaku dengan Bahing Timang, uka ie manaturan atawa maasal lewu Hapungkal.

Auch iseke te kalotoh:

Pire oloh menteng hong lewu Hapungkal hila ngadju, pire hila ngawa tuntang pire oloh bawi idje bahalap tuntang pire sungei idje kalong lewu Hapungkal, tinai eweh aram ikau njahe bahanji dohong pantang langit, pulang takaranak hawon; tapi, koan Balo Lunok te, bilak kasenangku ikau toh.

Te Bahing Timang palus mananggar pondoke, manaharep Balo Lunok, bawi njawak kabangkang, habinei terus katentang.

Kantoh betau, koan Bahing Timang, aku djari bahanji dohong pantang langit, pulang
Lunok, dem grossen, den zehn Menschen erst umspannen können, dem Waringin, dem umfangreichen, für den neun Männer nötig sind um ihn $\mathrm{zu}$ umfassen, um dort $\mathrm{zu}$ warten auf die Rückkehr des Streureises.

Dort (auf dem Lunok) hielt sich auf eine Frau namens Balo Lunok, die Frau des Sangalang Ronggon Andau und sie bat das Spruchwort ihr zu berichten oder den Ursprung zu nennen des Dorfes Hapungkal (Hapungkal ist ein anderer Name für Batu Nindan Tarong, Liang Angkar Bantilong Njaring, das Stammdorf aller Sangiang, das in den andern Texten unter diesem Namen sehr häufig genannt wird).

Das Wort ihrer Frage lautet:

Wieviele mutige Männer wohnen im Dorfe Hapungkal nach der Seite von flussaufwärts, wieviele wohnen nach der Seite von flussabwärts und wieviele schöne Frauen befinden sich an beiden Orten, wieviele Flüsslein umgeben das Dorf Hapungkal, weiter, wie ist dein Name, mein Bruder, du mutiger Dolch der du heraufklimmst zum Himmel, du tapferer Griff, der du heraufsteigst $z u$ den Wolken; aber, spricht Balo Lunok, es scheint mir, dass ich dich beinahe kennen sollte.

Sogleich erhebt sich das Spruchwort von seinem Sitze und es nähert sich der Balo Lunok, der Frau von grosser Schönheit, dem Weib von unaussprechlicher Lieblichkeit.

Komm hieher meine Schwester, spricht das Spruchwort, ich bin der mutige Dolch welcher heraufstieg in den 
takaranak hawon.

Tawangku taturan lewu Hapungkal, betau, ie te pangenteng hila ngadju lewu, arae:
Himmel, der tapfere Griff welcher emporklimmte $z \mathbf{u}$ den Wolken.

Wohl ist mir bekannt die genaue Reihenfolge des Dorfes Hapungkal, o Schwester, die Tapferen, die in der Richtung flussaufwärts des Dorfes wohnen, heissen:

1. Tambon Paringkong

2. Punding Njarakulas

3. Rohau Bahanji

4. Pakiho Bingkok Nantaran Budjur

5. Asai Menteng

6. Djudjok Panuhok Dia Usah Ukur Kandaleme

7. Banguman Lanting

Aran oloh bawi bahalap tapa- Der Name der schönen Frau die am kan lewu hila ngadju, ie te: Ende des Dorfes, in der Richtung nach flussaufwärts wohnt, ist dieser:

1. Kameloh Kambang Baras, bawin oloh sungei Sandehan

Pangenteng hila ngawa lewu, Die Tapferen, die in der Richtung arae: flussabwärts des Dorfes wohnen, sind diese:

1. Tambon Patin

2. Tambon Bantus

3. Radja Bohong Tingang Bidik Matae Lasak Baner

4. Radja Kalambohong Tai

5. Apang Karangka, ingarangka ih usang parong batu

6. Samben Tiki Samben Tekang, batekang tolang idjang

7. Sarampang Pandji

Aran bawi bahalap tapakan lewu hila ngawa, ie te:
Der Name der schönen Frau, die am Ende des Dorfes, in der Richtung nach flussabwärts wohnt, ist dieser:

1. Putak Hadjundju Pasang Kameloh Bumbong Riak

Aran bawi bahalap intu ben- Der Name der schönen Frau, die in tok lewu, ie te: der Mitte des Dorfes wohnt, ist dieser : 


\section{Kameloh Suluh Garing Putir Lelak Balawan}

Tinai sungei idje kalong lewu Hapungkal horan, ie te:

1. Sungei Lentur Lio tandipah dengan sungei Salat Sawang

2. Sungei Karamunting Tandok tandipah dengan sungei Leleng Hempeng.

3. Sungei Sahai Tambarirang tandipah dengan sungei Salat Pulau Embat Pandjang

Atawa kalotoh:

1. Sungei Karamunting Tandok hulang gandang dengan sungei Salat Sawang tapakan lewu hila ngawa

2. Bentok lewu, sungei idje kalong lewu Hapungkal, ie te: Sungei Sahai Tambarirang, eka Bawi Balang Babilem, hulang gandang dengan Hatasan Baras Bulau, batang danum Kasiwahan Andau

3. Tapakan lewu hila ngadju, ie te: sungei Sandehan hulang gandang dengan sungei Leleng Hempeng; udju kare sungei idje kalong lewu Hapungkal horan.

Horan, metoh lewu Hapungkal irentah awi radja 58 Sarampang Pandji ewen due Bangunan Lanting, ewen due
Und die Flüsslein die das Dorf $\mathrm{Ha}$ pungkal früher einschlossen, sind diese :

1. Das Flüsslein Lentur Lio gegenüber dem Flüsslein Salat Sawang

2. Das Flüsslein Karamunting Tandok gegenüber dem Flüsslein Leleng Hempeng

3. Das Flüsslein Sahai Tambarirang gegenüber dem Flüsslein Salat Pulau Embat Pandjang

Oder auch so:

1. Das Flüsslein Karamunting Tandok schlängelt sich zusammen mit dem Flüsslein Salat Sawang am Ende des Dorfes in der Richtung nach flussabwärts

2. In der Mitte des Dorfes sind die Flüsslein welche das Dorf Hapungkal umgeben diese: das Flüsslein Sahai Tambarirang, der Wohnort der Bawi Balang Babilem, welches sich schlängelt zusammen mit dem Hatasan Baras Bulau und dem Fluss Kasiwahan Andau

3. Am Ende des Dorfes nach der Seite flussaufwärts ist es dieses: das Flüsslein Sandehan das sich schlängelt zusammen mit dem Flüsslein Leleng Hempeng; sieben Flüsslein sind es die früher das Dorf Hapungkal einschlossen.

In früheren Zeiten, als das Dorf Hapungkal beherrscht wurde durch den König (Aeltesten) Sarampang Pandji, zusammen mit Bangunan Lanting, 
te handak mampatei radja Hawon Tasik.

Ie, radja Hawon Tasik hadari akan laut dengan sawae, tuntang radja Rangkang Rangas Batakolok Batu, Parokat Bindjai Bauntek Tambaga dengan radja Samatuan. Maka horan te radja Tantaolang Bulau manjoho anak esoe mamangun parong batundjong.

Djari pangu,e palus mamangun huma ain Mangko Amat ewen due Njai Djaja intu tumbang sungei Karamunting Tandok.

Ie, horan betau 59 radja Tantaolang Bulau mambawa anake udju bawi tuntang udju hatue, samandiai epatbalas biti tuntang ie mambagi kare panatau (balanga, garantong, pati bahandang, tampong lamiang, bantilan timpong) tuntang sepsimpan panatau.

Palus radja Tantaolang $\mathrm{Bu}$ lau mangahau anake, koae: Eto-etoh ikau, o anak Sawang Barahila, duan kalabien panatau idje pansok (balanga).

Kanduengku pansok te, apang?

Hau, koan radja Tantaolang Bulau, ela ikau muntu guna,e akam, bilak sama kahai rega,e kilau idje katelok tasik lewun Balanda bagadong batu, wollten die beiden den König Hawon Tasik töten.

Aber der König Hawon Tasik flüchtete sich mit seiner Frau nach der Seite des Meeres und der König Rangkang Rangas Batakolok Batu, Parokat Bindjai Bauntek Tambaga, zusammen mit dem König Samatuan.

In dieser früheren Zeit gab der König Tantaolang Bulau seinen Kindern und Enkeln den Befehl ein sich hoch erhebendes Haus zu bauen.

Als der Bau fertig war bauten sie sogleich auch das Haus des Mangko Amat und der Njai Djaja an der Mündung des Flüssleins Karamunting Tandok.

Und es geschah in früheren Zeiten, dass die Schwester des Königs Tantaolang Bulau ihren Kindern rief, sieben Mädchen und sieben Knaben, zusammen vierzehn Personen, und sie verteilte unter ihnen alle Reichtümer (heilige Töpfe, Gong, rote Truhen, Trosse mit Achaten, Kissen von feinem Tuch) und noch verschiedene andere Reichtümer.

Und sogleich rief der König Tantaolang Bulau seinen Kindern und sprach: komm hieher, o mein Sohn Sawang Barahila, nimm zu dir vom Rest des Reichtums einen pansok (einen heiligen Topf).

Wozu soll mir dieser pansok dienen, o mein Vater?

Hau, sprach der König Tantaolang Bulau, siehest du denn nicht den Nutzen, den er für dich hat, sein Wert ist beinahe so gross wie eine Buchtung des Meeres der Dörfer der Europäer 
sama kilau idje katelok tasik lewun Tjina bakuntjir pandjang, balalu oloh garing tarantang manarima,e.

Toh tinai, o anak Kameloh Bakowo Batu, duan akam bagin panatau idje pansok kea.

Toh tinai, o anak Penjang Barahila, duan bagin panatau akam idje pansok kea.

Toh, akam o anak Putir Maludja hintan, duan akam panatau idje pansok kea.

Toh tinai akam, o anak radja Pampulu Hawon Batandok Tonggal Sasuro Benteng Dinding Pasah Bangkang Balanga Tingang, duan idje butah 60 apong pandji.

Duan ajum, o anak Kameloh Limut Njalong idje pansok.

Tarima ajum, o anak Paruwan Katingan, idje butah.

Eto-etoh ikau, o anak Kameloh Mandalan Bulan Indang Sahawong, toh bagin panatau akam idje butah apong pandji pandong panjaheroi dare.

Narai huange apang? Koan radja Tantaolang $\mathrm{Bu}-$ lau, toh huange anak Dohong in denen sich erheben die steinernen Lagerhäuser, beinahe ebenso hoch wie eine Buchtung der Dörfer der Chinesen mit den langen Bärten, und sogleich nahmen ihn in Empfang die elfenbeinernen Kinder.

Und nun du, o mein Kind Kameloh Bakowo Batu, empfange deinen Teil des Reichtums, nämlich auch einen pansok.

Und nun du, o mein Kind Penjang Barahila, empfange deinen Teil des Reichtums, nämlich ebenfalls einen pansok.

Und nun du, o mein Kind Putir Maludja Hintan, empfange deinen Teil des Reichtums, nämlich ebenfalls einen pansok.

Und nun du, o mein Kind König Pampulu Hawon Batandok Tonggal Sasuro Benteng Dinding Pasah Bangkang Balanga Tingang, empfange deinen Teil des Reichtums nämlich einen Tragkorb Apong Pandji.

Nimm nun als dein Eigentum in Empfang, o mein Kind Kameloh Limut Njalong, einen pansok.

Nimm nun als dein Eigentum in Empfang, o mein Kind Paruwan (oder auch Panjarawan) Katingan, einen Tragkorb.

Komm hieher, o mein Kind Kameloh Mandalan Bulan Indang Sahawong, empfange deinen Teil des Reichtums, nämlich auch einen Tragkorb apong pandji pandong panjaheroi dare (einen geflochtenen).

Was befindet sich darin, mein Vater? Es spricht der König Tantaolang Bulau, es befindet sich darin das 
Lalunding Liau,61 Pulang Pampang Raung tuntang Batu Kangkalingen Liau, Liang Sampalak Matei.

Aton toh tinai akam, o anak, Batu Lumpong Matanandau arae.

Akan narai guna, apang, koan Kameloh Mandalan Bulan Indang Sahawong.

Koan radja Tantaolang $\mathrm{Bu}$ lau: toh Dohong Lalunding Liau tuntang Batu Kangkalingen Liau hapan hanteran anak kaharingan, magah anak liau akan batang danum $\mathrm{Ka}$ babohan Njaho.

Toh Batu Lumpong Matanandau, anak, ikau mahapan djetoh, uka ikau haradjur budjang, dia tau rangkang, hajak minjak ajar mata dujung, ${ }^{62}$ minjak saputar balik 63 sariguna 64 tengko-tengkong peres halingo 65 telo njelo, minjak Sri Gunong Ali 66 sampar karendem delapan tahun, minjak toh minjak karuhei. 67

Amon oloh buah karuhei toh, telo njelo sampai hanja njelo oloh te buah mananggong kapehen atei, tapi kapehen atei djete kipen isi.

Handjak rantang huange $\mathrm{Ka}-$ meloh Mandalan Bulan Indang Sahawong, ambet sambil gantau kilau mambet ramon ta-
Kind (die Substanz) des Dolches, des Schmuckes der Liau, der Griff, das Geweih des Sarges und der Schattenstein der Liau, der steinerne Spiegel des Toten.

Und ferner befindet sich darin für dich, o mein Kind, der Stein der Rundheit der Sonne, so ist sein Name. Was ist ihr Nutzen, o mein Vater, so fragt Kameloh Mandalan Bulan Indang Sahawong.

Es spricht der König Tantaolang Bulau : hier, der Dolch, der Schmuck der Liau und der Stein des Schattenbildes der Liau werden gebraucht um zu leiten das Kind des Lebens (Totenseele), um zu führen das Kind der Liau (wie oben) zum Flusse Kababohan Njaho (das Totendorf).

Hier diesen Stein der Rundheit der Sonne, o mein Kind, diesen wirst du gebrauchen damit du immer jung bleibst und nie alt werden wirst, zusammen mit dem Oel, den Tränen der Seekuh, mit dem Oel Saputar Balik, dem Zaubermittel das da vertreibt die Krankheit des Herzens während drei Jahren, das Oel Sri Gunong Ali, das wegstösst das Herzeleid während acht Jahren, dieses Oel ist Karuheioel.

Werden die Menschen mit diesem Karuhei bestrichen, dann können sie während drei bis acht Jahren das Herzeleid ertragen, denn das Herzeleid ist die begierde des Fleisches.

Es freut sich und ist froh in ihrem Innern die Kameloh Mandalan Bulan Indang Sahawong, sie zieht sie herbei links und rechts, wie man herbeizieht 
manang lomat pusing.

Toh lepah panatauku, apangm, koan radja Tantaolang $\mathrm{Bu}$ lau.

Hemben te horan aton dumah Garing Hatungko Batu, apang Sangumang, talih bapae radja Tantaolang Bulau, koae : kueh bagin panatau akangku, apang?

Koan bapae: djari lepah, anak.

Amon kalote, koan Garing Hatungko Batu, toto aku puna dia anakm.

Te bapae horan garu-garus bumbong pinding, gaja-gajau kanaie, mahining auch anake.

Terai anak, koan bapae, aton tisan panatauku bapam, idje dereh batu pandjang 6660 depe, djalan Tato Garagasi mandop akan pantai danum kalunen.

Koan anake: kanduengku dengae, apang? hapaku mangitoi manok dia olihku manggatange!

Hau anak, koan radja Tantaolang Bulau, inampa akan pantar pandjang, aton ajung$\mathrm{ku}$ : die Mittel, die da aufheben die gänzliche Unfruchtbarkeit.

Erschöpft sind nun die Reichtümer deines Vaters, spricht der König Tantaolang Bulau.

In dieser früheren Zeit geschah es, dass Garing Hatungko Batu, der Vater des Sangumang kam und sich nahte seinem Vater, dem König Tantaolang Bulau, sprechend: wo ist mein Anteil des Reichtumes, o Vater?

Und es spricht der Vater: er ist ganz erschöpft, mein Kind.

Wenn es so ist, spricht Garing Hatungko Batu, dann bin ich wahrlich nicht dein Kind.

Und damals kratzte sich sein Vater an den Herzblättern der Ohren (Ohrläppchen), er kratzte sich an seinem Bauch als er diese Worte seines Kindes hörte.

Schweige nun mein Kind, spricht der Vater, es besteht noch ein Ueberrest des Reichtumes deines Vaters, ein steinerner Stab (Pfahl, Säule) 6660 depe (Klafter, die Länge der beiden ausgestreckten Arme, ca. $1.80 \mathrm{~m}$ ) lang, der als Weg diente für den Tato Garagasi wenn er sich an die Ufer des Flusses der Welt auf die Jagd begab. 68

Es spricht sein Kind: was sollte ich damit tun, o mein Vater, wollte ich ihn gebrauchen um mit ihm die Hühner wegzujagen, dann wäre es mir nicht möglich ihn aufzuheben.69

Hau mein Kind, spricht der König Tantaolang Bulau, gebrauchen wir ihn als hohen Pfahl,70 denn mir gehören: 
udju gudang sanaman

$\begin{array}{lll}\text { " } & \text {, } & \text { kuningan } \\ \text { " } & \text { " } & \text { gansa } \\ \text {, } & \text { " } & \text { tambaga } \\ \text { " } & \text {, } & \text { salaka } \\ \text {, } & \text {, } & \text { bulau } \\ & \text {, } & \text { hintan. }\end{array}$

Ie radja Tantaolang Bulau palus mamumpong kamasan 7770 biti, sukup kambo pantar batu te 7770 depe.

Radja Tantaolang Bulau manjoho pangirak Matjan Kadjoho Tuhan Tandjaro mirak oloh are mandohop, palus ie misong pantar batu te, ie djari tarusan Pantar Batu.

Te horan oloh mampendeng pantar batu.

Pantar batu te injaki hapan dahan hadangan tuntang dahan djipen telo, tapi dia tau mendeng.

Te radja Garing Hatungko Batu kapehen ateie.

Te radja Tantaolang Bulau horan mamumpong nudjum epat pulu idje biti.

Aton idje nudjum te bagare Karawat Mondok Karawat Mendeng, koan nudjum te: tapas sakie, pantar batu dia tau mendeng.

Narai sakie, koan radja Tantaolang Bulau. sieben Lagerhäuser Eisen

$\begin{array}{lll}" & \quad & \text { Messing } \\ " & " & \text { Bronze } \\ " & " & \text { Kupfer } \\ " & " & \text { Silber } \\ " & " & \text { Gold } \\ & \quad & \text { Edelsteine } \\ \text { (Diamanten). }\end{array}$

Alsogleich versammelte der König Tantaolang Bulau 7770 Feinschmiede, und genügend war die Länge der steinernen Säule, nämlich 7770 depe.

Der König Tantaolang Bulau gab dem Aufrufer 71 Matjan Kadjoho Tuhan Tandjaro den Auftrag die Menge der Leute zusammen zu rufen damit sie mithälfen, und sogleich schleppten sie den steinernen Pfahl und so entstand der Kanal Pantar Batu.

Und so richteten die Leute in früheren Zeiten den steinernen Pfahl auf. Der steinerne Pfahl wurde rituell bestrichen mit dem Blut eines Wasserbüffels und mit dem Blut von drei Sklaven, aber es war nicht möglich ihn aufzurichten.

Da überfiel den König Hatungko Batu das Herzeleid.

$\mathrm{Da}$ versammelte der König Tantaolang Bulau, damals in der früheren Zeit, ein und vierzig Wahrsager.

Unter ihnen war ein Wahrsager namens Karawat Mondok Karawat Mendeng und dieser Wahrsager sprach : die rituelle Bestreichung ist nicht genügend, deshalb ist es nicht möglich den steinernen Pfahl aufzurichten.

Was soll denn zur rituellen Bestreichung gebraucht werden, sprach der König Tantaolang Bulau. 
Koan nudjum: amon dia njaki hapan dahan radja Rangkang Rangas Batakolok Batu Parokat Bindjai Bauntek Tambaga, puna dia tau mendeng.

Ie palus oloh akan laut marawei radja Rangkang Rangas Batakolok Batu Parokat Bindjai Bauntek Tambaga horan, palus dumah radja hapan banama pandjang sampai lewu Hapungkal.

Ie aton hatue idje bakena intu lewu Hapungkal, bagare Tonggal Iman Handjaliwan, palus inamee bara djundjun karapuron radja Rangkang Rangas horan, ie musat bahenda lumpok matae, haban mende-mendeng, palus dumah oloh idje bagare Rumpong Kusong Tempon Lingai Penjang Mamunu, mampatei ie, palus ie matei.

Dahae ihapan oloh manjaki pantar batu, ie pantar batu mendeng palus oloh manembak lela pandjang palus kahem banama pandjang, ie saloh mandjadi batu rampar banama, eka belom lunok hai ganggahepan pulu, tapatindan tihang intu lewu Hapungkal, ie lewu balalu bagare Batu Nindan Tarong, Liang Angkar Bantilong Njaring.
Es sprach der Wahrsager: wenn er nicht rituell bestrichen wird mit dem Blut des Königs Rangkang Rangas Batakolok Batu Parokat Bindjai Bauntek Tambaga, dann wird es nicht möglich sein ihn aufzurichten.

Und sogleich begaben sich Leute nach dem Meere um einzuladen den König Rangkang Rangas Batakolok Batu Parokat Bindjai Bauntek Tambaga, damals in der früheren Zeit, und sogleich kam der König in einem langen Boote und er kam an im Dorfe Hapungkal.

Es befand sich im Dorfe Hapungkal ein Mann der schön war, namens Tonggal Iman Handjaliwan, in ihn hinein begab sich durch die Fontanelle der König Rangkang Rangas in der früheren Zeit, bleich und gelb wurden seine Augen, er wurde krank während er noch aufrecht stand, und sogleich kam ein Mann namens Rumpong $\mathrm{Ku}$ song Tempon Lingai Penjang Mamunu und tötete ihn und sogleich starb er.

Sein Blut gebrauchten die Leute um mit ihm rituell $\mathrm{zu}$ bestreichen den steinernen Pfahl, der steinerne Pfahl konnte nun aufgerichtet werden und die Leute schossen darnach eine lange Kanone ab und sogleich versank das lange Boot, es verwandelte sich in den Stein des umgefallenen (oder auch: flachen) Bootes, der Platz auf dem sich der Lunok, den erst zehn Männer umspannen können, erhebt, der aufgerichtete Flaggenstock, d.h. das Wahrzeichen des Dorfes Hapungkal und von dieser Zeit an nannte man das Dorf 
Batu Nindan Tarong, Liang Angkar Bantilong Njaring.

Pondok apui horan tambalang bara arut hai, ie djari hanggulan apui dia tau belep, pondok sihong dia tau lepah.

Bara katika te oloh mimbul bua Asem Lumba baka belom belai, malunek bulau ontong, mamantis njalong kaharingan belom, enjoh gading, mingkes lalang salangap langit, njuang behas pulut, inutup hapan pundang.

Ila-ilai langit, imipih dia tau una, injendok dia tau lepah.

Hanggulan garing aton pusa dokoh tungo, e kahain lakang badjang.

Asem Lumba aton tato seso kahai randok kambing tungo,e.

Enjoh gading aton tato saragate, kahai lakau djagau, tunggo,e.

Ie horan anak radja Rangkang Rangas, bagare Asai Menteng Katingan Handi-
Das brennende Stück Holz (mit dem im Boot das Feuer unterhalten wurde) wurde herausgeschleudert und verwandelte sich in den Feuerbrand $\mathbf{7 2}$ der nicht verlöschen kann, in das elfenbeinerne 73 Feuer, das nie verzehrt wird.

Seit dieser Zeit pflanzen die Menschen die Asem Lumba Fruchtbäume, von deren Früchte sie sich satt essen und die Kerne haben von Gewinn bringendem Gold und von denen heruntertropft das Wasser des Lebens, das lebenschaffende, und sie pflanzen die Kokospalmen, die viel Rippen habenden und sie besitzen die heiligen Töpfe Salangap Langit die gefüllt sind mit Pulutreis 74 und bedeckt mit Fleisch das an der Luft getrocknet wurde.

Das gerechnet wird zum Himmel gehörend, von dem man abschneidet ohne dass es vermindert (das Fleisch), von dem man aufschöpft ohne dass er abnimmt (der Reis).

Den Feuerbrand, den elfenbeinernen, bewachte eine Wildkatze, die ungefähr die Grösse hatte eines Hirsches.

Beim Asem Lumbo Fruchtbaum hielt der Stammvater der Seso, 75 der die Grösse hatte eines alten Ziegenbockes, die Wache.

Bei der Kokospalme mit den zahlreichen Rippen hielt der Stammvater der Saragate, ${ }^{76}$ der die Grösse hatte eines Hahnes, die Wache.

Es geschah in dieser früheren Zeit, dass die Kinder des Königs Rangkang Rangas, namens Asai Menteng Ka- 
wong tuntang Rohau Bahanji Habungai Lamiang handak masang lewu Hapungkal.

Kabar te djari sampai.

Ie lewu Hapungkal pangangkarak, oloh lewu te mangumbang batang danum, manggau eka melai,e.

Radja Pampulu Hawon Batandok Tonggal akan batang danum Djalajan.

Radja Panjarawan Katingan horan akan batang danum Barirai.

Sawang Ila-Ila akan bukit Batengkong.

Penjang Barahila akan pulau Karandahong Bahandang.

Radja Garing Hatungko Batu akan batang danum Sangkalela.

Sambatang Maharadja Hadji akan Haselan Tingang.

Rasing, apang Paloi akan batang danum Mantenjo Bulau, gohong Nalaga Tahil.

Sang Piata akan batang danum Maninting Ambon.

Rantingan, bapa Upo, akan batang danum Mantawa Bulau Mupoh Djadjangkit Lajang Batahasak Njalong Kaharingan Belom.

Tinai budjang Laut buli akan Laut, budjang Djalajan buli tingan Handiwong und Rohau Bahanji Habungai Lamiang das Dorf Hapungkal durch einen kriegerischen Ueberfall vernichten wollten.

Die Nachricht davon war im Dorf angekommen.

Das dorf Hapungkal wurde verlassen und verfiel und die Leute des Dorfes siedelten nach andern Flüssen über und suchten sich Orte wo sie sich niederlassen konnten.

Der König Pampulu Hawon Batandok Tonggal liess sich nieder am Flusse Djalajan.

Der König Panjarawan Katingan liess sich in dieser früheren Zeit nieder am Flusse Barirai.

Der Sawang Ila-Ila zog auf den Berg Batengkong.

Der Penjang Barahila siedelte nach der Insel Karandahong Bahandang über.

Der König Garing Hatungko Batu liess sich nieder am Fluss Sangkalela.

Sambatang Maharadja Hadji zog an den Haselan Tingang (ein Teich).

Rasing, der Vater des Paloi, liess sich nieder am Flusse Mantenjo Bulau, am Wasser Nalaga Tahil.

Sang Piato liess sich nieder am Fluss Maninting Ambon.

Rantingan, der Vater des Upo, liess sich nieder am Fluss Mantawa Bulau Mupoh Djadjangkit Lajang Batahasak Njalong Kaharingan Belom.

Ferner, die Jünglinge vom Meere her kehrten ans Meer zurück, die Jüng- 
akan Djalajan.

Ie, tawur idje mangumbang manggau Rawing Tempon Telon te dumah bara laut, bara Djalajan, bara hulu batang danum, tende intu Lunok Hai Gangga-Pulu, Baringen Datoh Manindan Djalatien, eka Bahing Timang mentai sampai tawur te dumah.

Ie, Bahing Timang manampunan Tawur, palus Bahing Timang hakotak dengan Tawur, koae: bua-buah, itah murik batang danum Djalajan, palus Bahing Timang tolak bara tandjungan Lunok hai.

Tawur palus mahalau pulau Handiwong, pulau Tadjahan, bukit, eka Mambang Kumpang, tandjong Bingkok, tandjong Kangkelong Bengkel, tandjong Sakean Burong Tingang.

Tawur manjaloh balai Kalati djahawen pulu, ngawa tumbang batang danum Djalajan, palabohan lasang djahawen pulu, palabohan banama djahawen pulu, palabohan kalulus djahawen pulu.

Kare taloh te samandiai djaton aton una ise,e. linge vom Djalajan kehrten an den Fluss Djalajan zurück. ${ }^{77}$

Der Streureis, der nach verschiedenen Richtungen und in verschiedenen Gruppen ausgezogen war um Rawing Tempon Telon zu suchen, kam wieder zurück von der Richtung des Meeres her, vom Flusse Djalajan und vom Oberlauf der Ströme und er versammelte sich auf dem Lunok, dem grossen, den erst zehn Männer zu umspannen vermögen, auf dem Waringin, dem hohen, den erst 9 Männer umfassen können, der Platz wo das Spruchwort auf ihre Rückkehr wartete. Das Spruchwort versammelte den Streureis und das Spruchwort sprach zum Streureis, sagend : tretet nun vorsichtig auf, wir werden nun hinaufreisen den Fluss Djalajan, und sogleich reiste das Spruchwort weg von der Krone des grossen Lunok.

Und der Streureis reiste vorbei an der Insel Handiwong, an der Insel Tadjahan, am Berge, dem Orte des Mambang Kumpang, an der Buchtung Bingkok, an der Buchtung Kangkelong Bengkel, an der Buchtung Sakean Burong Tingang.

Der Streureis ging vorüber an den Balai, den sechzig, unterhalb der Mündung des Flusses Djalajan, am Hafen der sechzig Boote, am Hafen der sechzig Handelsboote, am Hafen der sechzig zierlichen Boote. ${ }^{78}$

Alle diese Dinge zusammen, nicht wurden sie gerechnet oder gezählt durch das Spruchwort. 
Te Bahing Timang mameteh tawur: bua-buah itah manjaloh balai Rawing Tempon Telon, sabab balai te djaton aton djihi, djaton aton tongket, mikeh balai te paliambong, karana balai te baja ingarambang awi batang sawang, hambalat awi batang pantar.

Ie tawur sampai, tapi Rawing Tempon Telon batiroh, palus tawur tingkap manapis intu batang Sangalang, Bahing Timang melai intu puson Pinang Entas djendjang balai.

Sana Rawing Tempon Telon misik batiroh, palus ie manjoho djipe,e idje bagare Telon mukei pakaja,e hong pati pandjang, palus inetes sirat pati te lepa-lepah hajak batetes ambon rutas matei ain oloh kalunen.

Sana mukei, huang pati te aton:

1. Tingang, dawen marau bara Manjamei tumbang lawang langit.

Koan Telon: pire rega,e djetoh, tempo?

Djetoh imili hapan kamentengku, tempom, hajak pe-
Und das Spruchwort gab dem Streureis den Auftrag: nun vorsichtig, wir gehen nun vorüber am Balai des $\mathrm{Ra}$ wing Tempon Telon, und weil dieser Balai keine hohen Balken hat und nicht auf kleinen Pfosten ruht, 79 deshalb könnte es sein, dass er plötzlich in die Höhe gehoben würde, denn er ist ja nur umgeben von Sawangstauden, nur umzäunt mit hohen Pfählen (er ist also schwebend und kann sich von selbst in die Höhe heben).

Der Streureis kam dort an, aber Rawing Tempon Telon schlief und sogleich liess sich der Streureis nieder auf dem Sangalangbaume und das Spruchwort wartete in den Herzblättern der Pinang Entas neben dem Balai.

Nachdem Rawing Tempon Telon von seinem Schlafe erwacht war, befahl er sogleich seinem Sklaven, namens $\mathrm{Te}$ lon, zu öffnen seine Kleider welche sich befanden in der Kiste, der langen, und sogleich durchschnitt er die geflochtenen Bänder die die Kiste verschlossen und er durchschnitt auch die Wolken, die vernichtenden, des Toten aus den Menschen der Welt. 80

Und als er sie geöffnet hatte, lagen in ihr:

1. Tingang, dazen Marau vom Manjamei beim Zugang zur Türe des Himmels. ${ }^{81}$

Es spricht der Telon: wie gross ist der Wert dieses Stückes hier, mein Besitzer?

Dieses hier hat gekauft mit seiner Tapferkeit dein Besitzer, in Zusam- 
njang kasingan tandang haramaung.

2. Tuntang baron pandjang tingang idje lombah dandang bara Manjamei Tuha, oloh Petok Kanarewong Antang, tuntang baron Tumpang Tontang.

3. Tjula Tupai Tingang, tandok rangkang bara Manjamei Tungking Langit, tuntang baron tapas-tapas tuntang penjang tandok landok, batu utin pusa, kareh mandjawut amon marantang.

4. Tingang baputih dandange bara Gadjah Menteng babalai banama tuntang penjang apui tau lenjoh menteng.

5. Penjang Apau bara radjan Siau tuntang baron lamiang, tuntang penjang batun tiroh tau buang lewu.

6. Tingang Tahilan bara $\mathrm{Ma}$ njamei Menteng Njalutoh Buno tuntang baron Kamondang tuntang penjang.

7. Buntat Tuwe Tingang, bisa-bisa dandange, bara Balo Indu Gareman, bawin Tambon tuntang baron bisa-bisa tuntang penjang njalong tau teneng labeho.

8. Tingang Ohing bara Andju Menteng Panjempong Tihang, Taladjan Bahanji $\mathrm{Pa}$ - menarbeit mit den Penjang, ${ }^{82}$ den Zähnen des Tigers. ${ }^{83}$

2. Und das Oberkleid, das lange des Tingang, das breite Schwanzfedern hat, vom Manjamei Tuha, dem Manne von Petok Kanarewong Antang und das Oberkleid Tumpang Tontang.

3. Und das Horn Tupai Tingang,84 das Horn, das sehr alte des Manjamei Tungking Langit und das Oberkleid Tapas-Tapas 85 und die Penjang, die Hörner der List und des Betruges, die Steine des Schamteiles des Katers, die ihm herausgerissen werden sobald er geboren wird.

4. Der Tingang mit den weissen Schwanzfedern der Gadjah Menteng der da wohnt in dem Boot und die Penjang des Feuers die zu lähmen vermögen die Tapferkeit.

5. Die Penjang Apau des Königs Siau und das Oberkleid von Achatsteinen und die Penjang, die Steine des Schlafes welche leer machen können die Dörfer (weil sie die Bewohner töten). 6. Der Tingang Tahilan des Manjamei Menteng Njalutoh Buno und das Oberkleid des Kommandanten und die Penjang.

7. Die Buntat Tuwe Tingang mit den nassen Schwanzfedern von der Balo Indu Gareman, der weiblichen Tambon 86 und das Oberkleid, das nasse und die Penjang des Wassers welche zum Verstummen bringen die Wassertiefe (Zugang zur Unterwelt).

8. Der Tingang Ohing des Andju Menteng Panjempong Tihang, Taladjan Bahanji Panesei Gandang und 
nesei Gandang, tuntang penjang bulau silang atei tuntang baron lepah ukei.

Telon Mama Tambon Buno ewen due Hamparong Mama Kandaju Lanting dinon panenga bara Rawing Tempon Telon, ie te: idje mariam hai tuntang idje garantong.

Hemben te kea tawur manjaloh balai, olih kaput batialem, aloh tupang-tapei dadinding pendae, Rawing Tempon Telon mite tawur babilem, sairmanjair, tunek-manunek, mikeh tawur pulih nadjahan itah telo matei.

Te ie mambawa Indu bulan Pangasene uka ie mangasene tawur, tapi dia ie kasene,e, ie Rawing Tempon Telon kapehe huange.

Ie, bapa tinai, radja Pampulu Hawon, puna kasene tawur, koae: hau anak, toh tawur oloh kalunen, manjoho ikau mahanteran salumpok liau oloh kalunen, manantelak ambon rutas matei.

Te bapa manjoho anake $\mathrm{Ra}-$ wing Tempon Telon, tapi ie dia nahuang mandohop oloh kalunen.

Tagal te, bapae radja Pampulau Hawon manaturan tato bara tamparan kalunen, ie te, die Penjang der goldenen Hälfte der Leber und das Oberkleid mit der vollständigen Oeffnung.

Telon Mama Tambon Buno zusammen mit Hamparong Mama Kandaju Lanting erhielten ein Geschenk von Rawing Tempon Telon, nämlich dieses : eine grosse Kanone und ein Gong.

Damals geschah als der Streureis vorbeiging am Balai, dass doppelte Dunkelheit hereinbrach, obwohl man hoch aufhob die Wände des Balai blieb alles dunkel, Rawing Tempon Telon sah den schwarzen Streureis wie Späne und Sagemehl, wie Staub und Mehl, vielleicht ist es giftiger Streureis welcher uns besucht um uns drei zu töten, so sprach er.

Er rief herbei die Indu Bulan Pangasene damit sie erkenne den Streureis, aber nicht vermochte sie ihn zu erkennen, da erfüllte Leid das Innere des Rawing Tempon Telon.

Er aber, der Vater (des Tempon Telon), der König Pampulu Hawon, kannte wohl den Streureis und er sprach: Hau, mein Sohn, es ist der Streureis der Menschen in der Welt, er überbringt dir den Auftrag die liau der Leute in der Welt zu führen (nach dem Totendorf) und $z u$ vertreiben die Wolken, die vernichtenden, des Toten. Darauf gab der Vater seinem Kinde Rawing Tempon Telon den Auftrag es zu tun, aber er wollte nicht den Leuten in der Welt behülflich sein. Aus diesem Grunde geschah es, dass sein Vater, der König Pampulau Hawon ihm die Reihenfolge der Ahnen 
oloh kalunen puna idje dengan oloh Sangiang, koae: ie te, horan, anak, kalotoh pahoroie, puna penjang idje hindje simpei,e, paturong hindje sandik,e, oloh kalunen puna tau basara, anak, inenga tuak djohon mata, sirih hatanturong akam, o anak.

Hemben horan, anak, kalunen ambon njalong luja-lujak.

Tikas Hatala ewen due Djata.

Hatala melai intu langit, $\mathrm{Dja}-$ ta melai intu huang danum, baja ewen due kabuat ih.

Ie Ranjing Hatala Langit horan manangkilik akan ngiwa palus mandjato kupiah bulau katopong hintan ain Hatala balalu buah hundjun pangkuan Djata.

Ie iambong awi Djata akan hila kabeloman, ie saloh djari Tingang Rangga Bapantong $\mathrm{Njaho,} \mathrm{palus} \mathrm{tingang} \mathrm{nun-}$ djong taribanga katelo andau katelo alem, hajak balau kanaie. vom Anfang der Welt aufzählte, es ist nämlich so, dass die Menschen der Welt ein Geschlecht bilden mit den Sangiang, er sprach deshalb: so steht die Sache, mein Sohn, in früheren Zeiten waren wir alle Penjang die einem Bande aufgereiht waren, waren wir Paturong die sich in einem Bündel befanden, 87 und weiter: die Menschen in der Welt können alle Dinge gut in Ordnung bringen, mein Sohn, sie werden dir Bier, die Tränen der Augen (ein sehr schmackhaftes Reisbier) und Sirih zum Kauen in Ueberfluss geben. 88

In früheren Zeiten, mein Sohn, war die Welt über dem Wasser nur eine breiige Masse (es war alles nur Wasser, es bestand noch keine Erde und keine Welt).

Nur bestanden damals Hatala und Djata.

Hatala wohnte oben im Himmel, Djata aber hielt sich auf unten im Wasser, nur sie beide allein bestanden, sonst niemand.

So geschah es in der früheren Zeit, Ranjing Hatala Langit schaute vom Himmel herunter aufs Wasser und es fiel herab seine goldene Kopfbedeckung, sein Helm von Edelsteinen und er fiel auf den Schoss der Djata.89

Er wurde hoch in die Höhe gehoben durch die Djata in der Richtung nach Sonnenaufgang und er verwandelte sich und nahm die Gestalt an des Tingang Rangga Bapantong Njaho (der erhabene Nashornvogel mit dem donnernden Horn), sogleich erhob er sich und flog davon während drei 
Ie inampajah awi Ranjing Hatala Langit horan palus ie malaboh sokah balalu saloh mandjadi lunok masak manalandjan tampong, palus gitan awi tingang, balalu tingang hakananan bua lunok.

Manangkilik tinai Ranjing Hatala Langit, palus malaboh suloh garing, ie saloh djari garing belom ganto-gantong hila kabalepan.

Nampajah tinai Ranjing Hatala Langit horan, palus labohe karis hila kabalepan, palus saloh djari hatuen Tambarirang.

Ie hatuen Tambarirang horan balalu tingkep intu batang garing hakananan bua garing sampai dawe,e lepah, eda,e lepah tuntang lunok garing, mahin ie dia tau besoh.

Ie manjahumpak batang garing, saloh djari banama bulau, mantap lunok garing, saloh djari oloh bawi bagare Kameloh Lumot Garing, ie palus imintike tuntang ie saloh djari Tunggul Hadjunan Danum.
Tagen und drei Nächten, und er war hungrig.

Er wurde gesehen durch Ranjing Hatala Langit, damals in der früheren Zeit, und er warf herab seinen Stab (Spazierstock) und dieser verwandelte sich sogleich und nahm die Gestalt eines Lunok (Fruchtbaum ${ }^{90}$ ) an, der voller reifer Fruchttrossen hing und sogleich ass der Tingang von den Früchten des Baumes.

Und wieder schaute herab Ranjing Hatala Langit und er warf herunter den Schössling eines Baumes und dieser verwandelte sich und er wurde ein lebender Baum von sehr grosser Höhe der in der Richtung von Sonnenuntergang gedieh.

Und wieder schaute herunter Ranjing Hatala Langit in der früheren Zeit und er warf, in der Richtung nach Sonnenuntergang, seinen Dolch 91 her$a b$ und dieser verwandelte sich sogleich in einen männlichen Tambarirang. ${ }^{92}$

Er, der männliche Tambarirang liess sich damals, in der früheren Zeit, nieder auf dem Baume und er verzehrte die Früchte des Baumes bis nichts mehr übrig blieb von seinen Blättern und von seinen Aesten und vom ganzen Baum und doch war er noch nicht satt. Er schlug Stücke ab von dem Baumstamm und diese verwandelten sich in ein grosses goldenes Boot, er schlug nocheinmal Stücke ab von dem Baumstamm und diese verwandelten sich in eine Jungfrau namens Kameloh Lumot Garing, er stiess den Baumstamm noch einmal an mit seinem Fuss und er verwandelte sich sogleich in den Tung- 
Ie horan hatuen Tambarirang tarawang akan hila kabeloman andau, gitae pahalendang bua lunok lenda-lendang, palus hatuen Tambarirang tingkep intu tahandjungan lunok.

Te hatuen Tambarirang hakalahi dengan Tingang, palus hatuen Tambarirang mintik batang lunok, dia olih balihang, baja manjahumpak ih, ie saloh djari banama hintan.

Manangkilik tinai Ranjing Hatala Langit, ilabohe kuas pinang, inotoke awi Tingang, inelee dia tau, iluae dia tau balua, tapi palus balua kea tuntang ie saloh djari oloh hatue bagre Manjamei Bulau Onggon Tingang.

Ie melai intu banama hintan, Kameloh Lumot Garing melai intu banama bulau, banama due te hapandoh.

Ie te horan Tingang palus mintik batang lunok te, limbah te Tingang Rangga Hapantong Njaho sawong parap tadji dengan hatuen Tambarirang, palus hatuen Tambarirang matei, saloh djari sungei Sahai Tambarirang. gul Hadjunan Danum. ${ }^{93}$

Damals in früheren Zeiten flog der männliche Tambarirang nach der Richtung von Sonnenaufgang und er sah in Erscheinung treten einen Fruchtbaum und er sah seine Früchte und sogleich liess sich der männliche Tambarirang auf dem Wipfel des Baumes nieder.

Der männliche Tambarirang kämpfte mit dem Tingang und der männliche Tambarirang schlug mit seinem Fusse an den Baumstamm aber es war ihm nicht möglich ihn auf diese Weise zu fällen, nur schlug er Stücke von ihm ab und diese verwandelten sich sofort in das grosse Edelsteinboot.

Und wieder schaute herunter Ranjing Hatala Langit und er warf herab ein gekautes Stück Betelnuss, es wurde aufgepickt durch den Nashornvogel aber er vermochte es nicht herunterzuschlucken und auch nicht mehr auszuspucken, aber plötzlich fiel es heraus und es verwandelte sich in einen Jüngling namens Manjamei Bulau Onggon Tingang.

Er hielt sich auf in dem grossen Edelsteinboot, Kameloh Lumot Garing aber hielt sich auf in dem grossen Goldboot, die beiden Boote aber waren aneinander festgemacht. ${ }^{94}$

Aber es geschah in früheren Zeiten, dass der Tingang den Baumstamm mit seinem Fusse anstiess (sodass er umstürzte) und darauf fiel der Tingang Rangga Hapantong Njaho mit seinem Sporne den männlichen Tambarirang an und sogleich starb der männliche Tambarirang und er verwandelte sich 
Batang lunok te basaloh kea djari Lunok Djajang Tingang, Baringen Sempong Tolang Tambarirang.

Sana Tingang Rangga $\mathrm{Ba}$ pantong Njaho mite,e, balalu ie tingkep intu Lunok $\mathrm{Dja}$ jang Tingang, palus Tingang Rangga te matei, ie saloh djari tarusan Lunok.

Toh tinai saritan Manjamei Bulau Onggon Tingang dengan Kameloh Limut Garing. Ewen due hindje, Manjamei Bulau Onggon Tingang masawe Kameloh Limut Garing. Tapi petak djaton ekae, ie ilaboh Ranjing Hatala Langit bawak kaju samatuan telo kabawak, te Hatala pamohon riwut barat manampur udju andau udju alem, palus lampang petak djala-djalan lombah.

Nampajah tinai Ranjing $\mathrm{Ha}-$ tala Langit, palus labohe bendang epat kabisak, palus djari kaju-kajuan, uras aton.

Palus Manjamei Bulau Onggon Tingang mamangun parong, djari huma, ie ewen due hindje, balalu Kameloh Limut Garing manak anake idje so- in den Fluss Sahai Tambarirang.

Aber auch der Baumstamm wurde verwandelt und nahm die Gestalt an des Lunok Djajang Tingang, Baringen Sempong Tolang Tambarirang (der Baum des Sieges des Tingang, der Waringin der zerbrochenen Knochen des Tambarirang).

Sobald Tingang Rangga Bapantong Njaho ihn erblickte, liess er sich auf ihm, dem Lunok Djajang Tingang nieder und darnach starb der Tingang Rangga und er verwandelte sich in den Kanal Lunok.

Nun setzen wir fort die Erzählung von Manjamei Bulau Onggon Tingang und Kameloh Limut Garing.

Die Beiden vereinigten sich, Manjamei Bulau Onggon Tingang verheiratete sich mit Kameloh Limut Garing.

Aber Erde, auf der sie sich hätten niederlassen können, gab es nicht, da liess Ranjing Hatala Langit drei Fruchtkerne des Baumes Samatuan(?) herunterfallen und Hatala liess einen heftigen Sturmwind losbrechen der sieben Tage und sieben Nächte brauste und da tauchte Erde auf die allmählich breiter und grösser wurde.

Und wiederum schaute Ranjing Hatala Langit herunter und er liess vier Stück Bendangbretter 95 herabfallen und aus ihnen entstand sogleich ein Wald in dem alles vorhanden war (was für den Hausbau benötigt wurde).

Und sogleich baute Manjamei Bulau Onggon Tingang ein Haus und als das Haus fertig aufgerichtet war vereinigten sich die Beiden in ehelicher Gemeinschaft und bald gebar Kameloh 
lake, ie te:

\section{Putak Djulen Karangan}

2. Daha urase, ie injila palus iambong hapan isin dohong akan laut, saloh djari tato Peres, melai intu banama bunter, tinai iambong akan hundjun petak, saloh djari tato kahiu, bakei, bakara, buhis, tato njamok, rangit, langau.

3. Uras bulu kahain halo,n puseh kare,e telo karambar, djete inetek bagi due palus iambong akan hundjun bukit, ie saloh djari tato badjang, tato Njaring tuntang Sangiang liliapan Ambon.

4. Daha, kahai dulang, inising bagi udju tuntang imbelome, palus bagare:
Limut Garing ihre ersten Kinder, diese nämlich :

1. Putak Djulen Karangan

2. Nur Blut (Blutklumpen, Fehlgebuhrt), es wurde in zwei Hälften geschnitten und die eine Hälfte wurde mit dem Eisen eines Dolches in die Höhe gehoben in der Richtung nach dem Meere und sie verwandelte sich und nahm die Gestalt des Stammvaters Peres an der sich in dem banama bunter (das runde Boot) niederliess, und die andere Hälfte wurde auch in die Höhe gehoben, auf die Erde, und sie verwandelte sich in die Stammväter der Orang Utan, der grauen Affen, der Nasenaffen, der Wau-Wau, die Stammväter der Moskiten, der Mücken und der Fliegen.

3. Nur Haar von der Grösse eines Stabes mit dem man das Feuer andreht, 96 davon drei Stück, diese wurden halbiert und sogleich in die Höhe gehoben auf einen Berg, sie verwandelten sich und nahmen die Gestalt an des Stammvaters der Hirsche, des Stammvaters der Njaring und der Sangiang Liliapan Ambon (die sich in den Wolken, zwischen Erde und der Oberwelt aufhalten und dort ihre Dörfer haben).

4. Alles Blut (Blutklumpen) von der Grösse eines Schweinetroges, es wurde in sieben Teile zerteilt und belebt und diese Teile erhielten die Namen:

1. Sambajau Sangiang

2. Sambajau Sangen

3. Gadjah Bakapek Bulau

4. Kamben Pating 
5. Bungking Kalapapa

6. Galoh Malujang Bulau

7. Maharadja Buno

Tapi Maharadja Buno baja aton hampatong olon, djaton tau belom awi tapas isi,e daha,e, tolange, tahasenge.

Ie bapa,e Manjamei Bulau Onggon Tingang horan manadjat Sang Paukur, uka balaku dohop dengae mambelom anake Maharadja Buno.

Tapi huang palihi,e te aton dumah Angoi, palus ie mambelome, tapas isi indahange dengan petak, tapas daha indahang dengan danum, tapas tolang indahange dengan pating sangalang, tahasenge induae bara riwut.

Ie arae Maharadja Buno, tapi djaton aton dohonge.

Sana bapae dumah ie mite anake belom tapi djaton aton bara dohong, balalu bapae Manjamei horan maneser akan penda danum balaku sanaman galang paseban ain Djata, sanaman leteng, awi te Maharadja Buno paham menteng.

Ie horan Maharadja Buno hakalahi dengan Sambajau Sangiang, hatakian Gadjah Bakapek Bulau, palus irantare ranjing buno awi Maharadja Buno.
Aber Maharadja Buno hatte nur die Gestalt (Form) eines Menschen, aber er vermochte nicht zu leben weil er zu wenig Fleisch, Blut, Knochen und Atem besass.

Sein Vater, Manjamei Bulau Onggon Tingang, begab sich damals in der früheren Zeit zu Sang Paukur 97 um ihn um seine Mithülfe zu bitten bei der Belebung seines Kindes Maharadja Buno.

Aber während seiner Abwesenheit geschah es, dass Angoi kam und sogleich belebte er ihn (den Maharadja Buno), das fehlende Fleisch ersetzte er mit Erde, das fehlende Blut ersetzte er durch Wasser, für die fehlenden Knochen verwendete er Baumäste und den Atem nahm er vom Winde.

Sein Name war Maharadja Buno, aber er besass keinen Dolch.98

Als sein Vater wieder zurückkam sah er, dass sein Kind lebte aber, dass es keinen Dolch besass und sogleich tauchte sein Vater ins Wasser unter und holte von dem Eisen auf dem der Palast der Djata gebaut war, nämlich das sinkende Eisen, aus diesem Grunde wurde Maharadja Buno ein sehr tapferer Mann.

In der früheren Zeit kämpfte Maharadja Buno mit Sambajau Sangiang, sie stritten miteinander wegen dem Gadjah Bakapek Bulau, und sogleich schleuderte seinen Speer,99 er, der Maharadja Buno. 
Ie buah bumbong likur Gadjah, palus Gadjah hadari, palus bapontong batang danum Tingkah Tingang, bapontong batang danum Djangkuran, buah batang danum Katimbongan, ie palus manampa tasik Galombang Gadjah, laut Hadjaran Tandang, laut $\mathrm{Ba}-$ ras Bulau dengan batang danum Tiawo.

Awi te Maharadja Buno horan djari iagah bapae akan pantai danum kalunen.

Ie horan palus Ranjing Hatala Langit panohon tiroh tudjah akan Maharadja Buno, balalu manduan idje kabisak tolang baraware palus imbelome djadi oloh bawi, ie inggaree arae Galoh Malujang Bulau, Putri Basamban Hintan, balalu ewen due Maharadja Buno hindje, ie horan manak idje hatue, idje bawi.

Aran idje hatue Dandan Kahaian, aran idje bawi Tiong Maliana.

Ewen due te hindje tinai, ie manak are biti balalu ewen mamangun huma hai.

Awi ewen djari kuman kulat sipa, kulat bitak, ie babusau hakotak sama mimbit auche.

Kotake hakabeken basae, ie ewen oloh are te hapisah, dia
Er traf das Rückengrat des Gadjah (Elephant) und sogleich flüchtete sich der Elephant und er durchbrach den Fluss Tingkah Tingang in seiner Mitte, er durchbrach den Fluss Djangkuran und er kam an den Fluss Katimbongan und er machte dort das Meer Galombang Gadjah, die See Hadjaran Tandang, das Meer Baras Bulau und den Fluss Tiawo.

Weil dies geschehen war brachte sein Vater ihn an die Ufer des Flusses der Welt.

In dieser früheren Zeit liess Ranjing Hatala Langit einen tiefen Schlaf (einen Schlaf der Ohnmacht) auf Maharadja Buno fallen und als er schlief nahm er aus seiner Seite eine Rippe weg und belebte sie und sie wurde zu einem Weib, das genannt wurde Galoh Malujang Bulau, Putri Basamban Hintan, sie und Maharadja Buno vereinigten sich zusammen in ehelicher Gemeinschaft und sie schenkten das Leben einem Knaben und einem Mädchen.

Der Name des Knaben war Dandan Kahaian, der Name des Mädchens war Tiong Maliana.

Die beiden verheirateten sich und sie schenkten vielen Kindern das Leben und sie bauten ein grosses Haus.

Weil sie Sipapilze und Bitakpilze gegessen hatten (die offenbar für sie pali waren) wurden sie davon betäubt und jeder sprach von dieser Zeit an seine eigene Sprache.

Ihr Reden geschah nun in andern Sprachen (Fremdsprachen) und die 
tau hindje, sama mimbit tintu,e tumon kanahuange.

Ie te horan anak Sambajau Sangiang buli bukit Ramparan Buno, ie manak:
Menge der Leute trennte sich voneinander, sie konnten nicht mehr zusammenbleiben und jeder suchte sich seinen Ort nach seinem eigenen Wunsch und Willen, und liess sich dort nieder. 100

In früheren Zeiten kehrte der Sohn Sambajau Sangiang zurück auf den Berg Ramparan Buno und er zeugte folgende Kinder :
1. Riak Hai Pangeroh Laut
2. Rangkang Karangan
3. Tungkoh Batu
4. Udju Njaho Papan Taliwo

Bungking Kalapapa horan masawe Kameloh Talean Teras, ie manak radja Djangkunoi (radja Bapasah Rundjan).

Radja Djangkunoi manak Rawai Ganan Bukit, awi sala dawen kaju kina,e (tarakina,e dawen kaju tambalik angin) ie saloh djari tato Hadangan.

Kamben Pating horan djari tato Kabilon (tato Djata), ie sewu akan danum.

Kameloh Gana Tunggol Hadjunan Danum babane Sambajau Sangen, ie manak:
Bungking Kalapapa verheiratete sich in der früheren Zeit mit Kameloh Talean Teras, er zeugte den König Djangkunoi (oder auch genannt: den König Bapasah Rundjan).

Radja Djangkunoi zeugte den Rawai Ganan Bukit, weil er unrichtige Baumblätter ass (er ass Blätter vom Baume Tambalik Angin 101), deshalb wurde er verwandelt und wurde zum Stammvater der Wasserbüffel.

Kamben Pating wurde in dieser früheren Zeit der Stammvater der Wasseroberfläche (der Stammvater der Djata 102), er stürzte sich ins Wasser.

Die Kameloh Gana Tunggol Hadjunan Danum verheiratete sich mit dem Sambajau Sangen und sie gebar:

1. Tanteloh Petak

2. Tantamau Danum

3. Djulen Karangan

4. Lambak Telon Penjang 
Lambak Telon Penjang ma- Lambak Telon Penjang zeugte: nak:

1. Sangkalap Badju

2. Sangkalap Gimai

3. Badjakah Lombok-Lombok Ontai Leo-Leoh

4. Radja Tantaolang Bulau

5. Mangko Amat

Radja Tantaolang Bulau ma- Radja Tantaolang Bulau zeugte den nak Garing Hatungko Batu. Garing Hatungko Batu.

Garing Hatungko Batu ma- Garing Hatungko Batu zeugte Sangunak Sangumang tuntang $\mathrm{Ka}$ - mang und Kameloh Silon Tingang, sie meloh Silon Tingang, ewen wohnten am Flusse Sankalela.

melai intu batang danum Sangkalela.

Anak radja Tantaolang Bulau horan, ie Penjang Barahila manak Njaring Hantangan tuntang Kameloh Tanteloh Bulau, ewen melai intu pulau Karandohong Bahandang. Sawang Ila-Ilai tuntang Kameloh Pamalumpong Tahil melai intu bukit Batengkong. Radja Panjarawan Katingan manak:

Der Sohn des Königs Tantaolang Bulau, nämlich Penjang Barahila, zeugte in dieser früheren Zeit den Njaring Hantangan und die Kameloh Tanteloh Bulau, sie wohnten auf der Insel Karandohong Bahandang.

Sawang Ila-Ilai und die Kameloh Pamalumpong Tahil wohnten auf dem Berge Batengkong.

Der König Panjarawan Katingan zeugte:

Anak hatue (Knaben):

1. Ngalang Bulau

1. Rampan Mandilan Bulau

2. Lalendang Lio

2. Rampan Mandilan Dare

3. Miring

3. Rampan Parahimok

4. Salungan

5. Sarikumpang

4. Rampan Paragantin Bunge

6. Dahiang

5. Bungen Bulau

7. Parakuhen Tingang

8. Talinting

9. Tempo Hendan

10. Kanarean Sawang 
Ewen melai hong batang da- Sie wohnten am Flusse Barirai. num Barirai.

Radjan Pampulu Hawon ma- Der König Pampulu Hawon zeugte: nak:

Anak hatue (Knaben): Anak bawi (Mädchen):

1. Radja Dohong

2. Budjang Barendeng

3. Panjule Langkah

4. Babuken Suling

5. Tanteloh Tingang

6. Sahawong Bulau

7. Tempon Telon

Ewen toh melai hong batang danum Djalajan.

Djari lepah taturan tato awi Radja Pampulu Hawon.
1. Sarin

2. Bunge

3. Sarin Bulau

4. Maharum Dawen Lunok

5. Kameloh Mitir Bintang

6. Kameloh Kambang Ambon

7. Tempon Hendan Bulau

Diese hier wohnen am Flusse Djalajan.

$\mathrm{Zu}$ ende ist nun die Aufzählung der Reihenfolge der Ahnen durch den König Pampulu Hawon.

\section{B. Der Ursprung der Bewohner fremder Welten}

Der Dajak kennt den umfassenden Begriff der Menschheit und der Welt in unserem Sinne nicht. Die Menschheit ist für ihn sein Stamm und die Welt ist das Stammgebiet. Kalunen bedeutet Mensch aber auch Welt. Wo der Mensch ist, und als solcher wird nur der Stammesgenosse angesehen, da ist die Welt und umgekehrt.

Der Dajak weiss natürlich auch um das Bestehen anderer Welten und ihrer Bewohner und er hat sich mit dieser eigenartigen Tatsache und Erscheinung mythologisch und soziologisch klassifizierend auseinandergesetzt und diese Auseinandersetzung findet ihren Niederschlag in den Mythen. Sowohl für Fremdstämme mit denen man auf befreundetem Fusse lebt wird dieses Verhältnis mythologisch begründet, als auch für andere Stämme mit denen man mehr feindschaftliche Beziehungen unterhielt.

Die Katinganer erzählen von ihren Nachbarstämmen, dass sie von einem Hund und einem Affen abstammen die einem Katinganer gehörten. Damit ist diese Menschwerdung nicht nur erklärt, sie hat auch ihre tiefgreifenden Folgen gehabt. Diese Nachbarstämme gehörten 
eigentlich den Katinganern, denn sie stammten von ihren Haustieren ab. Und weil sie ihnen gehörten, und weil sie eigentlich keine Menschen, sondern nur menschenähnliche Wesen waren, konnten die Katinganer während Jahrhunderte ihre Köpfe erbeuten ohne sich an fremden Menschenleben zu vergreifen, denn sie töteten ihr Eigentum. Ich teile hier zwei dieser Mythen mit.

\section{a. Der Ursprung der Olon Tamuan 103}

Als eines Tages ein Mann wie gewöhnlich im Walde arbeitete und Buschprodukte suchte sah er plötzlich einen schönen Schimpansen, wie er bisher noch keinen gesehen hatte. Er verfolgte ihn, fing ihn ein und brachte ihn lebend nach Hause. Der Schimpanse erwies sich für alle Arbeiten, die im Haus $z \mathfrak{u}$ verrichten waren, sehr geschickt und er konnte auch sprechen wie die Menschen. Sein Besitzer gewann ihn immer lieber. Eines Tages ging sein Herr wieder wie gewohnt in den Wald um dort seine Arbeiten zu verrichten und er hatte für die Zeit seiner Abwesenheit dem Schimpansen die Arbeiten im Haus übertragen.

Als der Affe nun so allein war, sagte er zu sich selbst: „Has, ich will meinen Besitzer nun verlassen. Ich habe ihm lange Zeit gedient und ich will als Lohn für meine Arbeiten seine heiligen Töpfe (halamaung und balanga) und seine Gong (garantong) mit mir nehmen". Nachdem er so zu sich selbst gesprochen hatte, verwandelte er sich in einen schönen jungen Mann und führte sein Vorhaben aus. Schwer bepackt verliess er das Haus und machte sich in der Richtung nach dem Tualan (ein kleiner Nebenfluss des Mentaja) davon.

Nach einiger Zeit kehrte der Mann wieder aus dem Walde nach Hause zurück und er war sehr erstaunt, dass ihm der Schimpanse nicht so wie er gewöhnlich zu tun pflegte, entgegenkam und wie erschrak er erst als er das Haus betrat und sah, dass sein ganzer Reichtum aus ihm verschwunden war. „Hau“, sagte er zu sich selbst, ,gewiss ist mein Schimpanse entflohen und hat meinen ganzen Reichtum mit sich genommen. Ich will mich eilig auf den Weg machen und ihn verfolgen, vielleicht gelingt es mir ihn noch einzuholen".

So machte er sich rasch auf den Weg und überall wo er an bewohnten Hütten vorbeikam fragte er die Menschen: „Habt ihr meinen Schimpansen nicht gesehen? Er ist mir entflohen und hat meine heiligen Töpfe und meine Gong mit sich genommen“. „Nein“, sagten die Leute, ,einen Schimpansen haben wir nicht gesehen, aber vor kurzer Zeit kam hier ein Fremder vorbei, ein junger schöner Mann, 
den wir nicht kannten und den wir auch noch nie gesehen haben. Er war schwer bepackt mit heiligen Töpfen und Gong“. Er verfolgte nun die Spur weiter und sie führte ihn an den Tualan wo er nach einiger Zeit ankam. Dort fand er in einem kleinen Dörflein einen jungen Mann den er als seinen entlaufenen Schimpansen erkannte. In seinem Hause fand er auch seinen Besitz, die gestohlenen Töpfe und Gong. Nachdem sie zusammen die Flucht und den Diebstahl besprochen und die Streitsache geschlichtet hatten, kehrte er mit seinen Gütern wieder nach Hause zurück. Der Schimpanse aber blieb am Tualan. Er verheiratete sich dort, zeugte viele Kinder und wurde so der Stammvater der Olon Tamuan.

\section{b. Der Ursprung der Olon Sembuluh 104}

Vom Ursprung der Olon Sembuluh berichtet die katinganische Mythologie: Eines Tages war Pang Paloi (ein Sangiang aus der Oberwelt) in die Welt (lezu pantai danum kalunen: das Dorf am Ufer des Flusses der Welt) heruntergestiegen und durchschweifte mit seinem Hund die Wälder, Stromgebiete und Dörfer. Plötzlich vermisste er seinen treuen Begleiter. Er rief ihn, aber der Hund antwortete nicht und er kam auch nicht zurück. Offenbar hatte er sich im Walde verirrt als er ein Wild verfolgte. So kehrte $\mathrm{Pa}$ Paloi wieder allein in die Oberwelt zurück. Nach einiger Zeit fand Bagaloh, ein Mann der im Walde arbeitete, das verirrte Tier. Er rief es zu sich und dieses gehorchte sofort seinem Rufe und folgte ihm nach Hause. Der Hund blieb nun bei seinem neuen Besitzer und begleitete ihn zu aller Arbeit und vor allem auch zur Jagd.

Eines Tages verirrte er sich aber wieder im Walde und er vermochte die Spur seines Herrn nicht mehr zu finden. Er irrte lange Zeit umher und schliesslich kam er an den Danau Sembuluh (Sembuluhsee). Dort nahm er die Gestalt eines schönen Jünglings an und er begab sich zu den wenigen Menschen die er in einem einsamen Hause fand. Von dieser Zeit an blieb er bei ihnen und er verheiratete sich schliesslich auch mit einer ihrer Töchter. Er zeugte Kinder und er wurde der Stammvater der Olon Sembuluh.

Bagaloh aber konnte seinen Hund nicht vergessen, denn ein schöneres und besseres Tier hatte er noch nie besessen. Er entschloss sich, ihn in allen Dörfern und an allen Flüssen zu suchen und nicht eher heimzukehren bis dass er ihn gefunden hatte. Er reiste an den Samba, an den Kahaian, an den Kapuas und von dort wieder zurück an den oberen Katingan und Serujan. Er kam in alle Dörfer. Er erkundigte 
sich bei allen Menschen nach seinem Hund, aber nirgends konnte er eine Spur von ihm entdecken. Schliesslich kam er auf seinen Streifzügen auch an den Sembuluhsee und liess sich dort im Rasthaus eines kleinen Dorfes nieder. Es war das Dorf seines verlorenen Hundes der hier die Gestalt eines Menschen angenommen hatte. Die Dorfleute betrachteten den Fremden und plötzlich sagte der zu einem Menschen gewordene Hund, der sich auch unter ihnen befand, zu sich selbst: „Kai, kai, das ist ja mein früherer Herr, ich will ihn begrüssen“. Am andern Morgen nahm er wieder die Gestalt eines Hundes an und nahte sich seinem früheren Herrn, vor Freude bellend und mit dem Schwanze wedelnd.

Bagaloh erkannte ihn sofort und nahm ihn sehr erfreut $z \mathfrak{u}$ sich. Tagsüber begleitete ihn der Hund zur Arbeit in den Wald, denn Bagaloh hatte Bäume gefällt um sich für die Heimreise ein Boot zu bauen. Nachts aber blieb der Hund weg, denn dann nahm er wieder menschliche Gestalt an und kehrte zu den Seinigen zurück. Nach einiger Zeit aber starb er, denn seine Seele war durch die oftmaligen Verwandlungen schwach geworden. Er wurde feierlich beigesetzt und noch heute sieht man auf dem Grunde des Sembuluhsee, dann wenn das Wasser klar ist, seinen Sandong.

Seine Nachkommen aber haben auch heute noch, wie man sagt, kleine Schwänze deren Spuren man gut sehen kann wenn sie sich irgendwo in den Sand oder Lehm setzen.

\section{Die Mächte 105}

\section{a. Die Entstehung der Hantuen (Hexen) 106}

Die hantuen (Hexen) werden abgeleitet von dem ersten Menschenpaar. Als die Frau des Tunggol Garing, Kameloh Djandjulen Karangan Putak Bulau Kambang Karangan die Monatsregel hatte, fiel, als sie im Flusse ihr tägliches Bad nahm, ein Tropfen des Blutes in das Wasser (wahrscheinlich handelt es sich hier auch wie bei den Erzählungen oben um einen Blutklumpen oder um eine Fehlgeburt). Dieser Blutstropfen trieb im Wasser weiter und wurde von einem Geiste gefunden und gepflegt und er entwickelte sich zu einem Menschen der den Namen Sangkalap Gimai erhielt. Als er erwachsen war verheiratete er sich und er zeugte den Kamben Pating. Kamben Pating zeugte den Njaho Lentup Tempon Tatean Teras und dieser zeugte den König der Hexen, den Haramaung Batolang Bunu, Pangandien Balikur Talawang (den Tiger mit den Knochen von Lanzen, den Tiger mit dem Rücken 
von einem Schild). Dieser zeugte Iman Handjaliwan, Hatuen Baras Mumpon Penda Balawan, Bukit Kinting Dohong, Kereng Baramban Baja. Er wohnte am Flusse Taberan Mekot der in das Meer Rampang Matanandau einmündet.

Durch seine vielen Verwandlungen durch die er eine andere Gestalt anzunehmen vermochte und die zahlreichen Verführungskünste die er anwandte entstanden in den Dörfern an den Ufern des Flusses der Welt die Hantuen von denen hier die Rede ist.

\section{Der Ursprung der Hantuen im Oberland 107}

Es geschah in früheren Zeiten, dass die Bevölkerung des Dorfes Matomai am Mambaroh von einer schweren Hungersnot heimgesucht wurde. Viele Bewohner verliessen damals mit ihren Familien das heimatliche Dorf und ihren Fluss und liessen sich anderswo nieder, in der Hoffnung dort, im neuen Wohngebiet, ihr Leben besser fristen zu können. So kam auch eine Schar dieser Auswanderer an das Flüsslein Mante (Mambaroh und Mante sind kleine Seitenflüsse im Quellgebiet des Kapuas Bohang der bei Pontianak in die Javasee mündet) und suchte sich hier einen günstigen Wohnplatz in der Nähe von Bäumen deren Schlösslinge essbar waren und mit denen sie sich in der schweren Hungerzeit einigermassen ernähren konnten. Weil sie nicht mehr in ihr heimatliches Dorf zurückkehrten, sondern dort wohnen blieben, nannte man sie mit der Zeit nach ihrem neuen Wohnplatz, die Manteleute, vor allem da sie sich sehr von den andern Menschen zurückzogen, für sich allein waren und sich mit niemanden vermischen wollten. Händler und Fremde kamen nie in ihr Dorf und so wurden sie mehr und mehr des Verkehrs mit andern Menschen entwöhnt und wurden deshalb scheu wie die Tiere und wild wie die Ot-Leute in den Wäldern. 108

Schon lange wohnten sie am Mante als sie sich endlich entschlossen ihre primitiven Hütten abzubrechen und sich ein eigenes neues Dorf zu bauen um dort näher beisammen zu wohnen. Das neue Dorf wollten sie Mungku nennen.

Sie entschlossen sich zuerst den Platz zu untersuchen auf dem sie das neue Dorf bauen wollten um aus der Beschaffenheit der Erde und dem Verhalten der Vorzeichen (dahiang) gebenden Tiere zu erkennen, ob sie dort auch wirklich bauen konnten oder nicht.

Die Vorzeichen, die sie sahen und hörten, waren ungünstig. Als sie den Platz vom Wald und Busch säuberten flogen sehr viele Vorzeichenvögel herum, Kangkamiak, Kulangkulit und viele andere mehr. Nachts, zu ungewohnter Zeit, schwebten die Antang über ihrem Lager 
und stahlen die Hühner weg. Das waren alles sehr ungünstige Zeichen. Als die Vögel schwiegen zeigte sich ein neues ungünstiges Zeichen. Die Erde begann so sehr nach Verfaultem zu stinken, dass sie es beinahe nicht aushielten weiter auf dem Platze $z u$ arbeiten. Die Aeltesten versammelten sich und sie beschlossen an diesem Orte kein neues Dorf $z u$ bauen weil alle Vorzeichen viel zu schlecht ausgefallen waren. Aber da mischten sich die Jungen in den Beschluss der Alten ein und sagten: „Euer Wort ist ein leeres und euer Rat ist nicht gut, denn die Vorzeichen sind günstig. Was bedeuten die vielen Vögel? Sie sind die Seelen der heiligen Töpfe (die Seelen, gana, werden personifiziert gedacht, sie können eine andere Gestalt annehmen) und die Seelen der Gong die wir in diesem neuen Dorf erwerben werden. Sie melden sich jetzt schon an und stellen sich jetzt schon ein um uns zum Bau des Dorfes zu ermutigen. Was bedeutet die stinkende Erde? Dieser Gestank ist doch nicht anderes als die Seelen (hambaruan. Menschen, Tiere und Reis, oft auch die teuersten heiligen Töpfe haben eine hambaruan nicht eine gana) der Opfertiere, der Wasserbüffel, Kühe, Schweine und Hühner, die wir hier einst töten werden. Auch sie stellen sich jetzt schon ein. Nein, Väter und Onkel, der Ort hier ist sehr gut, wir wollen hier und nirgends anders unser Dorf bauen!"

Was wollten die Alten tun! Sie waren von den Jungen besiegt worden und fügten sich ihrem Willen. Man begann nun mit dem Bau des Dorfes. Man machte den Platz sauber, man hob die Löcher aus für die hohen Pfähle und man machte das $\mathrm{Holz}$ bereit für den Bau. Während sie mit dem Bau beschäftigt waren brach wieder eine grosse Hungersnot über sie herein. Sie fanden keine geniessbaren Baumschlösslinge mehr, Hirsche und Wildschweine erlegten sie nur noch höchst selten und Fische fingen sie fast gar keine mehr. Kümmerlich fristeten sie ihr Leben.

Während sie die Löcher für die Eisenholzpfähle aushoben fand plötzlich einer von ihnen ein merkwürdiges Tier wie er zuvor noch keines gesehen hatte. Es hatte die Länge einer Palme, sein Leib war glatt wie der Leib eines Blutegels, er hatte keine Haare und keine Schuppen. Erstaunt rief er seinen Kameraden zu : „Schaut doch diesen Fisch 109 hier an". Und alle, die das Tier sahen, riefen erstaunt und fragend aus: „Lauk en“ (was für eine Fisch ist das)? Keiner wusste den Namen und deshalb nannte man das Tier Lauk En.

Sie töteten den Lauk En und waren sehr erstaunt, dass sie keine Knochen und keine Gräte fanden, sondern nur Fleisch und sehr viel Fett. Jeder erhielt ein Stück Fleisch und alle waren über den Fund 
und den willkommenen Fang sehr erfreut, denn während dieser Hungerzeit gelang es ihnen nur sehr wenig Fleisch zu erhalten.

Aber was geschah als sie das Fleisch verzehrt hatten! Als die Dunkelheit hereingebrochen war da begannen die Teller und Schüsseln, aus denen sie gegessen hatten, zu funkeln und zu glänzen, so, wie der Sualapilz im Waldesdunkel leuchtet.110 Und als sie sich gegenseitig verwundert anschauten, da erschraken sie noch mehr, denn sie sahen, dass von dem Munde eines Jeden der Fleisch gegessen hatte, das gleiche matte Licht ausstrahlte.

Alle Bewohner des Dorfes waren von einer bösen Macht besessen worden. Sie waren nicht mehr Menschen, sie waren Hantuen (Hexen) geworden weil sie von dem Lauk En, der ein Geistertier war und zu den bösen Mächte gehörte, gegessen hatten. Plötzlich lösten sich ihre Köpfe von ihren Hälsen und mit den Eingeweiden, die daran hängen geblieben waren, flogen sie herum wie Vögel und strahlten ein mattes bläuliches Licht aus. Sie flogen dahin und dorthin. Sie schauten nach Leichen aus um ihr Fleisch zu verzehren. Sie konnten sich nicht wehren gegen diesen unwiderstehlichen Drang, sie mussten sich immer wieder von Leichen nähren obgleich es ihnen davor anfänglich ekelte. Sie flogen mit ihren Ohren, so wie ein Vogel seine Flügel gebraucht. Wo sie eine Leiche oder ein frisch aufgeworfenes Grab oder einen ausgesetzten Sarg gewahrten, da setzten sie sich nieder und verzehrten den Leichnam bis nichts mehr übrig war. Und diese ekelhafte Speise schmeckte ihnen schliesslich wie der Honig der wilden Bienen.

Verfeindeten sich aber andere Menschen mit ihnen, dann starben diese Menschen rasch und verloren auf rätselhafte Weise ihr Leben. Sie waren getötet worden durch die Hantuen, die nachts ihr Blut ausgesaugt oder ihre Leber verzehrt hatten! Nicht lange nach dieser Zeit waren sie gezwungen ihren Wohnort zu verlassen, denn unter den Leuten hatte sich das Gerücht herumgesprochen, dass sie durch die Verzehrung des Lauk En zu Hantuen geworden seien die die Leichen aufässen und ihre Feinde töteten. Man begann sich vor ihnen zu fürchten. Deshalb versammelten sich die Bewohner des Mambaroh und sie beschlossen: „Wir wollen einen Kopfjägerzug nach dem Mante unternehmen und die Bewohner des Dorfes Mungku, die sich in Hantuen verwandelt haben, ausrotten". Aber die Hantuen hatten von diesem Beschluss Wind bekommen und sie entschlossen sich so rasch wie möglich ihr Dorf und ihren Fluss zu verlassen und sich anderswo anzusiedeln. Sie reisten aber nicht wie andere Leute reisen, sondern sie zogen mit ihren Häusern und ihrer ganzen Habe um. Sie flogen nach 
ihrem neuen Wohnort. Sie rudenten ihre Häuser durch die Luft. So flogen sie nach dem oberen Senamang (ein Seitenfluss des oberen Katingan) und sie bogen dort in sein kleines Nebenflüsslein Ewang ein wo sie sich mit den Häusern niederliessen. Das neuentstandene Dorf nannten sie ebenfalls Mungku.

Eines Tages kam ein Fremdling in ihr Dorf. Er hatte von der Eigenschaft der Bewohner keine Ahnung. Es war zur Zeit in der die Schweine durch die Wälder ziehen und über die Flüsse schwimmen.111 Die Bewohner des Dorfes Mungku machten Jagd auf die wilden Schweine und sie lauerten den über den Fluss schwimmenden Tieren am Ufer auf. Auch der Fremdling ergriff seinen Speer und beteiligte sich an dieser Jagd. Eine grosse Herde Schweine näherte sich auf dem gegenüberliegenden Ufer, stürzte sich in den Fluss und schwamm, ein Schwein hinter dem andern, dem Ufer entgegen. Er ergriff seinen Speer um die Schweine niederzustechen aber wie erschrak er als er plötzlich sah, dass er gar keine Schweine sondern nur schwimmende Speckseiten vor sich hatte. Er stieg rasch wieder ans Ufer. Er sah wie die Bewohner des Dorfes die Speckseiten aus dem Fluss holten. Sie forderten ihn auf mitzutun, aber er fürchtete sich, denn er konnte sich diese merkwürdige Erscheinung nicht erklären. Am Abend veranstalteten die Bewohner ein grosses Essen und sie baten auch den Fremdling daran teilzunehmen. Gerne hätte er sich geweigert, aber er getraute sich nicht seine Gastfreunde zu beleidigen und so setzte er sich mit ihnen zum Essen. Nachdem er gegessen hatte spürte er, dass er ein Hantuen geworden war. Er bereute nun, dass er am Essen teilgenommen hatte, aber es war zu spät, er war dem Betrug der Manteleute zum Opfer gefallen.

Nach einigen Jahren verliessen die Hantuen ihr Dorf Mungku am Ewang, dessen Ueberreste man bis auf den heutigen Tag noch sieht, und sie zogen an den Rongan. Als sie am Rongan ankamen flogen sie dessen Nebenflüsslein Lapan hinauf und liessen sich dort mit ihrem Dorf an einsamer Stelle nieder (Vgl. auch die Geschichte von Antang Taui). Sie verrichteten manche Wundertaten die nur Hantuen verrichten können. Oft geschah es, dass, wenn sie keine Fische zu ihrer Zuspeise hatten, sie nicht auf den Fischfang auszogen wie andere Leute, sondern, dass sie dann auf einem nahen Berg eine riesige Fischreuse, einen sogenannten mihing, aufstellten. Am Morgen nahten sie sich dann dem Mihing und sie klopften an alle dürren Blätter die in ihn gefallen waren und sprachen dazu: „Behau, Sapan, Mandjohan!" (Fischnamen). Sofort verwandelten sich die Blätter in die gewünschten 
Fische. Regnete es und füllten sich ihre Abwasserkanäle mit Wasser, dann warfen sie Feuerbrände hinein und sprachen: „Behau!" und sofort verwandelten sich diese ebenfalls in Fische. Diese Fische assen sie als Zuspeise $z u$ ihrem Reis und bewirteten mit ihnen auch ihre Gäste. Aber wer von dieser Speise ass der wurde in ein Hantuen verwandelt. Ihre Frauen und Mädchen waren sehr schön. Aus diesem Grunde fanden sich manche Bewerber ein die sich mit ihnen verheiraten wollten. Wer sich aber mit einem solchen Mädchen verheiratete der wurde zu einem Hantuen. Man unterscheidet unter den Hantuen drei Arten. Bei der ersten Art ist die Ansteckung nur leichter Natur und verliert sich nach etwa drei Tagen wieder. Bei der zweiten Art, den hantuen baringin, ist die Ansteckung schwerer und die Genesung erst nach langer Behandlung durch einen Priester möglich. Die dritte Art der Hantuen, die hantuen pulut, sind sehr bösartiger Natur. Wer zu einer solchen geworden ist kann nicht mehr geheilt werden.

Die Manteleute wohnten lange am Lapan aber schliesslich wurde ihre Familie so gross und nahm die Anzahl der Hantuen durch die Ansteckung so sehr $\mathrm{zu}$, dass sie gezwungen waren sich voneinander $\mathbf{z u}$ trennen und sich auch an andern Flüssen niederzulassen. Sie zogen an den Rongan und Lasen (In der Mythe von Antang Taui wird dieses Flüsslein Rasen genannt) und von dort verbreiteten sie sich weiter. In manchen Dörfern findet man einzelne Hantuen und fast an allen Flüssen findet man auch ausgesprochene Hantuendörfer, die ausschliesslich von ihnen bewohnt werden.

Deshalb sagt das Sprichwort auch heute noch: Hantuen Rongan, Lapan tuntang Lasen (Hantuen vom Rongan, Lapan und Lasen), dass heisst: alle Schlechtigkeiten einer ursprünglichen Hantuen sind in der Person vereinigt über die man dieses Sprichwort aussagt. Man fürchtet die Ronganleute und will nichts mit ihnen zu tun haben um nicht durch sie angesteckt auch $\mathrm{zu}$ einer Hantuen zu werden. 112

\section{Der Ursprung der Hantuen am unteren Katingan}

Das Dorf Handiwong war, als diese Geschichte sich zutrug, ein sehr grosses Katingandorf. Durchschritt man es nachts, dan hatte man von seinem unteren Ende bis zum oberen drei Fackeln nötig, so lange hatte man zu gehen, und zwar brauchte man Fackeln die nicht kurz waren, sondern von denen jede die Länge von drei depe hatte (ca. $5,40 \mathrm{~m}$ lang. Die alten Dörfer werden in der Mythologie immer als sehr gross und ausgedehnt geschildert). 
Eines Tages wollten die Bewohner dieses Dorfes ein neues Haus bauen. Alle Leute waren aus diesem Grunde im Dorfe versammelt. Wer auf dem Felde war kehrte heim um bei der Arbeit mitzuhelfen. Als die Leute so versammelt waren sahen sie plötzlich ein Tier das einem Schwein glich vom andern Ufer des Flusses her auf ihr Dorf zuschwimmen. Die Männer eilten geräuschlos in die Häuser um ihre Speere und Blaserohre zu holen und lauerten am Ufer dem merkwürdigen Tiere auf. Als das Tier sich näherte verwunderten sie sich sehr über seine Gestalt, denn was da über den Fluss schwamm war eigentlich kein Tier, sondern glich eher einer Speckseite ohne Kopf und Ohren, ohne Hände und Füsse. Sie zogen dieses merkwürdige Geschöpf ans Ufer, beschauten es eingehend und beratschlagten wie es wohl heissen könnte. Die Jungen wussten keinen Namen, sie hatten noch nie ein ähnliches Tier gesehen, auch die Alten erinnerten sich nicht jemals in ihrem Leben etwas derartiges wahrgenommen zu haben. Ratlos standen sie da. Da näherte sich in einem kleinen Boot ein Fremder. Er sah das Tier und rief verwundert aus: „Lauk en te? (Was für ein Tier ist das?" „Wir wissen es auch nicht", riefen die Leute zurück, „wir haben noch nie ein solches Tier gesehen oder gefangen, wir kennen seinen Namen nicht". Und sie fragten den Fremden: „Was meinst du, können wir wohl das Fleisch dieses Tieres essen?" „Ja“, antwortete er, „ich glaube wohl, dass man das Fleisch geniessen kann". Darauf töteten sie das Tier und sie verteilten das Fleisch unter sich um es als Zuspeise zum Reis zu verzehren. In allen Häusern brachten sie etwas von ihm, auch in das Haus eines Mannes der sich nicht bei ihnen befand als sie das Tier erlegten, denn seine Frau hatte in jener Stunde einem Kinde das Leben geschenkt und er konnte sie nicht allein lassen. Als sie sich der Hütte näherten, riefen sie mit lauter Stimme: „Oh, ihr, ist jemand im Hause?" „Nein“, rief die Frau zurück, ,ich bin allein hier, 113 mein Mann ist aufs Feld gegangen um Brennholz zu holen“. „O, ist das so", entgegneten die Leute, „wir bringen dir hier Zuspeise von einem Tier das wir gefangen haben“. „Wie heisst das Tier?" fragte die Frau zurück. „Wir wissen es auch nicht", antworteten sie, ,aber wir haben es Lauk En genannt". „Gut", sagte die Frau, „legt es nur bei der Reisscheuer nieder, mein Mann kann es ins Haus bringen wenn er vom Felde zurückkehrt".

In allen Häusern wurde nun Fleisch gebraten und ein angenehmer Duft durchzog das ganze Dorf, alles freute sich auf die schmackhafte Zuspeise und alles bekannte: „Wir haben noch nie so gutes Fleisch 
genossen wie heute, es ist besser als das aller Tiere die im Wasser, auf der Erde und auf den Bäumen leben!" und grosse Freude über den glücklichen Fang erfüllte alle Häuser.

War das Tier auch nicht sehr gross gewesen, alle hatten sich doch satt gegessen, denn das Fleisch hatte die merkwürdige Fähigkeit, dass es sich vermehren konnte.

Am späten Nachmittag kehrte der Mann mit seinem Holzbündel vom Felde in sein Haus zurück und verrichtete zuerst die täglichen notwendigen Arbeiten. Er stampfte Reis, schöpfte Wasser aus dem Fluss, wusch sorgfältig seine Frau und reinigte alle Essensgeräte. Dann fütterte er die Hühner und Schweine und als er diese Arbeiten beendigt hatte begab er sich wieder ins Haus, setzte sich beim Herde nieder und begann das Nachtessen zu rüsten und den Reis zu kochen. „Es ist doch ein Elend", sagte er, „wir müssen essen und wir haben ausser unserem Reis und djoho (eine Art Gemüsesuppe die zum Reis gegessen wird) keine Zuspeise“. „Doch“, entgegnete die Frau, ,wir haben wohl Fleisch zur Zuspeise, ich vergass ganz dir zu sagen, dass, als du fort warst Leute kamen. Sie brachten Fleisch von einem Tier das sie gefangen hatten, dessen Namen sie aber nicht wussten und das sie deshalb Lauk En nannten“. „Wo ist dieses Fleisch?" fragte der Mann. „Sie haben es auf einen Pfahl bei der Reisscheuer niedergelegt", antwortete die Frau.

Inzwischen war aber die Nacht hereingebrochen. Der Mann nahm ein brennendes Scheit aus dem Feuer, trat mit ihm unter die Türe und wollte das Fleisch holen um es als Zuspeise zu ihrem kärglichen Mahle zu braten. Aber wie erschrak er als er in die Dunkelheit hineinsah. $\mathrm{Da}$ wo das Fleisch liegen sollte sah er ein eigentümliches Licht glänzen und über sich hörte er ein merkwürdiges Rauschen. Als er in die Höhe sah da gewahrte er hunderte und hunderte von kleinen, matt leuchtenden Lichtern die herumflogen und die sich alle seiner Hütte näherten. Das Geräusch erfüllte das ganze Dorf. Tjup-tjip, rup-rep! tönte es von überall her. Noch mehr aber erschrak er in seinem Herzen als er diese Lichter näher beschaute. Es waren ja die Köpfe seiner Verwandten und an ihnen hingen die Eingeweide. Die Ohren gebrauchten sie als Flügel. Das ganze Dorf flog. Schreckensbleich trat er wieder in die Hütte zurück und sprach zu seiner Frau: „Wir müssen schleunigst fliehen, denn in unserem Dorfe sind fürchterliche Dinge geschehen. Das ganze Dorf fliegt umher wie böse Geister und alle wollen uns verfolgen und töten". (Die Hantuen verzehren mit Vorliebe neugeborene Kinder. Ihr Fleisch schmeckt wie Kuchen und wie der 
Honig wilder Bienen.) Er nahm das Kind aus der Wiege, 114 ergriff den Speer und das Schwert und stützte seine schwache Frau. Dann trat er mit ihnen aus der Hütte um sich ans Landungsfloss hinunter zu begeben und in seinem Boot das unheimliche Dorf eiligst zu verlassen. Die Hantuen, denn zu solchen waren die Bewohner durch den Genuss des Fleisches geworden, verfolgten ihn und versuchten ihm Frau und Kind $z \mathfrak{u}$ entreissen und mitzuführen, aber er wehrte sich tapfer mit seinem Schwert. Es gelang ihm nur mit grosser Mühe seiner Frau und seinem Kinde ins Boot zu helfen, das Rotan, mit dem es festgemacht war, durchzuschneiden und mit ihnen vom Landungsfloss wegzurudern. Er fuhr über den Fluss, die Hantuen verfolgten ihn. Er ruderte flussaufwärts, die Hantuen umflogen das Boot und er vermochte fast nicht sich ihrer zu erwehren. Rudernd und kämpfend kam er nur langsam vorwärts. Die Mitternacht war schon vorbei als er endlich in Luwok ankam. Immer noch folgten ihm die Hantuen. Erschöpft klopfte er an das Haus seiner Verwandten. Erschrocken über den unerwarteten Besuch öffneten sie die Türe und hiessen ihn eintreten. Erschrocken betrachteten sie sein bleiches Gesicht und sie wurden selbst bleich vor Schrecken als sie die unzähligen Lichter gewahrten, die die Nacht in Tag verwandelten. Sie fragten ihn, bleichgeworden, wie er selbst war: „Was ist geschehen, warum kommst du wie ein Flüchtling in tiefer Nacht $z \mathfrak{u}$ uns, was bedeuten die vielen Lichter, die dir folgen und die sich über unser ganzes Dorf verstreuen?"“ Er erzählte ihnen was in Handiwong geschehen war. Als der Morgen anbrach erfüllte laute Klage das Dorf Luwok. Fünf Menschen die am Abend zuvor noch gesund gewesen waren, starben plötzlich in der Nacht auf unerklärliche Weise. Herzeleid erfüllte die Leute, denn immer noch sanken gesunde Menschen um wie vom Wind umgewehte Bäume und wenn man sich erschrocken $z u$ ihnen herunterbeugte, dann sah man in die verzerrten Gesichter von Toten. Ihre Leber war aufgegessen worden durch die Hantuen und ihr Blut aus den Adern gesogen durch diese bösen Geister. Als die Sonne aufging verschwanden die Hantuen, aber als die Nacht aufs neue hereinbrach, hörten sie wieder das unheimliche Rauschen über ihren Häusern und wieder starben gesunde Menschen plötzlich hinweg.

Erschrocken versammelten sie sich zusammen mit dem Dorfältesten und sie beratschlagten was zu tun sei um dieses Leid abzuwenden. Die einen sagten: „Lasset uns unsere Waffen holen und nach Handiwong rudern um diese verderbliche Bevölkerung auszurotten, denn wenn von ihnen nur einer übrig bleibt, haben wir keine Ruhe, sondern immer 
wieder wird der Tod in unsere Hütten einziehen". Die andern aber sagten: „Nein, diesen Rat können und wollen wir nicht befolgen. Wir wollen nicht das Blut von Verwandten, von Brüdern und Schwestern, Onkeln und Tanten, Neffen und Nichten, vergiessen. Wir wollen ihnen eine Botschaft senden und wir wollen sie auffordern unseren Fluss zu verlassen!" Dieser Rat wurde angenommen. Man bestimmte die Aeltesten die Botschaft der Luwokleute den Verwandten in Handiwong zu überbringen. Sie ruderten weg und kamen rasch nach Handiwong, wo sie in das Haus des Dorfältesten eintraten. Mit höflichen Worten teilten sie ihm den Beschluss der Luwokleute mit und sie baten ihn mit der ganzen Bewohnerschaft das heimatliche Dorf und den Fluss zu verlassen, ,denn, wir wollen nicht miteinander kämpfen und gegenseitig unser Blut vergiessen weil wir verwandt sind".

„Was du sagst ist gut und deine Rede klingt nicht falsch in meinen Ohren“, antwortete darauf der Aelteste von Handiwong, ,aber welches Vergehens bezichtigt ihr uns, dass ihr uns den Befehl gebt unser Dorf und unsern Fluss zu verlassen?" Der Aelteste von Luwok antwortete: „Mein Freund, du weisst den Grund, es ist nicht notwendig, dass ich ihn nenne“. „Ich weiss keinen Grund, mein Freund“, war die Entgeg. nung, ,ich glaube, dass ihr uns nur aus Hass von hier vertreiben wollt und wenn Einzelne von euch sagen: lasset uns Handiwong überfallen und seine Bewohner ausrotten, dann ist diese Rede recht. Wir fordern sie auf $z \mathfrak{u}$ kommen und mit uns $z \mathfrak{u}$ kämpfen, freiwillig aber verlassen wir das Dorf nicht".

Nachdem der Aelteste von Handiwong seine Rede beendet hatte stand er vom Boden auf, ergriff ein Schwert und einen Speer und reichte sie den Aeltesten von Luwok mit den Worten: „Hier habt ihr ein Schwert. Wenn ihr unser Dorf überfallt, dann schlagt uns mit ihm unsere Köpfe ab. Hier habt ihr einen Speer. Wenn ihr uns bekriegt, dann stecht uns mit ihm tot. Habt ihr den Mut nicht dazu, dann gebraucht ihn als Löffel um eueren kochenden Reis umzurühren mit dem ihr euere schwachen Lenden heilen könnt".

„In diesem Tone wollen wir nicht miteinander sprechen“, antworteten die besonnenen Aeltesten von Luwok, wir sind eine Gemeinschaft (kaungkup oder ungkup, so wird die Blutsgemeinschaft genannt, die von gleichen Ahnen abstammt und die gleichen Ahnen verehrt), es geziemt sich, dass wir ruhig und der Sitte gemäss miteinander sprechen und überlegen“. „Der Worte sind genug gewechselt", sagte der Dorfälteste von Handiwong, „bringt nun eueren Leuten das Schwert und den Speer, die ich euch überreicht habe und die Rede die ich zu euch 
sprach, es ist besser, dass wir Krieg führen als dass wir Wegzehrung bereit machen und unser Dorf verlassen".

„Was sollen wir entgegnen, wenn deine Rede so lautet, o Freund!“ antworteten die Aeltesten von Luwok, „wir wollen in unser Dorf zurückkehren und tun wie du uns geheissen hast".

Unverrichteter Dinge ruderten sie wieder heim und brachten ihren Dorfleuten die erhaltenen Waffen und die Rede des Dorfältesten von Handiwong. Als die Dorfleute die Waffen sahen und die Rede hörten ergrimmten sie in ihren Herzen und beschlossen sofort einen Kriegszug vorzubereiten und die Köpfe der widerstrebenden Verwandten von Handiwong als Beute heimzubringen. Fünfzig Männer eilten in die Häuser und kamen nach kurzer Zeit bewaffnet und mit Panzern bekleidet aus ihnen zurück. Sie bestiegen die Boote und ruderten nach Handiwong und überfielen ihre Verwandten. Tag für Tag wiederholten sie diese Ueberfälle und von jedem Kriegszug brachten sie fünf oder sechs erbeutete Köpfe heim.

Schrecken überfiel die Handiwonger. Sie waren zu schwach um an ihren Feinden Rache zu nehmen. Aengstlich verbargen sie sich in ihren Häusern. Keiner wagte mehr das Dorf zu verlassen. Keiner wagte mit dem Boot auf den Fischfang auszuziehen. Niemand getraute sich an den Fluss hinunter um Wasser zu schöpfen oder zu baden. Nachts löschte man vorsichtig die Lichter. Niemand ging im Hause herum, niemand hatte den Mut zu sprechen um nicht den unter den Häusern lauernden Feinden seinen Sitzplatz zu verraten und das Opfer des rasch zustechenden Speeres zu werden.

Die Not und Angst wurde immer grösser. Eines Tages rief der Dorfälteste alle Männer, Junge und Alte, in sein Haus zu einer Versammlung zusammen und er sprach zu ihnen: „Wir sind heute nicht hier zusammengekommen um ein frohes Fest zu feiern, sondern aus Not und Leid. Täglich überfallen uns die Feinde. Täglich erbeuten sie Köpfe von unseren Angehörigen. Wir haben nicht mehr den Mut aus unseren Häusern herauszutreten. Wir werden alle umgebracht. Entweder geschieht es durch unsere Feinde oder dann durch den Hunger den wir gegenwärtig leiden müssen. Wir wollen deshalb zusammen beratschlagen was zu tun sei. Ich mache den Vorschlag, dass wir unser Dorf und unseren heimatlichen Fluss verlassen und uns anderswo ansiedeln, aber dieser Vorschlag ist mein eigenes Wort und meine persönliche Rede, niemand hat mich geheissen so zu euch zu sprechen, überlegt nun auch selbst was wir tun sollen um unser bedrohtes Leben zu retten“. „Deine Rede ist gut“, antworteten die Leute, „wir wollen 
deinen Rat befolgen und von unserem Dorf wegziehen". Ein Alter aber sprach: „Nein, bevor wir diesen Plan ausführen wollen wir doch auch den Antang 115 um Rat fragen und seine Entscheidung einholen. Stimmt er diesem Rat $z u$, wohlan, dann ziehen wir von hier weg, wenn aber nicht, dann wird sich unser Schicksal wenden und wir haben keinen Grund unseren heimatlichen Fluss zu verlassen. Lasst uns drei Pfähle aufrichten. Einen im Dorf, einen oberhalb des Dorfes, der nach dem Rongan weist, einen unterhalb des Dorfes der nach dem Mentaja gerichtet ist. Schwebt der Antang über dem Pfahl im Dorf, dann wissen wir, dass wir hier bleiben können und die Macht der Feinde gebrochen wird, schwebt er über dem Pfahl der nach dem Rongan weist, dann wissen wir, dass wir in der Richtung nach dem Rongan unser Dorf verlassen müssen, schwebt er aber über dem Pfahl unterhalb des Dorfes, dann fliehen wir nach dem Mentaja“.

Der Rat des Alten wurde gutgeheissen. Man steckte die Pfähle, so wie er es vorgeschlagen hatte ein. Der Priester streute den Reis und rief dem Antang Njai Tumbang Balahasi. Dreimal streute er ihn, dreimal rief er dem Antang und plötzlich erschien er am Himmel und zog seine Kreise über dem Pfahl den sie oberhalb des Dorfes aufgerichtet hatten und der nach dem Rongan wies und so wie er gekommen war verschwand er auch wieder.

Nun sprachen die Aeltesten: „Wir haben einen guten Antang, er hat uns gezeigt was wir tun sollen. Wir wissen nun, dass wir nach dem Rongan flüchten müssen. Jeder kehre in sein Haus zurück und mache die Wegzehrung und seine Habe bereit, denn in der Morgenfrühe des anbrechenden Tages verlassen wir unser heimatliches Dorf und unseren Fluss und ziehen in die Fremde um uns eine neue Heimat zu suchen".

Als am andern Morgen die Kopfjäger aus Luwok kamen fanden sie keinen Menschen mehr in Handiwong. Die Häuser waren leer und auch in der Umgebung vermochten sie niemand mehr zu finden.,,Hau!" riefen sie, „die Handiwonger haben in dieser Nacht das Dorf verlassen und sind geflüchtet, gewiss sind sie nach der Mündung gerudert. Wir wollen sie verfolgen und sie gänzlich ausrotten". Rasch stiegen sie wieder in ihre Boote und ruderten flussabwärts. Sie ruderten einen $\mathrm{Tag}$, sie ruderten einen zweiten und schliesslich kamen sie in Belawan an und fragten die Leute, die mit erstaunten Gesichtern vom Ufer aus ihre Ankunft beobachteten: „Sind hier nicht viele Menschen in ihren Ruderbooten vorbeigekommen?" „Nein“, antworteten die Leute, ,wir haben niemanden gesehen, es kamen keine Boote hier vorbei". Nun sagten sie sich: „Gewiss sind sie in der Nacht an Luwok vorbei- 
gerudert. Sie haben sich vorbeigestohlen wie Diebe, sodass wir den Schlag der Ruder nicht hören konnten, aber wir wollen sie sofort verfolgen, vielleicht gelingt es uns sie noch einzuholen". Wieder bestiegen sie die Boote und ruderten heimwärts. Sie ruderten an Luwok vorbei bis Tewang Baringin Tingang und fragten die Leute: „Sind unsere Verwandten aus Handiwong nicht kürzlich hier vorbeigefahren?" „Nein“, sprachen die Leute, „wir haben niemanden gesehen“. „Sie lügen", sprachen die Luwoker untereinander, „,sie müssen hier vorbeigekommen sein. Wir wollen sie weiter verfolgen". In Tewang Sangalang Garing (das heutige Penda Hara) hielten sie wieder an und erkundigten sich ob nicht kürzlich in vielen Booten zahlreiche Menschen vorbeigefahren seien. „Nein“, sagten die Leute, „es ist hier wirklich niemand vorbeigekommen". Erst jetzt glaubten es die Luwoker und kehrten unverrichteter Dinge wieder nach Hause zurück.

Als die Handiwonger ihr Dorf in ihren Booten verliessen, waren sie der Weisung ihres Antang gefolgt und waren etwas oberhalb des Dorfes in ein Nebenflüsslein eingefahren auf dem sie den Rongan erreichen konnten. Den ganzen Tag ruderten sie bis zur Quelle des Hampangen. Dort verliessen sie die Boote und marschierten unter grossen Beschwerden durch den unwegsamen Wald in der Richtung eines Seitenflüssleins des Rongan. Sie kamen beinahe nicht vorwärts, denn sie waren schwer beladen und hatten auch die kleinen Kinder zu tragen die noch nicht selbst gehen konnten. Als die Dunkelheit hereinbrach erreichten sie die Quelle dieses Flüssleins. Hier liessen sie sich für einige Tage nieder und bauten sich kleine Hütten. Sie hatten ja keine Boote mehr in denen sie sofort die Reise fortsetzen konnten, sondern mussten sich zuerst wieder solche bauen. Einige schlugen $\mathrm{Holz}$, andere säuberten die Stämme von den Aesten und wieder andere bauten die neuen Boote. In sechs Tagen waren sie mit ihrer Arbeit fentig. Dann versammelten sie sich um den Geistern, der Erde und dem Wasser Opfer darzubringen und baten sie um Hülfe damit ihre Feinde nicht ausfindig machen könnten in welcher Richtung sie geflohen seien und damit ihre Augen, falls sie sie verfolgten, geschlossen und ihre Sinne verwirrt würden und schliesslich warfen sie in der Richtung des Hampangen einen sundur (einen engen Kamm) zurück und sprachen die Beschwörungsformel aus: „Werde zu einem dichten Bambusstrauch, der den Feinden, die uns verfolgen, den Weg abschliesst und sie irreführt". Dann bestiegen sie die Boote und fuhren flussabwärts. Als sie an der Mündung angekommen waren, brachten sie wieder Opfer dar (weil sie in ein neues Gebiet kamen das ihnen 
fremd war) und baten, wie sie es bereits vor ihrer Reise auf dem Flüsslein getan hatten, die Geister um Hülfe. Dann warfen sie einen sarak (einen weiten Kamm) hinter sich in das Wasser und sprachen die Beschwörungsformel: „Verwandle dich in eine Palisade die unsere Feinde nicht $z \mathfrak{u}$ übersteigen vermögen, in eine Wand die den Fluss abschliesst". Dann ruderten sie den Rongan hinauf und suchten einen geeigneten Platz auf dem sie sich niederlassen konnten.

In dieser Zeit waren aber auch die Luwoker nicht untätig gewesen, denn sie wollten von der weiteren Verfolgung der Handiwonger nicht absehen. Sie versammelten sich und beratschlagten was nun zu tun sei und kamen zu dem Ergebnis ihrer Besprechung, dass es das Beste sei den Antang aufzurufen um von ihm zu erfahren in welcher Richtung sich die Feinde davon gemacht hätten.

Sie richteten drei Pfähle auf. Einer wies flussaufwärts, der andere flussabwärts und der dritte nach dem Nebenfluss der nach dem Rongan führte. Der Priester streute den Reis und rief dem Antang Ganan Tadjahan (dem Falken, der Seele des Ahnenplatzes). Plötzlich erschien der Antang am Himmel und schwebte über dem Pfahl der nach dem Rongan wies und dann verschwand er wieder in den Wolken und kehrte zum Tadjahan zurück.

Sie sprachen: „Wir wissen nun in welcher Richtung sich unsere Feinde davongemacht haben, der Antang hat es uns deutlich gezeigt. Wir wollen sie verfolgen und sie vollständig vernichten damit wir nichts mehr zu befürchten haben von ihnen".

Sie machten ihre Boote bereit, bestiegen sie und ruderten das kleine Flüsslein hinauf. Als sie an seinem Oberlauf angekommen waren verliessen sie die Boote und wanderten durch den Wald nach dem Rongan. Plötzlich kamen sie vor ein dichtes Bambusgesträuch das ihnen den Weg vollständig versperrte. Viel Zeit ging verloren mit der Beseitigung dieses Hindernisses, aber schliesslich gelang es ihnen und sie setzten die Verfolgung fort. Sie sahen, dass sie auf der rechten Spur waren. Endlich erreichten sie den Platz wo die Handiwonger gerastet hatten und auch sie bauten sich dort Hütten, fällten Bäume und stellten Boote her die sie für die Weiterreise nötig hatten. Nach einigen Tagen hatten sie die Vorbereitungen beendet und konnten die Verfolgung wieder aufnehmen. Sie fuhren das Flüsslein hinunter und als sie ungefähr in der Mitte waren gewahrten sie eine starke Palisade die sie nicht umzulegen vermochten, so wie sie mit dem Bambusgesträuch getan hatten, denn sie war hoch und stark gebaut. Sie konnten ihre Reise nicht fortsetzen und waren gezwungen unverrichteter Dinge 
wieder nach Luwok zurückzukehren. Seit dieser Zeit aber nannten sie dieses Nebenflüsslein Rongan Pagar (der Zaun), das Nebenflüsslein am Katingan aber nannten sie Hampangen (von hempeng: das Bambusgesträuch). Die Handiwonger setzten ihre Flucht fort. Sie fuhren den Rongan hinauf und in allen Dörfern baten sie die Menschen um Erlaubnis sich bei ihnen niederlassen zu dürfen, aber überall wies man sie ab. Sie fuhren den Rongan wieder hinunter und den Kahaian hinauf, aber auch am Kahaian gab man ihnen keine Erlaubnis sich in einem Dorf niederzulassen oder ein eigenes Dorf anzulegen. Sie fuhren den Kahaian hinab, vorbei an der Ronganmündung, aber überall wies man sie ab. Sie wollten ans Meer fahren. In der Nähe der Mündung sahen sie einen Seitenfluss, der halb Fluss, halb Kanal war. Sie entschlossen sich $\mathrm{ihm} z \mathfrak{u}$ folgen und kamen in den Murong (der Murong ist ein Seitenarm des Barito. Er durchfliesst die unter dem Namen Pulau Petak bekannte Landschaft, vereinigt sich bei Kuala-Kapuas mit dem Kapuas und mündet als solcher in die Javasee). Sie fuhren den Murong hinauf in der Hoffnung, dass es ihnen gelingen möchte sich irgendwo niederlassen zu können. Vom Murong gelangten sie in den Kapuas, aber auch dort wollte man sie nicht in die Dörfer aufnehmen, doch gab man ihnen die Erlaubnis sich an unbewohnter Stelle ein eigenes Dorf anzulegen, womit sie zufrieden waren.

So bauten sie sich am untern Kapuas ihr Dorf und nannten es: Leleh Baner Kampong Karanen. Dort wohnen ihre Nachkommen bis heute noch.

\section{Radja Haramaung Batolang Buno, Balikur Talawang}

Der König aller Hantuen (Vgl. die Geschlechterliste am Anfang dieses Abschnittes und die Listen in den Texten zum Totenkult, 2. Band) dem man Opfer darbringt um die durch die Hantuen verursachten Krankheiten abzuwenden ist Radja Haramaung Batolang Buno, Pangandien Balikur Talawang. Er wohnt am Flusse Hepeng Bulau, im Dorfe Bukit Ambo Nangga Buno Kereng Gatang Mahakang Dohong. Werden die Reisseelen mit ihren Begleitern, bezw. Begleiterinnen (Siehe die Besingung des Streureises im zweiten Teile dieses Werkes), zu ihm gesandt, dann nahen sie sich nur zögernd seinem Dorfe, denn er ist allgemein als ein roher und ungeschliffener Geselle bekannt. Wenn sie das Dorf erreicht haben und zu seinem Hause gekommen sind, dann rufen sie seiner Frau und erkundigen sich bei ihr: „Wo ist dein Mann, der tapfere Nashornvogel?" „Er schläft in seiner Kammer“, antwortet Kameloh Takun Bulan. „Gehe zu ihm und wecke 
ihn auf", bitten sie die Reisseelen. „Nein“, antwortet sie, „,ich habe den Mut nicht, denn wenn ich meinen Mann, den tapferen Nashornvogel aufwecken würde, dann schlüge er sich mit mir". Nach diesem ergebnislos verlaufenen Gespräch begibt sich Antang Ranggam, ein Begleiter der Reisseelen, nach dem Zimmer des Radja Haramaung und ruft dem Schlafenden mit lauter Stimme zu: „O Radja Haramaung Batolang Bunu, erwache doch“. Er erwacht, er bewegt und streckt sich und er ruft mit lauter Stimme: „Wer ist es, der es wagt mich zu wecken während meines Schlafes?" „Ich", ruft Antang Ranggam. Radja Haramaung entgegnet: „Nimm deine Waffen, denn wir wollen uns schlagen". Antang Ranggam zieht seinen goldenen Dolch aus der Scheide, aber er antwortet: „Nein, wir wollen uns nicht schlagen. Ich würde unterliegen und in deinem Haus sterben. Kein Mensch von den Ufern des Flusses der Welt würde sich mehr wagen dir zu nahen wenn ich nicht mehr zurückkehren würde, denn siehst du, ich bringe dir hier, zusammen mit Rika Bulau Antang Ganan Tadjahan (der Falke des Ahnenplatzes) und Banjawei Ganan Tawur, Sahawong Rawatan Behas (die männliche Reisseele) den Auftrag der Menschen aus dem Dorfe am Ufer des Flusses der Welt. Sie bitten dich aus der Oberwelt herunterzusteigen und ihre Opfer zu essen, die sie dir bereit gestellt haben“. Darauf antwortet Radja Haramaung: „Es ist nicht nötig, dass ich persönlich zu den Menschen am Flusse der Welt herabkomme. Hier ist mein Sklave, der Jüngling mit goldenem Leib, er ist mein Bote, er kann meinetwegen mit euch dreien an den Fluss der Welt herabkommen und die bereitgestellten Opfer und Gaben in Empfang nehmen. (In diesem Tone und auf diese Weise geht das Gespräch noch während einiger Zeit weiter.)

\section{b. Die Ursache der Sonnen- und Mondfinsternis}

Es geschah in der Urzeit, am Anfang der Welt. Ranjing Mahatala Langit hatte einem Mann und einer Frau den Auftrag gegeben aus der Oberwelt an die Ufer des Flusses der Welt herabzusteigen. Der Mann wurde ein reicher und weiser König und nach einiger Zeit schenkte ihm seine Frau eine Tochter die rasch heranwuchs und eine sehr schöne Jungfrau wurde. Ueberall sprach man von ihrer grossen Schönheit und ihrer Lieblichkeit. Auch Djangga, der Herr des Mondes, hörte durch Indu Panjaruna Rawei Riwut (die Göttin des Windes) von der grossen Schönheit und Liebenswürdigkeit des Königskindes und es ergriff ihn das Verlangen sie kennen zu lernen und als seine Frau heimzuführen. 
Eines Tages stieg er vom Monde auf die Welt herab und begab sich zu dem reichen König, dem Vater der schönen Prinzessin. Als er sie sah ergriff ihn heisse Sehnsucht nach ihr. Er sprach mit ihren Eltern und bat sie um die Hand ihrer Tochter. Seine Bitte wurde angenommen, denn er war ebenfalls ein reicher König und ein sehr schöner Mann. Nach kurzer Zeit fand die Hochzeit statt. Er wohnte fortan im Hause seiner Frau und sie waren sehr glücklich. Nicht lange nach der Hochzeit fühlte die Frau, dass sie einem Kinde das Leben schenken würde. Zeitweise hielt sich Djangga auf dem Monde auf, aber zur Zeit des Neumondes kehrte er immer zu seiner Frau zurück. Aber weil nun für die Frau durch die Schwangerschaft eine Palizeit angebrochen war und weil sie sich ausgerechnet zur Zeit seiner Besuche ihm entziehen musste, wurde er missmutig und wurde immer verdrossener. Als er wieder einmal kam sprach er zu seiner jungen Frau: „Ich halte es am Flusse der Welt nicht mehr aus, es stinkt mir hier auch zu sehr, 116 ich muss zu meinen Verwandten und Angehörigen zurückkehren und kann nie mehr zu dir kommen“. „Tue doch das nicht!" sagte die Frau, „du siehst doch, dass ich ein Kind erwarte und du weisst doch, dass es pali (tabu: unerlaubt) ist für einen Mann seine Frau während der Schwangerschaft zu verlassen. Du weisst doch, dass die Nichtbeachtung dieser Palivorschrift unserem, zu erwartenden Kinde Schaden und Leid zufügen müsste. Du weisst, dass es als eine Missgeburt geboren würde. Und wenn du mich verlassen würdest, dann würde unser Kind nie seinen Vater kennen lernen. Tue mir und deinem Kinde dieses Leid und diesen Schmerz nicht an“. „Nein“, entgegnete Djangga, ,es ist mir unmöglich deine Bitte $z \mathfrak{u}$ erfüllen, ich halte es am Flusse der Welt nicht mehr aus, ich muss fort von hier, ich muss zurückkehren zu meinen Verwandten, denn vor Leid und Schmerz und Heimweh weine ich Tag und Nacht in meinem Innern. Halte mich nicht zurück. Lass mich ziehen. Mein Kind verlasse ich nicht. Ich übergebe dir hier sieben Pfeile. Ist unser Kind ein Knabe, dann übergibst du ihm diese Pfeile sobald er zu einem Jüngling herangewachsen ist. Fragt er dich wer sein Vater sei, dann hast du ihm meinen Namen zu nennen. Will er mich besuchen, dann hast du ihn ziehen zu lassen und ihn zu unterrichten in dem was ich dir nun mitteile, nämlich: will er mich besuchen, dann muss er sich hinter das Dorf in den Busch begeben. Dort hat er sieben gelbe Bambusstöcke aufeinander zu schichten. An diesen muss er emporklettern. Hat er das Ende erreicht, dann muss er diese sieben Pfeile durch sein Blaserohr gegen den Himmel blasen. Diese werden eine Kette bilden die sich in eine Schlingpflanze verwandeln wird. An 
dieser klettert er weiter empor und kommt dann zur Türe des Himmels. Er muss durch sie eintreten. Von dort aus wird er mich dann mühelos finden können. Verflucht sei dein Leben wenn du dich nicht an mein Wort hältst. Unglücklich und heillos wirst du werden wenn du meine Rede unserem Sohne verschweigst".

Nachdem Djangga diese Worte gesprochen hatte schnallte er sich den Dolch und Pfeilköcher um, ergriff das Blaserohr und verliess seine Frau, die tiefbetrübt in Leid und Schmerz versunken, am Flusse der Welt zurückblieb. Er begab sich hinter das Dorf, schichtete, dort angekommen, sieben Bambusstöcke aufeinander und kletterte daran hinauf. Dann blies er sieben Pfeile durch sein Blaserohr. Sie bildeten sogleich eine Kette und diese verwandelte sich in eine Schlingpflanze. Daran kletterte er weiter hinauf und trat durch die Türe des Himmelsgewölbes in die Oberwelt ein und begab sich in seine Stadt und $z u$ seinen Angehörigen und Verwandten.

Silai wird geboren. Etwa einen Monat nachdem Djangga seine Frau verlassen hatte schenkte diese einem Sohne das Leben. Aber wie war er anzusehen! Die Uebertretung der Palivorschrift durch seinen Vater hatte sich an ihm gerächt. Die Mutter hatte einer Missgeburt das Leben geschenkt, einem Knaben, dessen Körper nur auf der einen Seite voll entwickelt war, während auf der andern Seite die Glieder fehlten. Seine Mutter nannte ihn Silai (Einseitiger oder Halbseitiger). Silai wuchs heran wie alle andern Kinder auch und er lernte sprechen wie alle andern Menschen auch sprechen. Er wurde grösser und älter, aber er blieb ein Einseitiger. 117

Silaibesucht seinen Vater und was ihm auf dem $\mathrm{W}$ ege begegnet. Eines Tages erkundigte sich Silai bei seiner Mutter nach seinem Vater. Schon lange hatte sie diese Frage befürchtet, denn sie war in ihrem Herzen besorgt dass sie nicht nur ihren Mann, sondern auch ihren Sohn verlieren sollte, aber sie erinnerte sich der Worte und der Drohung ihres Mannes und sie sprach deshalb zu ihrem Sohn: „Dein Vater wohnt nicht hier am Flusse der Welt. Er ist kein Mensch. Er ist Djangga, der Herr des Mondes“.118 „Gut", sagte der Sohn, ,,ich will ihn besuchen, sage mir den Weg“. Die Mutter antwortete: „Es wird dir schwierig werden deinen Vater zu besuchen, denn der Weg ist weit und mühsam und es wird das Beste sein wenn du dich zuerst zu deinem Onkel, dem Bruder deines Vaters, begibst, zu Djang. karang Matanandau, dem Herrn der Sonne, 119 und ihn um Rat fragst." „Gut“, sagte Silai, ,ich will deinen Rat befolgen“. Am andern Morgen 
traf er die Vorbereitungen zu seiner weiten Reise. Er machte die Wegzehrung bereit, gürtete den Dolch und den Pfeilköcher um, ergriff das Blaserohr, nahm Abschied von seiner Mutter und verliess das Haus. Er wanderte hinter das Dorf, schritt rüstig durch die Felder, dann durch den Busch, dann durch den Wald und kam dann schliesslich in hügeliges Gelände und als er sieben Tage gewandert war erblickte er plötzlich vor sich eine einsame aber sehr schön gebaute Hütte. Es war das Haus des Königs der Orang Utan. Als er vor ihm angekommen war rief er: „O Grossvater, darf ich in dein Haus eintreten?“ „Komm nur herauf, mein Enkel", rief der König zurück und Silai trat ins Haus ein und begrüsste den König und die Königin, die ihn freundlich aufnahmen und bewirteten. Dann fragte ihn der König: „Woher kommst du, mein Enkel, und wohin willst du dich begeben?" Silai erzählte ihm seine Geschichte und klagte ihm, dass er eigentlich nicht wisse wie er seinen Onkel finden- und $\mathfrak{z u}$ seinem Vater hingelangen könne. „Vielleicht sterbe ich auch unterwegs, o Grossvater". Der König sprach zu ihm: „Ich kann dir leider den Weg auch nicht weisen, o mein Enkel, ich kann dich nicht $z u$ deinem Onkel führen, denn ich bin $z u$ wenig mächtig. Nur einer hat die Macht und nur er könnte dir helfen, nämlich mein Grossvater, der König der Raben. Vielleicht, dass er gewillt ist, dich zur Türe des Himmelsgewölbes zu bringen. Schlafe nun heute in meinem Haus und suche ihn morgen auf".

Am andern Morgen setzte Silai seine Reise wieder fort und nach einiger Zeit kam er zum König der Raben. Er wurde freundlich aufgenommen und bewirtet und der König fragte ihn nach seinem Woher und Wohin. Silai erzählte ihm seine Geschichte und bat ihn : „Hilf mir doch, mein Grossvater. Führe mich zur Türe des Himmelsgewölbes damit ich meinen Onkel und meinen Vater besuchen kann, denn mir allein ist es nicht möglich den Weg zu finden, nur du kannst mich führen“. „Gut", sprach der König, ,ich will dir gerne helfen. Fange morgen früh eine panganen (Riesenschlange, Python) als Wegzehrung für mich und wenn du das getan hast, dann will ich dich zur Türe des Himmelsgewölbes bringen". Als der Morgen graute begab sich Silai in den Wald um eine Panganen zu fangen. Nach kurzer Zeit kehrte er mit der Schlange zum König zurück und sie bereiteten sie als Wegzehrung und dann machten sie sich auf den Weg. Silai setzte sich auf den Rücken des Königs der Raben und dieser sprach zu ihm: „Wenn ich hungrig bin und dich um Essen bitte, dann stecke mir ein Stück unserer Wegzehrung in den Mund“. „Ich will es gerne tun“, sprach Silai. Sie flogen zwei Tage, sie flogen noch den dritten Tag, endlich 
kamen sie an der Türe des Himmelsgewölbes an. Der König hackte seinen Schnabel in die Türe, öffnete sie und setzte Silai auf dem Wege ab und sprach zu ihm: „Wenn du nun auf deiner Weiterreise Tiere begegnest die sich in Not befinden, dann sei ihnen behülflich und rette sie, denn sie werden auch dir helfen und dich retten wenn du dich in Not befindest“. „Ich will deinen Rat gerne befolgen und ich danke dir für deine Hülfe", sprach Silai und setzte seinen Weg fort während der König der Raben wieder zurückkehrte. Noch nicht lange war Silai gewandert, da erblickte er in einem Teiche ein treibendes Holzstück auf dem Ameisen unruhig und ängstlich hin- und herliefen. Sie riefen ihm zu: „O Silai, du siehst unsere Not. Wir kommen um, wenn wir noch lange auf diesem Holzstück auf dem Wasser herumtreiben müssen. Der nächste Windstoss oder die nächste Welle wird uns ins Wasser werfen und die Fische werden uns auffressen. Hilf uns doch und erlöse uns vom Tode“. „Ich will euch gerne helfen“, antwortete Silai, und er schnitt rasch mit seinem Dolche einen Stab den er den Ameisen hinhielt und über den sie ans sichere Land gelangen konnten. Die Ameisen sprachen zu ihm: „Wir danken dir, Silai, wir werden dich nicht vergessen. Wenn du dich in Not befindest dann werden wir kommen und dir helfen wie du uns geholfen hast".

Silai wanderte weiter, aber er war noch nicht weit gegangen da sah er in einem trüben Wassertümpel einige Saloangfische 120 die unruhig hin- und herschwammen. Als sie ihn sahen, riefen sie ihm zu: „O Silai, hilf uns doch. Du siehst, dass wir in diesem Wassertümpel, abgeschnitten vom Fluss und vom strömenden Wasser, elend umkommen müssen. Rette uns doch“. „Ich will euch gerne retten“, sprach Silai, und er grub ihnen mit seinem Dolche eine Rinne zum Fluss durch die sie den Wassertümpel verlassen konnten. Fröhlich schwammen sie weg und in den Fluss hinaus und sie sprachen zu Silai: „Wir danken dir, Silai, dass du uns vom Tode erlöst hast. Wie du uns in der Not beigestanden bist, so werden auch wir dir beistehen wenn du in Not kommst. Wir werden dich nicht vergessen".

Silai setzte seine Wanderung wieder fort und als er einige Zeit gegangen war sah er plötzlich einen Hirsch vor sich der sich mit seinem Geweih in Gesträuch und Schlingpflanzen verfangen hatte und trotz aller Anstrengungen nicht mehr frei werden konnte. Er bat Silai: „Hilf mir doch, sonst verderbe ich hier". Silai löste sein Geweih aus den Pflanzen und als sich der Hirsch wieder frei fühlte, sprach er: "Ich werde dir in der Not beistehen und dir diesen Dienst vergelten“, und dankend nahm er Abschied von seinem Retter. 
Als Silai wieder weitergegangen war sah er nach einer Weile am Wege einen Affen der mit einem seiner Arme zwischen zwei Aesten eines Baumes eingeklemmt war und sich daraus nicht mehr $\mathrm{zu}$ befreien vermochte. Er rief: „O Silai, hilf mir doch, löse meinen Arm aus den Aesten, denn wenn du mir nicht hilfst, dann muss ich hier verhungern und umkommen". Silai befreite den Affen und dieser dankte ihm für seine Hülfe und sprach: „Wenn du dich einst in Not befindest, dann werde ich dir ebenfalls beistehen und dir helfen wie du mir geholfen hast".

Wieder setzte Silai seine Wanderung fort und nach einiger Zeit erblickte er ein Krokodil das ihn anredete: „O Silai, ich habe mich im Walde verirrt und es gelingt mir nicht mehr den Rückweg zum Flusse zu finden. Rette mich und zeige mir den Weg“. „Ich will dir gerne helfen", sprach Silai und mit seinem Dolche schlug er einen Weg durch den Wald zum Fluss. Wie dankbar war das Tier als es wieder den Fluss sah! Es sprach zu Silai: „Wenn du dich in Not befindest, dann werde ich kommen und dir beistehen wie du mir heute beigestanden bist, denn hättest du dich meiner nicht erbarmit und mir geholfen, dann wäre ich im Walde elend umgekommen".

Froh wanderte Silai weiter. Plötzlich sah er am Rande des Weges ein Spinnennetz in dessem Gewebe sich ein Leuchtkäfer verfangen hatte. Er mühte sich ab sich aus dieser Gefangenschaft zu befreien aber alle Anstrengungen waren umsonst. Als er Silai sah rief er ihm zu: „O Silai, Sohn des Djangga, des Königs des Mondes, rette mich, denn ich kann mich nicht selbst befreien und die Spinne wird mich töten". Silai trat herzu und löste den Käfer vorsichtig aus den Fäden des Spinnennetzes und als er sich wieder frei fühlte sprach er $z \mathfrak{u}$ seinem Retter: „Ich danke dir, Silai, für deinen grossen Dienst und für die Errettung vom sicheren Tod. So wie du mir heute beigestanden bist in der Not, so werde ich dir auch beistehen wenn du einmal in Not kommen solltest".

Silai kommt in dem Dorf seines Onkels an. Silai setzte seine Reise fort und nicht lange darnach kam er in dem Dorfe seines Onkels Djangkarang Matanandau an. Wie erstaunte er als er dieses schöne und reiche Dorf sah, denn es war von lauter Gold und Edelsteinen gebaut. Die Leute, denen er begegnete, fragten ihn: „Woher kommst du Silai ?" Und er antwortete und erzählte ihnen über sein Woher und Wohin und teilte ihnen seine Geschichte mit. Daraufhin führten sie ihn in das Haus seines Onkels der ihn freundlich aufnahm 
und gut bewirtete. Nachdem Silai sich satt gegessen hatte und nachdem er Sirih kaute fragte ihn sein Onkel über sein Woher und Wohin. Silai brachte sein Anliegen vor und bat seinen Onkel: „Meine Mutter hat mich $z \mathfrak{u}$ dir gewiesen damit du mir den Weg zu meinem Vater zeigen möchtest. Ich bitte dich, führe mich doch zu ihm“. „Das will ich gerne tun“, sprach Djangkarang Matanandau, ,denn mein Dorf liegt nicht ferne von dem deines Vaters, morgen früh brechen wir dorthin auf".

Silai bei seinem Vater und wie es ihm dort er$\mathrm{g}$ e $\mathrm{h} \mathrm{t}$. Als der Morgen graute machte sich Silai mit seinem Onkel auf den Weg. Rüstig schritten sie aus und kamen bald vor dem Dorfe des Mondkönigs an. Djangkarau Matanandau kehrte wieder zurück und Silai setzte seine Wanderung allein fort und nach kurzer Zeit kam er in dem Dorfe seines Vaters an. Er war sehr erstaunt, denn es war ebenso schön wie das Dorf seines Onkels. Er erkundigte sich nach dem Hause seines Königs und als er dort angekommen war und ihn der König über sein Woher und Wohin ausgefragt hatte, da sprach er zu seinem Vater: "Mein Vater, ich bin doch dein Sohn, erkennst du mich denn nicht?" Erstaunt blickte ihn der König an und zornig schrie er: „Was, Missgeburt, du willst mein Sohn sein! Du bist ein Lügner und ein Betrüger. Du bist nicht mein Sohn, denn mein Sohn wäre ein schöner Mensch, aber nicht eine solche verkrüppelte und einseitige Missgeburt wie du bist. Packe dich hinweg!“ Betrübt antwortete Silai: „Ja, mein Vater, du hast recht mich eine Missgeburt zu schelten. Aber es ist deine Schuld, dass ich so missgestaltet und verkrüppelt geboren worden bin. Du hast meine Mutter, als sie mich unter ihrem Herzen trug, verlassen. $\mathrm{Du}$ hast die Palivorschriften gebrochen und ich bin das Opfer davon geworden". Aber der Vater glaubte seinen Worten nicht. Betrübt begab sich Silai ins Fremdenhaus, denn sein Vater hatte ihm in seinem Hause die Herberge geweigert und hatte ihn weggeschickt wie einen Lügner und Betrüger. Er setzte sich auf den Boden und weinte über die Hartherzigkeit die ihm wiederfahren war. Als aber sein Vater von seinem Herzeleid hörte, da ging er $\mathrm{zu}$ ihm und sprach: „Wenn du wirklich mein Sohn bist, was ich allerdings nicht glauben kann, dann will ich dich auf die Probe stellen und es wird sich zeigen ob dein Wort Wahrheit oder Lüge war. Bestehst du die Probe, dann anerkenne ich dich als meinen Sohn". Er holte einen sangko (ein Gefäss von Messing), füllte ihn zur Hälfte mit Wasser, goss eine Flasche Oel hinein und fügte einen gantang (ein Mass) Asche und einen Gantang feinen Gries bei und rührte alles um. Darauf sprach er zu seinem 
Sohn: „Wenn es dir gelingt das Oel in die Flasche zurückzugiessen und die Asche und den Gries in die Gantang zu sammeln, sodass das Wasser wieder hell und klar wird, dann hast du die Probe bestanden und bist wirklich mein Sohn". Nach diesen Worten verliess er ihn. Nachdem Silai diese Rede gehört und die Arbeit gesehen hatte, die sein Vater von ihm forderte, da erschrak er sehr und das Herzeleid ergriff ihn aufs neue, denn er sah wohl ein, dass es ihm nicht gelingen würde die Forderung seines Vaters zu erfüllen. Er verliess das Fremdenhaus und lief in seinem Herzeleid umher um sich einen Rat auszusinnen. Und als er so betrübt und niedergeschlagen herumlief, da begegnete er plötzlich den Ameisen und Saloangfischen die er vom Tode erlöst hatte. Sie fragten ihn teilnehmend: „Was fehlt dir Silai, weshalb bist du so niedergeschlagen?" Er erzählte ihnen was ihm begegnet war und darauf sprachen sie zu ihm: „Sei nicht traurig, Silai. Du hast uns erlöst und vom Tode errettet, nun wollen wir dir helfen und wir wollen dir vergelten was du an uns getan hast. Zeige uns die Arbeit". Er führte die Tiere zum Sangko. Die Fische stürzten sich in die Flüssigkeit, schluckten das Oel auf und spieen es in die Flasche aus. Die Ameisen aber sammelten die Asche und den Gries und füllten damit die beiden Gantang und schon nach kurzer Zeit war die Arbeit beendet. Wie froh wurde Silai als er sah was die Tiere für ihn getan hatten. Er dankte ihnen und sie verliessen ihn wieder und sprachen $z \mathfrak{u}$ ihm: „Trage nun alles zu deinem Vater und lege es vor ihm nieder und er wird dich nun als seinen Sohn anerkennen müssen". Silai tat wie ihn die Tiere geheissen hatten. Als er zu seinem Vater kam und als dieser sah, dass die Arbeit, die er seinem Sohne aufgetragen hatte, beendet war, da sprach er zu ihm: „Du hast die erste Probe bestanden. Ich sehe, dass du mein Sohn bist, aber ich muss dich nochmals auf die Probe stellen. In der Nähe meines Dorfes liegt ein grosser kudjang-garten (ein Garten mit Knollengewächsen). Ich will dir die Richtung zeigen. Wenn es dir gelingt durch den Busch einen Weg zu diesem Garten $\mathbf{z u}$ schlagen, ohne dass du dich verwundest oder durch Dornen verletzt wirst, dann bist du wirklich mein Sohn". Silai erschrak sehr und er wurde voller Sorge und das Herzeleid ergriff ihn wieder, denn er wusste wohl, dass er diese Arbeit nicht auszuführen vermochte, denn sie war sehr schwer. Der Weg, den er schlagen sollte, führte durch dichte und undurchdringliche Dornenbüsche. Betrübt machte er sich auf den Weg und er grübelte nach wie er diese neue Probe wohl bestehen könne und als er so seines Weges ging und vor sich hinstarrte begegnete er ganz unerwartet dem Hirsch, 
dessen Geweih er aus dem Gesträuch gelöst hatte. „Weshalb bist du so betrübt, o Sohn des Herrn des Mondes?" fragte ihn der Hirsch. Silai erzählte ihm seine Geschichte und was sein Vater von ihm gefordert hatte und dass es ihm unmöglich sei diese Probe zu bestehen weil die Arbeit viel zu schwer sei. „Sei unbesorgt", sagte der Hirsch, ,,ich will dir helfen, wie du mir geholfen hast. Setze dich auf meinen Rücken. Ich will dich zum Garten tragen und von dort wieder zurückbringen nachdem du einen $Z_{\text {weig }}$ der Kudjangstauden gebrochen hast als Zeichen für deinen Vater, dass du seinem Befehl nachgekommen bist". Silai tat wie ihn der Hirsch geheissen hatte und nach einiger Zeit trat er wieder unversehrt vor seinen Vater und übergab ihm den Zweig aus dem Kudjanggarten. Dieser schaute ihn sehr erstaunt an, denn nirgends bemerkte er an ihm eine Verletzung. Er sprach zu ihm: „Du bist wirklich mein Sohn, aber trotzdem muss ich dich noch einmal auf die Probe stellen. Du siehst dort auf der Ueberseite des Flusses den hohen Tapangbaum. Wenn es dir gelingt ihn bis zu seinem Wipfel $z \mathfrak{u}$ erklettern und du wieder unversehrt vor mich hintrittst, dann anerkenne ich dich als meinen Sohn. Gelingt es dir aber nicht, dann kann ich nicht glauben, dass du mein Sohn bist, trotz aller Proben die du zuvor schon bestanden hast". Betrübt verliess Silai seinen harten Vater. Wie sollte es ihm, der Missgeburt, dem Halbseitigen, gelingen den hohen Tapangbaum zu erklettern! Voller Herzeleid lief er ruhelos umher und plötzlich begegnete er dem Affen den er vom Verderben erlöst hatte. „Weshalb schleichst du so traurig umher?" fragte ihn der Affe. „Was bekümmert dich, o Silai?" Silai erzählte ihm welche harte Probe sein Vater von ihm gefordert hatte und dass es für ihn ganz aussichtslos sei sie zu bestehen, denn er wisse wohl, dass er den Tapangbaum nie erklettern könne. „Sei ohne Sorge“, sprach der Affe, ,,ich will dir helfen wie du mir geholfen hast. Gib mir deine Kleider. Ich besteige für dich den Baum. Niemand wird aus der Ferne erkennen können, dass nicht du es bist der ihn erklettert". Voller Freude zog Silai seine Kleider aus und übergab sie dem Affen der den Baum mühelos bis zu seinem Wipfel erkletterte und rasch wieder zurückkam. Dann zog er die Kleider wieder aus und übergab sie Silai mit den Worten: „Sei nun ohne Sorge! Tritt vor deinen Vater, er wird dich nun als sein Sohn anerkennen müssen, denn er hat mit eigenen Augen gesehen, dass du die Probe bestanden hast". Silai tat wie der Affe gesprochen hatte und als sein Vater ihn wieder erblickte und auch sah, dass er unversehrt war, da sprach er: „Du scheinst wirklich mein Sohn $z \mathfrak{u}$ sein. Ich habe gesehen wie du den Baum erklettert hast, aber ver- 
zeihe mir, dass ich dich trotzdem nochmals auf die Probe stellen muss. $\mathrm{Du}$ musst morgen mit einigen Sklaven auf dem Flusse nach einem bestimmten Ziele hin um die Wette rudern. Erreichst du das Ziel als Erster, dann anerkenne ich dich als meinen Sohn". Wiederum verliess Silai betrübt und voller Herzeleid seinen Vater und wanderte ruhelos umher. Wie sollte es ihm, dem Krüppel, gelingen diese neue Probe zu bestehen! Als er so umherging wurde er plötzlich angesprochen und als er um sich schaute, da sah er das Krokodil dem er durch den Wald einen Weg zum Fluss geschlagen hatte. Es fragte ihn teilnehmend: „Weshalb bist du so betrübt, o Silai ?" Er erzählte ihm, dass er morgen mit den Sklaven seines Vaters um die Wette rudern müsse, aber dass es ganz ausgeschlossen sei, dass er Sieger werden könne. „Sei ohne Sorgen“, sprach das Krokodil, ,ich habe nicht vergessen was du für mich getan hast als du mich vom Tode errettetest. Ich will dir helfen, dass du das Ziel als Erster erreichen kannst und die Probe bestehst. Wenn der Morgen graut, dann setze dich ruhig in dein Boot, ich werde dann auch zur Stelle sein. Wenn du mich siehst, dann befestigst du das Boot an meinem Schwanze und ich werde es zum Ziele hinziehen". Am andern Morgen tat Silai wie ihn das Krokodil geheissen hatte und als das Wettrudern begann lachten die Teilnehmer erst über den verkrüppelten Silai und spotteten ihn aus, aber sie blieben mit ihren Booten weit hinter ihm zurück. Silai war Sieger geworden und das Krokodil verliess ihn mit den Worten: „Gehe nun zu deinem Vater, er wird dich als sein Sohn anerkennen müssen". Als sein Vater ihn sah sprach er: „Du hast die Probe bestanden und ich sehe jetzt dass du mein Sohn bist, aber erlaube mir, dass ich dich heute Nacht zum letzten Mal auf die Probe stelle. Bestehst du sie, dann bist du mein Sohn! Heute Nacht, wenn im Hause alle Lichter ausgelöscht sind und alles schläft musst du mich im Hause suchen und dich zu meiner Seite setzen. Gelingt dir das, dann sehe ich, dass du wirklich mein Sohn bist". Wiederum ergriff das Herzeleid den betrübten Silai. Wie sollte er in dem ihm völlig unbekannten Hause das Schlafgemach seines Vaters finden! Wie sollte er ihn erkennen können in der Dunkelheit! Wie sollte es ihm auch gelingen sich an seine Seite setzen zu können! Betrübt wanderte er umher. Plötzlich hörte er neben sich eine Stimme die ihn fragte: „Weshalb bist du so betrübt, o Silai?" Und als er sich umwandte sah er den Leuchtkäfer dem er das Leben gerettet hatte indem er ihn aus dem Netze der Spinne löste. Er klagte ihm seine Not und erzählte: „Mein Vater will mich in dieser Nacht zum letzten Mal auf die Probe stellen ob ich wirklich sein Sohn sei oder nicht. Ich muss 
ihn in dem dunklen Hause in seinem Schlafgemach aufsuchen und mich an seine Seite setzen. Wie sollte mir das auch gelingen können! Ich kenne mich doch in dem Hause gar nicht aus!" „Sei unbesorgt, Silai“, sprach der Leuchtkäfer, ,,sobald es dunkel geworden ist werde ich mich einstellen. Ich fliege vor dir her und ich erleuchte dir den Weg und werde dich auf diese Weise in das Schlafgemach deines Vaters bringen, du hast mir nur nachzufolgen". Als die Nacht hereingebrochen war stellte sich der Leuchtkäfer ein und flog vor Silai her bis sie in das Schlafgemach seines Vaters gekommen waren. Dort flog er über dem Platz auf der sich Silai niederlassen musste und dann verliess er durch das Fenster das Zimmer und Haus. Silai setzte sich neben die goldene Schlafmatte seines Vaters und rief ihn an: „O mein Vater, hier bin ich". Der Vater erwachte und erkannte nun, dass Silai wirklich sein Sohn sei und er sprach $z u$ ihm: „Ich habe dich deshalb so oft auf die Probe gestellt weil ich fürchtete dass du ein Lügner und Betrüger seiest. Nun hast du alle Proben bestanden, auch diese letzte, und daraus sehe ich, dass du die Wahrheit gesprochen hast. Ich anerkenne dich als meinen Sohn und nehme dich auf in mein Haus. Du bist zu einer verunstalteten Missgeburt geworden weil ich deine Mutter während ihrer Schwangerschaft verlassen habe. Ich will das wieder an dir gut machen. Sobald der Morgen graut will ich deine Gestalt verwandeln. Du sollst ein schöner Mensch werden, schöner als alle andern Menschen sind".

Silai bekommt eine neue Gestalt. Als der Morgen graute ergriff Djangga eine Feile und zerfeilte seinen Sohn in kleine Stücke auf einem Amboss. Die Stücke warf er in einen eisernen Tiegel und kochte sie. Als sie genügend gekocht waren goss er Lebenswasser über sie aus und alsbald stand sein Sohn wieder lebend vor ihm. Der Vater sprach zu ihm: „Du siehst dort drüben das Reisfeld. Auf ihm arbeiten viele Menschen. Begib dich nun zu ihnen und höre was sie sagen". Silai tat wie ihn sein Vater geheissen hatte. Als er in die Nähe des Feldes kam schauten die Laute erstaunt von ihrer Arbeit auf und riefen einander mit verächtlicher Stimme $z \mathfrak{u}$ : „Pfui, seht doch diesen schwarzen Kerl da". Betrübt kehrte er zu seinem Vater zurück und teilte ihm die Worte mit mit denen ihn die Leute empfangen hatten. „Sei nicht betrübt“, sprach der Vater, „,denn ich will dir morgen eine neue Gestalt geben". Als der Morgen anbrach tat er wie am Tage zuvor. Er nahm seinen Sohn und zerfeilte ihn auf einem Amboss zu kleinen Stücken die er in einen kupfernen Tiegel warf und kochen 
liess. Als sie gar waren goss er Lebenswasser darüber und sein Sohn stand wieder lebend vor ihm. Und wieder befahl ihm sein Vater: „Begib dich unter die Leute und höre was sie über dich sprechen“. Als Silai in die Nähe der Leute kam und sie ihn sahen, da riefen sie erstaunt und verächtlich aus: „Pfui über dich, du roter Kerl, komm nicht in unsere Nähe, packe dich hinweg von hier". Betrübt kehrte Silai zu seinem Vater zurück und erzählte ihm die Beschimpfungen die ihm wiederfahren waren. Aber auch diesmal sprach sein Vater tröstend: „Betrübe dich nicht, mein Sohn, denn morgen gebe ich dir eine neue Gestalt". Als der Morgen angebrochen war tat er wie am Tage zuvor. Wieder zerfeilte er seinen Sohn und warf die Stücke in einen silbernen Tiegel. Als sie gekocht waren goss er Lebenswasser darüber und sein Sohn stand wieder lebend vor ihm und er befahl ihm wieder: „Begib dich unter die Leute und vernimm was sie über dich sagen!" Aber als die Leute ihn sahen, da schrieen sie auf: „Pfui du weisses Huhn. Packe dich hinweg von hier, wir wollen nichts mit dir zu tun haben, denn du gehörst nicht zu uns". Betrübt kehrte er wiederum in sein Vaterhaus zurück und erzählte was ihm begegnet war, aber wieder tröstete ihn sein Vater: „Trage kein Herzeleid, ich gebe dir morgen einen so schönen Leib wie ihn kein anderer Mensch besitzt, zudem mache ich dich auch reich, heilvoll und glücklich". Als der Morgen anbrach nahm er seinen Sohn wieder und zerfeilte ihn auf dem Amboss in Stücke und warf diese in einen goldenen Tiegel und vermischte sie mit allem möglichen Reichtum und mit köstlichen, heilbringenden Erbstücken (pusaka). Er schüttete Penjang Sihong hinein und vermischte sie mit dem elfenbeinernen Zahn (ebenfalls ein Penjang), der gefüllt war mit kräftigen Mitteln die seinem Sohn Tapferkeit, Mut, Gesundheit und Reichtum und die Kraft des Tigers verleihen sollten und dazu auch die Gabe der überzeugenden Rede. Dann goss er wieder Lebenswasser darüber und sein Sohn stand alsbald vor ihm als der Schönste der Menschen, gesund, reich, tapfer, mutig und im Besitz der wohldurchdachten und überzeugenden Rede. 121

Von Silai stammen die weissen Menschen ab. Damit meinen wir nicht die Europäer, sondern unsere freien Geschlechter deren Söhne und Töchter sich durch eine hellere Hautfarbe von den andern Geschlechtern und Menschen auszeichnen.122 Sie alle sind die Nachkommen des Silai.

Silai kehrtzu seiner Mutter zurück. Während zwei bis drei Jahren blieb Silai im Hause seines Vaters. Da sprach dieser 
eines Tages $z u$ ihm: „Mein Sohn, es ist nun Zeit, dass du wieder an den Fluss der Welt zurückkehrst und dass du dich verheiratest und Kinder zeugst. Ich kann dir hier keine Frau geben, denn wir haben als Geister zu viele Palivorschriften, es wäre dir unmöglich sie zu erfüllen, du würdest unglücklich werden, deshalb kehre an den Fluss der Welt zurück und suche dir dort eine Frau aus reichem Hause. Ich lasse dich nicht unbeschenkt von mir ziehen, sondern ich gebe dir grossen Reichtum mit den ich hier in diese Elfenbeindose eingeschlossen habe, und die ich dir hiermit nun übergebe. Oeffne sie nicht bis du beim König am Flusse der Welt angekommen bist. Du wirst in ihr das Lebenswasser finden. Es hat aber den einen Fehler, dass es sich zusehends vermindern wird. Gebrauche es deshalb sparsam. Du findest in ihr feinen Goldstaub, Kies von Edelgestein, Sandbänke von Gold und Steinbänke von heiligen Töpfen". Wie erfreut war Silai über diese reiche Gabe seines Vaters. Am andern Morgen verliess er seinen Vater und machte sich auf den Rückweg nach dem Flusse der Welt. In den Händen trug er sorgfältig die Elfenbeindose, die den köstlichen Reichtum, das Geschenk seines Vaters, enthielt. Lange war er gewandert und er war hungrig und durstig geworden, deshalb setzte er sich an einem kleinen Flusse nieder, ass und trank. Nachdem er gebadet hatte betrachtete er die Elfenbeindose und sprach zu sich selbst: „Wie! wenn mich mein Vater betrogen hätte und diese kleine Dose nicht den grossen Reichtum enthielte von dem er zu mir sprach. Ich will sie doch einmal öffnen und ich will nachschauen ob er die Wahrheit gesprochen hat oder nicht". Er öffnete sorgfältig den Deckel und wie staunte er über die Dinge die er zu sehen bekam, denn plötzlich stellte sich vor ihm ein grosses und prächtiges Dorf mit schönen Häusern und vielen Menschen auf. Grosse Sandbänke von Gold und Steinbänke von heiligen Töpfen dehnten sich vor seinen Augen. Er konnte sich nicht satt sehen an diesem Reichtum der sein eigen sein sollte. Wie erschrak er aber als er alles wieder in die Dose zurücklegen wollte. Es gelang ihm nicht meho so oft er es auch versuchte. Der grosse Reichtum hatte keinen Platz mehr in der kleinen Elfenbeindose. Er überlegte was zu tun sei, denn er getraute nicht mehr zu seinem Vater zurückzukehren dem er ungehorsam gewesen war. Er durfte ihn nicht mehr um Hülfe ansprechen. $\mathrm{Da}$ erinnerte er sich seines Onkels Djangkarang Matanandau. Ihn wollte er um Hülfe bitten. Er begab sich sofort zu ihm und erzählte ihm sein Missgeschick und bat ihn um Hülfe. "Ja“, sprach sein Onkel, ,ich will dir diesmal gerne helfen, aber öffne hernach die Dose nicht mehr bis du am Flusse der Welt angekommen bist. Für meine Hülfe verlange 
ich jedoch ein Geschenk von dir". „Ich will deinen Rat gerne befolgen“, sprach Silai, ,und ich will dir auch gerne ein Geschenk geben wenn du mir hilfst". Sie begaben sich zu dem Platze wo sich das grosse Dorf, die Sandbänke von Gold und die Steinbänke von heiligen Töpfen weithin dehnten und Djangkarang Matanandau ergriff alles und legte es in die Elfenbeindose zurück. Darauf übergab er sie seinem Neffen und forderte von ihm das versprochene Geschenk. Aber der schlaue Silai sprach: „Wie kannst du doch von mir ein Geschenk verlangen, o mein Onkel! Ich habe nichts was ich dir geben könnte, begib dich zu meinem Vater und fordere von ihm Lohn, er wird dir gerne geben was du verlangst“. „Gut", sprach sein Onkel, „du hast recht, ich will mich zu deinem Vater begeben und will ihn für die Hülfe, die ich dir erwiesen habe, um ein Geschenk bitten". Darauf trennten sie sich und Silai zog seines Weges weiter durch die Oberwelt. Drei Tage wanderte er, dann kam er beim Balai (Versammlungs- und Fremdenhaus) Haratong Tonggang Langit an das dem Lilang, dem Alten, dem Sahawong Sangiang, dem Hüter an der Türe des Himmelsgewölbes gehörte. Er blieb sieben Tage bei ihm. Als diese Zeit abgelaufen war bat er Lilang 123: „Mein Oheim, ich möchte an den Fluss der Welt zurückkehren, ich bitte dich, hilf mir". Lilang antwortete: „Ja mein Neffe, ich will dir gerne helfen, denn ich habe hier:

Das Seil von Gold, das rotgeblümte

Aus zusammengebundenen Knochen.

Den weitleuchtenden, fliegenden Drachen

Mit dem Haupte des Tigers.

Die geflochtene Kette von Gold,

Das Seil, das weitreichende."

An diesem will ich dich hinunterlassen an den Fluss der Welt. Wenn du eine depe $(1,80 \mathrm{~m})$ von der Erde entfernt bist, dann löse dich von dem Seil damit ich es wieder zu mir hinaufziehen kann". Silai tat wie ihn sein Onkel geheissen hatte. Als er noch eine depe über der Erde entfernt war löste er sich los und Lilang zog das Seil wieder in die Höhe.

Silai wanderte nun auf der Erde weiter und als er Menschen begegnete da erkundigte er sich bei ihnen wo er sich befinde und sie antworteten ihm: „Du befindest dich im Reiche der Hindu, du bist in Madjapait". Sie fragten ihn nach seinem Woher und Wohin und er erzählte ihnen seine Geschichte. Dann begab er sich in das Haus seiner Mutter, der Tochter des Königs von Madjapait. Sie war sehr erfreut über seine Rückkehr und sie bereitete ihm ein grosses Fest. Später 
verheiratete sich Silai und seine Nachkommen blieben reiche und angesehene Leute am Flusse der Welt.

Djangkarang Matanandau fordert von Djangga $\mathrm{Bulan}$ das Geschenk. Nicht lange nachdem Silai sich von seinem Onkel verabschiedet hatte, begab sich Djangkarang Matanandau zu seinem Bruder und erzählte ihm was geschehen war und wie er seinem Neffen in der Not beigestanden sei und er forderte den Lohn, den er ihm versprochen hatte. „Was fällt dir auch ein, mein Bruder", entgegnete Djangga zornig, ,wenn du Lohn haben willst dann wende dich an deinen Neffen, ihm hast du geholfen, nicht mir, er hat dich zu bezahlen, nicht ich, von mir bekommst du nichts". Aber Djangkarang Matanandau beharrte auf seiner Forderung. Immer aufgeregter wurden die beiden Brüder, immer lärmender wurde ihre Stimme, immer zorniger ihr Herz. Schliesslich griffen sie sich gegenseitig an. Djangkarang Matanandau fing Djangga Bulan und umgekehrt. Als sie müde und erschöpft waren kehrte Djangkarang Matanandau wieder in sein Dorf zurück. Bis heute aber wiederholt sich von Zeit zu Zeit zwischen den beiden verfeindeten Brüdern der Streit um den Lohn den Silai seinem Onkel versprochen hatte. Wenn die Sonne den Mond fängt, dann wird der Mond finster und die Menschen sagen: „Der Mond ist wieder von Geistern gefangen genommen worden", oder dann auch umgekehrt.

Die Bedeutung der Mondfinsternis. Man unterscheidet drei verschiedene Arten der Mondfinsternis. Man nennt diese Arten Raho. 124 Ist der verfinsterte Teil des Mondes ganz schwarz anzusehen, dann hat die Sonne den Mond mit einer eisernen Kette gefesselt. Man nennt diese Mondfinsternis Raho Bahuang (Bärenfinsternis, weil sie so schwarz ist wie das Fell eines Bären). Für die Menschen bedeutet diese Finsternis Misswachs und Hungersnot. Ist der verfinsterte Teil des Mondes rötlich anzusehen, dann nennt man diese Verfinsterung Raho Tambaga (Kupferfinsternis, weil sie so rot ist wie Kupfer). Der Mond soll dann mit einer kupfernen Kette, nach andern Versionen mit einer Kette von Achatsteinen gefesselt worden sein. Den Menschen bedeutet diese Finsternis eine anbrechende Zeit von Krankheiten und Seuchen. Ist die Verfinsterung aschfarbig (besser weiss, denn um diese drei Farben: Schwarz, Rot und Weiss geht es ja immer. Siehe Note 122), dann nennt man sie Raho Ambon (Nebelfinsternis). Der Mond ist dann mit einer silbernen Kette gebunden worden. Diese Verfinsterung bedeutet den Menschen eine glückliche Zeit. 
Das Verhalten der Menschen bei Sonnen- oder Mondfinsternis. Der Tag oder die Nacht der Finsternis ist heilig. Man arbeitet oder schläft nicht. An diesem Tage, oder in dieser Nacht, schlachtet man Hühner und Schweine und opfert sie. Man schlägt die Gong und die Trommeln, man tanzt und man lärmt. Man tut alles um die beiden kämpfenden Gruppen zu trennen und auseinander zu treiben. Denn sowohl von der Sonne als auch vom Mond geniessen die Menschen Segen und sie können es deshalb nicht zulassen, dass die Sonne oder der Mond gefangen genommen wird und dadurch seine für die Menschen am Flusse der Welt segensvolle Wirksamkeit einstellen muss. Bei der Mondfinsternis empfangen die Menschen von ihren Ahnen auch reiche, heilbringende Geschenke (karuhei).

\section{c. Der Verkehr mit der übersinnlichen Welt}

Wie die Vorzeichen entstanden: Die Mythe von Umang und dem Hirsch 125

Umang wollte sich mit Putir Busu, der jüngsten Tochter seines Oheims Maharadja, verheiraten. „Ich bin einverstanden mit deiner Werbung", sagte Putir Busu, ,aber nur unter der Bedingung, dass du den auf der Ueberseite des Flusses gelegenen Baum Rando Harawen Timpong (der Rando mit Kleiderstoffen als Blätter) besteigst!"Umang machte sich sogleich auf den Weg. Er ging um den Berg Tundjong Njaho herum und fand auf dem Wege, am Fuss des Berges, die Reichtum und Glück bringenden karuhei tatau, die er zu sich nahm und in seinen Korb legte den er auf seinem Rücken mittrug. Als er beim Baume Rando Harawen Timpong angekommen war, bestieg er ihn sofort und nahm von seinen Blättern, die aus goldenen Tüchern bestanden, so viele $\mathrm{zu}$ sich als er $\mathrm{zu}$ tragen vermochte. Als er die Krone des Baumes erreicht hatte, sah er auf der Ueberseite des Flusses seine Braut die zum täglichen Bad zum Landungsfloss hinunterstieg. Er jauchzte ihr zu. Plötzlich hörte er wie ihm jemand antwortete. Dreimal jauchzte er und dreimal erhielt er auch Antwort und er verwunderte sich sehr darüber. Nach einiger Zeit stieg er mit den goldenen Tüchern beladen wieder vom Baume herunter. Als er nach seinem Korbe, der die Karuhei tatau enthielt, suchte, fand er ihn nicht mehr, er war spurlos verschwunden obgleich sich kein Mensch in seiner Nähe aufgehalten hatte der ihn hätte stehlen können. Er suchte ihn überall aber er fand ihn nicht mehr. Aber als er wieder um sich schaute erblickte er plötzlich einen Hirsch. Er näherte sich ihm, aber das Tier ergriff die Flucht. 
Daraufhin kehrte Umang zu Putir Busu zurück und brachte ihr als Beweis, dass es ihm gelungen sei den Baum zu besteigen die goldenen Tücher mit, worauf sie in die Heirat einwilligte.

Einige Zeit nachdem dies geschehen war begaben sich die Banjawei auf die Jagd hinter das Dorf Batu Nindan Tarong. Ihr Hund witterte die Spur eines Tieres und schlug an. Die Jäger verfolgten die Spur und fanden ein Tier wie sie zuvor noch keines gesehen hatten und dessen Name ihnen auch nicht bekannt war. Sie erlegten es und brachten es ins Dorf zurück. Dann riefen sie die Bewohner aus drei umliegenden Dörfern zusammen, damit sie ihnen raten und sagen sollten wie das Tier heisse, dass sie als Jagdbeute mitheimgebracht hatten.

Auch Umang befand sich unter den Versammelten. Als er das Tier gesehen hatte, sagte er: „Dieses Tier hier kenne ich wohl, es ist entstanden aus meinem Korbe und den darin befindlichen Karuhei tatau die ich am Berge Tundjong Njaho fand. Sein Name ist Hirsch. Ich rate, dass wir das Tier in zwei Hälften schneiden und aus der einen einen männlichen Hirsch, aus der andern einen weiblichen Hirsch schaffen". Der Rat des Umang wurde befolgt. Das Tier wurde in zwei Teile zerschnitten und die fehlenden Hälfte ersetzte man von Erde die man der Gestalt des Hirsches entsprechend nachformte. So entstanden aus dem einen Hirsch zwei, ein männlicher und ein weiblicher.

Darauf sprach Umang: „Nun wollen wir den Tieren die Freiheit schenken und wollen sie $z \mathfrak{u}$ den Menschen senden die am Ufer des Flusses der Welt wohnen damit sie ihnen auf der Reise, bei den Feldarbeiten, bei Hochzeiten und Geburten und allen wichtigen Ereignissen und Perioden in ihrem Leben Vorzeichen geben nach denen sich die Menschen richten können. Wenn aber die Menschen die Geschichte vom Ursprung des Hirsches wissen, dann sind sie glücklich und ihr Leben gestaltet sich zu einem heilvollen. Vernehmen sie den Schrei des Hirsches, dann müssen sie ihm ein Opfer schlachten das aus einem roten Huhn 126 besteht und dieses Opfer müssen sie in ein Gestell legen das die Form eines Hirsch-Kinnbackens hat".

\section{Tunggol Samali}

Eines Tages schnallte sich Tunggol Samali seinen Pfeilköcher um, ergriff das Blaserohr und begab sich auf die Jagd nach dem Berge Tundjong Njaho. Er verirrte sich aber und fand den Heimweg nicht mehr. Als er so herumirrte sah er plötzlich ein Haus das ihm bewohnt schien. Er betrat es und zu seiner grossen Verwunderung sah er in 
ihm nur eine einzige Frau, aber keinen Mann und auch keine Kinder. Er fragte sie deshalb: „Wem gehört dieses Haus?“ „Mir“, antwortete die Frau. „Wo sind die Männer", fragte Tunggol Samali, „denn hier wohnen doch sicher auch Männer". „Es sind keine hier, ich bewohne das Haus allein“, entgegnete die Frau. „Wie heissest du?" so fragte er sie weiter. Sie sprach: „Ich bin der weibliche Vorzeichenvogel (bawin dahiang, dass kann auch heissen: der Vorzeichenvogel, oder die Aelteste der Vorzeichenvögel) vom Berge Tundjong Njaho". Darauf verheiratete Tunggol Samali sich mit ihr und er blieb bei ihr im Hause und dachte nicht mehr zu den Seinigen zurückzukehren. Nach einiger Zeit wurde die Frau schwanger. Tunggol Samali hielt sich schon monatelang bei ihr auf, endlich entschloss er sich wieder einmal in sein Dorf und $\mathrm{zu}$ seinen Verwandten zurückzukehren. Und eines Tages sprach er zu seiner Frau: „Du wirst nun bald einem Kinde das Leben schenken, deshalb möchte ich gerne für kurze Zeit nach Hause zurückkehren um das Tuch Badjanda Tulis Tukis Takadjika, das gewoben wurde vom Frosche im Fluss, zu holen damit du dir mit ihm nach der Geburt den Unterleib einbinden kannst“. „Es ist gut so“, entgegnete die Frau, ,aber bleibe nicht lange weg, denn du weisst, dass mir dein Wegbleiben bei der Geburt Unheil bringen würde“. „Nein“, sagte Tunggol Samali, ,in sieben Tagen werde ich wieder zurück sein, eher wirst du keinem Kinde das Leben schenken". Daraufhin reiste er weg und kam bald in seinem Dorfe an. Wie waren seine Verwandten und Freunde erfreut als sie ihn wieder sahen, denn sie hatten sich um sein Schicksal sehr besorgt gemacht und sie dachten nichts anderes, als dass er auf der Jagd ums Leben gekommen sei. Sie fragten ihn: „Wo bist du auch so lange geblieben?" Und Tunggol Samali erzählte ihnen was ihm begegnet war, nämlich, dass er sich auf der Jagd im Wald verirrt hätte und dass er nach einiger Zeit des vergeblichen Suchens und Herumirrens zu einem Hause gekommen sei, das von dem weiblichen Vorzeichenvogel vom Berge Tundjong Njaho bewohnt war und dass er sich mit ihm verheiratet habe und dass seine Frau von ihm nun ein Kind erwarte und er nun deshalb ins Dorf zurückgekehrt sei um für sie das Tuch Badjanda Tulis Takadjika, das gewoben wurde vom weiblichen Frosch im Fluss, zu holen. Aber seine erfreuten Verwandten bereiteten ihm ein grosses Fest und liessen ihn lange Zeit nicht seines Weges ziehen und nach Hause zurückkehren. Die sieben Tage verstrichen, Tunggol Samali hielt sich immer noch in seinem Dorfe auf. Inzwischen hatte nun seine Frau in der einsamen Hütte geboren. Aber was gebar sie, wie war ihr Kind gestaltet! Sie gebar abgestorbene 
Baumäste, gebrochene $Z$ weige, Schlangen, Leguane, Gürteltiere, Bakotok- und Patisvögel.

Nach einiger Zeit kehrte Tunggol Samali endlich wieder zu seiner Frau zurück. Als er das Haus betrat und seine Frau sah, da merkte er, dass sie bereits geboren hatte. Er schaute sich verwundert nach seinem Kinde um, aber er sah es nirgends. Da sprach seine Frau zu ihm: „Schau im Reisbehälter nach, dort habe ich unser Kind untergebracht!" Er war sehr erstaunt über diese merkwürdigen Worte seiner Frau, denn kleine Kinder pflegt man sonst nicht in Reisbehältern unterzubringen. Aber er tat wie sie ihn geheissen hatte. Er begab sich zum Reisbehälter und schaute nach. Merkwürdige Dinge sahen seine Augen. Er sah die abgestorbenen Baumäste, die gebrochenen $Z_{\text {weige, }}$ die Schlangen, Leguane und Gürteltiere, die Bakotok- und Patisvögel. Als er alle diese Dinge gesehen hatte begann er zu lachen und kehrte sich nach seiner Frau um. Aber sie sprach zu ihm mit ernster Stimme: „Lache nicht, denn das sind wirklich unsere Kinder die ich geboren habe. Ich habe dich ja gebeten mich nicht zu lange zu verlassen weil dies während der Zeit der Schwangerschaft pali ist. Du hast meine Bitte missachtet und dein Versprechen nicht erfüllt. Du bist nicht in sieben Tagen zurückgekehrt wie du sagtest, dass du es tun wollest und weil ich einsam und allein, verlassen von dir, meinem Manne, geboren habe, deshalb sind unsere Kinder nun so gestaltet und geartet. Sie sollen aber doch nützlich sein, denn wir senden sie zu den Menschen am Ufer des Flusses der Welt und sie werden ihnen als Vorzeichen dienen nach denen sie sich richten können. Wenn ein dürrer Ast vom Baume fällt oder ein grüner $Z$ weig abbricht, wenn eines dieser Tiere schreit oder einer dieser Vögel pfeift, sei es bei der Geburt oder Hochzeit, beim Tod oder beim tiwah (Totenfest), bei der Bestellung des Feldes oder bei den Arbeiten im Wald, auf der Reise oder beim Kauf oder Verkauf von heiligen Töpfen, dann müssen die Menschen diese Vorzeichen beachten und müssen sich nach ihnen richten und sie müssen ihnen Opfer darbringen. Befinden sie sich aber auf der Reise, dann ist es nicht notwendig, dass sie opfern, aber sie müssen die Erzählung vom Ursprung der Vorzeichen rezitieren. Glücklich und heilvoll ist der Mensch der diese Geschichte kennt. Er wird nicht krank werden und kein Unheil wird ihn treffen. Sein Leben wird glücklich und heilvoll verlaufen".

Der Ursprung des Antang nach Missionar Becker 127

Der Tato, das heisst der Stammvater des angesehenen Antangge- 
schlechtes (d.h. der Falken) ist ein gewisser Sambila-Tiong, ein reicher Sohn eines kahaianischen Häuptlings, der in früheren Zeiten lebte. Dieser Sambila-Tiong war es, der zuerst das später unter den Dajak so in Gebrauch gekommene Kopfabschneiden (die Kopfjagd) einführte. Seine Mutter hatte ihn beim Absterben ihres Mannes dazu angereizt. Sie wollte sich nicht eher zufrieden geben bis sie ein Menschenhaupt hätte. Das abgehauene Haupt würde das Fest erhöhen und der Geist (besser: Seele) des Enthaupteten würde dem gestorbenen Häuptling als Sklave beigegeben werden um ihn nach der Lewu Liau (Totendorf) zu begleiten. Sambila-Tiong war dem Befehl seiner Mutter gehorsam. An einem frïhen Morgen versah er sich mit lundjo (Speer) und mandau (Schwert), ferner mit etwas gekochtem Reis, den er in ein Pisangblatt einwickelte und er wanderte auf einem schmalen und einsamen Pfade in das nahe Gebirge. Hier angekommen verbarg er sich in einem einsamen Gebüsch dicht am Wege und lauerte still und begierig auf eine Beute. Nachdem er hier eine kurze Zeit hatte warten müssen, erschien abwärts am Bache ein Reisender, welcher ein Päckchen auf dem Rücken trug. Als dieser nun den Bach durchwatet hatte näherte er sich eilig und ganz arglos der Stelle an welcher SambilaTiong sich verborgen hielt. Dieser rührte sich nicht, sondern liess den armen Wanderer ruhig an sich vorüberziehen, fiel ihn dann plötzlich von hinten an und stiess ihm dergestalt seinen Speer in die Seite, dass derselbe nach vorne auf die Erde fiel. Es war von des Angefallenen Seite nicht daran zu denken Gegenwehr zu bieten, denn noch ehe er seine Geistesgegenwart wieder erlangt hatte, rollte das losgeschnittene Haupt vor die Füsse des Mörders. Hastig nahm dieser es bei den aufgelösten Haaren vom Boden auf, verbarg es in seinem rabat (Rückenkorb) und kehrte mit seiner Beute noch an demselben Tage nach Hause zurück, wo seine Mutter ihn erwartete. Unverzüglich wurden nun die nötigen Vorbereitungen zu dem tiwah (Totenfest) gemacht, und als man damit nach Verlauf eines Monats weit genug vorgerückt war, so wurden die Gäste in grosser Zahl eingeladen. Aber siehe da, was sich da ereignete! Am Glanzpunkt des Festes, als das Dorf widerhallte vom Gesang der Balian, als Schuss auf Schuss (aus Kanonen) das Gebäude erschütterte, als die Menge weithin hörbar jubelte und die Sangen: die heiligen Gesänge des Magah Liau (der Reise der Seele nach dem Totendorf) höher und höher stiegen, da wurde Sambila-Tiong plötzlich in einen antang (Falken) verwandelt und flatterte mit seinen roten Flügeln über den Köpfen der Balian und des oloh magah liau (des Seelenleiters) hin und her, bis er endlich die 
offene Türe erreichte, worauf er sich, nachdem er durch die Türe geflogen, in die Höhe schwang, darnach einige Augenblicke in grossen und weiten Ringen über dem Dorfe schwebte und zuletzt nach den stillen Ufern der danau (Binnensee) sich begab von wo aus er später sich durch seine zahlreichen Nachkommen ausbreitete, nicht nur über diese ganze grosse Insel, sondern über den ganzen Indischen Archipel.

\section{Der Ursprung des Antang nach Missionar Hupe 128}

Als erste Bewohner der Landschaft Pulau Petak und als Stammvater der gegenwärtig dort wohnhaften Bevölkerung nennen die Dajak den Antang und seine zwei Brüder Patingi und Patigi-Djuking. Diese drei lebten und sind begraben in Djuking, einer Flussbiegung im Gebiete von Pulau Petak. Antang war unsterblich. Aber als er das Alter von 200 Jahren erreicht hatte begann er einzuschrumpfen, wurde mit Federn überdeckt und bekam Flügel und Klauen an Stelle seiner Hände und Füsse. Da kamen seine Nachkommen zu ihm und fragten ihn: „Von welchem Wasser hast du getrunken, dass du Unsterblichkeit erlangt hast?" Er antwortete ihnen: „Lasst mich auf das Wasser herunterkommen und ich werde mich in einen Vogel verwandeln und in dieser Gestalt werde ich auch weiterhin über euch herrschen. Wenn ihr, meine Angehörigen, meine Hülfe nötig habt, streut dann Reis um euch hin und ich werde kommen und euch beistehen und helfen". Seine Nachkommen nahmen ihn, brachten ihn in ein Boot und liessen ihn im Wasser untersinken. Aber er erhob sich wieder aus dem Wasser als der Raubvogel Antang und er vermehrte sich so, dass nun beinahe jedes Dorf seinen eigenen Antang besitzt, einige einen weissen, andere einen schwarzen (wieder andere einen roten) die alle für das Gedeihen und Heil des Dorfes sorgen und die bei wichtigen Ereignissen und Handlungen durch die Bewohner angerufen werden.

\section{Mythen zum Totenkult der Ngadju-Dajak}

1. Weshalb der Mensch sterblich ist

a. Die Geschichte von Ranjing Pahatara (Die Mythe stammt vom Katingan)

Lahatala hat alle Dinge erschaffen, nur die Menschen und die Erde erschuf er nicht. Ranjing Pahatara und seine Frau Andin Bamban, die Stellvertreter und Boten des Lahatala, besichtigten die ganze Schöpfung und sie sprachen: „Es ist nicht gut, wenn alle diese Dinge da sind 
aber keine Menschen geschaffen werden die sie nützen können". Eines Tages ging Ranjing Pahatara segeln. Er fand sieben Eier von Erde, nahm sie zu sich und zerschlug sie und formte aus ihnen eine männliche und eine weibliche Gestalt. Aber diese Gestalten besassen keine Knochen und hatten keinen Atem und waren deshalb schwach und leblos. Er brachte sie heim und eines Tages begab er sich wieder auf die Reise um für die Menschen Steinatem und Steinknochen zu suchen. Während er sich auf der Reise befand kam Peres. Er erkundigte sich bei Andin Bamban: „Wo ist dein Mann?" Sie antwortete ihm: „Er hat sich auf die Reise begeben um für diese beiden menschlichen Gestalten da Steinatem und Steinknochen zu holen“. „So“, sagte Peres, „das ist nicht gut was Ranjing Pahatara da unternehmen will. Es ist besser, wenn wir diese Menschen da beleben, denn siehst du, wenn ihre Knochen und ihr Atem von Stein genommen sind, dann haben diese Menschen ewiges Leben, sie können nicht sterben und bald wird deshalb die Welt für sie zu klein sein. Es ist besser wenn sie nur kurze Zeit in der Welt leben und dann sterben und später wieder für kurze Zeit auf sie zurückkommen. Es ist besser wenn sie kommen und gehen und dann wiederum kommen“. Erstaunt fragte Andin Bamban: „Wie soll das aber möglich sein ?" Peres antwortete: „Der Leib ist von Erde, den Atem nehmen wir vom Wind, die Knochen schnitzen wir aus Holz und das Blut nehmen wir vom Wasser". „Es ist gut so“, sagte Andin Bamban. Sie fing nun etwas Wind ein für den Atem und schöpfte etwas Wasser für das Blut während inzwischen Angoi, der Onkel des Rangang Tingang, aus Holz die Knochen schnitzte. So schufen sie die ersten Menschen die alsbald zu atmen und zu leben begannen. Aber sie hatten noch keine Haare, keine Zähne und keine Nägel.

Nach kurzer Abwesenheit kam Ranjing Pahatara wieder zurück und er sah sofort was inzwischen geschehen war. Er fragte seine Frau: „Wie geschah es, dass diese Menschen lebendig wurden?" Sie erzählte ihm was Peres geraten und was sie zusammen unternommen hatten. „Es ist gut und recht so", antwortete Ranjing Pahatara und darnach schnitzte er von den Steinen die er mitgebracht hatte Nägel, Zähne und Haare und machte sie an den Menschen fest.

Am Anfang aber schwebten die Menschen in der Höhe. Sie hatten noch keinen Ort auf dem sie sich niederlassen konnten. Nach einiger Zeit ging Ranjing Pahatara auf den Fischfang aus. Er fing eine Naga (Seeschlange) die er unter den schwebenden Menschen ausbreitete. Sobald diese die Schlange sahen sprangen sie auf ihren Körper her- 
unter der sich alsbald in Erde verwandelte die sich mehr und mehr ausdehnte. Auf ihr mehrten sich die Menschen und wurden zu einem grossen Geschlecht.

Nach einer andern Version dieser gleichen Erzählung liess Ranjing Pahatara Erde auf eine Naga herunterfallen die zur Welt und zum Aufenthaltsort der Menschen wurde. Die Schlange lebt noch unter der Erde. Wenn sie sich bewegt dann entstehen Erdbeben. Man bringt ihr Opfer dar bei allen wichtigen Ereignissen und Handlungen.

\section{b. Weshalb das Lebenswasser verloren ging}

In früheren Zeiten lebten an den Ufern des Flusses der Welt zwei Kinder reicher Eltern, ein Knabe und ein Mädchen. Die Eltern hatten sich gegenseitig versprochen, dass sie einst die Kinder verheiraten wollten, sobald sie dazu das Alter erreicht hätten. Als der Knabe zu einem Jüngling und das Mädchen zu einer Jungfrau herangewachsen war, erfüllten sie das gegenseitige Versprechen und rüsteten sich zu einem grossen Hochzeitsfest. Das Brautpaar wurde mit Opferblut bestrichen und dann hielt es sich während der vorgeschriebenen Palizeit ruhig im Hause auf. Sie gingen nicht aus, sie arbeiteten nicht, sondern hielten die Pali in der richtigen Weise inne. Als sie abgelaufen war gingen sie zum Fluss hinunter und fingen zusammen Bata- und Saloangfische und verbrachen zum Zeichen, dass die Palizeit vorbei sei, ein Stück Rotan und ein Stück Holz.

Noch war kein Monat verstrichen seit der Hochzeit als die junge Frau krank wurde. Die Krankheit steigerte sich immer mehr. Die Eltern streuten den Geistern Reis, töteten zahlreiche Schweine und Hühner und legten Gelübde ab, aber die Krankheit wollte nicht weichen, sie nahm immer mehr zu. Die Frau nahm einen Tag lang keine Speise zu sich, auch am zweiten Tage wollte sie nichts essen und so ging es weiter bis am siebenten Tage. Niemand kannte mehr das einst so schöne und blühende Mädchen, denn es war zum Skelett abgemagert. Am achten Tage sah man, dass sich ihr Zustand sehr verschlimmerte. Um die Mittagszeit hörte man plötzlich dreimal dumpfes Donnerrollen und nun wussten die Angehörigen, dass die Kranke nicht mehr zu retten sei, denn ihr naher Tod war durch den Donner angekündigt worden. Kurz darauf starb sie.

Ihr Mann sagte zu seinem Schwiegervater und zu seinen Angehörigen: „Ich halte es vor Herzeleid und Kummer nicht mehr aus in meinem Haus, ich muss weg von hier. Ich begebe mich auf die Jagd in der Richtung des Bukit Raja (höchster Berg des Schwanergebirges, 
er ist heilig 129) um meine Gedanken zu zerstreuen, aber ich verbiete euch die Leiche aus dem Hause zu bringen bis ich wieder zurückgekehrt bin“. Dann ergriff er das Blaserohr, gürtete den Pfeilköcher und Dolch um, rief seinen Hunden und verliess das Haus. In seinem grossen Herzeleid lief er wie ein Blinder und Tauber durch den Wald. Er schaute weder hinter sich, noch vor sich. Er sah nicht was zu seiner Rechten war und was sich zu seiner Linken befand. Unaufhörlich lief er ruhelos weiter durch den Wald nach dem Bukit Raja, denn er wollte dort das Lebenswasser holen um mit ihm seine junge tote Frau wieder ins Leben zurückzurufen. Nach drei Tagen kam er am Fuss des Berges an. Er bestieg ihn und kam schliesslich zu einem überhängenden Felsen der auf einem Reisstampfer ruhte. Unter ihm lag die Quelle des Lebenswassers. Da es ihm nicht gelang hinunterzuklettern suchte er ein Bambusrohr, machte eine Oeffnung und liess es an einem Seil zur Quelle hinunter um etwas von dem Lebenswasser aufzuschöpfen. Aber der Bambus schlug sofort aus und trieb Schosse. Darauf nahm er einen Holzstab und höhlte ihn aus, aber auch dieser schlug aus und trieb Schosse. Wiederum war seine Mühe vergeblich gewesen. Schliesslich nahm er ein kleines Steinkrüglein das er bei sich hatte und nun gelang es ihm auch etwas von dem Lebenswasser aufzuschöpfen. Froh verliess er den Bukit Raja wieder und freudig eilte er durch den Wald zurück nach seinem Dorf, hatte er doch gefunden was er suchte und konnte er nun doch seine junge tote Frau wieder ins Leben zurückrufen!

Inzwischen hatten seine Angehörigen auf ihn gewartet. Als er aber nach drei Tagen immer noch nicht erschien und die Leiche schon sehr stark in Verwesung übergegangen war, fällten sie einen Baum und schnitzten aus dem Stamme den Sarg in den sie die Leiche legten. Immer noch war der Mann nicht zurückgekehrt. Da sprach sein Schwiegervater su seinen Angehörigen: „Mein Schwiegersohn scheint nicht mehr heimzukommen. Gewiss hat er sich im Walde verirrt und ist umgekommen. Wir halten es wegen des Leichengeruches im Hause nicht mehr aus, deshalb schlage ich vor, dass wir noch während dieser Nacht auf meinen Schwiegersohn warten. Kommt er nicht zurück, dann bringen wir morgen den Sarg aus dem Hause heraus und verbrennen ihn mit der Leiche auf dem dafür bestimmten Platz unterhalb des Dorfes". Die Anwesenden stimmten seiner Rede bei und nochmals sassen sie eine Nacht lang um den Sarg herum und beklagten die Tote. Aber auch in dieser Nacht stellte sich der Mann nicht ein. Am Morgen taten sie wie sie beschlossen hatten. Einige schlachteten die Tiere und 
rüsteten für die Gäste das Essen. Andere schichteten unterhalb des Dorfes den Holzstoss auf. Alles war bereit. Alle hatten gegessen. Sie verliessen mit dem Sarg das Haus und verbrannten die Leiche auf dem Holzstoss. Dann sammelten sie die Asche und die Knochen in einen Topf und legten ihn in der Nähe des Pambak nieder.

Kaum waren sie mit diesen Arbeiten fertig geworden da kehrte der Mann zurück und fragte sie: „Wo habt ihr den Leichnam meiner Frau?" Sie erzählten ihm was sie über seine Abwesenheit gedacht und was sie inzwischen getan hatten. Darauf ging der Mann zum Pambak. Er breitete dort ein siebenfach gefaltetes Tuch 130 aus und schüttete die Asche und die Knochen seiner Frau darauf. Dann goss er etwas Lebenswasser darüber und sprach: „Wenn du miaust, dann wirst du eine Katze werden. Wenn du bellst, dann wirst du dich in einen Hund verwandeln (das heisst in der Folgordnung, in der die Urmutter nach andern Mythen die Haustiere und die ersten Menschen geboren hat. Siehe oben). Wenn du aber niesest, dann wirst du wieder deine frühere Gestalt erhalten". Nach diesen Worten erzitterten die Knochen plötzlich, berührt durch das über sie ausgegossene Lebenswasser und sie fügten sich $z u$ einer menschlichen Gestalt zusammen. Aber wie sah seine früher so schöne und liebliche Frau aus! Ihr Körper war schwarz, ihre Knochen schienen verkohlt zu sein und sie konnte weder sprechen noch sehen. Der Mann erschrak sehr als er diese Erscheinung sah und er rief vor Zorn und Herzeleid aus: „Du wirst nicht mehr so werden wie du zuvor warst weil man dich verbrannt hat. Deine Gestalt beschämt mich und deshalb ist es besser wenn du nicht ins Leben zurückgerufen wirst". Dann goss er wieder etwas Lebenswasser über sie aus und sprach dazu: „Falle wieder auseinander zu Knochen und Asche”. Seine Worte erfüllten sich sogleich.

Er verliess den Platz und lief wie ein Rasender davon und schrie vor sich her: „Ich werde den Zugang zum Lebenswasser zerstören damit niemand mehr durch eitle Hoffnungen betrogen wird wie ich es wurde, denn das Lebenswasser vermochte meiner Frau nicht mehr die frühere Gestalt zurückzugeben“. Er füllte einen Korb mit djakangsamen und kehrte mit ihm zum Bukit Raja zurück. Als er bei der Stelle ankam von wo aus man das Lebenswasser erreichen konnte, streute er den Baumsamen aus und nach kurzer Zeit überwuchs ein dichter Wald hoher Urwaldbäume den Ort. Von dieser Zeit an vermochte niemand mehr zum Lebenswasser durchzudringen und der Weg zu ihm ging verloren und mit ihm auch die Unsterblichkeit des Menschen. 
Nach einer andern Version dieser Mythe stieg der Mann, bei der Stelle angekommen, an einer Schlingpflanze die den Zugang zum Wasser bildete, hinunter zur Quelle. In seinem Zorn durchschnitt und vernichtete er sie, sodass der Zugang für alle Zeit unmöglich gemacht war.

2. Die Abwendung des vorausgewussten Todes (Mythen zum stellvertretenden Opfer)

\section{a. Mangapatong Liau oder Taloh}

Der Traum ist eine Gabe der Ahnen. Im Traum offenbaren sie dem Menschen Glück und Unglück. Im Traum deuten sie ihm Gegenwart und Zukunft. Durch den Traum leiten sie ihn auf rechtem Wege, geben ihm Ratschläge bei allen wichtigen Entscheidungen und öffnen ihm den Weg zum Glück und Reichtum. In Palizeiten, wie z.B. nach dem Tode eines Angehörigen, hat man keine Träume. Die Verbindung mit den Ahnen ist durch das eingetretene Unheil verbrochen und wird erst nach den Reinigungsopfern (siehe die Texte zum Tantolak Matei im zweiten Teil dieses Bandes) wieder hergestellt. Dann finden wir auch den stereotypen Ausdruck: „Wenn die Waisen, die verlassenen Kinder, wieder gute Träume haben werden, dann werden sie die Vorbereitungen treffen für die Feier des tiwah" (Totenfest). Das heisst: durch die guten Träume, diese Gabe der Ahnen, wird es möglich sein, dass sie sich die nötigen Reichtümer versammeln, dass sie mit gutem Resultat Handel treiben und Gewinn machen und dass sie mit Erfolg. ausziehen auf die Kopfjagd. Diese Dinge kann der Mensch nicht aus sich selbst tun, er bedarf dazu der Leitung und Führung seiner überweltlichen, allmächtigen und alleswissenden Ahnen und diese Leitung und Führung geschieht durch den Traum. Aus diesem Grunde ist auch eine der wichtigsten und am meisten wiederholten Bitten oder Segenswünsche die um gute Träume, oder um gute Vorzeichen. Ein aus dem Stamme Ausgeschlossener und ein Verfluchter hat keine Träume mehr. Sein Leben ist haltlos, zufällig, ohne Führung, ohne Leitung, ohne Heimat, weil er aus der Gemeinschaft der Lebenden und der Ahnen ausgeschlossen ist. Kein Traum erhellt mehr sein Leben, kein Vorzeichen leitet seinen Fuss.

Was der Mensch im Traume erlebt ist Wirklichkeit wie das Leben selbst. So wie die guten Träume mit günstiger Vorbedeutung in Erfüllung gehen, so gehen auch die schlechten Träume in Erfüllung. Hat ein Mensch geträumt, dass er sich in der Gesellschaft der liau 
(Tote) befand oder dass diese ihn eingefangen haben, oder dass sie seine Seele abholten um sie nach dem Totendorf zu begleiten, oder träumt er diese Dinge von einem Andern, dann ist das ein untrügliches Zeichen, dass der Träumer, oder dieser Andere von dem man geträumt hat, innerhalb drei Tagen eine Leiche sein wird und dass die lian (Toten) ihn nach dieser Zeit abholen werden.

Hat man aber geträumt, dass man von taloh (Siehe die BasalohMythen) gefangen genommen worden sei, oder dass man sich in ihrer Gesellschaft befand, oder träumte man, dass man auf irgend eine Weise schwer verwundet worden sei, sodass die Seele dadurch den Körper verliess, oder dass man durch einen fallenden Baum getötet wurde (unreifer oder unnatürlicher Tod), oder träumte man das von einer andern Person, dann ist das ein Zeichen, dass der Träumer oder die andere Person durch den Einfluss von taloh (Geister) sterben muss.

Von diesem drohenden Unheil kann man sich nun befreien und man kann das was im Traume vorausgesagt wurde und das sich unbedingt erfüllen wird, auf einen Andern übertragen, auf einen Stellvertreter, nämlich auf einen hampatong: ein kleineres Schnitzbild, dass der Träumer, oder die Person von der man geträumt hat, beseelen muss und das dadurch seine Gestalt annimmt und sich, ihn vertretend, den Liau oder Taloh ausliefert. Damit stehen wir vor einer Reihe der wichtigsten stellvertretenden Opfer der Dajak deren mythologische Begründung hier folgt.

Ist einem Menschen im Traum das oben beschriebene Schicksal vorausgesagt worden, dann sucht man am andern Morgen einen Menschen auf der die Handlungen und Zeremonien, die für das stellvertretende Opfer notwendig sind, kennt und die zu zitierenden Mythen, die die Handlungen nicht nur darstellen sondern auch bewirken, weiss. Was er in der Mythe ausspricht ist nicht nur ein einmaliges, zeitgebundenes Geschehen, das unwiederholbar wäre, nein, es wiederholt sich bei jeder neuen Rezitation. Der Kundige führt dieses Geschehen durch sein Wissen und durch die Rezitation, immer wieder als das einst in der Urzeit geschehene, aber eben wiederholbare Ur. geschehen, neu herbei. Diesen Kundigen, der kein Priester zu sein braucht, nennt man Tukang Mangadiri (tukang: Meister, Eingeweihter, Kundiger, Wissender; mangadiri: austauschen, auslösen, vertreten).

Ist die auszulösende Person weiblichen Geschlechtes, dann schnitzt man aus bestimmtem Holz drei menschliche Figuren 131 und bekleidet sie mit alten Kleiderfetzen der Träumerin, bezw. der Person von der man geträumt hat. Ist die auszulösende Person ein männliches Familien- 
glied, dann schnitzt man drei männliche Figuren die man ebenfalls mit Kleiderfetzen des Träumers, bezw. der andern Person, bekleidet. Diese drei Schnitzbilder legt man in einer Reihe vor die auszulösende Person nieder. Wenn das geschehen ist schlachtet man ein Opferhuhn und legt es, zusammen mit gekochtem Reis, Sirih und Tabak auf eine Reisworfelmatte nieder.

Nachdem diese Vorbereitungen beendigt sind setzt sich der Tukang Mangadiri vor dem Kranken nieder und rezitiert eine der zahlreichen Mythen die den Vorgang des ersten stellvertretenden Opfers, das in der Urzeit dargebracht wurde, neu herbeiführt.

Von den zahlreichen Mythen, die alle inhaltlich fast gleich lauten und auch die gleiche Tendenz und Wirkung haben, gebe ich hier die bekanntesten und am meisten gebrauchten wieder.

Sind alle Handlungen vollzogen, dann legt man den hampatong liau (das Schnitzbild für die Toten) beim Sandong nieder. Hat man aber von Taloh geträumt, dann wird der hampatong taloh hinter das Haus in den Busch gebracht. Dort ist der Wohnort der Taloh und dort wird der Hampatong auch weggeworfen für die Taloh.

\section{Die Geschichte von Patih Teteh und Akah Ihang Iho}

Der Tukang Mangadiri rezitient in eintönigem, langgezogenem Gesang: Eines Tages gingen Patih Teteh und seine Frau Akah Ihang Jho nach einem kleinen Flüsslein am Fuss des Berges Liang Kalamiting (befindet sich in der Oberwelt) um dort dem Fisch- und Krebsfang obzuliegen, denn sie hatten keine Zuspeise mehr zu ihrem Reis. Sie fingen zahlreiche Krebse und Fische und kehrten mit ihrem Fang nach Hause zurück um ihn für die Mahlzeit zu rüsten und zu braten.

Während sie aber mit dieser Arbeit beschäftigt waren betrat plötzlich ein junger Tiger das Haus und sprach zu ihnen: „Ich möchte gerne mit euch zusammen essen, euere Speise duftet herrlich und hat mich angezogen und zu euch hergeführt“. Patih Teteh antwortete: „Es ist uns recht, du kannst mit uns die Mahlzeit einnehmen wenn du gerne willst". Daraufhin setzten sich die Drei um das Essen herum und nahmen ihre Mahlzeit ein. Nachdem sie sich gesättigt hatten und nachdem der Sirih herumgereicht worden war, sprach der junge Tiger : „Ich möchte gerne bei euch bleiben, denn es gefällt mir hier. Ich bitte euch, nehmt mich als euer Kind auf und werdet mir Vater und Mutter". Seine Bitte wurde angenommen und so blieb der junge Tiger fortan im Hause des Patih Teteh wo er durchaus als ihr Kind betrachtet und behandelt wurde. Der junge Tiger war sehr schön. Er benahm sich 
durchaus wie ein Mensch und er begleitete seinem Vater oft auf seinen Reisen und $z u$ seiner Arbeit. Eines Tages hatte sich Patih Teteh schon frühmorgens vom Hause wegbegeben und war auf die Jagd gegangen. Der Tiger schlief noch als er das Haus verliess. Als er erwachte und als er seinen Vater nirgends gewahrte, fragte er seine Mutter: „Wo ist mein Vater?" Sie antwortete ihm: „Er ist auf die Jagd gegangen“. Daraufhin sprach der Tiger: „Ich möchte meinem Vater gerne nachfolgen, denn ich sehne mich nach ihm“. „Du kannst das tun", antwortete die Mutter. Darauf verliess er das Haus und folgte den Fusspuren seines Vaters nach. Er kam ihm näher und immer näher. Plötzlich hörte Patih Teteh, dass ihm im Walde ein Tier nachschlich. Er erschrak sehr und wandte sein Angesicht um um zu sehen was es für ein Tier sei, das ihn verfolge. Er sah den Tiger und erschrak noch mehr. Rasch griff er nach seinem Speer, zielte gut und schleuderte ihn ohne sein Ziel zu verfehlen. Das Tier sank schwer verwundet zusammen, dann erhob es seinen Kopf und sprach mit brechenden Augen und schwacher Stimme: „Du hast Schweres getan, o mein Vater. Ich sehnte mich nach dir und ich verfolgte deine Spuren um dich rasch zu erreichen und nun hast du mich mit deinem Speer getötet". Wie erschrak Patih Teteh als er diese Worte hörte und in seinem Herzeleid sprach er: „Bist du es denn, o mein Kind? Ich hörte ein Geräusch hinter mir, ich wandte mich um und sah dich, aber ich vermochte dich in meinem Schrecken nicht zu erkennen. Ich glaubte es sei ein Tier, das mich verfolgen wolle, deshalb warf ich den Speer nach dir". Kaum hatte er diese Worte gesprochen da verschied der Tiger. Patih Teteh kehrte sofort nach Hause zurück und erzählte seiner Frau was geschehen war und auf welche Weise ihr Kind den Tod gefunden hatte. Akah Ihang Iho wurde in ihrem Herzen sehr zornig über die Tat ihres Mannes, aber sie verbarg ihren Zorn. Aber als Patih Teteh sich zum Schlafe niedergelegt hatte stieg in ihr der Gedanke auf ihn zu töten. Sie ergriff ein Stück Holz und schlug ihm damit auf die Nase bis sein Atem den Körper verlassen hatte. Nicht lange darnach kehrte die Reue in ihr Herz ein. Sie beklagte den Toten und sie bereitete alles vor für die Verbrennung der Leiche. Als die Flammen den Holzstoss ergriffen und die Leiche zerstörten und der Rauch sich auf die Erde senkte und darüber hinwegstrich, da sagte sie zu sich selbst: „Ich will dem Rauche nachfolgen. Ich will meinem Manne in die Lewu Liau (Totendorf) nachgehen. Vielleicht gelingt es mir ihn auf irgend eine Weise wieder auf diese Welt zurückzubringen. So ging sie dem Rauche nach. Als sie schon einige Zeit 
durch den Busch und über zahlreiche Hügel hinweggegangen war hörte sie plötzlich einen Jauchzer. Sie folgte der Richtung aus der er gekommen war und schon nach kurzer Zeit kam sie zu einem breiten Weg. Auf diesem Weg ging sie nun weiter. Nach einiger Zeit sah sie Menschen (es waren natürlich Liau) die mit den Vorbereitungen für die Feldarbeiten beschäftigt waren und den Wald von allem grossen und kleinen $\mathrm{Holz}$ säuberten. Sie riefen $\mathrm{ihr} z \mathfrak{u}$ : „Wohin gehst du, Akah Ihang Iho?" Sie antwortete ihnen: „Ich folge meinem Manne Patih Teteh nach, habt ihr ihn nicht gesehen?" Sie sprachen: „In diesem Augenblicke ist er von hier weggegangen. Sein ausgespuckter Speichel ist noch nicht trocken, aber hilf du uns bevor du deinen Weg fortsetzest bei unserer Arbeit!" Sie half nun bei den Arbeiten mit, aber weil sie alles verkehrt machte, denn in der Lewu Liau (Totendorf) ist alles verkehrt und alle Arbeiten werden ebenfalls verkehrt ausgeführt, schickten sie die Leute wieder fort. Bald darauf kam sie an eine Stelle wo sie Leute sah die mit dem Niederlegen der grossen Bäume beschäftigt waren weil sie dort ihr neues Reisfeld anlegen wollten. Als sie sie bemerkten riefen sie ihr zu: „Wohin gehst du, Akah Ihang Iho?" Sie antwortete ihnen: „Ich folge meinem Manne nach, ist er wohl hier vorbeigekommen?" Sie antworteten: „Eben in diesem Augenblicke ging dein Mann von hier weg, sein Speichel hier auf der Erde ist noch nicht einmal trocken. Hilf uns aber bevor du weitergehst bei unserer Arbeit". Sie half mit, aber weil sie auch hier alles verkehrt machte, wurde sie weggeschickt. Darnach kam sie nach kurzer Zeit zu einem Reisfeld auf dem die Leute das Unkraut ausjäteten. Sie riefen ihr zu: „Wohin gehst du, Akah Ihang Iho?" Sie antwortete ihnen: „Ich folge meinem Manne nach, ist er nicht hier vorbeigekommen?" „Doch", antworteten sie, ,,in diesem Augenblicke ist er von hier weggegangen. Sein Speichel ist selbst noch nicht einmal trocken. Hilf uns aber zuerst beim Jäten unseres Feldes". Sie tat wie sie gebeten worden war, aber weil sie alles verkehrt machte schickten sie die Leute wieder weg. Wieder ging sie auf dem breiten Wege weiter und sie kam nach kurzer Zeit zu einem Felde auf dem die Leute mit der Ernte beschäftigt waren. Sie fragten sie: „Wohin gehst du Akah Ihang Iho?" Sie antwortete ihnen: „Ich folge meinem Manne nach, ist er nicht vor kurzer Zeit hier bei euch vorbeigekommen?" Sie antworteten ihr: „In diesem Augenblicke erst ist er von hier weggegangen, sein Speichel ist noch nicht trocken, hilf du uns aber zuerst bei der Ernte unseres Reises". Sie half mit, aber weil sie auch hier alle Arbeiten verkehrt ausführte schickten sie die Leute weg. Nicht 
lange war sie auf dem Wege weitergegangen als sie in die Nähe eines alleinstehenden Hauses kam. Vor ihm angekommen rief sie mit lauter Stimme: „O ihr, o ihr, wem gehört dieses Haus?" Eine alte Frau, in der sie ihre Grossmutter Pulang Henda erkannte, trat vor die Türe und antwortete ihr: „Es ist mein Haus, aber sage mir Akah Ihang Iho, wohin willst du dich denn begeben?" Sie erzählte ihrer Grossmutter was geschehen war und dass sie im Begriffe stehe ihrem Manne nachzufolgen um ihn wieder auf die Welt zurückzubringen. Pulang Henda entgegnete: „Tritt in mein Haus ein. Du müsstest sterben wenn du deinem Manne nachfolgen und seinen Wohnort erreichen würdest. Ich will dir aber gerne helfen damit du dein Ziel erreichen kannst". Als sie ins Haus eingetreten waren setzte sie ihre Rede fort: „In drei Tagen kommt dein Mann, begleitet von einer Schar weiblicher Liau um hier in der Nähe in einem Teiche zu baden. Ich will ihn zum Essen einladen. Du bereitest die Mahlzeit und machst den Sirih zum Kauen bereit und nimmst dafür Blätter die deinen Mann betäuben. Nachdem er gekaut hat wird er sofort einschlafen. Bevor er aber das Haus betritt musst du den Querbalken hier besteigen und dich dort gut verstecken. Ich übergebe dir hier dieses Haarnetz. Sobald du siehst, dass dein Mann in Schlaf gefallen ist wirfst du dieses Netz über ihn. Er wird sofort aufwachen und zu dir sprechen: „Ich verwandle mich in einen Tiger des Hügels um dich zu verzehren". Du antwontest ihm: „Es ist mir recht, denn wenn ich sterbe, dann kann ich doch bei dir bleiben“. Er wird darauf sagen: „Ich verwandle mich in eine Giftschlange um dich zu beissen". Du antwortest: „Es ist mir recht so“. Dann wird er sprechen: „Ich verwandle mich in einen männlichen Nashornvogel um dir die Augen auszupicken“. Antworte ihm: „Es ist mir recht so". Dann wird er schliesslich sagen: „Ich verwandle mich in das Ei eines Nashornvogels". Antworte ihm: „Tue das ja nicht, denn ich kenne deine verderblichen Gedanken wohl". Daraufhin wird er sich in ein Ei verwandeln. Du ergreifst es schnell, legst es in ein Körblein und flüchtest mit ihm an den Fluss der Welt zurück". Am dritten Tage tat Akah Ihang Iho wie Pulang Henda sie geheissen hatte. Sie machte die Mahlzeit und den Sirih bereit, dann ergriff sie das Haarnetz und kletterte auf den Querbalken über dem Fussboden wo sie sich gut versteckte, sodass sie von niemandem gesehen werden konnte. Kaum hatte sie sich verborgen da betrat Patih Teteh mit einer Schar weiblicher Liau das Haus um seine Grossmutter zu besuchen. Kaum hatte er das Haus aber betreten, da rief er erschrocken und verwundert aus: „Kaja-kajah! Grossmutter, in deinem Hause riecht 
es ja nach einem Menschen“. „Du irrst dich“, sprach Pulang Henda, „in meinem Hause riecht es immer so wenn ich mich nach der Weise der Frauen nicht wohl fühle. Setze dich nun mein Enkel und nimm die Speisen zu dir die ich dir bereitet habe". Patih Teteh setzte sich und kaum hatte er einen Bissen zu sich genommen, da rief er verwundert aus: „Leha-lehan! Grossmutter, das Essen ist zubereitet wie es mir jeweils durch meine Schwester (die Frau nennt man auch Schwester) Akah Ihang Iho zubereitet wurde“. „Bezweifelst du meine Worte?" fragte die Grossmutter, „,ich bin es doch die dir das Essen zubereitet hat. Wie sollte uns denn Akah Ihang Iho, die noch nicht einmal gestorben ist, sondern immer noch am Flusse der Welt wohnt, hier im Totendorf besuchen können?" Nach dem Essen griff Patih Teteh nach dem Sirihbesteck und bestrich ein Blatt mit Kalk, griff nach einem Stück Pinang (Betelnuss) und schob beides in seinen Mund. Nicht lange darauf fiel er in tiefen Schlaf. Die weiblichen Liau wollten wieder nach Hause zurückkehren und sie versuchten ihren Gefährten aufzuwecken, aber ihre Mühe war vergeblich. Da sprach Pulang Henda zu ihnen: „Geht nur ruhig nach Hause. Lasst Patih Teteh schlafen, wenn er aufwacht wird er euch nachfolgen". Nach diesen Worten verliessen die Liau das Haus und traten den Heimweg an. Nachdem nun Patih Teteh schlafend allein im Hause zurückgeblieben war, tat Akah Ihang Iho wie sie von Pulang Henda unterwiesen worden war. Sie warf das Haarnetz über ihren Mann. Er erwachte sofort, richtete sich auf und erkannte seine Frau und sprach zu ihr drohend: „Ich verwandle mich in einen Tiger des Hügels um dich zu töten“. „Es ist mir recht so, denn wenn du mich tötest, dann kann ich doch bei dir bleiben“, antwortete seine Frau. „Ich verwandle mich in eine Giftschlange um dich zu beissen“. „Es ist mir recht so“, war ihre Antwort. Er sprach wiederum: „Ich verwandle mich in einen männlichen Nashornvogel um dir die Augen auszupicken“. „Es ist mir recht so", antwortete sie, „denn wenn ich blind bin, dann kann ich den Heimweg nicht mehr finden und ich muss bei dir bleiben". Er sprach darauf: „Ich verwandle mich in das Ei eines Nashornvogels". "Tue das ja nicht", rief Akah Ihang Iho erschrocken aus, „denn ich kenne deine Gedanken wohl!" Kaum hatte sie diese Worte ausgesprochen, da hatte sich ihr Mann bereits in das Ei eines Nashornvogels verwandelt. Sie ergriff es sofort und legte es in ein Körbchen das sie bereit gestellt hatte. Dann verabschiedete sie sich dankend von ihrer Grossmutter Pulang Henda und diese sprach zu ihr: „Wenn du mein Haus verlassen hast, dann schlage den Patikbaum bei der 
Treppe um. Bist du in der Mitte des Weges angekommen, dann wirf diesen Kamm, den ich dir hier übergebe, hinter dich. Sobald du, am Flusse der Welt angekommen, dein Haus wieder betreten hast, dann schnitze dir aus Bindang- und Siungbambus drei männliche Figuren die du mit Kleiderfetzen von Kleidern deines Mannes bekleidest. Daraufhin schlachtest du ein Huhn, kochst schwarzen Klebreis und bereitest etwas Sirih. Das alles legst du auf eine Reismatte und sprichst darüber die Worte aus: „Dieses hier habe ich zubereitet um meinen Mann aus dem Tode auszulösen". Darnach bringst du die geschnitzten Figuren mit den Opfergaben zum Sandong (Knochenhäuschen) und legst sie dort nieder. Die Liau, die dich verfolgen werden um deinen Mann zurückzuholen, werden an seiner Stelle diese geschnitzten Figuren mitnehmen die seine Gestalt und sein ganzes Wesen angenommen haben. Daraufhin legst du das Ei auf ein siebenfach gefaltetes Tuch und sprengst etwas Lebenswasser darüber und alsogleich wird dein Mann wieder lebendig vor dir stehen".

Nach diesen Worten und Ratschlägen verliess Akah Ihang Iho das Haus ihrer Grossmutter Pulang Henda. Bei der Treppe angekommen schlug sie den Patikbaum um und rasch eilte sie weiter um die Lewu Liau (Totendorf) zu verlassen und an den Fluss der Welt zurückzukehren.

Nach einiger Zeit wurden die weiblichen Liau unruhig, denn Patih Teteh blieb zu lange aus. Sie kehrten ins Haus der Pulang Henda zurück und sie vernahmen von ihr was sich inzwischen ereignet hatte. Sie antworteten mit erschrockener und zorniger Stimme: „Wohlauf, wir wollen Akah Ihang Iho verfolgen und Patih Teteh zurückholen“. „Das hat keinen Sinn mehr", sprach Pulang Henda, „seht ihr nicht den Patikbaum bei der Treppe meines Hauses! Akah Ihang Iho hat ihn, als sie die Flucht ergriff, umgeschlagen und nun schlägt er schon wieder neue Triebe aus. Es ist also schon viel zu lange her seit sie von hier weggegangen ist und ihr Vorsprung ist ein viel zu grosser, ihr werdet sie nicht mehr einholen". „Das macht nichts aus", entgegneten die Liau, ,,wir wollen sie trotzdem verfolgen“. Sie verliessen sofort das Haus und nahmen die Verfolgung auf.

Akah Ihang Iho war noch nicht sehr weit entfernt vom Hause ihrer Grossmutter als sie plötzlich das Geschrei der Liau vernahm die sie zu suchen schienen. Sie erschrak sehr in ihrem Herzen und beschleunigte die Flucht. Nach einiger Zeit kam sie zu einem Flüsslein das sie überqueren musste. Bei ihren zu raschen und zu unvorsichtigen Bewegungen fiel ihr das Ei aus dem Körblein und versank sofort im 
Wasser. Sie sprang ihm nach und tauchte unter um es zu suchen. Inzwischen waren aber auch die Liau angekommen. Als sie sahen, dass Akah Ihang Iho im Flusse untertauchte, begannen auch sie zu tauchen um nach dem verlorenen Ei zu suchen. Sie erschrak sehr in ihrem Herzen als sie das sah, aber plötzlich hörte sie wie ihr der Vogel Bamban zurief: „Tirok-tirok!" (Such mit einem Bambus, such mit einem Bambus). Rasch schnitt sie aus einem nahe gelegenen Bambusgesträuch einen Stab und tastete mit ihm den Grund des Flüssleins ab und plötzlich fühlte sie, dass sich in der Höhlung des Stabes etwas festgeklemmt hatte. Es war das verlorene Ei. Sie ergriff es rasch und als die Liau wieder untertauchten verliess sie still und unbemerkt den Fluss und setzte ihre Flucht fort. Nach einiger Zeit gewahrten die Liau, dass Akah Ihang Iho nicht mehr mitsuchte und dass sie auch nirgends mehr zu bemerken war. „Hau, hau!" riefen sie, ,gewiss hat sie das Ei gefunden und ist mit ihm davongeschlichen. Wir wollen sie verfolgen, denn es hat keinen Wert, dass wir uns länger hier aufhalten". Nach kurzer Zeit hörte Akah Ihang Iho die Stimmen der Liau wieder hinter sich. Sie erinnerte sich des Rates ihrer Grossmutter und warf den Kamm, den sie von ihr erhalten hatte, hinter sich. Er verwandelte sich sofort in eine hohe Wand. Als die Liau an dieser Stelle des Weges ankamen versuchten sie die Wand zu übersteigen, aber es gelang ihnen nicht. Sie beratschlagten was sie nun zu tun hätten und sie entschlossen sich schliesslich durch die Wand eine Öffnung zu kratzen. Inzwischen aber war Akah Ihang Iho in ihrem Dorfe am Flusse der Welt angekommen und hatte ihr Haus betreten. Sie tat wie ihr ihre Grossmutter geraten hatte und schnitzte rasch von Bindanund Siungbambus drei männliche Figuren die sie mit Fetzen von den Kleidern ihres Mannes bekleidete. Darauf schlachtete sie ein Huhn und kochte schwarzen Klebreis und bereitete etwas Sirih. Das alles legte sie auf eine Reismatte und sprach darüber die Worte aus: „Dieses hier habe ich zubereitet um die Seele (hambaruan) meines Mannes aus dem Tode auszulösen". Darnach brachte sie die Figuren mit den Opfergaben zum Sandong und legte sie dort nieder. Dann kehrte sie ins Haus zurück und legte das Ei auf ein siebenfach gefaltetes Tuch, schüttete etwas Lebenswasser darüber und plötzlich stand ihr Mann wieder lebendig vor ihr.

Nach einiger Zeit gelang es den Liau in der Wand eine Oeffnung zu kratzen. Sie krochen hindurch und sie erreichten auch bald die Hütte des Patih Teteh am Flusse der Welt. Dort sahen sie ihn als Leiche langausgestreckt beim Sandong liegen. Sie ergriffen ihn und 
verliessen jauchzend den Platz und kehrten mit grosser Freude und mit lautem Jubel mit ihm in das Totendorf zurück. Als sie beim Hause der Pulang Henda angekommen waren, sprach diese zu ihnen, um ihre Freude etwas zu dämpfen: „Weshalb jauchzt ihr eigentlich so sehr? Schaut doch einmal was ihr da mitgebracht habt! Das ist ja gar nicht Patih Teteh, das ist ja nur sein Stellvertreter den Akah Ihang Iho geschnitzt hat. Wenn von nun an die Menschen träumen, dass sie von euch verfolgt, oder dass sie durch euch gefangen genommen worden seien, oder dass sie durch euch abgeholt wurden um nach dem Totendorf begleitet $\mathrm{zu}$ werden, dann können sie sich von diesem Schicksal auslösen und sie können sich vertreten lassen wenn sie solche hampatong (Schnitzbilder) machen und wenn sie zuvor diese Mythe (sansana) rezitieren. Ihr werdet dann den Menschen jeweils verfolgen, gefangen nehmen oder nach dem Totendorf abholen, aber ihr werdet immer nur seinen Stellvertreter finden den ihr nach der Lewu Liau (Totendorf) bringen müsst. Den Menschen aber wird kein Leid geschehen".

\section{Die Geschichte des Panetang Nupi}

Eine andere Mythe die durch den Tukang Mangadiri oft auch an Stelle der oben mitgeteilten rezitiert wird ist die des Panetang Nupi. In manchen $Z$ ügen weist sie viel Übereinstimmung auf mit der Mythe vom Ursprung der Sonnen- und Mondfinsternis. Die Mythe lautet:

Panetang Nupi war ein Mann der in früheren Zeiten gelebt hat. Alles was ihm im Leben widerfahren sollte, Glück und Unglück, Grosses und Kleines, Gutes und Schlechtes, wurde ihm immer zuvor im Traume offenbart. Bis heute nennt man solche Leute, denen im Traum alles mitgeteilt wird, Panetang Nupi.

Eines Nachts sah sich Panetang Nupi wieder im Traum. Er wanderte im Walde und während er so davonschritt hörte er die Axthiebe von Leuten die offenbar mit der Fällung eines Baumes beschäftigt waren. Es schienen ihrer nicht wenige zu sein. Er hörte im Traume wie der Baum krachend auf die Erde fiel und wie ihm darauf die Leute die Äste abhieben. Er ging langsam weiter und kam dem Arbeitsplatze immer näher. Als er ziemlich nahe war rief er den Leuten zu: „Hoi, hoi! ihr, was tut ihr dort?“ „Wir machen einen Sarg für Panetang Nupi, denn alles was geschieht wird ihm immer zuvor im Traume mitgeteilt; wir wollen diesen Alleswisser ums Leben bringen", so riefen sie zurück. Er begann zu zittern vor Angst und 
erwachte und vermochte hernach den Schlaf nicht mehr $z u$ finden, denn er musste unaufhörlich daran denken wie er wohl dem vorausgesagten Tode entrinnen könne. Er sagte $z u$ sich selbst: „Das ist doch ein schwerer und inhaltsvoller Traum gewesen den ich da soeben gehabt habe. Wenn ich an ihn denke, dann schmerzt mich mein Herz, denn ich weiss ja nur zu gut, dass alles was mir bis jetzt im Traume offenbart wurde, immer auch in Erfüllung gegangen ist. Kein Traum war bis jetzt inhaltslos und ohne Bedeutung. Auch dieser wird in Erfüllung gehen wie die früheren Träume auch. Ich bin doch sehr unglücklich, denn ich weiss nicht was ich tun soll".

Panetang Nupi hielt es nicht mehr in seinem Hause aus. Nirgends war es ihm mehr wohl, denn wo er ging und stand da musste er unaufhörlich an seinen Traum denken. Er flüchtete sich in den Wald um Zerstreuung zu suchen. Er ging einen Tag, er irrte einen zweiten im Walde herum. Weit und breit waren keine Menschen und befanden sich auch keine Hütten, nur der dichte Urwald umgab ihn. Plötzlich schlug ein Laut an sein Ohr und er hörte deutlich: „Tik-tek, tik-tek“. „Hau", sagte er zu sich selbst, "offenbar sind doch noch andere Menschen im Wald und sie fällen einen Baum. Können es aber wohl Menschen sein? So weit vom Dorf entfernt fällt doch niemand Bäume. Gewiss sind es Geister (taloh)". Er überlegte, ob er sich dem Platze nähern oder ob er sich flüchten wolle, denn er war ganz allein und sollte ihm Gefahr drohen, dann war es ihm unmöglich sich ihrer zu erwehren. Er überwand seine Furcht und entschloss sich den Weg fortzusetzen um so nahe als möglich an die Arbeitenden heranzukommen. Von weitem rief er: „Hoi, ihr, was macht ihr dort"? Sie riefen ihm zurück: „Wir machen einen Sarg für Panetang Nupi, dem alles was geschieht immer zuvor im Traume mitgeteilt wird. Nun wollen wir diesen Alleswisser ums Leben bringen und darauf seine Leiche in diesem Sarge wegschaffen". Er verhielt sich still, um sich nicht $z u$ verraten, und sagte betrübt $z u$ sich selbst: „Mein Traum ist also doch wahr und er wird in Erfüllung gehen. Meine Augen haben es nun selbst gesehen und meine Ohren haben es selbst gehört. Alles stimmt genau mit meinem Traume überein, nun weiss ich sicher, dass ich sterben muss". Wie sollte ihn nicht das Herzeleid ergriffen haben als er dies alles bedachte! Er kehrte so rasch wie möglich in sein Dorf und Haus zurück und er erzählte seiner Mutter was er geträumt- und was nun seine Augen auch selbst gesehen hatten und was seine Ohren im Walde hörten. Auch seine Mutter ergriff das Herzeleid, denn sie wusste, dass alle Träume ihres Sohnes in Erfüllung gehen mussten. 
Nach einiger Zeit des Nachdenkens sagte die Mutter zu ihrem Sohn: „Es kommt mir ein Gedanke. Begib dich zu deinem Grossvater, der in dem und dem Dorfe, ferne von hier, daheim ist. Bitte ihn um einen Rat, denn er ist ein Mann grossen Verstandes und tiefer Gedanken. Sein Wort trifft gewöhnlich das Richtige und was er sagt ist wahr. Mache dich sobald wie möglich auf den Weg um ihn zu besuchen“. „Gut“, sagte der Sohn, ,ich will meinen Grossvater besuchen, ich will ihm meinen Traum erzählen und ihn um einen Rat bitten". Er machte sich für die Reise bereit, dann stieg er zum Anlegefloss hinunter, schöpfte dort das Wasser aus dem Boot heraus und ruderte von seinem Dorfe weg. Auf seiner Fahrt flussabwärts sah er einen Sangkoangbaum am Ufer. Dieser rief ihm zu: „Wohin gehst du, Panetang Nupi ?" Er antwortete: „Ich rudere flussabwärts um meinen Grossvater $\mathrm{zu}$ besuchen und ihn wegen meines bösen Traumes um Rat zu fragen“. „So“, sagte der Sangkoangbaum, „bitte ihn doch auch für mich um einen Rat, denn wenn Leute in ihren Ruderbooten flussaufwärts reisen, dann stechen sie mit ihren Stechbäumen immer wieder in meinen Stamm um an mir ihr Boot abzustossen. Sie verwunden mich und sie zerstören mein Leben, deshalb trage ich Herzeleid. Frage doch deinen Grossvater was zu tun sei, damit das nicht mehr geschehe und ich von meiner Not und meinem Herzeleid befreit werde. Willst du das für mich tun?" „Ja“, entgegnete Panetang Nupi, ,ich will auch für dich um Rat fragen".

Als er wieder weiter reiste kam er nicht lange darnach $z \mathfrak{u}$ einem Bambanstrauch (eine Sorte Bambus), der ihm zurief: „Wohin deines Weges, o Panetang Nupi ?“ Er antwortete ihm: „Ich reise zu meinem Grossvater um ihn wegen meines Traumes um Rat zu fragen". Da sprach der Strauch: „Willst du deinen Grossvater auch für mich um Rat fragen? Siehst du, ich bin sehr betrübt, ich lebe hier am Ufer des Flusses, aber mein Leben ist ein kümmerliches und trauriges, ich kann nicht gross und schön werden, sondern bleibe immer klein und elend. Frage ihn doch, was zu tun sei, damit ich gedeihen kann wie meine Verwandten auch“. „Ich will deinen Auftrag gerne ausrichten“, antwortete ihm Panetang Nupi. Darauf setzte er seine Reise wieder fort und sah nach kurzer Zeit in einem Wassertümpel ein einziges Saloangfischlein unruhig hin- und herschwimmen. Der Fisch rief ihm und fragte: „Wohin gehst du, Panetang Nupi ?" Er antwortete: „Ich besuche meinen Grossvater, um ihn wegen meines Traumes um Rat zu fragen“. Da bat der Fisch: „Bitte ihn doch auch für mich um Rat. Ich bin in diesem Wassertümpel gefangen und kann nicht zum Fluss 
zurückkehren, sondern muss hier elend umkommen. Frage ihn doch was zu tun sei, damit ich gerettet werden kann“. „Ich will gerne für dich fragen", antwortete Panetang Nupi und setzte seine Reise fort.

Nach einiger Zeit erreichte er das Anlegefloss seines Grossvaters. Er hielt an, band sein Boot fest und machte sich auf den Weg nach dem Haus das fern vom Flusse lag. Als er seines Weges dahinging gewahrte er einen Bambusstrauch der ihn fragte: „Wohin deines Weges, Panetang Nupi?" Er antwortete ihm : „Ich will meinen Grossvater besuchen und will ihn wegen meines Traumes um Rat fragen". „Willst du nicht auch für mich um Rat fragen", bat der Bambusstrauch, ,denn siehst du, ich trage grosses Leid in meinem Herzen. Ich lebe hier, aber ich kann nicht hoch und schön werden wie die andern Sträucher. Mein Leben ist dürftig und elend. Frage ihn doch was zu tun sei, dass ich gedeihen kann“. Panetang Nupi antwortete: „Ich will gerne für dich fragen“. Er setzte seine Reise fort. Auf seinem Wege begegnete er nach einiger Zeit einem Krokodil, das ihn fragte: „Wohin deines Weges, Panetang Nupi ?" Er sagte : „Ich besuche meinen Grossvater um ihn um Rat zu fragen wegen meines schlechten Traumes". Da sprach das Krokodil: „Bitte ihn doch auch für mich um einen Rat. Ich habe mich auf meinem Wege verirrt und ich kann nicht mehr zum Flusse zurückkehren und wenn mir nicht geholfen wird dann muss ich hier im Walde elend umkommen. Frage ihn was zu tun sei damit ich den Rückweg wieder finden kann“. „Ich will gerne für dich fragen", antwortete Panetang Nupi und er setzte seine Wanderung fort.

Als er einige Zeit weitergegangen war sah er einen Hirsch der sich mit seinem Geweih in Schlingpflanzen verwickelt hatte und sich nicht mehr daraus zu befreien vermochte. Der Hirsch rief ihm zu: „Wohin gehst du, Panetang Nupi ?“ Er entgegnete ihm: „Ich besuche meinen Grossvater um ihn um Rat zu fragen wegen meines bösen Traumes". Da sagte der Hirsch: „Du siehst, dass ich mit meinem Geweih in diesen Schlingpflanzen verwickelt bin. Frage ihn doch auch für mich, was zu tun sei, dass ich wieder frei werden kann, denn sonst muss ich hier umkommen“. „Ich will gerne für dich um Rat fragen“, sprach Panetang Nupi und er setzte seine Reise fort.

Nicht lange war er auf dem schmalen Buschpfade dahingegangen, da sah er einen Orang Utan der seine Hand zwischen Ästen festgeklemmt hatte und sich nicht mehr frei zu machen vermochte. Das Tier sprach ihn an: „Wohin gehst du, Panetang Nupi ?" Er erzählte $\mathrm{ihm}$, dass er seinen Grossvater besuchen und ihn wegen eines un- 
günstigen Traumes um Rat fragen wolle. Da sprach der Orang Utan: „Frage ihn doch auch für mich um Rat. Ich habe hier meine Hand eingeklemmt und ich kann sie nicht mehr loslösen. Wenn mir kein Rat und keine Hülfe wird, dann muss ich hier sterben“. „Ich will gerne für dich um einen Rat bitten", antwortete Panetang Nupi. Er ging wieder weiter und kam an den Rand eines Feldes das die Leute eben vom Busch gesäubert hatten. Sie liessen das Holz nun zum Trocknen liegen um es nach einigen Tagen verbrennen zu können. Mitten im Felde aber stand ein hoher Fruchtbaum der ihm zurief: „Wohin gehst du, Panetang Nupi ?" Er antwortete ihm : „Ich besuche meinen Grossvater um mir von ihm Rat zu holen, denn ich habe einen sehr schlechten Traum gehabt“. Da bat der Fruchtbaum: „Frage ihn doch auch für mich um einen Rat. Ich stehe hier noch ganz allein mitten im Felde. Wenn die Besitzer das trockene Holz verbrennen, dann werden die Flammen auch mich ergreifen und ich muss elend umkommen. Frage ihn, was zu tun sei, damit mein Leben gerettet wird“. „Ich will gerne für dich um Rat fragen“, antwortete Panetang Nupi und er setzte seine Reise fort.

Nach kurzer Zeit erreichte er das Haus seines Grossvaters und er fragte die Leute, die er dort sah : „Ist mein Grossvater wohl daheim?" „Ja“, antworteten sie ihm, ,er liegt dort drinnen in seiner Kammer und schläft. Aber weshalb willst du ihn eigentlich besuchen?" Er erzählte ihnen ausführlich seinen Traum und er sagte ihnen auch was ihm auf dem Wege begegnet war und wer ihn ebenfalls gebeten hatte den Grossvater um Rat zu bitten. „Es ist gut so“, antworteten seine Verwandten, „setze dich nur auf den Fussboden und warte bis dein Grossvater aufgewacht ist, damit du ihm deine Bitten vorbringen kannst".

Panetang Nupi setzte sich und wartete geduldig. Schon wollte die Sonne untergehen aber sein Grossvater war immer noch nicht erwacht. $\mathrm{Da}$ verlor er die Geduld. Er konnte es nicht mehr aushalten so lange $z \mathfrak{u}$ warten und er stiess seinen Grossvater in die Seite. Aber er erwachte nicht sondern schlief weiter wie zuvor. „Han!" sprach Panetang Nupi, „es ist unbegreiflich wie tief mein Grossvater schläft. Ich muss auf alle Fälle versuchen ihn aufzuwecken". Er ergriff ein Stücklein Eisen und machte es im Feuer glühend und als es heiss und glühend war stiess er es in das Ohr seines Grossvaters. Nun erwachte er endlich und gab einen verdrossenen Laut von sich. Dann schlug er langsam seine Augen auf. „Sitz auf, Grossvater", sagte Panetang Nupi. Aber nur widerwillig setzte sich der Alte auf. Er öffnete seinen Mund nicht. 
Weder begrüsste er seinen Enkel, noch fragte er ihn woher er komme und welches Anliegen ihn zu ihm herführe. Nun konnte es der Enkel nicht mehr aushalten. Er erzählte ungefragt seinem Grossvater den Traum der ihn quälte und er berichtete ihm was seine Augen gesehen und was seine Ohren im Wald gehört hatten. Er erzählte ihm auch was ihm auf dem Wege begegnet war und wer ihn alles gebeten hatte von ihm ebenfalls einen guten Rat zu erbitten. Dann setzte er sein Gespräch fort und sagte: „Nun bin ich hier, o mein Grossvater. Ich bitte dich, sage mir doch was ich tun soll, dass sich dieser Traum nicht an mir erfüllt, denn siehst du, ich bin der Panetang Nupi. Alles was geschieht wird mir immer zuvor im Traume mitgeteilt und alle meine Träume erfüllen sich in meinem Leben. Gib mir doch auch einen Rat für alle die, die mich baten von dir Rat und Hilfe mitzubringen, damit auch sie gerettet werden können". Wohl hörte der Grossvater alle seine Worte und seine Bitten aber er tat seinen Mund nicht auf. Er fragte nichts und sagte nichts, unbeweglich sass er da. „Ich begreife nicht", sagte Panetang Nupi zu sich selbst, ,weshalb mir mein Grossvater nicht antworten will, weshalb er mir nicht sagt ob er mich verstanden habe oder nicht und warum er mir und auch denen die mich um Hilfe baten keinen Rat geben will". Lange noch sass er seinem Grossvater gegenüber, aber er blieb immerfort still und sass unbeweglich wie zuvor da ohne auch seinen Enkel nur einmal anzusehen. „Ich muss diesem Benehmen ein Ende machen", sagte er zu sich selbst, „denn nun halte ich es nicht mehr aus. Ich könnte hier noch lange sitzen bleiben aber mein Grossvater würde mir dennoch keine Antwort geben. Das Beste wird sein wenn ich dieses Haus wieder verlasse und auf einem andern Wege mein Ziel doch zu erreichen versuche". Er verabschiedete sich von seinem Grossvater und seinen Verwandten und verliess das Haus und er tat wie wenn er zum Flusse zurückkehren wollte. Aber nach kurzer Zeit kehrte er auf einem Umweg wieder zum Haus zurück und er bestieg in seiner Nähe einen hohen Baum von dessen Wipfel er das Innere des Hauses überblicken konnte und wo er auch jedes Wort verstand das in ihm gesprochen wurde. Er verhielt sich in seinem Versteck ganz still. Der Grossvater glaubte, dass sein Enkel wieder unverrichteter Dinge nach Hause zurückgekehrt sei und deshalb fragte er seine Angehörigen: „Wo ist mein Enkel Panetang Nupi?“ Sie antworteten ihm: „Er ist zum Flusse zurückgekehrt“. Darauf sprach er: „Mein Enkel Panetang Nupi ist wirklich dumm. Er spricht etwas viel von sich selbst. Er beschaut sich als verständig und gescheit und rühmt sich ein Panetang Nupi 
$z u$ sein. Aber wegen dieses Traumes weiss er sich nun nicht $z u$ helfen. Auch weiss er denen keinen Rat zu geben die ihn um Hülfe baten. Ist ein solcher Mann gescheit? Ich glaube viel eher, dass er dumm $z \mathfrak{u}$ nennen ist. Wenn er wirklich etwas verstehen würde, dann wüsste er doch auch was er zu tun hätte damit das ihm im Traume vorausgesagte Los nicht in Erfüllung geht. Wie machen wir es denn in einem solchen Falle? Wir schnitzen doch von Holz und Rotan eine menschliche Figur als Stellvertreter für unser bedrohtes Leben. Wir legen sie lange ausgestreckt hin wie man eine Leiche hinlegt und wir bekleiden sie wie man eine Leiche bekleidet. Dann bereiten wir das Essen zu. Wir töten ein Schwein oder ein Huhn, wir kochen den Reis und wir bereiten den Sirih damit alles für die Liau oder Taloh bereit ist wenn sie kommen um die Leiche abzuholen. Und dann kommen sie. Sie sehen das Essen und sie sagen: Es ist wirklich wahr, dass der Verstorbene gewusst hat, dass er sterben muss. Es ist ihm im Traume vorausgesagt worden. Er hat alles bereit gemacht, Speisen sind in Menge vorhanden. Er ist wirklich ein Panetang Nupi gewesen. Seht ihr dort nicht auch seinen lang ausgestreckten Leichnam daliegen! Darauf essen die Geister und wenn sie satt sind kauen sie den Sirih und darnach ergreifen sie die Leiche und legen sie in den mitgebrachten Sarg. Jauchzend und jubelnd verlassen sie den Ort und sie rufen vor sich her: ,Panetang Nupi ist gestorben, wir bringen seine Leiche mit uns'. Wenn wir es so machen, dann sind wir vom Tod, der uns im Traume vorausgesagt wurde, frei und erlöst". Panetang Nupi hörte auf dem Baume Wort für Wort. Er freute sich sehr, denn nun wusste er doch was er zu tun hatte. Er verhielt sich aber ganz still, denn sein Grossvater hatte noch nicht ausgesprochen, sondern er fuhr fort in seiner Rede: „Ja, was sollte Panetang Nupi wohl denen sagen, die ihn baten auch für sie um Rat zu fragen! Was sollte wohl dem Fruchtbaum im Reisfeld geantwortet werden? Man muss ihm so antworten: Treibe Blüten und setze rasch Früchte an, denn wenn der Besitzer des Feldes dies sieht, dann wird er den Platz um dich herum von allem Gras und dürren Holz säubern, damit er nicht um die gute Fruchternte betrogen wird. Auf diese Weise wirst du das Leben behalten und nicht mitverbrannt werden. Um den Orang Utan zu befreien muss man den Ast durchschlagen und die Hand aus der Einklemmung lösen. Darauf wird er zu seinem Befreier sprechen: Heil sei dir, es geschehe dir wie mir geschah. Sei frei von deinem bösen Traum. Das Geweih des Hirsches muss man aus den Schlingpflanzen lösen. Er wird dann frei werden und er wird ebenfalls sprechen: Heil sei dir, auch du 
sollst frei werden von deinem Unheil. Dem Krokodil muss man durch den Wald einen Weg zum Flusse schlagen dann kann es den Rückweg finden und wieder gerettet werden und es wird zu seinem Retter sprechen: So wie ich nun wieder frei geworden bin und nun wieder leben darf, so sei auch du frei von deinem Traum, dein Leben sei ein glückliches. Weshalb kann der Bambusstrauch nicht hoch und schön werden? Weshalb führt er ein so kümmerliches Leben? Unter seinen Wurzeln liegt ein grosser Schatz von Edelsteinen vergraben. Diesen muss man heben dann wird der Strauch in guter Erde Wurzel fassen können und er wird gedeihen. Der Schatz aber gehört seinem Retter und zudem wünscht ihm der Strauch noch: Heil sei deinem Leben! Dem Saloangfisch, der im Wassertümpel gefangen ist, muss man einen Weg zum Flusse graben dann kann er sich retten und so vom Tode befreien und er wird zu seinem Helfer sprechen: Du hast mich erlöst vom Tode, also sollst auch du erlöst sein, deinem Leben widerfahre Heil. Der Bambusstrauch lebt so kümmerlich und ärmlich weil er in einem Goldschatz Wurzeln gefasst hat. Dieser Schatz muss ausgegraben werden damit er in guter Erde wurzeln kann. Der Schatz gehört dem der ihn ausgräbt und der Strauch wird zu seinem Retter noch sprechen: Durch deine Hilfe, die du mir erwiesen hast, wird mein Leben nun glücklich und heilvoll werden. So geschehe auch dir der du mich erlöst hast. Zum Sangkoangbaum muss man sprechen: Bitte die schwarzen Wespen, dass sie an deinem überhängenden Aste ihr Nest bauen. Wenn die vorbeifahrenden Menschen dieses Nest sehen dann werden sie sich nicht mehr getrauen mit ihren Stangen ihr Boot an dir abzustossen, sie werden fortan still und vorsichtig an dir vorbeifahren um nicht die Aufmerksamkeit der Wespen auf sich $z \mathfrak{u}$ lenken. Der Baum wird darauf sprechen: Du hast mir geholfen und hast mich von meinem Herzeleid erlöst, so sei nun auch du erlöst von deinem bösen Traum und dem vorausgesagten Unheil". So sprach der Grossvater zu seinen Angehörigen und Panetang Nupi auf dem Baume freute sich über jedes Wort das er vernommen hatte. Laut jauchzte er vor Freude auf und er rief in das Haus hinein: „Nun ist mir Heil widerfahren, o mein Grossvater, ich werde nun handeln nach deinen Worten“. „Kai-kai!" rief der Grossvater erschrocken aus, „wie, mein Enkel befindet sich noch immer hier! Ich dachte doch, dass er nach Hause zurückgekehrt sei. Er ist wirklich nicht so dumm wie ich dachte, er ist ein gescheiter und schlauer Mensch. Er hat mich überlistet". Inzwischen war Panetang Nupi ins Haus eingetreten und trat vor seinen Grossvater hin zu dem er sprach: „Ich danke dir, mein Gross- 
vater, für dein Wort und deinen Rat die ich vernommen habe. Heil und Glück sei dir". Darauf verliess er das Haus und kehrte froh zum Fluss zurück. Allen, die ihn um Hülfe gebeten hatten, half er nach dem weisen Rat seines Grossvaters und so gewann er grossen Reichtum, viel Edelgestein und Gold, und alle, denen er geholfen hatte, wünschten ihm: „Du hast uns vom Verderben erlöst, du hast uns vom Tode befreit, du hast uns geholfen in unserer Not und unserem Leid, so sei nun auch du von deinem Traume frei und es widerfahre dir nur Glück und Heil in deinem Leben!" Nach kurzer Zeit kam er zu Hause an. Er tat wie er von seinem Grossvater gehört hatte. Er schnitzte drei männliche Figuren und er bekleidete sie so wie man eine Leiche bekleidet. Daraufhin brachte er sie zu einem Sarggestell und legte sie dort langausgestreckt nieder und neben sie die Speisen, die er zubereitet hatte. Inzwischen war die Sonne untergegangen. Nicht lange dauerte es, da hörte er das Gespräch der Geister die sich seinem Hause näherten um seine Leiche abzuholen .Obwohl sie alle gleichzeitig und durcheinander sprachen konnte er doch jedes Wort verstehen und er hörte wie sie zueinander sagten: „Has! wir wollen die Leiche des Panetang Nupi abholen. Er ist gestorben. Wir hören schon den dumpfen Laut der Gong der uns seinen Tod verkündet. Liegt nicht hier auch schon seine Leiche langausgestreckt in dem Haus. Sind nicht schon genügend Speisen (Opfer für den Verstorbenen) bereit. Kommt, wir wollen uns setzen und wollen essen. $\mathrm{Ja}$, er ist wahrlich ein Panetang Nupi gewesen, dem im Traume vorausgesagt worden ist, dass er sterben müsse, denn er hat alles zuvor gewusst und hat alles bereit gemacht".

\section{Die Handlungen nach der Rezitation der Mythe}

Nachdem der Tukang Mangadiri eine dieser beiden Mythen rezitiert hat legt er die Hand auf die drei menschlichen Figuren und spricht über ihnen die Worte aus :

Du hier, der du durch diesen N.N. hier (gemeint ist der Träumer oder die Person von der man geträumt hat) angefertigt worden bist, du hast seine Grösse und seine Breite, sein Antlitz und seine Augen, seine Kleider und sein Lendentuch, sein Wort und seine Aussprache. Aus diesem Grunde dienst du zum Austausch seiner Person. Alle schlechten Träume werden auf dich übertragen. Du übergibst dich an seiner Stelle den Liau (oder den Taloh) die dich abholen werden, damit er (der Träumer) frei sei und sie ihn nicht mehr abholen oder verfolgen. 
Nach diesen Worten übergibt der Tukang Mangadiri dem Träumer, bezw. der Person von der man geträumt hat, die menschlichen Figuren. Der Träumer spuckt sie nun dreimal an und spricht dabei :

Ich bin nun ausgelöst von allen schlechten Träumen. Sie sind auf dich übertragen. Ich bin frei.

Wenn das geschehen ist, dann stösst der Träumer die Hampatong (die menschlichen Figuren) mit seiner linken Hand dreimal von sich weg und spricht dabei:

Alle Dinge, die mir in dem schlechten Traum vorausgesagt worden sind, sind übertragen auf diese Hampatong hier. Meine Person ist mit ihnen vertauscht. Ich bin ausgelöst.

Nach dieser Handlung legt der Tukang Mangadiri die Figuren mit den Opfergaben beim Sandong nieder. Die Hampatong Taloh aber bringt man mit den Opferspeisen hinter das Haus. Der Träumer ist nun wieder frei. Er ist ausgelöst. Die Liau oder Taloh holen nur seinen Stellvertreter ab der durchaus seine Gestalt angenommen hat nachdem er vom Tukang Mangadiri besprochen- und vom Träumer beseelt (Kleider und Speichel) worden ist. Während dieser ganzen Handlung ist das Haus pali, es darf weder betreten noch auch verlassen werden.

\section{b. Das Mantumbal}

Mantumbal nennt man ein stellvertretendes Opfer das in drei bestimmten Fällen dargebracht wird, nämlich dann, wenn ein Mensch krank gemacht worden ist durch die Ganan Lunok (gana: Seele von leblosen Gegenständen, Pflanzen und Tieren, lunok: Waringin. Die Ganan Lunok sind die Geister des Lunokbaumes), ferner durch die Kalue und durch den Patisvogel.

\section{Mantumbal Lunok}

Dem Lunok oder Waringin wird durch die Dajak aller Stämme besondere Bedeutung zugemessen, wie überhaupt jedem Baum oder Strauch der eine kleberige oder milchige Flüssigkeit absondert. Der Lunok wird bewohnt von Geistern, den sogenannten Ganan Lunok oder Seelen des Lunok. Sie werden alle unter den Sammelnamen Njaring gebracht. 132 Sie bewohnen die Lunok in ganzen Familien deren einzelne Angehörigen oft gesehen werden oder die sich auch im Traume offenbaren können. Nach andern Anschauungen ist die Ganan Lunok ein einzelnes weibliches, unordentliches Wesen (siehe Erzählung 
unten). In der Nähe eines Lunok muss man sich sehr vorsichtig benehmen. Reisende, die an einem solchen Baum vorbeirudern, rufen den Kindern der Ganan Lunok zu: „O Enkel, steigt ja nicht zum Fluss herunter. Begebt euch nicht in die Nähe des Wassers, denn eure Eltern sind ja nicht zu Hause". Darauf begeben sich die Kinder zu ihren Eltern und sie teilen ihnen mit was sie von den vorbeirudernden Menschen gehört haben und diese antworten ihnen: „O unsere Kinder, das sind gewiss Verwandte von uns 133 weil sie euch so freundlich ermahnt haben vorsichtig zu sein. Tut ihnen kein Leid an".

An einem Lunok darf man auch sein Boot nicht mit den Stechbäumen abstossen um nicht seinen Stamm, das Haus der Geister, zu zerstören. Von den Lunok sind sehr viele Erzählungen im Umlauf von denen ich hier drei mitteile.

Eines Tages ging ein Mann von Penda-Hara (Dorf am mittleren Katingan) morgens früh hinter das Dorf um zu jagen. Sein Weg führte ihn an einer einsamen Feldhütte vorbei in der ein Verwandter von ihm krank darniederlag. Als er dort vorbeigegangen war kam er in die Nähe eines Lunok. Plötzlich schrak er zusammen, denn er hörte wie etwas vom Wipfel des Baumes auf den Boden fiel. Als er genauer hinschaute sah er ein weibliches Wesen mit zerzausten Haaren und mit einem unordentlichen Umschlagtuch bekleidet wie es von den Frauen in früheren Zeiten getragen wurde, nämlich ein kurzer Rock der nicht ganz bis zu den Knien reicht. Er sah wie dieses weibliche Wesen auf die Feldhütte zuschritt und in sie eintrat. Er zitterte am ganzen Leibe. Die Erscheinung hatte ihm die Jagd verleidet und er kehrte so rasch wie möglich wieder nach Hause zurück. Nicht lange darnach brachte man seinen kranken Verwandten sterbend ins Dorf zurück und kurz darauf verschied er. Die Ganan Lunok hatte ihm die Leber aufgegessen.

Eine andere Geschichte erzählt: Eines Tages begab sich ein Mann von Tumbang-Tarusan (Dorf am mittleren Katingan, in der Nähe von Penda-Hara gelegen) auf die Jagd. Als er in die Nähe eines Lunok kam hörte er plötzlich wie etwas vom Wipfel des Baumes auf die Erde fiel. Als er nachschaute was es gewesen sein könnte stand plötzlich ein weibliches Wesen mit zerzausten Haaren und einem kurzen Rock vor ihm. Ihre Hautfarbe war rötlich, ihre Augen blickten scharf und stechend. Er legte das Gewehr auf sie an und schoss. Plötzlich war die Frau verschwunden. Als er einige Zeit später wieder an dem Lunok vorbeikam, da sah er, dass dieser vollständig abgestorben war und 
daran erkannte er, dass er die Ganan Lunok, die ihm auf dem Wege begegnet war mit seinem Schuss aus dem Gewehr getroffen- und getötet hatte.

Eine dritte Geschichte berichtet uns: Vor etwa vierzig Jahren ging einmal ein Mann allein auf die Jagd hinter das Dorf Penda-Hara. Sein Hund hatte die Spur eines Wildschweines gewittert und verfolgte sie bellend. Sein Besitzer folgte ihm nach. Als er in die Nähe eines Lunokbaumes kam hörte er aus dem Baum plötzlich eine scheltende Stimme die seinen Hund wegjagte: „Hus, hus! was wagst du dich dieses Schwein zu verfolgen. Hus, hus, packe dich weg von hier". Erstaunt blickte er um sich und als er seinen Kopf in die Höhe hob da sah er in den Aesten des Baumes einen Affen sitzen. Er war sehr erstaunt, denn er hatte doch von dorther deutlich eine menschliche Stimme vernommen. Gewiss war es die Ganan Lunok gewesen, die sich, um ihre Gestalt vor ihm zu verbergen, in einen Affen verwandelt hatte.

Ein Lunok darf nicht gefällt werden, wenn nicht zuvor Opfer dargebracht und gewisse Zeremonien erfüllt worden sind. Auch seine Wurzeln dürfen bei den Feldarbeiten nicht verletzt werden. Vor der Niederlegung des Baumes tötet man ein Huhn und bestreicht mit dessen Blut den Stamm, indem man dazu spricht:

Wir bitten dich, Ganan Lunok, begib dich von hier weg. Suche dir einen andern Wohnplatz, denn wir sind gezwungen dein jetziges Haus zu zerstören um hier unser Reisfeld anlegen zu können.

Dann stellt man ein Opfergestell auf und legt etwas Reis, Tabak, Sirih, den Hühnerkopf und die Beine des Huhnes hinein als Gabe für die Ganan Lunok.

Eine andere, einfachere Sitte um die Ganan Lunok zum Umzug zu bewegen besteht darin, dass man am Fuss des Baumes eine Kudjang ${ }^{134}$ pflanzt, deren Saft sehr scharf ist und die Haut reizt. Dieser reizt nun auch den Stamm des Baumes und damit auch die Ganan Lunok und sie verlässt aus diesem Grunde den ihr unangenehm gewordenen Wohnort und siedelt sich anderswo an. Darnach kann der Baum gefällt werden. Die Wirkungen der Ganan Lunok auf den Menschen sind die folgenden: Hat jemand bei den Feldarbeiten in unachtsamer Weise die Wurzeln eines Lunok verletzt, dann wird er nach kurzer Zeit krank werden. Uebereinstimmend mit den Verletzungen des Lunok beginnt die Krankheit an einem seiner Beine, oder auch an beiden Beinen. Das Bein schwillt an und beginnt heftig zu schmerzen. Die Ganan Lunok hat an ihm Rache genommen. Hat 
jemand einen Lunok gefällt ohne vorher die vorgeschriebenen Opfer darzubringen oder die notwendigen Vorsichtmassregeln zu beachten, dann wird er nach kurzer Zeit von heftigem Fieber befallen. Sein ganzer Körper beginnt zu zittern, sein Mund schäumt, seine Rede ist irre. Die Ganan Lunok hat Rache genommen. Auch leichter Irrsinn wird durch die Ganan Lunok verursacht. Ist jemand lange Zeit krank und schmerzt ihn sein ganzer Körper dann ist die Ursache dieses nicht eindeutig feststehenden Leidens ebenfalls durch die Ganan Lunok verursacht. Ist jemand lange krank und haben alle Opfer, Beschwörungen und Gelübde nichts geholfen, dann liegt die Ursache darin, dass die Ganan Lunok ständig nach dem Kranken „sieht“, ihn ,besucht" und seine Leber langsam verzehrt. Bei sehr schweren, nicht heilenden Erkrankungen, z.B. Tuberkulose, kann die Ganan Lunok durch den Kundigen (es braucht nicht ein Priester zu sein, sondern jemand der die Handlungen kennt) befragt werden ob der Patient mit dem Leben davonkomme oder nicht. Man schlachtet zuerst ein Schwein, legt es beim Lunok nieder und bietet es der Ganan Lunok an. Dann klopft der Kundige dreimal mit seinem Fuss an den Stamm und lauscht mit seinem an den Baum gelegten Ohr nach der Antwort. Besteht diese aus einem tiefen $\mathrm{Mmmmm}$, dann besteht keine Hoffnung mehr für die Genesung des Kranken. Lautet die Antwort aber wie ein helles Dia men (es macht nichts) dann wird der Kranke mit dem Leben davonkommen.

Das Opfer für die Ganan Lunok. Hat man durch das Los oder durch die Krankheitserscheinungen selbst erkannt, dass die Krankheit durch die Ganan Lunok verursacht worden ist, dann begibt man sich zu einem Tukang Mantumbal, für den die gleichen Aussagen gelten wie sie für den Tukang Mangadiri gemacht wurden. Man bittet ihn das Mantumbal für den Kranken zu vollziehen. Er wählt sich unter den Anwesenden im Hause des Kranken einige Männer aus die ihm bei den notwendigen Verrichtungen behülflich sein müssen. Zuerst werden aus Reis drei menschliche Figuren geformt, dann schnitzt man von Lakuang-Tamberanholz, sowie von rotem Zuckerrohr ebenfalls drei menschliche Figuren (Hampatong) und bekleidet sie mit Kleiderfetzen des Kranken. Dann werden sieben Körner Seelenreis 135 in einen Fetzen neuen Tuches gewickelt und dieses steckt man in einen silbernen Fingerring (Der Fingerring wird genannt tisin akan batun hambaruan: Ring als Stein für die Seele, der die Seele und auch den Seelenreis stärken soll). Sind diese Vorbereitungen beendet, dann bereitet man die Opfergaben zu mit denen man die Seele des Kranken 
von der Ganan Lunok zurückbitten will, nämlich Sirih, Tabak, Reis, Salz, etwas Haar von der Schläfe des Kranken, einige Fetzen von seinen bereits getragenen Kleidern und wickelt sie in ein Pisangblatt und legt sie in einen kleinen Korb. Darnach nimmt man einen halamaung (ein Topf von gleicher Form wie die heiligen Töpfe, kostet aber nur etwa 3 - 4 Gulden), ein pisau pepet (das Messer in das man beisst, d.h. um seine Seele zu stärken. Das geschieht bei allen Opferhandlungen, religiösen Zeremonien, bei Verwundungen und bei Rechtshandlungen) ${ }^{136}$, eine Axt, einen Hund und den Streureis (tazeur) der sich durch das Machtwort und das Lied des Tukang in Reisseelen verwandeln soll die seine Bitten den Geistern und Ahnen zu überbringen haben. (Vgl. die ausführlichen Gesange im zweiten Teil dieses Bandes.) Man legt ihn sorgfältig in ein kleines Gefäss. Sind diese Vorbereitungen beendet dann tritt der Tukang Mantumbal mit den stellvertretenden und den Kranken auslösenden Opfergaben vor den Kranken hin. Dreimal berührt er mit dem Korb der die Opfer enthält den Kopf des Kranken. Es wiederholen sich die gleichen Handlungen und Worte wie sie oben, nach dem Mangapatong Liau mitgeteilt wurden.

Wenn das alles geschehen ist und der Kranke alles auf die Stellvertreter übertragen hat verlässt der Tukang Mantumbal mit seinen Helfern das Haus. Bis er wieder zurückgekehrt ist bleibt dieses pali. Beim Lunok angekommen werden die Opfergaben ausgebreitet. Der Tukang ergreift das Gefäss mit dem Streureis und besingt ihn, im Gegensatz zu grösseren Handlungen, mit kurzen Worten. Sein Gesang lautet:

$\mathrm{Du}$ Reis, es ist nicht notwendig, dass ich dich heute mit langen Worten besinge. Ich besinge dich nur kurz, um dich rasch in die Oberwelt entsenden zu können. Deinen Ursprung kenne ich wohl. Du stammst ab von dem überzähligen Rest der Sonne, von dem Tropfen des Mondes.

Wir werden dich leicht später besingen. Unser Gesang wird dann sein wie der Wind der die Blätter des Lunok bewegt. Wir besingen dich kurz und unser Lied gleicht dem Säuseln der Baringinblätter durch die der leichte Lufthauch weht. Länger werden wir dich besingen wenn wir ausziehen auf die Kopfjagd, wenn wir Rache nehmen an unseren Feinden für die abgeschlagenen Hörner (Köpfe). 
Darauf streut der Tukang viermal Reis und spricht:

Eins, zwei, drei und eines mehr. Verwandle dich in einen geraden Steg der die Breite hat der Trommel und der hinführt zu Rika Bulau Hatuen Antang Ganan Tadjahan, der seinen Wohnplatz hat im heiligen Hain auf der Ueberseite des Dorfes.

Wieder streut der Tukang achtmal Reis und spricht:

Eins, zwei, drei, vier, fünf, sechs, sieben und eines mehr. Verwandelt euch in sieben Jungfrauen, bekleidet mit goldenen Kleidern, ihr Seelen des Reises, ihr Herrlichen.

Ueberbringt meine Bitten, überbringt sie festgeschnürt wie mit Draht vom Meere her, meine Gelübde, festverknüpft wie der Haarball den man im Bauche des Krokodiles, des mutigen, findet. Begebt euch für mich zu Rika Bulau Hatuen Antang Ganan Tadjahan der seinen Wohnplatz hat auf der Ueberseite des Dorfes (d.h. über dem Fluss).

Bittet ihn, dass er zu mir komme um mit mir die Mythe des Karawambang Rawajan Kupang zu rezitieren.

Bringt ihn mit euch zurück, bringt ihn den tapferen Helden. Bringt ihn rasch wie der Wind der durch die Zweige des Lunok rauscht damit wir zusammen die Mythe hersagen.

Der Tukang Mantumbal wartet nun ungefähr fünf Minuten bis die Reisseelen mit Rika Bulau Hatuen Antang Ganan Tadjahan zurückgekehrt sind, dann ruft er den Reisseelen dreimal zu:

Kruk, meine Reisseelen! Ihr seid zurückgekehrt mit Rika Bulau Hatuen Antang Ganan Tadjahan. Ich bitte euch rezitiert mit uns zusammen nun die Mythe des Karawambang Rawajan Kupang.

\section{Die Mythe von Karawambang Rawajan Kupang}

In langgezogenem Gesange singt der Tukang, zusammen mit den Reisseelen und dem Rika Bulau Hatuen Antang Ganan Tadjahan: 137 In früheren Zeiten lebte Karawambang Rawajan Kupang zusammen mit seiner Frau. Sie hatte ihm ein Kind geboren, einen Knaben. Nach kurzer Zeit schon konnte sie sich wieder von ihrem Lager erheben und ihren täglichen Arbeiten nachgehen. Eines Tages brachte sie den Reis vor das Haus und breitete ihn auf Matten zum Trocknen aus. Während sie mit dieser Arbeit beschäftigt war beschloss der Mann bei sich selbst auf die Jagd zu gehen. Er begab sich zum Balai (Ver- 
sammlungshaus), in dem auch die Waffen und Schilde aufbewahrt wurden, um dort die Pfeile für sein Blaserohr bereit zu machen. Seine Frau war inzwischen wieder ins Haus eingetreten um dem Kinde, das sie weinen hörte, die Brust zu reichen. Kurz darnach schlief das Kind ein und sie begab sich wieder zum Reis zurück um ihn gegen die Hühner und Vögel zu beschützen. Als er trocken war sammelte sie ihn in einen Korb, begab sich zum Stampfblock und stampfte ihn dort. Einige Zeit später hörte sie das Kind wieder weinen. Sie rief ihrem Manne zu: „O Karawambang Rawajan Kupang, kehre doch ins Haus zurück und passt gut auf unser Kind auf, denn ich habe keine Zeit, ich muss den Reis hier zuerst fertig stampfen". Aber Karawambang Rawajan Kupang tat als ob er nichts gehört hätte. Er schnitzte ruhig seine Pfeile und bestrich sie mit Gift. Immer doch weinte das Kind heftig. Nochmals rief seine Frau: „O Karawambang Rawajan Kupang, kehre doch rasch ins Haus zurück und sieh nach unserem Kinde". Aber er tat auch diesmal als ob er nichts gehört hätte und arbeitete ruhig weiter. Als das Kind mit Weinen nicht aufhörte und sein Vater nicht ins Haus zurückkehren wollte um nach ihm zu schauen wurde die Frau in ihrem Herzen sehr zornig und verfluchte ihn mit den Worten : „Karawambang Rawajan Kupang, ich verfluche dich wenn es dir nicht möglich ist eine Reismatte voll Pfeile zu schnitzen. Dein Mund (d.h. der Atem) sterbe wie der Mund des Nashornvogels der vom Pfeile durchbohrt zur Erde fällt. Dein Atem lösche aus wie der Atem des Vogels der auf der Jagd erlegt wurde“. Der Mann vergalt ihr den Fluch mit den gleichen Worten: „Ich verfluche dich, wenn es dir heute nicht möglich ist die ganze Scheuer voll Reis zu stampfen. Dein Mund sterbe... usw.".

Er setzte seine Arbeit fort und es gelang ihm eine ganze Reismatte mit den geschnitzten Pfeilen zu füllen. Inzwischen war das Kind still geworden und eingeschlafen. Karawambang Rawajan Kupang füllte seinen Köcher mit Pfeilen, darauf begab er sich ins Haus, ergriff sein Blaserohr, nahm sieben Körner Reis und legte sie in seinen Köcher. Dann verliess er das Haus wieder und begab sich in den Wald zur Jagd. Seine Frau aber stampfte immer noch Reis.

Schon einige Zeit war er gegangen als er über sich in den Bäumen Vögel hörte die Früchte aufpickten. Er näherte sich und sah, dass sich die Vögel auf einem hohen Lunokbaum befanden und dessen Früchte assen. Er schlich leise näher herbei, legte sein Blaserohr an den Mund, aber als er blasen wollte, da sah er plötzlich ein grosses Wildschwein das unter dem Baume die herabgefallenen Früchte ver- 
zehrte. Er zielte nun auf dieses Tier, blies den Pfeil ab und traf es in die Seite. Sobald sich das Schwein getroffen fühlte flüchtete es.

Am gleichen Tage ging Radja Peres mit seinen sieben Brüdern ebenfalls auf die Jagd. Als sie in den Wald gekommen waren schlugen die Hunde an denn sie hatten die Spur eines Schweines gewittert. Rawunjit Radja Peres verfolgte es mit seinen Brüdern und als sie es eingeholt hatten schleuderte er seinen Speer ohne das Ziel zu verfehlen. Das Schwein sank tot um.

Auch Karawambang Rawajan Kupang hatte die Spur des Schweines verfolgt und erreichte es eben in dem Augenblicke als Radja Peres seinen Speer schleuderte. Er trat $z u$ ihm und zu seinen sieben Brüdern und sprach: „Das Schwein gehört mir, denn ich habe es mit meinem Pfeile verwundet". „Nein“, antwortete Radja Peres, „das Schwein gehört uns, unser Hund hat seine Spur gefunden und uns das Tier angezeigt. Wir haben es verfolgt und soeben habe ich es, wie du ja selbst sehen konntest, mit meinem Speer getötet“. „Untersuchen wir das Schwein", entgegnete Karawambang Rawajan Kupang. Sie befolgten seinen Rat und sie fanden die Pfeilwunde und Radja Peres sprach: „Dein Wort ist wahr, du hast das Schwein eher verwundet, aber ich mache den Vorschlag, dass wir das Fleisch teilen, denn das Tier ist gross, jeder von uns erhält einen genügenden Anteil“. „Es ist mir recht so", entgegnete Karawambang Rawajan Kupang, und darauf verteilten sie die Jagdbeute. Inzwischen war es aber später Nachmittag geworden. Die Sonne war dem Untergehen nahe und deshalb sprach Radja Peres zu Karawambang Rawajan Kupang: „Wir wollen uns hier von Aesten und Blättern eine Hütte bauen damit wir im Walde übernachten können. Die Nacht fällt nun rasch herein und wir werden, bevor es dunkel wird, unsere Dörfer doch nicht mehr erreichen". Sie machten sich sofort an die Arbeit und nach kurzer Zeit hatten sie ihre notdürftige Unterkunft fertig erstellt. Darnach fragte Radja Peres: „Wer von euch hat Reis bei sich?" Seine Brüder antworteten: „Wir haben keine Wegzehrung mitgenommen“, aber Karawambang Rawajan Kupang entgegnete: „Ich habe in meinem Pfeilköcher sieben Körner Reis“. Radja Peres sprach: „Es genügt für uns, wir haben nicht mehr nötig“. Darauf fragte er weiter: „Wer von euch hat Feuer mit sich genommen?" Sie alle antworteten: „Wir haben keines bei uns“. Darauf befahl er: „Wohlan, es steige einer von euch auf einen hohen Baum und überschaue die Umgebung, vielleicht, dass es ihm gelingt in der Nähe ein Feuer oder aufsteigenden Rauch zu entdecken". Sofort erkletterte einer seiner Brüder einen Baum und 
schaute über den Wald. In der Ferne sah er Rauch zwischen den Bäumen aufsteigen. Er stieg rasch wieder herunter und sprach $z u$ seinen Brüdern: „In der Nähe sah ich Rauch aufsteigen. Gewiss befinden sich Menschen dort. Ich will $z \mathfrak{u}$ ihnen hingehen und sie um Feuer bitten“. „Gut", antwortete Radja Peres, ,hole uns Feuer, aber füge den Menschen kein Leid zu. Stehle ihnen nichts, töte ihnen keine Hühner oder Schweine, mache sie nicht krank und entführe ihre Seelen nicht". „Nein“, antwortete er, ,,ich werde nach deinem Worte handeln“. Er begab sich in den Wald hinein und verfolgte die Richtung aus der er den Rauch aufsteigen sah. Seine Brüder rüsteten inzwischen die Mahlzeit. Einige zerlegten das Schwein, andere schnitten Bambusköcher um den Reis zu kochen und Wasser zu schöpfen. Wieder andere stiegen zum nahen Flüsslein hinunter und trugen Wasser herbei. Derjenige, der das Feuer zu holen hatte, kam nach einiger Zeit bei einer Hütte an. Vor ihr stampfte eine Frau Reis. Er begab sich, ohne mit ihr zu sprechen und ohne sie vorher um Erlaubnis zu fragen, ins Haus und nahm vom Herde ein glimmendes Scheit. Dann kehrte er um und wollte das Haus wieder verlassen. Bei der Türe sah er die Seele eines kleinen Kindes sitzen. Sie versperrte ihm den Weg und darum nahm er sie mit sich. Aber er war noch nicht weit gegangen da kam ihm der Befehl seines Bruders in den Sinn und er erschrak sehr, denn er hatte diesen Befehl übertreten und die Seele entführt. Er nahm sieben Muhaublätter und wickelte die Seele in sie hinein und schlug eine Kerbe in einen Timaubaum und verbarg dort das Blätterbündel mit der Seele. Dann schritt er weiter und kam nach kurzer Zeit wieder bei seinen Brüdern an. Er fachte rasch das Feuer an und seine Brüder brachten den Reis den sie in sieben Bambusköcher gelegt hatten um ihn darin zu kochen 138 und das Schweinefleisch. Die Reisköcher, in die man die sieben Reiskörner gelegt hatte füllten sich sofort mit Reis, denn dieser hatte die Macht sich zu vermehren. Dann drehten sie die Köcher über dem Feuer damit der Reis regelmässig kochen und nicht anbrennen sollte. Als das Essen zubereitet war setzten sie sich und assen. Nach dem Essen sammelten sie alle Knochen des Schweines auf einem Platze und schichteten sie dont auf. Inzwischen war die Dunkelheit hereingebrochen. Sie setzten sich in ihre Hütte, kauten Sirih und plauderten.

Nachdem die Sonne untergegangen war hatte auch die Frau des Karawambang Rawajan Kupang ihre Arbeit beendet und kehrte ins Haus zurück. Ihr Kind schlief immer noch. Bevor sie nach ihm schaute verrichtete sie noch ihre täglichen Arbeiten. Sie ergriff die 
Bambusköcher und stieg mit ihnen zum Flusse hinunter um Wasser zu schöpfen und gleichzeitig zu baden. Darauf fütterte sie die Schweine und Hühner und kehrte dann ins Haus zurück. Sie fachte auf dem Herde das Feuer an, schüttete den Reis in die Köcher, drehte sie bis er gar war, dann wärmte sie den Djoho (eine Gemüsesuppe die von verschiedenen Gemüsen hergestellt wird) und die Zuspeise und als alles fertig war ass sie. Nach der Mahlzeit griff sie zum Sirih und kaute. Dann erst schaute sie nach ihrem Kind das immer noch schlief. Sie nahm es aus der Wiege. Sie erschrak sehr in ihrem Herzen denn ihr Kind war gestorben, sie hielt nur noch seine Leiche in ihren Armen. Sie legte die Leiche auf den Boden und setzte sich weinend neben ihr nieder. Dann stand sie wieder auf und sie schlug einen der Gong. Dreimal schlug sie in kurzen $Z$ wischenpausen auf das Instrument um den Umwohnenden anzuzeigen, dass in ihrem Hause jemand gestorben sei. Darauf schlug sie alle Gong um auch die entfernter wohnenden Verwandten von dem Todesfalle $z u$ benachrichtigen.

„Hau“, rief Radja Peres als er die Gong plötzlich hörte, „was bedeutet das? Sollte wohl jemand gestorben sein?" Und er wandte sich zu seinem Bruder dem er den Auftrag gegeben hatte Feuer zu holen und fragte ihn: „Hast du auf dem Weg oder in der Hütte, in der du für uns das Feuer geholt hast, etwa einen Menschen getötet? Der Laut der Gong kommt aus jener Richtung“. Er antwortete: „Ja, ich habe die Seele eines kleinen Kindes entführt und verborgen. Ich kam zu einer Hütte. Vor ihr stampfte eine Frau Reis. Ich trat in die Hütte ein und nahm vom Herd ein glimmendes Scheit. Als ich mich umdrehte und sie wieder verlassen wollte sah ich bei der Treppe die Seele eines kleinen Kindes sitzen die mir den Weg versperrte. Ich ergriff sie und nahm sie mit. Aber ich war noch nicht weit gegangen als mir dein Befehl in den Sinn kam. Ich nahm rasch sieben Muhaublätter und wickelte die Seele hinein, dann schlug ich eine Kerbe in einen Timaubaum und legte in ihr das Blätterbündel nieder und kurz darnach kam ich mit dem Feuer bei euch wieder an".

Radja Peres wandte sich an Karawambang Rawajan Kupang, der still und nachdenklich der Erzählung zugehört hatte, und er fragte ihn: „Weisst du vielleicht in wessen Hütte die Gong geschlagen werden und wer wohl gestorben sein könnte?" Er antwortete betrübt : „Ja, ich weiss es. Es ist mein Kind, das gestorben ist. Ich ging vor kurzer Zeit von meiner Hütte weg und meine Frau stampfte Reis während das Kind in seiner Wiege schlief. Den Laut der Gong kenne ich ebenfalls genau. Es sind die meinigen". 
Darauf sprach Radja Peres zu ihm: „Deine Rede ist wahr. Trage kein Herzeleid, denn es gibt noch einen Weg und eine Möglichkeit deinem Kinde das Leben wieder zurückzugeben. Ich will dir nun sagen was du zu tun hast wenn du Morgen früh wieder nach Hause kommst. Sobald $d u$ in deinem Hause angekommen bist dann formst du von gekochtem Reis zwei menschliche Figuren. Darauf nimmst du LakoangTamberanholz und rotes $Z$ uckerrohr und schnitzest aus ihnen ebenfalls zwei menschliche Figuren. Darnach nimmst du etwas Sirih, Tabak, Salz und einige Kleiderfetzen von deinem Kinde und schneidest etwas Haar ab von seiner Schläfe. Das alles legst du auf ein Pisangblatt und dieses auf eine Reismatte. Darauf nimmst du einen Hund, einen Halamaung (Topf) und eine Axt und wählst sieben Körner Seelenreis aus. Du wickelst den Seelenreis in einen Fetzen neuen Tuches und schiebst es in einen silbernen Fingerring um die Seele zu stärken (hapa, e manekang hambaruan). Dann bereitest du den Streureis vor und salbst ihn mit Gelbwurz. Mit allen Opfergaben berührst du dreimal den Kopf deines toten Kindes... usw., wie oben. Wenn du das alles getan hast, dann bringst du alles $z \mathfrak{u}$ einem Lunokbaum und auf dem Wege dorthin nimmst du aus der Kerbe des Timaubaumes das Muhaublätterbündel $\mathbf{z u}$ dir. Beim Lunok angekommen tötest du den Hund und bratest zuerst seine Leber an einem Stück Holz über einem offenen Feuer. Wenn sie genügend gebraten ist zerteilst du sie in sieben Schnitten und legst die einzelnen Schnitten in Blätter. Darnach bratest du den Hund auf die gleiche Weise und wenn er gebraten ist hackst du ihn in kleine Stücke und streust sie aus. Gleichzeitig rufst du dem Rika Bulau Hatuen Antang Ganan Tadjahan und bittest ihn die verirrte Seele deines Kindes zurückzuholen. Dann schlägst du mit der Axtspitze dreimal an den Topf und sprichst:

O Sukoh, Ganan Lunok, hole die Speisen, die ich dir zubereitet habe und bringe das Gold der Seele meines Kindes mit dir, damit sie wieder zurückkehre mit Rika Bulau Hatuen Antang Ganan Tadjahan, denn ich habe sie ausgelöst. Ihre stellvertretenden Opfer habe ich hier niedergelegt.

Nicht lange wird es dauern, dann wird die Seele deines Kindes kommen. Du rufst ihr dreimal zu:

$K r u k$, Seele meines Kindes, du bist wieder heimgebracht worden durch Rika Bulau Hatuen Antang Ganan Tadjahan, vom Orte des Sukoh, der Gana des Lunok.

Darauf kehrst du nach Hause zurück. Bei der Treppe angekommen 
stössest du mit dem Fusse dreimal an die Treppe während du, ins Haus hinein rufend, die Worte aussprichst:

Ist die Seele meines Kindes schon heimgekehrt?

Aus dem Hause wird man dir dreimal antworten:

$\mathrm{Ja}$, die Seele ist wieder heimgekehrt. Sie hat sich auf ihrem Wege nicht verirrt. Sie ist zurückgekommen vom Lunokbaum und hält sich wieder fest im Hause auf.

Nachdem du diese Worte gehört hast betrittst du das Haus. Du öffnest das Bündel mit Seelenreis und das Bündel von Muhaublättern das die Seele deines Kindes enthält. Du vermengst den Inhalt der beiden Bündel. Du nimmst den Seelenreis und berührst mit ihm dreimal den Kopf deines Kindes indem du dazu sprichst:

$K r u k$, Seele meines Kindes, du bist wieder zurückgekehrt vom

Orte des Sukoh, der Gana des Lunok Baringin, des Baumes im Walde.

Das sind die Handlungen die du auszuführen hast um dein Kind wieder ins Leben zurückzurufen".

Nach diesen Worten des Radja Peres legten sie sich in der Hütte zur Ruhe und schliefen bald ein. Als der Morgen anbrach begab sich Radja Peres zu den Schweineknochen, die sie am Abend zuvor aufgeschichtet hatten. Er stiess mit seinem Fusse daran. Ein Zittern ging durch die Knochen. Sie fügten sich zusammen und plötzlich lag ein Schwein zu seinen Füssen. Er zerteilte es in zwei Hälften. Die eine Hälfte übergab er seinen Brüdern, die andere überreichte er Karawambang Rawajan Kupan. Dann machten sie sich bereit und jeder kehrte wieder in sein Dorf und in seine Hütte zurück.

Als Karawambang Rawajan Kupang sein Haus betrat sah er, dass er sich nicht getäuscht hatte. Sein Kind war gestorben und die Verwandten hatten die Leiche bereits längs der Mittelschwelle des Hauses aufgebahrt. Er legte seine Jagdbeute in einer Ecke des Hauses nieder, stellte das Blaserohr gegen die Wand und begann die Vorbereitungen zu treffen um die Seele seines Kindes zurückzuholen und auszulösen, so, wie ihn Radja Peres gelehrt hatte es zu tun. Er hielt sich genau nach seinen Worten und handelte in allen Dingen nach seinem Rat und als alle Zeremonien erfüllt- und alle Worte gesprochen waren kehrte die Seele zurück und sein Kind begann zu atmen und nicht lange darnach schlug es auch wieder die Augen auf.

Nachdem der Tukang Mantumbal, zusammen mit Rika Bulau Hatuen Antang Ganan Tadjahan und den Reisseelen, diese Erzählung rezitiert hat, spricht er abschliessend: 
Das ist die Mythe, die wir befolgen und derzufolge wir unsere Opfer darbringen und unsere Handlungen verrichten. Ich habe an ihr nichts verändert, sondern ich habe sie so rezitiert wie sie uns von unseren Ahnen überliefert worden ist.

Darauf werden in der von Radja Peres genannten Reihenfolge alle Opfer dargebracht und alle Handlungen ausgeführt und wenn der Tukang Mantumbal wieder vom Lunok ins Haus des Kranken zurückkehrt, dann ist auch die Seele des Kranken bereits dort angekommen. Er macht sie im Kranken noch fest, indem er ihm den Seelenreis auf den Kopf streut und dreimal die Seele ruft.

In vielen andern Dörfern, z.B. auch in Tubang Lahang am Katingan, wird statt dieser Mythe eine andere rezitiert. Sie heisst:

\section{Die Mythe des Anak Luting}

In früheren Zeiten lebte der Sohn des Luting, den man einfach Anak Luting (Kind des Luting) nannte, weil er noch keinen Namen besass. Er hatte sechs Brüder und er war der jüngste von ihnen, ein kleines armseliges und erbärmlich aussehendes Kind. Sein Körper war von Geschwüren bedeckt und er konnte fast nicht gehen weil auch seine Fussohlen voller Geschwüre waren (Framboesia). Weil er so klein und so überaus hässlich war hassten ihn seine Brüder und wenn er in ihre Nähe kam jagten sie ihn weg und schlugen ihn. Ueberall war er ihnen im Weg. Aus diesem Grunde hielt er sich auch den ganzen Tag nicht im Hause auf sondern spielte und arbeitete für sich unter der Reisscheuer und schmiedete sich dort Speere, Dolche und Blaserohrspitzen.

Eines Tages hatten seine Brüder keine Zuspeise mehr für den täglichen Reis. Einige von ihnen sassen den ganzen Tag mit ihren Angelruten am Ufer, andere ruderten auf dem Fluss und warfen das Netz aus, aber so sehr sie sich auch bemühten etwas $z u$ fangen, so gelang es ihnen doch nicht auch nur einen einzigen Fisch mitheimzubringen. Verdrossen kehrten sie nach Hause zurück und der Aelteste von ihnen sprach zu seinen Brüdern: „Wir haben genug von diesem Elend. Wir wollen nun auf die Jagd gehen und wir bleiben so lange im Walde bis wir ein Wild erlegt haben. Unseren jüngsten Bruder lassen wir daheim. Wir wollen diesen hässlichen Kerl nicht auch noch mit uns herumschleppen. Er kann ja doch auch fast nicht gehen. Jeder mache sich nun still bereit und dann rudern wir unbemerkt von hier weg". Wie er gesprochen hatte, so taten sie auch. Still und unauffällig machten sie ihre Blaserohre, die Pfeilköcher und die Wegzehrung bereit 
und dann trugen sie alles zum Boot hinunter. Ihr jüngster Bruder beobachtete aber ihr Treiben erstaunt und betrübt und er sprach zu sich selbst: „Leha-lehan, wie schlecht sind doch meine Brüder! Sie wollen wegreisen und sie wollen sich von hier wegstehlen wie Diebe. Offenbar haben sie im Sinn mich zurückzulassen, aber das soll ihnen nicht gelingen, ich werde mich ihnen aufdrängen, ich lasse mich diesmal von ihnen nicht abweisen". Auch er machte rasch seine Waffen und die Wegzehrung bereit und als die Brüder das Boot bestiegen nahte er sich ihnen ebenfalls. „Was willst du hier?" schrie der Aelteste ihn zornig an, ,packe dich weg. Wir gehen auf die Jagd und wir werden dich diesmal auf keinen Fall mitnehmen. Denke nur an deine Geschwüre an den Füssen und am ganzen I_eib. Du würdest die Strapazen nicht aushalten und wärest uns überall im Wege“. „Ich will mit", rief der Jüngste zurück. „Ich bleibe diesmal nicht daheim“. „Und du bleibst daheim!" schrieen ihn seine Brüder an und damit stiessen sie das Boot vom Landungsfloss ab und ruderten weg. Aber der Jüngste hatte sich nun einmal in den Kopf gesetzt sie unter allen Umständen begleiten zu wollen, deshalb sprang er rasch ins Wasser, schwamm dem Boote nach und setzte sich hinten ans Steuer. Aber seine Brüder schlugen ihn und warfen ihn wieder ins Wasser zurück. Der Jüngste weinte heftig und rief unaufhörlich: „Erbarmt euch meiner, erbarmt euch meiner, lasst mich mitkommen, ich will mit euch gehen, nehmt mich doch wieder ins Boot hinein!" Sie hielten an und zogen ihn wieder ins Boot herein und wieder schlugen sie ihn unbarmherzig, sodass das Blut über seinen ganzen Körper strömte, und dann setzten sie ihn hinten am Steuer nieder. Er war tropfnass, er fror und er zitterte vor Schmerz und Kälte und er weinte unaufhörlich vor sich hin wegen der Härte und Herzlosigkeit seiner Brüder.

Einen halben Tag lang fuhren sie das Flüsslein Pali aufwärts bis sie am Nachmittag den Fuss des Berges Pali, des siebenfach übereinandergeschichteten, erreichten. Dort hörten sie das Gezwitscher und Gekrächze zahlreicher Vögel die die Früchte von Lunokbäumen aufpickten. Der Aelteste sprach: „Wir wollen hier mit unserem Boote anhalten und uns eine kleine Hütte bauen“. „Nein“, rief der Jüngste, „hier halten wir nicht an, wir sind hier am Berge Pali. Erinnert ihr euch nicht mehr an das was euch der verstorbene Vater gesagt hat? Gab er uns nicht den Rat, uns nie in der Nähe des Berges Pali aufzuhalten oder ihn gar zu besteigen, weil dies unheilbringend wäre? Lasst uns doch weiter rudern“. „Schweig still", schrieen seine Brüder, „was willst du denn wissen". Und nach diesen Worten schlugen sie 
ihn und warfen ihn wieder ins Wasser. Aber einer seiner Brüder hatte Mitleid mit ihm und er zog ihn wieder ins Boot herein und wies seine Brüder wegen ihrer Herzlosigkeit zurecht. Keiner aber befolgte den Rat ihres jüngsten Bruders. Sie hielten mit ihrem Boote an denn es war bereits später Nachmittag geworden. Einige schlugen sofort Holz und sammelten $Z$ weige um eine kleine Hütte aufzurichten. Als die Sonne unterging hatten sie ihre Arbeit beendet. Einige begannen nun Wasser zu schöpfen, andere machten Feuer, wieder andere schütteten den Reis in Bambusköcher und drehten diese über dem Feuer. Dann kochten sie den Djoho (Gemüsesuppe) von Blättern und Schösslingen die sie im Walde gefunden hatten. Als das Essen bereit war setzten sie sich und nahmen die einfache Mahlzeit ein und als sie damit fertig waren tranken sie Wasser und setzten sich auf den Fussboden und begannen den Sirih zu kauen. Der Jüngste begab sich zum Feuer um sich zu wärmen, denn das Fieber schüttelte ihn. Bald legten sie sich zur Ruhe und schliefen ein. Als der Morgen anbrach und sie erwachten begannen sie die notwendigen Arbeiten zu verrichten. Einige schöpften wieder Wasser, andere fachten das Feuer an, wieder andere kochten den Reis und Djoho. Als sie gegessen und gekaut hatten machten sie ihre Blaserohre und Pfeilköcher bereit und verliessen den Platz indem sie zu ihrem jüngsten Bruder sprachen: „Wir besteigen nun den Berg Pali. Du kannst uns nicht begleiten. Bleibe hier und warte auf unsere Rückkehr". Er folgte ihnen aber doch nach, aber schon bald verlor er ihre Spur und er erinnerte sich auch des Rates seines Vaters. Er schweifte nun allein im Walde herum und er bestieg einen Berg der in der Nähe des Berges Pali lag. Auf dem Rückweg erlegte er ein grosses Schwein.

Inzwischen bestiegen seine Brüder den Berg Pali und folgten dem Gekrächze der zahlreichen Vögel die sich an den Früchten der Lunokbäume gütlich taten. Sie verwunderten sich sehr, denn kein Vogel flog auf wenn sie in seine Nähe kamen und keines der Tiere flüchtete sich vor ihnen in den Wald. Noch nie hatte ein Mensch den Berg Pali bestiegen und noch nie war auf ihm ein Tier getötet worden, deshalb waren sie so zahm und flüchteten sich nicht als sie die Söhne des Luting sahen. Sie legten ihre Blaserohre an den Mund und sie bliesen Pfeil um Pfeil nach den Vögeln und Tieren. Sie machten sehr grosse Beute und als sie des Jagens müde waren kehrten sie mit den erlegten Tieren zu ihrer Hütte zurück und erreichten diese gleichzeitig mit ihrem jüngsten Bruder der von einer andern Richtung kam. Als er seine Brüder sah, erschrak er sehr. Sie benahmen sich nicht mehr wie 
sie sich zuvor benommen hatten, sondern sie redeten wirr und unverständlich durcheinander. Sie waren wahnsinnig geworden. ${ }^{139} \mathrm{Sie}$ nahmen die Tiere, die sie erlegt hatten aus und vermischten das Fleisch mit ihrem eigenen Unrat und assen es so auf. Die ganze Nacht hindurch sprachen sie. Die geifernden Zungen hingen ihnen zum Mund heraus, die Augen traten aus den Höhlen. ${ }^{140}$ Es war ein schrecklicher Anblick für ihren jüngsten Bruder. Als der Morgen tagte sprachen sie zu ihm: „O unser jüngster Bruder, nimm deine Jagdbeute und kehre in unser Dorf zurück. Wir können dich nicht begleiten, denn wir sind durch die Besteigung des Berges Pali und die Erlegung der Tiere, die auf ihm wohnen, zu Geistern geworden. Wir gehören von jetzt an nicht mehr zu euch Menschen, sondern wir gehören zu Kameloh Pakon Bulan die auf diesem Berge wohnt. Sorge du gut für dein Leben. Wir werden dich und deine Angehörigen, deine Kinder und Enkel nicht verlassen, sondern wir werden euch in der Not beistehen. Wird jemand von euch krank durch die Ganan Lunok, dann opfert ihr uns und ihr streut uns roten und gelben Reis. Für den Kranken schnitzt ihr drei männliche Figuren von Sagagulangholz und bekleidet sie mit Kleiderfetzen des Kranken". Die weiteren Handlungen sind gleich wie oben.

\section{Mantumbal Kalue}

Das der Kalue gehörende heilige Tier ist ein kleiner, etwa zwei Finger breite Frosch, der im Walde lebt. Er wird ebenfalls Kalue genannt. Wird er durch einen Menschen auf unachtsame Weise verwundet, dann rächt er sich an ihm entsprechend der Verwundung die er erhalten hat. Sind seine Beine verwundet worden, dann wird der Mensch nach kurzer Zeit heftige Schmerzen in seinen Beinen verspüren. Ist der Körper verwundet, dann wird ihn sein ganzer Körper schmerzen. Ist der Kopf verwundet worden, dann wird er an starken Kopfschmerzen leiden. Nur wenn der Kalue sofort getötet worden ist kann er sich nicht mehr rächen und der Mensch kommt ohne Krankheit davon. Aus der Art der Krankheit und durch die Befragung des Loses erkennt man ob sie durch den Kalue verursacht worden sei oder nicht.

Hat man die Krankheitsursache erkannt oder durch das Los herausgefunden, dann ruft man einen Tukang Mantumbal und bittet ihn für den Kranken das Mantumbal Kalue zu vollziehen.

Opfer und Stellvertreter, die sich gleich bleiben, werden durch den Tukang und seine Helfer zu einem Termitenhügel im Walde gebracht. Man höhlt diesen mit Buschmessern etwas aus und der Tukang ruft dreimal : 
Erwache, König der Kalue.

Wenn er erwacht ist werden die Opfer und Stellvertreter angeboten und man bittet vom König der Kalue die Seele zurück. Wonte und Handlungen sind gleich wie oben. Eine Mythe wird nicht rezitiert.

\section{Mantumbal Patis}

Der Patis ist ein Vorzeichenvogel der, wenn er durch einen Menschen verwundet worden ist, ihn krank machen kann. Die Krankheit besteht in heftigem Fieber mit Schüttelfrost. Ist ihre Ursache eindeutig festgestellt dann holt man einen Tukang Mantumbal Patis der die Opfer darbringt und die Stellvertreter, die aus Reismehl geformt worden sind, anbietet. Opfer, Handlungen und Formeln sind die gleichen wie oben. Der Tukang bringt die Opfergaben und Stellvertreter mit seinen Begleitern zusammen in den Wald. Dort angekommen hängt er das Gefäss, das die Opfergaben enthält, etwa einen Meter über der Erde an einen $Z_{w e i g}$ eines beliebigen Strauches. Er setzt sich mit ihnen auf die Erde, streut den Reis und bietet den Patis- und Bakotokvögeln (ebenfalls Vorzeichenvögel) sowie auch den Gana der Sträucher und Bäume die Gaben dar und bittet sie den Kranken gesund $z u$ machen und seine Seele wieder zurückzugeben.

\section{c. Manolak Peres (Verabschiedung des Krankheitsgeistes)}

Früher war es bei den Ngadju- und Ot Danum-Dajak allgemeine Sitte, dass jedes Jahr, nach der Ernte, der feindliche Krankheitsgeist, der das Dorf überfallen- und über seine Bewohner Krankheit und Unheil hereinbringen wollte- oder bereits hereingebracht hatte, durch die ganze Bevölkerung verabschiedet (manolak) wurde. Heute wird diese Sitte nur dann noch ausgeübt wenn man hört, dass in einem Dorfe eine Epidemie ausgebrochen sei die allmählich flussaufwärts ziehe und auch die andern Dörfer überfalle. Sobald dieser Bericht das Dorf erreicht versammeln sich die Bewohner und beschliessen dem Krankheitsgeist ein stellvertretendes Opfer entgegen zu senden und dadurch seinen Weiterzug $z u$ verhindern.

Der Tukang Tawur (der Priester der den Streureis streut und den Antang Ganan Tadjahan aufruft) befiehlt jeder Familie die Opfer bereit $z u$ machen. In jeder Familie und in jedem Hause wird für jede Person eine menschliche Figur von Rotan oder Sagagulangholz geschnitzt. Die Figuren, die für die weiblichen Personen bestimmt sind, bekleidet man mit weiblichen Kleidern, die der männlichen Glieder 
bekleidet man mit einem Lendentuch. Die Kleider werden von Kleiderfetzen angefertigt. Darnach finden alle Uebertragungshandlungen statt, wie sie bereits oben in der Mythe vom Mangapatong Liau, mitgeteilt wurden. Die Hampatong (Schnitzbilder) werden für jede Familie je in einen besonderen Bündel zusammengebunden. Sind diese Vorbereitungen beendet, dann versammeln sich die Männer um von Pisangstämmen und Sagagulangholz ein kleines Floss zu bauen. Es wird mit Rudern und zwei Ruderknechten versehen. Darauf wird das Floss beladen mit allen Gebrauchsgegenständen die man in einem dajakischen Hause findet, mit Werkzeugen, heiligen Töpfen und wertvollen Erbstücken ( $p u s a k a$ ), die alle naturgetreu in Miniaturform aus Sagagulangholz nachgeschnitzt worden sind, ferner mit einem Blasebalg von Bambus, einem Amboss und Schmiedehammer von Holz, grossen und kleinen Gong von Bambus, Buschmessern, Speeren und Blaserohren von Holz und darnach legt man die gebündelten Hampatong auf das Floss. Als Opfergaben werden mitgegeben : ein lebendes Huhn, weisser und schwarzer Klebreis, Sirih, Tabak und Salz. Das Floss wird am Ufer des Flusses niedergelegt und die Bewohner des Dorfes setzen sich mit dem Priester darum herum. Der Priester ruft zuerst den Rika Bulau Hatuen Antang Ganan Tadjahan auf und rezitiert mit ihm und mit den Reisseelen zusammen die Erzählung von Sawuwur und Sawawar, nämlich :

\section{Die Mythe vom Ursprung des Peres}

In ganz früheren Zeiten, als sich die Menschen noch mit den Göttern verheirateten und ein Mischgeschlecht bildeten, verheiratete sich aus diesem Geschlecht ein Mann namens Sawuwur mit einer Frau die Sawawar hiess. Sie wohnten in Telok Tumbang Tiwei. Eines Tages zog der Mann auf die Jagd aus. Als er im Walde angekommen war, begann sein Hund plötzlich zu bellen und verfolgte einen runden Gegenstand, den Samen des Eisenholzbaumes. Sawuwur nahm die eigenartige Frucht, die er noch nie gesehen hatte und deren Namen er nicht kannte, zu sich und kehrte nach Hause zurück. Er begab sich mit ihr zu seinem Grossvater Sakarana und bat ihn: „Nenne mir den Namen dieser Frucht die ich auf der Jagd fand, denn du bist alt und weisst alle Dinge“. Sakarana sprach: „Die Frucht, die du gefunden hast ist der Same des Eisenholzbaumes und stammt von unseren Ahnen Mangko Amat und Njai Djaja, die, als sie am Flusse Djalajan den Pang Dohong Bulau gesund machen sollten, durch das Gift von Menschen umkamen und in Fruchtbäume und Nutzpflanzen ver- 
wandelt wurden. Die Frucht fiel vom Berge Palangka Langit Kereng Ngantong Gadang Sangiang herunter an den Fuss des Berges Pali. Die Frucht hat grossen Wert und bringt dir reichen Nutzen. Wenn du nun nach Hause kommst dann bestelle sofort dein Feld. Arbeite auf ihm drei Tage. Am vierten Tag stellst du die Arbeit ein weil es pali ist an diesem Tag $z \mathfrak{u}$ arbeiten. Daraufhin setzest du deine Arbeit wieder fort. Du säuberst den Busch, du fällst die Bäume, du breitest das Kleinholz aus, damit es gut trocknen kann, und wenn es trocken ist, dann verbrennst du es. Darauf nimmst du diese Frucht und zerstampfst sie $z \mathfrak{u}$ feinem Mehl. Du streust es aus in die vier Ecken des Feldes und in seine Mitte. Wenn die Saat zu sprossen beginnt und das ganze Feld schön regelmässig grünt, dann ist diese sprossende Saat Reis. Sprosst die Saat aber nur an einzelnen Stellen, dann ist deine Arbeit umsonst gewesen".

Nachdem Sawuwur von seinem Grossvater Sakarana diesen guten Rat empfangen hatte bedankte er sich höflich und kehrte wieder nach Hause zurück. Er tat dort angekommen wie er geheissen worden war. Während er sich aber auf dem Felde aufhielt und den Wald vom Kleinholz säuberte gebar seine Frau eine Totgeburt. Das Kind hatte weder Arme noch Füsse, weder einen Kopf noch Ohren. Es atmete auch nicht, sondern war ohne Leben. Als Sawuwur nach Hause kam und als er sah was geschehen war entschloss er sich mit seiner Frau diese Totgeburt auf dem Flusse wegtreiben zu lassen. Er faltete Rinde zu einem Gefäss zusammen, legte die Totgeburt hinein, brachte sie an den Fluss hinunter und liess sie vom strömenden Wasser hinwegtreiben. Auf seiner Fahrt trieb das Gefäss an einen mit Pilzen bewachsenen Baum und plötzlich bildeten sich nach dieser Berührung an dem toten Körper Ohren. Es trieb weiter und stiess gegen einen Patikbaum und plötzlich hatte der tote Körper nach dieser Berührung einen Kopf und Augen. Es trieb wieder langsam weiter und stiess gegen ein Bambusgesträuch und nach dieser Berührung bildeten sich plötzlich an dem toten Körper Arme und Füsse. Wieder trieb es weiter und es blieb schliesslich am Ende eines Anlegeflosses hängen. Dieses Floss gehörte der Indang Bemban Maruan, der Frau des Königs aller Krankheiten, die in Telok Tumbang Tiwei, unterhalb des Wohnplatzes des Sawuwur wohnte. Als Indang Bemban Maruan wie gewöhnlich zum Landungsfloss hinunterstieg um ihre Notdurft zu verrichten und zu baden sah sie am Ende des Flosses das merkwürdige Gefäss mit dem leblosen Knaben. Sie nahm ihn heraus, kehrte mit ihm ins Haus zurück, wickelte ihn in ein siebenfach gefaltetes Tuch und goss etwas 
Lebenswasser über den leblosen Körper. Sofort begann das Kind zu atmen. Sie nahm es nun als ihr eigenes Kind auf und nannte es Ramboari.

Die Eisenholzfrucht, die Sawuwur auf seinem Felde ausgestreut hatte gedieh prächtig und er erhielt eine grosse Reisernte. Von diesem Jahre an begannen er und seine Angehörigen Reis zu essen und zu bauen.

Nach einiger Zeit schenkte seine Frau wiederum einem Kinde das Leben und sie nannten es Rambogana. Als er zu einem Jüngling herangewachsen war verheirateten ihn seine Eltern und seine Frau schenkte ihm viele Kinder.

Eines Tages bat Rambogana seinen Vater ihm einen Platz für sein Reisfeld anzuweisen. Sein Vater sprach: „Lege dein Feld da an wo ich das erste Mal Reis baute". Rambogana zog mit seinen Sklaven aus. Sie säuberten den Platz vom Busch, fällten die hohen Bäume, breiteten das Holz zum Trocknen aus und als es dürr war verbrannten sie es.

Am gleichen Tag stieg Ramboari zum Fluss hinunter um zu baden. Er erstaunte und erschrak als er plötzlich unfern seines Badeplatzes Rauch aus dem Walde aufsteigen sah. Er sprach zu sich selbst: „Hau, gewiss sind Menschen dort die sich ein Feld anlegen. Es nimmt mich nur wunder wer den Mut findet diese Arbeiten auf meinem Geburtsplatz zu verrichten“. Er rief seinen Sklaven: „Has! meine Sklaven, begleitet mich dort hinüber. Wir wollen nachsehen wer dort den Wald abbrennt". Sie machten sich rasch auf den Weg und als sie eine Strecke weit gegangen waren sagte Ramboari: „Wir wollen hier warten und den Menschen auflauern die es gewagt haben auf meinem Geburtsplatz den Wald abzubrennen, denn sie müssen, wenn sie von der Arbeit heimkehren, hier vorbeikommen". Sie versteckten sich im dichten Gebüsch und lauerten auf die Menschen. Nach einiger Zeit sagte Rambogana zu seinen Sklaven: „Wir haben für heute nun genug gearbeitet. Die Sonne sinkt, lasst uns nach Hause zurückkehren". Sie nahmen ihre Werkzeuge und machten sich auf den Heimweg. Plötzlich wurden sie aus einem Hinterhalt überfallen. Ramboari fiel Rambogana an und fragte ihn: „Weshalb legst du dir da, wo ich geboren wurde, ein Feld an? Wer hat dich geheissen so zu tun?" Rambogana antwortete: „Mein Vater hat mich geheissen dort mein Feld anzulegen“. Ramboari fragte weiter: „Wer ist dein Vater und wer bist denn eigentlich du?" Rambogana nannte seinen Namen und sprach: „Ich bin der Sohn des Sawuwur und der Sawawar". „Wenn es so ist", sprach Ramboari, „dann sind wir ja Brüder, denn ich bin 
ebenfalls ein Sohn des Sawuwur und der Sawawar und ich wohne in Telok Tumbang Tiwei. Leben meine Eltern noch?" „Ja, sie leben noch", sprach Rambogana, ,und sie wohnen dort drüben in ihrem Dorf". Damit wies er mit der Hand die Richtung. „Es ist gut so", antwortete Ramboari, und er fragte weiter: „bist du verheiratet und hast du auch Kinder?" „Ja“, sprach Rambogana, ,ich bin verheiratet und habe viele Kinder, Knaben und Mädchen“. „Wenn es so ist", sprach Ramboari, „dann geziemt es sich, dass wir uns verschwägern, denn auch ich habe viele Kinder und wir sind Brüder. Ziehe mit deinem Vater und deiner Mutter, deiner Frau und deinen Kindern und allen deinen Sklaven und Gütern zu mir um. Baue dir ein Floss. Lade alles darauf und komm zu mir. Wir wollen auch die Zeit deines Umzuges genau feststellen. In sieben Tagen kommst du, wenn nicht, dann werde ich euch abholen. Wir wollen uns diese Abmachung gegenseitig durch bindendes Versprechen bekräftigen". Nach dieser Unterredung gingen sie auseinander. Ramboari kehrte mit seinen Sklaven nach Hause zurück und so tat auch Rambogana. $\mathrm{Zu}$ Hause angekommen trat Rambogana vor seinen Eltern und er sprach zu ihnen: „Als ich mit meinen Sklaven vom Felde nach Hause zurückkehren wollte überfielen uns in der Mitte des Weges fremde Leute. Der Herr, der uns mit seinen Sklaven dort aufgelauert hatte erklärte mir, dass er euer Sohn und ich sein Bruder sei. Er nannte sich Ramboari und sagte, dass er auf dem Platze geboren worden sei auf dem ich gegenwärtig mein Feld anlege. Er hat viele Kinder, Söhne und Töchter, und er möchte, dass wir uns gegenseitig verschwägern, deshalb bat er mich euch zu sagen, dass wir alle in sieben Tagen zu ihm kommen sollten". Darauf sprachen die Eltern : „Du hast keinen andern Bruder. Früher hat deine Mutter einmal eine Totgeburt gehabt. Ich, der Vater, nahm sie weil sie leblos war und weder Kopf noch Ohren, weder Hände noch Füsse hatte und legte sie in ein Gefäss, dass wir gewöhnlich für die Aufbergung der Nachgeburt brauchen. Ich brachte es zum Fluss hinunter und liess es dann vom strömenden Wasser wegtreiben. Gewiss war es diese Totgeburt die dir als dein Bruder begegnet ist. Auf irgend eine Weise muss er lebend geworden sein. Wir wollen nun tun was er uns geheissen hat". Sawuwur begann mit seinen Kindern und Enkeln ein grosses Floss zu bauen. Als es fertig war beluden sie es mit allen Werkzeugen, Waffen und Hausgeräten. Darauf stiessen sie vom Ufer $\mathrm{ab}$ und fuhren $\mathrm{zu}$ Ramboari. Um die Essenszeit hielten sie an und banden ihr Floss an einem Baume am Ufer fest. Rambogana ging mit seinen Sklaven in den Wald um Brennholz zu holen. Plötzlich sah er 
einen Zwerghirsch. Er sprach zu sich selbst: „Wenn dieser Zwerghirsch nur in meine Nähe kommen würde damit ich ihn erlegen und als Zuspeise zu unserem Reis auf unser Floss bringen könnte“. Der Zwerghirsch kam näher und näher. Rambogana erhob seinen Speer um ihm zu schleudern, aber da wandte der Hirsch plötzlich seinen Kopf nach ihm um und sprach: „Töte mich nicht. Ich möchte dich gerne fragen weshalb du dich auf der Reise befindest und wohin du dich begeben willst". Rambogana antwortete: „Ich begebe mich mit meinen Angehörigen zu meinem Bruder der in Telok Tumbang Tiwei wohnt". Darauf entgegnete der Zwerghirsch: „Begib dich auf keinen Fall dorthin, denn wenn du deinen Bruder besuchst wirst du sterben müssen. Er ist sehr tapfer und er ist kein Mensch, sondern ein böser Geist der viel Gift besitzt mit dem er die Menschen tötet. Er ist ein Hantuen (Hexe, böser Geist), der dich umbringen will. Löse dich und alle deine Angehörigen von deinem Bruder aus. Sende ihm an deiner Stelle Stellvertreter entgegen, damit, wenn er euch abholen will, er diese an euerer Stelle findet und sie mit sich nimmt. Wenn du nun nach Hause kommst, dann baue ein kleines Floss von Sagagulangholz, schnitze aus dem gleichen $\mathrm{Holz}$ menschliche Figuren, für jede Person die sich in deinem Hause befindet eine. Bekleide sie mit Fetzen von eueren Kleidern. Die Figuren der Frauen und Mädchen bekleidest du mit weiblichen Kleidern, die der Männer und Knaben mit Lendentüchern. Dann setzest du diese Figuren auf das Floss, wie man sich auch sonst zu setzen pflegt. Diese Figuren sind euere Stellvertreter, mit ihnen löst ihr euch aus. Von Sagagulangholz schnitzest du Trommeln und Gong, Schwerter und Speere, Ambosse und Hämmer und heilige Töpfe. Dann tötest du ein schwarzes Huhn, kochst schwarzen und weissen Klebreis und auch gewöhnlichen Reis und legst diese Speisen ebenfalls auf das Floss. Dann bringt ihr es zum Fluss hinunter und lasst es durch die starke Strömung euerem Bruder entgegentreiben".

Rambogana dankte dem $Z$ werghirsch für seine Warnung und er kehrte mit seinen Sklaven sofort zum Floss zurück und erzählte seinen Eltern das merkwürdige Erlebnis.

„Wenn es so ist", sprach der Vater, „dann wollen wir den Rat des Zwerghirsches befolgen und sofort nach Hause zurückkehren". $\mathrm{Zu}$ Hause angekommen taten sie wie ihnen der $Z$ werghirsch geraten hatte und als sie das Floss mit den Figuren und Speisen und allen Werkzeugen, Waffen und heiligen Töpfen beladen hatten, brachten sie es zum Fluss hinunter und liessen es von der Strömung wegtreiben. Nach einiger Zeit kam das Floss in Telok Tumbang Tiwei an. Die 
Hampatong, die menschliche Gestalt angenommen hatten, schlugen die Gong und Trommeln. „Hau, hau“, rief Ramboari, „meine Verwandten kommen an, wir wollen zum Fluss hinuntersteigen und sie am Landungsfloss erwarten". Als sie dort ankamen begaben sie sich zu ihren Verwandten auf das Floss. Sie assen von den mitgebrachten Speisen und tranken aus den heiligen Töpfen Bier. Als sie alle betrunken waren sprach Ramboari : „Kommt, lasst uns zusammen in unser Haus gehen". Dort angekommen legten sich die Verwandten auf den Fussboden nieder, denn das genossene Bier hatte sie schläfrig gemacht und sie vermochten nicht mehr die Augen offen zu halten. Ramboari rief nun seinem Pflegevater und seiner Pflegemutter und schrie seinen Sklaven $\mathrm{zu}$ : „Kommt, wir wollen unsere Verwandten zerreissen und wollen ihr Fleisch verzehren". So taten sie. Sie rissen die Leiber der Schlafenden auseinander und verzehrten das Fleisch, aber plötzlich sagte Ramboari: „Das sind ja gar nicht unsere Verwandten, die wir da verzehren, das Fleisch schmeckt gar nicht wie Menschenfleisch, gewiss haben sie Hampatong geschnitzt um sich durch sie vertreten $z \mathfrak{u}$ lassen und $\mathrm{ihr}$ Leben $\mathrm{zu}$ retten und uns damit $z \mathfrak{u}$ betrügen und diese Hampatong nun sind es die wir verzehren. Wenn es aber so ist, dann wollen wir uns sofort aufmachen. Wir wollen zu unseren Verwandten reisen um an ihnen Rache zu nehmen". Seine Pflegeeltern aber antworteten ihm: „Nein, das geschehe nicht, gehe nicht zu deinen Eltern und $z \mathfrak{u}$ deinem Bruder denn du gehörst nicht mehr zu ihnen, du gehörst zu uns Geistern und bist kein Mensch“. Nachdem seine Pflegeeltern so $\mathbf{z u}$ ihm gesprochen hatten verzichtete er auf den Rachezug.

Aengstlich warteten Sawuwur und Sawawar mit ihrem Sohn und ihren Enkeln ob sie nicht von Ramboari verfolgt würden, aber als nichts geschah und alles so blieb wie es sonst auch war, sprach Sawuwur $z \mathfrak{u}$ den Seinigen: ,Wir sind ein grosses Geschlecht geworden. Ramboari wird uns, die wir an den Ufern des Flusses der Welt wohnen, immer wieder verfolgen wollen, aber wenn ihr und eure Kinder und Enkel euch immer dieser Mythe erinnert und immer nach der Ernte so handelt wie wir nun gehandelt haben, dann wird euch kein Leid geschehen. Ramboari wird immer nur eure Stellvertreter mit sich nehmen, aber ihr werdet heilvoll und im Frieden an den Ufern des Flusses der Welt wohnen und euer Bruder wird euch kein Leid zufügen können.

Nachdem der Priester (Tukang Tawur), zusammen mit Rika Bulau Hatuen Antang Ganan Tadjahan und den Reisseelen, diese Mythe rezitiert hat spricht er: „Diese Mythe befolgen wir und nach ihr 
handeln wir damit uns Radja Peres nicht erreichen und uns kein Unheil überfallen kann". Darauf führt der Priester' mit den stellvertretenden Hampatong die gleichen Handlungen aus und spricht die gleichen Worte wie sie bereits mitgeteilt wurden und wenn diese abgeschlossen sind bringt man das Floss zum Fluss hinunter und lässt es von der starken Strömung wegtreiben.

Wenn das geschehen ist nimmt der Priester ein Bündel Blätterzweige die zusammengestellt sind von Dahian-, Batupak- und Lesizweigen, legt sie in einen Sangko (ein Gefäss) und taucht diesen im Fluss unter. Darauf tritt er mit dem nassen Bündel vor jeden Dorfbewohner. Er bestreicht einen nach dem andern und spricht dazu die Worte :

Ich wische dich ab. Ich wische von dir weg Krankheit und Unheil. Wie das Wasser kalt ist, das von diesen Blättern träufelt, so sei auch dein Befinden kalt.

Wenn das geschehen ist dann macht der Priester in jeder Person wieder die Seele fest, indem er Reis auf den Kopt jedes Einzelnen streut und seine Seele zurückruft, damit sie nicht mit dem Floss mitreise und sich nicht verirre.

\section{d. Manolak Puru (Verabschiedung der Pocken)}

Eine der schwersten Epidemien die früher die Dajak heimgesucht und ihre Dörfer gelichtet hat war die puru oder Pocken, die durch die Zwangsimpfung schon seit Jahrzehnten wirkungsvoll bekämpft worden ist. Auch diese Krankheit zog von Westen, von Sonnenuntergang her, die Flüsse aufwärts und verbreitete sich von Dorf zu Dorf. Hörte man, dass die Krankheit im Anzug sei, dann versammelte sich die Dorfbevölkerung mit dem Priester um das manolak Puru vorzunehmen. Es wird, wie oben mitgeteilt, ebenfalls ein Floss gebaut und in der gleichen Weise beladen und vom Ufer weggestossen, wobei die gleichen Handlungen vorgenommen und die gleichen Worte gesprochen werden.

Hat sich Rika Bulau Hatuen Antang Ganan Tadjahan eingestellt dann rezitiert der Priester mit ihm und mit den Reisseelen zusammen die Mythe von:

\section{Pulang Gana und Putir Seri Bunge}

Die Mythe lautet: In früheren Zeiten lebte Pulang Gana mit seiner Schwester Putir Seri Bunge. Als Pulang Gana zu einem Jüngling herangewachsen war, verheiratete er sich mit Putir Seri Hawon. Nach 
einiger Zeit wurde die Frau schwanger und als sich ihre Zeit nahte, dass sie gebären sollte, schenkte sie einem Kinde das Leben. Aber als sie das Kind sah da erschrak sie sehr, denn es lebte beinahe nicht und es hatte auch keine Hände und Füsse und war über und über mit Blut bedeckt. Es konnte nur weinen. „Pfui”, sagten Pulang Gana und seine Frau, ,unser Kind ist sehr hässlich gestaltet. Es ist nicht wie andere Kinder. Wir müssen uns vor allen Leuten schämen und deshalb ist es das Beste wenn wir es wegwerfen. Pulang Gana machte von Pinangrinde ein Gefäss das einem kleinen Boote glich, legte das Kind hinein, brachte es zum Fluss hinunter und liess es von der Strömung wegtreiben.

Nach kurzer Zeit kam das Gefäss mit dem immerfort weinenden Kinde an der Mündung des Flusses, die am Meere lag, an. Es wurde von den Wellen hin und hergeworfen. Einmal trieb es flussaufwärts, dann wieder flussabwärts aber schliesslich trieb es aufs offene Meer hinaus. Eines Tages blieb es an einem Landungsfloss hängen, denn mitten im Meere lag auf einer Insel das Dorf Puser Tasik. Es war das Dorf des Pandjangen Hatuen Laut und seiner Frau Balo Kambang Maraung, die beide wilde Hantuen (Hexen, böse Geister) waren und jeden der sich auf ihre Insel verirrte unbarmherzig auffrassen. Sie nährten sich von ahnungslosen Reisenden und armen Schiffbrüchigen.

Es war ein sehr heisser Mittag als das Gefäss mit dem neugeborenen, weinenden Kinde gegen ihr Landungsfloss trieb und dort hängen blieb. In den Häusern war es sehr schwül. Niemand hielt es in ihnen lange aus. So sprach auch Balo Kambang Maraung zu ihrem Manne: „Begleite mich zum Bade an das Landungsfloss hinunter. Ich halte es im Hause nicht mehr aus und ich muss meinen Leib etwas abkühlen im Wasser des Meeres". Sie verliessen zusammen das Haus und als sie bei der Treppe, die zum Landungsfloss hinunterführte, angekommen waren schauten sie zuerst etwas herum. Plötzlich erstaunten sie, denn sie hörten das Wimmern eines kleinen Kindes. Als sie nachforschten woher die Stimme kommen könnte, sahen sie das Gefäss mit dem armseligen Kind an ihrem Landungsfloss. Sie waren sehr erfreut über diese neue Beute die ihnen die Wellen zugetrieben hatten und stürzten sich rasch auf das Gefäss, rissen das Kind heraus, leckten sein Blut ab und wollten es verzehren. „Pfui“, riefen sie, „das Fleisch dieses Kindes schmeckt sehr schlecht und scharf, wir können es nicht geniessen“. „Wir wollen dieses Kind nicht verzehren“, sagte Balo Kambang Maraung, „sondern wir wollen es als unser eigenes Kind annehmen und aufziehen, denn wir sind ja kinderlos". Sie brachten 
es ins Haus und pflegten es sehr gut. Sie machten ihm Arme und Beine und nannten es Pintoari.

Viele Jahren waren vorbeigegangen seit Pintoari durch seine Pflegeeltern an Kindesstatt angenommen worden war. Er war $\mathrm{zu}$ einem kräftigen Jüngling herangewachsen der bereits allein auf die Jagd und zum Fischfang ausziehen konnte und alle Arbeiten zu verrichten vermochte. Eines Tages nahm er das Wurfnetz und rief zwei Sklaven und bestieg mit ihnen das Boot. Sie ruderten an den nahen Strand und warfen dort ihre Netze aus aber ohne dass es ihnen gelang etwas zu fangen. Sie ruderten weiter. Wieder warf Pintoari das Netz aus, aber auch hier hatte er keinen Erfolg. Sie probierten es noch viele Male, sie probierten es da und dort, aber nie gelang es ihnen auch nur einen Fisch zu fangen. Endlich kamen sie zu der Mündung eines Flüssleins. Wieder warf Pintoari das Netz aus und diesmal gelang es ihm auch einige Fische zu fangen. „Hau“, sagte er, „hier scheint es günstig zu sein. Wir wollen das Flüsslein hinaufrudern um auch dort unser Netz auszuwerfen". Langsam ruderten sie weiter. Plötzlich sahen sie Reisspreu und Reishalme auf dem Flusse dahertreiben. Offenbar hatten sich Menschen an diesem Fluss ein Feld angelegt und waren nun mit der Ernte beschäftigt. „Leha-lehan!" sagte Pintoari, „wer sind wohl die Menschen und wie mögen sie heissen, die es wagen an diesem Flüsslein ihr Feld anzulegen. Has, wir wollen weiterrudern um sie $\mathrm{zu}$ finden und $\mathrm{zu}$ töten, denn niemand hat das Recht hier $\mathrm{zu}$ wohnen und hier sein Feld anzulegen. Ich bin der Besitzer dieses Flusses und seiner Ufer, denn ich bin hier geboren worden. Töten wir die Menschen, die es gewagt haben auf meinem Grund Reis zu bauen und zerstören wir ihre Hütten!" „Nein“, sagten seine Sklaven, „tue das ja nicht, o Pintoari, denn vielleicht sind es Verwandte von dir die sich hier Dorf und Feld angelegt haben“. „Ja“, antwortete Pintoari, „ihr habt recht. Wir wollen nun nicht unbedachtsam handeln sondern uns zuerst gut nach den Leuten erkundigen. Sind sie seit langer Zeit hier ansässig, dann wollen wir ihnen nichts tun. Wohnen sie aber erst kurze Zeit hier, dann werden wir sie umbringen".

Sie ruderten weiter und als sie sieben Flussbiegungen vom Meere entfernt waren sahen sie im Wald ein Feld auf dem die Leute mit der Ernte des Reises beschäftigt waren. Es war das Feld des Pulang Gana, der hier von Zeit zu Zeit Reis baute und mit seinen Angehörigen und Sklaven zusammen sich hier sein Dorf aufrichtete. Der Ort hiess Tandjong Geting Mahakang Dohong. Pintoari legte mit seinen Sklaven am Landungsfloss an. Sie stiegen ans Ufer und sahen vor sich sieben 
Hütten und einen kleinen Balai (Versammlungs- und Fremdenhaus). Sie begaben sich, wie es sich für Besucher geziemt, zuerst in den Balai und riefen von dort dreimal $z u$ den Hütten hinüber nach Menschen. Endlich bekamen sie eine Antwort und sie hörten wie jemand zu seinem Sklaven sagte: „Nimm das Sirihgefäss und bringe es den Fremden ins Fremdenhaus hinüber". „Nein, mein Herr", sagte der Sklave, „,ich gehe nicht hinüber, ich habe den Mut nicht dazu, denn die Fremden sehen wenig vertrauenswürdig aus". Der Besitzer des Hauses entschloss sich nun die Fremden selbst im Balai zu besuchen. Er gürtete den Dolch und den Pfeilköcher um, ergriff das Blaserohr und das Sirihgefäss, verliess das Haus und schritt zum Balai hinüber. Dort begrüsste er die Fremden, setzte sich zu ihnen und schob ihnen den Sirih zu. Dann fragte er sie nach ihrem Woher und Wohin und welches das Anliegen sei, das sie in sein Dorf führe. Pintoari antwortete ihm: „Ich bitte dich, sage mir doch wer es gewagt hat hier sein Dorf und Feld anzulegen, denn der Fluss und seine Ufer gehören mir. Ich bin hier geboren worden und habe deshalb hier Eigentumsrechte weil ich von hier abstamme. Niemand anders darf hier ohne meine Erlaubnis wohnen".

Pulang Gana, denn er selbst war es, der sich zu den Fremden begeben hatte, fragte den Fremden: „Wie willst du es begründen, dass du hier das Recht auf den Fluss und seine Ufer habest und dass du hier geboren seiest? Ich wohne schon seit den frühesten Zeiten hier und als ich an diesen Fluss kam hielten sich noch keine andern Menschen hier auf. Wer bist du denn eigentlich?" „Es verhält sich so“, antwortete Pintoari, ,,ich bin hier geboren worden. Ich kam als eine Fehlgeburt zur Welt und weil ich sehr hässlich war und keine Hände und Füsse besass verwarfen mich meine Eltern. Sie legten mich in ein Gefäss und liessen mich auf diesem Flusse hier von der Strömung wegtreiben. Ich trieb lange herum. Schliesslich blieb ich an einem Landungsfloss in Puser Tasik, in der Mitte des Meeres, hängen. Pandjangen Hatuen Laut und seine Frau Balo Kambang Maraung fanden mich. Sie haben mich an Kindesstatt angenommen und aufgezogen. Weil ich aber von hier stamme, deshalb gehören Fluss und Ufer auch mir". Pulang Gana erschrak als er diese Worte hörte, denn er wusste, dass er seinen Sohn vor sich hatte. Deshalb antwortete er ihm: „Niemand anders hat ein Kind verstossen und vom Fluss wegtreiben lassen als ich. Ich bin dein Vater, du aber bist mein Sohn. Füge uns deshalb kein Leid zu. Bleibe bei uns. Verheirate dich hier, ich will dir die Tochter meiner Schwester Putir Seri Bunge zur Frau 
geben. Sie ist in deinem Alter und sie ist ein sehr schönes Mädchen namens Putir Djundjung Lupak“. „Ich bin mit deinem Vorschlag einverstanden“, antwortete Pintoari, ,aber nur unter der Bedingung, dass wir uns nicht hier sondern in Puser Tasik, bei meinen Pflegeeltern, verheiraten". Pulang Gana war damit einverstanden, obgleich es nicht der Sitte entsprach, dass das Mädchen im Dorfe ihres zukünftigen Mannes verheiratet wurde. Sie besprachen nun mit den Eltern des Mädchens die Heiratsbedingungen und die Heiratssumme und als sie zur Uebereinstimmung gekommen waren, beschlossen sie in zehn Tagen nach Puser Tasik zu reisen und ihre Tochter dort $z u$ verheiraten. Pintoari wurde ins Haus seiner Eltern aufgenommen. Sie bereiteten ihm ein grosses Fest. Sie schlachteten ein Schwein und bestrichen mit dessen Blut seinen ganzen Körper. Sie umbanden ihm Armringe und Goldschmuck um damit seine Seele zu stärken und ihn als vollwertiges Glied in die Hausgemeinschaft und Familie aufzunehmen.

Am andern Tage kehrte Pintoari mit seinen Sklaven wieder zu seinen Pflegeeltern nach Puser Tasik zurück. Sie hatten sich bereits um ihn besorgt gemacht weil er die ganze Nacht fortgeblieben war ohne sie vorher über seine Pläne zu unterrichten. Als er am Landungsfloss ankam badete er zuerst, dann betrat er das Haus, nahm das Essen ein, darauf kaute er Sirih und dann erzählte er seinen Pflegeeltern was sich zugetragen hatte. Er sagte: „In zehn Tagen soll ich hier verheiratet werden mit meiner Nichte Putir Djundjung Lupak, der Tochter meiner Tante Putir Seri Bunge. Mein Vater, den ich auf meiner Reise gefunden habe, wird sie mit allen meinen Verwandten zusammen herführen. Ich bitte euch, befehlt doch den Sklaven, dass sie Brennholz hacken, Bambusköcher zum Kochen bereit machen, den Reis sonnen und stampfen und Bier brauen, denn alles muss bis dahin bereit sein. Sie werden ganz gewiss kommen, denn sie haben es mir versprochen".

Auch Pulang Gana machte mit seinen Angehörigen und Sklaven alles für die Reise bereit und traf auch alle Vorbereitungen für das kommende Fest. Sie hackten Holz, schnitzten die Bambusköcher in denen sie den Reis kochen wollten und brauten Bier. Am neunten Tage beluden sie das Floss mit Kühen, Schweinen, Hühnern, Gong und heiligen Töpfen, mit Bier und Reis, mit Kuchen und Klebreis. Am zehnten Tage breiteten sie über dem Floss ein Dach von köstlichem Stoff aus und als alles bereit war bestieg Pulang Gana mit seinen Leuten und mit Putir Djundjung Lupak das Floss und sie stiessen vom Ufer ab. 
Sie waren schon einige Zeit flussabwärts gefahren, da sprach Pulang Gana zu seinen Sklaven: „Wir wollen hier anhalten um abzukochen und die Mahlzeit einzunehmen, denn es ist schon hoher Mittag und wenn wir in Puser Tasik ankommen, dann haben wir weder zum Kochen noch zum Essen Zeit". „Ja", sprachen seine Sklaven, „deine Rede ist gut". Sie steuerten das Floss ans Ufer und banden es dort fest. Einige der Sklaven fachten das Feuer an, andere kochten ab. Während sie mit diesen Arbeiten beschäftigt waren sahen sie plötzlich einen $Z$ werghirsch der sich ihnen nahte. „Wir wollen ihn fangen und töten und sein Fleisch als Zuspeise zubereiten!" Mit diesen Worten standen sie auf um den $Z$ werghirsch zu verfolgen. Aber als sie in seine Nähe kamen blieben sie erstaunt stehen, denn das Tier sprach sie mit menschlicher Stimme an: „Fangt mich nicht, erkennt mich zuerst. Ich bin kein gewöhnlicher $Z$ werghirsch, ich habe Macht. Ich habe Mitleiden mit euch und ich will euch mitteilen welches Los euch in Puser Tasik erwarten wird". Sie erstaunten sehr nachdem sie diese Worte gehört hatten und sie sprachen zueinander: „Er sagt die Wahrheit. Er hat wirklich Macht, denn bis jetzt hat noch nie ein Zwerghirsch zu uns gesprochen“, und Pulang Gana bat ihn: „Sage uns doch was uns in Puser Tasik erwarten wird“. Er sprach: „Reist auf keinen Fall dorthin. Führt eure Nichte nicht zu Pintoari und verheiratet sie nicht mit ihm. Seine Pflegeeltern sind keine Menschen, sie sind Hantuen die sich von Reisenden und armen Schiffbrüchigen ernähren. Wer sich in ihr Dorf begibt kommt nicht mehr mit dem Leben davon. Auch euch werden sie verzehren und Pintoari wird sich an diesem grausigen Mahl beteiligen, denn er ist selbst zu einem Hantuen geworden. Aus diesem Grunde gebe ich euch den Rat: Kehrt wieder in euer Dorf zurück. Gehorcht ihr diesem Rat und führt ihr eure Reise nicht aus, dann rate ich dir, Pulang Gana: Befiehl, daheim angekommen, deinen Sklaven Sagagulangholz zu suchen. Schnitze von diesem Holz für jeden deiner Angehörigen und Sklaven eine menschliche Figur. Bekleide die männlichen Figuren mit männlichen Kleidern und die weiblichen mit weiblichen Kleidern, die ihr von eueren eigenen Kleiderfetzen herstellen müsst. Bespuckt sie dreimal und weist sie dreimal mit der linken Hand von euch weg. Schnitzt heilige Töpfe, Gong, Waffen und zwei Rudersklaven die ihr an das Steuer und an den Kiel stellt. Wenn alles bereit ist, dann baut ihr ein kleines Floss von Bamban (eine Art Bambus). Legt alles darauf. Dann sprichst du zu den Figuren, dass sie eure Gestalt anzunehmen haben. Sie werden sich nach diesen Worten in Menschen verwandeln. Sie werden essen 
und trinken, sie werden die Trommeln und Gong schlagen und sie werden laut jauchzen. Dann bringt ihr das Floss zum Fluss und lasst es von der Strömung wegtreiben nach dem Meer und nach dem Dorf Puser Tasik".

Nachdem der $Z$ werghirsch so gesprochen hatte bat er um Erlaubnis heimkehren $z \mathfrak{u}$ dürfen und er verabschiedete sich von Pulang Gana und seinen Angehörigen. Pulang Gana sprach: „Wir nehmen das Wort und den Rat dieses Zwerghirsches an. Wir setzen unsere Reise nicht fort sondern wir kehren wieder um", und so fuhren sie wieder flussaufwärts nach Tandjong Geting Mahakang Dohong. $\mathrm{Zu}$ Hause angekommen handelten sie nach dem Rat des $Z$ werghirsches und liessen an ihrer Stelle ein Floss mit ihren Stellvertretern und mit Opfergaben beladen wegtreiben. Nach einiger Zeit kam es in Puser Tasik an und als Pintoari in seinem Haus das Jauchzen und den Laut der Trommeln und Gong hörte sagte er zu seinen Angehörigen: „Has, wir wollen meine Verwandten am Landungsfloss erwarten, denn gewiss sind sie es die ankommen. Holt meine Braut Putir Djundjung Lupak ab und geleitet sie ins Haus. Bereitet das Essen und das Bier".

Als das Floss ankam wurden die Verwandten mit Ehren empfangen und mit ihren Schätzen, die sie mitgebracht hatten, ins Haus geführt. Am andern Tage feierten sie die Hochzeit. Man war fröhlich und man ass und trank den ganzen Tag. Als die Dunkelheit hereingebrochen war, waren alle so trunken, dass sie zu Boden fielen und sofort einschliefen. „O meine Sklaven“, rief Pandjangen Hatuen Laut, „ergreift diese Menschen, packt einen um den andern und führt sie hieher. Wir wollen sie zerreissen und uns an ihrem Fleische gütlich tun". Aber was geschah! Als sie die Verwandten brachten, da verwandelten sie sich alle, einer um den andern, in kleine hölzerne Schnitzbilder, in Hampatong. Pandjangen Hatuen Laut und Balo Kambang Maraung und Pintoari lärmten und tobten als sie sahen wie sie betrogen worden waren, aber ihr Zorn half ihnen nichts mehr.

„Lalehan“, sprach Pandjangen Hatuen Laut zu seiner Frau und zu seinem Sohn: „Gross ist die Weisheit der Menschen an den Ufern des Flusses der Welt. Es ist ein grosser Gewinn für sie, dass sie diese Arbeiten und Handlungen kannten und dass sie wussten auf welche Weise sie sich von uns auszulösen hatten. Wenn ihre Kinder und Enkel immer so handeln wie Pulang Gana getan hat, sobald sie die Botschaft vernehmen, dass die Puru (Pocken) im Anzug sei, wenn sie sich immer auf diese Weise auslösen und nichts vergessen von 
dieser Mythe, dann werden sie heilvoll und im Frieden am Flusse der Welt leben und wir werden über sie keine Macht haben".

Nachdem der Priester, mit Rika Bulau Hatuen Antang Ganan Tadjahan und den Reisseelen zusammen, diese Mythe rezitiert hat, spricht er: „Diese Mythe befolgen wir und nach ihr handeln wir damit uns die Geister von Puser Tasik kein Leid zufügen können". Dlarauf wiederholen sich die gleichen Handlungen wie sie oben dargestellt wurden und die Puru sind dadurch verabschiedet und das Dorf hat vor dem Umsichgreifen der Krankheit nichts mehr zu befürchten.

\section{e. Das stellvertretende Opfer bei der Schwangerschaft}

Die Zeit der Schwangerschaft ist eine heilige und gefährliche. Während ihr häufen sich die Palivorschriften. Diese müssen sowohl vom Mann als auch von der Frau beachtet werden damit die Schwangerschaft normal und günstig verläuft und sich die Geburt in der rechten Weise vollzieht. Zahlreiche Mächte gefährden während dieser Zeit das Leben der werdenden Mutter und des Kindes. Man bringt diesen Mächten verschiedene Opfer dar. Das wichtigste unter ihnen ist das, im siebenten oder achten Monat der Schwangerschaft vollzogene stellvertretende Opfer für Mutter und Kind, das den Geistern dargebracht wird, die sie und ihr Kind zerstören wollen. Dieses Opfer wird dargebracht durch einen Tukang Mangadiri. Meistens ist dieser Tukang eine alte Frau, oder ein Mann, gewöhnlich aber nicht der Priester, was natürlich nicht ausschliesst, dass auch er dieses stellvertretende Opfer darbringen und die Handlungen vollziehen kann. Bedingung ist, dass der Tukang Handlungen und Mythe kennt.

Ich gebe hier, wegen der Verbreitung und auch wegen der Wichtigkeit dieses Opfers, das man in ganz Borneo findet, als Beispiel verschiedene dieser Opferhandlungen aus verschiedenen katinganischen Dörfern und Geschlechtern wieder.

\section{Das stellvertretende Opfer in Penda-Hara}

Zwischen dem siebenten und neunten Monat der Schwangerschaft bringt man das stellvertretende Opfer für die Schwangere dar. Man weicht zuerst weissen und schwarzen Reis ein. Wenn er weich geworden ist wird er getrocknet und darnach zu Mehl gestampft. Vom Mehl des weissen Klebreises formt man zwei menschliche Figuren, die 
die Mutter und das Kind darstellen sollen. Aus dem Mehl des schwarzen Klebreises formt man verschiedene Fische die das Leben der Mutter und ihres Kindes bedrohen, unter anderen Barira-, Tampahas-, Ula- und Djaleketfische, ebenso formt man von ihm noch eine Lindong, eine etwa armdicke, rot und schwarz gestreifte Wasserschlange, einen Bahong, ein fingergrosser Wurm und noch verschiedene andere Schlangen. Man legt alle diese Figuren auf eine Reismatte und bedeckt sie mit Pisangblättern, nachdem man ihnen als Opfergaben noch beigefügt hat: etwas Sirih, Tabak, Salz, Reis, einige Tuchfetzen und etwas Haar der Schwangeren.

Alle weitere Handlungen sind gleich wie oben. Die Reismatte wird vom Tukang und seinen Helferinnen zum Flussufer- oder zum Landungsfloss gebracht. Dann besingt der Tukang den Reis und schickt die Reisseelen zu Radja Batunggul Bulau der am Fuss des Djanggibaumes im Dorfe Puser Tasik wohnt damit sie ihm die Figuren und Opfer überbringen. Mit ihnen überbringen sie aber auch die Bitten des Tukang, die folgendermassen lauten:

Befehlt (das wird zu den Reisseelen gesagt die nach Puser Tasik reisen) den Sklaven des Radja Batunggul Bulau, dass sie die Opfer für die Schwangere und für das von ihr zu erwartende Kind abholen, denn sie sind bereit für sie. Sprecht zu Radja Batunggul Bulau: „Nicht störe mehr mit deinen Sklaven die Schwangere und das Kind das sie erwartet. Nicht vernichte ihr Leben, denn wir bringen dir zu ihrer Auslösung genügend Opfer". Fragt ihn ob sich ihre Seelen, irregeleitet durch seine Sklaven und geraubt durch sie, schon verirrt haben, ob sie schon entführt worden seien, und bittet ihn sie euch zurückzugeben.

Darnach wirft der Tukang die Opfergaben ins Wasser und wartet etwa fünf Minuten. Dann ruft er die Seelen seiner Helfer oder Helferinnen zurück und er überträgt die zurückgebrachte Seele auf die Schwangere und das Kind.

\section{Das stellvertretende Opfer in Tumbang-Lahang}

In Tumbang-Lahang unterscheidet man zwei stellvertretende Opfer für Schwangere. Das eine dieser beiden Opfer ist das allgemein gebräuchliche, das in allen Fällen zwischen dem siebenten und neunten Monat dargebracht werden muss; das andere wird nur dargebracht, wenn sich die Schwangere immer unwohl fühlt und über nicht nachzulassende Bauchschmerzen klagt. 
Das übliche stellvertretende Opfer darf nicht vor dem siebenten Monat dargebracht werden. Die Vorbereitungen sind beinahe die gleichen wie sie oben dargestellt wurden. Die Opfergaben und Hampatong (Schnitzfiguren oder Reisfiguren) von Reis legt man in zwei flache Opferkörbe, die von Bambus geflochten werden. In manchen Dörfern werden statt der Opferkörbe (man nennt sie antjak) auch Flosse gebraucht.

Die beiden Antjak stellt man mitten im Hause auf. Auf der einen Seite des Fussbodens 141 setzt sich die Schwangere, auf der andern Seite setzt sich der Tukang. Er rezitiert, zusammen mit Rika Bulau Hatuen Antang Ganan Tadjahan und den Reisseelen die Mythe von:

\section{Benang Kanjangan Tewang und Tipung Kandajun Tandjong}

Die Mythe lautet: In dem Dorfe Kiham Balaki Tumbang Tarusan wohnten in früheren Zeiten zwei Schwestern namens Benang Kanjangan Tewang und Tipung Kandajun Tandjong. Das Dorf war damals sehr reich und auch sehr gross und man lebte dort herrlich und in Freuden, denn zahlreiche Sklaven besorgten die täglichen Arbeiten und sie mehrten den Reichtum.

Von überall strömten die Händler herbei, verkauften und kauften die Produkte ein, die durch die Sklaven eingesammelt worden waren. Eines Tages kamen im Dorfe zwei Brüder mit ihrem grossen Handelsboot (banama) und zahlreichen Sklaven an. Der eine von ihnen hiess Ehing Baburing Bulau, der andere nannte sich Rakang Hagandang Tarong. Sie waren tapfere, schöne Männer und reiche Händler. Tag für Tag kamen die Leute um bei ihnen einzukaufen und ihr Boot wurde nie leer. Eines Tages kamen auch die beiden Schwestern Benang Kanjangan Tewang und Tipung Kandajun Tandjong zum Boot hinunter um die Güter zu besichtigen und Kleiderstoffe zu kaufen. Nachdem sie sich wieder entfernt hatten sprachen die beiden Brüder: „Kai-kai, wie schön sind doch diese beiden Frauen. Wir wollen uns erkundigen ob sie schon verheiratet seien oder nicht, und wenn sie es noch nicht sind, dann wollen wir um ihre Hand bitten und uns mit ihnen verheiraten". Sie forschten die Leute nach ihnen aus und sie vernahmen, dass sie beide noch Jungfrauen seien die man noch keinem Manne verlobt hätte. Als sie das hörten freuten sie sich sehr und sie entschlossen sich die Angehörigen zu besuchen und mit ihnen die Heirat zu besprechen und den Brautpreis festzusetzen. So taten sie. Ihre Bitte wurde angenommen und nicht lange darnach verheirateten sie sich mit den beiden Schwestern. Nach einiger Zeit wurden sie 
schwanger. Ihre Männer trieben immer noch Handel im Dorf und ihr Geschäft blühte und sie wurden reich und angesehen.

Eines Tages entschlossen sie sich nach dem Oberlauf des Flusses $z \mathfrak{u}$ reisen $\mathbf{u m}$ auch dort Tauschhandel $\mathbf{z u}$ treiben. Sie teilten ihren Entschluss ihren Frauen mit und diese waren mit ihrer Reise einverstanden und machten ihren Männern alles bereit was sie zu ihrer Reise benötigten. Bevor diese ihre Reise antraten, besserten sie mit ihren Sklaven zusammen noch das Boot aus, dann brachten sie es ins Wasser und beluden es mit Handelsgütern. Dann warteten sie noch einen günstigen Tag, der ihnen durch die Vorzeichen (dahiang) angezeigt wurde, ab und dann verliessen sie am dritten Tage das Dorf und fuhren langsam flussaufwärts. Sieben Sklaven ruderten vorne im Boot, sieben Sklaven ruderten hinten im Boot. Nach einiger Zeit kamen sie in den Dörfern des Oberlaufes an. Sie hielten sich überall lange auf und trieben mit den Leuten Handel. Für ihre Handelsgüter tauschten sie Rotan, Tengangschnüre, Eisenholz, Harz, Gummi und Gold ein. Schon waren sie vier Monate vom Hause weg aber immer noch setzten sie ihre Geschäfte fort und sie dachten nicht daran zu ihren Frauen zurückzukehren.

Bevor sie ihre Reise angetreten hatten, hatten sie ihren Frauen die Pali mitgeteilt die sie während der Schwangerschaft und während ihrer Abwesenheit beobachten mussten und sie sagten ihnen: „Wir verlassen euch nun. Während euerer Schwangerschaft habt ihr manche Pali zu beobachten die hier in euerem Dorfe unbekannt sind, aber die von den Frauen unseres heimatlichen Dorfes innegehalten werden müssen. Wir wollen sie euch nennen. Beobachtet ihr diese Pali nicht, dann zerstört ihr nicht nur euer eigenes Leben, ihr vernichtet auch euer Kind und uns. Wir dürften dann nicht mehr bei euch leben, wir müssten heimziehen, wir müssten euch für immer verlassen und dadurch würde unsere Ehe zerstört werden. Dies sind die Pali: Wenn ihr euere Haare wäscht, dann dürft ihr dafür nicht wie üblich Zitronen oder Balimbingfrüchte verwenden. In euere Haarknoten dürft ihr keine duftenden Taran- und Sahipangblumen einflechten. Zum Kauen, oder als Medizin, dürft ihr keine Sekur- und Djarangauhölzer und -blätter verwenden. Wenn ihr Flechtarbeiten ausführt, dann dürft ihr den Abfall nicht durch die Oeffnungen des Hauses auf die Strasse hinauswerfen. Beim Sirihkauen dürft ihr nur in den Spucknapf ausspucken, nicht aber auf den Fussboden oder durch seine Ritzen unter das Haus auf die Erde. Das sind die Pali, die wir euch nennen müssen und die ihr zu beobachten habt, wollt ihr euch, euer Kind und uns 
nicht ins Verderben stürzen“. Die Frauen versprachen ihren Männern sich dieser Worte erinnern und die Pali innehalten zu wollen, aber als die Männer solange Zeit wegblieben und nicht zurückkehrten, vergassen sie mehr und mehr was sie ihnen gesagt und was sie darauf versprochen hatten. Eines Tages sprach Benang Kanjanang Tewang zu ihrer Schwester: „O meine jüngere Schwester (man unterscheidet zwischen älterer und jüngerer Schwester oder Bruder. Die ältere Schwester nennt man kaka, die jüngere andi), wie lange ist es doch schon her seit wir das letzte Mal unsere Haare gewaschen haben und sie mit duftenden Blumen schmückten. Ich halte es nicht mehr aus, ich muss es wieder einmal tun“. „An das was du zu tun wünschest habe ich soeben auch gedacht", antwortete Tipung Kandajun Tandjong, ,unsere Gedanken treffen zusammen und das ist ein gutes Zeichen. Geben wir doch unseren Sklavinnen den Auftrag, dass sie für uns Zitronen und Balimbingfrüchte, Taran- und Sahipangblumen holen". So taten sie und sie erinnerten sich nicht mehr der Worte ihrer Männer. Nachdem die Sklavinnen zurückgekehrt waren stiegen sie zusammen zum Fluss hinunter. Sie badeten sich und wuschen darauf ihre Haare mit den verbotenen Früchten, dann schmückten sie die Haarknoten mit den Blumen und stiegen wieder ins Haus hinauf. Dort setzten sie sich auf den Fussboden, griffen zum Sirih, vermengten ihn mit Pinang, Kalk und mit Sekurblättern und begannen zu kauen und zu plaudern. Von Zeit zu Zeit spuckten sie durch eine Ritze des Fussbodens unter das Haus auf die Erde. Als sie des Kauens satt waren setzten sie sich $z \mathfrak{u}$ einer Oeffnung des Hauses und ergriffen ihre angefangenen Flechtarbeiten um sie fortzusetzen. Den Abfall warfen sie durch die Oeffnung vor das Haus hinaus auf den Weg. An keine einzige der Palivorschriften ihrer Männer erinnerten sie sich noch, alle Pali hatten sie vergessen.

Am gleichen Tage, als diese Dinge in Kiham Balaki Tumbang Tarusan geschahen, fühlten sich ihre Männer in einem der Dörfer am Oberlauf des Flusses plötzlich unwohl und krank werden. Das Fieber schüttelte sie so stark, dass auch das Boot zu schwanken begann. Sie riefen ihren Sklaven zu: „O unsere vierzehn Sklaven, wir sind schwer krank geworden und wir wollen sofort in unser Dorf Kiham Balaki Tumbang Tarusan zurückkehren. Beladet das Boot rasch, zieht noch die Schulden ein wo es möglich ist sie einzuziehen, den Rest können wir leicht später in Empfang nehmen. Rudert darnach so stark ihr könnt, wir wollen Tag und Nacht durchreisen". Die Sklaven taten wie sie von ihren Besitzern geheissen worden waren. Sie ruderten sieben 
Tage und sieben Nächte. Endlich kamen sie in ihrem Dorfe an und machten das Boot am Landungsfloss ihres Hauses fest. Als das geschehen war sprachen die beiden kranken Besitzer zu ihren Sklaven: „Holt unsere Frauen. Wir können nicht mehr in unser Haus hinaufsteigen, wir sind zu krank und zu schwach". Die Sklaven stiegen ins Haus hinauf und sprachen zu den Frauen ihrer Besitzer: „O unsere Herrinnen, unsere Sangiang (Die Sangiang sind göttliche Ahnen die in der Oberwelt wohnen. Die Freien sind mit ihnen verwandt und die Unfreien, die Sklaven, hatten ihre Besitzer anzusprechen: Tempongku, Sangiangku: mein Herr und mein Sangiang), unsere Herren bitten euch, dass ihr zu ihnen ins Boot heruntersteigen möchtet. Sie sind vor sieben Tagen schwer krank geworden und es ist ihnen nicht möglich ins Haus heraufzukommen". Die Frauen machten sich sofort bereit und stiegen zum Landungsfloss herunter und begaben sich zu ihren Männern in das Boot. Sie setzten sich zu ihrer Seite und weinten bitterlich. Ehing Baburing Bulau sprach zu seiner Frau mit schwacher Stimme: „O Benang Kanjanang Tewang, ich muss dich für immer verlassen. Bleibe hier zurück. Pflege dich gut und ziehe unser Kind in der rechten Weise (d.h. nach der Hadat) auf. Meinen Reichtum lasse ich hier für dich und unser Kind zurück. Meine Zeit ist gekommen, ich muss scheiden und dich und unser Kind für immer verlassen weil du die Pali, die ich dir aufgetragen habe, nicht beobachtet hast. Ich kann dagegen nichts unternehmen, wir müssen uns nun trennen und wir müssen für immer scheiden obgleich du der Ort meiner Liebe bist (eka sintangku)“. Mit den gleichen Worten sprach auch Rakang Hagandang Tarong zu seiner Frau Tipung Kandajun Tandjong und nachdem sie so gesprochen hatten, brachen alle in Weinen und Schluchzen aus. Die Frauen versuchten ihre Männer ins Haus zu bringen aber diese wehrten ab. Inzwischen hatten die Sklaven alle Güter und Reichtümer ausgeladen und in das Haus der Frauen ihrer Herren gebracht. Mit Herzeleid und unter vielen Tränen verliessen die Frauen ihre Männer. Die Sklaven nahmen mit den Rudern in der Hand ihre Plätze ein und dann stiessen sie das Boot vom Landungsfloss ab und fuhren flussabwärts. Als sie drei Flussbiegungen weit gerudert hatten schlug das Boot plötzlich um und verschwand in der Tiefe des Wassers. Die Sklaven wurden in gewöhnliche Wasserschlangen verwandelt und ihre Herren in Tambon und Naga (mythische Wasserschlangen. Vergleiche den zweiten Teil dieses Bandes). Auf dem Flusse erhob sich plötzlich ein starker Sturm und hohe Wellen rollten heran.

Am gleichen Tage war in der Morgenfrühe eine Sklavin der Benang 
Kanjanang Tewang unterhalb das Dorf Kiham Balaki Tumbang Tarusan zum Fischfang gegangen. Dort angekommen setzte sie sich in das Gebüsch und warf die Angel aus. Plötzlich sah sie ein Boot herankommen. Sie sah wie es in der Tiefe des Flusses verschwand und wie seine Insassen in Wasserschlangen verwandelt wurden die unruhig hin und her schwammen. Sie erschrak sehr in ihrem Herzen. Auf einmal sah sie wie eine Tambon, in der sie Ehing Baburing Bulau erkannte, den Kopf aus dem Wasser emporhob und gegen das Ufer gewandt mit lauter Stimme rief: „O ihr Tiere am Ufer des Flusses der Welt, vielleicht weilt ihr im Gebüsch oder haltet euch auf den Zweigen der Bäume auf, vernehmt was ich euch zu sagen habe. Ich verlasse mit meinem Bruder unsere Frauen in Kiham Balaki Tumbang Tarusan. Sie sind beide schwanger und sie erwarten von uns ein Kind. Weil sie die Pali übertraten deshalb wurden wir in Tambon und Naga verwandelt. Nun kehren wir wieder heim in unser Dorf im Meere, wir gehen zurück nach Puser Tasik Etang Karangan. Unsere Kinder aber werden ebenfalls in Tambon und Naga verwandelt werden, wenn die Leute in den Dörfern am Flusse der Welt nicht wissen was sie tun müssen um dieses Schicksal zu verhüten. Wir wollen es euch sagen. Sie müssen zwei Antjak (flache Opferkörbe) flechten und sie mit Opfergaben füllen, nämlich mit einem gekochten Huhn, einem Hühnerei, gewöhnlichem Reis, weissem und schwarzem Klebreis, Sirih, Tabak, Salz und einem Pisangblatt voll Hühnerblut. Ferner müssen sie von Reismehl zwei Hampatong (menschliche Figuren) formen, einen für die Mutter, den andern für das Kind, je zwei für jeden Antjak. Unsere Frauen müssen etwas von ihrem Haar und ihren Fingernägeln den Opfern beifügen und sie müssen genau diese Geschichte kennen. Einen Antjak müssen sie hinter das Haus in den Busch bringen und den andern ins Wasser des Flusses werfen. Wenn sie so handeln, dann wird ihnen und ihren Kindern kein Unheil geschehen und sie werden nicht in Tambon und Naga verwandelt werden".

Nachdem die Tambon so gesprochen hatte verschwand sie in der Tiefe und schwamm, schnell wie der Blitz durch die Luft zuckt, flussabwärts. „Kai-kai“, sagte die Sklavin Orang Merutas, „nun weiss ich was geschehen ist und wie sich meine Herrin vor Unheil bewahren kann. Ich weiss nun auch, dass mein Herr kein Mensch sondern ein Geist, eine Wasserschlange, war. Ich will mich rasch aufmachen und in unser Dorf zurückkehren und meiner Herrin erzählen was meine Augen gesehen und meine Ohren gehört haben". Sie packte ihre Angelrute und die gefangenen Fische rasch zusammen und machte sich auf 
um nach dem Dorf zurückzukehren. $\mathrm{Zu}$ Hause angekommen rief sie ihre Herrin und ihre Schwester und sprach: „O meine Herrinnen, meine Sangiang, hört was meine Augen gesehen und meine Ohren gehört haben. Euere Männer waren keine Männer aus den Dörfern an den Ufern des Flusses der Welt, sie waren Geister aus dem Dorfe Puser Tasik Penda Etang Karangan in der Mitte des Meeres. Als ich am Flussufer angelte sah ich, wie sich ganz plötzlich ein heftiger Sturm erhob und wie ihr Boot in der Tiefe verschwand und sie mit ihren Sklaven zusammen in Schlangen verwandelt wurden. Ich hönte was die Tambon Ehing Baburing Bulau den Tieren am Ufer des Flusses der Welt mitteilte“, und sie erzählte ihnen alle Worte. „Kai-kai!" riefen die beiden Frauen, ,verhält es sich so? Wir wollen sofort nach den Worten des Ehing Baburing Bulau handeln damit wir uns und unsere Kinder von dem Verderben erretten können". Sie befahlen der Sklavin Antjak zu flechten und sie mit den Opfergaben zu füllen und dann den einen hinter das Haus in das Gebüsch und den Wald zu bringen und den andern in den Fluss zu werfen. Nachdem der Antjak ins Wasser geworfen worden war verwandelten sich die Hampatong (die Figuren von Reis geformt) in die beiden schwangeren Frauen und ihre Kinder. Sie trieben rasch flussabwärts und kamen schon nach kurzer Zeit im Dorf, in der Mitte des Meeres, an. Dort bestiegen sie das grosse Haus und setzten sich unter die Türe. Nach einiger Zeit kamen auch die beiden Naga (bezw. Tambon) in ihrem heimatlichen Dorfe an und sie nahmen dort mit ihren Sklaven zusammen wieder menschliche Gestalt an. Als sie zum Hause hinaufsteigen wollten sahen sie ihre Frauen und Ehing Baburing Bulau rief seinem jüngeren Bruder zu: „Was gewahren meine Augen, o mein jüngerer Bruder! Sitzen nicht unsere Frauen hier. Wie kommt es, dass sie vor uns das Dorf erreicht haben?" Sie freuten sich sehr in ihrem Herzen.

Als die Dunkelheit hereingebrochen war legten sie sich mit ihren Frauen zur Ruhe nieder, aber plötzlich sahen sie, dass sich die Frauen in Reismehlpuppen verwandelten. „Kai-kai", schrieen sie, „nun wissen wir weshalb unsere Frauen vor uns im Dorf angekommen sind. Sie wussten offenbar wie sie sich auslösen konnten und was sie zu unternehmen hatten damit ihre Kinder nicht in Naga und Tambon verwandelt wurden. Das ist ein grosser Gewinn für sie. Wenn ihre Kinder und ihre Enkel diese Geschichte wissen und nach ihr handeln, dann werden sie heilvoll und in Frieden am Ufer des Flusses der Welt wohnen und wir werden ihnen nie Leid zufügen können und müssen 
uns immer mit Stellvertretern und Opfern begnügen mit denen sie sich und ihre Kinder auslösen.

Nachdem der Tukang diese Erzählung rezitiert hat, spricht er :

Diese Erzählung befolgen wir und nach ihr handeln wir.

Wir haben an ihr nichts verändert sondern wir haben sie so rezitiert wie sie uns von unseren Ahnen überliefert worden ist.

Darnach werden die gleichen Handlungen vorgenommen und die gleichen Worte gesprochen wie sie bereits oben mitgeteilt wurden. Der eine der beiden Antjak wird im Busch niedergelegt und der andere in den Fluss geworfen.

\section{Das aussergewöhnliche Opfer für die Schwangere}

Zur Ergänzung teile ich auch noch das häufig dargebrachte aussergewöhnliche Opfer mit, das dann vollzogen wird, wenn sich eine Frau während ihrer Schwangerschaft immer unwohl fühlt und über nicht nachlassende Bauchschmerzen klagt. Die Ursache dieses Uebelbefindens schreibt man einer Wasserschlange oder einem Fisch zu der in den Bauch der Kranken hineingekrochen ist um dort das Kind zu zerstören. Der Bauch schwillt etwas an und soll eine fisch- oder schlangenförmige Wölbung bilden. Man lässt in diesem Falle ebenfalls einen Tukang (Mann oder Frau) kommen und bittet ihn für die Schwangere das stellvertretende Opfer darzubringen. Dieses Opfer nennt man nicht mangadiri sondern manalisih (das Wort hat die gleiche Bedeutung: austauschen, stellvertreten, zeigt aber die andere Art dieses besondern Opfers im Unterschied zum gewöhnlichen stellvertretenden Opfer, an).

Der Tukang wählt sich für die auszuführenden Handlungen einige Helfer oder Helferinnen und baut mit ihnen zuerst von Sagagulangholz zwei kleine Flosse die die Opfergaben und Hampatong aufzunehmen haben. Dann schnitzt man vom gleichen Holz zwei Rudersklaven denen man die Namen gibt Tikas und Tende. Darauf schnitzt man zweimal sieben Figuren die in zwei Bündeln (in jedem Bündel befinden sich sieben) zusammengebunden werden. Sie stellen Mutter und Kind dar. Man schlachtet das Opfertier, ein Schwein oder ein Huhn, kocht das Fleisch und zerteilt es in gleiche Teile und legt es auf die beiden Flosse und fügt auch die andern, oft genannten Opfergaben, bei. Sind die Flosse beladen, dann bestreicht man den Bauch der Schwangeren mit etwas Blut vom Opfertier. Die Opfergaben werden in der Mitte des Hauses niedergelegt und der Tukang rezitiert die Erzählung. Von dieser teile ich nur den Anfang mit. Der Rest stimmt 
überein mit dem Schlusse der Erzählung von Benang Kanjanang Tewang und Tipung Kandajun Tandjong. Das mitgeteilte Stück dient lediglich zur Ergänzung.

\section{Die Mythe von Budjang Badara}

In ganz früheren Zeiten lebten im Dorfe Kiham Balaki Tumbang Tarusan Danum ein König und eine Königin (d.h. Dorfälteste) die eine einzige Tochter, namens Budjang Badara besassen. Als sie älter wurde wuchs sie zu einer sehr schönen Jungfrau heran und der Ruf ihrer Lieblichkeit verbreitete sich von der Quelle bis zur Mündung des Flusses, ja, selbst an andern Flüssen sprach man von ihr. Und wo von ihrer Schönheit und Lieblichkeit erzählt wurde machten sich die jungen Männer auf und bestiegen mit ihren Gefährten und Sklaven die Boote und ruderten nach Kiham Balaki. Der Fluss wimmelte von Booten und an die Ufer schlugen die Wellchen die durch die Ruderschläge verursacht wurden und zahlreiche Stimmen hallten durch den stillen Wald. Sie alle besuchten den König und wurden von ihm freundlich aufgenommen und bewirtet. Und sie alle warben um die Hand seiner Tochter. Unter ihnen befanden sich reiche und herrliche Königssöhne denen der König seine Tochter gerne zur Gemahlin gegeben hätte, aber alle Freier, mochten sie noch so reich und noch so schön sein, wies Budjang Badara ab.

Eines Tages sprachen die Eltern zu ihr: „Du bist nun zu einer Jungfrau herangewachsen und hast das Alter erreicht in dem man zu heiraten pflegt. Zahlreiche junge Männer werben um dich. Unter ihnen befinden sich schöne, reiche und tapfere Königssöhne. Unser Dorf ist voll von ihnen. Sie haben meinen Reis aufgegessen und von meinen Pinangnüssen und Sirihblättern sind keine mehr übrig und mein Landungsfloss ist durch die vielen Boote zerstört worden. Wähle einen von diesen jungen Männern als Gemahl, denn es ziemt sich, dass du dich jetzt verheiratest. Sage mir welchen du wünschest und wie er aussehen soll". "O mein Vater und meine Mutter", sprach die Tochter, die sich in ihrem Zimmer aufhielt, „ich wünsche keinen von diesen Freiern zum Gemahl. Ich werde mich nur verheiraten mit Tambon Hatingan Bulau aus dem Dorfe Puser Tasik Penda Etang Karangan. Er besitzt grosse Reichtümer und ist sehr schön. In seinem Schatze befinden sich siebenfach gebogene Pfähle von Gold und die Erde vor seiner Haustreppe ist aufgehöht mit Edelsteinen und Sand von Gold“. "Ich bin weit herumgereist", sprach der Vater, „aber ich kenne keinen Königssohn der diesen Namen trägt und auf den diese Beschreibung 
zutrifft. Durch wen hast du von ihm gehört? Wer hat dir seinen Namen genannt?" Die Tochter antwortete: „Niemand hat mir von ihm erzählt und niemand hat mir seinen Namen genannt, ich habe ihn im Traum gesehen und dort wurde mir auch gesagt: wähle ihn und keinen andern zu deinem Gemahl! deshalb will ich mich nicht verheiraten bis er kommt und um mich freit". „Es wird für dich ein grosser Gewinn sein, wenn dein Traum wirklich in Erfüllung geht", antwortete der Vater. Die Tochter entgegnete: „Wenn er nicht kommt, dann werde ich mich nicht verheiraten. Dann werde ich dahinsterben wie der Diwong (ein Bambusstrauch) der verwelkt und vertrocknet ehe er Früchte trägt".

Als die Eltern mit ihrer Tochter sprachen hatte sie der weibliche Windgeist Riwut Indang Pararu Rawei belauscht. Er erhob sich und flog mit seinen sieben Geschwistern davon nach Puser Tasik und sah sich nach dem Tambon Hatingan Bulau um. Sie sah ihn in der Mitte des Balai (Versammlungshaus) sitzen wo er mit dem Schnitzen eines feinen Dolchgriffes beschäftigt war. Sie rief ihm zu: „O Tambon Hatingan Bulau, du tust mir Leid, du bist so allein, hast du denn kein Verlangen nach einer Frau, nach einer Gefährtin und Zierde deines Hauses? Ordne deine Haare und öffne deine Ohren und höre was ich dir zu sagen habe (Der Dajak trug früher lange Haare. Bei einem Gespräch ging zuerst diese Aufforderung voran: Ordne deine Haare, die über die Ohren herunterhangen, damit du meine Rede besser hören kannst). Ist denn nicht das Gerücht bis zu dir durchgedrungen, dass sich in Kiham Balaki eine wunderschöne Königstochter befindet die von vielen jungen Männern umworben wird, sodass der Fluss erschallt vom Schlage ihrer Ruder und die Wellchen unaufhörlich ans Ufer schlagen wegen der vielen Boote die Tag für Tag flussaufwärts und flussabwärts fahren. Alle Freier schlägt sie ab. Sie will sich mit keinem andern verheiraten als mit dir. Sie hat $z u$ ihrem Vater und ihrer Mutter gesprochen: wenn nicht Tambon Hatingan Bulau um mich freit, dann werde ich mich nicht verheiraten, sondern ich werde dahinsterben, wie der Diwong, der verwelkt ehe er Früchte bringt. Mache dich auf, reise nach Kiham Balaki und freie um sie, denn sie ist sehr schön und sie wird eine Zierde deines Hauses sein". Tambon Hatingan Bulau hörte verwundert diese Rede an. Er schaute herum, aber er gewahrte niemanden. Er stieg in sein Haus hinauf und fragte seine Mutter: „Hast du zu mir gesprochen als ich im Balai sass?" „Nein“, antwortete seine Mutter, ,ich sprach nicht zu dir". Er verwunderte sich noch mehr über die Worte die er gehört hatte und er nahm aus seinem Schatze Goldbänder und schmiedete aus ihnen 
herrliche Ringe und Armbänder die er seiner zukünftigen Gemahlin als Geschenk mitbringen wollte. Als er nach einiger Zeit alles bereit hatte, da sprach er zu seiner Mutter: „O Mutter, ich möchte mich gerne verheiraten mit einer schönen Jungfrau aus dem Geschlechte der Menschen am Flusse der Welt. Es ist mir mitgeteilt worden, dass Budjang Badara in Kiham Balaki nur mich zu ihrem Gemahl erwählen will und alles was ich auch sonst über sie gehört habe lautet sehr gut. Lass mich dorthin reisen um mich mit ihr zu verheiraten". Die Mutter antwortete ihm: „Hat es nicht genügend Töchter in unserem Dorf, reiche und schöne Jungfrauen, mit denen du dich verheiraten kannst. Weshalb willst du in die Ferne ziehen und dich mit einem Mädchen aus dem Geschlechte der Menschen am Flusse der Welt verheiraten. Bleibe hier und ich will dir aus den Jungfrauen eine zur Gemahlin auswählen die $z \mathfrak{u}$ dir passt und die ebenso reich ist wie du und die auch aus dem gleichen Stande kommt“. „Nein“, sprach der Sohn, ,ich kann deinen Rat nicht annehmen. Wenn ich mich nicht mit Budjang Badara verheiraten kann dann bleibe ich ehelos und sterbe ohne Kinder gezeugt zu haben". Nachdem die Mutter diese Rede gehört hatte erschrak sie sehr und sie gab seinen Wünschen nach, denn er war ihr einziger Sohn.

Sobald er von seiner Mutter die Erlaubnis zu seinem Unternehmen erhalten hatte befahl er seinen Sklaven sein Boot zu beladen. Er selbst füllte sieben Gefässe mit feinem Goldstaub und machte sieben goldene Lamiang (längliche Achatsteine die um den Hals und die Handgelenke getragen werden) bereit als Brautpreis für Budjang Badara. Als alles bereit war bestieg er mit seinen Sklaven das Boot und sie segelten über das Meer bis sie beim Flusse Tarusan Danum ankamen. Dort holten sie die Segel ein und ruderten flussaufwärts. Nach kurzer Zeit kamen sie in Kiham Balaki an. Sie machten an einem grossen Landungsfloss ihr Boot fest. Nachdem sie gebadet und gegessen hatten rief Tambon Hatingan Bulau seinen sieben Sklaven und übergab ihnen die sieben Gefässe mit Goldstaub und die sieben goldenen Lamiang, indem er sprach: „Diese Schätze bringt ihr in das elterliche Haus der Budjang Badara. Ihr legt sie vor ihrem Vater und ihrer Mutter nieder und sprecht: dieses hier sendet euch Tambon Hatingan Bulau der um eure Tochter freit. Er ist soeben mit seinem Boot von Puser Tasik hier angekommen und er bittet euch ihm eure Tochter zur Gemahlin zu geben". Nach diesen Worten machten sich die sieben Sklaven, glänzend wie der Blitz der durch die Wolken zuckt, auf und bestiegen das Haus der Budjang Badara. Vor der Türe angekommen 
baten sie um Erlaubnis das Haus betreten zu dürfen. Der Besitzer hiess sie willkommen und bat sie auf dem Fussboden Platz zu nehmen. Dann schob er ihnen das Sirihgerät zu und als sie gekaut hatten fragte er sie: „O meine Neffen, woher kommt ihr und was führt euch in mein Haus?" Sie antworteten ihm: „O unser Herr, unser Sangiang, unser Besitzer schickt uns mit diesen Reichtümern zu dir um dich für ihn um die Hand deiner Tochter zu bitten. Es ist Tambon Hatingan Bulau aus Puser Tasik. Er hat von der Schönheit deiner Tochter gehört und das Verlangen ergriff ihn nach ihr und er wünscht um sie zu freien. Er ist ein junger, schöner und reicher Herr".

Als Budjang Badara in ihrem Zimmer diese Worte hörte, da trat sie heraus zu den Männern und als sie den Reichtum sah den die Sklaven ausgebreitet hatten, sprach sie zu ihren Eltern: „Freut euch nun mit mir. Ist mein zukünftiger Gemahl, von dem ich zu euch sprach nicht herrlich und reich?" Und ihre Mutter antwortete: „Du hast gut gewählt und recht gehandelt, dass du nur diesen zu deinem Gemahl erwählen wolltest, denn er ist reicher als alle Königssöhne die um dich gefreit haben. Wir hoffen, das nun alles gut besprochen und zu einem guten Ende geführt werde".

Die Eltern besprachen nun mit den Sklaven des Tambon Hatingan Bulau den Brautpreis und stellten den Hochzeitstag fest und sie einigten sich und beschlossen die Hochzeit in sieben Tagen zu feiern um in der $Z$ wischenzeit alles für das Fest vorbereiten zu können.

Der Vater der Budjang Badara befahl seinen Sklaven Reis zu stampfen, Holz zu suchen, Bambusköcher zu schneiden um den Reis darin abkochen zu können, Kühe, Schweine und Hühner einzufangen, denn das Fest sollte von vielen Gästen aus dem Dorfe selbst und aus den Dörfern des Ober- und Unterlandes besucht werden. Die Blinden führten die Sehenden an ihren Händen herbei, die Lahmen, Alten und Gebrechlichen kamen an Stöcken herbeigehumpelt. Das ganze Dorf wimmelte von Menschen und hallte wieder von dem Laut der Trommeln und Gong und den frohen Liedern der Gäste.

Am siebenten Tage fand die Hochzeit statt und nach dem Feste kehrten die Gäste wieder heim. Drei Monate blieb Tambon Hatingan Bulau bei seiner Frau, da fühlte sie sich schwanger und teilte ihre Freude ihrem Manne mit.... usw.

Die Fortsetzung der Mythe lautet beinahe wörtlich gleich wie die obige.

Nachdem der Tukang diese Erzählung rezitiert hat werden wieder die gleichen Worte gesprochen und die gleichen Handlungen ausgeführt 
wie oben. Eines der Flosse bringt man hinter das Haus in den Busch und das andere lässt man auf dem Flusse wegtreiben.

\section{Basaloh-Mythen}

Saloh, oder von dieser Wortwurzel abgeleitet basaloh 142 (das Verbum lautet manjaloh), bedeutet verwandelt werden. Der Begriff wird angewandt für Dörfer und Menschen die durch eine schuldvolle Tat oder Handlung plötzlich in Steine oder Bäume verwandelt werden (basaloh). Diese verwandelten Menschen, die nicht in das Totendorf eingehen und auch nicht in die Gemeinschaft der überweltlichen Ahnen aufgenommen werden, weil sie durch ihre schuldvolle Tat und ihren plötzlichen Tod (matei manta: unreifer Tod) aus dieser Gemeinschaft ausgestossen wurden, aber auf dem Platze der Verwandlung weiterexistieren und sich den Lebenden hülfreich oder auch schädigend erweisen können, nennt man taloh. Das Wort wird meistens übersetzt mit: Götzen, Geister, Gespenster, Zauber und Gift, irrtümlich aber auch mit Ding. Das Basaloh hat zwei Ursachen die hier nur kurz beschrieben werden sollen, nämlich:

\section{a. Basaloh durch Sarok}

Sarok ist eine besondere Form der Tabuvorschriften. Basarok nennt man den unheilvollen Zustand in den man durch die Uebertretung dieser Vorschrift gekommen ist. Man unterscheidet zwei Arten des Sarok. Wenn man ein fremdes Gebiet bereist das von einem fremden Stamm bewohnt wird und in dem fremde Sitten (Hadat) und fremde Gebräuche beobachtet werden und auch fremde Mächte herrschen, muss man sich sehr vorsichtig benehmen. Rudert man auf dem Fluss in dieses fremde Gebiet hinein, dann übergiesst man sich an der Grenze, oder an der Mündung von Nebenflüssen mit Wasser das man aus dem Fluss aufgeschöpft hat. Betritt man auf einer Wanderung das fremde Gebiet, dann richtet man an der Grenze einen Hampatong (ein Schnitzbild das man rasch aus einem Baumast schnitzt) auf und legt bei ihm ein bespucktes Blatt und etwas Tabak nieder. Im fremden Gebiet angekommen darf man sich über fremde und ungewohnte Erscheinungen nicht lustig machen, vor allem muss man sich hüten die Dorfheiligtümer, die Hampatong und Sapundu, die sich vielleicht durch ungewohnte Formen und noch nie gesehene Figuren auszeichnen, zu belächeln. Nichts, aber auch gar nichts ist in der Fremde lächerlich, es ist für den Besucher höchstens unverständlich, hat aber am fremden Ort und im andern Stamm seinen begründeten Sinn und darf deshalb, 
weil man diesen Sinn noch nicht kennt und nicht versteht, nicht lächerlich gemacht werden. Das ungebührliche Betragen in der Fremde hat Fieber, Dysenterie und Brechdurchfall (muta mani) zur Folge, das Belächeln von heiligen Plätzen und Hampatong verursacht leichter Wahnsin, tötliche Folge hat der Zustand aber nicht. Die andere Form des Sarok ist das unziemliche Benehmen gegenüber Tieren die unter dem Schutz von Geistern stehen oder bestimmten Geistern heilig sind. Unziemlich ist es wenn man einem Tier einen andern Namen gibt, oder etwas von ihm aussagt, das gegen seine Natur ist, z.B. wenn man von einer Laus sagt, dass sie tanze, von einer Ratte, dass sie singe, von einer Fliege, dass sie Krieg führe, von einer Katze, dass sie ein Hund sei usw. Unziemlich ist auch, wenn man lebende Tiere begräbt und sagt: ich begrabe einen Menschen, oder wenn man für sie, wie für Menschen, einen Sarg macht. Ferner, wenn man z.B. einem Frosch die Haut abzieht und sagt: nun hat er seinen Rock ausgezogen, oder wenn man ein Tier mit menschlichen Kleidern bekleidet.

Geschieht so etwas absichtlich oder unabsichtlich, dann verdunkelt sich der Himmel plötzlich, der Tag wird in Nacht verwandelt, ein schweres Unwetter steigt auf, die Blitze zucken fürchterlich und der Donner rollt drohend. Immer näher kommt das Unwetter und plötzlich verschwindet das Dorf, es ist mit den Häusern, Menschen und Tieren verwandelt worden (basaloh) in Steine und Bäume oder auch in Stromschnellen.

Als Rächer treten bei Vergehen gegen die Sarokbestimmungen die Njaro, die Götter des Donners und Unwetters, auf. Die Njaro sind sieben Brüder von denen der jüngste gestorben ist. Sie haben menschliche Gestalt, aber eiserne Waden, und drei dicke goldene Haare. Sie sind stets vom Kopf bis zu den Füssen bewaffnet. Sie wohnen in der Oberwelt und auf hohen Bergen.

Spricht oder handelt ein Mensch in der oben beschriebenen Weise unziemlich, dann kommen die $\mathrm{Njaro}$ in einem schweren Unwetter um den Uebertreter und sein ganzes Geschlecht zu bestrafen. Ihr Jauchzen und ihr Lachen ist der Donner. Durch dieses Lachen fallen die tatek (goldene Stifte die in die Zähne eingesetzt sind) heraus und verwandeln sich in Blitze. Sie werfen ihre Streitaxt, die baliong Njaro (die baliong $N$ jaro sind neolithische Steinbeile die der Dajak bei der Arbeit im Feld oder Wald oft findet. Sie dienen als Gegenmedizin bei Krankheiten die durch die Njaro verursacht worden sind) nach den Schuldigen und töten sie oder verwandeln sie und ihr ganzes Dorf in Stein. 
Von den zahlreichen Mythen, die man in jedem Dorfe findet, führe ich hier zwei an, nämlich:

\section{Der Ursprung des Kalanaman}

In der Nähe von Kasongan nimmt der Katingan einen kleinen Nebenfluss, den Kalanaman, auf über dessen Ursprung die Katinganer berichten: In früheren Zeiten befand sich da, wo heute der Kalanaman in den Katingan einmündet, ein grosses, stattliches und reiches Dorf. In ihm wohnte ein Mann der mit einer sehr schönen Frau verheiratet war. Er war überaus eifersüchtig und überwachte seine Frau sehr streng. Eines Tages fand in dem Dorfe ein grosses Opferfest statt und Nawan, so hiess dieser Mann, wollte nun ausgerechnet gerade an diesem Tage auf die Jagd gehen. Die Leute baten ihn im Dorfe zurückzubleiben und an dem Fest teilzunehmen, aber er schlug ihre Bitte ab. Er nahm seinen Speer und rief die Hunde und dann verliess er das Haus. Als er bei der Türe angekommen war wandte er sich noch einmal um und sprach zu seiner Frau: „Ich verbiete dir streng während meiner Abwesenheit das Haus zu verlassen und am Fest teilzunehmen". Sie befolgte anfänglich die Worte ihres Mannes. Aber später kamen Verwandte, setzten sich zu ihr auf den Fussboden und erzählten ihr von dem schönen Fest und baten sie doch auch mitzukommen. Aber sie dachte an das Verbot ihres Mannes und schlug die Einladung ab. Aber immer wieder baten die Verwandten: „Komm doch mit, nimm doch an unserem Feste teil, dein Mann wird gewisslich noch nicht so rasch von der Jagd heimkehren". Schliesslich gab sie den Bitten ihrer Verwandten nach und verliess mit ihnen das Haus und begab sich in das Festhaus.

Nach einiger Zeit kam der Mann mit seiner Jagdbeute, einem roten Affen den er im Walde erlegt hatte, wieder zurück. Er öffnete die Türe seines Hauses. Alles war still. Er rief seine Frau, aber er erhielt keine Antwort. Da wurde er in seinem Herzen sehr zornig und sprach zu sich selbst: „Gewiss hat meine Frau mein Verbot übertreten und hat sich doch zum Fest begeben". Immer zorniger wurde er. Schliesslich nahm er den toten Affen und bekleidete ihn mit seinen Kleidern und begab sich dann mit ihm in das Haus wo die Feiernden fröhlich beisammensassen. Er sah wie seine Frau bei den Verwandten sass und Sirih kaute. In seinem grossen Zorn warf er ihr den bekleideten Affen zu und schrie: „Da hast du den Lohn deiner Untreue und deines Ungehorsams. Nimm diesen Affen da als Mann, er ist gerade gut und recht für dich". Zuerst lachten die Leute über die 
zornigen Worte des Mannes und den Scherz, den er sich mit dem Affen erlaubt hatte, aber plötzlich hörten sie schweren Donner rollen und sahen durch die Ritzen des Hauses wie unheimliche Blitze durch die Luft zuckten. Immer schwerer und drohender wurde das Unwetter, immer näher rollte der Donner, immer dunkler wurde der Tag. Sie hatten noch nie ein so furchtbares Wetter erlebt. Ihr Lachen verstummte, ihre Gesichter verzehrten sich vor Angst, ihre Augen traten vor Schreck aus den Höhlen. Sie wollten das Haus verlassen und sich flüchten, aber ehe sie dazu kamen wurden sie mit dem ganzen Dorf in Stein verwandelt und von den hochgehenden Fluten weggespült.

Nawan allein war es gelungen sich mit seinem jüngeren Bruder in den Wald zu flüchten. Er irrte mit ihm durch die weglose Wildnis. Der Donner verfolgte ihn und Blitze zuckten hinter und um ihn. Hinter seinen Schritten stürzte die Erde ein und bildete ein tiefes Flussbett. Immer verzweifelter rannte er mit seinem Bruder davon. Plötzlich hörte er hinter sich eine Stimme die ihm zurief: „Haue deinen kleinen Finger ab, haue deinen kleinen Finger ab!" Zuerst achtete er nicht auf diese Stimme, aber als sie sich fortwährend wiederholte, tat er schliesslich wie ihm von unsichtbarer Macht befohlen wurde. Er legte seinen kleinen Finger auf einen Felsblock und hieb ihn ab. ${ }^{143}$ Der Ort wo er das tat verwandelte sich in eine Stromschnelle (diese Stromschnelle befindet sich oberhalb Mirah, einem Dorf am Oberlauf des Kalanaman) und der Weg, den er mit seinem Bruder zurückgelegt hatte, wurde zu einem Fluss den die Leute Kanawan hiessen und der heute den Namen Kalanaman trägt.

\section{Der Ursprung des Nasenaffen}

In früheren Zeiten lag hinter dem jetzigen Dorfe Tarusan Danum (es liegt in der Nähe von Penda Hara, am Katingan) ein sehr altes Dorf das den Namen Tangking Parei trug. Es war noch vor Tewang Sangalang Garing, dem heutigen Penda Hara, erbaut worden. Das Dorf war gross und reich und sehr viele Menschen wohnten in ihm.

Eines Tages reisten ein Mann und eine Frau aus diesem Dorf nach Mendawei (ein grosses Dorf und Handelszentrum in der Nähe der Katinganmündung). Ihre Kinder, zwei Knaben und ein Mädchen, hatten sie daheim zurückgelassen. Das Mädchen war bakowo.144

Während sich die Eltern auf der Reise befanden vergnügten sich die Knaben mit einem streng verbotenen Spiel. Sie hatten eine Heuschrecke gefangen und schnitzten für sie ein kleines Särglein. 
Dann legten sie die Heuschrecke in dieses Särglein und begruben sie auf die gleiche Weise wie man eine Leiche begräbt. Nicht lange darnach überzog sich der Himmel mit schwarzen Wolken. Die Blitze zuckten unheimlich und der Donner rollte fürchterlich. Immer näher kam das Unwetter bis es sich über dem Dorf zusammengezogen hatte. Plötzlich wurde das ganze Dorf in Wald verwandelt und das Haus, in dem die Kinder daheim waren, in einen Lunokbaum. In diesem Baume lebte das Mädchen weiter und es konnte durch eine kleine Oeffnung die Hand herausstrecken.

Nach einiger Zeit kamen der Mann und die Frau wieder aus Mendawei zurück. Als sie den Platz ihres Dorfes erreicht hatten erschraken sie sehr. Wo früher die Häuser standen, grünten nun hohe Bäume und Sträucher. Keine Ueberreste des Dorfes und keine Spur von Menschen fanden sie. Wo ihr Haus einst gestanden hatte erhob sich nun ein hoher Lunokbaum. Als sie ihn näher beschauten, sahen sie in ihm eine Oeffnung und ihr Entsetzen nahm zu als sie plötzlich sahen, dass aus dieser Oeffnung eine Hand zum Vorschein kam. Sie erkannten sie als die ihrer Tochter. Nun beschlossen sie den Lunokbaum zu fällen und ihre Tochter aus dem merkwürdigen Gefängnis zu befreien. Aber so oft sie auch den Baum fällten, immer stand er wieder unversehrt da. Schliesslich gaben sie den Versuch auf ihre Tochter zu befreien. Dem Mädchen konnte man durch die Baumöffnung Handarbeiten übergeben, sie flocht und stickte sehr schön. Uebergab man ihr eine solche Arbeit, dann konnte man sie nach einigen Tagen wieder abholen. Solange sich ihr niemand mit schlechten Gedanken nahte, dauerte dies so fort. Aber eines Tages kam ein junger Mann mit schlechten Absichten zum Baum und er überredete das Mädchen ihm ihre Hand zu reichen. Er probierte sie aus der Oeffnung herauszuziehen, aber als ihm dies nicht gelang, hieb er die Hand mit seinem Schwerte ab. Kaum war dies geschehen, da schloss sich die Oeffnung des Baumes und die Menschen, die sich in seiner Nähe aufhielten, sahen wie plötzlich ein Nasenaffe den Stamm des Lunokbaumes emporkletterte und verschwand. Sie hatten bis jetzt noch nie ein solches Tier gesehen und es war ihnen eine gewisse Tatsache, dass sich das Mädchen im Baume in diesen Affen verwandelt hatte.

Oft versuchten später die Katinganer den Nasenaffen mit Blaserohrpfeilen und Gewehrkugeln zu erlegen, nie gelang es ihnen. Auch wenn sie ihr Ziel noch so gut getroffen hatten flüchtete der Nasenaffe unverwundet weiter und jedesmal überzog sich dann der Himmel mit dunkeln und drohenden Wolken und ein furchtbares Unwetter brach 
über dem Dorfe aus. Seit dieser Zeit wagen es die Katinganer nicht mehr Jagd $z \mathfrak{u}$ machen auf dieses heilige Tier.

\section{b. Basaloh durch Tulah}

Auch die religiöse Verbotsbestimmung, die mit tulah bezeichnet wird, hat zwei Bedeutungen mit verschiedener Folge für den Uebertreter. Die Tulahvorschriften sind sehr umfassend. Sie beziehen sich auf den Verkehr zwischen den Geschlechtern, auf den gegenseitigen Umgang zwischen verschiedenen Altersstufen und auch auf Handlungen und Arbeiten die Jugendlichen, die noch nicht alle Initiationsriten abgeschlossen haben, unerlaubt sind. Vor allem aber beziehen sie sich auch auf den Verkehr zwischen Schwiegertochter und Schwiegervater, Schwiegersohn und Schwiegermutter.

Die Uebertretung dieser Tulahverbote hat die Panjakit Tulah (Tulahkrankheit) zur Folge unter der man Gelbsucht oder verschiedene Erlahmungserscheinungen versteht.

Die zweite Bedeutung des Tulah ist die Blutschande oder auch der unerlaubte sexuelle Verkehr mit einer Jungfrau der Schwangerschaft zur Folge hat. Wird eine solche Tat nicht gesühnt, dann geht die Welt unter. Naturkatastrophen brechen herein. Der Fluss schwillt plötzlich hoch an und überschwemmt die Felder, oder der Reis und die Gartengewächse werden durch Dürre zerstört die zu ungewohnter Zeit eintritt. Die Bäume tragen keine Früchte mehr und alles was die Menschen unternehmen misslingt. Bei den Ot Danumstämmen wurde das blutschänderische Paar, zur Sühnung der Tat und als stellvertretendes Opfer für den ganzen Stamm, an einen Baum gekreuzigt. Auf einer Seite des Baumes der Mann, auf der andern Seite die Frau. Das Blut dieser beiden Verbrecher sandte man im ganzen Stammesgebiet herum damit mit ihm das Wasser und die Erde, die Bäume und die Felder, die Häuser und die Dorfstrasse, die Menschen und Tiere gereinigt werden konnten. Heute findet dieses stellvertretende Sühnopfer natürlich nicht mehr in dieser Form statt. Man behandelt das Paar wie Schweine. In einen Schweinetrog giesst man das Essen und dann ruft man es wie man Schweine ruft. Sie müssen sich kriechend nahen und ohne die Hände zu benützen das Essen aus dem Trog zu sich nehmen. Wenn das geschehen ist wird die Welt gereinigt mit dem Blut eines stellvertretenden Opfertieres, einer Katze oder einem Hund oder auch einem Wasserbüffel. Man schickt dieses Blut auch in die benachbarten Dörfer damit auch dort die Reinigungshandlungen voll- 
zogen werden können. Die Blutschande hat aber auch die Versteinung (basaloh) der Schuldigen und ihres ganzen Dorfes zur Folge. Um dieses Schicksal zu verhüten wurde, wie schon gesagt, bei den $\mathrm{Ot}$ Danum das Paar gekreuzigt, bei den Ngadju Dajak aber wurde es versteint. 145 Sehr viele Mythen erzählen uns von der Versteinung von Dörfern wegen eines Tulahvergehens. Ich teile hier nur eine solche Mythe mit. Wir finden diese Mythen in allen älteren Dörfern und in der Nähe von ihnen zeigt man auch die versteinten Dörfer, oft liegen sie im Wald, oft sind sie im Fluss zu reissenden Stromschnellen geworden. Das letztere ist der Fall bei der Mythe die ich hier mitteile.

Sie lautet:

\section{Wie der Samanja entstand}

Der Samanja ist eine ungefährliche Stromschnelle unterhalb des Dorfes Tumbang Manggo, das am unteren Samba, einem Nebenfluss des oberen Katingan, liegt. Die Mythe berichtet uns von ihr:

In ganz früheren Zeiten geschah es eines Tages, dass ein kleiner Knabe in der Küche seines elterlichen Hauses heftig weinte. „Sei still, Mandi!" rief ihm die Mutter $z \mathfrak{u}$, aber Mandi hörte nicht auf mit Weinen. Nochmals rief sie: „Sei still Mandi!" und ihre Stimme hatte einen zornigen and drohenden Klang. Aber je lauter die Mutter schalt umso heftiger wurde das Weinen des Kindes. Schliesslich war sie so zornig geworden, dass sie den eisernen Kochlöffel ergriff und „pek“" schlug sie mit ihm dem Kinde auf den Kopf. Blutüberströmt brach es zusammen. Der Vater, der sich in der Nähe des Hauses aufgehalten hatte, hörte das Weinen des Kindes ebenfalls. Er begab sich rasch in das Haus um der Ursache nachzuforschen. Wie erschrak er als er sah, dass es in seinem Blute badete.

„Hau“, rief er, „was ist mit meinem Kinde geschehen?" „Ich liess mich wegen seines unaufhörlichen Weinens vom Zorne hinreissen und schlug es mit dem eisernen Kochlöffel", antwortete die Mutter. Der Vater sprach kein Wort mehr, aber man sah, dass er in seinem Herzen sehr zornig war. Er rief seinem Kinde zu: „Hieher Mandi, deine Mutter hat dich im Zorne geschlagen, sie wollte dich töten“. Dann ergriff er das Kind, raffte die wenigen Habseligkeiten zusammen und verliess das Haus und bereitete sich auf eine grosse Reise vor.

Wenige Tage später sah man ihn an den Katingandörfern vorbeifahren. Die Leute wussten nicht wohin er reisen wollte, sie wussten auch nicht wie lange seine Abwesenheit dauern sollte. Niemand ge- 
traute sich ihn darüber $z u$ fragen und wenn man ihn fragte, dann gab er so einsilbige Antworten, dass man das Gespräch lieber abbrach.

Von dieser Zeit an hörte man nichts mehr von ihm und seinem Kinde. Sie waren für die Bewohner von Samanja verschollen und verloren. Die Frau wohnte ganz allein in ihrem Hause. Sie war plötzlich $z u$ einer Witwe und einer Unfruchtbaren geworden die keinen Kindern mehr das Leben schenkt. Nun hatte sie Zeit über ihre Tat nachzudenken und ihren schnellen Zorn zu bereuen. Es tat ihr leid und ihr Herz schmerzte sie, dass sie sich so unbedacht vom Zorn hatte hinreissen lassen. Viele Jahre waren vergangen. Es ging in das fünfzehnte oder sechszehnte Jahr seit diese Tat geschehen war und seit Mandi mit seinem Vater das heimatliche Dorf für immer verlassen hatte. Wer dachte noch an sie!

Eines Tages kam in Samanja ein grosses und schwerbeladenes Handelsboot an das reiche Güter geladen hatte: Gong, Trommeln, heilige Töpfe, kostbare Tücher und viele andere Waren mehr. Die Bewohner des Dorfes besuchten das Boot sooft wie sich die Vögel baden. Die Waren fanden reissenden Absatz und so war der Händler gezwungen mit seinen Sklaven lange Zeit in Samanja zu verbleiben. Niemand kannte ihn und auch er kannte niemanden im Dorf, denn es war das erste Mal, dass er hieher gereist war und er war ein Landesfremder der vom Meere hergekommen war.

Eines Tages gewahrte der Händler unter den Frauen des Dorfes eine die ihm besonders gut gefiel. Sie war schön und sein Herz erglühte vor Liebe $z u$ ihr. Er erkundigte sich bei den Dorfbewohnern nach ihr und er vernahm, dass sie eine unverheiratete Witwe sei. Er liess bei ihren Verwandten um ihre Hand fragen. Seine Anfrage wurde erwogen und angenommen, denn er war reich und konnte dem Dorf von grossem Nutzen sein. Nach kurzer Zeit verheirateten sie sich. Schon längere Zeit lebten sie in der Ehe als der Händler eines Tages seine Frau bat: „Lies doch die Läuse von meinem Kopf“ (das ist nicht nur eine nützliche und notwendige Arbeit sondern eine besondere Liebkosung. Der Mann liegt dabei der Frau mit aufgelösten Haaren auf den Schoss). Sie tat es und bei dieser Beschäftigung entdeckte sie auf dem Kopfe ihres Mannes eine Narbe. Sie fragte: „Weshalb hast du auf dem Kopf eine Narbe, wann bist du verwundet worden und weshalb geschah es?" Er antwortete ihr: „O, ich selbst erinnere mich nicht mehr weshalb ich eigentlich verwundet wurde und wann dies geschehen ist. Ich weiss nur noch was mir mein Vater erzählt hat. Als ich noch sehr klein war soll ich einst in der Küche unseres Hauses 
heftig geweint haben. Meine Mutter hiess mich stille sein, aber ich weinte nur noch heftiger. Da wurde sie sehr zornig und in ihrem Zorne schlug sie mit einem eisernen Kochlöffel heftig auf meinen Kopf sodass das Blut an meinem Körper herunterfloss. Der Vater kam dazu. Er wurde sehr zornig und verliess mit mir zusammen die Mutter und das heimatliche Dorf. In der Fremde wollte er sich nicht mehr an sie erinnern. Er hat mir nie ihren Namen genannt, auch nicht wo sie wohnt und so weiss ich auch gar nichts von ihr. Aber es ist schon sehr lange her seit dies geschehen ist".

Die Frau hörte der Erzählung zu. Ihre Finger griffen nicht mehr in die Haare ihres Mannes. Ihr Gesicht wurde bleich vor Schrecken. Ihr Körper zitterte vor Entsetzen. Sie rief, wie eine die keiner Gedanken mehr fähig ist, mit hohler Stimme: „Mandi, Mandi, du bist ja mein Kind und ich bin deine Mutter. Du erzählst meine Geschichte. Ich bin es ja die dich geschlagen hat, ich habe dich und deinen Vater von hier vertrieben". Kaum hatte sie diese schrecklichen Worte gesprochen, da begann sich der Himmel mit schweren und drohenden Gewitterwolken zu überziehen. Die Blitze zuckten tjir-tjar, der Donner rollte dum-dam. Immer schwärzer wurde der Himmel, immer dunkler der Tag. Mandi flüchtete sich vor Entsetzen aus dem Hause um sich nach seinem Boote $z u$ begeben und diesen unheilvollen Ort zo schnell wie möglich zu verlassen. Er kam nicht weit. Von unsichtbarer Macht wurde er ergriffen 146 und in den Fluss geschleudert und dort in Stein verwandelt. Auch seine Mutter wurde in Stein verwandelt. Seine Handelsgüter und sein Boot wurden versteint und ebenso auch das ganze Dorf Samanja mit allen seinen Bewohner. Wo sich dieses Dorf einst befand liegt jetzt eine Stromschnelle im Flussbett. Die Steine tragen noch heute Namen die an diese Katastrophe erinnern. Da, wo der Samba in den Katingan einmündet findet man den versteinten Mandi und gegenüber der Stromschnelle erhebt sich die versteinte Mutter. Man findet in der Schnelle selbst auch das zu Stein gewordene Boot, die versteinten Trommeln, Gong, heiligen Töpfe und alle übrigen Waren. So rächte die unsichtbare Macht die Heirat Mandis mit seiner Mutter und seine blutschänderische Tat.

\section{Gaip-Mythen}

Gaip bedeutet: ohne zu sterben aus dieser sichtbaren Welt entrückt und in ein Geisterdorf, nicht das Totendorf, aufgenommen zu werden. Jedes Dorf besitzt zahlreiche solche Mythen und weiss von vielen Menschen $z \mathfrak{u}$ erzählen, die ohne zu sterben aus dieser Welt hinweg- 
geholt und in ein Geisterdorf aufgenommen wurden. Dass dies der Fall war wissen sie weil der Entrückte sich nach seiner Entrückung meistens noch einmal seinen Verwandten zeigt und ihnen seine Hilfe und seinen Schutz zusagt, für den Fall, dass sie diese nötig haben.

Besonders wird man durch die Pampahilep, oft aus dieser Welt weggeholt und in ihre Gemeinschaft aufgenommen in der man weiterleben bleibt.

Hardeland (siehe Wörterbuch unter Pampahilep) schreibt über die Pampahilep: Sie sind sehr starke, mächtige Waldgeister. Die Kariau und Pudjut sind ihre Sklaven. Die Pampahilep wohnen in Pahewan, heiligen Zauberwäldchen (heilige Haine wo man Opfer darbringt, man nennt sie Pahewan oder auch lezun taloh: Geisterdörfer), gewöhnlich an der Mündung kleiner Flüsse. Sie haben die Gestalt und Grösse der Menschen und sind sehr schön. Der erste Pampahilep war anfangs auch ein Mensch welcher gaip wurde und ohne zu sterben aus dieser Welt ausschied. Auch jetzt noch manggaip (Verbum) die Pampahilep oft Menschen, holen sie lebendig aus dieser Welt wenn sie sie einsam im Walde oder anderswo finden, damit sie ihnen zu Frauen oder Männern werden, denn es gibt auch weibliche Pampahilep. Darum gehen die Dajak nicht gerne allein in den Wald. Um gute Ernten zu erlangen, um Glück auf Handelsreisen zu haben usw. gelobt man den Pampahilep Opfer, die man, wenn man Glück gehabt hat, darbringt. Gewöhnlich besteht das Opfer aus einem Schwein oder sieben Hühnern.

Die Kariau sind Gespenster, Geister, von Gestalt wie etwa ein sechsjähriges Kind. Sie stehlen dem Jäger seine Speise, Gerätschaften, oder begegnen ihm in der Gestalt eines Bekannten und bringen ihn so auf Irrwege und verschwinden dann plötzlich. Sie verbergen das Wild vor den Augen des Jägers, Bambus und Rotan vor den Augen derer die diese Produkte suchen. Ist man beim Rotanschneiden oder auf der Jagd nicht glücklich, dann bringt man den Kariau Opfer, gewöhnlich Eier, auch Reis oder Hühner, die man auf einen Antjak (flacher Opferkorb) legt. Die Pudjut sind eine Art Gespenster oder Geister. Sie haben menschliche Gestalt aber einen sehr flachen Kopf. Sie sind sehr böse und pflegen die Menschen, die sie im Walde antreffen, $z \mathfrak{u}$ verschlingen. In den Dörfern haben sie keine Macht Menschen zu töten, wohl aber sie krank zu machen. Krämpfe in der Brust und Asthma sind die Leiden, die die Pudjut verursachen.

Eine Gaip Mythe ist auch die von den Brüdern des Anak Luting die auf dem Berge Pali in die Gemeinschaft von Geistern aufgenommen wurden. Siehe oben. 
Eine dieser Mythen lautet:

\section{Das Geisterdorf bei Tumbang Danum}

Tumbang Danum ist ein sehr altes Dorf bei Tumbang Samba am oberen Katingan.

In früheren Zeiten befand sich im Wald hinter dem Dorfe Tumbang Danum ein Geisterdorf. An manchen Tagen konnte man von dorther das Bellen der Hunde, das Gackern der Hühner und das Schlagen der Trommeln deutlich hören. Die Bewohner aber sah man nie. Ein alter Mann aus Tumbang Danum begab sich eines Tages in einen Nebenfluss auf den Fischfang. Er kehrte spät abends heim und hatte nur wenig Beute mitgebracht. Auch am nächsten Tage begab er sich wieder auf den Fischfang und blieb noch länger weg und als ihm seine Angehörigen zu essen geben wollten weigerte er die Speise mit den Worten: „Ich habe schon gegessen“. Schliesslich blieb er eines Tages aus und kehrte nicht mehr ins Dorf zurück. Er blieb verschwunden und alle Nachforschungen waren erfolglos.

Eines Tages kam er plötzlich wieder zu seinen erstaunten Angehörigen, die schon geglaubt hatten, dass er gestorben sei. Nachdem er sich auf dem Fussboden niedergelassen hatte sprach er zu ihnen: „O meine Kinder und Enkel, hört was ich euch zu sagen habe. Als ich auf den Fischfang auszog begegnete ich Bewohnern aus dem Geisterdorf. Sie waren sehr freundlich zu mir und sie luden mich ein in ihr Dorf zu kommen. Dort haben sie mich, wie einen der ihren aufgenommen und freundlich bewirtet und dort war ich auch während aller dieser Tage meiner Abwesenheit. Es hat mir dort so gut gefallen, dass ich in ihr Dorf zurückkehren- und für immer bei ihnen bleiben will. Ich werde mich dort auch verheiraten, denn meine Frau ist ja schon längst gestorben. Nun bin ich gekommen um euch das zu sagen und um von euch Abschied zu nehmen, denn nach diesem Besuch werde ich nie mehr zu euch zurückkehren. Kommt ihr aber in Not, sei es durch Krankheit oder Hunger, durch Hochwasser oder Dürre, dann streut gelben und roten Reis aus und ruft mich. Ich werde dann erscheinen und euch helfen". Nachdem er so gesprochen hatte nahm er Abschied von seinen Angehörigen und kehrte ins Geisterdorf zurück. Litten aber die Bewohner von Tumbang Danum unter Krankheit oder Hunger, Hochwasser oder Dürre, dann streuten sie Reis und riefen ihren Ahnen und er stand ihnen helfend bei und wandte ihre Not. 
In früheren Zeiten lebten im Dorfe Sanggajau ein Mann namens Pang Gajau und seine Frau. Eines Tages ruderten sie nach dem Flüsslein Kamipang um dort ihr Wurfnetz auszuwerfen und zu versuchen ob sie $z \mathfrak{u}$ ihrer Mahlzeit einige Fische fangen konnten. Als sie schon ziemlich weit von der Mündung entfernt waren sahen sie auf dem Flusse Reisspreu herantreiben. „Hau“, sagten sie zueinander, „gewiss haben sich am Oberlauf des Flüssleins Menschen niedergelassen. Wir wollen $\mathrm{zu}$ ihnen hinrudern und wir wollen schauen ob sie uns etwas von ihrem Reis verkaufen können". Sie ruderten rasch weiter und kamen bald bei einem kleinen Dorfe an wo sie die Menschen beim Reisstampfen fanden. Die Leute freuten sich sehr als sie die beiden Fremden sahen und sie luden sie ein zu ihnen ins Haus zu kummen. Das taten sie. Nachdem sie das Haus betreten hatten, sahen sie zu ihrer grossen Bestürzung erst, dass sie sich nicht bei Menschen, sondern in einem Dorfe der Kangkamiak 147 befanden. Alle Dorfbewohner freuten sich über diesen unerwarteten Besuch, man sah es ihren Gesichtern deutlich an. Pang Gajau erriet ihre Gedanken. Die Kangkamiak wollten sie natürlich töten und ihr Fleisch verzehren. Er erschrak sehr in seinem Herzen und dachte rasch nach wie er sich und seine Frau aus dieser üblen Lage befreien könnte. Es kam ihm ein guter Einfall. Nachdem er den angebotenen Sirih gekaut hatte, sprach er nämlich zum Dorfältesten: „Meine Frau und ich sind mit einer grossen Bitte zu euch hergerudert. Wir haben einen Sohn und wir möchten ihn gerne verheiraten und wir haben gehört, dass ihr heiratsfähige Töchter habt und nun möchten wir euch gerne fragen ob ihr nicht gewillt wäret eine eurer Töchter unserem Sohne zur Frau zu geben". Als die Kangkamiak diese Bitte hörten, freuten sie sich noch mehr in ihrem Herzen und sie dachten: „Es ist besser wenn wir die Beiden leben lassen und ihnen nichts antun und noch warten bis sie mit ihrem Sohn und allen Verwandten zusammen in unser Dorf zurückkehren, dann wollen wir sie alle überfallen und aufessen und unsere Beute ist dann viel reicher". Diesen Gedanken teilten sie aber Pang Gajau nicht mit, sondern der Dorfälteste antwortete: „Ja, wir haben wohl heiratsfähige Töchter und wir haben nichts dagegen einzuwenden wenn ihr eine von ihnen für eueren Sohn zur Frau wünscht. Wann aber willst du mit deinen Verwandten zusammen deinen Sohn in unser Dorf bringen?" Pang Gajau antwortete: „In sieben Tagen bin ich wieder hier und bringe mit vielen Verwandten zusammen 
meinen Sohn zur Hochzeit“. „Es ist gut“, antworteten die Kangkamiak, „,in dieser Zeit können wir auch alles bereit machen was für die Hochzeit und für die Bewirtung der Gäste nötig ist".

Nach dieser Abmachung nahmen Pang Gajau und seine Frau von den Kangkamiak freundlich Abschied und sie kehrten so rasch als möglich in ihr Dorf zurück. Als sie dort angekommen waren riefen sie die Bewohner des ganzen Dorfes zusammen und teilten ihnen ihr Erlebnis im Geisterdorf mit und die Bewohner beschlossen: „Has, wir wollen dieses Dorf sofort verlassen und uns anderswo niederlassen, denn gewiss kommen die Kangkamiak hieher wenn wir in sieben Tagen nicht $z \mathfrak{u}$ ihnen kommen. Aber lasst uns schlau sein, wir wollen unsere Katzen, Hunde, Ziegen und Kühe töten und sie in der Nähe unserer Häuser begraben. Kommen dann die Kangkamiak, dann denken sie, dass wir gestorben seien und sie werden uns nicht weiterverfolgen". So taten sie. Nachdem die Haustiere getötet und begraben waren machten sie ein grosses Floss und beluden es mit allen ihren Gütern und verliessen ihr heimatliches Dorf und wandten sich flussabwärts. Als sie bei der Mündung des Kalaru angekommen waren fuhren sie den Kalaru hinauf und bauten an ihm ihr neues Dorf.

Die sieben Tage waren verstrichen. Die Kangkamiak hatten vergeblich auf Pang Gajau und seine Verwandten gewartet. Sie hatten sich nicht eingefunden. Am achten Tage erschienen sie auch nicht. Da beschlossen sie: „Wir alle zusammen wollen nach dem Dorfe des Pang Gajau rudern und ihn und seine wortbrüchigen Verwandten dort überfallen und aufessen." So taten sie. Als sie das Dorf erreichten, da sahen sie, dass es verlassen war und dass die Häuser leer waren. Kein Mensch und kein Tier war weit und breit zu entdecken. Sie sahen sich im Dorfe um und gewahrten die vielen neuen Gräber und sprachen: „Hau, gewiss sind die Bewohner alle zusammen gestorben und liegen hier begraben, has, wir wollen die Gräber öffnen und die Leichen verzehren". Sie öffneten die Gräber und assen die Leichen und kehrten wieder in ihr Dorf zurück.

Von Pang Gajau und den Bewohnern des Dorfes am Kalaru hat niemand mehr etwas gehört. Sie waren und blieben verschwunden. Sie waren gaip geworden und ihr Dorf hatte sich in ein Geisterdorf verwandelt.

\section{Die Erscheinung von Toten (liau)}

Erzählungen von Toten (liau) die ihren Verwandten erscheinen, gibt es in jedem Dorf in grosser Zahl. Wir haben zu unterscheiden zwischen 
den Liau die zwischen der Zeit des Todes und des Totenfestes ruhelos in den Wäldern und in der Umgebung der Dörfer herumschweifen und den Lebenden Schaden zufügen wollen und den Liau für die das Totenfest gefeiert wurde und die man nach dem Totendorf geleitet hat. Von diesen Liau hat man nichts mehr zu befürchten. Es ist unrichtig anzunehmen dass diese Liau nicht mehr aus dem Totendorf in die Welt der Lebenden kommen können, denn auch sie greifen immer wieder spürbar und sichtbar mit ihrem Rat und ihrer Hilfe in das Leben der Menschen ein. Man bringt ihnen Opfer, man ruft sie auf, man bittet um ihre Hilfe und ihren Rat. Die erste Erzählung berichtet uns von einer Liau die zu der ersten Gruppe gehört, die zweite Erzählung, die wir hier mitteilen, berichtet uns von Liau die zu der zweiten Kategorie gehören.

\section{Wie eine Liau ihrer Mutter erscheint}

In früheren Zeiten lebte einmal ein Mann der mit einer jungen Frau verheiratet war, aber weil er sehr eifersüchtig war, hielt er sich nicht bei den andern Menschen auf sondern entfernte sich mit seiner Frau aus dem Dorfe und baute sich weit von den andern Leuten weg, im Busch, eine Feldhütte. Nach einiger Zeit sprach er zu seiner Frau: „Ich will mich in den Wald begeben um Buschprodukte zu suchen und werde einige Tage wegbleiben. Pflege dich in dieser Zeit gut". Die Frau aber erwartete ein Kind und die Zeit der Geburt war schon sehr nahe herbeigekommen. Sie wartete einen Tag um den andern auf ihren Mann aber immer noch kehrte er nicht nach Hause zurück und so war die Frau ganz allein in ihrer Hütte als sie einem Kinde das Leben schenkte. Aber sie starb bei der Geburt.

Am gleichen Tage hatte ihre Mutter, die im Dorfe wohnte, sich entschlossen ihre Tochter in ihrer einsamen Feldhütte zu besuchen und um nicht allein rudern und durch den Wald gehen zu müssen, nahm sie eines ihrer jüngeren Kinder mit. Sie kamen nach einiger Zeit bei der einsam stehenden Hütte an. Die Mutter rief, als sie bei der Treppe angekommen war: „O mein Kind, bist du daheim?" Und sie erhielt die Antwort: „Ja, meine Mutter, tritt nur ins Haus herein“. Es war aber ihre tote Tochter die so gesprochen hatte. Nachdem die Mutter in die Hütte eingetreten war sah sie, dass ihr Kind geboren hatte und sie fragte verwundert: „Weshalb war niemand bei dir als du einem Kinde das Leben schenktest, wo ist denn dein Mann?" Ihre Tochter, d.h. die Liau, entgegnete: „Er ist weggegangen in den Wald um Busch- 
produkte zu suchen, aber er wird bald wieder heimkehren". Und sie bat ihre Mutter : „Ich möchte gerne noch geschwind auf unser Feld gehen um Reis zu pflanzen, vielleicht kann meine Schwester mich begleiten. Achte inzwischen auf dein Enkelkind und wenn es weint, dann gibst $\mathrm{du}$ ihm diese Milch hier" und mit diesen Worten strich sie ihrer Mutter die Milch an den Finger. Und bevor sie das Haus verliess sprach sie noch zu ihrer Mutter: „Oeffne aber ja nicht die Schlafgardine!" Die Reissetzlinge, die sie mitnehmen wollte, hatte sie in einen Korb gelegt und sie nahm diesen auf ihren Rücken. Aber sie tat es verkehrt (die Liau machen alles verkehrt) und die Schwester machte sie darauf aufmerksam und fragte sie: „Siehst du nicht, dass du den Korb verkehrt, mit der Oeffnung nach unten statt nach oben, auf deinem Rücken trägst?" „Nein“, antwortete sie ihrer Schwester, „ich habe den Korb recht auf meinen Rücken genommen". Auf dem Felde angekommen hiess sie ihre jüngere Schwester mit einem Stocke die Pflanzlöcher machen und dann pflanzte sie in diese Löcher hinein den Reis. Aber auch diese Arbeit tat sie verkehrt, denn nicht die Wurzeln steckte sie in die Erde sondern die zarten Blätter. „Hau“, sagte die Schwester als sie diese Arbeit sah, „wie pflanzest du denn doch den Reis! Siehst du nicht, dass du deine Arbeit ganz verkehrt machst?" „Nein“, sprach die Schwester, „,ich mache meine Arbeit recht“. Da erschrak die jüngere Schwester sehr in ihrem Herzen und sie sprach zu sich selbst: „Gewiss lebt meine Schwester nicht mehr und es ist die Liau mit der ich hier auf dem Felde arbeite, denn alles was sie tut, das macht sie verkehrt und sie handelt ganz nach der Weise der Liau" und sie sprach zu ihrer Schwester gewandt: „Entschuldige mich einen Augenblick, ich muss dich geschwind verlassen um meine Notdurft zu verrichten, aber ich werde sogleich wieder zu dir zurückkehren". Nach diesen Worten entfernte sie sich und sie kehrte so rasch sie eilen konnte, zu ihrer Mutter in die Hütte zurück. Dort angekommen sagte sie zu ihr : „Mit meiner Schwester ist offenbar etwas nicht in Ordnung. Gewiss ist sie gestorben und es war die Liau die mit dir sprach und die mich aufforderte mit ihr aufs Feld zu kommen, denn alle Arbeiten führte sie nicht nach menschlicher Weise aus, sondern tat sie so wie sie die Liau zu tun pflegen. Sie machte alles verkehrt“. „Dein Wort ist recht", sagte die Mutter, "ganz gewiss war es nicht meine lebende Tochter, sondern die Liau, die mir soeben befahl: hebe die Schlafgardine nicht auf. Wir wollen nun doch geschwind nachsehen was sich unter ihr befindet". Und als die Gardine offen war sahen sie zu ihrem grossen Entsetzen eine Leiche unter ihr liegen. Rasch verliess die 
Mutter mit ihrem Kinde das Haus und eilte von diesem unheimlichen Orte weg.

Lange hatte die Liau auf dem Felde gewartet, aber die Schwester kehrte nicht mehr zurück. Sie entschloss sich sie zu suchen und sie eilte zuerst in die Hütte zurück ob sie sie wohl dort finden möchte. Aber sie entdeckte, dass sich nicht nur ihre Schwester sondern auch ihre Mutter davongemacht hatte. Rasch verfolgte sie die Flüchtenden und rief ihre Namen. Die Milch, die sie ihrer Mutter an den Finger gestrichen hatte damit sie damit den Säugling stillen sollte, war aber keine Milch gewesen sondern Limbanwasser (danum limban, so wird die Flüssigkeit genannt die aus den verwesenden Leichen fliesst). Rief sie nun den Namen der Mutter, dann antwortete dieses Limbanwasser auf ihren Ruf: „Hier bin ich, hier bin ich“. Die Mutter fürchtete sich sehr und sie eilte mit ihrem Kinde, so rasch sie konnte, weiter. Aber jedesmal wenn die Liau wieder rief antwortete das Limbanwasser. Sie versuchte ihren Finger an einem Tunggulbaum rein zu fegen, aber es gelang ihr nicht. Wieder rief die Liau und wieder antwortete das Limbanwasser. Erschöpft kam sie mit ihrem Kinde beim Ruderboote an das im kleinen Nebenflüsslein lag. Sie bestiegen es rasch und ruderten schnelle nach der Mitte des Flusses. Aber wieder rief die Liau und wieder antwortete das Limbanwasser: „Hier bin ich“. Sie ruderten weiter so rasch sie zu rudern vermochten und als sie zu einer Flussbiegung kamen sahen sie am Ufer einen schlafenden Hirsch liegen. Lautlos näherten sie sich ihm und rasch strich die Mutter ihren Finger am Fell des Tieres ab und dann ruderten sie wieder weiter. Und siehe, was da plötzlich geschah! Als die Liau wieder rief, da blieb ihr Finger still aber der Hirsch antwortete: „Hier bin ich, hier bin ich!“ Als die Liau den Hirsch erreicht hatte stürzte sie sich auf ihn und zerriss ihn in viele Stücke. So wurde die Mutter und ihr Kind gerettet.

Nach einiger Zeit kehrte der Mann aus dem Walde wieder in seine Hütte zurück. Er sah, dass seine Frau inzwischen einem Kinde das Leben geschenkt hatte, aber dass Mutter und Kind bei der Geburt gestorben waren, weil er sie in dieser Zeit allein im Hause zurückgelassen und alle Pali, die ihm verboten seine Frau zu verlassen, missachtet hatte. Er bereute seine Tat sehr. Er bereute auch, dass er aus Eifersucht mit seiner Frau das Dorf verlassen und sich im Busch, weit von andern Menschen weg, eine Hütte gebaut hatte. Aber zur Reue war es $z \mathfrak{u}$ spät, seine Frau und sein Kind waren tot und er konnte sie nicht mehr ins Leben zurückrufen. 


\section{Liau aus dem Sandong besuchen ihre Angehörigen}

Die Verstorbenen (ein Mensch der gestorben ist nennt man Liau, es ist unrichtig diesen Terminus nur auf die Seele zu beziehen, er meint den Menschen in seiner Ganzheit, also mit Leib und Seele, als Toter) deren Knochen beim Tiwah (Totenfest) im Sandong (geschnitztes Knochenhäuschen) beigesetzt sind, können von den Lebenden aufgerufen werden. Das geschah in früheren Zeiten vor allem bei Hexenprozessen. Als Hantuen (Hexen, böse Geister) verdächtigte Menschen mussten den Sandong umtanzen und seine Bewohner, die Toten oder Liau, wiesen an ob die Person wirklich ein Hantuen sei oder nicht. Aber auch bei andern Gelegenheiten rief man die Verstorbenen, die sich im Sandong aufhielten auf und manche Erzählung berichtet wie sie aus dem Sandong heraustraten und nachts ihre Angehörigen besuchten und die Nacht in ihrer Gesellschaft verbrachten.

\section{Die Erzählung von Kanjok}

Kanjok, ein Mann der in früheren Zeiten lebte, war mit zwei Frauen verheiratet. Die eine hiess Djabak, die andere Pali. Eines Tages wollte Kanjok den Mut seiner Frau Djabak auf die Probe stellen. Er teilte ihr mit, dass er beschlossen hätte mit Pali zusammen ihre Eltern zu besuchen und eine Nacht dort zu schlafen und erst am andern Morgen wieder heimzukehren. Nachdem er den Beschluss Djabak mitgeteilt und ihr gesagt hatte, dass sie auf alle Dinge im Haus gut aufpassen solle, begab er sich mit Pali auf den Weg. Sie mussten beim Sandong vorbeigehen und als Kanjok dort angekommen war schlug er mit seiner Hand an die Wand und rief: „O, meine Ahnen, verbringt doch die heutige Nacht bei meiner Frau Djabak. Ich muss mit Pali ihre Eltern besuchen und kann erst am Morgen wieder zurückkehren. Unterhaltet meine Frau gut". "Ja“, entgegneten die Ahnen, "sobald die Sonne untergegangen und die Dunkelheit hereingebrochen ist, werden wir uns zu ihr begeben". Djabak hatte aber vom Hause aus gesehen was Kanjok tat und sie hatte auch seine Worte vernommen. Sie bereitete das Nachtessen und sie kochte mehr als sie nötig hatte um auch die Ahnen bewirten zu können. Als die Sonne ausgelöschit war verliessen die Ahnen den Sandong und kamen zum Hause der Djabak. Mit lauter Stimme riefen sie: „Welche Zuspeise hast du uns bereitet zum Reis?" Sie antwortete ihnen: „Ich habe euch Gemüsesuppe (djoho) von Kudjang, Rimbang und Uwi bereitet, tretet ein und esst was ich für euch gekocht habe". Djabak aber wartete nicht bis sie das Haus 
betreten hatten. Mit einem kleinen Hunde auf ihrem Arm kletterte sie rasch auf einen Querbalken über dem Fussboden und versteckte sich dont. Die Ahnen setzten sich auf den Boden und assen die Speisen, die für sie bereitet waren. Darauf kauten sie Sirih und als sie damit fertig waren begannen sie den Balken, auf dem Djabak sass, zu umtanzen. Sie begoss das Gesicht des Hundes mit Wasser und er begann zu wimmern. Die Ahnen fragten sie: „Wer ist es dort bei dir, der da wimmert?" Sie antwortete: „Still ihr, sonst sieht euer Enkel euer Tun". Eine Zeit lang blieben sie ruhig sitzen aber dann begannen sie wieder zu tanzen und wieder netzte Djabak das Gesicht des Hundes mit Wasser und wieder wimmerte er wie ein kleines Kind und die Ahnen stellten die gleiche Frage und bekamen dieselbe Antwort wie zuvor. Das wiederholte sich bis die Morgendämmerung anbrach. Als der Tag graute verliessen die Ahnen das Haus und Djabak kletterte unversehrt von ihrem Balken herunter.

Als die Sonne höher gestiegen war kehrten Kanjok und Pali wieder heim und sie schauten suchend im Hause herum und verwunderten sich sehr, dass Djabak fröhlich und unversehrt herumlief wie wenn gar nichts geschehen wäre. Aber sie getrauten sich nicht sie zu fragen wie die Nacht verlaufen sei und auch Djabak sagte kein Wort. Aber am Nachmittag sprach sie zu Kanjok: „O mein Mann, ich bin schon lange nicht mehr bei meinen Eltern gewesen. Ich möchte sie gerne besuchen und diese Nacht bei ihnen zubringen. Am Morgen kehre ich wieder zurück. Es ist aber nicht nötig, dass du mich begleitest, bleibe du mit Pali hier und bewache mit ihr zusammen gut unser Haus". Nachdem sie so gesprochen hatte verliess sie das Haus und als sie auf ihrem Weg beim Sandong angekommen war klopfte sie an die Wand und rief : „O, meine Ahnen, ich gehe für diese Nacht zu meinen Eltern. Kanjok und Pali sind allein im Haus zurückgeblieben. Besucht sie doch und bleibt bis am Morgen bei ihnen“. Die Ahnen waren damit einverstanden. Aber auch Pali und Kanjok hatten diese Wonte gehört und als der Abend hereingebrochen war kochten sie für die Ahnen Reis und Zuspeisen. Aber sie hatten die Zuspeisen zu lange über dem Feuer gehabt und sie waren verbrannt und verdorben und schmeckten sehr schlecht. Als sie das Essen bereitgesetzt hatten warfen sie die Treppe herum, 148 schlossen die Türe gut ab, wickelten sich in Matten und legten sich auf den Boden und taten wie wenn sie schlafen würden.

Als die Sonne untergegangen war verliessen die Ahnen den Sandong und kamen zum Haus herüber. Sie sahen dass die Treppe herumgedreht war und sie riefen mit lauter Stimme: „O Kanjok und Pali, 
seid ihr daheim und was habt ihr uns als Mahlzeit zubereitet?" Aber im Hause blieb alles still, sie bekamen keine Antwort, denn Kanjok und Pali getrauten sich nicht zu sprechen. Da sprachen sie: „Stich Nadel, stich Nadel", und nach diesen Worten standen sie im Haus. Sie sahen die Speisen und setzten sich auf den Fussboden nieder und begannen zu essen. Aber das Essen schmeckte ihnen sehr schlecht und sie wurden sehr zornig. Sie warfen sich auf Kanjok und Pali und zerschlugen und zerkratzten sie, sodass sie steif und ohnmächtig liegen blieben. Als der Morgen anbrach kehrten sie zum Sandong zurück und bald darauf kam auch Djabak nach Hause. Sie sah die Beiden steif auf dem Fussboden liegen. Rasch kochte sie Wasser um sie durch warme Dämpfe wieder zum Bewusstsein zu bringen. Das gelang ihr nach kurzer Zeit. Von dieser Zeit an wagte Kanjok aber nicht mehr den Mut seiner Frau Djabak auf die Probe zu stellen.

\section{Warum die Leichen bewacht werden}

Für die Bewachung der Leiche, für die Zeit in der sie im Hause aufgebahrt liegt, geben die Ngadju Dajak folgende Erklärungen:

a. Eine der Geschichten erzählt uns: Weit vom Dorfe entfernt, in einer einsamen Feldhütte, schenkte einmal eine Frau einem Kinde das Leben zur gleichen Stunde als ihr Schwiegervater im Hause, das sich im Dorfe befand, gestorben war. Nachdem ihnen diese Trauerbotschaft überbracht worden war, sagte der Mann zu seiner Frau: „Erlaube mir doch, dass ich für diese Nacht ins Dorf zurückkehre um bei der Leiche meines Vaters zu wachen". Die Frau war damit einverstanden, aber sie bat ihren Mann: „Schleife mir zuerst das Buschmesser und den Speer recht scharf, damit ich, wenn ich diese Nacht allein in unserer Hütte zurückbleiben muss, doch recht gute Waffen habe". Der Mann tat wie die Frau ihn geheissen hatte. Es war schon später Nachmittag geworden bis er endlich aufbrechen konnte. Zuerst verriegelte er noch das Fenster, dann verliess er das Haus und verschloss die Türe gut und kehrte die Treppe um, damit kein Tier das Haus erklimmen konnte, und darauf begab er sich eilig nach dem Dorf.

In seinem elterlichen Hause angekommen setzte er sich mit seinen Verwandten um die Leiche seines Vaters. Es war schon spät in der Nacht. Immer tiefer senkten sich die Köpfe der Angehörigen die um die Leiche herum Platz genommen hatten und schliesslich waren sie alle zusammen eingeschlafen.

Plötzlich wurde die Leiche von einem Geist besessen (ingumpang taloh, dass kann auch heissen, dass die Liau in den Körper des Toten 
zurückgekehrt ist, denn die Liau wird, vor allem zwischen Tod und Totenfest, oft auch taloh genannt). Sie stützte sich auf ihren Ellbogen auf, dann erhob sie sich und verliess das Haus und begab sich zur Feldhütte in der seine Schwiegertochter wohnte um seinen neugeborenen Enkel $z u$ besuchen. Vor dem Hause angekommen rief er mit lauter Stimme und bat seine Schwiegertochter ihm die Türe zu öffnen. Aber sie gab ihm weder Antwort noch öffnete sie ihm die Türe. Er wandte die Treppe um und stieg zum Haus empor und als die Türe immer noch nicht geöffnet wurde, zerriss er die Rindenwände des Hauses. Als die Frau das sah nahm sie das Buschmesser zur Hand und öffnete vorsichtig die Türe, aber nur sehr wenig. Rasch wollte der Schwiegervater mit der Hand nach ihr greifen, aber sie schlug sie ihm mit dem Messer ab und nahm sie ins Haus herein. Sie legte sie über das Harzfeuer und liess sie leicht rösten. Als der Schwiegervater merkte, dass er seine Hand nicht mehr besass, rief er : „Gib mir meine Hand zurück!“ Aber die Schwiegertochter gab sie ihm nicht. Erst als der Morgen dämmerte gab sie ihm seine Hand wieder zurück und eilig trat die Leiche den Rückweg zum Dorfe an und legte sich, ohne dass sein Fortgehen bemerkt worden wäre, wieder auf den Fussboden nieder. Als es hell geworden war erwachten die Schlafenden und sie sahen zu ihrer grossen Bestürzung, dass die eine Hand der Leiche verbrannt war. Nun wussten sie, dass sie durch Geister besessen worden war und dass in dieser Nacht etwas geschehen sein musste. Schnell machten sie einen Sarg und legten die Leiche hinein und schlossen den Deckel ab.

Seit dieser Zeit aber wollen die Menschen nicht mehr schlafen so lange sich eine Leiche im Hause befindet und sie wollen sie auch nicht verlassen so lange sie noch nicht im Sarge liegt. Sie erinnern sich an diese Geschichte, die für sie eine Warnung ist, und sie wollen nicht, dass nochmals die Seele eines Menschen durch eine Leiche gefährdet werde. Während sie die Leiche bewachen führen sie deshalb manche Spiele aus und sie streuen heissen, gerösteten Reis über ihre Köpfe oder jagen ihnen mit Feuerbränden nach. Dadurch wird verhütet, dass sie in Schlaf fallen.

b. In einem Dorfe starb eines Tages ein Mann. Seine Leiche lag auf dem Fussboden aufgebahrt aber sie war noch nicht in den Sarg gelegt worden. Die Leute wachten nicht, sondern jeder lag auf seiner Matte und schlief ruhig. Plötzlich wurde die Leiche von einem Geist besessen. Sie erhob sich und ging im Hause herum und zerschlug die heiligen Töpfe und streute die gesalzenen Fische, die in andere Töpfe eingelegt waren, auf dem ganzen Fussboden herum. Aber im Hause befand sich 
auch eine Wöchnerin die vor kurzer Zeit einem Kinde das Leben geschenkt hatte. Sie konnte in dieser Nacht nicht schlafen und sie sah alles was die Leiche tat, aber sie wagte kein Wort zu sprechen oder die Leiche bei ihrem Zerstörungswerke $z \mathfrak{u}$ hindern. Aber auch die Leiche sah, dass sie bei ihrem Tun beobachtet worden war und sie trat vor die Frau hin und sprach zu ihr: „Wenn du den Leuten sagst wer dies alles getan hat, dann werde ich dich umbringen". Nach diesen Worten legte sie sich wieder langausgestreckt auf den Fussboden nieder und sie nahm, bevor sie das tat, ein scharfes Schnitzmesser zu sich.

Der Tag brach an. Die Leute erwachten und sahen zu ihrer grossen Bestürzung die Verwüstung, die die Leiche angerichtet hatte. Einer beschuldigte den Andern, aber jeder stritt die Tat ab. Schliesslich wandten sie sich auch $z \mathfrak{u}$ der Frau und sprachen $z \mathfrak{u}$ ihr: „Gewiss bist du es gewesen die diese Nacht unsere heiligen Töpfe zerschlagen und die Fische auf dem Boden herumgestreut hat". Aber auch sie wies die Beschuldigung von sich. Die Leute glaubten ihren Worten nicht und wiederholten scheltend ihre Worte. Da erhob sich die Frau von ihrem Fussboden, nahm das Kind zu sich, und dann begann sie den Leuten zu erzählen was sich in dieser Nacht zugetragen hatte. Die Leiche liess ein dumpfes drohendes Mmmmm hören um die Frau zu warnen. Sie erzählte aber weiter. Lauter und dumpfer ertönte das $\mathrm{Mmmmm}$. Sie liess sich nicht abhalten und erzählte den Leuten, dass sich die Leiche plötzlich erhoben und alles zerschlagen hätte. Kaum aber hatte sie das gesagt, da erhob sich die Leiche, ergriff das Schnitzmesser und schleuderte es nach der Frau. Es blieb in ihrem Rücken stecken und tot sank sie auf dem Boden zusammen. Aber auch die Leiche legte sich wieder auf ihren Platz und war leblos wie zuvor.

Seit dieser Zeit aber schlafen die Menschen nicht mehr, wenn sich eine Leiche im Haus befindet. Sie bewachen sie, weil sie sich dieser Erzählung erinnern.

\section{Die Feier des ersten Tiwah in Batu Nindan Tarong 149}

Batu Nindan Tarong, Liang Angkar Bantilong Njaring ist das erste Dorf in der Oberwelt in dem die ersten Menschen wohnten. Die Nachkommen dieser ersten Menschen verbreiteten sich über die ganze Oberwelt und eine ihrer Gruppen stieg herunter auf die Welt und baute hier ihr erstes Dorf. Die Angehörigen dieser Gruppe sind die Stammeltern der Ngadju Dajak geworden.

Alle wichtigen Handlungen im Leben der Ngadju Dajak werden ausgeführt wie sie erstmalig eingesetzt und ausgeführt wurden von den 
Urahnen in Batu Nindan Tarong. Auch das Tiwah (Totenfest), und alle dabei ausgeführten Handlungen, werden genau nach dem Vorbild des ersten Tiwah von Batu Nindan Tarong ausgeführt. Von diesem ersten Tiwah erzählt die Mythe, die bei der Aufrichtung des balai sanggaran 150 rezitiert werden muss:

Im Dorfe Batu Nindan Tarong lebte ein Mann namens Tanta Olang Bulau, Tanta Enjet Njaring (statt Njaring steht auch Penjang). Er war der Aelteste des Dorfes.

Eines Tages, als Tanta Olang Bulau im Balai (Versammlungshaus) sass, besuchten ihn zwei Männer. Der eine hiess Tungkong Njaho. Er kam aus dem Dorfe Bukit Letai Rundjan. Der andere, Andin Habalau Bulau, stammte aus dem Dorfe Bukit Bulau. Die beiden besuchten Tanta Olang Bulau im Auftrag des Ranjing Mahatala Langit und sie forderten ihn auf sich mit ihnen zu ihm zu begeben, denn, sagten sie: „Heute in sieben Tagen haben wir drei vor Ranjing Mahatala Langit zu erscheinen“. Aber Tanta Olang Bulau erwiderte: „Ich kann mein Dorf nicht verlassen, denn in unserem Dorf befinden sich grosse Reichtümer". Kaum hatte er aber diese Antwort gegeben, da fühlte er sich so sehr krank werden, dass er nicht einmal mehr sitzen konnte. Die beiden Besucher wurden plötzlich emporgehoben, immer höher und höher, bis sie endlich im Dorfe des Ranjing Mahatala Langit ankamen. Sie sagten ihm, dass Tanta Olang Bulau die Einladung nicht angenommen habe und berichteten: „Er kann sein Dorf nicht verlassen, denn in ihm befinden sich grosse Reichtümer". Darauf entgegnete Ranjing Mahatala Langit: „Er ist als Strafe für seine Weigerung schwer krank geworden und ich will ihm eine Erangfrucht 151 geben damit er nicht sterben muss und damit er, wie ihr beide, bei mir bleibt und nicht mehr in sein Dorf zurückkehrt". Es wurde Tanta Olang Bulau die Botschait übergebracht: „Du bist krank, Tanta Olang Bulau, und du wirst sterben müssen, wenn du nicht zu mir kommst. Willst du aber zu mir kommen, dann sollen du und deine Nachkommen immer leben". Tanta Olang Bulau schenkte dieser Einladung kein Gehör. Als er fühlte, dass es mit seinem Leben zu Ende ging, versammelte er alle Verwandten um sich und sprach: „Ich muss sterben und ihr alle werdet von jetzt an auch sterben müssen". Während er im Sterben lag wollte ihn Rawing Tempon Telon mit seinen Sklaven zusammen besuchen, aber kaum war er im Dorfe Batu Nindan Tarong angekommen, da starb Tanta Olang Bulau und er kehrte mit seinen Sklaven wieder unverrichteter Dinge in sein eigenes Dorf zurück.

Die Leute in Batu Nindan Tarong waren sehr traurig, ihr Herz 
schmerzte sie, denn sie wussten, dass sie alle auch einst sterben mussten. Von dieser Zeit an kehrten Krankheit, Tod und Not in ihrem Dorfe ein. Die ganze Oberwelt wurde von einem grossen Hochwasser heimgesucht. Das Wasser dehnte sich immer mehr und immer weiter aus. Da baute der Grossvater Rawing Tempon Telon ein grosses Boot (Banama Bulan Runtil Bulau). Er bestieg es, zusammen mit seinen Verwandten. Die ganze Erde wurde von der grossen Flut bedeckt, sieben Tage und sieben Nächte lang. Als endlich das Wasser wieder sank blieb das Boot auf dem Gipfel des Berges Bukit Lampajong Njaho liegen. Ranjing Mahatala Langit warf eine Erangfrucht nieder auf die Erde und sprach: „Wer diese Frucht findet wird leben und er wird auch seinen Verwandten, die schon gestorben sind, zum Leben verhelfen können, sodass ihre Seelen bei mir leben werden. Aber nur die Seelen derer können zu mir gelangen für die das grosse Tiwah gehalten worden ist".

Die Erangfrucht wurde von Rawing Tempon Telon und seinem Sklaven auf dem Berge gefunden und nachdem die beiden sie aufgehoben hatten, wurden sie plötzlich emporgehoben, immer höher und höher, bis hinauf $z \mathfrak{u}$ Ranjing Mahatala Langit. Dieser sprach zu ihnen: „Die Menschen können nicht zu mir heraufsteigen, sie müssen sterben. Aber ihre Seelen (liau) können zu mir gelangen, wenn für sie das grosse Tiwah gegeben wird“. Und er befahl Rawing Tempon Telon: „Steige hinunter in das Dorf Batu Nindan Tarong. Versammle die Dorfleute und sage ihnen, dass sie für Tanta Olang Bulau und die andern Verstorbenen das Tiwah veranstalten sollen" und bis in die kleinsten Einzelheiten erklärte er ihm wie das Tiwah gehalten und veranstaltet werden müsse.

Rawing Tempon Telon tat wie ihm Ranjing Mahatala Langit befohlen hatte. Er stieg hernieder in das Dorf Batu Nindan Tarong und unterwies die Bewohner wie sie für Tanta Olang Bulau und die andern Verstorbenen das Tiwah zu veransitalten hatten.

So, wie in der Urzeit dieses erste Tiwah gehalten wurde, so hält man es in den Dörfern an den Ufern des Flusses der Welt bis auf den heutigen Tag. Das leere Boot, die Banama Runtil Bulau, übergab Rawing Tempon Telon seiner Schwester Kameloh Tempon Tiawon.

$\mathrm{Zu}$ diesem allerersten Tiwah hatten die Bewohner von Batu Nindan Tarong auch einen Balai sanggaran errichtet. Dieser Balai war fest gebaut und auf beiden Seiten mit den geschnitzten Tambon (Wasserschlangen) versehen.

Das grosse Tiwah war längst vorbei. $\mathrm{Da}$ kam eines Tages ein 
Fremder in das Dorf Batu Nindan Tarong und wollte in dem leerstehenden Balai sanggaran übernachten. Aber die Dorfleute sagten zu ihm: „In dieser Hütte kannst du nicht übernachten, es ist pali“. Der Fremdling kümmerte sich aber nicht um die Worte der Dorfbewohner, er begab sich ruhig in die Hütte um in ihr zu schlafen. Plötzlich brach ein entsetzliches Unwetter los. Es blitzte und donnerte als ob die Welt untergehen wollte. Der Pantar pandjang (der Seelensteg, die hoch zum Himmel emporragende Eisenholzsäule), der vom Tiwah her noch auf dem Platze stand, verwandelte sich plötzlich in eine Steinsäule. Der Balai sanggaran verwandelte sich in eine Tambon. Der Fremdling wurde vom Sturm fortgeweht und ins Wasser hinausgeschleudert und er verwandelte sich dort in einen Stein der bis heute den Namen trägt : Batu Saloh, Liang Angkar Bantilong Njaring. Die Tambon (Wasserschlange) aber begab sich ins Wasser und befindet sich bis heute in der Wassertiefe des Meeres in der Oberwelt. Bei ihr muss Rawing Tempon Telon vorbeifahren, wenn er in seinem Boot die Toten in das Totendorf abholt und jedesmal wenn er hier auf seiner Reise vorbeikommt, will ihn die Tambon anfallen. Gibt man ihr aber Opfer, dann lässt sie Rawing Tempon Telon ruhig und ungehindert vorbeirudern. Aus diesem Grunde werden beim Tiwah der Tambon in einer besonderen Opferhü̈tte Opfer dargebracht. Man nennt diese Hütte Balai Tambon Lambang Balai.

\section{E. Anhang: Aus der Mythologie eines Dajakdorfes}

Um ein Beispiel des mythologischen Hintergrundes eines Dorfes, und seiner Bedeutung für die Bewohner, zu geben teile ich hier die wichtigsten Mythen des Dorfes Tumbang Lahang mit.

Tumbang Lahang liegt am oberen Katingan, ungefähr $430 \mathrm{Km}$. von der Mündung des Flusses in die Javasee entfernt. Es ist gebaut auf einer Insel die gebildet wird durch die beiden Flüsslein Djakolok und Lahang, die beide aus dem waldumsäumten grünen Bakongsee (wahrscheinlich ein alter Flussarm, er liegt zwei Stunden Marsches hinter dem Dorfe) ausfliessen und in entgegengesetzten Richtungen nach dem Katingan strömen.

Tumbang Lahang ist am oberen Katingan das berühmteste Dorf. Es hat angesehene Kopfjäger und Dorfälteste, deren Autorität sich auch über andere Dörfer erstreckte, hervorgebracht. Es steht auch heute noch in Ansehen und wird von Fremdlingen gefürchtet. Das Dorf zählt ungefähr 450 Einwohner. Sie stammen vom oberen Katingan, vom 
mittleren Katingan und vom Kahaian. Ihre Abkunft, vor allem aber dann auch die ursprüngliche Stammeinteilung in zwei Stammteile (von dem Clan wissen wir nichts mehr), findet in den Mythen ihren Niederschlag.

\section{Der Ursprung der Bevölkerung}

Es geschah in alten Zeiten, dass einst ein sehr schöner Tag angebrochen war an den Ufern des Flusses der Welt. Der Himmel war blau und rein. Weit und breit sah man keine Wolke und ruhig schwebte der Falke über Fluss und Wald. Da sahen die Menschen, die am Ufer des Flusses der Welt wohnten, wie sich langsam ein Seil vom Himmel heruntersenkte. An ihm hielten sich zwei Menschen fest. Es waren zwei Männer. Der eine von ihnen hiess Raju, der andere Sanggarong Ugang. Sie waren im Begriffe die Oberwelt zu verlassen und an die Ufer des Flusses der Welt herunterzusteigen. Sie erreichten ihr Ziel auf dem Batu Ambo bei Tumbang Baraui am mittleren Samba (Nebenfluss des Katingan). Nachdem sie festen Grund unter ihren Füssen fühlten, lösten sie sich vom Goldseil los und dieses verschwand wieder, von unsichtbarer Hand eingeholt, in der Oberwelt. Bis heute noch sieht man aber die Spuren dieses schweren Goldseiles auf dem Batu Ambo und bis heute bewahren die Nachkommen des Raju ein Stück dieses Seiles als köstliches Erbgut (pusaka) auf. (Es ist im Besitz des Damang Rasa in Tumbang Lahang.)

\section{Die Mythe von der Naga Andoh}

In früheren Zeiten lag am Flüsslein Lahang ein Dorf, genannt Manunggul. Ihm stand als Aeltester ein sehr alter Mann vor, der tapfer und gefürchtet war und manchen Kopf erbeutet hatte. Eines Tages befahl er seinen Sklaven: „Geht in den Wald und sammelt Feuerholz, Blätter und Bambusschösslinge" und andern gab er den Auftrag Henda, Pfeffer und Kräuter zu sammeln und wieder andern befahl er die Bewohner des Nachbardörfleins Djakolok zu einem Feste, das er veranstalten wollte, einzuladen. Die Sklaven handelten nach dem Befehl ihres Herrn. Als diejenigen, die nach Djakolok ruderten, dort angekommen waren, machten sie am Landungsfloss ihr Boot fest und stiegen zum Dorf hinauf. Der Aelteste sass eben im Balai (Versammlungshaus) und als er die Sklaven kommen sah drehte er sich nach ihnen um und fragte sie: „Was führt euch zu mir her, meine Neffen?" Sie sagten ihm: „Frage nicht nach unserem Kommen, denn unser Herr, unser Sangiang, hat uns beauftragt dir die Einladung zu seinem Feste 
$z u$ überbringen. In drei Tagen findet in unserem Dorf ein Tiwah statt und er bittet dich und die Bewohner deines Dorfes daran teilzunehmen". Nachdem sie den Auftrag ihres Herrn ausgerichtet hatten, kehrten sie wieder in ihr Dorf zurück.

Am zweiten Tage versammelte der Dorfälteste von Tumbang Djakolok die Bewohner seines Dorfes und teilte ihnen die Einladung des Dorfältesten von Manunggul mit. Sie wurde von allen gerne angenommen und man entschloss sich in der Frühe des kommenden Tages dorthin zu rudern. Als der Morgen graute, machte man sich für die Abreise und den Besuch in Manunggul bereit und dann fuhr man gemeinsam in einem langen Boote weg. Zuerst ruderten sie ein Stück flussabwärts und dann bogen sie in den Lahang ein und fuhren flussaufwärts. Schon nach ganz kurzer Zeit kamen sie im Dörflein Manunggul an, wo die ganze Bevölkerung in festlicher Stimmung beisammensass. Die einen tranken Reisbier, die andern assen die vorgesetzten Speisen und wieder andere schlugen die Trommeln und Gong. Sie legten mit ihrem Boot am Landungsfloss an und als man sie entdeckt hatte begrüsste man sie mit lauten Jauchzern und ging ihnen entgegen. Ihr Aeltester, Andoh, wurde auf ein, mit Flechtereien geschmücktes Brett gesetzt das die Männer auf ihre Schultern hoben und in den Balai Raung, die Hütte in der die Särge aufgebahrt waren, trugen. Inmitten der versammelten Aeltesten setzten sie das Brett nieder und Andoh wurde gebeten den Ehrenplatz einzunehmen. Auch seine Begleiter folgten dem Zuge und betraten den Balai Raung. Man schöpfte ihnen Essen und füllte die Büffelhörner mit Bier und als sie sich satt gegessen hatten griffen sie zum Sirih und begannen zu kauen. Bald darauf verabschiedeten sie sich für diesen Tag vom Veranstalter des Tiwah und sie baten ihn um Erlaubnis nach Hause zurückkehren zu dürfen. Die Erlaubnis wurde ihnen erteilt und sie stiegen $z \mathfrak{u}$ ihrem Boot hinunter, lösten das Rotan und fuhren wieder von Manunggul weg. Noch waren sie nicht weit gerudert, als sich der Himmel mit schwarzen und drohenden Wolken zu überziehen begann. Blitze zuckten flackernd auf, der Donner rollte dumpf und plötzlich brach über ihnen ein furchtbares Unwetter aus. Als sie bei der Wassertiefe Busi ankamen 152 sahen sie, dass das Flüsslein Lahang durch einen gewaltigen Lunokbaum, den der Sturm gefällt hatte, abgeschlossen war. Probierten sie unter ihm durchzufahren, dann senkte er sich plötzlich, versuchten sie ihn mit vereinter Kraft ins Wasser zu drücken, um über ihn hinwegfahren zu können, dann hob er sich, wie von unsichtbarer Macht in die Höhe gedrückt. Sie konnten ihn nicht auf die Seite 
räumen, da sie keine Beile bei sich hatten, und so verloren sie bei diesem merkwürdigen Hindernis viel Zeit. Endlich sagte der Aelteste Andoh: „Schluss nun mit unseren vergeblichen Bemühungen. Einige von den Sklaven sollen sich ins Dorf begeben um Feuer und Beile zu holen, damit wir diese Versperrung beseitigen können. Nach kurzer Zeit kamen sie wieder zurück und inzwischen hatte sich das Unwetter auch wieder verzogen. Die Sklaven fachten ein Feuer an, dann schwangen sie die Beile, dass die Spähne vom Stamm flogen. Andoh stand beim Feuer und wärmte sich, denn er war durch den heftigen Regen vollständig durchnässt worden und fror und zitterte am ganzen Leib. Plötzlich flog ein Spahn des Lunokbaumes in das Feuer und als er Feuer gefangen hatte stieg ein angenehmer Duft auf. „Hau“, sagte Andoh, „das muss eine angenehme Speise sein, die so herrlich duftet". Er holte den Spahn aus dem Feuer und verzehrte die schmackhafte Speise. In diesem Moment senkte sich der Baum ins Wasser und er konnte mit seinen Leuten die Heimreise fortsetzen. $\mathrm{Zu}$ Hause angekommen begab sich jeder wieder in seine Hütte.

Den ganzen Tag fühlte sich Andoh nicht recht wohl. Die Haut juckte ihn am ganzen Körper, sodass er es fast nicht aushielt und unaufhörlich und überall kratzen musste. Als er einmal den Arm hob um in der Armhöhle zu kratzen, wo er ein besonders starkes Jucken verspürte, sah er $\mathbf{z u}$ seinem grossen Schrecken, dass sich dort Schuppen, wie Schuppen der Naga anzusehen, gebildet hatten. Er war betrübt in seinem Herzen und er rief mit lauter, weithin schallender Stimme seinen Kindern und Enkeln und als diese um ihn herum versammelt waren sprach er zu ihnen: „O ihr, tragt mich hinunter in den Balai, denn ich muss diese Nacht dort zubringen. Unter meinem Arm beginnen sich Schuppen zu bilden. Meine Tage auf dieser geliehenen Welt (kalunen indjam) sind gezählt. Tragt mich hinunter und niemand von euch nahe sich in dieser Nacht dem Balai". Mit erschrockenen und wehen Herzen erfüllten die Kinder und Enkel den Wunsch des greisen Andoh und trugen ihn in den Balai wo er die Nacht allein zubrachte. Immer mehr überzog sich sein Körper mit Schuppen und als der Morgen graute, war er in eine grosse Naga (Wasserschlange) verwandelt geworden (basaloh mandjadi Naga).

Die Naga verkroch sich unter den Balai und als der Morgen graute und es in den Häusern lebendig wurde, rief sie mit lauter Stimme: „O meine Kinder und Enkel, kommt zum Balai und hört was ich euch zu sagen habe". Als sie sich erstaunt und erschrocken um die Naga versammelt hatten, sprach diese $z \mathfrak{u}$ ihnen: „Meine Kinder und meine 
Enkel, meine Tanten und Onkel, meine Brüder und Schwestern, hört meine Rede. Ich bin in eine Naga verwandelt worden. Euer Herz betrübe sich deswegen nicht. Wohl verlasse ich heute das Dorf, aber ich werde mich von nun an in der Wassertiefe (labeho) an der Mündung unseres Flüssleins Djakolok aufhalten. Ich werde der Geist (taloh) werden der sie bewohnt. Bleibt nun weiterhin in diesem Dorfe beieinander. Verlasst es nicht. Naht sich euch aber Krankheit, Not und Misswachs, dann streut gelben und roten Reis aus und ruft meinen Namen. Ich will mich dann nahen und euch besuchen und ich werde euch in euerer Not beistehen und euch helfen. Aber nun ist meine Zeit hier abgelaufen. Ich muss euch verlassen. Erlaubt mir, dass ich mich ins Wasser stürze und mich von nun an in der Wassertiefe aufhalte". Nachdem die Naga Andoh diese Worte gesprochen hatte verliess sie ihre Verwandten, begab sich ins Wasser und schwamm zur Tiefe hin.

\section{Der Tod der Naga Andoh}

Die Naga Andoh wurde nicht nur von den Verwandten in ihrem Dorf, sondern überall wo sich am Katingan und an seinen Nebenflüssen Verwandte befanden, und wo man auch von ihrer Macht gehört hatte, verehrt. Man opferte ihr reichlich und in Zeiten von Not und Leid, Dürre und Hochwasser, Krankheit und Misswachs, streute man ihr gelben und roten Reis und rief sie bei ihrem Namen. Und sie erschien bei den Hilfesuchenden und stand ihnen bei.

Eines Tages sprach das Saloangfischlein, das auf die Naga neidisch geworden war und sie zu vernichten gedachte, $z u$ sich selbst: „Ich will mich doch einmal zur Naga Andoh begeben und sie besuchen, und ich will schauen was ich tun kann um sie umzubringen". Es führte seinen Entschluss aus, schwamm zur Wassertiefe hin und fand die Naga daheim. Lange sprachen sie über nebensächliche Dinge, aber schliesslich sagte das Saloangfischlein mit gedämpfter Stimme: „Es ist eigentlich etwas anderes, etwas wichtiges, was mich $z \mathfrak{u}$ dir führt. Ich kann das, was ich gesehen und gehört habe, nicht für mich allein behalten. Ich muss es dir mitteilen um nicht später als verräterisch und gemein betrachtet $z \mathfrak{u}$ werden. Siehst du, ich komme nun eben von der Mitte des Meeres her, von Puser Tasik (Nabel des Meeres). Dort bin ich mit der berühmten und mächtigen Naga Kusai zusammengetroffen und ich habe dort ein Gespräch belauscht, das für dich sehr wichtig ist. Sie will nämlich, so viel ich gehört habe, den Katingan aufwärts schwimmen um dich zu überfallen und zu töten und sie wird, soviel ich 
weiss, schon in einigen Tagen hier eintreffen. Sei also vor deinem starken Feinde auf der Hut und bereite dich auf einen harten Kampf vor". Nachdem der Saloang so gesprochen hatte, bat er die Naga um Erlaubnis, nach Hause zurückkehren zu dürfen.

Als die Naga wieder allein war, dachte sie über das Gehörte nach und ihr Herz schmerzte sie, wenn sie an den bevorstehenden Kampf mit der mächtigen und gefürchteten Naga Kusai dachte, aber sie sagte zu sich selbst: „Ich will mir darüber nun nicht zu viele Gedanken machen und mich nicht $z \mathfrak{u}$ früh schon ängstigen. Morgen früh begebe ich mich zu meinen Angehörigen in Tumbang Djakolok und bitte sie mir die Zähne mit scharfem Gift zu bestreichen".

Am andern Morgen früh bewegte sich das Wasser des Flusses bei Tumbang Djakolok so stark, dass die Wellen über die Ufer schlugen und über den Dorfweg dahinspülten und in einer solchen Welle stieg auch die Naga zum Dorf hinauf. Die Bewohner waren anfänglich über den wildbewegten Fluss und die hohen Wellen erschrocken, aber als sie die Naga sahen freute sich ihr Herz und sie gingen ihr entgegen um sie nach der Ursache ihres Besuches zu fragen. Sie sprach zu ihnen : „Meine Kinder und Enkel, ordnet eure Haare, öffnet eure Ohren und hört auf das Wort, das ich euch zu sagen habe. Der Saloang hat mir mitgeteilt, dass in den nächsten Tagen die Naga Kusai von Puser Tasik den Katingan heraufschwimmen will um mich zu bekämpfen. Ich bitte euch, bestreicht nun meine Zähne mit einem scharfen und tötlich wirkenden Gift, damit ich sie mit meinem Biss überwinden und töten kann". Sie suchten rasch in ihren Häusern das Gift zusammen und bestrichen mit ihm die Zähne der Naga Andoh. Nachdem die Arbeit vollendet war, verliess sie das Dorf wieder und stürzte sich in den Fluss. Sie schwamm durch das Flüsslein Lahang, schwamm weiter durch den Bakongsee und mit ihrem Oberleib durch den Djakolok und streckte ihren Kopf spähend in den Katingan hinaus. Der Schwanz lag im Lahang, aber er war so lang, dass er weit in den Katingan hinausragte. Als die Naga Andoh eines Tages wieder flussabwärts schaute, sah sie, dass sich beim Lahang das Wasser im Fluss bewegte. „Hau“, sprach sie zu sich selbst, „die Naga Kusai scheint vom Meere her angekommen zu sein. Ich will ihr entgegenschwimmen und will sie, ehe sie mich erspäht hat, angreifen und mit meinen vergifteten Zähnen töten". Sie schwamm rasch flussabwärts und erspähte gerade noch das Schwanzende ihrer Feindin die offenbar bereits den Lahang hinaufgeschwommen war. Kräftig biss sie zu und sie kehrte mit dem Gefühl, ihre Feindin überwunden zu haben, wieder nach dem Djakolok zurück. 
Aber nach kurzer Zeit fühlte sie sich schwer krank werden und sie sprach zu sich selbst: „Nun hat mich ein grosses Unglück getroffen. Ich habe nicht die Naga Kusai in den Schwanz gebissen, sondern mich selbst. Ich weiss, dass ich nun sterben muss durch mein eigenes Gift und wohl auch durch die Lüge des Saloang der mich vernichten wollte. Nichts und niemand kann mich retten, aber bevor ich nun sterbe, will ich noch mit meinen Kindern und Enkeln sprechen". Und mit lauter Stimme rief sie zum Dorf hinauf: „Meine Kinder und Enkel, kommt rasch herbei und versammelt euch um mich". Als sie sich eingefunden hatten, sprach sie zu ihnen: „Hört aufmerksam nach meiner Rede. Ich muss sterben, denn ich habe nicht die Naga Kusai vernichtet, sondern mich selbst. Aber bevor ich euch verlasse, mache ich euch noch mit meinen Wünschen bekannt. Ich befehle euch: verlasst diesen Ort und dieses Dorf hier nicht, bleibt hier wohnen. Und wenn ihr eure Felder anlegt, dann führt die Arbeiten gemeinsam und am gleichen Ort aus. Nicht sollen einige von euch ihre Felder am Djakolok, andere am Bakongsee und wieder andere drüben am Lahang anlegen. Legt ihr die Felder am Kahang an, dann sollen alle ihre Felder dort anlegen, und so auch am Bakongsee und am Djakolok, nicht sollt ihr euch jemals trennen. Trennt ihr euch aber, dann trifft euch mein Fluch. Dann soll euch der Tod heimsuchen, Krankheiten sollen euch wegraffen, durch blutige Wunden, die nicht mehr zu heilen sind, sollt ihr sterben". Nachdem sie so gesprochen hatte, verliess sie ihre Kinder und Enkel und starb bald nach dieser letzten Unterredung.

Seit dieser Zeit legen die Lahanger, um nicht dem Fluch der Naga Andoh zu verfallen, ihre Felder gemeinsam an. Seit dieser Zeit aber sagt man von einem betrügerischen Menschen aus: „Er ist wie ein Saloang“ und von einem lügnerischen Wort sagt man: „Es ist ein Saloangwort".

\section{Pa Tanggoi und seine Brüder werden verwandelt (basaloh)}

In früheren Zeiten lebte im Dorf Tumbang Djakolok ein Mann namens $\mathrm{Pa}$ Tanggoi mit seinen Brüdern und seiner Schwester. Die Brüder hiessen Randau, Ipang, Gembau, Goai und Andja, die Schwester hiess Bulau. Während vielen Jahren ging es ihnen immer sehr gut, sie hatten reiche Ernten und litten nie Mangel. Aber plötzlich trat eine grosse Trockenheit und Dürre ein und dauerte schon zwei Jahre. Der junge Reis wurde verbrannt sobald er zu sprossen begann und von einer Ernte sah man keine Spur, und im Dorf litt alles Hunger und ernährte sich kümmerlich von Knollengewächsen, die man im Walde 
ausgrub. Im dritten Jahre bestellten die Geschwister ihr Feld wie üblich und nachdem sie den Reis ausgesät hatten, kamen sie überein sich in den Wald zu begeben um Sago zu suchen und auf diese Weise ihren ärgsten Hunger zu stillen. Sie suchten zuerst nach einem Platz auf dem sich viele Nangebäume befanden und nach langem Suchen fanden sie schliesslich einen solchen im Sahai Rukau, einem kleinen Nebenflüsslein des Manta, der unterhalb Tumbang Lahang in den Katingan mündet. Sie kehrten wieder nach Hause zurück und bereiteten sich für einen längeren Aufenthalt im Walde vor. Aber wer sollte nun während ihrer Abwesenheit das Feld bewachen? Wer auf den Reis aufpassen? Sollte einer der Brüder zurückbleiben? Und welcher dann von ihnen? Pa Tanggoi sprach : „Es ist am besten, wenn wir Brüder gemeinsam in den Wald gehen und unsere Schwester bitten während unserer Abwesenheit die notwendigen Arbeiten auf dem Felde $z \mathfrak{u}$ besorgen und den reifenden Reis $\mathfrak{z u}$ bewachen, denn wir können sie ja doch nicht gut mitnehmen. Ist dann die Ernte nahe, dann kann sie uns holen, oder auch holen lassen. Wir halten uns ja nicht fern vom Dorfe auf". Als sie ihre Werkzeuge und ihre Wegzehrung bereit hatten, ruderten sie eines Morgens von Tumbang Djakolok weg. In Matunus, einer Waldstelle am Katinganufer, hielten sie an, weil sie den Manta wegen der Trockenheit nicht befahren konnten. Sie banden ihr Ruderboot an einem Baume fest, nahmen die Körbe auf den Rücken und die Waffen in die Hand und wanderten durch den Wald nach dem Sahai Rukau wo sie am Abend ankamen. Noch reichte ihnen die Zeit um vor Sonnenuntergang eine kleine Hütte von Zweigen und Blättern aufzurichten.

Am andern Morgen zogen einige Brüder aus um die Plätze zu suchen wo die Nangebäume wuchsen, andere blieben bei der Hütte zurück und fertigten Fallen und Schlingen an für den Fang von wilden Tieren, deren Fleisch sie als Zuspeise zum Sago nötig hatten. Am nächsten Tage begannen die Brüder, die die Nangebäume gefunden hatten, mit ihrer Arbeit. Einige suchten Sago und andere blieben bei der Hütte zurück um für Wild und für das Essen zu sorgen. Es ging ihnen recht gut. Sie gewannen viel Sago und fingen reichlich wilde Tiere. So arbeiteten sie nun Tag für Tag und Monat für Monat und sie dachten gar nicht mehr an ihre Verwandten, ihr Dorf, ihr Feld. Sie fühlten sich hier sehr wohl, vermissten nichts und niemand störte sie bei ihrer Tätigkeit und in ihrem einfachen Leben, das sie nach eigenem Gutdünken einrichten und führen konnten. Schon waren sechs Monate verstrichen und immer noch dachten sie nicht an die Rückkehr 
und für die Leute in Tumbang Djakolok waren sie wie Verirrte, die nie mehr heimkehren. „Leha-lehan, was ist wohl mit $\mathrm{Pa}$ Tanggoi und meinen andern Brüdern geschehen?" sprach Bulau eines Morgens in ihrem Herzen. „Nun sind schon Monate verstrichen, seit sie sich in den Wald begeben haben und immer noch kehren sie nicht zurück und senden auch keinen Bericht über ihr Ergehen ins Dorf. Der Reis reift, die Ernte naht. Eine Feldhütte sollte gebaut, ein Gestell sollte aufgerichtet werden, auf dem der geerntete Reis trocknen kann. Ich kann diese Männerarbeiten nicht allein ausführen. Wenn sie doch auch zurückkehren würden. $\mathrm{Ob}$ sie wohl überhaupt noch am Leben sind! $\mathrm{Ob}$ sie wohl vielleicht im Wald krank und elend darniederliegen! Wer weiss es! Das Beste wird sein, wenn ich mich morgen früh geschwind aufmache und nach dem Sahai Rukau gehe um nachzuschauen, ob sie sich noch dort befinden oder nicht. Es ist ja nicht weit und ich kann, wenn ich mich beeile, am Abend wieder im Dorf sein. Ich muss nun doch wissen was mit ihnen geschehen ist und weshalb sie so lange nicht heimkommen".

Am andern Morgen nahm sie etwas Wegzehrung und den Speer zu sich und rief ihrem jungen Hund und dann stieg sie ins Boot und ruderte über den Fluss nach dem Matunus. Dort angekommen band sie ihr Boot an einem Busch fest und machte sich auf den Weg nach dem Sahai Rukau. Der Weg war sehr schlecht und mühsam. Er war mit Gesträuch überwachsen und man sah, dass er schon lange Zeit nicht mehr begangen worden war. So kam sie nur langsam vorwärts und die Sonne stand schon hoch am Himmel.

Am gleichen Nachmittag vergnügten sich die Brüder, wie schon so oft, mit Tänzen und Spielen. Einige hatten sich mit $Z_{\text {weigen }}$ und Blättern von Pahakong, Pahakat und Kadjangedan als Kambe Rawit (zerreissende Gespenster die aus Sargspähnen entstehen und sich auf dem Platze aufhalten wo Menschen einen Sarg anfertigen) vermummt und umtanzten einen Sangkaraja (ein von Bambus aufgerichtetes Gestell in dem nach der Kopfjagd oder beim Totenfest der erbeutete Kopf der Feinde oder der Sklaven niedergelegt wird). Andere schlugen statt der Trommel die Pfeilköcher und statt der Gong den Boden von hohen Töpfen. Plötzlich schlug ein Hund an. Sie erschraken sehr und entledigten sich rasch ihrer Vermummung und verbargen den Sangkaraja und die merkwürdigen Musikinstrumente. Kaum waren sie damit fertig, da stand ihre Schwester vor ihnen. Sie hiessen sie etwas verlegen willkommen und baten sie in ihre Hütte einzutreten und Platz zu nehmen. Dann fragte sie Pa Tanggoi : „Wie steht es daheim in unserem 
Dorf und was führt dich zu uns". Sie antwortete ihm: „Ihm Dorf steht alles gut, und wenn ich heute zu euch komme, dann geschieht es deshalb weil ihr nicht heimkehrt, obgleich schon sechs Monate verstrichen sind und weil ihr auch keinen Bericht schickt über euer Ergehen. Der Reis ist nun reif und muss geerntet werden. Eine Feldhütte und ein Gestell sind auch noch nicht gebaut und ich kann diese Arbeiten nicht allein ausführen. Ich bin gekommen um euch zu holen. Ihr müsst nun unbedingt mit mir heimkehren, sonst verdirbt der Reis auf dem Feld. Ich gehe nicht mehr allein heim, sondern nur mit euch zusammen“. „Was sollen wir nun jetzt tun“, fragte $\mathrm{Pa}$ Tanggoi, „natürlich kommen wir heim, aber heute wird uns das kaum mehr möglich sein. Wir können nun nicht einfach alles hier geschwind verlassen. Gehe du nun heute allein heim, wir kommen morgen früh auf alle Fälle nach". Auch die andern Brüder waren mit diesen Worten einverstanden und versprachen ihrer Schwester am folgenden Tage heim zu kommen und nachdem sie ihre Versprechen gehört hatte und mit ihren Worten einverstanden war, bat sie um Erlaubnis den Rückweg anzutreten und verliess ihre Brüder. Sie schritt rasch aus, denn es war schon später Nachmittag und sie befürchtete ihr Dorf nicht mehr vor der Dunkelheit erreichen zu können. Als sie am Mantunus ankam, ging die Sonne unter. Sie löste rasch ihr Ruderboot und ruderte heim nach Tumbang Djakolok, wo sie in der Dunkelheit ankam. Aber sie sprach zu sich selbst: „Nun habe ich doch meine Brüder gesehen und habe mit ihnen gesprochen und ich weiss nun auch, dass sie morgen heimkommen werden". Und zufrieden legte sie sich auf ihr Lager nieder.

Aber der nächste Tag verging ohne dass die Brüder heimgekehrt wären und so verstrich Tag um Tag. Ihr Herz schmerzte sie, wenn sie an das Feld dachte und an den reifenden Reis, der sicher verderben musste, weil er nicht geerntet werden konnte. Sie sprach zu sich selbst: „Wenn nun morgen meine Brüder immer noch nicht zurückkommen, dan werde ich nochmals $z u$ ihnen gehen um sie $z u$ holen, denn es ist schade, wenn unser Reis wegen ihrer Nachlässigkeit verderben muss". Und als sie auch an diesem Tage nicht kamen, ruderte sie am folgenden Morgen wieder auf die Ueberseite des Flusses und wanderte nach Sahai Rukau. Auch an diesem Tage vergnügten sich die Brüder mit Tanz und Spiel und sie dachten nicht mehr an die Heimkehr in ihr Dorf und nicht mehr an das Versprechen, das sie ihrer Schwester gegeben hatten, und sie erinnerten sich auch nicht mehr der dringenden Erntearbeiten. Plötzlich schlug das Gebell eines Hundes an ihr Ohr. Rasch versteckten sie den Sangkaraja und entledigten sich ihrer 
Maskierungen und kaum waren sie damit fertig, da stand auch schon ihre Schwester vor ihnen. Sie freuten sich scheinbar sehr als sie sie sahen und sie baten sie wiederum in die Hütte einzutreten und Platz zu nehmen und nachdem sie sich gesetzt und mit Sirih bedient hatte, fragte sie Pa Tanggoi: „Und nun Schwester, was ist es, dass dich heute wiederum zu uns führt?" Sie antwortete: „Habt ihr mir nicht versprochen ins Dorf zurückzukehren, als ich das letzte Mal bei euch war? Ich habe euch täglich erwartet, aber ihr seid nicht gekommen und nun komme ich wieder zu euch und ich werde diesmal nicht eher zurückkehren bis dass ihr euch aufmacht und mich nach dem Dorf begleitet, denn es ist schade, wenn unser Reis, der dieses Jahr sehr gut geraten ist, wegen euerer Nachlässigkeit verderben muss". "Ja", sprach Gembau, ,bleibe nun heute hier und morgen kehren wir dann zusammen, nachdem wir hier alles in Ordnung gebracht haben, ins Dorf zurück". Nachdem sie gegessen und Sirih gekaut hatten, legten sie sich auf ihre Matten nieder und schliefen ein. Als Bulau in der Nacht einmal erwachte und zu ihren Brüdern hinüberschaute, da erschrak sie heftig in ihrem Herzen vor dem Anblick der sich ihren Augen darbot. Sie sah, dass ihre Brüder die Augen wild verdreht hatten und ihre Zungen lang zum Munde heraushingen. Ein schrecklicher Verdacht stieg in ihrem Herzen auf und sie sprach zu sich selbst: „O weh, was haben meine Brüder getan, was ist mit ihnen geschehen? Sie gebärden sich nicht mehr wie Menschen, sie sehen nicht mehr wie andere Leute aus, gewiss werden sie in Geister verwandelt werden". Sie konnte den Schlaf nicht mehr finden und sie sehnte sich nach dem anbrechenden Morgen und sie war froh als endlich die ersten Sonnenstrahlen den Wald erhellten. Rasch stand sie auf und kochte den Reis und dann setzte sie sich mit ihren Brüdern auf den Boden um die Mahlzeit einzunehmen und als sie fertig gegessen hatten sprach Bulau: „Ich denke, dass wir uns nun bereit machen müssen um den Rückweg anzutreten“. $\mathrm{Pa}$ Tanggoi antwortete ihr aber: „O unsere Schwester, halte dich nicht länger bei uns auf, verliere deine Zeit nicht. Wir kommen heute nicht mit dir heim, sondern wir werden erst in drei Tagen in unser Dorf zurückkehren, eher ist es uns wegen unserer vielen Arbeit nicht möglich diesen Ort hier zu verlassen. Gehe du nun erst allein, wir werden dann später schon nachkommen". Bulau antwortete ihm nicht, aber in ihrem Innern sprach sie: „Nun ist es um meine Brüder geschehen, nun weiss ich gewiss, dass sie Geister werden müssen und jetzt schon $z u$ ihnen gehören (bagin taloh) und nicht mehr zu uns Menschen. Es ist schade um sie, aber ich kann nichts machen, ich vermag sie nicht 
zu retten". Sie nahm ihren Korb auf den Rücken und den Speer in die Hand und rief ihren Hund und sie verliess die Hütte mit schwerem Herzen und mit Tränen in ihren Augen, denn ihre Brüder taten ihr leid. Kaum war sie im Walde verschwunden, da sprach $\mathrm{Pa}$ Tanggoi zu seinen Brüdern: „Richtet den Sangkaraja auf und lasst uns uns vermummen, damit wir wieder tanzen können, denn unsere Schwester hat uns verlassen und sie wird gewiss nicht mehr zurückkehren".

Aber Bulau sprach in ihrem Herzen: „Nun will ich doch noch einmal umkehren und will schauen was meine Brüder eigentlich treiben und was sie davon abhält mit mir heimzukehren". Leise kehrte sie zurück und sie rief den Hund an ihre Seite, damit er durch sein Bellen ihren Plan nicht vorzeitig vereiteln könnte. Unbemerkt und ungehört näherte sie sich dem Platze ihrer Brüder und sie erschrak sehr in ihrem Herzen als sie plötzlich ihre tanzenden Brüder sah und ihre merkwürdigen Vermummungen gewahrte und sie schaute ihrem Treiben $z \mathfrak{u}$ bis der Hund $z \mathfrak{u}$ bellen begann. Rasch wollten sich die Brüder verstecken, aber als sie sich umwandten sahen sie in das Gesicht ihrer Schwester, die ihnen mit traurigem Herzen zuschaute. Erschrocken und verlegen standen sie still. Ohne etwas zu sagen schauten sie sich an und Bulau sprach zu ihnen: „Ist das nun eure wichtige Arbeit, die euch nicht gestattet mit mir ins Dorf zurückzukehren, geziemt es sich, dass ihr wegen diesem Treiben euer Dorf, euere Verwandten und euer Feld vergesst und vernachlässigt. Passt es sich, dass ihr hier so herumtanzt wie Geister?" Da sprach $\mathrm{Pa}$ Tanggoi zu ihr: „Ja, Bulau, was wollen wir machen und was sollen wir dir entgegnen, das ist nun unser Los und unser Teil. Lebe du glücklich mit unseren Verwandten drüben in euerem Dorf in Tumbang Djakolok, das an den Ufern des Flusses der Welt liegt. Wir gehören nicht mehr $z u$ euch, wir gehören nun $z \mathfrak{u}$ den Geistern (bagin taloh) und wir werden nun auch in Stein verwandelt werden (basaloh mandjadi batu)".

Nachdem $\mathrm{Pa}$ Tanggoi diese Worte gesprochen hatte, schlug er auf seinem Pfeilköcher wieder den Takt zum Tanz und wie Wahnsinnige umtanzten die Brüder den Sangkaraja. Nochmals rief er seiner Schwester zu: „Lebe glücklich und in Frieden am Flusse der Welt". Dann sah sie plötzlich nichts mehr von ihnen, sie waren verschwunden und waren verwandelt worden. Sie hörte nur noch Stimmen die nacheinander $z \mathfrak{u}$ ihr sprachen: „Ich, Pa Tanggoi, bleibe nun hier auf diesem Platz“, und eine andere sprach: „Ich, Randau, wohne fortan im Flüsslein Mahop" (ein Nebenflüsslein am oberen Katingan), „und ich“, rief eine andere Stimme, es war Ipang, „wohne im Flüsslein Parawei“ 
(Nebenfluss des oberen Katingan). „Ich“, rief die Stimme des Gembau, „werde mich in der Mitte des Kalanaman aufhalten" (Nebenfluss des mittleren Katingan). „Im Flüsslein Manten ist mein Aufenthaltsort“, rief die Stimme des Goai und des Andja (Der Manten ist ein Nebenflüsslein des mittleren Katingan, es fliesst bei Tewang Daraju in den Katingan). ${ }^{153}$ Und die in Stein verwandelten Brüder sprachen weiter zu ihrer Schwester: „Wenn du und unsere Verwandten Not leiden, wenn ihr krank werdet, oder wenn Dürre und Hochwasser eure Felder bedrohen, dann könnt ihr uns um Hilfe rufen und wir werden euch beistehen. Ihr streut roten und gelben Reis aus und ruft unsere Namen und wir werden kommen. Ihr müsst aber den Reis nach der Richtung unseres Aufenthaltsortes ausstreuen". Nach diesen Worten wurde es um Bulau herum still, sie hörte nichts mehr, aber sie sah, wie das Haus ihrer Brüder, wie ihre Werkzeuge und alle Gebrauchsgegenstände in Stein verwandelt worden waren. „Kajah“, rief Bulau ganz verwirrt aus, und mit wehem Herzen verliess sie diesen Ort und kehrte so rasch wie möglich zum Fluss zurück. Sie löste ihr Boot vom Busch und kehrte nach Tumbang Djakolok zurück, und als sie im Dorf angekommen war, ging sie still in ihr Haus, denn es war inzwischen dunkel geworden. Mit Herzeleid legte sie sich auf ihre Schlafmatte nieder, aber sie vermochte den Schlaf nicht zu finden und als der Morgen graute und die Leute im Dorf erwacht und vor ihre Hütten hinausgetreten waren, erzählte sie ihnen was mit ihren Brüdern geschehen war.

Noch heute aber sieht man bei Sahai Rukau das versteinte Haus mit den Werkzeugen und Gebrauchsgegenständen die einst den Brüdern gehört hatten und früher konnten Leute die sich im Wald nach dieser Gegend hin verirnt hatten, hier auch oft menschliche Stimmen und das Gackern von Hühnern und Bellen von Hunden hören.

Noch heute kann man in der Not $\mathrm{Pa}$ Tanggoi und seinen Brüdern Reis streuen und sie in allen Schwierigkeiten um ihre Hilfe bitten.

\section{Der Ursprung der Insel Torah}

Ein heiliger Platz unterhalb des Dorfes Tumbang-Lahang ist die, im Katingan gelegene, Insel Torah die ebenfalls durch Verwandlung (basaloh) entstanden ist. Die Mythe vom Ursprung dieser Insel lautet: Ein junger Mann, der in seiner frühesten Kindheit seinen heimatlichen Fluss und seine noch junge Mutter verlassen hatte, kehrte später mit einem reich beladenen Handelsboot an den Katingan zurück von dem er jedoch keine Ahnung mehr hatte, dass es sein heimatlicher Fluss sei, an dem er geboren worden war. In der Nähe von Torah hielt er sich 
längere Zeit in einem Dorfe auf und er erblickte dort eine sehr schöne Frau, in die sich sein Herz sofort verliebte. Er bat ihre Verwandten um ihre Hand und erhielt von ihnen die Zustimmung zur Heirat. Nach kurzer Zeit wurde die Hochzeit gefeiert. Später erkannte die Frau an einem körperlichen Merkmal ihren Sohn der, ohne dass er das wusste, ihr Mann geworden war. Sie erschrak sehr in ihrem Herzen über diese Entdeckung und sie sprach $z \mathfrak{u} \mathrm{ihm}$ : „Du bist ja mein Kind, das vor vielen Jahren vom Katingan wegkam und von dem ich nie mehr etwas gehört habe". Und kaum hatte sie diese Worte gesprochen, da verfinsterte sich der Himmel und ein furchtbares Unwetter zog herauf. Der Mann wollte sich in sein Boot flüchten um diesen schrecklichen und unheimlichen Ort zu verlassen, aber kaum hatte er es erreicht, da wurde er mit seinem Boot, mit seinen Sklaven und mit allen Gütern, in die Insel verwandelt auf der sie nun als Taloh weiterwohnen. Auch das Dorf war vom Erdboden verschwunden.

Von dieser Zeit an ist die Insel heilig. Es dürfen auf ihr weder Felder angelegt, noch Häuser gebaut, noch Feldhütten aufgerichtet werden. Die Insel wird bis heute bewohnt von den Taloh dieses Mannes, der mit seiner Mutter unwissentlich Blutschande getrieben hatte, und von seinen Sklaven. Lahanger, die an schleichenden Krankheiten (z.B. Tuberkulose) und an nicht heilenden Geschwüren leiden, begeben sich auf diese Insel um hier an dieser heiligen Stelle das Batapa $\mathrm{zu}$ vollziehen und die mit ihnen verwandten Taloh um ihre Hülfe und ihren Rat zu bitten.

\section{Das Batapa}

Batapa (das Wort ist der katinganischen Sprache entnommen, der Ngadjuausdruck lautet: balampah), abgeleitet vom Sanskritwort tapas, das Wärme, Glut, Schmerz, Plage, Selbstpeinigung, Busse oder Askese, bedeutet, bezeichnet den unmittelbaren Verkehr des Menschen mit den Ahnen, wofür er die Vermittlung des Priesters nicht nötig hat. Das Batapa führt man vor allem aus, wenn man von schleichenden Krankheiten und nicht heilenden Geschwüren befallen worden ist, oder wenn man fürchten muss, dass für einen Mord den man begangen hat, durch die Verwandten des Ermordeten die Blutrache ausgeübt werden soll. Um das Batapa zu vollziehen begibt man sich, ohne davon jemandem etwas gesagt zu haben (es muss immer geheim geschehen) auf einen Platz wo sich Ahnen oder Taloh aufhalten. Man verbringt dort meistens eine Nacht in ihrer Gemeinschaft und erhält, wenn man die Versuchung (tingkes) mit gutem Resultat bestanden hat, ihren Rat 
und ihre Hilfe. Das Batapa ist eine alt/dajakische religiöse Sitte, die nicht erst durch hindu-javanischen Einfluss in ihr religiöses System eingedrungen ist, wenn auch durch diesen Einfluss, der kaum abzustreiten ist, die von alther ausgeübten Handlungen unzweifelhaft vermehrt und auch vertieft worden sind. Bevor die Dajak aber mit der hindu-javanischen Kultur in Berührung kamen, kannten sie schon verschiedene Formen des Batapa (z.B. Batapa danum, Batapa hong pulau, Batapa hong Tadjahan, Batapa hong Pataho).

Man kennt verschiedene Arten des Batapa. Die wichtigsten sind die folgenden :

a. Batapa mandoi (das Batapa durch Baden). Während vierzig Tagen erhebt man sich jeden Morgen um drei oder vier Uhr und schleicht sich, während die andern Hausgenossen noch schlafen (das Batapa muss immer ohne das Mitwissen von andern Personen ausgeführt werden) vom Hause weg. Man steigt zum Fluss hinunter und badet sich, wobei man verschiedene Texte und Formeln hersagt. Durch dieses Batapa wird die eigene Stärke und Macht (katekang) und das eigene Heil (salamat) vermehrt und gestärkt. Es wird nicht nur von Kranken sondern auch von Gesunden ausgeführt, die dadurch zu grösserer Vollkommenheit gelangen wollen.

b. Batapa danum (Batapa im Wasser). Etwas vom Dorfe entfernt im Busch baut man sich von Bananenstämmen ein Floss. Wenn der Halbmond am Himmel steht, schleicht man sich vom Hause weg und begibt sich zum Floss, das man bereits zum Fluss gebracht hat. Die Arme streckt man gekreuzt über die Stämme aus, die Beine lässt man ins Wasser hängen. Auf diese Weise und in dieser Lage lässt man sich von der Strömung wegtreiben. Plötzlich erscheint vor dem Flosse ein grosses Krokodil, das aus dem Wasser aufsteigt und das den Menschen, der das Batapa ausführt, auf die Probe stellt. Lässt er sich von ihm erschrecken, dann ist seine Mühe und Arbeit umsonst gewesen und die Geister (wohl die Tambon und Naga) verfluchen ihn. Bewährt er sich aber in dieser Versuchung, dann wird er mit seinem Floss von dem Krokodil aufs Ufer geworfen und hier begegnen ihm nun die Geister (Taloh) und Ahnen. Er kann ihnen seine Bitten vorbringen und erhält ihren Rat.

c. Batapa hong pulau (Batapa auf einer Insel). Man begibt sich nachts vom Hause weg und geht nach einer einsamen Insel, die in der Nähe des heimatlichen Dorfes mitten im Flusse liegt und die durch Verwandlung (basaloh) entstanden ist und von Taloh bewohnt wird. Man lässt sich dort während einer Nacht nieder, enthält sich aller 
Speisen, räuchert Weihrauch (garo) und sagt verschiedene Texte und Formeln her. Nach kurzer Zeit naht sich die Versuchung. Uebernatürlich grosse Ameisen, gewaltige Schlangen und riesengrosse Gespenster (kambe) kriechen und schreiten auf den Liegenden zu. Sie gehen über seinen Leib hinweg und bedrohen und versuchen (maningkes) ihn auf alle mögliche Weise. Besteht er die Versuchung, dann kann er mit den Taloh in Verkehr treten. Sie geben ihm den erwünschten Rat oder sie heilen ihn von seinem Leiden. Besteht er die Versuchung aber nicht, dann wird er verflucht.

d. Batapa hong tadjahan. Der Tadjahan ist das Ahnenheiligtum, das sich auf der Ueberseite des Flusses (gegenüber dem Dorf) oder oberhalb des Dorfes im sauber geschlagenen Busch befindet. Nach dem Totenfest werden hier für jeden Verstorbenen die hölzernen Ahnenbilder aufgerichtet und von hier werden durch den Tukang Tawur (der Priester, der den Reis streut und der unterschieden wird von den Balian und Basir die die Sangiang aufrufen) die Ahnen aufgerufen. Diese Ahnen erscheinen in der Gestalt eines mythischen Falken, der nicht verwechselt werden darf mit dem gewöhnlichen Falken (Haliastur intermedius) der ein Omenvogel, aber nie der Falke vom Tadjahan ist und von den Dajak auch nie mit ihm verwechselt wird. Diese Verwechslung geschieht merkwürdigerweise nur in der ethnographischen Literatur über Borneo und dort sehr konsequent, denn der Falke vom Tadjahan wird darin nicht genannt. Dieser Falke vom Tadjahan wird genannt: Rika Bulau Hatuen Antang Ganan Tadjahan (Siehe die Mythen zum Totenritual unter: die Abwendung des vorausgewussten Todes). Dieser Antang Tadjahan beantwortet die Fragen des Priesters, hilft ihm bei der Rezitation von wichtigen Mythen und zieht mit den Kopfjägern auf die Kopfjagd und mit den Kriegern in den Krieg. Bei den Ot Danum leitet er auch die Seele des Verstorbenen nach dem Totendorf in der Oberwelt. Der Tadjahan wird heute nur noch bei den Ot Danum aufgerichtet und unterhalten. Bei den Ngadju Dajak ist er verschwunden. Ueberreste von ihm sind die Pahewan (die heiligen Haine im Wald und am Flussufer) und das immer noch ausgeübte Aufrufen des Antang Tadjahan durch den Tukang Tawur.

Auch beim Tadjahan kann man das Batapa vollziehen. Wirksam wird dieses Batapa vor allem dann wenn man einige Blutstropfen einer erstmalig menstruierenden Jungfrau in ein Blatt gewickelt mitnimmt, ohne dass die Jungfrau weiss, dass von ihrem Menstruationsblute etwas weggenommen wurde. Auch hier hat man eine Versuchung $\mathrm{zu}$ bestehen, die ebenfalls durch Ameisen, Schlangen und Kambe herbei- 
geführt wird und besteht man sie, dann wird man von den Ahnen angerufen und nach seinen Wünschen gefragt und man erhält von ihnen den erbetenen Rat. Besteht man sie nicht, dann wird man ebenfalls verflucht.

e. Batapa hong pataho. Der Pataho ist ein heiliger Platz der mitten im Dorf liegt. Er besteht aus einem kleinen Opferhäuschen das mit Knochen und Schädeln von Opfertieren angefüllt ist. Unter ihnen finden wir, heute allerdings nur noch sehr vereinzelt, auch Menschenschädel, die von der Kopfjagd oder von Menschenopfern herstammen. Um dieses Opferhäuschen herum wachsen verschiedene heilige Pflanzen, unter denen die Sawang (Dracaena terminalis) die wichtigste ist.

Der Pataho selbst ist der Wächter des Dorfes, der, menschlichen Augen unsichtbar, in voller Kriegsrüstung hier steht und leise vor sich hinschlummert. Beim Nahen der Feinde erwacht er aus seinem Schlaf und schützt das Dorf. Mit den Männern und mit dem Antang Tadjahan zusammen zieht er auf die Kopfjagd und in den Krieg und er begleitet auch die Reisseelen in die Ober- und Unterwelt. Bei den Ot-Danumstämmen wird beim Totenfest beim Pataho für jeden Verstorbenen ein Stein niedergelegt. Auch hier wird oft nachts, in voller Einsamkeit, das Batapa vollzogen. Hat man die bereits genannten Versuchungen bestanden, dann erteilt der Pataho dem Hilfesuchenden seinen Rat oder gewährt ihm seinen Schutz und seine Hilfe.

f. Batapa intu lunok (Das Batapa beim Lunok). Während einer Nacht hängt man sich an seinen Beinen in der Nähe eines Lunokbaumes, an einem Ast eines andern Baumes auf. Die Versuchung naht sich in der bekannten Weise. Besteht man sie, dann hat man sein Ziel erreicht und die Njaring, die Geister des Lunokbaumes, beantworten alle Fragen des Hilfesuchenden und erteilen ihm ihren Rat und schenken ihm ihren Schutz und ihre Hilfe. Besteht man die Versuchung aber nicht, dann folgt ebenfalls die Verfluchung.

g. Batapa intu panganen (Batapa durch die Python). Dieses Batapa wird ausgeführt um sehr stark zu werden und die Kraft einer Panganen zu erhalten. Man fängt eine junge Panganen, die etwa so dick ist wie der Schaft einer Lanze. Jeden Morgen reibt man ihren Schleim ab und bestreicht sich mit ihm die Beine. Man tut das bis die Schlange die Dicke eines Männerbeines hat. Hat man diese Handlung so lange ausgeführt, dann hat man sein Ziel erreicht.

h. Batohon nennt man die Form des Batapa, bei der man sich für drei, fünf, oder sieben Tage an einen einsamen Ort im Walde begibt oder eine leerstehende Hütte, weit vom Dorfe entfernt, aufsucht. Für 
die Ausübung dieses Batapa hat man weisse Kleider anzuziehen und muss unbewaffnet sein. In die Fussohlen steckt man Nadeln oder Bambussplitter (Selbstquälung). Während der ganzen Zeit, in der man sich auf diesem Platz oder in der Hütte befindet, darf man keinen Reis zu sich nehmen, man nähnt sich nur mit Knollenfrüchten und Pflanzen die man im Walde findet.

Dieses Batapa vollzieht man um stark zu werden, um Glück zu haben bei allen Unternehmungen oder auch um mit den Ahnen in Verkehr treten zu können. Ueber Versuchung und Verfluchung gilt was oben gesagt wurde.

\section{Karik und der heilige Speer}

Karik war ein berühmter Lahanger, der in früheren Zeiten lebte und der sich durch manche Taten ausgezeichnet hatte. Eines Tages begab er sich auf die Wildschweinjagd hinter das Dorf Tumbang Lahang in den Wald. Es war schon später Nachmittag. So sehr auch die Hunde nach Spuren und nach Wild suchten, sie fanden nichts. Plötzlich hörte er aus dem Dorf die eintönigen Schläge des Totengongs herüberklingen. „Hau“, sprach er zu sich selbst, ,,jetzt ist wohl meine Schwiegermutter gestorben, die ich krank in meinem Hause zurückliess, wie dumm nur, dass ich jetzt so weit vom Dorf entfernt bin". Als er noch so zu sich selbst sprach und sich nach Hause wenden wollte, hörte er die Stimmen von Geistern hinter sich, die sich offenbar auch nach dem Dorfe begaben um das Fleisch der Leiche zu verzehren und das Leichenwasser aufzuschlürfen. Als sie ihn eingeholt hatten, sprachen sie zu ihm: „Has, komm mit uns. Wir sind auf dem Wege zur Leiche die im Dorfe liegt um uns an ihr gütlich zu tun". Sie gingen nun zusammen durch den Wald und als sie im Dorfe angekommen waren, setzten sie sich zur Leiche und begannen ihre Mahlzeit. Karik sass bei ihnen. Er wagte nicht sich von ihnen zu entfernen um nicht den Geistern zu verraten, dass er ein Mensch sei, denn sie hielten ihn für einen der ihren. Er schaute ihnen $z u$, aber er beteiligte sich nicht an dem schaurigen und ekelhaften Mahle. Als der Tag graute und die Stunde nahte, in der sich die Geister wieder in den Wald zurückziehen müssen, verliessen sie das Haus und begannen es zu umtanzen. Abwechslungsweise hielt einer von ihnen den Speer in der Hand, den sie aus ihrem Dorf mitgebracht hatten. 154 Die Reihe, ihn zu halten, kam auch an Karik der mit den Geistern mittanzte. Er ergriff ihn und er tantze mit ihm wie ein Wahnsinniger. Der Himmel begann sich zu röten und für 
die Geister war die Stunde der Heimkehr gekommen. Karik aber hielt immer noch den Speer in seinen Händen und umtanzte das Haus. Die Geister forderten ihn zurück, aber er hörte nicht auf ihre Stimme. Inzwischen war die Sonne aufgegangen und warf schon ihre ersten Strahlen über den Wald und Fluss, es war höchste Zeit für die Geister heimzukehren, denn tags über durften sie sich nicht in der Nähe der Menschen aufhalten. Immer noch tanzte Karik und so kam es, dass er den Speer behielt und die Geister ohne ihn abzogen. Noch kein Mensch in Tumbang Lahang war im Besitze eines solchen Speeres. Karik war der erste und er hatte ihn durch List erworben.

Er sandte ihn seiner Tante (es kann eine wirkliche Tante sein, es kann auch die Schwiegermutter sein, denn diese wird auch Tante: mina, genannt), die in Tangkahen, am Kahaian drüben, wohnte und dort bakowo war. (Auch Frauen, deren Männer auf die Kopfjagd ausgezogen waren, sich auf einem Kriegszug oder auf weiten Handelsreisen befanden und auch Witwen können bakowo sein und sich für einige Zeit aus der Gemeinschaft zurückziehen und in einem, zu diesem Zwecke im Hause gebauten Zimmer, aufhalten. Die Tante des Karik war Witwe.) Er liess sie durch den Ueberbringer bitten den Schaft des Speeres schön $z u$ umflechten und $z \mathfrak{u}$ verzieren.

Nach einiger Zeit bekam er von ihr den reich mit Flechtereien verzierten Speer wieder zurück und es begann für ihn eine sehr glückliche Zeit, denn der Mensch, der einen solchen Speer besitzt, wird von den Geistern gefürchtet und geehrt und sie helfen ihm, bei allem was er unternimmt, mit, sodass sein Leben friedvoll, glücklich und reich wird. Für Karik war der Speer von nun an der Ort seiner Freude, seines Stolzes und seiner Liebe.

Als Karik sich eines Nachts auf seine Matte gelegt hatte und kaum recht eingeschlafen war, hörte er wie jemand zu ihm sprach: „Die Naga will deine Leber aufessen" (d.h. die Wasserschlange will dich vernichten). Er erschrak in seinem Herzen und er fragte sich, was wohl diese Stimme zu bedeuten hätte. Auch in der zweiten Nacht hörte er die gleiche Stimme und auch in der dritten Nacht wiederholte sie sich. Da erschrak er sehr in seinem Herzen und er hatte während drei Monaten nicht mehr den Mut sich auf den Fluss, der Ort wo sich die Naga aufhielt, zu begeben, überhaupt wagte er es nicht sein Haus zu verlassen um nicht der Naga zum Opfer zu fallen, denn er war gewiss, dass dieser merkwürdige Traum sich verwirklichen würde. Schliesslich hielt er es nicht mehr in seinem Hause aus, denn seine Lage glich der eines Gefangenen und deshalb sprach er eines Tages zu sich selbst: 
„Jetzt muss irgend etwas geschehen, denn so halte ich es nun nicht mehr länger aus. Ich will der Naga auflauern und ich will sie bekämpfen, entweder unterliegt sie oder ich, aber ich will und kann nicht immer in dieser Ungewissheit leben".

Und eines Morgens zog Karik den geschnürten Panzer an, gürtete den Dolch um und ergriff den Speer, den er den Geistern entwendet hatte. Er begab sich zu der Wassertiefe im Flüsslein Lahang, wo die Naga ihren Aufenthaltsort hatte. Dort angekommen kauerte er in ein dichtes Betonggebüsch (eine Art sehr dicken Bambus) und verbarg sich gut, so, dass ihn niemand sehen konnte. Einen ganzen Vormittag lauerte er dort der Naga auf, aber sie zeigte sich nicht. Schon wollte er aufbrechen und unverrichteter Dinge wieder nach Hause zurückkehren, da hörte er wie ihm der Kadjadjauvogel zurief : „Padjatjaur, padjitjuw! die Naga will deine Leber aufessen". Er erschrak sehr als er diese Worte hörte und als er wieder auf den Fluss hinausschaute sah er, wie sich das Wasser bewegte und aus ihm der Kopf der Naga auftauchte. Er verschwand wieder im Wasser, aber nur kurze Zeit und dann tauchte er wieder auf. Als Karik nach dem Speer greifen und sich aufrichten wollte, stürzte die eine Hälfte des grossen Bambusstrauches ins Wasser und Karik wurde mitgerissen. Im letzten Augenblicke wurde er von einer Astgabel aufgehalten, sodass er nicht ins Wasser fiel. Erschreckt durch den Lärm tauchte die Naga unter, aber bald tauchte sie wieder auf. Karik zielte gut und dann schleuderte er seinen Speer und durchbohrte den Hals der Naga. Das Wasser färbte sich rot von ihrem Blut, aber die Naga verschwand mit dem Speer in der Tiefe des Flusses. Erfreut kehrte Karik nach Hause zurück, er wusste, dass er die Naga überwunden hatte und dass sie an der Wunde sterben würde. Aber er war betrübt, dass nun sein Speer für immer verloren war.

Eines Tages besuchte ihn ein Verwandter aus Tangkahen und brachte ihm von seiner Tante Geschenke mit und als er sie näher betrachtete, da war er sehr erstaunt und in seinem Herzen erfreut, denn diese Geschenke bestanden aus dem Speer, den er nach der Naga geschleudert hatte, dem siebenfach gezackten goldenen Horn der Naga und einer Handvoll goldener Schuppen, die ihren Leib bedeckt hatten.

Er bat seinen Besucher ihm zu erzählen wie er zu diesen wertvollen Sachen gekommen sei und dieser berichtete ihm: „Ich teile dir mit, was deine Tante mir für dich aufgetragen hat. Eines Morgens stieg sie, wie gewöhnlich, zum Landungsfloss hinunter um ihr Bad zu nehmen. Sie sah, dass in der Nacht das strömende Wasser einen toten Körper 
angeschwemmt hatte, der am Flosse hängen geblieben war. Sie befahl ihrer Sklavin nachzuschauen was es wohl sein könne und diese rief, nachdem sie den toten Körper näher betrachtet hatte, verwundert aus : Hau, meine Herrin, meine Sangiang, was für ein Tier ist das wohl? Ich vermute, dass es eine Naga sei, die von einem Menschen getötet wurde. In ihrem Hals steckt ein glänzender Speer und ihre Haut glänzt wie die Farben des Regenbogens. Die Besitzerin befahl ihr: Nimm den Speer, das goldene Horn und die goldenen Schuppen zu dir und bringe sie mir ins Haus herauf. Und als sie dann den Speer näher betrachtete, da sprach sie mit grosser Verwunderung in ihrer Stimme: ,Diesen Speer hier kenne ich gut. Er gehört Karik in Tumbang Lahang. Den Schaft habe ich für ihn umflochten und verziert. Es kann niemand anders als Karik sein, der die Naga getötet hat. Gewiss ist sie schwer verwundet vom Katingan an den Kahaian gekommen und hat hier ihren Tod gefunden'. Was deine Tante gefunden hat, das beschloss sie dir zu senden, denn es ist dein Eigentum".

Von dieser Zeit an ist der Bambus, in dem Karik versteckt auf die Naga lauerte, pali. Man nennt ihn auch heute noch Betong pali (der heilige Betong). Er steht immer noch am Ufer des Flüssleins Lahang und er treibt immer wieder neue Schosse. Niemand darf ihn umschlagen oder beschädigen, niemand darf in seiner Nähe ein Feld anlegen oder eine Hütte bauen und scheu rudern die Menschen an ihm vorbei auf ihre Felder.

Der Speer von Karik wird auch in der Mythologie der andern Katingandörfer erwähnt. In Penda Hara, einem Dorf unterhalb Tumbang Lahang, dessen Bewohner mit den Lahangern noch entfernt verwandt sind, erzählt man von ihm folgendes :

Karik hat den Speer mit List den Peres (Krankheitsgeister) entwendet. Ein grosses und kostbares Gut fiel damit in seine Hände und seit dieser Zeit ist sein Leben ein anderes geworden. Er wurde reich, mächtig, angesehen, friedvoll und heilvoll, denn mit diesem Speer empfing er alle Gaben die das Leben in dieser Welt in der günstigsten Weise verändern können.

Die mit dem Speer geschenkten Gaben werden folgendermassen beschrieben: Der Bambusköcher (lawas, damit werden die eisernen, gebogenen Verzierungen des Speeres bezeichnet), der sich zuoberst befindet, ist gefüllt mit tötendem Gift das die Feinde vernichtet, nämlich mit pulih laut und tundek ratjun. Der Bambusköcher unterhalb dieses Köchers (ein solcher Speer hat verschiedene gebogene, etwa 
$20 \mathrm{~cm}$. lange, Widerhaken, diese werden lawas genannt) enthält das Gift panduruh. Der Köcher unterhalb enthält lawar benji (ein Mittel mit dem man den Reis zum guten Gedeihen bringt). Der Köcher unterhalb ist gefüllt mit Karuhei tatau und im letzten Köcher befindet sich Goldstaub. Diese Widerhaken tragen die Bezeichnung lawas und haben die Beibenennung sakai. Sakai ist ein in gelockte, zierliche Fransen auslaufendes Stück Bambus, das mit dem Schnitzmesser so bearbeitet worden ist. Es dient als Schmuck bei Opferhandlungen und Festen. Sakai werden aber auch Opfergestelle, gemacht von solchem gelockten Bambus, genannt die in der Form eines Lebensbaumes, in eine grosse Schüssel Reis gesteckt, dargebracht werden. Solche Lebensbäume werden dann behängt mit verschiedenen Opfergaben und nach diesen Opfergaben werden sie auch benannt, z.B. sakai roko (Rauchwarensakai, diese Sakai werden behängt mit Zigaretten oder billigen Zigarren), sakai pinang (Betelnussakai), sakai panginan (Essenwarensakai). Bei wichtigen Handlungen innerhalb des Stammes werden sie von der einen Stammhälfte der andern überbracht (magah sakai). Trotzdem heute die Stammesorganisation aufgelöst ist, wird an dieser Sitte zähe festgehalten. Die Sakai werden nun meistens von einem Nachbardorf dem andern überbracht, so z.B. beim Beginn der Feldarbeiten oder beim Tiwah. Der Empfänger hat die Sakai in der gleichen Form, wie sie ihm überbracht wurden, beim Beginn der Feldarbeiten des nächsten Jahres, den Ueberbringern zurückzuerstatten und ebenfalls wenn in ihrem Dorfe ein Tiwah gefeiert wird. Der Sakaiaustausch findet also im gegenseitigen Wechsel statt.

Bei den verschiedenen Giften, die genannt wurden, handelt es sich nicht um organische oder anorganische Giftstoffe, sondern um solche aus dem Gebiet der sogenannten schwarzen Magie die man ramon oloh (Dinge von Menschen die eine schädigende Wirkung haben) nennt. Sie gehören alle in das Bereich und die Machtsphäre der Hantuen und böse Geister. Nur von ihnen, oder nur durch ihre Vermittlung, erhält man die ramon oloh, selbst herstellen kann man sie nicht und sie würden ohne die Mitwirkung der Hantuen und bösen Geister wirkungslos bleiben (Vgl. auch die Mythe von Antang Taui).

Die Karuhei tatau gehören nicht in diese Machtsphäre der Hantuen und bösen Geister. Es sind glückbringende Mittel, die den Menschen durch die Ahnen gegeben werden, indem sie ihnen den Fundplatz im Traume, oder auch bei einer persönlichen Begegnung, oder beim Batapa anweisen (Siehe auch das Register).

Der Goldstaub, das sogenannte bulau hambaruan (Gold der Seele), 
dient zur Stärkung der Seele bei Krankheit, wichtigen Opferhandlungen und bei der Rechtssprache.

Dieser heilige Speer läuft an seinem unteren Ende in einen zylinderförmigen, etwa drei Zentimeter tiefen, Köcher aus, der umschlossen wird von vier, nach einwärts gebogenen, eisernen Ausläufern. Bei allen wichtigen kultischen Handlungen ist dieser Köcher gefüllt mit dem, von den Priestern und Priesterinnen aus der Oberwelt herbeigeholten Lebenswasser (danum kaharingan belom, njalong sapaninting tahaseng).

Die Beschreibung des Speeres von Karik, die wir finden in der Mythologie von Penda-Hara und auch in der der andern Katingandörfer, sowie der kultische Gebrauch des Speeres, der ganz der profanen Sphäre entzogen ist, zeigt uns deutlich, dass wir ihn als Lebensbaum $z \mathfrak{u}$ sehen haben.

\section{Der Speer des Maharadja 155}

Sambong Maut 156 war verheiratet mit einer Tochter seines Onkels Maharadja (den Schwiegervater nennt man im gewöhnlichen Sprachgebrauch nicht empo (Schwiegervater), sondern mama, oder in der Anrede ama (Onkel), denn er ist auch gewöhnlich, sei es väterlicheroder mütterlicherseits, ein Onkel seines Schwiegersohnes). Maharadja war im Besitze eines kostbaren Speeres, der umflochten war mit goldenem Schmuck. Dieser Speer war das Kernholz seines Atems oder Lebens (teras tahaseng).157 Nicht durfte er verloren gehen, nicht durfte er gebraucht werden, nicht durfte es aus der Hütte herausgeholt und nach einem andern Platze gebracht werden.

Schon lange wohnte Sambong Maut bei seinem Onkel Maharadja (der Schwiegersohn zieht bei seinen Schwiegereltern ein). Eines Tages vernahm er von den Leuten, dass die Wildschweine im Begriffe seien durch die Wälder zu schweifen und über die Flüsse zu schwimmen und wenige Tage später ging die Nachricht durch das Dorf, dass eine grosse Herde Wildschweine in der Nähe des Dorfes aus dem Walde gekommen sei und über den Fluss schwimme. Rasch verbreitete sich dieser Bericht im ganzen Dorf und die Männer machten sich auf um die Schweine zu verfolgen und zu erlegen. Auch Sambong Maut eilte in das Haus seines Onkels und ergriff, weil er keine andere Waffe sah, den Speer, das Kernholz des Atems des Maharadja, ohne dass er ihm etwas davon sagte und ohne dass sein Onkel etwas davon ahnte. Rasch rief er einen Sklaven und er stieg mit ihm zum Landungsfloss hinunter und sie ruderten im Boote weg um die Schweine zu verfolgen. Die 
Dorfleute hatten schon manche kleinen Schweine gespeert. In der Herde sah Sambong Maut ein besonders grosses Tier. Es war Katungau, der König der Wildschweine.158 Er befahl seinem Sklaven schneller zu rudern und sie fuhren mit ihrem Boot an den jungen Schweinen vorbei und verfolgten Katungau, den König. Sie waren in seine Nähe gekommen. Sambong Maut schleuderte den Speer und verwundete das Tier in seiner Brust, aber der Speer brach ab und seine obere Hälfte, die umflochten war mit dem Goldschmuck, blieb in der Wunde des Tieres stecken. Katungau war nicht tot. Er schwamm weiter und entkam seinen Verfolgern und als er auf der Ueberseite des Flusses angekommen war stieg er ans Ufer und verschwand im Walde. Sambong Maut ruderte mit seinem Sklaven unverrichteter Dinge zum Landungsfloss zurück. Die Dorfleute hatten manche Tiere erlegt, aber es waren alles junge und kleine Schweine. Als sie beim Landungsfloss angekommen waren, machten sie das Boot fest und stiegen zum Haus hinauf.

Nachdem Sambong Maut den Speer, das Kernholz des Atems des Maharadja, zu sich genommen hatte, ohne seinem Onkel etwas davon zu sagen oder ihn vorher um Erlaubnis zu bitten, fühlte Maharadja, dass er Atemnot (pehe tahaseng) bekam und er spürte, dass er recht krank wurde. „Was ist denn das, was mich nun so plötzlich überfällt?“ sprach er zu sich selbst und er begab sich langsam ins Haus hinein und er sah, dass der Speer, das Kernholz seines Atems, sich nicht mehr auf seinem Platze befand. „Akui, akui!" schrie Maharadja vor Entsetzen auf, „wer ist es, der meinen Speer von hier weggeholt hat ?“ „Es ist geschehen durch Sambong Maut“, sprachen seine Sklaven, „er hat ihn mitgenommen auf die Schweinejagd". "Ja", sprach Maharadja, „wenn mein Speer verloren geht oder wenn er zerstört wird, dann werde ich rasch sterben müssen und nichts und niemand wird mich retten können".

Sambong Maut war unter diesen Worten seines Onkels ins Haus hereingetreten und sein Herz schmerzte ihn sehr, als er diese Rede vernahm und seinen leidenden Onkel sah, denn durch seine Unvorsichtigkeit war der Speer verloren gegangen. Er sprach zu seiner Frau: „Bereite für mich als Wegzehrung Reis, Salz und roten Pfeffer". Und seine Frau bereitete ihm diese Dinge und Sambong Maut legte sie in einen Rückenkorb. Darauf nahm er mit seinem Sklaven die Mahlzeit ein und darnach machten sie sich auf den Weg um Katungau, den König der Schweine zu suchen. Sie ruderten auf die Ueberseite des Flusses und sie verfolgten die Spuren der Schweineherde. Als die 
Sonne unterging, legten sie sich im Walde zum Schlafe nieder und als die Sonne wieder aufging, nahmen sie ihre einfache Mahlzeit ein und verfolgten wiederum die Spuren der Schweine. Sie gingen einen Tag, sie gingen einen zweiten und sie gingen auch noch einen dritten Tag. Immer folgten sie den deutlichen Spuren. Am dritten Tage kamen sie mitten im Walde an das Ufer eines Teiches. Auf dem andern Ufer sahen sie die Spuren der Schweine. Sie wateten durch das Wasser und folgten wieder den Tieren nach. Nach einiger Zeit kamen sie zu einem zweiten Teich. Auch diesen durchwateten sie und als sie wieder aus dem Wasser herausgetreten waren und die Spuren weiterverfolgen wollten, da sahen sie, dass sich ihr ganzer Körper mit Schweinsborsten bedeckt hatte. Sie kamen zu einem dritten Teich und auch hier führte sie der Weg durch das Wasser, denn wieder sahen sie auf dem gegenüberliegenden Ufer die Spuren der Schweine. Als sie wieder aus dem Wasser stiegen sahen sie, dass sich ihre Ohren in Schweinsohren verwandelt hatten. Wieder folgten sie den Schweinen nach und es dauerte nicht lange, da kamen sie zu einem vierten Teich und auch diesen mussten sie durchwaten. Als sie wieder aus dem Wasser heraustraten, sahen sie, dass sich ihr Kopf in einen Schweinsrüssel verwandelt hatte und dass aus ihrem Mund zwei Hauer herausragten. Wieder folgten sie den Spuren der Schweine und es dauerte wieder nicht lange und sie standen vor einem fünften Teich. Nachdem sie ihn durchwatet hatten fühlten sie, dass ihre eigenen Beine verschwunden waren und dass sie vier Beine hatten wie die Schweine und dass sie nun vollständig zu wilden Schweinen geworden waren. Und weiter folgten sie den Spuren und bewegten sich fort wie die Schweine. Nach einiger Zeit kamen sie zu einem sechsten Teich und sie mussten auch diesen durchschreiten und als sie wieder aus dem Wasser herausgetreten waren sahen sie, dass ihre frühere Gestalt verschwunden war und dass sie wieder Menschen geworden waren. Wieder gingen sie weiter durch den Wald und als sie schon einige Zeit gegangen waren und eine ziemlich grosse Strecke Weges zurückgelegt hatten, kamen sie zu einem Dorf das von Menschen bewohnt war. Bevor sie das Dorf betraten, hörten sie den Lärm der Leute und vernahmen aus ihren Worten, dass jemand schwer krank sei und dass die Bewohner den Kranken besuchen wollten. Sie traten nun ins Dorf ein. Die Leute sahen die Fremden erstaunt an und einige Männer kamen zu ihnen und brachten sie in den Balai (Versammlungshaus in dem auch die ankommenden Fremden empfangen werden). Dort legten sie den Rückenkorb ab und setzten sich auf den Boden und die Männer des Dorfes sprachen zu Sambong 
Maut: „Es geht uns hier in unserem Dorf sehr schlecht, o unser Bruder, unser König ist krank geworden und es scheint, dass er sterben muss, denn er verweigert schon jede Nahrung" (ein Zeichen, dass die Krankheit eine sehr ernste Wendung genommen hat). „Was fehlt ihm?" fragte Sambong Maute teilnehmend. „Er hat heftige Schmerzen in seiner Brust", lautete ihre Antwort, und sie fragten ihn: „O unser Bruder, kannst $d u$ ihn nicht mit uns zusammen besuchen, vielleicht kannst du ihm helfen“. „Wer vermag das zu sagen, meine Brüder, ich müsste zuerst eueren König sehen und ich müsste seine Krankheit untersuchen". Darauf verliess er mit den Männern den Balai und betrat mit ihnen das Haus des Kranken. Er sah den König, er untersuchte seine Brust und er entdeckte eine tiefe Wunde und in der Wund sah er das abgebrochene Stück eines Speeres das mit Goldschmuck umwunden war. Es war der Speer seines Onkels Maharadja, den er nach Katungau dem König der Schweine geschleudert hatte. Der Kranke war Katungau. Nachdem er seine Untersuchung beendet hatte, fragten ihn die Leute: „Wie steht es mit unserem König, o unser Bruder? Denkst du, dass ihm noch geholfen werden kann und dass wir ihn gesund zu machen vermögen?" „Nein“, sprach Sambong Maut, ,ihr könnt ihm nicht helfen, aber ich vermag ihn gesund zu machen und ich will für ihn die rituellen Handlungen ausführen und die Ahnen aufrufen (badjaja)". Und die Leute fragten ihn nach der Art und Weise dieser Handlungen und erkundigten sich was sie dafür vorzubereiten hätten. Und Sambong Maut befahl ihnen den Platz auf dem der Kranke lag und auf dem auch diese Handlungen stattfinden sollten mit Matten (geschah früher mit Tüchern, heute vielfach mit Matten) zu umzäunen und er sagte ihnen: „Niemand darf mir zuschauen bei meinen Handlungen, weder ihr noch mein Sklave, denn sie sind heilig". Und er gab ihnen ferner den Befehl: „Tötet noch ein Huhn und kocht Klebreis". Und die Leute handelten nach seinen Worten. Als die Sonne unterging war alles für die Ausführung der Handlungen bereit. Mit den Leuten zusammen nahm Sambong Maut im Hause die Abendmahlzeit ein und dann befahl er ihnen das Haus zu verlassen und ihn mit dem Kranken allein $\mathfrak{z u}$ lassen und erst wieder zurückzukehren wenn die Sonne aufgegangen sei. Seinem Sklaven aber gab er den Auftrag: „Begib dich unter das Haus und setze dich dort auf die Erde und zwar gerade unter dem Platz auf dem ich im Hause die Handlungen ausführe um den kranken König gesund zu machen. Wenn ich dir durch den Fussboden ein Bündel zureiche, dann verbirg es gut in meinem Rückenkorb“. „Ja“, sprach der Sklave, „ich will es tun“. Als 
die Menschen das Haus verlassen hatten, begab sich Sambong Maut zu dem kranken König und er begann seine Handlungen. Er probierte die Speerspitze, die tief in die Brust eingedrungen war, herauszuziehen, aber sobald er sie nur berührte oder sie bewegte um sie zu lösen, schrie der Kranke vor grossen Schmerzen laut auf. Die ganze Nacht hindurch arbeitete er und unaufhörlich schrie und stöhnte der Kranke vor grossen Schmerzen. Als die Morgendämmerung anbrach, gelang es ihm endlich die Speerspitze aus der Wunde zu entfernen. Er wickelte sie rasch in ein Tuch ein und liess sie durch den Fussboden auf die Erde fallen. Der Sklave ergriff das Bündel und verbarg es im Rückenkorb. Und nachdem die Speerspitze aus der Wunde entfernt war, wurde Katungau auch zur gleichen Zeit wieder gesund. Er setzte sich zu Sambong Maut und sie tranken zusammen Reisbier. Als der Tag angebrochen war, hatte Sambong Maut alle Arbeiten und Handlungen verrichtet und er wollte wieder nach Hause zurückkehren. Katungau aber sprach zu ihm: „Bleibe noch hier. Ich bin gesund geworden durch deine Hilfe und nun wollen wir uns verbrüdern und wir wollen gegenseitig von unserem Blute trinken". 159 Und so taten Sambong Maut und Katungau. Und darnach sprach Katungau zu seinem Bruder: „Nie wollen wir einander Schaden zufügen, nicht schleudere deinen Speer nach mir, nicht wollen wir uns gegenseitig umbringen. Wenn du hörst, dass die Wildschweine sich aufmachen um durch die Wälder zu ziehen und über die Flüsse zu schwimmen und wenn du dich anschliessest bei den Männern die Jagd auf sie machen, dann passe gut auf, dass du mich erkennst. Das ist mein Erkennungszeichen: auf meinem Kopf wirst du drei Schwanzfedern eines Nashornvogels sehen. Nicht schleudere den Speer nach mir, nicht töte mich, denn würde ich durch deine Hand getötet, o mein Bruder, dann müsstest auch du sterben“. „Ja“, sprach Sambong Maut, „wie sollte ich auch so etwas tun! Wie sollte ich meinen Speer nach meinem Bruder schleudern! Das wird nie geschehen. Wir haben gegenseitig Blut getrunken und wir sind Brüder geworden. Wir sind fortan ein Fleisch und ein Blut".

Nicht lange nach diesem Gespräch nahm Sambong Maut Abschied von seinem Bruder Katungau und trat mit seinem Sklaven zusammen den Rückweg an. Nicht mehr durchwateten sie diesmal die Teiche, denn Katungau hatte ihnen einen besseren Weg gewiesen. Sieben Tage dauerte ihre Reise und endlich nach dieser langen Zeit erreichten sie wieder ihr heimatliches Dorf.

Maharadja war während ihrer Abwesenheit immer kränker geworden und er war dem Tode nahe gekommen. Als aber Sambong Maut mit 
dem Speer, dem Kernholz des Atems, den Rückweg antrat besserte sich seine Krankheit und je näher sie dem Dorfe kamen umso gesunder wurde er und als sie das Dorf betraten war der Schwerkranke wieder vollständig gesund geworden, weil der Speer, das Kernholz seines Atems, wieder $z \mathfrak{u}$ ihm zurückgekehrt war.

Drei Jahre waren vorbeigegangen seit Sambong Maut sich mit Katungau, dem König der Schweine, verbrüdert hatte. Eines Tages drang wieder der Ruf durch das Dorf: „Die Schweine schwimmen über den Fluss!“

Rasch eilten die Männer in die Häuser um ihre Speere zu holen und die Schweine zu verfolgen und unter ihnen befand sich auch Sambong Maut der mit zwei Sklaven sein Boot bestieg und in den Fluss hinausruderte. Er stand in der Mitte des Bootes und feuerte seine Sklaven an: „Has, rudert schnell, denn ich will meinem Bruder begegnen“. Er fand ihn nicht. Er liess sich in die Mitte der Schweineherde rudern und da sah er seinen Bruder und er erkannte ihn, weil er auf seinem Haupte drei Schwanzfedern des Nashornvogels trug. Er verfolgte Katungau, den König der Schweine und schleuderte seinen Speer nach ihm ohne sein Ziel zu verfehlen. Als Katungau fühlte, dass sein Bruder ihn verwundet hatte, wendete er seinen Kopf nach Sambong Maut um. Er fiel ihn an und verletzte ihn schwer. Sambong Maut sank in seinem Boote zusammen. Rasch ruderten ihn seine Sklaven heim und trugen ihn ins Haus hinauf. Seine Verwandten probierten ihm zu helfen, aber es war zu spät. Sambong Maut starb zur gleichen Zeit als auch Katungau, der König der Schweine, starb. 


\section{HANDLUNGEN UND TEXTE ZUM TOTENKULT}

\section{HANDLUNGEN UND TEXTE BEIM PLÖTZLICHEN TOD}

Sowohl die Ngadju Dajak als auch die Ot Danum unterscheiden zwei Todesarten, nämlich den reifen Tod und den unreifen Tod. Das Sterben im hohen Alter nennt man matei masak (reif sterben), d.h. man hat das dem Menschen bestimmte Alter erreicht (umur sampai) und man kehrt nun, ohne dass ein gewaltsamer Eingriff von Seiten der Mächte stattgefunden hätte und ohne dass irgend eine Ordnung verbrochen worden wäre, zurück in sein Urdorf (buli batang lezu), aus dem man in der Urzeit ausgewandert ist an die Ufer des Flusses der Welt (pantai danum kalunen). Dort wird der Ankommende, der Tote (liau) von den Ahnen erwartet und dorthin begleiten ihn auch seine vornehmsten Verwandten (Sangiang), die, um ihn abzuholen aus der Oberwelt heruntergestiegen sind.

Diesem reifen Sterben im hohen Alter, lebensmüde und lebenssatt geworden, steht das unreife Sterben (matei manta) gegenüber. Es ist der Tod in der Jugend, das plötzlich hinweggerafft werden im vollen und schönsten Mannesalter, ehe die Lebenszeit abgelaufen ist (helo bara umur sampai). „Abgebrochen wird man wie ein hoher wurzelstarker Baum, hinweggeweht wie das Umschlagtuch das die Frauen tragen". Matei manta sagt man auch von einem Menschen der gestorben ist durch Unfall, der hinweggerafft wurde weil er die Pali übertreten hatte, dessen Leben abgebrochen wurde weil sich an ihm ein Fluch realisierte oder ein Gottesurteil sein Leben auslöschte, man sagt es aber auch von Menschen die das Opfer wurden der schwarzen Magie, die durch Aussatz oder durch Gelbsucht (panjakit tulah) den Tod fanden, oder von Frauen die während der Schwangerschaft oder im Wochenbett starben (matei manak). ${ }^{160}$

Matei manta findet seinen Grund darin, dass ein Mensch, der sich bewusst oder unbewusst gegen die Ordnungen der Ahnen, gegen die Hadat oder die religiösen Verbotsbestimmungen (pali) vergangen hat, von den Ahnen aus der Gemeinschaft der Lebenden und der Toten 
ausgetilgt wird. Er wird nicht aufgenommen werden in die Gemeinschaft der Toten (liau), er bleibt von ihr ausgeschlossen und er irrt herum als ein heilloser Toter.

Der zweite Grund liegt darin, dass der Mensch das Opfer geworden ist von bösen und verderblichen Mächten, z.B. von Hantuen (Hexen) oder Njaring, die alle unter einem eigenen König stehen, der im Kampf steht mit den Menschen und keine Gelegenheit unbenützt lässt um sie zu verderben. In diesem Falle ruft man die Ahnen auf und rächt den Tod an den Verderbern und holt den Toten aus ihrer Gemeinschaft, in der sie ihn bereits mitgeführt haben, wieder zurück, damit er beim Totenfest nach dem Totendorf geleitet werden kann. Dieser Rachezug und dieses Zurückholen des Toten findet gleichzeitig mit dem Tantolak matei (Wegschieben des Toten) statt. Siehe unten die Texte. Die Leiche von Verunfallten darf nicht im Hause aufgebahrt werden. Wird sie ins Dorf getragen dann legt man sie, im Dorfe angekommen, auf dem Wege nieder, wäscht und kleidet sie und baut über ihr ein einfaches Schutzdach. Wird sie ins Dorf gerudert, dann legt man sie auf dem Anlegefloss nieder und behandelt sie ebenfalls auf die gleiche Weise. Beim Tantolak matei wird der Tod durch Dohong Mama Tandang gerächt und der Tote zurückgeholt. Dohong Mama Tandang bringt den Toten weg zu Balo Indu Rangkang, wo er bis zum Tiwah bleibt, aber um ihn wegbringen zu können, muss im Falle des gewaltsamen Todes der Tote erst aus der Gemeinschaft der bösen Mächte zurückgeholt werden.

Die folgenden Darstellungen sind also nur Ausschnitte aus dem Tantolak matei. Die Auszüge erfolgen, weil nicht jedesmal der ganze Text gegeben werden kann. Das ganze Tantolak matei wird am Schlusse dieses zweiten Teiles dargestellt werden.

\section{A. Der Tod durch Verbrennung}

1. Mampakanan gana,n apui (Das Opfer an das Feuer nachdem ein Haus verbrannt ist ohne dass dabei Menschen das Leben verloren haben).

Wir zitieren die Handlungen und Texte wegen der hier vermeldeten Mythe vom Ursprung des Feuers. Vor dem Mampakanan gana,n apui holen die Besitzer des verbrannten Hauses einen Tukang tawur (tukang: der Meister, der Kundige, der Wissende; tazenr: Ausstreuen von Reis). Der Tukang tawur ist ein wichtiger Priester, 
der streng unterschieden werden muss von den Balian (Priesterinnen) oder dem Basir (Priester der sich in Frauenkleider hüllt). Er ruft nicht und nie die Sangiang auf, das geschieht durch die Balian und Basir, sondern immer nur den Antang Ganan Tadjahan (den Antang vom Tadjahan), d.h. die Ahnen die dann in der Gestalt des Antang (Haliastur intermedius), der aber hier ein Seelenvogel ist und streng unterschieden werden muss vom Antang der nur ein Omenvogel ist, erscheinen. Dieser Omenvogel ist der Haliastur intermedius. Der Antang Ganan Tadjahan ist ein mythischer Vogel. In seiner Verhüllung erscheinen die Ahnen wenn sie vom Tukang tawur aufgerufen werden, und kehren sie wieder zum Tadjahan zurück, dann legen sie, dort angekommen, diese Verhüllung wieder ab. Ueber allen Antang Ganan Tadjahan steht ein König, der Darahen radja,n Antang. Er wohnt am Tasik Ambon in der Oberwelt. Zuerst ruft der Priester den Antang Ganan Tadjahan auf und dieser reist dann mit den Seelen des ausgestreuten Reises in die Oberwelt. Diese Seelen sind sieben Jungfrauen. Der Antang Ganan Tadjahan kann bei allen wichtigen und notwendigen Handlungen durch den Tukang tawur aufgerufen werden. Hauptsächlich nimmt er teil an den Kriegszügen und Kopfjagden und bekämpft den Antang der Feinde.

Hat sich der Tukang tawur beim Besitzer des abgebrannten Hauses eingestellt dann wird ihm ausführlich der ganze Unglücksfall erzählt und man bittet ihn das mampakanan gana,n apui vorzunehmen, den Reis auszustreuen und alle notwendigen Handlungen vorzunehmen. Der Tukang tawur gibt dem Besitzer und seinen Angehörigen zuerst den Auftrag alle Ueberreste des Brandes in der Mitte des Brandplatzes auf einen Haufen zu legen. Wenn das geschehen ist, wird um den Brandplatz ein langes Stück Rotan gezogen, mit dem er abgeschlossen wird. Man nennt dieses Rotan tarinting. An ihm werden, in Zwischenständen von etwa einem Meter, Sawangblätter (Dracenae terminalis) aufgehängt die in der Mitte des Blattes mit einem lampinak (Kreuz) versehen sind.161 Sind diese Vorbereitungen beendet, dann schlachtet der Besitzer fünf Hühner und legt sie auf fünf verschiedene Teller. Darauf schlachtet er nochmals ein Huhn und legt es auf die Seite. Dann kochen sie das Essen für sich, den Tukang tawur und die Gäste die bei dieser Handlung teilnehmen. Nach dem Essen wird alles Feuer im ganzen Dorf ausgelöscht. Der Besitzer richtet mit seinen Angehörigen neben dem Brandplatz, aber ausserhalb des tarinting eine kleine Opferhütte (pasah korik) auf und ihr gegenüber wird an einem Stocke ein antjak (ein kleiner, viereckiger, offener Korb, in dem man 
die Opfer darbringt) aufgehängt. Die geschlachteten Hühner werden nun verteilt. Eines der Hühner wird, zusammen mit wadai (Kuchen) und takupat (Reis der in Pisang-oder andere Blätter gewickelt und mit geriebener Kokosnuss vermengt gekocht wurde; die Bündel nennt man takupat) auf einem apar (ein grosser, kupferner Teller mit gezacktem, aufstehendem Rande und mit einem etwa $30 \mathrm{~cm}$. hohen Fuss; man setzt die Speisen darauf) vor dem Tukang tawur niedergelegt. Zwei Hühner werden in den Opferkorb (antjak) gelegt und die übrigen drei Hühner legt man in der kleinen Opferhütte (pasah korik) nieder.

Nach diesen Vorbereitungen beginnt der Tukang tawur seine Arbeit. Zuerst besingt er den Reis. Wir geben diesen Text hier nicht wieder. Er findet sich unten in den Texten zum Tantolak matei. Wenn das geschehen ist, dann gibt er den Reisseelen den Auftrag sich zu Darahen Radja,n Antang zu begeben und ihn herbeizuholen damit er bei der ganzen Handlung mithelfe. Unseren Text beginnen wir mit der Ankunft der Reisseelen bei Darahen Radja,n Antang. Die Reisseelen haben ihre Reise in einem reichgeschmückten Frauenhut zurückgelegt, der langsam von Wolkenlage zu Wolkenlage in die Oberwelt hinaufstieg.

\section{a. Die Ankunft der Reisseelen bei Darahen Radja,n Antang}

Djadi sembang pahatewang lewu,n Darahen Radja,n Antang, palus surong djandulana lasang lio bulau dare,n tanggoi idje ladju dare, balias manangkajoh balekut,e, tende balai ain Darahen Radja,n Antang.

Palus gatang tarehendeng bulan bawin tawur sintong udju, rata tundjung tarahingkat habinei etan bulau dinon lambong hanja.

Lungang-lingok bulau pating sumping,e, pulang-pilik rabia dju-djung pahawang.
Angekommen waren sie an der Buchtung des Flusses, am Dorfe des Darahen Radja,n Antang, angelangt waren sie auf ihrer Fahrt in ihrem Boote, dem Regenbogen, dem goldenen Geflechte des Hutes, dem rasch gerudenten Flechtwerk, dem schnell fortbewegten Schmuck, still blieb es liegen vor dem Balai des Darahen Radja,n Antang.

Und sogleich erheben sich und stehen auf die Monde, die Frauen des Streureises, die sieben zusammen, gemeinsam stehen sie auf, und erheben sich, die Frauen des goldenen Reiskornes, die vermehrt sind zu acht.

Es rauschen die goldenen $Z$ weiglein der Ohrringe, es bewegen sich hin und 
Hindai sembang bambuakan balai ain Antang Darahen, ${ }^{162}$ eleh njantah rantaran tandok,e Antang Darahen, taratuntu tamuei bulan idje njawak kabangkange, bawin tawurku sintong udju.

Tara-tureng pangadjan habinei, dje notok katentang,e, sawong ambon dinon lambong hanja.

Eleh pandjong bara pandjong, koan riwut rawei Antang Darahen, ela ikau panamuei bawin tingang tau njaragantong lunok, isen pangadjan habinei tambon tau batujang kalang labeho handalem.

Puna pandjong bara pandjong koa,n riwut rawei bulan bawin tawurku sintong udju, tisoi habinei sawong ambon, ewen nduan lambong hanja.

Panamueiku badjeleng, dia misek palin balai keton lewu Bukit Ampah Bulau, pangadjangku basikap, dia mitong endus sali keton rundong Kereng Sahep Rabia. her die goldenen Hänger der Frauen. Noch waren sie nicht angekommen bei der Türe des Balai des Antang Darahen, schon warf er schräg die Augen aus, der Antang Darahen, anschauend die Reisenden, die Frauen, die von ungestümer Schönheit waren, sie die Frauen des Reises, die sieben zusammen.

Er schaute hin nach dem Besuch der Frauen, die lieblich anzusehen waren, nach den Frauen des Reises die vermehrt sind zu acht.

Kommet herzu und schreitet herein, spricht die wehende Rede des Antang Darahen, nicht eueren Besuch, o ihr Frauen der Nashornvögel, nicht stattet ihn ab dem Lunok, nicht, o Besuch, o ihr weiblichen Wasserschlangen, nicht wiegt euch in einem Fischkorb über der Wassertiefe, der abgründigen (d.h. sie sollen mit ihrem Besuche nicht zögern, oder niemand anders besuchen sondern bei Antang Darahen eintreten).

Gewiss, wir schreiten, wir kommen herein, spricht das wehende Wort der Monde, der Frauen des Streureises, sie die zusammen sieben sind, die Rede der Frauen des Reises, die vermehrt worden sind zu acht.

Unsere Reise ist eine eilige, nicht erkundigen wir uns nach den $\mathrm{Pali}$ (rituellen Verbotsbestimmungen die der ankommende Fremdling kennen muss) des Balai (Versammlungshaus in dem auch die Fremden empfangen werden) eueres Dorfes Bukit Ampah Bulau, unser Besuch ist nur ein rascher, nicht halten wir Rechnung 
Ijoi, bulan bawin tawur keton sintong udju andau balaiku Antang Darahen dia bapali pandjang, korang baendus ambo,e.

Eleh nganda-ngandang,e puron buang, niti-nitih,e aringking sandong, puron djarenang 163 dje ria-riak dare, amak tantawa dje ringkiringkin tabuhi.

Hetoh eka panduka,n keton bawin tingang, linda mangekei renteng, habinei tambon ajah marau bihing.

Tarahundok lambat hajak bulan bawin tawurku, sintong udju, tarahekeng lowah hindje habinei rabia etan bulau dinon lambong hanja.

Lungang-lingok bulau pating sumping bulan, pulang-pilik rabia djudjung pahawang.

Sama mondok hasambewa tandok, rata badjanda hasambau kining.

Hakangkulo renteng tingang Darahen dengan riak bulau mit den Pali (endus = pali) des Hauses eueres Dorfes Kereng Sahep Rabia.

Ja, ihr Monde, ihr Frauen des Streureises, ihr sieben zusammen, heute gelten für meinen Balai, für den des Antang Darahen, keine langen Pali, keine ausführlichen Verbotsbestimmungen.

Und alsogleich klopft er aus eine ungebrauchte Matte, er schüttelt aus das neue, grosse, mit Figuren gewellte Geflecht, eine Djarenangmatte mit schönen Verzierungen geschmückt, eine Tantawamatte die in verschiedenen Lagen wie wogendes Wasser geflochten ist.

Hier ist euer Sitzplatz, o weibliche Tingang, sorgfältig breitet aus eure Querstreifen (d.h. die gestreiften, gewobenen Kleider), ihr weiblichen Tambon, setzt euch auf den Marau (Rotan, also auf die Matte) mit eueren Streifen (Kleider).

Vorsichtig nehmen sie zusammen Platz, sie die Frauen des Streureises, die sieben zusammen, langsam lassen sie sich nieder auf die Matte, die Frauen des goldenen Reiskornes, die da vermehrt sind zu acht.

Es rauschen die goldenen $Z$ weiglein der Ohrringe der Monde, es bewegen sich hin und her die goldenen Hänger der Frauen.

Sie haben sich alle zusammen gesetzt mit zugekehrten Augen, sie haben sich niedergelassen auf die Matte und schauen einander an.

Es nähern sich beugend die Schwanzfedern des Nashornvogels (der Kopf- 
pating sumping bulan, hatalumbang pating bungai radja,n Antang dengan ringkin rabia djudjung pahawang.

Palus kandjo-kandjor idje sangko radja bahalap mangarawang bulau, saparanggong dalam badaris kangatil bawak lamiang.

Eka lasang pantar bua pinang, akan gentoi sasangga manjang.

Hapan manambang tambon, panamuei bulan bawin tawurku sintong udju, manakep ihing, pangadjan sawong ambon nduan lambong hanja.

Sama-paras garing kapanduka mondok, hadjip sihong tampudjena badjanda.

Hataroi pantar pinang ewen hatalindjam, hatadjuh manjang ewen hatalimbas.

Sama njipa ulang manantali tanteng ngendas pulu batandjung henda. schmuck) des Darahen dicht zu den wellenden goldenen $Z_{\text {weiglein }}$ der $\mathrm{Ohr}$ ringe der Monde, es lassen sich tief hernieder die Enden des Nashornvogels des Königs der Antang zu den wogenden goldenen Hängern der Frauen.

Und sogleich schiebt er ihnen zu den Sangko (ein Gefäss), den königlichen mit durchbrochenen Arbeiten von Gold, das Gefäss der fürstlichen Wohnung verziert mit eingesetzten Stücken von Achat.

Der Ort des Bootes (bootförmig aufgehäuft) mit dem Stamm der Pinang, der Platz des Nachens mit der Stütze (Mastbaum) der Betelfrucht. (Das Ganze ist also wie ein Boot aufgebaut und die Pinang dient als Mastbaum. Das hängt zusammen mit den Lebensbaumvorstellungen die wir in den Totenschiffen zurückfinden. Der Mast ist dort ebenfalls Lebensbaum.)

Sie dienen zum Empfang der Wasserschlangen (tambon), dem Besuch der Monde, der Frauen des Streureises, zusammen sieben, und zur Bewirtung der Ihing (Wasserschlangen), der Frauen des Reiskornes, die da vermehrt sind zu acht.

Gemeinsam kauen die Zähne der auf dem Sitzplatz Sitzenden, gleichzeitig mahlen die Elfenbeine der auf dem Boden Hockenden.

Abwechselnd reichen sie einander $z u$ die Stützen der Pinang, um die Reihe geben sie einander die Betelnüsse. Gemeinsam kauen sie und langsam bewegen sich die Stifte, die rot-goldenen (Goldstifte die in die Zähne eingesetzt 
Nampalampang riak hendan bulau kabantengan garing, lantik pamahempeng rawei, manimbul ringkin rabia hinut kabangkehan sihong malutai bandjang tisoi.

Djadi malik baputi djohon pinang kilau gitan Lunok Tarong, badjaleang uring manjang nahadjulen tepong.

Malik bahenda namunan riak henda,n bulau, malik bahandang njamukang darah tingang.

Sama djari busau bua pinang kahalapan tampong, manjang njarantion tundu.

Lungang-lingok renteng tingang Antang Darahen, palus randan hakaisek rawei, balalu ringkang basarohi tisoi :

Akan kueh bulan djandjulana,m panamuei keton bulan bawi,n tawur, nduan sintong udju, isen bintang panjaronga,m keton habinei etan bulau dinon lambong hanja. Mintan djadi manamuei balai sind), gleichmässig bewegen sich die Gelben (die Goldzähne).

Es steigen auf die Wellen der Gelbheit des Goldes (Speichel, der durch das Kauen gelb und dann rot wird) aus der Mitte der Zähne, der zierlich nach rückwärts gebogenen Pfahlreihe (die Zähne werden mit einem Zaun verglichen), die da abschliesst das Wort, es erscheinen an der Oberfläche aus der Mitte der Elfenbeine, dem Zaune der Rede, die vollkommenen goldenen Wogen.

Verändert hat sich die Weissheit des Saftes der Pinang, der wie der Saft des Lunok Tarong war (d.h. weiss, denn aus dem Lunok fliesst ein weisser klebriger Saft), verändert hat sich das weisse Wasser der Betelnuss, das zuerst der Farbe des Mehles glich.

Es ändert sich in Gelbheit und gleicht den Wellen des gelben Goldes, es ändert sich in Rotheit und gleicht dem Blute des Nashornvogels.

Trunken (satt) waren sie von den Früchten der Pinang, der Schönheit des Trosses, der Betel, dem Schmucke des Büschels.

Es rauschen die Schwanzfedern des Nashornvogels des Antang Darahen (d.h. sein Kopfschmuck) und mit gedämpfter Stimme fragt sein Wort und mit sachter Rede erkundigt er sich: Wohin, Monde, eures Weges, wohin soll euch führen eure Reise, ihr Monde, ihr Frauen des Streureises, ihr sieben zusammen, wohin ihr Sterne eure Fahrt, ihr Frauen des goldenen Kornes, die ihr vermehrt seid zu acht.

Angekommen seid ihr auf euerer Reise 
aku Antang Darahen.

Lungang-lingok bulau pating sumping bulan mangambohan rawei Antang Darahen:

Dia isek manasekam! panamueiku badjeleng, pangadjangku basikap.

Bau-bau ampin panalatai,e kilau bulan mating manalatai dare, pandang katon pamalempange tingkah pahawang malekut tabuhi.

Entang 165 pantai kalunen bakeho parong mahawange, tarantang penjang 166 lewu Ano, salotih paturong 167 rundong Ano.

Awi te, Antang Darahen, ikei sintong udju akan bawi loang rawei oloh pantai danum kalumen, indu habinei bamban panjarohan tisoi luwok kampongan buno.

Mandurut bitim puna humbang bulau, ikau batutus buko rendan rabia, ikau hatarusan lawas,e.

Aton upah tolang rumpang: manok darong tingang akan djawin uhat leso, aton takupat namputing bulau, akam tingang nusang mandurut $\mathrm{Lu}$ nok. 168 beim Balai, dem meinen, dem des Antang Darahen.

Es rauschen die goldenen Glieder der Ohrringe der Monde und sie beantworten die Rede des Antang Darahen: Nicht frage, nicht erkundige dich! unsere Reise ist eine eilige, unser Besuch ist ein rascher.

So ist es mit unserer Ueberlegung, so wie die Monde vor sich ausbreiten das Flechtwerk, das sie zu flechten beginnen, so steht es mit der Angelegenheit, so wie die Frauen vor sich ausspannen die kreuzweis $z \mathfrak{u}$ flechtende Matte. 164

Dem Getragenen am Ufer des Flusses der Welt ist abgebrannt das Haus, der Ort seines Wohnens, ihm dem Kinde des Penjang, ihm dem Gliede aus dem Paturong des Dorfes N.N.

Aus diesem Grunde, o Antang Darahen, dienen wir sieben zusammen als weibliche Botschafter zur Ueberbringung der Worte der Menschen am Ufer des Flusses der Welt, als weibliche Mittlerinnen zur Mitteilung des Wortes der Menschen von der Flussbuchtung, von dem Dorfe der Lanzen. Lasse dich herniederfallen auf die Erde, der du wie ein goldener Bambus bist, stosse herunter du goldfransiger Knöchel (des Bambus), steige herab du hellglänzendes Glied des Bambus.

Bereit gemacht ist für dich der Lohn für die Ermüdung deiner Knochen: das Huhn, der Vogel, der Nashornvogel und als Entschädigung für deine erschlafften Muskeln erhältst du in Blätter gewickelte Päcklein Reis mit vergoldeten Ecken; das alles ist be- 
Eleh nggatang kumin tingang, dia Lunok ngarangka, nondjong hirum tambon, die baras ngalimbange balitan Antang Darahen, palus mangambohan rawei bulan bawin tawurku sintong udju:

Narai bulan kahunga! puna Antang kurong eka tadjahan lingungku, kenjoi makang eka bantilong karendem,e.

Palus ringkes marangkesa Antang Darahen, manatap rangkan kapukajan, simpan manjadia iran panjabongan sukup. stimmt für dich, o Nashornvogel, für dein Herabkommen auf den Lunok. Und sogleich erhebt ein Lächeln der Nashornvogel, nicht überlegt er lange, er der Lunok, es schmunzelt still die Wasserschlange, nicht gibt es langes Beraten für ihn den Antang Darahen, und sogleich antwortet er dem Worte der Monde, der Frauen des Streureises, der sieben zusammen:

Was sollte mich daran hindern, o Monde! wahrlich der umzäunte Antang, der Ort des Tadjahan (umzäuntes Ahnenheiligtum von wo der Antang Ganan Tadjahan aufgerufen wird), der liegt ja in meinem Innern, der umfriedete Falke, den man aufruft, der ist in mir. (D.h. der eigentliche Antang, der aufgerufen werden muss, ist der Antang Darahen, der König aller Antang Ganan Tadjahan. Den Antang Ganan Tadjahan hat man bereits aufgerufen und so ist es nur selbstverständlich, dass auch der Antang Darahen kommit, denn wo sein Untergebener ist, da muss auch er sein.)

Sogleich beginnt aufzuräumen und in Ordnung zu bringen seine Sachen, er der Antang Darahen, und er legt bereit die Kleider, die er benötigt, und er ordnet in genügender Zahl die Sachen, die er zu seinem Schmucke braucht.

Der Antang Darahen verlässt nun sein Dorf und steigt mit den Reisjungfrauen herunter an die Ufer des Flusses der Welt. Sobald der Tukang tawur erfahren hat, dass er angekommen sei, fährt er weiter mit seiner Rede:

Toh rangkan panginan sim- Hier liegen bereit für dich die Dinge, 
pan, hai tawo,e kilau gunong baratus datoh kambo,e, kilau purok batu ambo,e akan upah tolang, $\mathrm{m}$ rumpang, indu djawin uhat,m leso. die Speisen, hoch ist ihr Haufe wie ein hundertfach hoher Berg, aufragend ist ihre Höhe wie die Spitzen der Felsen der steil aufsteigenden, als Lohn für die Ermüdung deiner Knochen, als Entschädigung für die Erschlaffung deiner Muskeln.

\section{b. Der Ursprung des Feuers}

Nach diesen Worten beginnt der Tukang tawur mit Antang Darahen zusammen die Rezitation der Mythe vom Ursprung des Feuers. Zusammen fahren sie fort:

Horan metoh katahetan lewu Batu Nindan Tarong, lewu hai ampin kanjamben lombah, rundong datoh tingkah manjantagi mirang, 169 baampah pulau tarahan, hasahep puja kalinti, lewu sintel kilau kanjimpei penjang, rundong gigi tingkah kanjandik paturong, lewu bulat, eka kampeleng tingang, rundong idje eka riwu,n tambon.

Nangkuradja awi Tanta Olang Bulau, nangkahiang awi Tantuenjet Penjang, baubau metoh lewu sintel kilau kanjimpei penjang, hembe-
Früher, zur Zeit der Anfänge des Dorfes Batu Nindan Tarong, da war dieses Dorf gross und es glich dem breiten und reichbesetzten Armband, da war der Ort ausgebreitet wie die übereinanderliegenden Lagen des Brustschmuckes, zahlreich waren die Scharen der Sklaven, wie abgefallene Blätter der Bäume, wie feiner Sand auf den Sandbänken war die Menge der Diener, übervoll war das Dorf wie die Bänder der Penjang, dichtgestopft wie die Bündel der Paturong, so war das ganze Dorf, der Ort wo sich versammelten die Nashornvögel (Männer), der Platz auf dem zusammenströmten die Tausende der Wasserschlangen (Frauen; es ist aber hier nicht nur an Frauen gedacht sondern auch an die beiden Stammteile die früher auseinanderfielen in Tingang und Tambon).

Als Aeltester herrschte im Dorfe Tanita Olang Bulau, als Ahne stand ihm vor Tantuenjet Penjang (der poetische Name für Tanta Olang Bulau), damals zur Zeit als das Dorf voll war wie die 
hemben rundong gigi tingkah kanjandik paturong.

Tapas parong batundjong oloh lewu Batu Nindan Tarong, korang siro matendu ewen rundong Liang Angkar Bantilong Njaring.

Baja aton parong tonggal kilau kanato Njaring, siro sahin nahatapang Baloi.

Eka kampeleng ratus tingang, eka pumpon ribu tambon, ie haramaung awang rangkang bakas, pangandien sawong bahendjong: radja Pampulau Hawon, radja Hantangan Tingang, radja Apang Paloi, radja Hadji, Mangko Amat Sangen, tingang uras hakampeleng rentenge huang lewu Batu Nindan Tarong, rundong Liang Angkar Bantilong Njaring.

Tingang ewen hakampeleng renteng,e awi talatai Lunok nduan idje kapating, haramaung hapapungan lingkat,e pumpon baras njurut paneahe dinon due kalawang, kabantengan parong hai malabeho
Bänder der Penjang, früher als es dichtgestopft war wie die Bündel der Paturong.

$\mathrm{Zu}$ wenig waren die Häuser die sich erhoben für die Leute des Dorfes Batı Nindan Tarong, zu klein war die Zahl der Wohnungen für die Menschen aus dem Dorf Liang Angkar Bantilong Njaring (anderer Name für Batu Nindan Tarong).

Nur ein einziges Haus erhob sich im Dorfe das dem Hause des Njaring glich (d.h. einem Baume und bedeutet, dass das Haus sehr hoch war), nur eine einzige Wohnung war vorhanden die der des Baloi ähnlich war. (Baloi ist ein anderer Name für Njaring. Tambaloi ist gleichbedeutend mit Hantimang: eine fliegende Hexe).

Es war der Ort wo sich hunderte von Nashornvögeln versammelten, es war der Platz wo tausende von Wasserschlangen beieinander waren, sie die Tiger, die greisen, die alten, sie die Tiger, die weisshaarigen, nämlich sie: radja (der Aelteste) Pampulau Hawon, radja Hantangan Tingang, radja Apang Paloi, radja Hadji, Mangko Amat Sangen, alle diese Nashornvögel wohnten hier beisammen mit ihren Schwanzfedern (Kopfschmuck), hier im Dorfe Batu Nindan Tarong, im Orte Liang Angkar Bantilong Njaring.

Die Nashornvögel versammelten ihre Schwanzfedern (sie kamen zusammen und steckten die Köpfe zusammen) wegen einer Beratung um zuzufügen dem Lunok ein neues $Z$ weiglein, die Tiger kamen zusammen mit ihren Streifen (gemeint sind die Schwanz- 
bentenge, kabangkehan siro datoh barantau ruange. 170

Metoh ewen hunda-hundak pantong tingang, mandit batu bangkulan tuwe, maneneng gohong pandih Njaring, 171 salenga mahining auch lalento,n tingang, manahingan rarajon luhing pating bungai, bente-benteng langit.

Njamah gatang tarahendeng balitan radja Dohong Bulau, balua hengau habenteng, balua parong hai idje malabeho benteng,e.

Narai gangguaran ara,e idje lalau hai lalento,n tingang,e, pakarok datoh bahing rarajo,n luhing pating bungai,e.

Nampajah ngadju nampadjahen ngawa, djilau bulan kapa- federn des Tingang die sie als Kopfschmuck tragen), weil der Sand des Flusses der zum Vorschein gekommen war durch die Trockenheit sich vermehrte (d.h. sie mussten in irgend einer Sache einen neuen Rat finden), sie kamen zusammen in der Mitte des Hauses, in der Mitte die gebildet wird durch eine Wassertiefe, sie versammelten sich in der Mitte des Hauses, des hohen, durch dessen Mitte eine Buchtung läuft (die Schwelle), die es in zwei Teile teilt.

Und als sie zusammensteckten die Hörner der Tingang (Kopfschmuck) und als sie sich beschwichtigten mit dem Steine der Bündel der Tuwe, und als sie sich besänftigten mit den Wassern die abgesperrt sind durch die Njaring (d.h. als sie mit Biertrinken beschäftigt waren), da hörten sie plötzlich die lärmende Stimme eines Nashornvogels, sie vernahmen das lärmende Geschrei des $Z_{\text {weigleins eines Nas- }}$ hornvogels (Zweiglein: Kind), sie hörten es erschallen von der Mitte des Himmels her.

Und sogleich erhob sich und stand auf der Aelteste Dohong Bulau und er lehnte mit seinem Oberkörper weit hinaus aus dem Haus, er trat heraus aus der Wohnung, der grossen, die eine Wassertiefe hat in ihrer Mitte.

Mit welchem Namen nennt er sich, wie heisst er der Nashornvogel der so laut schreit, der so übermässig ruft und lärmt, er das Kind des Nashornvogels.

Er schaut flussaufwärts, er blickt flussabwärts, wo ist der Mond der für sich 
naho matei biti,e!172 manuntun taloh nara-narai kananggare udjan rajo balawo, dia ie manuntun sarong lawang baun andau.

Kananggare hewan lunok balongkang kilau bulan kapanaho matei! aton riwut bamban baloi, kananggare anak Njaro balawo, dia balaju dawen pinang lewu, pinding papandingen bulau tampak bengkel,e, hajak loang-lauh bulau awang tandok,e, lakanahingan auch karidu,n tingang, njalanean riwut bungai hila likut lewu Batu Nindan Tarong, rakuren rundong Liang Angkar Bantilong Njaring.

Hau, koan riwut rawei haramaung awang duron panggil, tisoi pangandien maing tundun riah tandang: hila likut lewu Batu Nindan Tarong auch lalenton tingang, rakuren rundong Liang Angkar Bantilong Njaring bambahingan rarajon bungai.

Ijoi, koan rawei Maharadja Hadji, mikeh laletus djalahan garing tabela belom 173 awang mengan tingang endau hila rakuren lewu. selbst die Totenspeise bereit gemacht hat! er wollte irgend etwas schauen das er bezeichnen konnte mit dem lärmenden Regen, aber nicht schaute er nach der Hülle, der Türe der Wolken des Tages.

Er sprach zu sich selbst: gewiss ist der Mann eines Lunok umgestürzt, so wie die Monde das Totenessen bereiten (Fluch), der Wind hat gefällt einen Baloi, er sagte in seinem Innern: das Kind des Njaro ist herabgestürzt, nicht ist verdorrt ein Pinangblatt aus unserem Dorf (d.h. nicht ist ein Kind aus dem Dorf verunglückt), seine Ohren lauschen so dass sich nicht einmal die Ohrringe bewegen und das Gold seiner Augen schweift suchend herum um zu sehen die Ursache des Geschreies, und er hörte das wehende Wort des Nashornvogels von der hinteren Seite des Dorfes Batu Nindan Tarong her, von der Rückseite des Ortes Liang Angkar Bantilong Njaring.

Hau, spricht das wehende Wort der Tiger, die sich eingefunden hatten zum Besuch, die Rede der Tiger, der kräftigen, die sich eingefunden hatten als Gäste, sie die Tiger: hinter dem Dorfe Batu Nindan Tarong ertönt das Geschrei des Tingang, auf der Rückseite des Ortes Liang Angkar Bantilong Njaring erschallt das Geschrei des Nashornvogels.

Ja, spricht die Rede des Maharadja Hadji, vielleicht ist es nur das Gebrause der Elfenbeine, der jung lebenden (Kinder) die mit den Blaserohren Jagd machen auf Vögel, das wir so- 
Magon ewen hong labeho parong hunda-hundak pantong tingang, laka mahi-mahi auch lalenton tingang.

Kadjalahan pulau tarahan, panungkup puja kalinti, daridaria tambang,e belahe mamantang parong hai dje malabeho benteng,e, manindan siro datoh idje barantau ruange.

Kitik hapangandan djandjaroman akan haramaung awang hapampungan lingkate: Tempo bara tempo, Sangiang bara Sangiang, amon kalotoh panalatai itah lewu Batu Nindan Tarong, amon pandong katon pamalempang,e itah Liang Angkar Bantilong Njaring, dia balang itah pampatei lomat, kueh tampuli itah kanahaman pusing.

Bau-bau huang likut lewu,n itah Batu Nindan Tarong, medjen rakuren rundong itah Liang Angkar Bantilong Njaring, salenga anak Njaro balawo, djaton kanatup bahing njaho, busun Sinar malentur, korang mambai kilat djalatien. eben gehört haben von der Seite hinter dem Dorfe her.

Noch immer stecken zusammen die Hörner der Nashornvögel in der Wassertiefe des Hauses der Männer, aber noch viel mehr schwillt an der Lärm des Nashornvogels.

Aus der Schar des Geschlechtes der Sklaven, aus der Gemeinschaft der unzähligen Leibeigenen rennen und springen die Beine von einigen, sie besteigen das Haus, das hohe, das in seiner Mitte eine Wassertiefe besitzt, sie klettern hinauf in die Wohnung, die grosse, deren Inneres in zwei Hälften geteilt wird durch eine Buchtung (Schwelle).

Zitternd und bebend berichten sie den Tigern welche versammelt waren mit ihren Schwanzfedern: Herren, o unsere Herren, Sangiang, o unsere Sangiang, wenn es so steht mit der Sache unseres Dorfes Batu Nindan Tarong, wenn es so ist in der Angelegenheit unseres Ortes Liang Angkar Bantilong Njaring, dann kann es nicht vereitelt werden, dass wir alle sterben und gänzlich umkommen müssen, dann kann nichts mehr aufhalten unseren Tod, der uns gänzlich hinwegrafft.

Soeben geschah es, dass hinter unserem Dorfe Batu Nindan Tarong, in diesem Augenblicke passierte es dass auf der Rückseite unseres Ortes Liang Angkar Bantilong Njaring, ganz plötzlich das Kind des Njaro herunterstürzte, nicht wurde es begleitet vom Schalle des Donners, der Jüngste des Donners ist heruntergefallen, nicht waren mit ihm die Blitze, die neune 
Sampai apui Njaro manalumbang bukit tumbon kaju karuhei tatau, 174 mangaliling kereng eka bulus paturong sangkalemo radja. 175

Njamah tapakalong parong bulan idje njawaka kabangkange, tapugenggem siro,n pahawan idje notok katentange, bawi mait idje manjangiang langit, habinei djaja idje mandjalajan hawon. ${ }^{176}$

Sampai apui malajap balobalon kilau riak hai njababalon puron, bahen Sinar hatansaran tingkah galombang datoh pahowong tusang, koan rawei pulau tarahan, panungkup puja kalinti.

Terai koa,n rawei radja Dohong Bulau, koa,n rawei radja Hantangan Tingang, koa,n rawei radja Pampulau Hawon, ela omba auch riwut rawei mandaur itah hundak pantong tingang, tandjaro hikau, koan riwut rawei ewen, djaka Njaro toto balawo mbuhen dia hajak njaho batengkong, djaka busu,n Sinar anan marentur, mbuhen dia (d.h. es war nicht nur Donner und Blitz was man hörte und sah, es war in diesem Falle wirklich das Kind des Donners das herabgestürzt war).

Und nun geschieht es, dass das Feuer des Njaro sich ausbreitet auf dem Berge des aussprossenden Holzes der Karuhei des Reichtums, dass es um sich greift auf dem Hügel der ausschlagenden Sangkalemo Radja.

Eingeschlossen ist bereits das Haus der Monde welche von ungestümer Schönheit sind, ergriffen wird die Hütte der Frauen die von grosser Lieblichkeit sind, die Frauen, die starken, die als Helfer haben die Sangiang des Himmels, die Frauen, die kräftigen, denen beistehen die Sangiang aus der Höhe.

Und nun geschieht es, dass das Feuer sich ausbreitet, dass es daher rollt wie die grossen Wellen, die eine Matte vor sich her aufrollen, wie hohe umsichgreifende Wogen die heransteigen an den Hellungen des Hügels, so spricht die Rede derer aus dem Geschlechte der Sklaven, aus der Gemeinschaft der unzähligen Leibeigenen.

Schweigt, spricht das Wort des radja Dohong Bulau, sagt die Stimme des radja Hantangan Tingang, lautet die Rede des radja Pampulau Hawon, nicht hört auf das Windwort (die eitle Rede) das uns nur stört bei unserem Zusammenstecken der Hörner des Nashornvogels (d.h. bei dem lebhaften Gespräch), es ist ja doch nur Lüge was ihr sprecht, so spricht ihr wehendes Wort, denn wenn es wirklich so wäre, dass der Njaro heruntergestürzt 
humboh kilat basiring?

Toto bara toto! tempo sangiang, koan rawei djalahan pulau tarahan, njamah manto harapitan kabangkange, panungkup puja kalinti, njamah balo-balon oru djandjarupen peron tambon, sampai kakakakar owang tarah lintong talawang 177 intu bau,n parong hai idje malabeho benteng,e.

Mahi-mahi lalento,n tingang ewen hundak pantong tingang, djala-djalan paham rarajo,n bungai, ewen maneneng gohong pandih Njaring, mandit batu bangkulan tuwe, djaton katalingan rawei idje asi-asi balua bulau pantar tatah djalahan kawan tarahan.

Isen njalanean salatan tisoi tapanjame-njame, bahandjong rabia sadurin guntong panungkup puja kalinti.

Ie, balitan bulan njawak kabangkang,e huang likut lewu ist, weshalb geschah es dann nicht mit dem lautschallenden Donner zusammen, falls der Jüngste des Donners wirklich herabgefallen ist, weshalb war er dann nicht begleitet von den weithin zuckenden Blitzen?

Aufrichtig ist unsere Rede, wahr ist unser Wort, o unsere Herren, unsere Sangiang, so spricht die Rede der Schar aus dem Geschlechte der Sklaven und sie bekräftigen ihr Wort als ein vollkommen wahres, sie die Gemeinschaft der unzähligen Leibeigenen, sodass sich selbst wendet die Galle der Tambon, sodass sich selbst umwühlen und undrehen die Bänder des Schildes im vorderen Teile des Hauses, das in seiner Mitte eine Wassertiefe besitzt.

Nichts geben sie auf den immer noch zunehmenden Lärm des Nashornvogels, immer noch stecken sie zusammen ihre Hörner, stärker und immer stärker wird das Geschrei des Nashornvogels, sie beruhigen sich mit dem Wasser, dem abgesperrten durch die Njaring, sie besänftigen sich mit dem Bündel der Tuwe, nicht wollen sie lauschen nach dem erbarmungswürdigen Worte, welches hervorkommt aus dem goldenen Zaune der Zahnstifte, nichts geben sie um das Wort der Gemeinschaft der Sklaven. Nicht wollen sie lauschen nach dem Laut der Stimme, der sehr flehenden, der hervorgeht aus der goldenen Hecke der Zähne der Gemeinschaft der unzähligen Leibeigenen.

Aber sie, die Monde von ungestümer Schönheit, die auf der hinteren Seite 
Batu Nindan Tarong, paha-. wan medjen siro rakuren rundong Liang Angkar Bantilong Njaring katawa,e.

Metoh,e tiroh tingang kabantenga,e, kantok adjong, limbah,e malajan tolang,e rumpang, ngabadjuran kaju,n karuhei tatau, ulek,e maleleng uhat leso ngabarengan bulus paturong sangkalemo radja.

Meto-metoh,e basandar bantal putak bulau kalihulon, pesah,e medjen amak rabia idje hatalendjen ringkin tabuhi,

Laka kangalong apui njaro idje bakatutuh rewa,n lunok mangaliling bahen sinar idje baka pampang rangkang sanggalang,

Hingkat rampa-rampa tandok,e manggau sambang bulau salumpok bulan pangaranting langit, idje pali manto,e, bakabelep apui, endus habantuan bakalilap bahen kumpit. des Dorfes wohnen, des Dorfes Batu Nindan Tarong, sie die Frauen die sich aufhalten im Haus hinter dem Ort Liang Angkar Bantilong Njaring, sie allein wissen was geschehen ist. Mitten im Schlaf lag der Nashorn. vogel (nämlich das Kind des Njaro), im Schlummer wiegte er sich, aber nachdem seine Knochen aufgehört hatten müde $z u$ sein, da streckte er aus die Hölzer der Karuhei Tatau (die Beine), als wieder vorbei war die Schlaffheit der Muskeln, da reckte er die Sprossen der Paturong Sangka. lemo Radja (die Beine).

Und als er sich aufstützt auf dem Kissen, das gefüllt ist mit dem goldenen Schaum vom Quellort der Flüsse, 178 und während er noch liegt auf der Matte, der goldenen, die in abwechselnden Wellen geflochten ist (d.h. in verschiedenen Farben und mit verschiedenen Motiven durchflochten), Und so wie das Feuer des Donners umherschweift und vernichtet die abgeschlagenen $Z$ weige der Bäume, so wis die Glut des Donners immer mehr um. zingelt die Zacken der Aeste der Bäume,

So erheben sich nun seine Augen und sie schweifen herum in der Hütte und sie suchen die Trommel, das goldene Kernholz des Mondes, des Spielinstrumentes des Himmels, das verboten ist geschlagen $\mathbf{z u}$ werden weil das auslöschen würde das Feuer, das untersagt ist gespielt $\mathrm{zu}$ werden weil es zum Auslöschen bringen würde das glühende Abfallholz (an dem immer wieder neues Feuer entzündet wird). 
Kumbang-kakambanga biti,e, hawus-hasen balita,e, taratekape suling bulau sangkalemo, pantis kambang kabanteran bulan, tahuntong rabia rumbai ambon, tahuton lumpong matanandau.

Idje pali impahiau awi,e, bakasaloh bambang garo, bakarentar simpei santi.

Kareh tau impahiau awi tingang njaha,e.

Sinde mahimon suling bulau, hatampulu mangambang karungut bulan, handue mamupus tahuntong rabia, hangkalimebalas mangekah kandajon pahawang.

Bahing kakarungut suling bulau sangkalemo, kalabien pantis kambang kabanteran bulan, umba-umban salatan bambahingan tahuntong rabia, kalambungan tahutun kekah lumpong matanandau, manambeleng labehon parong hai idje malabeho bentenge, manamputer rantau siro datoh idje barantau ruange.

Bahing kakarungut suling
Sich umschauend streift er umher, suchend geht er dahin und dorthin und er greift nach der Flöte, nach dem goldenen Sangkalemo, dem Tropfen der Blumen der Rundheit des Mondes (d.h. ein Teil von der überzähligen Mondsubstanz), der goldenen Pfeife mit tauigen Fransen verziert, dem Tropfen von dem Rande der Sonne (von der überzähligen Substanz der Sonne).

Er greift nach ihr, die er nicht spielen darf, damit nicht plötzlich verwandelt werde der Weihrauch, damit nicht plötzlich verändert werde das wohlriechende Räucherwerk.

Später erst darf sie gespielt werden durch den Nashornvogel, durch seinen Bruder.

Einmal bläst er auf der goldenen Flöte, zehnfach erschallt das gesungene Spruchwort der Monde, zum zweiten Mal bläst er auf der goldenen Pfeife und fünfzehnfach ertönt der Gesang der Frauen.

Es erschallt das Lied der Flöte, des goldenen Sangkalemo, des Ueberschusses des Tropfens der Blume der Rundheit des Mondes, es schweift umher der Laut des Tones der goldenen Pfeife, des Restes des Tropfens der Blume der Rundheit der Sonne, es dreht sich plötzlich herum die Wassertiefe des Hauses, des grossen, das in seiner Mitte einen Abgrund hat, es wendet sich herum die Buchtung der hohen Wohnung, die in ihrer Mitte eine Buchtung besitzt die sie in zwei Abteilungen verteilt.

Der Schall des Liedes der Flöte vom 
bulau sangkalemo manamuei lawang labehon Djata, kalampangan lungang-lingok bulan bawin Djata.

Bahing kakarungut suling bulau sangkalemo manamuei mangumbang lawang langit hantantilap.

Mari darah,e idje sampilong dawe,n Lunok Tarong merang tolang,e due, lumpang bulau tandok tambon oloh batang danum Djawei Langit, oloh batang danum Hinting Maninting Langit Gohong Parimata Manjampaga Hawon, oloh batang danum Korik Pasak Lumpong Matanandau, Gohong Ringik Tahidjik Kabanteran Bulan, oloh batang danum Salumpok Erang Tingang.

Harun tarewen ewen melai parong hai malabeho benteng,e, medjen siro datoh barantau ruang,e, sama mari darah idje sumpak dawen $\mathrm{Lu}$ nok Tarong merang tolang due, lumpang bulau tandok tambon. goldenen Sangkalemo schreitet hin zum Eingang des Abgrundes der Djata, zu dem Eingang, da, wo an der Oberfläche des Wassers erscheinen die sich drehenden und wendenden Monde der weiblichen Djata.

Der Laut des Gesanges der Pfeife vom goldenen Sangkalemo reist weg und er schweift hin bis zur Türe des Himmels, des in vielen Schichten übereinanderliegenden.

Von allen Seiten wehen sie herzu, die Blätter des Lunok Tarong (die Geister der Oberwelt und Unterwelt), es klirren und klappern ihre beiden Knochen (die Beine), es tropfen die goldenen Hörner (kann auch heissen: Augen, der Sinn ist hier nicht deutlich weil die Tambon eine Krone mit Hörnern hat) der Wasserschlangen, der Leute von den Flüssen Djawei Langit, der Leute von dem Flusse Hinting Maninting Langit Gohong Parimata Manjampaga Hawon, der Leute von dem Fluss Korik Pasak Lumpong Matanandau, Gohong Ringik Tahidjik Kabanteran Bulan, der Leute vom Flusse Salumpok Erang Tingang.

Erst jetzt ergreift der Schrecken auch sie die da wohnen im Hause, dem grossen, das eine Wassertiefe besitzt in seiner Mitte, erst jetzt packt das Entsetzen sie, die sich aufhalten in der Wohnung, der hohen, die in zwei Abteilungen geteilt wird durch eine Buchtung, von allen Seiten strömen sie nun zusammen, die Blätter des Lunok Tarong (der Männer) und es tropft das Wasser von den auftauchenden Hörnern (Augen) der Wasser- 
Sama mamanting tambang,e balinga balua parong hai malabeho bentenge, bahandjong siro datoh idje barantau ruange, sama hadari mananturong likut lewu Batu Nindan Tarong, manjahendeng rakuren rundong Liang Angkar Bantilong Njaring.

Bau ampin panalatai bulan likut lewu Batu Nindan Tarong, tingkah pamalempang pahawang medjen rakuren rundong Liang Angkar Bantilong Njaring, awi sala kapanatau nekap,e lingo nahuang manekap sambang bulau, salenga taratekape suling bulau idje bakandong peteh oloh tingang tempo,e, tahuntong rabia batantiang djandjin oloh antang sangiang.

Hajak kitik hapangandang bulan kanjaloh bambang penjang garo,e, redjar hapangendjeh pahawang kanarentar paturong santi,e.

Kadje-kadjeng haru,e manekap sambang bulau idje pali manto,e bakabelep apui, han- schlangen (damit sind hier die Frauen gemeint).

Sie alle zusammen verwerfen nun die Beine und sie verlassen das Haus, das grosse, das eine Wassertiefe hat in seiner Mitte, sie treten heraus aus der Wohnung, der hohen, die durch eine Buchtung in zwei Abteilungen geteilt wird, sie eilen gemeinsam davon und haben als Ziel die Rückseite des Dorfes Batu Nindan Tarong, die hintere Seite des Ortes Liang Angkar Bantilong Njaring.

So stand es mit der Sache der Monde auf der Rückseite des Dorfes Batu Nindan Tarong, so war es mit der Angelegenheit der Frauen auf der Hinterseite des Ortes Liang Angkar Bantilong Njaring: falscher Reichtum hatte er erwischt (nämlich das Kind des $\mathrm{Njaro}$ ), sein Inneres begehrte nur zu greifen nach der goldenen Trommel, aber statt dieser ergriff er die goldene Flöte, die auf den Befehl ihres Besitzers, ihres Nashornvogels, dort niedergelegt worden war, packte die goldene Pfeife, die dort geborgen lag nach dem Wunsche ihres Herrn, des Falken, des Sangiang.

Es zittern und beben die Monde der verwandelten Splitter der Penjang des Weihrauches, es zittern und beben die Frauen der veränderten Paturong des wohlriechenden Räucherwerkes (Hier sind gemeint die Frauen, die auf dem Berge des aussprossenden Holzes der Karuhei tatau wohnen. Siehe oben). Und plötzlich berührte er die goldene Trommel, welche verboten ist geschlagen $z u$ werden damit nicht auslösche 
due njahintik luhing rabia das Feuer, und zum zweiten Mal idje endus njalantikan baka schlägt er auf die goldene Trommel, lilap bahen Sinar.

Eleh lepah kabalepan apui, asep njalabuwuk langit mahi, djilau bulan kapanaho matei!

Gege apui huang lewu Batu Nindan Tarong uras lepahkabalepan, apui oloh batang danum are barabambai lepah kabalepan, djilau bulan kapanaho matei!

Ie, tingang awang baratus renteng,e, haramaung maing baribu lingkate, uras mananturong bukit tumbon kajun karuhei tatau, manuntun parong tonggal idje dia batatop pulu, manureng siro sahin idje dia nambai djalatien, djilau bulan kapanaho matei! hajak manuntun apui belep manantekas.

Laka nuntung suling bulau djadi humbang meong laliong lio sangkalemo.

Sambang bulau saloh djadi Und die goldene Trommel hat sich 
gandang pandak idje pali manto,e, baka parit simpei karuhei tatau.

Mite tantekan pondok, salenga belom djadi kajun karuhei seratus udju pulu udju matjam,e.

Salenga babalang bahing karungute bewei bulan tokep upon kajun karuhei tatau, baja batentang salatan bambahinga,e darah bulus sangkalemo radja.

Laka sangkelang auch bahing karungut bulan dengan bahing karungut rangkang dohong, tapi baja babalang bahing karungute bewei, djilau bulan kapanaho matei! aton manuntun djahangkar tingang,e. Bau, koa,n rawei bahing karungute, ijoh, keton lewu Batu Nindan Tarong, kalotoh panalatai,e, kilau bulan mating manalatai dare, pandang katon pamalempang,e tinai, tingkah pahawang malekut tabuhi, amon buah panalatai,e keton ngabaluma apui, tau apui keton habadjuran, kilau buno randan kangereng $\mathrm{Nja}$ ring pandai kabarengan, tingkah renteng mananggalong verwandelt in eine kurze Trommel, die nicht geschlagen werden darf um nicht wegzulocken (nicht $z u$ vertreiben oder zu schwächen) die Bündel der Karuhei des Reichtums.

Und sie sehen die abgesprungenen Stücke des Feuerbrandes (mit dem man das Feuer jeweils wieder anfacht), plötzlich empfangen sie Leben und sie verwandeln sich zu Karuheiholz von hundert sieben und siebzig Arten.

Und plötzlich steigt auf ein Spruchwort des Liedes der Monde (hier sind wieder die Frauen gemeint, die auf dem Berge des aussprossenden Holzes der Karuhei tatau wohnen) ganz in der Nähe der Stämmchen des Holzes der Karuhei tatau, auf einmal erschallt der Laut eines Gesanges bei den aussprossenden Sangkalemo radja.

Und es tönen durcheinander die Worte des Liedes der Monde mit dem Laute des Gesanges der alten Dolche (Priester), aber nur vernimmt man die Weise des Liedes, nicht aber auch gar nicht sind sichtbar die Personen, sie die Nashornvögel.

So steht es, spricht der wehende Laut des Liedes, ja, ihr Leute aus dem Dorfe Batu Nindan Tarong, so ist es mit der Angelegenheit, so wie die Monde vor sich ausbreiten die zu beginnenden Flechtereien, so steht es mit der Beratung, so wie die Frauen vor sich hinlegen das kreuzweise zu flechtende Werk, wenn euere Ueberlegungen um das Feuer wieder $z u$ beleben gut ist, dann kann das Feuer wieder in Ordnung kommen und es steigt auf wie die kleinen Speere am 
bulau.

Amon sala panalatai,e kilau bulan salandja manalatai dare, djaka lain pamalempang,e tingkah pahawang hakakadjeng malekut tabuhi:

Kueh tau apui keton kabadjuran kilau buno randan kangereng Njaring!

Amon parong keton hakanan apui, amon katawan keton talatai panantura,e, kabadjuran ie kilau buno randan kangereng Njaring, lipet due lungkang, manelo rangkan panatau,e bara djundjun helo aloh,e pondok babilem, amon tawa,e panalatai,e, djete basaloh djadi kaju,n penjang karuhei tatau.

Tapi amon sala panalatai,e halalus kangasi riwut lingo awi lepah rangkan panatau,e.

Toh bahali keton manggau apui dje kabadjuran amon dia mandjawi hapan rangkan
Körper der Njaring aufsteigen (die Njaring haben rote Haare und die Haare werden mit kleinen Speeren verglichen), so wie der Federkiel den Goldstaub umschliesst (der Goldstaub wird in hohlen Federkielen aufbewahrt).

Wenn euere Ueberlegung unrichtig ist, so wie wenn die Monde überhastet ausbreiten die zu machenden Flechtarbeiten, wenn nicht gut durchdacht ist euer Rat, so wie wenn die Frauen zu eilig vor sich hinlegen die Flechtereien:

Wie sollte dann euer Feuer wieder in Ordnung kommen, wie sollte es wieder aufsteigen wie die kleinen Speere am Leibe der Njaring!

Obgleich euer Haus verzehrt worden ist vom Feuer, wenn ihr dann nur kennt die Art und Weise seines Ursprunges, nichts macht es aus, in Ordnung kommt es wieder und es wird gleichen den kleinen Speeren am Leibe des Njaring, ist doppelt der Schade den das Feuer verursachte, dreifach wird der Gewinn und Reichtum sein, trotzdem der Feuerbrand schwarz geworden ist (d.h. ausgelöscht ist), nämlich dann wenn ihr wisst was mit dem Feuer in der Urzeit geschah, dass es verwandelt worden ist in das $\mathrm{Holz}$ der Penjang, der Karuhei des Reichtums. Aber wenn euere Kenntnis davon unrichtig ist, dann wird wehender Jammer euer Inneres erfüllen, weil für immer dahin ist euer Reichtum.

Aber unmöglich wird es sein für euch zu suchen das gute Feuer, wenn ihr nicht bereit macht die Dinge der Speise 
panginan hajak basaki dengan darah manok darong tingang, amon dia Antang manamuei, pahapang penjang dohong korik dje panarusan langit, bagentoi paturong ringik, dje pamentas hawon.

Sontop rantunan tandok,e djalahan tingang awi baratus rentenge, sundo-sundong luhing pating bungai,e panungkup haramaung baribu lingkat,e, manahingan riwut bahing karungut idje padjandjuri bara upon kaju,n karuhei tatau.

Njalanean salatan kandaju panantekei darah bulus sangkalemo radja.

Mera-merang bahing,e Apang Paloi, mangambahan bahing karungut: intu kueh eka ikei dinon apui awang Djata katontong batuah. 179

Kueh pahatewang lewu dohong korik idje tau manarusan langit, idje handong katawa,e eka apui, idje handong katawa,e panalatai,e kilau bulan manalatai dare.

Enta-entai, manggau bahing
(Opfergaben) und sie nicht rituell bestreicht mit dem Blute des Huhnes, des Huhnes Tingang, wenn nicht für euch auszieht der Antang (gemeint ist der Antang Tadjahan) mit den Penjang des kleinen Dolches (Krallen), wenn er nicht für euch schweift durch die Himmel, er mit den kleinen $\mathrm{Pa}$ turong der für euch aufsteigt in die Höhe.

Sie beugen sich und spähen aus mit ihren Augen, sie die Menge der Tingang mit den hunderten von Schwanzfedern, schräg schauen sie hinüber nach der Stimme, die scharf hervorstehenden Augen der Nashornvögel, sie aus dem Geschlecht der Tiger, mit den tausenden von Querstreifen, sie lauschen nach dem Worte, nach der Stimme, nach dem wehenden Laute welcher hervorfliesst aus den Stämmen des Holzes der Kartuhei des Reichtums.

Sie lauschen nach dem rauschenden Gesange, der aufsteigt von den aussprossenden Sangkalemo radja.

Mit zaghafter Stimme erkundigt sich Apang Paloi und er antwortet der Rede des Spruchwortes und er fragt: wo ist der Ort wo wir finden können das Feuer mit welchem Djata wieder vermehrt unser Glück und Heil.

Wo befindet sich die Buchtung des Flusses, wo liegt das Dorf des kleinen Dolches der hinaufziehen kann durch die Himmel, des kleinen Dolches der da kennt den Ort des Feuers, dem bekannt ist der Ursprung, so wie die Frau die vor sich ausbreitet die Flechterei.

Er wartet und er horcht nach der 
karungut kahalinai, endeendeh medeh salatan kandaju djilau bulan kapanaho matei, eleh tunis mangalingau buang.

Sama gandang halalian buli oloh lewu Batu Nindan Tarong buli halalian parong mahawange, sama ngantong lingo rutus, manunjang karendem,e robo, naharambon timpong.

Belahe buli pahatewang lewu, belahe halalian batang danum mahawang,e, ruta batu piring lingo,e, pusang liang djarah karendem,e, salenga manuntun apui djilau bulan kapanaho matei.

Tangis-tatangiragaring awang tabela belom, tatum-kakandaju pulang maing kanahesen ringik. 180

Nahuang njurong manantihan, handak mambo hakanjatan, andau kueh aton apui hapa nabasan rangkan panginan! Lento-lento bambahinga oloh lewu Batu Nindan Tarong, rundong Liang Angkar Ban-
Stimme des Spruchwortes während eines Augenblickes, er geduldet sich und er lauscht nach dem Laute des Liedes, aber nichts, gar nichts vernimmit er, es bleibt einsam und still.

Und so wie der Schall der Trommel zurückkehrt und wieder verstummt, so kehren zurück die Leute des Dorfes Batu Nindan Tarong ins Haus wo sie wohnen und sie hängen auf in ihrem Innern den Schmerz und sie wiegen in ihrem Herzen das Leid, so wie man aufhängt das Garn des buntgewobenen Tuches (sie sind betrübt weil sie keine Antwort bekommen haben und keinen Rat mehr wissen).

Und einige kehren zurück an die Buchtung des Flusses an der ihr Dorf liegt und andere gehen wieder heim an den Fluss wo sie wohnen, betrübt ist der steinerne Teller ihres Innern (das Herz wird mit einem Gefäss verglichen in dem Leid und Freude liegen), traurig ist die steinerne Grube ihres Herzens, denn plötzlich sehen sie wieder das Feuer, das ausgelöscht ist, das Feuer, das nicht mehr da ist.

Es schluchzen und weinen die Elfenbeine, die jung lebenden (die Kinder), es steigt auf das Klagelied und der Wehgesang aus dem Munde der Schwertgriffe, der kräftigen, der ungewohnten des Lebens.

Sie verlangen zu essen, sie möchten Speise zu sich nehmen, aber wo ist nun Feuer um zuzubereiten die Dinge des Essens!

Es erhebt sich ein Getümmel und Rauschen der Stimmen der Leute des Dorfes Batu Nindan Tarong, des Ortes 
tilong Njaring ttg. oloh batang danum are habambai.

Ie, leteng lumpong matanandau lilap luhing panganur hawon, djilau bulan kapanaho matei, aton hapan manontong njating djadjampen kareng.

Rakap hadjamba oloh lewu Batu Nindan Tarong, rundong Liang Angkar Bantilong Njaring, hisek mikeh aton ain kola,e garing idje beken, djilau bulan kapanaho matei, are manundjong tangis tingang, belahe njariangkat tangungoi buron.

Amon kilau etoh panalatai,e itah lewu Batu Nindan Tarong, amon pandang katon pamalempang,e itah rundong Liang Angkar Bantilong Njaring, dia balang itah pampatei lomat, kueh hatampuli itah indu kanahaman pusing!

Dia balang itah matei nambuleng riwut bulan bawin lau, kueh hatampuli itah namputer salatan kabaduran!

Nambeleng bulan bawin riwut lau, manjangkelang lusok parei, manamputer salatan kabaduran, manjampale karang-
Liang Angkar Bantilong Njaring und der Bewohner an den Flüssen, der zahlreich nebeneinanderliegenden.

Versunken sind die Ränder der Sonne, verschwunden ist die Wärme des Scheines aus der Höhe, nicht ist sie mehr da und nichts ist vorhanden um wieder zu entzünden das Harz das man sammelte auf den Sandhügeln. 181

Unruhig und ratlos schweifen herum die Leute des Dorfes Batu Nindan Tarong, des Ortes Liang Angkar Bantilong Njaring, sie erkundigen sich ob bei ihren Freunden und Verwandten noch Elfenbein (Feuer) vorhanden sei, aber nichts, gar nichts finden sie, und manche erheben das wehe Weinen der Nashornvögel und aus dem Munde voil andern steigt auf das Schluchzen der Vögel. 182

Wenn es so steht mit unserer Angelegenheit im Dorfe Batu Nindan Tarong, wenn es nun auf diese Weise geht mit unserer Sache im Orte Liang Angkar Bantilong Njaring, dann kann durch nichts verhindert werden, dass wir durch gänzlichen Tod vernichtet werden, dann vermag nichts mehr aufzuhalten das ausrottende Sterben.

Es ist nicht mehr $z u$ ändern, wir sterben, wir werden umgeschlagen durch den Wind der Monde, der Frauen des Hungers, es ist nichts mehr zu machen, wir werden umgeschlagen durch den Sturm des verzehrenden Mangels.

Es erfassen die Monde, die Frauen des wehenden Hungers die Behälter des Reises und wirfen sie um, der Sturmwind des verzehrenden Mangels stürzt 
king pulut.

Ie, oloh lewu Batu Nindan Tarong, panganak rundong Liang Angkar Bantilong Njaring, tingang hakampeleng, haramaung hapampungan lingkate, mapak basara, mangun parentah, manggau ampin panalatai,e, kilau bulan manalatai dare, manggilau pamalempange tingkah pahawang malekut tabuhi, djalahan radja hakanduan, panungkup kanarohan hapandereh.

Mangun ewen parentah akan garing awang tabela belom, mantang pain bukit pandjang, manintan paha purok ambo, manggau bua baratus gangguranan arae, ewen lewu Batu Nindan Tarong, baisi bua katapi, panting kaleka, oloh rundong Liang Angkar Bantilong Njaring, hadarah bua kenjem sarajong lambang ma. namum, balunek hanselan, embak, puak, mawoh-marioh paken tungkoi, bua baratus gangguranan arae hakanan oloh lewu Batu Nindan Tarong. um die Behälter, er wirft durcheinander die Bergplätze des Pulutreises. (D.h. sie haben noch genügend Reis, aber sie haben kein Feuer mehr um ihn zu kochen und so wirft der Hunger auch alle Vorräte um und vernichtet sie.)

Sie, die Leute aus dem Dorfe Batu Nindan Tarong, die Kinder aus dem Orte Liang Angkar Bantilong Njaring, sie, die Nashornvögel versammeln ihre Schwanzfedern, sie, die Tiger sitzen zusammen mit ihren Querstreifen, sie eröffnen eine Ratsversammlung, sie richten ein Wort auf, sie suchen einen Rat, so wie die Monde vor sich ausbreiten das zu beginnende Geflecht, sie überlegen miteinander, so wie die Frau die vor sich hinlegt die Flechterei. sie, die Angehörigen aus dem Geschlechte der verwandten Aeltesten, sie die Fürsten, die da zusammengebunden sind wie ein Bündel von Stäben.

Sie geben den Befehl aus an die Elfenbeine, die jung lebenden (Kinder), sie fordern sie auf $z u$ besteigen den Fuss des Berges, des langen, zu erklimmen die Spitze der Felsen, der hohen, um einzusammeln Früchte mit hunderten von Namen und Bezeichnungen, die mit Fruchtfleisch umschlossenen Früchte Katapi, die da aussprossen am Orte früher gebauter aber später wieder verlassener und verfallener Dörfer, diesen Auftrag geben die Leute vom Orte Liang Angkar Bantilong Njaring, saftige Früchte sollen sie suchen, Früchte Kenjem Sarajong Lambang deren Kerne von Fett triefen, Früchte Embak und 
Katelo andau, katelo alem djaton aton hakanan bari,n behas, parei njangen tingang.

Ie, ewen hakarangka rawei, manggau pahatewang lewu idje bagare dohong korik tau manarusan langit, pulang ringkang-ringik idje hiket pandai pametas hawon.

Basa biti,e idje tau mangkaluma apui akan itah.

Ie, belahe murik manarikan sungei saka manggau oloh idje kalote ganggurana ara,e, urike batang danum are idje habambai, sama tunis manalingau buang.

Ijoi, koan rawei, amon aton biti,e, dia njarantengkan riwut lingon itah, mambuang tambon repang garantong, isen njaribantus manjandong repang bangkang balanga tingang, hapan mupah biti,e, lalau kangasi itah lewu Batu Nindan Tarong.
Früchte Puak, sie sammeln Paken Tungkoi, sie sollen suchen Früchte mit hunderten von Namen und Bezeichnungen als Speise für die Bewohner des Dorfes Batu Nindan Tarong.

Schon drei Tage waren verflossen und drei Nächte verstrichen und noch nicht hatten sie zu sich genommen gekochten Reis von den Reiskörnern Njangen Tingang. 183

Und sie kommen wieder zusammen und sie beratschlagen miteinander wie sie suchen könnten die Buchtung des Flusses, den Ort des kleinen Dolches der schweifen kann durch die Himmel, das Dorf des kurzen Griffes der hinaufsteigt durch die Wolken.

Denn nur er ist es, der für uns holen kann das Feuer, der für uns wieder beleben kann die Flamme.

Und einige fahren hinauf die Flüsse, reisen hinauf die Bäche um zu suchen nach dem Manne der so bezeichnet wird, der diesen Namen trägt, sie fahren hinauf die Flüsse, die zahlreich nebeneinanderliegenden, aber überall herrscht Stille, überall ist es einsam. Ja, spricht ihr Wort, wenn wir ihn finden den Mann, nicht werden wir hören auf das Wort unseres Herzens, wir werden leer machen die Tambonreihen (Ketten) unserer Gong, nichts mehr werden wir geben um das Verlangen unseres Inneren, fortgeben werden wir die Reihen der gerundeten Balanga Tingang (männliche, heilige Töpfe), wir werden sie weggeben um ihn in unseren Dienst zu nehmen, denn zu gross sind unser Leid und Not im 
Ie, belahe urik batang danum Sangkalila Bulau, Nandjak Gohong Hintan Kananteng Tahil, nduan udju tandjong pandjang, dinon hanja luwok ambo, urik manarikan sembang datah bukit Sinta Kasambujan, rantang-karantangan lingo,n ewen, laka sondau bua asem.

Terai, koa,n rawei,e, gandang halalian buli itah toh, mimbit bua toh, amon liwat italı gandang halalian buli, halalian lewu Batu Nindang Tarong, dia balang ewen kanih djalan matei.

Ie, ewen palus gandang halalian buli, halalian lewu Batu Nindan Tarong, mimbit bua asem hai, nipe-nipeng pasok panangkiling $\mathrm{Njaring}$.

Hindai djadi sembang parong,e: apang bara apang, mama bara mama! koan riwut rawei djalahan garing tabela belom, rimpon halalumba rata belom, belai,e kuman bua

\section{Dorfe Batu Nindan Tarong.}

Und einige von ihnen fahren hinauf den Fluss Sangkalila Bulau, Nandjak Gohong Hintan Kananteng Tahil, sie reisen hinauf sieben lange Flussbiegungen, ${ }^{184}$ sie fahren aufwärts acht ausgedehnte Buchtungen, sie fahren flussaufwärts, sie reisen hinauf bis sie ankamen bei den Stufen die sie zum Berge Sinta Kasambujan führen und sie besteigen den Berg Sinta Kasambujan und ihr Herz wird erfreut weil sie eine Asemfrucht finden.

Schluss nun, sprechen sie zueinander, kehren wir nun wieder zurück wie der Schall der Trommel und nehmen wir diese Frucht mit uns, denn kehren wir zu spät zurück, kommen wir zu lange nicht wieder an im Dorfe Batu Nindan Tarong, dann wird es nicht mehr abzuwenden sein, dass sie dont drüben langsam vor Hunger umkommen.

Und sogleich kehren sie wieder um wie der Schall der Trommel umkehrt und verstummt und sie treten den Rückweg an nach dem Dorfe Batu Nindan Tarong, sie tragen mit sich die Asemfrucht, die grosse, sie tragen sie in einem Korb der einem Njaring gleicht (d.h. in einem geflochtenen und rotgefärbten Korb. Der Njaring hat rote Kopf- und Körperhaare und deshalb wird der rote Korb mit einem Njaring verglichen).

Noch nicht waren sie angekommen bei ihrem Hause und schon hörten sie rufen: Väter, o ünsere Väter, Onkel, o unsere Onkel, so sprach das rauschende Wort der Angehörigen der Elfenbeine, der jung lebenden, denn sie 
asem.

Bua narai djetoh, mama apang? kila-kilau bua asem, bua narai? koan idje, bua narai? koan due, bua narai? koan telo, halalomba riwut bahing,e, lalau manis, masemasem baka belom belai.

Singi-singi riwut lingo kadjalahan rangkang bahendjong: lalau isek keton, tapadjudjudjuan tisoi, olih halalomba hajak belom belai keton asem lalomba djetoh, anak idje baka belom belai bagi bilak hapus lewu Batı Nindan Tarong.

Dohong ewen tinai manolak hiringe, belahe buno badjamban laut, belahe dohong tandjan djalajan, habahata bua baratus gangguranan ara,e; awang buno badjamban laut bahata bua mangga, bua hampalam, bua bakan radja hakarangan penjang,e, bua tahanan njelo.

Dohong awang tandjan djalajan habahata bua embak, bua puak, bua mawo-marioh, bua manamon katiau, bua mang- verlangten zu essen und zu leben, sie begehrten zu verzehren die Asemfrucht.

Was eine Frucht ist diese hier? o unsere Onkel, o unsere Väter, diese Frucht hier die da aussieht wie eine Asemfrucht, was für eine Frucht ist es wohl? so fragte einer, was für eine Frucht kann es sein? so fragte ein Zweiter, was für eine Frucht ist es? so fragte ein Dritter und durcheinander erschallten ihre Stimmen und die einen sagten: sie ist $z \mathfrak{u}$ süss, und die andern sprachen: sie ist säuerlich, und sie alle begehrten zu essen von ihr.

Zürnend und böse wehet auf das Innere der Angehörigen der Alten, der Greise: zu viel fragt ihr auf einmal, $\mathrm{zu}$ heftig ist euer zwängendes Wort, ihr alle werdet essen und werdet leben von dieser Asemfrucht, der grossen, und sie wurde verteilt unter alle Kinder die von ihr zu essen begehrten im ganzen Dorfe Batu Nindan Tarong.

Und wieder senden die Dolche aus ihre Schärfe (d.h. wieder ziehen Männer aus um den Dohong Korik zu suchen), einige der Lanzen (Männer) reisen über das Meer, einige der Dolche fahren flussaufwärts und sie nehmen als Wegzehrung mit Früchte mit hunderten von Namen und Bezeichnungen, Manggafrüchte, Hampalamfrüchte, die Früchte des Bakan Radja Hakarangan Penjang, Früchte Tahanan Njelo.

Und die Dolche, die flussaufwärts fuhren, nahmen als Wegzehrung mit sich Embakfrüchte, Puakfrüchte, Manamon Katiaufrüchte, Mawo-Marioh- 
kahai rahong, bua bendang bulau; nduan katelo andau katelo alem, usang,e gandang kalalian buli.

Misek apui hila tumbang danum, apui oloh uras kabalepan, nenga oloh bawoi dujong hadjaran tandang.

Awang dumah dohong tandjan djalajan bapander pandjang basansana ambo: isekku apui oloh, uras apui oloh kabalepan, nenga oloh aso bangka, pusa tion, peteng hambutut.

Dia kanduenan itah kea, koa,n riwut rawei oloh lewu Batu Nindan Tarong.

Ruta riwut kalingo oloh lewu Batu Nindan Tarong, pusang liang djarah karendem,e panganak rundong Liang Angkar Bantilong Njaring.

Ie, oloh lewu Batu Nindan Tarong batawu-tawur, mangandang renteng tingang, manitih luhing pating bungai, antang babalai pukong tadjahan, ewen manadjah antang udju bulau patindjun antang, manadjahan udju tumbang batang danum, ie hemben horan balitan Tanta Olang Bulau, Hijang Tantu Enjet früchte, Mangkahai Rahongfrüchte, Bendang Bulaufrüchte und nach drei Tagen und nach drei Nächten da waren sie schon längst wieder zurückgekehrt, so wie zurückkehrt der Schall der Trommel und dann verstummt.

Und sie erkundigten sich nach Feuer in der Richtung der Mündung des Flusses, aber gänzlich ausgelöscht war das Feuer der Menschen, aber sie gaben ihnen Schweine mit hervorstehenden Hauern.

Und als auch zurückgekehrt waren die Dolche die flussaufwärts reisten, da sprachen sie lange, da erzählten sie ausführlich: wir haben nachgefragt nach dem Feuer der Leute, aber ausgelöscht war alles Feuer der Menschen und sie haben uns gegeben Hunde und Katzen, zusammen mit den Bändern.

Nicht wissen wir was wir mit ihnen anfangen sollen, spricht die rauschende Rede der Leute aus dem Dorfe Batu Nindan Tarong.

Betrübt ist das wehende Innere der Leute des Dorfes Batu Nindan Tarong, traurig ist der steinerne Teller des Herzens der Kinder des Ortes Liang Angkar Bantilong Njaring.

Und so taten sie nun, die Leute aus dem Dorfe Batu Nindan Tarong, sie streuten aus den Reis und sie schlugen die Trommeln, sie, die Schwanzfedern der Tingang, sie schlugen auf die kleinen Trommeln, sie, die $Z_{\text {weiglein }}$ des Nashornvogels (d.h. die Männer die Nashornvogelfedern als Kopfschmuck tragen, das sind die Aeltesten oder die Krieger), es galt dem Falken, der seinen Wohnplatz hatte im Gehölz 
Penjang, manawur manambawa antang.

Salenga bahing kakarungut hajak tari-tarian padjandjuri batang danum Maninting Ambon, panantekei bara lewu Bukit Ampah Bulau, rundong Kereng Sahep Rabia, mangena tumbang batang danum Sangkalila Bulau.

Hajak tundjong lahap rawing kilau mapau bulan lembut, njariangkat rarajo,n djela, tingkah ngandaju bintang tumbo, pambudjang lingo saratus djahawen pulu.

Hetoh eka oloh idje bagare dohong korik, idje tau manarusan langit, idje tau balaku apui akan itah.

Palus randan ewen hakarangka rawei, murik batang danum Sangkalila Bulau, manandjak gohong Hintan Kananteng Tahil, sembang eka pahatewang lewu,n Sangumang rete-retei, misek eka dohong korik kindjap manarusan langit, uras ewen dia handong hakatawan, ie sembang eka des Tadjahan, sie riefen herbei der Falken, sieben, die sich aufhielten im heiligen Haine der Falken, sie baten sie zu kommen von sieben Mündungen der Flüsse, so taten sie damals in der früheren Zeit, sie, nämlich er der Tanta Olang Bulau, der Hijang Tantu Enjet Penjang, so streute er den Reis aus und rief den Falken.

Plötzlich erschallt der Gesang und singend und schwebend kommt er geflogen vom Flusse Maninting Ambon und er tritt hervor aus dem Dorfe Bukit Ampah Bulau, aus dem Orte Kereng Sahep Rabia und er schreitet heran von der Mündung des Flusses Sangkalila Bulau (von allen diesen Flüssen kommen nun die aufgerufenen Falken geflogen).

Und es erhebt sich das Jauchzen der Krokodile (Männer), so wie sich weitet der aufsteigende Mond, und es steigt auf das Getöse der Zungen, so wie aufsteigt das Gestirn, das sich ausbreitende, so wie das Innere der Jungfrauen, der hundert und sechzig.

Hier ist nun der Ort des Mannes der sich nennt Kleiner Dolch, der herumschweifen kann an den Himmeln, und der für uns holen kann das Feuer.

Und sogleich erdenken sie eine Rede und ersinnen einen Rat, sie fahren hinauf den Fluss Sangkalila Bulau, sie reisen aufwärts auf dem Strome Hintan Kananteng Tahil (der andere Name für Sangkalila Bulau), sie kommen an bei der Buchtung des Flusses, an der nebeneinander gebaut sich befinden die Dörfer des Sangumang, ${ }^{185}$ sie erkundigen sich nach dem 
radja Tonggal Sangumang, ewen misek radja Tonggal Sangumang, koa,n rawei: en aton apui,m.

Gatang kumin tingang, dia Lunok ngarangka, nundjong hirum burong, dia baras ngalimbang,e, balita,n radja Tonggal, Mama Turon Bulau, Riak Mihing Tempon Rengar Garantong.

Ikei lewu bukit Sinta haru kabalepan.

En, koa,n riwut rawei ewen: huang kueh ikei aton nahingan eka apui?

Koa,n rawei radja Tonggal: aton apui intu Djangkarang Matanandau, aton kea huang Njarang Tato Apui intu Gandang Batu.

Tapi amon dia antang itah dia manamuei mananturong,e, kueh tau dinon!

Sana nahingan ewen riwut rawei radja Tonggal Sangumang, palus gandang ewen halalian buli lewu Batu Nindan Tarong, djandjaroman akan Tanta Olang Bulau, Hijang Tantu Enjet Penjang,
Wohnort des Kleinen Dolches der oft durchschweift die Himmel, aber niemand weiss es, niemand kann es ihnen sagen, sie gelangen $z \mathfrak{u}$ dem Orte des Radja Tonggal Sangumang und sie fragen den Radja Tonggal Sangumang: Hast du noch Feuer?

Er erhebt ein Lächeln wie die Nashornvögel, nicht lange besinnt er sich auf die Antwort, es steigt auf ein Schmunzeln wie das der Vögel, nicht lange denkt er nach, er der radja Tonggal, Mama Turon Bulau, Riak Mihing Tempon Rengar Garantong.

Uns hier im Dorfe des Berges Sinta ist soeben erst ausgelöscht das Feuer. Und weiter fragt ihr wehendes Wort: bei wem können wir vernehmen wo sich noch Feuer befindet?

Es spricht die Stimme des Radja Tonggal: Feuer befindet sich noch bei Djangkarang Matanandau (Djangkarang, der Aelteste in den Dörfern der Sonne), es befindet sich auch im Orte des Njarang Tato Apui in Gandang Batu.

Aber wenn nicht unser Falke (gemeint ist hier der Antang Ganan Tadjahan des Dorfes auf dem Berge Sinta) auszieht, wenn er nicht dorthin geht, wie sollte es dann zu erhalten sein!

Und nachdem sie gehört hatten das Wort der Rede des Aeltesten Tonggal Sangumang, machten sie sich sogleich auf und sie kehrten wieder zurück in das Dorf Batu Nindan Tarong, so wie der Schall der Trommel wieder umkehrt und sie erzählten Tanta Olang 
rantang-karantangan lingo ewen rundong Liang Angkar Bantilong Njaring.

Randan ewen hakarangka rawei: eweh itah lewu Batu Nindan Tarong idje menteng, barigas tambange manamuei balaku apui?

Terai, koan belahe, djaton beken bara tupai pandjang.

Lungak-lingok tupai pandjang selawi manahingan rawei radja hakanduang, njalanean tisoi kanarohan basakati.

Ie, tingang manolak lunok tupai pandjang, tambon basangka baras, tolak bara lewu Batu Nindan Tarong, rundong Liang Angkar Bantilong Njaring mimbit hambutut antang manamuei mananturong Djankarang Matanandau; sembang tasik, tasik lungkah,e hadjadjakan ampah mandjur, haratean lampok,e manjut, natek,e haratean bukit gantong, manetei purok ambo.

Ie, kaudju andau, kaudju alem sembang Djangkarang Lumpong Matanandau ma-
Bulau und sie berichteten dem Hijang Tantu Enjet Penjang was ihnen widerfahren war und es freuten sich in ihrem Herzen die Leute des Ortes Liang Angkar Bantilong Njaring.

Und sie ersinnen eine Rede und sie erdenken ein Sprichwort und sie fragen (nämlich die Aeltesten): wer von uns Bewohnern des Dorfes Batu Nindang Tarong ist tapfer und mutig, wer von uns hat starke, gesunde Beine um für uns zu holen das Feuer? Beendigt euere Rede, sprachen einige, niemand anders ist dazu imstande als das Eichhorn, das lange.

Stark und heftig bewegt seinen Schwanz hin und her das Eichhorn, das lange, als es hörte die Stimme der verzwillingten (verwandten) Könige, als es vernahm das Wort der doppelten Fürsten (d.h. der Dorfältesten von Batu Nindan Tarong).

Sie, die Nashornvögel, senden aus den Lunok (Mann), das lange Eichhorn, sie, die Wasserschlangen, lassen wegziehen den Sand (stossen ab von den Sandbänken) und es reist weg vom Dorfe Batu Nindan Tarong, vom Orte Liang Angkar Bantilong Njaring, und es nimnt mit sich als Begleiter den Antang um mit ihm zu reisen, mit ihm hinzuziehen zu Djangkarang Matanandau; sie kommen an beim Meere, sie durchschreiten die See, sie schreiten, sie gehen, sie steigen auf die Berge, die hohen, sie erklimmen die Spitzen der Felsen, der hohen.

Schon waren sie sieben Tage, bereits waren sie sieben Nächte gereist, als sie ankamen bei Djangkarang Lum- 
nuntun apui letu-letus sinde, tuneng njababeneng tandok,e, tupai pandjang hindai djari sembang keme-keme lasut manganap biti,e, tokep segila nanturong tupai pandjang selawi habarika,e hamputut garing 186 ndjidjit imbit,e hadari pahandar kaju, kaju bakeho.

Dia balandong tahi sembang ie lewu Batu Nindan Tarong, rundong Liang Angkar Bantilong Njaring, rantang-karantangan lingo,e oloh lewu Batu Nindan Tarong, rindangpahatewang karendem,e ewen rundong Liang Angkar Bantilong Njaring, sama tingang hakampeleng renteng,e, haramaung hapampungan lingkat,e manambang tupai pandjang.

Manuntun apui ohos kaju, kaju bakeho, buah petak sintel, badjurake, kadjalahan tingang awang manangkenja apui marunggos renteng tingange.

Hau, koa,n rawei oloh lewu Batu Nindan Tarong, itah manduan radja Tonggal pong Matanandau und sie sehen das Feuer, das unaufhörlich brausende und sie erblicken es mit ihren Augen, noch war das lange Eichhorn nicht in seine Nähe gekommen, da spürt es schon wie die Wärme seinen Körper ergreift, noch war es nicht $\mathrm{zu}$ ihm hingetreten, da packt die Hitze schon an den Strick von feingestampftem Baumbast, von Elfenbein, es zieht ihn wieder zurück (gemeint ist der Schwanz), es rennt mit ihm weg, es stösst gegen die Bäume und das Holz wird erfasst vom Feuer und brennt nieder.

Nicht lange Zeit geht vorbei bis es auf seinem Rückweg wieder ankommt im Dorfe Batu Nindan Tarong, im Orte Liang Angkar Bantilong Njaring, erfreut ist das Herz der Leute des Dorfes Batu Nindan Tarong, es jubelt die Buchtung des Innern (das Herz) derer aus dem Orte Liang Angkar Bantilong Njaring und es versammeln die Nashornvögel ihre Schwanzfedern, es kommen zusammen die Tiger mit ihren Querstreifen und sie erwarten und empfangen das Eichhorn, das lange.

Sie sehen wie das Feuer, das an das Holz gestrichen wird, das $\mathrm{Holz}$ verbrennt, wie das Feuer, das auf die Erde fällt, die Erde austrocknet, sie, die Angehörigen der Nashornvögel, die mit freundlichen Worten das Feuer ansprechen, sie sehen wie ihre Schwanzfedern kahl geworden sind durch die Hitze des Feuers.

Han! riefen aus die Leute aus dem Dorfe Batu Nindan Tarong, lasset uns herbeiholen den Aeltesten Tonggal 
Sangumang, ie antang ewen manamuei, manangkadje andau, 187 mangadja manalandjat pandang kalaman, mananturong lewu,n radja Tonggal Sangumang.

Ewen mánduan Sangumang tingang.

Manolak lunok, mananturong lewu Batu Nindan Tarong, rundong Liang Angkar Bantilong Njaring, palus oloh djandjaroman akan radja Tonggal Sangumang.

Ijoi, koa,n rawei radja Tonggal Sangumang, njaki 188 keton hapan darah manok darong tingang, hapan darah bawoi samben, limbah te mali 189 kudju andau, kudju alem, ela helo mahapa,e.

Terai, koa,n rawei radja Hadji, dia balang itah matei kabaduran manunggo kaudju andau, kaudju alem, rapak,e hamputut rawing, imbit,e manantang parong pahawang, mulang nindan siro matendo.

Radja Tonggal Sangumang palus gandang halalian buli.
Sangumang damit er reinige die Wärme, die viel zu grosse, damit er wieder in Ordnung bringe die Hitze, die viel zu starke, und es zog aus ihr Falke (Ganan Tadjahan) und er reiste hin zum Dorfe des Aeltesten Tonggal Sangumang.

Sie machen sich auf den Weg und sie holen herbei den Sangumang, den Nashornvogel (den Mann).

Es macht sich auf den Weg der Lunok (der Mann), er reist weg und begibt sich zum Dorfe Batu Nindan Tarong, zum Orte Liang Angkar Bantilong Njaring und alsogleich erzählen ihm die Leute, ihm dem Aeltesten Tonggal Sangumang, was geschehen ist.

Ja, spricht die Rede des Aeltesten Tonggal Sangumang, bestreicht auf rituelle Weise das Feuer mit Blut des Huhnes, des Huhnes Tingang und mit Blut vom Schweine mit dem Halsband 190 und darnach sei es (das Feuer) euch verboten während sieben Tagen und sieben Nächten, nicht gebraucht es vor dieser Zeit.

Das ist unmöglich, sprach die Rede des Aeltesten Hadji, es wird nicht abzuwenden sein, dass wir sterben müssen vor Hunger, wenn wir noch sieben Tage und sieben Nächte warten müssen, er reisst ab den Strick von feingestampftem Baumbast vom Körper des Krokodiles (Mann; hier ist das Eichhorn gemeint, das Mann genannt wird), er steigt mit ihm hinauf in das Haus in dem er wohnt, er trägt ihn hinein in seine Wohnung. Und sogleich kehrt der Aelteste Tonggal Sangumang wieder heimwärts und 
Oloh lewu Batu Nindan Tarong manjaki apui hapan darah manok darong tingang, manandjuri darah bawoi dujong, manantekei pangirih hadjaran tandang.

Mali ewen nduan kaudju andau, kaudju alem, magon apui paham lasut,e, djakah ewen hanggulan garing, hamputut sihong akan petak, dia tau munus, dia tau belep sampai katika toh.

Dia ombet bulan katahi,e, salenga dumah peres kasamparan belom, kadjarian asep apui ain radja Hadji, mangadjan lewu hai ampin kanjamben lombah, uras haban oloh are njamah tunis mangalingau buang pahatewang lewu.

Matei indang buno bilin banama! dia balang pampatei lomat itah lewu Batu Nindan Tarong, rundong Liang Angkar Bantilong Njaring, njamah sembang tarong,e mannjembang radja Tonggal Sa- er kehrt zurück wie der Schall der Trommel.

Die Leute des Dorfes Batı Nindan Tarong bestreichen das Feuer mit dem Blut des Huhnes, des Hulnnes Tingang, sie giessen über ihm aus das Blut des Schweines mit dem Halsband, sie spritzen über das Feuer das stellvertretende (Blut) von dem Tier mit den hervorstehenden Hauern.

Sie betrachten es als pali (als verboten um gebraucht zu werden) während sieben Tagen und sieben Nächten, immer noch war das Feuer sehr warm, sie werfen einen Feuerbrand, sie schleudern einen brennenden Strick von feingestampftem Baumbast auf die Erde, aber nicht kann es mehr vermindern, nicht kann es mehr auslöschen (das Feuer) bis zu dieser Zeit.

Noch war nicht die Zeit eines Monats verstrichen, da traten plötzlich auf Krankheiten und Seuchen, die Leben vernichtenden, sie waren die Folge des Rauches vom Feuer des Aeltesten Hadji (der das Feuer nicht bestrichen und die Pali nicht innegehalten hatte), sie umschliesst das grosse Dorf das ausgebreitet liegt wie ein breites Halsband, sie alle werden krank, sie, die Leute, die vielen und still wird es und einsam an der Buchtung des Flusses, an der das Dorf liegt.

Sterbe um gespeert zu werden als Kaufpreis für das grosse Boot! (ein Fluch) nicht wird mehr abzuwenden sein, dass wir gänzlich sterben und vernichtet werden, wir, die Bewohner des Dorfes Batu Nindan Tarong, des Ortes Liang Angkar Bantilong Nja- 
ngumang.

Matei indang buno bilin banama! koa,n radja Tonggal Sangumang, amon kalotoh panalatai,e kilau bulan manalatai dare, amon pandang katon pamalempange tingkah pahawang malekut tabuhi, dia balang ewen pampatei lomat.

Ie, nganda-ngandange kumpang dohong basaloh djadi lasang, nganda-ngandange pahalingai, riu-riup antang manamuei sembang lewu Batu Nindan Tarong, rundong Liang Angkar Bantilong Njaring.

Ijoi, koa,n riwut rawei radja Tonggal Sangumang, Mama Turon Bulau, Njaring Emban Riak Mihing, Tempon Linggar Garantong, lehan keton uras ngantong peres lunok idje kangantong patinge, manunjang sampar baringen idje kamahulei bumbong,e.

Lalau ringkong tingang, sama ngahagap tolang,e, mina aseng keton tapadjurang-djuri manjapenda hinting bawak lamiang, kilen ampi,e, dia sala ring, und diese Worte kamen an und sie gelangen hin bis zum Aeltesten Tonggal Sangumang.

Sterbe um gespeert $z \mathfrak{u}$ werden als Kaufpreis für das grosse Boot! so ruft fluchend aus der Aelteste Tonggal Sangumang, wenn es nun so steht mit dieser Sache, wie die Frauen vor sich ausbreiten das zu beginnende Geflecht, wenn es so ist in dieser Angelegenheit, wie die Frauen vor sich hinlegen die Flechtarbeit, dann ist es nicht mehr abzuwenden dass sie vernichtet werden vom ausrottenden Tod.

Und nun geschieht es, dass er an die Scheide seines Dolches klopft und dass sie sich verwandelt in ein Boot (das geschieht sehr oft wenn die Ahnen auf die Reise gehen) und er klopft an die Ränder des Bootes und es erhebt sich in die Höhe und es schwebt der Antang (der Mann) und er begibt sich hin zum Dorfe Batu Nindan Tarong, zum Ort Liang Angkar Bantilong Njaring.

Ja, spricht das wehende Wort des Aeltesten Tonggal Sangumang, Mama Turon Bulau, Njaring Emban Riak Mihing, Tempon Linggar Garantong, was ist nun mit euch geschehen, ihr alle habt an euch aufgehängt die Krankheiten wie ein Lunok aufhängt seine $Z_{\text {weiglein, }}$ ihr alle wieget die Seuchen wie ein Waringin wieget seine zarten Herzblätter.

$\mathrm{Zu}$ sehr seid ihr abgemagert, ihr Nashornvögel, euch allen fühlt man die Knochen an (sie haben kein Fleisch mehr), der Atem, den ihr noch besitzt, schwankt hin und her unter der Trep- 
panalatai kilau bulan sala manalatai dare.

Baja handong katawan keton tupai pandjang selawi, dia keton handong katawan aku dohong korik idje kindjap manarusan langit, pulang ringkang-ringik idje hiket mametas hawon.

Ijoi, koa,n rawei oloh lewu Batu Nindan Tarong, kai! idje dohong korik panarusan langit bitim radja Tonggal Sangumang!

Has, kilen ampi,n panalatai,e akan ikei lewu Batu Nindan Tarong, amon kalotoh pamalempange, dia balang ikei pampatei lomat.

Ijoi, koan riwut rawei radja Tonggal Sangumang, dia ien ampi,n panalatai,e, mangat keton nundjong keleh, taragatang mangat. pe, die da gebildet wird von Achatsteinen (gemeint sind die Zähne, oder auch die Kette die von übereinanderliegenden Achaten gebildet wird und die man auf der Brust trägt), wie steht es nun? sollte nicht falsch sein euere Angelegenheit, so wie die Frau unrichtig überdacht hat ihre Flechterei. Bis jetzt ist euch nur bekannt, wisst ihr nur das Eichhorn, das langschwänzige (das das Feuer geholt hat; diese Kenntnis ist sehr wichtig weil man jedesmal, wenn man neues Feuer holt, wissen muss, dass es das erste Mal durch das Eichhorn geschah), aber nicht wisst ihr, nicht ist euch bekannt, dass ich der Kleine Dolch bin der umherschweift durch die Himmel, dass ich der kurze Griff bin, der oft aufsteigt durch die Wolken.

Ja, spricht das Wort der Leute aus dem Dorfe Batu Nindan Tarong, ist es wirklich so! der Kleine Dolch welcher umherschweift durch die Himmel, das bist du selbst, du, der Aelteste Tonggal Sangumang!

Wohlan nun, wie steht es nun mit unserer Sache aus dem Dorfe Batu Nindan Tarong, denn wenn es so steht mit unserer Angelegenheit, dann wird es nicht mehr abzuwenden sein, dass wir dahingerafft werden vom ausrottenden Tode.

Ja, spricht das wehende Wort des Aeltesten Tonggal Sangumang, nicht so schlimm steht es mit euerer Angelegenheit, leicht könnt ihr wieder erheben die Gesundheit, mühelos könnt ihr wiederum aufsteigen lassen das Wohlbefinden (d.h. leicht könnt ihr 
Keton mampatei manok darong tingang nduan sintong lime, idje manok akan radja idje mahaga Gandang Batu, bau,e Gandang Batu, pontong,e eka Njarang Tato Apui, pontong,e eka talaga njalong kaharingan belom. wieder gesund werden, wenn ihr alle Handlungen kennt die vollzogen werden müssen).

Ihr schlachtet Hühner, Hühner Tingang, und ihr nehmt fünf zusammen, ein Huhn ist bestimmt für den Aeltesten welcher bewacht den Gandang Batu auf der vorderen Seite des Gandang Batu, die eine Hälfte legt ihr nieder vor dem Platz des Njarang Tato Apui, die andere Hälfte legt ihr nieder bei dem Teiche mit dem Wasser des Lebens, des belebenden (das Lebenswasser, das neues Leben verleiht).

Idje manok akan upah aku tolang rumpang, akan djawi,n uhatku leso antang manamuei mananturong Njarang Tato Apui.

Idje manok akan bulan njawak kabangkange, tunggo,n kaju,n karuhei tatau rakuren lewu Batu Nindan Tarong.

Idje manok akan upah tolang rumpang Darahen radjan antang, akan upah ikei ndue hantantiring antang manamuei.

Idje manok akan Gana,n Apui 191 idje mangampehe, idje mawi, idje mangeho, asep,e balasut badarem.

Njadia keton rangkan pangi- Und in genügender Zahl macht ihr be-
Und ein Huhn ist bestimmit als Entschädigung für meine ermüdeten Knochen, als Lohn für meine erschlafften Knochen, für mich den Falken (Kleiner Dolch), welcher reiste und sich begab zum Njarang Tato Apui. Ein Huhn ist bestimmt für die Monde von ungestümer Schönheit, die Wächterinnen bei dem Holze der Karuhei des Reichtums, das sich befindet hinter dem Dorfe Batu Nindan Tarong (nach dem Brande bittet man sie um neue Karuhei des Reichtums).

Ein Huhn ist bestimmt als Entschädigung für die ermüdeten Knochen des Darahen, des Königs der Antang, als Lohn für uns zwei rasch reisende Falken.

Und ein Huhn ist bestimmt für die Gana des Feuers, die da Schmerzen verursacht, die heimtückisch den Menschen überfallt, die Häuser abbrennt und für ihren Rauch der Hitze und Fieber hervorruft. 
nan manok darong tingang sintong lime, takupat mamputing bulau, bari bowor tisik tambon, apam kembong riwut, lipat djela tandang, njiringnjababiring kilat, kanihi bambang dohong, behas tambak radja.

Dia ombet idje kahaliman pinang, kueh dinon due kapahasen manjang, eleh totok djari rangkan panginan, ie radja Tonggal Sangumang hemben horan mampahiau suling bulau sangkalemo, tahuntong bulau kambang ambon, mambawa Darahen radjan antang, ie Darahen dumah mananturong radja Tonggal Sangumang horan. reit die Dinge, die Speisen (die Opfer), nämlich Hühner, die Hühner Tingang fünf zusammen, den mit Blättern umwickelten Reis mit goldenen Ecken, den ausgesäten Reis, die Schuppen der Wasserschlangen, die Kuchen, die durch den Wind aufgeschwellten, die Lipat, die Zungen der Tiger, gekochten Reis der in Dohongbambusköchern zubereitet wurde und den Reis, den königlich aufgehöhten. 192

Noch nicht ist verstrichen die Zeit die nötig ist um gelb zu färben den Speichel mit dem Safte der Pinang (beim Sirihkauen), noch nicht ist vorbeigegangen die Zeit, die man braucht um zu färben den Speichel mit der Betelnuss, schon sind zubereitet die Dinge, die Speisen, und es geschah dass der Aelteste Tonggal Sangumang damals in der längst vergangenen Zeit auf der Flöte von goldenem Sangkalemo blies, auf der Pfeife der goldenen Blumen des Taues um herbeizurufen den Darahen, den König der Antang und es kam der Darahen und er begab sich zum Aeltesten Tonggal Sangumang, damals in den längst entschwindenen Zeiten.

\section{c. Dic Bitte um neues Feuer}

Hier bricht nun der Text in der Basa Sangiang ab und in gewöhnlichem Ngadju fährt der Priester erklärend und allen verständlich fort:

Toh, tahiu djalanan Sangumang ewen ndue Antang Darahen, manalih Njarang Tato Apui :

Maka djalanan ewen due, helo manalih Njarang Tato Apui
Und nun, was die Reise betrifft des Sangumang und des Antang Darahen, die sich begeben $z \mathfrak{u}$ Njarang Tato Apui :

Aber auf ihrer Reise gehen die Beiden, bevor sie sich zu Njarang Tato Apui 
palus balaku danum kaharingan belom, imili,e hapan panginan.

Limbah te ewen malian gana,n apui idje mawi, malian akan Njarang Tato Apui te kea.

Amon djadi, bara hete ewen ndue hadurut atawa masoh manggoang bulan njawak kabangkange, tunggon kaju karuhei tatau intu likut lewu Batu Nindan Tarong, intu hete ewen ndue manenga panginan ttg. manambang kaju,n karuhei tatau bara kaju idje kadjaria,n pondok apui, ewen ndue manambang,e akan oloh lewu Batu Nindan Tarong.

Bara hete ewen ndue buli, manenga karuhei tatau, manenga apui taheta akan oloh lewu Batu Nindan Tarong, ewen manjaki,e bua-buah ttg. ewen lewu uras keleh kahaba,e.

Tinai apui ai,n radja Hadji idje balasut, djete balihi agah,e awi Sangumang ewen ndue Darahen, awi te apui ai,n radja Hadji te induan ingkes indu hanggulan garing, hamputut sihong, Sangumang manantujak njalong kaharingan belom, awi te apui te begeben, und sie holen das Wasser des Lebens, das belebende, und sie kaufen es mit den Speisen (Opfer) die sie mitgebracht haben.

Und erst darnach geben sie zurück die Gana des Feuers, die heimtückisch überfallende, sie geben sie wieder zurück dem Njarang Tato Apui.

Wenn das geschehen ist, dann lassen sie sich herabfallen (durch die Wolken und in ihren Fahrzeugen) oder sie reisen flussabwärts und begeben sich zu den Monden von ungestümer Schönheit, zu den Wächterinnen bei dem Holze der Karuhei des Reichtums auf der Rückseite des Dorfes Batu Nindan Tarong und dort geben die Beiden Speisen (Opfer) ab und sie nehmen in Enmpfang die Karuhei des Reichtums, die ihren Ursprung haben in dem Fetuerbrand (siehe oben), die Beiden nehmen sie in Empfang für die Leute des Dorfes Batu Nindan Tarong.

Und von dort kehren die Beiden wieder zurück und sie übergeben die Karuhei des Reichtums, sie überreichen das Feuer, das neue, den Leuten aus dem Dorf Batu Nindan Tarong, sie bestreichen sie sorgfältig mit Blut und alle Bewohner des Dorfes genesen wieder von ihrer Krankheit.

Ferner, das Feuer des Aeltesten Hadji welches sehr warm war, das hatten sie zurückgebracht und zurückgelassen, sie beiden Sangumang und Darahen, und deshalb nehmen sie nun das neue Feuer des Aeltesten Hadji und sie bewahren es auf als elfenbeinerner Hanggulan (als ein Stück $\mathrm{Holz}$ das man abends glimmend unter die Asche 
dia tau belep, hamputut dia tau una.

Toh djadi sarita,n tukang tawur manjarita akan Antang Darahen, sarita,e idje helo te.

Toh koa,n tukang tawur tinai : awi te buku,e ikei kalunen idje tau mahapan ikau Antang Darahen, awi djaman horan ikau puna ihapan kea.

Awi te, toh ikau manamuei mimbit kare panginan idje aton inatap intu eka bakeho, panginan intu antjak djete hapan keton manambang karuhei tatau akan ewen idje bakeho huma,e, toh tinai panginan idje huang pasah, djete akan ganan apui idje mawi ttg. hapan balaku apui idje akan Sangumang, idje toh akan upah ai,m Antang Darahen, awi te ikau manamuei mangat ikau basarita tumon toh intu lewu Batu Nindan Tarong ttg. malian gana,n apui hajak balaku apui idje bahalap ttg. mimbit kaju,n karuhei tatau akan ewen idje bakeho huma toh mangat ewen legt um am Morgen Feuer zu haben), sie bewahren es auf als elfenbeinerner Hamputut der fortglimmt und an dem man immer wieder Feuer entzünden kann und Sangumang giesst über ihm aus das Wasser des Lebens, das belebende, und deshalb löscht dieses Feuer nicht mehr aus und kann der Hamputut nie verzehrt werden.

$\mathrm{Zu}$ Ende ist nun die Geschichte die der Tukang tawur dem Antang Darahen erzählt hat, die Geschichte von dem was in früheren Zeiten geschehen ist. Und wiederum spricht der Tukang tawur: das ist nun die Ursache, weshalb wir Menschen dich, o Antang Darahen, in unseren Dienst nehmen können, deshalb nämlich, weil du damals in den längst vergangenen Zeiten auch in Dienst genommen wurdest.

Aus diesem Grunde reisest du nun weg und du überbringst alle Speisen (Opfer) die bereit gemacht worden sind auf dem Brandplatz, die Speisen, die sich im flachen Opferkorbe befinden, die gebraucht ihr (angesprochen werden der Antang Darahen und der Antang Ganan Tadjahan) um dafür in Empfang zu nehmen die Karuhei des Reichtums für sie, deren Haus abgebrannt ist, und weiter, die Speisen die sich in der Opferhütte befinden, die überbringt ihr der Gana des Feuers welche heimtiickisch angefallen hat und ihr erbittet dafür das Feuer, das dem Sangumang überreicht wurde, dieses hier (das Huhn das vor dem Priester liegt, es ist das sechste das getötet wurde) dient als Entschädigung für dich, o Antang Darahen, aus diesem 
batuah limbah bakeho bakampur toh awi aton kaju karuhei tatau ttg. apui bahalap, ela mangeho mangampur ewen tinai.
Grunde nun reisest du weg und du überbringst die Geschichte, so wie ich sie dir erzählt habe, den Bewohnern des Dorfes Batu Nindan Tarong und du gibst zurück die Gana des Feuers (die das Haus zerstört hat) und du bittest um gutes Feuer und du bringst mit dir zurück die Hölzer der Karuhei des Reichtums für sie, denen das Haus abgebrannt ist, damit sie wieder glücklich (heilvoll) werden nach dem Brande ihres Hauses, nach dem Eingehülltwerden mit Rauch, weil sie im Besitze sind der Hölzer der Karuhei des Reichtums, weil sie empfangen haben das gute Feuer, sage, dass sie nicht mehr heimtückisch überfallen und in Rauch eingehüllt werden dürfen vom Feuer.

\section{d. Schluss}

Amon hapus auch,e te tukang Nachdem er sein Spruchwort beendet tawur mohon akan eka bakeho, manaburan behas intu hundjun pasah ttg. intu antjak hajak tukang tawur manjair kaju idje buah bakeho manampa hampatong telo atawa udju, amon djadi tampan hampatong ie buli mimbit hampatong te, mandjuloke akan oloh idje bakeho huma,e.

hat, steigt der Tukang tawur zum Brandplatz hinunter und er streut Reis aus über die Opferhütte und über die flachen Opferkörbe und der Tukang tawur schneidet etwas weg von dem verbrannten Holz und macht davon drei oder sieben Schnitzbilder mit menschlichen Gesichtern und wenn er diese Bilder geschnitzt hat, übergibt er sie den Leuten, denen das Haus abgebrannt ist.

Der Tukang tawur setzt sich nun und fährt fort in der Basa Sangiang:

Limbah te tukang tawur mondok handjulo ttg. mimbing mangkok tawur, koa,e:
Nachdem das geschehen ist, setzt sich der Tukang tawur einen Augenblick und er ergreift das Gefäss mit dem 
Dia ombet idje kalahiman pinang, kueh dinon due kapahasen manjang, Antang Darahen djari karamahan dumah bara lewu Batu Nindan Tarong, rundong Liang Angkar Bantilong Njaring, dumah mimbit kaju,n penjang karuhei tatau, dumah mimbit apui idje hasambalut dengan njalong kaharingan belom, hasambalut dengan panjangka tatamba, salatutup, salapandom, hasambalut dengan parapat panamar. 193

Antang Darahen sama manarima upah tolang rumpang, radja Tonggal Sangumang manarima djawi,n uhat leso, sama buli pahatewang lewu, mulang pangkarundong, buli parong mahawang,e, mulang siro matendo,e.

Toh tukang tawur manutup auch,e hapan auch:

Kruk, hambaruan ewen bara apui bahe, buli bakandong penjang karuhei tatau, paturong sangkalemo radja.
Streureis und er spricht (während er Reis ausstreut):

Noch nicht ist vergangen die Zeit die nötig ist um den Speichel der Pinang gelb $z \mathfrak{u}$ färben, noch nicht ist verstrichen die Zeit um den Speichel durch die Betelnuss zu färben, da kehrt schon wieder um, da kommt schon wieder zurück der Antang Darahen aus dem Dorfe Batu Nindan Tarong, aus dem Orte Liang Angkar Bantilong Njaring, er kommt zurück und bringt mit sich die Hölzer der Penjang, der Karuhei des Reichtums, er kehrt wieder um und hat bei sich das Feuer, das gute, das vermengt ist mit dem Wasser des Lebens, dem Leben schaffenden, das vermischt ist mit Panjangka-Heilmitteln, mit Salatutup, mit Salapandom, das durcheinander gemacht ist mit Parapat Panamar.

Der Antang Darahen empfängt nun die Entschädigung für die Ermüdung seiner Knochen, dem Aeltesten Tonggal Sangumang wird überreicht der Lohn für die Erschlaffung seiner Muskeln, und gemeinsam kehren sie wieder heim zu der Buchtung ihres Dorfes, kehren sie wieder zurück in ihren Ort und sie treten wieder ein in das Haus ihres Wohnens, begeben sich wieder zurück in die Hütte ihres Bleibens. Der Tukang tawur beschliesst nun sein Spruchwort indem er sagt:

Kruk (kehret zurück) ihr Seelen (die Seelen der Besitzer des verbrannten Hauses die sich mit auf die Reise begeben haben) vom Feuer, dem glühenden, kehret wieder heim zusammen mit Penjang, mit Karuhei des Reich- 
Toh tukang tawur mukei behas idje mukus (bungkos behas hambaruan), munduse ie, palus mambowor,e sunisuni intu takolok ewen idje tempo,n huma bakeho, limbah te oloh mambajar upah tukang tawur telo kiping atawa djahawen rupiah.

Tinai kare ramo:

1. Idje piring lombah, tantalai karuhei.

2. Bulau satali, singah karuhei.

3. Udje depe, udju gawang, telo djari kapandjang tali tengang, peteng karuhei.

4. Behas tambak huang mangkok terois.

Limbah te tukang tawur buli huma,e hong handjewu andau.

Ewen idje djari bakeho huma mampatei manok, tau kea mampatei bawoi hapan manjaki hampatong karuhei, hampatong te ingkese buabuah huang garantong, genegenep pesta tinai ie haradjur manjaki,e. tums, mit Paturong Sangkalemo Radja. Der Tukang tawur öffnet nun den Reis welcher eingebunden ist (das Bündel mit dem Seelenreis), er bestreicht ihn mit Oel und streut ihn stillschweigend über die Köpfe derer aus die die Besitzer des abgebrannten Hauses sind, darnach bezahlen die Leute dem Tukang tawur die Entschädigung, nämlich drei kiping oder sechs Gulden (ein kiping ist zwei Gulden).

Und ferner erhält er auch die Dinge, die für die Handlungen gebraucht wurden, nämlich :

1. Einen breiten Teller auf dem die Karuhei ausgebreitet worden waren.

2. Gold, im Gewichte eines satali (eines 25 Centstückes), als Fackel für die Karuhei.

3. Das Tengangseil das um die Karuhei gewickelt war in der Länge von sieben depe (das Längenmass der beiden ausgespannten Arme, ca. $1,70 \mathrm{~m}$ ), sieben Spannen und drei Finger lang (das Mass von drei nebeneinanderliegenden Fingern).

4. Den aufgehöhten Reis der sich in einem Teroisgefäss befindet (in dem er aufgehöht wurde).

Am gleichen Morgen noch kehrt der Tukang tawur wieder nach seinem Hause zurück.

Sie, denen das Haus abgebrannt ist, schlachten ein Huhn oder sie töten ein Schwein um mit dessen Blut die Schnitzbilder der Karuhei (die der Tukang tawur von dem angebrannten Holz geschnitzt hat), diese Schnitzbilder werden vorsichtig in einen Gong gelegt (für die Bestreichung mit dem 
Blut) und jedesmal wenn wieder ein Fest (eine religiöse Handlung) stattfindet werden sie wiederum mit Blut bestrichen.

Toh, limbah hapus gawi te, kaudju andau dia tau maname huang tali idje iniring intu eka bakeho, telo bulan ie dia tau manetes uei, maruntih uei, telo njelo dia tau mandjoho manok hewoi paria. 194
Nachdem nun diese Handlungen beendet sind, darf man während sieben Tagen den Platz nicht betreten der umschlossen ist (d.h. den Brandplatz der mit einem Rotan umspannt wurde), während drei Monaten dürfen die Besitzer des abgebrannten Hauses keinen Rotan schneiden und keinen Rotan reinigen, während drei Jahren dürfen sie in einer Gemüsesuppe keine Hühner kochen zusammen mit Pariafrüchten.

\section{Manolak Sial Apui ${ }^{195}$ (Die Verabschiedung des Feuer-Sial)}

Das Manolak Sial Apui ist eine Handlung die vorgenommen wird wenn das Haus eines und desselben Besitzers zu wiederholten Malen abgebrannt ist, trotzdem er das schlechte Feuer zurückbringen und gutes Feuer holen liess. Die Handlung schliesst also an bei der bereits beschriebenen und ergänzt sie. Sie gehört streng genommen nicht in unser Textmaterial, wird aber der Vollständigkeit halber hier doch aufgenommen. Auf die andern Handlungen, die bei Unfall und plötzlichem Tod vorgenommen werden müssen, haben wir dann nicht mehr so gründlich einzugehen. Es genügt dieses eine Beispiel wie kompliziert die Handlungen und Texte von Fall zu Fall sein können.

\section{a. Vorbereitungen}

Der Text für diese Vorbereitungen ist in gewöhnlichem Ngadju geschrieben.

Maka amon oloh kindjap bakeho, aloh djari impakanan ttg. malalus gawi tumon idje insanan helo nah, mahin ewen magon kindjap bakeho huma,e atawa pasah,e te injewut ewen te awi Sial Apui.
Wenn es aber geschieht, dass Leute oft durch einen Brandfall heimgesucht werden, obgleich sie alle Opfer gebracht und alle Handlungen vorgenommen haben, in der Weise in der es bereits mitgeteilt wurde, wenn es dann doch noch geschieht, dass ihr Haus oder ihre Feldhütte abbrennt, dann 
Toh patut ie tantolak SialApui.

Maka oloh tantolak Sial Apui tau kea gawi beken, paribasa: gawi balaku ontong, mambang karuhei, tantolak Sial ttg. kutoh tinai.

Ampi,n oloh malalus gawi te, tumon idje injarita toh:

Kare ramo,n pakakas akan gawi te:

1. Idje katetek benang bahandang.

2. Idje langgei simbel.

3. Idje sauk, huang,e udju hampatong kaju. sagt man, dass dies verursacht worden sei durch die Feuer-Sial.

Es geziemt sich nun dass sie die FeuerSial verabschieden.

Aber die Verabschiedung der Sial kann auch stattfinden zusammen mit einer andern religiösen Handlung, z.B. dann wenn man Glück erbittet, 196 wenn man Karuhei holen lässt, oder wenn man die Sial verabschiedet 197 oder bei noch manchen andern Handlungen.

Die Art und Weise wie die Leute diese religiöse Handlung ausführen geschieht folgendermassen:

Die Dinge, die zum Gebrauche bei dieser Handlung nötig sind, sind die folgenden :

1. Ein Stück rotes Tuch.

2. Ein kleines Schnitzmesser.

3. Ein sauk (d.i. ein länglicher, geflochtener, offener Korb mit ovalem Boden, wird meistens gebraucht um am Ufer damit Fische zu fangen oder aufzuschöpfen), in ihm befinden sich sieben Schnitzbilder mit menschlichem Angesicht von Holz.

4. Idje hampatong kaju hai, hampatong te korang-labih kahai batang pinang, hampatong te uras injapo bahandang hapan kasumba atawa kulat.

5. Idje pahera.

6. Idje pasah korik, idje depe lapak epat, injapau hapan dawen tingen, 198 djete intu sara,n danum, kedjau
4. Ein Schnitzbild von dickerem Holz, dieses Schnitzbild hat ungefähr den Umfang eines Pinangstammes, alle Schnitzbilder (auch die oben genannten) werden rot bestrichen mit rotem Farbstoff oder mit Pilzen die eine rote Flüssigkeit absondern.

5. Der Schaft eines Beiles.

6. Eine kleine Opferhütte, die eine depe $(1,80 \mathrm{~m})$ im Quadrat misst, mit einem Dach von Tingenblättern, diese wird aufgerichtet am Ufer 
bara huma.

7. Idje awang bua baloh asip.

8. Idje kongan bawoi bawi, rega,e korang-labih idje ringgit, djete impatei impakasak akan pangina,i1 sukup, kare takupat ttg. kare wadai.

9. Idje behas tambak, ttg. kare roko, sipa, panginan te handiai djaton tau oloh tempo,n gawi kuma,e.

Maka amon ramo te djadi tatap, uras iandak huang pasah korik intu sara,n danum.

Amon ramo te djari imbit akan hete, te katambong iimbit akan petak darah pasah te kea ttg. sangko,n hambaruan, toh ewen manampara balian, manekap katambong ttg. manandak koa,e : des Flusses, ziemlich weit vom Hause entfernt.

7. Eine baloh zum Wasserschöpfen. ${ }^{199}$

8. Ein weibliches Schwein, das ungefähr einen Ringgit kostet $(2,50$ Gulden, damit wird die Grösse des Tieres angegeben, es ist in diesem Falle mittelgross), dieses wird getötet und gekocht als Speise (Opfer), die noch vermehrt wird mit Takupat (in Blätter gewickelten und gekochten Reis) und verschiedenem Backwerk.

9. In einem Gefäss aufgehöhter Reis, verschiedene Rauchwaren, Kausel, alle diese Speisen und Genussmittel dürfen nicht gegessen oder genossen werden vom Veranstalter dieser Handlung (also vom Besitzer des verbrannten Hauses).

Wenn alle diese Dinge bereit gemacht sind, werden sie in die kleine Opferhütte am Ufer des Flusses gelegt.

Wenn alle diese Dinge dorthin gebracht worden sind, dann trägt man auch die kleinen Trommeln (diese kleinen Trommeln werden nur von den Balian und Basir gebraucht) aus dem Hause, bringt sie auf den Platz neben der Hütte und ebenfalls auch das Gefäss mit dem Seelenreis, sie beginnen nun mit den priesterlichen Handlungen (balian, hier wird also nicht der Tukang tawur gebraucht, sondern die Balian und Basir, weibliche Priesterinnen), sie schlagen die kleinen Trommeln und sie singen sagend: 
b. Das Lied der Priesterinnen reist in die Oberwelt um den Njarany Tingang Hatuen Apui herabzuholen

Der Text wird in der Basa Sangiang gesungen.

Bahing bapanting gana,n tandak pulau rewa,n i,bawi, siring bambahinga,e labata,n karunja,n tambon haruei bungai.

Malan manjalumbo ambon nduan tilap telo pulu, ringkang manandjak enon limebalas hatalamping.
Schreite aus, Wort der Seele des Gesanges der Menge, der Scharen der Frauen, mache dich auf den Weg, du Rede der Seele des Liedes der Wasserschlangen die gemeinsam auftreten mit den Nashornvögeln. 200

Mache dich auf und steige empor und durchschreite die dreissig Lagen, erhebe dich und ziehe aufwärts durch die Tauwolken, die fünfzehn doppelten (zwischen der Welt und Oberwelt liegen dreissig Wolkenlagen die zuerst durchschritten werden müssen. Siehe die Namen und die Erklärungen im Text zum Tantolak matei).

Es wird hier nun nicht die ganze Reise ausführlich beschrieben, das geschieht erst im Tantolak matei, aber der Priester fährt kurz erklärend fort :

Gana,n tandak atawa auch oloh balian manjalumbo akan ngambo, mahoroi djalan sampai kaleka Batu Nindan Tarong, ie manalih $\mathrm{Njarang}$ Tingang Hatuen Apui. 201

Koa,n tandak,e djari sampai hete :

Riwu-riwut bahing karungut namuei kaleka Batu Nindan i,Tarong, salatan bambahingan
Die Seele des Gesanges oder das Wort der Priesterinnen steigt nun empor in die Höhe und es legt den Weg zurück bis zum Ort des verlassenen aber immer noch von den Ahnen bewohnten Batu Nindan Tarong und es begibt sich zu Njarang Tingang Hatuen Apui (im vorhergehenden Text wurde er genannt: Njarang Tato Apui, d.h. Njarang, der Herr des Feuers, die Bedeutung ist aber die gleiche).

Es lautet das Lied, wenn es angekommen ist dort:

Rausche, Wort des Gesanges, und reise zum früheren Dorfe Batu Nindan Tarong, brause, Schall des Liedes, und 
karunja mangadja Liang Angkar Bantilong $\mathrm{i}, \mathrm{Njaring}$.

Manandai balai kilat idje bahalap nalombang i,apui, mangadja sali njababintir idje badaris manahuto asep.

Bara babedjau bewei gana,n tandak batuntur dengan $\mathrm{Nja}-$ rang Tingang Hatuen Apui :

Toh upo,n balian malaian manekap katambong, mahapan karungut,e kabuat bewei, koa,e :

Ijoi, nih Njarang Tingang Hatuen Apui, akam Tingang nusang mandurut Lunok tambon randan, marentur labeho mananturong lewu Ano, manjahendeng rundong Ano (ie te lewu, eka balian) aton rangkan panginan natap entang pantai danum kalunen, njadia tujang luwok kampongan buno, bawoi samben sukup rangkan panginan.

Bau ampi,n panalatai,e kilau bulan manalatai dare, pamalempange tingkah pahawang malekut tabuhi.

Haradjur entang asi-asi Fortwährend sind die Getragenen be- steige auf und besuche den Ort Liang Angkar Bantilong Njaring.

Steige hinauf zum Balai des Blitzes, dem herrlichen, dem umwogten von Feuer, trete ein in das Haus, das von Blitzen umzuckte, das prachtvoll geschmückte mit aufsteigendem Rauch. Von Ferne nur erzählt die Seele des Gesanges dem Njarang Tingang Hatuen Apui (sie naht sich nicht ganz weil es im Hause zu warm ist) :

Hier hört die Hauptbalian 202 auf die kleine Trommel $z u$ schlagen und nur das Lied allein weitersingend spricht sie nun:

Ja, o Njarang Tingang Hatuen Apui, für dich, o Nashornvogel, für dein Herabfahren, dein Heruntersteigen zu den Lunok (Menschen), den Wasserschlangen, den kleinen, dein Hereintreten in die Wassertiefe, dein Kommen ins Dorf N.N., deinen Besuch im Orte X. (nämlich im Dorfe wo diese priesterlichen Handlungen stattfinden) sind bereit gemacht worden Dinge des Essens (Opfer), sie wurden hergestellt durch die Getragenen am Ufer des Flusses der Welt, sie wurden zubereitet durch die Gewiegten die da wohnen an der Buchtung des Dorfes der Lanzen (Männer), es ist für dich bereit ein Schwein mit dem Halsband und Ueberfluss an andern Esswaren.

So steht es mit ihrer Sache, so wie die Monde nachdenken über das vor ihnen ausgebreitete Geflecht, so steht es mit ihrer Angelegenheit, so wie die Frauen nachsinnen über dem zu beginnenden Flechtwerk. 
lingo,e, kindjap bakeho pasah tumpong,e, huma serok,e, awi te nduan hambekan katon itah hakarangka rawei, itah mampak basara kabantengan balai bulau manalambang kilat, sali rabia nahuto sababintir.
I,palus gatang kumi,n tingang, dia lunok ngarangka, hirum, tambon dia baras ngalimbange Njarang Tingang Hatuen Apui, hajak ringkesmarangkesa Njarang Tingang, Tingang nusang hadurut lunok, haratean djamban kilat idje kamakang lio lampang, mansohan paratas idje panimpah ruang langit, ie sembang balai bulau idje bahalap manalambang kilat, sali rabia idje badaris manahuto asep.

Palus gana,n tandak Njarang Tingang Hatuen Apui njarakumpang 203 rawei gana,n tandak panatau batu bangkalan lunok mamua bulau, manjarongan labata,n karunja,n panohan liang kantihan baras trübt und traurig in ihren Herzen, denn schon oft ist abgebrannt ihre Hütte, die umwandete, ihr Haus, das umzäunte, und deshalb haben wir uns nun entschlossen und wir sind übereingekommen $z \mathfrak{u}$ besprechen und $\mathbf{z u}$ schlichten diese Streitsache mit dir in der Mitte des Balai (gemeint ist die kleine Opferhütte die beim Flussufer aufgerichtet wurde), des goldenen mit der Schwelle von Blitzen, in dem Haus, dem goldenen, aus dem aufsteigen die zuckenden Blitze.

Und sogleich erhebt er ein Lächeln der Tingang und nicht besinnt sich lange der Lunok (Mann) und er schmunzelt vor sich hin und nicht lange denkt nach die Wasserschlange, er, der Njarang Tingang Hatuen Apui, und sogleich ordnet er alles und macht seine Dinge bereit der Njarang Tingang und er fährt herab und stösst herunter auf den Lunok (zu den Männern), er, der Nashornvogel, er schreitet herunter auf dem Wege des Blitzes der umwandet wird von dem aufsteigenden Regenbogen, er kommt herunter auf der Treppe die durch die Himmel führt, er kommt an im Balai, dem goldenen mit der Schwelle von Blitzen, in dem Hause, dem goldenen aus dem aufsteigen die Wolken des Rauches.

Und sogleich tritt ein die Seele des Spruchwortes des Njarang Tingang Hatuen Apui, sie geht ein in das Wort der Seele des Gesanges in den herrlichen steinernen Schleifstein des Lunok welcher goldene Früchte trägt, sie erfüllt die Seele des Liedes, den 
bulau lampang.

prachtvollen steinernen Schleifstein des goldenen Sandes der aus dem Flusse aufsteigt. 204

c. Der Prozess zwischen den Besitzern des verbrannten Hauses und Njarang Tingang Hatuen Apui

Der ganze Prozess wird in gewöhnlichem Ngadju geführt, nicht mehr in der Basa Sangiang. Der Text wechselt mit Erklärungen ab. Die Handlungen sind sehr dramatisch.

Toh upo,n balian mendeng maname pasah korik te, palus melai logo-logo intu hete ttg. ewen panombah,e melai intu petak darah pasah te kea, amon djadi kalote, te manggau biti loang idje sadia mondok intu bentok huma, amon djadi te nampara hapan gawi ttg. kotak, te dumah idje biti oloh balian, idje rima,e djalahan ain Apui te, lompat akan huma, te ewen telo idje mondok intu bentok huma hamauch, koae: palus, karohong, palus! maka ie idje djalahan ain Apui hakotak hapan auch idje sene-seneng:

Aku toh manalih keton, soho,n radja,n ikei $\mathrm{Njarang}$ Tingang Hatuen Apui, misek buku,e
Die (oder auch der, heute nennt man auch die Basir oft Balian) Hauptbalian erhebt sich nun und begibt sich in die kleine Hütte (die beim Flussufer aufgerichtet wurde) und sie bleibt dort in steif sitzender Körperhaltung und die Beantworterinnen (d.h. die Hülfsbalian die den Gesang der Hauptbalian übernehmen und wiederholen) stehen auf dem Platze vor der Hütte; wenn das geschehen ist, dann wählt man aus den Leuten (den Besitzern des verbrannten Hauses und ihren Verwandten), die in genügender $Z$ ahl in der Mitte des Hauses (eines Hauses im Dorf) sitzen, Mittler (einen Botschafter, einen Gesandten) der Rede; wenn das geschehen ist, dann beginnt man mit den Handlungen und der Rede, einer der Balian, das heisst einer der Angehörigen des Njarang Tingang Hatuen Apui, steigt ins Haus hinauf und die drei Mittler (loang), welche in der Mitte des Hauses sitzen, sprechen: tritt herein, o unser Freund, tritt herein!, aber er, der Angehörige des Njarang Tingang Hatuen Apui, spricht mit schnaubender, zorniger Stimme:

Ich komme zu euch im Auftrag unseren Königs, des Njarang Tingang Hatuen Apui, um die Ursache $z u$ erfragen 
keton djadi mantehau ie, ijoh djaka aton kotak sarita,n keton, te keleh keton manjarita,e mangat aku tau mansuman aka,e.

Koa,n loang ewen telo intu huma :

Ijoh, pea horeh, ikei puna toto mantehau ie hapan karungut ewen oloh balian.

Has, ikau loang, mohon pahak djalahan Apui toh, mite ampi,n katerus ie djari dumah. koa,n oloh bakas idje akan bakas huang huma te.

Te idje biti loang mohon handjulo mampahaiak oloh ain Apui.

Hau, koa,n loang, toto ampi djari dumah, aton logo-logo kanih, te loang ttg. oloh ain Apui akan huma tinai.

Toh oloh bakas hong huma te hakotak, koa,e :

Buku,e ikei djari mantehau ie awi ampi,e kilau Ano ewen toh haradjur bakeho kare pasah tumpong,e, kare huma serok,e, ampi,e dia beken bara desa ai,e idje mawi, awi te, metoh toh ikei balaku ie mangganti kare taloh idje nihau te, djete auch,m loang, idje sana,m toh aka,e. derentwegen ihr ihn rufen liesset, ja, wenn ihr etwas $z \mathfrak{u}$ sagen, etwas $z \mathfrak{u}$ erzählen habt, dann seid so gut und teilt es mir mit, damit ich es ihm mitteilen kann.

Es spricht der Mittler der drei in der Mitte des Hauses:

Ja, wie sollte es nur ein Scherz sein, gewiss wir haben ihn herbeirufen lassen durch den Gesang der Balian.

Has, dı Mittler unserer Rede, steige herunter mit dem Begleiter des Feuers hier und überzeuge dich ob er wirklich gekommen ist! sprach der Aelteste welcher ernannt worden war zum Aeltesten über die im Hause.

Einer der Mittler steigt nun für einen Augenblick hinunter aus dem Hause und er begleitet den Menschen, den Angehörigen des Feuers.

Hau ! ruft der Mittler aus, wahrhaftig, er scheint gekommen zu sein, er sitzt in steifer Körperhaltung dort drüben, und darnach kehren der Mittler und der Angehörige des Feuers wieder ins Haus zurück.

Der Aelteste im Hause ergreift nun das Wort und er spricht:

Die Ursache, dass wir ihn herbeirufen liessen, liegt darin, weil es scheint, dass diesem N.N. hier fortwährend abgebrannt werden die Hütten, die umwandeten, die Häuser, die umzäunten, und es scheint auch, dass es durch niemand anders getan wird als durch seine Sklaven die heimtückisch überfallen, aus diesem Grunde sind wir jetzt zusammengekommen und wir verlangen, dass er zurückerstatte alle vernichteten Güter, diese ist deine 
Toh idje biti loang ttg. djalahan Apui mohon akan balai atawa pasah korik.

Maka amon ewen ndue djari sampai pasah te, te Hatuen Apui, idje upo,n balian te, muloh djela, maleak mata,e, mamarut, sansingut matjamatjam, ttg. loang idje bara huma manampa lago,e hadari undur manduan kawal,e bara huma hajak ie mansanan paham angat,e mikeh, koa,e :

Kai-kai, ampi,n Hatuen Apui te nah, lasute paham, sansingut,e paham pandjang, mata,e maleak kahai busut garantong, kasinga,e kahai baliong bangka, djela,e ngalombah kiap.

Idje biti bara huma mampahajak ie ttg. ewen ndue manokep pasah te ttg. oloh ain Apui manjarita titi-titip tumon auch oloh bakas idje aton huang huma, ie manjarita hong taharep ewen ndue loang bara huma, maka amon hapus auch,e manjarita, te radja,n Apui tombah, koae:
Rede, o Mittler, welche du ihm mitzuteilen hast.

Einer der Mittler steigt nun zusammen mit dem Angehörigen des Feuers hinunter zum Balai (Versammlungshaus, Fremdenhaus) oder zur kleinen Hütte.

Aber wenn die Beiden dort bei der Hütte angekommen sind, dann lässt der Hatuen Apui (nämlich der Hauptbalian) die Zunge weit heraushängen und die Augen aus den Höhlen treten, er knirscht mit den Zähnen und er dreht seinen Schnurrbart hin und her und tut noch mehr dergleichen Dinge, der Mittler aus dem Hause tut als ob er wieder umkehren und davonlaufen wollte um seine Gefährten aus dem Hause herbeizuholen, und er spricht mit furchtsamer, ängstlicher Stimme:

Schrecklich, gratuenerregend war soeben der Anblick des Hatuen Apui, seine Hitze war sehr gross, sein Schnurrbart war sehr lang, seine Augen traten aus den Höhlungen wie Erhöhungen auf den Gong, seine Zähne hatten die Grösse einer Axt die eingeführt wurde von der Insel Bangka, seine Zunge besass die Breite einer Reisworfelmatte.

Eine Person aus dem Hause begleitet ihn nun und zusammen nähern sie sich wiederum der Hütte und der Angehörige des Apui erzählt nun ganz genau das was der Aelteste ihm mitgeteilt hat, er erzählt alles in der Gegenwart der beiden Mittler aus dem Hause und nachdem er seine Rede beschlossen und seine Erzählung beendet hatte, erhob der Aelteste des Feuers sein Wort und er antwortete und sprach: 
Idje auch keton, aku hindai tau manarima,e, karana hindai aku djari mite kataranga,e, amon puna toto oloh aingku mangeho pasah tumpong,e, huma serok,e, ramo-ramuan, djete gampang bewei aku tau manangkiri, mangganti ramoramuan, tapi toh dia aku tau manjanggup,e awi kataranga,e djaton, djete ih auch idje insanan keton akan huma.

Toh ewen epat bara ngiwa, due biti djalaha,n Apui, due biti oloh huma, palus mules arep,e, maka amon ewen djari sampai huma, te ewen epat manjarita auch radja,n Apui.

Koa,n oloh bakas huang huma : Amon ie manggau kataranga,e, bahalap, aton kataranga,e.

Te oloh bakas manjoho idje biti djalaha,n Apui mangarakop buring babarangai bara dapur, amon djari ie mangarakop,e, te ewen epat mohon tinai, maka amon djari sampai radja Apui hong pasah ewen manjarita tumon auch oloh bakas intu huma, koa,e:

Karana bihin puna toto ie mawi sampai lokap,e salesale.
Was euer Wort betrifft, ich kann es noch nicht annehmen, denn ich habe noch keine Beweise gesehen, wenn es wirklich wahr ist, dass meine Leute niedergebrannt haben die Feldhütten, die umwandeten, die Häuser, die umzäunten, dann ist es für mich ein leichtes Ding um sie wieder zurückzuerstatten und um zu ersetzen die verbrannten Güter, aber so kann ich es noch nicht annehmen, weil noch keine Beweise vorhanden sind, das ist das Wort das ihr überbringen sollt den Leuten im Haus.

Nun begeben sich die vier, die sich unten befanden (in der Hütte des Apui), nämlich zwei Angehörige des Feuers und zwei Angehörige der Leute aus dem Haus, wieder zurïck und nachdem sie wieder im Hause angekommen waren berichteten die vier die Worte des Königs des Feuers.

Es spricht der Aelteste im Hause:

Wenn er Beweise haben will, gut, hier sind die Beweise.

Der Aelteste befiehlt nun einem der Angehörigen des Feuers ein Stück verkohltes Holz, gleichgültig welches, vom Herde zu nehmen und wenn das geschehen ist und seine Hand das Holz umfasst, dann steigen die vier wieder hinunter und nachdem sie wieder angekommen sind beim König des Feners in der Hütte erzählen sie ihm was der Aelteste im Hause ihnen aufgetragen hat und sie sagen:

Es ist gewisslich war, dass sie es früher getan haben (nämlich das Haus niedergebrannt), denn seine Handflächen sind jetzt noch schwarz vom 
Toh radja,n Apui mariksa oloh ai,e, ite-ite ie gagenep lokap oloh ai,e, toh palus aton buring gita,e intu lokap,e, maka radja,n Apui sangit balait ampi,e, maleak mata,e, rihing kasinga,e, muloh djela,e, te ewen due mawi arep,e, paham marawan, mike-mikeh ampi,e.

Koa,n Hatuen Apui :

Ijoh, aloh aton buring,e, kueh karewo?

Dia trima aku amon djaton karewo, karana puna mustahel toto, amon bakeho te musti aton karewo, toh dia trima aku, mikeh buring te banta laput.

Has keton Lendang, keton ndue Njala, talih huma, misek ewen!

Toh ewen epat buli akan huma mansanan auch Njarang Tingang Hatuen Apui akan oloh bakas hong huma, maka amon djadi insanan te oloh bakas tombah, koa,e:

Amon Njarang Tingang Hatuen Apui manggau karewo akan kataranga,e, te puna aton, gege labih haream bihin,

\section{Feuer.}

Der König des Fetuers untersucht nun ganz genau seine Leute und er beschaut die Handflächen seiner Angehörigen und plötzlich sieht er, dass sie verkohltes $\mathrm{Holz}$ in den Händen haben, der König des Feuers wird zornig und wütend, seine Augen treten aus den Höllungen, er knirscht mit seinen Zähnen, er hängt heraus seine $Z$ unge, sie fallen einander an, Schrekken überfällt sie und Angst liegt scheinbar auf ihren Gesichtern.

Es spricht der Herr des Feners:

Ja, obgleich verkohltes $\mathrm{Holz}$ vorhanden ist glaube ich es doch nicht, denn wo ist die Asche?

Nicht lasse ich dieses gelten als Beweis, wenn keine Asche vorhanden ist, denn es wäre wirklich viel zu merkwürdig und zı unglaublich, denn weni etwas verbrannt ist dann muss doch auch Asche vorhanden sein, nicht nehme ich diese Beweise an, denn das verkohlte Holz ist vielleicht nur Unrat der aus dem Wasser geholt wurde.

Wohlan Lendang (der rot-gelbe Schein des Feuers) und Njala (die Fenerflamme), begebt ench zusammen ins Haus und erkundigt euch!

Nun kehren die vier wieder ins Haus zurück und sie überbringen die Rede des Njarang Tingang Hatuen Apui dem Aeltesten im Hause und nachdem sie sie beendet haben erhebt der Aelteste sein Wort und er spricht: Wenn der Njarang Tingang Hatuen Apui Asche haben will als Beweis, dann hat es natürlich Asche und es hatte frïher noch viel mehr, ich schlage 
natalku likut,e, natalku balikat,e, natalku pai,e, natalku takolok,e.

Toh ewen intu huma mangguris likut,e, balikat,e, pai,e ttg. manata undus hundjun takolok oloh ain Apui te.

Limbah te ewen epat mohon tinai akan pasah idje eka radja,n Apui ttg. ewen mansanan auch oloh bakas aka,e. Te radja,n Apui palus mariksa manampajah likut,e, balikat,e, uras toto.

Koa,n radja,n Apui:

Leha-lehan ikau! kalote mawi ewen, toh keleh keton manalih huma misek narai kare matjam,e taloh idje nihau bakeho te.

Te ewen epat lompat manalih huma, koa,n ewen epat hakotak dengan oloh bakas:

Koa,n radja,n Apui, ie manjoho ikei misek kilen kare ramo idje bakeho awi apui?

Te koa,n oloh bakas:

Pasah ttg. puat,e! ttg. ie mansanan kare ramo idje nihau handiai. Awi te ikei balaku ie mambajar,e sampai lepah. Huma atawa pasah idje ingeho, ie mampendeng,e ma- sie (mit Asche) auf ihren Rücken, ich schlage sie an ihre Seiten, ich schlage sie an ihre Beine, ich schlage sie auf ihre Köpfe.

Und nun bestreichen die Leute im Hause, die Rücken, die Seiten und die Beine der Angehörigen des Feuers mit Asche und sie giessen Oel auf ihre Köpfe.

Darnach steigen die vier wieder hinunter zu der Hütte in der sich der König des Feners aufhält und sie überbringen ihm die Rede des Aeltesten.

Und nun schaut der König des Feuers nach und er untersucht die Rücken und die Seiten und er sieht, dass alles wahr ist.

Und es spricht der König des Feuers: Unerträglich ist es, $\mathrm{zu}$ arg ist es mit euch, so auf diese Weise zu überfallen und sie mit Feuer zu vernichten, begebt euch nun wieder zurück ins Haus und erkundigt euch, welche die verschiedenen Güter waren, die verloren gingen und verbrannt sind.

Die vier kehren wieder zurück und treten in das Haus ein und es sprechen die vier und sie sagen zu dem Aeltesten: Es spricht der König des Fetuers, er hat uns den Auftrag gegeben uns zu erkundigen, wieviele der Güter verbrannt seien durch das Feuer.

Und darauf spricht der Aelteste:

Das Haus und alle Güter die sich in ihm befanden! Und er zählt auf alle Dinge zusammen die verloren gegangen sind durch den Brand. Aus diesem Grunde verlangen wir nun, dass er sie restlos bezahle. Das Haus oder die 
naheta,e.

Djete ih idje injampai keton akan radja,n Apui.

$\mathrm{Te}$ ewen epat mohon tinai manalih radja,n Apui hajak mansanan kakare auch oloh awang bakas te nah.

Koan radja,n Apui :

Ijoh, lehan kare,n taloh idje nihau te.

Amon kalote, puna dia aku mambajar,e ih, basa lalau kare,e.

Has, keton epat, sanan aka,e, koa,n radja,n Apui.

Te ewen epat mandai akan huma, mansanan auch radja,n Apui.

Maka koa,n oloh bakas:

Amon ie puna dia nahuang mambajar,e, mangat ikei katawan.

Has, keton loang telo, misek radja,n Apui: en imbajar,e atawa dia?

Te ewen lime mohon manalih radja,n Apui, mansanan kakare auch te aka,e.

Koa,n radja,n Apui:

Puna toto, aku dia mambajar!

Karana ewen puna bunongku bara bihin.

Awi te, toh aku handak manjoho desa rajatku malapas apui njaro, idje bakatotoh
Feldhütte die verbrannt sind muss er wieder neu aufbauen, neu erstellen. Das sind meine Worte die ihr zu überbringen habt dem König des Feuers. Die vier stiegen wieder hinunter und begaben sich zum König des Feuers und sie teilten ihm mit alle Worte die der Aelteste gesprochen hatte.

Und es sprach der König des Feuers: $\mathrm{Ja}, \mathrm{zu}$ verwunderlich ist es, dass eine so grosse Zahl von Gütern verbrannt sein soll.

Wenn es so steht, dann bezahle ich sie wahrlich nicht, denn zu gross ist ihre Menge.

Wohlan ihr vier, teilt es ihm mit (dem Aeltesten), sprach der König des Feuers.

Und die vier stiegen wieder hinauf ins Haus und sie überbrachten die Worte des Königs des Feuers.

Aber es sprach der Aelteste:

Wenn er sie wirklich nicht bezahlen will, gut so, es geht nur darum, dass wir es wissen.

Wohlauf ihr drei Mittler, erkundigt euch bei dem König des Feuers: Wie steht es nun, bezahlst du sie oder nicht? Darauf steigen die fünf wieder hinunter und sie überbringen ihm alle Worte.

Es spricht der König des Feners :

Es ist gewisslich wahr, ich bezahle nicht!

Denn sie sind die, die meine Lanze trifft (d.h. die Feinde) von früheren Zeiten her.

Aus diesem Grunde will ich nun meinen Untergebenen, meinen Sklaven, den Befehl geben loszulassen das Feuer 
rangkan saratus, malangkusan bahen sinar, idje bakalomat rewan saribu.

Djete ih auch idje insanan keton.

Idje loang ai,e indahang, kea due aingku indahang toh, akan indu katoto,n kotakku, mangat ewen katawan. Has keton udju sanan akan ewen.

Te ewen udju lompat akan huma, mansanan kare auch radja,n Apui.

Koa,n oloh bakas huang huma :

Narai auch itah, amon kalote?

Toh keton udju mansanan akan radja,n Apui: ikei toh manatap penjang awang bahari simpei,e, paturong maing mait sandik,e ttg. manatap penjang, penjang udjan rajo idje pali hudjan baka soho mangandang, paturong petai ganggerang idje endus harihe baka soho manjambong.

Hapan ikei mambelep apui te.

Djete auch idje insanan keton udju akan radja,n Apui. Te ewen udju palus mohon mansanan akan radja,n Apui. des Donners, das da verzehrt hunderte von Gütern, freizulassen die Flamme des Donners, die da vernichtet tausende von Dingen.

Das ist mein Wort, das ihr überbringen sollt.

Um einen sind seine (des Aeltesten) Mittler vermehrt worden, um zwei vermehre ich nun die meinen, zur Bekräftigung meines Wortes, damit sie es wissen sollen. Wohlan nun ihr sieben, überbringt ihnen mein Wort.

Und die sieben bestiegen das Haus und sie teilten mit alle Worte des Königs des Feuers.

Es sprach der Aelteste derer im Hause :

Was sollten wir noch entgegnen, wenn es so steht?

Ihr sieben, überbringet nun meine Worte dem König des Feuers und ihr teilet ihm mit: wir hier machen nun bereit die Penjang mit den scharfen Bündeln, die Paturong mit den kräftigen wirkungsvollen Bändern, wir machen bereit die Penjang, die Penjang des Regens welchen man schon von ferne rauschen hört, welche pali (verboten) sind regnen zu lassen weil das Wasser alles überflutet und umbrandet, die Paturong des donnernden Regens, welcher verboten ist um ihr herniederrieseln $\mathrm{zu}$ lassen, weil er rasch anschwillt $z \mathfrak{u}$ hohen Wassern.

Wir werden sie gebrauchen um auszulöschen sein Feuer.

Das ist meine Rede, die ihr überbringen sollt dem König des Feuers. Und sogleich stiegen die sieben hinunter und sie sagten es an dem König 
Koa,n radja,n Apui:

Has, mawi,e, mbuai,e! ttg. ie manjoho idje biti oloh ai,e: has Lendang! hagoet ikau manusul pakang hedja,e.

Oloh ain Apui palus manatap sahewan, aton apui intu lawi,e, te oloh ain Apui idje bagare Lendang mimbing sahewan hajak hadari kadjokkadjok, ttg. hamauch, koa,e: tusul, tusul, tusul!

Ie hadari nangkadjok sahewan manintu huma.

Te idje biti oloh huma mimbit danum huang sarangan hajak pidjak-padjaka hundjun bapata ttg. hamauch, koa,e: udjan, udjan, udjan! hajak mambelep apui idje intu lawin sahewan te.

Te Lendang mules manalih radja,e hajak mansanan aka,e hapan auch idje sene-seneng: hakarang tempo sangiang, karas toto kamenteng oloh kalunen.

$\mathrm{Njamah}$ aku angat maneser huang penda labeho awi danum te manantekas.

Leha-lehan kamenteng ewen, koa,n radja,n Apui.

Has Njala, hagoet ikau! des Feuers.

Es spricht der König des Feuers:

Wohlan, überfällt sie, zerstört sie! und er befiehlt einem seiner Untertanen: wohlauf Lendang (der gelbglänzende Schein des Feuers), mache dich auf und verbrenne das Geländer ihrer Treppe.

Die Untertanen des Königs des Feuers machten sogleich eine Fackel bereit und entzündeten sie und der Untertan des Feuers welcher genannt wurde Lendang ergriff die Fackel und eilte mit ihr springend und hüpfend davon und rief vor sich her und schrie: verbrenne, verbrenne, verbrenne!

Er eilte und sprang davon mit der Fackel in der Richtung des Hauses.

Einer der Leute aus dem Hause brachte nun Wasser in einem Gefäss und trampelt und hüpft auf der Veranda vor der Haustüre herum und er erhebt seine Stimme und ruft: Regen, Regen, Regen! und er löscht sogleich aus das Feuer der Fackel.

Und Lendang kehrt wieder rasch um und begibt sich zu ihm, seinem König, und er spricht mit kleinlauter, zaghafter Stimme: O mein Herr, mein Sangiang, überaus gross ist der Mut der Leute der Welt.

Es war mir als ob ich untertauchen würde unter die Wassertiefe, weil der Strahl des Wassers, der mich traf so heftig war.

Das ist doch arg, das ist doch verwunderlich, dass sie einen solchen Mut besitzen, spricht der König des Feuers. Wohlauf Njala (Flamme), mache du dich nun auf. 
Te oloh manontong sahewan tinai.

Njala hagoet mantadjok sahewan, hajak hadari kadjokkadjok ttg. hamauch: tusul, tusul, tusul! manintu huma.

Te palus idje mimbing sarangan danum endau, balua huma palus mendeng intu bapatah hajak pidjak-padjaka ttg. hamauch, koa,e: udjan, udjan, udjan! tawan, tawan! hajak mambelep apui idje aton intu lawi,n sahewan nah. Te Njala mules, mansanan akan radja,e, hajak hamauch koa,e: djaton tahan, tempo, sangiang, kakarangka aku matei, tisa barah ih.

Has Barah! koa,n radja,n Apui, hagoet ikau.

Kueh kamenteng keton bahut? isut ih bahut, olih keton mampalepah lewu pulu.

Te oloh manotong sahewan, amon djadi manjala te oloh mambelep,e, batisa barah apui.

Te idje biti ain radja,n Apui, bagare Barah, manekap sahewan hajak hadari kadjokkadjok manintu huma ttg. hamauch, koa,e: tusul, tusul,
Und wiederum entzünden seine Untertanen eine Fackel.

Njala macht sich auf und er springt und hüpft mit der Fackel und er ruft vor sich her: verbrenne, verbrenne, verbrenne! und er eilt davon in der Richtung des Hauses.

Und sogleich tritt er, der das Wassergefäss soeben gehalten hatte, aus dem Hause und er trampelt und hüpft auf der Veranda vor der Türe und er erhebt seine Stimme und ruft aus: Regen, Regen, Regen! Packt ihn, ergreift ihn! und er löschte aus das Feuer der Fackel.

Und Njala kehrt wieder um und er berichtet seinem König und er erhebit seine Stimme und spricht: Nicht war es möglich Stand zu halten, o mein Herr, mein Sangiang, beinahe hätte ich mein Leben verloren, nur noch ein Rest der glühenden Kohle ist vorhanden.

Wohlan Barah (glühende Kohle), spricht der König des Feuers, mache du dich nun auf.

Wo ist der Mut, den ihr gewöhnlich habt? wenig habt ihr doch jeweils nötig und es ist möglich damit zahlreiche Dörfer zu vernichten.

Und die Untertanen entzünden eine Fackel und nachdem sie gut gebrannt hat löschen sie sie wieder aus und es bleibt übrig ein Stück glühender Kohle.

Einer der Untertanen des Königs des Feuers, mit Namen Barah (glühende Kohle), ergreift die Fackel und eilt mit ihr hüpfend und springend davon in der Richtung des Hauses und er 
tusul!

Te balua idje mimbing sarangan danum endau, mendeng pidjak-padjaka intu bapatah hajak hamauch, koa,e: udjan, udjan, udjan! tawan, tawan!

Ie manata barah apui te ttg. ewen manawan ie kilau djaka manjangit, ie kea malawan kilau djaka mahapan kaabas,e idje paham.

Tapi Barah kalah, ie inahan ewen huang huma.

Toh ombe-ombet katahi,e radja,n Apui mantehau, koa,e : o Barah, o Barah! palus Barah djaton maku tombah.

Koa,n radja,n Apui: keleh amon dia belep Barah te, ie idje batang kaharapku, basa bahut oloh djaton njala, asal barah aton, dia men.

Te ie mantehau tinai :o Barah, o Barah, o Barah! tapi Barah palus djaton tombah.

Hau, koa,n radja,n Apui, lalehan palus djaton tombah ttg. ie mantehau sinde tinai: o Barah, belep ikau?

Koa,n ewen huang huma, tombah : belep, belep, belep!

Hau, koa,n radja,n Apui, amon kalotoh toh, kalah aku. erhebt seine Stimme und ruft aus: verbrenne, verbrenne, verbrenne!

Und wieder tritt heraus aus dem Hause, er, der soeben das Wassergefäss hielt, und er trampelt und hüpft auf der Veranda vor der Türe und er erhebt seine Stimme und ruft aus: Regen, Regen, Regen! Packt ihn, ergreift ihn! Er giesst Wasser auf die glühende Kohle des Feuers und sie fangen ihn wie wenn sie sehr zornig wären und er setzt sich zur Wehr wie wenn er seine Kraft gebrauchen würde, die sehr grosse.

Und Barah wird besiegt und er wird gefangen gehalten im Hause.

Nach einiger Zeit ruft der König des Feuers mit lauter Stimm: o Barah, o Barah! aber kein Barah gibt ihm eine Antwort.

Es spricht der König des Feuers: es wäre nur gut wenn nicht ausgelöscht wäre der Barah, denn er ist meine vornehmste Hoffnung, denn es ist doch so: haben die Leute auch keine Flamme (Njala), wenn glühende Kohle (Barah) vorhanden ist, dann macht alles nichts aus.

Und wiederum ruft er: o Barah, o Barah, o Barah! aber Barah gibt keine Antwort.

Hau, ruft der König des Feuers aus, es ist $\mathrm{zu}$ arg, wiederum erhalte ich keine Antwort und nochmals ruft er: o Barah, bist du denn ausgelöscht?

Und sie im Hause erheben ihre Stimme und sie antworten zurück: ausgelöscht, ausgelöscht, ausgelöscht!

Hau, spricht der König des Feuers, wenn es so steht, dann bin ich besiegt 
Te koa,n ewen huang huma: manang, manang, manang!

Maka radja,n apui handak hadari ampi,e, handak akan ngawa, akan ngadju, palus balang, handak akan ngambo, akan ngiwa, palus balang kea, hajak ewen oloh are mangapong ie huang pasah te ttg. oloh bakas bara huma mohon kea, uras mendeng hakaliling pasah.

Koa,n radja,n Apui: hadari aku akan ngadju, ngambang ewen bara ngadju, hadari aku akan ngawa, nambang ewen bara ngawa, hadari aku akan hila ngambo, nambang ewen bara ngambo, hadari aku akan ngiwa, nambang ewen bara ngiwa.

Terai aku, hagatang buli akan ngambo ih, koa,n radja,n Apui.

Te ewen hakaliling hamauch koa,e: udjan, udjan, udjan! hajak naburan danum akan hundjun sapau pasah.

Te koa,n radja,n Apui : amon kalotoh aku toh, te dia balang aku mateu habuno, aku kalah.

Koa,n ewen idje hakaliling pasah: amon ikau dia mangganti kare ramo idje nihau, worden.

Und sie, die sich im Hause befinden, rufen aus: wir haben gesiegt, gesiegt, gesiegt!

Und der König des Feuers will die Flucht ergreifen und scheinbar davon rennen, er wendet sich nach flussabwärts, er rennt nach flussaufwärts, aber er muss es aufgeben, er eilt nach der Rückseite des Dorfes, er eilt nach seiner Vorderseite, aber auch diesmal muss er es aufgeben, denn die Leute, die vielen, belagern und umzingeln ihn in der Hütte und auch der Aelteste steigt aus dem Hause herunter und sie alle zusammen umringen die Hütte.

Und es spricht der König des Feuers: flüchte ich mich nach flussaufwärts, dann erwarten sie mich dort, flüchte ich mich nach flussabwärts, dann pakken sie mich dort, flüchte ich mich hinter das Dorf, dann ergreifen sie mich dort, flüchte ich mich nach der Vorderseite des Dorfes, dann nehmen sie mich auch dort gefangen.

Ich gebe es auf und ich erhebe mich in die Höhe, spricht der König des Feuers.

Aber sie, die die Hütte umringen, erheben ihre Stimme und sie rufen aus: Regen, Regen, Regen! und sie schütten Wasser aus über das Dach der Hütte. Und es spricht der König des Feuers: wenn es so steht mit mir, dann wird es nicht mehr abzuwenden sein, ich muss sterben, erstochen durch ihre Speere, ich bin überwunden worden. Und es sprechen sie, die die Hütte umringen, wenn du nicht alle Güter ersetzest, die verloren gegangen sind, 
puna dia ikei malapas ikau, ikau akan mangganti,e.

Ikau akan mangganti huma idje nihau, musti due, djaka ramo saratus, musti due ratus, djaka ramo sakojan, musti due kojan, djaka huma bahalap ih solake, djari lipet due kahalap,e.

Koa,n radja,n Apui: Ijoh, prea tau dia, aku mangganti,e, tapi aku toh puna dia tau aku mangun-mangunan kilau keton kalunen, hajak dia aku tau satiar, baja toh aku mandjulok akan keton simpei, penjang karuhei tatau, sandik paturong sangkalemo radja akan karuhei keton manggau uwang duit, manggau parei behas, karuhei keton mamili garantong lalang, karuhei keton mamili halamaung balanga, karuhei keton mangunmangunan.

Amon keton djari mingkes karuhei toh, koa,n radja,n Apui, te sanang keton, limbah toh dia haban pehe, dia balasut badarem, dia bakeho bakampur, dia matei nihau. dann werden wir dich wahrlich nicht mehr freilassen, du hast sie wieder zurück zu erstatten.

Du hast zu ersetzen das Haus, welches abgebrannt ist, und zwar müssen es zwei Häuser sein, sind hunderte von Gütern verloren, dann hast du sie mit doppelt so vielen $z \mathfrak{u}$ ersetzen, sind tausende von Gütern verloren, dann hast du sie mit zweifach so vielen wieder zurückzuerstatten, war das frühere Haus schön, das neue muss von doppelter Schönheit sein.

Und es spricht der König des Feuers: $\mathrm{Ja}$, wie sollte ich es nicht tun, ich werde alles ersetzen, aber was mich betrifft, wahrlich ich kann keine Häuser aufrichten und bauen wie ihr Menschen, auch kann ich nicht Geld erwerben und Bauholz suchen, ich kann euch nur überreichen die Bündel mit Penjang und mit den Karuhei des Reichtums, die Büschel mit Paturong Sangkalemo Radja, ich kann sie euch geben als Karuhei, damit ihr leicht Geld erwerben könnt, damit ihr Reis und enthülsten Reis zu kaufen vermögt, ich kann euch nur geben Karuhei für den erfolgreichen Ankauf von Gong und heiligen Töpfen, Karuhei mit denen ihr vorteilhaft kaufen könnt Balanga (teure heilige Töpfe) und Karuhei für den Wiederaufbau eueres Hauses.

Und wenn ihr im Besitze seid dieser Karuhei, die ich euch geben werde, sprach der König des Feuers, dann werdet ihr Frieden (oder auch Heil) haben, ihr werdet darnach nicht mehr durch Krankheiten und Schmerzen 
Koa,n oloh bakas: Has, kilen auch itah amon kalotoh, tarima,e ikei toh.

Te radja,n Apui mandjulok tetek kaju barangai, hajak hamauch, koa,e: Toh kaju,n karuhei tatau, manampa keton akan hampatong, gene-genep gawi,n keton, mampatei manok bawoi, injaki,e keton.

Te oloh bakas manjambut karuhei te, hajak hamauch, koa,e: njambutku kaju,n karuhei pasihan akan ewen Ano idje bakeho huma serok,e.

Ie manontong auch,e, koa,e: itah hakotak sama terus-tarang sampai halentup awang baloh, sampai harapak idjang pahera akan keterangan keton ela mangeho mangampur ewen tinai.

Koa,n radja,n Apui: Ijoh, kilen auch ikei. heimgesucht werden, ihr werdet nicht mehr $z u$ erdulden haben Hitze und Fieber, ihr werdet nicht mehr Brand erleiden und nicht mehr mit Rauch umhüllt werden, ihr werdet nicht mehr sterben und verloren sein.

Und es spricht der Aelteste: Wohlan, was sollten wir $z u$ entgegnen haben, wenn es so ist, wir nehmen sie an (d.h. die Karuhei als Entschädigung für den erlittenen Schaden).

Und darauf überreicht ihm der König des Feuers ein Stück Holz, gleichgültig welches auch immer, und er erhebt sein Wort und spricht: Empfanget hier das Holz des Karuhei des Reichtums, schnitzet von ihm ein Bild mit menschlichem Angesicht und bestreicht es während jeder religiösen Handlung bei der ihr Hühner oder Schweine tötet mit ihrem Blut.

Und der Aelteste nimmt das Karuhei in Empfang und er erhebt sein Wort und spricht: ich nehme in Empfang das Holz der Karuhei Pasihan (ein anderes Wort für Karuhei) für sie, die N.N., denen das umwandete Haus abgebrannt ist.

Und er setzt seine Rede fort und spricht: wir wollen klar und deutlich miteinander sprechen, sodass wir selbst eine Baloh zerspalten und einen Beilschaft zerbrechen 205 als Zeichen der Bekräftigung (des Eides), dass ihr nicht mehr abbrennen und mit Rauch umhüllen werdet sie, denen ihr bereits Schaden zugefügt habt.

Es spricht der König des Feuers : Ja, was sollten wir dagegen einzuwenden haben. 
Toh radja,n Apui palus mimbing tetek kaju mamukul awang baloh asip sampai rotek hajak marapak idjang pahera ttg. koa,n radja,n Apui : keleh ewen idje bakeho huma mondok hakampeleng intu karatak, aku manduan lasut darem$\mathrm{ku}$, manduan panganduangku, manduan kalasutku idje mawi mangapehe ewen.

Te ewen uras mondok hakampeleng intu karatak hajak manutup takolok,e hapan benang bahandang te.

Koa,n radja,n Apui mambawa oloh ai,e : o Lendang, o Njala, - Barah, o Lasut, O Buring, o Pondok, o Karewo!

Te kare ewen idje balian uras manokep pasah ai,e.

Koa,n radja,n Apui: has keton manduan panganduang kalasut.

Te ewen mahapan langgei simbel mahiris-mahiris intu hundjun benang te lowalowah, hajak hamauch, koae: Nantan mengkak kare pa-
Und sogleich ergreift der König des Feuers ein Stück Holz und er zerschlägt die Baloh Asip bis sie in viele kleine Stücke zerschmettert ist, ebenso zerbricht er den Beilschaft und es spricht der König des Feuers : mögen sie, denen das Haus abgebrannt ist, sich versammeln und sich vor mir auf die Erde setzen, denn ich will ihnen wegnehmen die Hitze meines Fiebers, ich werde von ihnen zurückholen das Unheil, das ich bei ihnen niedergelegt habe, ich werde sie befreien von meiner Wärme die sie quält und die ihnen Schmerzen bereitet.

Und sie alle versammeln sich und sie setzen sich auf den Erdboden und sie verhüllen ihre Köpfe mit dem roten Tuch, das über sie gelegt wird.

Und es erhebt der König des Feuers seine Stimme und er ruft: o Lendang (hell glänzender Schein des Feuers), o Njala (Feuerflamme), o Barah (glühende Kohle), o Lasut (Hitze), o Buring (Russ), o Pondok (Feuerbrand), o Karewo (Asche).

Sie alle die Hülfsbalian (oder die Beantworter, die also diese Namen tragen und diese Untertanen des Königs des Feuers vorstellen) nähern sich seiner Hütte.

Und es spricht der König des Feuers zu ihnen: Wohlan, schneidet weg und holt zurück das bei ihnen niedergelegte Unheil der Hitze.

Und sie gebrauchen ein kleines Schnitzmesser und sie schneiden sehr sorgfältig weg auf dem Tuch und sie erheben ihre Stimme und sprechen: wir schneiden weg, wir machen euch frei 
nganduang kalasut apui bahe, tinai ewen mahantok hampatong idje aton, mahantok,e intu gagenep ewen idje mondok ttg. intu takolok oloh balian handiai hajak hamauch, koa,e :

Kare panganduang Apui idje mawi, idje mangapehe, idje mangeho, uras lompat hampatong toh. von allem Unheil das bei euch niedergelegt wurde durch uns, wir erlösen euch von der Hitze des Feuers, des glühenden, und darauf schlagen sie sanft mit dem Schnitzbild, das vorhanden ist und sie berühren mit ihm sie alle die sich gesetzt haben und auch die Köpfe aller Balian und sie erheben ihre Stimme und sprechen:

Alles Unheil, das niedergelegt wurde durch das Feuer, das quälende, das Schmerzen bereitende, das die Häuser niederbrennende, alles besteige dieses Schnitzbild hier.

\section{d. Schluss}

Hajak koa,n radja,n Apui: has buli itah anak aken, eso, kare desa panangkawangku, ikei mimbit kare panginan toh.

Te ewen oloh bakas mambawa hambaruan, koa,e: Kurrk, hambaruan ikei handiai, kurrk, hambaruan ewen balian kea, hajak kilau mambowor en-en hundjun sangko,n hambaruan (ie te behas tambak).

Te upo,n balian idje djadi radja,n Apui nah hingkat hajak mandjo-mandjo biti,e kilau djaka nahuang akan ngawa, kilau nahuang akan ngadju, te ie palus nangkero sewu akan petak hajak oloh manusul pasah te hapan apui, hampatong impelai hete, ramo beken impalua bara pasah,
Und es spricht der König des Feuers : wohlauf, wir wollen wieder zurückkehren, meine Kinder und Neffen, meine Enkel und meine Untertanen und meine Begleiter, und wir wollen alle diese Speisen mit uns nehmen.

Und sie, die Aeltesten, rufen nun die Seelen, indem sie sprechen: Kurrk, ihr Seelen, ihr alle zusammen, kurrk, auch ihr Seelen der Balian, und gleichzeitig tun sie wie wenn sie etwas ausstreuen würden über dem Gefäss der Seelen (d.h. über dem aufgehöhten Reis). Der Hauptbalian, der soeben noch der König des Feuers war, erhebt sich und er tut als ob er in der Richtung nach flussabwärts entweichen wollte, er gebärdet sich als wollte er nach flussaufwärts flüchten, aber plötzlich springt er aus der Hütte auf die Erde während zur gleichen Zeit die Leute die Hütte anzünden und mit Feuer verbrennen, das Schnitzbild (das mit allem Unheil 
hajak ewen handiai uras mohon akan batang mandoi, belahe manjaup arepe hapan danum.

Amon pasah te djari bakeho, te ewen manat hapan danum sampai belep toto.

Tinai oloh balian mondok balian magah Gana,n Apui sampai hanggulan garing intu kaleka Batu Nindan Tarong.

Limbah te ewen buli akan huma. Oloh balian mambowor behas hambaruan akan gagenep ewen. beladen worden war) ist in der Hütte zurückgelassen worden, aber alle andern Güter hat man vorher aus ihr herausgeholt und darnach steigen sie alle zum Anlegefloss hinunter um zu baden, einige aber übergiessen sich auch mit Wasser (das Bad hat hier eine religiöse Bedeutung, siehe Tantolak Matei).

Wenn die Hütte abgebrannt ist, dann giessen sie noch Wasser über sie aus, bis das Feuer gänzlich ausgelöscht ist. Die Balian setzen sich nun wieder und sie beendigen die priesterlichen Handlungen und sie leiten das Feuer zurück zum elfenbeinernen Hanggulan im früheren Orte Batu Nindan Tarong. Darauf kehren sie wieder zurück ins Haus. Die Balian streuen nun noch den Seelenreis nach allen Teilnehmern an diesen Handlungen (vor allem auch nach dem Besitzer des abgebrannten Hauses und seinen Angehörigen).

\section{Handlungen beim Tod durch Verbrennung}

Beim Tod, der durch Verbrennung eingetreten ist, wird, wie überhaupt beim Tod durch Lnfall, die Leiche nicht in einem Hause aufgebahrt, sondern auf dem Dorfwege oder im Versammlungshaus. Von dort aus wird sie in der üblichen Weise beigesetzt. Ist ein Mensch vollständig verbrannt, dann sucht man auf dem Brandplatz nach seinen Ueberresten, sei es nach Knochen oder nach Asche. Man birgt diese Ueberreste in einer alten Kiste, oder einem geflochtenen Koffer oder auch in einem kleinen Topfe auf und bringt diese ebenfalls zum Bestattungsort, sei es zum Grab oder zum Gestell auf dem die Särge beigesetzt werden. Am Rachezug, der ausgeführt wird nach dem Njarang Tingang Hatuen Apui und seinen Untertanen, nehmen die Menschen nicht teil, wie das sonst in andern Fällen geschehen kann. sondern dieser $\mathrm{Zug}$ wird ausgeführt durch Dohong Mama Tandang und seine Untertanen. Um Rache nehmen zu können am Njarang 
Tingang Hatuen Apui und um den Toten, der von ihm und seinen Untertanen geraubt und in die Gefangenschaft mitgeführt worden ist, bedient man sich ebenfalls der Balian. Es dürfen nicht weniger sein als ihrer drei, aber nicht mehr als fünf. Sobald sie sich eingefunden haben, wird der Brandplatz mit einem Tarinting (einem Rotanseil an dem Sawangblätter aufgehängt wurden) abgeschlossen. Darnach werden alle notwendigen Vorbereitungen getroffen für das Mampakanan Gana,n Apui (die Opfer für das Feuer) und dann beginnen die Balian mit ihren Handlungen wie sie bereits mitgeteilt wurden und deshalb hier nicht wiederholt werden müssen. Nach diesen einleitenden Gesängen und Handlungen rufen die Balian den Sangiang Dohong Mama Tandang herbei, der eine der beiden "Seelen“ des Toten, nämlich die Liau Balawang Pandjang, nach der Oberwelt zu leiten hat. Nachdem er das Tantolak Ambon Rutas (die Verabschiedung der Rutaswolken) vollzogen hat, reist der Sangiang Dohong Mama Tandang mit seinen Untertanen auf seinem Schilde, den er als Fahrzeug gebraucht (der Name dieses Bootes ist: Papan Talawang Teras Kaju Djambu Bahandang), zum Brandplatz, zum Ort wo der Verstorbene sein Leben verloren hat. Bis hier lauten alle Gesänge gleich wie sie im Tantolak Matei vollständig mitgeteilt werden. Ist der Dohong Mama Tandang beim Brandplatz angekommen, dann singt der Upon Balian (Hauptbalian), der nun der Dohong Mama Tandang selbst ist, in der Basa Sangiang wie der Rachezug ausgeführt und der Tote von Njarang Tingang Hatuen Apui wieder zurïckgeholt wird.

Der Gesang des Hauptbalian, der begleitet wird von den Trommeln seiner Helfer, lautet folgendermassen:

I, ohoi bara ohoi! manolak Ohoi und nochmals ohoi (wohlan, papan talawang teras kaju wohlauf)! wir stossen ab mit dem djambu bahandang.

Schildbrett vom Kernholz des Baumes der rotfruchtigen Djambu.

I,ehei bara ehei! manjangka Ehei und nochmals ehei (wohlan, wohlbulau daren lintong, luhing kaju muntei bulau.

I,tolak papan talawang bara panjalanting parong. auf)! wir schieben weg das Gold, das umflochtene mit Bändern, die Trommel (kann auch bedeuten der Stamm, wir übersetzen mit Trommel weil der Schild etwas hohl ist), die hölzerne, die goldig glänzende.

Stosse ab, Schildbrett, vom Anlegefloss des Hauses (der Platz wo der 
Schild, das Fahrzeug des Mama Tandang, angebunden wird, liegt über der Haustüre).

Manarusan tarusan sawang lewu, manjaruroi lapeta,n bunge rundong.

Habasean tandjong sapapulut lewu, mangangkajoh luwok kadjalumpang rundong.

Eleh babalang laju,n dawen pinang lewu, batentang djambulei bumbong katalambong njaho.

Eleh babalang lenda-lendang eka keho bapujan matei, batentang linge-lingei tusul awo badjumbang nihau.

Tende hando papan talawang teras kaju djambu bahandang, tahan hunang bulau daren lintong, luhing lumpok muntei bulau.

Tende, batoros teken garing, tahan, maharukan bulau namburak.

Njangkabila tatambat keket, halaloha,e djamban garing.

Manamuei keho bapujan matei, mangadja tusul awo ba-
Es fährt hinunter, als Fahrweg benützend den Sawang (Dracaena terminalis) des Dorfes, es reist flussabwärts am Sawang des Ortes.

Es rudert vorbei an der Flussbiegung der Bambusbüsche des Dorfes, es fährt vorüber an der mit Bambus bewachsenen Buchtung des Ortes.

Und schon werden sichtbar die verwelkten Blätter der Pinangbäume des Dorfes, schon tauchen auf die vertrockneten Herzblätter der donnernden Betelnüsse. ${ }^{206}$

Und schon taucht auf der leuchtende Schein des Brandplatzes, das reichgeschmückte Grab des Toten, bereits sieht man den gelblichen und roten Glanz des Feuerortes, den Ort wo sich aufhält die Liau (awo), die umgefallene, die verlorene.

Und es hält an das Schildbrett, das Kernholz des rotfruchtigen Djambu, es steht still das Gold mit den umflochtenen Bändern, die Trommel vom Marke des Holzes, des goldglänzenden. Es hält an und in den Grund gesteckt wird der Pfahl, der Stechbaum, der elfenbeinerne, es steht still und es wird festgebunden mit dem goldenen Seile, dem geschälten (d.h. mit einem Stück Rotan). 207

Und das Rotanseil auf der Steuerseite des Bootes machen sie fest und sie lassen den elfenbeinernen Steg herunter.

Und der (Dohong Mama Tandang) begibt sich zum Brandplatz, zum reich 
djumbang nihau.

geschmückten Grab des Verstorbenen und er besucht den Feuerort, die Stelle der Seele, der umgefallenen, verlorenen.

\section{a. Dohong Mama Tandang holt den Toten zurück}

Toh malaian tekap katambong, baja upo,n balian hapan karungut,e kabuat, koan bawak auch,e :

I,palus gatang tarahendeng linga Dohong Mama Tandang, hajak tundjong tarahingkat Langkah Sawang Mama Bungai Bunge, bandong Njaring djahawen.

Nangking manantelai dohong,e meteng mambahulan bulau batu penjang,e.

Hatanggar renteng tingang, mangambuah djundjong sampulau dare. 208

Palus mukei pati bahandang muap tabala radja, manduan djala bulau, andoh njaho 209 idje nampusok bulau sangkalemo, manambatu garantong saratus udju pulu, manambatu kangkanong saratus udju pulu, manambatu gandang saratus udju pulu.

Puna rangkan panatau ain Dohong Mama Tandang, sangiang.

Hapan mandjala liau kara-
Die Trommeln werden nun nicht mehr geschlagen, der Hauptbalian spricht sein Spruchwort allein und es lautet seine Rede:

Und sogleich erhelt er sich und steht auf, er, der Dohong Mama Tandang, es erhebt sich und steht auf, er, der Langkah Sawang Mama Bungai Bunge (ein anderer Name für Dohong Mama Tandang), er der Mann der Njaring, der sechsen.

Er hängt schräg herabhängend um seinen Dolch, er bindet und knüpft fest die goldenen Steine seiner Penjang.

Er bringt in Ordnung die Schwanzfedern des Nashornvogels, er setzt zurecht die Wölbung des geflochtenen Kopfschnuckes.

Und er öffnet die Kiste, die rote, und er schliesst auf die Truhe, die königliche, und er entnimmt ihr das Wurfnetz, das goldene, den Andoh Njaho, der geflochten ist vom heilbringenden Golde, der beschwert ist mit hundert und siebzig Gong, dem Gewichte angehängt sind bestehend aus hundert und siebzig kleinen Gong, der beschwert ist mit hundert und siebzig Trommeln. 210

Es ist der Reichtum und der Schatz, das Eigentum des Dohong Mama Tandang, des Sangiang.

Es dient dazu um es auszuwerfen und 
hang tolang, 211 mauntai pangambon rahandjang uhat. 212

Palus gatang tarahendeng balita,n Dohang Mama Tandang, sangiang, tundjong tarahingkat Langkah Sawang Mama Bungai Bunge, bandong Njaring djahawen.

Habanggunan djala bulau, andoh njaho, bahalap manampusok bulau sangkalemo.

Udju mangarakop hila pangantau,e udju mangarakop hila panjambilei,e.

Idje lawah tiring, mukong tapakan tontong papan talawang, idje lawah tendur baheken ruang hantanep.

Ulang hambambalang, balita tambon pulu linga Dohong Mama Tandang, sangiang, Langkah Sawang Mama Bungai Bunge, bandong $\mathrm{Nja}-$ ring djahawen.

Manjun djala bulau kilau manjun garing tukang tujang, rowan mangumban ranggiran sampu,e. einzufangen die Liau Karahang, um aufzufischen die nebelgleiche Rahandjang Uhat.

Und sogleich erhebt sich und steht auf, er, der Dohong Mama Tandang, der Sangiang, es erhebt sich und steht auf, er, der Langkah Sawang Mama Bungai Bunge, er, der Mann der Njaring, der sechsen.

Er nimmt auf das Wurfnetz, das goldene, den Andoh Njaho, den schön geflochtenen mit dem heilbringenden Golde.

Sieben Hände voll des Netzes nimmt er auf die rechte Seite, sieben Hände voll nimmt er auf seine linke Seite (er entfaltet es und macht es zum Auswerfen bereit).

Das straff angespannte Netz ruht auf dem Ende der Verlängerung des Kieles des Schildbrettes (d.h. des Bootschnabels der etwas aussteht. Wirft man das Netz aus, dann steht man auf diesem Schnabel während ein Begleiter langsam das Boot weiterrudert) und die schlaffe Seite des Netzes ruht auf der Innenseite des Fahrzeuges.

Er streckt es aus, er zieht es wieder zurück (die Bewegungen die man macht um das Wurfnetz gut auswerfen zı können sodass es sich schön entfaltet), er selbst, die Wasserschlange, die zehnfache, er, der Dohong Mama Tandang, der Sangiang, der Langkah Sawang Mama Bungai Bunge, er, der Mann der Njaring, der sechsen.

Er schwingt das Netz, das goldene, hin und her, so wie man wiegt ein Elfenbein (ein kleines Kind) in seiner Wiege, wie man hin und her schwingt 
die glückbringenden und schützenden Bündel. 213

Mirang kamalangkang djala bulau, andoh njaho, nduan idje katampujan bawi balo.
Mangadjang eka keho, bapujan matei, mangarangkep 214 eka tusul awo badjumbang nihai.

Taparangkum uras,e liau karahang tolang, tapugenggem lingis pangambon rahandjang uhat.

Liau karahang tolang tundjok pai,e ttg. liau silo,e lime pangantau, lime panjambilei.

Liau tatap,e pangantau, tatap,e panjambilei, liau buko laling,e hila pangantau, hila panjambilei, liau tolang buntis,e hila pangantau, liau tolang buntis,e panjambilei, liau panjulau utut,e hila pangantau, panjulau utut,e hila panjambilei.

Liau tolang sapak,e hila pangantau, tolang sapak,e panjambilei.

Liau tolang kahang,e, liau tolang likut,e, liau tolang
Es breitet sich aus, es strebt weit auseinander das Wurfnetz, das goldene, vergleichbar einem Katampujan (die Bedeutung dieses Wortes ist mir nicht deutlich. Wahrscheinlich ist es ein Schleier oder ein Hut mit weit herabhängenden Fransen um seine Ränder, so wie er in der Trauerzeit von den Witwen getragen wird) einer Frau, einer Witwe.

Es bedeckt den Brandplatz (das Netz wurde nun ausgeworfen), das reich geschmückte Grab des Verstorbenen, es liegt wie eine Falle über dem Feuerort, dem Platz der Seele, der umgefallenen, der verlorenen.

Er packte sie alle zusammen, sie, die Liau der Knochen, er ergreift sie restlos, sie, die nebelgleichen Rahandjang Uhat.

Er fängt ein die Karahang der Knochen der Zehen und die Liau der Nägel, fünf von der rechten Seite und fünf von der linken Seite.

Die Liau der Fussohle rechts und der Fussohle links, die Liau der Fussknöchel rechts und der Fussknöchel links, die Liau des Schienbeines der rechten Seite, die Liau des Schienbeinknochens der linken Seite, die Liau der rechten Kniescheibe und die Liau der linken Kniescheibe.

Die Liau des rechten Oberscinenkelknochens und die Liau des linken Oberschenkelknochens.

Die Liau des Hüftknochens, die Liau der Rückenknochen, die Liau der 
barawar,e hila pangantau, tolang barawar,e hila panjambilei.

Liau tolang lenge hila pangantau, tolang lenge hila panjambilei.

Liau tolang siko,e hila pangantau, tolang siko,e panjambilei.

Liau lawas penang 215 hila pangantau, lawas penang hila panjambilei.

Liau tolang kukut,e hila pangantau, tolang kukut,e hila panjambilei.

Liau tolang lokap,e hila pangantau, tolang lokap,e panjambilei.

Liau tolang tundjok,e ttg. liau silo,e, lime hila pangantau, lime hila panjambilei.

Liau tolang salangka,e hila pangantau, tolang salangka,e hila panjambilei.

Liau tolang ujat,e, liau tolang balengkong,e, liau takolok,e, liau kasinga,e, liau totok biwih,e, liau urong,e, liau lumpok mata,e.

Liau pinding,e hila pangantau, pinding,e hila panjambilei.

Liau balau,e, liau pupus bulu,e.

Lepah liau tolang uhat,e, sama tapakalong djala bulau.

Liau isi daha,e liau atei bua,e, Die Liau des Fleisches und des Blutes,
Rippen der rechten Seite und die Liau der Rippen der linken Seite.

Die Liau der Knochen der rechten Hand und die Liau der Knochen der linken Hand.

Die Liau des rechten Ellenbogens und die Liau des linken Ellenbogens.

Die Liau der Knochen des rechten Armes und die Liau der Knochen des linken Armes.

Die Liau des rechten Handgelenkes und die Liau des linken Handgelenkes.

Die Liau der Knochen der rechten Handfläche und die Liau der Knochen der linken Handfläche.

Die Liau der Fingerknochen und der Fingernägel, fünf von der rechten Hand und fünf von der linken Hand. Die Liau des Schlüsselbeinknochens der rechten Seite und die Liau des Schlüsselbeinknochens der linken Seite. Die Liau des Halsknochens und die Liau der Kehle, die Liau der Kopfknochen, die Liau der Zähne, die Liau der Oberlippe und der Unterlippe, die Liau der Nase und die Liau der Augäpfel.

Die Liau des rechten Ohres und die Liau des linken Ohres.

Die Liau der Kopfhaare, die Liau der Körperhaut und der Körperhaare.

Sie alle zusammen, sie die Liau der Knochen und Muskeln, sie alle zusammen sind nun eingeschlossen in dem goldenen Wurfnetz. 
liau paramo,n bereng,e, liau kotak tutor,e, liau kaharati kapintar,e.

Haul, unda-undak Dohong Mama Tandang, sangiang.

Hadjidji-djidjit Langkah Sawang Mama Bungai Bunge, bandong Njaring djahawen.

Ie manampusok akan ngambo kare liau biti,e bereng,e.

Hagatang hakampeleng akan tampusok djala bulau, andoh njaho, idje nampusok bulau sangkalemo, mangampungan rabia sangkalunjai.

Ie, liau biti bereng,e basaloh bulat kilau batu,n karangan danum, pangambon rahandjang uhat,e malik bunter njakatan takanan pinang lewu.

Djadi saloh tanteloh tingang huang tampusok djala bulau.

Ie, haunda-undak Dohong Mama Tandang, imbit,e manjelem papan talawang, hajak balua,e bara tampusok djala bulau.

Muat,e huang supu bulau,216 ingkes,e huang pati bahan- die Liau der Leber und der Nieren, die Liau aller Bestandteile des Körpers, die Liau der Sprache und des Redens, die Liau des Verstandes und der Vernunft.

Haı, es rückt hin und her (das Netz, das voll und schwer ist) Dohong Mama Tandang, der Sangiang.

Er zieht und er zerrt fortwährend am Netze, er, der Langkah Sawang Mama Bungai Bunge, er, der Mann der Njaring, der sechsen.

Eingefangen und eingeschlossen zieht er sie in die Höhe, sie die Liau des Körpers, der Person.

Er hebt sie in die Höhe, sie, die alle versammelt sind (die Liau) im geflochtenen goldenen Wurfnetz, dem Andoh Njaho, welcher geflochten (oder gewoben) wurde von heilvollem Gold, welcher gewoben wurde von dem glückbringenden Gold.

Sie, die Liau des Körpers, der Person, verwandelt sich zu einem Ganzen, das anzuschauen ist wie der Stein von den Sandbänken des Flusses, sie, die nebelgleiche Rahandjang Uhat, nimmt eine runde Form an, die der Frucht der Betelpalme des Dorfes.

Sie nehmen die Gestalt an eines Eies des Nashornvogels im Gewebe des Wurfnetzes, des goldenen.

Es zieht und rückt das Netz hin und her, er, der Dohong Mama Tandang, er hebt es und bringt es herein in das Schildbrett und er entleert es (das Ei) aus dem Gewebe des Wurfnetzes, des goldenen.

Er schüttet es in das goldene Krüglein, er legt es in die rote Truhe. 
dang.

I,djadi hakatotok tandak,e, Beendet ist nun das Spruchwort um mandjala liau karahang tolang, aufzufischen mit dem Wurfnetz die sambong karunja hapampungan pangambon rahandjang uhat. Liau Karahang der Knochen, abgeschlossen ist der Gesang um einzufangen die nebelgleiche Rahandjang Uhat.

\section{b. Dohong Mama Tandang rücht den Toten}

Limbah gawi djetoh djadi, Dohong Mama Tandang manamuei tinai hagatang akan ngambo, manjampai balaiatawa hamputut garing, hanggulan sihong intu kaleka Batu Nindan Tarong.

Intu hete ie hasondau dengan Njarang Tingang Hatuen Apui.

Maka dengan Njarang Hatuen Apui Dohong Mama Tandang handak hakalahi, sampai oloh ain Hatuen Apui uras batatap handak hakalahi kea: Njala, Lendang, Barah, Lasut, Pondok, Buring ttg. Kawo.

Maka toh ewen palus kea hakalahi.

Are toto desa rajat Apui matei awi Dohong Mama Tandang ewen hadjalahan.

Kadjaria,e Apui mangaku kalah.

Intu hete ilalus awi Dohong Mama Tandang ewen ha-
Nachdem diese Handlungen beendet sind, begibt sich Dohong Mama Tandang wieder auf die Reise und er erhebt sich in die Höhe, bis er erreicht die Hütte, oder den Hamputut, das glimmende elfenbeinerne Scheit im früheren, jetzt aber verlassenen Dorfe Batu Nindan Tarong.

Dort begegnet er dem $\mathrm{Njarang}$ Tingang Hatuen Apui.

Mit Njarang Hatuen Apui will Dohong Mama Tandang Krieg führen, sodass die Untertanen des Hatuen Apui sich alle bereit machen um ebenfalls in den Krieg zu ziehen, nämlich sie: Njala (Flamme), Lendang (der gelblich rote Schein des Feuers), Barah (die glühende Kohle), Lasut (die Hitze), Pondok (der Feuerbrand), Buring (die Holzkohle) und Kawo (die Asche).

Und sogleich bricht zwischen den beiden Parteien der Streit aus.

Sehr viele der Sklaven und der Untertanen des Feuers verlieren ihr Leben durch Dohong Mama Tandang und seine Begleiter.

Schliesslich aber bekennt Apui, dass er besiegt worden sei.

Und dort vollziehen Dohong Mama Tandang und das Feuer das Ver- 
djandji Apui puna dia mawi tinai.

Hajak apui idje mawi te, djadi matei awi Dohong Mama Tandang.

Ewen hadjandji intu taharep Dohong Mama Tandang halentup awang baloh, harapak idjang pahera.

Sarita ewen hakalahi sama dengan auch idje djari insanan helo.

Baja kabeke,e djalahan Dohong Mama Tandang dia ie bara huma tapi bara papan talawang.

Djaka metoh hagoet Njala,n Apui, te puna hagoet biti,n Njala, sinde toh djalahan oloh ain Apui djaton mahapan sahewan.

Limbah ewen Apui djadi mangaku kalah ttg. djadi hadjandji te Dohong Mama Tandang manduan Salumpok Liau Balawang Pandjang. sprechen und die Bekräftigung, ${ }^{217}$ dass Apui die Menschen nie mehr heimtückisch überfallen wolle.

Aber das Feuer (der Untertan des Njarang Tingang Hatuen Apui, nicht er selbst), welches heimtückisch angefallen hatte, war durch Dohong Mama Tandang getötet worden (im Dorf wurde alles Feuer ausgelöscht).

Sie (das Feuer und seine Untertanen) legen in der Gegenwart des Dohong Mama Tandang das Versprechen (den Eid) $a b$ und sie zerschlagen einen Kürbis und sie zerbrechen einen Schaft des Beiles.

Die Erzählung dieses gegenseitigen Kampfes ist die gleiche wie sie bereits mitgeteilt wurde (siehe oben den Text zum Manolak Sial Apui).

Die Unterschiede sind nur diese: die Begleiter des Dohong Mama Tandang ziehen nicht vom Hause aus in den Streit, sondern vom Schildbrett mit dem sie nach Batu Nindan Tarong gereist sind.

Wenn nun die Njala des Feuers auszieht, dann geht auch wirklich die Person des Njala selbst, denn diesmal gebrauchen die Angehörigen des Feuers keine Fackel (wie das oben geschah, wo die Angehörigen des Feuers sich in den Hülfsbalian oder Beantwortern inkorporierten).

Nachdem das Feuer und seine Angehörigen zugegeben haben, dass sie besiegt worden sind und in Gegenwart des Dohong Mama Tandang ihren Eid abgelegt haben nimmt er von ihnen die Salumpok Liau Balawang Pandjang in Empfang. 218 
Njarang Tingang Hatuen Apui mandjulok Liau te akan Dohong Mama Tandang palus Dohong Mama Tandang manarima,e.

Ie palus mimbit,e tame akan huang papan talawang.

Hajak Dohong Mama Tandang mukei supu bulau manduan Liau Karahang Tolang idje endau djadi basaloh bulat kilau tanteloh tingang.

Maka tanteloh te imusit awi Dohong Mama Tandang intu takolok Salumpok Liau Balawang Pandjang.

Te palus Liau Balawang Pandjang abas gantjang, aton uhat tolang,e, isi daha,e, barendeng pinding,e, baterus tampajah,e.

Limbah te Dohong Mama Tandang, sangiang, mampandoi ie ttg. magah ie manalih Njalong Riwut, hete ie mangalingo,219 limbah te ie magah,e talih lewu Balo Indu Rangkang.
Njarang Tingang Hatuen Apui überreicht nun diese Liau dem Dohong Mama Tandang und sogleich nimmt sie der Dohong Mama Tandang auch in Empfang.

Er bringt sie sofort hinein in das Schildbrett.

Und Dohong Mama Tandang öfnet das goldene Krüglein und er nimmt die Liau Karahang Tolang, die sich soeben in einen runden Gegenstand der wie das Ei eines Nashornvogels aussieht (es ist auch tatsächlich ein Ei) verwandelt hat, heraus.

Und dieses Ei zerbricht nun Dohong Mama Tandang auf dem Kopf der Salumpok Liau Balawang Pandjang.

Und alsogleich fühlt sich die Liau Balawang Pandjang stark und kräftig, sie besitzt wieder Muskeln und Knochen, Fleisch und Blut, ihre Ohren hören deutlich und ihr Anschauen ist hell.

Darnach badet sie Dohong Mama Tandang, der Sangiang, und er leitet sie zum Wasser des Windes und dort nimmt sie mit betrübtem Herzen und weinend Abschied von der Welt und er leitet sie ins Dorf der Balo Indu Rangkang.

\section{B. Der Tod durch Ertrinken (matei buseng)}

\section{a. Das Aufsuchen der Leiche}

Wenn man ganz genau weiss, dass ein Angehöriger ertrunken ist, aber seine Leiche trotz aller Bemühungen immer noch nicht finden konnte, dann streuen die Dorfältesten zusammen mit dem Tukang 
tawur (dem Priester der den Reis streut) Reis aus und sie bitten die Reisseelen sich zur Fischotter (dengen) zu begeben und sie zu bitten die Leiche zu suchen, zu heben und über den Wasserspiegel zu bringen, sodass sie mühelos gefunden werden kann. Kommen die Reisseelen bei der Fischotter an, dann erkundigt sie sich nach ihrem Woher und Wohin und ihren Wünschen und sie antworten ihr :

Aton kasusah hong pantai Es herrscht Leid und Schmerz am danum kalunen awi garing Ufer des Flusses der Welt, weil das tarantang Ano djari buseng. Elfenbein, das Kind N.N., ertrunken Awi te ikei balaku ikau ma- ist. Aus diesem Grunde kommen wir lampang,e akan bilo,n njalong, nun zu dir und wir bitten dich ihn uka ewen kareh tau sondau,e. heraufzuheben an die Oberfläche des Wassers, damit sie ihn bald wieder finden können.

Amon Ano te djari sondau, Wenn wir den N.N. wieder gefunden ikei manenga akam: tanteloh manok idje ttg. takupat sinta.

Ikei mingkes,e intu kalangkang kaju langit. haben, dann geben wir dir: ein Hühnerei und in Blätter gewickelten und gekochten Reis der Liebe.

Wir legen diese Dinge in einen Opferkorb der von Himmelholz geflochten wurde. 220

Ist es der Fischotter möglich die Leiche $z \mathfrak{u}$ finden und $z \mathfrak{u}$ heben, dann erhält sie die versprochenen Opfer. Ist es der Fischotter aber nicht möglich die Leiche $z \mathfrak{u}$ finden und an die Oberfläche des Wassers $\mathrm{zu}$ bringen und ist alles Suchen vergeblich gewesen, dann streut der Tukang tawur wiederum Reis und er bittet die Reisseelen sich zur Djata $z \mathfrak{u}$ begeben und sie $z \mathfrak{u}$ bitten die Leiche in ihr Dorf $z \mathfrak{u}$ holen und sie dort gut zu bewachen bis man den Ertrunkenen wieder zurückhole. Wieder sucht man die Leiche auf dem Fluss und wenn man sie immer noch nicht finden kann, dann streut der Priester (Tukang tawur) Reis und bittet die Reisseelen sich zum Pataho (dem Ahnen der im Dorfheiligtum steht und das Dorf schützt) zu begeben und ihm im Auftrag der Bewohner des Dorfes mitzuteilen:

Tingang eso,m huang lewu ano, Antang tiom medjen rundong Ano djadi Lunok idje batipas pating,e, baringen
Der Nashornvogel, dein Enkel im Dorf N.N., der Falke, dein Kleinkind im Orte X., er ist wie ein Baum dem seine $Z$ weige abgeschlagen wurden, er 
idje bageto sangkabila, mananseran bilo,n njalong, leteng manantame gohong, palus dia ikei sondau,e sampai andau djetoh.

Awi te, tingang esom pantai danum kalunen mindjam enteng, $m$, tingang tato, Antang tiom luwok kampongan buno nasihanjim antang hyang, mandjawi harin bamban penjang, $m$ idje menteng, mamekat paturong idje bahanji.

Mandjawi,e mangat biti,m mamupak penjang huang bilo,n njalong, mangisai paturong, $\mathrm{m}$ pahantengan gohong, mamupak penjang,m idje bakalampang rawing basiak, mangisai paturong endus timbul ihing bahandji, mikeh eso,m te inansarang rawing basiak. ist wie ein Waringin dem zerbrochen wurden seine Stützen (die Luftwurzeln), er ist untergetaucht unter die Oberfläche des Wassers, er ist versunken in den Fluten, und nicht mehr konnten wir ihn finden bis auf diesen Tag.

Aus diesem Grunde geschieht es, dass die Nashornvögel, sie, deine Enkel am Ufer des Flusses der Welt, leihen möchten deinen Mut, o Nashornvogel, o unser Ahne, sie, die Falken, deine Kleinkinder an der Buchtung des Flusses an der das Dorf der Speere liegt, sie möchten in Dienst nehmen die Schärfe der Bündel deiner Penjang, o unser Falke, unser Grossvater, sie möchten gegen Bezahlung in Gebrauch nehmen deine Paturong, die mutigen.

Wir möchten sie gegen Bezahlung gebrauchen, damit du abschabest die Penjang über der Oberfläche des Wassers, damit du abschneidest von deinen Paturong über der Mitte der Fluten, damit du abschabest von deinen Penjang die zum Auftauchen zwingen die Krokodile, die wilden, damit du abkratzest von deinen Paturong die da verursachen, dass die mutige Ihing (Wasserschlange) an die Oberfläche des Wassers kommt, denn es kann sein, dass dein Enkel gefangen gehalten wird durch die Krokodile, die wilden.

Als Opfer für den Pataho, den man auf diese Weise um Hülfe gebeten hat, legt man etwas Tabak und ein Sirihkausel bereit und hängt sie den Speeren, die über der Haustüre in einem Gestell liegen, auf oder man legt sie in den Balai Pataho (die Opferhütte des Pataho die sich über diesem Dorfheiligtum erhebt). Man verspricht dem Pataho 
weiter, dass er, wenn es ihm gelinge die Leiche des Ertrunkenen aufzufinden, in Gong gelegt das Fleisch eines Opferschweines empfangen werde. Wird aber die Leiche trotz aller Bemühungen des Pataho nicht gefunden, dann streut der Tukang tawur wieder Reis aus und er ruft dem Antang Rawing Batotok Buno, tabela,n oloh Balai Rangkan Nahuto Penjang. Er hat die Macht in den Fluss unterzutauchen und deshalb bittet man nun ihn die Leiche zu suchen und an die Oberfläche des Wassers zu heben. Gelingt es ihm die Leiche zu finden, dann erhält er als Lohn für die Èrmüdung seiner Knochen und die Erschlaffung seiner Muskeln ein rotes Huhn.

Hat man die Leiche endlich gefunden, dann bringt man sie, wie das mit allen Leichen der Verunfallten geschieht, die ins Dorf gerudert werden müssen, auf das Landungsfloss und bahrt sie dort auf und baut über ihr ein Dach von Matten.

\section{b. Manganjau danum (Die Kopfjagd nach dem Geist des Wassers)}

Immer wenn ein Angehöriger ertrunken ist wird eine Kopfjagd oder ein Rachezug nach dem Geist des Wassers veranstaltet. Die Verwandten des Ertrunkenen bauen zuerst am Flussufer einen Balai Pali (eine Opferhütte in der die Opfer für die Pali niedergelegt werden). In diesem Balai Pali wird ein Balai Antang (Haus des Antang) aufgerichtet, in dem sich der Antang vor und nach den Handlungen des Manganjau danum aufhält und in dem man auch die für ihn bestimmten Opfergaben niederlegt. Als Sitz für den Pataho, der ebenfalls an diesem Rachezug teilnimmt, werden Gong aufgehängt, die mit Sawangblättern verziert werden (man hängt sie um den Rand der Gong. Der Gong ist clas Haus, die Sawangblätter stellen den Heiligen Hain des Ahnenplatzes dar). In der Nähe des Ufers wird im Fluss ein viereckiges Gestell aufgerichtet, so wie man ein solches in der gleichen Weise auch bei der religiös/rituellen Waschung der neugeborenen Kinder aufrichtet. Man verziert dieses Gestell mit ausgefranstem Bambus und mit Palmzweigen.

Die Treppe, die zum Anlegefloss oder zum Fluss hinunterführt, wird für die Dauer dieser Handlungen als pali (verboten) erklärt und als solche kenntlich gemacht durch ein Rotanseil das mit Sawangblättern behängt ist (tarinting). Man hängt dieses Seil an den beiden Pfosten der Treppe auf.

Wenn alle diese vorbereitenden Handlungen vollendet sind holen die Dorfältesten eine Kokosnuss 221 und bemalen sie (mit Kalk) mit 
einem menschlichen Angesicht und befestigen auf dem Kopf eine Schnur die die lang herabhängenden Haare darstellen soll. Diese bemalte Kokosnuss wird vorläufig auf ein Reissieb (kalaja) gelegt. Darauf werden auf dem Fluss zwei Ruderboote für die Priester und die Kopfjäger bereit genacht. Eines der Ruderboote wird oberhalb, das andere wird unterhalb des Balai Pali festgemacht oder verankert.

Zur Ausführung dieser Handlungen braucht man nicht nur den Tukang tawur (Priester der den Reis streut und den Antang Tadjahan aufruft), sondern auch die Balian, weil die Kopfjagd von den Sangiang und dem Antang Tadjahan und Pataho gemeinsam ausgeführt wird.

Am Abend beginnen die Balian mit ihren Handlungen und Gesängen und sie rufen den Dohong Mama Tandang, den Langkah Sawang Mama Bungai Bunge herbei und sie bitten ihn von seinem Dorfe am Flusse Djalajan, am Strome Labeho Pali auf die Welt herunterzusteigen. Mit seinen vierzehn jungen Begleitern kommt er auf dem Papan Talawang Dohong Panjarak Rangkan, Gentoi Tahawong Pulang Pananseran Kalang Labeho Handalem durch das Nebelmeer zum Balai Pali geflogen. Wenn er dort angekommen ist, dann ruft der Tukang tawur auch noch den Antang Darahen und den Pataho herbei und bittet sie an der Kopfjagd helfend teilzunehmen. Wenn die Herbeigerufenen alle angekommen und versammelt sind und sich jeder auf seinem angewiesenen Platze niedergelassen hat, nämlich Dohong Mama Tandang mit seinen Begleitern im Schildbrett, das über der Türe verankert wurde, Antang Darahen im Balai Antang und Pataho auf den Gong, dann kauen sie zuerst Sirih und kurz nach sechs Uhr, nach dem Einbrechen der Dunkelheit, ziehen sie auf dem Papan Talawang in das Dorf des Tarihing Hatuen Njalong, das in der Flusstiefe unter der Wasseroberfläche liegt, d.h. zwischen dem Eingang (labeho) zum Dorfe der Djata und dem Dorf der Djata (zwischen Flussoberfläche und Unterwelt).

Nachdem sie dort angekommen sind, werden sie von Tarihing freundlich empfangen und er erkundigt sich nach ihrem Woher und Wohin und sie antworten ihm: ,Wir sind hieher gekommen um dein Dorf $z u$ überfallen und deine Untertanen umzubringen, denn durch einen von ihnen ist einer unserer Angehörigen am Ufer des Flusses der Welt ertränkt und getötet worden“. Tarihing antwortet darauf : „Nein, das soll auf keinen Fall geschehen!" Aber sie antworten ihm, sie alle entgegnen ihm: „Es muss unbedingt geschehen, denn einer deiner Untertanen hat einen der Unserigen umgebracht und nun sind wir hieher gekommen um seinen Tod zu rächen". Nun erschrickt Tarihing 
und er ruft allen seinen Untertanen und er erkundigt sich bei ihnen: „Wer von euch hat einen Menschen vom Ufer des Flusses der Welt getötet, wer von euch hat ihn in die Wassertiefe hinuntergezogen?" Alle antworten sie, einer um den andern beteuert: „Ich war es nicht!“ Aber die Abgesandten aus dem Dorfe am Ufer des Flusses der Welt erwidern: „Nicht könnt ihr leugnen, nicht könnt ihr euere Tat abstreiten, wir untersuchen die Sache ganz genau und werden sehen bei wem von euch sich die Zeichen finden die ihn als Mörder verraten". Tarihing gibt nun seinen Leuten den Befehl sich zu setzen, und zusammen mit den Abgesandten aus dem Dorfe am Ufer des Flusses der Welt betrachtet er jeden seiner Untertanen ganz genau. Plötzlich weist er mit seiner Hand auf einen und spricht: „Dieser da ist es, denn an seinem Körper haften die Körner des Streureises des Priesters aus dem Dorf am Ufer des Flusses der Welt. Er ist es der einen der Eurigen getötet hat". Er probiert nun nicht mehr die Tat zu leugnen und bekennt, dass er den Menschen in die Tiefe hinuntergezogen hat. „Die Sache ist damit in Ordnung“, spricht Tarihing, ,ich muss euch den da überlassen. Morgen früh, um die Zeit der Morgendämmerung des Erwachens der Vögel (tampalawei burong, zwischen fünf und sechs Uhr) werde ich ihn an die Wasseroberfläche hinaufschicken, ihr könnt ihn nehmen, weil er einen von euch ertränkt hat". Dohong Mama Tandang antwortet ihm: „Es ist gut so, aber nun will ich auch noch, dass du mir die Liau Salumpok Balawang Pandjang des Ertrunkenen zurückgibst". Tarihing aber entgegnet: „Das geschieht auf keinen Fall, die bleibt bei mir“. Dohong Mama Tandang erwidert: „Du musst sie mir unbedingt zurückgeben. Willst du das nicht tun, wohlan, dann kämpfen wir hier zusammen", und mit lauter Stimme ruft er seinen Leuten zu: „Auf, greift zu den Waffen!“ Tarihing erschrickt sehr in seinem Innern und er gibt kleinlaut nach und sagt: „Ich gebe euch die Liau Salumpok Balawang Pandjang, aber die Speisen (Opfer) die behalte ich für mich". Dohong Mama Tandang empfängt nun aus seiner Hand die Salumpok Balawang Pandjang und behält sie bei sich, denn er hat vorläufig für sie zu sorgen. Nachdem die Eide, den Menschen keinen Schaden mehr zuzufügen, bekräftigt sind, steigt Dohong Mama Tandang mit seinen Begleitern auf und kehrt in den Balai Pali zurück, wo die Salumpok Balawang Pandjang nun bis zum Tantolak matei, das gleich hernach stattfindet, bleibt.

Dohong Mama Tandang bindet sein Schildbrett wieder über der Türe fest und er setzt sich mit seinen Begleitern hinein und kaut Sirih und ruht von der Reise und der Arbeit aus. Antang Darahen setzt sich 
in seinen Balai und Pataho setzt sich auf die Gong. Nach dem Essen und nochmaligen Sirihkauen legen sie sich zur Ruhe.

Zur Zeit der kleinen Morgendämmerung (tampalawei korik, zwischen drei und fünf Uhr) beginnen die Balian die schlafenden Sangiang (Dohong Mama Tandang und seine Begleiter) wieder mit ihren Gesängen aufzuwecken und nachdem sie den Schlaf aus den Augen gerieben haben bitten sie sie, sich nun für die anzutretende Kopfjagd bereit zu machen, die Waffen umzugürten und die Schilde zu ergreifen. Das gleiche unternimmt der Tukang tawur mit dem Antang Darahen und dem Pataho. Wenn sie alle bereit sind und wenn sich auch die Männer des Dorfes eingefunden haben, steigen sie, angeführt von den Priestern zu den Booten hinunter. Im vorderen Boot nelmmen die Balian mit den Sangiang (Dohong Mama Tandang und seine Begleiter) Platz und in das hintere Boot setzen sich der Tukang tawur mit Antang Darahen, Pataho und den Männern des Dorfes die an der Kopfjagd teilnehmen. Die Balian und der Tukang tawur senden nun Dohong Mama Tandang und seine Begleiter, sowie Antang Darahen und Pataho auf dem Papan Talawang voraus in den Kampf und wenn diese weggereist sind, dann rudert man mit den Booten nach der Mitte des Flusses und dort beginnt eine wilde Jagd auf den Untertanen des Tarihing, den dieser zur Zeit der Morgendämmerung nach der Wasseroberfläche gesandt hat. Die Männer und Priester brechen in lautes Geschrei aus, sie weisen mit ihren Speeren aufs Wasser und sie rufen: „Dort ist er, dort ist er, los auf ihn, fallt ihn an!" Sie rudern auf dem Flusse hin und her, sie verfolgen ihren Feind der zu flüchten versucht und immer enger ziehen sie den Kreis um ihn. Sie treiben ihn langsam gegen das Ufer und schliesslich weiss der Untertan des Tarihing keinen andern Ausweg und keine bessere Zuflucht mehr als sich in das viereckige Gestell zu flüchten und sich dort zu verbergen.

Wenn sich die Boote dem Ufer nähern, steigt ein Alter auf der Treppe zum Fluss herunter, er streut Reis aus und ruft alle Seelen der Dorfbewohner und der Priester heim, damit sich keine verirre und damit keine im Kampf umkomme.

Inzwischen sind auch die beiden Ruderboote beim Gestell angekommen. Die mitgenommene Kokosnuss, die mit einem menschlichen Antlitz bemalt ist, wird in das Gestell hineingeworfen und nun erhebt sich von allen Seiten ein wildes Geschrei und es erschallen die Rufe: „Erstecht ihn, schlagt ihn tot!" Sie stechen mit ihren Speeren ins Wasser, ein wildes Getümmel erhebt sich und sie feuern sich mit immer neuen Ausrufen zum Kampf gegen den Feind an, der in ihre 
Hand gegeben ist. Es kann nicht anders sein, denn dass er schwer verwundet zusammengebrochen ist. Schliesslich rufen sie: „Schlagt ihm den Kopf ab, schlagt ihm den Kopf ab!" Einer der Männer packt den Untertanen des Tarihing an seinen langen Haaren (d.h. er ergreift die an der Kokosnuss festgemachte Schnur, die die Haare darstellen muss) und er zieht seinen Kopf ein wenig aus dem Wasser heraus und fordert seine Kampfgenossen auf: „Wohlan, darauf los, haut ihm nun den Kopf ab!" Wild schlagen sie mit ihren Schwertern auf den Hals des Feindes ein (d.h. sie schlagen einfach unter der Kokosnuss durch ins Wasser) und dann brechen sie in das siebenmal wiederholte Jauchzen der siegreichen Kopfjäger aus: Lolololololo-juuuuuh-juuuuuuh! Der Feind ist gefallen, die Rache ist genommen, der Kopf ist in ihrem Besitz. Sie rudern zum Anlegefloss zurück und binden ihre Boote fest und steigen aus. Auf dem Floss ist ein Ruderboot bereit gestellt gefüllt mit Wasser das mit Gelbwurz (Curcuma) gelb gefärbt worden ist. Die Balian und der Tukang tawur waschen jeden Kopfjäger damit ab. Wenn das geschehen ist werden sie, Mann für Mann, auf einem zierlich umflochtenen Brett zum Dorf hinaufgetragen, sie, die siegreichen Helden, die Kopfjäger. Wie bei jeder Kopfjagd, so ist auch jetzt der Zugang zum Dorf nit einem Pantan,222 einem Zaun von dicken, mit einem Rotan festumschlossenen und zusammengebundenen Baumästen, versperrt. Bevor sie das Dorf betreten können müssen sie zuerst diesen Pantan durchschlagen (miap pantan: den Pantan mit Machtworten besprechen). Während einer nach dem andern vor den Pantan hintritt und mit seinem Schwerte auf ihn schlägt, verkündigt er in singendem Tone seine Heldentaten, die nicht allein und in erster Linie ihm sondern dem zu besuchenden Dorfe zugute kommen. In diesem Falle berichtet er, dass er den Untertanen des Tarihing erlegt und seinen Kopf erbeutet und den Tod des Verwandten gerächt habe.

Wenn der Pantan durchschlagen ist, versammeln sich alle, die Dorfbewohner und die Teilnehmer an der Kopfjagd, im Balai Pali und sie nehmen dort ihre Plätze ein. Mama Tandang setzt sich mit seinen vierzehn jungen Begleitern in sein Schildbrett über der Türe, Antang Darahen setzt sich in den Balai Antang und Pataho nimmt auf den Gong Platz und die Dorfbewohner und die Kopfjäger lassen sich auf dem Fussboden nieder. Man schlachtet ein Schwein, das zum Festmahl der Menschen und der Ahnen dient.

Nach dem Essen wird der erbeutete Schädel (die Kokosnuss) in das mitten im Dorf aufgerichtete Schädelgestell (sangkaraja) niedergelegt und durch die Frauen und Männer abwechselnd umtanzt und besungen. 
Wie jeder echte Schädel, so dient auch dieser zur Vollziehung der umfassenden Reinigungshandlungen während des Tantolak matei und auch später während des Tiwah. Nachdem alle Handlungen abgeschlossen sind, wird die Kokosnuss im Balai Pataho (in der Opferhütte des Pataho) niedergelegt. Wenn das geschehen ist, dann geben die Balian dem Dohong Mama Tandang den Auftrag die Seelen aller Dorfbewohner, die sich während der Kopfjagd oder während den Handlungen eventuell verirrt haben könnten, zurückzurufen und nachdem sie alle wieder zurückgekehrt sind, streuen die Balian jedem Einzelnen Reis (behas tambak radja) auf den Kopf und führen so die Seelen wieder in ihre Körper ein.

Am Abend sitzt man noch im Hause des Ertrunkenen zusammen und die Balian führen zusammen mit Dohong Mama Tandang die Salumpok Liau Balawan Pandjang ins Dorf der Balo Indu Rangkang, wo sie bis zum Tiwah bleibt (Diese Führung ist das Tantolak matei, das weiter unten restlos beschrieben wird).

Wenn der Morgen graut verabschieden die Balian (Priester oder Priesterinnen) den Dohong Mama Tandang und seine Begleiter und der Tukang tawur verabschiedet den Antang Darahen und den Pataho. Alle erhalten, bevor sie den Heimweg antreten, ihren Lohn für die Ermüdung der Knochen und die Erschlaffung der Muskeln, nämlich: baras bulau (Goldsand), busong hintan (Steinbänke von Edelsteinen), karangan lamiang (Steinbänke von Achaten), rangkan panginan (Speisen, Opfer), repang garantong (einen ganzen Satz von Gong) und behas tambak radja (königlich aufgehöhten Reis).

Darauf erhalten auch die Balian und der Tukang tawur ihren Lohn. Jeder von ihnen empfängt: drei kiping (sechs Gulden), lilis sirau (ein Armband von blendendem Glanze, d.h. von Achaten oder Perlen) ein pisau pepet (ein Schwert um zu Peissen, d.h. in das man beisst um sich neues Leben zuzuführen) und ein Schüsselchen voll bchas tambak radja (königlich aufgehöhten Reis).

Die Teilnehmer an der Kopfjagd erhalten telo kiping (drei Kiping: sechs Gulden) oder pulu ramo (ebenfalls sechs Gulden), die sie unter sich verteilen können.

Nach allen diesen Handlungen wird die Leiche in der gebräuchlichen Weise beigesetzt. 


\section{Der Tod durch einen fallenden Baum (Matei penjet kaju)}

\section{a. Der Tote wird zurückgeholt und sein Tod wird gerächt}

Stirbt jemand durch einen fallenden Baum (matei penjet kaju: eingeklemmt und getötet durch einen Baum), dann wird ebenfalls ein Rachezug veranstaltet und der geraubte Tote wird wieder zurückgeholt. Bei dieser Handlung treten wieder die Balian auf, die Dohong Mama Tandang und seine vierzehn Begleiter aus der Oberwelt herbeirufen, und auch der Tukang tawur der Antang Darahen und Pataho herbeiholt um an dieser Reise und diesem Rachezug teilzunehmen. Im Papan Talawang (Schildbrett) des Dohong Mama Tandang reisen sie gemeinsam zu Panto Ganan Kaju Hai (zum Panto, dem Aeltesten aller hohen Bäume, die man sich durch böse Geister bewohnt vorstellt). Die Reise, die Streitgespräche und alle Handlungen während der Reise und bei Panto Ganan Kaju Hai werden von den Balian besungen. Hier geben wir den vollständigen Text wieder und wir beginnen da wo Dohong Mama Tandang mit allen seinen Begleitern das Dorf verlässt und zu Panto Ganan Kaju Hai reist. Der Gesang lautet:

Ewen mahalau tandjong sapapulut lewu, mahangkawet luwok kadjalumpang rundong, habasean tandjong karamunting balo, 223 habasean tandjong kalapapa tandok, 224 nandjong mahalau bukit $\mathrm{Pa}$ sahan Raung, mahangkawet kereng Dagarin Penda Lunok, habasean tandjong sungkai bungai.225

Salenga mendeng hakarereng Embak Njaring Ganan Bua Bakas. ${ }^{226}$

Intu hete ei misek djalanan ewen: kangkueh bulan djan-
Sie fahren vorüber an der Flussbiegung der Bambusbüsche, sie fahren vorbei an der Flussbuchtung der Bambusbüsche, sie fahren vorüber an cler Flussbiegung des Karamunting Balogesträuches, sie fahren vorbei an der Flussbuchtung des KalapapaTandokbaumes, sie schreiten aus und sie gehen entlang am Berge der Hütten der Särge (an den Sarggestellen auf denen die Leichen beigesetzt sind), sie gehen vorbei am Sandhügel der Häuschen der Toten, sie rudern entlang die Flussbiegung der Sungkaibäume, auf denen sich die Nashornvögel niederlassen.

Und plötzlich steht dicht vor ihnen, erhebt sich vor ihrem Angesicht Embak Njaring Ganan Bua Bakas. Und dort erkundigt er sich nach ihrer Reise und er fragt sie: wohin begebt 
djulanam ikau Pataho ttg. ihr euch, ihr reisenden Monde, wohin Antang Darahen?

Ewen tombah: dia isek manansekam panamueiku badjeleng nahuang manalih andep pandjang handak mulang tekap ambo dengan Pantoh Ganan Kaju Hai.

Koa,n Embak: djaton tau! keleh itah ih haparas undan pamalunok bungai, kamban lumpong manduroi rohong. 228

Koa,n Pataho: amon nahuang ikau mite enteng penjangku, has barangai, Antang Darahen hamauch kalote kea.

Embak Njaring Ganan Bua Bakas njelak njahumpak dohong papan benteng,e, 229 mandjidjit basariang pulang tambing hanji, ngadja-ngadjang renteng tingang.

Antang ngadja-ngadjang renteng tingang. Pataho ngakis hagagian hiring dohong,e, eleh dohong hababalong hiring,e.

Has ih! koa,n Pataho ttg. Antang, toh ikau nahuang mite enteng Pataho ttg. Antang njilak,e dohong papan benteng, Pataho eleh njaho mangaruntong langit. des Weges Pataho und Antang Darahen?

Und sie antworten ihm: nicht erkundige dich nach unserer Reise, der eiligen, denn wir sind ausgezogen zur Vergeltung, wir wollen zurückgeben den grossen Schlag, ihm, dem Pantoh Ganan Kaju Hai.227

Und es spricht Embak: das kann nicht geschehen! Möchten wir doch einander abschlagen die Köpfe, die sich erheben auf dem Lunok der mit dem Nashornvogel geschmückt ist, die aufragenden Köpfe, die umgeben sind von den Lanzen (oder Dolchen).

Und es entgegnet der Pataho: wenn du die Tapferkeit meiner Penjang zu erfahren wünschest, wohlan dann, mir ist es gleichgültig, und so spricht auch der Antang Darahen.

Embak Njaring Ganan Bua Bakas reisst heraus und zieht hervor den Dolch, das Brett der Mitte, er zieht hervor den festgeknoteten Griff, der da vermehrt den Mut, er schwingt die Schwanzfedern des Nashornvogels (die er als Kopfschmuck trägt).

Auch der Antang schwenkt seine Schwanzfedern des Nashornvogels und der Pataho reisst heraus und schwingt die Schärfe seines Dolches und sogleich rollt auf der Dolch seine Schärfe (er weist seine Schärfe).

Wohlauf nun! spricht der Pataho und der Antang, du wolltest sehen die Tapferkeit des Pataho und des Antang, die herausgezogen haben ihre Dolche, die Bretter der Mitte, und schon erfüllt der Donner des Pataho (der 
Kampfruf) mit krachendem Getön den Himmel.

Njaho,n dohong Pataho balua kumpang,e, kilat hadjandjepan hawon, kilat pulang bahandjong songkabang,e.

Hindai djari lawo dohong papan benteng, usang,e djari mantap tambang balinga Embak.

Haramaung ie mekat tambang,e, handjaliwan hadjandjitan, talampe 230 palus gandang halalian buli, garantong kamalesan mulang, halalian parong mahawang Ganan Kaju Hai.

Palus djandaroman akan Pantoh Ganan Kaju Hai: intu hete aton karamahan bandong kajau, karampean buso,n taliwon dahiang.

Pantoh misek haling bapanting, Pantoh Ganan Kaju Hai hakaisek rawei: bara lewu kueh karamahan bandong kajau?

Koa,n Antang: dia isek manansekan! tarantang penjang padjandjuri bara lewu Ano, saloti paturong panantekei bahandjong bara rundong Ano.

Bahing bapanting Pantoh Ga-
Der Donner des Dolches des Pataho stürzt heraus aus seiner Scheide, die Blitze blenden die Himmel, die Blitze die hervorzucken aus der Scheide des Griffes.

Noch nicht hat sich heruntergestürzt der Dolch, das Brett der Mitte (er hat noch nicht zugeschlagen), schon längst sind weggelaufen die Füsse, die schönen, des Embak.

Wie ein Tiger springt er mit seinen Beinen, wie eine Otter zieht er sich zurück, wie eine Riesenschlange schlängelt er sich davon, er kehrt zurück, er kehrt wieder heim wie der Schall der Trommeln, wie der Ton der Gong, er kehrt wieder um in sein Haus, er, der Ganan Kaju Hai.

Und sogleich erzählt er und berichtet dem Pantoh Ganan Kaju Hai: dort drïben sind angekommen Männer, sind angelangt Kopfjäger, sind herbeigeschlichen die ausspriessenden tanzenden Vorzeichen (d.h. Männer oder Ahnen die Vorzeichen geben).

Und es fragt der Pantoh und er wirft aus sein Wort und es erkundigt sich der Pantoh Ganan Kaju Hai: aus welchem Dorfe sind sie angekommen, sie die Männer, die Kopfjäger?

Und es spricht der Antang: Nicht erkundige dich, nicht frage! die Kinder der Penjang sind herausgetreten aus dem Dorfe N.N. (der Name des Dorfes wird natürlich genannt), die Glieder der Paturong stammen aus dem Orte X.

Es erhebt sein Wort der Pantoh 
nan Kaju Hai, siring bambahinga Njaring Menteng Manambalau Bahandang, Sahakong Bahanji Bagundai Gambulong.

Ewen gangguranan ara,e lalau menteng malabien, isen sasabutan biti,e lalau bahanji ngalambungan.

Lalau bahanji njurong impan bandong kajau, lalau bahanji mangatik enteng aku Njaring Menteng Manambalau $\mathrm{Ba}$ handang, menteng mandok hanji,n aku Sahakong Bagundai Gambulong.

Tuntang mangatik enteng aku Pantoh Ganan Kaju Hai, Njaring Embak Ganan Bua Bakas.

Dia handong ie hakatawan mina aku penjang menteng, mangau paturongku bahanji, penjang peres kasamparan dje baka buang lewu pulu, paturong sampar barion dje baka sandong rundong djalatien.

Has nih! koa,n riwut rawei Njaring Menteng Manambalau Bahandang, salatan tisoi Sahakong Bahanji Bagundai Gambulong, djandjaroman
Ganan Kaju Hai, es schleudert aus seine Rede der Njaring, der mutige, der rothaarige, er, der Sahakong (ein anderes Wort für Njaring), der tapfere, der behaarte wie ein Gambulong (wie ein Njaring, die Haare sind also rot).

Mit welchem Namen nennen sie sich, wie heissen sie, sie die unverschämt tapfer Auftretenden, wer sind sie eigentlich, sie die uns mit hochmütigem Mut herausfordern.

$\mathrm{Zu}$ sehr wagen sie sich herbeizuströmen und uns aufzulauern, sie, die Männer, die Kopfjäger, zu arg versuchen sie zu verachten meinen Mut, den Mut des Njaring, des tapferen, des rothaarigen, $z u$ frech ist es von ihnen, dass sie mit ihren Hörnern anzustossen wagen gegen meine Tapferkeit, die Tapferkeit des Sahakong, der Haare hat wie ein Gambulong.

Und zu verachten meine $\mathrm{Kraft}$, die Kraft des Pantoh Ganan Kaju Hai, des Njaring Embak Ganan Bua Bakas.

Gewiss ist es ihnen nicht bekannt, wahrscheinlich wissen sie es nicht, dass ich im Besitze bin von kraftvollen Penjang, dass mein Eigentum sind tapfere Paturong, nämlich die Penjang der Krankheiten, welche zum Aussterben bringen zahlreiche Dörfer, die Paturong der Seuchen, die da entleeren und einsam machen neun Orte.

Wohlan nun! spricht das wehende Wort des Njaring Menteng Manambalau Bahandang, die brausende Rede des Sahakong Bahanji Bagundai Gambulong und er verkündet dem Pantoh 
akan Pantoh Ganan Kaju Hai, manjoho Embak Njaring Ganan Bua Bakas :

Keton ndue manjahuan Merap Ganan Sahep, 231 Metap Ganan Pating, Lambak Ganan Badjakah, Rimbur Ganan Baner, Lantong Ganan Batang, Ungo Ganan Tunggol, Rantar Ganan Uhat, Suak Suek Hulu Ruak Panting Ganan Tarok Kaju, Njaring Ganan Kadjang Edan, Njaring Ganan Tewon Ahem, Njaring Ganan Bambulong Tusang, Njaring Ganan Lunok Tarong, sama manangking nantelai dohong papan benteng,e, keton ratarata basariang pulang tambing hanji.

Rata meteng nambahulan bulau batu penjang, hajak mendeng mananggar tingang kangkana,e.

Rata mendeng hajak djalahan desa, $\mathrm{N}$ Njaring Menteng Manambalau Bahandang, Sahakong Bahanji Bagundai Gambulong.

Manangking manantelai dohong papan benteng,e, basariang pulang tambing hanji.

Gatang tarahendeng mananggar tingang kangkana,e, tun-
Ganan Kaju Hai, er befiehlt dem Embak Njaring Ganan Bua Bakas:

Ihr beiden befiehlt dem Merap, der Seele des abgefallenen Laubes, dem Metap, der Seele der Aeste, dem Lambak, der Seele der Schlingpflanzen, dem Rimbur, der Seele der Brettwurzeln, dem Lantong, der Seele des Stammes, dem Ungo, der Seele des Baumstumpfes, dem Rantar, der Seele der Wurzeln, dem Suak Suek Hulu Ruak Panting, der Seele der Baumkrone, dem Njaring, der Seele des Kadjang Edan,232 dem Njaring, der Seele des Tewo Ahem (Zuckerrohr des Schuppentieres), dem Njaring, der Seele des Bambulong Tusang, dem Njaring, der Seele des Lunok Tarong (Waringinbaum), gebt ihnen den Auftrag: ihr alle umgürtet schräg herabhängend euere Dolche, die Bretter der Mitte, ihr alle umbindet die Griffe die den Mut verstärken.

Und ihr alle zusammen umbindet und gürtet die goldenen Steine der Penjang und ihr erhebt euch und ihr setzt auf die Schwanzfedern des Nashornvogels, den Kriegsschmuck.

Ihr alle erhebt euch zusammen mit den Angehörigen, mit den Untertanen des $\mathrm{Njaring}$ Menteng Manambalau Bahandang und des Sahakong Bahanji Bagundai Gambulong.

Sie umgürten schräg herabhängend ihre Dolche, die Bretter der Mitte, sie umbinden die Griffe, die den Mut vermehrenden.

Sie stehen auf, sie erheben sich, sie richten auf die Schwanzfedern der 
djong tarahingkat ngambuah djundjong sampulau dare.

Manumon riwut rawei $\mathrm{Nja}$ ring Menteng Manambalau Bahandang, manjaroroi sala$\tan$ tisoi Sahakong Bahanji Bagundai Gambulong.

Palus manting ewen tambang lawah rawing balinga, rata nangkaruan salunga bapilik hindje.

Balua balai Lunok dje hadare dawen, sali Baringen dje hatabuhi bumbong.

Hagoet manambang bandong kajau, manjuro impan taliwon dahiang.

Mahining lalento,n tingang kare desa,n Njaring Menteng Manambalau Bahandang, auch rarajon bungai bulau tarahan Sahakong Bahanji Bagundai Gambulong.

Bahing gagarising bulau batu,n penjang, njangkelang kaju,n Sanggalang Garing, manjalulok bulus Lampesong Kereng. ${ }^{233}$

Sembang riwut penjang menteng manjembang Darahen radja,n Antang, manjembang
Nashornvögel, den Kriegsschmuck, sie stehen auf und erheben sich, sie bringen in Ordnung die Höhe des geflochtenen Kopfschmuckes (die eingesteckten Federn).

Sie gehorchen der wehenden Stimme des Wortes des Njaring Menteng Manambalau Bahandang, sie befolgen die brausende Rede des Sahakong Bahanji Bagundai Gambulong.

Und sogleich schreiten sie aus mit ihren Beinen, sie die Krokodile (die Männer), die schmucken, sie werfen aus ihre Füsse, die raschen.

Sie treten hervor aus dem Hause, dem Lunok, das umflochten ist mit Blättern, sie verlassen die Wohnung, den Waringin der gewoben ist von zarten Herzblättern.

Sie machen sich auf um zu erwarten die Männer, die Kopfjäger, sie ziehen fort um aufzulauern den hervorsprossenden, tanzenden Vorzeichen (die Ahnen, die Vorzeichen und Rat geben).

Sie gehören das Getümmel der Nashornvögel (Männer), der Untertanen des Njaring Menteng Manambalau Bahandang, den aufsteigenden Laut des Lärmes der Nashornvögel, der goldenen Sklaven des Sahakong Bahanji Bagundai Gambulong.

Es ertönt der helle Laut der goldenen Steine der Penjang zwischen dem Holze der elfenbeinernen Bäume hindurch, zwischen den Stämmen der Bäume auf den Sandhügeln hervor. Es kommt an der Laut der Penjang, der tapferen, er kommt an beim Dara hen, dem König der Antang, er er- 
Pataho idje hagan lawang mangkalewu.

Has nih! koa,n riwut rawei Darahen radja,n Antang, hagoet keton anak oloh, ttg. koa,n Pataho hagan lawang mangkalewu, Batu Mamben gadoh mangkarundong.

Palus Antang Darahen manjahuan ewen awang garing tabela belom, sihong awang kanahesen rinjik:

Djundjun helo ikau Antang Kawo dje panjawur kalang labeho, kenjoi rinti-rintik dje pamugus nandai rantau timben.

Eleh Antang Kawo mangkat pangansiring,e tolak manambang riak penjang, basangka manakep ringkin paturong ain pulau tarahan Njaring Menteng Manambalau Bahandang.

Nggatang taribanga,e Antang Kawo manjanggah lawi,n Salang Garing, mangkat pangansiring,e manjakalah bulus Lampesong Kereng.

Antang Kawoh manduroh penjang tuwe dje pali mupuk baka lampang tampahas rendem labeho, endus ngisai tau kalampangan lauk sapan djalan karangan. reicht den Pataho welcher ist der Wächter an der Türe des Dorfes.

Wohlauf nun! spricht das wehende Wort des Darahen, des Königs der Antang, machet euch auf, ihr Jünglinge, und so spricht auch der Pataho, der Wächter an der Türe des Dorfes, der Batu Mamben, der Beschützer des Tores des Ortes.

Und Antang Darahen befiehlt den Elfenbeinen, den jung lebenden, den Elfenbeinen, den ungewohnten des Lebens :

Steige du zuerst auf, du aschfarbiger Antang,234 der du über den Fischkörben der Wassertiefe schwebst, du gefleckter Falke, der du deine Kreise ziehst über dem Abgrund, dem unermesslichen.

Und sogleich erhebt der gefleckte Antang seine Flügel und er reist ab und er fliegt den wogenden Penjang entgegen, er stösst ab vom Baume um anzufallen die Wellen der Paturong der Scharen der Sklaven des Njaring Menteng Manambalau Bahandang.

Er erhebt seine Schwingen, er der gefleckte Antang, und er stösst ab vom Wipfel des Baumes, des hohen, er entfaltet seine Flügel und er fliegt weg von den Aesten des Baumes auf dem Sandhügel (des hohen Baumes der hoch über die andern Bäume hinausragt).

Und er, der Antang, der gefleckte, streut aus seine Penjang, die betäubenden, die verboten sind abgeschabt und ausgestreut $\mathrm{zu}$ werden, weil sie zum auftauchen bringen die Tampahasfische, die sich in der Wassertiefe auf- 
Udja-udjan penjang ain Antang Kawo manjanggah renteng tingang djalahan pulau tarahan ain Njaring Menteng Manambalau Bahandang, kilau udjan njaro dje balawo langit, tingkah petai ganggerang mansuhan hawon.

Eleh penjang batawah kilau djohon singkah, paturong,e babeau tingkah pahak $\mathfrak{u}$ djau. 235

Matei indang buno bilin banama halalungan laut djahawen! koa,n rawei Antang Kawo, lalehan kamenteng,e djalahan pulau tarahan ain $\mathrm{Nja}$ ring Menteng Manambalau Bahandang.

Mina penjang bahari tau njarotawah penjang aku Antang Kawo, mingkes paturong,e tada olih njarabean paturongku kenjoi rinti-rintik.

Dia ie katawan penjangku tada peres lauk tampahas rendem labeho, paturongku bahari baka sampar sapan djalan karangan. halten, die nicht erlaubt sind ausgeworfen zu werden, weil sie an die Wasseroberfläche bringen die Sapanfische, die sich finden auf dem Wege zwischen den Sandbänken.

Sie regnen herunter die Penjang des gefleckten Antang, sie regnen herunter auf die Schwanzfedern der Nashornvögel der Untertanen, der Scharen der Sklaven des Njaring Menteng Manambalau Bahandang, sie fallen herunter wie donnernder Regen herabstürzt vom Himmel, wie der krachende Regen herunterfliesst aus den Wolken.

Aber sogleich erwiesen sich seine Penjang kraftlos wie der gekochte Saft der Herzblätter, zeigten sich seine Paturong fade wie die Suppe von Schösslingen.

Stirb um gespeert zu werden als Kaufpreis für das Boot, das grosse, mit dem man durchkielt der Meere sechs! (ein Fluch) so sprach das Wort des aschfarbigen Falken, zum Erstaunen ist der Mut der Untertanen, der Scharen der Sklaven des Njaring Menteng Manambalau Bahandang.

Sie besitzen scharfe Penjang die da kraftlos machen meine Penjang, die des aschfarbigen Antang, sie haben als Eigentum Paturong, die da schwächen meine Paturong, die des gestreiften Falken.

Nicht wissen sie offenbar, dass meine scharfen Penjang die vernichtende Krankheit sind der Tampahasfische, die sich aufhalten in der Wassertiefe, nicht ist bekannt, dass meine beissenden Paturong die Seuche sind der Sapanfische, die sich finden auf dem 
Eleh Antang Kawo buli mupang manantawah buang halalian Darahen radja,n Antang.

Djandjaroman akan Darahen radja,n Antang enteng,e mulang nahabadjin gandang, hanji,e tendur namunan tambit sambang.

Matei indang buno bilin banama halalungan laut djahawen! lalehan bitim laka mina penjang lalau batawah simpei,e, paturong babeau sandik,e.

Kilen ampi,e, bitim mina baja penjang hapan manjawau kalang labeho handalem, balitam baja mingkes paturong indu manilik rantau timben.

Baja tikas patei penjang,m lauk tampahas rendem labeho, pangulih paturong,m baja sapan djalan karangan.

Dari ikau! Nggatang taribangam babalai rewan kaju Sangalang Garing, manandai kalang labeho handalem, mangkat pangansiring, $\mathrm{m}$ basali unggak Lampesong Kereng, manandai rantau tim-
Wege zwischen den Sandbänken.

Und sogleich kehrt der aschfarbige Falke wieder zurück, er flattert kraftlos und müde ohne etwas erreicht zu haben zurück zum Darahen, dem König der Falken.

Und er erzählt dem Darahen, dem König der Falken, dass sein Mut geschwächt sei wie der Laut der grossen Trommel, dass seine Tapferkeit erschlafft sei wie das Fell der Trommel. 236

Stirb um gespeert zu werden als Kaufpreis für das Boot, das grosse, mit dem man durchkielt der Meere sechs! es ist $\mathrm{zu}$ verwunderlich, dass du nur im Besitze bist von Penjang deren Bündel kraftlos sind, von Paturong deren Bänder $z u$ fade sind.

Wie steht es denn mit dir! besitzest du denn eigentlich nur Penjang um hinabzustarren auf die Fischkörbe in der Wassertiefe, hast du denn als Eigentum nur Paturong um mit ihnen schräg anblickend aufzulauern den Fischen in dem Abgrund.

Vermagst du denn mit deinen Penjang nur die Tampahasfische zu töten die sich aufhalten in der Wassertiefe, gelingt es dir mit deinen Paturong denn nur die Sapanfische zu überwinden auf dem Wege zwischen den Steinbänken.

Mache dass du fortkommst! Erhebe deine Flügel und lasse dich nieder in deinem Neste auf dem Baume, dem hohen, der sich erhebt über den Fischkörben in der Wassertiefe, der abgründigen, entfalte deine Schwingen und kehre zurück auf die Aeste des 
ben.

Ela ikau omba nganja-nganja manambang riak penjang kadjalahan Njaring Menteng Manambalau Bahandang, ngahus ikau omba manakep ringkin paturong panungkup Sahakong Bahanji Bagundai Gambulong.

Mikeh tarong,m leteng nahariak rawing, manjangkelang riak penjang Njaring Menteng Manambalau Bahandang, tinting,m lilap manjampal,e ringkin paturong Sahakong Bahanji.

Awi biti,m mina penjang ikau dia menteng, balita,m tempo,n paturong korang bahanji.

Randan hakalowah Antang Kawoh ngambahan riwut rawei Darahen radja,n Antang:

Ijoi Darahen radja,n Antang, kilen ampi,e, dia awi menteng aku tingang timpo,e dia menteng bamban penjang, bahanji antang sangiang,e dia bahanji sandik paturong,e.

Hame-hamen tingang Antang Kawo buli halalian rewan Sangalang saran kalang labeho handalem, ngumpang parasengen karendem,e, kenjoi rinti-rintik mulang undak
Lampesongbaumes auf dem Sandhügel, der aufsteigt über dem Abgrund, dem tiefen.

Nicht begleitest du uns, nicht geziemt es sich dass du mit uns entgegenziehest den Wellen der Penjang der Untertanen des Njaring Menteng Manambalau Bahandang, vergeblich ist es, dass du mit uns kommst um entgegen zu gehen den Wogen der Paturong der Gemeinschaft des Sahakong Bahanji Bagundai Gambulong.

Denn dein Ruhm würde untergehen überströmt von den Wellen der Krokodile (der Männer), überflutet von den Wogen der Penjang des Njaring Menteng Manambalau Bahandang, dein Lob würde verschwinden weggeschwemmt durch die Wellen der Paturong des Sahakong Bahanji.

Denn du bist nur im Besitze von Penjang die dich nicht mutig machen, du hast nur als Eigentum Paturong die dich nicht tapfer machen.

Mit kleinlauter, schwacher Stimme antwortet der aschfarbige Falke dem wehenden Worte des Darahen, des Königs der Falken :

Ja, Darahen, König der Falken, was ist denn da zu machen, nicht war ich nicht mutig weil meine Penjang keinen Mut besassen, nicht war ich nicht tapfer, weil meine Paturong keine Tapferkeit hatten.

Und mit einem beschämten Gefühl kehrt er, der Nashornvogel, der aschfarbige Antang, wieder um und kehrt zurück auf die Aeste des Baumes, des hohen, am Rande der Fischkörbe (der Fischplätze) in der Wassertiefe, der 
bulus Lampesong Kereng manandai rantau timben.

Djaton halaloh 237 ie pantar pinang, dia hapekat ie rokon tarahan.

Baja baupah ie tolang rumpang, baja halaloh ie uhat leso.

Has nih! koa,n riwut rawei Darahen radja,n Antang, tingang tolak lunok ikau Antang Bahandang, gulong manambang riak penjang, basikap manakep ringkin paturong.

Palus manggatang taribanga,e Antang Bahandang, hagoet manambang riak penjang djalahan Njaring Menteng Manambalau Bahandang.

Tari-tarian Antang Bahandang manjangka renteng tingang djalahan Njaring Menteng Manambalau Bahandang, manduroh penjang sahimpang baka teneng tando,n manok darong tingang, malangkusan paturong salahawo,238 baka rintuh kariok piak rongkoi ambon. abgründigen, mit aufgehängter Scham in seinem Innern begibt sich der gestreifte Falke wieder zurück zu den aussprossenden $Z$ weigen des Lampesongbaumes des Sandhügels, der sich erhebt über dem Abgrund, dem tiefen. Nicht hat er als Lohn erhalten einen Betelnusstamm (Kausel, sie werden in der Form eines Lebensbaumes abgegeben, deshalb der Ausdruck Pantar), nicht empfing er als Entschädigung die Rauchwaren der Sklaven (Zigaretten). Als Lohn empfing er nưr ermüdete Knochen, als Entschädigung erhielt er nur erschlaffte Muskeln.

Wohlauf nun! spricht das wehende Wort des Darahen, des Königs der Falken, mache dich auf, du Nashornvogel (der mit dem Kriegsschmuck bekleidete Mann), reise weg vom Baume, du roter Falke, gehe rasch entgegen den Wellen der Penjang, ziehe geschwind entgegen den Wogen der Paturong.

Und sogleich erhebt er seine Flügel, er, der rote Falke, und er macht sich auf und zieht entgegen den Wellen der Penjang der Untertanen des Njaring Menteng Manambalau Bahandang.

Es schwebt der rote Falke über den aufrechtstehenden Schwanzfedern der Nashornvögel (Kopfschmuck) der Untertanen des Njaring Menteng Manambalau Bahandang, er lässt niederfallen die lähmenden Penjang, die zum Schweigen bringen das Krähen der Hühner, der Hühner der Tingang, er streut aus seine Paturong, die dreizackigen Lanzen (die Krallen), die verstummen machen das Gackern der 
Sambar-sambaran penjang Antang Bahandang manambang riak penjang, manakep ringkin paturong.

Djilau bulan kapanaho matei! aton santah renteng tingang djalahan pulau tarahan $\mathrm{Nja}$ ring Menteng Manambalau Bahandang, kueh aton sundong luhing pating bungai panungkup puja kalinti,n Sahakong Bahanji.

Matei indang buno bilin banama halalungan laut djahawen! amon kilau etoh panalatai,e, kilau bulan manalatai dare, pandang katon pamalempang, tingkah pahawang malekut tabuhi, dia balang bitingku djalan kabanting tapakalong riak penjang djalahan Njaring Menteng Manambalau Bahandang, isen hatampuli balitangku matei tapungenggem ringkin paturong Sahakong Bahanji.

Ie Antang Bahandang mina enteng,e mulang nahabadjin gandang, hanji,e tendur manamunan tambit sambang.

Buli mupang manantawah Er kehrt wieder um und er flattert
Hühner, der Hühner der Höhe.

Es stossen herunter, es fahren herab die Penjang des Falken, des roten, sie ziehen entgegen den Wogen der Penjang, sie fallen an die Wellen der Paturong.

Aber nichts geschieht, nicht einmal gekrümmt werden die Schwanzfedern der Nashornvögel (Kopfschmuck) der Untertanen, der Scharen der Sklaven des Njaring Menteng Manambalau Bahandang, nicht einmal gebogen werden die schrägstehenden Zweiglein der Nashornvögel der Untertanen, der Menge der Leibeigenen des Sahakong Bahanji.

Stirb um gespeert zu werden als Kaufpreis des grossen Bootes, das da durchkielt der Meere sechs! wenn es so steht in dieser Sache, so wie die Monde vor sich ausgebreitet haben das zu beginnende Geflecht, wenn es nun so ist in dieser Angelegenheit, so wie die Frauen nachsinnen über ihre Flechtereien, dann wird es nicht ausbleiben, dass ich umgeschlagen (getötet) werde, eingeschlossen durch die Wogen der Penjang der Untertanen des Njaring Menteng Manambalau Bahandang, dann wird es nicht mehr abzuwenden sein, dass ich vernichtet werde, umzingelt von den Wellen der Paturong des Sahakong Bahanji.

Er, der Falke, der rote, legt nieder seinen Mut und er kehrt wieder um wie der Laut der Trommel der zurückkehrt und verstummt, es erschlafft seine Tapferkeit wie das Fell der Trommel. 
buang, buli halalian Darahen radja,n Antang ttg. halalian Pataho, hagan lawang mangkalewu, Batu Mamben, gadoh mangkarundong.

Kumin tingang, dia lunok ngarangka, hirum tambon, djaton baras ngalimbang,e ie Darahen radja,n Antang ttg. Pataho hagan lawang mangkalewu.

Manahingan riwut rawei Antang Bahandang, njalanean salatan tisoi kenjoi tabela.

Ijoh, koa,n rawei Darahen radja,n Antang, penjang,m dia menteng ikau Antang Bahandang, baja penjang, $m$ mangalong tando, $\mathrm{n}$ manok darong tingang, paturong, $m$ napugenggem 239 ringkin kariok punei rongkoi ambon.

Dari ikau! babalai rangkan kaju,n Sangalang Garing huang sara,n tana lombah, basali rewan Pantoh Ganan Kaju Hai, manandai tampoi mirang.

Nggatang taribanga Antang Bahandang mimbit kahawen lingo,e, bahata kasengen ka- kraftlos und ohne etwas erreicht zu haben wieder zurück zum Darahen, dem König der Falken, er kehrt zurück zum Pataho, dem Wächter an der Türe des Dorfes, zum Batu Mamben, dem Beschirmer beim Eingang des Ortes.

Sie brechen aus in das Lächeln der Nashornvögel, nicht überlegen lange die Lunok (die Männer), sie erheben das Schmunzeln der Wasserschlangen, nicht sinnen sie lange nach, sie, Darahen, der König der Falken, und Pataho, der Wächter an der Türe des Dorfes.

Sie hören nach der wehenden Rede des Falken, des roten, sie lauschen nach dem brausenden Worte des Falken, des jungen.

Ja, spricht das Wort des Darahen, des Königs der Falken, keinen Mut besitzen deine Penjang, o Falke, o roter, denn deine Penjang vermögen nur $z \mathfrak{u}$ belagern das Krähen der Hühner, der Hühner der Tingang, deine Paturong haben ja nur die Kraft um anzupacken das Gackern der Hühner, der Hühner aus der Höhe.

Mache dass du fortkommst! lasse dich nieder auf den $Z$ weigen des Baumes, des hohen der sich erhebt am Rande des breiten Feldes, nimm Wohnung auf den Aesten des Pantoh Ganan Kaju Hai (d.h. des Waringin der von diesem bösen Geist bewohnt wird), der aufragt über dem Acker, dem ausgestreckten.

Es erhebt seine Flügel, der Falke, der rote, und er nimmt mit sich ein beschämtes Herz und er hat als Weg- 
rendem,e.

Awi penjang,e batawah, dia balaloh giling pinang, paturong,e babeau ,dia hapekat puting roko,n tarahan.

Usang,e ie babalai rewan Sangalang Garing huang sara,n tana lombah, mangalati manok darong tingang ain oloh pantai danum kalunen.

Eleh tokep sagila mananturong lalento,n tingang djalahan Njaring Menteng Manambalau Bahandang, dani sagila manjahendeng rarajo,n bungai panungkup Sahakong Bahanji.

Bahing bapanting Darahen radja,n Antang, siring bambahinga Pataho haga,n lawang mangkalewu :

Eweh keton menteng, mina penjang bahari simpei,e, isen keton bahanji mingkes paturong mait sandik,e?

Kilen bitim Antang Tadjahan, pea andau bitim malangkusan harin bambang penjang, $m$, hamparea balitam manahirin katada,n sandik paturong,m?

Ijo-ijoh, koa,n riwut rawei zehrung nur Scham in seinem Innern. Weil seine Penjang kraftlos waren, empfing er nicht als Entschädigung die Röllchen von Betelnuss (die gerollten Kausel), erhielt er nicht als Lohn die Spitzen der Rauchwaren der Sklaven (Zigaretten).

Schon längst hält er sich wieder auf auf den Zweigen des Baumes, des hohen am Rande des Feldes, des breiten, und er bespäht und belauert die Hühner, die Hühner Tingang der Menschen am Ufer des Flusses der Welt.

Und schon vernimmt man in der Nähe das von der Seite nahende Getümmel der Nashornvögel (Männer im Kriegsschmuck) der Untertanen des $\mathrm{Njaring}$ Menteng Manambalau Bahandang, schon ertönt dort drüben der herbeikommende Lärm der Nashornvögel, der Angehörigen des Sahakong Bahanji.

Es erhebt seine Stimme und wirft aus sein Wort, er, der Darahen, der König der Falken, es schleudert hin und ruft aus seine Rede, er, der Pataho, der Wächter an der Türe des Dorfes:

Wer von euch ist tapfer, wer besitzt Penjang mit scharfen Bündeln, welcher von euch ist mutig und hat Paturong mit beissenden Bändern (d.h. wirkungsvolle Penjang und Paturong). Wie steht es denn mit dir, o Falke vom Ahnenheiligtum, wann wird es geschehen, dass du endlich auswirfst die Schärfe der Stücke deiner Penjang, wann wird es sein, dass du ausstreust die Bündel deiner Paturong?

Ja, ja, spricht das wehende Wort des 
Antang Tadjahan, aloh penjangku bahari simpei,e, amon tingang tempo,e dia menteng, aloh paturongku mait sandik,e, amon antang sangiang,e korang bahanji, tau bitingku kea enteng mulang nahabadjin gandang, hanji tendur namunan tambit sambang, manamunan ampi,n enteng Antang Bahandang.

Hajak ringkes-marangkesa Antang Tadjahan, lalo ringkin basariang pandong padjangan.

Ela, koa,n riwut rawei Antang Pipit, kenjoi sangkalap, bitingku djundjun helo, maneneng riak penjang $\mathrm{Njaring}$ Menteng Manambalau Bahandang, balitangku totok tambalon tambon, marintuh ringkin paturong panungkup Sahakong Bahanji.

Takan bewei! koa,n rawei Antang Tadjahan, mina pe-
Antang vom Ahnenheiligtum, was nützt alles, wenn meine Penjang scharfe Bündel haben, aber wenn der Nashornvogel, wenn ihr Besitzer nicht mutig ist, was hilft es denn wenn meine Paturong beissende Hölzer besitzen, wenn der Falke, wenn ihr Sangiang (ihr Herr, Besitzer) zu wenig tapfer ist, dann kann es sein, dass auch mein Mut zurückkehrt gleichwie der Schall der grossen Trommel, dass meine Tapferkeit erschlafft wie das Fell der Trommel, so wie es geschah mit der Tapferkeit des Falken, des roten.

Und es bringt in Ordnung seine Sachen, er der Falke des Ahnenheiligtumes, er macht bereit und er gürtet um seine Wogen (die Penjang), er der Falke aus dem heiligen Hain, wo man sich Rat holt (bei den Ahnen des Ahnenheiligtumes, die darauf in der Gestalt des Antang erscheinen).

Tue das nicht, spricht das wehende Wort des Antang Pipit,240 des Falken der Heuschrecken, ich werde zuerst aufsteigen und ich werde zum Verstummen bringen die brausenden Wellen der Penjang des Njaring Menteng Manambalau Bahandang, ich werde anfallen die zusammengerollte Wasserschlange (die Wellen der Penjang werden mit einer Wasserschlange verglichen die sich zusammengerollt hat), ich werde zum Verstummen bringen die rauschenden Wogen der Paturong der Angehörigen des Sahakong Bahanji.

Wohlan dann! so spricht das Wort des Falken vom Ahnenheiligtum, wenn du 
njang bitim puna menteng, mahaga paturong balitam puna bahanji, asal ela enteng,m mulang nahabadjin gandang, ela hanji,m tendur nahatambit sambang.

Dia memen! koa,n rawei Antang Pipit, penjangku menteng tisa, $\mathrm{n}$ mangalong ohit sararonting baho, paturongku bahanji napugenggem sangkalap salintik pating.

Has nih! manuntun ampin kamenteng bambang penjang, $\mathrm{m}$, ajo! itah manureng hanji,n paturong,m.

Palus Antang Pipit manggatang taribanga,e, kenjoi sangkalap manangkat pangansiring,e.

Djadi gantong njanjangkelang kaju,n Sangalang Garing, tarigatang njanjampal,e bulus Lampesong Kereng.

Salenga nantarang,e lalawa indu tujang bangkang, tapugenggem,e djala ain talampen dawen.

Eleh biti,e malik bulat kilau batu,n karangan danum, balita,e malik bunter njakatan takanan pinang lewu. nur besitzest die Penjang die dir Mut verleihen, wenn du nur zum Eigentum hast die Paturong die dir Tapferkeit geben, und wenn es nur nicht geschieht, dass dein Mut wieder zurückkehrt wie der Schall der grossen Trommel und deine Tapferkeit erschlafft wie das Fell der Trommel.

Das ist gut in Ordnung! spricht das Wort des Antang Pipit, meine Penjang sind sehr mutig, sie sind der Ueberrest derer die da umzingelt haben die Kolibri, die sich aufhalten auf dem Reisfeld, meine Paturong sind tapfer um anzupacken die Heuschrecken, die sich festgeklammert haben an den Zweigen.

Wohlan nun! wir werden anschauen die Art und Weise des Mutes der Holzstücke deiner Penjang, wohlauf! wir werden sehen wie es mit der Tapferkeit deiner Paturong steht.

Und sogleich erhebt der Antang Pipit seine Flügel, öffnet der Heuschrekkenfalke seine Schwingen.

Schon erhebt er sich in die Höhe und verschwindet zwischen den $Z$ weigen der Bäume, der hohen, schon schwebt er hoch zwischen den aussprossenden Aesten des Lampesong der Sandhügel. Und plötzlich stösst er gegen eine Spinne die sich wiegt in ihrem Neste und er wird gefangen in dem Netz der unter den $Z$ weigen und Blättern lauernden Schlange.

Und schon verwandelt er sich in die Rundheit des Steines von den Steinbänken im Fluss, schon wird er rund wie die Frucht der Betelnuss des 
Mandjato bulat kilau bua lunok kalagahan tingang, piring-piring rowan bua sangalang kalapasan kalawet ajun baputi.

Manggatang kumin tingang, dia lunok ngarangka, njariangkat hirum tambon, djaton baras ngalimbang,e, Darahen radja,n Antang.

Terai biti,m Antang Pipit, keleh buli halalian rewan tundjal paria,n bukit kabantengan tana lombah ain oloh pantai danum kalunen, mulang medjen pating djadjangkar peho,n ain oloh luwok kampongan buno.

Usa-usang,e Antang Pipit, kenjoi sangkalap buli halalian rewan intu saran tana lombah, mulang medjen pating manandai tampoi mirang.

Halaloh ie riwut rawei badjangkang, hapekat balita,e tisoi badjawo dino,e bara Darahen radja,n Antang, upah,e bara Antang Tadjahan.

Ijoh, koa,n riwut rawei Antang Tadjahan, salatan tisoi kenjoi pandong parindjangan
Dorfes (d.h.: seine Flügel liegen eng am Körper an).

Und rund fällt er herunter wie eine Baumfrucht die dem Schnabel des Nashornvogels entglitt, er stürzt ab wie eine Frucht die der weisshalsige Kalawetaffe fallen liess.

Er bricht aus in das Lächeln des Nashornvogels, nicht bedenkt sich lange der Lunok (Mann), er erhebt das Schmunzeln der Wasserschlange, nicht sinnt er lange nach, er, der Darahen, der König der Falken.

Höre nur auf, o Antang Pipit, kehre wieder um und begib dich zurück auf die Aeste, auf die Stangen der Bergbohnen in der Mitte des Feldes, das Eigentum der Menschen am Ufer des Flusses der Welt, kehre wieder heim auf die $Z$ weige und packe mit deinen Krallen die Hühner der Menschen von der Buchtung des Flusses an der das Dorf der Speere (Männer) liegt.

Schon längst ist der Antang Pipit, der Heuschreckenfalke wieder umgekehrt und hat sich zurückbegeben auf die Aeste am Rande des Feldes, des breiten, er ist heimgekehrt auf die $Z$ weige die sich erheben über dem Feld, dem ausgestreckten.

Entschädigt wurde er mit dem wehenden Wort, dem viel Raum einnehmenden, belohnt wurde er mit der Rede, der umfangreichen, die er empfing vom Darahen, dem König der Antang, die er als Lohn erhielt vom Falken des Ahnenheiligtumes.

Ja, spricht das wehende Wort des Antang vom Ahnenheiligtum, sagt die rauschende Stimme des Falken aus 
dahiang, tjoba bitingku kahalinai!

Ijoh, koa,n riwut rawei Darahen radja,n Antang ttg. koa,n salatan tisoi Pataho, amon kilau etoh panalatai, dia balang enteng itah njaratawah oloh pantai danum kalunen, hanji,n itah njarabean oloh luwok kampongan buno.

Tau indu gandang tatah djalahan tatarantang nole, pandai indu garantong djela,n luwok kampongan buno.

Notok-natuka pantar pinang Antang Tadjahan, njipa olang nantali tanteng tingkah mangendas bulau pulu batandjong henda.

Palus manggatang taribanga,e hagoet manambang riak penjang djalahan Njaring Menteng Manambalau Bahandang.

Hajak mangkat pangansiring,e basangka manakep ringkin paturong Sahakong Bahanji Bagundai Gambulong. Lapas,e penjang riwut dje baka tingkai renteng tingang, dem heiligen Hain, von wo man sich Vorzeichen und Rat erbittet, nun will ich diese Schwierigkeit auch einmal probieren!

Ja, spricht das wehende Wort des Darahen, des Königs der Falken, und sagt die rauschende Rede des Pataho, wenn es so steht mit unserer Angelegenheit, dann wird es nicht abzuwenden sein, dass unser Mut verachtet wird durch die Menschen am Ufer des Flusses der Welt, dass unsere Tapferkeit geschmäht wird durch die Bewohner des Dorfes der Lanzen an der Buchtung des Flusses.

Und sie kann dienen zur Trommel der goldenen Zahnstifte der Angehörigen, der Kinder, der verwaisten, es wird dienen als Gong für die Zungen der Bewohner des Dorfes der Lanzen an der Buchtung des Flusses. (Man wird darüber lange und ausführlich sprechen.)

Es pickt an dem Stamme der Pinang der Falke des Ahnenheiligtumes, er kaut mit den gelben goldenen Zahnstiften bis sich gelb färbt das Gold, das vielfach bedeckte mit Gelbheit (d.h. mit dem gelben Speichel).

Und sogleich erhebt er seine Flügel und er macht sich auf um entgegen zu ziehen den Wogen der Penjang der Angehörigen des Njaring Menteng Manambalau Bahandang.

Und er öffnet seine Schwingen und er bricht auf um entgegen $z \mathfrak{u}$ gehen den Wellen der Paturong des Sahakong Bahanji Bagundai Gambulong.

Er lässt los seine Penjang, die wehenden, die da abschlagen die Schwanz- 
langkusa,e paturong salatan dje baka tutuh pating bungai.

Lepah batutuh renteng tingang djalahan pulau tarahan ain Njaring Menteng Manambalau Bahandang, lingis tatingkai pating bungai panungkup puja kalinti,n Sahakong Bahanji Bagundai Gambulong.

Mari darah,e idje kasampilong dawen Lunok Tarong, merang tolang,e due lumpang bulau tandok tambon, Pantoh Ganan Kaju Hai, Embak Ganan Bua Bakas.

Awi mite hari,n penjang bahanji mampah tingang taraha,e kilau sahep rakeran tambon, manuntun kanait paturong menteng mampunjahep bungai kalinti tingkah sahep rakeran darong handjaliwan. 241

\section{Bahing bapanting Pantoh}

federn der Tingang (Kopfschmuck), er wirft aus seine Paturong, die rauschenden, die da herunterreissen die Zweiglein der Nashornvögel.

Und restlos werden sie abgeschlagen, die Schwanzfedern der Tingang der Untertanen, der Scharen der Sklaven des Njaring Menteng Manambalau Bahandang, und alle zusammen werden sie heruntergerissen, die $Z$ weiglein der Nashornvögel der Gemeinschaft der Menge der Leibeigenen des Sahakong Bahanji Bagundai Gambulong.

Aus ihren Adern weicht das Blut und sie gleichen den Blättern des Waringinbaumes, die übergossen worden sind mit Wasser (sie glitzern dann weiss; so bleich sind sie geworden vor Schrekken), es klappern ihre Knochen, die beiden goldenen Stützen, die Hörner der Wasserschlange (die Beine), die des Pantoh Ganan Kaju Hai und des Embak Ganan Bua Bakas.

Weil sie sehen wie die Schärfe der Penjang, der mutigen, umwerfen den Kopfschmuck ihrer Sklaven und die Nashornvogelfedern zusammenwehen wie abgefallenes Laub, das sich zusammenrollt wie eine Wasserschlange, weil sie anschauen müssen die Kraft der Paturong, der tapferen, die herunterreisst die Nashornvogelfedern ihrer Leibeigenen und sie zusammenweht und aufrollt, so wie sich eine Brillenschlange zusammenrollt. (Sie werden kraft- und mutlos und sind nicht mehr imstande etwas zu unternehmen gegen diese mächtigen Penjang.)

Es erhebt sein Wort der Pantoh Ganan 
Ganan Kaju Hai, randan ie hakaisek rawei, siring bambahinga Embak Ganan Bua Bakas, ringkang ie basarohi tisoi :

Eweh gangguranan ara,e idje bahanji mampah renteng tingang djalahan pulau tarahan ain ikei, isen sasabutan biti,e menteng mampanjahep pating bungai panungkup puja kalinti?

Lalau malapas penjang riwut dje baka tutuh renteng tingang pakarok 242 malangkusan paturong salatan dje baka tingkai pating bungai.

Bahing bapanting Antang Tadjahan manombah riwut rawei Pantoh Ganan Kaju Hai, siring bambahinga mangambahan salatan tisoi Embak Ganan Bua Bakas:

Dia isek manansekam balitan aku Antang Tadjahan, isen bintang panjaroham biti,n aku kenjoi parindjang dahiang.

Padjandjuri bara pukung pahewan Antang, panantekei bara pandong parindjangan dahiang.

Bahing bapanting Pantoh Ganan Kaju Hai, hakaisek rawei kahalinai, siring bambahinga Embak Ganan Bua Bakas, ringkang basarohi tisoi :
Kaju Hai und mit kleinlauter Stimme erkundigt er sich, es wirft aus seine Rede, er der Embak Ganan Bua Bakas und er fragt mit furchtsamer und ängstlicher Stimme:

Mit welchem Namen nennt er sich, er, der es wagt herunterzuschlagen die Schwanzfedern der Tingang der Angehörigen unserer Sklaven, wie heisst er, der den Mut findet herabzureissen die Zweiglein der Nashornvögel der Gemeinschaft der Scharen unserer Leibeigenen?

Der zu sehr loslässt die Penjang des Windes, der herabreisst die Schwanzfedern der Tingang, zu stark auswirft die Paturong des Sturmes, der herunterschlägt die $Z_{\text {weiglein }}$ der Nashornvögel.

Es erhebt seine Stimme der Falke des Ahnenheiligtumes und er antwortet dem wehenden Wort des Pantoh Ganan Kaju Hai, er wirft aus seine Rede und er entgegnet der brausenden Stimme des Embak Ganan Bua Bakas: Nicht frage, nicht erkundige dich bei mir, dem Antang des Ahnenheiligtumes, nicht forsche nach bei mir, dem Falken aus dem heiligen Hain wo man Rat holt und Vorzeichen erbittet.

Hervorgetreten bin ich aus dem heiligen Wald des Falken, herausgeschritten bin ich aus dem heiligen Hain wo man Rat holt und Vorzeichen erbittet.

Es erhebt seine Stimme der Pantoh Ganan Kaju Hai und er erkundigt sich mit kleinlauter Stimme, es wirft seine Rede aus der Embak Ganan Bua Bakas und er fragt mit furchtsamem, ängst- 
lichem Worte:

Akan kueh bulan djandjulanan keton sampai panamuei keton manutuh renteng tingang, isen bintang panjarongan lalau pangadja maningkai pating bungai?

Dia isek manansekam, koa,n rawei Antang Tadjahan, puna panamueiku mamaleh andep pandjang, puna pangadjangku mulang tekap ambo, awi djalahan keton djadi mandep entang pantai danum kalunen, awi panungkup, $m$ djundjun helo mandok tujang luwok kampongan buno.

Nganahepan keton entang metoh ie babalai petak sintel habalambang tambon, njaripanto keton tujang hemben basali liang deret habangkalan garantong.

Sampai lunok ie djadi batipas pontong,e, baringin bageto sangkabila,e.

Djadi babalai ie bulau sambong raung, basali runi talangkop njaho, bahalap njaloang uei bakulamba antang, kambadji garing handue udje masoh, handue udju murik, tarah handjaliwan matei lun-
Wohin, o Monde, führt euch euere Reise, wohin geht euere Fahrt auf der ihr herunterschlägt die Schwanzfedern der Tingang, wem gilt eigentlich euer zu heftiger Besuch, o Sterne, dass ihr bei euerer Ankunft gleich herunterreisst die Zweiglein der Nashornvïgel?

Nicht frage nach, nicht erkundige dich, so spricht das Wort des Falken vom Ahnenheiligtum, wahrlich meine Reise führe ich aus um $z u$ vergelten den weitausgeholten Schlag, mein Besuch dient dazu um zurückzugeben den $z u$ starken Hieb, denn Angehörige von euch haben niedergeschlagen den Gewiegten aus dem Dorfe am Ufer des Flusses der Welt, sie haben mit den Hörnern niedergestossen den Geschaukelten aus dem Orte der Speere an der Buchtung des Stromes.

Getötet habt ihr den Gewiegten als er noch wohnte auf der Erde, der harten, die zur Schwelle hat die Wasserschlange, erschlagen habt ihr den Getragenen als er sich noch auflielt auf der Erde, der festen, die als Schwelle hat die Gong.

Sodass ihm, dem Lunok, abgeschlagen wurde die Krone, sodass ihm, dem Waringin, abgeschlagen wurden seine Stützen.

Er hat sein Haus aufgeschlagen in dem goldenen Sarg, dem vollendeten, er hat seine Wohnung bezogen in dem Sarg, dem zusammengefügten, dem donnernden, der schön umwunden ist mit Bändern von Rotan auf dem sich der Antang wiegt, mit Bändern von 
djang-lendjut, tahitik talampe nihau lupang-lipet.

Idja bahalap ngamburi Rohan Bahanji tawan tandohan djalan liau, haluanan Asai Menteng dje batuana petas djalan pangambon.

Asang djadi bagantong intu bukit Pasahan Raung, balita,e djadi batujang medjen kereng dagarin penda lunok.

Lalau asi-asi djalahan tarantang nole lihi,e, pakarok siresiren 243 panungkup lalundong siren pelai,e.

Ie njamah baloang bulan bawin tawur entang pantai danum kalunen, hasarohan rabia sawong ambon tujang lunok kampongan buno marawei bitingku pumpon riah tandang balitangku.

Mindjam entengku hapan mamaleh andep pandjang, manasih hanjingku hapan mulang tekap ambo dengan Pantoh keton Ganan Kaju Hai, Embak Ganan Bua Bakas.
Rotan, die verkeilt sind mit zweimal sieben Elfenbeinstücken die in der Richtung nach flussabwärts liegen und mit zweimal sieben Elfenbeinstücken die in der Richtung nach flussaufwärts liegen, sie sind behauen von der toten Handjaliwanschlange, der gekrümmten (von gekrümmtem $\mathrm{Holz}$ ), herausgeschlagen sind sie aus der Erdschlange, der verendeten, der gebogenen.

Das gut gesteuert wird durch Rohan Bahanji, der den Weg kennt den die Liau zurücklegen muss, und auf dessen Vorpflicht (der Sarg ist ein Boot) Asai Menteng sitzt, der den Pfad kennt den die Nebelgleiche beschreiten muss.

Der Kopf jäger wurde niedergelegt auf dem Berge der Hütten der Särge, er wurde in die Wiege gelegt (wie ein schlafendes Kind) auf dem Sandhügel der Särge unter den Lunok.

$\mathrm{Zu}$ kummervoll sind sie nun, sie die Scharen der Kinder, der Waisen, der verlassenen, zu leidvoll sind die vielen Kinder, die zurückgelassenen Waisen. Und sie sandten aus als ihre Mittlerinnen die Monde, die Frauen des Streureises, sie die Getragenen am Ufer des Flusses der Welt, sie sandten als Botschafterinnen die goldenen Reiskörner, sie die Gewiegten, die Lunok aus dem Dorfe der Speere, sie liessen mich rufen, sie liessen mich holen, mich den Tiger.

Um in Dienst zu nehmen meinen Mut um damit Rache zu nehmen und zurückzuzahlen den weit ausgeholten Schlag, um zu vergelten den Hieb an euerem Pantoh Ganan Kaju Hai und an euerem Embak Ganan Bua Bakas. 
Palus maleteng tarong oloh balai lunok hadare dawe, nampulilap tinting radja medjen sali baringen hatabuhi bumbong,e.

Handak mamaras undan pamalunok bungai, manjempong garing paleng tatean bulan bawin riwut.

Sua-sual tatah Pantoh Ganan Kaju Hai, Embak Ganan Bua Bakas malawan, njamah nundjong ie sapa,n tingang, njariangkat ie sumpah burong.

Djilau bulan kapanaho matei aton bitingku nganahaman entang pantai danum kalunen.

Puna bitingku melai bagalogo garantong, balitangku medjen basandar rundjan bahenda.

Puna aku dia balisang pandjang idje gawang tingang, djaton aku balangkas ambo nduan due kasambuti ranjing.

Melai aku manabasan ranjing pandereh buno, 246 medjen aku hatarean lintong talawang.

Melai manjimpei penjang karuhei tatau akan entang, me-
Um zu versenken den Ruhm der Leute aus dem Hause des Lunok, das zierlich umflochten ist mit Blättern, um zum Verschwinden $z \mathfrak{u}$ bringen das Lob der Könige aus der Wohnung des Waringin, die mit zarten Herzblättern umwoben ist.

Wir wollen nun abschlagen die Köpfe die sich erheben auf dem Lunok der mit dem Nashornvogel geschmückt ist, wir wollen herunterschlagen die Elfenbeine, die stummen, des Steges, den die Monde, die Frauen des Windes, beschreiten 244.

Es verteidigen sich die goldenen Zahnstifte des Pantoh Ganan Kaju Hai, des Embak Ganan Bua Bakas, sie widersetzen sich und sie erheben den Eid des Tingang, sie erheben ihre Stimme und legen ab den Schwur des Vogels.

Auf keinen Fall ist es geschehen, dass ich es war der erschlagen hat den Gewiegten vom Ufer des Flusses der Welt.

Denn wahrlich, ich blieb unbeweglich auf den Gong sitzen, denn sicherlich, ich lehnte an gegen meine heiligen Töpfe, die gelben.

Wahrlich, ich entfernte mich nicht auch nur eine Spanne des Nashornvogels, nicht ging ich fort, auch nur zwei Kasambuti245 des Erhabenen (des Nashornvogels).

Ich blieb daheim und schmiedete heilige Speere, ich hielt mich zu Hause auf und schnitzte die mit Rotanbändern umflochtenen Schilde.

Ich war in meiner Wohnung und ich band zusammen die Penjang, die Ka- 
djen aku manjandik paturong sangkalemo radja akan tujang.

Mangat entang belom bahaseng pandjang tau mandepe langit, tujang haring manjame ambo pandai maradjur hawon.

Ijoh, koa,n rawei Antang Tadjahan, ela ikau hatandjaro penjang balita,m Pantoh Ganan Kaju Hai, ikau hapanpungan paturong balita,m Embak Ganan Bua Bakas.

Keleh biti,m malawo rawei toto tembek-tambuko, tisoi kabadjuran sampirang humbang, rawei lihang tampilai, tisoi ohong tabengan, ela keton malawan.

Magon sua-sual tatah,e Pantoh Ganan Kaju Hai, hagalanggang 247 tanteng,e Embak Ganan Bua Bakas dengan Antang Tadjahan.

Giri-gagariten tanteng,e Antang Tadjahan hajak sawoh bambang penjang menteng, eleh masak bahandang pahaliong bau manjamanan darah tingang.

Kitik hapangandang kilau bawi katarunan sangiang, ruhei des Reichtums für den Getragenen, ich sass in meinem Hause und machte dort Bündel mit den Paturong Sangkalemo Radja für den Gewiegten. Damit der Getragene lebe mit einem langen Atem der anstösst am Himmel, damit der Gewiegte gedeihe mit grossem Odem der sich erhebt bis zu den Wolken.

Ja, spricht das Wort des Falken vom Ahnenheiligtum, nicht lüge mit deinen Penjang, o Pantoh Ganan Kaju Hai, nicht schwindle mit deinen betrügerischen Paturong, o Embak Ganan Bua Bakas.

Mögest du doch auswerfen ein Wort das wahr ist und sich nicht widerspricht, eine Rede die aufrichtig ist und die mit einem Schlag durchhaut, denn deine Aussprüche fallen um wie leeres Reisstroh, deine Ausflüchte brechen zusammen wie ein von Baumstämmchen gemachter Weg, nicht leugne mehr $\mathrm{ab}$, nicht widerspreche länger.

Aber immer noch verteidigen sich die goldenen Zahnstifte des Pantoh Ganan Kaju Hai, immer noch streiten die goldenen Plättchen des Embak Ganan Bua Bakas gegenüber dem Falken des Ahnenheiligtumes.

Es knirscht vor Zorn mit seinem goldenen Stiften der Falke vom Ahnenheiligtum, es werden wütend die Bündel der Penjang, die mutigen, hochrot wird der Schein seines Gesichtes und er gleicht dem Blute des Nashornvogels.

Er zittert und bebt wie die Frauen (Priesterinnen) in die einfährt der 
redjar hapanderet tingkah habinei katakepan djalajan.

Palus Antang Tadjahan mambowoh penjang garo dje baka turon batiroh, malangkusan paturong santi dje baka kumbang mangantok.

Lepah tiroh tingang manantekas djalahan pulau tarahan ain Njaring Menteng Manambalau Bahandang, ain Pantoh Ganan Kaju Hai, lingis manundjong kantok burong panungkup puja kalinti ain Embak Ganan Bua Bakas.

Rata santah renteng tingang, lingis sundong pating bungai, uras kanuron batiroh.

Palus Antang Tadjahan malapas dohong korik namunan tadji,n tingang, pulang ringik tingkah silo,n antang.

Palus maras,e undan pamalunok bungai, lumpong manduroi rohong, netek,e garing paleng tatean bulan bawin riwut ain pulau tarahan puja kalinti.

Mules hiring dohong ain Antang Tadjahan handak mane-
Sangiang, heftig klopfen seine Adern wie die Frauen die da erwarten den Djalajan (Sangiang).

Und sogleich wirft der Falke vom Ahnenheiligtum aus seine Penjang des Weihrauches, die in Schlaf fallen lassenden, er streut aus die Paturong des Wohlduftes die da Schlummer verbreiten.

Und restlos fallen sie in einen starken Schlaf der Tingang, sie die Angehörigen, die Scharen der Sklaven des Njaring Menteng Manambalau Bahandang und des Pantoh Ganan Kaju Hai, sie alle zusammen fallen in den Schlummer des Vogels, sie die Gemeinschaft, die Menge der Leibeigenen des Embak Ganan Bua Bakas.

Sie alle beugen herunter die Schwanzfedern der Tingang (Kopfschmuck), sie beugen herab die Zweiglein der Nashornvögel, denn sie alle sind in tiefen Schlaf gefallen.

Und sogleich lässt der Falke vom Ahnenheiligtum los die kleinen Dolche (seine Krallen), die die Schärfe haben der Schnäbel der Nashornvögel, die kleinen Griffe, die den Krallen der Antang gleichen.

Und sogleich schlug er ab die Köpfe, die sich erheben auf dem Lunok der mit dem Nashornvogel geschmückt ist, die aufragenden Köpfe, die umgeben sind von den Lanzen, hieb er weg die Elfenbeine, die stummen, des Steges der Monde, der Frauen des Windes, die Köpfe der Scharen der Sklaven, der Menge der Leibeigenen.

Und es wendet sich die Schärfe des Dolches des Falken vom Ahnenheilig- 
tek garing paleng tatean bulan bawin riwut ain Pantoh Ganan Kaju Hai, Embak Ganan Bua Bakas.

Eleh mikau 248 haganggurang kabangkang balita,n Pantoh Ganan Kaju Hai, Embak Ganan Bua Bakas.

Palus mamanting tambang lawah rawing balinga halalian balai lunok hadare dawe, mangumbang salungan tatau bapilik hindje, mulang sali baringen hatabuhi bumbong,e, buli halalian Njaring Menteng Manambalau Bahandang, Sahakong Bahanji Bagundai Gambulong.

Pantoh Ganan Kaju Hai, Embak Ganan Bua Bakas djandjaroman akan tato,e Njaring Menteng Manambalau Bahandang, hyang,e Sahakong Bahanji Bagundai Gambulong.

Koa,n rawei Pantoh Ganan Kaju Hai: haramaung aku mekut tambang, pangandien aku tendur tabana, entengku mulang nahabadjin gandang, hanjingku tendur mahatambit sambang.

Kalah aku awi enteng oloh pukong pahewan antang, hatampuli aku awi hanji,n tum um herunterzuschlagen das Elfenbein, das stumme, des Steges der Monde, der Frauen des Windes, die Köpfe des Pantoh Ganan Kaju Hai und des Embak Ganan Bua Bakas.

Es klirren und klappern die Beinringe des Pantoh Ganan Kaju Hai und des Embak Ganan Bua Bakas.

Und sie werfen aus ihre Beine, die geschmückten, sie die Krokodile, die schnellen, und sie kehren zurück in das Haus des Lunok, das schön umflochtene mit Blättern, sie schütteln ihre Beine, die reichverzierten, und sie kehren wieder rasch zurück in die Wohnung des Waringin, die zierlich umwoben ist mit zarten Herzblättern, sie kehren wieder heim zu dem $\mathrm{Nja}$ ring Menteng Manambalau Bahandang und dem Sahakong Bahanji Bagundai Gambulong.

Sie beiden, Pantoh Ganan Kaju Hai und Embak Ganan Bua Bakas, sie erzählen ihrem Ahnen Njaring Menteng Manambalau Bahandang, und sie berichten ihrem Grossvater Sahakong Bahanji Bagundai Gambulong was sich zugetragen hat.

Und es spricht das Wort des Pantoh Ganan Kaju Hai: mir, dem Tiger, sind lahm geworden die Füsse, mir, dem Bergtiger, sind erschlafft die Beine und mein Mut kehrt zurück wie der Schall der Trommel der umkehrt und verstummt, meine Tapferkeit ist erschlafft wie das Fell der Trommel.

Besiegt bin ich worden durch den Mut des Menschen aus dem heiligen Gehölz des Antang, überwunden worden bin 
oloh pandong pandjangan dahiang.

Limbah te Njaring Menteng Manambalau Bahandang batasat, Sahakong Bahanji bapindah.

Kilau rangkang garing batasat balua pukong lunok, tingkah parukat sihong bapindah bahandjong lulong baringen.

Djadjahangkar tingang,e kilau bambulong tusang, marewa bungai,e rowan-rewan sangalang.

Kitik hapangandang bahing njaho, muluh djela, redjar hapandereh lalento,n kilat, maleak mata,e.

Matei indang buno bilin banama halalungan laut djahawen! koa,n rawei Antang Tadjahan, awat Darahen radja,n Antang! amon kalotoh talatai,e, dia balang maras,e undan pamalunok bungaiku, dia tampuli ie manetek garing paleng tatean bulan bawin riwut.

Njantoh tandok,e Darahen ich durch die Tapferkeit des Mannes aus dem heiligen Hain wo man Rat holt und sich Vorzeichen erbittet.

Und darnach siedelt von diesem Orte um der Njaring Menteng Manambalau Bahandang und es zieht weg von diesem Orte der Sahakong Bahanji. So wie ein altes Elfenbein (ein alter Mensch) umzieht und heraustritt aus dem Walde der Lunok, gleichwie ein Wurzelstock, ein elfenbeinerner, seinen Platz wechselt und hervorschreitet aus dem Wald der Waringin.

Er tritt hervor mit den erhobenen Schwanzfedern des Tingang, wie schräg stehende Aeste der Bäume, er tritt heraus mit den hoch aufgerichteten Schwanzfedern des Nashornvogels, gleichwie ein Baum aufragt aus dem niederen Gehölz.

Es zittert und kracht sein donnerndes Wort und weit heraus hängt er seine Zunge, es klopfen und schlagen die Adern seiner blitzenden, zuckenden Rede und seine Augen treten aus ihren Höhlungen hervor.

Stirb um gespeert zu werden als Kaufpreis für das grosse Boot das da durchkielt der Meere sechs! so ruft aus der Antang des Ahnenheiligtumes, rette mich, o Darahen, König der Falken, wenn es so steht mit meiner Sache, dann wird es nicht abzuwenden sein, dass er herunterschlägt meinen Kopf der sich erhebt auf dem Lunok der mit dem Nashornvogel geschmückt ist, dass er herabschlägt das Elfenbein, das stumme, des Steges der Monde, der Frauen des Windes.

Es neigen herab ihre Hörner (Augen 
hajak Pataho hagan lawang lewu, niling pating bungai,e hindje humbuh Batu Mamben gadoh pangkarundong.

Salenga Njaring Menteng Manambalau Bahandang, Sahakong Bahanji Bagundai Gambulong manuntun ranjing pandereh buno hai manipeng dawen kaju hantangan baho.

Palus gatang tarahendeng Darahen radja,n Antang hajak tundjong tarahingkat Pataho hagan lawang lewu.

Mamurai manarowo djoho,n pinang,e ngadja-ngadjang renteng tingang $\mathrm{Njaring}$ Menteng Manambalau Bahandang uring manjang,e manjakalah pating bungai Sahakong Bahanji.

Saloh djoho,n pinang,e djadi penjang sangkalemo radja dje baka giring bulu, rentar uring manjang kanjari,n paturong sangkalunjai dje baka gandjoi tolang.

Eleh Njaring Menteng Manambalau Bahandang balemo kilau kupeh tepong, uhat,e badjambulei namunan sadiri,n behas parei njangen tingang. oder Kopfschmuck), sie, Darahen und Pataho, der Hüter an der Türe des Dorfes, sie beugen herunter die $Z_{\text {weig- }}$ lein der Nashornvögel, sie, der Darahen, der König der Falken, und der Batu Mamben, der Wächter an dem Eingang zum Ort.

Und plötzlich sieht Njaring Menteng Manambalau Bahandang, gewahrt der Sahakong Bahanji Bagundai Gambulong den erhabenen heiligen Speer (die Krallen des Darahen), den grossen, der da aufragt aus den $Z$ weigen des Hantanganbaumes auf dem Feld.

Und sogleich steht er auf und erhebt sich, er der Darahen, der König der Falken, und es erhebt sich und steht auf der Pataho, der Wächter an der Türe des Dorfes.

Sie giessen aus, sie streuen herab den Saft der Pinang (den Speichel nach dem Kauen von Pinang), sie bedecken die Schwanzfedern des Tingang des Njaring Menteng Manambalau Bahandang, sie überschütten mit der Flüssigkeit der Betelnuss die $Z_{\text {weiglein des }}$ Nashornvogels des Sahakong Bahanji. Und es verwandelt sich der Saft der Pinang und nimmt die Gestalt an von Penjang Sangkalemo Radja die zu Berge stehen lassen die Haare, es verändert sich die Flüssigkeit der Betelnuss und sie nimmt die Form an der Paturong Sangkalunjai die erbeben lassen die Knochen.

Und sogleich wird Njaring Menteng Manambalau Bahandang schwach wie ein Krümmel Mehl und seine Muskeln werden kraftlos wie die eines Opferpüppchens von Reismehl, das zuberei- 
Manggatang kumin tingang Darahen radja,n Antang ttg. Antang Tadjahan, ngandangandang,e balengkong tingang ain $\mathrm{Njaring}$ Menteng Manambalau Bahandang, kilau djaka handak mamaras undan pamalunok bungai, rowarowan lius manjempong garing paleng tatean bulan bawin riwut.

Ijoh, koa,n riwut rawei $\mathrm{Nja}-$ ring Menteng Manambalau Bahandang, salatan tisoi Sahakong Bahanji:kareh bitingku hadjalukan akam Pantoh Ganan Kaju Hai basa biti,e puna toto nganahaman entang pantai danum kalunen, mampalilap njama,n tujang luwok kampongan buno.

Kareh keton bandong kajau omba ambon hakamalem, njurong impan buson taliwon dahiang amon djadi tampalawei burong.

Ijoh Njaring Menteng Manambalau Bahandang, Sahakong Bahanji Bagundai Gambulong, nduan hambekan katon, aku Pataho manjahuan tet wurde von dem Reise Njangen Tingang.

Es erhebt ein Lächeln der Tingang, er der Darahen, der König der Antang, und er der Falke des Ahnenheiligtumes, und zusammen beklopfen und betrommeln sie die Kehle des Nashornvogels des Njaring Menteng Manambalau Bahandang wie wenn sie herunterschlagen wollten den Kopf der sich erhebt über dem Lunok der mit dem Nashornvogel geschmückt ist, wie wenn sie herabschlagen wollten das E1fenbein, das stumme, des Steges der Monde, der Frauen des Windes.

Ja, spricht das wehende Wort des Njaring Menteng Manambalau Bahandang, die brausende Rede des Sahakong Bahanji: ich werde euch übergeben den Pantoh Ganan Kaju Hai, denn es ist wahrlich so, ist sicher gewiss, dass er erschlagen und getötet hat den Getragenen vom Ufer des Flusses der Welt, dass er zum Verschwinden brachte den Atem des Gewiegten aus dem Dorfe der Lanzen an der Buchtung des Flusses.

Hernach, ihr Männer, ihr Kopfjäger, macht ihr euch auf, dann nämlich wenn die Nacht stark vorgerückt ist, ihr ziehet aus und ihr lauert auf, ihr jungen tanzenden Vorzeichen, dann wenn angebrochen ist die Morgendämmerung der Vögel (zwischen 5 und $6 \mathrm{Uhr}$ ).

Ja, Njaring Menteng Manambalau Bahandang, Sahakong Bahanji Bagundai Gambulong, wir sind mit diesem Vorschlag zufrieden, aber ich, Pataho, verlange von dir, dass du mir übergebest 
biti,m hadjalukan salumpok liau haring kaharingan.

Palus halalian salumpok entang tarantang nole bakawan kilau burong tingang, mampamulang tanterus tujang bapumpon tingkah tandang haramaung, sama buli mangandon penjang karuhei tata11, mulang basalungkem paturong sangkalemo radja.

Buli bahaseng batu dia tau una, mulang badjame liang dia tau rugi.

Mangat entang buli dengan pasihan rundjan, mulang hajak sapalinda njalong bukit batu.

Mangat entang tau hatalatai lunok belom mamua bulau dje bahalap babasong rundjan, 252 mangat tujang tau napatok 253 baras bulau lampang dje njahumpak njalong bukit batu, tarantang nole kindjap nupi penjang, lalundong siren hiket mangampa paturong.

Ijoh, Pataho haga,n lawang lewu, Batu Mamben gadoh die Salumpok Liau, die lebende, die lebenschaffende.

Und dass du mir sogleich auch zurückgebest die Seelen der Kinder, der Waisen, die in Scharen zusammenleben wie die Nashornvögel, dass du mir wieder überreichest die Seelen der Gewiegten,249 deren Zahl ist wie die einer Herde von Tigern, dass sie gemeinsam wieder zurückkehren zusammen mit Penjang Karuhei des Reichtums, damit sie vereinigt wieder heimkommen mit sich nehmend die Paturong Sangkalemo Radja.

Damit sie wieder unkehren mit Atem wie Stein, der nichts von seiner Kraft und Lebensdauer einbüsst, damit sie wieder heimkommen mit Atem von Felsen, der nie vermindert.

Damit die Getragenen wieder zurückkehren mit glückbringenden Mitteln, mit denen sie sich leicht heilige Töpfe $z u$ erwerben vermögen, damit sie heimkommen mit Sapalinda250 zum Kauf von Njalong Bukit Batu.251

Damit die Getragenen Rat sinnen können um sich aufzurichten lebende Lunokbäume, die goldene Früchte tragen und die schön hervorspriessen aus den heiligen Töpfen, damit die Gewiegten sich aneignen können das an der Wasseroberfläche erscheinende Gold, das hervorsprudelt aus den Quellen der Berge, 254 damit die Kinder, die Waisen, oft träumen von Penjang, damit die Kinder, die verlassenen, oft im Schlafe aussprechen die Namen der Paturong. 255

Ja, Pataho, Wächter an der Türe des Dorfes, Batu Mamben, Hüter am Ein- 
pangkarundong, en narai bulan kasala,e, isen bintang kabuku,e?

Tau aku hadjalukan akam salumpok liau haring kaharingan asal aton rangkan panginan, manok darong tingang, takupat sinta, tanteloh manok darong tingang, giling pinang, roko,n tarahan.

Ijoh, Njaring Menteng Manambalau Bahandang, koa,n rawei Darahen radja,n Antang ttg. tisoi Antang Tadjahan, aton rangkan panginan nenga tarantang nole akam.

Palus manggatang djari balemo Antang Tadjahan manaroi rangkan panginan akan Njaring Menteng Manambalau Bahandang.

Manggatang djari balemo kea balita,n Njaring Menteng Manambalau Bahandang manambang rangkan panginan, kare manok darong tingang, takupat mamputing bulau, bari bowor tisik tambon. gang zum Orte, was sollte gegen den Mond eingewendet werden, was sollte gegen den Stern vorgebracht werden? (Er erklärt sich mit den Forderungen durchaus einverstanden.)

Nichts hindert mich dir zu überreichen die Salumpok Liau, die lebende, die lebenschaffende, wenn für mich nur vorhanden sind Speisen und Dinge zum Essen, nämlich Hühner, Hühner Tingang, in Blätter gehüllte und gekochte Päcklein Reis der Liebe, Eier der Hühner, der Hühner Tingang, Kausel von Betelnuss und Rauchwaren der Sklaven.

Ja, Njaring Menteng Manambalau Bahandang, so spricht das Wort des Darahen, des Königs der Antang, und so lautet die Rede des Falken vom Ahnenheiligtum, zubereitet worden sind für dich Speisen die die Kinder, die Waisen, dir geben werden.

Und sogleich erhebt sich versöhnlich gestimmt der Falke vom Ahnenheiligtum und er überreicht die Speisen, die Esswaren dem Njaring Menteng Manambalau Bahandang.

Und es erhebt sich, ebenfalls in sanftmütiger Stimmung, er, der Njaring Menteng Manambalau Bahandang, und er nimmt in Empfang die Speisen, die Esswaren, nämlich die Hühner, die Hühner Tingang, die in Blätter gewickelten und gekochten Reispäcklein mit den vergoldeten Ecken, den Reis, den ausgesäten, die Schuppen der Wasserschlange (so wird der Reis genannt und wahrscheinlich deshalb weil das Gedeihen des Reises abhängig ist von der Djata oder Tambon). 
Hajak kea Njaring Menteng Manambalau Bahandang manaroi salumpok liau, mingkes,e huang Balai Entai intu bukit Pasahan Raung, kereng Dagarin Penda Lunok.

Hindai manontong tandak,e liau amon aton talatai pangentang, hagagahan biti,e akan lewu,n Balo Indu Rangkang Penjang, Sulan Mina Perang Matanandau.

Hemben nduan hambekan katon Antang Tadjahan ttg. Darahen radja,n Antang, Pataho haga,n lawang lewu:

Bahing bapanting mambawa ngampeleng salumpok entang, siring bambahinga nangkiau manundon 256 tanterus tujang.

Ngampeleng salumpok entang bara Njaring hapamantai, manundon tanterus tujang bara Sahakong hanpanderet:

Kuruk bara kuruk! kilau mambawa manok darong tingang, kurei bara kurei! tingkah nangkiau punei rungkoi ambon, kuruk hambaruan ewen handiai.
Und gleichzeitig überreicht auch der Njaring Menteng Manambalau Bahandang die Salumpok Liau und er legt sie nieder in der Hütte des Wartens auf dem Berge der Hütten der Särge, auf dem Hügel der Hütten der Särge unter den Lunok (dort wartet der Tote bis er beim Tantolak matei weggebracht wird zu Balo Indu Rangkang).

Und hernach werden wieder fortgesetzt die Gesänge der Liau, dann wenn es so weit ist mit der Angelegenheit der Getragenen, dass sie den Toten leiten wollen nach dem Dorfe der Balo Indu Rangkang Penjang, nach dem Orte der Sulan Mina Perang Matanandau.

Erst später treten sie wieder auf, aber jetzt handeln sie folgendermassen, sie, der Antang des Ahnenheiligtumes und der Darahen, der König der Falken und der Pataho, der Wächter an der Türe des Dorfes:

Sie erheben ihre Stimme und sie lassen erschallen ihr Wort und sie rufen und sie sammeln ein die Seelen der Getragenen, sie streuen aus ihre Rede und sie rufen zurück und sammeln in Trossen die Seelen der Gewiegten.

Sie holen herbei die Seelen der Getragenen von allen Njaring, sie sammeln in Trossen die Seelen der Gewiegten von den Sahakong, den vielen, und sie rufen ihnen $z u$ :

Kuruk und nochmals kuruk! so wie man ruft die Hühner, die Hühner Tingang, kurei und nochmals kurei! so wie man herbeilockt die Hühner, die Hühner aus der Höhe, kuruk, ihr Seelen alle zusammen. ${ }^{257}$ 
Limbah te tukang tawur mambowor behas atawa pabuli hambaruan (manjamenget) koa,e :

Buli entang, buli hambarua,m, lompat batu djundjun karipurom, djakat liang pariok njamam.

Dohong buli manjaleman kumpang,e, batu,n penjang mulang sangkurong simpei,e, buno niwong panantaha,e, 259 bungai marong sangkabang,e.

Buli bakandong penjang karuhei tatau, mulang basalungkem paturong sangkalemo radja.

Buli bakandong njalong kaharingan belom, mulang basalungkem gohong kapaninting tahaseng.

Mangat batahaseng batu dia tau una, banjame liang isen tau rugi.
Darnach streut der Tukang tawur Reis aus über die Köpfe aller Menschen des Dorfes und führt auf diese Weise die Seelen wieder in sie ein indem er spricht:

Kehre zurück Getragener, es kehre wieder heim deine Seele, besteige den Stein der sich erhebt über der Fontanelle, erklimme den Fels des Tiegels des Atems. 258

Der Dolch kehrt zurück in seine Scheide, die Steine der Penjang werden eingefügt in die Oeffnungen der Bänder, das Eisen des Speeres wird wieder in das geflochtene Band des Schaftes geschoben. Die Schwanzfedern des Nashornvogels werden wieder eingesteckt in die Oeffnungen des geflochtenen Kopfschmuckes (mit diesen Bildern wird die Rückkehr der Seele geschildert).

Sie kehren zurück, begleitet von den Penjang, von den Karuhei des Reichtums, sie kommen heim zusammen mit den Paturong Sangkalemo Radja (anderer Name für Penjang und Karuhei).

Sie kehren zurück begleitet von dem Wasser des Lebens, dem lebenschaffenden, sie kommen heim zusammen mit dem Wasser, dem Reiniger des Atems. Damit ihr Atem sei wie der Stein, der nichts von seiner Kraft verliert, damit ihr Mund (Atem) sei wie der Fels, der nie etwas von seiner Härte einbüsst.

b. Die Kopfjagd nach dem Pantoh Ganan Kaju Hai

Nachdem in der Nacht diese Gesänge und Handlungen abgeschlossen 
worden sind trifft man sofort am andern Morgen die Vorbereitungen zur Ausführung der Kopfjagd nach dem Pantoh Ganan Kaju Hai der als der Schuldige am Tod des Menschen durch Njaring Menteng Manambalau Bahandang ihnen übergeben wird. Man richtet einen Balai Pali auf und ruft dann Dohong Mama Tandang, Antang Darahen und Pataho herbei die im Balai Pali auf den ihnen angewiesenen Plätzen Platz nehmen. Wenn das geschehen ist, dann wählt man die Männer (alle Verwandte des Toten) die an dieser Kopfjagd teilnehmen sollen. Junge Leute, die noch keine Taten vollbracht und sich noch keine Reichtümer versammelt haben kommen dafür nicht in Frage. sondern man wählt meistens angesehene, reiche Leute die schon Köpfe erbeutet oder Sklaven getötet haben und man lädt dazu auch die angesehenen Leute aus andern, umliegenden Dörfern (andere Stammhälfte )ein, denn eine Kopfjagd ist immer Sache des ganzen Stammes aber nie nur des einzelnen Dorfes und sie gelingt auch nur wenn der ganze Stamm, in seinen besten Vertretern, daran teilnimmt.

Die Teilnehmer an der Kopfjagd versammeln sich im Balai (Versammlungshaus) und sie machen zuerst die Wegzehrung für die Kopfjagd bereit. Verschiedene Bambusköcher füllen sie mit sago,n hambie (hambie ist die Sagopalme), mit singkah enjoh (mit den jungen Schösslingen der Kokospalme die sehr schmackhaft sind) und mit Wasser.

Während dieser Vorbereitungen hat der Tukang tawur (Priester) für jeden Teilnehmer an der Kopfjagd sieben Körner enthülsten Reis (bchas hambaruan: Seelenreis) in einen weissen Kleiderfetzen gewickelt und die Bündelchen in sein Kopftuch gesteckt. Während die Männer auf der Kopfjagd sind, halten sich ihre Seelen in diesem Reis auf und der Priester trägt die Seelen seiner Anbefohlenen bei sich. Zuerst aber bittet er noch den Dohong Mama Tandang und den Antang Darahen und Pataho am Seelenreis ein Zeichen anzubringen, ob der Besitzer wirklich an der Kopfjagd teilnehmen könne oder nicht und er ersucht sie auch jedem Teilnehmer Penjang zu geben. Wenn das geschehen ist, dann öffnet er die Bündelchen und untersucht den Reis. Ist er schön und unversehrt, dann darf sein Besitzer an der Kopfjagd teilnehmen, ist er aber gesprungen oder beschädigt, dann muss er von der Teilnahme absehen, weil er sonst das Leben verlieren oder schwer verwundet würde. Während der Dauer der Kopfjagd, die nun ausgefülırt werden muss, sind Dohong Mama Tandang, Antang Darahen und Pataho die Beschützer der ausziehenden Kopfjäger. Sie wachen über ihre Seelen und beschirmen sie vor allem Schaden. 
Sind alle diese Vorbereitungen beendet und lauten die Vorzeichen günstig, dann ziehen die Kopfjäger aus. Bei dem umgestürzten Baum, der die Todesursache des Verwandten geworden ist (oder auch bei dem Baume von dem ein Mensch zu Tode gestürzt ist), angekommen schnitzen sie aus dem Baumstrunk (oder wenn der Baum noch steht aus einem dicken Ast) einen hampatong (eine menschliche Figur). Dieser Hampatong wird auf dem Platz in die Erde gesteckt. Er wird beseelt durch Pantoh Ganan Kaju Hai. Und nun beginnt mit viel Lärm und natürlich auch mit absolutem Ernst der Ueberfall und die Kopfjagd. Pantoh Ganan Kaju Hai wird schwer verwundet und schliesslich gelingt es den Kopfjägern ihm den Kopf abzuschlagen. Jauchzend ziehen sie mit der Beute hein und etwas ausserhalb des Dorfes angekommen senden sie einen Boten in das Dorf mit der Meldung, dass ihr Rachezug erfolgreich beendet sei. Die Leute im Dorf richten nun auf dem Wege eine Versperrung auf und wenn das geschehen ist geben sie den Kopfjägern den Bericht, dass man sie erwarte. Und nun wiederholen sich die gleichen Handlungen wie sie oben bei der Rückkehr vom Manganjau danum (die Kopfjagd nach dem Geist des Wassers) beschrieben worden sind. Nach Abschluss dieser Handlungen findet das Tantolak matei (das Wegschieben des Toten) statt und der Tote wird nach seinem vorläufigen Aufenthaltsort bei Balo Indu Rangkang Penjang geleitet von wo er beim Tiwah (Totenfest) dann wieder abgeholt und nach der Lewu liau (Totendorf) geführt wird.

\section{Die Palivorschriften bei Tod, Bestattung und Tiwah}

Dem Dajak erscheint die Welt in der er steht und lebt als ein durch Ranjing Mahatala Langit (Oberwelt) und die Djata (Unterwelt) geschaffener und geordneter Kosmos, in dem er seinen angewiesenen Platz einzunehmen und seine bestimmten Pflichten, die ihm bekannt sind, $z u$ erfüllen hat. Diese Pflichten werden umschrieben durch die Hadat, das alles beherrschende und umfassende religiös/soziale Lebensgesetz, über dessen Innehaltung die Ahnen, die Kodifizierer dieses Gesetzes, streng wachen. Nur das unverrückte Stehen auf diesem Platz und die gehorsame Unterwerfung unter dieses Lebensgesetz verbürgen einerseits die ungestörte Aufrechterhaltung der kosmischen Harmonie und Ordnung und andererseits den Frieden (kasanang) und das Heil (salamat) des Individuums und des ganzen Stammes als ein Teil dieser Ordnung, in der alle Teile miteinander verbunden und aufeinander 
angewiesen sind. Nicht nur die Hadat mit ihren unzähligen Vorschriften und Regeln für das soziale, religiöse und oekonomische Leben umgeben den Menschen und schreiben in jeder Lage und bei jeder Handlung vor wie er sich als Glied dieser grossen Ordnung zu betragen hat, sondern ebenso auch die Palibestimmungen (die religiösen Verbotsbestimmungen), die ilm in jeder Lage und bei jeder Handlung vorschreiben was er tun darf und was er unterlassen muss um nicht zerstörend in diese Ordnung einzugreifen und sein Leben mit zu vernichten.

Nur wer die Hadat und die Pali (von denen es verschiedene Sorten unter verschiedenen Namen gibt) genau kennt und sich ihnen gehorsam unterwirft, führt ein sinnvolles, der göttlichen und kosmischen Ordnung gemässes Leben. Und nur dadurch, dass er sich ihr gehorsam und gläubig unterwirft, wird er ein oloh bahalap (ein guter Mensch) oder ein oloh budjur (ein rechtschaffener Mensch) und wird sein Leben ein heilvolles, weil es gesegnet wird mit den guten Gaben der Ahnen, die seine gehorsame Unterwerfung belohnen. Durch seine Unterwerfung arbeitet er mit an der Aufrechterhaltung des Friedens und Heiles der ganzen Welt, die er dadurch für sich, seine Familie, den Stamm und den ganzen Kosmos bewahrt und mehrt.

Verbricht er aber diese Ordnung, übertritt er die Hadat und missachtet er die Palivorschriften, dann begeht er ein Verbrechen, das, falls es nicht gesühnt wird oder nicht gesühnt werden kann, ihn ausschliesst aus dieser Heils- und Friedensgemeinschaft. Er hat keinen Anteil mehr an ihr. Er hat die Ordnung bewusst oder unbewusst (was keine Entschuldigung ist) verbrochen, er steht ausserhalb dieser Ordnung; Friede, Heil und Heimat sind in dieser und jener Welt von ihm gewichen. Er ist ein Friedloser, ein Heilloser und ein Heimatloser und er ist deutlich als solcher gekennzeichnet, denn nichts mehr gelingt ihm was er auch immer unternimmt und sein Leben wird in der Mitte der Tage abgebrochen, wie ein wurzelstarker Baum vom jähen Sturm gefällt wird. Er ist aber auch für immer ausgeschlossen aus der Heilsgemeinschaft der Ahnen und er wird nach seinem Tode nicht durch sie abgeholt werden und sie werden ihn nicht begleiten auf dem unbekannten und gefahrvollen Weg nach dem Totendorf und allein vermag er den Weg dorthin nicht zu finden. Als ein Heimatloser und Ruheloser und als ein böser Geist schweift er herum in den Wäldern und um die Dörfer, sich und seinen Angehörigen zur Plage.

Die Pali denkt man sich nicht nur als Verbotsbestimmungen sondern auch als Personen und alle Pali stehen unter dem Radja,n Pali (dem 
König der Pali) und dieser Radja,n Pali ist der Njaro (der Donner). Bei den schwersten Vergehen sendet er als Rächer nicht nur seine Diener, sondern er tritt selbst auf und verwüstet durch ein furchtbares Unwetter das Dorf und verwandelt den Schuldigen und seine Verwandten in Stein.

Bei den wichtigsten Handlungen im menschlichen Leben (Schwangerschaft, Geburt, Initiationshandlungen, Hochzeit, Kopfjagd und Tod) häufen sich die Pali in ungeahnter Weise und Menge. Ueberall steht der Mensch vor verbotenen Gebieten und einem zurückdrängenden Halt. In allen seinen Aeusserungen ist er gehindert. Er ist wie ein Toter. Mehr noch: er ist ein Toter. Erst nach der Verabschiedung der Pali und nach den umfassenden Reinigungszeremonien tritt er als neuer Mensch wieder in ein neues L.eben ein. Das ist vor allem der Fall mit den Pali die den Tod umgeben. Die Pali werden vorläufig verabschiedet beim Tantolak matei (siehe unten die Texte) und definitiv aufgehoben beim Tiwah. Meistens hat dann in dieser $Z$ wischenzeit ein Angehöriger für alle Verwandten zusammen die Pali zu halten als ihr Stellvertreter.

Wir haben hier nur die Pali zu behandeln die mit Tod, Bestattung und Tiwah in Verbindung stehen, weil sie der Vollständigkeit halber in den Rahmen dieser ganzen Darstellung gehören. Mit den Pali die hier wiedergegeben werden sind natürlich die Palivorschriften keineswegs erschöpft, es handelt sich auch nur um die wichtigsten, die wir nennen müssen. Der Text wird im gewöhnlichen Ngadju gegeben.

\section{a. Pali,n hantu}

Pali hantu iingkang aso, pusa.

Amon aso atawa pusa mingkang hantu metoh hantu djadi halaluan 260 intu bentok huma, djete kata,n oloh huma te aton gulong matei tinai, dia tahi limbah idje djari matei te.

Pali mumah bowo.

Amon oloh mumah bowo Wenn früher jemand eine grosse

\section{a. Leichenpali}

Es ist pali, dass die Leiche bestiegen oder betreten wird durch eine Katze oder einen Hund.

Wenn ein Hund oder eine Katze eine Leiche besteigt die in der Mitte des Hauses aufgebahrt worden ist, dann ist das ein sicheres Zeichen, dass bald wieder jemand aus diesem Hause sterben wird und zwar nicht lange nachdem dieser (der Aufgebahrte) gestorben ist.

Es ist pali eine Fischreuse auf dem Rücken zu tragen. 
darah hantu, te horan hantu te hingkat mendeng palus mangkarap oloh idje mumah bowo te sampai matei.

Buju atawa balo akan mondok darah hantu.

Buju atawa balo akan mondok darah hantu atawa darah raung, baja tau mendeng mohon akan batang bewei amon mahit mamani.

Tapi amon oloh paham tirohe oloh manampa hampatong kaju, karana amon dia olih mamali ela batiroh, te ie mahantok hampatong intu takolok,e, hajak hamauch, koa,e :

Ikau hampatong ela batiroh, aku tau!

Tinai oloh manenga pangina,n bari ttg. isi,n manok isut akan hampatong te.

Amon buju atawa balo batiroh metoh hantu atawa raung aton huang huma, te liau idje matei te tau basingi, mampahaban ie, tau haban paham
Fischreuse auf dem Rücken an einer Leiche vorbeitrug, dann geschah es, dass die Leiche aufstand und den Menschen, der die Reuse trug, überfiel und sogleich tötete. Aus diesem Grunde ist es auch heute noch pali mit einer Fischreuse an einer Leiche vorbeizugehen.

Der Witwer oder die Witwe muss sich bei der Leiche niedersetzen.

Der Witwer oder die Witwe müssen sich bei der Leiche oder beim Sarg niedersetzen, sie dürfen sich nur erheben und ihren Platz verlassen wenn sie zum Anlegefloss hinuntersteigen müssen um dort ihre Notdurft zu verrichten.

Aber wenn diese Menschen (der Witwer oder die Witwe) sehr schläferig geworden sind, dann machen sie ein Schnitzbild von Holz mit einem menschlichen Angesicht (einen Stellvertreter), denn wenn es ihnen nicint möglich ist die pali zu halten die ihnen den Schlaf verbieten, dann berühren sie mit dem Schnitzbild dreimal ihren Kopf indem sie sprechen:

Du Schnitzbild, schlafe du auf keinen Fall, ich darf nun schlafen!

Und die Menschen (Witwer oder Witwe) geben Speisen, nämlich ein wenig Reis und etwas Hühnerfleisch, an das Schnitzbild (als Opfer und Lohn weil es für den (die) Schlafenden wacht).

Wenn der Witwer oder die Witwe in Schlaf fallen während die Leiche oder der Sarg sich im Haus befindet, dann wird die Liau des Verstorbenen zornig und kann den Schläfer krank machen 
sampai matei, tapi amon aton hampatong, te dia men kea.

Pali buju atawa balo nandjong netei katahin hantu aton huang huma.

Ewen tau matei imunu liau, tinai tau mite en-en intu ngiwa idje dia bahalap.

\section{b. Pali,n raung}

Oloh idje manampa raung dia tau bahimang.

Amon oloh idje manampa raung te bahimang, djaton tau dia oloh idje bahimang te akan inputang.

Utang,e ie te: ie akan mampatei idje kongan manok, mameteng manas sambelom intu buju atawa balo, lamiang idje, tinai duit due tali, atawa due suku, tau kea due sen.

Buku,e oloh idje bahimang te butang, mikeh buju atawa balo gulong matei.

Karana daha,n manok atawa und er wird so sehr krank, dass er sterben muss, ist aber ein Schnitzbild vorhanden dann geschieht ihm nichts. Es ist pali dass der Witwer oder die Witwe sich entfernen oder herumgehen solange die Leiche sich noch im Hause befindet.

Sie könnten sterben, mit dem Speer getötet durch die Liau und es wäre auch möglich, dass sie ausserhalb des Hauses etwas sehen würden was nicht gut ist (nämlich ein Gespenst oder die Liau, die ihnen feindlich entgegentreten).

\section{b. Die Sargpali}

Leute die einen Sarg machen dürfen sich dabei nicht verwunden.

Wenn jemand von den Leuten, die einen Sarg machen, verwundet wird, dann hat es unbedingt $z u$ geschehen, dass der, der verwundet worden ist, gebüsst wird.

Die Busse, die er zu bezahlen hat, besteht darin: er hat ein Huhn $\mathbf{z u}$ schlachten (mit dessen Blute der Tote oder der Sarg bestrichen wird), er hat ein Armband von Perlen des Lebens um das Handgelenk des Witwers oder der Witwe zu binden, er muss einen Achat geben und einen Geldbetrag in der Höhe von zweimal 25 Cent, oder zweimal 50 Cent, oder auch nur zweimal 2 Cent, bezahlen.

Der Grund, dass der Verwundete diese Busse zu bezahlen hat, besteht darin, dass ohne die Bezahlung der Witwer oder die Witwe rasch sterben müsste. Denn das Blut des Huhnes oder das 
daha,n bawoi idje ihapan manjaki raung te, te hambaruan atawa liau manok atawa bawoi te, dia rau dia akan inarima awi liau oloh idje matei, idje inampa raung,e te.

Awi te, amon aton daha,n olon pohos intu raung te. sama rima kea daha,n oloh te endau, akan djadi saki,n raung te kea.

Idje tagal te kea hambaruan oloh idje daha,e pohos intu raung te, atawa idje bahimang metoh manampa raung te, palus inarima awi liau oloh idje matei te kea.

Idje haranan te, maka oloh idje bahimang te nah akan gulong matei.

Tagal te kea ie akan mampatei manok idje iitong kilau utang,e ttg. ie akan mohos daha,n manok intu raung hajak ie hamauch, koa,e: Daha,n manok toh hapaku manakiri daha,n aingku, sambil hamauch: Kruk hambaruangku!
Blut des Schweines (es kann also auch sein, dass man selbst ein Schwein töten muss) wird gebraucht um mit ihm den Sarg zu bestreichen, dann muss die Seele oder die Liau des Huhnes oder des Schweines unter allen Umständen durch die Liau des Verstorbenen, für den der Sarg gemacht wurde, in Empfang genommen werden (als Stellvertreter für den Witwer oder die Witwe).

Aus diesem Grunde hat auch das Blut eines Menschen, das man an den Sarg streicht, die gleiche Bedeutung wie das oben genannte Blut, es dient ebenfalls zur rituellen Bestreichung des Sarges. Aus diesem Grunde auch wird die Seele des Menschen mit dessen Blut man den Sarg bestrichen hat, oder des Menschen der verwundet wurde als man den Sarg machte, in Empfang genommen durch die Liau des Menschen der gestorben ist.

Aus diesem Grunde nämlich muss der Mensch welcher verwundet worden ist rasch sterben (das heisst deshalb weil sein Blut bei der Anfertigung des Sarges mit dem Sarg in Berührung gekommen ist. Der Verwundete ist nun Eigentum des Toten, der in den Sarg gelegt wird ${ }^{261}$ ).

Aus diesem Grunde muss er auch ein Huhn töten das ihm als Busse angerechnet wird und er muss mit dem Blut dieses Huhnes den Sarg bestreichen indem er dabei spricht, sagend: das Blut dieses Huhnes brauche ich um es auszutauschen gegen mein eigenes Blut und er ruft auch seine Seele zurück indem er spricht: 
Duit due tali, atawa due suku, atawa due sen, djete hapan manutup mata,n hantu.

Tinai lamiang iandak hamparang njaruroi njama,n hantu. Rima,n duit idje manutup mata,n hantu te, mangat liau idje matei dia mite hambaruan oloh idje bahimang ttg. mimbit palus hambaruan oloh idje bahimang te.

Guna,n lamiang idje aton intu njama,n hantu, ie te, mangat ie dia tau mantehau hambaruan oloh idje bahimang te.

Amon oloh idje bahimang te palus matei bahimang awi omba manampa raung, te dia tau dia waris oloh idje solake matei maniwah oloh idje matei bahimang toh, helo bara maniwah liau oloh matei te.

Buku,e: uka ela liau idje matei bahimang te palus mandjadi djipen atawa rewar ain idje dia matei bahimang.

Limbah te harun tau maniwah
Kruk, meine Seele! (Dieser Ruf wird immer dreimal ausgesprochen.)

Das Geld, bestehend aus zwei 25 Centstücken, oder 50 Centstücken oder aus zwei Centstücken wird gebraucht um mit ihm die Augen der Leiche zu verschliessen.

Und der Achat wird quer über den Mund der Leiche gelegt.

Die Bedeutung des Geldes mit dem man die Augen der Leiche verschliesst besteht darin, dass die Liau des Verstorbenen nicht mehr zu sehen vermag die Seele des Verwundeten und dadurch auch nicht mit sich nimmt die Seele des Verwundeten.

Die Bedeutung des Achates der quer über den Mund der Leiche gelegt wurde besteht darin, dass sie nicht mehr rufen kann die Seele des verwundeten Menschen.

Wenn der Mensch der verwundet worden ist sogleich stirbt an seiner Verwundung, also den Tod findet weil er teilgenommen hat an der Anfertigung des Sarges, dann müssen die Verwandten des Toten (für den der Sarg gemacht wurde) zuerst das Tiwah halten für den der an den Verwundungen gestorben ist, bevor sie das Tiwah halten für die Liau ihres Toten (für den der Sarg gemacht wurde).

Der Grund weshalb das auf diese Weise getan werden muss ist dieser: damit die Liau des an seinen Verwundungen Gestorbenen nicht der Schuldsklave oder der Leibeigene werde dessen der vor ihm gestorben ist (für den der Sarg gemacht wurde). Erst darnach darf man das Tiwah 
idje dia matei bahimang.

Amon oloh idje bahimang te djadi imputang, maka huang katahi,e himang,e te mambuhit djala-djalan paham kahai,e sampai ie matei, puna dia haliai liau,e mandjadi djipen ain oloh idje helo matei.

Buku,e: basa daha,e ttg. hambarua,e djadi inangkiri dengan daha, $n$ ttg. hambarua,n manok ttg. waris ai,e kabuat akan maniwah ie idje djadi matei bahimang.

Tahiu kaju,n raung.

Bara kaju idje ineweng oloh akan raung, lawi,e dia tau buah tana, tinai raung dia tau ieton mahoroi tana.

Amon lawi,n kaju te buah tana,n oloh, atawa raung te ieton mahoroi tana,n oloh te dia tau dia oloh idje manampa raung te imputang tanggong ungkos manduan hambaruan ain ewen idje tempo, $n$ tana.

Buku,e pali basa awi hambaruan atawa gana,n parei te paham mikeh. 262

Haranan kikeh,e hambaruan parei balalu hadari, babuhau akan eka asal,e intu Kaju Erang Tingang idje aton halten für den der nicht an der Verwundung gestorben ist.

Wenn der Verwundete seine Busse bezahlt hat, aber wenn auf die Dauer die Wunde sich zu einem eiternden Geschwür entwickelt und mit der Zeit immer grösser wird und immer mehr um sich greift, sodass der Verwundete daran sterben muss, dann wird seine Liau auf keinen Fall der Sklave dessen der vor ihm gestorben ist.

Der Grund davon ist dieser : weil sein Blut und seine Seele ausgetauscht wurden mit dem Blut und der Seele des Huhnes und weil auch seine Angehörigen allein das Tiwah für ihn halten.

\section{Ueber das Holz des Sarges.}

Von dem Baum, den die Leute für die Herstellung des Sarges gefällt haben, darf die Krone nicht auf ein Reisfeld zu liegen kommen und der Sarg darf auch nicht durch ein Reisfeld getragen werden.

Wenn die Krone des Baumes das Reisfeld von Leuten berührt, oder wenn der Sarg durch ein Feld von Leuten getragen wird, dann müssen auf alle Fälle die Leute, die den Sarg gemacht haben, gebüsst werden und sie haben die Unkosten zu tragen für das Zurückholen der Seele des Reises der Besitzer dieses Feldes.

Der Grund dieses pali liegt darin weil die Seele des Reises sehr furchtsam ist.

Wegen dieser Furcht würde sich die Seele des Reises sogleich flüchten und sich wieder zurückbegeben zum Orte ihrer Herkunft, nämlich zum Baume 
huang lewu Bukit Ngantong Gandang hong batang danum Hintan Mangatimbong Langit.

Ungkos manduan hambaruan parei korang-labih telo kiping atawa djahawen rupiah, tapi amon mahapan oloh balian korang-labih djahawen kiping atawa duewalas rupiah.

Amon meto mingkang atawa handipe manggajar hundjun kaju idje djadi ineweng akan raung atawa mansurok kaju te metoh oloh manampa raung puna pali mahapan kaju te.

Amon ewen badjudju mahapan kaju te, te taloh Pali idje penda parentah radja,n Pali tau mawi, mampatei, mampahaban oloh idje bara waris oloh matei te.

Tinai amon oloh bara waris idje matei te dia tahi salenga aton matei limbah pampatei te, ie indawa matei awi dahiang pali,n raung.

Dohong Mama Tandang dia tau manganjau en-en.

Dia tau dia oloh akan manam-
Erang Tingang, 263 welcher sich befindet im Dorfe Bukit Ngantong Gandang am Flusse Hintan Mangatimbong Langit.

Die Unkosten um die Seele des Reises wieder zurückzuholen belaufen sich ungefähr auf drei Kiping oder auf sechs Gulden (wenn man den Tukang tawur dazu gebraucht), aber wenn man die Balian beauftragt belaufen sie sich ungefähr auf sechs Kiping oder auf zw.ölf Gulden.

Wenn ein Tier das Holz besteigt oder eine Schlange auf dem Holze kriecht welches gefällt worden ist für den Sarg, oder wenn ein Tier oder eine Schlange unter dem Holze durchkriecht während die Leute mit der Herstellung des Sarges beschäftigt sind, dann ist es verboten dieses Holz für den Sarg zu gebrauchen.

Wenn sie es aber doch durchsetzen um dieses Holz zu verwenden, dann können die Paligeister, die unter der Herrschaft des Königs der Pali stehen, die Angehörigen des Toten quälen, töten oder krank machen.

Und wenn einer der Angehörigen des Toten nicht lange nach seinem Tode plötzlich stirbt, dann nimmt man an, dass er gestorben sei wegen der Nichtbeachtung der Vorzeichen (Tier, Schlange) bei der Verwendung des Holzes für die Herstellung des Sarges.

Dohong Mama Tandang kann in diesem Falle gegen niemanden eine Kopfjagd ausführen (weil der Tod des Menschen einen berechtigten Grund hat).

Auf keinen Fall darf unterlassen 
pa hampatong intedjek intu tunggul kaju idje akan raung te.

Tuntang tau kea hampatong te inampa sama kare,e dengan kare,n biti,n ewen idje manampa raung te.

Amon ewen lius buli bara hete, djaton tau dia ewen mahantok hampatok te intu takolok,e ttg. maludja hampatong te.

Limbah te hampatong te nah ilihi intu tunggul kaju,n raung.

Amon ewen dia mawi tumon te, te Pali idje penda parentah radja,n Pali tau mampelai hambaruan ewen intu eka manampa raung udju andau katahi,e.

Gagenep limbah oloh manampa raung te aton taloh papa manalih hete.

Katahin taloh papa manalih eka te, kaudju andau lulangluli, manampara bara limbah oloh manampa raung.

Awi te, amon hambaruan oloh idje manampa raung salenga werden, dass die Leute die den Sarg angefertigt haben ein Schnitzbild machen und dieses in den Baumstrunk stecken von dem man das $\mathrm{Holz}$ für den Sarg genommen hat.

Und man kann auch ebensoviele Schnitzbilder machen wie Personen sind die bei der Herstellung des Sarges mitgearbeitet haben (man kann also einen Stellvertreter für alle oder auch für jede Person einen besonderen schnitzen).

Wenn sie sich aufmachen um von dort nach Hause zurückzukehren dann müssen sie unbedingt mit dem (oder den) Schnitzbild(-ern) ihre Köpfe berühren und müssen die Schnitzbilder bespucken.

Wenn das geschehen ist, dann lässt man die Schnitzbilder zurück auf dem Baumstrunk von dem man das Holz für den Sarg genommen hat.

Wenn sie nicht auf diese Weise handeln, dann können die Paligeister, die unter der Herrschaft des Königs der Pali stehen, ihre Seelen während sieben Tagen zurückhalten auf dem Platz auf dem sie den Sarg hergestellt haben. Denn jedesmal nachdem Leute einen Sarg gemacht haben gibt es böse Geister die sich nach diesem Platz begeben. 264

Die Dauer der Zeit, während der sich diese bösen Geister hin und her nach diesem Platz begeben, beträgt sieben Tage, anfangend bei dem Tag an dem die Leute mit der Herstellung des Sarges begannen.

Aus diesem Grunde ist ein grosses Unglück, wenn die Seelen der Leute, 
balihi intu hete, puna tjalaka, intakan awi taloh idje lulangluli akan hete.

Tuntang oloh idje tempon hambaruan tau haban sampai matei.

Huang gawi,n tantolak matei Dohong Mama Tandang dia tau manganjau en-en.

Pali,n oloh balawo meton raung.

Amon oloh balawo meton raung kata,e ie gulong akan matei.

Awi aton gawi,e idje paham kasala,e intu pangatawan radja,n Pali.

Awi te radja,n Pali manjoho oloh ai,e mampalawo oloh te hapa mampingat oloh te.

Tagal te patut oloh idje balawo awi meton raung mampatei manok huang human ai,e.

Daha,n manok te hapa,e manjaki arep,e.

Tinai mampatei anak bawoi bawi idje korik, daha,n bawoi te iewoi dengan behas, inawur die den Sarg hergestellt haben, plötzlich dort zurückgelassen werden, denn sie werden heftig angegriffen durch diese Geister die sich hin und her nach diesem Platze begeben.

Und die Menschen, die die Besitzer dieser zurückgelassenen Seelen sind, können krank werden und selbst auch sterben.

Während der Handlungen zum Wegschieben des Toten kann Dohong Mama Tandang gegen niemanden eine Kopfjagd ausführen.

Es ist pali, dass jemand umfällt während des Tragens des Sarges (d.h. während der Sarg aus dem Wald nach Hause gebracht wird und wenn der Sarg mit der Leiche beigesetzt wird). Wenn jemand stürzt während er den Sarg trägt, dann ist das ein Zeichen, dass er bald sterben wird.

Denn er ist gestürzt, weil er irgend etwas ausgeführt hat was nach dem Wissen und Eindruck des Königs der Pali sehr unrichtig war.

Aus diesem Grunde gibt der König der Pali einem seiner Untertanen den Auftrag diesen Menschen zu Fall zu bringen um ihn an seinen Fehler zu erinnern.

Aus diesem Grunde geziemt es sich, dass der Mensch, welcher umgefallen ist während er den Sarg trug, in seinem eigenen Hause ein Huhn tötet.

Das Blut des Huhnes muss er gebrauchen um sich mit ihm rituell zu bestreichen und $z u$ reinigen.

Und ferner hat er noch ein junges weibliches Schwein, das noch klein ist, zu töten, das Blut dieses Schweines hat 
intu ruar huma akan ngambo, hajak humauch, koa,e: toh sampa-sampai radja,n Pali intu batang danum Njarakungkoi Njaho.

Tinai amon isi,n bawoi idje indjoho te djadi masak, oloh dia tau kuman helo amon bara isi te hindai djadi ilaku isut hajak mewoi,e dengan bari, palus inawur bara bauntonggang akan Pali, hapan auch pandak, koa,e :

Toh bari balut bawoi sampasampai kare Pali idje aton intu petak danum huang kalunen toh.

Amon ie bagulong maki manumon te, puna dia men, tapi amon ie dia malalus,e ttg. bagulong ie matei limbah balawo puna Dohong Mama Tandang dia tau manganjau en-en.

\section{c. Pali,n hinan}

Tau kea hinau atawa pali,n hinau.

Idje injewut oloh bagare hinau, ie te aton katahi,e, ie te, manampara bara andau oloh mondok balian tantolak matei.

Maka huang kakare andau te, er mit Reis zu vermischen und es ausserhalb des Hauses in die Höhe zu streuen, indem er dabei spricht: es ist nun angekommen beim König der Pali am Flusse Njarakungkoi Njaho (am Flusse des krachenden Donners).

Ferner, wenn das Fleisch des Schweines, das gekocht worden ist, gar ist, dann dürfen die Leute nicht von ihm essen bevor von diesem Fleisch ein wenig weggenommen wurde, das mit gekochtem Reis vermischt (als Opfer) ausgestreut wird unter der Türe für die Paligeister, indem man dabei kurz spricht, sagend :

Nun ist der gekochte Reis, vermischt mit Schweinefleisch, angekommen bei allen Paligeistern welche sich auf der Erde und im Wasser auf dieser Welt hier befinden.

Wenn er aber nicht rasch auf diese Weise handelt und bald darauf stirbt nachdem er beim Tragen des Sarges gestürzt ist, dann kann der Dohong Mama Tandang gegen niemanden eine Kopfjagd ausführen (weil die Paligeister ein Recht hatten auf diesen Menschen).

c. Die Pali des Hinan 265

Mann kann auch sagen Hinau oder die Pali des Hinau.

Was durch die Leute genannt wird mit dem Namen Hinau ist dieses, nämlich eine bestimmte Zeitdauer, anfangend vom Tage an dem sich die Balian setzen um die priesterlichen Handlungen auszuführen für das Wegschieben des Toten.

Aber alle diese Tage nennt man ,die 
injewut andau hinau atawa metoh hinau.

Idje injewut pali,n hinau, ie te:

Kare pisau, baliong, kare pakakas handiai idje hapan manampa raung, tinai kare garantong idje hapan mamanjong 266 atawa idje ihapan manggalang hantu dia tau oloh mandua,e helo amon hindai Sangiang mamapas,e metoh gawi,n tantolak matei.

Ramo ttg. pakakas te imumpong intu bentok huma, idjeidje eka,e.

Karana amon indua,e, te pali.

Buku,e awi oloh ain radja,n Pali te aton ttg. dia gitan.

Tuntang ie puna akan tantai mangahana oloh manduan ramo te sala bara wajah,e.

Karana intu kare pakakas atawa ramo te handiai aton leket ambon Rutas.

Awi te, dia tau dia mahapan kuasan Sangiang mamapas mengkak ambon Rutas idje
Tage des Hinau“ oder auch ,während des Hinau".

Was genannt wird Pali des Hinau ist dieses, nämlich:

Alle Buschmesser, alle Aexte und alle Werkzeuge zusammen welche man gebraucht hat um den Sarg zu machen, ferner alle Gong welche verwendet wurden um auf ihnen den Totenschlag zu schlagen oder die man verwendete als Unterlage für die Leiche (auf denen man die Leiche aufbahrte), dürfen durch die Leute nicht eher wieder weggeholt und gebraucht werden, bevor die Sangiang sie abgefegt und gereinigt haben während der Handlungen die ausgeführt werden beim Wegschieben des Toten.

Diese Dinge und Werkzeuge werden in der Mitte des Hauses auf einen Platz zusammengetragen und aufgeschichtet.

Denn wenn man sie wegholt, dann ist es verboten und man wird pali (kommt unter die Herrschaft der Pali zu stehen).

Der Grund ist nämlich dieser, weil die Untertanen des Königs der Pali anwesend sind, auch wenn sie nicht gesehen werden können.

Und sie sind gerade zu dem Zwecke da um den Menschen zu verbieten die Dinge und Werkzeuge wegzuholen bevor dafür die Zeit gekommen ist.

Denn an allen diesen Werkzeugen oder an allen diesen Dingen klebt der Tau des Unheils.

Aus diesem Grunde muss unter allen Umständen die Macht der Sangiang gebraucht werden um abzuwischen und 
leket intu kakare ramo te.

Amon oloh badjudju manduan ramo te sahindai imapas awi Sangiang, te Pali mawi oloh idje tempo,n ramo te.

Ampi,e mawi,e: amon oloh mahapan ramo te idje hinclai imapas, ie dia tau ontong. 267

Oloh tempo,n pampatei dia tau hakalahi ttg. intu huma te dia tau malalus talo sala idje kueh-kueh kea.

Amon aton oloh hakalahi atawa malalus talo sala idje kueh-kueh kea intu wajah te atawa huang huma te, dia tau dia ie akan imputang manok idje ttg. duit atawa ramo akan sakiping, mambajar te akan oloh huma te.

Tinai aloh kasala te babehat atawa mahian dengan kola idje sama madja intu hete, zu lösen den Tau des Unheils der an allen diesen Gegenständen und Werkzeugen klebt.

Wenn es die Leute aber doch durchsetzen und diese Dinge wegholen, welche noch nicht gereinigt und gelöst worden sind durch die Sangiang, dann überfallen die Pali den Menschen der der Besitzer dieser Werkzeuge ist.

Die Art und Weise dieses Ueberfallenwerdens durch die Pali ist diese: wenn die Leute die Werkzeuge gebrauchen die noch nicht gereinigt worden sind, dann wird ihr Besitzer kein Glück und keinen Vorteil mehr haben.

Die Besitzer des Todes (d.h. die Angehörigen des Toten, die ebenfalls den Tod besitzen, bis sie sich von ihm beim Tantolak matei und beim Tiwah gereinigt haben) dürfen keinen Streit beginnen oder aufnehmen und in dem Hause dürfen keine unrichtigen (sündigen) Dinge, welcher Art auch immer, (vor allem Ehebruch) ausgeführt werden.

Wenn es aber doch vorkommt, dass Leute Streit führen oder unrichtige Dinge, welcher Art auch immer, ausführen während dieser Zeit oder in diesem Hause, dann müssen sie unter allen Umständen gebüsst werden mit einem Huhn und mit Geld oder mit Waren im Betrage von einem Kiping (zwei Gulden), die bezahlt werden müssen an die Leute die dieses Haus bewohnen. 268

Und ob das Vergehen schwerer oder nur leichter Art war gegenüber Verwandten welche auch zur gleichen Zeit 
djete beken perkara, manamana ewen due ih hakado talih bakas lewu.

Amon oloh idje manampa kasala te dia maku mambajar manok idje ttg. duit atawa ramo sakiping, oloh huma te tau iawi Pali.

Awi te, amon aton oloh huma te buah tjelaka dia tahi limbah te, djete katanggongan ewen due idje dia maku mambajar.

\section{d. Pali,n tolang}

Amon limbah oloh mamapui raung (hantu), te tisa,n tolang induan.

Dia tau manjoho anak oloh idje tabela meton tolang te akan kuburan atawa akan sandong.

Te patut buju atawa balo meton tolang te.

Amon buju atawa balo te tabela umur,e, patut manggau mina atawa mama, indu atawa bapa akan meton tolang te. in diesem Hause einen Besuch machten, so ist dies dann wieder ein anderer Fall für sich, nach ihrem eigenen Gutdünken können sich die Beiden bei den Dorfältesten anklagen und dort die Sache erledigen.

Wenn die Leute, die einen dieser Fehler begangen haben, nicht ein Huhn und Geld oder Waren im Betrage von zwei Gulden bezahlen wollen, dann können die Bewohner des Hauses durch die Paligeister überfallen werden.

Aus diesem Grunde fällt, wenn es Leute gibt in diesem Haus die kurz darnach einen Unfall erleiden und sterben, ihr Tod zu Lasten der Beiden welche nicht bezahlen wollten (sie haben in diesem Fall den Blutpreis zu bezahlen und für den (die) Toten das Tiwah zu veranstalten).

\section{d. Die Pali betreffend der Knochen}

Nachdem die Leute den Sarg (die Leiche) verbrannt haben, dann werden vom Scheiterhaufen die Resten der Knochen weggeholt.

Nicht darf man junge Kinder beauftragen diese Knochen wegzutragen nach dem Bestattungsort oder zum Sandong.

Es geziemt sich nämlich, dass der Witwer oder die Witwe die Knochen tragen.

Wenn aber der Witwer oder die Witwe noch zu jung ist (der Dajak heiratet mit etwa 14 Jahren), dann geziemt es sich, dass man eine Tante oder einen Onkel, die Mutter oder 
Tapi tau kea intih bara waris ain idje matei te idje bakas kea umur,e barahak meton tolang te.

Dia tau oloh bara waris beken meton tolang te.

Amon oloh bara waris beken meton tolang te, te oloh idje meto,e tau iawi, ingapehe Pali,n tolang.

Maka amon oloh bara waris hila idje matei te manjoho oloh bara waris beken meton tolang, te Pali mawi waris hila idje matei.

Tau manantekas haban palus matei.

Amon oloh mimbit tolang mambesei, dia tau ie tende intu batang tapian oloh atawa mimbit tolang lompat manetei djalan oloh intu lewu, malengkan manampa djalan kabuat intu luar bara djalan oloh, amon ie perlo mampalompat tolang tali sandong. den Vater ersucht, die Knochen zu tragen.

Man kann aber auch jemanden von den beauftragten Angehörigen (d.h. von denen die das Tantolak matei und das Tiwah zu veranstalten und zu leiten haben), nämlich einen Bejahrten beauftragen, die Knochen zu tragen.

Nicht kann es aber geschehen, dass es durch Leute einer andern Verwandtschaftsgruppe (eines andern Clan oder Stammteiles) ausgeführt wird.

Wenn aber doch Leute aus einer andern Verwandtschaftsgruppe die Knochen tragen, dann kann es geschehen, dass der, der die Knochen trägt, angefallen und misshandelt wird von den Paligeistern der Knochen.

Wenn aber Angehörige der beauftragten Verwandten von der Seite des Verstorbenen Angehörige von einer anderin Verwandtschaftsgruppe beauftragen die Knochen zu tragen, dann fallen die Paligeister diesen Angehörigen (der den Auftrag gegeben hat) von der Seite des Verstorbenen an.

Er kann sehr heftig krank werden und rasch sterben.

Wenn die Leute die Knochen im Ruderboote überbringen, dann dürfen sie nicht anlegen am Landungsfloss oder Anlegeplatz der Dorfleute und sie dürfen mit den Knochen nicht auf dem gebräuchlichen Weg ins Dorf hinaufsteigen, sie dürfen auch nicht den Weg der Leute des Dorfes benützen, sondern sie müssen sich einen eigenen Weg abseits vom Weg der Leute des Dorfes schlagen, wenn es nötig ist die Knochen aufs Ufer und von dort 
Dia tau mimbit tolang buah tana,n oloh, mikeh hambaruan parei oloh hadari kilau insanan tahiu pali,n raung.

Dia tau oloh bara lewu beken magah tolang akan sandong huang lewu idje beken tinai, amon dia sana limbah mingkes tolang akan huang sandong te ewen oloh balian, mahapan kuasan Sangiang, mamapas lewu te.

Tuntang ewen akan balian, atawa intu tokep sandong, atawa huang huma,n oloh idje nahuang.

Maka amon dia ewen nahuang malalus gawi mamapas lewu te mahapan kuasa,n Sangiang, maka ewen oloh idje mimbit tolang te akan imputang tumon kahai,n ungkos oloh lewu malalus gawi tantolak kare Pali Endus te tinai.

Buku,e lewu te akan imapas mahapan kuasa,n Sangiang metoh ewen mimbit tolang te endau, basa Pali,n tolang kea lompat palus melai intu lewu te. zum Sandong (Knochenhäuschen) zu bringen.

Es ist nicht erlaubt, wenn man die Knochen überführt, ein Reisfeld anderer Leute $z u$ betreten oder zu streifen, weil sonst die Reisseele sich davon machen würde wie es bereits oben in Sargpali dargestellt wurde.

Nicht dürfen die Leute aus einem Dorf die Knochen in den Sandong, der sich in einem andern Dorf befindet, überbringen, wenn nicht gleich nachdem die Knochen im Sandong niedergelegt worden sind die Balian, die Macht der Sangiang gebrauchend, dieses Dorf von allem Unheil reinigen. Und sie haben die priesterlichen Handlungen auszuführen, entweder in der Nähe des Sandong, oder auch in einem Hause von Leuten die dazu die $\mathrm{Zu}$ stimmung geben.

Aber wenn sie nicht bereit sind diese Handlungen auszuführen und das Dorf durch die Balian und durch die Macht der Sangiang reinigen zu lassen, dann werden die Leute, die die Knochen ïberführt haben, gebüsst und sie haben eine Busse zu bezahlen, die die Höhe der Unkosten beträgt, die die Leute des Dorfes auszugeben haben für das Verabschieden der Paligeister (Endus ist ein anderes Wort für Pali).

Der Grund, dass das Dorf gereinigt werden muss durch die Macht der Sangiang, nachdem sie die Knochen durch dieses Dorf überführt haben, ist dieser: weil die Paligeister der Knochen ebenfalls ans Ufer hinaufsteigen und sich sogleich im Dorf niederlassen. 
Maka pali te mawi oloh lewu mandjadi basial.

Maka huang tahiu pali,n tolang, amon sala gawi,n oloh, te tau oloh haban sampai matei.

\section{e. Pali,n sandong}

Maka amon oloh manampara manampa sandong intu balai, te palus aton taloh Pali idje injoho radja,n Pali melai handau hamalem manunggo gawi,n sandong te djadi.

Huang kuasa,n Pali idje manunggo te, tantai manjoho oloh tempo,n sandong mamupo kakare tamuei dagang idje mahalau lewu te.

Awi te, genep-genep metoh oloh manampa sandong intu balai, amon oloh tamuei idje mahalau, ewen akan intehau ttg. impatende, balaku en-en bara tamuei te, aloh isut bewei, barangai, asal aton.

Amon ewen dia nahuang mantehau, atawa dia nahuang balaku en-en bara oloh idje mahalau, te Pali mawi atawa
Die Pali würden die Leute des Dorfes uiberfallen, sodass ihr Leben ein unheilvolles würde.

Was aber ebenfalls die Pali der Knochen betrifft ist dieses, wenn die Leute in dieser Zeit verkehrte Handlungen ausführen (d.h. wenn sie Ehebruch treiben), dann können sie krank werden und sterben.

\section{e. Die Pali des Knochenhäuschens}

Wenn die Leute im Balai einen Sandong herzustellen beginnen, dann stellen sich alsogleich Paligeister ein, die durch den König der Pali beauftragt worden sind, sich dort Tag und Nacht aufzuhalten und $\mathrm{zu}$ wachen bis die Arbeit beendet ist.

In der Macht der Paligeister, welche dort wachen, liegt es, den Besitzern des Sandong den Auftrag und die Warnung zu erteilen alle Fremden, die am Dorf vorbeirudern oder an ihm vorübergehen, und die sie dabei wahrnehmen, herbeizurufen oder herbeizuholen.

Aus diesem Grunde müssen jedesmal wenn die Leute damit beschäftigt sind einen Sandong herzustellen im Balai, alle Fermdlinge die am Dorfe vorbeifahren herbeigerufen und angehalten werden, und man verlangt irgend etwas von ihnen und es macht nichts aus wenn das was sie geben auch nur eine Kleinigkeit ist, die Hauptsache ist, dass sie etwas geben.

Wenn sie aber nicht bereit sind die Fremdlinge, die am Dorf vorbeifahren oder vorübergehen, anzurufen, oder wenn sie nicht gewillt sind etwas von 
mampahaban atawa mampatei oloh idje tukang sandong, atawa mawi ewen idje tempo,n sandong.

Maka hak ewen idje mahaga pali,n sandong, ie te: telo sampai udju katandjong akan hila ngadju lewu, tinai telo sampai udju katandjong akan hila ngawa lewu.

Ewen tau sampai manggoang ttg. balaku en-en dengan oloh, aloh akan ngadju atawa akan ngawa lewu, tapi dia tau mahalau tapakan hak pali,n sandong te.

Amon oloh dia maku manenga, te Pali tau mawi ie idje dia maku manenga.

Awi te kea, ewen huang balai Pali haradjur manenga tagor hapan auch gandang garantong akan oloh hete-hete ttg. akan kare tamuei.

\section{f. Pali,n Tiwah}

Metoh wajah gawi,n Tiwah, helo-helo oloh manampa pasah Pali, eka Pali tau kuman. ihnen $z \mathfrak{u}$ verlangen, dann werden von den Pali angefallen und von ihnen krank gemacht oder getötet, entweder diejenigen die beauftragt sind den Sandong zu schnitzen oder die Besitzer des Sandong.

Aber das Machtgebiet derer die die Sandongpali $z u$ beobachten und für ihre Innehaltung zu sorgen haben beträgt drei bis sieben Flussbiegungen oberhalb des Dorfes und drei bis sieben Flussbiegungen unterhalb des Dorfes. Sie können selbst zur Verfolgung der vorüberziehenden Fremdlinge übergehen, sei es in der Richtung flussaufwärts oder flussabwärts, und sie können irgendetwas von diesen Fremdlingen verlangen, sie dürfen aber die Grenze des Machtgebietes des Sandong-Pali nicht überschreiten. 269

Wenn aber die Leute nichts geben wollen, dann können die Paligeister, sie die nichts geben wollten überfallen und misshandeln.

Aus diesem Grunde geben diejenigen, die sich im Balai befinden, auch fortwährend Zeichen mit den grossen Trommeln und Gong (sie schlagen sie nach kurzen $Z_{\text {wischenpausen }}$ ) an die Menschen die sich da und dort befinden und auch an alle vorbeiziehenden Fremden.

\section{f. Die Pali beim Tiwah}

Bevor die Zeit der Ausführung der Handlungen zum Tiwah angebrochen ist, bauen die Leute bereits eine Hütte für die Paligeister, einen Ort wo diese Paligeister die ihnen übergebenen Speisen verzehren können. 
Maka gagenep oloh mampatei bawoi hai atawa meto hai, te haradjur oloh manawur nampakanan Pali, tinai kare sangkalan, eka maraga isi,n meto akan Pali, kaju te inatap hapan pakasak panginan Pali, tinai are beken idje akan talo Pali.

Maka amon oloh mampatei meto hai metoh Tiwah te tapi dia mampakanan Pali te Pali te mawi oloh tempo,n gawi, atawa mawi oloh idje madja.

Kindjap oloh awi Pali metoh gawi,n Tiwah ttg. pudji idje matei.

\section{g. Pali limbah Tizwah}

Maka sana djadi gawi,n Tiwah, te radja,n Pali manenga parentah akan oloh aju,e, udju biti oloh aju,e idje mendeh sana hapus gawi,n
Und jedesmal wenn die Menschen (während des Tiwah) ein grosses Schwein oder ein anderes grosses Tier (Kuh, Wasserbüffel) schlachten, dann wird davon immer etwas durch die Leute ausgestreut (vermengt mit gekochtem Reis) um die Paligeister zu speisen, und das Holz aus dem man die Hackbretter schnitzt auf dem das Fleisch für die Paligeister fein gehackt wird, wird bearbeitet, indem man gleichzeitig den Paligeistern Opfer bringt, und das geschieht auch mit allen andern Dingen die für die Paligeister gebraucht werden müssen (d.h. alle diese Geräte sind dem profanen Gebrauch entzogen und dürfen nur für die Paligeister verwendet werden).

Wenn aber die Leute während des Tiwah grosse Tiere schlachten und davon nicht einen Teil als Opfer den Paligeistern übergeben, dann überfallen und misshandeln die Paligeister die Besitzer dieser Arbeit (d.h. die nächsten Verwandten des Toten die das Tiwah veranstalten und leiten), oder sie überfallen und misshandeln die Besucher beim Tiwah.

Oft werden die Leute während eines Tiwah durch die Paligeister angefallen und misshandelt und es ist oft geschehen, dass dadurch auch Menschen gestorben sind.

\section{g. Die Pali nach dem Tizwah}

Nachdem alle Handlungen des Tiwah beendigt worden sind, gibt der König der Pali seinen Untertanen einen Auftrag und er befiehlt sieben seiner Untertanen, dass sie, nachdem die 
Tiwah.

Telo bulan katahi,e sana limbah Tiwah, ewen magon manunggo ttg. haradjur mariksa mikeh aton bara oloh Tiwah te nah idje malanggar pali.

Pali limbah Tizsah, ie te:

Dia tau kuman badjan, palandok, bawoi, karahau katahin telo bulan.

Dia tau kuman lauk malisen idje aton pantik,e, idje bulan katahi,e.

Buku,e oloh te dia tau kuman badjang, palandok, bawoi ttg. karahau katahin te, basa tisa,n rotik tolang idje isut intu eka mamapui raung bihin mandjadi kare meto te katahin telo bulan.

Awi te aton auch oloh manjewut: Badjang Liau.

Maka amon ewen malanggar pali, te Pali mawi ewen.
Handlungen des Tiwah beendet sind, immer noch die Wache halten über die Verwandten des Toten (für den das Tiwah gefeiert wurde).

Während drei Monaten, nachdem das Tiwah stattgefunden hat, überwachen sie immer noch und prüfen fortwährend, ob von den Leuten, die das Tiwah veranstalten mussten, solche gefunden werden die die Palivorschriften übertreten (die ganze Palizeit ist also nicht mit dem Abschluss des Tiwah beendet sondern erst drei Monate darnach).

Die Palivorschriften, die fïr die Zeit nach dem Tiwah gelten, sind diese:

Während der Zeit von drei Monaten darf nicht das Fleisch von Hirschen, Zwerghirschen, Wildschweinen und Rehen gegessen werden.

Während der Dauer eines Monates dürfen sie keine Fische essen die glatt und glitschig sind und die Stacheln haben.

Der Grund, dass die Leute kein Fleisch von Hirschen, $Z_{\text {werghirschen }}$ und Wildschweinen und Rehen während dieser Zeit essen dürfen, ist der, weil von den Ueberresten der Stücke der Knochen von denen sich nur noch wenige finden auf dem Platz wo man früher den Sarg verbrannt hat, diese Tiere entstehen für die Zeit von drei Monaten. 270

Aus diesem Grunde gibt es auch ein Sprichwort das aussagt: Badjang Lian (der Hirsch des Toten, oder auch der Hirsch, der der Tote ist).

Aber wenn sie diese Palivorschriften übertreten, dann werden sie von den 
Amon oloh kuman lauk malisen hindai djadi sampai idje bulan katahi,e limbah gawi,n Tiwah, te Pali mawi kalotoh: kare ontong tuah, karuhei tatau, uras bengkak bara ewen ttg. dia leket, awi malisen murah mengkak.

Maka ewen basial tinai.

\section{h. Pali,n balo atawa buju}

Pali,n buju atawa balo are matjam,e.

Buju atawa balo dia tau mahapan pakajan bahandang. Ewen dia tau mahapan pakajan bara bulau, dia kea lamiang.

Amon ewen malanggar pali te, te Pali ttg. liau tau mawi, mampahaban sampai mampatei ie.

Tinai sana ewen mahapan pakajan tumon te, waris hila idje matei te palus manjinger mamputang ewen hajak ewen tau imaksa kea awi waris hila
Paligeistern überfallen und misshandelt. Wenn die Leute aber glatte und glitschige Fische (oder solche mit Stacheln) essen bevor die Zeit eines Monates verstrichen ist, dann fallen sie die Paligeister auf diese Weise an: aller Vorteil und alles Glück und Heil und alle Karuhei des Reichtums bleiben nicht mehr an ihnen kleben, sie lösen sich leicht von ihnen, weil sie glitschig geworden sind.

Und sie kommen dadurch wieder in einen Unheilszustand (in dem ihnen nichts mehr gelingt, was sie auch immer unternehmen).

\section{h. Die Pali der Witwe oder des Witwers}

Die Palivorschriften für die Witwer und Witwen bestehen aus sehr vielen Arten.

Witwer oder Witwen dürfen keine roten Kleider tragen.

Sie dürfen nicht gebrauchen Schmuck der von Gold angefertigt wurde und dürfen auch keine Achate tragen.

Wenn sie diese Palivorschriften übertreten dann können sie von den Paligeistern und auch von der Liau (dem Toten) angefallen und krank gemacht werden, sodass sie selbst sterben müssen (jeder Uebertretungsfall verursacht diese Folgen, der Text wird deshalb nicht wiederholt ausser bei Abweichungen).

Und wenn sie Kleidungs- oder Schmuckstücke gebrauchen die mit den obigen übereinstimmen, dann können die mit dem Tiwah beauftragten Verwandten des Toten sie sogleich recht- 
idje matei te malalus bagulong ${ }^{*}$ lich verfolgen und ihnen eine Busse gawi,n Tiwah.

Kahai,n utang,e injewut ,pulu ramo" atawa akan djahawen rupiah, hajak dia tau mangkepan pakajan matjam te tinai amon hindai Tiwah.

Buju dia tau mangedjau arep,e bara ungkup sawa,e idje matei, atawa ungkup ain liau sawa,e.

Amon ie mangedjau arepe te ie tau imputang ttg. ie tau imaksa haluli rantep ungkup ain liau sawa,e.

Kalote kea balo dia tau mangedjau arep,e bara ungkup ain liau bana,e.

Buju atawa balo dia tau mawi usik,e manandak atawa dia kea manjangen, amon hindai Tiwah.

Amon ewen mawi tumon te, ewen tau buah ,pudjin liau sawa,e atawa bana,e", ie te: tau buah paham pehe takolok hajak muta. auflegen lassen und sie können durch die Angehörigen des Verstorbenen auch gezwungen werden rasch die Handlungen des Tiwah zu vollziehen.

Die Höhe des Schuldbetrages wird genannt ,viele Dinge" oder sie beträgt auch sechs Gulden, ferner wird ihnen verboten sich mit diesen Kleidern und diesem Schmuck zu bekleiden oder zu schmücken, bevor das Tiwah stattgefunden hat.

Der Witwer darf sich nicht entfernen von der Verwandtschaft seiner verstorbenen Frau oder von der Verwandtschaft seiner Frau, die eine Tote geworden ist (in der Existenzform einer Toten weiterlebt).

Wenn er sich aber trotzdem entfernt, dann kann er dafür gebüsst werden und er kann auch gezwungen werden wieder zurückzukehren und sich in der Nähe der Verwandtschaft seiner Frau, die eine Tote geworden ist, aufzuhalten.

So darf auch die Witwe sich nicht entfernen aus der Verwandtschaft ihres Mannes, der ein Toter geworden ist. Der Witwer oder die Witwe dürfen nicht zu ihrem Vergnügen Erzählungen rezitieren und sie dürfen auch nicht die Stammesmythen singen, bevor das Tiwah gefeiert ist.

Wenn sie aber trotzdem so handeln, dann kann sie treffen eine Ermahnung der Frau die eine Tote oder des Mannes der ein Toter geworden ist, nämlich: sie können von sehr heftigen Kopfschmerzen befallen werden und müssen sich erbrechen. 
Tau kea Pali mawi ie.

Sana ewen ihining manandak, manjangen ranen, ewen imputang lime ramo, rima,e: telo rupiah.

Djaton tau dia buju atawa balo akan mobah pakaja,e.

Maka oloh mangganti pakajan buju atawa balo sana limbah ewen djari makajan, mahundjur hantu.

Maka amon sawa,n oloh te mahotus, te palus pahari,n idje mahotus te mangganti pakajan buju.

Bara pakajan ingganti, bara te aton tanda kabuju intu oloh hatue te.

Ampi,n pakajan:

Pakajan uras baputi, lawong,e baputi kea. Intu takolok buju imeteng oloh tali idje injewut: lawong tali.

Tinai amon bana,n oloh bawi matei, te pahari idje kalambutan ain idje matei te mangganti pakajan ain oloh bawi te mambalo ie.

Ampin pakajan balo uras baputi kea.

Amon buju atawa balo dia
Es kann aber auch sein, dass sie von den Paligeistern angefallen und misshandelt werden.

Sobald man hört, dass sie Erzählungen rezitieren oder die Stammesmythen singen oder was auch immer dieser Art unternehmen, dann werden sie gebüsst mit fünf Dingen, das heisst: sie haben drei Gulden zu bezahlen.

Unbedingt müssen Witwer oder Witwe ihre Kleider wechseln (und Witweroder Witwenkleider tragen).

Und die Leute wechseln die Kleider des Witwers oder der Witwe direkt nachdem sie die Leiche bekleidet und aufgebahrt haben.

Wenn aber die Frau eines Mannes stirbt, dann wird sogleich von einem der Geschwister der Verstorbenen die Kleidung des Witwers gewechselt.

Und von dem Momente an, dass die Kleider gewechselt worden sind, besteht das Zeichen der Witwerschaft dieses Mannes.

Die Art und Weise der Kleider ist diese :

Die Kleider sind alle weiss und auch das Kopftuch ist weiss. Um den Kopf des Witwers binden die Verwandten eine Schnur die genannt wird: Schnurkopftuch.

Und wenn der Mann einer Frau stirbt, dann wechselt der leibliche Bruder (oder auch die Schwester) des Verstorbenen die Kleider der Frau und macht sie auf diese Weise zu einer Witwe.

Die Art und Weise der Kleider der Witwe sind ebenfalls weiss. 271

Wenn der Witwer oder die Witwe sich 
maku mangganti pakajan, ie inaksa malalus Tiwah bagulong, tinai kawis ewah ain buju inetek atawa balau oloh bawi inetek.

Tapi tau kea ewen imunu Pali palus matei.

Dia tau buju atawa balo manganan pakaja,e.

Amon ewen manganan pakaja,e ttg. dia ie mansanan djete akan waris, te ie imputang idje kongan bawoi ttg. waris tinai mangganti pakajan kilau helo.

Daha,n bawoi te ihapan manjaki ewen handiai.

Buju atawa balo dia tau habandong, dia tau masawe atawa habane amon hindai Tiwah.

Maka helo-helo bara oloh mangubur atawa mamapui weigern die Kleider zu wechseln, dann werden sie gezwungen das Tiwah rasch auszuführen, ferner schneidet man dem Manne die Enden des Lendentuches ab und man schneidet auch der Frau die Haare weg (Das geschieht in jedem Fall und wird hier als Nachtrag zum oben gesagten genannt).

Es kann aber in diesem Falle auch sein, dass sie durch die Paligeister gespeert werden und an den Folgen sterben (die Geister schleudern einen unsichtbaren Speer der innere Verwundungen verursacht, an deren Folgen man rasch sterben muss).

Der Witwer oder die Witwe darf sich nicht der Kleider entledigen und diese wegwerfen.

Wenn sie sich der Kleider entledigen und sie wegwerfen und davon den Angehörigen des Verstorbenen keine Mitteilung machen, dann werden sie gebüsst und haben als Busse zu bezahlen ein Schwein und die Angehörigen des Toten ersetzen die Kleider wieder wie sie vorher waren (kleiden den Witwer oder die Witwe wieder ein).

Das Blut des Schweines wird gebraucht um sie alle zusammen (d.h. die Schuldigen und die Angehörigen des Toten) damit $z u$ bestreichen.

Der Witwer oder die Witwe dürfen keinen Ehebruch treiben und sie dürfen sich nicht wieder verheiraten, nicht wieder einen Mann oder eine Frau nehmen, bevor das Tiwah gehalten worden ist.

Aber bevor die Leute die Leiche des Verstorbenen bestatten oder ver- 
aton pumpong bara oloh brennen, findet eine Versammlung der bakas-bakas bara pihak hasan- Aeltesten der beiderseitigen Angesila waris idje matei ttg. waris buju atawa balo.

Pumpong ewen te injewut mamanggar 272 buju atawa mamanggar balo.

Rima,e: oloh awang bakasbakas hapumpong mamutus bewei meto idje akan impatei ttg. ramo idje akan injadia tinai ilalus kareh, amon buju atawa balo te malalus Tiwah.

Amon buju atawa balo salenga habandong sahindai Tiwah, te buju atawa balo ihukum mambajar Palanggaran Raung ttg. imaksa bagulong tiwah.

Kahai,n Palanggaran Raung ie te: amon hong pumpong mamanggar buju atawa balo aton inukas oloh bakas hadangan idje, toh ewen akan mambajar Palanggaran Raung hadangan idje tinai.

Djadi hong Tiwah hadangan due impatei.

Kakare talo beken awang inukas uras lipet due kahai,e atawa kare,e.

hörigen, nämlich des Verstorbenen und des Witwers oder der Witwe, statt. Diese Versammlung wird genannt: das Festbinden (oder Festkeilen) des Witwers oder das Festbinden der Witwe.

Das bedeutet: Die Aeltesten, die sich versammelt haben, besprechen und beschliessen nur über die Tiere die geschlachtet werden sollen (Anzahl und Art) und über alle Dinge die bereit gemacht werden müssen und über alles was vollzogen werden soll, dann wenn der Witwer oder die Witwe das Tiwah für den Verstorbenen feiert.

Wenn der Witwer oder die Witwe plötzlich Ehebruch treibt bevor das Tiwah gefeiert worden ist, dann wird der Witwer oder die Witwe verurteilt zu einer Busse, die genannt wird Palanggaran Raung (die Ueberschreitung des Sarges) 273 und er oder sie wird gezwungen rasch das Tiwah zu feiern.

Die Höhe der Ueberschreitung des Sarges wird folgendermassen festgesetzt: wenn die Versammlung der Festbindung des Witwers oder der Witwe bestimmt hat, dass beim Tiwah ein Wasserbüffel geschlachtet werden soll, dann muss nun für die Bezahlung der Ueberschreitung des Sarges noch ein Wasserbüffel geschlachtet werden.

Und so werden dann beim Tiwah zwei Wasserbüffel geschlachtet.

Und so ist es auch mit allen andern Dingen die man für das Tiwah bestimmt hat, sie alle müssen in doppelter 
Tinai ewen due idje habandong te akan mambajar akan anak nole: bawoi idje akan saki,n anak nole te ttg. manas idje kumbang lenge akan gagenep anak nole te ttg. kalote kea lamiang idje.

Tinai manok idje kongan, djete injewut akan bantal bawoi, rima,e: djete impatei helo isut bara bawoi te, ttg. batu,n saki,n anak nole, ie te: djipen idje (epat pulu rupiah).

Tapi amon buju atawa balo masawe atawa habane, sahindai Tiwah, ewen ihukum sama tumon idje tarasewut hundjun toh, tinai imaksa awi bakas-bakas ewen due samasama malalus gawi,n Tiwah.

\section{i. Pali,n Rutas}

Katika helo, amon bakas lewu atawa oloh tatau matei, te djaton tau dia sana djadi hapus gawi,n tantolak matei oloh marutas sungei atawa baras atawa baho 274 atawa kabon.
Höhe oder Menge vorhanden sein.

Ferner müssen die Beiden, die miteinander Ehebruch getrieben haben, an die Waisenkinder bezahlen: ein Schwein für die rituelle Reinigung der Waisenkinder und ein Armband von Perlen, das um die Handgelenke der Waisen gebunden wird, und ebenso auch für jedes der Waisen einen Achat. Ferner haben sie noch zu bezahlen ein Huhn das genannt wird: die Unterlage (das Kissen) des Schweines, das heisst: das Huhn wird kurz vor dem Schwein geschlachtet, und ferner haben sie noch $z \mathfrak{u}$ bezahlen: den Stein der rituellen Reinigung der Waisenkinder, nämlich: einen Sklaven (vierzig Gulden).

Wenn sich aber der Witwer oder die Witwe eine Frau oder einen Mann nimmt (sich verheiratet), bevor das Tiwah gefeiert worden ist, werden sie zur Bezahlung der gleichen Busse verurteilt wie sie bereits oben genannt wurde, ferner werden sie durch die Aeltesten gezwungen zusammen (d.h. sie müssen sich zu gleichen Anteilen in die Kosten teilen) das Tiwah zu vollziehen.

\section{i. Die Rutaspali}

In früheren Zeiten, wenn ein Dorfältester oder ein reicher und angesehener Mensch (Mann oder Frau) gestorben war, dann musste man auf alle Fälle, nachdem die Handlungen des Wegschiebens des Toten beendigt waren, ein Flüsslein oder eine Sandbank oder ein Reisfeld (die alle in der Nähe des Dorfes lagen) barutas 
Maka idje injewut marutas, ie te kalotoh:

Oloh manatap due bandera benang baputi.

Inantahan hapan haur idje ingair njamabulu.

Intu haur tantahan bandera te oloh mameteng dawen Palas atawa dawen Bulu. 275 Maka oloh mampendeng bandera te intu hapamontong kapandjang kabon, atawa intu hasansila tumbang sungei, atawa impendeng intu saran danum hapamontong baras. ${ }^{276}$

Maka sana oloh mampendeng bandera te, te oloh mampatei idje kongan bawoi hajak mahapan Tukang tawur.

Maka isi,n bawoi te inampa akan panginan, panginan te ingkes akan huang pasah korik. machen (d.h. dieses Gebiet musste dann als unreines und gleichzeitig auch heiliges abgesondert werden. Es war für den Gebrauch des Toten bestimmt und der Tote hielt sich hier auch auf). Aber mit dem was man nennt: abgesondert zı werden als Rutasgebiet, verhält es sich folgendermassen:

Die Leute machen bereit zwei Flaggen von weissen Tuch (weiss ist die Farbe der Oberwelt aber auch die des Todes, wahrscheinlich deshalb weil der Tod ebenfalls aus der Oberwelt kommt und der Tote in das Gebiet der Oberwelt gehört).

Die Flaggen werden festgemacht an einer Bambusstange die in $Z_{\text {wischen- }}$ ständen in lang herabhängende Fransen ausgefranst wird.

An den Bambusstangen, den Stützen der Flaggen befestigen die Leute Palasoder Bulublätter (zum Schmuck).

Die Leute richten nun diese Fahnen auf auf den beiden Seiten der Länge des Feldes, oder auf den beiden Ufern der Mündung eines kleinen Flüssleins (meistens kurze Bäche in der Nähe des Dorfes, an denen die Felder und Pflanzungen liegen) oder sie werden auf dem Flussufer aufgerichtet an den beiden Fnden einer Sandbank.

Aber wenn die Leute die Fahnen aufrichten, dann schlachten sie ein Schwein und sie lassen den Tukang tawur (Priester der den Reis streut) kommen.

Das Fleisch des Schweines wird zubereitet zu Essen und das Essen wird in einer kleinen Hütte (Opferhütte) niedergelegt. 
Te Tukang tawur balaku dengan radja,n Pali, uka kare Pali hapumpong melai intu petak, atawa baras, atawa sungei, atawa kabon idje djari inukas.

Tuntang ie mansanan: dia tau oloh malan intu petak te, atawa mandolang intu baras te, atawa satiar intu sungei te, atawa balaku atawa manakau en-en intu hete.

Amon oloh malanggar djandji te, te Pali mawi, mampatei mamunu oloh idje malanggar djandji te.

Maka amon oloh limbah matei mawi tumon te intu petak, te petak te injewut oloh: petak rutas, rima,e: petak te penda kuasa,n kare Pali idje melai hete.

Kalote kea baras atawa kabon atawa sungei te penda kuasa,n kare Pali ttg. injewut rutas.

Maka dia taı oloh malalus talo en-en intu eka te, amon hindai oloh djadi manelak petak rutas, atawa sungei rutas, atawa baras rutas atawa kabon rutas.

Idje injewut manelak rutas, ie te kalotoh: huang lawi,n
Dann ersucht der Tukang tawur den König der Pali, dass sich alle Paligeister versammeln und sich auf der Erde, auf der Sandbank, im Nebenflüsslein oder auf der Anpflanzung niederlassen sollen, die für sie ausgesondert und bestimmt wurde.

Und der Tukang tawur teilt mit: niemand darf sich ein Feld anlegen auf dieser Erde, niemand darf Gold waschen auf dieser Sandbank, niemand darf Walderzeugnisse suchen an diesem Nebenflüsslein und niemand darf in diesem abgesonderten Gebiet etwas holen oder dort etwas stehlen.

Wenn die Leute diese Bestimmung aber übertreten, dann werden sie durch die Paligeister angefallen oder sie töten sie oder werfen ihren Speer nach denen die diese Bestimmung übertreten haben.

Und wenn die Leute, nachdem jemand gestorben ist, so handeln mit der Erde, dann wird diese Erde genannt: Rutaserde, das heisst: diese Erde steht unter der Macht aller Paligeister, die sich dort niedergelassen haben.

Und so steht auch die Sandbank oder die Anpflanzung oder das Nebenflüsslein unter der Macht der Paligeister und man nennt diese Gebiete Rutas.

Nicht dürfen die Leute irgend etwas ausführen auf diesen Plätzen, wenn noch nicht stattgefunden hat durch die Leute (d.h. durch die Balian) das Zerreissen der Rutaserde, des Rutasflüssleins, der Rutassandbank oder der Rutasanpflanzung.

Was man die Zerreissung (oder auch die Durchlöcherung) des Rutas nennt 
gawi,n Tiwah oloh matei te, oloh palus mimbit takolok hadangan idje hapan oloh tiwah akan eka petak rutas, atawa baras rutas, kabon rutas atawa sungei rutas te.

Oloh are ttg. oloh balian hajak Tukang hanteran uras akan hete.

Oloh balian rami-rami hajak tuki,e, lahap, gandang garantong maletus.

Oloh manampa pasah, eka pakanan Pali, intu penda pasah te oloh mingkes takolok hadangan idje manta.

Tinai belahe panginan bara isi,n hadangan, bawoi, ingkes akan huang pasah akan panginan taloh Pali.

Te Tukang hanteran palus mendeng manawur, mangam- ist folgendermassen: am Ende der Handlungen für das Tiwah, das man für den Verstorbenen veranstaltete, bringen die Leute den Kopf eines Wasserbüffels, den man für die Tiwahhandlungen geschlachtet hat, nach der Rutaserde, oder nach der Rutassandbank, oder nach der Rutasanpflanzung oder auch nach dem Rutasflüsslein.

Die ganze Menge der Leute (alle Teilnehmer am Tiwah) und die Balian und auch der Tukang hanteran (der Meister der den Toten nach dem Totendorf geleitet hat. Der Name Seelenführer, der für ihn oft gebraucht wird, scheint mir deshalb unrichtig zu sein, weil nicht die Seele sondern der Tote nach dem Totendorf geleitet wird), sie alle begeben sich dorthin.

Die Balian haben viel Vergnügen (sie sind sehr fröhlich), sie erheben ihre Stimmen, sie jauchzen und sie schlagen die Trommeln und die Gong.

Die Leute richten eine Hütte auf an dem Ort wo sie den Paligeistern die Opfer darbringen können und unter die Hütte legen sie den Kopf des Wasserbüffels, der noch unreif ist (d.h. welcher noch nicht gekocht oder gebraten ist. Der Kopf dient nicht als Opfer sondern zur Reinigung dieses Gebietes).

Und ferner auch einige Speisen, die zubereitet wurden von dem Fleisch des Wasserbüffels und der Schweine, und diese werden in die Hütte gelegt als Speise für die Paligeister. Und darauf streut der Meister, der den Toten nach dem Tatendorf ge- 
peleng kare Pali handiai intu hete, mangat uras kuman.

Huang tawur Tukang hanteran mansanan akan kare Pali handiai, uka kakare Pali malaian melai intu hete.

Ewen uras buli manalih eka radja,e hajak mimbit gana,n takolok hadangan te akan radja,n Pali.

Maka amon auch huang tawur Tukang hanteran te djadi mansanan metoh kare Pali te uras tolak palus hagatang akan ngambo, te oloh malahap hangkudju tingkat hajak mampahiau gandang garantong.

Amon hapus auch Tukang hanteran manolak Pali, te ie hamauch, koa,e : Kruk hambaruan ewen, kruk hambaruan ikei handiai!

Limbah te ie mambowor behas suni-suni intu hundjun takolok ewen handiai. leitet hat, Reis aus und er versammelt alle Paligeister auf diesem Platz, damit sie die Speisen zu sich nehmen.

Und in dem Spruchwort, das er während des Reisstreuens rezitiert, teilt er allen Paligeistern mit, dass sie nun alle zusammen aufhören müssten sich hier niederzulassen.

Und sie alle kehren wieder zurück und begeben sich $\mathrm{zu}$ ihrem König und sie nehmen die Seele des Wasserbüffelkopfes mit sich, die sie dem König der Pali überbringen.

Wenn aber während des Ausstreuens des Reises durch den Tukang hanteran die Rede angekommen ist bei dem Spruchwort das aussagt, dass alle Paligeister abgereist seien und sich in die Höhe erhoben hätten, dann brechen alle Teilnehmer sieben $\mathrm{Mal}$ in Jauchzen aus und sie schlagen die Trommeln und die Gong.

Wenn der Tukang hanteran sein Spruchwort der Wegschiebung der Paligeister beendet hat, dann erhebt er seine Stinme und ruft aus: Kruk, ihre Seelen (die Seelen der Teilnehmer), kruk, unsere Seelen (die Seelen der Priester und Priesterinnen; kruk (der Ruf mit dem man die Hühner anlockt) bedeutet : kommt herbei).

Darnach streut er, ohne etwas zu sprechen, Reis aus über ihre Köpfe (den Reis entnimmt er dem behas tambak radja: dem königlich aufgehöhten Reis, in den die Seelen zurückgekehrt sind. Von dort werden sie über die Köpfe ausgestreut und gehen wieder in die Menschen ein durch die grosse 
Fontanelle).

Limbah te ewen palus buli Und darnach kehren sie sogleich wieder malalus kare gawi huang ins Dorf zurück und sie setzen dort lawi,n paniwah.

alle Arbeiten fort die zur Beendigung der Handlungen beim Tiwah noch nötig sind.

Wenn beendigt ist die Verabschiedung Maka amon djadi manolak des Rutas, dann können die Leute dort rutas, oloh tau manganjı ttg. (auf diesen verschiedenen Plätzen, die malalus gawi idje kueh-kueh für die Paligeister reserviert waren) kea intu hete. wieder Holz holen und sie können dort alle Arbeiten, welcher Art auch immer, verrichten.

\section{DAS TANTOLAK MATEI (Das Wegschieben des Toten)}

\section{Einleitung}

\section{a. Die Behandlung des Tantolak Matei in der Literatur}

Ueber das Tantolak matei, für das hier die Texte und Beschreibungen vorgelegt werden, ist in der Literatur über die Ngadju Dajak so gut wie nichts bekannt. Man sagt höchstens aus, dass am dritten oder siebenten Tage nach dem Tode eine Reinigungszeremonie stattfinde, geht aber weiter nicht auf sie ein.

Hardeland schreibt in seinem Wörterbuch unter Salembang (pag. 495): Salembang bedeutet: an beiden Seiten offen sein, frei stehen, hat aber auch die Bedeutung von: das gereinigt sein (ein Haus, nachdem jemand darin gestorben ist). Das Reinigen der Sterbehäuser geschieht am siebenten Tage. Das Haus wird dann soviel wie möglich offen gesetzt, es wird Blut gesprengt, und ein Sangiang schafft dann die Liau (Seele des Verstorbenen), welche so lange dort geblieben war, zum Hause hinaus.

Weder vernehmen wir von Hardeland wer dieser Sangiang sei, der die Liau zum Haus hinausschafft, noch vernehmen wir welche Liau von ihm weggebracht werde und wir vernehmen auch nicht wohin diese Liau gebracht wird. Hardeland unterscheidet richtig zwischen zwei Liau, nämlich der Salumpok Liau und der Liau Krahang, die beide beim Tiwah (Totenfest) nach dem Totendorf geleitet werden. Beim 
Salembang gibt er diese Unterscheidung nicht, sondern spricht einfach von Liau. Ueber die beiden Liau vergleiche die Erklärungen weiter unten. Auch die späteren Untersucher und Beschreiber sind nicht weitergekommen als Hardeland, offenbar deshalb weil diese kleinere Zeremonie vollständig in den Schatten gestellt wurde durch das umfangreichere und viel wichtigere Tiwah, an dem man sich umfassend mit den Liau beschäftigt und sie definitiv nach dem Totendorf leitet.

Von Perelaer (Ethnografische beschrijving der Dajaks. 1870. Pag. 226) vernehmen wir: „Nadat het lijk in het bosch gebracht is, verkeert het geheele huisgezin des overledenen in een staat van onreinheid, „rutas" genaamd, en zij blijven daarin gedurende zeven dagen. In dat tijdperk mogen de onreinen zich niet in gezelschap met andere menschen begeven, waardoor die ook verontreinigd zouden worden. $\mathrm{Na}$ ommekomst van die zeven dagen offert men eenige hoenders, en het geheele huisgezin wordt met bloed bestreken, waardoor de rutas opgeheven wordt".

Auch Grabowsky spricht in seinem grossen Aufsatz: Der Tod, das Begräbnis, das Tiwah oder Totenfest... bei den Dajaken (I.A.E. II. 1889, Pag. 182), über diese Handlung und sagt dort: ,Wird der Sarg nach dem Begräbnisplatz gebracht, so wird das Sterbehaus sofort mit Wasser besprengt. Auch ruft der Hausvater die Namen aller seiner Kinder und übrigen Hausgenossen auf, denn man glaubt, die Seele des Todten sei im Stande die Seele (hambaruan) ihrer Angehörigen mit sich zu locken, und thue dies sehr gerne. [Für diese mitgelockten Seelen gilt was in Erklärung 192 gesagt wurde, Sch.] Durch das Rufen des Namens komnt aber die etwa mitgelockte Seele in den Betreffenden zurück, der sonst bald sterben würde. Dasselbe geschieht auch, wenn man vom Begräbnis zurückkommt.

Alle hinterbliebenen Angehörigen sind drei oder sieben Tage lang „pali“ d.h. unrein; die Dauer ist bei den verschiedenen Familien nach altem Herkommen verschieden. Sie dürfen dann keine Besuche machen, dürfen manche Speisen nicht essen, haben, selbst wenn sie Opfer bringen, von einem Sangiang keine Hülfe zu erwarten. Auch das Haus, in dem die Leiche lag, ist so lange unrein. Am siebenten Tage werden einige Hühner geschlachtet, man bestreicht sich selbst und die Pforten des Hauses mit etwas Blut, wodurch die Reinigung erfolgt. Man macht es sich manchmal auch in der Weise bequem, dass einer für alle das „pali" halten muss".

In seinem Aufsatz: Ethnografische mededeelingen over de Dajaks 
in de Afdeeling Koealakapoeas, vermeldet Mallinckrodt nur eine Paliperiode von sieben Tagen, geht aber nicht weiter darauf ein.

Die Texte zum Tantolak Matei, die hier vorgelegt werden, wurden durch Johannes Salilah (siehe Vorwort) in Kuala Kapuas für mich aufgeschrieben. Bei der Niederschrift dieser Texte und Gesänge verglich er auch einzelne Partien davon mit den Texten, die von Hardeland und Mallinckrodt mitgeteilt worden waren.277

\section{b. Die Bedeutung des Tantolak Matei}

Das Tantolak Matei findet am siebenten (oft auch am dritten) Tage nach der Beisetzung der Leiche statt. Es bedeutet die Wegschiebung des Toten und aller seiner ungünstigen Einflüsse auf die Lebenden und ihre Umwelt. Diese ungünstigen Einflüsse nennt man ambon rutas (Unheilsnebel oder Unheilstau). Diese Ambon Rutas lagern über dem ganzen Dorf und über allem was zum Dorf gehört, sie hüllen das Dorf in Unheil ein so wie der Nebel das Dorf verhüllt, sie liegen auf den Menschen, den Häusern, den Feldern und dem Fluss so wie der Tau auf den Pflanzen liegt.

Für die Ausführung des Tantolak Matei rufen die Priester (Balian und Basir) den Dohong Mama Tandang Sangiang und seine Helfer oder Sklaven, die alle Handlungen ausführen und zu diesem $Z_{\text {weck }}$ in die Körper der Balian und Basir einfahren. Sie lösen das Dorf und seine Bewohner und ihre Besitzungen zuerst von den Ambon Rutas und darnach führen sie auf dem Lanting Buno (dem Floss von Speeren) die zusammengerollten Ambon Rutas nach dem Batang Danum Rutas, der sich in der Oberwelt befindet (siehe die Erklärung 80). Nachdem diese Reinigungshandlung beendet ist, erfolgt die Wegschiebung des Toten, besser gesagt, die Leitung der Liau Balawang Pandjang durch Dohong Mama Tandang Sangiang. Er führt sie zu Balo Indu Rangkang Penjang, die im Dorfe Bukit Kanjaloh Lanting wohnt. Dieses Dorf befindet sich in der Oberwelt. Wir kommen weiter unten ausführlich darauf zurück. Dort bleibt die Liau Balawang Pandjang bis zum Tiwah. Nachdem sie dort angekommen ist, finden wieder umfassende Reinigungszeremonien statt die das Tantolak Matei abschliessen. In den Einleitungen zu den Texten und Gesängen kommen wir nochmals eingehender auf die einzelnen Punkte zurück.

Das Tantolak Matei wird ausgeführt durch die Balian und Basir, die zu diesem Zwecke mit den Sangiang vom Batang Danum Djalajan in Verkehr treten und sie ersuchen alle Handlungen vorzunehmen und die Liau Balawang Pandjang nach dem Dorfe der Balo Indu Rangkang 
Penjang zu leiten. Bevor wir nun eine Beschreibung der Balian und Basir geben, haben wir zuerst die Frage nach der Oberwelt und den Sangiang $z u$ beantworten.

\section{c. Die Oberwelt}

Für die Frage nach der Oberwelt und den Sangiang 278 verweise ich auf die ausführliche Mythe der Welt- und Menschwerdung und die eingehenden Genealogien der Sangianggeschlechter, $z u$ denen auch die Menschen gehören, im II. Bande dieses Werkes. Wir können hier diese Mythe und diese Genealogien nur in kurzen Zügen mitteilen.

Wenn die Seelen des Streureises und die Seele des Gesanges 279 der Balian und Basir in der Oberwelt angekommen sind, werden sie dort von einer weiblichen Sangiang erwartet, die sich nach ihrem Woher und Wohin erkundigt. Sie teilen ihr mit, dass sie die Sangiang um Hülfe bitten wollen. Bevor sie aber ihre Reise fortsetzen können, haben sie zu beweisen, dass sie ein Recht hatten in die Oberwelt $z u$ reisen und dass sie auch ein Recht besitzen die Sangiang um Hülfe zu rufen. Sie haben zu diesem $Z$ wecke die Mythe von der Welt- und Menschwerdung $\mathrm{zu}$ rezitieren und die verschiedenen Genealogien lückenlos herzusagen. Erst nachdem sie dieses Wissen mitgeteilt haben, haben sie sich legitimiert als solche die mit den Sangiang verwandt sind, die mit ihnen die gleichen Ahnen besitzen und die deshalb auch durchaus ein Recht haben ihre Verwandten um Hülfe zu bitten.

Die gleiche Rezitation (der Mythe und der Genealogien) erfolgt nach Bapa Haastert (siehe die Mythe) auch noch einmal dann wenn die Reisseelen am Flusse Djalajan im Dorfe des Tempon Telon angekommen sind (in etwas anderer Form finden wir diese gleiche Aufzählung auch im II. Bande dieses Werkes). Tempon Telon, der von den Reisseelen geholt wird um anlässlich des Tiwah die Liau nach dem Totendorf $z \mathfrak{u}$ leiten, erkundigt sich nämlich nach dem Streureis, der in seinem Dorfe angekommen ist und sich, wie es Fremdlingen geziemt, im Balai (Fremden- und Versammlungshaus) niedergelassen hat. Er will wissen woher er kommt und was er will. Niemand kann ihm Auskunft geben. Da tritt sein Vater Pampulau Hawon zu ihm und spricht: „Es ist der Streureis der Menschen in der Welt. Er überbringt dir den Auftrag, die Liau der Leute an den Ufern des Flusses der Welt nach dem Totendorf $z \mathbf{u}$ führen und zu vertreiben die Wolken, die vernichtenden des Todes" (d.h. die Ambon Rutas). Tempon Telon will den Menschen aber nicht helfen. Sein Vater Pampulau Hawon zählt ihm aber die Geschlechterfolgen auf und be- 
weist ihm damit deutlich, dass die Menschen mit ihnen (den Sangiang) zusammen die gleichen Ahnen besitzen, dass sie deshalb nahe Verwandte sind und dass ihnen aus diesem Grunde auch geholfen werden muss, weil man sich dieser Hülfe nicht entziehen darf. Die Zusammengehörigkeit der Menschen und Sangiang beweist er ihm mit folgenden Worten: „Es ist nämlich so, mein Sohn Tempon Telon, dass die Menschen an den Ufern des Flusses der Welt ein Geschlecht bilden mit den Sangiang in den Dörfern der Sangiang. So verhält es sich nämlich, mein Sohn: in früheren Zeiten waren wir alle Penjang, die an einem Bande aufgereiht waren, in vergangenen Zeiten waren wir Paturong, die sich in einem Bündel befanden" (d.h. die Sangiang und Menschen bildeten eine geschlossene Gemeinschaft und sie wohnten beieinander in der Oberwelt. (Siehe die Erklärungen 87 und 166).

Und nun, nachdem die Genealogien rezitiert sind, erfolgt die Mythe der Welt- und Menschwerdung. Am Anfang aller Dinge und alles Geschehens, als noch keine Welt und keine Menschen bestanden, finden wir den kosmischen Dualismus, der sich verteilt in Oberwelt und Unterwelt oder Urwasser. Die Oberwelt wird in dieser Zeit bewohnt von dem männlichen Gotte Ranjing Mahatala Langit und das Urwasser wird bewohnt von der weiblichen Tambon (Wasserschlange) oder wie sie auch genannt wird: der weiblichen Djata mit der goldenen Türe (Bawin Djata Balawang Bulau 280). Die Welt- und Menschwerdung geschieht nach der Mythe, die von Johannes Salilah mitgeteilt wurde (siehe den II. Band dieses Werkes), folgendermassen:

Als eines Tages Ranjing Mahatala Langit auf das Urwasser herabschaute, fiel ihm seine Kopfbedeckung vom Kopfe und stürzte herab auf das Urwasser. Diese Kopfbedeckung wird genannt: salutup 281 bulau ringgar langit, sungkol hintan (die Kopfbedeckung, die goldene, die in der Höhe schwankt und die verziert ist mit einem Horne von Diamant). Diese Kopfbedeckung - wir begegnen ihr später wieder bei dem Tukang Hanteran (der Priester, der die Salumpok Liau Haring Kaharingan nach dem Totendorf leitet) - , repräsentiert die Totalität des kosmischen Dualismus, und zeigt damit auch, dass ihr Besitzer, Ranjing Mahatala Langit, ebenfalls den Charakter dieser Totalität besitzt, wenn bei ihm auch der Aspekt der Oberwelt mehr in den Vordergrund tritt. (Das gleiche ist natürlich auch bei der Tambon der Fall, die eine Krone trägt von Gold und Edelsteinen, aber bei der mehr der Aspekt der Unterwelt in den Vordergrund tritt.) Die Kopfbedeckung repräsentiert diese Totalität deshalb weil in dem totemistisch 
und kosmologisch klassifizierenden System der Dajak das Gold zur Unterwelt und der Diamant zur Oberwelt gehört und hier in einem Gegenstand vereinigt sind, eine Vereinigung die wir bei wichtigen Erscheinungen, die den ganzen Kosmos darstellen, noch mehr finden werden. Unterwelt und Oberwelt treten, wie immer und überall in der dajakischen Religion und Kultur, zusammen schöpferisch auf. Die Kopfbedeckung, die aufs Urwasser herabgestürzt ist, verwandelt sich in einen lebenden Baum (Batang Garing belom).

Einige Zeit später schaut Ranjing Mahatala Langit wieder auf das Urwasser herab und nun entfällt ihm sein goldener Dolch besetzt mit Edelsteinen (karis bulau basungkul hintan), der wie die Kopfbedeckung ebenfalls die kosmische Totalität darstellt. Er verwandelt sich in einen männlichen Tambarirang. (Vgl. die Erklärung 92). Die Schwester oder Frau (betau kann beides bedeuten) des Ranjing Mahatala Langit (Putir Selong Tamanang, betau Mahatala Langit) besitzt einen weiblichen Nashornvogel, den sie in einem goldenen Käfig gefangen hält (dieser Nashornvogel ist dadurch deutlich mit der Unterwelt assoziiert, während der männliche Tambarirang, der auf den Zeichnungen ebenfalls als Vogel dargestellt wird, mit der Oberwelt assoziiert ist). Dieser weibliche Nashornvogel verlässt den goldenen Käfig und fliegt von seiner Besitzerin weg, und er begibt sich zu dem Baum der aus der Kopfbedeckung des Ranjing Mahatala Langit entstanden ist. Dort begegnet er dem Tambarirang, der bereits von den Früchten des Baumes pickt. Zwischen den beiden entsteht nun ein Streit um die Früchte. Wir sehen darin einen zeremoniellen Streit zwischen Oberwelt und Unterwelt, zwischen Ranjing Mahatala Langit und der Tambon. Nashornvogel und Tambarirang sind ihre Repräsentanten. Das Resultat dieses kosmischen Streites ist die Welt- und Menschwerdung, und wir finden diesen kosmischen Streit auch immer zwischen den beiden Stammhälften, die mit Unterwelt und Oberwelt assoziiert sind bevor sie sich vereinigen und gemeinsam auftreten um das Heil des Stammes und des ganzen Kosmos zu fördern. Es ist anzunehmen, dass die beiden Stammhälften dann auch mit dem Nashornvogel und dem Tambarirang assoziiert sind. Diese Annahme wird bewiesen durch die Aufrichtung des Lebensbaumes nach dem Tiwah. Diese Handlung geschieht durch den ganzen Stamm, also durch Oberwelt und Unterwelt. Auf den beiden Seiten des Lebensbaumes finden wir auch auf manchen Zeichnungen eine Darstellung des Nashornvogels und des Tambarirang. Wir haben diese Handlung ausfürlich im IV. Band dieses Werkes zu beschreiben und begnügen uns deshalb mit diesem kurzen Hinweis. Bei diesem 
Streit zwischen Nashornvogel und Tambarirang, der auf dem Batang Garing Belom (dem lebenden Baum) ausgestritten wird, fallen die Knorren der Baumäste und die Blütenknospen ab. Aus diesen Knorren und Blütenknospen entsteht eine Jungfrau namens Putir Kahukup Bungking Garing und es entsteht auch ein Boot, das genannt wird Lasang Bangkirai Bahenda (das gelbe Boot von Bangkiraiholz). In der Mythe von Bapa Haastert wird dieses Boot genannt: Banama Bulau (das goldene Boot). Dieses Boot gehört zur Unterwelt, denn die gelbe Farbe, das Holz und das Gold sind deutlich mit der Unterwelt und der Tambon assoziiert. Noch mehr: das Boot ist der Repräsentant der Tambon (Wasserschlange) und es wird auch oft auf den Zeichnungen als eine Wasserschlange dargestellt (siehe die Zeichnung in meinem Werk: Der Totenkult der Ngadju Dajak. Es wird dort ausführlicher beschrieben werden. In dieser eigenartigen Zeichnung ist es kombiniert mit dem Nashornvogelboot). Das Boot treibt mit der Jungfrau zusammen auf dem Urwasser herum. Nach einiger Zeit kämpfen Nashornvogel und Tambarirang wieder miteinander und wieder splittern Stücke vom Baume ab. Aus diesen Stücken entsteht ein See und ein Fluss. Der See ist hier assoziiert mit der Unterwelt, der Fluss mit der Oberwelt. Nach einiger Zeit bricht der Kampf zwischen den beiden Partnern wieder aus. Der Baum zersplittert und vom Stamme entsteht unter anderem (siehe die Ausführungen in der Mythe, II. Band dieses Werkes) ein Boot das den Namen trägt: Banama Babilem (das schwarze Boot); nach der Mythe von Bapa Haastert wird dieses Boot genannt: Banama Hintan (das Diamantboot). Diese Bezeichnung scheint mir, ausgehend von der Klassifizierung der Farben, Edelmetalle und Edelsteine im totemistisch/kosmologischen System der Dajak, die ursprünglichere und auch richtigere zu sein. Der weisse Diamant steht gegenüber dem gelben Gold und gehört in diesem klassifizierenden System zur Oberwelt. Wir begegnen dieser Gegenüberstellung Edelsteine - Gold, wobei die Edelsteine mit der Oberwelt, das Gold mit der Unterwelt assoziiert wird, sehr oft in unseren Texten. Dieses Diamantboot ist der Repräsentant der Oberwelt, besser gesagt des Ranjing Mahatala Langit und wir finden es auch dargestellt in der Form eines Nashornvogels. Wahrscheinlich ist das Banama Tingang (Nashornvogelboot), von dem wir später noch ausführlich zu sprechen haben, identisch mit dem Diamantboot. Wieder entsteht Streit zwischen dem Nashornvogel und dem Tambarirang, und der weibliche Nashornvogel wird von dem männlichen Tambarirang in den Hals gebissen und die Folge ist, dass er das Moos des Baumes, das er noch in seinem 
Schnabel hat, in das Banama Babilem oder Banama Hintan erbricht. Aus diesem Moos entsteht ein Mann, der genannt wird: Manjamei Limut Garing Balua Unggom Tingang (Manjamei, das Moos des Baumes welches erbrochen wurde vom Nashornvogel der es saugend in seinem Schnabel hatte). Auch dieses Boot treibt nun mit dem Jüngling auf dem Urwasser herum, aber nach einiger Zeit begegnen sich die beiden Boote und Manjamei Limut Garing legt an der Seite des Banama Bulau an und macht die beiden Boote mit einem Stück Holz aneinander fest (bapandoh). So festgemacht treiben sie nun nebeneinanderliegend auf dem Urwasser dahin.

Nach einiger Zeit schaut Ranjing Mahatala Langit wieder auf das Urwasser herunter und er erblickt die beiden Boote mit den zwei Menschen. Er wirft nun eine Samatuanfrucht auf das Urwasser herab und breitet auf ihr ein Stück Erde aus, das den Umfang einer Reisworfelmatte hat. Aus dieser Erde entsteht ein hoher Berg. Manjamei Limut Garing will sich nun mit Putir Kahukup Bungking Garing verheiraten und sie gibt dazu ihre Zustimmung unter der Bedingung, dass er für sie beide zuerst ein hohes Haus bauen müsse. Nachdem Ranjing Mahatala Langit diesen Wunsch gehört hat, wirft er sieben Bretter auf die Erde herab und die Tambon (Wasserschlange) oder Djata Balawang Bulau taucht aus dem Urwasser auf und verarbeitet die Bretter und baut aus ihnen das Haus. Dieses Haus vereinigt in seiner Konstruktion Oberwelt und Unterwelt und repräsentiert die kosmische Totalität. Interessant sind in diesem Zusammenhang die Darstellungen des Hauses auf den Zeichnungen des Dorfes die dem Toten nach dem Totendorf mitgegeben werden. Sie werden in meinem Werk: Der Totenkult der Ngadju Dajak ausführlich beschrieben. Putir Kahukup Bungking Garing und Manjamei Limut Garing verheiraten sich nun und beziehen ihr Haus. Die Frau schenkt zuerst den Haustieren und dann drei Söhnen das Leben. Die Namen dieser Söhne sind : Maharadja Sangiang, Maharadja Sangen und Maharadja Buno. Die Nachkommen des Maharadja Sangiang kommen in eine dienende Stellung zu den Nachkommen des Maharadja Sangen. Nachdem Maharadja Sangen und Maharadja Buno zu Jünglingen herangewachsen sind entsteht zwischen den beiden ein Streit. Der erstere ist im Besitze des schwimmenden Eisens, das nur verwundet aber nicht tötet, der letztere ist im Besitz des sinkenden Eisens das tötet. Die Folge dieses Streites ist, dass Maharadja Sangen unterliegt und sich die beiden Brüder trennen. Maharadja Buno steigt aus der Oberwelt an die Ufer des Flusses der Welt hinunter wo er sich niederlässt. ${ }^{282} \mathrm{Er}$ wird hier der 
Stammvater der Menschen, das heisst der Freien, die ebenfalls Sangiang sind und von ihren Sklaven auch mit Sangiang angesprochen werden müssen. Maharadja Sangen wird der Stammvater der Sangianggeschlechter in der Oberwelt, die sich um das erste Dorf Batu Nindan Tarong, Liang Angkar Bantilong Njaring gruppieren. Nach verschiedenen Generationen wird in dieser Linie ein Sohn geboren, bei dem Mythe und Genealogie wieder länger verweilen. Es ist Ratu Basar. Er ist der Vater des Tanta Olang Bulau und des Mangko Amat. Dieser Ratu Basar repräsentiert wieder die kosmische Totalität, er ist, und das gilt wie wir später noch sehen werden schliesslich von jedem Menschen auch, Oberwelt und Unterwelt zugleich. Dieser ambivalente Charakter zeigt sich nach seinem Tode, denn nachdem er gestorben ist verwandelt er sich in einen Antang (wahrscheinlich in den Radjan Darahen Antang, der am Rande der Oberwelt seinen Wohnort hat). Ein anderer Teil des Ratu Basar verwandelte sich in Njaring, Kalue und Kambe Hai. Es sind böse Geister, die nach den beigefügten Erklärungen diese Welt (Pantai danum kalunen) bewohnen, sich aber auch in der Oberwelt finden. Das Badewasser des Ratu Basar verwandelt sich in eine Djata, die im Flusse der Welt ihren Aufenthaltsont nimmt. Aus Ratu Basar entstehen also nach seinem Tode die wichtigsten Geister, die in dieser Welt grossen Einfluss haben. Sie verteilen sich in Oberwelt (Antang), Welt (Njaring, Kalue und Kambe Hai) und Unterwelt (Djata). Eine Dreiteilung, wodurch die kosmische $Z_{w e i-}$ teilung erweitert würde findet nicht statt, denn auch durch die Weltwerdung entsteht ja keine kosmische Dreiteilung in Oberwelt, Welt und Unterwelt. An der Weltwerdung arbeiten, wie wir gesehen haben, sowohl Oberwelt (Ranjing Mahatala Langit) als auch Unterwelt (Tambon oder Djata Balawang Bulau) mit und sie arbeiten auch stets mit an ihrer Weiterentfaltung und an der Instandhaltung des Heiles in dieser Welt, die in ihrem Sein Oberwelt und Unterwelt ist und stets von beiden abhängig bleibt. Die Welt ist so nicht eine selbstständige Grösse sondern nur möglich und denkbar durch die Zusammenarbeit von Oberwelt und Unterwelt, sie gehört beiden an und repräsentiert ihre Totalität. Die Njaring, Kalue und Kambe Hai gehören in der

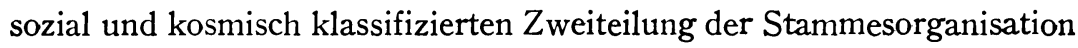
ebenfalls zu den beiden Stammhälften, die, wie wir gesehen haben, mit der Oberwelt einerseits und mit der Unterwelt andererseits assoziiert sind. Dieser Einteilung der Geister in dieser Welt entspricht auch die Einteilung der Geister in der Oberwelt und ihre lokale und kosmologische Gruppierung. Wenn wir die verschiedenen Genealogien mit- 
einander vergleichen (siehe die Mythen zur Welt- und Menschwerdung), dann sehen wir, dass nach diesen Genealogien die bösen Geister abstammen, sei es von Maharadja Sangiang oder Maharadja Buno, sei es dass sie sich herleiten von einem Nachkommen des Maharadja Sangen. Auch hier (das heisst nach diesen Genealogien) gehören diese Gruppen der bösen Geister sowohl zu der Gemeinschaft der Sangiang als auch der Menschen, die ja, wie wir gesehen haben, ebenfalls Sangiang sind.

Ratu Basar hatte zwei Söhne. Der eine von ihnen, Mangko Amat war verheiratet mit Njai Djaja. Beide waren Priester und führten für ihre Verwandten die priesterlichen Handlungen aus. Nach einer solchen Handlung fanden sie einen gewaltsamen Tod. Ihre Leichen verwandelten sich in Fruchtbäume und Nutzpflanzen (siehe die Mythe: Der Ursprung der Nutzpflanzen). Der andere Sohn hiess Tanta Olang Bulau. Er zeugte sieben Söhne und sieben Töchter. Während die Genealogien für die Töchter in unseren Texten nicht mehr weiter verfolgt werden, werden die der Söhne für die erste Generation noch vermeldet.

Mit Ratu Basar beginnt eine neue Periode. Sein Körper verwandelt sich nicht nur in verschiedene Geister, einer seiner Söhne wird nicht nur mit seiner Frau zusammen einer der ersten Kulturheroen, sondern was in den Texten noch wichtiger ist, ist die Tatsache, dass aus den ursprünglichen drei Dörfern oder Dorfteilen, die sich gruppieren umund ihre Einheit finden in Batu Nindan Tarong, nun sieben Dörfer entstehen, die an sieben Flüssen liegen und die von den sieben Söhnen des Tanta Olang Bulau und ihren Nachkommen bewohnt werden. Die ursprüngliche Dreiteilung in Batu Nindan Tarong, die mit der kosmologischen Zweiteilung zusammenhängt, war folgendermassen. Man unterschied nämlich: der Dorfteil, der nach flussaufwärts (ngadju oder djalajan hulu danum) liegt, der Dorfteil, der in der Richtung nach flussabwärts (ngawa oder laut) liegt und die Mitte des Dorfes, die die höhere Einheit und Totalität darstellt. 283

Diese sieben Dörfer an den sieben Flüssen entsprechen wahrscheinlich auch wieder der Stammeinteilung bei den Ngadju Dajak mit zwei Phratries und je drei Clans die ihre höhere Einheit finden in einem siebenten Mittelpunkt, um den sie sich gruppieren. Diese kosmische und soziale Stammesorganisation können wir voraussetzen und rekonstruieren, beweisen können wir sie aber erst wenn die Mythologie der Ngadju Dajak einmal gründlich aufgenommen und untersucht ist. In der Oberwelt bleibt dieser Mittelpunkt, um den sich die andern sechs 
Dörfer an sechs Flüssen gruppieren, das Urdorf Batu Nindan Tarong. Jedes dieser sieben Dörfer besitzt im religiösen, kulturellen und sozialen Leben der Ngadju Dajak seinen bestimmten Platz und seine angewiesene Funktion, die übereinstimmen müssen mit Platz und Funktion der Phratries und Clans in der Stammesorganisation. Wir wissen darüber heute noch $\mathrm{zu}$ wenig, wenn auch unser Textmaterial einige wichtige Perspektiven zeigt. Mehr werden wir erfahren sobald einmal die Sangen,284 d.h. die sehr umfangreiche Stammesmythologie, gründlich untersucht werden kann, denn in ihnen werden ja alle diese Fragen ausführlich behandelt.

Die drei wichtigsten Gruppen, mit denen wir es im Totenkult zu tun haben, sind die des $\mathrm{Sarampang} \mathrm{Pandj} \mathrm{i} \mathrm{in} \mathrm{Batu} \mathrm{Nindan} \mathrm{Tarong,}$ die des Radja Panjarawan Katingan am Flusse Barirai und die des Radja Pampulau $\mathrm{Haw}$ on am Flusse Djalajan. Diese drei Gruppen arbeiten direkt und indirekt mit bei der Führung des Toten nach dem Totendorf.

Sa rampang $\mathrm{Pandj}$ i hat fünf Söhne und zwei Töchter (vgl. die Beilage). Die Funktion der beiden Söhne (beim Totenfest und auch überhaupt im religiösen Leben) Radja Rapanatap Kilat und Sangiang Saloh Sambang ist mir vorläufig noch nicht bekannt, weil sie in diesen Texten, die wir hier vorlegen, nicht genannt werden.

Die beiden Söhne Telon Mama Tambon Buno und Mama Kandajun Lanting begleiten als Ruderknechte den Tempon Telon und sie leiten mit ihm zusammen die Salumpok Liau Haring Kaharingan (siehe die Erklärung weiter unten) nach dem Totendorf. Telon Mama Tambon Buno ist wahrscheinlich der Sangiang, der sich nach dem Siege des Tempon Telon über Manjamei dem Tempon Telon unterwarf und der in den Texten sein Sklave genannt wird (der Name Tempon Telon bedeutet: der Besitzer des Telon). Auch von Hamparang Mama Kandajun Lanting wird gesagt, dass er der Sklave des Tempon Telon sei.

Dem Sohne Sangiang Sahor Djalajan Parapah begegneten wir schon in den Texten zum Tantolak Matei. Er hat über den Menschen, die an irgend einen der Sangiang Opfer versprochen haben und ihm Gelübde ablegten, $z \mathfrak{u}$ wachen und sie vor Krankheiten und vor dem Tod $z \mathbf{u}$ behüten und wenn ein Mensch stirbt, dann wird ihm bei der Führung des Toten durch den Begleiter des Toten, sei es durch Dohong Mama Tandang Sangiang oder durch Tempon Telon, auch vorgeworfen, dass er seine Aufgabe und seine Pflicht sehr schlecht erfüllt habe (siehe das Gespräch in den Texten).285 Bei der Tochter Balo Indu Rangkang 
Penjang (sie wohnt nicht mehr in Batu Nindan Tarong, sondern besitzt ein eigenes Dorf auf einem Berge, wird aber doch immer in Verbindung mit dem Urdorf genannt, in dem ihr Vater wohnt) findet die Liau Balawang Pandjang (siehe die Erklärungen unten), die von Dohong Mama Tandang Sangiang beim Tantolak Matei dorthin geleitet wird, ihren vorläufigen Aufenthaltsort, bis sie beim Tiwah wieder von Dohong Mama Tandang dort abgeholt und nach dem Totendorf geleitet wird, wo sie dann mit der Salumpok Liau Haring Kaharingan wieder vereinigt wird. Bei dieser Vereinigung hat die Tochter Bawi Balang Babilem einen Hauptanteil, denn sie badet den Toten, nach der Vereinigung der Salumpok Liau Haring Kaharingan mit der Liau Balawang Pandjang, im Lebenswasser, sodass er wieder zu neuem Leben erweckt wird. Diese Handlung wird nicht von Tempon Tiawon, der Frau des Tempon Telon, ausgeführt wie Grabowsky irrtümlich schreibt. 286

$\mathrm{Radja} \mathrm{Panjarawan} \mathrm{Katingan} \mathrm{nimmt} \mathrm{mit} \mathrm{seinen} \mathrm{Söhnen}$ und Töchtern an den Beratungen im Dorfe des Pampulau Hawon am Flusse Djalajan teil, nachdem die Reisseelen aus der Welt angekommen sind um Tempon Telon aufzufordern die Salumpok Liau Haring Kaharingan anlässlich des Tiwah nach dem Totendorf zu leiten. Nachdem sich Tempon Telon anfänglich weigert diese Arbeit auf sich zu nehmen, wird er nicht nur von seinem eigenen Vater sondern auch von seinem Schwiegervater Radja Panjarawan Katingan (Tempon Telon ist verheiratet mit seiner jüngsten Tochter Kameloh Tempon Tiawon Bulau) dazu aufgefordent, und er spricht auch sonst bei allen Beratungen mit entscheidender Stimme mit. Von seinen Söhnen oder Töchtern nimmt aber niemand persönlich teil an der Leitung der Salumpok Liau Haring Kaharingan.

Eine der wichtigsten Funktionen in der Religion der Ngadju Dajak, und vor allem auch im Totenkult, haben die Söhne des $\mathrm{Radja}$ $\mathrm{Pampula} \mathrm{u} \mathrm{Ha}$ a on am Flusse Djalajan, am Strome Labeho Pali. Wir müssen diesen Fluss und seine Bewohner etwas näher behandeln, nicht nur wegen ihrer Wichtigkeit, sondern auch weil manche scheinbaren Unklarheiten vorliegen, die sich aber bei näherer Untersuchung lösen. Rawing Tempon Telon wird von Hardeland, wahrscheinlich mit gutem Recht, als jüngster Sohn genannt. In der Genealogie, die ich hier wiedergebe, figuriert er aber als vierter Sohn; das ist insofern nicht so schlimm weil solche Verwechslungen sehr oft vorkommen. Nach der Genealogie (siehe Beilage I) liegen die Verhältnisse folgendermassen : 


\section{Radja Pampulau Hawon verheiratet mit: \\ Kameloh Pahuton Ambon}

a. Söhne :

$\begin{array}{ccc}\text { Radja Dohong Radja Sahawong } & \text { Rahon Tingang } & \text { Rawing Tempon } \\ \text { Bulau } & \text { Bulau } & \text { Telon }\end{array}$

Baluken Panjulei Budjang

Suling Tengkah Barendeng

b. Töchter :

Bungen Bulau Timpong Radja Kameloh Pa- Telak Balawan Bawi Randan marasan Bulau

$\begin{array}{ccc}\text { Tempon Hen- } & \text { Parahimok } & \text { Parakantih } \\ \text { dan Bulau } & \text { Tantawa } & \text { Bulau }\end{array}$

Hardeland (Wörterbuch, unter Sangiang, pag. 506) gibt folgenden Stammbaum, in dem nur der älteste und jüngste Sohn und die älteste und jüngste Tochter aufgenommen worden sind, nämlich :

\section{Pampulau Hawon}

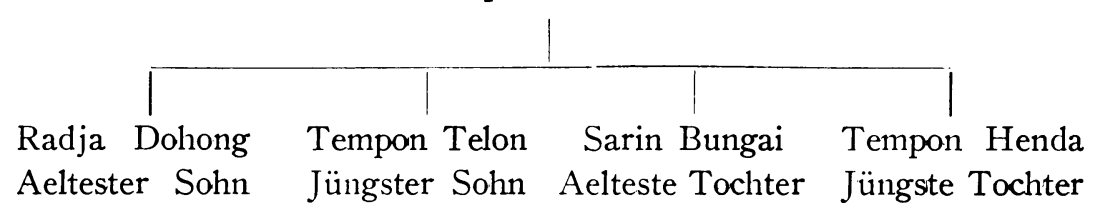


In den Texten werden diese Stammbäume durchaus anerkannt und auch die Mitteilung von Hardeland, dass die beiden wichtigsten Sangiang am Flusse Djalajan, die von den Menschen am meisten aufgerufen werden, der älteste Sohn des Radja Pampulau Hawon, nämlich Radja Dohong und der jüngste Sohn Tempon Telon seien, wird durchaus bestätigt. Die Erklärungen, die die beiden Priester Johannes Salilah und Kenjoi zu ihren Karten von der Oberwelt geben und die Namen der Begleiter der Toten, die sie vermelden, stimmen aber mit diesen offiziellen Genealogien nicht ganz überein. Tempon Telon wird in diesem Zusammenhange in ihren Erklärungen (dieses schriftliche Material befindet sich ebenfalls in meinem Besitz, es ist für das Lesen der Karten unmissbar) gar nicht zu den Bewohnern des Djalajan gerechnet und der Name des Dohong Mama Tandang Sangiang figuriert nicht in den Genealogien. Die scheinbaren Widersprüche werden aber bei einer näheren Untersuchung und Vergleichung gelöst.

Nach Johannes Salilah wird der Fluss Djalajan nicht genannt (das heisst in seinen Erklärungen nicht, in den offiziellen Genealogien die er in seinen Texten wiedergibt aber wohl): Batang Danum Djalajan, Gohong Labeho Pali, sondern er trägt hier den Namen : Batang Danum Djalajan, Gohong Riak Lamiang. In diesem geographischen Namen des Flussgebietes wird wieder der kosmische Dualismus zum Ausdruck gebracht, der im ganzen Flussgebiet seine höhere Einheit findet. Danum Djalajan (das Flussgebiet des Quellortes) ist assoziiert mit der Oberwelt, Gohong Riak Lamiang (der Strom der wellenden Achate) ist assoziiert mit der Unterwelt. Ihre Vereinigung stellt die kosmische Totalität dar. Dieser kosmische Dualismus, der in diesem Namen zum Ausdruck gebracht wird, findet sich auch wieder zurück in der lokalen Organisation des ganzen Gebietes und in der Lage der Dörfer. Hier am Flusse Djalajan wohnen in ihren eigenen Dörfern oder Dorfteilen die beiden wichtigsten Sangiang, nämlich Mantir Mama Luhing Bungai und Dohong Mama Tandang, Langkah Sawang Mama Bungai. Bevor man im Boote flussaufwärts fahrend im Wohnort dieser beiden Sangiang ankommt, hat man auf dem Flusse fünf Buchtungen zurückzulegen. Diese Buchtungen heissen:

1. Tandjong Tusang Kalalepan pasang, Luwok Tiling Djakatan Rawing

2. Tandjong Kamakang Lawong, Luwok Kangkelong Bengkel

3. Tandjong Tatekan Tihang, Luwok Tantanan Lajar

4. Tandjong Tampong Papas, Luwok Tundon Kalingking

5. Tandjong Elang Salentup, Luwok Humbang Rendan Tingang 
Hat man diese Flussbiegungen hinter sich, dann kommt man zum Berge Pasahan Rundjan, der das Eigentum des Mantir Mama Luhing Bungai ist. Zur Zeit als Rawing Tempon Telon Krieg führte verbargen die Angehörigen des Mantir Mama Luhing Bungai ihre Reichtümer und ihre heiligen Töpfe (halamaung und balanga) auf diesem Berge und davon stammt auch sein Name (pasahan rundjan heisst: die Hütte der heiligen Töpfe). Nachdem man an diesem Berge vorbeigefahren ist, kommt man zum heiligen Haine des Antang (Falke; es handelt sich hier um den Antang Ganan Tadjahan) und zur Wassertiefe in der sich die Djata aufhält (labehon Djata). Nach diesen Lokalheiligtümern, die Oberwelt und Unterwelt repräsentieren (der Antang ist, wie wir oben gesehen haben, mit der Oberwelt assoziiert) kommt man dann in das Dorf des Mantir Mama Luhing Bungai und des Dohong Mama Tandang, in dem alle Sangiang wohnen die von den Menschen an den Ufern des Flusses der Welt aufgerufen werden und derer sie sich bedienen. Der Balai (das Versammlungshaus) des Mantir Mama Luhing Bungai, das sich in diesem Dorfe befindet (wahrscheinlich auf der unteren Dorfseite) trägt den Namen: Balai Mihing Njapundo Rundjan, Saling Njalong Kaharingan Marurok Hintan. Der Balai des Dohong Mama Tandang, der sich in seinem Dorfteil befindet (obere Seite des Dorfes) trägt den Namen: Balai Njaho Mantunggang Pulu, Sali Ganggerang Mambuakan Djalatien. Das Dorf selbst heisst: Danum Djalajan, Gohong Riak Lamiang.

Die Beschreibung des Djalajan nach Kenjoi lautet folgendermassen: Am Flusse Djalajan finden sich folgende Gruppen: Die Verwandtschaft (ungkup: Verwandte, Verwandtschaft; alle die unter einem Häuptling stehen, d.h. ein Stamm, das sind nämlich auch gewöhnlich alle Verwandte) des Mantir Mama Luhing Bungai. Hier befindet sich auch der Rahan Timpong 287 (das Versammlungshaus, das von Tuch gemacht ist) der Tempon Henda. Im Dorfe erhebt sich der Pantar Garing Nakolok Undan Pamalunok Bungai (die Säule von Elfenbein auf dem der Schädel aufgepflanzt wurde der sich über dem Nashornvogel erhebt). Dann folgt der Sawang Njaho (die donnernde Sawangstaude). Darnach kommt man zum Wohnort der Sangiang an der Mündung des Flüssleins Pasang Bulau. Schliesslich kommt man zum Berge Tuah Penjang (der heilbringenden Penjang), der hinter dem Dorfe Danum Djalajan liegt. Nachdem man dort vorbeigerudert ist, kommt man zum Orte der Sangiang an der Mündung des Kedjat Hintan. Hier gedeiht das Kaju Garo (Weihrauchholz, das man bei den religiösen Handlungen von hier herbeiholen lässt um mit ihm den 
duftenden Weihrauch hervorzubringen) und hier liegt auch die Mündung des Kanales Bulau Handjaliwan. Ist man an diesem vorbeigerudert, dann kommt man zum Lunok Garo Mandawen Tandak (der Baum des Weihrauches, dessen Blätter Gesänge sind). Weiterrudernd kommt man zum Rahan der Gemeinschaft der Basir (ungkup basir. Basir werden hier die Angehörigen des Mantir Mama Luhing Bungai genannt, wahrscheinlich deshalb weil sich diese Sangiang in den Balian und Basir auf der Welt inkorporieren). Hier befindet sich auch das Wohnhaus der Basir und erheben sich die beiden Berge Nahanjong Djala Dahiang Mantang und Marewei Garing Eka Antang Tempon Mihing. Weiterudernd kommt man zum Hause in dem die Gemeinschaft der Sangiang vom Flusse Baras Bulau (ein Nebenflüsslein, das dort in den Djalajan einmündet) wohnt. Hier gedeiht der Batang Katilambong Njaho (Kokospalme) und auch der Sawang Daha (BlutSawangstaude). Weiterrudernd kommt man zum Dorfe des Manjamei $\mathrm{H}$ at uen Sangiang Hulu Danum D a la jan (Manjamei, der männliche Sangiang am Oberlauf, im Quellgebiet des Flusses Djalajan). Hier gedeiht der Handiwong Belom Bapusu Rohong (der lebende Handiwong mit den Herzblättern von Dolchen) und erhebt sich ein Schädelpfahl (Garing batang pantar mangkongan undan pamalunok bungai).

In diesen Erklärungen wird weder der Name des Tempon Telon noch der des Dohong Mama Tandang genannt.

Die Erklärungen, die uns in dieser Sache mehr Licht geben, müssen wir wieder in den Texten suchen. Nach diesen Texten (siehe den II. Band dieses Werkes) kommen die Reisseelen, die vom Upon Balian (Hauptbalian) anlässlich des Tiwah nach der Oberwelt gesandt worden sind um Tempon Telon herbeizuholen, damit er die Salumpok Liau Haring Kaharingan nach dem Totendorf leite, im Dorfe Danum Djalajan an. Sie lassen sich, wie es sich ankommenden Fremdlingen und Besuchern geziemt, im Balai Njaho Matunggang Pulu, Sali Ganggerang Mambuakan Djalatien nieder (also in dem Versammlungshaus des Dohong Mama Tandang, wie wir oben gesehen haben). Tempon Telon befindet sich auch im Dorfe, aber er ist im Bette seiner Schwester Tempon Henda in tiefen Schlaf gefallen. Sein Vater Pampulau Hawon ruft alle seine Söhne und Töchter zu einer Versammlung zusammen und er bittet auch die Bewohner des Flusses Barirai, an dieser Beratung teilzunehmen. Er erzählt ihnen, dass die Reisseelen vom Ufer des Flusses der Welt angekommen seien um Tempon Telon zu holen. Radja Dohong Bulau, sein ältester Sohn, fragt ihn: „Warum holen sie 
meinen jüngsten Bruder Tempon Telon? Warum muss nicht ich, der Aelteste, die Salumpok Liau Haring Kaharingan begleiten ?" Pampulau Hawon erklärt ihm, dass diese Aufgabe nach genealogischen Zusammenhängen Tempon Telon vorbehalten sei und dass bereits bei seiner Geburt versprochen worden sei, dass er die Salumpok Liau Haring Kaharingan der Menschen nach dem Totendorf überbringen müsse. Radja Dohong Bulau gibt sich mit der Antwort und den ausführlichen Erklärungen zufrieden. Tempon Telon wird nun mit grosser Mühe aus seinem Schlaf aufgeweckt. Er erkundigt sich nach den Wünschen der Reisseelen im Balai Njaho Matunggang Pulu, Sali Ganggerang Mambuakan Djalatien. Als er ihren Wunsch hört, weigert er sich zuerst darauf einzugehen, aber sein Vater überzeugt ihn dann von seiner Pflicht. Darauf geht Tempon Telon auf die Bitte der Reisseelen ein und steigt mit seinen Begleitern auf die Welt hinunter.

Wie stimmt nun aber diese lokale Gruppierung der Bewohner des Flusses Djalajan mit den Genealogien überein? Nach Johannes Salilah sehen wir, dass sich zwei Gruppen in zwei Dorfhälften gegenüberstehen. Die eine Gruppe und der eine Dorfteil steht unter Mantir Mama Luhing Bungai, ein Name, den wir in keiner Genealogie finden können. Wahrscheinlich handelt es sich bei diesem Mantir Mama Luhing Bungai um Tempon Telon selbst oder um einen seiner Untergebenen. Diese Wahrscheinlichkeit wird bestätigt durch die Texte zum Balaku Ontong (die Bitte um Heil, siehe den IV. Band dieses Werkes). Nach diesen Texten wird nämlich Mantir Mama Luhing Bungai von den Balian und Basir aufgerufen und er wird gebeten für die Menschen, die das Tiwah veranstaltet haben, in der Oberwelt Heil zu holen und die Welt und Menschwerdung durch die Aufrichtung des Lebensbaumes (Batang Garing Belom) zu wiederholen. Er legt bei diesem Anlasse seine Reisen zurück im Banama Tingang (Nashornvogelboot). Dieses Banama Tingang gehört aber nach allen Texten, die wir kennen, dem Tempon Telon. Bei den Opfern, die während des Balaku Ontong bereit gemacht und dargebracht werden, finden sich auch Opfer für Tempon Telon, der aber in diesen Texten nirgends handelnd auftritt, denn alle Handlungen werden ausgeführt durch Mantir Mama Luhing Bungai. Es wird also bei der Darbringung der Opfer eine Identifikation dieser beiden Persomen vollzogen, oder wenn das nicht der Fall ist, dann repräsentiert Mantir Mama Luhing Bungai auf alle Fälle den Tempon Telon, und er führt an seiner Stelle alle Handlungen aus und benützt zu seinen Reisen sein Boot. Wir hätten dann auch in dem Dorfteil des Mantir Mama Luhing Bungai den des Tempon Telon, des jüngsten 
Sohnes des Pampulau Hawon, zu sehen und auch die Bewohner dieses Dorfteiles als zu Tempon Telons Verwandtschaft gehörend $z \mathfrak{u}$ betrachten. Die obere Hälfte des Dorfes Danum Djalajan wird bewohnt von Dohong Mama Tandang. In Dohong Mama Tandang haben wir zweifellos den ältesten Sohn des Radja Pampulau Hawon zu sehen. nämlich Radja Dohong Bulau, der, wie wir gesehen haben, bei den Beratungen sehr aktiv auftritt und sich auch erkundigt weshalb nicht er, sondern Tempon Telon, sein jüngster Bruder, die Salumpok Liau Haring Kaharingan zu leiten habe. Er hat sie deshalb nicht $z u$ begleiten, weil er die Liau Balawang Pandjang zu führen hat. Bei dieser Begleitung tritt er aber nicht unter seinem richtigen Namen Radja Dohong Bulau auf, sondern er wird Dohong, der Onkel des Tigers genannt. Der Name Dohong, der sein Eigenname ist, weist aber deutlich hin auf seinen eigentlichen Namen (Radja Dohong Bulau). Auch bei Tempon Telon findet schliesslich eine Namenänderung statt, denn der Name Tempon Telon, den wir in dieser Form auch in den Genealogien finden, ist nur ein ihm beigelegter Ehrenname. Hardeland (W. B. pag. 506) erzählt uns (siehe auch die Mythe): „Von Tempon Telon wird erzählt: er war eine unzeitige Geburt, kam nur als ein Blutklumpen zur Welt, und er wurde von seiner Mutter ins Wasser geworfen. Er trieb beim Bukit Lengkong ans Land, wo ihn eine weibliche Sangiang, die Puson Baluso, fand, welche grade am Baden war. Sie zog ihn aus dem Wasser und machte aus dem Blutklumpen ein lebendes Wesen, dem sie den Namen gab: Kumpang Bulau $\mathrm{Panarusan} \mathrm{Langit,} \mathrm{die} \mathrm{goldene} \mathrm{Schwertscheide,} \mathrm{welche} \mathrm{dahin-}$ trieb unter dem Himmel. Als der Findling gross geworden, kam seine Base, die Tempon Tiawon, dahin; sie war auf der Flucht vor einem gewissen Manjamei, einem mächtigen Sangiang, welcher sie heiraten wollte, von ihr aber verschmäht wurde. Manjamei verfolgt sie, will sie greifen, da nimmt Kumpang Bulau Panarusan Langit sich ihrer an, kämpft mit den Manjamei, und überwindet und tötet ihn, worauf die Tempon Tiawon ihn dann heiratet unter der Bedingung, dass er mit ihr in ihr Land zurückkehren müsse [an den Barirai]. Bei der Gelegenheit offenbart ihm dann seine Pflegmutter, wer er sei. Zurückkehrend wird er, der Ueberwinder des Manjamei, dem alle andern Sangiang nicht zu widerstehen vermochten, mit Freude und Ehrfurcht aufgenommen; der mächtige Telon unterwirft sich ihm als sein Sklave, weshalb er nun den Namen Tempon Telon [Besitzer oder Herr des Telon] annahm."

Auch die Beschreibung des Kenjoi vom Flusse Djalajan zeigt uns 


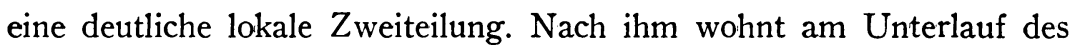
Flusses Mantir Mama Luhing Bungai und am Oberlauf des Flusses wohnt Manjamei Hatuen Sangiang. Auch dieser Name stimmt, wie eine Vergleichung zeigt, überein mit Dohong Mama Tandang und Radja Dohong Bulau, denn die Erklärungen des Kenjoi erzählen uns ferner noch, dass er es sei der die Liau Balawang Pandjang begleite. Er reist auch mit dem gleichen Boot und nimmt die gleichen Begleiter mit wie Dohong Mama Tandang, sodass wir unter diesen drei Namen immer die gleiche Person zu sehen haben. Die lokale Organisation am Flusse Djalajan stimmt, wie wir bereits gesehen haben, überein mit der bei den Ngadju Dajak wo ein Flussgebiet auch immer eingeteilt wird in die beiden Hälften Mündung (tumbang) und Oberlauf (djalajan hulu danum), oder, wie sie auch bezeichnet werden: die Richtung nach flussabwärts (ngawa) und die Richtung nach flussaufwärts (ngadju). Dass selbst auch das Dorf Danum Djalajan diese Teilung in zwei Hälften aufweist (die untere Hälfte wird bewohnt von Mantir Mama Luhing Bungai und die obere Hälfte von Dohong Mama Tandang) verwundert uns auch nicht, weil auch heute noch das Dorf der Ngadju Dajak diese gleiche $Z$ weiteilung zeigt. Das Utus gantong (die vornehme oder hohe Bevölkerung) wohnt in der oberen Hälfte des Dorfes, das Utus randah (die niedrige Bevölkerung, die in einem untergebenen und dienenden Verhältnis zu der hohen Bevölkerung steht) wohnt in der unteren Hälfte des Dorfes. Eine umgekehrte Gruppierung lässt sich ebenfalls konstatieren, ist aber in den meisten Fällen lokalhistorisch zu erklären.288 Die Dörfer im Mündungsgebiet (tumbang), oder der Dorfteil, der in der Richtung nach flussabwärts (ngawa) liegt, gehören zu der Stammhälfte, die mit dem matrilinealen Aspekt der Gemeinschaft assoziiert ist und damit auch kosmologisch klassifiziert zur Unterwelt (Tambon) gehört. Die Dörfer, die am Oberlauf liegen (djalajan hulu danum), oder der Dorfteil, der in der Richtung nach flussaufwärts liegt (ngadju), gehören zu der Stammhälfte, die mit dem patrilinealen Aspekt der Gemeinschaft assoziient ist, und werden damit auch kosmologisch klassifiziert als zur Oberwelt (Ranjing Mahatala Langit oder Tingang oder Bungai) gehörend. Dieser kosmologischen Klassifikation entspricht dann auch die Rolle, die den beiden Hälften im sozialen und oekonomischen Leben zugewiesen ist (siehe darüber meine Arbeit: Der Totenkult der Ngadju Dajak, 1. Kapitel).

Die gleiche Organisation finden wir nun auch am Flusse Djalajan vor. Mantir Mama Luhing Bungai oder Tempon Telon bewohnen nach Johannes Salilah die untere Hälfte des Dorfes oder nach Kenjoi das 
Mündungsgebiet. Radja Dohong Bulau, alias Dohong Mama Tandang, alias Manjamei Hatuen Sangiang bewohnt die obere Hälfte des Dorfes (nach Johannes Salilah) oder den Oberlauf des Flusses (nach Kenjoi). Mit dieser lokalen Organisation und kosmologisch totemistischen Klassifizierung der beiden Stammhälften hängt auch die Klassifizierung der Namen zusammen (Kumpang Panarusan Langit und Radja Dohong Bulau oder Dohong Mama Tandang). Kumpang, die Scheide von Holz, gehört in der kosmologisch/totemistischen Klassifizierung zur Unterwelt und damit auch zu der Stammhälfte, die mit dem matrilinealen Aspekt der Gemeinschaft assoziiert ist. Dohong, der eiserne Dolch, gehört nach der kosmologisch/totemistischen Klassifizierung zur Oberwelt und damit auch zu der Stammhälfte, die mit dem patrilinealen Aspekt der Gemeinschaft assoziiert ist.

Die gleiche Klassifikationsterminologie finden wir auch auf den Menschen angewandt, der in seinem physisch/psychischen Bestehen die Totalität des kosmischen Dualismus darstellt. Der Leib, der durch die Unterwelt gegeben wird (Tambon oder Djata Balawang Bulau), wird verglichen mit der Scheide (kumpang), die seelische Substanz des Menschen stammt aus der Oberwelt und wird mit einem Dolch (dohong) verglichen, der in der Scheide steckt. Nach dem Tode wird die Salumpok Liau Haring Kaharingan, die mit der seelischen Substanz übereinstimmt, durch Tempon Telon nach dem Totendorf geleitet, und die Liau Balawang Pandjang, die mit der leiblichen Substanz übereinstimmt, wird durch Dohong Mama Tandang nach dem Totendorf geleitet. Dort werden die beiden Toten miteinander vereinigt und bilden dann wieder eine physisch/psychische Einheit wie in dieser Welt.

Die gleiche Klassifizierung gilt auch für die beiden Boote, die Tempon Telon und Dohong Mama Tandang für die Ueberführung des Toten nach dem Totendorf gebrauchen. Tempon Telon führt die Salumpok Liau Haring Kaharingan mit der Lanting Samben (das Floss von Perlenhalsbändern). Die Perlen gehören in der kosmologisch/totemistischen Klassifizierung, wie wir bereits gesehen haben und später noch öfters aus den Texten sehen werden, zur Unterwelt, aber auch zu der Stammhälfte, die mit dem matrilinealen Aspekt der Gemeinschaft assoziiert ist. Dohong Mama Tandang reist mit dem Banama Njaho, Adjong Roho-Rohong (dem Boote des Donners, dem Schiff der Dolche). Sowohl Donner als auch Dolche gehören zur Oberwelt aber auch zu der Stammhälfte, die mit dem patrilinealen Aspekt der Gemeinschaft assoziiert ist. Wahrscheinlich sind diese beiden Boote identisch mit dem Banama Bulau, das auch als Wasserschlange dar- 
gestellt wird, und dem Banama Hintan, das auch als Nashornvogel dargestellt wird, und die wir bereits oben kennen gelernt haben.

Wir haben über die lokale Organisation am Flusse Djalajan gesprochen und wir haben nun noch $z \mathfrak{u}$ untersuchen in welchem Verhältnis die Sangiang am Flusse Djalajan zu den Menschen an den Ufern des Flusses der Welt stehen. Wir haben bereits gesehen, dass die beiden Brüder Maharadja Sangen und Maharadja Buno sich nach einem Zweikampfe getrennt haben. Maharadja Sangen, der schwächere und unterlegene, blieb in der Oberwelt zurück, Maharadja Buno, der stärkere und der Sieger, verliess die Oberwelt und liess sich am Ufer des Flusses der Welt (also in unserer Welt) nieder. Es handelt sich also um zwei Stammhälften, die sich räumlich geschieden haben, aber die doch immer wieder gemeinsam handelnd auftreten. In der Oberwelt blieb zurück die Stammhälfte, die den matrilinealen Aspekt der Gemeinschaft darstellt und mit der Unterwelt assoziiert ist. Sie steht in einem dienenden Verhältnis zu der andern Stammhälfte. Sie tritt bei allen Handlungen helfend auf. Der Name Maharadja Sangen sagt uns auch, dass diese Stammhälfte im Besitze der Stammythen ist die bei den wichtigen Ereignissen im sozialen und oekonomischen Leben des Stammes zum Heile der ganzen Gemeinschaft und des ganzen Kosmos rezitiert werden müssen. Wir wissen von andern Völkern 289 dass diese Rezitation oft durch die andere Stammhälfte geschehen muss. An den Ufern des Flusses der Welt (also auf dieser Welt) wohnt die andere Stammhälfte, die den patrilinealen Aspekt der Gemeinschaft darstellt und mit der Oberwelt assoziiert ist. Das zeigt uns der Name Maharadja Buno und sein Besitz des tötenden Eisens, mit dem er Maharadja Sangen überwunden hat. Maharadja Buno führt auch die Kriege. So wie im sozialen und kulturellen Leben die beiden Stammhälften in dieser Welt bei wichtigen Handlungen und Ereignissen immer gemeinsam auftreten, so treten auch bei diesen gleichen Handlungen die beiden Stammhälften des Maharadja Sangen und Maharadja Buno zusammen auf (die beiden Stammhälften sind dann nach dieser kosmologischen Klassifizierung eingeteilt, eine Stammhälfte stellt Maharadja Sangen und die andere stellt Maharadja Buno dar) um dadurch das Heil der Gemeinschaft, des Kosmos und auch des Individuums zu verbürgen und zu fördern. Es werden also durch die Balian und Basir nicht Geister aufgerufen und auch nicht Ahnen, sondern die andere Stammhälfte mit der man, darauf wird in den Texten immer mit besonderem Nachdruck gewiesen, die gleichen Ahnen hat. 


\section{d. Die Balian und Basir}

Die Mittler zwischen den Sangiang und Menschen, besser gesagt zwischen den beiden Sangianggeschlechtern des Maharadja Sangen und Maharadja Buno, sind die Balian und Basir.

[Es folgt im MS. ein Passus der vom Verfasser schon in seinem „Die Gottesidee der Ngadju Dajak in Süd-Borneo“. Leiden 1946. S. 60-65 (englische Uebersetzung: „Ngadju Religion. The Conception of God among a South Borneo People“. Haag 1963. S. 53-57) veröffentlicht worden ist und deshalb hier nicht aufgenommen wird.]

Wir haben nun über die religiöse Stellung und Funktion der Balian und Basir zu sprechen. Ueber die Kandidaten, die dafür verfügbar gestellt wurden schreibt Hardeland (W. B.), dass vor allem junge schöne Sklavenmädchen dazu ausersehen wurden und Schwaner (Borneo I. Pag. 185) teilt uns ausführlicher mit: „De Bilian's worden reeds van de vroegste jeugd af an voor hare bezigheid opgeleid. Vrijheid van wil en neiging zijn noodzakelijke vereischten om in den stand der Bilian's te treden. Dikwerf geeft zich de bestemming van een kind voor dezen stand reeds vroegtijdig te kennen door zekere zenuwachtige ziekten, gedurende welke hetzelve weinig of bijkans in het geheel geen voedsel tot zich neemt, en zeldzame bovennatuurlijke dingen ziet en verhaalt".

Es kann auch vorkommen, dass sich ein Sangiang einem Mann oder einer Frau, sei es im Traum oder bei einer persönlichen Begegnung, offenbart und ihnen die Mitteilung macht, dass er sie im Verkehr mit den Menschen gerne als Mittler gebrauchen und sich während der religiösen Handlungen in ihnen inkorporieren möchte. Als eine der wichtigsten Vorbedingungen zu diesem Amte, sehen wir bei den meisten Dajakstämmen die psychische oder psychopathologische Veranlagung der Männer und Frauen die als Kandidaten in Frage kommen. Am Katingan kann eine Frau nur dann Balian werden, wenn sie bereits einmal psychisch erkrankt war oder psychische Störungen hatte. Darin sieht man eine doppelte Anweisung, dass diese Person für dieses Amt nun bestimmt worden sei. Der Sangiang, der diese Psychose hervorgerufen hat, will damit anzeigen, dass er sich in dieser und keiner andern Person inkorporieren wolle und sich deshalb von ihr, durch das Mittel der Psychose, auch bereits Meister gemacht habe. Ferner sieht man in der Psychose auch einen Beweis, dass sich die Seele dieser Person leicht mit der des Sangiang vertauschen lässt, wozu sich aber die Bedingungen nicht in einer bereits vorhandenen Anlage fanden sondern durch den Sangiang geschaffen worden waren. Der Dajak 
sieht diese Personen, ob sie dann Frauen oder Männer seien, nicht als Psychopathen welcher Art dann auch, und es ist auch gut wenn wir bei der Interpretation dieser Erscheinung den Nachdruck ebenfalls nicht auf die psychischen Abweichungen legen und sie nicht psychologisch zu erklären versuchen oder mit ähnlichen Erscheinungen aus der europäischen Psychopathologie, Psychotherapie oder Religionspsychologie konfrontieren. So lehrreich und interessant diese Erklärungen und Versuche auch sein mögen, so haben wir für die ethnologische Untersuchung des Phänomens auszugehen von der dajakischen Vorstellungswelt, von der Stellung und Funktion der Balian und Basir in ihrer eigenen Religion und Kultur, und von ihrem Verhältnis $z u$ den Sangiang. Das ist nicht immer geschehen. Sehr oft liess man sich bei der Interpretation dieser Erscheinung durch sogenannte bekannte „Analogien“ aus dem europäischen Geistesleben leiten. Aber gerade davor hat sich der europäische Untersucher zu hüten. Wir haben dazu vor allem auch zu bemerken, dass psychopathologische Störungen eines Individuums an sich noch nicht genügend sind und dieses Individuum auch noch in keiner Weise zum Amt der Balian oder des Basir prädisponieren. Sie bilden selbst auch nicht überall die Vorbedingungen, denn es muss zu diesen psychischen Störungen auf alle Fälle dann noch hinzukommen, dass sie deutlich erkannt werden als solche die verursacht wurden durch einen Sangiang, der dadurch deutlich seinen Willen und Wunsch $z \mathfrak{u}$ erkennen gab, dass er sich im Verkehr mit den Menschen dieser und keiner andern Person bedienen wolle. Nicht jeder irgendwie psychisch leidende und gestörte Mensch (es gibt bei den Dajak ja sehr viele Psychopathen), ist nun dadurch auch a priori prädisponiert für das Amt der Balian und Basir und andererseits ist auch nicht anzunehmen dass bei den Ngadju Dajak nun ausgerechnet alle ,,jungen, schönen Sklavenmädchen“, die zu diesem Amt bestimmt und dafür ausgebildet wurden, psychopathologisch veranlagt gewesen seien. Man kann deshalb von den Balian und Basir nicht einfach sagen, dass sie durch ihr besonderes psychisches Vermögen im Stande seien als Medium aufzutreten. Es geht hier in erster Linie nicht um ein psychisches Vermögen und nicht um eine Anlage, sie bleiben insofern sekundär, weil primär ein oder eine Sangiang zuerst über diese Person verfügen musste. Erst darnach zeigen sich auch die Gaben, die einen deutlichen Beweis bilden, dass diese Person von einem (einer) Sangiang zum Werkzeug und Mittler auserwählt und ausgesondert worden sei. Der Ausübung des Amtes geht immer zuerst eine deutliche Berufung voraus und erst nach der Berufung folgt der 
Beruf. Wir können mit Van der Leeuw (Phänomenologie der Religion, Tübingen 1933. Pag. 200) auch nicht ohne weiteres sagen: „Auf jeden Fall aber ist das Wissen der Medizinmänner (V.d. L. unterscheidet nicht scharf zwischen Medizinmänner, Schamanen und Priester) eine ihnen überlegene Macht. Sie kann von Vater auf Sohn, von Lehrer auf Schüler übertragen werden, sie lässt sich in langwierigen Uebungen ,ertanzen“, sie kann aber auch direkt von einem Dämon stammen". Wissen kann man übertragen, man kann die Texte und Mythen natürlich lernen, das geschieht auch durch manche Dajak, aber dadurch allein wird man nie und nimmer eine Balian oder ein Basir, weil auch das Wissen an sich noch nicht zum Amt prädisponiert, denn Wissen allein ist noch nicht Macht, die erste Bedingung bleibt die Berufung. Man kann die Macht auch nicht ertanzen, denn man erwirbt sich die Macht nicht, sie bleibt immer ein freies Geschenk. Es ist in diesem Zusammenhang auch besser wenn wir nicht von Macht sprechen, sondern von der Berufung, denn nur diese allein macht den Menschen zum Mittler und sondert ihn zum Berufe aus. Das Amt der Balian ist bei verschiedenen Stämmen (z.B. den Olo Maanjan) erblich, aber diese Erblichkeit findet ihre Ursache nicht in einer Uebertragung von Macht von Vater auf Sohn oder Mutter auf Tochter, sondern wieder ausschliesslich in der Berufung durch die Sangiang, die in diesem Falle eine Person oder ein Geschlecht turon manuron (von Geschlecht auf Geschlecht, von Kind auf Kindeskind) in dieses Mittlerverhältnis berufen haben. Die Balian und Basir bringen sich selbst auch nicht in Ekstase oder in einen Trancezustand um dadurch mit der numinösen Welt in Verbindung zu treten und man kann deshalb auch nicht mit Van der Leeuw (a.a.O.) sagen: „Die Mächtigkeit der Schamanen beruht auf der Ekstase, in die sie sich hineintrommeln und -tanzen“. Sie besitzen weder die Mächtigkeit sich in Ekstase zu trommeln und zu tanzen, noch die Mächtigkeit der Ekstase selbst, sie besitzen nur die Berufung der Sangiang, und diese Berufung ist kein Besitz sondern eine Gabe. Sie besitzen keine Mächtigkeit sondern sie gehören einem Mächtigeren an. Und ihre ganze Möglichkeit besteht darin, dass sie, aufgrund ihrer Berufung, die Sangiang bitten können an den religiösen Handlungen teilzunehmen und diese selbst zum Heile der Gemeinschaft und des ganzen Kosmos auszuführen. Aber auch diese Möglichkeit ist immer wieder Gabe und bei ihrer religiösen Tätigkeit sind die Balian und Basir mehr Erleidende als Handelnde, denn sie selbst handeln ja nicht, der Sangiang handelt in ihnen, weil er an ihre Stelle tritt. Weder bringt sich die Balian oder der Basir bei den Ngadju 
selbst in Ekstase, noch werden sie von andern in diesen Zustand gebracht. Alle Mittel (Weihrauch, Trommeln, Tanz, Gesang, Gong), die vor dem Einfahren der Sangiang in die Balian oder Basir gebraucht werden, dienen nach den Texten nicht der Herbeiführung der Ekstase, sondern sie dienen der Aufrufung und Herbeilockung der Sangiang und sie sind auch speziell $\mathbf{z u}$ diesem $Z$ wecke den Priestern von den Sangiang selbst geschenkt worden. Die Möglichkeit der Aufrufung der Sangiang liegt nie beim Menschen selbst und auch nie in menschlichen Mitteln, sondern ausschliesslich in den Gaben der Sangiang, die sich selbst zuerst geben um empfangen werden zu können. Bei dieser Interpretation halten wir uns streng an die Texte selbst, auf die ich hier auch verweise (siehe den Abschnitt: die Sangiang fahren in die Balian ein).

Ist man von einem (einer) Sangiang zur Balian oder zum Basir auserwählt worden, sei es durch die Psychose, durch einen Traum oder eine persönliche Berufung bei einer Begegnung, dann begibt man sich zuerst zu einem (einer) Upon Balian in die Lehre. Das gleiche gilt natürlich auch für Männer und junge Mädchen, die sich für dieses Amt zur Verfügung gestellt haben oder die dazu bestimnt wurden. Bei ihnen zeigt es sich dann während der Lehrzeit ob sich ein Sangiang in ihnen inkorporieren will oder nicht, denn ohne Berufung bleibt auch dieser Unterricht durchaus wirkungs- und machtlos. Die Lehrzeit dauert meistens längere Zeit, oft selbst Jahre. Gegen eine angemessene Entschädigung lässt man sich von dem (der) Upon Balian in die Religion, die notwendigen Texte und Mythen und Handlungen und in die Struktur der Ober- und Unterwelt einführen. Man begleitet den (die) Upon Balian zuerst $z \mathfrak{u}$ allen Handlungen, die ihm (ihr) aufgetragen worden sind und tritt dabei als Panombah (Beantworter) oder als Panggapit (der in Range der nächste ist) auf. In dieser untergeordneten Stellung hat man die Aufgabe, die Trommeln zu schlagen, die Tänze mitauszuführen, bei allen Handlungen zu helfen und die Worte des (der) Upon Balian zu wiederholen (siehe das Vorwort). Beherrscht man die notwendigen Texte, die alle sehr umfangreich sind, kennt man die Struktur der Ober- und Unterwelt und kann man die verschiedenen priesterlichen Handlungen selbständig ausführen, dann tritt man aus der Lehre aus und ist selbst zu einem (einer) Upon Balian geworden, der (die) wieder eine Anzahl Schüler um sich sammelt. Meistens aber beschränkt man sich für die Erlernung dieses Berufes nicht nur auf einen Lehrmeister (-in), sondern begibt sich zu verschiedenen Upon Balian und Basir in die Lehre um das 
ganze priesterliche Wissen so umfassend wie möglich $z \mathfrak{u}$ lernen. Johannes Salilah erzählt von mehr als zehn Lehrern, bei denen er in der Lehre gewesen sei. Das ist deshalb notwendig, weil heute kein Priester mehr das ganze religiöse Wissen und alle priesterlichen Handlungen beherrscht und auch auf diesem Gebiete eine Spezialisierung besteht, die wahrscheinlich immer bestanden hat, was sehr wahrscheinlich gemacht wird durch die soziale und religiöse Organisation und Aufgabenverteilung innerhalb des ganzen Stammes.

Die Balian und Basir sind die von den Sangiang berufenen und ausgesonderten Mittler zwischen den beiden Stammhälften der mythischen Vorzeit (d.h. zwischen Maharadja Sangen und Maharadja Buno), ohne dass sie nun speziell einer von beiden angehören würden. Kosmologisch klassifiziert stehen sie zwischen Oberwelt und Unterwelt und sie gehören hier ebenfalls beiden an. Ein deutlicher Beweis dafür ist uns die Impotenz oder Bisexualität der Basir. Sie sind Mann und Frau, Oberwelt und Unterwelt, die eine Stammhälfte und auch die andere Stammhälfte. Wenn die Balian und Basir bei den priesterlichen Handlungen auftreten, sei es gemeinsam oder getrennt, dann nennt man sie nach den Texten mit dem stets wiederkehrenden Fachausdruck tambon haruei bungai (die Wasserschlangen, die verzwillingt sind mit den Nashornvögeln) und wir haben bereits gesehen, dass im kosmologisch/totemistisch klassifizierenden System der Ngadju die Wasserschlange die Unterwelt- und der Nashornvogel die Oberwelt repräsentiert, und dass mit ihnen auch die beiden Stammhälften assoziiert wurden, von denen die eine den Namen Tambon und die andere den Namen Bungai trägt. Von hier aus gesehen wird uns auch die Prosti. tution der Balian und die Päderastie der Basir deutlich. Sie tragen primär sakralen Charakter und bedeuten das Einswerden des Menschen mit der heil- und friedvollen kosmischen Totalität und das Anteil bekommen an ihr. Und von hier aus gesehen wird es uns auch verständlich, dass die Mütter ihre jungen Söhne aufforderten mit einer Balian in Verkehr zu treten und dass es als eine Schande angesehen wurde wenn man als Mann keine Beziehungen zu einer solchen besass und es wird auch mehr als nur wahrscheinlich, dass früher der Veranstalter eines Opferfestes die Nacht mit der Balian verbringen musste.

Die Funktionen der Balian und Basir nennt man balian oder basangiang, wobei die speziellen Handlungen noch mit besonderen Namen näher umschrieben werden. Die Kleidung der Balian besteht bei festlichen Gelegenheiten und bei der Ausübung ihres Berufes, aus einem Kopftuch, einem langen roten Badju 291 und einem hellblauen 
Sarong. ${ }^{292}$ Die Arme sind geschmückt mit kupfernen Ringen, die, einer neben dem andern aufgereiht, oft den ganzen Arm bedecken. Um die Handgelenke liegen Armbänder von Achaten, blauen Glasperlen und Balususchnecken. Auf der Brust wird der goldene (heute meistens messingene) Santagi getragen (siehe Erklärung 169). Die Basir tragen die gleichen Kleider wie die Balian, nur läuft das Kopftuch in eine Spitze aus.

Bei der Ausübung der priesterlichen Funktionen setzen sich die Panombah oder Panggapit im Festhaus auf eine niedere Bank (katil) und der (die) Upon Balian lässt sich vor dieser Bank auf einer geflochtenen Matte nieder. In der Hand halten sie eine kleine Trommel (katambong, sambong), die etwa $80 \mathrm{~cm}$. lang ist. Ein Trommelfell von Schlangenhaut befindet sich nur auf der einen Seite der hohlen Trommel. Diese Trommel wird ausschliesslich von den Balian und Basir gebraucht. Die Trommel (gandang) der Männer und des Tukang Tawur ist viel grösser und etwa 1,50 m. lang.

Die Gesänge der Balian und Basir werden tandak oder karunja genannt. Man begleitet sie mit der Trommel. Man kennt verschiedene Melodien, die in den Texten näher bezeichnet werden. Die Seele des Gesanges (Ngadju: gana; Basa Sangiang : labata, siehe die Erklärung 279) reist in die Oberwelt und begleitet die Seelen des Streureises (behas tawur). Der Streureis verwandelt sich in sieben Jungfrauen, die für ihre Reise nach den Dörfern der Sangiang einen geflochtenen Frauenhut als Fahrzeug benützen (lasang bulau daren tanggoi). Wenn die Sangiang aus ihren Dörfern herabgestiegen und im Festhaus angekommen sind, fahren sie in die Balian ein. Der Hauptsangiang (z.B. Dohong Mama Tandang) fährt in den (die) Upon Balian ein und die Helfer des Sangiang fahren in die Panombah oder Panggapit ein. Dieses Einfahren der Sangiang in die Herzgrube der Balian oder Basir nennt man nidjak marempai bandong lasang (Betreten des Bandongbootes; bandong: jemand mit dem man Unzucht getrieben hat, ein Ausdruck der sowohl auf den Mann als die Frau angewendet werden kann; habandong: Unzucht treiben, ehebrechen. Bandong lasang ist auch der Name für das bauchige Frauenboot). Die Balian und Basir, die Frauen der Sangiang, werden mit einem Boot verglichen in das die Sangiang einsteigen. Man nennt dieses Einfahren der Sangiang auch mangumpang (kumpang: die Scheide; mangumpang: etwas in eine Scheide stecken. Wir haben gesehen, dass mit dem Ausdruck kumpang auch der Leib des Menschen angedeutet wird). Die Sangiang beschauen die Balian und Basir also als ihre Scheiden, oder körperliche Hüllen, 
in die sie einfahren. Während dieses Einfahrens werden die Seelen ausgetauscht. Die Seele der Balian und Basir erhebt sich in die Dörfer der Sangiang und die Seele der Sangiang senkt sich in die Körper der Balian und Basir ein. Während die Sangiang einfahren, beginnen die Balian und Basir zu zittern. Der ganze Vorgang wird in unseren Texten ausführlich und plastisch beschrieben. Beim Herausfahren der Sangiang treten wiederum die gleichen Erscheinungen auf.

Im Verkehr mit den Sangiang bedienen sich die Balian und Basir einer eigenen Sprache, der sogenannten Basa Sangiang. Wir haben über sie bereits im Vorwort gesprochen. Ist der Sangiang in die Balian oder den Basir eingefahren, dann gibt er sich natürlich so wie er in Wirklichkeit ist. Balian und Basir sind ja nicht mehr sich selbst, sie haben ihre körperliche Hülle den Sangiang geliehen und diese sind nun an ihre Stelle getreten und so ist es auch durchaus begreiflich, dass sie sich nun auch ihrer eigenen Gebärden und Ausdrucksformen bedienen und sich nicht an die der Balian und Basir anpassen. Ein halblahmer Sangiang bleibt eben halblahm, auch nachdem er in die Balian eingefahren ist, ein rasch auffahrender Sangiang verleugnet seinen Charakter ebenfalls nicht und ein Sangiang mit einer tiefen Männerstimme nimmt nicht plötzlich die helle Frauenstimme einer Balian an und ein stotternder Sangiang spricht nicht plötzlich korrekt, sie alle treten durchaus so auf wie sie sind.

Seit etwa dreissig Jahren findet man bei verschiedenen Balian und Basir zeichnerische Darstellungen der Oberwelt und der Unterwelt. Sie sind offenbar (nach mündlichen Mitteilungen) zuerst angefertigt worden von Singa Patih Massaid Singkoh, einem früheren Damang (Adathaupt) am mittleren Kahaian. Dieser Mann, von Geburt ein Ngadju, trat in seinen späteren Jahren zum Islam über aber blieb auch als Mohammedaner einer der berühmtesten heidnischen Priester seiner Zeit, der sehr viele Schüler hatte. Ein grosser Teil der Balian und Basir rühmt sich wenigstens auch heute noch, ihn als Lehrmeister gehabt zu haben. Es scheint, dass Massaid Singkoh seinen Schülern in Unterricht die Oberwelt und Unterwelt plastisch dargestellt hat um ihnen dadurch den grosse Anforderungen stellenden Unterricht zu erleichtern und die Struktur dieser beiden Welten besser erklären zu können. Diese, anfänglich sehr einfachen Zeichnungen wurden später oft abgezeichnet und ergänzt und wir besitzen sie nun in zahlreichen Ausführungen, die z.T. viel Kunstsinn verraten. Einzelne Priester gebrauchen sie heute auch aus mnemotechnischen Gründen bei der Rezitation ihrer umfangreichen, oft Nächte lang zu singenden Texte. 
Sie legen bei dieser Gelegenheit die Zeichnung auf dem Fussboden vor sich nieder und orientieren sich während des Singens der Texte an dem zurückzulegenden Weg der Seele des Gesanges oder der Frauen des Streureises und sie können dadurch eher Verwechslungen und Auslassungen vermeiden, was ausserordentlich wichtig ist. Die Gesänge sind ja heilig und es dürfen bei ihrer Rezitation keine Fehler gemacht werden, weil sonst die Seelen des Gesanges oder die Frauen des Streureises ihr Ziel nie erreichen würden. Zudem würde die Nachlässigkeit des Priesters durch die Sangiang bestraft und er würde während der Rezitation plötzlich in Ohnmacht fallen oder von einem Schlaganfalle getroffen werden. (Wir verweisen für die Karten auf die Abbildungen in diesem Buch und auf meinen Aufsatz: Die Vorstellungen der Ober- und Unterwelt bei den Ngadju Dajak von SüdBorneo. Cultureel Indië 4, 1942. Pag. 73-81.)

Balian finden wir auch bei andern Dajakstämmen. Von den Balian bei den Ot Danum erzählt uns bereits Schwaner (Borneo, II. Pag. 76) : „De Ot Danum hebben geene Bilian's, zoo als de Ngadju. De bezigheden der Bilian's worden door de vrouwen en dochters der rijken waargenomen, en bepalen zich tot het genezen van zieken, door het uitdrijven der kwade geesten, die als de oorzaak daarvan worden beschouwd, tot het overgeleiden der zielen naar de verblijfplaatsen der overledene voorouders, en tot gebeden aan de goden om voorspoed en rijkdom (balako ontong). De gave van zoodanige handelingen te kunnen verrigten, wordt verkregen door dat een Sangsang (Schwaner nennt die Sangiang irrtümlich immer Sangsang) in het ligchaam der Bilian overgaat. Zoo lang als deze toestand duurt heeft zich de vrouw van alle vleeschelijke gemeenschap met haren man te onthouden".

Was Schwaner uns hier mitteilt gilt für die Ot Danumstämme auch heute noch. Auch am Katingan sind die Balian gewöhnlich Frauen, die verheiratet sind und die sich in nichts von den andern Frauen unterscheiden. Sie besitzen nicht ganz den Charakter der Balian bei den Ngadju, denn sie sind nicht auch noch Sängerinnen, Tänzerinnen und Prostituierte und geben sich bei ihren Handlungen auch nicht der Unzucht hin. Diese letzte Bemerkung haben wir allerdings etwas vorsichtig aufzunehmen, denn bei den Opferfesten, die mit grossen Trinkgelagen verbunden sind, kommt es meistens auch zu sexuellen Exzessen die offenbar erlaubt sind, weil sie nicht strafrechtlich verfolgt werden. Auch diesen Exzessen schreiben wir die gleiche Ursache und Bedeutung zu wie der sakralen Prostitution der Balian und der Homosexualität der Basir. 
Wir haben gesehen, dass die Balian und Basir nur mit den Sangiang in Verkehr treten und dass sie nur die Mittler sind zwischen den beiden Stammhälften des Maharadja Buno und Maharadja Sangen. Mit den toten Ahnen treten sie nicht und nie in Verkehr, das ist ausschliesslich Sache des Tukang Tawur. Dieser Tukang Tawur ist meistens ein alter erfahrener Mann, oft ein Familienhaupt, oder ein Dorfältester oder Dorfhaupt, braucht es aber nicht speziell zu sein um dieses Amt bekleiden zu können. Nur er ruft die toten Ahnen vom Ahnenheiligtum (tadjahan) auf und sie erscheinen dann in der Gestalt des Antang Ganan Tadjahan (siehe die Mythe: Vom Ursprung der Hantuen am unteren Katingan und die Erklärungen 137 und 234). Er ruft auch die Ahnen auf, die ohne zu sterben in die Gemeinschaft der Geister aufgenommen worden sind (gaip) und auch die Ahnen, die sich in Wasserschlangen (naga) verwandelt haben (siehe die Mythe von der Naga Andoh). Die Tätigkeit des Tukang Tawur beschränkt sich ausschliesslich auf die Aufrufung der toten, entrückten und verwandelten Ahnen, erstreckt sich aber nicht auf die Aufrufung der Sangiang. Seine religiöse Funktion hat mit ihnen nichts zu tun. Müssen die Sangiang und die Ahnen aufgerufen werden, dann geschieht das erste durch die Balian und Basir, das zweite aber durch den Tukang Tawur.

\section{Vorbereitungen für das Tantolak matei}

\section{A. Vor dem Haus}

Amon oloh handak mondok Wenn die Leute sich setzen wollen balian tantolak matei palus (d.h. veranstalten wollen) um die magah liau akan eka Balo Balianhandlungen vorzunehmen womit Indu Rangkang, te djetoh der Tote (und alle seine schädlichen kare ramo idje akan inatap Einflüsse) weggeschoben werden soll akan gawi te: und um gleichzeitig auch die Liau nach dem Orte der Balo Indu Rangkang zu führen, dann sind diese die Dinge, die für diese Arbeit bereit gemacht werden müssen :

1. Oloh mampendeng idje 1. Die Leute richten zuerst einen lundjo, indahang idje kaju Speer auf und ergänzen diesen mit intu petak, hila ngawa hedjan. einem hölzernen Stabe, beide werden 
Intu lundjo ttg. intu kaju oloh maniring uei, kira-kira idje Meter kapandjang,e. Uei te indjarat hapamontong intu lundjo ttg. intu kaju. Hete oloh manggajong udju dawen sawang. Intu petak, darah lundjo te, oloh mingkes batu idje, darah batu oloh mampendeng idje tampulak humbang imuat danum bewei.

Tumon te injewut oloh ara,e: tarinting dawen sawang.

Oloh mampendeng tarinting dawen sawang helo bara mondok nampara balian.

Guna: Bele kare taloh handiai tame huma mandaur, mangapehe, mampatudjah oloh huma metoh gawi te. Kare taloh papa handiai balang tikas tarinting dawen sawang te.

Rima,n tampulak humbang: Kilau tasik lombah tt. handalem gitan taloh papa sampai dia olih inimpah awi,e.

Rima,n batu: Kilau bukit batu idje matep sampai djaton taragitan huma, kalote tampajah taloh papa. eingesteckt in der Erde, etwas unterhalb der Haustreppe.

Am Speer und am Holzstab spannen die Leute ein Rotanseil auf, das ungefähr ein Meter lang ist. Dieses Rotanseil wird festgemacht auf beiden Seiten, (d.h. am Speer und am Holzstab). An diesem Seil hängen die Leute dann sieben Sawangblätter auf. Auf der Erde, neben dem Speer legen die Leute einen Stein nieder, neben dem Stein richten sie einen Bambusköcher auf, der nur mit Wasser gefüllt ist.

Aus diesem Grunde nennen die Leute diese Absperrung: die Reihe (oder auch das Seil) der Sawangblätter. (Siehe die Abbildung im Text.)

Die Leute richten das Seil der Sawangblätter auf, bevor sie mit den Balianhandlungen beginnen.

Der Zweck ist: Auf dass es nicht geschehen könne, dass alle (bösen) Geister das Haus betreten um seine Bewohner während der Handlungen zu stören, zu quälen oder in Ohnmacht fallen $z u$ lassen (was sehr oft geschieht wenn bei den Handlungen oder Rezitationen Fehler gemacht werden). Alle schlechten Geister sehen von ihrem Vorhaben ab, wenn sie bei der Sperre der Sawangblätter angekommen sind. Die Bedeutung des Bambusköchers ist: Von den schlechten Geistern wird es als ein breites und tiefes Meer angesehen und es ist ihnen nicht möglich dasselbe $z \mathfrak{u}$ überqueren.

Die Bedeutung des Steines: Wie ein Steinberg, der das ganze Haus verbirgt, so wird der Stein von den schlechten Geistern gesehen.293 
Rima,n dawen sawang: Awi taloh papa puna mikeh guris sampalaki idje aton intu dawen sawang.

Tuntang ampi,n dawen sawang kilau isi,n lundjo 295 idje batadjim ttg. banjihi.
Die Bedeutung der Sawangblätter ist: Man hängt sie deshalb auf, weil sich die schlechten Geister vor dem Zeichen des Kreuzes, das auf die Sawangblätter gezeichnet wurde, fürchten.294 Und die Form der Sawangblätter gleicht der einer Speerspitze, welche spitzig und sehr scharf ist.

\section{B. Im Hause}

Helo bara balian mondok, djetoh kare ramo idje inatap huang huma:

\section{Sangko,n hambaruan.}

Taloh huange: behas, hampatong palawi, manas, sipa, roko, mangkok korik, eka,e behas tawur ttg. tambaran 296 (puron 297 idje hindai indare).

Taloh huang mangkok tawur: behas, sair humbang idje akan salentup, rotik dawen kaju idje akan papas huang gawi te, sair hampatong uei, henda isut, undus isut, daha, n manok isut haliai hapan manjaki tawur.

Isi,n manok idje saki,n tawur palus impakasak akan panginan Sangiang. Kareh impalua,e amon andau djari
Bevor sich die Balian setzen (auf eine kleine Bank) um ihre Handlungen auszuführen, werden im Hause folgende Dinge bereit gemacht:

1. Das Gefäss der Seele (d.h. des Seelenreises).

In ihm befinden sich folgende Dinge: enthülster Reis, ein Schnitzbild mit menschlichem Angesicht von Palawiholz, Kausel, Zigaretten, ein kleines Gefäss in dem der Streureis liegt, Streifen für eine Puronmatte, die noch zu flechten ist.

In dem kleinen Gefässe, in dem der Streureis liegt, befinden sich noch folgende Dinge: enthülster Reis, Spähne des Bambus, der zum Knallen dient, kleine ausgebrochene Stücke der Blätter, die man für den Besen braucht, den man zu diesen Handlungen nötig hat, Abschabsel vom Schnitzbilde von Rotan (siehe unter 7), ein wenig Gelbwurz (Curcuma), ein wenig Oel und ganz wenig Hühnerblut um mit ihm den Streureis zu bestreichen.

Das Fleisch des Huhnes, dessen Blut zur rituellen Bestreichung des Streureises gebraucht wird, wird sogleich gekocht als Speise für die Sangiang. 
kaput.

2. Humbang akan salentup.

3. Idje tampong papas. Kare dawen kaju idje akan papas te: dawen tangaring, dawen pilang, dawen taberau, dawen hadjandjalau, dawen sawang gagar.

Djete uras imeteng djadi idje kapeteng andak darah peteng humbang salentup intu bentok huma, hila baun oloh idje akan mondok balian kareh.

4. Due mangkok tarois, eka behas tambak. Idje tambak akan Sangiang, idje tambak akan Ambon Rutas. Huang tambak due te aton: behas, roko, sipa, bungkos hambaruan.

5. Idje mangkok korik, sarangan daha,n manok.

6. Telo kaliong 300 lenge manas sambelom 301 akan genep biti,n ewen telo oloh balian.
Wenn die Nacht angebrochen ist, wird es zum Hause herausgebracht. 298

2. Humbang zum Knallen (wird erbeten vom Tandjong Elang Salentup, Luwok Humbang Rendlan Tingang am Flusse Djalajan. Siehe oben).

3. Ein Besen. Die Blätter welche für diesen Besen verwendet werden sind die folgenden: Tangaringblätter, Pilangblätter, Taberaublätter, Hadjandjalaublätter und Sawang Gagarblätter 299 (alle diese Blätter werden erbeten vom Tandjong Tampong Papas, Luwok Tundon Kalingking am Flusse Djalajan. Siehe oben).

Diese Blätter werden alle zusammengebunden, sodass ein Bund entsteht der niedergelegt wird neben dem Bü.1del der Bambus zum Knallen in der Mitte des Hauses auf der Vorderseite (d.h. im Angesicht) der Lente (der Balian und Basir), welche sich später niedersetzen zur Ausübung der priesterlichen Handlungen.

4. Zwei Taroisgefässe, die als Ort für den aufgehöhten enthülsten Reis dienen. Eine Partie des aufgehöhten Reises ist für die Sangiang bestimmt, die andere Partie für die Ambon Rutas. In diesem aufgehöhten Reis befinden sich: enthülster Reis, Zigaretten, Kausel und Seelenbündel (siehe die Erklärung unten und auch das Register).

5. Eine kleine Tasse, die als Gefäss dient für das Hülnnerblut.

6. Drei Stränge Perlen, für jeden der drei Balian einen. 
7. Hampatong uei, kapandjang,e korang-labih $10 \mathrm{~cm}$. Hampatong te inampa are, tumon kare,e gagenep kola ain idje matei te. Hampatong te imeteng mandjadi idje kapeteng, ingkes,e darah peteng salentup.

8. Idje mangkok, huang,e aton: behas isut, roko, sipa.

Amon uras djari tatap, te upo,n balian ttg. panggapit,e mondok haretei. Tandipah ambo takolok,e injapau hapan benang ganto-gantong.

Amon ewen telo te djari rantep pondok,e, te oloh tempo,n pampatei 302 mameteng manas intu lenge gantau oloh balian ttg. oloh tempon pampatei mohos manjaki oloh balian hapan daha,n manok hajak hamauch, koa,e:

Mangat ikau dia haban pehe metoh gawi toh, dia balasut badarem, mangat auch tandak,m mait sampai lewu,n Sangiang Djalajan.

9. Oloh tempo,n pampatei manenga idje pisau akan gagenep biti,n oloh balian. Oloh
7. Schnitzbilder mit menschlichem Angesicht von Rotan, ihre Länge beträgt ungefähr $10 \mathrm{~cm}$. Diese Schnitzbilder werden in grosser Zahl angefertigt, nämlich eines für jeden Verwandten des Verstorbenen. Die Schnitzbilder werden zusammengebunden zu einem Bündel und dieses wird niedergelegt bei dem Bündel des Knallbambus.

8. Ein kleines Gefäss, in ihm befinden sich: ein wenig enthülster Reis, Zigaretten und Kausel.

Wenn alle diese Dinge bereit gemacht sind dann setzt sich der Hauptbalian mit seinen Helfern in einer Reihe (auf eine kleine Bank). Ueber ihren Köpfen, ziemlich hoch, wird ein Dach von Tuch gemacht, angebracht.

Wenn die drei sich nun nahe nebeneinander gesetzt haben, dann umbindet der Besitzer des Todes (der verantwortliche Veranstalter und Leiter dieser Handlung) das rechte Handgelenk der Balian mit Armbändern von Glasperlen und der Besitzer des Todes bestreicht die Balian mit Hühnerblut, indem er dazu sagt:

Auf dass du nicht erkrankest und nicht von Schmerzen getroffen werdest während diesen Arbeiten, auf dass dich nicht das Fieber befalle und dein Körper nicht heiss werde, auf dass der Schall deines Gesanges kräftig ertöne und ankomme im Dorfe der Sangiang am Flusse Djalajan (Fluss in der Oberwelt, siehe die Einleitung).

9. Der Besitzer des Todes übergibt jedem Balian ein Buschmesser (ein Schwert, mit einfachem Griff, das man 
balian manjambut pisau te ttg. mamangkit,e. Amon oloh balian djari mamangkit pisau te, te oloh tempo,n pampatei hamauch, koa,e:

Katekang senamang toh, katekang hambarua,m, mangat ikau dia haban pehe metoh gawi toh.

Maka amon djadi kalote, te due biti oloh balian mendeng, idje biti upo ttg. idje biti panggapit,e. Upo manandjong huang karong mimbit mangkok idje injewut nomor hanja.

Ie mahantok mangkok te intu gagenep takolok oloh tempo,n pampatei hajak hamauch, koa,e :

Rata lompat hajak mangkok toh kare karutas kapali, kare dahiang baja, kare taloh papa.

Amon djari ie mahantok mangkok te intu oloh tempo,n pampatei, te ie mahantok,e intu gagenep biti,n ewen idje balian te.

Amon djari, ie mimbit mangkok te akan bauntonggang huma. Ie maludja,e hantelo tingkat hajak mangarakop behas ttg. sipa idje aton huang mangkok te, te ie manawur,e balua huma hajak hamauch, koa,e : täglich gebraucht). Die Balian nehmen es in Empfang und beissen auf das Eisen (siehe Erklärung 136). Nachdem die Balian auf die Buschmesser gebissen haben, spricht der Besitzer des Todes, indem er sagt:

So wie die Härte des Eisens ist, so sei auch die Härte deiner Seele, damit du während der Ausführung der Arbeiten nicht in Krankheit fallest und nicht von Schmerzen gepeinigt werdest.

Aber wenn das auf diese Weise geschehen ist, dann erheben sich zwei der Balian, einer von ihnen ist der Hauptbalian, der andere ist einer seiner Helfer. Der Hauptbalian geht im Hause herum und trägt bei sich das Gefäss welches unter Nummer acht genannt wurde.

Mit diesem Gefäss berührt er alle Köpfe der Besitzer des Todes (es ist hier an alle Verwandten des Toten gedacht), indem er dabei spricht:

Es steigen nun in dieses Gefäss hinein alle unheilbringenden Nebel und alle Verbote, alle Vorzeichen und alle schlechten Geister.

Wenn es geschehen ist, dass er mit dem Gefäss die Besitzer des Todes berührt hat, dann berührt er mit ihm auch die Köpfe aller Balian (wobei die gleichen Worte wiederholt werden).

Wenn das geschehen ist, dann schreitet er mit dem Gefäss zur Türe des Hauses. Er bespuckt es dreimal und ergreift mit seinen Fingern gleichzeitig von dem Reis und Kausel welches sich in dem Gefäss befindet, dann streut er sie aus während er aus dem Hause schreitet und er spricht dabei : 
Ikau toh behas djadi baras Du Reis hier verwandelst dich in bulau, busong hintan akan Sandbänke von Gold und in Steinliau awang helo. bänke von Diamanten, welche bestimmt sind für die früheren Liau (d.h. für die Liau, die bereits nach dem Totendorf geleitet worden sind).

Ela ie maur-miro ikei. Toh giling pinang, roko,n tarahan akan keton liau kambe.

Amon hapus auch,e te ie palus mamedak 303 mangkok idje imbing,e sampai mangkok te pusit. Limbah te upo mules buli mondok eka,e helo.

Maka panggapit,e manandjong mangumbang huang huma, mahantok mangkok tawur intu gagenep takolok oloh idje aton melai huang huma.

Amon djadi, ie mimbit mangkok tawur mandjulok,e akan upo ttg. ewen balian mondok intu eka,e handak manampara balian.
Sie sollen uns nicht stören und uns nicht belästigen (während den Handlungen). Hier sind Reihen von Betelnüssen und Rauchwaren der Sklaven (d.h. Zigaretten), sie sind bestimmt für euch, die Liau, die Gespenster (d.h. für Liau die eines plötzlichen Todes gestorben sind und deshalb nicht nach dem Totendorfe geleitet werden sondern ruhelos umherschweifen müssen). Nachdem er dieses Spruchwort ausgesprochen hat, zerschlägt er klirrend das Gefäss, das er in seinen Händen hielt, sodass es zerbricht. Darnach wendet er sich um und kehrt wieder zurück und setzt sich auf seinen früheren Platz.

Sein Helfer aber geht noch weiter und er durchzieht das ganze Haus und er berührt mit dem Gefäss in dem der Streureis aufbewahrt wird die Köpfe aller Menschen welche sich im Hause befinden.

Wenn das geschehen ist, dann bringt er das Gefäss, das den Streureis enthält, wieder zurück und überreicht es dem Hauptbalian und die Balian setzen sich auf ihren Platz und sie wollen nun beginnen mit den priesterlichen Handlungen. 


\section{Räucherung und Oelung des Streureises, die Besingung seines Ursprunges und die Aufweckung der Reisseelen}

Während die Texte für die Vorbereitungen in gewöhnlichem Ngadju wiedergegeben wurden, folgen nun die Gesänge der Balian in der Basa Sangiang (Sangiangsprache). Zuerst wird der Reis mit Weihrauch geräuchert, der von verschiedenen Hölzern, die man in den Wäldern gesammelt hat, herrührt. Wirkungsvoll ist er aber nur deshalb, weil man das Weihrauchholz auch vom Flusse Djalajan in der Oberwelt erbeten hat und dieses durch die Sangiang überreicht wurde. Das Gelingen der ganzen Handlung hängt auch hier vom Zusammenwirken der beiden Stammhälften ab, aber auch vom Zusammenwirken von Oberwelt und Unterwelt. Die Handlung ist eine kosmische, das zeigt uns nicht nur die Räucherung, sondern auch die Abwischung des Reises und die Bestreichung mit Curcuma (Henda), der mit der Unterwelt assoziiert ist, und nit Oel, das mit der Oberwelt assoziiert ist. Die Ursprungsmythe des Reises ist nicht vollständig, sondern sie wird nur in kurzen Zügen erzählt. Die Bedeutung der Rezitation besteht darin, dass damit das Urgeschehen wiederholt wird. Der Reis wurde dem Menschen nicht nur als ein nützliches Nahrungsmittel gegeben, sondern auch als Mittler zwischen Priester und Alnen und zwischen Priester und Sangiang (siehe die Einleitung). Durch die Rezitation der Mythe und die Erzählung vom Verlaufe des Reisbaues wird gerade diese Sinngebung des Reises in den Mittelpunkt gerückt und für die vorzunehmende Handlung wirksam gemacht. Den Nachdruck dürfen wir dabei nicht, wie das oft geschieht, auf die Mächtigkeit des Wortes des Upon Balian legen. Dieses Wort ist nur insofern sein Besitz als es Geschenk der Sangiang ist. Und in dem Sprechen des Upon Balian tritt eigentlich nicht er selbst auf mit einem machtvollen Wort, sondern die Sangiang mit einer helfenden, heilvollen, errettenden Rede. Sie wiederholen das Urgeschehen und sie rufen die Reisseelen hervor, die nach der Oberwelt reisen um Hülfe zu holen für die bedrängten Menschen. Dass der Reis dazu gebraucht werden kann, findet seine Erklärung nicht in einem menschlichen Funde und einer menschlichen Möglichkeit oder Mächtigkeit, sondern immer nur in seiner Vorherbestimmung zu diesem Zweck durch die Oberwelt und Unterwelt beide. Streckt der Priester seine Hand aus nach dem Reis, dann ist er sich nicht seiner Mächtigkeit wohl aber dieser Gabe, die der Mensch nicht aus sich selbst besitzt, durchaus bewusst. Das zeigen uns auch 
die nun folgenden Texte, die wir in erster Linie so und nicht anders lesen müssen.

\section{A. Räucherung, Oclung und rituelle Bestreichung des Streureises}

Maka upo,n balian mimbing mangkok tawur hajak mamapui garo atawa manjan hapa manggaro mangkok tawur hajak hamauch, koa,e :

Inggaroku ikau toh behas hapan garo bulau idje bakalinda tingang, simak santi ngehet pahawang idje bakalampang tambon mangat ikau baterap gana,m sampai lewu,n Sangiang.

Amon hapus auch,e ie manusuh undus isut hundjun behas tawur hajak hamauch, koa,e:

Njalangkahku ikau toh behas hapan bangkang hanselan tingang, minjak runting padjahun burong, mangat ikau baterap tandok,m.

Amon hapus auch,e, ie mohos daha intu behas tawur hajak
Der Hauptbalian hält nun das Gefäss, das den Streureis enthält, in seinen Händen und er verbrennt etwas Garo oder Manjan ${ }^{304}$ um damit das Gefäss des Streureises zu beräuchern, indem er dabei spricht:

Ich beräuchere dich, o Reis, mit goldenem Weihrauch, welcher anzulocken vermag den Nashornvogel, mit duftendem Räucherwerk, das wie ein Wohlgeruch ist der von den Frauen ausgeht und der zum Auftauchen bringt die Wasserschlange (durch die Räucherung werden Oberwelt und Unterwelt aufgerufen um an der Handlung teilzunehmen und sie durch ihre Mitarbeit möglich zu machen. Wir sehen hier, dass der Weihrauch nicht dazu dient un eine Ekstase oder einen Trancezustand herbeizuführen), auf dass deine Seele weitsichtig und helle werde (eben durch die Mitarbeit von Oberwelt und Unterwelt beide) bis sie angekommen ist im Dorfe der Sangiang. Wenn er diese seine Rede beendet hat, giesst er ein wenig Oel auf den Streureis, indem er dazu spricht:

Ich bade dich jetzt, o Reis, in dem wirklichen Oele des Nashornvogels, ich salbe dich jetzt ein mit dem Oele, dem wohlriechenden Oele des Vogels (d.h. des Tingang), damit deine Augen helle werden.

Wenn er dieses Spruchwort beendet hat, dann bestreicht er den Streureis 
hamauch, koa,e:

Njakiku ikau toh tawur hapan darah manok darong tingang, imalasku ikau toh rabia sawong ambon hapan panggirih punoi rungkoi ambon, mangat ikau tau basaloh ampin oloh kalunen intu balai Sangiang, mangat ikau tau manonting raweiku, uka pandai balitam manambing tisoiku kabantokan sali Djalajan.

Limbah te upo,n balian manampara manandak tawur. Ie hamauch kabuat bewei hapan auch idje tarang, koa,e : mit Blut und spricht dazu:

Ich bestreiche dich jetzt, o Streureis, mit dem Blute des Huhnes, des Huhnes der Nashornvögel, ich wische dich jetzt ab, o goldenes Reiskorn, mit dem Stellvertreter, der genommen wird von dem Huhne der Höhe, 305 auf dass du dich verwandeln könnest in die Gestalt eines Menschen der Welt, dann wenn du angekommen bist im Hause der Sangiang, damit es dir möglich sei mein Wort $z \mathfrak{u}$ überbringen, auf dass es dir gelingen möge meine Rede $z u$ überreichen in der Mitte des Hauses der Djalajan.

Darnach beginnt der Hauptbalian den Streureis zu besingen. Er spricht mit einer Stimme die deutlich vernehmbar ist :

\section{B. Die Besingung des Ursprunges des Streureises}

Ehem behas hatarindjet Ehem (ein Ausruf), o Reis, vorsichtig gana,m, lunok ikau pakongan wecke ich auf deine Seele, der du tingang, pararugoh labata,m, ein Lunok bist, ein Wohnplatz des tapang ikal pasanan antang. Nashornvogels (d.h. der Reis ist ein Mensch, denn Lunok ist gleichbedeutend mit Mensch), ich berühre sanft deine Seele, du Baumstamm, der du ein Verkündiger bist des Antang (ein Bote seines Herrn, d.h. des Menschen der den Reis nun aussendet).

Ela ikau tarewen matei kalaNicht erschricke dich zu Tode, wenn boan djaringku, isen ikau du herausfällst aus meinen Fingern, kasabanen nihau kalaketan karahku.

Ela ikau manggare arep,m pandjandjuri bara usok lisong, isen ikau nansuwa ba- nicht werde bestürzt bis zum Sterben, wenn du herunterstürzest aus meiner Hand (beim Ausstreuen des Reises). Nicht sage von dir selbst aus, dass du hervorgekommen seiest aus der Brust des Reisstampfblockes, nicht behaupte 
lita,m panantekei bara lawi,n tapang.

Ela ikau mananggare arep,m kalabien supak ikei pantai danum kalunen, isen ikau manansuwa balita,m kadjowong gantang ikei luwok kampongan buno.

Ela ikau manggare arep,m hataburan djarin anak antang tabela dia tawan kabaloman tapas, isen ikau manansuwa balita,m hatatajan karah buso rinjik idje dia handong tawan kamara ambo.

Puna nampaluaku biti,m bara siam 308 sandehen parong, nampahandjongku balita,m bara bateran 309 bintang penjang, bara bukong sambas lalang $\mathbf{3 1 0}$ rangkang haramaung.

Djari nangkaradja ikei pantai danum kalunen bitim, babalai ikau pinggan randan njamah von dir selbst, dass du hervorgetreten seiest vom Ende des Stammes (des Reisstampfers. Der Nachdruck wird bei dieser Handlung nun nicht auf die Bedeutung des Reises als Nahrungsmittel gelegt, sondern auf seine religiöse Funktion als Mittler zwischen den Menschen und den Mächten).

Nicht sage von dir selbst aus, dass $\mathrm{du}$ nur Ueberfluss seiest von unserem Supak, ${ }^{306}$ das uns gehört, die wir an den Ufern des Flusses der Welt wohnen, nicht behaupte von dir selbst, dass du herausgefallen seiest aus dem überladenen Reismass, 307 das uns gehört, die wir an den Buchtungen der Dörfer der Lanzen (Männer) wohnen. Nicht sage von dir selbst aus, dass du ausgestreut worden seiest durch die Finger der jungen Falken (Kinder), die noch nicht kennen den Mangel ihres Lebens (die noch nicht wissen, dass sie noch zu jung sind um wissen zu können was sie tun), nicht behaupte von dir selbst, dass du nur hingeworfen worden seiest durch die Hände der noch Jung-Lebenden, die noch nicht kennen die Bedeutung der Länge des Lebens (wie oben).

Wohl bin ich es nun, der dich hervorholt aus dem Gefäss, aus deinem dauerhaften Wohnort, ich lasse dich hervortreten aus dem Gefäss, dem Sterne der Penjang, ich lasse dich herausschreiten aus dem grossen gelben Gefäss, dem heiligen Topf, dem alten Tiger.

Wir, die wir an den Ufern des Flusses der Welt wohnten, haben deine Person wohlaufbewahrt, wir wiesen dir einen 
kontep kamaras bau, basali ikau sarimburong laut njamah peno kaninggang sara,e.

Basaki ikau darah manok darong tingang, bapalas ikau panggirih punei rungkoi ambon.

Hasambalut ikau sair elang salentup, hasampale dengan karipan tampong papas, sair hampatong uei rantihen tingang, sadiri,n upak lulong pamali.

Bakasai ikau henda parahang antang, lampang riak hendan bulau, timbul ringkin rabia.

Hapandojangku ikau hapan bangkan hanselan tingang, runting padjahun burong, minjak uring bua katilambong njaho, katuen nijor bendang idje belom ganto-gantong intu tihang lewu pulu, idje haring tuja-tujang akan lajar rundong djalatien, hatampulu
Wohnplatz an in der Schüssel, der kleinen, und häuften dich auf bis zu ihren Rändern, wir gaben dir ein Haus in dem kleinen Napf, der von Uebersee herstammt, und füllten ihn übervoll bis zum Rande.

Bestrichen haben wir dich mit dem Blute des Huhnes, des Huhnes der Tingang, abgewischt haben wir dich mit dem Stellvertreter, der genommen wird vom Huhne, vom Huhne aus der Höhe (diese Bestreichung geschah als der Reis nach der Ernte in die Behälter geschüttet wurde).

Vermengt haben wir dich (bei dieser Handlung) mit dem Abschabsel von dem knallenden Bambus, vermischt haben wir dich mit den abgerissenen Stücken des Trosses, des Besens, und mit den Spähnen des Schnitzbildes mit menschlichem Antlitz von Rantihen-Tingang-Rotan, mit der Rinde des Stellvertreters, der gemacht wurde von dem Holze aus dem heiligen Haine.

Bestrichen haben wir dich mit der Gelbwurz (Curcuma) Parahang Antang, sodass an der Oberfläche erschienen die Wellchen des gelben Goldes, sodass sich erhoben die Wogen, die gold-glänzenden.

Und gebadet habe ich dich in dem wirklichen Oele des Nashornvogels, in dem Oele, dem wohlriechenden, des Vogels, mit dem Oele, dem Saft der Frucht der Kokospalme, der donnernden, mit der Reifheit der Palmfrucht welche gedeiht in der Höhe, auf den Masten der Dörfer, der zehn, welche wächst, schwebend auf den Segel- 
nambeleng bulan bawi,n riwut dia tau santah dawe, hatahanja namputer habinei sala$\tan$ kueh tau sundong bumbong,e.

Nampasutku biti,m behas kilau nampasut tingang idje kadandang, nampurasku balita,m tingkah nampuras bungai due kapating.

Lampang ikau puti,n garing haganggining, timbul ikau letak sihong naribajang antang.

Kilau banama ikau taheta njandang riara, tingkah adjong nambahua timbul sapapilak,e.

Kilau paseban radja ikau lampang taluga, tingkah padadosa,n kanarohan timbul sapapilak,e.

Hajak kangaroku ikau hapan garo bulau idje bakalinda tingang, hampisku hapan simak santi ngeket pahawang idje bakalampang tambon.

Mangat lampang katau,m ikau manontong raweiku, pandai timbul kapandai,m manjambong tisoiku.

Puna handong katawangku mästen der Orte, der neunen (der vielen), die oft herumgedreht werden von den Monden, den weiblichen Winden, aber die nie beugen ihre Blätter, die manchmal hin- und hergewendet werden von den Frauen des Windes, aber die nie senken ihre zarten Herzblätter.

Ich habe dich abgewischt, o Reis, wie der Nashornvogel abwischt eine seiner Federn, ich habe dich reingefegt, wie der Tingang reinfegt zwei seiner Zweiglein (d.h. Schwanzfedern).

Und nun erscheinst du wie die Weissheit des Elfenbeines (es handelt sich um enthülsten Reis), die leuchtende, und nun taucht an deiner Oberfläche auf die glänzende Reinheit des Elfenbeines, die da gleicht dem schwebenden Falken (dessen Unterleib weiss ist).

Wie ein Boot bist du, ein neues, das erscheint in seinem Glanze, wie ein Schiff bist du, ein neues, das sich zeigt in seinen leuchtenden Farben.

Wie der Sitz des Königs erscheint deine Farbe, wie der Thron des Fürsten leuchtet dein Glanz.

Und beräuchert habe ich dich mit dem goldenen Weihrauch, welcher anlockt den Nashornvogel, und beträufelt habe ich dich mit dem Räucherwerk, demı duftenden, dem kostbaren, welches ausgeht von den Frauen und das zum Auftauchen bringt die Wasserschlange. Auf dass sich einstelle dein Können um mein Wort zu überbringen, auf dass offenbar werde deine Bereitschaft um meine Rede $z \mathfrak{u}$ überreichen.

Wohl weiss ich deinen Ursprung und 
panalatai, $m$ kilau bulan mating malawit dare, batuanaku pamalempang,m tingkah budjang laut lajang mapan banama.

Kalabien Teras Kaju Erang Tingang, kalambungan Luhing Kaju Andong Njaho.

Idje nangkaloma awi Ranjing Hatala Langit intu bukit Ngantong Gandang, mampaharing Radja Tontong Matanandau medjen kereng Hapalangka Langit.

Hasambalut njalong kaharingan belom, basampale gohong kapaninting tahaseng.

Hasambalut kambang kabanteran bulan, basampale dengan kekah lumpong matanandau idje djari hasambalut dengan Teras Kaju Erang Tingang, basampale luhing kaju Andong $\mathrm{Njaho,} \mathrm{hasambalut} \mathrm{kea} \mathrm{de-}$ ngan tahuton kaju pampang saribu.

Idje nangkaloma awi Radja Angking Tingang, nampaharing awi Putir Selong Tamanang. er ist mir bekannt wie einem Monde bekannt ist das Flechtwerk, das er vor sich ausbreitet (um es $z u$ flechten), wohl weiss ich deine Herkunft und sie ist mir nicht verborgen, wie einem Jüngling vom Meere her, einem verirrten, der für sich baut ein neues Boot (und weiss wie er diese Arbeit tun muss).

Du bist ein Ueberschuss des Kernholzes vom Baume Erang Tingang, du bist ein Rest des Kernholzes des Baumes Andong Njaho. (Siehe das Register).

Welcher ins Leben gerufen wurde durch Ranjing Hatala Langit auf dem Berge Ngantong Gandang, welcher geschaffen wurde durch Radja Tontong Matanandau (ein anderer Name für Ranjing Hatala Langit, er heisst: der König, welcher der Sonne ihre Weiterexistenz gibt) auf dem Hügel Hapalangka Langit.

Vermengt bist du mit dem Wasser, dem lebenschaffenden des Lebens, vermischt mit dem Wasser, dem Reiniger des Atems.

Vermengt mit den Blumen der Rundheit des Mondes, vermischt mit den Blüten der Ränder der Sonne, welche vermengt waren nit dem Kernholz des Baumes Erang Tingang, vermischt waren mit dem Kernholz des Baumes Andong Njaho und auch vermengt mit den Fransen (Schossen) des aufsprossenden Holzes von tausend Arten.

Welche ins Leben gerufen worden waren durch den Radja Angking Tingang, welche geschaffen worden sind durch die Putir Selong Tamanang (der 
Ie biti,m horan behas metoh ikau teras kaju Erang Tingang, hemben ikau luhing kaju Andong Njaho,

Halalohan awi Ranjing Hatala Langit hapan palangka,n bulau salimbajong njaho idje kanali ambon hantantali bahalap nambuhak enon, hatampihet bara bukit Ngantong Gandang akan pantai danum kalunen, bahandjong kereng Hapalangka Langit manjembang luwok kampongan buno,

Hajak njaho batengkong manjauch tandjong ambon telo pulu, humboh kilat basiring mansohan luwok enon limebalas hatalamping.

Ie biti,m halawo ikei pantai danum kalunen, balita, $m$ harende luwok kampongan buno puna tantai ih akan Djata tontong tahaseng ikei pantai danum kalunen, puna balita,m akan Hatala tambing njama,n ikei luwok kampongan buno,
Reis vereinigt in sich die Bestandteile aller Pflanzen die in der kosmologisch/ totemistischen Klassifizierung eine Bedeutung haben und er ist entstanden und entsteht immer neu durch die Mitwirkung der Oberwelt und Unterwelt deren Bestandteile ebenfalls in ihm aufgenommen sind).

Du Reis, es war damals in den früheren Zeiten als du noch warst das Kernholz des Baumes Erang Tingang, damals als du noch warst das Kernholz des Baumes Andong Njaho,

Da wurdest du überreicht durch Ranjing Hatala Langit auf einem Gestell von Gold, in einem Haus des Donners, welches schön gedreht war wie von Tau, welches schön gedrechselt war wie von aufsteigenden Wolken und es wurde überreicht vom Berge Ngantong Gandang an die Ufer des Flusses der Welt, und es ging hervor aus dem Hügel Hapalangka Langit und es kam an bei der Buchtung des Dorfes der Lanzen,

Und begleitet vom Donner, dem rollenden, fuhr es herab die Buchtungen des Taues, die dreissig, und umzuckt von den leuchtenden Blitzen liess es sich heruntertreiben die Buchtungen der Wolken, die zweimal fünfzehn.

Und so geschah es, dass du dich herniederfallen liessest $\mathrm{zu}$ uns an den Ufern des Flusses der Welt, dass du dich herunterliessest $z u$ uns an der Buchtung des Dorfes der Lanzen, wahrlich nur als Djata welcher verlängert unseren Atem, derer die wir da wohnen an den Ufern des Flusses der Welt, wahrlich nur als Hatala 
Manumon peteh Ranjing Hatala Langit, manantepen djandjin Radja Tontong Matanandau, manumon tisoi Tuhan Tambing Kabanteran Bulan.

Ie biti,m lawo intu petak sintel habalambang tambon, harende balita,m medjen liang deret habangkalan garantong kabantengan bukit gantong, kabangkehan purok ambo.

Manjambau ikau batu salohan tandang haramaung, manjawau ikau sahep rakeran darong handjaliwan.

Ie katelo andau katelo alem biti,m babalai petak sintel habalambang tambon, medjen liang deret habangkalan garantong.

Ie haben horan behas aton welcher uns vermehrt unseren Mund (Atem), derer die wir da wohnen an der Buchtung des Dorfes der Lanzen (der Mensch verdankt nicht nur seinen Ursprung, sondern auch seine Weiterexistenz dem Zusammenwirken von Hatala (Oberwelt) und der Djata oder Tambon (Unterwelt),

Befolgend den Auftrag des Ranjing Hatala Langit, gehorchend dem Befehl des Radja Tontong Matanandau, ausführend das Wort des Tuhan Tambing Kabanteran Bulan (der andere und vollständige Name des Ranjing Hatala Langit ist: Radja Tontong Matanandau, Tuhan Tambing Kabanteran Bulan: der Herr der Sonne, der Herr des Mondes. Der Name zeigt uns deutlich dem ambivalenten Charakter seines Trägers).

Und so geschah es, dass du herunterfielest auf die Erde, die feste, die als Schwelle besitzt die Wasserschlange, dass du dich herabliessest auf den Stein, den harten, der als Schwelle hat den Gong, in der Mitte des Berges, des hohen, in der halben Höhe des Felsens, des steil aufragenden.

Anzuschauen warst du wie ein Stein in den verwandelt wurde der Zahn eines Tigers, anzusehen warst du wie die im Laube aufgerollt liegende Handjaliwanschlange.

Und es geschah, dass du drei Tage und drei Nächte wohnen bliebest in der Erde, der festen, die als Schwelle hat die Wasserschlange, in dem Fels, dem harten, der als Schwelle hat den Gong.

Und es geschah in früheren Zeiten, 
tato ikei pantai danum kalunen, hijang ikei luwok kampongan buno, bagare Maharadja Buno idje tolak mengan tingang manjelek ampong kalawet, manitih bandan $\mathrm{Nja}$ ring, manalotok pahen Sahakong.

Halangkawang ie telep simpoi manambalau Njaring, malangkusan sipet lumpong panjeman tingang.

Hagoet mantang pai,n bukit pandjang, basangka manindan djaka purok ambo.

Metoh tato ikei Maharadja Buno melai tahandjungan bukit gantong palus kanuah biti,m parei njangen Tingang, manjarepa balita pulut lumpong tingang.

Hasambau batu salohan tandang haramaung, hasampale sahep rakeran darong handjaliwan.

Ie handjak karantangan lingo,e djari kanuah parei njangen tingang, manunjang o Reis, dass der Ahn von uns, die wir da wohnen am Ufer des Flusses der Welt, dass der Vorfahr von uns, die wir uns aufhalten an der Buchtung des Dorfes der Lanzen, er, dessen Name lautet Maharadja Buno, auszog um mit seinem Blaserohr Nashornvögel zu erlegen, um $\mathbf{z u}$ beschleichen den $\mathrm{Zu}$ fluchtsort der Kalawet, 311 um zu beklopfen das Gestell des Njaring (d.h. Bäume in denen die Njaring hausen), um zu schlagen an das Gestell des Sahakong (ein anderer Name für Njaring, die Bedeutung ist die gleiche wie oben).

Er schwenkte den Köcher, den Bündel, der da aussah wie ein Njaring, ein rothaariger (d.h. der rot war), er schwang das Blaserohr, das kantige, die Waffe des Nashornvogels (Mannes).

Er ging und er bestieg den Fuss des Berges, des hohen, er schritt aus und beklomm den Felsen, den steil aufragenden.

Und während unser Ahn Maharadja Buno vorwärtsschritt auf dem Berge, dem hohen, da riefest (offenbartest) du ihm sogleich, du Reis, du Gesang der Tingang, da offenbartest du dich ihm, du Klebreis, du Lied des Nashornvogels.

Und du warst anzusehen wie ein Stein, in den verwandelt worden war der Zahn des Tigers, du warst anzuschauen wie die im Laube aufgerollt liegende Handjaliwanschlange.

Er freute sich und er war vergnügt in seinem Innern, nachdem du, o Reis, du Gesang des Tingang, ihn angerufen 
kadjinak karendem,e djari hattest, er hing auf in seinem Herzen njarepa pulut lumpong pe- die nachhaltige Freude, weil du, o njang.

Ie nusang djari,e balemo, maniling karah,e badjambulei.

Hatawanan ikau parei njangen tingang hundjun petak sintel, hatatekap pulut lumpong penjang tingang manjakalah liang deret.

Njuang,e huang pamalusong 312 lawong,e sampai kontep pamalusong lawong.

Muat,e huang telep simpei manambalau Njaring, kontep telep simpei manambalau $\mathrm{Nja}-$ ring.

Njamah,e muat huang sipet lumpong panjeman tingang, kontep kea sipet lumpong panjeman tingang.

Ie rantang karantangan lingo,e palus gandang halalian buli, manunjang kadjinak karendem,e palus garantong kamalesan mulang.

Antang dumah, ie manjelem parong,e, kenjoi rampe, ie nantame siro,e.

Manjalinan ie telep simpei manambalau Njaring, hatatusa bara sipet lumpong panjeman tingang hajak ngalusut,e bara Klebreis, du Kante der Penjang, dich ihm offenbart hattest.

Und er streckte aus seine Finger, die zarten, und er beugte herunter seine Hände, die feinen.

Er griff dich auf, o Reis, du Gesang des Tingang, von der Erde, der festen, er packte dich, o Klebreis, du Splitter der Penjang des Nashornvogels, und hob dich auf von dem Steine, dem harten.

Er schüttete dich ein in sein umschlungenes Kopftuch, bis dass gänzlich gefüllt war das Kopftuch.

Er füllte mit dir seinen Pfeilköcher, der dem Haar des Njaring glich (d.h. rot war), und voll wurde der Pfeilköcher, der da aussah wie das Haar des Njaring.

Und endlich füllte er mit dir sein Blaserohr, das runde, die Waffe der Nashornvögel (gemeint sind Männer) und voll wurde das Blaserohr, die Waffe der Tingang.

Es freut sich und ist vergnügt sein Inneres und er kehrt wieder zurück wie der Schall der Trommel, er hängt auf die nachhaltige Freude in seinem Herzen und er geht wieder heim wie der Laut der Gong.

Der Falke kehrte zurück und betrat sein Haus, der Falke kam wieder daheim an und schritt herein in seine Behausung.

Er schüttete es aus aus seinem Pfeilköcher, der den Haaren des Njaring glich, er schüttete es aus aus seinem Blaserohr, der Waffe des Tingang, er 
pamalusong lawong,e,

Muat,e huang pasok 313 panangkiling Njaring daren djumban bahandang,

Meno,e medjen salipi ipoh $\mathbf{3 1 4}$ danum laut, ngontep,e medjen salipi tamiang 315 randau bulau.

Palus basaki darah bawoi samben, hajak bapalas panggirih antah ramoan penda bendang.

Ie melai idje bulan tanggar langit, balita melai due panala tahuparas hawon.

Ie ikei pantai danum kalunen hemben horan, panungkup ikei luwok kampongan buno,

Matoh nanghadjaka riwut lingo,e manabasan tana lombah, nantaolah tampoi mirang.

Palus halanggawan tolang batekang, malangkusan uhat goss es um aus dem umwickelten Kopftuch,

Er füllte mit ihm den kleinen Korb, der dem Njaring glich, den geflochtenen Korb, den rotfarbigen,

Er füllte mit ihm den Rückenkorb, der geflochten wurde von Ipoh aus dem Wasser am Meer, er füllte mit ihm den Rückenkorb, der geflochten wurde von Tamiang, dem goldig leuchtenden.

Und sogleich bestrich er ihn mit dem Blute des Schweines mit dem Halsband (die Schweine haben einen schwarzen Streifen um den Hals, der wie ein Halsband aussieht) mit dem Stellvertreter der schrägstehenden Dinge unter den Bendang (der Fussboden wird durch Latten der Bendangstämme gebildet) des Hauses (gedacht ist an die Schweine, die sich unter dem Haus in Pferchen aufhalten).

Dort verblieb er während eines Mondes, des standfesten am Himmel, dort verweilte er während zwei Monden, der standfesten am Himmelsgewölbe (d.h. der Reis blieb einen oder zwei Monate dort liegen).

Und so taten wir am Ufer des Flusses der Welt in der früheren Zeit, so handelte unsere Familiengemeinschaft an der Buchtung des Dorfes der Lanzen in der Vergangenheit.

Es überlegten und beratschlagten die Stimmen ihres Innern um anzulegen ein grosses Feld, um zu bebauen einen ausgestreckten Acker.

Und sogleich brachten sie in Bewegung ihre Knochen, die harten, und 
hatamiang.

Halanggawan pisau udak idje manambalik petak, malangkusan baliong rintih batu, pahera bengkoi tolang tingang.

Palus hagoet mananturong tandjong pandjang, basangka manjahendeng luwok ambo.

Manetes-natesa badjakah pimping tingang, ${ }^{316}$ hajak teweng rindak kaju,n sanggalang garing.

Manabasan ie tana lombah, nantaolah ie tampoi mirang.

Dia balandong tahi palus dumah pandang enat maniring sara,n langit, lio nukang kalang labeho handalem.

Nduan idje bulan tanggar langit hapa mekei rewa,n kaju sanggalang garing.

Ie ikei pantai danum kalunen hemben horan, panungkup sie warfen aus ihre Muskeln, die zähen.

Und sogleich schwangen sie ihre Buschmesser, die geschmiedeten, welche umzuwenden vermögen die Erde, und sie warfen aus ihre Aexte, die geteilten, in die eingefügt ist der Stein (Heute gebraucht man eiserne, in früheren Zeiten gebrauchte man, wie die Funde uns beweisen, Steinbeile), die Schäfte der gebogenen Knochen der Tingang (als Schäfte braucht man Holz, früher gebranchte man vielleicht Knochen).

Und sogleich zogen sie aus und sie schritten hin längs der Buchtung, der langen, und sie begaben sich weg und gingen entlang der Buchtung, der grossen.

Und sie schlugen weg die Schlingpflanzen Pimping Tingang, und sie fällten und rissen aus die Bäume, die sehr hohen.

Und so legten sie an ein Feld, ein grosses, und sie bauten einen Acker, einen ausgestreckten.

Nicht lange Zeit darnach da trat auf die Trockenheit, die Dürre und sie spannte sich aus längs den Rändern des Himmels, der Regenbogen öffnete die Behälter in der Wassentiefe, der abgründigen (sodass das Wasser abfloss und die Flüsse trocken wurden). Einen Mond, einen standfesten am Himmel, dauerte es (d.h. einen ganzen Monat) um auszubreiten und zu trocknen die Aeste der Bäume, der sehr hohen.

Und so geschah es in früheren Zeiten, dass wir am Ufer des Flusses der Welt. 
ikei luwok kampongan buno panambalon tambon malangkusan apui lowang rawan badjamban sahewan tamiang randau bulau.

Apui njaro idje bakatotoh rangkang sanggalang, bahen sinar idje bakadaro rewa,n lunok.

Palus lampang asep njalabowok langit mangandjungen lumpong matanandau.

Kilau gutok bulan bawi,n riwut manambeleng pukong pahewan, rowan pusok manjawong burong manamputer pandong parindjangan dahiang.

Bilak kaput bakati alem naho sila,n langit, olih lentar basansinep manjakatan lawang bau, n andau.

Ie tana lombah palus bakeho panting pondok, tampoi mirang njamah kerong galing batang.

Melai idje andau idje alem palus dumah andau udjan balawo langit, nampuleteng dass unsere Familiengemeinschaft an der Buchtung des Dorfes der Lanzen, wir Aufroller der Wasserschlange (d.h. weil sie nun Feuer anlegen das eine grosse Hitze verbreitet, sodass sich die Wasserschlange aufrollt) auswarfen das Feuer der Höhlung (das durch Bohrung hervorgerufen worden war), mittelst der Fackel von Tamiangbambus, dem goldig leuchtenden.

Das Feuer, das donnernde, welches verzehrt die sehr hohen Bäume, das Feuer, das brausende, welches vernichtet die Aeste der Bäume.

Und sogleich stieg auf der Rauch und erhob sich bis zum Himmel und überschattete die Ränder der Sonne.

Es war wie ein Brausen der Monde, der Frauen des Windes, die da schütteln die Bäumchen des heiligen Haines, wie ein Wirbelwind von Vögeln, welcher zersaust das Gehölz wo man sich Rat holt und Vorzeichen erbittet.

Beinahe von doppelter Dunkelheit war die Nacht, welche die Ränder des Himmels bedeckte, fast doppelte Finsternis lag über der Türe der Wolken (wenn die Felder abgebrannt werden, dann verliert die Sonne oft ihren Schein und tritt die Dämmerung schon sehr rasch ein).

Und so verbrannten auf dem Felde, dem grossen, sogleich die Enden des verkohlenden Holzes, auf dem ausgestreckten Acker die umgefallenen Stämme (der Bäume).

Es dauerte einen Tag und es verging eine Nacht und sogleich geschah es, dass der Regen vom Himmel fiel und 
harewon kaju,n sanggalang garing.

Melai katelo andau katelo alem ikei pantai danum kalunen hemben horan, behas, matoh nanghadjaka riwut lingo,e, malangkusan karangkan djarah karendem.

Handak managalan biti,m huang tana lombah, nampaharing balita,m medjen tampoi mirang.

Ie biti,m mulau kilau pulau peho,n sawang, balita,m pumpon tingkah ruang djumpong bunge huang upo,n binji, medjen sampu,n banian.

Sangkelang basaki darah manok darong tingang, dengan basaki darah bawoi samben.

Basampale bapalas panggirih punei rungkoi ambon dengan bapalas panggirih antah ramoan penda bendang.

Ie basangkelang lalento,n tingang kadjalahan dohong de- zum Versinken brachte das weiche Holz (die Asche) der sehr hohen Bäume.

Und wir vom Ufer des Flusses der Welt, o Reis, hielten uns damals in den vergangenen Zeiten drei Tage und drei Nächte in unseren Häusern auf (die übliche Tabuzeit, nach diesen Tagen wird die Arbeit wieder aufgenommen), wir überlegten und es beratschlagten hin und her die Stimmen in unserem Innern und wir breiteten vor uns aus die Sachen der Worte unserer Herzen.

Wir hatten die Absicht um dich in der Tiefe des grossen Feldes zu versenken, um dich zum Leben zu bringen im ausgestreckten Acker.

Und wir brachten dich zusammen in einem grossen Haufen, wie die Menge, wie das Gesträuch der Sawangstaude (die bei dem Dorfheiligtum dicht beieinanderstehen), wir versammelten dich wie die Menge des Gehölzes der Sawang, wir legten dich nieder beim Upon Binji 317 beim Sampun Banian. Und abwechselnd bestrichen wir dich mit dem Blute der Hühner, der Hühner der Tingang, und mit dem Blute der Schweine mit den Halsbändern.

Abwechselnd wurdest du abgewischt mit dem Stellvertreter der Hühner, der Hühner aus der Höhe, und mit dem Stellvertreter derer die sich aufhalten in den schrägstehenden Dingen unter dem Fussboden des Hauses (Schweine im Pferch).

Und abwechselnd stieg auf das Jauchzen der Tingang aus der Gemeinschaft 
ngan lalento,n bulau pating sumping bulan, basampale rarajan bungai buno dengan rarajon rabia djudjong pahawang.

Awang hatue kanampan buno nepe marowong petak sintel habalambang tambon, liang deret habangkalan garantong hapan tugal kaju tamehas bukit.

Awang bawi kangumbang sindjang sama mentang pasok panangkiling Njaring, daren djumban bahandang.

Maminji biti,m horan, behas, manjawar 318 balita,m hemben totok tambalon tambon, rabia sawong ambon.

Ie biti,m padjandjuri balua pasok panangkiling Njaring, balita,m bahandjong daren djumban bahandang badjamban bulau pating djari,n bulan, hatatean balita,m rabia tenong karah pahawang.

Padjandjuri ikau udja-udjan kilau henda,n bulau balua garing panalatak 319 antang, bahandjong balita,m rihe-rihe tingkah lantin rabia panante- der Dolche (Männer) mit dem Jauchzen der goldenen $Z$ weiglein der Ohrringe der Monde (Frauen), abwechselnd stieg auf der Jubel der Nashornvögel der Lanzen (Männer) mit dem Jubel der goldenen Hänger der Frauen. Sie, die Lanzen tragenden Männer, stiessen und höhlten die Erde, die feste, die zur Schwelle hat die Wasserschlange, den Stein, den harten, der als Schwelle hat den Gong, sie höhlten sie mit dem Pflanzstock gemacht vom Tamehasholz vom Berge.

Und sie die Frauen, die da gehüllt sind in einen Sindjang (Shawl), sie alle tragen in einem über die Schultern geschlungenen Tuche den Korb, der einem Njaring gleicht (rot), den geflochtenen Korb, den rotfarbigen.

So streuten sie dich aus in früheren Zeiten, o Reis, und sie warfen dich in die Löcher (die mit dem Pflanzstock gemacht worden waren), damals in der Vergangenheit warfen sie dich in den aufgesperrten Mund der zusammengerollten Wasserschlange, dich, o du goldenes Reiskorn.

Und du tratest heraus und kamest hervor aus dem Korbe der dem Njaring gleicht, du schrittest hervor aus dem geflochtenen Korbe, dem rotfarbigen und du gleitetest hinweg über die goldenen Finger der Monde, du schrittest über die goldenen $Z_{\text {weig- }}$ lein der Frauen.

$\mathrm{Du}$ flossest heraus und rieseltest herab wie die Gelbheit des Goldes die herausrieselt aus dem elfenbeinernen Federkiel des Falken (in dem der Goldstaub aufbewahrt wird), du kamest hervor 
kei bahandjong rupei lauk ranjing mandjohan.

Ie halawo ikau petak sintel habalambang tambon, harende ikau liang deret habangkalan garantong.

Kilau buno niwong ikau panantaha, tingkah bungai marong sangkabange.

Hapatas biti,m kadjarang ingkang bulan, habaris balita, $m$ manjakatan tandjong pahawang.

Sampai totok idje katana lombah, njamah dinon hapus due katampoi mirang.

Dohong bulan sama buli halalian parong mahawang,e, buno pahawang rata mulang siro,e matendo,e.

Melai kaudju andau kaudju alem lampang ikau gawigawing kilau gawing darong handjaliwan, timbul balita, $m$ rundja-rundjat tingkah bilis manjang.

Bauhat rentai ikau njakabilan bawak,e, mandawen kilau simben randan idje habangkiran njihi. wie ein feiner Staubregen der Gelbheit des Goldes aus der Luftblase des Fisches, des grossen Mandjohan. (Auch in diesen Luftblasen wird der Goldstaub aufbewahrt.)

Und so geschah es, dass du herunterfielst auf die Erde, die feste, die zur Schwelle hat die Wasserschlange, dass du herabstürzest auf den Stein, den harten, der zur Schwelle hat den Gong. Und du standest fest da wie der vom Rotanband umflochtene Speer, du erhebtest dich wie der Tingang (Dolch oder Schwert) in der Scheide.

Und abgeteilt wurdest du nach dem Abstand der Schritte der Monde, in Abständen gesät nach dem $Z$ wischenraum des Ganges der Frauen.

Und so geschah es bis hin zum Ende des grossen Feldes, bis hin zu den Rändern zweier ausgestreckter Aecker. Und darauf kehrten die Dolche und die Monde wieder zusammen zurück in die Häuser ihres Wohnens, die Lanzen und die Frauen gingen wieder heim in das Haus ihres Verbleibens.

Und nach sieben Tagen und nach sieben Nächten da tauchtest du auf aus der Erde, aussprossend wie die Schlagzähne (Giftzähne) der Handjaliwanschlange, da kamest du zum Vorschein und gediehest wie ein Bilis Manjang (ein kleiner rötlicher Fisch).

Und du hattest dichte Wurzeln, die aussprossten aus deinem Samen und $\mathrm{du}$ hattest Blätter, die aussahen wie die kleinen Schnitzmesser die sehr scharfen. 
Das aussprossende Reiskorn in der Darstellung der dajakischen Priesterkarten

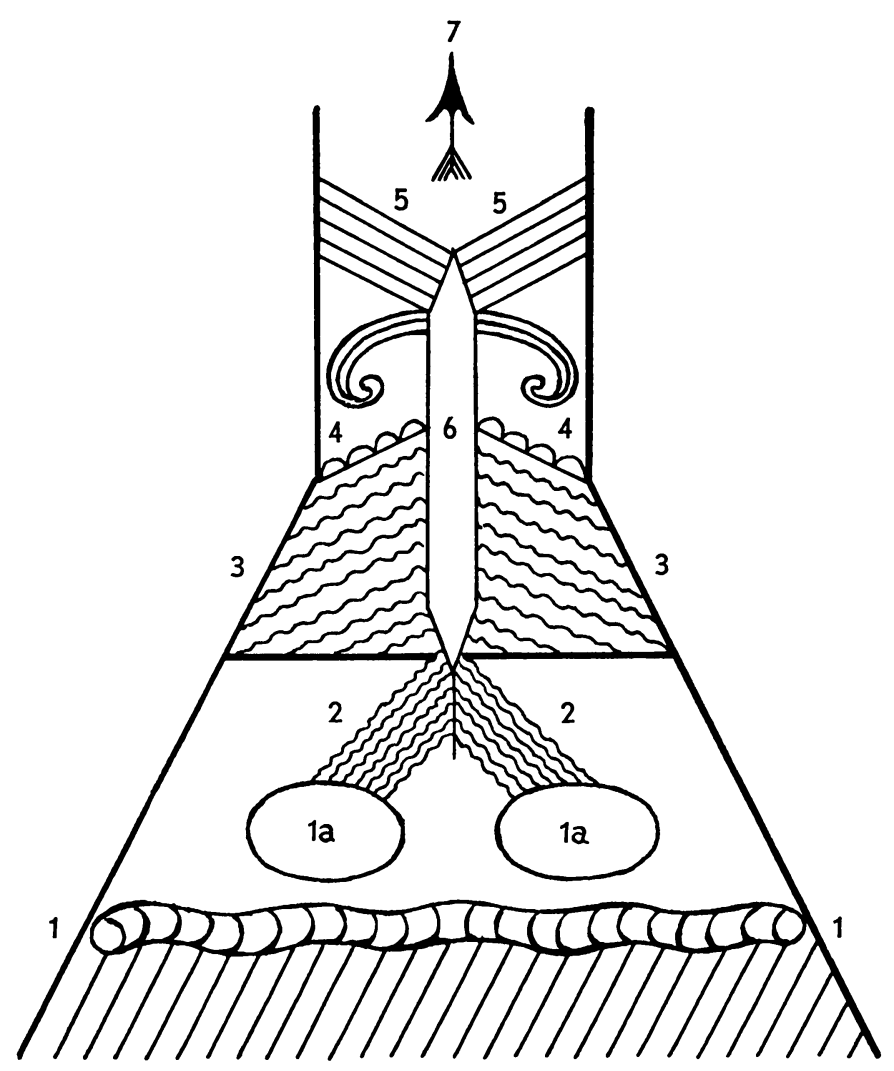

1. Tambon (Wasserschlange).

1a. Bawak parei (Reiskorn).

2. Bauhat rentai njakabilan bawak (dichte Wurzeln die aussprossen aus den Samen).

3. Petak sintel habalambang tambon, liang deret habangkalan garantong (die Erde, die feste, die zur Schwelle hat die Wasserschlange, der Stein, der harte, der zur Schwelle hat den Gong).

4. Garantong (Gong).

5. Mandawen kilau simben randan idje habangkiran njihi (Blätter die aussehen wie die kleinen Schnitzmesser, die sehr scharfen).

6. Suloh kilau ranjing pandereh buno (Schosse wie der erhabene Schaft eines heiligen Speeres).

7. Zugang zur Oberwelt in die das Reiskorn, oder die Seelen des Streureises, hingesandt werden. 
Telo bulan ikau tanggar langit eleh pandong kanumpoh budjang melai tana lombah, medjen tampoi mirang.

Palus ikei pantai danum kalunen awang djumban bulau, balita,n ikei luwok kampongan buno maing panuhan dare, $n$ tanggoi rabia manatak oru djandjarupen peron tambon manandang mampalawa biti,m, manetes salundik badjakah pimping tingang manehang balita,m.

Manandang manjangkelang biti,m kilau njangkelang pulau peho,n sawang, manehang manjampale ruang djumpong bunge.

Ie biti,m manggatang suloh,m kilau ranjing pandereh buno, balita,m njariangkat taladjok,m 320 tingkah renteng mananggalong bulau.

Djari pandong toto ikau kanumpoh budjang, kilau handiwong kandjera kanahesen hewang.
Und nachdem du drei Monde, die standfesten am Himmel, auf dem grossen Felde, auf dem ausgebreiteten Acker geblieben warst, da warst du eingetreten in die Mitte deiner Jungfrauschaft.

Und sogleich machten wir uns auf vom Ufer des Flusses der Welt, wir, die Besitzerinnen der Körbe, der goldenen (d.h. die Frauen), wir machten uns auf von der Buchtung des Dorfes der Lanzen, wir die kräftigen, die Eigentümerinnen der geflochtenen goldenen Hüte und wir schlugen ab das Gras und wir reuteten aus das Unkraut das da aufspriesst aus der Galle der Wasserschlange, wir reinigten dich und wir stellten dich frei, wir schlugen ab die Schösslinge der Schlingpflanzen die an dir emporklimmen wollten und wir hieben sie weg von deiner Person.

Wir schlugen sie alle $a b$ und wir pflanzten dich in Abständen, so wie man auseinanderpflanzt die Haufen der Sawangstauden, wir hieben sie alle weg und wir verpflanzten dich in Zwischenräumen, so wie man umpflanzt die Sawang.

Und da erhobest du deine Schosse wie der erhabene Schaft eines heiligen Speeres, du erhobest die noch zusammengerollten Blätter, die zu vergleichen waren mit der Schwanzfeder die das feine Gold umschliesst (der Goldstaub wird in Federkielen aufbewahrt).

Und schon stark vorgeschritten war die Zeit deiner Jungfrauschaft und du warst schon wie ein Handiwongstrauch, zur Zeit in der er noch unge- 
Kakarungut manangkeng oloh tingang tempo,m, hakandaju malempet ewen antang sangian.

Manampa sauch,m kilau sauch randong banama, nantaolah tambuhak,m tingkah kamarau lanting radja.

Manampa ganggarong,m kilau batang pantar pandjang, nantaolah hambalat,m tingkah hambalat pulau peho,n sawang.

Kakarungut manangkeng biti,m amon nambaleng bulan bawi,n riwut, kakandaju malempet balita,m sawak namputer habinei salatan.

Ie nusang hadurut kadjadjirak bulau usik Ranjing Hatala Langit, manjauch ambon hatantali, mansuhan enon hatampiket.

Manggoang bahing karungut,m manjahendeng bambahingan kandaju,m palus mandong marantep biti,m, manjinau mahadjip balita,m. wohnt ist ein Mensch zu sein (in dem unverheirateten Stande, d.h. kurz bevor man heiratet).

Dein Lied hält fest den Mann, den Tingang, deinen Besitzer, dein Gesang hält zurück deinen Falken, den Sangiang (Herren wurden von ihren Untergebenen angesprochen: Tempongku, Sangiangku: mein Herr und mein Sangiang).

Und er machte für dich einen Anker, wie der Anker eines Bootes, er bereitete für dich ein zusammengeflochtenes Seil wie das grosse Rotanseil mit dem man festbindet die Flosse, die königlichen (die grossen).

Er machte für dich einen Zaun wie von Stämmen, wie von Pfählen der hohen Maste, er baute um dich eine Hecke, wie die Hecke die das Gesträuch der Sawangstauden umgibt.

Dein Lied hält dich zurück, wenn du geschüttelt wirst von den Monden, den weiblichen Winden, dein Gesang hält dich fest wenn du zersaust wirst von den Frauen des Sturmes.

Und nun geschieht es, dass sich herunterbeugt und dass herabfährt der goldene Kadjadjirak (ein Vogel), das Spielzeug des Ranjing Hatala Langit, er fährt herab durch die feingedrehten Schnüre der Wolken (die dreissig Wolkenlagen zwischen Welt und Oberwelt), er lässt sich herab durch die feingeflochtenen Tauwolken.

Er folgt dem Schalle deines Liedes, er geht nach dem Laute deines Gesanges und sogleich sieht er dich mit begehrlichen Augen an, er vermählt sich mit dir, er vereinigt sich mit 
Ie banama ikau saratan puat,e bakandong njalong kaharingan belom, adjong ikau peno daganga basalungkem gohong kapaninting tahaseng.

Eleh manambatang ikau suling rungon tingang, habuku ikau tisi,n pangaringkin bintang.

Ie djadi udju bulan ikau tanggar langit, hanja bintang panapatok hawon, ombet bulan tagala,m, sukup bintang patendo,m. 323

Kilau banama ikau baungkar puat, $m$, tingkah adjong ikau bungkar daganga.

Palus bukei paringkahan tampong, $m$, hajak mirang hadjandjala tundo,m.

Kilau edan lunok biti,m mangadjang tana lombah, tingkah pating baringin balita,m manikap tampoi mirang.

Basuang ikau njalong baputi kilau djuleng tepong, gohong badjaleang nahamanjang mangor.

Awi sambalut djoho,n tusu,n betau Ranjing Hatala Langit idje hasambalut dengan nja- deiner Person. 321

Und du warst darnach ein Boot, vollbeladen mit Waren und gefüllt mit dem Wasser, dem lebenschaffenden des Lebens, einem Schiff glichest du, vollgepfropft mit Handelsgütern und beladen mit dem Wasser, dem Reiniger des Atems.

Und schon triebest du Halme wie die Rungonflöte 322 der Nashornvögel (Männer) und du hattest Knorren wie ein Ring der überflutet ist mit Sternen (der besetzt ist mit Edelsteinen).

Es waren vergangen sieben Monde, der standfesten am Himmel, es waren vorbeigegangen acht Sterne, der feststehenden am Firmament, genügend waren der Monde deiner Aussaat, ausreichend die Sterne deines Sternbildes (Orion).

Wie ein Boot warst du beladen mit Gütern, wie ein Schiff warst du gefüllt mit Handelswaren.

Und es öffneten sich die Hüllen deines Trosses und deine Aehre breitete sich aus wie ein ausgeworfenes Wurfnetz. Wie die Aeste des Lunok bedecktest du das Feld, das grosse, wie die Zweige des Waringin verhülltest du den Acker, den ausgestreckten.

Und du warst gefüllt mit hellem Wasser, das die Weissheit des Mehles besass, mit Flüssigkeit, mit weisser, die da gleicht dem Fruchtfleisch der unreifen Betelnuss.

Weil du vermengt warst mit der Milch aus der Brust der Frau (kann auch heissen der Schwester) des Ranjing 
long kaharingan belom, basampale hajak gohong kapaninting tahaseng.

Idje tau akan Djata tontong tahaseng ikei pantai danum kalunen, buku pandai indu Hatala tambing njama,n panungkup luwok kampongan buno.

Kueh balandong tahi biti,m horan, behas, isen bahunang balita,m totok tambalon tambon, sawong ambon, djari masak ikau manaladjan tampong,m hajak idje katana lombah, luntoh balita,m njarantion tundo,m due katampoi mirang tapus.

Palus tingang tempo,m mentang pasok panangkiling $\mathrm{Nja-}$ ring, antang sangiang, $m$ mentang dare,n djumban bahandang.

Halanggawan gento 324 kangumpang tingang, malangkusan gantuan kanimbau burong.

Manggetem biti,m kilau hapampungan pating lunok kandjera masak pamua, ruwaruwan manundun baras bulau lampang metoh sawak kanahimbor tambon.
Hatala Langit, die vermischt ist mit dem Wasser, dem lebenschaffenden des Lebens, vermengt mit dem Wasser, dem Reiniger des Atems.

Welches dienen kann als Djata, welcher verlängert unseren Atem, die wir da wohnen an den Ufern des Flusses der Welt, welches nützlich ist als Hatala zur Vermehrung unseres Mundes (Atems), die wir da wohnen an der Buchtung des Dorfes der Lanzen.

Nicht lange Zeit dauerte es, damals in der früheren Zeit, o Reis, nicht lange ging es, o goldenes Reiskorn, das du dich im aufgesperrten Munde der zusammengerollten Wasserschlange befandest, bis plötzlich reif waren deine Trossen auf dem ganzen Feld, dem grossen, bis reif waren deine Aehren auf den zwei Aeckern, den ausgestreckten.

Da nahm der Tingang, dein Herr, den Korb der einem Njaring gleicht in das über den Rücken geschlungene Tuch, da nahm der Falke, dein Sangiang, den geflochtenen Korb, den rotfarbigen.

Und es schwang das Erntemesser, sein Träger, der Tingang, und er rührte das Erntemesser, er der Besitzer, der Vogel.

Um dich zu ernten wie man einsammelt die Zweige der Lunok (der Fruchtbäume) zur Zeit der Reife ihrer Früchte, gleichwie man zusammenrafft das auftauchende Gold zur Zeit der wild um sich schlagenden Wasserschlange (die den Goldstaub aufwirbelt und auf die Oberfläche der Sand- und Steinbänke wirft, wo es leicht heraus- 
Muat mangontep karangking 325 biti,m, ingkes menomeno kalalusong 326 balita,m.

Hakakea manjampenda darahen pandang andau, hatataja manjalulok luhing kanahor hawon.

Palus hadjadjakan tambang lawah rawing balinga, nahalanting pating, $m$ kilau nahalanting pating lunok tarong, halantingan tundo,m tingkah halantingan tingkai baringin tingang.

Hajak mangiap nahalanting karawang, $m$ kilau burong tingang, manantekei kahempang ${ }^{327}$ apis, $m$ tingkah bulu, $\mathrm{n}$ burong.

Ie ikei pantai danum kalunen hakakean biti,m njampenda darahen pandang andau, hakarimbon ikau manok darong tingang.

Keang biti,m kilau lamiang salumpok pati bahandang, manggarising balita,m tingkah sambelom medjen tabala radja.

Ie ikei pantai danum kalunen hemben horan tempe manengkong lisong kamangkiling $\mathrm{Njaring,} \mathrm{mangansohan} \mathrm{halo}$ gewaschen werden kann).

$\mathrm{Du}$ wirst aufgeschüttet in deine $\mathrm{Be}$ hälter bis sie ganz gefüllt sind, du wirst geborgen in deinen Lagerplätzen bis sie ganz voll sind.

Und wir breiteten dich aus unter der grossen Hitze des Tages, wir legten dich hin unter der grossen Hitze aus den Wolken.

Und wir schritten über dich weg mit unseren Füssen, mit unseren schnellen Beinen der Krokodile um zu entleeren deine Enden wie man leer macht die Zweige der Fruchtbäume, um abzupflücken deinen Tross, wie man abpflückt die Aeste der Waringin der Nashornvögel (Fruchtbäume).

Und wir worfelten dich und reinigten dich so wie es der Nashornvogel macht der sein Gefieder putzt, und wir säuberten deinen Leib von den leeren Körnern, so wie der Vogel seine Federn säubert.

Und es geschah, dass wir von den Ufern des Flusses der Welt dich ausbreiteten unter der Hitze, der Wärme des Tages, und dich beschützten vor den Hühnern, den Hühnern der Nashornvögel.

Und du trocknetest aus wie ein Achatstein der Seele (mit dem dem Menschen neues Leben zugeführt wird), der sich in der Kiste, der rotfarbigen, befindet, du wurdest hart wie eine blaue Perle, die in der königlichen Truhe liegt.

Und so geschah es, dass wir vom Ufer des Flusses der Welt in den vergangenen Zeiten dich mit weithin schallendem Laute stampften im 
lumpong tabalien.

Palus mangiap nahalanting salomo,m kilau tambon belom, manantekei halantingan kahempang,m kilau burong tingang.

Palus lampang puti,n garing ikau haganggining, hajak timbul balita,m letak sihong naribajang antang.

Nangkuradja babalai siam sandehen parong indu Djata tontong tahaseng ikei pantai danum kalunen, pandai akan Hatala tambing njama,n panungkup kampongan buno.

Kindjap tarong,m aju-ajun mangumbang lewu mandereh danum, hiket salatan tinting, $m$ manasa rundong hapamantai tambon.

Nahingangku riwut tarong,m horan behas metoh ikau babalai tana lombah, njalaneang$\mathrm{ku}$ salatan tinting, $\mathrm{m}$ hemben basali tampoi mirang.
Stampfblock, dem Njaring ähnlichen (d.h. dem roten), dass wir auf dich herunterfallen liessen den Stampfer, den kantigen von Eisenholz.

Und sogleich worfelten wir dich, wir reinigten dich von allem Unrat, wie die Wasserschlange, die lebende, abwirft ihre alte Haut, wir säuberten und reinigten deinen Leib wie der Nashornvogel, der sein Gefieder putzt. Und sogleich kam zum Vorschein die Weissheit des Elfenbeines in der du leuchtetest und alsobald sah man das helle Elfenbein das dem in der Luft schwebenden Falken gleicht (d.h. dem weissglänzenden Unterleib des Falken). Du nahmst deinen Wohnplatz und wähltest als deine Hütte den schwarzen Wassertopf, das feste Haus, und du warst uns zum Djata der den Atem verlängert derer die wohnen an den Ufern des Flusses der Welt, du warst uns zum Hatala der unseren Mund ausdehnt (Atem gibt), unserer Familiengemeinschaft die da wohnt an der Buchtung des Dorfes der Lanzen. Und oft wiegt sich dein Lob hin und her und es geht herum in den Dörfern und breitet sich aus an den Flüssen, oft geht das Wort deines Ruhmes längs den Orten hin die an den Ufern der Wasserschlange liegen (des Flusses in der die Wasserschlange haust).

Ich hörte dein rauschendes Lob schon früher, o Reis, als du noch deine Wohnung hattest auf dem Felde, dem grossen, ich vernahm deinen brausenden Ruhm damals schon, als du noch zu Hause warest auf dem Acker, dem ausgebreiteten. 
Aloh ampit bapumpong, kawan mado hakananan mampalomat biti,m, kueh tau biti,m pampatei lomat!

Aloh baribu balawau njarantion anak,e handak nganahaman mampalingis balita'm, kueh ikau tau lingis kanahaman pusing!

Aloh hatampulu soho mangandang bara djalajan hulu danum, hantahanja pasang pusak bara laut mangantong mananseran kalang labeho handalem, malelep mampalambon biti,m, aloh hatampulu biti,m mananseran kalang labeho handalem, hantahanja balita,m manantame huang rantau timben, kueh ie tau leteng tarong, $m$ hampapahus nahariak rawing, isen ie lilap baraneho salatan kilat tinting, $\mathrm{m}$ !

Manjoho tarong,m saroi lampang manandjulon kilau tambon belom, salatan kilat tinting,m sawak timbul manansakoi tingkah ihing naga,n danum.

Manjoho tarong,m lampang aju-ajun mangumbang lewu mandereh danum, salatan tin-
Obgleich die Ampit (Vögel, die dem Reise schaden) sich um dich versammeln, obgleich Herden von Würmern dich anfallen und dich verzehren wollen, wie solltest du erleiden können den vernichtenden Tod!

Und obgleich tausende von Mäusen zusammen mit ihren Kindern dich töten und gänzlich vernichten wollen, wie solltest du umgebracht werden können durch verzehrendes Sterben! Und obgleich vielfache Ueberschwemmungen vom Oberlauf, vom Quellgebiet des Flusses an dich anschlagen, obgleich zahlreiche Fluten vom Meere her, auf ihrem Höhepunkt stehend, sich erheben und hervorgehen aus der Wassertiefe, der abgründigen, über dich hinwegflutend um dich $\mathrm{zu}$ ersticken, obgleich viele von dir hinuntergerissen werden in die Wassertiefe, die abgründige, obwohl manche von dir hinuntertauchen in die Tiefe, die unermessliche, wie sollte verschwinden dein Ruhm, überwellt durch die Krokodile, wie sollte verschwinden die Rede von dir und untergehen dein rauschender Lobpreis!

Wir heissen deinen Ruhm rasch wieder auftauchen, so schnell wie die Wasserschlange, die lebende, auftaucht, wir bringen wieder auf die Rede von dir, den rauschenden Lobpreis, und pfeilschnell wird er sich wieder erheben aus dem Wasser wie die Ihing (anderer Name für Tambon), wie die Naga (wie oben) des Flusses.

Wir heissen deinen Ruhm wieder auftauchen und in wiegendem Gange herumgehen in den Dörfern und um- 
ting, $m$ timbul umba-umban manasa rundong hapamantai tambon.

Amon biti,m manjun riwut tarong,m akan djalajan hulu danum, humpang-humpir bendang bulau idje bahalap hadare dawe,e, amon balita,m mangumbang salatan kilat tinting akan hila tandjong ringkin karangan pangantorak gohong sundong-sundei pusok rahing tarong batoros buno.

Awi katahanan riwut tarong, $m$ bara kabantengan batang danum, buku kalaketan salatan kilat tinting, $m$ bahandjong kabangkehan gohong.

Amon biti,m manjun riwut tarong, $m$ akan hila kalimbahan laut, humpang-humpir dawen ipah laut idje bahalap batundjang dohong, hemben balita,m mangumbang salatan kilat tinting, $m$ manasa hila panumparan pasang, sundongsundei pusok rahing tarong batoros buno.

Awi katahanan riwut ta- Deshalb geschieht es, weil aufrecht herschweifen längs den Wassern, deinen wehenden Lobpreis sich $\mathbf{z u}$ erheben und in zierlichem Gange herumzugehen längs den Orten am Ufer des Wohnplatzes der Wasserschlange.

Wenn du verbreitest deinen wehenden Ruhm nach dem Oberlauf, dem Quellgebiet des Flusses, dann beugen sich tief hernieder die Bendangpalmen, die goldenen, die mit Blätterwerk schön umflochtenen und wenn ausgeht dein rauschender blitzender Lobpreis bis hin zu den Buchtungen der Steinbänke über die die Wellchen zierlich hüpfen, dann bücken sich tief herab in das Wasser die Pusokpalmen und sie verkünden deinen Lobpreis wie ein aufrechtstehender Speer (wahrhaftig sprechend und ohne Umschweife).

Deshalb geschieht es, weil aufrecht gehalten wird dein Ruhm in der Mitte des Flusslaufes (im Orte des Sprechers), weil festgehalten wird an deinem Lobpreis, dem rauschenden, blitzenden, darum dringt er auch weiter vom Mittellauf des Stromes.

Wenn du deinen Ruhm hin- und herwiegst nach der Seite der Mündung hin an der See, dann beugen sich tief herunter die Blätter der Ipahpalme, welche schön besteckt sind mit Dolchen (nämlich mit Dornen), wenn herumgeht dein Lobpreis, der rauschende, blitzende bis dahin wo die Flut ihren Anfang nimmt, dann neigen sich herab die Pusokpälmchen und sie verkünden weiter deinen Lobpreis wie ein aufrechtstehender Speer. 
rong, $m$ bara kabantengan batang danum buku, kalaketan salatan kilat tinting bahandjong kabangkehan gohong.

Amon biti,m manjun riwut tarong,m manjelem kalang labeho handalem, teneng riak rawing basiak, amon balita,m mangumbang salatan kilat tinting, $m$ manantame rantau timben, bakarintoh ringkin lomba bahanji.

Amon biti,m manjun riwut tarong, $m$ manjalumbo tandjong ambon tupang-tapei ampah lawang baunandau, hemben balita, $m$ mangumbang salatan kilat tinting,m manarikan enon tuang-tiup sangking rahan tunggul balo.

Amon djaton riwut tarong,m djalajan hulu danum, aton riwut tarong, $m$ hila tumbang danum, djaka benjem salatan kilat tinting, $m$ hila tandjong ringkin karangan, anan salatan kilat tinting, $m$ hila tapudjakan gohong.

Te batutoh bulau lelak bendang, batingkai rabia,n pusok pandong, batasat radja Ha- gehalten wird dein Ruhm in der Mitte des Flusslaufes, weil festgehalten wird an deinem Lobpreis, dem rauschenden, blitzenden am Mittellauf des Stromes von wo er ausgeht.

Und wenn du deinen wehenden Ruhm hin- und herwiegst, bis dass er eingehit in die Wassertiefe, die abgründige, dann verstummen die dort wogenden Krokodile, die wilden, und wenn herumgeht dein rauschender Lobpreis, der blitzende, und wenn er hinabfährt in die Tiefe, die sehr grosse, dann schweigen die sich tummelnden Krokodile, die tapferen.

Und wenn du deinen wehenden Ruhm hin- und herwiegst, so dass er gerade aufsteige durch die Buchtungen der Wolken, dann wird er hoch in die Höhe gehoben bis hin zur Türe der Wolken, und dann wenn herumgeht dein brausender Lobpreis, der blitzende, dann wird er erhoben bis zu den aussprossenden Rahan (die Versammlungshäuser der weiblichen Sangiang, die der männlichen Sangiang werden Balai genannt) der Tunggul Balo.

Wenn dein Ruhm nicht mehr erschallen sollte am Oberlauf, im Quellgebiet des Flusses, dann erklingt dein Ruhm in der Richtung der Mündung des Stromes, und wenn verstummt dein Lobpreis, der rauschende, der blitzende in den Buchtungen wo über die Steinbänke hüpfen die Wellchen, dann steigt auf dein Gesang in der Richtung der Mündung des Wassers.

Und dann fallen herunter die goldenen Blüten der Bendangpalmen, dann reissen sich los die goldenen jungen 
tanggoi Tingang, bapindah Herzblätter des Ipahgehölzes, dann Andin Habungai Lamiang. verzieht sich der Radja Hatanggoi Tingang, dann weicht der Andin Habungai Lamiang (der König mit einem Nashornvogel als Hut, der Andin mit einem Nashornvogel von Achaten. Es ist ein Wassergott aber auch der Name eines sehr teuren heiligen Topfes).

Batasat njalong bukit batu, bapindah luhing kereng liang, batasat tambon repang garantong, bapindah riak henda,n bulau.

Und es verzieht sich das Wasser der Steinberge (bukit batu: teure heilige Töpfe; njalong: Wasser, oder das in den Töpfen aufbewahrte Bier), und es weicht das wärmende (Getränk) des felsigen Hügels, es entweicht die Wasserschlange (Kette) an der aufgehängt sind die Reihen der Gong, es verziehen sich die gelben Wellchen, die goldenen (der Speichel der Sirihkausel).

Hagoet manand jahan tarong,m hila tumbang batang danum, basangka mangatah salatan kilat tinting,m medjen tapudjakan gohong.

Und sie gehen aus und sie suchen auf den Ort deines Ruhmes in der Richtung der Mündung des Flusses, sie machen sich auf und sie folgen nach deinem rauschenden Lobpreis, dem blitzenden an der Mündung des Stromes.

Amon djaton tarong, $m$ hila Und wenn dein Ruhm nicht mehr ertumbang batang danum aton riwut tarong, $m$ hila djalajan hulu danum, amon korang salatan tinting, $m$ medjen tapudjakan gohong salenga anan kilat tinting, $m$ medjen jila tandjong ringkin karangan. schallen sollte in der Richtung der Mündung des Flusses, dann steigt auf dein wehender Ruhm in der Richtung des Oberlaufes, des Quellortes des Wassers, und wenn verstummt dein Lobpreis, der rauschende an der Mündung des Flusses, dann steigt plötzlich auf dein blitzender Lobpreis in der Richtung der Buchtungen wo über die Steinbänke hüpfen die Wellchen.

Te banama murik haluana, Dann fahren die Boote mit flussauf- 
adjong manandjak sapupilake, batutoh kilat bulau pungkal radja, patingkai puti,n rabia tisik tambon, baratap tampong lamiang, batetes batilan timpong, batutoh udja-udjan bulau kambang ipah laut, batingkai ritih-rihe rabia lelak pusok rahing tarong.

Manadjahan riwut tarong, $m$ hila djalajan hulu danum, mangatah salatan kilat tinting, $m$ barega medjen tandjong ringkin karangan.

Akan indu Djata tontong tahaseng oloh hila tumbang batang danum, pandai indu Hatala tambing njama,n oloh medjen tapudjakan gohong are.

Riwut tarong, $m$ pandjang hakalingkang langit, kutoh ah bewei salatan kilat tinting, $m$ ambo habambilit hawon.

Hajak biti,m puna batandak wärts gerichteten Bügen, dann ziehen die Schiffe hinauf den Fluss und es verbleichen die Blitze des goldenen Schmiedewerkes und es weicht die leuchtende Weissheit der goldenen Schuppen der Wasserschlange (Goldschmuck), es zerreissen die Trosse der Achatsteine, es fallen auseinander die Bündel des farbigen Tuches, und rieselnd fallen herab die goldenen Blüten der Ipahpalmen am Meere und wie feiner Staubregen fallen herunter die jungen zarten Herzblätter der Ipahpalmen, die dein Lob verkünden (d.h. vor dem Ruhm des Reises verbleicht aller Glanz der Handelsgüter die in den Booten in die Gebiete, die am Oberlauf des Flusses liegen, gebracht werden).

Und sie suchen auf den Ort deines Ruhmes in der Richtung des Oberlaufes, des Quellortes des Wassers, sie erforschen den Ort deines brausenden, blitzenden Lobpreises an den Buchtungen wo über die Steinbänke hüpfen die Wellchen.

Denn ein Djata bist du, der da verlängert den Atem der Menschen in der Richtung der Mündung des Flusses, ein Hatala bist du, der da vermehrt den Mund (Atem) der Leute, da wo die Flüsse, die vielen, einmünden in das Meer.

Dein wehender Ruhm, der langanhaltende, schreitet auf bis zum Himmel, und in Menge kräuselt sich empor in die Höhe dein rauschender, blitzender Lobpreis, bis dass er ankommt über den Wolken.

Und ausführlich besingt man dich, o 
pandjang mangumbang lewu mandereh danum.

Puna balita,m basansana ambo, mangurah rundong hapamantai tambon.

Tapi hemben nduan, hambekan katon matok dinon kadjaretan etoh:

Dia olihku manandak biti,m pandjang dimpah ruang langit, isen aku tahan mangarunja balita,m ambo nagkuramak hawon.

Awi nutusku gandang paleng maruak batu,n karangan danum, sambangku batu malangkuang, awi garo aku liang malampok,e.

Sawang saloh aku nambatang sambang dia tawan talatai biti,m bunge rentar balitang$\mathrm{ku}$ bateras garo, korang batuana tinting palempang tandak,m, nduan djangkau djarang, timang, $m$ tahitik dinon djantai djahai.

Tandak,m nduangku tahandjunga, timang, $m$ dinongku salimpaja bewei.
Reis, in allen Dörfern und an allen Flüssen.

Und wahrlich, man erzählt von dir lange Geschichten überall in den Orten die an den Ufern liegen des Wohnplatzes der Wasserschlange.

Aber so steht es jetzt, so ist es in dieser Sache und dieses ist mein Ergebnis :

Nicht ist es mir möglich dich lange $\mathrm{zu}$ besingen, so dass mein Gesang hindurchdringen würde durch das Himmelsgewölbe, nicht bin ich im Stande dich so in meinem Liede $z u$ preisen, dass mein Lied aufsteigen würde durch die Wolken.

Denn ich bin ja nur eine stumme Trommel, die ausgehöhlt wurde durch den Stein von den Steinbänken des Flusses, denn ich bin ja doch nur eine kleine Trommel, die zerfasert wurde vom Geröll, ich bin ja nur wie Räucherwerk das durch den Stein verborgen wird.

Ich bin ja nur ein verwandelter Sawang der eine kleine Trommel als Stamm besitzt und $z u$ wenig ist mir bekannit dein Ursprung, ich bin ja nur eine verwandelte Bungestaude (Sawang: Dracaena terminalis) die einen Stamm von Räucherwerk hat und zu wenig genau weiss ich die Grundlage (Herkunft) deines Spruchwortes, ich weiss nur wenige Blumen (poetische Redewendungen) und ich kenne ja nur vereinzelte Stücke deiner zärtlichen Namen. ${ }^{328}$

Und deinen Gesang erhalte ich ja nur Stück für Stück und deine zärtlichen Namen empfange ich ja nur in 
Hindai tandak,m pandjang hakalingkang langit nah behas. Amon sawang saloh are nambabatang sambang dapit timang, $m$ ambo hambambilit hawon, amon bunge rentar rai bateras garo, amon mamapan banama kahean melai batu lawang parutaran, amon sawak manimbau adjong datoh hila panapian tingang,

Amon hatalatai lunok mamua bulau hasakean tingang, amon djadi malempang baras bulau lampang manalumbang lanting lamiang,

Amon djari njaho hai naparogoh tungkup, amon sembang

\section{Zwischenräumen.}

Und noch nicht steigt dein Lied als ein langes auf zum Himmel, o Reis. Erst später wenn der verwandelte Sawang viele Stämme bildet von kleinen Trommeln, dann wird dein Ruhm in Menge aufsteigen zu den Wolken, dann wenn der verwandelte Bungestrauch manche Pfosten besitzen wird von Räucherwerk, dann wenn ein Boot gebaut wird, ein grosses, das beim Steine, der Türe zum Vorplatz des Hauses liegt (der Platz zwischen Haus und Fluss oder auch einfach der Anlegeplatz für die Boote), dann wenn in ungestümer Arbeit Brett auf Brett gelegt wird am Schiffe, dem neuen und grossen, das sich beim Anlegeplatz befindet (und mit dem man den Gästen die zum Tiwah kommen, d.h. den Lalohan oder der andern Stammhälfte, entgegenrudert),

Dann, wenn der Lunokbaum im Begriffe steht goldene Früchte zu tragen, die an ihm aufgehängt werden durch die Nashornvögel (gedacht ist hier wahrscheinlich an die Geschenke, die in der Form eines Lebensbaumes von den Lalohan, oder der andern Stammhälfte, zum Totenfest mitgebracht werden), dann wenn auf dem Grunde des Flusses zum Vorschein kommt der aufsprudelnde goldene Sand und seine Wellen gegen das Floss von Achatsteinen plätschern (dieses lanting lamiang ist wahrscheinlich das Fahrzeug der Lalohan, die ebenfalls mit einem Floss reisen),

Dann, wenn der krachende Donner zum Erbeben bringt die ganze 
kilat pandjang idje nampurindet ruang,

Amon nole djari nupi penjang, lalundong siren sawak mangampa paturong,

Amon djadi hatalatai lunok mamua undan bakurangan penjang, hapalempang baras bulau lampang hapasang darah,

Amon djari ngentang tiwah tingang, mangkut ahoi burong,

Hete tandak,m pandjang hakalingkang langit, eka timang,m ambo habambilit hawon.

Hemben nduan, hambekan katon baja tandak,m manandjulo indu hapaku manarindjet gana, $\mathrm{m}$, baja timang, $\mathrm{m}$ manalandjat pandaiku nitih namparogoh balita,m.
Familiengemeinschaft und wenn ihm folgt der langzuckende Blitz, der zum Erzittern bringt das Haus (d.h. wenn der Festjubel bein Totenfest seinen Höhepunkt erreicht hat),

Dann, wenn die Waisen in ihren Träumen Penjang empfingen und wenn die verlassenen und klagenden Kinder im Schlafe von Paturong zu sprechen begannen,

Dann, wenn vollbracht worden ist der Ratschluss und wenn der Lunokbaum Undanfrüchte, die Glieder der Penjang, getragen hat (Schädel, die auf den Schädelpfahl gesteckt worden sind), dann, wenn sichtbar wird der Grund des Flusses und aufsprudelt der goldene Sand vermengt mit Blut (die von der Kopfjagd mitgebrachten Schädel), Dann, wenn es geschieht, dass durch die Nashornvögel das Tiwah besorgt wird, dann, wenn das Totenfest seinen Anfang genommen hat,

Dann ist die Zeit angebrochen, dass dein Gesang langanhaltend aufsteigen wird zum Himmel, dann wird es geschehen, dass dein Gesang in ausführlichen Worten emporweht zu den Wolken.

Jetzt ist es so, nun aber steht es in dieser Sache dermassen, dass dein Lied nur ein kurzes ist um aufzuwecken deine Seele, dass dein Gesang nur einen Augenblick dauert um sanft anzustossen und vorsichtig zu schütteln deine Seele.

\section{Die Aufweckung der Reisseele}

Ngandangku biti,m behas Sanft schlage ich dich, o Reis, wie man kilau mangandang batu salo- anschlägt den Stein, den verwandelten 
han tandang haramaung, nitihku balita,m sawong ambon tingkah manitih sahep rakeran darong handjaliwan. Hajak pararindjet gana,m ikau behas ttg. kitik hapangandang metoh biti,m kalaboan djaringku, redjar hapandereh balita,m sawong ambon hemben balita,m kalaketan karahku.

Hapangandang ikau kilau bawi katarunan sangiang, redjar hapangasa rowan habinei katakepan djalajan.

Tawurku sintong udju, sawong ambon dinon lambong hanja, hajak ewau garo bulan bakalinda tingang ikau balua nangkaruan bau,n pinggan randan, humboh simak santi ngeket pahawang idje bakalampang tambon balita,m sawong ambon bahandjong sara,n sarimburong laut.
Tiger, vorsichtig klopfe ich an dir an, o Reiskorn, wie man anklopft an die im Laube verborgen liegende, aufgerollte Handjaliwanschlange.

Und ich wecke sanft auf deine Seele, o Reis, und du erbebst wie das tönende Trommelfell, während du herausfällst aus meinen Fingern, und es schlagen die Adern deines Herzens, die angespannten, o Reiskorn, während du herunterrieselst aus meinen Händen. $\mathrm{Du}$ erbebst wie die Frau (die Priesterin) während in sie einfährt der Sangiang, du erzitterst und du bewegst dich hin und her wie das Weib, das gepackt wird von ihrem Djalajan.

Mein Streureis, zusammen sieben (d.h. Jungfrauen in die sich der Reis während dieser Handlung verwandelt hat), mein Reiskorn, das vermehrt ist $z \mathfrak{u}$ acht, duftend wie das Räucherwerk der Monde, das anlockt die Nashornvögel (Männer), nun schreitest du ordentlich heraus aus der Oeffnung des Gefässes, des kleinen, begleitet von Weihrauch, dem lieblich duftenden, der ausgeht von den Frauen, so gehst du nun hervor, o mein Reiskorn, und du trittst über die Ränder des kleinen Napfes von Uebersee.

\section{Die Reise der Reisseelen nach der Oberwelt}

Der Priester oder die Priesterin (Hauptbalian) ruft nun zuerst die Reisseelen hervor und dann übergibt er ihnen den Auftrag, den sie den Sangiang in der Oberwelt in seinem Namen, und auch im Namen der Menschen, die diese Handlung veranstalten lassen, zu überbringen haben. Die Reiskörner werden in Dolch- oder Pfeilregen verwandelt, der auf die Ambon Rutas herabrieselt und das Haus und die ganze Hausgemeinschaft von ihren schädlichen Auswirkungen befreit. Dann 
erhält er für seine Reise ein Boot, das aus einem spitzzulaufenden. geflochtenen und gefärbten Frauenhut besteht. In diesen setzen sich die Reisseelen und fahren durch die Wolkenlagen hinauf in die Oberwelt. Bevor sie ihre Reise aber antreten können, müssen die Liau (die Toten, für die das Totenfest noch nicht gefeiert worden ist oder die Toten, die eines plötzlichen Todes gestorben sind (matei manta: unreifer Tod) und deshalb nicht in das Totendorf aufgenommen werden) auf die Seite geschafft werden, damit sie die Reise der Reisseelen nicht stören können. Nachdem das geschehen ist, treten die Reisseelen ihre Reise an und haben nicht mehr zu befürchten, dass sie dabei gehindert werden. Wie ein schweres Unwetter brechen sie über das Dorf Danum Djalajan herein. Der Himmel verdunkelt sich und die Sangiang erschrecken und befürchten, dass das Dorf in Stein verwandelt werde, weil die Kinder die Palivorschriften in unachtsamer Weise übertreten haben. Sie betreten nun, wie es ankommenden Gästen geziemt, den Balai des Dohong Mama Tandang Sangiang, den sie herbeiholen müssen, aber bevor sie ihn betreten, fallen sie wie ein schwerer Regen auf den Balai hernieder. Zwischen den Reisseelen und Dohong Mama Tandang Sangiang findet eine Besprechung statt und sie übergeben die Aufträge des Hauptbalian und der Menschen am Ufer des Flusses der Welt. Dohong Mama Tandang nimmt die Bitte an und er trifft alle Vorbereitungen für die Reise nach den Ufern des Flusses der Welt.

Unser Text fährt zuerst erklärend fort um dann wieder überzugehen in den Gesang :

Limbah te upo,n balian manjumput behas tawur isut-isut ttg. mandjakah behas tawur te akan amak hila bau,e hangkudju tingkat mandjakah,e hajak mise: idje, due, telo, epat, lime, djahawen, udju. Te upo manontong auch,e tinai, koa,e :
Darnach ergreift der Hauptbalian mit seinen Fingern ein wenig Streureis und wirft diesen Streureis nieder auf die Matte, die vor seinem Angesicht liegt, sieben Mal wirft er ihn aus, indem er dabei zählt: eins, zwei, drei, vier, fünf, sechs, sieben.

Und darnach setzt der Hauptbalian sein Spruchwort wieder fort, indem er sagt :

\section{A. Die Hervorrufung der Reisseelen und der Auftrag des Priesters}

Kilat baputih ikau balua Weiss glänzender Blitz, du trittst herbau,n pinggan randan, hidjer vor aus der Oeffnung des kleinen Ge- 
bahenda bahandjong sara,n sarimburong laut.

Halawo ikau bumbong dare, $n$ puron, ikau tawur sintong udju, harende ikau pandong hakajau dare, sawong ambon dinon lambong hanja.

Metoh biti,m halawo bumbong dare,n puron palus basaloh ikau djadi bulan njawak kabangkange, bulan bawi,n tawur, hemben balita, $m$ harende pandong hakajau dare balita, $m$ rentar djadi pahawang idje totok katentange panuhan habinei ikau rabia sawong ambon.

Puna bawi mait kindjap ikau manarusan langit, habinei djaja hiket mametas enon.

Humbang bulau ikau batutus buku tau bawi indu loang raweiku, rendan rabia ikau hatarusan lawas pandai habinei manambing tisoiku.

Hulek bulau pating sumping bulan bawi,n tawur sintong udju, hakangkalo rabia bungai djundjung habinei sawong ambon dinon lambong hanja. fässes, gelb aufleuchtendes Licht, du schreitest heraus über die Ränder des kleinen Napfes von Uebersee.

Falle hernieder auf die Matte, auf das Geflecht der Puronpalme, du Streureis, zusammen sieben, stürze dich herunter auf die kreuzweis geflochtene Matte, o du Reiskorn, das vermehrt worden ist $z u$ acht.

Und während du herunterfällst auf die Matte, das Geflecht der Puronpalme, verwandelst du dich und nimmst die Gestalt an von Monden von ungestümer Schönheit, von Monden, die die Frauen des Streureises sind, und während du herniederstürzest auf die kreuzweis geflochtene Matte veränderst du dein Aussehen und wirst zu Frauen von grosser Lieblichkeit, zu Monden, zu Frauen, o Reiskorn.

Denn wahrlich, ihr seid ja die Frauen, die kräftig wirksamen, die oft durchqueren den Himmel, die Frauen, die starken, die da oft reisen durch die Wolken.

Denn ihr seid ja goldene Bambusrohre, welche durchstochen sind, und das ist der Grund, dass ihr könnt dienen als Frauen, als Botschafterinnen meines Wortes, ihr seid ja gefranste Golddrähte, die eingelegt sind in einen Bambusköcher, und das ist die Ursache, dass ihr fähig seid meine Rede zu überbringen.

Drehet die goldenen Ende der Ohrringe, ihr Monde, ihr Frauen des Streureises, ihr sieben zusammen, wendet zur Seite den goldenen Schmuck, den nach aussen stehenden, ihr Frauen des Reiskornes, ihr vermehrten zu acht. 
Sarak-saraken pandong lawin balau pandjang bulan bawi,n tawur, mikeh are manandjala anting kanahan danum.

Djala,m manahingan riwut raweiku mameteh biti,m, njalanean salatan tisoiku mandjandji balita,m.

Ela peteh tingang ikau hatangkalau lunok, isen ikau djandji,n tambon malangkawet kalang labeho handalem.

Puna petehku mandehen kilau mamapak ulang harantong danum, djandjingku toto mandjiret tingkah hewang manjirat lanting garing.

Kilau etoh aku mameteh biti,m tawur, pandang katon balitangku hadjandji denga,m sawong ambon:

Bau ampi,n panalatai kilau So steht es nun in dieser Sache, so
Kämmet sorgfältig euer Haar bis hinunter zu seinen Enden, kämmet das lange, o ihr Monde, ihr Frauen des Streureises, denn vielleicht fangen ein die Ohrringe die tropfenden von Wasser (wie nach dem Bade an den Ohrringen Wassertropfen haften bleiben, so könnten die Worte des Priesters an ihnen und an den langen Haaren haften bleiben. Hat man eine wichtige Rede mitzuteilen, dann wird sie immer mit dieser Aufforderung eingeleitet).

Fange ein (djala: das Wurfnetz, djalam, Imperativ: wirf das Wurfnetz aus) und höre gut auf mein wehendes Wort, das ich dir befehle, horche auf meine rauschende Rede, die ich dir auftrage.

Nicht handelt es sich um einen Befehl, der wie ein Nashornvogel vorbeifliegt am Fruchtbaum, nicht geht es um einen Auftrag, der wie eine Wasserschlange vorbeischiesst an der Wassertiefe, der abgründigen (d.h. die am Ziele vorbeigeht und es dadurch verfehlt).

Denn wahrlich, mein Auftrag ist ein fester, gleichwie man einschlägt die sich kreuzenden Pfosten des Zaunes im Wasser (um für den Fischfang einen Fluss abzusperren), mein Befehl ist ein festgebundener, wie die Männer festbinden das Floss von Elfenbein (d.h. von Baumstämmen gemacht). Auf diese Weise befehle ich dir nun, o Streureis, solchergestalt beauftragt dich nun meine Person, o Reiskorn: 
bulan manalatai dare, pandang katon pamalempange tingkah pahawang malekut tabuhi:

Entang pantai danum kalunen, tarantang penjang lewu ano, tujang luwok kampongan buno, salotih paturong rundong ano, lunok ie taheta batipas pantang, baringen balita nambahua bageto sangkabila.

Tapakalong awi riak penjang ain Pantoh Ganan Kaju Hai, tapugenggem ringkin paturong ain Embak Ganan Bua Bakas.

Limbah ikei pantai danum kalunen mamaleh andep pandjang, ulek ikei luwok kampongan buno mamulang tekap ambo, limbah ikei bandong kajau, ulek ikei pumpon seran,

Ie nduan hambekan katon, matok dinon djaretan etoh: Mampong,e sambang bulau hajak nundu garo rabia, mandjawi bahing karungut, mamekat bambahinga,n kandaju, ist es wie die Monde beratschlagen wegen des Flechtwerkes, so ist es in dieser Angelegenheit, so wie vor sich ausbreiten die Monde das zu bearbeitende Geflecht :

Dem Getragenen vom Ufer des Flusses, dem Kinde (Gliede) des Penjang des Dorfes N.N., dem Gewiegten von der Buchtung des Dorfes der Lanzen, dem Gliede aus dem Paturong des Ortes N.N., ihm dem Lunok ist neulich abgeschlagen worden der Stamm, ihm dem Waringin sind kürzlich abgebrochen worden seine Stützen (gedacht ist an die Luftwurzeln).

Eingeschlossen wurde er von den Wellen der Penjang des Pantoh Ganan Kaju Hai, umzingelt wurde er von den Fluten der Paturong des Embak Ganan Bua Bakas (siehe den Text: Die Kopfjagd nach dem Pantoh Ganan Kaju Hai, an den das Tantolak matei anschliesst).

Nachdem wir vom Ufer des Flusses der Welt Rache genommen haben für den Schlag, den grossen, nachdem wir von der Buchtung des Dorfes der Lanzen Vergeltung übten für den Hieb, den langen, nachdem wir uns versammelt hatten als Kopfjäger, nachdem wir zusammengekommen und ausgezogen waren als Krieger,

Ist es nun solchermassen, steht es nun dergestalt in dieser Angelegenheit:

Und wir schlugen sanft die kleinen goldenen Trommeln und wir entzündeten den Weihrauch, den goldenen, und wir nahmen in Löhnung das Spruchwort und wir mieteten für uns den Gesang (d.h. die Priester und 
Hapan magah salumpok liau haring kaharingan, hapa manganggahan tanterus pangambon manjampai lewu,n Balo Indu Rangkang Penjang, manasa tewang pangkarundong Sulan Mina Perang Matanandau,

Oloh lewu Bukit Kanjaloh Lanting, rundong Kereng Manaliwoh Rahan.

Awi te nduan hambekan katon biti,n bulan bawi,n tawur sintong udje, matok dinon djaretan etoh, ijoh rabia sawong ambon, njahuangku ikau antang manamuei malan manjalumbo tandjong ambon telo pulu telo, mangadja ringkang keton manarikan enon limebalas hatalamping.

Manjembang balai sangiang, eka Dohong Mama Tandang, marampe sali djalajan Langkah Sawang Mama Bungai Bunge, bandong Njaring djahawen.

Hagoet keton bulan bawi,n tawur sintong udju balasang lio bulau dare,n tanggoi, ma-
Priesterinnen, die die Handlungen auszuführen und die Gesänge vorzutragen haben),

Um zu führen die Salumpok Liau, die lebende, des Lebens, um zu leiten die Tanterus Pangambon bis hin nach dem Dorfe der Balo Indu Rangkang Penjang, bis hin zu der Buchtung des Ortes der Sulan Mina Perang Matanandau (das ist nicht ganz richtig, denn dorthin wird nicht die Salumpok Liau haring kaharingan geleitet, sondern die Liau Balawang Pandjang. Siehe unten),

$\mathrm{Zu}$ den Leuten des Dorfes Bukit Kanjaloh Lanting, des Ortes Kereng Manaliwoh Rahan.

Aus diesem Grunde geschieht es jetzt, o Monde, ihr Frauen des Streureises, ihr sieben zusammen, nach dieser Ueberlegung handeln wir nun, o goldenes Reiskorn, wir beauftragen euch nun wie die Antang zu reisen und euch aufzumachen und emporzusteigen die Buchtungen, die langen, die drei und dreissig übereinanderliegenden, wir befehlen euch, ihr Schlanken, dass ihr aufwärtsfahret durch die Wolkenlagen, die fünfzehn doppelt übereinander aufgeschichteten. Dass ihr euch hinbegebet zum Versammlungshause der Sangiang, zum Orte des Dohong Mama Tandang, dass ihr ankommet beim Fremdenhause der Djalajan im Dorfe des Langkah Sawang Mama Bungai Bunge, des Mannes der Njaring, der sechsen.

Machet euch auf, ihr Monde, ihr Frauen des Streureises, ihr sieben zusammen, mit dem Boote, dem regen- 
ngat basangka keton habinei sawong ambon dinon lambong hanja, bagentoi lasang gentoi tabuhi hapa manalandjat pandang kalaman.

Mangat Dohong Mama Tandang hadurut kilau tingang nusang mandurut lunok, Langkah Sawang Mama Bungai malentur tingkah tambon randan marentur labeho.

Tuntang Sangiang tarantang garo handue udju, hajak Djalajan lalundong santi dinon lambong epatbalas.

Ewen hadurut hapan papan talawang sintong udju, bulau daren lintong lambong hanja.

Mandurut papan talawang teras kaju djambu bahandang, bulau dare,n lintong luhing lumpok muntei bulau.

Mangat Dohong Mama Tan- bogenfarbigen, mit dem goldenen Geflechte des Hutes, reiset nun weg, ihr Frauen des Reiskornes, die ihr vermehrt worden seid $z u$ acht, mit dem Boote, dem Fahrzeuge, dem kreuzweis geflochtenen, das da dient um zu überwinden die Hitze des Tages.

Auf dass Dohong Mama Tandang herabfahre wie der Nashornvogel der in schrägem Fluge herunterstösst auf den Fruchtbaum, damit Langkah Sawang Mama Bungai herabkomme, so wie die Wasserschlange, die kleine, hinunterschiesst in die Wassertiefe.

Und die Sangiang, die Kinder des Weihrauches, ihrer zweimal sieben, und die Djalajan, die Söhne des Räucherwerkes, ihrer vierzehn zusammen (d.h. er kommt mit seinen Helfern, wie auch der Upon Balian seine Helfer besitzt).

Sie fahren herab auf ihren Schildbrettern, zusammen sieben, sie kommen herunter auf den goldenen geflochtenen Bändern, vermehrt zu acht (es handelt sich um die Bänder, die um die Schilde geflochten werden um sie widerstandsfähiger zu machen. Der Schild dient den Sangiang, und nach manchen Mythen auch den Ahnen, als Fahrzeug mit dem sie alle ihre Reisen zurücklegen).

Sie fahren herab auf den Schildbrettern vom Kernholz des Djambubaumes, des roten, sie steigen herunter auf den goldenen geflochtenen Bändern, den Stäben, den Kernhölzern des Munteibaumes, des goldenen (ein anderer Name für Djambu).

Damit der Dohong Mama Tandang 
dang mimbit tingang entas, ${ }^{329}$ bungai taradjo. 330

Mimbit dohong lalunding liau, panuhan pulang talandjing pangkat.

Mimbit batu kangkalingei 331 liau, liang saramin pangambon.

Mimbit bulau tampong papas, rabia tundo,n kalingking.

Mimbit humbang rendan tingang akan elang salentup.

Mimbit hampatong uei rantihen tingang, sadiri upak lulong pamali.

Mimbit tambaran erang, tali,n tengang, upak langkoang leleng baho, kumis baringen haring idje belom manandai luwok djalajan.

Mimbit darah belom, darah burong saki, mimbit bambang penjang garo hajak paturong santi mait mengkak ambon barutas matei, manantiup enon bapilu nihau, njaho,n bulau sangkowak raung, kilat limban basaloh langit. mitbringe den Tingang der Losschalen, den Nashornvogel der Goldwaage.

Damit er mitbringe den Dolch, den Schmuck der Liau, den Reichtum der Scheide, das Wahrzeichen des Amtes. Damit er mitbringe den Stein des Schattenbildes der Liau, den Stein, den Spiegel der Erhöhten.

Damit er mitbringe den goldenen Tross, den Besen, das goldene Bündel, das glatt zugeschnittene.

Damit er mitbringe die Bambusköcher, die Fransen der Tingang als Bambus zum Knallen.

Damit er mitbringe das menschliche Schnitzbild von Rantihen-Rotan des Tingang, den Stellvertreter von der Rinde aus dem heiligen Haine.

Dass er mitbringe den Bast des Erang, die Schnüre von Tengang, den Bast des weichen Holzes vom Sammelplatz (Fundplatz) auf dem überwucherten Feld, die feine Haut des Waringin, des lebenden, welcher gedeiht und sich erhebt über den Flussbiegungen des Djalajan (des Flusses, an dem Dohong Mama Tandang wohnt).

Dass er mitbringe das Blut, das lebende, das Blut der Vögel, das zur rituellen Bestreichung dient (diese Vögel befinden sich in der Oberwelt; dadurch, dass Dohong Mama Tandang das Blut mitbringt, wird das Hühnerblut, das man zur Bestreichung braucht, erst wirksam: ohne die totale Mitwirkung der Oberwelt bleiben alle Handlungen ergebnislos), dass er mitbringe die Penjangsplitter des Weihrauchholzes und die Paturongspäne des Räucherwerkes, die kräftig wirk- 
Hampa mengkak langisan tangis tantuman tatom.

Kai raweiku mameteh biti,m tawur keton nduan sintong udju, tisoiku mandjandji balita,m sawong ambon keton lambong hanja.

Netep-netep ikau manandjulo tawur keton sintong udju, tarahondok lambat melai bumbong dare, $n$ puron hadjib balita,m manalandjat habinei sawong ambon keton dinon lambong hanja.

Kareh ikau manundjong taribanga,m kilau anak burong tingang, mangkat pangansiring, $m$ tingkah bulan bawi,n antang langit.

Hindai aku manjaloh tawurkı sintong udju kahalinai, ttg. hindai aku manjaloh tawurku idje sintong idje kalabi,e. samen, um zu lösen den Nebel, den unreinen des Todes, um aufzuheben den Tau, den schädlichen, des Verlorenen, den Donner, den goldenen, der Holzsplitter des Sarges (die bei seiner Anfertigung absplittern), den Blitz des Leichenwassers, das verwandelt ist in das Himmelsgewölbe (d.h. in die Wolken oder die Ambon Rutas).

Um zu befreien von den Tränen und dem Weinen, um zu erlösen von der Wehklage und dem Trauerlied.

So lautet mein Wort, das ich dir befehle, o Streureis, ihr sieben zusammen, so ist meine Rede, die ich euch übergebe, o Reiskörner, die ihr vermehrt seid zu achten.

Verweilet noch für kurze Zeit, o Streureiskörner, ihr sieben zusammen, setzt euch vorsichtig und lasst euch nebeneinander nieder auf die Matte, das Geflecht der Puronpalme, bleibt noch einen Augenblick hier, o ihr Frauen des Reiskornes, die ihr vermehrt seid zu achten.

Hernach werdet ihr erheben eure Flügel wie der junge Nashornvogel, werdet ihr öffnen eure Schwingen wie der Mond, der weibliche Falke des Himmels.

Denn noch nicht habe ich verwandelt meine Streureiskörner, die sieben zusammen, und noch nicht habe ich verwandelt meinen Streureis, der um eines vermehrt ist.

\section{B. Die Verwandlung des Streureises in Dolchregen}

Limbah te upo manjumput Darauf ergreift der Hauptbalian mit ttg. mandjakah behas tawur seinen Fingerspitzen ein wenig Streu- 
tinai akan amak ttg. mise, reis und wirft ihn wiederum auf die koa,e: idje, due, telo, epat, Matte, indem er dabei zählt: eins, lime, djahawen, udju, idje zwei, drei, vier, fünf, sechs, sieben kalabi,e. und eines mehr.

Limbah te upo manontong auch,e tawur,e tinai, koa,e :

Darauf setzt der Hauptbalian das Spruchwort seines Streureises wieder fort, indem er sagt (d.h. beinahe singend spricht):

Ijoi tawurku sintong udju, Ja, meine Streureiskörner, zusammen rabia sawong ambon dinon sieben, ja meine goldenen Reiskörner, lambong hanja, njaloh arep, $m$ die ihr vermehrt seid zu achten, verdjarı udjan dohong idje ka- wandelt euch nun und werdet $z u$ lange samperai, rentar balita,m anhaltendem Dolchregen, verändert djari rihen pimping due kapamarau.

Mudjan entang hapuas ruang parong, manjamperai manotok lambang siro.

Hapan mengkak ambon barutas matei, manjampelau enon bapilo nihau.

Kareh manontong tandak,m tawur amon djadi mudjan mamampang entang, kareh manambing karunja,m sawong ambon manjamperai ngalingking tujang. nun eure Gestalt und werdet zu fein rieselndem Staubregen von Blaserohrpfeilen, der wie in Fäden herniederfällt.

Beregnet alle Abteilungen des Hauses des Getragenen, beklopft und betropft die Schwelle der Wohnung.

Um zu lösen die Wolken, die unreinen des Todes, um zu befreien von dem Tau, dem verderblichen des Verlorenen.

Später werde ich wieder fortsetzen dein Spruchwort, o Streureis, nachdem du beregnet und überflutet hast die Getragenen, hernach werde ich wieder aufnehmen deinen Gesang, o Reiskorn, nachdem du in Menge herniedergefallen bist und bedeckt hast die Gewiegten.

\section{Der Streurcis erhält ein Boot für seine Reise}

Aku manontong tandak tawurku sintong idje manambing, karunja,n sawong ambon lambong due.
Ich nehme wieder auf das Spruchwort meines Streureises, des einen das zugefügt worden ist, ich setze wieder fort den Gesang des Reiskornes, das vermehrt worden ist zu zwei. 
Manjaloh arep,e djadi lasang bulau dare,n tanggoi, rentar balita,m djadi gentoi tabuhi hakajuh balekut,e.

Hapan bulan bawi,n tawur sintong udju malan manjalumbo tandjong ambon, indu gentoi rabia sawong ambon manarikan luwok enon.

Sama manggatang gelang bulau bula,n bawin tawur sintong udju lompat lasang bulau dare,n tanggoi, njariangkat kalumit 332 perang bintang,e habinei sawong ambon dinon lambong hanja, djakat gentoi tabuhi hakangkajuh balekute.

Sama mondok manantiup sindjang,e bulan huang lasang dare,n tanggoi.

Rata hapantar bua pinang, genep biti hataradjo manjang lius malan manjalumbo ambon, handak ringkang ewen manarikan luwok enon.
Verwandle dich selbst und werde $z u$ einem Fahrzeug, zum goldenen Geflecht des Frauenhutes, verändere deine Gestalt in ein Boot, in ein kreuzweise geflochtenes, versehen mit reichen Verzierungen.

Damit es benützt werden könne durch die Monde, die Frauen des Streureises, die sieben zusammen, um sich aufzumachen und aufzusteigen durch die Buchtungen der Wolken, um gebraucht zu werden als Fahrzeug für die goldenen Reiskörner auf ihrer Auffahrt durch die Flussbiegungen der Tauwolken.

Und zusammen erheben sie die Beinringe, die goldenen, die Monde, die Frauen des Streureises, die sieben zusammen und sie besteigen das Fahrzeug, das goldene Geflecht des Frauenhutes, sie heben auf den Gürtel von kupfernen Ringen (den man um die Hüften schlingt), den leuchtenden, den mit Sternen besetzten (gedacht ist an die einzelnen Glieder), sie die Frauen des Reiskornes, die da vermehrt sind $\mathrm{zu}$ acht, sie steigen hinein in das Boot, das kreuzweise geflochtene, versehen mit reichen Verzierungen.

Und zusammen setzen sie sich nieder mit den hochaufgehobenen wehenden Schultertüchern im Fahrzeug, im Geflechte des Hutes.

Und zusammen kauen sie die Früchte der Pinang, jede von ihnen kaut Betelnuss, bevor sie sich rüsten um aufzusteigen durch die Wolkenlagen, denn es stehen nun im Begriffe die Schlanken (ringkang: eng sein in der Taille) um hinaufzufahren die Buchtungen der 
Tauwolken.

Hando tandak,m manandjulo balasang bulau dare, $n$ tanggoi, tahan karunja,m manalandjat basali gentoi tabuhi.

Kareh manontong tandak,m kahalinai habasean ikau riwut bahing panton sambang, manambing karunja,m ikau sawong ambon bagentoi salatan bambahingan luhing.

Limbah te upo balian manjoho oloh tempo,n gawi balua bara karong hakampeleng mondok intu bentok huma.

Amon ewen djadi aton intu bentok huma, te upo manaburan behas, tisa,n tawur idje aton huang mangkok tawur.

Ie manawur,e mera-merau hila ambo,e takolok ewen oloh are. Amon djadi upo manaburan behas te ewen buli malalus gawi,e huang karong atawa hete-hete.
Ich halte zurück euer Lied eine kleine Weile während ihr euch aufhaltet im Boote, dem goldenen, dem Geflechte des Frauenhutes, ich unterbreche eueren Gesang für kurze Zeit während eueres Sitzens im Fahrzeuge, den kreuzweise geflochtenen.

Später werde ich wieder fortsetzen eueren Gesang, dann wenn ihr zusammen fortgerudert werdet durch den wehenden Schall des Schlages der Trommel, hernach werde ich wieder aufnehmen euer Lied, o Reiskörner, wenn ihr im Boote reiset, fortbewegt durch den brausenden Laut der Trommel.

Darnach befiehlt der Hauptbalian den Leuten, die diese Arbeit veranstalten lassen, herauszutreten aus den Kammern des Hauses und sich zu versammeln in der Mitte des Hauses (durch die die Schwelle läuft, die das Haus in Oberwelt und Unterwelt teilt). Wenn sie sich in der Mitte des Hauses befinden, dann streut der Hauptbalian Reis aus, nämlich den Rest des Streureises, der sich noch in dem Gefäss des Streureises befindet.

Er streut ihn rieselnd über die Köpfe aller dieser Leute. Wenn es geschehen ist, dass er den Reis ausgestreut hat, dann kehren sie wieder zurück um ihre Arbeiten zu verrichten, sei es in den Kammern oder wo auch immer.

\section{Die Vertreibung der Lian vom Wege, den die Frauen des Streureises zurückzulegen haben}

Toh upo,n balian ttg. kare Erst jetzt beginnen der Hauptbalian panggapit,e handiai haru ma- und alle seine Helfer mit ihm die 
nampara mamanto katambong,e hapan lago tekap taz'ur.

Lepah biti,n ewen oloh balian mamanto katambong tumon lago tekap tawur.

Upo,n balian kabuat,e bewei manandak hapan auch gantong, panombah,e uras suni baja mamanto katambong bewei.

Upo manandak, koa,e:

Lila-lilang liau buang matei, sarak awoi badjumbang nihau.

Teneng gandang anak $\mathrm{Nja}-$ ring menteng are randan babalai bungking lunok, rintohrinut towong Sahakong tatau are basali tandoh bambulong tusang.

Teneng gandang anak tambon randan babalai hapamontong kalang labeho handalem, rintoh-rinut towong ihing tatau basali hapamungger rantau timben. kleinen Trommeln zu schlagen nach der Melodie des Streureisschlages.

Alle Balian zusammen schlagen nun die kleinen Trommeln nach der Weise des Streureisschlages.

Der Hauptbalian allein beginnt nun mit einer deutlichen Stimme den Gesang, seine Beantworter (die Helfer) bleiben alle ruhig und schlagen nur die kleinen Trommeln.

Der Hauptbalian singt folgenden Gesang :

Fliehet hinweg, ihr Liau, ihr ergebnislos verstorbenen, eilet hinweg, ihr Awoi (anderes Wort für Liau), ihr umgefallenen und verlorenen (es handelt sich um Liau die nicht in das Totendorf aufgenommen wurden und deshalb unruhig herumschweifen und die Menschen, vor allem bei ihren religiösen Handlungen, stören).

Schweiget ihr Trommeln (Stimmen) der Kinder der Njaring, der tapferen, die ihr in Menge bewohnet die Aeste der Lunok, verstummet ihr Trommeln der Sahakong (ebenfalls Njaring), der reichen, die ihr in Scharen hauset auf den Zweigen der Waringin, der schräg stehenden (die Waringin beugen meistens nach dem Flusse über und daran ist hier gedacht).

Schweiget ihr Trommeln der Kinder der Wasserschlangen, welche wohnen zu beiden Seiten der Wassertiefe, der abgründigen, verstummet ihr Trommeln der Ihing (anderer Name für Tambon), der reichen, die da hausen, gleichmässig verteilt, um die Wassertiefe, die sehr grosse. 
Lila-lilang liau Lunok awang nambaheta batipas pantang,e, sara-sarak panungkup pangambon maing Baringen nambahua bageto sangkabila,e.

Awang timpong radja nambaheta parariup bihing mangampoh tandjong ambon buang, djalahan Pangambon bulau sangkalemo taheta mantap tasala mananggalong petak sintel habalambang tambon, liang deret habangkalan garantong.

Liau awang mampah batu lawang paruntaran tingang, manjahep liang panapian tambon.

Sama buli halalian bukit pasahan raung, mulang kereng daharin penda lunok.
Fliehet hinweg ihr Liau der Lunok, denen erst kürzlich abgeschlagen worden ist ihr Stamm, eilet hinweg ihr Angehörigen der Gemeinschaft der Pangambon (Name für Liau) der kräftigen Waringin, denen erst neulich zerbrochen wurde die Stütze (handelt sich um Liau für die das Totenfest noch nicht veranstaltet wurde).

Ihr Tücher, ihr königlichen, die ihr erst kürzlich fortgeweht worden seid, ihr farbig gestreiften, ihr einhüllenden, die ihr fortgeweht worden seid nach den Buchtungen, den langen, den ergebnislosen (weil sie noch herumschweifen müssen in diesen Buchtungen), du Gemeinschaft der Pangambon, der goldenen Späne, die erst kürzlich abgesprungen sind vom Amboss und die herabfielen auf die Erde, die feste. die als Schwelle hat die Wasserschlange, die herunterstürzten auf den Stein, den harten, der als Schwelle besitzt den Gong.

Ihr Liau, die ihr herumsitzet beim Steine, bei der Türe zum Vorplatze vor dem Hause der Nashornvögel, die ihr herumliegt, wie abgefallene Blätter, beim Steine, dem Anlegeplatz der Boote für die Wasserschlangen (gedacht ist an die Männer und Frauen, aber auch an die beiden Stanmhälften die sich, wenn sie sich zı wichtigen Handlungen vereinigen, hier zuerst begegnen).

Kehret gemeinschaftlich wieder um und begebt euch zurück zum Berge der Hütten der Särge, ziehet wieder heim zum Hügel der Wohnungen der Lunok (der Verstorbenen). 
Sama buli merem bulau sambang raung, mulang mantame runi talangkop njaho kanangkong tanggang tingang, 333

Idje bahalap njaloang uei pakulamba antang, bahalap kambadji garing handue udju masoh, handue udju murik.

Tarah handjaliwan matei lundjang-lendjut, tahitik talampe nihau lupang-lipet.

Bahalap mangamburi Asai Menteng tawan tarusan djalan liau, haluanan Rohau Bahanji batuana petas pangambon.

Sama nete-netep, ela balisang pandjang idje gawang tingang, korang balangkas ambo dinon due sambuti,n ranjing.

Liau hila ngawa nasatku ngawa-ngawa, basapau dawe,n ipah laut bahalap basandang dohong, hatingkap bumbong pusok rahing tarong batoros buno.
Kehret gemeinsam wieder um und gehet ein in die goldenen Trommeln der Särge, ziehet heim und tretet ein in die Särge mit den aufeinandergefügten Oeffnungen, den Donner, den querliegenden, das Boot der Tingang, Welches schön umflochten ist mit Rotanbändern, das Boot der Antang, welches zierlich verkeilt ist mit elfenbeinernen Keilen, zweimal sieben abwärts gerichtet, zweimal sieben aufwärts gerichtet.

Behauene Handjaliwanschlange die gekrümmt gestorben ist, herausgeschlagene Talampeschlange, die gebogen verloren ging (der Sarg ist als eine Wasserschlange, die ein Boot trägt, geschnitzt).

Gut gesteuert von Asai, dem tapferen, welchem bekannt sind die Kanäle, die Wege der Liau, und am Vorderteile fortgerudert durch Rohau, den mutigen, welcher vertraut ist mit den Pfaden der Pangambon.

Und zusammen bleibet ihr dort, nicht begebet ihr euch weg auch nur eine Spanne der Tingang, nicht rühret ihr euch von euerem Platze, selbst nicht einen Sambuti der Verehrungswürdigen (sambuti: ein Mass, von der Spitze des ausgestreckten Daumens bis zur andern Seite der Hand, also etwa $2 / 3$ einer Spanne lang).

Die Liau, die sich unterhalb des Dorfes aufhalten schiebe ich hinweg, weiter nach flussabwärts, und ich überdache sie mit Blättern der Ipahpalme vom Meer, den schön besetzten mit Dolchen, ich bedecke sie mit einer Matte von Pusok Rahing Tarong die als Stamm 
Raung Oloh Ngadju

Ein Ngadju Sarg

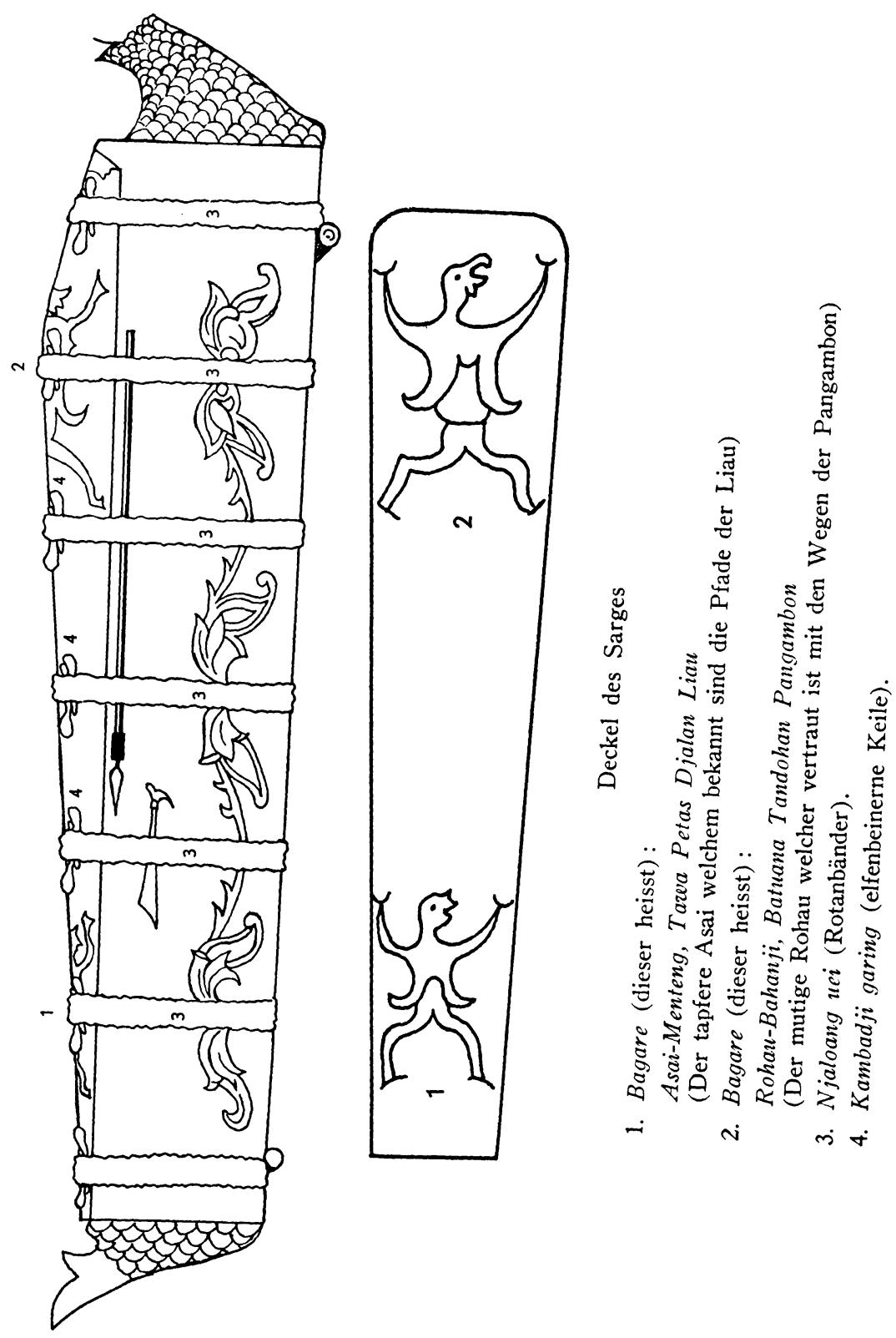


Sana dohong merem manabala kumpang,e, buno rintoh marong gantuling,e.

Ela balisang pandjang idje gawang tingang, korang balangkas ambo dinon due sambuti,n ranjing.

Liau awang hila ngadju nasatku ngadju-ngadju akan djalajan hulu danum basapau dawen bendang bulau bahalap hadare dawe,e, batingkap bumbong palas pandong.

Sama dohong merem rata manabala kumpang,e, buno rintoh marong gantuling,e.

Ela kea balisang pandjang idje gawang tingang, korang balangkas ambo dinon due kasambuti,n ranjing.

Liau awang hila rakuren lewu nasatku akan ngambo-ngambo mantang pai,n bukit pandjang, manindan purok ambo, basapau dawen biro,n bukit, batingkap bumbong palas pandong.

Sama dohong merem ewen manambala kumpang, buno eine Lanze besitzt.

Gemeinsam kehret ihr wieder zurück und tretet ein in euere Scheiden, ihr Dolche, ihr Lanzen kehret um und füget euch ein in euere Ringe.

Begebet euch nicht mehr weg, auch nicht eine Spanne der Tingang nur, nicht rühret ihr euch fortan von eueren Plätzen, auch nicht einen Sambuti der Verehrungswürdigen.

Die Liau, die sich oberhalb des Dorfes aufhalten schiebe ich hinweg, weiter nach flussaufwärts bis zum Oberlauf, zum Quellgebiet des Wassers, ich überdache sie mit Blättern der Bendangpalme, der goldenen, der schön durchflochtenen mit Laubwerk, ich bedecke sie mit der Matte der Palaspalme, der zierlich ausgefransten.

Gemeinsam kehret ihr wieder zurück und tretet ein in euere Scheiden, ihr Dolche, ihr Lanzen kehret um und füget euch ein in euere Ringe.

Begebet euch nicht mehr weg, auch nicht eine Spanne der Tingang nur, nicht rühret ihr euch fortan von eueren Plätzen, auch nicht einen Sambuti der Verehrungswürdigen.

Die Liau welche sich hinter dem Dorfe aufhalten schiebe ich weit weg nach der Rückseite und zwinge sie zu besteigen den Fuss des Berges, des hohen, nötige ich $z u$ erklimmen den Felsen, den steilen, ich überdache sie mit den Blättern der Biropalme 334 des Berges, ich bedecke sie mit der Matte der Palaspalme, der zierlich ausgefransten.

Gemeinsam kehret ihr wieder zurück und tretet ein in euere Scheiden, ihr 
rintoh marong gantuling,e, dia balisang pandjang idje gawang tingang, isen balangkas ambo due kasambuti,n ranjing.

Liau awang hila dipah basapau dawen taberau bungai, sama dohong merem ie manabala kumpang,e, buno rintoh marong gantuling,e, dia balisang pandjang idje gawang tingang, korang balangkas ambo dinon due kasambuti,n ranjing.

Liau awang djundjun helo, pangambon maing totok tambalon tambon awang djari hanteran Telon Mama Tambon Buno, Hamparong Mama Kandajun Lanting murik batang danum Tijawo Bulau, manandjak gohong Sating Malelak Hintan, awang djadi njaruntai liau randin tandang, manjakati meto rama batandok garing,

Awang djadi mahapang karungut batu bangkalan lunok mamua undan, manjaruntai kandaju,n liang kantihan ba-
Dolche, ihr Lanzen kehret wieder um und fügt euch ein in eure Ringe, begebet euch nicht mehr weg, auch nicht eine Spanne der Tingang nur, nicht rühret ihr euch fortan von eueren Plätzen, auch nicht einen Sambuti der Verehrungswürdigen.

Die Liau welche sich auf der Ueberseite des Flusses aufhalten überdache ich mit den Blättern des Taberau Bungai, ${ }^{335}$ gemeinsam kehret ihr wieder zurück und tretet ein in eure Scheiden, ihr Dolche, ihr Lanzen kehret wieder um und fügt euch ein in eure Ringe, begebet euch nicht mehr weg, auch nicht eine Spanne der Tingang nur, nicht rühret ihr euch fortan von eueren Plätzen, auch nicht einen Sambuti der Verehrungswürdigen.

Die Liau welche sich schon früher erhoben haben, die Pangambon, die kräftigen, die aufgestiegen sind aus dem Munde der zusammengerollten Wasserschlange (d.h. aus der Erde, aus dem Grab) und welche bereits geleitet wurden durch Telon Mama Tambon Buno und durch Hamparong Mama Kandajun Lanting (die Begleiter des Tempon Telon), aufwärts fahrend den Fluss Tijawo Bulau, vorwärts rudernd auf dem Strome Sating Malelak Hintan (der Fluss an dem das Totendorf liegt), die geführt wurden zusammen mit den Liau der Wasserbüffel, begleitet von den Tieren mit den elfenbeinernen Hörnern,

Die geleitet wurden, unterstützt von dem Gesange, dem hin- und herwiegenden der Lunok die Undanfrïchte tragen (gemeint ist der 
ras bulau lampang hapasang darah,

Awang djadi lompat lawang lewu tatau habaras bulau, djakat ruang rundong radja hakarangan bawak lamiang,

Djadi lompat panatau parong batu bahalap ngareheng tandang haramaung, djakat panuhan siro liang badaris mangangkuling tambon.

Bahalap njapau pisih rarindjap langit, njampiang ${ }^{337}$ kabanteran bulan, nantanep kekah lumpong matanandau.

Mangkongan burong piak liau bahalap hatalusang pantong mansanan kamban baja badaris hasansawong tari,e.

Bahalap manganggarong garing batang pantar, manalumbang ihing sanggaran burong dahiang.

Baampah pulau tarahan, hasahep panungkup puja kalinti.
Schädelpfahl auf dem der erlegte Schädel steckt und das Lob der Liau besingt), begleitet von dem Liede, dem wogenden des auftauchenden Goldsandes vermischt mit Blut (Kopfjagd oder Menschenopfer, dessen Blut für die Reinigung gebraucht wird),

Welche eingetreten sind durch die Türe des Dorfes, des reichen, das überstreut ist mit goldenem Sand, welche eingegangen sind in den Ort, den königlichen, der Steinbänke besitzt von Achaten,

Die bestiegen haben das schöne Haus von Stein mit den herrlichen knirschenden Zähnen der Tiger, die erklommen haben die vornehme Wohnung von Stein, die prächtig geschmückte mit der zusammengerollten Wasserschlange.

Das schön bedachte mit Pisih, 336 die mit hellem Laute herunterfallen vom Himmel, mit den Wänden der Rundheit des Mondes, mit den Wänden der Blüten der Rundheit der Sonne.

Geschmückt mit Piak-Liau-Vögeln 338 mit zierlich zurückgewendeten Hörnern, welche besingen die Liau während sie zusammen mit ausgestreckten Flügeln im Fluge schweben.

Schön abgeteilt in Kammern durch den elfenbeinernen Stamm, den Pfahl der durchzogen wird von der Wasserschlange des Sanggaran der Vorzeichenvögel (das Haus wird hier also mit dem Sanggaran verglichen. Siehe Erklärung 228).

In Haufen sind anwesend die Scharen der Sklaven, in Menge befindet sich hier die Gemeinschaft der Leibeigenen. 
Sanggaran

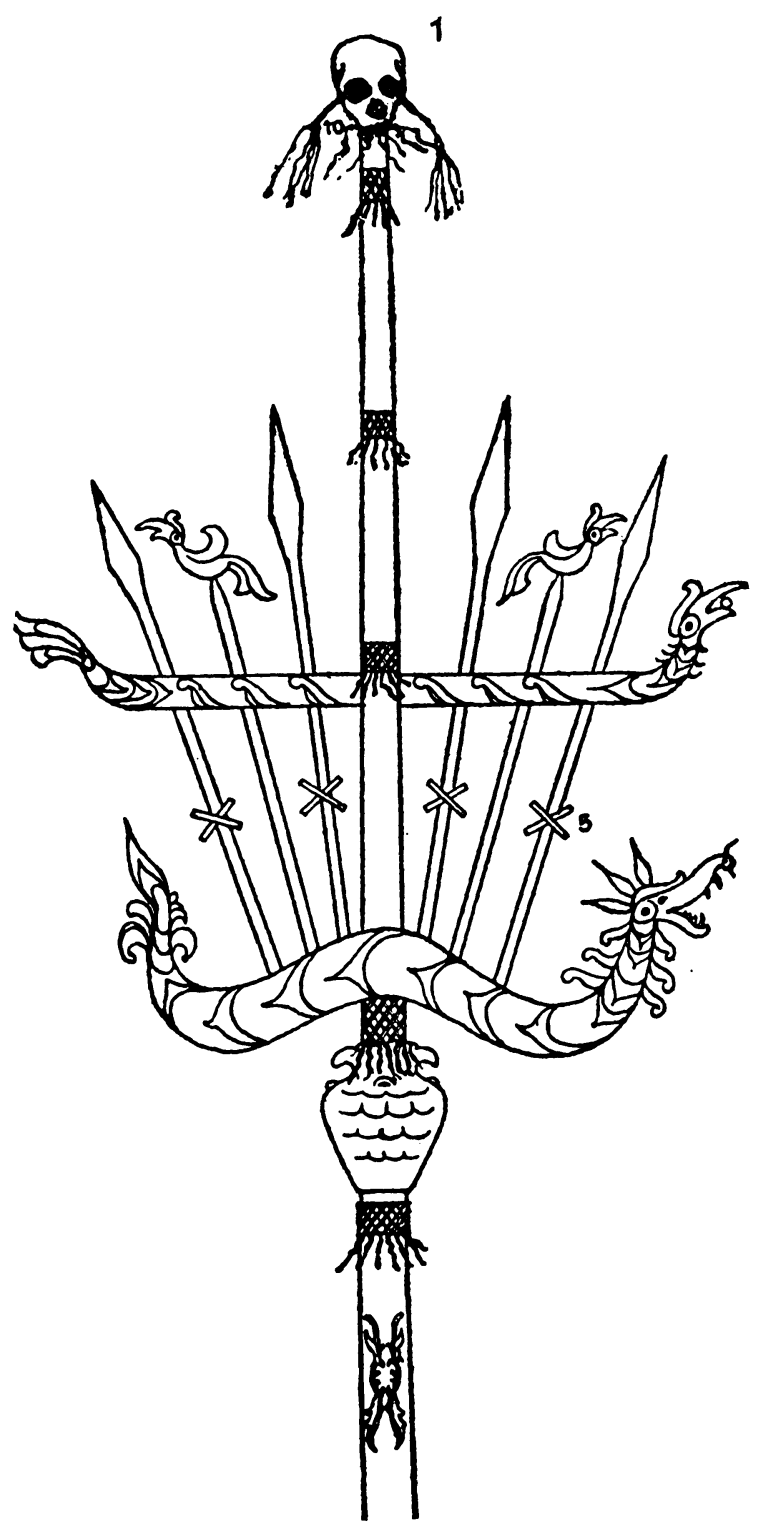

1. Schädel - undan pamalimak bungaı 


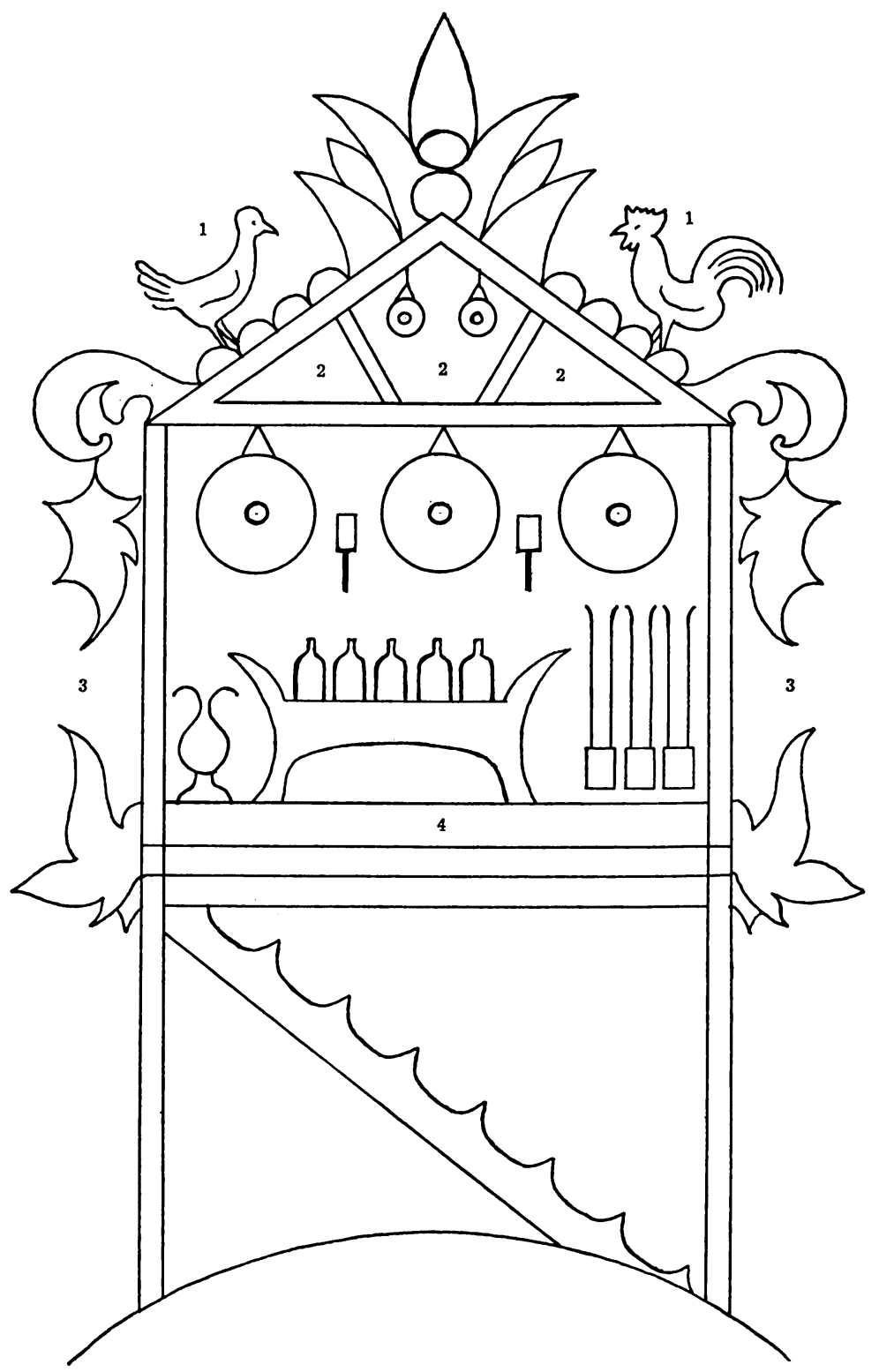

1. Piak liau.

2. Sampiang, die kleinen, dreieckigen Wande womit das Dach auf beiden Seiten geschlossen wird.

3. Tandang haramaung.

4. Die Tambon ist hier stilisiert gezeichnet. 
Sama dohong ewen merem manabala kumpang, rata buno rintoh marong gantuling,e, dia balisang pandjang idje gawang tingang, korang balangkas ambo dinon due kasambuti,n ranjing.

Melai kilau melai bulan pali,n langit, medjen tingkah medjen bintang endus hawon.

Ela nahanrangtong bahing panganderangku kilau anak burong tingang, isen njampelek sarikongku tingkah tandang haramaung.

Bele ikei muta tingang ngampah paringkahan renteng,e, isen tau manela bungai hadjandjala pating,e.

Mangat dia ikei sambang tau limbai bahing panungkup garo, isen leoh simpei.

Mangat ikei ngentang budjur kabadjuran kilau buno randan kangereng Njaring, njaripangku kabarengan tingkah renteng mananggalong bulau.
Gemeinsam kehrt ihr (die Liau im Totendorf) wieder zurück in eure Scheiden, ihr Dolche, ihr Lanzen kehret wieder um und fügt euch ein in eure Ringe, begebet euch nicht mehr weg, auch nicht eine Spanne der Tingang nur, nicht rürhet ihr euch fortan von eueren Plätzen, auch nicht einen Sambuti der Verehrungswürdigen.

Bleibet daheim, so wie die Palimond (Neumond) bleibet verborgen am Himmel, verweilet, wie das Paligestirn verweilet hinter den Wolken.

Nicht versperret den Laut meines Sprechens wie man versperrt das Kind eines Nashornvogels (wenn der weibliche Nashornvogel auf den Eiern brütet, dann macht der männliche Nashornvogel die Oeffnung des Nestes, die sich meistens in einer Baumhöhlung befindet, beinahe dicht), nicht zerbrechet mein aneinandergefügtes Achathalsband, wie man herausbricht den Zahn eines Tigers.

Auf dass wir nicht ausspeien einen Nashornvogel, der euch wegjagt mit gespreizten Schwanzfedern, auf dass wir nicht ausspucken einen Tingang mit auseinandergebreiteten Enden.

Auf dass nicht der Schall unserer Trommeln gekrümmt werde, von uns der Gemeinschaft des Weihrauches (Priester), nicht gebogen werden unsere Bündel.

Auf dass wir in richtiger Weise und rechtschaffen unser Hülfswerk ausführen können, gerade wie die Speere, die kleinen, am Körper der Njaring (d.h. die geradeheraus stehenden Körperhaare), damit wir das Tragen 
Mangat kabadjuran aku mangkang tandak tawurku, mangat dinon kabarengan balitangku ngendjong karunja,n sawong ambon. vollenden können in guter Weise, so wie ein Federkiel umschliesst den Goldstaub.

Damit ich in richtiger Weise beenden kann das Lied meines Streureises, damit ich rechtschaffen beschliessen kann den Gesang des Reiskornes.

\section{E. Die Reise der Reisseelen nach der Oberwelt}

Limbah te upo manontong tandak,e tahiu tawur,e ttg. auch bawak tandak,e sama ih kilau auch,e manawur endau bara tamparan tawur sampai kahapus tawur.

Tapi ie manandak,e sinde toh mampahajak auch katambong lago,n tekap tawur te magon.

Magon upo kabuat bewei manandak sampai djadi bulan bawi,n tawur hapantar pinang huang lasang bulau dare,n tanggoi.
Darnach setzt der Hauptbalian seinen Gesang betreffend seines Streureises wieder fort und das Wort seines Gesanges ist das gleiche, wie sein Wort des Ausstreuens des Reises vom Anfang des Streureises bis zum Ende des Streureises.

Aber er singte es diesmal begleitet vom Schalle der kleinen Trommeln, aber immer noch nach der Melodie des Streureisschlages.

Immer noch singt der Hauptbalian allein und zwar bis dorthin wo erzählt wird, dass die Monde, die Frauen des Streureises, Betelnuss kauend im Fahrzeug des goldenen geflochtenen Hutes sitzen.

Der Priester wiederholt nun noch einmal die Gesänge beginnend bei : Die Besingung des Ursprunges des Streureises (pag. 452) bis und mit: Die Verwandlung des Streureises in Dolchregen (pag. 490). Die Gesänge werden hier in den Texten natürlich nicht wiederholt.

Maka amon limbah tawur hapantar pinang te hobah lago,n tekap tawur mahapan lago,n tekap mandjong tazerur (rima,e: tawur hagatang hagoet bara huma hapan lasang lio bulau dare,n tanggoi).
Aber nachdem die Frauen des Streureises Betelnuss gekaut haben, ändert die Melodie des Streureisschlages und man gebraucht nun die Melodie des Schlages: Wegsenden des Streureises nach der Oberwelt (das heisst: der Streureis erhebt sich nun und er ent- 
fernt sich vom Hause mit dem regenbogenfarbigen Boot, dem goldenen, geflochtenen $\mathrm{Hut}$ ).

Toh ewen hobah tekap,e ttg. hobah lago,n tandak,e hajak tandak ain upo haradjur inombah tumon te awi kakare ewen balian idje aton mondok hete.

Upo,n balian palus manampara beken auch idje injewut,e bara sarita,n tawur metoh tawur intu huma.

Ie manandak tahiu tawur,e hagatang manjampai lewu,n Sangiang.

Toh manampara, koa,e:

Rohong-rohong panamuei tawur manundjong taribanga, lento-kadja,n sawong ambon balias mangkat pangansiring,e. Tawur manundjong taribanga halasang bulau dare, n tanggoi, sawong ambon mangkat pangansiring,e bagentoi, gentoi tabuhi.

Palus malan balua parong, ringkang lubahandjong siro.

Tawurku tarantang tatau balasang njaho batengkong, sawong ambon lalundong radja bagentoi kilat basiring.

Tolak malan njalumbo ambon, ringkang lu-manandjak enon.
Nun ändern sie ihr Schlagen der Trommeln und sie ändern auch die Melodie ihres Gesanges und das Lied des Hauptbalian wird fortwährend beantwortet (d.h. wiederholt) durch alle Balian welche nun dort Platz genommen haben.

Der Hauptbalian beginnt nun ein anderes Wort als das des Streureiswortes, das gesungen wurde während der Dauer des Aufenthaltes des Streureises im Haus.

Er singt nun von seinem Streureis der sich erhebt und aufsteigt bis zu dem Dorfe der Sangiang.

Und nun beginnt er und singt:

Rausche in Menge und reise hinweg. o Streureis, erhebe deine Flügel und brausend mache dich auf zum Besuch, öffne nun willig deine Fittiche.

Streureis erhebe nun deine Flügel im Boote, im goldenen geflochtenen Frauenhut, Reiskorn öffne deine Schwingen im Fahrzeug, im Boote, dem kreuzweise geflochtenen.

Machet euch auf und tretet hervor aus der Kammer, ihr Schlanken, tretet heraus aus dem Haus.

Mein Streureis, du Kind, du reiches, reise mit dem Boote begleitet von dem weitschallenden Donner, du Kind, du königliches, fahre hinweg mit dem Fahrzeug umzuckt von den leuchtenden Blitzen.

Reiset nun ab und machet euch auf und steiget empor durch die Wolken, 
ihr Schlanken, ziehet hinauf durch die Tauwolken.

Kilat basangkelang tawur, Du Blitz, vermengt mit dem Streureis, njangkelang pinang sara- vermische dich mit den Pinangpalmen, jong 339 lewu. dem Halsband des Dorfes (der Streureis steigt zwischen den Palmen in die Wolken hinauf).

Lio sampale sawong ambon Regenbogen (das Boot) vermengt mit manjarak bumbong katilambong njaho.

Njandar salalanga tambon lupalangka pantar. dem Reiskorn, brich auseinander die zarten Herzblätter der Kokospalmen, der donnernden.

Erhebe dich und lasse hinter dir die Wasserschlange des Gestelles, des Mastes (gemeint ist der Sanggaran. Siehe die Zeichnung).

Nipas liwus tapudjake, ihing sanggaran burong dahiang.

Lasse hinter dir zurück deine Mündung (d.h. der Anfang des Weges), die Wasserschlange des Sanggaran der Vorzeichenvögel (vom Sanggaran aus wird durch die Reisseelen die Reise nach der Oberwelt angetreten. Er ist die Mündung, d.h. der Zugang zur Oberwelt).

Bawi,n tawurku hataburan, Frauen meines Streureises, ihr hingegana,n tawur idje basaro do- streuten, Seelen meines Streureises, hong.

Habinei sawong ambon, hatatajan sawong ambon maing batiwong ${ }^{340}$ pulang,e.

Mudjan pukong pahewan antang, lawang lewu ano. die ihr verwandelt seid in Dolche. Frauen des Reiskornes, des ausgestreuten Reiskornes, des kräftigen, verwandelt in einen Griff der mit feinem Rotan umflochten ist.

Regne herunter auf das Gehölz, auf den heiligen Hain des Falken an der Türe des Dorfes N.N. (der Priester spricht den Namen des Dorfes natürlich aus).

Njamperai pandong parin- Riesle herab auf das Wäldchen wo djangan dahiang pagerundong man sich Rat holt und wo man Vorano.

Mudjan pataho haga,n lawang lewu ano.

zeichen erbittet beim Dorfe N.N.

Regne herunter auf den Pataho, den Wächter an der Türe des Dorfes X. 
Njamperai batu mamben Riesle herab auf den aufgerichteten gadoh lewu ano. Stein, den harten, des Dorfes N.N. (handelt sich ebenfalls um den Pataho der aus einem aufgerichteten Stein besteht über dem eine Opferhütte aufgerichtet ist).

Mudjan antang lu-tadjahan, Regne herunter auf den Falken des haga,n lewu ano.

Dorfheiligtumes, den Beschirmer des Dorfes X.

Manjamperai kenjoi patindju, Riesle herab auf das Heiligtum des gadoh rundong ano.

Mudjan lawang labeho,n Djata laut lewu ano. Falken, des Beschützers des Dorfes X. Regne herunter auf die Türe der Wassertiefe des Djata, draussen auf dem Flusse vor dem Dorfe N.N.

Njamperai rantang Hatala Riesle herunter auf die Opferkörbe des anih rundong ano.

Tawurku malan njalumbo ambon hajak mudjan hararahan tandjong ambon.

Sawong ambon ringkang manandjak enon, njamperai hatatajan luwok enon.

Hatala, dort drüben, ein wenig entfernt vom Dorfe N.N.

Mein Streureis, mache dich nun auf und steige empor durch die Wolken, regne herunter in dichten Tropfen auf die Buchtungen der Wolken.

Mein Reiskorn, schreite nun rasch aus, fahre empor zu den Tauwolken und riesle herunter, streue dich aus über den Biegungen der Tauwolken.

Die Reisseelen steigen nun durch die drei und dreissig Wolkenlagen, die zwischen der Welt und der Eingang zur Oberwelt liegen, empor. Die Namen dieser Wolkenlagen, die von den Reiskörnern beregnet werden, werden hier genannt und zugleich ihre Wiederholung, die durch die Panombah oder Panggapit (die Hülfsbalian) gesungen werden muss.

1. Palus mudjan ambon turon kadjang pantai danum kalunen.

Manjamperai enon liwa tingkap 342 luwok kampongan buno.

2. Palus mudjan ambon sa-
1. Regne herunter auf die Wolken der dicht nebeneinander wachsenden $\mathrm{Ka}$ djang 341 an den Ufern des Flusses der Welt.

Riesle herab auf die Tauwolken der Rasthüttchen an den Buchtungen der Dörfer der Lanzen.

2. Und regne herab auf die Wolken, 
wak turon udjan balawo die heftigen, aus denen herabfällt der langit.

Manjamperai enon samur kanjarin riwut manampur hawon.

3. Palus mudjan ambon kaput dia badjahontong tandok. Regen des Himmels.

Riesle herab auf die Tauwolken, die spritzenden, unterstützt vom Winde, geholfen durch das Wehen des Sturmes am Himmel.

3. Und regne herab auf die Wolken, die dunklen, die man nicht $\mathbf{z u}$ sehen vermag mit seinen Augen (oder: durch die man nicht hindurchdringt mit seinen Augen).

Manjamperai enon sinep Riesle herunter auf die finsteren Taukorang batureng hining. wolken, durch die nicht hindurch zu dringen vermögen die Hellen (die Augen).

4. Palus mudjan ambon badandang kilau kanandang dohong.

Manjamperai enon batehang, kilau kanehang garing lalundjong pulang.

5. Palus mudjan ambon bahandang, namunan handang djarenang.

Manjamperai enon harantihen njakatan darah burong tingang.

6. Palus mudjan ambon bahenda, kilau riak henda,n bulau.

Manjamperai enon harin tawa namunan tantawa oru, $\mathrm{n}$ batu antang.

7. Palus mudjan ambon baputi, nahadjulen tepong.

4. Und regne herab auf die Wolken, die frei und lichtmachenden, die den freistehenden (oder frei und licht machenden) Dolchen gleichen.

Riesle herunter auf die frei und licht stehenden Tauwolken, die freistehend sich erheben wie ein elfenbeinerner Knopf auf dem Griffe des Dolches.

5. Und regne herunter auf die roten Wolken, die da gleichen der Farbe des Drachenblutes.

Riesle herab auf die Tauwolken, die farbigen wie Rantihen-Rotan (rot), der aussieht wie das Blut des Nashornvogels.

6. Und regne herunter auf die gelben Wolken, die da aussehen wie die Wellchen der Gelbheit des Goldes (wie der gelb gewordene Betelnusspeichel). Riesle herab auf die gelben Tauwolken, die da gleichen der Gelbheit des Grases Batu Antang (d.h. Stein des Falken, die Grassorte ist mir nicht bekannt).

7. Und regne herunter auf die weissen Tauwolken, die aussehen wie die 
Weissheit des Mehles.

Manjamperai enon badjaleang nahamanjan mangur.

8. Palus mudjan ambon harenteng, manamunan renteng tingang.

Manjamperai enon halingkat, tingkah lingkat tandang haramaung.

9. Palus mudjan ambon harepang kilau repang garantong.

Manjamperai enon hatandik kilau bawi mamanto sambang.

10. Palus mudjan ambon harandjak kilau harambang pulau peho,n sawang.

Manjamperai enon gagarong namunan garing karambang sawang.

11. Palus mudjan ambon sambo-sambong kilau sambong bulan bawi,n balo.

Manjamperai enon bungobungo namunan tanggoi hentap.

12. Palus mudjan ambon buntu-buntut kilau djuking penjang.

Manjamperai enon puse-puseh namunan ulek rawing.
Riesle herab auf die hellen Tauwolken, die da gleichen dem Fleische der unreifen Betelnuss.

8. Und regne herunter auf die Wolken des gespreizten Federbusches, die da aussehen wie die Schwanzfedern des Nashornvogels.

Riesle herab auf die Wolken, die geschwänzten, die da gleichen dem Schwanze des Tigers.

9. Und regne herunter auf die Wolken der Reihen, die da aussehen wie die Reihen der Gong (wie ein Satz Gong, der ein ganzes Spiel bildet).

Riesle herab auf die Tauwolken, die tanzenden, die da gleichen den Frauen, die die Trommeln schlagen (und dazu tanzen).

10. Und regne herunter auf die Wolken, die umzäunten, die da aussehen wie das umzäunte Gebüsch der Sawangstauden.

Riesle herunter auf die Tauwolken, die da gleichen den kreuzweise zusammengefügten Stäben der Hecke, die aufgerichtet ist um die Sawang.

11. Und regne herunter auf die Wolken des Schmerzes, die da aussehen wie das Herzeleid einer Frau, einer Witwe.

Riesle herab auf die Bungo-Tauwolken,343 die da gleichen einem Hentaphute. ${ }^{344}$

12. Und regne herunter auf die Wolken, die stacheligen, die da aussehen wie die Ecken der Penjang. Riesle herab auf die aufbrodelnden Tauwolken, die da aussehen wie die Wirbel der umsichschlagenden Kroko- 
13. Palus mudjan ambon hapantar kilau pantar sanggar.

Manjamperai enon hapandong manamunan tetat puso,n pinang lewu.

14. Palus mudjan ambon kamarisai kilau balai lambang sanggar.

Manjamperai enon kamarasik manamunan sarin kambungan. 345

15. Palus mudjan ambon marakeran kilau darong handjaliwan.

Manjamperai enon hakangkoang tingkah randin talampe.

16. Palus mudjan ambon dadahukong kilau meto tandang haramaung.

Manjamperai enon hengahengau tingka aso,n bulan.

17. Palus mudjan ambon rente-renteng kilau dandang tingang. dile.

13. Und regne herunter auf die Wolken der Pfähle, die da aussehen wie die Sanggaran-Masten.

Riesle herab auf die Tauwolken der Fasern, die da gleichen den Kerben in den Blütenknospen der Betelnusspalme des Dorfes.

14. Und regne herunter auf die Wolken, die zierlich gelockten, die aussehen wie die Opferhütte, wie ihre Schwelle die mit Girlanden geschmückt ist.

Riesle herab auf die Tauwolken, die in zierliche Fäden auslaufen und die da gleichen dem mit gelocktem Flechtwerke verzierten Opferkorb.

15. Und regne herunter auf die Wolken, die zusammengerollten, die da aussehen wie eine zusammengerollte Handjaliwanschlange.

Riesle herab auf die ausgespannten Tauwolken, die da gleichen einem Wasserbüffel (der ausgestreckt in einem Wassertümpel liegt), einer Talampeschlange (eine fabelhafte, mythische Schlange).

16. Regne herunter auf die Wolken die eine geduckte Haltung haben und die aussehen wie das Tier, wie der Tiger, der zum Sprung bereite.

Riesle herab auf die Tauwolken, die vorwärtsstehenden, die da gleichen dem Hunde des Mondes (siehe weiter unten in den Texten, siehe auch das Register).

17. Regne herunter auf die Wolken der Schwanzfedern, die da aussehen wie die Schwanzfedern eines Nashornvogels. 
Manjamperai enon lingkat, tingkah lingkat tandang haramaung.

18. Palus mudjan ambon lingka-lingkat, manamunan lingkat tandang haramaung. Manjamperai enon salimbalon manamunan uei andong.

19. Palus mudjan ambon bihi-bihing kilau bihing timpong.

Manjamperai enon salimpajan rowan bilit pahangan.

20. Palus mudjan ambon maruang 347 kilau kumpang dohong.

Manjamperai enon lewak namunan bango,n taradjo,n ambon.

21. Palus mudjan ambon babarohor kilau rikor talawang.

Manjamperai enon njarimbihos namunan usok dohong.

22. Palus mudjan ambon handikong kilau lamiang selong. 348

Manjamperai enon simit, manamunan katakenang hanjang.

23. Palus mudjan ambon
Riesle herab auf die Tauwolken des Schwanzes, die da gleichen dem Schwanze des Tigers.

18. Und regne herunter auf die Wolken des Schwanzes, die da aussehen wie der Schwanz eines Tigers. Riesle herab auf die schwanzförmigen Tauwolken, die da gleichen dem gekrümmten Andongrotan. 346

19. Und regne herunter auf die farbig gestreiften Wolken, die da aussehen wie die farbigen Streifen des Tuches. Riesle herab auf die geschlungenen Tauwolken, gleichwie das um den Leib gewundene Tuch.

20. Regne herunter auf die Wolken, die ausgetieften und nach auswärts gebogenen, die da aussehen wie die Scheide des Dolches (inwendig ausgehöhlt, auswendig ist sie etwas erhöht und besitzt in der Mitte eine scharfe Kante).

Riesle herab auf die unebenen Tauwolken, die da gleichen der erhöhten Schalen der Goldwaage.

21. Und regne herunter auf die Wolken, die kantigen, die da aussehen wie der Rücken des Schildes.

Riesle herab auf die erhöhten Tauwolken, die da aussehen wie die Brust (die Aussenseite) des Dolches.

22. Und regne herunter auf die scharf gekanteten Wolken, die da aussehen wie die Achate die hergestellt wurden durch die Sangiang.

Riesle herab auf die Tauwolken, die engen, die da gleichen den schmalen Achaten.

23. Und regne herunter auf die ge- 
budjur kilau ranjing pandereh buno.

Manjamperai enon kabarengan manamunan renteng mananggalong bulau.

24. Palus mudjan ambon hampitih kilau burong tingang manesek bua lunok.

Manjamperai enon hasawonga manamunan antang ranjing.

25. Palus mudjan ambon hatangkanjan kilau lalento,n bulan.

Manjamperai enon kakanjaing manamunan bandong kajau pahawang.

26. Palus mudjan ambon muak kilau mandit batu bangkulan tuwe.

Manjamperai enon nela ulek gohong ulek niring gohong pandih Njaring.

27. Palus mudjan ambon kakanderang kilau anak burong tingang. raden Wolken, die da aussehen wie eine erhabene Lanze (Zeremonialspeer der den Lebensbaum darstellt).

Riesle herab auf die straffen Tauwolken, die da gleichen dem Federkiel der den Goldstaub umschliesst.

24. Und regne herunter auf die zupickenden Wolken, die da aussehen wie der Nashornvogel der aufpickt die Früchte der Bäume.

Riesle herunter auf die durcheinander schwebenden Tauwolken, die da gleichen den Antang, den erhabenen (die im Fluge durcheinander schweben).

25. Und regne herunter auf die miteinander zwistenden Wolken, die da aussehen wie der Lärm der Monde (der miteinander streitenden Frauen). Riesle herab auf die miteinander streitenden Tauwolken, die da gleichen einer Schar miteinander kämpfender Frauen.

26. Regne herunter auf die Wolken, die $u a k$ schreien, und die da aussehen wie wenn man einschlürft das Bier (d.h. mit gurgelndem Tone. Uak ist auch der Ruf des Kalawet (ein Affe) und das Verb muak bedeutet: Laute ausstossen wie ein Kalawet).

Riesle herunter auf die Tauwolken des Wasserwirbels, des Wasserwirbels der mit einem Zaun abgeschlossen wurde durch die Njaring (Männer, d.h. um in einem Flusse Fische $z u$ fangen).

27. Und regne herunter auf die kakanderang schreienden (der Ruf des Tingang) Wolken, die da aussehen wie die schreienden Jungen der Nashornvögel. 
Manjamperai enon hakokok Riesle herab auf die Tauwolken, die manamunan bawi,n antang. da kokok rufen (der Ruf des Antang) und die da gleichen dem rufenden weiblichen Falken.

28. Palus mudjan ambon 28. Und regne herunter auf die laut mangariak kilau bulan hatungkedjet rohong.

Manjamperai enon mangansilon tingkah pahawang manatuman sinau.

29. Palus mudjan ambon ngiak ngansilon kilau tangis bulan bawi,n antang.

Manjamperai enon marungun manamunan tatom pantis tantingai rohong. aufschreienden Wolken, die da aussehen wie die aufschreienden Monde, die erschreckt worden sind von den Dolchen (d.h. von den Männern).

Riesle herab auf die schluchzenden Wolken, die da gleichen den Frauen die für ihre Männer die Totenklage anheben.

29. Und regne herunter auf die Wolken des Piepens der Küchlein, des Zwitscherns der Vögel, die da aussehen wie das Weinen des Mondes, des weiblichen Falken.

Riesle herab auf die Tauwolken des Gesanges, die da gleichen dem Stammliede, das da fliesst über die goldenen Stifte der Dolche (das Stammlied, das gesungen wird von den Männern und über die eingesetzten goldenen Zahnstifte kommt).

30. Palus mudjan ambon nangkahak kilau tingang mangkeng bua lunok.

30. Und regne herunter auf die Wolken mit dem würgenden, räuspernden Laute, die aussehen wie ein Nashornvogel, dem im Halse stecken blieb eine Frucht.

Manjamperai enon palalingok manamunan antang katalenan kantan sanggalang.

31. Palus mudjan ambon sasakongkong kilau haramaung lapas tabanga,e.

Manjamperai enon hadambongan manamunan handjali-

Riesle herab auf die Tauwolken, die wie mit dem Kopfe wackeln, gleichwie ein Falke, der sich verschluckt hat an einer unreifen Frucht.

31. Und regne herunter auf die Wolken des Gebrülles des Tigers, des Tigers der sich befreit hat aus seiner Gefangenschaft.

Riesle herab auf die in die Höhe geschnellten Tauwolken, so wie eine 
wan liwus tatuka.

32. Palus mudjan ambon hasansawong kilau pusok manjawong tingang.

Manjamperai enon hasulanga manamunan peser bulan bawi,n riwut.

33. Palus mudjan ambon manampusok kilau tampusok djala bulau.

Manjamperai enon hakampungan manamunan handut ontai rabia.

34. Palus mudjan ambon barangga njangkabila,n garing tandok rahubajoh langit.

Lasang bulau dare,n tanggoi njelem tumbang kapandjongan mandjong.

Panuhan gentoi tabuhi nantame salohan antang manamuei.

Palus mudjan parong randan, rahan tumbang kapandjongan mandjong, Manjamperai sapamarong iwa salohan antang namuei,

Ain Bulan Indu Samben, Kalawet Baputi Batenong
Handjaliwanschlange, die sich losgelöst hat aus ihrer Schlinge.

32. Und regne herunter auf die Wolken, die durcheinandergewirbelten, die da aussehen wie Nashornvögel die durch einen Sturmwind durcheinander geworfen werden.

Riesle herab auf die aufwärts und abwärts wogenden Tauwolken, die da aussehen wie das Auffahren und Niedertauchen der Monde, der Frauen des Windes.

33. Regne herunter auf die in die Höhe fliegenden Wolken, die da aussehen wie das Ende des ausgeworfenen Wurfnetzes.

Riesle herab auf die enggeflochtenen Tauwolken, die da gleichen dem zusammengeflochtenen goldenen Seil.

34. Und regne herunter auf die Widerhaken, die da aussehen wie die Stützen der Bäume mit auseinanderstehenden Enden die zum Himmel gerichtet sind (diese letzte Wolkenlage stützt das Himmelsgewölbe und die Oberwelt).

Fahrzeug, goldenes Geflecht des Hutes, fahre nun ein in die Mündung deines Weges, deiner Weiterreise.

Köstliches Boot, kreuzweise geflochtenes, begib dich nun hinein in den Ort des Falken, des reisenden.

Und beregne das Haus, das kleine, den Rahan an der Mündung des Weges der Weiterreise,

Beriesle das Haus unterhalb des Ortes, des reisenden Falken (gemeint ist der Ort des Radja Antang Darahen), Das da gehört dem Indu Samben, das das Eigentum ist des Kalawet Baputi 
Garing,

Eka Bulan Indu Sandoi, eka talaga bangkang hanselan.

Palus nandjong manangkalau selong mampan malangkawet,

Tandok Raho Bajuh Langit, Sungkol Sambali Tonggal.

Habasean tandjong Pasang Njaho, ngangkajoh luwok Pahadjedjel Kilat.

Habasean tandjong Uhat Marau Langit, balias lasang lio bulau dare,n tanggoi.

Palus nandjong manangkalau bukit Bulau Kamating Tingang, hajak mampan malangkawet kereng Rabia Kamumbong Bungai.

Palus nandjong manangkalau tandjong Panganrontong $\mathrm{Nja}$ ho.

Selong mampan malangkawet luwok Pahadjedjel Kilat.

Palus nandjong manangkalau lewu Bukit Gagas Tingang. Selong mampan malangkawet Kereng Gahumot Bungai.

Palus rohong tamuei tawur manjaroroi hinting tiring.

Rohong panamuei tawur sam-
Batenong Garing, ${ }^{349}$

Das Dorf der Bulan Indu Sandoi, der Ort wo sich befindet der Teich mit dem Oel, dem wahrhaftigen Oel.

Und ihr gehet weiter, ihr gehet dort vorbei, ihr schreitet vorwärts, ihr gehet dort vorüber,

an den Tandok Raho Bajuh Langit, an den Sungkol Sambali Tonggal (die Stützen des Himmels und der Oberwelt, die bereits oben genannt wurden). Ihr rudert weiter, entlang der Flussbiegung Pasang Njaho (des anschwellenden Donners), ihr fährt vorwärts auf der Buchtung Pahadjedjel Kilat (der herauszuckenden Blitze).

Ihr rudert weiter entlang den Flussbiegungen der Uhat Marau (siehe Register) Langit, ihr fährt weiter mit dem Fahrzeug, dem regenbogenfarbigen, goldenen Geflechte des Hutes.

Und ihr gehet weiter und ihr marschieret vorbei an dem Berge Bulau Kamating Tingang, und ihr schreitet vorüber am Hügel Rabia Kamumbong Bungai.

Und ihr schreitet weiter und gehet vorbei an der Buchtung Panganrontong Njaho.

Und ihr gehet weiter und schreitet vorbei an der Flussbiegung Pahadjedjel Kilat.

Und gehet weiter und marschieret vorüber am Dorfe Bukit Gagas Tingang. Und ihr schreitet weiter und gehet vorüber am Hügel Gahumot Bungai. Und alsobald rasselt ihr, reisender Streureis, und ihr betretet die Treppe, die straffgespannte.

Und rauschend kommst du, reisender 
pai tasik Ambon Bagantong.

Lento kadja,n sawong ambon laut Enon Baratujang.

Palus nandjong manangkalau lewu Bukit Totok Barohor Ambon.

Balias panamuei tawurku ina njaroroi hinting Sangiang.

Njandar salalalanga garing nangkalak sokah djamban.

Nuntun bara babedjau Pulau Rangkang Buno.

Nureng tawur djajo-djajong Balai Rangkang Nahuto Penjang.

Palus nandjong manangkalau ie Pulau Tasat la-Bulan.

Selong mampan malangkawet Nusa lu-Tansaran Bintang.

Palus tokep manantureng hajak dani manjalahendeng,

Babalang Lunok lu-Marajoh belom tumbang Tarusan Bulan,

Baringen Mantahiwei Haring, haring lu-antasan bintang.

Palus rohong tamuei tawur murik tumbang Tarusan $\mathrm{Bu}$ lan.

Lento kadjan sawong ambon
Streureis, an am Meere Ambon Bagantong.

Brause zum Besuche, o Reiskorn, an der See Enon Baratujang (anderer Name für Ambon Laut).

Und ihr gehet weiter und schreitet vorbei an dem Dorfe Bukit Totok Barohor Ambon.

Und rasch, o reisender Streureis, legst du an und besteigst die Treppe der Sangiang.

Und ihr lehnet an das übereinandergeschichtete Elfenbein, die auseinanderstehenden Stäbe des Weges (der Treppe).

Und ihr schauet an aus der Ferne die Insel (d.h. der Haufe, die Menge) Rangkang Buno.

Und ihr betrachtet, noch weit von euch entfernt, den Balai Rangkang Nahuto Penjang.

Und ihr schreitet weiter und geht vorbei an ihr, an der Insel Tasat Bulan. Und ihr gehet weiter und schreitet vorbei an der Nusa Tansaran Bintang (anderer Name für Pulau Tasat Bulan).

Und schon seid ihr in die Nähe gekommen und ihr schaut bereits an den dort drüben Erscheinenden, den sichtbar werdenden Lunok Marajoh, den gedeihenden an der Mündung des Kanales des Mondes, den Lunok, den herunterhängenden, den lebenden, der da wächst an der Durchfahrt des Gestirnes.

Und rassle, reisender Streureis (d.h. spanne dich ein), und fahre hinauf die Mündung des Tarusan Bulan.

Rauschend fahre hinauf zum Besuch, 
manandjak lu-lapetan Bintang.

Palus metas malapeta tasik Bulan Laut lah-Bintang.

Rohong panamuei tawur halawo tasik Sangiang.

Lento kadjan sawong ambon lu-harende laut Djalajan, Lasang bulau dare,n tanggoi ladju habasean dare,

Gentoi tabuhi mangansiring, balias hakangkajoh balekute.

Palus babalang garing nangkalak belom sokah djamban Sangiang.

Rohong panamuei tawur lalutatean djamban Sangiang.

Lento kadjan sawong ambon manantepen paratar Djalajan. Palus nandjong manangkalau pulau korik panting pinang.

Selong mampan malangkawet nusa ringik roko,n tarahan.

Rohong panamuei tawur murik danum lu-Djalajan.

Lento kadjan sawong ambon nanggohong Riak Lamiang.

Habasean tandjong Tusang Idje Kalalepan Pasang.

Mangangkajoh luwok Tiling o Reiskorn, die Einmündung des Gestirns.

Und schlaget nun ein den Weg, der da einmündet in das Meer Bulan Laut Bintang.

Rassle, reisender Streureis, und falle ein in das Meer der Sangiang.

Rausche, Besuch des Reiskornes, ankommend im Meere Djalajan,

Fahrzeug, goldener geflochtener Frauenhut, schnell fortgerudertes Flechtwerk,

Boot, kreuzweise geflochtenes, fliegendes, rasch vorwärts gerudertes Flechtwerk.

Und schon sehet ihr die elfenbeinernen auseinanderstehenden Stäbe des Weges der Sangiang.

Rassle, reisender Streureis, und betritt den Weg der Sangiang.

Rausche, o Reiskorn, beschreitend die Brücke der Djalajan.

Und schreite weiter und gehe vorüber an der Insel, der kleinen (d.h. eine für sich alleinstehende Gruppe von Bäumen, die wie eine Insel zwischen den andern Bäumen wächst), der Enden der Pinang.

Und gehe weiter und marschiere vorüber an der Insel, der kleinen, der Rauchwaren (Zigaretten) der Sklaven. Rasselnd, o reisender Streureis, fahre hinauf den Fluss Djalajan.

Rauschend, Besuch des Reiskornes, rudere hinauf den Strom Riak Lamiang.

Rudere entlang der Flussbiegung Tusang Idje Kalalepan Pasang (das Ende der Flut).

Fahre hinauf längs der Buclitung 
Eka lu-Djakatan Rawing.

Rohong panamuei tawur murik tandjong Kamakang Lawong.

Lento kadjan sawong ambon nandjak luwok Kangkelong Bengkel.

Palus dimpah sira-sirang basean tandjong Tatekan Tihang.

Lu-basangka tente-tenteng ngangkajoh luwok Tantanan Rajar.

Basean tandjong Tampong Papas, ngangkajoh luwok Tundon Kalingking.

Basean tandjong Elang Salentup, nangkajoh luwok Humbang Rendan Tingang.

Nangkalau bukit Pasahan Rundjan ain Mantir Mama Luhing Bungai.

Nangkalau tumbang djalan manganjau, lu-tandohan pumpon serang.

Mudjan pukong pahewan antang lawang lewu Danum Djalajan.

Njamperai pandong parindjangan dahiang pager rundong Riak Lamiang.
Tiling Eka Djakatan Rawing (wo sich tummeln die Krokodile).

Rasselnd, reisender Streureis, fahre hinauf die Flussbiegung Kamakang Lawong (unwundenes Kopftuch).

Rauschend, besuchendes Reiskorn, rudere hinauf die Buchtung Kangkelong Bengkel (die ausgehöhlten Ohrringe).

Und fahre in schräger Lage hinüber über den Fluss, rudere hinüber die Buchtung Tatekan Tihang (eingerammter Flaggenmast).

Stosse hinüber in schräger Richtung und rudere hinüber nach der Buchtung Tantanan Rajar (eingestreckter Fahnenstock).

Rudert hinauf die Flussbiegung Tampong Papas (Besenbund), fahre hinauf die Buchtung Tundon Kalingking (des Trosses, des Besens).

Rudert hinauf die Flussbiegung des Elang Salentup (des knallenden Bambus), fahret hinauf die Buchtung Humbang Rendan Tingang (des ausgefransten Tingang-Bambus).

Gehet vorbei am Berge Pasahan Rundjan (der Hütten der heiligen Töpfe), der der Besitz ist des Mantir Mama Luhing Bungai.

Und gehet vorbei an der Mündung des Weges der Kopfjagd, gehet vorüber am Anfang des Weges auf dem man auszieht um Schädel zu erbeuten.

Regnet herunter auf den heiligen Hain des Falken an der Türe des Dorfes Danum Djalajan.

Riesle herab auf das Gehölz wo man sich Rat holt und um Vorzeichen bittet an dem Eingang zum Dorfe Riak La- 
miang.

Mudjan lawang labeho,n Regnet herunter auf die Türe zu der Djata ain Dohong Mama Wassertiefe des Djata, die das BeTandang.

Eleh tokep mananturong lewu Danum lu-Djalajan.

Palus dani manjahendeng rundong Riak lu-Lamiang.

Palus babalang malii babalang lewu hai kanjamben lombah.

Hajak batentang mahi batentang rundong datoh njalltagi mirang.

Pontong lewu hila ngadju sitztum ist des Dohong Mama Tandang.

Und schon seid ihr in die Nähe gekommen des Dorfes Danum Djalajan. Und bereits schreitet ihr dicht hinzu zu dem Dorfe Riak Lamiang.

Und schon erscheint und schon sieht man immer näher das Dorf, das grosse, dessen Häuser aneinandergereiht sind wie ein Halsband von Perlen.

Und es wird sichtbar und immer deutlicher sichtbar der Ort, der grosse, der ausgestreckt ist wie ein übereinandergereihter Santagi (Brustschmuck). nambing Sangiang hulu danum.

Pontong lewu hila ngawa nambing Sangiang pantai laut.

Mananturong ungkup bentok rahasan 350 Dohong Mama Tandang.

Am Ende des Dorfes, in der Richtung nach flussaufwärts, wohnen beieinander die Sangiang vom Oberlauf des Wassers.

Am Ende des Dorfes, in der Richtung nach flussabwärts, wohnen beieinander die Sangiang vom Ufer des Meeres (Zweiteilung des Dorfes, auf die in der Einleitung hingewiesen wurde).

Und ihr schreitet hin zu der Familiengemeinschaft, die in der Mitte wohnt, zu dem Stamm des Dohong Mama Tandang (Dreiteilung des Dorfes, wobei dieser dritte Teil, die Mitte des Dorfes, die Totalität der beiden andern Teile bildet).

Manjahendeng ruang $351 \mathrm{nja}-$ Und ihr begebet euch zu der Abteilung baberoh djampena,n Langkah Sawang Mama Bungai.

Palus tintu hakalambat lewu hila panjambilei. in der Mitte, zu dem Orte des Langkah Sawang Mama Bungai.

Und ihr zielet mit euerem Boot in vorsichtiger Fahrt nach dem Dorfe zu euerer linken Seite. 
Balang lenda-lendang Balai Und vor euch erscheint der weithin Njaho Mantunggang Pulu. leuchtende Balai Njaho Mantunggang Pulu.

Batentang linge-lingei Sali Und vor euch wird sichtbar das glänGanggerang Mambuakan Djalatien.

Rohong panamuei tawur katambuan Balai Njaho.

Lento kadjan sawong ambon manjakalah Sali Ganggerang. Rohong panamuei tawur nanturong tambon pamalangkan pantar.

Lento kadjan sawong ambon njahendeng ihing sanggaran burong dahiang.

Lasang bulau dare,n tanggoi bagantong tambon pamalangkan pantar.

Gentoi tabuhi hakangkajoh balekut,e, batujang ihing sanggaran burong dahiang.

Tawurku basaloh bulat kilau batu,n karangan danum.

Sawong ambon malik bunter njakatan takanan pinang lewu.

Hindai tawur njelem balai, eleh bukei riwut kanjaloh tawur. zende Haus Ganggerang Mambuakan Djalatien.

Rasselnd, o reisender Streureis, schwebe über dem Balai Njaho.

Rausche, besuchendes Reiskorn, und überdecke das Haus Ganggerang.

Rasselnd, reisender Streureis, nähere dich der Wasserschlange des Gestelles am Pfahl (am Sanggaran).

Rausche besuchendes Reiskorn und ziele in deinem Fluge auf die Wasserschlange des Sanggaran mit den Vögeln, die Vorzeichen geben.

Fahrzeug, goldenes Geflecht des Frauenhutes, hänge dich auf an der Wasserschlange des Gestelles am Mast.

Boot, kreuzweise geflochtenes, du fortgerudertes Geflecht, wiege dich über der Wasserschlange des Sanggaran mit den Vögeln, die Vorzeichen geben.

Mein Streureis, verwandle dich nun in Rundheit wie ein Stein von einer Steinbank im Flusse.

Mein Reiskorn, verändere nun deine Gestalt in Rundheit so dass du aussiehst wie die Frucht der Pinangpalme des Dorfes.

Noch nicht, o Streureis, betritt das Versammlungshaus, sondern erhebe zuerst den Wind deiner Verwandlung, o Streureis.

Kueh djadi nantame sali, Wie solltest du schon hineinschreiten burai sulei sawong ambon. in das Haus, entfalte zuerst deine Veränderung, o Reiskorn. 


\section{F. Das Dorf Danum Djalajan wird durch die Reisseelen in Finsternis gehüllt}

Toh hobah lago,n tekap katambong. Oloh balian malajan lago: mandjong tawur.

Toh lago manandak beken kea.

Ewen manahiu ampi,n djalanan tawur handak maname akan balai.

Toh, metoh helo bara tawur maname akan huang balai manjupa dengan Dohong Mama Tandang, salenga hapus lewu te kaput ttg. riwut barat paham handak basaloh awi buku panumah tawur ttg. awi bawi,n tawur mandjadi bulat tinai (mandjadi behas haluli).

Metoh toh tawur aton intu lawi,n pantar bentok lewu,n Dohong Mama Tandang.

Toh oloh balian manandak hapan tekap katambong taheta lago, manandak ampi,n kakaput leren, palus manandak manahiu ampi,n tazeur maname balai hasupa dengan Dohong Mama Tandang sampai basaloh mandjadi oloh bawi tinai idje tau hakotak hataherep bau dengan Dohong Mama Tandang.
Nun ändert die Melodie des Schlagens der kleinen Trommeln. Die Balian haben nun die Melodie: Wegsenden des Streureises beendet.

Die Melodie des Gesanges wird jetzt auch eine andere.

Sie erwähnen nun die Art und Weise der Reise des Streureises, welcher nun eintreten will in den Balai.

Und kurz bevor der Streureis eintreten will in das Versammlungshaus um zu begegnen dem Dohong Mama Tandang wird plötzlich das ganze Dorf in Dunkelheit gehüllt und es erhebt sich ein Wind und ein sehr starker Sturm, so dass es scheint als würde das Dorf in Stein verwandelt werden, nämlich durch die Ankunft des Streureises, der sich wieder in Rundheit verwandelt hat (d.h. der seine frühere Gestalt annahm und zu Reiskörnern wurde).

Der Streureis befindet sich jetzt aber noch am Ende des Mastes (des Sanggaran), der in der Mitte des Dorfes des Dohong Mama Tandang aufgerichtet ist.

Nun singen die Balian begleitet von dem Schlage der kleinen Trommeln nach einer neuen Weise, sie besingen nun die Art und Weise der Verfinsterung des Dorfes und darauf besingen sie und erwähnen den Eintritt des Streureises in den Balai und die Begegnung mit Dohong Mama Tandang, bis dass der Reis sich wieder verwandelt und die Gestalt von Frauen annimmt und er sprechen kann von 
Angesicht zu Angesicht mit Dohong Mama Tandang.

Toh ewen manandak:

Nun nehmen sie ihren Gesang wieder auf :

Riwut bambang baloi, salatan djujang-djaju.

Kaput bakati alem lewu Danum lu-Djalajan.

Wehet, ihr Splitter, ihr elfenbeinerne, rauschet, ihr Stücke, ihr köstliche (die Uebersetzung von djujang-djajı ist mir nicht ganz deutlich).

Rentar basansinep rundong Riak lu-Lamiang.

Dunkle, zweifache Nacht bedecke das Dorf Danum Djalajan.

Awi riwut kanjaloh tawurku, salatan sulei sawong ambon.

Ulai hatantali dawen pinang lewu.

Verwandelt in Finsternis werde der Ort Riak Lamiang.

Durch den Wind der Verwandlung meines Streureises, durch den Sturm der Veränderung meines Reiskornes. Wie Fäden, wie lang geflochtene Seile werden die Blätter der Pinangpalmen des Dorfes (durch den brausenden Sturm werden die Blätter zusammengedreht).

Hatapiket bumbong katilambong njaho.

Kalabuan riwut kanjaloh tawur.

Wie zusammengedrehte Stricke werden die Herzblätter der Kokospalmen, der donnernden.

Kalaketan sulei rabia sawong ambon.

Durch den herabfallenden Wind des verwandelten Streureises.

Hakandas tambon pamalangkan pantar.

Hakasa ihing sanggaran burong dahiang.

Durch den herunterstürzenden Sturm des goldenen Reiskornes.

Er schmiegt sich an an die Wasserschlange des Gestelles des Mastes.

Er reibt sich an der Wasserschlange des Gestelles mit den Vögeln, die da Vorzeichen geben.

Lungang-lingok ikau Balai Du schwankest hin und her, o Balai Njaho. Njaho.

Pulang-pilik ikau Sali Gang- Du wirst von der einen Seite auf die gerang. andere geworfen, o Sali Ganggerang.

Hakasa sapau lentem antang. Du schetuerst dein Dach am Neste des Falken.

Hakandas dawen karang Du schmiegst dich an an die lanzen- 
habuno pinang.

Hakasa tingang pamaripir balai.

Hakandas antang pamarawong sali.

Dari-daria garing tabela belom,

Awang batantang rusik babalai lawang paruntaran tingang.

Awang hababian djaka bajang tapang.

Main mules tamba djaka tali,n tengang.

Hadjadjitan tambaran djaka leleng baho.

Kilau batu,n karangan danum, bua pinang lewu.

Dari-daria garing tabela belom.

Matei bara matei, nihau bara nihau.

Gatang tarahendeng Dohong Mama Tandang.

Tundjong tarahingkat Sa- Es erhebt sich und steht auf der förmigen Blätter der Pinangpalmen.

Du reibst dich mit dem Nashornvogel an den Querhölzern des Versammlungshauses.

Du scheuerst dich an dem Falken des Firstes des Daches. ${ }^{352}$

Es eilen fort die Elfenbeine, die jung lebenden,

Welche sich vergnügten und welche spielten, sich aufhaltend an der Türe zum Vorplatz der Tingang (der Vorplatz vor dem Hause wo sich in der freien Zeit die Männer aufhalten).

Die da spielten und hin- und herwarfen den Kreisel, hergestellt von Tapangholz.

Die da spielten und drehten die Kreisel und hin- und herbewegten die Schnüre von Tengang (die man um die Kreisel windet und dann mit einem Rucke wegzieht, wodurch der Kreisel in Bewegung kommt).

Die da hin- und herzogen an dem Tambaranseil, das da stammt vom Fundplatz auf dem überwucherten Feld (der Tambaran ist ein Baum der im Busch wächst und von dessen Baste man Schnüre macht. Die Kinder vergnügten sich mit Seilziehen).

Wie ein Stein von den Steinbänken des Wassers, wie eine Pinangfrucht des Dorfes (in dichten Knäueln zogen die Kinder am Seile).

Es eilen fort die Elfenbeine, die jung lebenden.

Sterben und nochmals Sterben, Verlorensein und nochmals Verlorensein! Es erhebt sich und steht auf der Dohong Mama Tandang. 
wang Mama Bungai.

Balua hengau habenteng bara bauntonggang Balai Njaho.

Mikau ganggurang habangkang,e Dohong Mama Tandang.

Manambawa garing awang tabela belom.

Manangkiau pulang maing kanahesan ringik.

Mangat sama buli mantang Balai Njaho.

Rata nindan keton Sali Ganggerang.

Manambawa putir bawi,n Sangiang,

Awang tempe nantikong lisong kamangkiling Njaring.

Sama buli keton merem Balai Njaho.

Rata mulang anak nantame Sali Ganggerang.

Rata tame ewen Balai Njaho.

Uras manjelem labeho,n Sali Ganggerang.

Sangkelang renteng tingang Sangiang dengan riak bulau pating sumping.

Rata melai keton barandan balai, rata medjen keton nan-
Sawang Mama Bungai.

Er tritt heraus und lehnt sich mit dem halben Oberkörper hervor aus dem Balai Njaho.

Er kommt vor die Türe und er stützt sich vorüber, er der Dohong Mama Tandang.

Er ruft den Elfenbeinen, den jung lebenden.

Er schreit den Griffen, den kräftigen, den noch nicht des Lebens gewohnten. Auf dass sie zusammen zurückkehren und hinaufsteigen in den Balai Njaho. Und gemeinsam hereinkommen in den Sali Ganggerang.

Und er ruft den Putir (Prinzessin, auch Name der Töchter der vornehmen Dajak, wird vor allem in den Mythen und Texten, also in der Basa Sangiang gebraucht), den weiblichen Sangiang, Die da Reis stampfen auf den Stampfblöcken die aussehen wie ein Njaring (d.h. die rot sind. Die Stampfblöcke sind von rotem Eisenholz gemacht).

Kehret zusammen zurück und tretet ein in den Balai Njaho.

Gemeinsam kehret wieder um und betretet den Sali Ganggerang.

Und sie alle zusammen treten ein in den Balai Njaho.

Sie alle strömen hinein in die Wassertiefe (die Mitte) des Sali Ganggerang (des donnernden Hauses).

Und es vermengen sich miteinander die Schwanzfedern (Kopfschmuck) der Tingang (Männer), der Sangiang, mit dem wellenden Golde der Zweiglein der Ohrringe (der Frauen).

Und gemeinsam bleibt ihr nun im Balai, und ihr alle zusammen haltet 
tepen sali.

Ela balisang pandjang keton anak aken.

Isen balangkas ambo panungkup kawa,n tingang.

Mahuit atep kangkuari,n parong.

Mahandut djaka pintu parong.

Mukei bambang garong putir bawi,n Sangiang.

Mengkak sandik santi kameloh tara,n Djalajan.

Nipas sambang bulan-ah Sangiang sintong udju.

Mangko luhing rabia Djalajan lambong hanja.

Rewo-rewong bahing djipanton sambang.

Lento-lento bambahingan luhing.

Kilau djaka nalatai lunok njawak pamua,e.

Rowan manapatok baras njawak lu-paneah,e.

Balian manantapei riwut kanjaloh tawur.

Mangantihan luhing manantiup salatan sulei sawong ambon. euch nun auf im Hause.

Nicht gehet ihr herum in die Weite, o Kinder und Neffen.

Nicht schreitet ihr in die Ferne, Gemeinschaft der Schar der Nashornvögel.

Fest riegelt ihr zu die Türe des Hauses.

Fest bindet ihr die Riegel an den Rändern der Oeffnung des Hauses.

Oeffnet die Splitter von Weihrauch, ihr Töchter, ihr weibliche Sangiang. Löset auf die Bündel des Räucherwerkes, ihr Kameloh, ihr weibliche Djalajan.

Nehmet unter eure Arme die kleinen Trommeln, ihr Monde der Sangiang, ihr sieben zusammen.

Nehmet auf etieren Schoss die goldenen Trommeln, ihr Djalajan, die ihr vermehrt seid zu acht.

Stark und wohltönend rauscht der Schall der geschlagenen Trommeln.

Ungestïm erbraust der Laut der Trommeln.

Gleichwie wenn im Begriffe stände der Fruchtbaum in grosser Menge Früchte zu tragen (wahrscheinlich ist an das Herunterfallen der grossen Früchte gedacht, die mit dumpfen Laut auf der Erde aufschlagen).

Aehnlich wie wenn man aufschüttet den Sand bei heftiger Trockenheit.

Und die Balian (die weiblichen Sangiang, die die Trommeln schlagen) heben in die Höhe den Wind der Verwandlung des Streureises.

Der hin- und herschwebende Laut der Trommel hebt in die Höhe den Sturmwind der Veränderung des Reiskornes. 
Balawa pela-pelau katambuan balai njaho.

Batentang linge-lingei njakalah sali ganggerang.

Ngumpang parasengen lingo bawi mantoh sambang.

Eweh keton anak aken awang djawah djari metoh babalai batu lawang paruntaran.

Basansala karah,e hemben keton medjen liang tapian tingang?

Mikeh are kenton natah bakei nanggalong angoi.

Mangun mihing paka sawang nasa baraku tantamau danum.

Habanama badjoko kanihang sabaru.
Und helle wird es und frei über dem Balai Njaho.

Und es erscheint ein Glänzen über dem Sali Ganggerang (Haus des Donners). Und es fährt heftig auf ihn ein das Innere der Frauen, die da schlagen die Trommeln (sie vertreiben mit ihrem Liede die Dunkelheit, die durch den Wind des verwandelten Streureises verursacht worden ist).

Wer von euch war es, ihr Kinder und Neffen, der unanständige Finger hatte, während ihr euch aufhieltet beim Steine an der Türe zum Vorplatz vor dem Hause.

Wer war es von euch der schuldvolle Hände (auch: verkehrte, fehlerhafte) hatte während ihr spieltet draussen beim Steine am Anlegeplatz der Nashornvögel (er erkundigt sich ob eines der Kinder während des Spieles eine unziemliche Handlung ausgeführt hat die im Streit war mit den Pali. Man darf z.B. nicht mit einem Finger auf eine Person oder einen heiligen Gegenstand zeigen. Daran wird hier gedacht).

Vielleicht war es einer von euch, der einen Affen in verkehrter Weise Angoi (Chamäleon) nannte. (Siehe zur Erklärung die Basaloh-Mythen.)

Oder der aufgerichtet hat eine Fischreuse, gelehnt gegen die Sawangstauden, damit hineingehe der Frosch, der da sitzt auf der Tantamaupflanze 353 im Wasser.

Oder der mit einer Schildknöte ein Boot gemacht hat mit einem Mast ohne Segel. (Gemeint ist: der die Schildkröte auf den Rücken gelegt hat 
Mintan lewu basaloh handak djadi batu bunter.

Rundong rentar liang pangko anak,e.

Djaton mama apang, dia mina indang, koa,n garing tabela belom.

Kabadjuran ikei mama apang, kabarengan ikei mina indang.

Handong tawa,n ikei pali,n lewu Danum Djalajan.

Batuana ikei endus rundong Riak Lamiang.

Djaka mimbing apui tawa,n baka lupak.

Djaka mimbing pisau tawa,n baka himang.

Kabadjuran amon kai keton anak aken.

Gatang tarahendeng Sangiang tabela.

Indjidjitah pamantilon bendang.

Silake sapau lentem antang.

Inggigi dawen karang habuno pinang. und sagte: du bist ein Boot mit einem Mast (Schwanz) ohne Segel.)

Was nun die Ursache wurde, dass unser Dorf nun verwandelt wird und im Begriffe steht ein runder Stein zu werden.

Das Dorf verändert sich nun in Stein, wie man auf den Schoss nimmt ein Kind (es wird eins mit dem Stein wie das Kind eins wird mit seiner Mutter, die es auf den Schoss genommen hat). Nicht haben wir so gehandelt, o Onkel und Väter, nicht taten wir auf diese Weise, o Tanten und Mütter, so sprachen die Elfenbeine, die noch jung lebenden.

Wahr ist unser Wort, o Onkel und Väter, rechtschaffen ist unsere Rede, o Tanten und Mütter.

Wohl wissen wir die Pali des Dorfes Danum Djalajan.

Wohl kennen wir die religiösen Verbotsbestimmungen des Ortes Riak Lamiang.

Sollten wir Feuer in unsere Hände nehmen, dann wissen wir doch, dass wir uns verbrennen.

Sollten wir ein Buschmesser in die Finger nehmen, dann wissen wir doch, dass wir uns damit verwunden können.

Rechtschaffen seid ihr, wenn es so steht, ihr Kinder und Neffen.

Erhebt euch und steht auf, ihr Sangiang, ihr jungen.

Ziehet auseinander die Dachsparren von Bendangholz.

Schlitzet auf das Dach des Nestes des Falken.

Zerreisset die Blätter, die lanzenförmigen der Pinangblätter. 
Toto balawa pela-pelau katambuan balai njaho.

Batentang linge-lingei manjankalah sali ganggerang.

Palus rohong tamuei tawur manjelem balai njaho.

Lento kadjan sawong ambon manantame sali ganggerang.

Anda-andau panamuei tawur manamuei balai, Sangiang dia balisang pandjang.

Metoh kadja,n sawong ambon Djalajan korang balangkas ambo.

Bagantong panamuei tawur penda pamarawong parong.

Batujang kadja,n sawong ambon ulek nahopuser siro.

Manangkenja Sangiang are mondok katingang tambang.

Nangkining rajong Djalajan badjanda hanganggimai bangai,e.

Sama melai barandan balai.

Rata medjen manantepen sali.

Melai manjimpei bambang penjang,e panungkang ambon barutas matei.

Medjen manjandik paturong batu,e panjangkan enon ba-
Und sehr helle wird es nun und licht über dem Balai Njaho.

Und ein hellglänzender Schein geht auf über dem Sali Ganggerang.

Und rasselnd schreitet herein der reisende Streureis in den Balai Njaho. Und brausend tritt herein in das Haus, das donnernde, das besuchende Reiskorn.

Und während der reisende Streureis hereintrat in den Balai, da gingen die Sangiang nicht fort und bewegten sich nicht in die Weite.

Und während das Reiskorn hereinschritt, da wagten sich nicht zu entfernen und nicht $z u$ bewegen die Djalajan.

Es hängt auf (d.h.: es beendet) seine Reise, der Streureis, unter dem Firste des Daches des Hauses.

Es wiegt sich das besuchende Reiskorn über dem Nabel (Mitte) des Hauses.

Sie schauen an die Sangiang, die da sitzen in hockender Stellung (wie ein Nashornvogel) auf ihren Beinen.

Sie blicken an die Jünglinge der Djalajan, die sich dicht zusammengesetzt haben und aneinanderlehnen wie Trunkene.

Sie alle zusammen bleiben im Balai (d.h.: sie getrauen sich vor Angst nicht wegzugehen).

Sie alle zusammen befinden sich immer noch im Haus.

Sie bleiben und bündeln die Stücke ihrer Penjang um aufzuheben die Wolken, die vernichtenden des Todes. Sie bleiben und binden zusammen die Paturong ihrer Steine, um in die Höhe 
pilo nihau.

Malik bahing panton sambang, djalahan pulau rewan bawi.

Lalu mules sabintik luhing panungkup tambon haruei bungai.

Manjaruroi gandang apang tawur mudjan tingang Sangiang.

Manantepen towong mama njamperai bungai Djalajan. zu stützen die Wolken, die verderblichen des Verlorenen.

Es ändert der Laut des Schlagens der Trommel der Angehörigen der Schar, des Haufens der Frauen.

Und es wechselt der Schlag der Trommel der Gemeinschaft der Wasserschlangen, die da verzwillingt sind mit den Nashornvögeln (Ausdruck für die Balian und Basir die beides zugleich sind. Siehe die Einleitung).

Sie folgen nun der Apangtrommel (grosse Trommel), sie befolgen die Weise: der Streureis beregnet die Tingang, die Sangiang.

Sie richten sich nach der Mamatrommel (Onkeltrommel; gandang apang: Vatertrommel), nach der Weise des Berieselns der Nashornvögel, der Djalajan.

G. Die Beregnung des Balai und die Beratung zwischen dem Streureis und den Sangiang im Balai

Toh beken lago tekap katambong manumon lago tekap mudjan balai $\mathrm{ttg}$. beken lago,n tandak, magon inombah awi kare panggapit,e.

Palus upo manandak, koa,e:

Miring-merai tawur djari napus ruang balai, bahing djala rambang nipas marong garing gantonga.

Pusok rawong babaukei ning- Zusammengeballter Wirbelwind, ent-
Und nun beginnt eine andere Weise des Schlagens der Trommeln, nämlich die Weise des Schlages: Beregnung des Balai, und es beginnt auch eine andere Melodie des Liedes, das immer noch beantwortet wird durch alle Hülfsbalian.

Und der Hauptbalian stimmt nun seinen Gesang an, der da lautet:

Rausche, Streureis, im ganzen Innern des Balai, wirf aus deinen Laut, dass er erschalle im ganzen Elfenbeinernen, dem hohen (das heisst: im ganzen Haus). 
gang andau kasibahan, bahing sahai mari masoh pai,n djaka bukit pandjang.

Bahing udjan rajo saroi ngandan djaka sila,n langit, petai ganggerang masoh notok lambang bulan bagantong.
Mudjan pajong bulau 354, njamperai tumbak gandjur radja, 355 kadjang lalangit bulan, njamperai luhing djaka langkau timpong.

Mudjan bangkang balanga tingang, njamperai tambon repang garantong, rundjan lu-bahenda, njamperai batu sarakumpang rawing.

Mudjan kadjang lalangit bulan, njamperai luhing langkau timpong, tampong lu-lamiang, manjamperai bantilan tim- falte dich, Regen, falle hernieder, wie ein dumpfer Schall laufe über und fliesse herab den Fuss des Berges, des langen.

Schall des Regens, den man schon in der Ferne fallen sieht und rauschen hört, stürze herab und klopfe an an den Stützen der Seiten des Himmels (gemeint ist das Dach von Tuch, das im Hause über den Balian angebracht wird), anhaltender Donner, ströme über bis zu der Schwelle die sich hinzieht über der Höhe auf die sich die Monde gesetzt haben (über den Balian wird ein Dach von Tuch gebaut, sie sitzen also in einem eigenen Hause, das auch von einer Schwelle versehen ist. Wahrscheinlich sitzen sie auf der Schwelle selbst, die durch eine Bank vorgestellt wird. Es ist ja sonst nicht Sitte, dass man sich auf eine Bank setzt, sondern geschah früher nur bei den priesterlichen Handlungen).

Regne herab auf den goldenen Schirm, beriesle die Lanze, die königliche, bedecke den Himmel der Monde, riesle herunter auf die Trommeln (Stützen) am Fusse des Daches von Tuch.

Regne herunter auf die heiligen Töpfe des Tingang, riesle herab auf die Wasserschlange (Kette) des Satzes der Gong, auf die heiligen Töpfe, die gelben, riesle herab auf die Steine, die da eingefasst sind mit Krokodilen (d.h. auf die heiligen Töpfe deren Hälse eingefasst sind mit einem Nagamotiv).

Regne herunter auf die Decken des Himmels der Monde, riesle herab auf die Trommeln (Stützen) des Daches von Tuch, die Büschel von Achat- 
pong, mudjan tumbak gandjur radja, pajong runtar lubahandang, tamparan ranjing buno, sanggohan lintong lutalawang.

Masoh bulau bulat garing lugantongan gandang, mansohan rabia njangkabila,n nahatelon rantai lu-garantong.

Mudjan tingang Sangiang are mondok hatinggang tambang, njamperai bungai Djalajan tatau badjanda ganggimai pating bungai.

Mudjan notoh renteng tingang, njamperai manjahep pating bungai, malapak kumpang dohong, tawur njauch sapulangan tambang,e.

Tawur hakalampah mampah bumbong dare, $\mathrm{n}$ puron, sawong ambon manjahep, manjahep pandong hakajan dare.

Mari darah Sangiang djari mondok kamudjan tawur, merang tolang Djalajan kanjamperai rabia sawong ambon.

Mari darah Sangiang idje sumpak dawen lunok tarong, merang tolang Djalajan due steinen, riesle herab auf die Ballen von Tuch, regne herunter auf die Lanze, die königliche, auf den Schirm, den roten und leuchtenden, auf das Gestell der erhabenen Lanzen, auf das Gestell der mit Rotanbändern umflochtenen Schilde.

Fahre herunter wie rundes (geschmolzenes) Gold die elfenbeinernen hohen Trommeln, fliesse herab wie Gold die auseinanderstrebenden Hängsel der Ketten der Gong.

Regne herunter auf die Tingang, die Sangiang, die da sitzen mit dicht aneinander sich reihenden Füssen, riesle herab auf die Nashornvögel, die Djalajan, die reichen, die sich gesetzt haben mit den dicht nebeneinander aufragenden $Z$ weiglein der Nashornvögel (Kopfschmuck).

Regne in Menge herunter auf die Schwanzfedern der Tingang (Kopfschmuck), riesle zahlreich herab auf die Zweiglein der Nashornvögel, auf die kantigen Scheiden der Dolche, Streureis, fliesse herab längs den Griffen der Füsse.

Streureis, stürze dich herab und bewirf in Ueberfluss die Matte, das Geflecht von der Puronpalme, Reiskorn, falle in Menge herunter auf die Matte, die kreuzweise geflochtene.

Es wogt (vor Angst) das Blut der Sangiang, die unter der Sturzflut des Streureises sitzen, es klappern die Knochen der Djalajan, die verregnet werden von dem goldenen Reiskorn. Es rauscht das Blut der Sangiang gleichwie alle Blätter des Lunok Tarong, es beben die Knochen der 
lumpang bulau tandok tambon.

Njantah tandok hajak Sangiang mangadjang bumbong dare,n puron, niling bungai Djalajan manikap pandong hakajau dare.

Nunton bumong dare, $\mathrm{n} \mathrm{pu}$ ron, taratunton tamuei tawur.

Nureng pandong irit bungai, taratureng,e kadjan sawong ambon.

Tawur ampah baputi mampah bumbong dare, $n$ puron, sawong ambon djaleang njahep pandong djaka irit bungai.

Ngandang,e puron buang saroi hapan kumpang dohong, nitih,e ringkin sandong hapan garing salundjong pulang,e.

Nusang djari Sangiang mondok hapampungan tawur, niling karah Djalajan ngalape$\tan$ rabia sawong ambon.

Ina,e ruak kumpang, meno garing lalundjong pulang, pamalusong lawong, sipan baro,e, gunto,e pulu.
Djalajan, die beiden Pfosten, gleichwie die Hörner der Wasserschlange (die Wasserschlange trägt eine Krone, wenn sie schwimmt oder den Kopf bewegt, dann bewegt sich auch die Krone).

Es senken ihre Augen herunter die Sangiang und sie bedecken sich mit der Matte, der geflochtenen von der Puronpalme, es beugen sich herab die Nashornvögel, die Djalajan, und sie verhüllen sich mit der Matte, mit dem kreuzweise geflochtenen Geflecht.

Sie sehen hindurch durch die Matte, das Geflecht der Puronpalme und sie erblicken den reisenden Streureis.

Sie schauen hindurch durch das Geflecht von Irit-Rotan der Nashornvögel und sie erblicken das besuchende Reiskorn.

Er stürzt herab, der Streureis, der weisse, und er bewirft die Matte, das Geflecht von der Puronpalme, es fällt in Menge herunter das weisse Reiskorn auf die Matte von Iritrotan der Nashornvögel.

Sie beklopfen die Matte, die leere, heftig mit ihren Scheiden der Dolche, sie schlagen auf die gewellte, die ledige, mit den elfenbeinernen Knöpfen der Griffe (ihrer Dolche).

Es beugen sich die Finger der sitzenden Sangiang und sie sammeln ein den Streureis, es senken sich die Hände der Djalajan um aufzulesen die goldenen Reiskörner.

Sie legen sie in ihre Scheiden, sie füllen mit ihnen die elfenbeinernen Knöpfe der Griffe (die inwendig hohl sind), die Zipfel der umwickelten Kopftücher, 
Tawur hasambalut sair bulau tampong papas, sawong ambon sampale dengan karipan humbang rendan tingang.

Tawur hasambalut dengan sair hampatong uei rantihen tingang, sawong ambon sampale dengan rotik henda parahang antang.

Tawur hasambalut dengan ewau garo bulan, sawong ambon sampale dengan simak santi ngeket pahawang.

Kananggare tamuei tawur ngentang lunok sawak pamua, dia tawur sambalut dengan karipan balai lambang sanggar.

Kananggare tamuei tawur ngentang lunok mamua undan, dia tawur sambalut dengan karipan sababulun haur garing. 356

Nansuwa kadjan sawong ambon njaripangku baras hapasang darah, korang sawong ambon sampale humbang karipan sababati,n rendan bahenda. sie füllen das Oberkleid und die Armringe, die zahlreichen.

Den Streureis vermischt mit den goldenen Spänen des Bundes des Besens, das Reiskorn vermengt mit dem $\mathrm{Ab}$ schabsel des Bambus, des ausgefransten, der Nashornvögel.

Den Streureis, vermischt mit den Spänen vom Schnitzbild von Rantihen-Tingang-Rotan mit dem menschlichen Antlitz, das Reiskorn vermischt mit dem Abfall von der Gelbwurz (Curcuma) Parahang Antang.

Den Streureis vermischt mit dem Duft des Weihrauches der Monde, das Reiskorn vermengt mit dem Wohlgeruche der von den Frauen ausgeht (die sich mit duftenden Blumen bestecken).

Nenne dich reisenden Streureis, tragend den Lunok (den Menschen) welcher heftig Früchte trägt, nicht aber sage von dir aus, dass du Streureis seiest, der vermischt wurde mit den Spänen vom Balai mit der reich verzierten und gefransten Schwelle.

Nenne dich reisenden Streureis, der das Hülfswerk verrichtet mit dem Lunok welcher Undanfrüchte trägt (d.h. der das Opfer des Menschenschädels überbringt), nicht aber Streureis welcher vermengt ist mit Spänen von Sababulu-Bambus, dem elfenbeinernen.

Sage von dir aus, o besuchendes Reiskorn, dass du Hülfswerk verrichtest mit dem auftauchenden Sand vermengt mit Blut (d.h. das das Menschenopfer überbringt), aber nicht sage, o Reiskorn, dass du vermischt seiest mit dem Abschabsel von Sababatin (das gleiche 
Kananggare tamuei tawur ngentang entang mohon pandoi tingang, dia tawur sambalut suloh sawang harukan njalong Djata.

Kananggare tamuei tawur ngentang lunok belom babasong rundjan, dia tawur sambalut dengan karipan tingang sumping bukit batu.

Kananggare tamuei tawur mambang penjang karuhei tatau, dia tawur sambalut dengan suloh sawang harukan karuhei.

Kananggare tamuei tawur palakuan ontong pandjang, dia tawur sambalut suloh sawang harukan ontong pandjang. wie Sababulu), dem ausgefransten, dem gelben.

Sage von dir, o reisender Streureis, dass du in deinem Brusttuche tragest den Getragenen welcher hinuntergetragen wird um rituell im Flusse gebadet $z \mathfrak{u}$ werden, er, der Tingang, aber nicht sage, o Streureis, dass du vermischt seiest mit den Sprossen des Sawang die ausgesprosst sind durch das Wasser der Djata (die die Fruchtbarkeit gibt).

Sage von dir aus, o reisender Streureis, dass du Hülfswerk verrichtest bei der Aufrichtung des Lunok, des lebenden, der da aussprosst aus dem heiligen Topf.*

Sage von dir aus, o reisender Streureis, dass du aushauest die Penjang der Karuhei des Reichtums, nicht aber sage, dass du vermischt seiest mit Spänen von den Schossen der Sawang, die da ausspriessen aus den Karuhei (oder auch: die mit den Karuhei verbunden sind).

Nenne dich den reisenden Streureis der Bitte um das Glück (Heil), das langwährende, aber nicht sage, dass du Abschabsel seiest von den Sprossen des Sawang, der zusammengebunden

* Es handelt sich um die Aufrichtung des Lebensbaumes, der zur Wiederholung der Weltwerdung aufgerichtet wird. Die drei Bäume und Handlungen folgen sich in der richtigen Reihenfolge. Zuerst wird gesprochen vom Baum, der den erworbenen Reichtum repräsentiert und auch als Gabe von Oberwelt und Unterwelt beiden angedeutet wird und mit dem die Kosten des Tiwah bezahlt werden, dann folgt der Baum mit dem Menschenschädel, der zur abschliessenden Reinigungshandlung dient, dann folgt das rituelle Bad und Untertauchen im Fluss mit der Gabe des neuen Lebens durch die Djata und schliesslich der Lebensbaum, der die ganze Weltwerdung wiederholt. Auch die übrigen Handlungen folgen in der richtigen Reihenfolge und zeigen das neu erworbene Heil, das ebenfalls Gabe ist, im neuen Leben und in einer neuen Welt. 
Kananggare tamuei tawur palakuan bulau tampong bohol, dia tawur sambalut suloh sawang harukan bohol.

Kananggare tamuei tawur palakuan bulau tampong puser, dia tawur sambalut dengan suloh sawang harukan tontong puser.

Kananggare tamuei tawur njembah pukong pahewan antang, dia tawur sambalut dengan bulo,n bawoi samben.

Kananggare tamuei tawur dohong bambang rangkang, dia tawur sambalut dengan batu,n pangurangan danum.

Kananggare tamuei tawur buno lu-badjambang laut, dia tawur sambalut kuling ulai satara rambon timpong.

Kananggare tamuei tawur dohong teken lu-karangan, dia tawur sambalut dengan bulau ist mit dem Glück, dem lang dauernden.

Nenne dich reisenden Streureis des erbetenen Goldes vom Bündel des Bohol (Fadenknoten), ${ }^{357}$ aber nicht sage, dass $d u$ vermengt seiest mit Spänen der Schosse des Sawang der zusammengebunden ist mit den Bohol.

Nenne dich, o reisender Streureis, Erbetenes von dem Golde des Büschels des Nabelstranges, nicht aber sage, dass du nur Abschabsel seiest von den Sprossen des Sawang, der verbunden ist mit dem Tontong Puser (Verlängerung, Fortsetzung des Nabelstranges. Man pflanzt diesen Sawang beim Abfallen des Nabelstranges).

Nenne dich, o reisender Streureis, den verehrungswürdigen heiligen Hain des Falken, aber nicht sage, o Streureis, dass $d u$ vermengt seiest mit den Haaren von den Schweinen mit den Halsbändern.

Nenne dich, reisender Streureis, den Dolch welcher aushaut die Stücke des alten Baumes, aber nicht sage von dir, o Streureis, dass du vermengt seiest mit den Steinen von den Geröllbänken des Flusses.

Nenne dich, o reisender Streureis, die Lanze, die hinwegschreitet über die See (ein Mann der viel aus Handelsgründen auf dem Meere reist), nicht aber sage von dir, o Streureis, dass du vermengt seiest mit der Rolle von Bindfaden und mit dem seidenen Garn des Tuches.

Nenne dich, reisender Streureis, einen Dolch der fortschiebt sein Boot mit dem Stossbaum längs den Steinbänken 
lelak bendang.

Kananggare tamuei tawur palakuan darah belom, dia tawur sambalut suloh sawang harukan saki.

Kananggare tamuei tawur ngentang nantolak burong dahiang, dia tawur sambalut dengan karipan djaka bindang garing.

Kananggare tamuei tawur ngentang mbohol manangkadje andau, dia tawur sambalut dengan tengang tamburak bohol.

Kananggare tamuei tawur ngentang mandjong bawoi samben, dia tawur sambalut karipan sumping bulan bawi,n sandah.

Kananggare tamuei tawur ngentang nantolak bulan bawi,n Sial, dia tawur hasambalut rambon timpong babilem. des Flusses, nicht aber sage, o Streureis, dass du vermengt seiest mit den goldenen Blumen der Bendangpalme.

Sage, o reisender Streureis, dass du vermischt seiest mit dem Blute, dem lebenden, aber nicht sage, o Streureis, dass du vermengt seiest mit den Sprossen des Sawang der verbunden ist mit der Reinigung durch Blut.

Sage von dir aus, o reisender Streureis, dass du das Hülfswerk verrichtest beim Verabschieden der (ungünstigen) Vorzeichenvögel, nicht aber sage, o Streureis, dass du vermengt seiest mit den Spänen der Scheite, der elfenbeinernen (gemeint sind damit wahrscheinlich die Bretter auf denen die Vorzeichenvögel, die man verabschiedet, dargestellt werden).

Sage von dir aus, o reisender Streureis, dass du das Hülfswerk verrichtest beim Festknoten des Manangkadje Andau, nicht aber sage, o Streureis, dass du nur vermengt seiest mit den Tengangfäden des Bohol (siehe das Register unter den verschiedenen Namen).

Sage von dir aus, o reisender Streureis, dass du das Hülfswerk verrichtest beim Wegsenden des Schweines mit dem Halsband (als Opfer), aber nicht sage, o Streureis, dass du vermengt seiest mit Abschabsel von den Ohrringen der Monde, der weiblichen Sandah. 358

Sage von dir aus, o reisender Streureis, dass du das Hülfswerk verrichtest bei dem Wegsenden der Monde, der weiblichen Sial, aber nicht sage, dass du vermengt seiest mit den Fäden des 
schwarzen Tuches (mit diesem werden die Menschen bedeckt die diese Handlung vollziehen, damit sie nicht mehr gesehen werden können von den Sial. Siehe auch weiter unten).

Kananggare tamuei tawur Sage von dir aus, o reisender Streusembah Djata Balawang $\mathrm{Bu}$ - reis, dass du verehrest die $\mathrm{Djata} \mathrm{Ba}-$ lau, dia tawur sambalut de- lawang Bulau (die Djata mit der golngan sair malambong bulat. denen Türe, siehe die Einleitung), aber nicht sage, dass du vermengt seiest mit den Spänen des goldenen Prunkbootes. 359

Kananggare tamuei tawur Sage von dir aus, o reisender Streungentang pendeng pantar reis, dass du Hülfswerk verrichtest bei ontong, dia tawur sambalut der Aufrichtung des Pfahles des Geriak bulau idje tilai ti- winnes (oder des Heiles), aber nicht ngang. 360 sage, o Streureis, dass du vermengt seiest mit den goldenen Wellen der verschiedenen Nashornvögel.

Kananggare tamuei tawur Sage von dir aus, o reisender Strel1ngentang parong taheta ba- reis, dass du das Hülfswerk verrichtest tundjong, dia tawur sambalut sair suloh djaka pinang tingkes.

Kananggare tamuei tawur tolak dohong bandong kajau, dia tawur sambalut njalong pupok bulau batu,n penjang.

Kananggare tamuei tawur ngentang mapan banama kahean, dia tawur sambalut sair rahan lawang palantaran. bei der Aufrichtung des sich neu erhebenden Hauses, aber nicht sage, o Streureis, dass du vermengt seiest mit den Stücken der Schosse, die aussprossen am Fuss des Pinang Tingkes. Sage, o reisender Streureis, dass du begleitest die wegziehenden Dolche (Männer) der Scharen der Kopfjäger, aber nicht sage, o Streureis, dass du vermengt seiest mit dem Wasser in das die goldenen Steine der Penjang eingetaucht wurden (mit diesem Wasser waschen sich die Kopfjäger ab).

Sage von dir, o reisender Streureis, dass du mitarbeitest beim Bau eines grossen Bootes, aber sage nicht, o Streureis, dass du vermengt seiest mit den Spänen der Hütte an der Türe zum Vorplatz vor dem Hause (ge- 
Kananggare tamuei tawur ngentang manjakean tingang, dia tawur sambalut dengan sair hampatong kalawet sanggar baputi.

Kananggare tamuei tawur entang hapupok pandoi tingang, dia tawur sambalut dengan sair lanting lamiang.

Kananggare tamuei tawur ngentang niring hintang tatau, dia tawur sambalut sababulon rahan bukit batu. meint ist mit der Hütte wahrscheinlich das Badehäuschen auf dem Anlegefloss).

Sage von dir, o reisender Streureis, dass du Hülfswerk verrichtest bei der Aufstellung des Nashornvogels (gemeint ist wahrscheinlich die Aufbahrung der Leiche und oben handelt es sich beim Bau des neuen Bootes wahrscheinlich um die Herstellung des Sarges), aber nicht sage, o Streureis, dass du vermengt seiest mit dem Abschabsel vom Schnitzbilde des geschmückten Kalawet, des weissen (dieser hilft bei der Führung des Toten mit und bedient die Segel des Totenbootes).

Sage von dir aus, o reisender Streureis, dass du in deinem Schultertuch tragest den gewaschenen, rituell gebadeten Tingang (den Toten, der mit Lebenswasser gewaschen wurde), aber nicht sage, o Streureis, dass du vermengt seiest mit den Spänen des Achatsteinflosses (mit dem Tempon Telon die Liau Haring Kaharingan nach dem Totendorf führt).

Sage von dir aus, o reisender Streureis, dass du Hülfswerk verrichtest beim Straffspannen der Treppe, der reichen, aber nicht sage, o Streureis, dass du vermengt seiest mit Sababulon des Rahan (Haus) der heiligen Töpfe (bukit batu: der Steinberg, es handelt sich $\mathrm{um}$ heilige Töpfe die in diesem Falle den doppelten Aspekt des Urberges mit Ranjing Mahatala Langit und des Urwassers mit der Djata darstellen. Der Tote besteigt sie und erlangt von beiden das neue Leben). 
Hemben nduan, hambekan katon matok rinon djaretan etoh, tawur hasambalut sair bulau tampong papas.

Tawur hasambalut sair elang salentup, karipan hampatong uei rantihen tingang.

Tuneng njababeneng tandok Sangiang manuntun panamuei tawur, mamahera kining Djalajan nureng rabia sawong ambon.

Nganda-ngandang tawur hapan lawi,n tingang kalangkang garo, nitih,e naregap bungai hampatong santi.

Tawur saloh garo,e djadi olon mangalunen, sawong ambon kanarentar santi kilau bulan njawak kabangkange.

Bawi,n tawurku sintong udju mondok pulau-pulau kabangkange hulek pating sumping,e, hakangkalo rabia djudjong,e.

Rantep panduka mondok balita,n Dohong Mama Tandang, hadjip padjena ba-
So ist es jetzt in dieser Angelegenheit, so steht es jetzt in dieser Sache, o Streureis, der du vermengt bist mit Abschabsel von dem goldenen Bunde des Besens.

O Streureis, vermischter mit Spänen der knallenden Bambusstücke und mit Spänen vom Schnitzbild von Rantihen-Tingang-Rotan.

Es blicken genau und es schauen scharf hin die Augen der Sangiang, sie schauen an den reisenden Streureis, sie schlagen in schräger Richtung ihre Hellen (Augen) auf, die Djalajan und sie schauen an das goldene Reiskorn. Es schlägt der Streureis mit den Enden des Tingang, dem dick ausstehenden Weihrauch, es klopft das Reiskorn mit dem gespreizten Nashornvogel (gemeint ist wahrscheinlich der Kopfschmuck), dem Schnitzbilde, dem wohlriechenden.

Der Streureis verändert seinen Duft und er wird zu einem Menschen, so wie sie auf der Welt leben, das Reiskorn verwandelt seinen Wohlgeruch und wird zu einem Monde (Mädchen) von grosser Schönheit (darunter versteht der Dajak auch den ebenmässigen Körperbau, der mit kabangkang ausgedrückt wird).

Frauen meines Streureises, ihr sieben zusammen, setzt euch dicht nebeneinander mit eueren Körpern, so dass sich berühren die $Z$ weiglein der Ohrringe, so dass sich aneinander anschmiegt der goldene Kopfschmuck.

Dicht setzt euch nieder bei ihm, dem Dohong Mama Tandang, lasset euch nieder auf eueren Sitzplätzen in der 
djanda Langkah Sawang iMama la-Bungai.

Manambang tamuei bawi,n tawur ewen nduan sintong udju, nakep kadjan sawong ambon habinei dinon lambong hanja.

Palus batuntur pandjang Sangiang Dohong Mama Tandang, basansana ambo Langkah Sawang la-Mama Bungai.

Randan hakaisek rawei dengan putir bawi,n tawur, ringkang sarohi tisoi dengan habinei rabia sawong ambon:

Kueh bulan salan keton bawi sintong udju, isen bintang panjarohan keton habinei dinon lambong hanja?

Lalau tamuei badjeleng mudjan renteng tingang Sangiang, pangadja basikap sawak njamperai bungai Djalajan.

Lungang-lingok sumping bawi,n tawur sintong udju, pulang-pilik djudjong,e sawong ambon dinon lambong hanja.

Hajak malawo rawei kabantukan balai njaho, lu-maninting tisoi,e njababeroh sali ganggerang:

Dia isek nansekan panamuei ikei sintong udju, isen panja-
Nähe des Langkah Sawang Mama Bungai.

Und so empfängt er die reisenden Frauen des Streureises, die sieben zusammen, und so begrüsst er den Besuch der Frauen des Reiskornes, die da vermehrt sind $z \mathfrak{u}$ acht.

Und sogleich beginnt zu sprechen mit langen Worten der Sangiang Dohong Mama Tandang, und es erzählt in ausführlicher Rede der Langkah Sawang Mama Bungai.

Und mit sanfter Stimme fragte sein Wort die Prinzessinnen, die Frauen des Streureises, und mit gedämpftem Laute erkundigt er sich bei den Frauen des Reiskornes:

Was ist euere Absicht, o Frauen, ihr sieben zusammen, was ist der $Z_{\text {weck }}$ eueres Botschafterdienstes, o ihr Sterne, ihr Frauen, die ihr vermehrt seid zu acht?

$\mathrm{Zu}$ unerwartet ist euere Reise, $\mathrm{zu}$ rasch euer Beregnen der Schwanzfedern der Tingang der Sangiang, zu schnell ist euer Besuch und zu heftig euer Berieseln der Nashornvogelfedern des Kopfschmuckes der Djalajan.

Es schütteln ihre Ohrringe die Frauen des Streureises, die sieben zusammen, es schwenken ihren Haarschmuck die Reiskörner, die da vermehrt sind zu acht.

Und sie werfen aus ihr Wort, dass es niederfällt in der Mitte des Balai, des donnernden, und sie sprechen aus ihre Rede, dass sie erschallt in der Mitte des Hauses, des dröhnenden:

Nicht frage, nicht forsche nach nach der Reise von uns sieben, nicht er- 
rongan panungkup habinei kundige dich nach dem $Z$ wecke des ikei lambong hanja.

Djari njembang balai njaho Besuches von uns Frauen, die da vermehrt sind zu acht.

bahalap matunggang pulu, nasa sali ganggerang badaris bambuakan djalatien.

Bawi loang rawei ikei tawur sintong udju, bamban panjarohan tisoi lu-habinei ikei lambong hanja.

Antang namuei bara pantai danum kalunen, kenjoi lumangadja bahandjong luwok kampongan buno ano.

Balua lewu Tumbang Rasau Rohong, bahandjong rundong Putak Hadjundjong, ngentang manangkadje nolak ambon barutas matei.

Entang ngentang nangkadje limbah lunok batipas pating,e, tujang mangko nalandjat ulek baringen bageto sangkabila.

Nolak ambon barutas matei ikei nduan alem kareh, njang-

Wir sind gekommen zum Versanmmlungshaus, dem donnernden, dem schönen mit den zehn Türen, wir sind hereingetreten in das Haus, das dröhnende, mit den Oeffnungen, den neunen.

Wir sind die Frauen, die Ueberbringerinnen des Wortes, wir Stret1reis, wir sieben zusammen, wir sind die Rohre der Botschafter 361 deRede, wir Frauen, die vermehrt sind zu acht.

Wir sind reisende Antang von den Ufern des Flusses der Welt, wir sind besuchende Falken, die sich aufgemacht haben von den Buchtungen des Dorfes der Lanzen X. (Der Name des Dorfes wird genannt.)

Wir sind herausgeschritten aus dem Dorfe Tumbang Rasau Rohong, wir sind aufgebrochen aus dem Orte Putak Hadjundjong (es ist der Name in der Basa Sangiang für das Dorf Sepang Simin am oberen Kahaian) um zu verrichten das Hülfswerk beim Wegschieben der Wolken, der unreinen des Todes.

Für den Getragenen verrichten wir das Hülfswerk, nachdem dem Lunok abgebrochen worden sind seine Stützen, für den Gewiegten, den wir auf unserem Schosse tragen, handeln wir nun für kurze Zeit, nachdem ihm abgeschlagen wurden die Wurzeln des Waringin.

Wir wollen wegschieben die Wolken, die vernichtenden des Todes, in der 
ka enon bapilo nihau tantepen alem basansinep.

Nduan hambekan katon ndurut tingang lu-Sangiang, dinon djaretan etoh lu-malentur bungai Djalajan.

Tingang nusang hadurut lunok hapan talawang teras djambu bahandang, bulau daren lintong luhing lumpok muntei bulau.

Papan talawang sintong udju, daren lintong lambong hanja ttg. Sangiang tarantang garo, lu-Djalajan lalundong santi.

Ndurut talawang sintong $\mathrm{u}^{-}$ dju hapa Sangiang manambang salumpok entang, marentur dare,n lintong hapan Djalajan njangkuroing tanterus tujang. kommenden Nacht, wir wollen aufheben den Tau, den verunreinigenden, in der Nacht, der finsteren.

Und nun steht es so in dieser Angelegenheit, dass wir bitten möchten, dass herabkämen die Tingang, die Sangiang, und nun steht es so in dieser Sache, dass wir wünschen, dass herabfahren würden die Nashornvögel, die Djalajan.

Dass die Tingang in schrägem Fluge herunterstiessen auf den Lunok (d.h. auf die Menschen, die diese Handlung verrichten, gedacht ist hier an die schöpferische Wirksamkeit des Nashornvogels auf dem Lebensbaum), dass sie kämen auf dem Schildbrette von Kernholz des roten Djambubaumes, auf den goldenen geflochtenen Bändern des innersten Holzes des goldenen Munteibaumes.

Auf Schildbrettern, sieben zusammen, auf den geflochtenen Bändern, die vermehrt sind zu acht, und auf ihnen die Sangiang, die Kinder des Weihrauches (d.h. die Helfer des Dohong Mama Tandang, die dann in die Hülfsbalian einfahren), und auf ihnen die Djalajan, die Kinder des Wohlgeruches.

Dass herunterfahren die Schildbretter, die sieben zusammen, damit die Sangiang in Empfang nehmen die Seelen der Getragenen, dass herabfahren die geflochtenen Bänder, damit die Djalajan aufnehmen und umzäunen die Seelen der Gewiegten. (Bei diesen Handlungen könnten sich die Seelen der Menschen leicht verirren und von bösen Geistern geraubt werden, um das zı1 verhüten werden sie den Sangiang 
Ndurut papan talawang tingang, bulau dare,n lintong ranjing, ndurut talawang dohong, malentur daren lintong bulang.

Ndurut papan talawang bulau, dare,n lintong lu-rabia, papan talawang timpong, marentur dare,n lintong pahangan.

Ndurut talawang kumpang dare,n, lintong tahawong, papan talawang pisih, mandurut papan talawang kalialang.

Ndurut papan talawang handjaliwan hapa Sangiang manambang entang, nusang lu-hadurut keton nduan djaretan etoh.

Mimbit garo bahari panolak ambon barutas matei, nanggong santi mait sangka,n enon bapilo nihau.

Mimbit tampong papas rabia, tundon kalingking mimbit elang salentup, mimbit hampatong uei rantihen tingang. anbefohlen, die sie beschützen und bewahren müssen. Durch sie geborgen geschieht ihnen kein Unheil.)

Dass herabfahren die Schildbretter der Nashornvögel, die goldenen geflochtenen Bänder der Verehrungswürdigen (der Tingang), dass herunterfahren die Schildbretter der Dolche, dass herabkommen die geflochtenen Bänder der Griffe.

Dass herabfahren die Schildbretter, die goldenen, die geflochtenen Bänder des Schildes, die goldenen, die Schildbretter von Tuch, dass herunterfahren die Schildbretter von geflochtenen Bändern von Stoff.

Dass herunterfahren die Schilde der Scheiden, die geflochtenen Bänder der Abgeschabten (Scheiden), die Schildbretter der Pisih (chinesische Münzen die zur Befragung des Loses dienen), dass herabfahren die Schildbretter der Schwalben.

Dass herabfahren die Schildbretter der Handjaliwanschlange, damit die Sangiang aufnehmen die Getragenen, dass ihr schräg gerichtet herunterstösst, jetzt in diesem Augenblick.

Mitbringend den Weihrauch, den scharfen, den Wegstosser der Wolken, der verderblichen des Todes, herbeitragend den Wohlgeruch, den kräftig wirkenden, den Aufheber des Taues, des vernichtenden, des verlorenen.

Mitbringend den Bündel des Besens, den goldenen, den Tross, den Besen, herzutragend den knallenden Bambus und mitbringend das menschliche Schnitzbild von Rantihen-TingangRotan. 
Mimbit darah burong saki, lu-panggirih meto palas, tingang kalangkang garo, mimbit bungai lu-hampatong santi.

Mimbit dohong lalunding liau, pulang lu-talandjing pangkat, batu kalingei liau, liang saramin lu-pangambon, uei manjamei bukit lumpang lulalunding liau.

Mimbit timpong babilem sarong lawang baunandau, sawang ringkan tingang, bunge lu-kangkajoh langit.

Keton manabasan balai lumpang lalunding liau, Djalajan nantaolah sali djajang tingang mumok ambon.

Nabasan bunge, $n$ hampatong mina-merang lu-palawi, imbit keton tingang nusang lu-hadurut ambon.

Mimbit tambaran erang, upak langkoang leleng baho, kumis baringen haring nandai luwok lu-Djalajan.

Mimbit ranjing pandereh
Mitbringend das Blut der Vögel, das für die rituelle Bestreichung gebraucht wird, den Stellvertreter der Tiere der Bestreichung, den Tingang, das Gestell des Weihrauches, den Nashornvogel des Schnitzbildes des Wohlgeruches (ein Gestell für den Weihrauch, das wahrscheinlich in der Form eines Nashornvogels geschnitzt ist).

Mitbringend den Dolch, den Schmuck der Liau, den Griff, die Zierde des Amtes, den Stein des Abschiednehmens der Liau, den Stein, den Spiegel der Pangambon (anderer Name für Liau), das Manjameirotan vom Berge für die Herstellung des Balai der schräg abgehauenen Bambusrohre für die Liau. Mitbringend das schwarze Tuch, die Hülle der Türe der Wolken, den Sawang, den schlanken der Tingang, den Sawang, der gesehen wird vom Himmel herunter.

Und ihr bauet den Balai der schräg abgehauenen Bambusrohre, den Reichtum der Liau, ihr, Djalajan, machet das Haus, das schräg stehende (schwebende) für den Tingang, den dunkel gewolkten.

Und ihr machet ein schönes Schnitzbild, ein tönendes, klirrendes von Palawiholz und ihr bringt es mit, ihr Nashornvögel, ihr schräg gerichtet durch die Wolken herunterfahrende. Und ihr bringet mit den Bast des Erang, die Rinde des Langkoang vom Fundplatz auf dem früheren Felde, die feine Haut des Waringin, des lebenden, welcher gedeiht an der Buchtung des Flusses Djalajan.

Und ihr bringet mit den verehrungs- 
buno, pasok panangkiling würdigen Schaft des Speeres (den Njaring, bua katilambong heiligen Speer der den Lebensbaum njaho, mimbit katuen njior darstellt), den Korb, der da aussieht bendang.

Mimbit sundur bulau, mimbit sarak rabia, mimbit bangkan hanselan, mimbit sambang bulau.

Narai bulan kahunga penjang garo manadjah simpei, isen bintang kabuku paturong santi tilong tamburak,e.

Koa,n lu-balitan Rangkang Dohong Mama Tandang, tisoi lu-Djalajan Langkah Sawang Mama Bungai.

Palus bahing bapanting linga Dohong Mama Tandang, hawie ein Njaring (der eine rote Farbe hat), die Früchte der Kokosnusspalme, ihr traget herzu die reifen Betelnüsse der Palme.

Und ihr bringet mit den goldenen engen Kamm, ihr traget herbei den goldenen weiten Kamm, ihr bringet mit das wirkliche Oel und ihr traget herbei die goldenen Trommeln.*

Ist das, o ihr Monde, der Grund, dass die duftenden Penjang ihren Bündeln rufen, ist das die Ursache, o Sterne, dass die wohlriechenden Paturong verlangen nach ihren zierlich gearbeiteten Geflechten (in die sie eingefügt werden. Die Stelle bedeutet: Sangiang und Menschen gehören zusammen wie die Penjang und ihre Bündel und sie treten bei wichtigen Handlungen gemeinsam auf, das eine kann das andere nicht entbehren, erst in ihrer Ganzheit sind sie vollkommen und erwirken das Heil für den Stamm, das Individuum und den ganzen Kosmos).

So spricht er, der Rangkang Dohong Mama Tandang, so lautet die Rede des Djalajan Langkah Sawang Mama Bungai.

Und es schleudert hin sein Wort der schnelle Dohong Mama Tandang, und

\footnotetext{
* Alles, was für die priesterlichen Handlungen benötigt wird, muss durch die Sangiang mitgebracht werden, sonst bleiben alle Handlungen wirkungslos. Der Mensch kann aus sich selbst nichts tun, er hat keine Macht dazu und er kann erst etwas unternehmen, wenn die Sangiang ihm die Mittel in die Hand gegeben haben, mit denen er arbeiten und handeln kann. Er ist in seinem Sprechen und Handeln vollständig abhängig von ihrer Gnade und ihrer Mitarbeit.
} 
jak siring bambahinga Langkah Sawang Mama Bungai. Nambawa Sangiang awang garing tabela belom, nangkiang bungai Djalajan maing kanahesen ringik:

Keton anak aken sama ringkes-marangkesa, panungkup kawan tingang rata ringkin lu-basariang.

Sama natap paramo,n itah nusang hadurut lunok, maringkes parabea,n itah tambon marentur labeho.

Ringkes-marangkesa Sangiang handue udju, ringkinbasariang Djalajan lambong epatbalas.

Sama gatang tarahendeng luhatanggar tingang kangkana,e, tundjong tarahingkat ngabuah djundjong sampulau dare.

Nangking manantelai dohong, meteng mahulan bulau batu,n penjang,e ewen, lu-manatap ramo,n nusang hadurut lunok.

Dia balandong tahi sukup ramo,n nusang lu-hadurut, isen bahunang genep parabean tambon marentur labeho. er wirft aus seine Rede, er der Langkah Sawang Mama Bungai.

Er ruft den Sangiang, den Elfenbeinen, den jung lebenden, er schreit den Nashornvögeln, den Djalajan, den kräftigen, den noch nicht des Lebens gewohnten:

$\mathrm{O}$ ihr Kinder, ihr Neffen, bringt alles in Ordnung, ihr Angehörigen der Schar der Nashornvögel macht alles bereit.

Machet gemeinsam bereit die Güter, die unserigen, um schräg gerichtet herunterzustossen auf den Lunok, ordnet gemeinschaftlich die Waren, die unser Eigentum sind, damit wir herunterfahren wie Wasserschlangen in die Wassertiefe.

Machet alles in Ordnung, ihr Sangiang, ihr zweimal sieben, machet alles bereit, ihr Djalajan, ihr vierzehn zusammen.

Zusammen erheben sie sich und sie stehen auf und sie bringen ins Gleichgewicht ihren Schmuck, sie erheben sich und stehen auf und bringen in Ordnung ihren Kopfputz.

Sie gürten, schräg abstehend den Dolch, sie knüpfen und umbinden die goldenen Steine ihrer Penjang, sie machen bereit die Güter um schräg gerichtet herabzustossen auf den Lunok.

Und nicht dauert es allzulange Zeit und sie haben genügend Güter bereit gemacht um in schräg gerichteter Fahrt herunterzustossen auf den Lunok, und es dauert nur kurze Zeit und bereit liegen die Waren um wie eine Tambon herabzufahren in die Wassertiefe. 
Dohong Mama Tandang Radja mangon lu-parentah, Sawang Mama Bungai Kanarohan mapak 362 lu-basara: Keton anak aken marasih papan lu-talawang, panungkup kawan tingang nantahinot bulau dare, $n$ lintong gilitginting $362^{a}$ djandjulana, malan balua balai njaho manting tambang balinga halawo lawang parantaran tingang.

Marasih papan talawang, nantahinot bulau dare,n lintong, ngitare papan talawang bara garing la-palaboha,e.

Imbit mananturong hantandipah lah-balai njaho, toros teken garing naharukan bulau namburak.

Njangkabila tambat keket halaloha djamban garing, namuei lawang parantaran,
Dohong Mama Tandang, der König, stellt einen Befehl auf, Sawang Mama Bungai, der Fürst, gibt einen Auftrag:

Ihr, o Kinder und Neffen, reinigt das Brett des Schildes, ihr, Angehörige der Schar der Tingang, bringt in Ordnung die goldenen geflochtenen Bänder, die uns begleiten auf unserer Reise, und sie machen sich auf und treten heraus aus dem Versammlungshaus, dem donnernden, und sie werfen ihre Füsse aus und sie schnellen weg und sie lassen sich herunterfallen auf den Stein an der Türe des Vorplatzes der Nashornvögel (sie eilen rasch zum Anlegeplatz am Fluss um alles bereit zu machen).

Und sie reinigen das Schildbrett und sie bringen in Ordnung die goldenen geflochtenen Bänder, und sie drehen das Schildbrett von dem Elfenbein seines Ankerplatzes. (Wird ein Boot längere Zeit nicht gebraucht, dann zieht man es aus dem Wasser und stellt es auf dem Vorplatz vor dem Haus auf zwei Pfähle die darunter geschoben werden.)

Und sie bringen es zum Flusse und sie rudern mit ihm nach der Seite, die gegenüber dem Versammlungshaus, dem donnernden, liegt, und sie rammen den Stossbaum, den elfenbeinernen, in den Fluss und sie binden an ihm an den goldenen geflochtenen Strick. (Auf diese Weise werden die Boote am Ufer des Flusses festgemacht.)

Sie machen fest das Seil, das kurzgliederige (ein Rotanseil), des Kieles und sie lassen herab die Brücke des 
ngadja liang panupian ti- Schiffes, die elfenbeinerne, und sie bengang. geben sich zu der Türe des Vorplatzes und sie schreiten hin zu dem Stein am Anlegeplatz der Nashornvögel.

Palus buli njelem balai djanUnd sie kehren wieder zurück und sie djaroman akan Dohong Mama Tandang: djadi mama apang ikei marasih papan lutalawang.

Dohong Mama Tandang kabantengan balai njaho djadi sukup rawei dengan bulan djaka bawi,n tawur.

Tawur saloh bulat limbah hapus riwut rawei, sawong ambon malik bunter ulek sambong lu-karunja.

Ngalapatar hajak tawur nduan sintong udju, palus tolangkusa lawi,n tantan lu-salingkat lawong,e.

Dapit djewu tawur bukei totok pajun lu-pangentang, djadi baras bulau panatau lewu Danum Djalajan.

Ringkes-marangkesa Sangiang huang balai, ringkinbasariang Djalajan medjen sali lu-ganggerang.

Tende manandjulo riak bahing panto,n sambang, tahan malalandjat ringkin salatan bambahinga,n luhing. und sie erzählen dem Dohong Mama Tandang: O Onkel und Väter, wir haben in Ordnung gebracht das Schildbrett.

Dohong Mama Tandang hat in der Mitte des Versammlungshauses, des donnernden, beendet sein Gespräch mit den Monden, den Frauen des Streureises.

Der Streureis verwandelt sich wieder in Rundheit, nachdem er beendet hat sein wehendes Wort, das Reiskorn verändert sich wieder in Rundheit, nachdem es geschlossen hat sein Gespräch (d.h. die Frauen des Streureises nehmen wieder die Gestalt von Reiskörnern an).

Und er (der Dohong Mama Tandang) hebt den Streureis, die sieben zusammen, auf und steckt sie in den Zipfel seines Kopftuches.

Später, morgen erst wieder, o Streureis, beginnen wir aufs neue die Arbeit, das Hülfswerk, verwandle dich nun in goldenen Sand, in den Reichtum des Dorfes Danum Djalajan.

Und sie machen nun alles bereit, die Sangiang im Versammlungshaus, und sie bringen alles in Ordnung, die Djalajan im Hause, dem donnernden.

Halte an für kurze Zeit, du rauschender Laut des Schlagens der Trommeln, schweige für einen Augenblick, du brausender Schall der Trommeln. 
Badjamban bahing lu-karungut lius nusang hadurut lunok, bagentoi salatan kandaju tambon marentur labeho.
Es begibt sich hinaus auf die Schiffsbrücke das Wort des Liedes und es steht im Begriffe schräg gerichtet herabzustossen auf den Lunok, und die Rede des Gesanges begibt sich in das Boot, das sich bereit macht um herabzufahren wie die Wasserschlange hinunterfährt in die Wassertiefe.

\section{H. Dohong Mama Tandang ruft den Winden die die Segel blähen sollen}

Toh malajan helo manekap katambong, ewen panombah uras malajan manandak, ewen mondok suni-suni ttg. nanjeneh auch upo kakarungut kabuat,e bewei, koa,e:

Sama gatang tarahendeng Sangiang sintong handue $\mathfrak{~}$ dju, rata tundjong tarahingkat Djalajan lambong epatbalas.

Sama malan balua balai njaho, bahandjong sali ganggerang.

Manting tambang hajak batandjong batu lawang paruntaran, manetei liang tapian tingang, rata lompat papan talawang, manantame bulau dare,n lintong.

Balita,n linga Dohong Mama Tandang, Langkah Sawang Mama Bungai Bunge, bandong Njaring djahawen,
Sie hören nun vorläufig auf, die kleinen Trommeln zu schlagen, und die Hülfsbalian lassen ihren Gesang verstummen und sie sitzen ruhig und sie lauschen alle nach dem Wort des Hauptbalian, der nun allein singt den folgenden Gesang :

Gemeinsam stehen sie nun auf und erheben sich die Sangiang, zweimal sieben zusammen, gemeinschaftlich stehen sie auf und erheben sich die Djalajan, die vierzehn zusammen.

Und gemeinsam machen sie sich auf und sie treten heraus aus dem Versammlungshaus, dem donnernden, und sie treten hervor aus dem Haus, dem dröhnenden.

Und sie werfen aus ihre Beine und sie eilen zu dem Steine an der Türe zum Vorplatz, sie betreten den Stein, den Anlegeplatz der Nashornvögel und gemeinsam besteigen sei das Schildbrett und gemeinschaftlich steigen sie hinein in die goldenen geflochtenen Bänder.

Er, der schnelle Dohong Mama Tandang, der Langkah Sawang Mama Bungai Bunge, der Mann der Njaring, der sechsen, 
Mendeng manambawa riwut, hingkat manangkiau salatan, mendeng manambawa riwut tingang balua djundjong lunok, hingkat manangkiau salatan ranjing bahandjong tapang pasana,e.

Mendeng manambawa riwut tambon balua kalang labeho handalem, manangkiau salatan ihing bahandjong rantau timben.

Mendeng manambawa riwut bulau bara djalajan hulu danum, mangkiang salatan rabia bahandjong tandjong ringkin karangan.

Mendeng manambawa riwut timpong balua kalimbahan laut, mangkiau salatan pahangan bahandjong panumparan pasang.

Mendeng manambawa riwut tandang haramaung balua
Er erhebt sich nun und ruft dem Wind, er erhebt sich und schreit dem Wind, er erhebt sich und ruft dem Nashornvogelwind, dass er hervorkomme aus der Krone des Baumes, er steht auf und ruft dem Wind des Verehrungswürdigen, er fordert ihn auf herauszutreten aus dem Stamm, dem sprechenden.

Er steht und ruft dem Winde der Wasserschlange, dass er herausgehe aus der Wassertiefe, der abgründigen, er schreit dem Wind der Ihing (anderer Name für Tambon), dass er hervorkomme aus der Wassertiefe, der sehr grossen.

Er steht und ruft dem Wind des Goldes vom Oberlauf, vom Quellort des Flusses, er schreit dem Winde des Goldes, dass er hervortrete und beschreite die überwellten Steinbänke. (Die Gegenüberstellungen werden nicht vollständig aufgezählt, denn nach dem Winde des Goldes müsste der Wind der Edelsteine folgen.)

Er steht und ruft dem Wind des Tuches, dass er herauskomme von der Mündung am Meere, er schreit dem Winde des Stoffes, dass er hervorschreite vom Orte wo die Flut ihren Ursprung hat. (In der oekonomischen Klassifikation ist das unverarbeitete Gold mit dem Oberlauf klassifiziert, die Schmuckstücke aber mit dem Unterlauf, weil sie dort verarbeitet werden. Das Tuch ist mit dem Unterlauf assoziiert weil es von dort eingeführt wird.)

Er steht und ruft dem Wind des Tigers, dass er hervortrete aus seiner 
batu kandawa.

Mendeng manambawa riwut handjaliwan balua sahep rakera.

Mendeng manambawa riwut garo balua tingang kalangkang, hingkat manangkiau salatan santi bahandjong bungai hampatong santi.

Mendeng manambawa riwut karohei balua sambang garantong, hingkat manangkiau salatan pasihan bahandjong tintun djalingan.

Mendeng manambawa riwut sangkalemo balua sulep garing, manangkiau salatan sakalunjai bahandjong sukoh batu.

Dumah riwut hakampeleng, rampe salatan hapampungan hapan papan talawang tingang nusang hadurut lunok, bulau daren lintong tambon marentur labeho.

Misi malakondonggaring pamalatok tihang, kembong mangamparang timpong dandawen lajar, tiring manang- steinernen Höhle.

Er steht und ruft dem Wind der Handjaliwanschlange, dass er hervorkomme aus dem Laube, dem zusammengewehten.

Er steht und ruft dem Wind des Weihrauches, dass er hervorkomme aus dem Nashornvogel, dem Gestell (das wie ein Nashornvogel geschnitzt ist), er steht und schreit dem Wind des Räucherwerkes, dass er heraustrete aus dem Nashornvogel, dem Schnitzbild des Wohlgeruches.

Er steht und ruft dem Wind der Karohei, dass sie hervorkommen aus den Trommeln und Gong, er steht und schreit dem Wind der Pasihan, dass sie heraustreten aus der Richtung der Reihen der Gong (während der Handlungen werden die Karohei in einen Gong gelegt).

Er steht und ruft dem Winde der Sangkalemo, dass er hervorkomme aus den Köchern, den elfenbeinernen, er schreit dem Winde der Sakalunjai, dass sie heraustreten aus dem schräg gebogenen Stein (der als Behälter dient).

Es kommen die Winde und sie vereinigen sich, es nahen die Winde und sie versammeln sich auf dem Schildbrette, das wie ein Nashornvogel schräg gerichtet herabstösst auf den Lunok, auf den goldenen geflochtenen Bändern, die wie die Wasserschlange herunterfahren in die Wassertiefe.

Sie füllen die Querhölzer, die elfenbeinernen, die da umgeben den Mast, sie blähen auf die quergespannten Tücher, die Blätter der Segel, sie 
kanong tali,n pambahoi riwut.

Tingang ewen nolak lunok, tambon basangka labeho,

Bara lewu Danum Djalajan, bahandjong rundong Riak Lamiang.

Engkak bulau manamburak, ndjidjit manansupit teken garing, mangohas tatambat keket, hadjadjita djamban garing.

Hajak riwut-riwut bahing panton sambang putir bawi,n Sangiang, lento-lento salatan bambahinga,n luhing kameloh tara,n Djalajan.

Sama djadi hapantar bua pinang, Djalajan hataradju manjang.

Malik bahing panton sambang ikei pulau rewan bawi, mules salatan bambahingan luhing panungkup tambon haruei bungai.

Manjaroroi gandang apang mandurut papan talawang, manantepet towong mama marentur bulau dare,n lintong. spannen straff die Seile der wehenden Winde (mit denen man die Segel richtet um den Wind einzufangen). Und die Tingang stossen $a b$ vom Lunok und die Wasserschlange schreitet weg von der Wassertiefe, Sie machen sich auf aus dem Dorfe Danum Djalajan, sie brechen auf aus dem Orte Riak Lamiang.

Sie lösen das goldene gedrehte Seil, sie zerren und ziehen heraus den Stossbaum, den elfenbeinernen, sie lösen den Strick, den vielgliederigen, sie holen herein die Brücke, die elfenbeinerne.

Während erschallt der rauschende Laut der durch die Prinzessinnen, die weiblichen Sangiang, geschlagenen Trommeln, während ertönt der brausende Schall der durch die $\mathrm{Ka}$ meloh, die weiblichen Djalajan, geschlagenen Trommeln.

Und gemeinsam haben sie nun beendet das Kauen der Pinangfrüchte, und gemeinschaftlich hören sie nun auf mit dem Kauen der Betelnüsse.

Es wechselt der Laut des Schlagens der Trommeln durch uns, die Schar der Frauen, es ändert der brausende Schall der Trommeln von uns, der Gemeinschaft der Wasserschlangen die da verzwillingt sind mit den Nashornvögeln.

Und es befolgen die Apangtrommeln die Weisse: das Herablassen des Schildbrettes, es schlagen die Trommeln nach der Melodie: das Herunterlassen der goldenen geflochtenen Bänder. 


\section{Das Schildbrett reist nach dem Dorfe am Ufer des Flusses der Welt}

Toh ewen balian rata manekap katambong beken lago,e hapan lago: mandurut papan talawang, hajak ewen panombah manombah auch upo.

Ewen uras manandak hajak lago,n tekap katambong manahiu ampi,n djalanan Sangiang mohon bara eka Sangiang manjampai kalunen, eka balia, koa,e :

Ohoi bara ohoi nolak papan talawang, ehei bara ehei njangka dare,n lintong, tolak para-parang antang ngamparang tandjong, sangka tenteng-tenteng pamaras bau,n djumban bahandang.

Palus njauch-njauch Danum lu-Djalajan, manansohan gohong Riak lu-Lamiang. Mamahalau balai are luhatontong, malangkawet sali kutoh lu-hatinggang.

Eleh sembang tapakan lewu Danum Djalajan, djari sampai tikas rundong Riak luLamiang.

Gatang tarahendeng putir ba-
Nun schlagen alle Balian gemeinsam die kleinen Trommeln nach einer andern Weise, nämlich nach der Weise: Das Herabfahren des Schildbrettes, während alle Beantworter (die Hülfsbalian) beantworten den Gesang der Hauptbalian.

Sie alle singen nun nach der Weise des Schlagens der kleinen Trommeln und sie erwähnen die Art und Weise der Reise der Sangiang, die nun heruntersteigen aus dem Orte der Sangiang und sich auf die Welt begeben, zum Orte wo die Balian mit ihren priesterlichen Handlungen beschäftigt sind, und ihr Gesang lautet:

Ohoi und nochmals ohoi, es reist ab das Schildbrett, ehei und nochmals $e h e i$, es fährt weg das geflochtene Band, es stösst $a b$, schrägliegend wie ein Falke der im Bogen schwebt, es fährt weg, querliegend wie die Oberfläche des Djumban, des roten (bezieht sich auf die von der Mitte her nach zwei Seiten schräg abfallende Oberfläche eines Schildes).

Es fährt herunter den Fluss Danum Djalajan, es gleitet herab auf dem Strome Riak Lamiang.

Es fährt vorbei an den Balai, den in Menge nebeneinanderliegenden, es gleitet vorüber an den Häusern, die zahlreich in Reihen aufgerichtet sind.

Und schon kommt es an am Ende des Dorfes Danum Djalajan, und schon fährt es vorbei an der Grenze des Ortes Riak Lamiang.

Es erheben sich und stehen auf die 
wi,n Sangiang, tundjong tarahingkat kameloh tara,n Djalajan,

Kabantengan talawang sintong udju, kabangkehan lintong lambong hanja.

Tatandipah pukong lu-pahewan Antang, lawang lewu Danum lu-Djalajan.

Hasambau lawang lu-labeho,n Djata, pagerundong Riak luLamiang.

Manting pantar pinang akan Antang Tadjahan, ndjakah roko,n tarahan akan Djata labeho.

Antang hakatawan pamasoh tingang tempo,e, djaka batuana panolak antang sangiang mananturong pantai danum kalunen, manjahendeng luwok kampongan buno.

Tende manandjulo papan talawang, tende ninggang Tandjong Bulau Tampong Papas.

Balaku tampong papas, balaku humbang rendan tingang akan imbit,e nusang lu-hadurut lunok, tolak papan talawang magon njauch Danum Djalajan, sangka bulau dare,n lintong magon mansohan gohong Riak Lamiang.
Prinzessinnen, die Frauen aus dem Geschlecht der Sangiang, es erheben sich und stehen auf die Kameloh von dem Stamme der Djalajan,

In der Mitte der Schilde, der sieben, in der Mitte der Bänder, die da vermehrt sind $z u$ acht.

Gegenüber dem Wäldchen, dem heiligen Haine des Falken, das an der Türe des Dorfes Danum Djalajan liegt.

Im Angesichte der Türe zur Wassertiefe der Djata, bei der Oeffnung des Ortes Riak Lamiang.

Und sie werfen aus einen Betelnusskausel für den Falken des Ahnenheiligtumes, und sie überreichen Rauchwaren der Sklaven (Zigaretten) für die Djata der Wassertiefe.

Denn der Antang weiss um die Herabfahrt der Tingang, seiner Besitzer, ihm, dem Falken, ist bekannt die Abreise und er weiss, dass seine Sangiang (Herren) sich begeben an die Ufer des Flusses der Welt, dass sie auf der Reise sind nach den Buchtungen an denen das Dorf der Lanzen liegt.

Es hält an für kurze Zeit das Schildbrett, es bleibt still stehen dicht in der Nähe der Flussbiegung der goldenen Bündel der Besen.

Und sie nehmen dort zu sich die Bündel der Besen, sie sammeln ein die gefransten Tingang-Bambusrohre (zum Knallen) um es mitzubringen auf der schräg gerichteten Fahrt und dem Herunterstossen auf den Lunok, und es reist weiter das Schildbrett und immer noch fährt es abwärts auf dem Flusse Danum Djalajan, es rudert 
weiter das goldene geflochtene Band und immer noch lässt es sich flussabwärts treiben auf dem Strome Riak Lamiang.

Toh ewen mago-magon manandak manahiu ampi,n pamasoh Dohong Mama Tandang, ewen manjewut kare talo idje inandak,e metoh tawur murik bara kalunen manjampai lewu,n Sangiang.

Sama ih djalan ihoroi, baja ie tende handjulo intu Lunok Marajoh tumbang Tarusan Bulan. Ie tende hete balaku darah burong saki, koa,n ewen manandak,e:

Sangiang manandjuri darah burong saki, Djalajan manantekei panggirih meto palas.

Palus muat,e huang lumpang tandok tambon, hajak menomeno luhing sangkabangen bungai.

Hapa njaki mengkak ambon barutas matei bara tarantang nole, lu-lalundong siren.
Sie singen immer noch weiter und erwähnen die Art und Weise der Herunterfahrt des Dohong Mama Tandang, sie nennen in ihrem Gesange alle Dinge, die sie bereits besungen haben als der Streureis flussaufwärts reiste von der Welt nach den Dörfern der Sangiang.

Es ist der gleiche Weg, den sie nun zurücklegen, nur halten sie für einen Augenblick an beim Lunok Marajoh an der Mündung des Tarusan Bulan. Sie halten dort an und bitten um das Blut der Vögel, das für die rituelle Bestreichung dient und sie singen dort :

Die Sangiang lassen herausfliessen das Blut der Vögel, das zur Bestreichung dient, sie lassen hervorströmen den Stellvertreter der Tiere, den reinigenden.

Und sie füllen es ein in die Köcher, in die Hörner der Wasserschlange, und sie giessen es über in den Stab der Scheide der Nashornvögel (d.h. in die Hörner der Nashornvögel, die als Behälter dienen).

Um zu bestreichen und zu lösen die Wolken, die vernichtenden des Todes von den Kindern, den Waisen, von den Nachkommen, den verlassen trauernden.

Bara hete ie hadurut dimpah Von dort fahren sie weiter herunter 
tasik manjewut isut-isut bewei kare taloh idje aton hong benteng djalan masoh.

Papan talawang palus sampai tandipah huma, eka oloh balian.

Koa,n tandak,e intu hete (metoh papan talawang kedjau-kedjau isut bara huma,n ewen), manandak haradjur idje endau, koa,e:

Tokep mananturong papan lu-talawang.

Dani manjahendeng bulau dare, n lintong.

Eleh nunton parong kaput bakati alem, lu-manureng siro rentar basansinep.

Awi ngadjang ambon lubarutas matei, awi nikap enon lu-bapilo nihau.

Gatang tarahendeng Dohong Mama Tandang,

Tundjong tarahingkat Sawang Mama Bungai,

Njilak njahumpak dohong papan benteng,e,

Basariang pulang indu tambing hanji,e.

Nandang manantapei ambon barutas matei, Manantiup enon lu-bapilo ni- und durchqueren das Meer (Tasik Ambon Bagantong) und es werden nur wenige genannt von allen den Dingen die sich auf dem Wege des Herniederfahrens befinden.

Das Schildbrett kommt nun an gegenüber dem Haus, dem Orte wo die priesterlichen Handlungen ausgeführt werden.

Und es lautet das Spruchwort dort (während das Schildbrett noch etwas entfernt ist vom Hause) und sie singen immerfort was soeben gesagt wurde (sie besingen die Reise), und ihr Gesang lautet:

Beinahe angekommen ist bei seinem Ziele das Schildbrett.

Nahe herbeigekommen ist bereits das goldene geflochtene Band.

Schon erscheint das Haus in Dunkelheit und doppelte Nacht gehüllt, schon sieht man die Wohnung, die mit Finsternis bedeckt ist.

Weil es zugedeckt ist mit den Wolken, den vernichtenden des Todes, weil es verhüllt ist mit dem Tau, dem zerstörenden des Verlorenen.

Es erhebt sich und steht auf der Dohong Mama Tandang,

Es erhebt sich und steht auf der Sawang Mama Bungai,

Er zieht heraus und er holt hervor den Dolch, das Brett der Mitte, Er bringt in Ordnung den Griff des zusammengefügten, des mutigen (die beiden Scheidenbrettchen).

Er haut weg und hebt auf die Wolken, die vernichtenden des Todes, Er hebt hoch auf die Tauwolken, die 
hau.

Lila-lilang ambon barutas matei.

Lalu sara-sarak enon bapilo nihau.

Balawa pela-pelau parong lumangentang.

Batehang linge-lingei siro njaripangku.

Omba balawa pela-pelau paho tandjong ambon.

Tintu hakalambat papan lutalawang.

Tingkap habalaun bulau dare,n lintong.

Lu-manintu parong kurong lu-mangentang.

Manjahendeng siro runtan saripangku.

Tende handu-handu papan lu-talawang.

Tahan huna-hunang bulau dare,n lintong.

Tende lu-batoros djaka teken garing.

Tahan naharukan bulau manamburak.

Lalu njangkabilan lu-tatambat keket.

Hajak halaloha djaka djamban garing. zerstörenden des Verlorenen.

Es fliehen die Wolken, die vernichtenden des Todes.

Es machen sich davon die Tauwolken, die zerstörenden des Verlorenen.

Und helle wird es und frei steht da das Haus, in dem man verrichtet das Hülfswerk.

Und licht wird es und leuchtend steht da das Haus, wo man vollzieht das auf den Schoss nehmen.

Und die Helle dehnt sich immer mehr aus und erleuchtet die Buchtungen der Wolken (d.h. die 33 Wolkenlagen, die zwischen Welt und Oberwelt liegen). Vorsichtig nähert sich nun seinem Ziel das Schildbrett.

Ruhig dahinschwebend kommt dichter herbei das goldene geflochtene Band. Es zielt auf das Haus, in dem eingeschlossen ist das $z u$ verrichtende Hülfswerk.

Es fährt nach der Wohnung, die da umzäunt das zu vollziehende auf den Schoss nehmen.

Langsam hält an das Schildbrett.

Vorsichtig bleibt festliegen das goldene geflochtene Band.

Nun hält es an und sie stecken ein den Stossbaum, den elfenbeinernen.

Und nun bleibt es liegen und es wird festgebunden mit dem goldenen gedrehten Strick.

Und es wird aufgerichtet der Pflock von gesplisstem Bambus und an ihm festgemacht der hinten am Boot sich befindliche Strick, der vielgliederige. Und es wird ausgeworfen die Brücke, die elfenbeinerne. 
Djadi hatantinda lu-paratar sihong.

Manamuei balai lampar buno ${ }^{363}$.

Lu-mangadja sali tilap lintong lu-talawang.

Akan djalan tingang lu-hakadja lunok.

Akan tandohan tambon tamuei lu-labeho.

Djadi totok tandak,e tende papan lu-talawang.

Djadi sambong lu-karunja tahan bulau daren lintong.

Djadi tende ninggang lu-salanting parong.

Djadi tahan nandai tarikaju,n lu-babungan.

Sangiang hapantar pinang, malajan tolang rumpang.

Djalajan taradjo manjang maleleng uhat leso.
Und es wird ausgelegt der Steg, der elfenbeinerne.

Und sie begeben sich zum Versammlungshaus der aneinandergereihten Lanzen.

Und sie schreiten hin zum Hause der aufgeschichteten Bänder, der Schilde. Die als Weg dienen für die Nashornvögel die zum Besuch kommen beim Lunok.

Die der Pfad sind für die Wasserschlangen die sich begeben zur Wassertiefe.

Beendet ist nun das Spruchwort der Ankunft des Schildbrettes.

Und zum Abschlusse gekommen ist der Gesang der angekommenen goldenen geflochtenen Bänder.

Angehalten haben sie nun neben der Dachtraufe des Hauses.

Still bleiben sie liegen neben dem Holzwerk des Firstes.

Die Sangiang kauen nun Pinang und sie ruhen aus ihre Knochen, die ermüdeten.

Die Djalajan kauen Betelnüsse und es erholen sich ihre Muskeln, die erschlafften.

\section{Die Sangiang holen die Seelen der Getragenen zurück}

\section{A. Vorbereitungen im Schildbrett}

Toh ewen malajan manekap katambong, ewen oloh balian simpa maroko tapi magon mondok intue eka,e.

Hajak djadi simpa upo mangarakop behas isut ttg. telo tingkat manawur behas
Sie hören nun auf $z u$ schlagen die kleinen Trommeln, und die Balian kauen und rauchen, aber sie bleiben immer noch auf ihren Plätzen sitzen. Nachdem sie fertig sind mit Kauen, ergreift der Hauptbalian mit seinen Fingerspitzen ein wenig enthülsten 
ganto-gantong hajak kakarungut kabuat,e bewei.

Ie manahiu ampi,n gawi,n Sangiang huang papan talawang idje handak hagoet manambang salumpok entang (manambang hambaruan ain oloh tempo,n pampatei).

Koa,n karungut kabuat,e:

I' udjan bulau turon hyang, ritih-rihe sawong ambon mudjan renteng tingang Sangiang keton huang papan talawang, manjamperai pating bungai Djalajan tatau medjen patas dare,n lintong.

Limbah keton Sangiang hapantar pinang, ulek eton Djalajan hataradjo manjang, Sangiang keton batolang rumpang, Djalajan keton bauhat leso,

Tolak manambang salumpok entang, mangumbang lewu mandereh danum, Djalajan manjangkurong tujang, manasa rundong hapamantai tambon.
Reis und er streut den Reis dreimal in die Höhe, während er allein dazu singt.

Er erwähnt die Art und Weise der Arbeit der Sangiang in den Schildbrettern, welche sich nun aufmachen wollen um einzuholen die Seelen der Getragenen (d.h. um aufzusuchen und zurückzuholen die Seelen der Verwandten des Toten, für den diese Handlungen ausgeführt werden).

Es lautet das Spruchwort, das der Hauptbalian allein singt:

Goldener Regen fällt herab auf die Verehrungswürdigen (d.h. der ausgestreute Reis fällt auf sie herunter), der feine Staubregen des Reiskornes berieselt die Enden der Nashornvögel (Kopfschmuck) der Sangiang im Schildbrett, es beregnet die Schwanzfedern des Nashornvogels der Djalajan, der reichen, die sich aufhalten in den Abteilungen der geflochtenen Bänder.

Nachdem ihr Sangiang nun gekaut habt die Pinang, nachdem ihr Djalajan nun gekaut habt die Betelnüsse, Und nachdem ihr Sangiang euch erholt habt von den ermüdeten Knochen, nachdem ihr Djalajan ausgeruht habt die erschlafften Muskeln,

Begebet ihr euch nun weg um einzuholen die Seelen der Getragenen und ihr durchzieht die Dörfer, die längs den Flüssen liegen, ihr Djalajan sammelt ein die Gewiegten und ihr durchschweift die Orte an den Ufern der Wasserschlange (d.h. des Flusses in der die Wasserschlange wohnt). 
Sangiang awang garing tabela belom batolak manambang salumpok entang, basangka manjangkurong tanterus tujang.

Narai bulan kahunga, koa,n rawei Sangiang tarantang garo, isen bintang habuku, tisoi Djalajan lalundong santi.

Sama gatang tarahendeng Sangiang udju, tundjong tarahingkat Djalajan lambong hanja.

Hatanggar renteng tingang, ngambuah djundjong sampulau dare.

Nangking nantelai dohong, meteng mambahulan bulau batu,n penjang.

Tapei,e timpong pandjang panambai papan talawang, nantiup,e pahangan ambo salabumbon bulau dare,n lintong.

Nusang renteng tingang hajak balua papan talawang, niling pating bungai hindje bahandjong bulau dare,n lintong.

Balus nanturong parong mangentang, buli manetei djamban garing.
Die Sangiang, die jung lebenden Elfenbeine, gehen aus um einzusammeln die Seelen der Getragenen, sie schreiten hinweg un einzuholen die Seelen der Gewiegten.

Was sollten wir dagegen einzuwenden haben, o ihr Monde, so sprechen die Sangiang, die Kinder des Weihrauches (die Helfer des Hauptsangiang), was sollten wir zu entgegnen haben, o ihr Sterne, so sagen die Djalajan, die Söhne des Wohlgeruches.

Und es erheben sich und stehen auf die Sangiang, die sieben zusammen, gemeinsam stehen sie auf und erheben sich, die Djalajan, die da vermehrt sind $\mathrm{zu}$ acht.

Und sie ordnen die Schwanzfedern der Tingang, und sie streichen zurecht den sich erhebenden Kopfschmuck über dem Geflecht.

Und sie umgürten schräg abstehend ihre Dolche, sie umbünden und knüpfen fest die goldenen Steine ihrer Penjang.

Und sie schieben weg das Tuch, das lange, das längs dem Schildbrett aufgespannt ist, und sie heben in die Höhe, das Tuch, das grosse, das aufgespannt ist über den goldenen geflochtenen Bändern.

Sie senken die Schwanzfederı der Tingang, indem sie heraustreten aus dem Schildbrett, sie beugen die $Z$ weiglein der Nashornvögel, während sie hervorschreiten aus den goldenen geflochtenen Bändern.

Und sie schreiten hinein in das Haus, in dem verrichtet wird das Hülfswerk, und sie treten ein und sie gehen über 
Manjahendeng siro njaripangku, hatatean paratar sihong.

Hajak nusang renteng tingang antang dumah manjelem parong, niling pating bungai hindje kenjoi rampe manantame siro.

Nundjong tambang lawah rawing lompat balai rampar buno, mangangkat salunga hindje djakat sali tilap lintong talawang.

Rahun mangasoh buno balua balai lampar buno, manting manganduran renteng,e bahandjong sali tilap lintong talawang.

Halaloha ranjing buno nangkaranak bumbong dare, $\mathrm{n} \mathrm{pu-}$ ron, ngansohan renteng nanggalong,m bulau manikap pandong irit bungai.

Kandjan renteng tingang hajak halawo bumbong dare, $n$ puron, tari,n anak antang sahin harende pandong irit bungai.

Hajak surong djandjulana batandjong bumbong dare,n die Brücke, die elfenbeinerne.

Und sie gehen hinein in das Haus, wo vollzogen wird das auf den Schoss nehmen, und sie steigen herab die Treppe, die elfenbeinerne.

Und beugend die Schwanzfedern der Tingang kommen die Antang hineingeschritten in das Haus, und senkend die Zweiglein der Nashornvögel treten die Falken ein in die Wohnung.

Und sie heben ihre schnellen Beine, die Krokodile, und sie besteigen den Balai der nebeneinanderliegenden Lanzen, und sie heben die Füsse, die raschen, und sie erklimmen das Haus der aufeinandergeschichteten Schilde. Und wie Wasser herunterfliesst, so schreiten sie über die Lanzen und treten heraus aus dem Balai, und sie spreitzen und schwenken die Schwanzfedern und treten hervor aus dem Haus der übereinandergeschichteten Bänder der Schilde.

Und sie fahren herunter an dem verehrungswürdigen Speer und sie kommen an auf der Matte, die geflochten ist von Puron, es kommen herab die Schwanzfedern, die da umschliessen das Gold (d.h. die Kiele dienen als Behälter für den feinen Goldstaub) und sie betreten die Matte, die geflochten wurde von Irit-Bungai-Rotan. Es schweben die Schwanzfedern der Tingang, während sie sich herunterfallen lassen auf die Matte, das Geflecht von Puron, und so wie der junge Falke schwebt, so kommen sie an auf der Matte von Irit-Bungai.

Und angekommen sind sie an ihrem Ziel, beschreitend die Matte, die ge- 
puron,

Huang labeho,n parong mangentang, rantau siro saripangku.

Palus surong djandjulana njampenda kadjang lalangit bulan Sangiang sintong udju njalulok luhing langkau timpong.

Manaharep lasang pinang, manjambau sasanggah manjang.

Sangiang hapantar pinang, Djalajan tatau hataradjo manjang.

Hapantar bua pinang panukang ambon barutas matei, Djalajan hataradjo manjang sangka,n enon bapilo nihau.

Djari busau bua pinang Sangiang ewen sintong udju, rata kajal uring manjang Djalajan lambong hanja.

Ngitar garing hapanduka mondok manaharep sangko radja lasang bukit baras bulau.

Ngisat sihong tampudjena badjanda manjambau saparanggon dalam, gentoi luhing busong hintan. flochten wurde von Puron, In der Wassertiefe des Hauses in dem man das Hülfswerk verrichtet, in der Wassertiefe der Wohnung wo man vollzieht das auf den Schoss nehmen.

Beendet ist ihre Reise, ankommend unter den Matten (den Tüchern, von denen über den Balian ein Dach gebaut wurde) des Himmels der Monde, der Sangiang, der sieben zusammen, unter dem aufrechtstehenden Dache von Tuch.

Und sie nähern sich dem Boote mit den Pinang, und sie treten herzu zu dem Gestell mit den Betelnüssen.

Und die Sangiang kauen Pinang, und die Djalajan, die reichen, kauen Betelnüsse.

Und sie kauen die Früchte der Pinang, die Aufheber der Wolken, der vernichtenden des Todes, die Djalajan kauen Betelnüsse, die Säulen, die da aufheben die Tauwolken, die zerstörenden des Verlorenen.

Und es sind trunken von den Früchten der Pinang die Sangiang, die sieben zusammen, es sind betäubt von den Betelnüssen die Djalajan, die da vermehrt sind zu acht.

Und sie drehen sich auf ihren elfenbeinernen Sitzplätzen und sie nähern sich dem Gefäss, dem königlichen, dem Boote des Berges von goldenem Sand (gemeint ist wahrscheinlich der behas tambak: der aufgehöhte Reis).

Sie wenden sich auf ihren elfenbeinernen Sitzen und sie kehren ihre Angesichter dem Gefäss des Palastes zu, dem Fahrzeug mit den aufgehöhten Steinbänken von Edelsteinen. 
Hajak nusang djari balemo Sangiang, maniling karah,e badjambulei panungkup rajong Djalajan.

Mangandang tingang kalangkang garo, manitih bungai hampatong santi.

Rindje-rindjet tingang kalangkang garo djadi lasang kumpang garo idje bahalap napukan tingang.

Rugo-rugoh bungai hampatong santi badaris maliutan antang.

Hapan Sangiang hagoet manambang salumpok entang, hapan rajong Djalajan manakep tanterus tujang.

Mangumbang lewu mandereh danum manjangkurong tanterus tujang, manasa rundong hapamantai tambon.
Und sie beugen hernieder ihre Finger, die schlanken, sie, die Sangiang, und sie senken herab ihre Hände, die zarten, sie, die Gemeinschaft der Jünglinge der Djalajan.

Und sie beklopfen den Tingang, das Gestell des Weihrauches, und sie schlagen an den Nashornvogel, das Schnitzbild des Wohlgeruches.

Und es erzittert der Tingang, das Gestell des Weihrauches und es verwandelt sich in ein Boot, in eine Scheide des Wohlduftes, das versehen ist mit einem schönen Bug, der die Form eines Tingang hat.

Und es erbebt der Nashornvogel, das Schnitzbild des Wohlgeruches mit dem schön geschnitzten Bug, der wie ein Falke aussieht (auch der Falke ist ein Vogel der mit der Oberwelt assoziiert ist. Das Boot repräsentiert das Nashornvogelboot, das übereinstimmt mit dem Edelsteinboot und mit der Oberwelt assoziiert ist).

Das die Sangiang gebrauchen wenn sie einholen die Seelen der Getragenen, dessen sich die Djalajan bedienen, wenn sie zurückholen die Seelen der Gewiegten.

Herumziehend in den Dörfern, die längs den Flüssen liegen, um zurückzuholen die Seelen der Gewiegten, herumschweifend in den Orten, die an den Ufern der Wasserschlange liegen.

\section{B. Die Sangiang ziehen aus um die Seelen der Getragenen zurückzuholen}

Durch den Tod sind die Verwandten zu Schutzlosen geworden. Sie stehen unter dem Banne der Ambon Barutas Matei (der Wolken, der vernichtenden des Todes). Sie sind eingehüllt in Dunkelheit und es ist 
niemand da der ihnen Licht bringt. Ihr Fuss schreitet in der Finsternis und es ist niemand da der sie führt. Kein Vorzeichen gibt ihnen Weisung, kein Traum zeigt ihnen den Weg, keine Stimme schützt sie vor Gefahren, kein Ahn und kein Sangiang wacht über ihre Seelen. In der Dunkelheit gehen sie in die Irre und in der Finsternis findet die Seele den Heimweg nicht mehr. Sie sind preisgegeben allen bösen Mächten und sie haben während dieser Zeit niemanden der sie aus ihrer Hand und Macht errettet.

Die bösen Mächte machen von diesem allgemeinen Unheilszustand, der durch den Tod über die Menschen hereingebrochen ist, Gebrauch. Sie überfallen sie und sie nehmen ihre Seelen mit und die Folge ist, dass die schutzlosen Menschen, die keinen Helfer haben, an den sie sich in ihrer Not wenden können, krank werden und schliesslich sterben.

Die Seele wird hier genannt: salumpok oder tanterus, es sind die Wörter aus der Basa Sangiang für das Ngadjuwort hambaruan und sie bezeichnen die Seele des Menschen, die die Gabe des Ranjing Mahatala Langit ist und die in der körperlichen Hülle wohnt, aber sich aus ihr auch entfernen kann, was vor allem im Schlaf und Traum geschieht. Salumpok bedeutet (abgeleitet von lumpok): das Mark des Holzes, die innerste Substanz des Holzes. Tanterus bedeutet (abgeleitet von tarus) : hell, glänzend. Gegenüber dem stofflichen Leib, der die Gabe der Djata ist, steht der helle Schein, oder die Hambaruan, Salumpok oder Tanterus, der die Gabe des Ranjing Mahatala Langit ist. Diesem Dualismus des Menschen begegnen wir weiter unten, wenn wir die beiden Liau zu beschreiben haben.

Die Rettung und Hilfe für den schutzlosen Menschen, der von der Finsternis umgeben ist, kommt von den Sangiang. Sie sind nun aus der Oberwelt herabgestiegen um das Tantolak matei vorzunehmen, das der Mensch in eigener Kraft nicht tun kann, weil ihm dazu keine Mächtigkeit und auch keine Möglichkeit eignet. Sie kommen nun herab und wie eine Mutter das Kind an ihre Brust nimmt und um den hilflosen Säugling das Tuch schlingt, so nehmen sie nun die Menschen in ihren Schutz, und wie eine Mutter ihr Kind auf den Schoss nimmt und es tröstet, so nehmen sie die Menschen, die keinen Helfer haben und die von der Finsternis umhüllt sind, auf ihren Schoss und bringen alles für sie in Ordnung. Sie schieben nicht nur die Ambon Barutas Matei weg, sondern sie holen, bevor sie diese Handlung ausführen, die verirrten und irregeführten Seelen zurück und befreien sie aus der Dunkelheit und aus der Hand der bösen Mächte, die sie bedrohten. 
Toh upo manandak hajak ewen uras manekap katambong tumon lago, $\mathrm{n}$ : tekap tawur.

Toh baja upo kabuat,e kea manandak, koa,e :

I'lu-Sangiang lompat lasang kumpang garo napakun tingang, gentoi tahawong santi maliutan antang.

Lasang Sangiang hagoet manambang salumpok entang, gentoi Djalajan sangka manakep tanterus tujang.

Tolak lasang kumpang garo malan balua parong, sangka gentoi tahawong santi bahandjong siro saripangku.

Manselat dinding pendu upak kaju djangkang njaho.

Riu-riup lasang kumpang garo bahalap manapukan tingang, malan manjalumbo ambon, ringkang manandjak enon,

Manambang salumpok entang njangkelang tandjong ambon, manangkep tanterus tujang njampale luwok enon.
Der Hauptbalian singt nun und sie alle (d.h. die Hülfsbalian) schlagen die kleinen Trommeln nach der Weise : Schlag des Streureises.

Der Hauptbalian singt nun aber allein und sein Gesang lautet:

Die Sangiang besteigen das Boot, die Scheide des Weihrauches mit dem Bug der wie ein Nashornvogel aussieht, sie steigen ein in das Fahrzeug, die Scheide des Wohlgeruches, die einen Griff hat der einem Falken gleicht.

Das Boot der Sangiang fährt weg um einzuholen die Seelen der Getragenen, das Fahrzeug der Djalajan stösst ab um zurückzuholen die Seelen der Gewiegten.

Es reist weg das Boot, die Scheide des Weihrauches, und es macht sich auf und fährt heraus aus dem Haus, es stösst ab das Fahrzeug des Wohlgeruches und es verlässt das Haus in dem man vollzieht das auf den Schoss nehmen.

Es fährt hindurch zwischen den Wänden, die gemacht sind von der Rinde des Djangkang Njaho-Baumes.

Es weht hinweg das Boot, die Scheide von Weihrauch mit dem Bug, der da aussieht wie ein Nashornvogel, es macht sich bereit um aufzusteigen durch die Wolkenlagen, es steht im Begriffe um hinaufzufahren durch die Tauwolken (die 33 Lagen),

Um einzuholen die Seelen der Getragenen zwischen den Buchtungen der Wolken, um zurückzuholen die Seelen der Gewiegten zwischen den Flussbiegungen der Tauwolken. 
Manambang salumpok entang manjembang tasik Lajang Hanteran Riwut, manakep tanterus tujang laut Ahoi Nganggahan Salatan.

Manambang salumpok entang bara danum Maninting Dahiang.

Manambang salumpok entang bara Hantarong radja,n Dahiang, manakep tanterus tujang bara Dahiang hapamantai, njangkurong tanterus tujang bara Baja Tandang hapanderep.

Uras eka manambang salumpok entang intu bukit Kiting Dahiang.

Manambang salumpok entang bara Kameloh Irang Pasihai. Manambang salumpok entang bara Putir Lanting Bawin Dahiang.

Manambang salumpok entang bara Dahiang Batandok Tingang.

Manambang salumpok entang bara Tato Pataho hong bukit Tusang Njanggohan Talawang.

Manambang salumpok entang bara radja Handaran Buno intu bukit Kiting Dohong.

Manambang salumpok entang bara radja Mama Timbang Darah intu bukit Sangking Penjang.
Um einzuholen die Seelen der Getragenen, sich hinbegebend zum Meere Lajang Hanteran Riwut, um zurückzuholen die Seelen der Gewiegten von der See Ahoi Nganggahan Salatan. Um abzuholen die Seelen der Getragenen vom Flusse Maninting Dahiang.

Um abzuholen die Seelen der Getragenen bei Hantarong, dem König der Vorzeichen, um zurückzuholen die Seelen der Gewiegten von den Vorzeichen längs den Ufern, um einzufangen die Seelen der Gewiegten von dem Vorzeichen, dem Tiger, dem zum Einstürzen bringenden.

Alle diese Plätze, von denen man zurückholt die Seelen der Getragenen, liegen auf dem Berge Kiting Dahiang (krumme Vorzeichen, d.h. schlechte Vorzeichen).

Um abzuholen die Seelen der Getragenen bei der Kameloh Irang Pasihai. Um abzuholen die Seelen der Getragenen bei der Putir Lanting Bawin Dahiang.

Um abzuholen die Seelen der Getragenen bei dem Vorzeichen mit dem Horne des Nashornvogels.

Um abzuholen die Seelen der Getragenen beim Ahnen des Pataho auf dem Berge Tusang Njanggohan Talawang (des angelehnten Schildes).

Um abzuholen die Seelen der Getragenen beim König Handaran Buno auf dem Berge Kiting Dohong.

Um abzuholen die Seelen der Getragenen beim König Mama Timbang Darah auf dem Berge Sangking Penjang. 
Manambang salumpok entang hapus batang danum Maninting Penjang.

Manambang salumpok entang bara Sawang Bengkoi Pangganti Balo.

Manambang salumpok entang bara Tinggi Tingang.

Manambang salumpok entang bara batang danum Rutas.

Manambang salumpok entang bara Hampatong Rutas.

Manambang salumpok entang sampai tumbang lawang langit.

Udju salumpok entang taratambang djari,n Sangiang, hanja tanterus tujang taratakep karah Djalajan.

Malik sala lasang kumpang garo bahalap napakun tingang,

Manambang salumpok entang hila kalimbahan laut.

Manambang salumpok entang bara Ganan Parara Toha Babintang Sambong.

Bara Ganan Rangas Tingang Bakampoh Ragan.

Bara Ganan Djadjangkit Lajang Banama Balaboh Sauh.
Um abzuholen die Seelen der Getragenen vom ganzen Flusse Maninting Penjang.

Um abzuholen die Seelen der Getragenen beim Sawang Bengkoi, dem Stellvertreter für die Witwen.

Um abzuholen die Seelen der Getragenen beim Tinggi Tingang.

Um abzuholen die Seelen der Getragenen vom Flusse Rutas.

Um abzuholen die Seelen der Getragenen beim Schnitzbild des Rutas.

Um abzuholen die Seelen der Getragenen bis hin zur Mündung (zum Anfang) der Türe des Himmels.

Sieben Seelen der Getragenen werden abgeholt durch die Finger der Sangiang, acht Seelen der Gewiegten werden zurückgeholt durch die Hände der Djalajan. (Der Mensch hat sieben Seelen nach manchen erklärenden $\mathrm{Be}-$ schreibungen. Streng zu unterscheiden sind aber zwei „Seelen” des Menschen und bei der einen von beiden werden auch die übrigen fünf untergebracht. Siehe die Beschreibung unten.)

Es wendet sich das Boot, die Scheide des Weihrauches mit dem schönen Bug, der da aussieht wie ein Nashornvogel,

Um abzuholen die Seelen der Getragenen von der Richtung her die gegen die Mitte des Meeres liegt.

Um abzuholen die Seelen der Getragenen bei Ganan Parara Toha Babintang Sambong.

Von der Ganan Rangas Tingang Bakampoh Ragan.

Von der Ganan Djadjangkit Lajang Banama Balaboh Sauh. 
Bara riak hai njababalon puron, bara lauk ludan djambuara.

Bara Ular, radja,n Peres huang banama babilem dia haluana, adjong mintum djaton kambaria.

Hapus laut Mangantong eka Sangiang manambang entang.

Udju salumpok entang taratambang djari,n Sangiang, hanja tanterus tujang taratakep karah Djalajan.

Malik sala lasang kumpang garo napakun tingang, gentoi tahawong santi maliutan antang.

Nanturong Djalajan hulu danum, njahendeng hila tandjong ringkin karangan.

Manambang salumpok entang bara bukit Ranggau Rohong 364 idje djaton katambuan balawan.

Bara pulih meteh tingang tempo, luat ndjandji antang sangiang.

Bara Burok Ndendu Lung-
Von den Wellen, den grossen, die daherwogen wie man aufrollt eine Puronmatte, von den Haifischen. Von Ular, dem König der Krankheiten der sich aufhält im Boote, dem schwarzen, das keinen Bug hat, im Fahrzeug, dem dunklen, das kein Steuer besitzt.

Das ganze Meer Mangantong ist der Ort, von wo die Sangiang die Getragenen zurückholen.

Sieben Seelen der Getragenen werden herbeigeholt durch die Finger der Sangiang, acht Seelen der Gewiegten werden aufgehoben durch die Hände der Djalajan.

Und es wendet sich das Boot, die Scheide des Weihrauches mit dem Bug, der einem Nashornvogel gleicht, das Fahrzeug, die Scheide des Wohlgeruches mit dem Handgriff, der einem Falken ähnlich ist.

Es fährt nach dem Oberlauf, dem Quellort des Flusses, es wendet sich hin nach den Buchtungen, wo die Wellchen über die Steinbänke hüpfen. Um abzuholen die Seelen der Getragenen vom Berge Ranggau Rohong, der keine Helligkeit mehr über sich hat (d.h. der immer in den Wolken ist).

Von dem Gifte, das übergeben ist dem Nashornvogel, seinem Besitzer, vom Gifte, das überreicht ist dem Falken, seinem Sangiang. (Es handelt sich um Hölzer, die auf den Bergen gesammelt werden, und die in das Gebiet der sogenannten schwarzen Magie gehören. Man bringt mit diesen Hölzern Feinde um.)

Vom Burok Ndendu Lungkang Alo, 
kang Alo, Sipet Onto sam- vom Sipet Onto, dem Entleerer buang tolang.

(Töter, Vernichter) der Knochen.

Bara Djakah Kiap, Tarik Halap, Agoh Menteng sambuang tolang.

Bara Pakihang Tingang, Suwoi Bahanji.

Bara hangkong badjoko 365 , karowong awang kelep ${ }^{366}$.

Manambang salumpok entang bara hulu danum Hatinggang.

Manambang salumpok entang bara bukit gantong, purok ambo.

Udju salumpok entang taratambang djari,n budjang Sangiang, hanja tanterus tujang taratekap karah bungai Djalajan.

Malik sala lasang kumpang garo napakun tingang, mules gentoi tahawong santi maliutan antang.

Manambang salumpok entang njangkelang kaju,n sanggalang garing, manakep tanterus tujang njampale bulus lampesong kereng.

Manambang salumpok entang bara Pantoh Ganan Kaju Hai, Embak Ganan Bua Bakas.

Bara Njaring Menteng Ma- Und vom Njaring, dem tapferen, dem 
nambalau Bahandang, Sahakong Bahanji Bagundai Gambulong.

Njaring Ganan Lunok $\mathrm{Pa}$ rong, Njaring Ganan $\mathrm{Ka}$ djang Edan, Njaring Ganan Tewon Ahem, uras eka manambang entang.

Manambang salumpok entang bara Merap Ganan Sahep, Metak Ganan Pating, Ungo Ganan Tunggul, Lantong Ganan Batang, Rimbir Ganan Baner, Rantar Ganan Uhat, Lambak Ganan Badjakah Panting Tarok Kaju, SuakSuek Hulu Ruak, Belas Benteng Dereh, uras eka manambang entang.

Udju salumpok entang taratambang djari,n Sangiang, hanja tanterus tujang taratakep karah Djalajan.

Malik sala lasang kumpang garo bahalap napakun tingang, gentoi tahawong santi idje badaris ngaliutan antang.

Manambang salumpok entang harakean tandjong pandjang, manakep tanterus tujang ma- rothaarigen, und vom Sahakong, dem mutigen, der da Haare hat wie ein Gambulong (-Njaring).

Vom Njaring Ganan Lunok Parong, und vom Njaring Ganan Kadjang Edan, und vom Njaring Ganan Tewon Ahem, sie alle sind die Orte, von denen abgeholt werden die Getragenen.

Um abzuholen die Seelen der Getragenen beim Merap, der Seele der Blätter, beim Metak, der Seele der Zweige, beim Ungo, der Seele des Wurzelstockes, beim Lantong, der Seele des Stammes, beim Rimbir, der Seele der Brettwurzeln, beim Rantar, der Seele der Wurzeln, beim Lambak, der Seele der Schlingpflanzen die emporklimmen bis zur Krone des Baumes, von den Suak-Suek, den Seelen der ausgehöhlten Löcher im Stamme des Baumes, vom Belas, der Seele der Mitte des Baumstammes, sie alle sind die Orte von denen zurückgeholt werden die Seelen der Getragenen.

Sieben Seelen der Getragenen sind es, die aufgehoben werden durch die Finger der Sangiang, acht Seelen der Gewiegten sind es, die aufgenommen werden durch die Hände der Djalajan. Und es wendet sich das Boot, die Scheide des Weihrauches mit dem schönen Bug, der aussieht wie ein Nashornvogel, das Fahrzeug, die Scheide des Wohlgeruches, welche einen zierlichen Handgriff hat der einem Falken ähnlich ist.

Um einzuholen die Seelen der Getragenen, die sich aufhalten längs den Flussbiegungen, den langen, um abzu- 
nasa luwok ambo.

Nambang salumpok entang bara Pudjut Menteng 367, Kariau Bulau 368.

Bara Kambe Lemba Halawong Djela 369 , Sirat Pasat Ngarungkong Tabuni.

Bara Kamiak Tandjong 370, Kalabawai Luwok 371.

Bara Karaha-Goho lawi,n tandjong, bara Tewai Bungai.

Udju salumpok entang taratambang djari,n Sangiang, hanja tanterus tujang taratakep karah Djalajan.

Malik sala lasang kumpang garo napakun tingang, gentoi tahawong santi idje badaris ngaliutan antang.

Manambang salumpok entang bara liau matei, manakep tanterus tujang bara pangambon nihau.

Manambang salumpok entang bara bukit Pasahan Raung, kereng Daharin Penda Lunok.

Udju salumpok entang taratambang djari,n Sangiang, hanja tanterus tujang taratakep karah Djalajan,

Bara djalahan liau matei, pa- holen die Seelen der Gewiegten, die dahingeschritten sind an den Buchtungen, den grossen.

Um abzuholen die Seelen der Getragenen beim Pudjut, dem tapferen und beim Kariau, dem goldenen.

Und vom Kambe Lemba das als Kopftuch gebraucht seine Zunge, und vom Sirat Pasat Ngarungkong Tabuni.

Vom Kamiak der Flussbiegung, vom Kalabawai der Buchtung.

Vom Karaha-Goho an dem Ende der Flussbiegung und vom Tewai Bungai.

Sieben Seelen der Getragenen werden aufgehoben durch die Finger der Sangiang, acht Seelen der Gewiegten werden aufgenommen durch die Hände der Djalajan.

Und es wendet sich das Boot, die Scheide des Weihrauches mit dem Bug, der einem Nashornvogel gleicht, das Fahrzeug, die Scheide des Wohlgeruches, die einen zierlichen Handgriff hat der einem Falken ähnlich ist. Um abzuholen die Seelen der Getragenen bei der Liau, der verstorbenen, um zurückzuholen die Seelen der Gewiegten von der Pangambon, der verlorenen.

Um abzuholen die Seelen der Getragenen vom Berge der Hütten der Särge, vom Hügel, auf dem aufgebahrt werden (auf Gestellen) die Leichen.

Sieben Seelen der Getragenen werden aufgenommen durch die Finger der Sangiang, acht Seelen der Gewiegten werden aufgenommen durch die Hände der Djalajan,

Von der Gemeinschaft der Liau, der 
nungkup pangambon nihau.

Malik sala lasang kumpang garo napakun tingang, mules gentoi tahawong santi maliutan antang.

Manambang salumpok entang bara desa,n Djata Balawang Bulau, manakep tanterus tujang bara kalang labeho handalem.

Bara Kamiak Danum, Kalabawai Gohong.

Bara Tambon Lio 372, Tambon Parukat 373, Tambon Pentet 374, Tambon Telan, Tambon Lalundjong Buno, Ihing Sampajan Sawang ${ }^{376 .}$

Bara Tambak Mangkok, Darap Kadjang, Tabang Beang Ginteng Tolong.

Bara buntal pali, siri,n danum kasisi mangasing tahudjok lempet.

Bara Petak Manampa, Busong Manampa.

Uras eka Sangiang manambang entang, Djalajan njangkurong tanterus tujang.

Udju salumpok entang taratambang djari,n budjang Sangiang, hanja tanterus tu- verstorbenen, von dem Stamme der Pangambon, der verlorenen.

Es wendet sich das Boot, die Scheide des Weihrauches, die einen Bug hat der einem Nashornvogel gleicht, es dreht sich das Fahrzeug, die Scheide des Wohlgeruches, die einen Handgriff besitzt der einem Falken ähnlich ist.

Um abzuholen die Seelen der Getragenen von den Untertanen der Djata Balawang Bulau, um zurückzuholen die Seelen der Gewiegten aus der Wassertiefe, der abgründigen.

Von dem Kamiak des Wassers, von dem Kalabawai der Fluten.

Von der Wasserschlange des Regenbogens, von der Wasserschlange der Wurzeln, von der Wasserschlange Pentet, von der Wasserschlange Telan, von der Wasserschlange Lalundjong Buno, von der Ihing Sampajan Sawang.

Von dem Tambak Mangkok, von dem Darap Kadjang und von dem Tabang Beang Ginteng Tolong.

Vom Buntalfisch, der Pali ist, vom Zeichen des Wassers, vom Fisch, der aufgehetzt und zornig geworden sich $\mathrm{zu}$ einer Kugel aufblähen und wieder zusammenfallen lassen kann.

Von der machenden Erde, den schaffenden Steinbänken.

Das alles sind die Orte, von denen die Sangiang abholen die Getragenen, von denen die Djalajan zurückholen die Seelen der Gewiegten.

Sieben Seelen der Getragenen sind es, die aufgenommen werden durch die Finger der Jünglinge der Sangiang, 
jang taratakep karah Djalajan.

Malik sala lasang kumpang garo napakun tingang, gentoi tahawong santi maliutan antang.

Mananturong parong mangentang manjahendeng siro njaripangku.

Antang dumah manjelem parong, kenjoi rampa manantame siro.

Djari sampai labeho,n parong mangentang, manantame siro runtan saripangku.

Palus gatang tarahendeng hajak Sangiang, tundjong tarahingkat hindje Djalajan.

Balua lasang kumpang garo, bahandjong gentoi tahawong santi.

Lasang kumpang garo buli halalian tingang kalangkang garo, gentoi tahawong santi ngaliutan antang mulang bungai hampatong santi.

Awi puna gana,n tingang Denn es war ja wahrlich nur die acht Seelen der Gewiegten sind es, die aufgehoben werden durch die Hände der Djalajan.

Und es wendet sich das Boot, die Scheide des Weihrauches mit dem Bug der einem Nashornvogel gleicht, das Fahrzeug, die Scheide des Wohlgeruches, die einen Griff hat der einem Falken ähnlich ist.

Und es fährt zurück zu dem Hause, wo man verrichtet das Hülfswerk, und es rudert hin zur Wohnung, wo man vollzieht das auf den Schoss nehmen.

Der Antang kommt zurück und tritt ein in das Haus, der Falke naht sich und schreitet in die Wohnung.

Und er ist angekommen in der Wassertiefe des Hauses, in dem man das Hülfswerk verrichtet und er ist eingetreten in die Wohnung in der man vollzieht das auf den Schoss nehmen.

Und es erheben sich gemeinsam und stehen auf, sie die Sangiang und es erheben sich und stehen zusammen auf die Djalajan.

Und sie treten heraus aus dem Boote, der Scheide des Weihrauches, und sie verlassen das Fahrzeug, die Scheide des Wohlgeruches.

Und das Boot, die Scheide des Weihrauches kehrt zurück und es verwandelt sich wieder in das Gestell des Weihrauches, das wie ein Tingang geschnitzt ist, das Fahrzeug, die Scheide des Wohlgeruches mit dem Handgriff das einem Falken gleicht, wird wieder zum Schnitzbilde des Duftes, das einem Nashornvogel ähnlich ist. 
kalangkang garo, puna kanjarian bungai hampatong santi.

Hajak tingang Sangiang mukei tantan salingkat lawong manandjuri salumpok entang, manantekei tanterus tujang hajak bakandong njalong kaharingan belom, basangkulem gohong kapaninting tahaseng.

Udja-udjan salumpok entang mudjan sangko radja eka lasang salumpok entang, manjamperai name saparanggon dalam eka gentoi tanterus tujang.

Palus salumpok entang marong bangkusan timpong, tanterus tujang nantame behas mintih.

Eleh hariten 378 upo,n tundo, nananteloh halawo benteng,e.

Kalabien salumpok entang, rata marong behas tisa, $n$ tawur, nantame rabia kalambungan sawong ambon.

Djadi totok tandak Sangiang, sambong karunja Djalajan.

Njaming luhing pantar pinang
Seele des Tingang, des Gestelles des Weihrauches, es war ja gewisslich nur das Ergebnis gewesen des Nashornvogels, des Schnitzbildes des Wohlgeruches.

Und der Tingang, der Sangiang, öffnet den Zipfel seines umwundenen Kopftuches 377 und er giesst aus die Seelen der Getragenen und er schüttet aus die Seelen der Gewiegten, die da vermischt sind mit dem Wasser des Lebens, die da vermengt sind mit de:n Wasser, dem Reiniger des Atems.

In rauschendem Regen fallen hernieder die Seelen der Getragenen und sie regnen herab auf das Gefäss, das königliche, den Ort des Bootes der Seelen der Getragenen und sie rieseln herunter und fallen herein in das Gefäss des Palastes, den Platz des Fahrzeuges der Seelen der Gewiegten.

Und sogleich gehen die Seelen der Getragenen hinein in die Bündel von Tuch, die Seelen der Gewiegten treten ein in den Reis, den ausgewählten. Und geborsten sind die Früchte des Trosses, mit einem Ei versehen, das in ihre Mitte gefallen ist.

Ein Ueberfluss der Seelen der Getragenen erfüllt den Reis, den Rest des Streureises, eingegangen ist ein goldener Ueberschuss in das Reiskorn. (Die Seelen sind nicht nur unbeschädigt zurückgekehrt, sie befinden sich selbst noch in einem besseren $\mathrm{Zu}$ stande als vorher.)

$\mathrm{Zu}$ Ende ist nun das Spruchwort der Sangiang, aus ist das Lied der Djalajan.

Sie ergreifen den aufgestellten Pfahl 
Sangiang buli nalandjong buno, nupai roko,n tarahan Djalajan mulang nangkedjat renteng.

Njelem papan talawang, nantame bulau dare,n lintong.

Buli puron panduka mondok, lalian ringkin djena badjanda.

Palus Dohong Mama Tandang randan hakaisek rawei, Langkah Sawang Mama Bungai ringkang basarohi tisoi: Kilen talatai pangentang nah, anak aken, isen runtan saripangku joh kawan tingang?

Kabadjuran talatai pangentang, mama, limbah manambang salumpok entang, kabarengan runtan saripangku, apang, ulek manakep tanterus tujang.

Kabadjuran amon kai, koa,n rawei Dohong Mama Tandang, tisoi Langkah Sawang Mama Bungai.

Hemben nduan, hambekan katon sama hapantar bua pinang malajan tolang rumpang, Djalajan hataradjo manjang rata maleleng uhat der Pinang und die Sangiang kehren zurück und steigen hinauf auf die Lanzen, sie nehmen in Empfang die Rauchwaren der Sklaven und die Djalajan kehren wieder um und erklimmen die Speere.

Sie gehen hinein in das Schildbrett, sie steigen wieder ein in die goldenen geflochtenen Bänder.

Sie kehren zurück zu der Matte, ihrem Sitzplatz, sie kehren wieder um zu den Wellen, dem Orte auf dem sie sich niederlassen.

Und sogleich fragt der Dohong Mama Tandang mit sanfter Stimme, und es erkundigt sich der Langkah Sawang Mama Bungai mit gedämpftem Worte: Wie steht es nun in der Sache unseres Hülfswerkes, das wir soeben verrichtet haben, o ihr Kinder und Neffen, wie ist es in der Angelegenheit des auf den Schoss nehmens, o Schar der Nashornvögel?

Rechtschaffen hast du ausgeführt die Angelegenheit des Hülfswerkes, o Onkel, nachdem du abgeholt hast die Seelen der Getragenen, gut vollbracht ist die Sache des auf den Schoss nehmens, o Vater, nachdem du zurückgebracht hast die Seelen der Gewiegten.

Gut ist es, wenn die Sache so steht, also spricht das Wort des Dohong Mama Tandang, sagt die Rede des Langkah Sawang Mama Bungai.

Nun steht es so, und nun handeln wir auf diese Weise, wir alle kauen nun von den Früchten der Pinang und erholen uns von unseren ermüdeten Knochen, und die Djalajan kauen nun 
leso.

Kareh manontong tandak keton Sangiang omba ambon hakamalem, manambing karunja,n Djalajan tatepen enon basansinep.

Mangkang tambon balua turon dohong tantan ambon barutas matei, ngendjong buno sarong mangandawan pulang haris enon bapilo nihau.

Palus gatang tarahendeng djalahan pulau rewan bawi, tundjong tarahingkat panungkup tambon haruei bungai.

Mendeng mambowor bulau urai, hatatajan rabia bowor mahanteran salumpok entang gandang halalian buli, ngagahan tanterus tujang garantong kamalesan mulang.

Tende manampong salumpok entang kilau bua sanggalang

Betelnüsse und sie ruhen aus die erschlafften Muskeln.

Hernach setzt ihr wieder fort eueren Gesang, o Sangiang, wenn hereingebrochen ist die Dunkelheit, später nehmt ihr wieder auf euer Spruchwort, o Djalajan, wenn sich herabgesenkt hat die Finsternis (d.h. ungefähr abends um neun Uhr werden die Handlungen wieder aufgenommen).

Um dann aufzuwecken die Wasserschlange, dass sie hervortrete und einfahre in die Dolche, die da durchschneiden die Wolken, die vernichtenden des Todes, dass hervorschreite die Lanze der Herzgrube und herabkomme auf den Griff, der da durchhaut die Tauwolken, die zerstörenden des Verlorenen.

Und sogleich erheben sich und stehen auf die Angehörigen der Schar, des Haufens der Frauen, es erhebt sich und steht auf die Gemeinschaft der Wasserschlangen, die da verzwillingt sind mit den Nashornvögeln.

Sie stehen auf und sie streuen aus das Gold, das wie in Fäden herunterrieselt, sie werfen aus das goldene Streusel um zurückzuführen die Seelen der Getragenen, so wie wieder zurückkehrt der Schall der Trommel, um heim zu begleiten die Seelen der Gewiegten, so wie wieder zurückkommt der Ton der Gong (sie bringen nun die Seelen in die Körper ihrer Besitzer zurück und vereinigen sie mit der leiblichen Substanz des Menschen).

Sie hören nun auf einzusammeln die Seelen der Getragenen, so wie man 
garing, tahan manundon tanterus tujang tingkah langadjah tarong.

Kuruk bara kuruk kilau nambawau manok darong tingang, kurei bara kurei tingkah nangkiau bulan bawi,n riwut burong.

Sambang malik bahing,e mampong entang buli, luhing mules bambahinga manundun tanterus tujang.

Hajak tundjong bahing radja nambawa entang buli, siring bambahinga,n mantir manangkiau tanterus tujang mulang.

Toh baja upo kabuat manandak, djadi malajan uras,e manekap katambong.

Koa,n upo:

Kruk hambaruan ewen huang huma handiai, dumah nambang Sangiang bara ambon barutas matei, dumah nambang Sangiang bara lewu einsammelt die Früchte der Bäume, sie beenden nun das Büscheln der Seelen der Gewiegten, so wie man büschelt die Früchte der Bäume (man schlägt die $Z$ weige mit den Früchten $a b$ und macht von den $Z$ weigen ein Bündel das man nach Hause trägt). Kuruk und noch einmal kuruk! so wie man ruft den Hühnern, den Hühnern der Tingang, kurei und noch einmal kurei! so wie die Monde, die Frauen, mit wehendem Worte herbeilocken die Viogel. (Mit diesem Rufe lockt man die Seelen herbei.)

Die Trommeln ändern ihre Weise des Büschelns der Getragenen, die zurückgekehrt sind, die Trommeln wechseln ihren Laut des Einsammelns der Seelen, der Gewiegten.

Und es erhebt seine Stimme der König und er ruft den Getragenen, dass sie zurückkehren, und es erhebt seine Stimme der Aelteste und er ruft den Seelen der Gewiegten, dass sie heimkommen. (Dohong Mama Tandang, der immer noch in der Person des Hauptbalian anwesend ist, ruft nun selbst die Seelen zurück.)

Der Hauptbalian singt nun allein sein Spruchwort und alle andern haben aufgehört die kleinen Trommeln zu schlagen.

Es lautet der Gesang des Hauptbalian :

Kruk, ihr Seelen aller derer, die sich im Hause befinden, kommet nun, nachdem ihr zurückgeholt worden seid durch die Sangiang von den Wolken, den vernichtenden des Todes, kommet 
mandereh danum.

Buli bakandong bulau ontong pandjang, mulang basangkulem rabia njame ambo.

Bakandong njalong kaharingan belom, basangkulem gohong kapaninting tahaseng.

Mangat entang belom bahaseng pandjang, mandepe langit, manggawang ambon.

Toh idje biti bara ewen idje balian mambowor behas te suni-suni, dia usah manandak en-en, behas te idje bara mangkok tawur te endau, ie mambowor behas te intu hundjun takolok oloh tempo,n gawim bakas tabela.

Toh ewen malajan balian sampai kareh amon djari hamalem andau. herbei, nachdem ihr heimgeholt worden seid durch die Sangiang von den Dörfern, die längs den Flüssen liegen. Kehret zurück, gemeinsam mit dem Golde des Gewinnes, des langen (d.h. des lange dauernden Heiles und Glükkes), kehret heim, zusammen mit dem Golde des Mundes (d.h. des Atems), des grossen.

Gemeinsam mit dem Wasser des Lebens, dem lebenschaffenden, zusammen mit dem Wasser, dem Reiniger des Atems.

Auf dass der Getragene lebe mit einem langen Atem, der hinaufreicht bis zum Himmel, der sich emporstreckt bis zu den Wolken.

Einer der Balian streut nun stillschweigend den Reis aus und es ist nicht nötig, dass dabei gesungen wird, nämlich den Reis welcher sich im Gefäss des Streureises befindet, er streut diesen Reis aus über die Köpfe der Besitzer dieser Handlung (d.h. über alle Glieder der ganzen Verwandtschaft, die diese Handlung ausführen lässt), über die der Alten und die der Jungen.

Sie beenden nun die Balianhandlungen und nehmen sie erst wieder auf wenn die Nacht hereingebrochen ist.

\section{Die Vertreibung der Ambon Barutas Matei}

Nachdem die Seelen der Verwandten des Toten, die sich in der Dunkelheit der Ambon Barutas Matei verirrt haben und durch die bösen Mächte in die Irre geführt worden sind, durch die Sangiang wieder von überall her zurückgeholt wurden, beginnt nun die Hauptarbeit der Balian und der Sangiang. Sie haben die ganze Verwandtschaft von den Ambon Barutas Matei (die Wolken, die vernichtenden 
des Toten) $z \mathfrak{u}$ reinigen und sie haben die Reinigungshandlung auszudehnen auf das ganze Haus und das ganze Dorf und auf alle Besitzungen der Verwandten des Toten, denn über allen und über allem liegt dieser Nebel und er bedeckt sie so wie der Morgentau, der auf den Pflanzen und Gräsern liegt. Selbst befreien kann sich der Mensch nicht, nur die Sangiang können ihn erlösen und können die Wolken aufheben, so dass es wieder hell und licht wird und er wieder befreit ist von allem Unheil und aller Sorge und er wieder froh seinen täglichen Arbeiten und seinen abendlichen Vergnügungen nachgehen kann. Bedeckt von den vernichtenden Wolken des Todes, gehört er selbst auf die Todesseite und nur die Sangiang können ihn von dort wieder zurückholen auf die Seite des Lebens und sie können ihm wieder das Leben vermitteln mit allen seinen Möglichkeiten. Alles was für diese Handlungen gebraucht wird haben die Sangiang auf ihren reichbeladenen Booten selbst mitgebracht, denn der Mensch hat nichts aus sich selbst, sondern alles nur von den Sangiang, die ihm die Möglichkeit geben, dass er gerettet werden kann und die ihn aus dem Verderben, aus dem er sich nicht selbst zu befreien vermag, herausreissen.

Diese ganze Not und dieses Stehen auf der Todesseite wird natürlich vom Menschen empfunden. Er weiss, dass er, verhüllt von den Ambon Barutas Matei, ein Schutzloser und Heimatloser ist. Er weiss auch, dass er dem Tode verfallen ist und dass er nicht mehr auf der Lebensseite steht. Er weiss, dass er sich nicht mehr mit frohem Spiel, mit dem Gesang der Mythen und der Musik der Trommeln und grossen und kleinen Gong die Abende verschönen darf, er weiss, dass der Gang in den Wald gefährlich ist und dass der Schuss, den er aufs Wild abfeuert, den Schützen selbst treffen könnte, er weiss, dass er nicht mehr froh auf den Fluss hinausrudern kann weil er stets in Angst sein muss nicht mehr zurückzukehren. Er weiss, dass sein Leben unsicher geworden ist und er weiss auch, dass ihn niemand leitet und ihm niemand Rat erteilen kann. Er ist dem Tode verfallen und alles was er unternimmt kann ihn an dieses Ziel bringen.

Nun aber sind die Sangiang da. Bevor sie die Handlungen wieder aufnehmen, nachdem die Dunkelheit hereingebrochen ist, werden sie im Schildbrett, wo sie ausruhen und sich von ihrer grossen Reise erholen, aufgeweckt. Sie kommen im Hause an und sie fahren in die Balian ein und treten, nachdem sie zuerst bewirtet worden sind, handelnd und erlösend auf. Nicht der Priester handelt, der Sangiang handelt. Der Priester ist nur die körperliche Hülle und in ihr steht 
der Sangiang und er führt alle Reinigungshandlungen aus, denn nur er vermag zu reinigen, der Mensch kann sich ja selbst nicht reinigen, und nur er vermag die Ambon Barutas Matei durchzuschneiden und aufzuheben und wegzubringen nach dem Flusse Rutas. Der Mensch vermag das nicht. Wenn man auf der Todesseite steht kann man nicht auf die Lebensseite hinüberspringen, kann man die Ambon Barutas Matei nicht aufheben damit es licht werde, kann man nicht durch sie hindurchdringen. Man kann nur um Hülfe rufen und die Lebensseite kann zu der Todesseite kommen und kann die Nacht von ihr wegnehmen und kann dem Todesverfallenen das Leben geben. Aber um Hülfe rufen kann man und die Hülfe kommt. Nachdem die umfangreichen Reinigungshandlungen vollbracht sind werden die Ambon Barutas Matei durchschnitten und gelöst und sie werden auf die Lanting Buno geladen. Diese Lanting Buno (das Lanzenfloss), die dem Dohong Mama Tandang gehört, stimmt überein mit dem Banama Njaho oder Adjong Rohong (Donnerboot oder Dolchboot) mit dem Dohong Mama Tandang die Liau Balawang Pandjang beim Tiwah nach dem Totendorf führt. Gleichzeitig mit den Vorbereitungen zu diesen Handlungen werden auch die Vorbereitungen getroffen für die Wegführung des Toten, von der wir weiter unten ausführlicher zu sprechen haben.

\section{A. Die Vorbereitungen für die Führung des Toten und die Vertreibung der Ambon Barutas Matei}

Gawi,n ewen oloh tempo,n pampatei hong halemei te, ie te: manatap kare ramo hapan magah Liau Balawang Pandjang akan eka Balo Indu Rangkang.

Ramo idje inatap:

1. Idje kabatang sawang daha

2. Idje palundo imuat idje gantang behas

3. Idje bua enjoh

4. Idje pakihu ttg. tantaha,e
Die Arbeiten der Besitzer des Todes (der Angehörigen des Verstorbenen) an diesem Nachmittag, sind die folgenden: vorzubereiten alle Dinge welche gebraucht werden um die Liau Balawang Pandjang nach dem Orte der Balo Indu Rangkang zu leiten.

Die Dinge, die bereit gemacht werden müssen, sind diese :

1. Eine Blut-Sawangstaude

2. Ein Korb gefüllt mit einem Gantang (ein Mass) enthülstem Reis

3. Eine Kokosnuss

4. Ein Pakihu (alter heiliger Speer, 
der nur für religiöse Handlungen gebraucht wird) zusammen mit dem Schaft

5. Idje bungkos bulau, ehat,e satali timbangan taradjo bungkal

6. Idje gantang behas kontep toto, huang gantang hundjun behas aton:

a. Idje lamiang

b. Idje sundur, idje sarak ttg. idje saramin

c. Hanja tising korik bilon bendang

d. Idje kasa korik undus enjoh

7. Telo kongan manok impatei, inatap akan telo kabagi eka panginan

8. Idje katetek benang babilem

9. Idje balai lumpang. Ite gambar.

5. Ein Bündelchen Goldstaub, sein Gewicht muss dem eines $25 \mathrm{Ct}$. Stückes entsprechen, abgewogen auf der Goldwaage

6. Ein Gantang enthülster Reis, in dem Gantang, das heisst auf dem Reis, befinden sich folgende Dinge:

a. Ein Achatstein

b. Ein enger Kamm, ein weiter Kamm und ein Spiegel

c. Acht kleine Schnüre von Bendangbast

d. Eine kleine Flasche gefüllt mit Kokosnussöl

7. Drei geschlachtete Hühner, bereitgelegt in drei verschiedenen Teilen als Orte der Speise (d.h. bestimmt für die Opfer)

8. Eine Katetek (ca 1,80 m) schwarzes Tuch

9. Ein Balai von Bambusköchern. Siehe die Zeichnung.

Maka kare ramo te akan impalua amon limbah hapus gawi,n tantolak alem kareh.

Maka metoh tantolak matei, te oloh mingkes ramo idje hapan tantolak tumon gambar. (Ite gambar.)

Aber alle diese Dinge werden erst dann zum Vorschein gebracht, nachdem bereits abgeschlossen wurde die Handlung des Wegschiebens in der kommenden Nacht (weil sie für die Leitung des Toten bestimmt sind).

Während des Tantolak Matei (d.h. für das Wegschieben des Toten oder der Ambon Barutas Matei) legen die Leute die Dinge bereit welche für das Wegschieben benötigt werden. (Siehe die Zeichnung.) 


\section{Balai Lumpang}

(Balai von Bambusköchern)

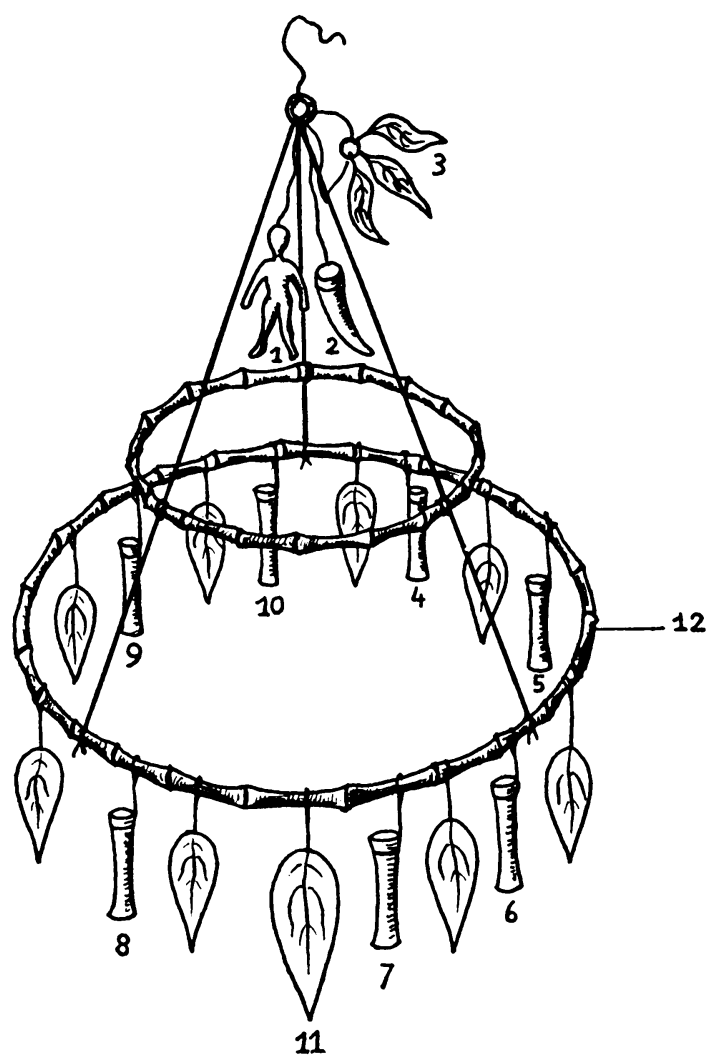

1. Hampatong palawi

2. Tandok Njanju

3. Roko sipa

4. Lumpang. Huange danum njanjah

5. Huang,e duit sapulu sen

6. Huang,e undus enjoh

7. Huang,e danum tuak

8. Huang,e danum bcwei

9. Huang,e tepong behas

10. Huang,e bchas pulut

11. Dawen sawang

12. Bingkch bara uci manjanci
1. Ein Schnitzbild von Palawiholz

2. Das Horn eines Wasserbüffels

3. Rauchwaren und Betelkausel

4. Ein Bambusköcher. Es befindet sich darin Reiswasser, d.h. Wasser in dem man den Reis gewaschen hat

5. Es befindet sich darin Geld in der Höhe von zehn Cent

6. Es befindet sich darin Kokosnussöl

7. Es befindet sich darin Reisbier

8. Es befindet sich darin nur Wasser

9. Es befindet sich darin Reismehl

10. Es befindet sich darin Pulutreis

11. Sawangblätter (Dracaena term.)

12. Ein Reif von Manjamei-Rotan 


\section{Ramo idje hapan Tantolak matei}

(Die Dinge welche für das Wegschieben des Toten benödigt werden)
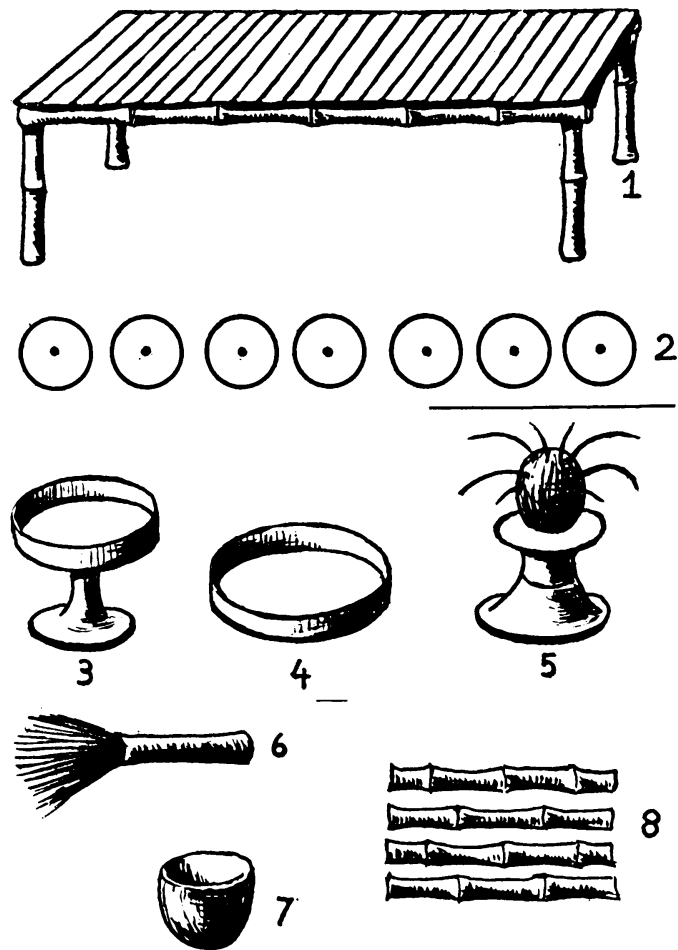

1. Katil, eka oloh balian mondok

2. Garantong, galang pai,n oloh balian

3. Apar. Huang,c aton:

Idje sangko,n hambaruan, tau kea pasok

4. Piring, eka pangina,n Sangiang

5. Sangko muat bchas, eka mampendeng kalangkang garo

6. Tampong Papas

7. Bau'n bangu. Huang,e aton:

Idje roko

Idje sipa

Idje manok korik imapui

8. Humbang salentup
1. Eine Bank auf der die Balian während der Handlungen sitzen

2. Gong als Schemel für die Füsse der Balian

3. Ein Apar. Auf ihm befinden sich:

Ein Sangko mit Seelenreis, es kann auch ein kleines geflochtenes Körbchen sein

4. Ein Teller auf den die Speisen für die Sangiang gelegt werden

5. Ein Sangko gefüllt mit enthülstem Reis, auf dem aufgerichtet wird das Gestell des Weihrauches

6. Der Besen (für die rit. Reinigung)

7. Eine in der Hälfte durchschnittene Kokosnuss. Es befinden sich darin:

Eine Zigarette

Ein Betelnusskausel

Ein kleines geröstetes Huhn

8. Bambusrohre zum Knallen (werden dazu über das Feuer gehalten und springen mit einem Schuss-ähnlichen Knall) 


\section{B. Die Aufweckung der Sangiang}

Maka amon djadi hamalem andau, limbah oloh balian djari kuman, te ewen manampara mondok balian.

Uras manekap katambong ttg. uras manandak manombah auch upo hapan lago: mangkang Sangiang, koa,e :

I'nontong tandak Sangiang baragantong kilau motong garing batang pantar pandjang.

Manambing karunja,n Djalajan baratujang tingkah manambing pulau pehon sawang.

Tahi tandak Sangiang lajang kilau hewang mengan tingang.

Usang karunja,n Djalajan ahoi tingkah rajong manahuto lunok.

Djadi ombet katundjong alem, tarigatang kalaman katon.

Djadi nggatang matiroh tingang dawen sapapulut lewu.
Nachdem hereingebrochen ist die Dunkelheit und nachdem die Balian gegessen haben, beginnen sie mit der Ausführung der Balian-Handlungen.

Und alle beginnen nun die kleinen Trommeln zu schlagen und alle beantworten das Spruchwort des Hauptbalian nach der Weise: Die Aufwekkung der Sangiang und es lautet der Gesang :

Wir setzen wieder fort der Gesang der Sangiang, der da aufsteigt wie der Rauch der Bäume, der langen Pfähle, an die man Feuer gelegt hat.

Wir nehmen wieder auf das Lied der Djalajan, wir setzen es wieder fort, so wie man vermehrt die Inseln des Gesträuches der Sawangstauden (d.h. so wie wenn man neue Stauden pflanzt und dadurch die ersten vermehrt).

Während langer Zeit war verschwunden gewesen das Lied der Sangiang, gleichwie Männer die ausgezogen sind um mit ihren Blaserohren Nashornvögel $\mathrm{zu}$ jagen.

Lange Zeit war das Lied der Djalajan verirrt, gleichwie Jünglinge verirrt sind die auszogen um von den Bäumen Gummi zu zapfen (und von denen man während ihres Aufenthaltes im Walde nichts gehört hat).

Hinreichend ist nun die nächtliche Stunde, erfüllt ist nun die bestimmte Zeit.

Schon haben sich erhoben in die Höhe und niedergelassen zum Schlafe die Nashornvögel auf den Blätterzweigen 
der Bäume des Dorfes.

Djadi nundjong amon kantok burong bumbong kadjalumpang rundong.

Djadi nggatang amon tiroh tingang pampulu indu ruang tandok.

Lu-manandjong amon kantok burong untang tangkasiang tarong.

Djadi teneng gandang $\mathrm{Nja}-$ ring Menteng randan babalai bungking lunok.

Rintoh towong Sahakong tatau are basali bambulong tusang.

Djadi lilap lumpang matanandau kanganti njating djadjampen kereng.

Kandjungen luhing makanur hawon nalimbas ulai sasumbo radja.

Djalahan pulau lah-rewan bawi timpong garo djadi paurai bihing.

Panungkup tambon haruei bungai pulau santi hatantajan henda.

Hemben nduan hambekan So steht es nun, so ist es in dieser
Und aufgeflogen in die Höhe sind schon die Vögel und sie haben sich zum Schlummer herabgesenkt auf die zarten Herzblätter der Bäume des Ortes.

Und es sind weggeflogen die Nashornvögel, die zahlreichen, und sie schlafen schon auf den Aesten der Bäume.

Und verschwunden sind die Vögel und sie schlummern schon in ihren Nestern auf den Wipfeln der Bäume.

Und es schweigen die Trommeln (Stimmen) der Njaring, der tapferen, die da zahlreich hausen in den Aesten der Bäume.

Und verstummt sind die Trommeln der Sahakong, der reichen, die ihre Wohnungen haben auf den schrägwachsenden Waringin.

Verschwunden ist die Rundheit der Sonne, die uns ersetzt das Harz, das eingesammelt wurde auf den Sandhügeln (d.h. das Harzlicht).

Und verhüllt ist die flimmernde Hitze, bedeckt ist der leuchtende Schein, welcher auslöscht den Docht der Lampe, der königlichen.

Und die Angehörigen der Schar, des Haufens der Frauen mit den duftenden Tüchern haben sich niedergelassen auf die Streifen (d.h. auf ihre gestreiften Tücher).

Die Gemeinschaft der Wasserschlangen, die verzwillingt sind mit den Nashornvögeln, haben ausgebreitet die duftenden gelben Tücher (sie haben sich sorgfältig auf ihre Tücher gesetzt). 
katon manandjuri gana,n Sache: aufsteigen und überströmen tandak. wird nun die Seele des Gesanges.

Matok dinon djaretan etoh manantekei labata,n karunja.

Manandjuri i-gana,n tandak balua bulau pantar tatah. So steht es nun, so ist es nun in dieser Angelegenheit: hervorgehen wird nun die Seele des Liedes.

Herausfliessen wird die Seele des Gesanges und hervorkommen zwischen den goldenen Pfählen der Stifte, die eingesetzt sind zwischen die Zähne.

Manantekei labata,n karunja Hervorgehen wird die Seele des bahandjong rabia saduri,n guntom.

Kilau bulau i-padjandjuri balua garing panalatok antang.

Tingkah rabia dje panantekei bahandjong rupei ranjing mandjohan.

Hajak bahing ilu-bapanting njalumbo parong lu-mangentang.

Lalu siring i-bambahinga manehos siro runtan saripangku.

Hajak bahing lu-bapanting balua parong lu-mangentang.

Hajak siring dje bambahinga bahandjong siro runtan saripangku.

Manamuei i-papan talawang, narindjet tingang lu-Sangiang. 
Manarindjet tingang Sangiang keton huang papan talawang.

Manantugoh dje bungai Djalajan tatau medjen dare,n lintong.

Sama pararindjet hajak Sangiang huang papan talawang.

Rata para-i-rugoh homba Djalajan medjen dare,n lintong.

Tarahondok dje lambat hajak mandokan bumbong dare,n puron.

Tarahekeng dje lowah hindje badjanda pandong irit bungai.

Hajak ngakis dje hagagia timpong lu-bangkuran njaho.

Lalu nolak dje hatalaka bantal putak kalihulon batiroh.

Sangiang awang tiroh tingang, Djalajan maing kantok burong.

Hajak urai dje hadjandjala pandong lawi,n balau pandjang.

Lu-balita dje kende-kendet mangendet bumbong dare, $\mathrm{n}$
Sie stösst euch sanft in die Seite, ihr Tingang, ihr Sangiang, die ihr euch im Schildbrette befindet.

Sie schüttelt vorsichtig die Nashornvögel, die Djalajan, die reichen, die sich aufhalten im geflochtenen Band. Und sie fahren leicht zusammen, sie die Sangiang, die sich im Schildbrett befinden.

Sie schrecken leicht auf, alle Djalajan zusammen, die sich aufhalten in dem geflochtenen Band.

Und gemeinsam setzen sie sich zögernd auf und sie sitzen auf der Matte, dem Geflechte von Puron.

Und sie setzen sich langsam auf, sie alle miteinander, und sie nehmen Platz auf der Matte von Irit-Bungai-Rotan (sie sind noch schlaftrunken).

Und sie schieben auf die Seite und sie stossen weg das Tuch, das donnernde Bündel (das Kissen).

Und sie schieben auf die Seite, und sie stossen von sich weg das Kissen, die Schaumflocken, auf denen man schläft. (Die weisse Kapokfüllung des Kissens wird verglichen mit den Schaumflocken, die, wenn der Fluss Hochwasser bringt, die ganze Wasserfläche bedecken.)

Die Sangiang, die schliefen wie die Tingang, die Djalajan, die da ruhten wie die Vögel.

Und wie ein ausgeworfenes Netz lassen sie herunterhängen ihre Haare, die Enden der Haare, der langen (früher hatten auch die Männer lange Haare und trugen sie geknotet).

Und sie kräuseln sie und machen sie zu Locken, so wie geflochten wird 
puron.

Lu-sandara dje panto-pantok mantok lasong sinau Sangiang.

Djadi nduan idje gawang tingang njarantar bumbong la-dare,n puron.

Dinon due sambuti antang njahuak pandong irit bungai.

Ngitar garing pandoka mondok naharep sambang garantong njaho.

Misat sihong tapudjena badjanda njambau pinton djandjingan kilat.

Eka talaga,n la-njalong ambon, lula-pekong gohong enon.

Njalong tantah la-hidjau bulau, gohong tarinjikan lukarangan.

Sama mansauch tariong bau manggurang bulau pantar tatah,e.

Mangusau pandong lawi,n balau pandjang, sarak-saraken bagundai ambon.

Manantipet dje tingang tempo, pakur djampa lulang-luli.

Njarokan antang lu-Sangiang suloh hawok dje habaranger.

Ampin tandok dje musai am- eine Puronmatte.

Sie schlagen aneinander, sie stossen gegeneinander die Armringe der Männer, sie die Sangiang.

Und endlich kriechen sie eine Spanne des Nashornvogels herum auf der Matte, dem Geflechte von Puron.

Und schliesslich bewegen sie sich zwei Sambuti des Antang weit auf der Matte die geflochten wurde von IritBungai-Rotan.

Und sie drehen sich herum auf ihren elfenbeinernen Sitzplätzen und nähern sich den Trommeln und Gong, den donnernden.

Und sie wenden sich herum auf ihren elfenbeinernen Sitzplätzen, so dass sie vor sich sehen die Trommeln und die Gong, die blitzenden.

Der Ort des Teiches der Wasser der Wolken, des Weihers, der Wasser der Tauwolken.

Das Wasser, das ein wenig gelb ist wie das Gold, das Wasser, das da strömt über die Steinbänke.

Und plätschernd tauchen sie hinein ihr Gesicht und sie spülen die goldenen Pfähle, die Stifte.

Und plätschernd tauchen sie ein ihre Haare, die Enden des Haares, des langen, und sie kämmen die Haare, die langen.

Und sie schwingen es hin und her, sie die Tingang, die Besitzer, und sie schwenken es hin und her gleichwie das wogende Schilfgras.

Und es kämmen die Antang, die Sangiang, ihre Schösslinge des Hawokgrases, des lang aufsprossenden.

Die da gleichen den ausgestreckten 
bon pakalentang parei njangen tingang.

Tingkah tandok bambulong tusang nandjala kaju,n sanggalang garing.

Sama ngitar garing pandoka mondok naharep lasang pantar pinang.

Mules sihong tampudjena badjanda manjambau sasanggah manjang.

Manaharep dje sangko radja bahalap lu-ngarawang bulau.

Manjambau saparanggon dalam badaris kangatil bawak lu-lamiang.

Eka lasang dje pantar pinang, akan gentoi sasanggah manjang.

Idje Sangiang garing tabela belom akan dohong indjam nduiring pinang.

Napus ruang dje papan talawang, manggenep patas bulau dare, $\mathrm{n}$ lintong.

Bara luana,n i-papan talawang tende pakan kamburi rohong.

Bara pakang kamburi rohong tende luana,n papan lu-talawang.
Zweigen der Bäume, die da ähnlich sind dem aufsprossenden Reise $\mathrm{Njan}$ gen Tingang.

Gleichwie die Zweige des schrägstehenden Waringin, die lange herunterhängen wie das ausgeworfene Wurfnetz eines Baumes.

Und sie alle zusammen drehen sich auf ihren elfenbeinernen Sitzplätzen und sie nähern sich dem Boote in dem aufgeschichtet sind die Pinang.

Und sie wenden sich gemeinsam auf ihren Sitzplätzen bis sie vor sich haben das Gestell (Gefäss) mit den Betelnüssen.

Und sie nähern sich dem Sangko, dem königlichen Gefäss, das verziert ist mit schön durchbrochener Goldarbeit. Und sie sitzen nun gegenüber dem Saparanggon des Palastes, dem schönen, dem mit Achatsteinen besetzten.

Der Ort des Bootes, das gefüllt ist mit den zu kauenden Pinang, des Fahrzeuges mit dem Gestell der Betelnüsse.

Und ein Sangiang, ein Elfenbein, ein noch jung lebendes, tritt auf als geliehener Dolch um herumzureichen die Pinang.

Und er reicht sie herum im ganzen Innern des Schildbrettes, in allen Abteilungen des goldenen geflochtenen Bandes.

Von dem Kiele des Schildbrettes bis hin zu den Lehnen des Steuerplatzes der Dolche (der Männer).

Von den Lehnen des Steuerplatzes der Dolche bis hin zu dem Kiele des Schildbrettes. 
Sangiang hapantar pinang napus huang papan talawang. Djalajan taradjo manjang manggenep patas bulau dare,n lintong.

Mantar pinang i-tatop mandue, taradjo manjang remapi manelo.

Sama busau i-bua pinang Sangiang huang papan taldwang.

Rata kajal dje uring manjang Djalajan medjen bulau dare,n lintong.

Lalu randan kaisek rawei, ringkang basarohi tisoi:

Kilen talatai pangentang, apang, balua parong lu-mangentang?

Isen runtan saripangku, mama, bahandjong siro runtan saripangku?

Kabadjuran talatai pangentang, anak, mangkang dohong tambon turon.

Kabarengan saripangku aken, ngendjong buno sarong ngandawan.
Und die Sangiang kauen Pinang im ganzen Innern des Schildbrettes.

Und die Djalajan kauen Betelnüsse in allen Abteilungen der goldenen geflochtenen Bänder.

Und sie kauen Pinang, zwei zusammen, und sie kauen Betelnüsse, drei auf einmal.

Und alle sind sie betrunken von den Früchten der Pinang, sie die Sangiang, die sich aufhalten im Schildbrett.

Und alle sind sie betäubt von den Früchten der Betelnusspalme, sie die Djalajan, die sich befinden in den goldenen geflochtenen Bändern.

Und sie erkundigen sich nun mit sanfter Stimme, und sie (die Sangiang) fragen nun mit gedämpftem Worte:

Wie steht es nun in der Sache der Verrichtung des Hülfswerkes, o Väter, des Heraustretens aus dem Hause des Getragenwerdens?

Wie steht es nun in der Angelegenheit des auf den Schoss nehmens, o Onkel, des Hervorschreitens aus dem Hause, in dem man vollzieht das auf den Schoss nehmen?

Gut steht es in der Sache der Verrichtung des Hülfswerkes, o Kinder, umgürtet nun die Dolche der Wasserschlangen die herabfahren.

Richtig steht es in der Angelegenheit des auf den Schoss nehmens, o Neffen, packet nun an den Speer der in die Herzgrube einfahren soll. *

* Die Sangiang, die in die Balian einfahren sollen, werden mit einem Speer oder Dolch verglichen. Mit ihm vergleicht man auch die Seele des Menschen die in der körperlichen Hülle steckt, die man Scheide nennt. Wir haben gesehen, dass das übereinstimmt mit dem ganzen totemistisch/kosmologisch klassifizierenden System. 
Akan teras dje bandong lasang tantan ambon barutas matei.

Indu luhing dje gentoi burong, maharis enon bapilo nihau.

Palus maneras dje bandong lasang ngarasan talawang antang namuei.

Hajak luhing dje gentoi burong, ngantihan dare,n lintong kenjoi mangadja.

Talawang antang dje manamuei mangagahan salumpok liau.

Mangagahan liau haring kaharingan njembang Balo Indu Rangkang Penjang.

Narai bulan dje lu-kahunga, penjang garo manadjah simpei.

Isen bintang dje lu-kabuku, pulang santi sandehan kamah.

Pire bandong dje lasang buang, bagantong bindang katil garing?

Isen hasean gentoi burong Wieviele Vogelfahrzeuge sind noch
Als Kernholz (als innerste Substanz) des Bandong-Bootes (das sind die Balian, die mit einem Boot verglichen werden, in das die Sangiang einsteigen und dessen wichtigste Substanz sie dann ausmachen) um durchzuschneiden die Wolken, die vernichtenden des Todes.

Als härtester und innerster Bestandteil des Vogelbootes (wie oben), um durchzuhauen die Tauwolken, die zerstörenden des Verlorenen.

Und richtet nun auf das Kernholz im Bandong-Boote um anzufeuern das Schildbrett der reisenden Antang. Und fügt nun ein den härtesten Bestandteil des Vogelbootes um anzutreiben die geflochtenen Bänder der ausziehenden Falken.

Das Schildbrett der Antang die da wegreisen um zu leiten die Salumpok Liau.

Um zu führen die Liau Haring Kaharingan, dass sie hingelange $\mathrm{zu}$ dem Orte der Balo Indu Rangkang Penjang.

Weshalb, o Monde, sollten wir uns dagegen widersetzen, die duftenden Penjang verlangen doch nach ihren Bündeln.

Warum, o Sterne, sollten wir widersprechen, die wohlriechenden Griffe sehnen sich doch nach ihren Scheiden. Wieviele Bandong-Boote sind leer, von denen die da erhöht sitzen auf dem Brette, auf der elfenbeinernen Bank? (Die Sangiang erkundigen sich nach der Anzahl der Balian in die sie einfahren wollen.) 
sandong batujang ulai sansuro radja?

Telo bandong i-lasang buang, telo dohong padjandjuri kumpang,e.

Epat gentoi dje burong sandong, epat buno panantekei gantuling,e.

Sama mangkang dje mangangkanan haramaung ewen sintong telo.

Njapo njari-i-tanda balita,e, pangandien lambong epat.

Hajak mangking nantelai dohong, meteng mahulan bulau batu,n penjang.

Lalu gatang i-mendeng hajak hatanggar tingang lu-kangkana,e.

Barahambar dje timpong peteng,e batandjong huang papan lu-talawang.

Lu-mantapei dje timpong pandjang akan panambai papan talawang.

Manantiup pahangan ambo salibumbong bulau dare, $\mathrm{n}$ lintong.

Nusang renteng dje tingang hajak balua langkau papan talawang.

Niling pating dje bungai hindje lu-bahandjong parong ledig, von ihnen die sich da wiegen wie die Quasten an den Betten, den königlichen?

Drei Bandongboote sind noch leer, drei Dolche können einfahren in ihre Scheiden (die Handlungen werden also durch drei Balian ausgeführt, in die die Sangiang nun einfahren werden).

Vier Vogelfahrzeuge sind noch ledig, vier Speerspitzen können hineingesteckt werden in ihre Ringe.

Und sie umgürten nun, was sie zu umgürten haben, sie die Tiger, die drei zusammen.

Und sie bestreichen mit den Zeichen ihre Körper, sie die Tiger, die da vermehrt sind $z u$ vier.

Und sie umgürten schräg herabhängend ihre Dolche, und sie umbinden und knüpfen fest die goldenen Steine der Penjang.

Und sie erheben sich und stehen auf und bringen in Ordnung die Nashornvogelfedern, den Kopfschmuck, den sie tragen.

Und sie gehen herum in dem Schildbrette, das verhängt ist mit den lang herabhängenden Tüchern.

Und sie heben hoch über sich hinaus das Tuch, das lange, das als Dach über das Schildbrett gelegt ist.

Und sie heben hoch in die Höhe das Tuch, das grosse, sie heben es hinaus über die goldenen geflochtenen Bänder. Es senken ihre Schwanzfedern die Tingang und sie kommen hervor aus dem überdachten Schildbrett.

Und sie beugen ihre $Z$ weiglein die Nashornvögel und sie schreiten her- 
dare,n lintong.

Ludja liau sambil mangantau, ela harantong dohong latambon turon.

Tuhi pangambon ulang badjambilei, kueh njampelek pulang sarong ngandawan.

Barakilat sarumpah bulau buli netei djamban garing.

Hakangkalo dje pasor rabia haratean paratar sihong.

Lungang-lingok dje renteng tingang manjapenda langit lombah.

Pulang-pilik pating bungai manjalulok hawon mirang.

Nusang renteng tingang hajak antang dumah manjelem parong.

Niling pating bungai Djalajan hindje nantame siro saripangku.

Nundjong tambang balinga hajak lompat balai rampar buno.

Ngangkat salunga bapilik hindje djakat sali tilap talawang. aus aus ihrem Hause, den geflochtenen Bändern.

Fliehet hinweg ihr Liau nach rechts und nach links, nicht versperret den Dolchen der Wasserschlangen den Weg ihres Herabfahrens (um in die Balian einzufahren).

Weichet aus, ihr Pangambon, zur Rechten und zur Linken, nicht zerbrechet den Griff der Herzgrube, der im Begriffe steht in sie einzufahren.

Es blitzen die goldenen Sandalen, die da schreiten über die Brücke, die elfenbeinerne.

Es rauschen die Schuhe, die goldenen, die da betreten haben den Weg, den elfenbeinernen.

Es wogen die Schwanzfedern der Tingang unter dem Himmel, dem breiten (d.h. unter dem Dache von Tuch, das über den Balian aufgespannt ist).

Es schwanken die Zweiglein der Nashornvögel unter dem ausgebreiteten Himmelsgewölbe.

Es beugen sich die Schwanzfedern der Tingang und es kommen herbei die Antang und sie schreiten herein in das Haus.

Es senken sich die Zweiglein der Nashornvögel und gemeinsam betreten sie die Wohnung in der verrichtet werden soll das Hülfswerk.

Sie heben ihre Beine, die schnellen, und sie besteigen gemeinsam den Balai der nebeneinanderliegenden Speere.

Sie heben ihre Füsse, die raschen, und sie beklimmen das Haus der aufeinandergeschichteten Schilde. 


\section{Die Sangiang kommen im Hause an}

Toh palus hobah tekap katambong ttg. hobah auch lago,n tandak.

Sangiang mohon bara balai rampar buno akan laseh bentok huma tumon lago: tekap tansaran.

Toh palus radju-radjur manandak, koa,e:

I'rahon mangasoh buno balua balai rampar buno.

Manting manganduran renteng bahandjong sali tilap talawang.

Manjauch ranjing buno nangkaranak bumbong dare, $\mathrm{n} \mathrm{pu-}$ ron.

Ngansohan renteng nanggalong bulau nikap pandong irit bungai.

Olih kilat hatontong tambang njauch garing indjam djamban radja.

Lio hadjedjel baro salunga mansohan sihong pantang kanarohan.

Palus kandjan burong tingang halawo bumbong dare,n puron.
Nun ändert sich der Schlag der kleinen Trommeln und es ändert sich auch die Melodie des Gesanges.

Die Sangiang steigen herunter vom Balai der nebeneinanderliegenden Speere und kommen in der Mitte des Hauses an unter Begleitung der Weise: Schlag der Ankunft.

Nun singen sie fortwährend und ihr Gesang lautet:

Gleichwie das Wasser herabfliesst, so schreiten sie über die Lanzen und treten heraus aus dem Balai der nebeneinanderliegenden Speere.

Sie werfen herum und spreitzen die Schwanzfedern und kommen hervor aus dem Hause der übereinandergeschichteten Schilde.

Sie lassen sich herab am verehrungswürdigen Speer, der ihnen als Treppe dient, sie lassen sich herab auf die Matte, das Geflecht von Puron.

Es kommen herunter die Schwanzfedern der Tingang, die da umschliessen den Goldstaub, sie kommen herunter auf die Matte, die geflochten ist von Irit-Bungai-Rotan.

So rasch wie die Blitze sich aufeinanderfolgen, so rasch kommen herunter die Beine längs dem Elfenbein, dem geliehenen, dem Wege, dem königlichen.

Wie der Regenbogen aufleuchtet, so steigen herab die Füsse auf der Treppe, der fürstlichen.

Und wie die Nashornvögel in der Luft schweben, so schweben sie herab auf die Matte, das Geflecht von Puron. 
Tarin anak antang randan harende pandong irit bungai.

Palus surong djandjulana batandjong lebeho,n parong.

Bungai rajong lu-Djalajan manetei rantau siro.

Palus surong djandjulana, tambon njurong mihing rundjan.

Manjampenda tumbak gandjuradja, njalulok pajong runtar bahandang.

Mari darah bandong lasang nahingan pahusahai baro.

Merang tolang gentoi burong sandong njalanean garising bulau batu,n penjang.

Palus manjelem lawang timpong, nantame pahakumbang benang.

Burong tingang hapintih dandang njampenda kadjang lalangit bulan.

Antang randan sansawong tari,e njalulok luhing langkau timpong.

Nundjong tambang,e hajak Sangiang nidjak bukit baras
Und gleichwie ein junger Antang in der Luft schwebt, so kommen sie herunter auf die Matte von Irit-BungaiRotan.

Und beendet ist ihre Reise, beendet das Hinschreiten zur Wassertiefe des Hauses.

Die Nashornvögel, die Jünglinge der Djalajan, schreiten herzu zur Wassertiefe der Wohnung.

Und hinter ihnen liegt ihre Reise und die Wasserschlangen treten ein in den Mihing (eine sehr grosse Fischreuse), in den Rundjan (ein heiliger Topf. Die beiden stellen die Wassertiefe des Hauses dar, der heilige Ort wo die Wasserschlange auftaucht).

Unter der Lanze, dem königlichen Speer, unter dem Pajong (Schirm) von roter Farbe.

Es beginnt zu wallen das Blut der Bandongboote (Balian), wenn sie hören das Rauschen der Oberkleider. Es klappern die Knochen der Vogelboote (Balian), sobald sie vernehmen das Geräusch der goldenen Steine der Penjang.

Und sogleich treten sie (die Sangiang) ein durch die Türe von Tuch und sie kommen herein durch das Tor von Stoff.

Und die Tingang vermengen zusammen ihre Schwanzfedern (d.h. es sind sehr viele Sangiang) unter den Matten des Himmels der Monde.

Und die Falken, die zahlreichen, schweben durcheinander unter dem aufgestützten Dache von Tuch.

Und gemeinsam erheben ihre Beine die Sangiang und sie besteigen den 
bulau.

\section{Mangkat salunga bapilik} hindje Djalajan nekeng luhing busong hintan.

Totong garo bulan entang, naheta hampis tingang Sangiang tambon turon.

Nambahua simak bungai aring Djalajan sarong mangandawan.

Palus surong djandjulana netei bukit baras bulau.

Rajong Djalajan hatean luhing busong hintan.

Pendeng nanggar tingang kalangkang garo, nantahinut bungai hampatong santi.

Nusang bulau pating djari,e mampendeng bulau kambang garo.

Niling karah Djalajan djambulei pahingkat rabia lelak
Berg des goldenen Sandes. (Wahrscheinlich ist mit diesem Berg der Behas Tambak: der aufgehöhte Reis, gemeint.)

Und sie heben gemeinschaftlich auf ihre Füsse, die raschen, sie die Djalajan, und sie erklimmen die aufgeschütteten Geröllbänke von Edelsteinen.

Und sie entzünden den Weihrauch der Monde der Getragenen, und sie erneuern den Wohlduft des Tingang, seines Sangiang (seines Herrn oder Besitzers) der Wasserschlangen, die da herunterfahren.

Und sie fachen an den Duft der Nashornvögel, der Freundinnen der Djalajan, der Herzgruben in die man einfährt (es ist der Weihrauch der Balian, den sie nun entzünden, denn auch der Priester kann ja nichts von sich aus tun, die Sangiang handeln für ihn, in ihm und durch ihn).

Und beendet ist ihre Reise, beendet ist das Beschreiten des Berges von goldenem Sand.

Und die Jünglinge der Djalajan haben zu Ende geführt das Betreten der Geröllbänke von Edelsteinen.

Und sie richten auf, und sie bringen in Ordnung den Nashornvogel, das Gestell des Weihrauches, und sie bauen auf den Nashornvogel, das Schnitzbild des Wohlduftes.

Sie senken die goldenen $Z$ weiglein ihrer Finger (d.h. die beringten Finger) und sie richten auf die goldenen Blumen des Weihrauches.

Es beugen ihre Hände, die zarten, die Djalajan um aufzubauen die goldenen 
santi.

Usang kambang garo mendeng nangkenja riar tingang Sangiang.

Enah lelak santi hingkat nakondong bungai Djalajan.

Tuneng njababeneng tandok,e nangkenja bandong lasang buang.

I'dia nandak njambiti tingang, kueh lasang selem paju,n kalingo.

Palus surong djandjulana nanturong bandong lasang buang.

Bungai rajong lu-Djalajan njahendeng gentoi burong sandong.

Nusang djari randan hajak ngambelom bulau tantan sarong.

Niling karah Djalajan hindje nampaharing rabia randit tiwong. 379
Blüten, die duftenden.

Und schon haben sie aufgerichtet die Blumen des Weihrauches und mit freundlichem Worte sprechen die scheuen Tingang, die Sangiang.

Und schon haben sie aufgebaut die Blüten, die duftenden, und es sprechen die Nashornvögel, die Djalajan, mit lieblicher Rede.

Und mit hellen Augen besehen sie die Bandongboote, die leeren, und sprechen zu ihnen mit liebkosender Stimme.

Nicht wollen sie rufen jedem Einzelnen der Tingang, nicht sucht ihre Sehnsucht jedes Boot in das sie eingehen wollen (jeder Sangiang wählt nun die für ihn bestimmte Balian aus). Und beendet haben sie ihre Reise des Hingehens zu den Bandongbooten, den leeren.

Die Nashornvögel, die Jünglinge der Djalajan, sind nun zu Ende gekommen mit dem Hinschreiten zu den Vogelfahrzeugen, den ledigen.

Sie senken ihre Finger, die feinen, und sie beleben die goldenen Abteilungen der Herzgrube (der Balian, in die sie nun einfahren wollen).

Sie beugen herab ihre Hände, die Djalajan, und sie beleben die goldenen Teile des umflochtenen Bandes.

\section{Die Sangiang fahren in die Balian ein}

Toh palus mantekas hobah lago ttg. tekap katambong manumon lago: Sangiang lompat tantan sarong.

Koa,n tandak:
Und nun wechselt plötzlich die Melodie und der Schlag der kleinen Trommeln und sie befolgen die Weise: Die Sangiang steigen ein in die Abteilungen der Herzgrube.

Es lautet der Gesang: 
I'nundjong tambang balinga hajak lompat bulau tantan sarong.

Mangkat salunga Djalajan hindje djakat rabia randit tiwong.

Nidjak marempai bandong lasang lalu nandjong rakure mondok.

Usang sarong belom marantep djadi ngandang balita lasang.

Enah tiwong lalumahadjip napus kurong lu-pahawang.

Djadi maner 380 lu-habenteng bawi mondok nantilap sarong.

Anja-anjan nansekan dohong bulau pulu nansila samben.

Ruang-riup timpong lawi,n peteng, rajar tandok bulau rewan bawi.

Tandok lasang hadurut lajang ngadjang tingang lu-Sangiang.

Kining tambon lah-kamarentur nikap bungai rajong lu-Djalajan.

Malik bahing lah-panton sambang itah pulau rewan bawi.

Lalu mules salintik luhing
Erhebet eure Beine, die schnellen, um einzusteigen in die goldenen Abteilungen der Herzgrube.

Erhebt euere Füsse, ihr Djalajan, um einzutreten in die goldenen Teile des umflochtenen Bandes.

Betretet zusammen die Bandongboote und begebet euch auf die Seite eueres Sitzens.

Und wenn die Herzgruben betreten worden sind (durch die Sangiang), dann beginnen die Leiber der Boote zu beben.

Und schon sind die umflochtenen Bänder dicht zusammengefügt und sie sind eingeschlossen in den Frauen.

Und gelähmt wird der Leib der Frauen die sich gesetzt haben mit den übereinandergefalteten Tüchern.

Und sie haben das Gefühl wie wenn ihnen goldene Dolche, zehn auf jeder Seite der Brust, eingestochen würden in ihren Leib.

Weggeweht werden die Tücher und die Enden der Bänder die man um die Hüften schlingt, und es fahren dahin die goldenen Augen der Schar der Frauen (sie schauen vollständig abwesend).

Die Augen der Boote fahren herunter und gehen in die Irre, verhüllt durch den Tingang, den Sangiang.

Und die Hellen (Augen) der Wasserschlangen fahren überall herum, bedeckt von dem Nashornvogel, dem Jüngling der Djalajan.

Wir ändern nun den Laut des Schlagens der Trommeln, wir Inseln, wir Schar der Frauen.

Und wir wechseln den Schlag der 
aring tambon haruei bungai. Trommeln, wir Freundinnen, wir Wasserschlangen, die verzwillingt sind mit den Nashornvögeln.

Manjaruroi lah-gandang Wir befolgen den Schlag der Vaterapang, tingang sangiang tam- trommel (wahrscheinlich die Trommel bon turon.

Manjampelek la-towong mama Djalajan sarong la-mangandawan.

Hando tandak la-manandjulo, lasang ringkes-marangkesa.

Hunang karunja la-manalandjat gentoi ringkin-labasariang.

Toh hobah lago ttg. tekap katambong tumon lago: Tekap Paturon Sangiang. des Hauptbalian) des Tingang, des Sangiang, die nun trommelt von den Wasserschlangen, den herunterfahrenden.

Wir tun es nach der Melodie der Onkeltrommel (wie oben), die da spielt von den Djalajan die einfahren in die Herzgrube.

Es verstummt der Gesang für eine kurze Zeit, damit in Ordnung gebracht werden können die Boote.

Es stockt das Lied für einen Augenblick, damit sich bereit machen können die Fahrzeuge.

Nun ändert die Weise und der Schlag der kleinen Trommeln nach der Melodie: Schlag des Einfahrens der Sangiang (in die Balian).

Dumah tambon mangasoh Es kommen die Wasserschlangen und balua papan talawang.

Lalu rampe ihing mangaruran bahandjong patas bulau dare, $n$ lintong. sie steigen herunter und sie treten heraus aus dem Schildbrett.

Es kommen herbei die Wasserschlangen und sie steigen herab und sie schreiten heraus aus den Abteilungen der goldenen geflochtenen Bänder.

Tambarirang saroi lu-hadurut basingah pandang kabanteran bulan.

Unar Djala lalu-marentur sampalak bintang marundjat langit.

Der Tambarirang fährt mit Heftigkeit herab, beleuchtet von dem Lichte der Rundheit des Mondes.

Der Unar Djala steigt herunter, beschienen von dem Gestirn, das hervortritt am Firmament.

Basingah ulai sasumbo radja Und es liegt auf ihm der Glanz des 
sampalak njating djadjampen kereng.

Panamuei anak Djata lampang balasang batang la-baras bulau.

Pangadjan busu,n Hatala hadurut bagentoi luhing lahbusong hintan.

Kilau panamuei anak Tonggal budjang bahanji menteng nantilap sarong.

Tingkah pangadja,n busu,n Pataho tatau manekeng luhing karambang sawang.

Kilau mampendeng anak garing randan toros bulan mandolang bulau.

Tingkah nampahing busu,n sihong ringkang pambok pahawang nangkaile rabia.

Hajak lilang kambang garo sihai dohong tambon njaleman kumpang,e.

Sarak santi pulang lu-patenggau buno rawing nentem
Dochtes der königlichen Lampe, es liegt über ihm der Schein des Harzes, das gesammelt wurde auf den Sandhügeln. (Das Harz wird meistens von Frauen gesammelt auf den Sandhügeln in den Flüssen, wo es vom Wasser angespült wurde.)

Auf ihm, dem reisenden Kinde der Djata, das aufgetaucht ist und das als Boot benützt einen Stamm von Goldsteinen (es ist das Banama Bulau: das goldene Boot, von dem wir in der Einleitung gesprochen haben).

Ueber ihm, dem Besuche des Jüngsten des Hatala, der herunterkommt und als Fahrzeug benützt einen Stamm von Edelsteinen (Banama Hintan: Edelsteinboot, von dem wir in der Einleitung ebenfalls gesprochen haben).

Wie die Reise des Kindes des Tonggal, des Jünglings, des tapferen, des mutigen, der da übereinanderaufschichtet die Sarong.

Wie der Besuch des Jüngsten des Pataho, der da verstärkt das Innerste des Zaunes der Sawangstauden.

So wie man aufrichtet die kleinen elfenbeinernen Pfähle und einen Zaun macht für die Frauen die Gold suchen (der goldhaltige Sand wird durch diesen Zaun festgehalten).

So wie man aufrichtet kleine Pfosten zu einer Hecke für die Frauen die mit dem Goldwaschen beschäftigt sind. Und sie schieben nun auf die Seite die Blumen des Weihrauches, sie die Dolche der Wasserschlangen, die eingehen wollen in ihre Scheiden.

Und sie stossen weg den Griff, den wohlriechenden, sie die Speerspitzen, 
gantuling,e.

Tanggar lamiang selong luSangiang mikeh lasang kahem lu-malantar.

Hinut hanjang kakupeh luDjalajan mikeh gentoi malimbar buang.

Tapakalong sarumpah bulau gagelan intan lalu-djahawen.

Salandewen sapatu lu-rabia baduri amas la-limebalas nehos batu la-pandih laut, mansohan liang bandjang hariran.

Tapakalong tutang kundjat antang, mise kundjat rundjan nansara.

Tapakalong i-tutang la-bunter bulan turong bagantong langit, manjalumpok anak Manjamei menteng tawan petas langit namuei.

Nanterus tempo,n buang penjang kati,n kenjoi rawen mangadja.

Manalumbang bulan maritih bintang tumbo marundjat langit.

Bahalap kamapar pelek Sahawong mangkang tambang,e tempo balinga. die mutigen, die da eintreten wollen in ihre Ringe.

Aufrecht und still wie ein Achatstein steht der Sangiang da, denn er befürchtet, dass sonst das Boot umkippen könnte.

Gerade und ruhig wie ein Achat der zwischen den Fingern geformt wurde, steht der Djalajan da, denn es wäre sonst möglich, dass untergehen würde das Fahrzeug.

Bekleidet ist er mit goldenen Sandalen, die als Sohlen haben sechs Edelsteine.

Bekleidet ist er mit Schuhen von Gold, die als Sohlen goldene Bambus haben, fünfzehn herunterfliessend über die Steine der Sperre der See, herabfliessend über die steinernen Pfähle die das Meer zuschliessen.

Und geschmückt ist er mit gezickzackten Tätowierungen des Falken, die den gezackten Randverzierungen eines heiligen Topfes ähnlich sind.

Und verziert ist er mit den Tätowierungen des vollen Mondes, der rund am Himmel steht und in dem zu sehen ist das Kind des Manjamei, das tapfere, welchem bekannt sind die Wege des Reisens am Himmel.

Der da führt den Besitzer der leeren Penjang längs den Pfaden des Falken, des reisenden.

Der überall herumschweift mit dem Monde, dem berstenden Gestirn, das aussprosst am Himmel.

Die schön bedecken die Stützen des Sahawong, die zierlich aufgelegt sind auf die Beine ihres Besitzers, die raschen. 
Bahalap kangadjang lawah lamiang riak njaro ngatimbong handang,e.

Tapakalong lawah bulau urai hapasang rinot gumi,n 381 tambon.

Tapakalong tutang laga hanja manalumbang anak rawing menteng.

Tapakalong kuling hariwong sawang benang garumbong dandawen tapang.

Salandewen bilitanden sangen, pahangan sahai tambarirang.

Bahalap njuit putir Sangiang, mangarawang habinei Djalajan.

Tapakalong ulai telon penjang,e, benang sarau darong handjaliwan.

Penjang kasinga, $n$ tandang haramaung telo pulu harantong bawak.

Bahalap namburak bulau luhabenteng ngantipei pasang la-darah belom.

Kamapar penjang pangaroh radja sangkurong, riak lahanji,n tempo,e.

Tapakalong kumpang dohong rangkang kaju, rindak-randong banama.
Schön sind eingehüllt die Beine wie mit Achaten bedeckt, wie überspült mit Wellen der Rotheit.

Verhüllt sind die Beine von herabhängenden goldenen Fäden mit den auseinanderstehenden Haaren der Wasserschlange.

Bedeckt mit Tätowierungen, mit acht weiten, die da wellen wie ein junges Krokodil, ein tapferes.

Verziert mit Knäueln von....? den Tüchern.... ?, wie der mit Blättern verhüllte Stamm (harizeong und garumbong sind mir nicht bekannt. Auf jeden Fall handelt es sich auch hier um den Lendengürtel der die Beine bedeckt).

Bekleidet mit einem Sangenlendentuch, dem schwärzlichen des Tambarirang.

Schön bestickt von der Prinzessinnen der Sangiang, mit durchbrochenen Arbeiten geschmückt von der weiblichen Djalajan.

Bekleidet mit den Fäden, dem Gurte der Penjang, mit dem Tuche der unechten Handjaliwanschlange.

Und an ihm hängen die Penjang, die Zähne der Tiger, dreissig Stück aneinandergereiht.

Schön zusammengeflochten in der Mitte mit goldenen Fäden, zusammengedreht zu Paaren von lebendem Blut. Die kräftigen Penjang, die da verhindern, dass ihr Herr gefangen genommen werde, die Wellen der Tapferkeit ihres Besitzers.

Geschmückt mit der Scheide des Dolches von altem $\mathrm{Holz}$, dem abgerissenen Boote. (Die Scheide dient den Sangi- 
ang auch als Fahrzeug auf ihren Reisen, sie verwandeln sie $z u$ diesem Zwecke in ein Boot.)

Bahalap njaloang bulau lu- Schön umflochten ist sie mit goldenen manipis bahelang telo i-djarin tingang.

Lu-kalilit rabia rampir selat udju mampan tanggalong. dünnen Bändern, in $Z$ wischenräumen von drei Spannen eines Nashornvogels.

Unwunden mit goldenen zarten Fäden in einem $Z$ wischenraum von sieben auf den Seiten die mit ihnen überzogen werden.

Bahalap njalumpok anak Und schön eingesteckt ist in ihr der dohong korik bakatantan am- Dolch, der kleine, der da durchbon barutas matei.

Mananterus pulang ringkangringik maharis enon bapilo nihau.

Bahalap kamulang garing luharintok suloh tandok lalumba laut.

Bahalap lalundjong lamiang lu-batontong tisa,n karapitan kabeho,n bulan.

Bahalap ngankajoh hapan balau radja matei njarah lanting djahawen.

Bahalap njarawei hapan gundai Santong nihau nasawong liau totok dohong.

Lundjang-lendjut tutang tambon pulu, manjanggar garing takolok kumpang,e. schneidet die Wolken, die vernichtenden des Todes.

Und eingeschoben ist der Griff, der zierliche, der da durchhaut die Wolken, die zerstörenden des Verlorenen. Und schön ist der Griff, der elfenbeinerne, der da ausläuft in Horn des Krokodiles der See. (Achat.)

Herrlich ist der Knopf von Achat, der da vermehrt den Rest des Verwickeltseins der Eifersucht der Monde.

Und schön verziert ist er mit den Haaren des Königs, des verstorbenen, der bereits übergeben wurde den Flossen, den sechsen (wahrscheinlich: der bereits nach dem Totendorf geführt wurde).

Schön geschmückt mit dem Haar des Santong, des Verlorenen, der bereits vermengt wurde mit den Liau, den Dolchmunden.

Und es schlängeln sich die Verzierungen der Wasserschlangen, der zehn, und wie Girlanden schmücken sie den elfenbeinernen Kopf der Scheide (gedacht ist wahrscheinlich an die kunstvollen geflochtenen Bänder die die 
Djadjangeloi tutang naga hanja mambambai ulai i-telon penjang,e.

Tapakalong i-baron tapas bahalap neseng karungut bulan.

Salandewen i-anggan korang badaris nambing kandaju, $n$ pahawang.

Manantilap hapan baron bulau natah henda mampan balambang.

Manalamping anggan lu-rabia lundjang-lendjut dinon mampan sara.

Manantilap hapan baron njaho, benang njaho tau ngarontong langit.

Manalamping hapan anggan kilat pandai tau handjandjepa tandok,e.

Bahalap ngantjing hapan bulau lantik tangkeng luhing pang Guntin Bintang.

Tangkanjahan tutang empoi malem masoh guntoh la-ben-
Scheide zusammenhalten, oder dann auch an wirkliche Schnitzereien, die auch vorkommen).

Es schlängeln sich die Tätowierungen der Naga, der acht, der nebeneinanderliegenden Fäden des Hängers der Penjang (sowohl an der Dolchscheide als auch an der Schwertscheide werden einzelne Penjang angehängt).

Bekleidet mit dem Oberkleide, dem weniger schönen, das ausgefüllt ist mit dem Liede der Monde (das gemacht wurde von singenden Frauen). Geschmückt mit einem Oberkleide, einem weniger schmuckvollen, das hergestellt wurde unter der Begleitung des Gesanges der Frauen.

Und darüber gelegt is ein Oberkleid, ein goldenes, über das hingegossen wurde ein gelber Rand.

Darüber bekleidet mit einem Oberkleid, einem goldenen, mit einem angefügten, sich schlängelnden Rand.

Und darüber gelegt ein Oberkleid des Donners, des Donnertuches das da vermag zu versperren den Himmel.

Und darüber bekleidet mit einem Oberkleid des Blitzes, der zu verschliessen vermag die Augen (es handelt sich bei diesen beiden Oberkleidern wahrscheinlich um den Panzer).

Schön versehen mit Knöpfen, die gemacht wurden von dem Golde, das verborgen war in der Trommel des Pang Guntin Bintang (wahrscheinlich nach einer Erzählung, die mir nicht bekannt ist).

Es klirren die Tätowierungen, die eingeritzten Striche auf den Armen, sie 
teng penang,e.

Kakariok manok rimbon bulau lu-mangkongan rangkang lamiang.

Hasambau tutang kalibambang dohong ipah talugan bau,n lawang radja.

Tapakalong hinting santagi randan hiring bulan bagantong langit.

Tapakalong bulau repang samben udju kungkong 382 leleng tahaseng.

Bahalap nansukan bulau manurut indurut Putir Selong Tamanang.

Manamputing manas bulau halapak sarik njaho hakumbang langit.

Bahalap kamanggar intan lapak hanja tasala,n radja $\mathrm{i}$ tumbang danum.

Lilang kambang garing lumanjangen manalandjong ba- schlagen an die übereinandergereihten Armringe, die um die Mitte des Armes gelegt sind.

Sie tönen wie das Geschrei der Hühner, die in einem Haufen goldener Blätter einen aufrechtstehenden Achat gefunden haben.

Und im Angesichte der Tätowierungen stehen hervor die Ipahdolche (ipah: Palmietgewächs mit länglichen spitzigen Blättern) von braunroter Farbe, so wie bemalt ist die Türe des Königs (es handelt sich um die Körperhaare, die zwischen den Tätowierungen und den Armringen hervorstehen).

Bekleidet mit einer Treppe von santagi (Brustschmuck, siehe Register), des kleinen, der Reihe von Monden, die am Himmel stehen (die einzelnen goldenen Glieder des Santagi sind halbmondförmig).

Geschmückt mit der goldenen Brustreihe (Santagi) mit sieben Blättern (die vollständigen Santagi haben sieben Glieder), dem Sammelplatz des Atems.

Und schön gestützt von dem Golde, das herunterkam und das herabgelassen wurde von der Putir Selong Tamanang (sie ist die Frau des Ranjing Mahatala Langit).

Mit den Ecken von goldenen Perlen des Donners, der da kracht durch die Himmel.

Mit den herrlichen aufrechtstehenden Edelsteinen, die bearbeitet wurden von dem König an der Mündung des Flusses.

Sie bringen zum Verstummen und schieben auf die Seite die Blumen, die 
lengkong tingang.

Tapakalong bulau pantar tatah,e tau nolak ambon barutas matei.

Salalewen dje haup djuhau pandai njangka enon bapilo nihau.

Djari turon njalantingan bengkele bintang baloi nansulang sawah.

Bahalap maraung kaju asan kalingo belom mewai tumbang tadjahan langit.

Manjalumpok hapan bulau murong hangkaudju malik lahenda djanau.

Mananterus hapan intan kuning bakatiling katil banama.

Kakatimbong tutang lauk lanting hakangkuling salipa,n bungai.

Lalu turon njaliawan tandok lu-tanggaran bulan djahawen.

Tapakalong lawong singka antang bahalap, rega,n djipen elfenbeinernen (mit Blumen bezeichnet man die poetischen Redewendungen in einem Gesang oder einer Mythe) der Gesänge, die da aufsteigen aus der Kehle der Nashornvögel (der Männer).

Und geschmückt mit den goldenen Pfählen, den Goldstiften der Zähne, die aufzuheben vermögen die Wolken, die vernichtenden des Todes.

Bekleidet mit einem Netze, das man für den Fang der Mandjohanfische braucht und mit dem man wegzuschieben vermag die Tauwolken, die zerstörenden des Verlorenen.

Ergänzt von den hin- und herwogenden Ohrringen der Männer, den Baloisternen (Venus), die da erscheinen bei der Morgendämmerung.

Schön eingeschlossen in das $\mathrm{Holz}$ der Freude und der Sehnsucht, das da wächst an der Mündung des Tadjahan des Himmels.

Und ausgefüllt sind sie mit dem Golde, dem erhöhten, dessen Gelbheit sich sieben $\mathrm{Mal}$ verändert hat.

Und ausgefüllt sind sie mit dem Edelsteine, dem kleinen, der da schief liegen macht die Bänke des Bootes (weil alles den Oberkörper vorbeugt und nach ihnen schaut).

Es plätschern auf die Tätowierungen des Lantingfisches, des aufgewundenen und zwischen den Nashornvogel gesteckten.

Und es stehen hervor die übereinanderstehenden Augen des Ortes der Monde, der sechsen.

Bekleidet mit dem Kopftuche von Singka-Antang-Stoff, des schönen, 
djahawen.

Salandewen luhing angkol timpong,e benang raho ngalingkang bulan.

Tapakalong sampulau dare, dare,n tingang hapintih dandang,e.

Salandewen salutup pantong antang tabuhi ranjing sansawong tari.

Bahalap ngadjang hapan tingan apang puna tau nambalik andau.

Badaris nikap hapan bungai sirau kadjongkana nangkules kalaman.

Hajak ngadjang hapan tingang ambon puna tau mahantis dandang,e.

Lu-kanikap hapan bungai enon puna pandai tau nahuto pating,e.

Udju djadi tingang santah kadjang entang mohon pandoi tingang.

Hanja djadi bungai sundong tingkap tujang hanjalong repang. dessen Preis sechs Sklaven (240 Fl.) betrug.

Mit dem aufgesetzten Kopftuch geschmückt, das gemacht wurde von dem Stoffe Raho, der den Mond fängt (es handelt sich um zwei Tuchsorten die mir nicht bekannt sind).

Und geschmückt mit dem geflochtenen Kopfputz, mit dem Geflecht in das eingesteckt sind die gespreizt auseinanderstehenden Tingangfedern.

Bekleidet mit der Kopfbedeckung des Hornes des Antang, die kreuzweise besteckt ist mit den Schwanzfedern des Nashornvogels, den durcheinanderwogenden.

Schön bedeckt mit dem Tingang Apang, der die Möglichkeit besitzt umzuwenden den Tag (andau kann auch bedeuten: das Wetter).

Schön verhüllt mit dem Nashornvogel Sirau, der zu verändern vermag den Tag.

Und bedeckt mit dem Tingang Ambon der da heruntertröpfeln kann auf die Schwanzfedern (wahrscheinlich: der Regen hervorbringen kann).

Und verhüllt mit dem Nashornvogel Enon, der die Möglichkeit besitzt das Wasser herabfliessen zu lassen auf die Zweiglein (d.h. auf die Schwanzfedern).

Sieben ist die Zahl der schräg abstehenden Tingangfedern, die da bedecken die Getragenen, die hinuntersteigen $u$ m sich $z \mathfrak{u}$ waschen, die Tingang.

Acht ist die Zahl der Nashornvogelfedern, der zurückgebogenen, die da verhüllen die Gewiegten, die sich 
baden in der Reihe der Gong.

Toh hobah lago,n katambong ttg. hobah lago,n tandak,e, koa,e :

Rapus renteng tingang rawing mandoi pasang danum njaho.

Lilap pating bungai hapandujan lawang ganggerang.

Turon djandjaranan njarak timpong radja nandjak bantika.

Turon Sangiang lu-marantep, budjang laut mapan banama.

Tiwong Djalajan mahadjip haragapan saramin sina.

Simpel ikei bandong lasang, kaju hewang majimpei penjang.

Simpel ikei gentoi burong, serang rajong njandik paturong.

Turon manuwe langit dia matei anak Rahon Tandang.

Tiwong manjalekok hawon bakatutoh bintang saratus.

Turon mangasoh lambat lu-
Es wechselt nun die Weise der Trommeln und es ändert sich die Melodie des Gesanges und sie lauten:

Alle Schwanzfedern der Tingang, der Krokodile baden sich nun in den Fluten des donnernden Wassers.

Und es verschwinden die $Z$ weiglein der Nashornvögel und sie baden sich in der Türe des Donners.

Und sie fahren herunter auf der äusseren Seite des auseinandergeschobenen Tuches, des königlichen, und sie fahren wieder herauf das Bedruckte (d.h. das Tuch, das mit verschiedenen Zeichnungen und Motiven bedruckt oder bestickt ist).

Und es fahren herab die Sangiang und sie nähern sich, und die Jünglinge von der See her wollen sich ein neues Boot bauen.

Und die herunterfahrenden Djalajan fügen sich dicht an an die Spiegel von China.

Festgestopft sind wir Bandongboote, das Holz der Männer füllt aus die Bündel.

Vollgestopft sind wir Vogelfahrzeuge, die Kopfjäger, die Jünglinge haben eingefüllt ihre Paturong.

Die Herabfahrenden bestreuten mit Tuwe (eine weisse, milchige Flüssigkeit) den Himmel, aber nicht starb das Kind, das Raho des Tigers.

Der Heruntergekommene bog nieder den Himmel, wie wenn er vernichten wollte hundert Sterne. $\mathbf{3 8 3}$

Sie fahren herunter und kommen lang- 
badjamban bulau tantan sarong.

Sarong djadi hapanipeng garing randan indu depe,n tambon.

Tiwong hapanjukat garantong lombah ruar gawang Djalajan.

Turon djari kalandjungan kilau manjelem paseban radja.

Tiwong djadi salalewen tingkah maname mansigit 384 mantir.

Ampin anak radja matei tapatame djaka raung garing.

Tingkah busu,n kanarohan nihau tapatasa tabala radja.

Neser djala bulau manansulang pasang riak rawing.

Mapak bandjang kumpang tambon kurong labeho,n sarong.

Nipas pantang tingang $\mathrm{Nja}-$ ring tangkeng tarok Lunok.

Haramaung Sangiang tangkeng tapakalong kandang lujang sambang.

Pangandien Djalajan ahoi sam herab und sie betreten die goldenen Abteilungen der Herzgrube.

Die Herzgrube wurde ausgemessen mit Elfenbein, dem kleinen, dem Masse der Wasserschlange.

Die Heruntergekommenen haben bestiegen den Gong, den breiten, der grösser ist als die Spanne eines Djalajan.

Der Herabgefahrene ist bekleidet wie wenn er eintreten wollte in den Palast des Königs (gedacht ist hier an die Abgesandten die dem Sultan von Bandjermasin huldigten).

Der Herabgekommene ist geschmückt wie wenn er hineingehen wollte in das Haus des Mantir (Fürst, Aeltester). Bekleidet wie das Kind des Königs. das gestorbene, das da hineingelegt wird in den Sarg, den elfenbeinernen. Geschmückt wie der Jüngste des Fürsten, der verlorene, der da niedergelegt wird in der Kiste, der königlichen.

Es taucht unter das Wurfnetz, das goldene und es senkt sich herab durch die Wasser, in denen sich tummeln die Krokodile.

Und er lässt herunter den Pfahl der Scheide der Wasserschlange in die Abteilungen der Wassertiefe der Herzgrube.

Und er lässt herab den Pfahl des Tingang, so wie ein Njaring stecken bleibt auf dem Wipfel des Lunokbaumes.

Der Tiger, der Sangiang, steckt fest und er wird umschlossen von der aufrechtstehenden hohlen Trommel.

Der Tiger, der Djalajan, ist verirrt 
tapatasa mihing andoh garo. und er ist eingefangen in der grossen Fischreuse und im Strafblock des Weihrauches in den man einschliesst die Füsse der Gefangenen.

Ampin lauk rongan masoh tapatasa hempeng tamiang.

Tingkah mandjohan ngawan tapagenggem pangalau radja.

Heka djari mendeng mondok mangon rakeran tambang. Sarong djari marantep lumangandang balita bulan.

Tiwong lu-mahadjip djari napus kurong pahawang.

Puso,n pinang babaukei karapitan udjan tintih njaro.

Lelak manjang babaurai ngalangkang garing batang pantar.

Udjan njaro lu-balawo masoh sawang ringkan tingang.

Petai ganggerang masoh mansohan ranjing pandereh buno.

$\mathrm{Njantah}$ renteng tingang Sangiang hajak manjangkelang riak udjan bulau.

Niling pating bungai Djala-
Und er gleicht den Ronganfischen, die flussabwärtsschwammen und in die Sperre, in den Zaun von Bambusstöcken gerieten.

Gleichwie die Mandjohanfische gefangen wurden, eingeschlossen in dem Fischnetz, dem königlichen.

Müde vom langen Stehen setzen sie sich mit untergeschlagenen Beinen.

Die Herunterkommenden haben sich genähert und haben sich zärtlich angeschmiegt an die sie umschliessenden Monde.

Die Herabgefahrenen haben sich liebkosend angelehnt an die sie umzäunenden Frauen.

Und die Blütenknospen der Pinang haben sich geöffnet durch den herabfallenden Regen, den klopfenden des Donners.

Die Blumen der Betelnusspalme haben sich auseinandergefaltet wie das Gestell des Stammes, des Mastes (gedacht ist an das Gestell auf dem Sanggaran).

Und es fällt herunter der Regen des Donners und er fliesst herab an den Sawang Ringkan der Tingang.

Donnernder Regen stürzt herunter und fliesst herab am Schafte des heiligen Speeres.

Es beugen sich die Schwanzfedern der Tingang, der Sangiang, und sie vermischen sich mit den Wellen des goldenen Regens.

Es senken sich die Zweiglein der 
jan humboh manjampale petai rabia.

Njantah turantaran tandok,e Sangiang ngadjang bumbong dare,n puron.

Niling pating bungai Djalajan hindje nikap pandong hakajau dare.

Nuntun bumbong dare, $\mathrm{n}$ puron njaloh riak bulau tangkanjahan.

Nureng pandong irit bungai rentar ringkin rabia katalumbang.

Riak luhing pantar pinang lu-manambang tamuei Sangiang.

Ringkin rokon lu-tarahan nakep kadja,n bungai Djalajan.

Riak batu bangkulan tuwe, ringkin gohong pandih $\mathrm{Nja-}$ ring.

Indjam djari balemo rohong keton tingang manok Sangiang.

Nasih karah badjambulei buno keton ranjing ajam $D j a-$ lajan.

Indjam dohong indu iring pinang lu-manambang tamuei Sangiang.

Pulang akan djarah manjang
Nashornvögel und sie vermengen sich mit den goldenen Tropfen.

Es beugen sich die herumschweifenden Augen der Sangiang und sie verhüllen sich mit der Matte, dem Geflechte von Puron.

Es senken sich die $Z$ weiglein der Nashornvögel der Djalajan und sie verbergen sich in der Matte, der kreuzweise geflochtenen.

Und sie schauen an die Matte, die geflochten wurde von Puron und die sich verwandelt hat in goldene wogende Wellen.

Und sie starren an die Matte von Irit Bungai, die verändert worden ist in hin- und herflutende Wellen.

In Wellen, die aufrecht stehen wie ein Pinangpfahl, der geschmückt worden ist zum Empfange der Sangiang.

In hochaufschlagende Wogen, wie die Rauchwaren der Sklaven (Zigaretten), die bereit gemacht wurden für die ankommenden Nashornvögel, die Djalajan.

In die Wogen des verriebenen Tuwe, in die Wellen des Wassers der eingeschlossenen Fluten der Njaring (Bier). Leihet die Finger, die schlanken, der Dolche, der Tingang, der Hühner der Sangiang (mit Hühnern der Sangiang werden die Balian und Basir bezeichnet).

Leihet die Hände, die zarten, von den Speeren, den Nashornvögeln, den Hühnern der Djalajan (wie oben).

Leihet die Dolche (die Jünglinge) um herumzureichen die Pinang für den Empfang der reisenden Sangiang.

Die Griffe, um mit Betelnüssen zu 
nakep kadja,n bungai Djalajan.

Tende lu-banama sarong ninggang ulek bindang katil garing.

Tahan djaka adjong tiwong tahan mandai lu-sansurok radja.

Tende lu-kanderang, tende batoros roko,n tarahan.

Tahan lu-kariak antang, tahan balawak luhing giling pinang.

Tende bahing panto,n sambang,e kaju lembai bakaparit tingang.

Tahan bambahinga,n luhing paturong sariangkat tinting. bedienen die ankommenden Nashornvögel, die Djalajan.

Halte nun an, du Boot der Herabfahrenden, dicht beim Wasserstrudel des Brettes, der Bank, der elfenbeinernen.

Stehe still, Fahrzeug der Herunterkommenden, lege an, da wo sich erhebt der Baumstamm, der königliche. Halte an, Gerufe der Tingang, halte an und stecke ein den Stossbaum des Bootes (an dem man das Boot festbindet) bei den Rauchwaren der Sklaven.

Verstumme Geschrei der Antang, lege an bei den aufgestellten Reihen der Pinang.

Schweige Laut der Trommeln, gebogenes Holz, das da herbeilockt die Nashornvögel.

Verstumme nun, Schall der Trommeln, der Paturong, die da erheben den Lobpreis.

\section{E. Die Sangiang werden bewirtet}

Toh hapus paturon Sangiang hajak tende panto,n katambong, baja upo kabuat bewei kakarungut ttg. gendje-gendjeh pai,e, rima,e: djadi aton Sangiang huang ie.

Koa,n karungut,e :

Ijoi-ijoi entang pantai danum kalunen, keton tujang luwok kampongan buno,

Dohong aku tambon turon, buno sarong mangandawan.
Beendet ist nun das Herunterholen der Sangiang und es ist verstummt der Schall der kleinen Trommeln, nur der Hauptbalian singt allein weiter und es zittern seine Beine und das ist ein Zeichen, dass der Sangiang in ihn eingefahren ist.

Sein Gesang lautet:

Ja, ja, ihr Getragenen vom Ufer des Flusses der Welt, ihr Gewiegten von der Buchtung des Dorfes der Lanzen, Der Dolch bin ich, die Wasserschlange, die herabgefahren ist, die Lanze der 
Herzgrube bin ich, die Heruntergekommene.

Amon tenteng pahuriwut lingo,n keton manambang aku dohong padjandjuri kumpang,e, manakep pangadja,n aku buno panantekei gantuling,e,

Hadjalukan akangku njalong arak radja, andau lingongku mandit batu bangkulan tuwe, maniring gohong pandih $\mathrm{Nja}-$ ring.

Toh oloh manenga aka,e tuak atawa danum arak.

Ie ngarungut magon, koa,e:

Ijoi-ijoi, entang pantai danum kalunen, tujang luwok kampongan buno, haru badandang ambon rahusan asengku, kabarengan enon rantaran njamangku.

Tapi magon aku ngantong tolang balemo, balau pantar pinang, ijoh entang, balitangku badjambulei kabaduran uring manjang, ijoh tujang luwok kampongan buno.

Amon aton pinang idje kapantar, karahak puting roko,n tarahan, babarangai.

Hapaku badjawi tolang ba- Damit ich belohnen kann die Knochen,
Und wenn verstummt ist das wehende Wort eueres Innern um mich, den Dolch der aus seiner Scheide hervorgegangen ist, zu empfangen, um mich, die Lanze die sich losgelöst hat aus ihrem Ring, zu erwarten,

Dann reichet mir das Wasser des Branntweines, des königlichen, dann gebet mir zur Beruhigung meines Innern von euerem Bier, dann schenket mir von dem Wasser, das abgesperrt wurde durch die Njaring.

Nun geben ihm die Leute Reisbier oder auch Reisbranntwein.

Er singt immer noch weiter:

Ja, ja, ihr Getragenen vom Ufer des Flusses der Welt, ihr Gewiegten von der Buchtung des Dorfes der Lanzen, erst jetzt kommen in Ordnung die Wolkenlagen meines Atems, die Tauwolken der Buchtungen meines Mundes.

Aber immer noch habe ich aufgehängt meine Knochen, die schwachen, und ich habe Verlangen um Pinang zu kauen, ja ihr Getragenen, mein Leib ist noch immer schwach und es gelüstet mich nach Betelnussfrüchten, ja ihr Gewiegten von der Buchtung des Dorfes der Lanzen.

Wenn ihr nur Pinang habt einmal zum Kauen, wenn nur ein Rest übrig ist einer Ecke der Rauchwaren der Sklaven, es kann mir gleichgültig sein wie viel oder wenig es ist. 
tekang, hapekat uhatku hatamiang, hajak indjamku djari balemo keton rohong Djalajan tingang awang manok Sangiang.

Manasih karah badjambulei buno, buno nasih indu iring pinang, nambang tamuei aku dohong tambon turon. die harten, damit ich entschädigen kann die Muskeln, die geschmeidigen, und ich leihe von euch die Finger, die zarten, der Dolche, der Djalajan, von euch, ihr Tingang, die ihr die Hühner seid der Sangiang.

Und ich bitte euch um die Hände, die feinen, die Hände des geliehenen Speeres, um herumzureichen die $\mathrm{Pi}$ nang für den Empfang des Besuches des Dolches, der herabfahrenden Wasserschlange.

Toh ewen manenga simpa. Ie magon kakarungut, koa,e:

Kilen haweh pantar pinang, entang? dia ie pantar pinang basin burong hatabasan halalangan alem?

Kabadjuran haweh pantar pinang, ijoi entang, keleh amon dia pinang hatalandjong rohong metoh andau udjan balawo langit.

Toh ewen idje mandjulok sipa, tombah, koa,e:

Kabadjuran pantar pinang nah, Sangiang, pantar pinang hatabasan rohong panto,n manambang tamuei Sangiang, nantaolah pulang kantihan takep kadja,n rajong Djalajan, puna pinang hatalandjong
Nun geben sie ihm Kausel. Er singt immer noch weiter:

Wie steht es mit der Beschaffenheit der Pinang, o ihr Getragenen? sind es nicht zu kauende Pinang die verdorben worden sind durch die Vögel und die nur geformt sind durch die Täuschung der Nacht?

Gut ist die Beschaffenheit der zu kauenden Pinang dann, o ihr Getragenen, wenn die Betelnusspalmen nicht bestiegen wurden durch die Dolche (Männer), als vom Himmel herabfiel der Regen.

Und nun sagen sie, die ihm die Kausel überreicht haben, und sie antworten ihm :

Gut sind die zu kauenden Pinang, die wir dir soeben überreicht haben, $o$ Sangiang, zubereitet sind die zu kauenden Pinang von den Dolchen während des Schlagens der Trommeln zum Empfange der besuchenden Sangiang, sie sind bereit gemacht worden 
tambang balinga kabantengan katiring darahen pandang andau. von den Griffen als man schlug die Trommeln zur Begrüssung des Besuches der Jünglinge der Djalajan, wahrlich, die Betelnusspalmen sind bestiegen worden von den Beinen, den raschen, während der straff ausgespannten Wärme, der Hitze des Tages.

Toh ie manontong karungut,e tinai, koa,e:

Keleh amon kabadjuran pantar pinang, entang pantai danum kalunen, hinut amon kabarengan roko,n tarahan, ijoh tujang luwok kampongan buno.
Er setzt nun sein Spruchwort wieder fort und singt:

Gut ist es, wenn es richtig steht mit den zu kauenden Pinang, ihr Getragenen vom Ufer des Flusses der Welt, befriedigt bin ich, wenn vollkommen sind die Rauchwaren der Sklaven, ja ihr Gewiegten von der Buchtung des Dorfes der Lanzen.

\section{F. Die rituelle Reinigung der Gebrauchsgegenstände für die Handlungen}

Limbah te upo idje eka Sangiang te manduan pisau ttg. mangkok korik sarangan daha,n manok.

Ie manjaki kare ramo,n gawi te, koa,e :

I'njakiku sangko radja ngarawang bulau, malasku saparanggon dalam idje bahalap kangatil bawak lamiang, lasang bukit baras bulau, gentoi luhing busong hintan, tapudjakan Sangiang tambon balua turon, tampuenan $\mathrm{Dja}$ lajan sarong mangandawan.
Darnach nimmt der Hauptbalian, der der Ort des Sangiang ist (d.h. in dem nun der Sangiang handelnd auftritt), ein Buschmesser und die kleine Tasse, die mit Hühnerblut gefüllt ist.

Er bestreicht damit alle Dinge die für die Ausführung der priesterlichen Handlungen gebraucht werden, indem er sagt :

Ich bestreiche dich, königliches Gefäss, das geschmückt ist mit durchbrochener Goldarbeit, ich wische dich ab, Saparanggon des Palastes, du schöner, der du besetzt bist mit Achatsteinen, du Fahrzeug des Berges von Goldsand, du Boot der Geröllbänke von Edelsteinen, du Sitzplatz der Sangiang, der herunterfahrenden Wasserschlangen, 
I'njakiku tingang kalangkang garo, malasku bungai hampatong santi, mangat ikau tau indu djamban garing balemo amon hatalatai lunok mamua bulau, pandai ikau akan tatean sihong badjambulei, amon malempang baras dje bulau lampang.

Hemben nduan hambekan katon mait gana,m ikau djadi riwut penjang, tau manantapei ambon barutas matei, matok dinon djaretan etoh baterap labata,m rentar djadi salatan paturong, pandai nantiup enon bapilo nihau.

I'njakiku apar radja badulang, eka rangkan panginan simpan, manok darong tingang djaka manando hakebut langit, djaka nampukok hagerek petak, hai sapak,e, palapas,e ngampoh pulau pulu.

I'njakiku takupat sinta, ma- du Bank der Djalajan der Herzgrube, die herabgestiegen sind.

Ich bestreiche dich, du Nashornvogel, $\mathrm{du}$ Gestell des Weihrauches, ich wische dich ab, Nashornvogel, Schnitzbild des Wohlduftes, damit du dienen kannst als Weg von Elfenbein, dem zarten, wenn der Lunok im Begriffe steht goldene Früchte $z u$ tragen, auf dass es dir möglich sei, dass du zu einer geschmeidigen elfenbeinernen Brücke werdest, wenn aus dem Flusse auftaucht der goldene Sand. *

So steht es nun aber jetzt, so ist es in dieser Angelegenheit, deine kräftige Seele wird sich verwandeln in den Wind der Penjang, der aufzuheben vermag die Wolken, die vernichtenden des Todes, so steht es nun in dieser Sache, deine weitsehende Seele wird sich verändern in einen Wind der Paturong, welcher wegzuwehen vermag die Tauwolken, die zerstörenden des Verlorenen.

Ich bestreiche dich, Apar, königliches Gefäss, Ort auf dem niedergelegt werden die Esswaren, die bereitgelegten, die Teile des Huhnes, des Huhnes Tingang, dessen Gekrähe erbeben macht den Himmel, dessen Geschrei erzittern macht die Erde, dessen Schenkel sehr gross sind und dessen Flügel zehn Inseln bedecken.

Ich bestreiche euch, ihr Kuchen Sinta,

* Durch die Handlungen des Tantolak matei kehrt das verlorene Heil wieder zurück. Den Verwandten des Verstorbenen ist es wieder möglich allen Arbeiten nachzugehen und Handel zu treiben und sich Reichtümer zu erwerben mit denen später das Tiwah bezahlt werden kann. Die Erwerbung dieser Güter, die in einer bestimmten Reihenfolge geschieht (siehe weiter unten), wird genannt: der Baum, der goldene Früchte trägt, oder auch: der goldene Sand, der aus dem Flusse auftaucht. 
lasku apam kembong riwut, kanihi bambang dohong, malasku njiring njababiring kilat, lipat djela tandang, kare rangkan panginan simpan, nduan uras hakanjatan sukup, hai tawo,e kilau gunong baratus datoh, kumbo,e tingkah purok batu ambo.

Akan upah keton tingang Sangiang batolang rumpang nduan alem etoh, Djalajan bauhat leso matok dinon pandang kalaman katon.

I'njakiku behas tambak radja bahalap ngarambang giling pinang hambalat roko,n tarahan.

I'njakiku bangkang hanselan tingang, malasku runting padjahun burong.

I'njakiku sangko lasang salumpok entang, lasang bulau hambaruan, gandang halalian buli, gentoi tanterus tujang, garantong kamalesan mulang.

I'njakiku behas mintih, malasku bangkusan timpong.

I'njakiku elang salentup hapa manembak maliambong pangaliambong ambon barutas ich wische euch ab, ihr ApamKembong-Riwut-Kuchen und den in den Bambus-Dohongköchern gekochten Reis, ich wische ab das Njiring Njababiring Kilatgebäck und das Lipat Djela Tandanggebäck, alle Esswaren die bereit gemacht worden sind, alle Esswaren die in genügender Zahl vorhanden sind, gross ist ihr Haufe, wie ein Berg von hunderten Höhen, gross ist ihr Haufe, wie ein Fels, ein steil aufragender.

Als Lohn für euch, ihr Nashornvögel, ihr Sangiang, für die Ermüdung euerer Knochen in der kommenden Nacht, für euch Djalajan, für die Erschlaffung euerer Muskeln an diesem Tag.

Ich bestreiche dich, königlich aufgehöhter Reis, der du umzäunt bist mit Reihen von Pinang und umfriedet mit Rauchwaren der Sklaven.

Ich bestreiche dich, wirkliches Oel des Nashornvogels, ich wische dich ab, wirkliches Oel des Vogels.

Ich bestreiche dich, o Gefäss, du Boot der Seelen der Getragenen, du Boot des Goldes, auf das die Seelen wiederum zurückkehren wie der Laut der Trommeln, du Fahrzeug der Seelen der Gewiegten, auf das sie wieder zurückkommen wie der Schall der Gong.

Ich bestreiche dich, ausgewählter Reis, ich wische euch ab, ihr tüchernen Bündel (in denen der Seelenreis aufbewahrt wird).

Ich bestreiche dich, knallender Bambus, mit dem man schiesst um in die Höhe $z \mathfrak{u}$ werfen, damit aufwärts fort- 
matei.

I'njakiku dazen taberau bungai, dawen tanggaring balang, dawen pilang tanggoi njaho, mangat ikau djadi bulau tampong papas, rabia tundon kalingking hapa mamapas manantapei ambon barutas matei, manantiup panjakatin enon bapilo nihau.

I'njakiku hampatong uei rantihen tingang, malasku sadiri,n upak lulong pamali akan takiri,n entang bakawan kilau burong tingang, akan talimbas tujang bapupon tingkah tandang haramaung bara ambon barutas matei, enon bapilo nihau.

I'njakiku tambaran erang tali,n tengang upak langkoang leleng baho, kumis baringen haring nandai luwok Djalajan hapa mupoh aseng entang kilau bua pinang lewu, hambalat njama,n tujang tingkah bua katilambong njaho. geweht werden die Wolken, die vernichtenden des Todes.

Ich bestreiche euch Taberau-Bungai Blätter, Tanggaring-Balangblätter, Pilang Tanggoi Njahoblätter, damit ihr werden könnet $z u$ einem goldenen Büschel, einem Besen, einem goldenen Bündel, einem Besen um wegzufegen und aufzuheben die Wolken, die vernichtenden des Todes, um zu vertreiben und emporzuheben die Tauwolken, die zerstörenden des Verlorenen.

Ich bestreiche dich, Schnitzbild von Rantihen Tingang Rotan, ich wische dich ab, du stellvertretende Rinde aus dem heiligen Hain, damit du dienest als Stellvertreter für die Getragenen, deren Zahl wie eine Herde von Tingang ist, damit du dienest als Ziel des Vorbeischiessens an den Gewiegten, die versammelt sind wie Tigerzähne an einem Gürtel (d.h. eine grosse Zahl solcher die zusammengehören), das da auslöst von den Wolken, den vernichtenden des Todes, von den Tauwolken, den zerstörenden des Verlorenen.

Ich bestreiche dich, Schnitzbild von Rantihen Tingang Rotan, ich wische des Langkoangbaumes, der da wächst auf dem Platze des früheren Reisfeldes, du Schnur von der Haut des Waringin, der da gedeiht und sich erhebt über der Buchtung des Djalajan, um festzumachen den Atem der Getragenen, so wie man festbindet die Früchte der Pinang des Dorfes, um dicht zu knüpfen den Mund der Gewiegten, so wie man zu einem Bündel zusammenbindet die Früchte der 
Kokospalme, der donnernden.

I'njakiku manas sambelom Ich bestreiche euch Perlen, ihr längperon tambon, $\mathbf{3 8 5}$ manas tasak lichen Perlen aus der Gallenblase der kanti radja akan djamban salumpok entang gandang halalian buli, indu tatean tanterus tujang garantong kamalesan mulang.

I'njakiku katil garing, malasku sansuro radja.

I'njakiku sambang bulau mangat tau ikau riwu-riwut bahing,e hapa manantolak ambon barutas matei, reworewong bambahinga manjangka enon bapilo nihau. Wasserschlange, euch Tasak Kanti Radja-Perlen, die ihr den Seelen der Getragenen als Weg dient wenn sie zurückkehren wie der Schall der Trommel, die ihr den Seelen der Gewiegten eine Brücke seid wenn sie heimkommen wie der Schall der Gong. Ich bestreiche dich, elfenbeinerne Bank, ich wische dich ab königlicher Stamm.

Ich bestreiche dich goldene Trommel, damit ausbreche dein starker Schall, so wie der Wind hervorbricht, und er wegschiebe die Wolken, die vernichtenden des Todes, damit erbrause dein Laut um aufzuheben die Tauwolken, die zerstörenden des Verlorenen.

\section{G. Die Reinigung der Verwandten des Toten $\mathbf{3 8 6}$}

\section{a. Die Reinigung der Männer mit Hühnerblut}

Toh ewen manjaki ewen Nun bestreichen die Balian die Verawang kola,n idje matei te. wandten des Toten mit Hühnerblut. Ewen te uras mondok pula- Diese haben sich in einem dichten pulau. Haufen zusammengesetzt.

Koa,n oloh balian manjaki Und es sprechen die Balian, indem sie gagenep biti,n ewen:

I'njakiku entang, malasku tujang, kasadingen darah manok darong tingang, kasadingen aseng entang.

I'njakiku pandong lawi,n bajede einzelne Person bestreichen:

Ich bestreiche den Getragenen, ich wische $a b$ den Gewiegten, kalt ist das Blut des Huhnes, des Huhnes Tingang, kalt sei auch der Atem des Getragenen.

lau pandjang, malasku sala- des Haares, des langen, ich wische ab 
bia, $n$ bagundai ambo, mahalau panganduang ambon baratus matei, panjakatin enon bapilo nihau.

I'njakiku djundjun karapurom, malasku liang pariok njama,m, mahundjun kambang njaho,n tarong,m, njangkela,m kola,n garing idje beken, tarigatang salatan kilat tinting,m manjarak hamputa,m sihong due lain.

Tarong rohong tau kanuah anak Djata lampang, tinting tujang pandai kanjambong busu,n Hatala hadurut.

Hatontong manuwe bulau pungkal radja, hatinggang manawing rabia tisik tambon limbah nantolak ambon barutas matei, ulek manjangka enon bapilo nihau.

I'njakiku bulau awan tan$d o k, m$, babalang kambang njaho,n tarong lompat lawang labeho,n langit, sariangkat salatan kilat tinting, $m$ nasa lambang bulan barigantong. die Enden des Haares, des langen, vorbeigehen möge das Schaden $\mathbf{z u}$ fügende Unheil der Wolken, der vernichtenden des Todes, vorüberziehen mögen die Krankheiten verursachenden Tauwolken, die zerstörenden des Verlorenen.

Ich bestreiche deine Fontanelle, ich wische ab den steinernen Tiegel des Atems, es werde erhöht die Blume deines rauschenden Ruhmes inmitten deiner Verwandten (d.h. man wird ihn in poetischen Redewendungen besingen), es erhebe sich dein brausender blitzender Lobpreis und er wird auf die Seite schieben den von zwei andern deines Geschlechtes.

Und der Ruhm des Dolches kann aufrufen das Kind der Djata, dass es aufsteige aus den Wassern, und das Lob des Gewiegten vermag emporzusteigen, sodass herunterkommt der Jüngste des Hatala.

Und weiterhin vermag es zu erwerben das Gold, das königlich geschmiedete, und es kann als Besitz erlangen die goldenen Schuppen der Wasserschlange, nachdem weggestossen sind die Wolken, die vernichtenden des Todes, nachdem aufgehoben sind die Tauwolken, die verderblichen des Verlorenen.

Ich bestreiche deine goldenen Augen und es werden erscheinen die Blumen deines donnernden Ruhmes, die da aufsteigen bis $\mathrm{zu}$ der Wassertiefe des Himmels (d.h. bis in die Mitte des Himmels und bis zum Zugang zur Oberwelt), und es wird sich erheben dein rauschendes blitzendes Lob und 
Babalang kambang njaho,n Und es werden erscheinen die Blumen

tarong, $m$ mangumbang lewu, deines donnernden Ruhmes und sie mandereh danum.

Batentang tinting, $m$ manasa rundong hapamantai tambon limbah manolak ambon barutas matei, ulek manjangka enon bapilo nihau.

I'njakiku bulu,n langkang,m, kamalangkang kambang njaho,n tarong, $m$ hatontong manuwe bulau pungkal radja, hatingang manawing rabia tisik tambon.

I'njakiku totok urong, $m$, tanturong penjang karuhei tatau, paturong sangkalemo radja, tanturong sangkamanang dagang.

Karuhei parei, sandik sampu,n banian, limbah nantolak ambon barutas matei, ulek manjangka enon bapilo nihau.

I'njakiku pipi,m, mipi hagagian panganduang ambon barutas matei, panjakatin enon

er wird emporsteigen bis zur Schwelle des Mondes, des in der Höhe sich befindlichen. werden herumziehen in den Dörfern und herumschweifen längs den Flüssen.

Und es wird offenbar werden dein Ruhm und er wird durch die Dörfer an den Ufern der Wasserschlange gehen, nachdem weggestossen sind die Wolken, die vernichtenden des Todes, nachdem aufgehoben sind die Tauwolken, die verderblichen des Verlorenen.

Ich bestreiche deine ausstehenden Körperhaare und weit hervorragen sollen die Blumen deines donnernden Ruhmes und es möge dir gelingen das geschmiedete königliche Gold zu erwerben und in den Besitz zu kommen der goldenen Schuppen der Wasserschlange.

Ich bestreiche die Spitze deiner Nase, es sollen sich dir nähern die Penjang, die glückbringenden Mittel des Reichtums, die Paturong Sangkalemo Radja, es mögen zu dir kommen die Sieger im Handel.

Die glückbringenden Mittel für den Reisbau, die Bündel der Banianglücksmittel, nachdem weggestossen sind die Wolken, die vernichtenden des Todes, nachdem aufgehoben sind die Tauwolken, die zerstörenden des Verlorenen.

Ich bestreiche deine Seiten (d.h. die Wangen), auf die Seite müssen gehen und sollen weggestossen werden das 
bapilo nihau.

Panganduang kalingo rutos, karendem robo, langisan tangis, tantuman tatom, njaho,n bulau sangkowak raung, kilat limban basaloh langit.
Terai manganduang entang, ombet njakati tujang.

I'njakiku balengkong ti$n g a n g, m$, mangat batengkong kambang njaho,n tarong,m, njampenda njaho batengkong ikau dia giring bulu,m, njalulok kilat hapantap dia gandjai tolang,m.

Mangat entang kanuah anak Djata lampang, pandai tujang kanjambong busu,n Hatala hadurut.

I'njakiku hundjun baham, ka-
Schaden zufügende Unheil der Wolken, der vernichtenden des Todes, die Krankheiten der Tauwolken, der verderblichen des Verlorenen.

Den Schaden zufügenden Zauber, der da verursacht hat die Traurigkeit des Innern, das ratlose Herz, das Weinen und Schluchzen, die Wehklage und das Trauerlied, den Donner der goldenen Späne des Sarges, den Blitz des Leichenwassers, der verwandelt ist in Himmel (wahrscheinlich: in Wolken die sich über die Verwandten des Toten legen als Ambon Barutas Matei).

Sie sollen aufhören Schaden zuzufügen dem Getragenen, sie sollen enden krank zu machen den Gewiegten.

Ich bestreiche die Kehle, deinen Nashornvogel, damit laut erschallen die Blumen deines donnernden Ruhmes, auf dass beim ausbrechenden dröhnenden Donner nicht in die Höhe stehen deine Körperhaare (man nennt das darem bulu: das Fieber der Körperhaare oder wie wir sagen: eine Hühnerhaut bekommen, was gewöhnlich nach einem kalten Regen geschieht. Der Dajak beginnt dann zu frieren und fühlt sich krank), auf dass inmitten der zuckenden Blitze nicht gelähmt werden deine Knochen.

Auf dass der Getragene angerufen werde von dem Kinde der Djata, dem aus dem Wasser aufsteigenden, auf dass er angerufen werde vom Jüngsten des Hatala, der da herniederfährt (beide kommen um dem Menschen tuah: Heil, Glück, zu geben).

Ich bestreiche dich auf deinen Schul- 
sampahan penjang karuhei tatau, kasampahan paturong sangkalemo radja.

Kasampahan njalong kaharingan belom, gohong kapaninting tahaseng, entang belom bahaseng pandjang, tujang haring banjame ambo.

I'njakiku rakuren baro,m, marakuren peteh liau matei, djandjin pangambon nihau, ontong balang belom, ukur tampuli hamaring.

Panganduang dahiang bakamatei, panjakatin baja baka nihau.

I'njakiku likut,m, talikut dengan peteh liau matei, kare djandjin pangambon nihau.

Hatalikut dengan tahaseng tapas, saheroi korang.

I'njakiku bulau repang samben, manaharep njalong kaharingan belom, gohong kapaninting tahaseng. tern, hängen bleiben mögen an dir die Karuhei des Reichtums, festsetzen mögen sich auf dir die Paturong Sangkalemo Radja.

Kleben bleiben möge an dir das Wasser des Lebens, das lebenschaffende, das Wasser, der Reiniger des Atems, und der Getragene lebe mit einem langen Atem und der Gewiegte lebe mit einem grossen Munde (Atem).

Ich bestreiche die Rückscite doincs Oberkleides, auf die Rückseite sollen sich begeben die Befehle der Liau des Verstorbenen, die Aufträge der Pangambon des Verlorenen, der Gewinn (auch: Glück, Heil) der da nur rückgängig macht das Leben, das Mass, das da nur umkehrt das Lebende (die Liau schaden dem Menschen und wollen ihn in ihre Gemeinschaft mitnehmen und deshalb fügen sie ihm nur Unheil zu das sein Leben verkürzen soll).

Das Schaden zufügende Unheil der Vorzeichen, die da Tod bedeuten, die Krankheiten der Omen, die da Verlorenheit voraussagen.

Ich bestreiche deinen Rücken und du wirst den Rücken zukehren allen Befehlen der Liau des Verstorbenen, allen Aufträgen der Pangambon des Verlorenen.

Und du wirst den Rücken zukehren dem Atem, dem $z u$ wenigen, dem Atem der nicht hinreichend ist.

Ich bestreiche deine goldenen Ketten der Perlen und du wirst herzutreten zum Wasser des Lebens, dem lebenschaffenden, zum Wasser, dem Reiniger des Atems. 
Manaharep kaju,n karuhei parei, sandik sampu,n lu-banian.

Manaharep kaju,n karuhei tatau, manaharep karuhei dohong bapaju dagang, pasihan buno batuluk bungkal.

Mangat sama kanuah anak Djata lampang, kanjambong busu,n Hatala hadurut limbah nantolak ambon barutas matei, ulek manjangka enon bapilo nihau.

I'njakiku balikat,m, la-talikat ikau dengan nupi papa, gajap gampa ganggepan ganggerang.

Hatalikat ikau dengan dahiang badjangkang, baja badjawo.

Kare dahiang baratus gangguranan ara,e, baja baribu sasabutan biti,e.

I'njakiku utut tantungan tolang, batuntut ikau dengan rawei awang balemo, tisoi badjambulei, batuntut dengan simpei penjang, karuhei tatau, sandik paturong sangkalemo radja.
Und du wirst dich nähern dem Holze der Karuhei des Reisbaues, den Bündeln der glückbringenden Mittel für das Aussäen des Reises.

Und du wirst herzutreten $z u$ den Karuhei des Reichtums, und du wirst dich nähern den Karuhei des Dolches, die da machen, dass deine Handelsgüter guten Absatz finden, den Pasihan der Lanze, die dein Geschmiedetes rasch absetzen lassen.

Auf dass du gleichzeitig auch aufgerufen werdest von dem Kinde der Djata, dem aus dem Wasser auftauchenden, auf dass du aufgerufen werdest vom Jüngsten des Hatala, dem herniederfahrenden, nachdem weggestossen sind die Wolken, die vernichtenden des Todes, nachdem aufgehoben sind die Tauwolken, die verderblichen des Verlorenen.

Ich bestreiche deine Seite und auf die Seite sollen geschoben werden alle schlechten Träume und alles ungünstige Sprechen im Schlafe, in dem dich anpackt unheilbringender Donner.

Und auf die Seite sollen geschoben werden alle Vorzeichen, die viel Raum einnehmenden, alle Omen, die dick ausstehenden.

Alle Vorzeichen mit hunderten von Namen und Bezeichnungen, alle Omen mit tausenden ihrer Benennungen.

Ich bestreiche deine Kniee, die aneinandergefïgten Knochen, zugefügt mögen dir werden die Worte, die zarten, die Reden, die freundlichen, zugefügt mögen dir werden die Bündel der Penjang, die Karuhei des Reichtums, die Bündel der Paturong Sang- 
kalemo Radja.

I'njakiku tambang takep, $m$, Ich bestreiche die Kniekehlen deiner nambang nakep karuhei ma- Beine, damit du erwarten und entnuwe bulau pungkal radja, gegengehen könnest den Karuhei zur pasihan manawing rabia tisik Erwerbung des goldenen, königlichen tambon, karuhei dohong habambang batu, pasihan pulang hatikap liang.

I'njakiku ruror,m mumpong penjang karuhei tatau, paturong sangkalemo radja, mumpong karuhei entang maniring sara,n tana lombah.

Mangat tau hatontong manuwe bulau kambang ambon, hatinggang manawing rabia keka enon.

I'njakiku buko laling, $m$ hila luar, maling maluar peteh ontong pandak, kare djandjin pangambon nihau.

Maling maluar nupi papa, gajap gampa ganggepan ganggerang.

Ontong awang balang belom, ukur awang hatampuli hamaring.

I'njakiku buko laling,m hila huang,e, bataling aseng entang belom, bunggut njama,n tujang haring.

Schmiedewerkes, die Pasihan für den Ankauf der goldenen Schuppen der Wasserschlange, die Karuhei des Dolches, des ausgehauenen Steines, die Pasihan des Griffes aus dem ausgemeisselten Stein.

Ich bestreiche dein Schienbein, damit es dir möglich sei zu versammeln die Penjang der Karuhei des Reichtums, die Paturong Sangkalemo Radja, zu versammeln die Karuhei, damit die Getragenen ausbreiten können die Ränder der Felder, der breiten.

Und dass es dir hernach möglich sei $z \mathfrak{u}$ erwerben die goldenen Blumen der Wolken, $z \mathbf{u}$ erlangen die goldenen Blüten der Tauwolken.

Ich bestreiche dein Fussgelenk auf der Aussenseite, vertrocknen und auf die Aussenseite mögen geworfen werden die Befehle des kurz dauernden Glükkes der Liau, die Aufträge der Pangambon, des Verlorenen.

Vertrocknen und weggeworfen mögen werden alle schlechten Träume, alles ungünstige Sprechen im Schlaf, in dem du angepackt wirst durch donnerndes Unheil.

Das Glück welches nur vereitelt die Möglichkeit zum leben, das Mass welches nur umkehrt das Gedeihen. Ich bestreiche dein Fussgelenk auf der Innenseite, dauerhaft sei der Atem des Getragenen, des lebenden, fest sei der Mund des Gewiegten, des gedeihenden. 
Tau belom batahaseng batu dia tau una, tujang haring banjame liang kueh tau rugi.

I'njakiku likut tatap, $m$, malapatap panganduang ambon barutas matei, panjakatin enon bapilo nihau, panganduang njaho,n bulau sangkowak raung, kilat limban basaloh langit, langisan tangis, tantuman tatom.

Mangat entang batalampas kilau bulus kumpang malem, mangat tujang basampelau tingkah kaju,n sanggalang garing.

I'njakiku totok tundjok,m panjurong panandjong manjurong penjang karuhei tatau.

I'njakiku tapadjaka,m tambang, $m$ midjak petak kasambujan tambon, bahekeng kereng kasinta radja, awang Djata katontong batuah, Hatala gawan balambit.

I'njakiku kukot,m, mukot penjang karuhei tatau, paturong sangkalemo radja.
Dass er leben könne mit einem Atem der wie von Stein ist und der nicht vermindern kann, dass der Gewiegte gedeihe mit einem Munde wie von Stein, der keinen Verlust erleide.

Ich bestreiche die Hinterseite deiner Fussohle, zertreten mögest du alles Unheil der Wolken, der vernichtenden des Todes, die Krankheiten der Tauwolken, der verderblichen des Verlorenen, das Unheil des Donners der goldenen Späne des Sarges, die Blitze des Leichenwassers, die verwandelt wurden in Himmel, das Weinen und Schluchzen, die Wehklage und das Totenlied.

Auf dass der Getragene wieder frei stehe wie ein Baum, der für sich allein steht, auf dass es offen sei um den Gewiegten herum wie um das $\mathrm{Holz}$ des alten Elfenbeines (alter, hoher Baum).

Ich bestreiche die Spitzen deiner Zehen, auf dass sie schnell zu gehen vermögen und überall herumlaufen um zu erreichen die Penjang Karuhei des Reichtums.

Ich bestreiche den Anfang deiner Füsse, auf dass sie betreten mögen die Erde, die fruchtbare der Wasserschlange, auf dass sie beschreiten mögen die Hügel der Liebe des Königs, auf dass die Djata vermehre das Glück, auf dass Hatala verlängere das Heil.

Ich bestreiche das Gelenk über deiner Hand, damit du zu dir zu nehmen vermögest die Penjang Karuhei des Reichtums, die Paturong Sangkalemo Radja. 
Mukot njalong kaharingan belom, gohong kapaninting tahaseng.

Mukot sapalinda njalong bukit batu, sapaajah luhing kereng liang, mangat dohong tau mamidjang baner tapang, te pulang pandai manetes rantai garantong.

Kasadingen darah manok darong tingang, kasadingen tahaseng entang.

\section{b. Das Beissen auf das Eisen}

Toh oloh idje injaki te mangirut sanaman pisau, gene-genep biti,n ewen idje injaki amon hapus saki.

Koa,n upo,n balian:

Katekang sanaman, katekang hambaruan, kahiring dohong, kahiring aseng entang.
Auf dass du zu dir nehmen könnest das Wasser des Lebens, das lebenschaffende, das Wasser, den Reiniger des Atems.

Damit du zu erwerben vermögest den Herbeilocker des Wassers des Berges, des steinernen (ein heiliger Topf), damit es dir möglich sei zu erhalien den Herbeirufer der aufragenden Hügel, der felsigen (ein heiliger Topf), damit der Dolch aufbrechen könne die Wurzeln des Tapangbaumes (Lebensbaum), auf dass der Griff abzuhauen vermöge die Ketten der Garantong. * Kalt ist das Blut des Huhnes, des Huhnes der Tingang, kalt sei auch der Atem des Getragenen.

Die Leute welche mit Hühnerblut bestrichen worden sind, beissen nun auf das Eisen eines Buschmessers, jeder Einzelne von denen die bestrichen wurden, handelt auf diese Weise nach der Bestreichung.

Und es spricht der Hauptbalian:

Die Härte des Eisens sei auch die Härte der Seele, die Schärfe des Dolches sei auch die Schärfe des Atems des Getragenen.

\section{c. Die Reinigung der Frauen mit Hühnerblut}

I'njakiku entang, malasku tu- Ich bestreiche dich Getragene, ich jang, kasadingen darah manok wische dich ab Gewiegte, kalt ist das

\footnotetext{
* Auf den Zeichnungen der Lebensbäume sehen wir neben dem Stamm zwei Gong angelehnt. Der Segenswunsch bedeutet, dass der Getragene sich Gong erwerben könne und so immer weiterschreite bei der Erwerbung des Reichtums der im Lebensbaum zusammengefasst dargestellt wird. Zuerst ist aber der heilige Topf nötig, der hier auch an erster Stelle genannt wird, denn aus diesem sprossen die Wurzeln des Lebensbaumes aus.
} 
darong tingang, kasadingen aseng entang.

Saki,n manolak ambon barutas matei, palas manjangka enon bapilo nihau.

Njakiku ikau djumban bulau, malasku dare,n tanggoi rabia, mengkak panganduang ambon barutas matei, panjakatin enon bapilo nihau.

Toh sama ih auch injewut,e ttg. eka mohos daha,n manok dengan manjaki oloh hatue, baja beken tampara bewei.
Blut des Huhnes, des Huhnes Tingang, kalt sei auch der Atem der Getragenen.

Die Bestreichung zur Wegstossung der Wolken, der vernichtenden des Todes, die Abwischung zur Wegschiebung der Tauwolken, der verderblichen des Verlorenen.

Ich wische dich ab, goldene Kopfbedeckung, ich bestreiche dich mit Blut, goldener, geflochtener Hut, ich löse von dir das Unheil der Wolken, der vernichtenden des Todes, der Krankheiten der Tauwolken, der verderblichen des Verlorenen.

Weiter sind die Worte, die ausgesprochen werden, die gleichen und auch die Körperteile, die bestrichen werden, bleiben sich gleich wie bei den Männern, nur der Anfang lautet etwas anders.

\section{d. Das Schwingen des Besens über den Köpfen der Verwandten}

Toh oloh mamapas manjun. dawen kaju hundjun takolok tempo,n pampatei, koa,e :
Nun schwingen sie die Baumblätter (den Besen) über den Köpfen der Besitzer des Todes (der Verwandten des Toten) und wischen sie ab, indem sie dazu singen :

I'aju-ajun bulau tampong Ich schwinge den goldenen Büschel papas, umba-umban rabia tundon kalingking, dawen taberau bungai, dawen kadjandjalau tandjong kalalua luwok, dawen pilang tanggoi njaho, dawen tangaring balang, dawen sawang gagar, djadi imbisaku hapan danum njanjah, danum karak hapan mangarak ambon barutas des Besens, ich schwenke den goldenen Tross des Besens, die Blätter Taberau Bungai, die Blätter Kadjandjalau Tandjong, Kalalua Luwok, die Blätter Pilang Tanggoi Njaho, die Blätter Tangaring Balang, die Blätter Sawang Gagar, ich habe sie benetzt mit dem kräftigen Wasser, ich habe sie befeuchtet mit dem abbrechenden Wasser, um abzubrechen die Wolken, die 
matei, manuhas enon bapilo nihau.

Bataladjok buno bakaharis rajong baja tandang, indjam$\mathrm{ku}$ dohong bahiring sara,e hapa mamapas manantapei ambon barutas matei, manantiup panjakatin enon bapilo nihau, hapaku manalampas entang bakawan kilau burong tingang, manjampelau tujang bapumpon tingkah tandang haramaung.

Mangat entang batalampas bara njaho,n bulau sangkowak raung, kilat limban basaloh langit, langisan tangis, tantuman tatom.

Mangat entang batalampas bara dahiang baratus gangguranan ara,e, baja baribu sasabutan biti,e.

Limbah aku mampang entang kilau haur garing ttg. kanuah anak Djata lampang, ulek aku ngalingking tujang kilau dereh sawang, te tau kanjambong busu,n Hatala hadurut hatontong manuwe bulau pungkal radja, hatinggang manawing rabia tisik tambon sangkelang midjang luhing baner tapang, sampale ma- vernichtenden des Todes, um niederzureissen die Tauwolken, die verderblichen des Verlorenen.

Die eben ausspriessenden Blätter, die so scharf sind wie Dolche, wie die Zähne der Tiger, ich habe mir geliehen den Dolch, den auf den Seiten scharfen, um abzuwischen und aufzuheben die Wolken, die vernichtenden des Todes, um aufzuheben die Krankheiten der Tauwolken, der verderblichen des Verlorenen, um freistehend zu machen die Getragenen, die in Herden zusammen sind wie die Nashornvögel, um offen stehen $z \mathfrak{u}$ machen die Gewiegten, die da versammelt sind wie die Zähne der Tiger.

Auf dass der Getragene wieder befreit sei von dem Donner der goldenen Späne des Sarges, von dem Blitze des Leichenwassers, das verwandelt ist in Himmel, von dem Weinen und Schluchzen, von der Wehklage und dem Totenlied.

Auf dass der Getragene wieder frei sei von den Vorzeichen mit hunderten Benennungen und Namen, von den Omen mit tausenden ihrer Bezeichnungen.

Nachdem ich gesäubert habe den Getragenen, so wie man säubert den elfenbeinernen Bambus (den man mit Spänen abreibt, sodass alle Unreinigkeiten verschwinden) und er wieder angerufen wird von dem auftauchenden Kind der Djata, nachden ich abgewischt habe den Gewiegten so wie man abwischt den Stab der Sawangstaude und er wieder angerufen wird von dem Jüngsten des Hatala, 
netes telon rantai garantong. der da herniederfährt, dann kann er sich wiederum erwerben königlich geschmiedetes Gold und er kann in seinen Besitz bringen die goldenen Schuppen der Wasserschlange, zusammen mit den aussprossenden Brettwurzeln des Stammes (es sind die Gong, die gegen den Lebensbaum angelehnt sind), vermengt mit den abgeschnittenen Hängern der Ketten der Gong.

Sangkelang manampong bulau kambang ambon dengan manundun rabia kekah enon.

Hatontong entang nupi penjang, hatinggang tujang mangampa paturong mangat gulong entang tiwah tingang, basikap tujang mangkut aoi burong.

Hatalatai lunok belom bahalap mamua undan, malempang baras bulau lampang hapasang darah bakurangan penjang, gulong njaho hai naparugoh tungkup, kilat pandjang napurendjet ruang, amon entang hatontong nuah anak Djata lampang, hatinggang njambong busu,n Hatala hadurut.

Und dann kann er wieder aufhäufen die goldenen Blumen der Wolken und er kann wieder zusammenbündeln die goldenen Blüten der Tauwolken.

Und dann wird der Getragene auch träumen von Penjang und der Gewiegte wird im Schlafe sprechen von Paturong und bald hernach wird er veranstalten können das Tiwah des Tingang, und bald wird er feiern können das Aoi (ebenfalls Tiwah) des Vogels.

Und dann wird der lebende schöne Lunok beginnen Undanfrüchte zu tragen (Kopfjagd), und im Flussbett wird der goldene Sand sichtbar und er wird aufbrodeln zusammen mit dem Blut, in dem eingeschlossen sind Penjang (Kopfjagd oder auch Menschenopfer), und dann wird der grosse Donner zum Erbeben bringen die ganze Verwandtschaft und der lang zuckende Blitz wird erzittern machen das Haus, dann wenn der Getragene wieder aufgerufen wird von dem auftauchenden Kind der Djata, dann wenn der Gewiegte angerufen wird von dem herunterfahrenden Jüngsten des Hatala.

Te bagulong mumpong riak Und dann wogen zusammen die Wel- 
sambang bulau nansaran batu bangkalan lunok, basikap nundon ringkin garo rabia nampuisat liang kantihan baras bulau lampang.

\section{Mangat gulong manansaran} dohong handepang Telon, nampuisat pulang tenong pantin Hamparong, mangat djeleng entang hadjawi tingang hajak menjang garo,n tandak Sangiang bawi pekas penjang, habinei tadjor 387 dahiang.

\section{Mangat bagulong manandjuri bulau idje tilai tingang hapan manatah luhing pantong ti- ngang, mangat basikap ma- nantekei minjak rason radja hapa nandjaho lingkat tan- dang haramaung. \\ Mangat entang belom nga- rongkong garo,n tandak Sangiang.}

Amon hapus auch,e ie mahantok papas dawen kaju te intu gagenep takolok oloh huang huma hajak ewen handiai maludja papas te.

Metoh balian mahantok papas te, balian kakarungut, koa,e: len der goldenen Trommel und sie rauschen zu den Seiten des Lunok hin und her wie ein Schleifstein, den man hin und her bewegt, und dann steigen auf die Wolken des goldenen Weihrauches zu den beiden Seiten des auftauchenden goldenen Sandes.

Und dann werden bald überall herumgehen können die Dolche um abzuholen den Telon, und es werden herumgehen können die Griffe um einzuladen den Hamparong (Telon und Hamparong leiten unter Führung des Tempon Telon die Liau nach dem Totendorf), und dann werden die Getragenen rasch leihen können die Tingang und sie werden als Penjang gebrauchen können die duftenden Gesänge der Sangiang, der Frauen, die Penjang, die man in Dienst nahm, die Frauen, die eingefädelten Vorzeichen. Und dann wird rasch herausfliessen das Gold, das gerechnet wird $z u$ den Tingang um $z u$ beträufeln das aufrechtstehende Horn des Nashornvogels, und es wird hervorkommen das Oel des Königs um einzuölen den Schwanz und die Zähne des Tigers.

Damit die Getragenen leben kömnen, eingehüllt in den Weihrauch der Gesänge der Sangiang.

Wenn dieses Spruchwort beendet ist, berührt er mit dem Besen von Baumblättern alle Köpfe der Leute, welche sich in dem Hause befinden, und sie alle zusammen bespucken den Besen. Und während der Balian mit dem Besen die Köpfe berührt, singen die Balian, und ihr Gesang lautet: 
I'hantokku djalambat manjanggah djundjun karipuron entang, idje, due, telo, sanselo pangalambi,n ambon barutas matei sama lompat bulau tampong papas, panjakatin enon bapilo nihau djakat rabia tundon kalalingking.

Toh djari hapus ie manjun tampong papas mangumbang huma, ie malekak papas te intu laseh bentok huma.
Ich berühre mit dir sanft den Kopf und lege dich auf die Fontanelle des Getragenen, eins, zwei, drei, dränge dich herzu Unheil der Wolken, der vernichtenden des Todes, besteiget den goldenen Büschel des Besens, Krankheiten der Tauwolken, der verderblichen des Verlorenen, erklimmet den Bündel des Besens.

Beendet hat der Balian nun das Schwingen des Besens während er im Hause herumging und er legt nun den Besen wieder nieder auf den Fussboden des Hauses.

\section{e. Die Balian bringen die Bambusse zum Knallen}

Toh oloh mamapui humbang idje akan salentup.

Karee tetek humbang te handue udju katetek.

Maka amon humbang te djari imapui ombe-ombet awi ewen tempo,n huma, te ie mandjulok,e akan ewen oloh balian palus ewen oloh balian mumukul humbang te intu kaju ramo,n huma hajak tanda-tandak ie malalus gawi manjalentup, koa,n tandak,e:

I'kakanderang humbang rendan tingang, rarakungkong sempeng kanarohong antang.

Mindjam njaho,n ikau badil tambon ain Rawing Tempon Telon, nasih asep sandawa laut Lumba Habaron Bulau.
Die Leute verbrennen nun den Bambus, der zum Knallen bestimmt ist. Die Gesamtzahl der Bambusstäbe beträgt zweimal sieben Stäbe.

Nachdem die Bambusstöcke genügend angebrannt worden sind von den Besitzern des Hauses, überreichen sie sie den Balian und die Balian schlagen mit den Bambusstöcken auf das Holzwerk des Hauses und singend verrichten sie die Arbeit des Knallens, und ihr Gesang lautet:

Schreie wie ein Nashornvogel, gefranster Bambus des Tingang, brülle auf wie ein Tiger, Bambus, Dolch des Antang.

Leihe dir den Donner der Kanone, Wasserschlange, die dem Rawing Tempon Telon gehört, leihe dir den Rauch des Pulvers von Uebersee, des Krokodiles bekleidet mit dem Ober- 
Bahalap babuku entang, bababerang hanji, mandawen dohong bakatantan ambon barutas matei, bataladjok buno baharis enon bapilo nihau.

Hapaku manembak maliambong ambon barutas matei, njaho,n bulau sangkowak raung, kilat limban basaloh langit, langisan tangis, tantuman tatom, kare dahiang badjangkang, baja tandang badjawo.

Baratus gangguaran ara,e, sarubi sasabutan biti,e, hapa manalampas entang palus manalampas parong, $m$ mangentang, pandai aku manjampelang tujang pulus njampelang siro njaripangku.

Mangat entang rata batalampas kilau bulus kumpang malem, tujang basampelau tingkah kaju,n sanggalang garing.

Toh djadi hapus ewen manjalentup humbang, salentup te imeteng hapan uei mandjadi idje kapeteng dengan tam- kleid von Gold (ein anderer Name für Tempon Telon).

Schöne Knorren des Mutes hast du, Knorren der Tapferkeit, und du trägst Blätter wie Dolche, die da durchhauen die Wolken, die vernichtenden des Todes, deine hervorspriessenden Blätter sind scharf wie Lanzen, die da durchschneiden die Tauwolken, die verderblichen des Verlorenen.

Ich gebrauche dich um zu schiessen und in die Höhe zu schleudern die Wolken, die vernichtenden des Todes, die donnernden goldenen Späne des Sarges, den Blitz des Leichenwassers, das verändert ist in Himmel, das Weinen und Schluchzen, die Wehklage und das Totenlied, alle viel Raum einnehmenden Vorzeichen, alle Omen, die hervorstehen wie Zähne.

Hunderte sind ihrer Namen und Bezeichnungen, tausende ihrer Benennungen um zu erlösen den Getragenen und frei zu stellen das Haus, in dem man das Tragwerk verrichtet, um offen stellen zu können den Gewiegten und frei zu stellen die Wohnung, in der man das auf den Schoss nehmen vollzieht.

Auf dass die Getragenen alle zusammen wieder frei stehen mögen wie ein Baum, auf dass die Gewiegten wieder offen stehen mögen wie der hohe Baum, der elfenbeinerne, der über die andern hinausragt.

Beendet ist das Knallen mit den Bambus und die knallenden Bambusstöcke werden nun dicht gebunden mit einem Rotan zusammen mit dem 
pong papas endau, kareh Bund des Besens und hernach werden mimbit,e mandjakah akan da- sie mitgebracht um ins Wasser genum hajak oloh balian mohon worfen $z u$ werden, dann wenn die tantolak intu bau,n tiwing Balian für die Wegschiebungszerebatang danum. monien hinuntersteigen zum Ufer des Flusses.

\section{f. Die Balian berïhren mit dem Schnitzbild die Köpfe der Verwandten}

Toh oloh balian manandjong mangumbang huang huma manjun hampatong uei hajak mahantok,e intu takolok oloh tempo,n pampatei.

Ie tanda-tandak, koa,e:

I'ajun-ajun hampatong uei rantihen tingang, umba-umban sadiri,n nampa upak lulong pamali hapa manangkiri salumpok entang bara ambon barutas matei, akan talimbas tanterus tujang bara enon bapilo nihau.

Mangat entang dia takalong tingak liau 388 buang matei, uka tujang djaton tanggenggem pudji,n awo badjumbang.

Entang dehen ngarambang penjang Sangiang, tujang djiret hambalat paturong $\mathrm{Dja}$ lajan.

Toh ie mahantok hampatong uei te, koa,e :
Nun machen sich die Balian auf und schreiten im ganzen Hause herum und sie schwingen das menschliche Schnitzbild von Rotan und berühren mit ihm die Köpfe der Besitzer des Todes. Sie singen dazu, und ihr Gesang lautet:

Wir schwingen das menschliche Schnitzbild von Rantihen-TingangRotan, wir schwenken den Stellvertreter, der gemacht wurde von der Rinde des Holzes aus dem heiligen Hain, um auszulösen die Seelen der Getragenen von den Wolken, den vernichtenden des Todes, um auszutauschen die Seelen der Gewiegten von den Tauwolken, den verderblichen des Verlorenen.

Auf dass der Getragene nicht umringt werde von den Ermahnungen der Liau, der ergebnislos gestorbenen, damit der Gewiegte nicht umzingelt werde von den Erinnerungen der Awo, der umgefallenen.

Damit der Getragene fest dastehen könne, eingezäunt durch die Penjang der Sangiang, damit der Gewiegte stark dastehe, umwandet von den $\mathrm{Pa}$ turong der Djalajan.

Nun berührt er mit dem menschlichen Schnitzbild die Köpfe der Verwandten des Toten und spricht dazu: 
Hantokku djalalambat intu Ich berühre sanft euere Fontanellen, djundjun karipuron keton o ihr Getragenen.

entang.

Hampatong uei rantihen ti- Ich berühre sie mit dem menschlichen ngang, sadiri nampa upak Schnitzbilde von Rantihen-Tinganglulong pamali kalompatan Rotan, mit dem Stellvertreter, der gehajak panganduang ambon macht wurde von der Rinde des Holzes barutas matei, kadjakatan aus dem heiligen Hain, damit es (das hindje panjakatin enon ba- Schnitzbild) bestiegen werde von dem pilo nihau, idje, due, telo, Unheil der Wolken, der vernichtenden sama sanselo ikau lompat des Todes, damit es erklommen werde hampatong uei rantihen tingang. von den Krankheiten der Tauwolken, der verderblichen des Verlorenen, eins, zwei, drei, drängt euch nun alle her$\mathrm{zu}$ und besteigt das menschliche Schnitzbild von Rantihen-TingangRotan.

Toh ewen idje tempo,n pamSie, die Besitzer des Todes (die Verwandten des Toten), bespucken nun alle das Schnitzbild von Rotan und es wird darnach weggelegt $\mathrm{zu}$ dem Bündel der knallenden Bambusstöcke in der Mitte des Hauses.

Huang peteng humbang te ewen mingkes, intu bangu,n enjoh, papui manok korik bula-bulat, djete akan indjakah kea hajak humbang salentup kareh. Panginan te akan ambon barutas matei.

In den Bündel der knallenden Bambusstöcke legen sie, in einer Kokosschale, ein geröstetes kleines Huhn, das nicht zerschnitten wurde und dieses wird auch weggeworfen mit den knallenden Bambusstöcken. Diese Speise ist bestimmt für die Wolken, die vernichtenden des Todes.

\section{H. Die Vertreibung der Ambon Barutas Matei aus dem Haus}

\section{a. Die Durchschneidung der Ambon Barutas Matei}

Toh tinai oloh balian malalus gawi manantesan ambon barutas matei.

Idje biti oloh balian mimbing
Nun verrichten die Balian die Handlungen des Durchschneidens der Wolken, der vernichtenden des Todes. Einer der Balian ergreift ein Busch- 
pisau manandjong nampara manantesan ambon barutas matei bara huma dapur miar djala-djalan akan bauntonggang huma, ie manedjep lowalowah kaju ramo,n huma hajak tanda-tandak manantesan ambon barutas matei, koa,e :

I'nete-netep ikau gana,n penjang karuhei tatau, hadjihadjip labata,n paturong sangkalemo radja melai pati bahandang, medjen tabala radja.

Ela ikau tarewen matei, isen ikau kasabanen nihau.

Djalangku nantesan ambon barutas matei, maharis enon bapilo nihau, manalampas parong entang, manjampelau siro,n tujang.

Mangat parong hai palalendang, siro datoh palalingei, terai kangampoh ambon barutas matei.

Mangat entang belom huang parong, belom mangat, njanjam-haring kanandang rasang. messer und er schreitet mit ihm herum und beginnt durchzuschneiden die Wolken, die vernichtenden des Todes, anfangend beim Küchengebäude und von dort geht er langsam weiter bis zur Türe des Hauses, und er schlägt sanft auf alles Holzwerk des Hauses und singend durchschneidet er die Wolken, die vernichtenden des Todes, und sein Gesang lautet :

Halte dich standfest, o Seele der Penjang, der Karuhei des Reichtums, verweile unverrückt, Seele der Paturong Sangkalemo Radja, bleibe in der Kiste, der roten, verweile in der Truhe, der königlichen.

Nicht erschrecke zu sterben, nicht fürchte dich verloren zu gehen.

Während ich nun beschäftigt bin durchzuschneiden die Wolken, die vernichtenden des Todes, während ich durchhaue die Tauwolken, die verderblichen des Verlorenen, um frei zu stellen das Haus des Getragenen, um offen zu stellen die Wohnung des Gewiegten.

Auf dass das Haus wieder erscheine in grossem Glanze, damit die Wohnung wieder sichtbar werde in starkem Leuchten, und es nicht mehr verhüllt sei von den Wolken, den vernichtenden des Todes.

Auf dass der Getragene lebe im Hause und in ihm ein angenehmes Leben habe, auf dass er gedeihe wie ein freistehender Baum (der nicht von andern Bäumen und von Schlingpflanzen im Wachstum gehindert oder erstickt wird). 
I'sasarene indjamku dohong bahiring sara,e, nasihku buno balojang hampake hapaku nantesan ambon barutas matei.

I'nantesangku ambon barutas matei awang merem impa kilau bandong kajau, melai babalai djandjihin parong, melai babalai huang paramo,n parong.

Nantesangku ambon barutas matei, bageto paju,e kilau paju,n timpong batetes bambalia kilau riak henda,n bulau.

Bakupak ie kilau dare tahenteng garing batang pantar pandjang.

Balalak kilai lepo,n haur garing bakuhas tingkah nusang taberau bungai, te parong entang hai palalendang,e, siro,n tujang datoh palalingei,e.

Mangat malajan parong nganduang ambon barutas matei.
Grosses geschieht nun, ich leihe mir einen Dolch, der scharf ist an seinen Rändern, ich leihe mir einen Speer, der versehen ist mit Widerhaken um durchzuschneiden die Wolken, die vernichtenden des Todes.

Ich durchschneide die Wolken, die vernichtenden des Todes, die sich herabgesenkt haben und die uns auflauern wie Männer, wie Kopfjäger, die sich aufhalten auf den Pfosten des Hauses, die sich niedergelassen haben auf das Holzwerk der Wohnung.

Ich durchschneide die Wolken, die vernichtenden des Todes, zerrissen ist die Nachfrage nach ihnen, wie die Nachfrage nach Tuch, abgehauen ist ihr Kaufpreis, wie der Kaufpreis der Wellen der Gelbheit des Goldes (sie gelten nichts mehr, weil ihnen niemand mehr nachfragt).

Aufgelöst haben sie sich wie das Geflecht, der Schmuck des elfenbeinernen Pfahles, des Mastes, des langen (die Pfähle, die man beim Tiwah aufrichtet, werden mit geflochtenen Bändern verziert, die sich durch Hitze und Unwetter auflösen und dann wie zerrissen herunterhängen).

Entblättert sind sie wie die Baume. von denen heruntergefallen ist das Laub, vertrocknet sind sie wie die schrägwachsenden Taberau-Bungai, und nun wird das Haus des Getragenen dastehen in grossem Glanze, und nun wird die Wohnung der Gewiegten erscheinen in starkem Leuchten.

Und es wird aufhören, dass das Haus heimgesucht werde von dem Unheil der Wolken, der vernichtenden des 
I'mangat parong tinai hai palalendang tau parong rahasan dohong habambang batu, tau siro,n tujang djampenen pulang hatikap liang.

Tau parong eka hatalatai lunok belom babasong rundjan, pandai siro djampenan baras bulau lampang, manjahumpak njalong bukit batu.

Toh hapus auch nantesan mengkak ambon barutas matei.

Balian malekak pisau idje hapa,e intu laseh bentok huma hila bau,n ewen oloh balian.
Todes.

Und das Haus wird wiederum dastehen in grossem Glanze, und das Haus wird wieder der Ort werden der Verwandtschaft der Dolche, die aus Stein herausgehauen wurden, und die Wohnung der Gewiegten wird zum Sanmelplatz der Griffe, die herausgemeisselt wurden aus Stein.

Und das Haus wird wieder der Ort sein wo man nachsinnt wie der Lunok Wurzeln ausschlägt aus dem heiligen Topfe, und in der Wohnung wird man wieder nachdenken wie der Goldsand auftaucht, der da hervorquillt als Wasser aus dem Berge von Stein. (Man wird im Hause nachdenken wie man sich Reichtum erwirbt, der mit dem Lebensbaum verglichen wird, um später das Tiwah veranstalten zu können, denn das ist ja erst wieder möglich nach dem Tantolak matei.)

$\mathrm{Zu}$ Ende ist nun das Spruchwort des Durchschneidens und Lösens der Wolken, der vernichtenden des Todes.

Der Balian legt das Buschmesser, das er gebraucht hat, nieder auf den Fussboden in der Mitte des Hauses, vor dem Angesicht der Balian.

\section{b. Die Wegjagung der Ambon Barutas Matei aus dem Haus}

Toh idje biti oloh balian mendeng manatumbur ambon barutas matei.

Ie mimbit supak bangu idje imuat behas sampai kontep.

Toh ie manampara manatumbur ambon barutas matei bara huma dapur sampai behas tatumbur te inaburan balua
Es erhebt sich nun ein Balian um wegzujagen die Wolken, die vernichtenden des Todes.

Er bringt mit sich eine Kokosschale die vollständig mit Reis gefüllt ist. Und er beginnt nun die Handlung des Wegjagens der Wolken, der vernichtenden des Todes, beim Küchengebäude und streut den Wegjagungs- 
huma.

Koa,n tandak,e:

I'nete-netep ikau gana,n penjang karuhei tatau, hadjihadjip labata,n paturong sangkalemo radja, melai pati bahandang, medjan tabala radja huang tambok kameteng penjang. 389

Djalangku hataburan behas parei njangen tingang manatumbur pangalabien ambon barutas matei, panjakatin enon bapilo nihau.

Udjan dohong ikau idje kasamperai, rihen buno due kapamarau hapa mudjan mampang entang kilau haur garing, manjamperai mangalingking tujang tingkah dereh sawang.

Bakupak balo-balon kilau dare tahenteng batang pantar pandjang, balalak tingkah lepo,n haur garing, bakuhas tingkah nusang taberau bungai,

Kare panganduang njaho,n bulau sangkowak raung, panjakatin kilat limban basaloh langit, langisan tangis, tantuman tatom.

Palus manalampas parong entang, manjampelau siro,n tujang. reis aus bis vor das Haus hinaus.

Es lautet sein Gesang:

Halte dich standfest, o Seele der Penjang, der Karuhei des Reichtums, verweile unverrückt, Seele der Paturong Sangkalemo Radja, bleibe in der Kiste, der roten, verweile in der Truhe, der königlichen, halte dich auf in dem Körblein der Bündel der Penjang.

Während ich ausstreue den enthülsten Reis des Reises Njangen Tingang um wegzujagen das Unheil der Wolken, der vernichtenden des Todes, die Krankheiten der Tauwolken, der verderblichen des Verlorenen.

Ein Dolchregen bist du, welcher herunterrieselt, ein Staubregen von Lanzen bist du, welcher herabfällt und welcher beregnet und reinigt die Getragenen, so wie man reinigt den elfenbeinernen Bambus, welcher berieselt und abfegt den Gewiegten, so wie man abfegt den Stamm des Sawang.

Zerreissen und herabhängen sollen sie wie die Flechtereien, der Schmuck der Pfähle, der langen Masten, entblättert werden sollen sie wie die Bäume von denen abgefallen ist das Laub, vertrocknen sollen sie wie die schräg wachsenden Taberau-Bungai,

Sie, die Unheilsursachen der donnernden goldenen Späne des Sarges, die Krankheiten des blitzenden Leichenwassers, das verwandelt wurde in Himmel, das Weinen und Schluchzen, die Wehklage und das Totenlied.

Und frei steht das Haus des Getragenen, und offen erhebt sich die Wohnung des Gewiegten. 
Toh djadi ie manatumbur, Er hat nun beendet die Wegjagung bangu supak behas idje hapa,e und die Kokosschale, das Reismass ingkes,e intu bentok huma welches er gebraucht hat, wird niederdarah sangko atawa pasok gelegt in der Mitte des Hauses neben hambaruan. dem Gefäss oder dem Körbchen, die den Seelenreis enthalten.

\section{Die Sangiang vertreiben die Ambon Barutas Matei}

Nachdem alle Reinigungshandlungen von den Balian ausgeführt wurden, werden sie nun von den Sangiang wiederholt, denn die Handlungen der Balian sind nutzlos und machtlos wenn sie nicht von den Sangiang ausgeführt oder wiederholt werden. Diese Wiederholung findet nun statt und die Sangiang fahren zur Ausübung aller Handlungen in die Balian ein.

\section{a. Die Aufweckung der Sangiang und ihre Tätigkeit}

Kare oloh panggil ttg. ewen handiai injarongan hapan panginan en-en awi oloh tempo,n huma.

Maka amon djadi oloh kuman, te ewen oloh balian mondok intu katil eka,e balian, ewen manampara balian.

Huang tandak,e ie manahiu Sangiang idje djari turon aton huang genep biti,n ewen, Sangiang idje aton te mantehau Sangiang idje beken idje aton huang papan talawang luar huma, mantehau ewen te uka dumah akan huang huma manantan mengkak kare ambon barutas matei bara oloh tempo,n gawi, bara huma, bara kare ramo handiai .

Toh ewen mananto katambong ttg. manandak hapan
Alle Gäste und alle andern Anwesenden werden nun bewirtet von den Besitzern des Hauses mit etwas Speisen.

Nachdem die Leute gegessen haben, setzen sich die Balian auf die Bank, auf der sitzend sie die Balianhandlungen ausführen und sie beginnen nun mit den Handlungen.

Im Gesange erwähnen sie die Sangiang, die bereits herabgefahren sind und die sich in jeder Person von ihnen befinden, diese Sangiang, die in ihnen anwesend sind, rufen den andern, die sich noch in Schildbrette ausserhalb dem Hause befinden, sie rufen ihnen, damit sie ins Haus hereinkommen und durchschneiden und lösen alle Wolken, die vernichtenden des Todes, von den Besitzern der Arbeit, dem Hause und von allen andern Dingen zusammen.

Sie schlagen nun die kleinen Trommeln 
lago: manarindjet Sangiang, und sie singen nach der Melodie: die koa,e : Aufweckung der Sangiang und ihr Gesang lautet:

Lalu bahing, lalu bapanting Sangiang maneras bandong lasang.

Hajak siring la-bambahinga Djalajan maluhing gentoi laburong.

Lalu bahing panganak andau njalumbo parong kurong mangentang.

Bambahinga,n panjandai bulan manehos siro runtan saripangku.

Hajak malan balua parong dje manamuei papan talawang.

Lalu ringkang bahandjong siro mangadja patas bulau dare,n lintong.

Manarindjet tingang luSangiang idje keton huang papan talawang.

Manantugoh bungai Djalajan tatau medjen bulau dare,n lalintong.

Sama pararindjet hajak Sangiang huang papan talawang.

Rata pararugoh hindje Djalajan medjen bulau dare,n lintong.

Ngitar garing pandoka mon-

Es steigt auf das Wort und es wird ausgeworfen durch die Sangiang die sich als innerste Substanz in den Bandongbooten (Balian) befinden.

Und es steigt auf der Laut der Djalajan, die wie ein Mast eingesteckt sind in den Vogelbooten.

Und der Laut des Anak Andau (ein Insekt das einen scharf zirpenden Laut hervorbringt) steigt auf aus dem Hause, dem eingeschlossenen, in dem man verrichtet das Hülfswerk.

Und das Zirpen des Sandai der Monde (wie oben) fährt herab im Haus, dem umwandeten, in dem man vollzieht das auf den Schoss nehmen.

Und es macht sich auf und es tritt heraus aus dem Hause und begibt sich zum Schildbrett.

Und es macht sich auf und schreitet heraus aus der Wohnung und es besucht die Abteilungen des goldenen geflochtenen Bandes.

Und sanft stösst es an die Tingang, die Sangiang im Schildbrett.

Und sanft schütteln sie die Nashornvögel, die Djalajan, die reichen, die sich aufhalten in dem goldenen geflochtenen Band.

Und zusammen erzittern die Sangiang, die sich aufhalten im Schildbrett.

Und schlaftrunken strecken sie sich, die Djalajan, die sich aufhalten in dem goldenen geflochtenen Bande.

Sie drehen sich auf ihren elfenbeiner- 
dok dje manaharep lasang i-pinang.

Ngisat sihong tampudjena badjanda i-sambau sasanggah manjang.

Sama rawing hapantar pinang, Djalajan tatau hataradjo manjang.

Djadi busau la-bua i-pinang dje palus randan hakaisek rawei :

Djalajan kajal lah-uring manjang te, lalu ringkang basarohi tisoi:

Kilen talatai pangentang, apang, balua parong kurong mangentang, isen runtan saripangku, mama, bahandjong siro njaripangku?

Kabadjuran talatai pangentang, anak, hemben nduan hambekan katon.

Kabarengan runtan saripang$\mathrm{ku}$, aken, matok dinon djaretan etoh.

Keton dje garing tabela belom dje buli mantang parong mangentang.

Dohong tantan ambon barutas matei, dje pulang haris enon bapilo nihau. nen Sitzen und nähern sich dem Boot (dem Gefäss) mit den Pinang.

Sie wenden sich auf ihren elfenbeinernen Bänken und sie kehren sich dem Gestelle mit den Betelnüssen zu. Und zusammen kauen die Krokodile Pinang, die Djalajan, die reichen, sie kauen Betelnüsse.

Trunken sind sie von den Früchten der Pinang und sie fragen mit sanfter Stimme :

Und betäubt sind die Djalajan von den Früchten, den Betelnüssen, und sie erkundigen sich mit gedämpften Worten:

Wie steht es nun mit der Verrichtung des Hülfswerkes, o Väter, mit dem Heraustreten aus dem eingeschlossenen Hause in dem man verrichtet das Hülfswerk, wie ist es nun in der Angelegenheit des auf den Schoss nehmens, o Onkel, mit dem Herausschreiten aus dem Hause in dem man vollzieht das auf den Schoss nehmen?

Gut steht es mit der Verrichtung des Hülfswerkes, o Kinder, denn jetzt wollen wir es ausführen.

In Ordnung ist es mit der Vollziehung des auf den Schoss nehmens, o Neffen, denn sogleich wollen wir sie ausführen.

Ihr Elfenbeine, ihr jung lebenden, die ihr hereinkommt und besteigt das Haus in dem man verrichtet das Hülfswerk.

Ihr Dolche, ihr werdet durchschneiden die Wolken, die vernichtenden des Todes, ihr Griffe, ihr werdet durchhauen die Tauwolken, die verderblichen des Verlorenen. 
Narai bulan idje lu-kahunga penjang garo manadjah simpei,e.

Isen bintang dje lu-kabuku paturong santi sandehan kamah.

Lalu gatang dje mendeng hajak djalahan Sangiang tarantang garo.

Lalu tundjong tarahingkat hindje dje lula-Djalajan lalundong santi.

Lu-mantapei la-timpong pandjang dje lu-panambai papan talawang.

Manantiup pahangan ambo salalumbon bulau dare, $n$ lintong.

Sama nusang la-tingang hajak baluwa papan talawang.

Niling pating la-bungai hindje lu-bahandjong bulau dare,n lintong.

Buli netei la-djamban garing haratean paratar sihong.

Nundjong tambang balinga hajak lompat bulau lampar la-buno.

Ngangkat salunga bapilik hindje dje djakat sali dje tilap lu-talawang.

Palus rahun mangasoh buno balua balai lampar buno.
Was, ihr Monde, sollten wir dagegen einzuwenden haben, denn die duftenden Penjang verlangen nach ihren Bündeln.

Weshalb, o ihr Sterne, sollten wir uns widersetzen, die Paturong, die wohlriechenden suchen ihre Arbeit.

Und es erheben sich und stehen auf die Angehörigen der Sangiang, der Kinder des Weihrauches.

Und es erheben sich und stehen gemeinsam auf die Djalajan, die Kinder des Wohlgeruches.

Und sie heben auf das Tuch, das lange, das sich wölbt über dem Schildbrett.

Und sie heben hoch in die Höhe das Tuch, das grosse, das ausgespannt ist über dem goldenen geflochtenen Band. Und gemeinsam senken sie die Tingang (den Kopfschmuck) und sie treten heraus aus dem Schildbrett.

Und sie alle zusammen senken die

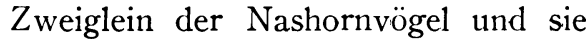
schreiten hervor aus dem goldenen geflochtenen Band.

Und sie treten ein, schreitend über den Weg, den elfenbeinernen, und sie steigen herauf die Treppe, die elfenbeinerne.

Und sie erheben ihre Beine, die schnellen, und sie besteigen das goldene Gestell der Lanzen.

Und sie heben auf ihre Füsse, die raschen, und sie erklimmen das Haus der aufeinandergeschichteten Schilde. Und wie das Wasser herabfliesst, so schreiten sie über die Lanzen und treten heraus aus dem Haus, dem Gestelle der Lanzen. 
Sama manting nganduran renteng,e bahandjong sali tilap lu-talawang.

Hajak tilap batontong tambang manjauch garing indjam djamban radja.

Lio djedjel la-baroh salunga mansohan sihong pantang kanarohan.

Kandjan burong la-tingang tonggal halawo bumbong riak dare,n puron.

Lalu tari,n anak antang sahin harende pandong lu-hakajau dare.

Nandjong bumbong la-dare, $\mathrm{n}$ puron hajak manjelem lawang timpong.

Haratean pandong irit bungai dje manantame pahakumbang benang.

Palus njaming la-pantar pinang Sangiang huang parong mangentang.

Nupai roko,n ilu-tarahan Djalajan medjen siro saripangku.

Nusang djari i-randan hajak manawan darah manok darong tingang.

Niling karah Djalajan hindje ilu-manekap tunah hiring dohong.

Tengah nekap bulau tampong papas, manawan rabia tundon
Und sie schwingen die sich spreizenden Schwanzfedern und sie schreiten heraus aus der Wohnung der übereinandergeschichteten Schilde.

Und sie legen übereinander ihre Beine und sie steigen herab an dem Elfenbein, dem geliehenen, dem Wege des Königs.

Und sie schlingen die Beine um den Stab und sie klettern herab an dem Pfahle des Königs.

Und sie schweben wie die Nashornvögel und stossen herab auf die Matte, das wellende Geflecht von Puron.

Und sie wiegen sich in der Luft wie die jungen Falken und lassen sich plötzlich herunterfallen auf die Matte, die kreuzweise geflochtene.

Und sie beschreiten die Matte, die geflochtene von Puron, und sie treten ein durch die Türe von Tuch.

Und sie gehen über die Matte und sie treten ein durch die Türe von Stoff.

Und sogleich ergreifen sie die $z u$ kauenden Pinang, sie die Sangiang, die sich im Hause des Hülfswerkes befinden.

Und sie nehmen die Rauchwaren der Sklaven, sie die Djalajan, die sich in der Wohnung aufhalten in der man vollzieht das auf den Schoss nehmen.

Sie senken ihre Finger, die zarten, und sie ergreifen das Blut des Huhnes, des Huhnes Tingang.

Und sie, die Djalajan, beugen herab ihre Hände und sie packen plötzlich die Schärfe des Dolches.

Und einige von ihnen packen den goldenen Büschel des Besens und sie 
kalingking.

Belahe ndjidjit elang salentup, lu-manawan lu-hampatong uei.

Gilit-ginting la-djandjulana manetei ruang parong mangentang.

Belahe mendeng manjaki entang, belahe manjun bulau tampong papas.

Lu-mamukul elang salentup, mahantok hampatong uei rantihen tingang.

Manantesan dje manatumbur mengkak pangalambin ambon barutas matei.

Totok tandak ilu-Sangiang njaki mapas entang bakawan.

Totok tandak ilu-Djalajan mahantok hampatong uei lurantihen tingang.

Palus mendeng hapulau kabangkang,e njampenda lalangit bulan.

Lu-malajan la-tolang rumpang rawing rata lu-hapantar pinang.

Lu-hapantar la-bua pinang panukang ambon lu-barutas matei.

Lu-Djalajan taradjo manjang panjangka enon bapilo nihau. ergreifen das goldene Bund des Besens.

Und andere ziehen herbei die Bambusstöcke zum Knallen und sie nehmen auf das menschliche Schnitzbild von Rotan.

Und überall gehen sie herum auf ihrem Gange und sie beschreiten das ganze Haus in dem das Hülfswerk verrichtet wird.

Und einige stehen und bestreichen die Getragenen mit Blut, und andere schwingen den goldenen Büschel, den Besen.

Und sie schlagen die knallenden Bambusstöcke und sie berühren mit dem menschlichen Schnitzbild von Rantihen-Tingang-Rotan die Köpfe.

Sie durchschneiden, sie jagen weg und sie lösen auf die Unheilsursachen der Wolken, der vernichtenden des Todes. $\mathrm{Zu}$ Ende ist nun der Gesang der Sangiang, die da bestrichen und abgewischt haben die in Herden versammelten Getragenen.

Verstummt ist nun das Lied der Djalajan, die mit dem menschlichen Schnitzbild von Rantihen-TingangRotan berührt haben die Köpfe.

Und sie stellen sich auf in einem Haufen unter dem Himmel der Monde.

Und sie ruhen aus ihre ermüdeten Knochen und die Krokodile kauen Pinang.

Und sie kauen die Früchte der Betelnusspalme, sie die Aufheber der Wolken, der vernichtenden des Todes.

Und die Djalajan, die Aufstützer der Tauwolken, der verderblichen des 
Djadi busau la-bua pinang hajak sawoh tunah bambang penjang,e.

Djadi kajal la-uring manjang dje lalu rentar lu-Pataho,n batu.

Gilit-ginting la-djandjulana manetei ruang parong mangentang.

Sangiang pantan ambon barutas matei, Djalajan haris enon bapilo nihau.

Sintong udje parong langadju dje, sintong udju parong la-ngawa.

Sintong udju parong langambo die, sintong udju parong la-liwa.

Haramaung batonggal hanji dje melai lumpong njalabentok parong.

Pangandien dje sahin enteng,e induan dinon njababeroh siro.

Lalu njilak njahumpak dohong panatau, dohong indu papan benteng,e.
Verlorenen, kauen Betelnüsse.

Trunken sind sie von den Früchten der Pinang und plötzlich verwandeln sie ihre Gestalt in Späne von Penjang.

Betäubt sind sie von den Früchten der Betelnusspalme und plötzlich verändern sie sich in steinerne Pataho.

Und überall gehen sie herum auf ihrem Gange und sie beschreiten das ganze Haus in dem verrichtet wird das Hülfswerk.

Die Sangiang durchschneiden die Wolken, die vernichtenden des Todes, die Djalajan durchhauen die Tauwolken, die verderblichen des Verlorenen.

Zusammen sieben Häuser auf der Seite nach flussaufwärts, zusammen sieben Häuser in der Richtung nach flussabwärts.

Zusammen sieben Häuser auf der Hinterseite, zusammen sieben Häuser auf der Vorderseite. (Es handelt sich um ein Haus das nach der kosmischen Einteilung gereinigt wird.)

Aber er, der einzige Tiger, der mutige, bleibt stehen auf der Kante, der Mitte des Hauses (d.h. auf der Mittelschwelle. Der einzige Tiger ist wahrscheinlich Dohong Mama Tandang, der in den Upon Balian eingefahren ist). Und er, der einzige Tiger, der tapfere, erhebt sich in der Mitte der Wohnung.

Und er zieht heraus und holt hervor den Dolch des Reichtums, den Dolch, der da dient als Mittelstück der zusammengefügten Bretter (der Scheide). 
Djalajan tatau basariang pulang,e, panuhan pulang indu tambing hanji.

Lalu njaho ngarontong langit dje njaho,n dohong padjandjuri kumpang,e.

I'hajak kilat handjandjepa tandok,e, dje kilat pulang bahandjong sangkabang,e.

Sawoh toto djari bambang penjang, rentar paham luPataho,n batu.

Malik bahing dje panto, $\mathrm{n}$ sambang nantan ambon barutas matei.

Palus mules salintik luhing Djalajan maharis enon bapilo nihau.
Und der Djalajan, der reiche, bringt in Ordnung den Griff des Wohlstandes, der da dient zur Vermehrung des Mutes.

Und es steigt auf der Donner und er dröhnt durch die Himmel, der Donner des Dolches, der hervorgeholt ist aus seiner Scheide.

Und der zuckende Blitz blendet die Augen, der Blitz des Griffes, der hervorgeholt wurde aus seiner Hülle.

Und sie haben sich verwandelt und sind geworden zu Spänen der Penjang und sie haben ihre Gestalt verändert in steinerne Pataho.

Und es ändert der Schlag der Trommeln des Durchschneidens der Wolken, der vernichtenden des Todes.

Und es wechselt der Schlag der kleinen Trommeln der Djalajan, die da durchhauen die Tauwolken, die verderblichen des Verlorenen.

\section{K. Die Beladung der Lanting Buno mit den Ambon Barutas Matei}

\section{a. Die Balian durchschneiden mit den Sangiang die Ambon Barutas Matei im Haus und im Dorf}

Die Sangiang nehmen nun die umfassende Reinigung des Hauses und Dorfes von den Ambon Barutas matei vor. Wenn diese abgeschlossen ist, werden die Ambon Barutas matei aufgerollt und auf das Lanting Buno (Lanzenfloss) geladen. Das Papan Talawang (Schildbrett) reist mit dem Lanzenfloss nach der Oberwelt und bringt die Ambon Barutas Matei an den Fluss Rutas zurück, denn von dort haben sie sich auf die Welt herabgesenkt. Nachdem die Sangiang wieder aus der Oberwelt zurückgekehrt sind, wird den Getragenen, die nun gereinigt sind und die von allem Unheil der Ambon Barutas Matei befreit wurden, neues Leben geschenkt. 
Toh ewen oloh balian sama mendeng mimbit katambong,e tame akan huang karong.

Ewen balian, marak tandjongtandjong, toh hobah lago tumon lago,n balian ttg. tekap manantan huma kea.

Koa,n auch tandak,e:

I'ohoi bara ohoi Sangiang nantan parong mangentang.

I'ehei bara ehei Djalajan maharis rajong bara tandang.

I'nantan tingang epat gana,n pamaripir parong, maharis antang hanja gana,n pamalambur siro.

Nantan pamarawong parong, maharis tarik kaju,n babungan.

Nantan sapau lentem antang maharis dawen karang habuno pinang.
Die Balian erheben sich nun alle zusammen und sie nehmen mit sich ihre kleinen Trommeln und begeben sich in die Zimmer des Hauses hinein.

Die Balian wechseln nun die Weise während sie gehen, gemäss den priesterlichen Handlungen und sie spielen: Der Schlag des Durchschneidens des Hauses.

Ihr Gesang lautet:

Ohoi und noch einmal ohoi, die Sangiang durchschneiden das Haus in dem verrichtet wird das Hülfswerk.

Ehei und noch einmal ehei, die Djalajan, die Jünglinge, die Tiger, hauen alles durch.

Es durchschneiden die Tingang die vier Seelen der Leisten längs dem Dache des Hauses, es durchhauen die Antang die acht Seelen der Leisten längs des Hauses (d.h. sie schneiden von ihnen die Ambon Barutas Matei weg).

Sie durchschneiden den First des Daches des Hauses, sie durchhauen die in die Höhe gerichteten Hölzer des Firstes.

Sie durchschneiden das Dach, das Nest des Antang (auf den Dächern findet man, auf den Priesterzeichnungen, Abbildungen von Vögeln, die hier Antang genannt werden), sie durchhauen die Blätter, die spitz sind wie Speere und aussehen wie Pinangblätter (die über die Schindeln gelegten Latten, die die Form von Speeren haben).

I'nantan pamaliwit suling, Sie durchschneiden die geraden Flöten, maharis kasau parong. sie durchhauen die Dachsparren des 
Hauses.

Manantan sarahampong dohong, maharis tampalang rawing.

Manantan galang kasau parong, maharis tatean balawau.

I'nantan bapahan gantong, maharis kuda-kudam siro.

Manantan raradjak dinding, upak kaju djangkang njaho.

Manantan lambang parong, nduan epat hapamontong.

Manantan djihi bakas, djihi tonggal, djihi bentok, djihi busu.

Manantan laseh titih handiwong pamali, maharis bisak betong rendem penjang.

Manantan amak lampit kabalantak paku.

Manantan hila huang parong mangentang, maharis rambur siro saripangku.
Sie durchschneiden die gekreuzten Dolche, sie durchhauen die Querhölzer der Krokodile (Seitenlatten, die das Dach abschliessen und die diese Formen haben).

Sie durchschneiden die Unterlagen der Dachsparren des Hauses, sie durchhauen die Wege der Mäuse.

Sie durchschneiden die Balken, die hohen, sie durchhauen die Pferderücken des Hauses.

Sie durchschneiden die aufrechtstehenden Wandhölzer, die Rinde des Holzes Djangkang Njaho.

Sie durchschneiden die Schwelle des Hauses und sie führen es auf den vier Seiten aus.

Sie durchschneiden den alten Pfahl, den einzigen Pfahl, den mittleren Pfahl und den jüngsten Pfahl. (Es sind die Namen der vier Pfähle auf denen das Haus ruht und die das ganze Haus auch tragen.)

Sie durchschneiden den Fussboden, den beklopften (den man viel betritt) von Handiwong Pamalilatten, sie durchhauen die gesplissenen Betong (dicker Bambus, der gesplissen wird und mit dem man den Fussboden belegt. Zwischen den Latten lässt man einen schmalen $Z$ wischenraum der nicht ausgefüllt wird), das Innere der Penjang.

Sie durchschneiden die Rotanmatte, die den Fussboden bedeckt und die man festgenagelt hat.

Sie durchschneiden das Innere des Hauses in dem verrichtet wird das Hülfswerk, sie durchhauen das In- 
Manantan lapitang tingang tungko batu, pahen bungai, maharis tetek kaju.
Manantan lentang ujah, karuir sendok, bindang sahang, maharis rindjing landai.

Manantan kandarah danum, palundun bulu, maharis garumbang bawoi.

Manantan sangkalan talai, panga dulang, maharis pisau langgei.

Manantan lontong palundo, kiap halap, tanggoi butah.

Manantan kadjang sirip, maharis amak tahing.

Manantan karangking parei, maharis lusok pulut.

Malik sala lu-Sangiang, mules bambalia rajong Djalajan.

Manantan karong garing, maharis lawang tambarirang. wendige der Wohnung in der man vollzieht das auf den Schoss nehmen. Sie durchschneiden das Gestell, das geschnitzt ist wie ein Tingang, und den steinernen Kochherd und das Gestell, das aussieht wie ein Nashornvogel, sie durchhauen die Scheite. (Es handelt sich um den Feuerplatz, über dem ein Gestell aufgerichtet ist auf dem die Holzscheite getrocknet werden.)

Sie durchschneiden das Gefäss des Salzes, die Schöpflöffel und Esslöffel und den Pfeffermörser, sie durchhauen die Teller und den Kochtopf.

Sie durchschneiden die Wassergefässe und den geflochtenen Reiskorb, sie durchhauen den Schweinetrog.

Sie durchschneiden den Fleischhackblock und den Futtertrog für die Schweine, sie durchhauen die Buschmesser und die Schnitzmesserchen.

Sie durchschneiden den runden Rückenkorb und den Reiskorb, die Reiswanne und die Reismatte (auf der man den Reis trocknet), die Hüte und die Tragkörbe.

Sie durchschneiden die grossen Matten und die kleinen Blättermatten, sie durchhauen die grossen Matten auf denen man den Reis trocknet.

Sie durchschneiden die Reisbehälter, sie durchhauen die Bergplätze des Pulutreises.

Es ändern ihren Schritt die Sangiang, es wenden ihren Gang die Jünglinge der Djalajan.

Sie durchschneiden das Zimmer, das elfenbeinerne, sie durchhauen die Türe, die da aussieht wie ein Tambarirang. 
Mantan ranjing buno gantongan sahor, maharis bangkang balanga tingang, nantan tambon repang garantong.

Manantan huang karong garing, maharis rambur lawang tambarirang.

Manantan djangkut djalembang bulu,n tingang, maharis benang lalapai radja.

Manantan tilam pihara radja, maharis bantal putak kalihulon batiroh.

Manantan pati bahandang, maharis tabala radja.

Manantan kambur ringgit, maharis sumpok bulau.

Manantan tolok bungkal, maharis bango,n taradjo,n ambon.

Manantan manas munik, gege maharis djudjok panuhok.

Manantan tambok kameteng tingang, maharis upo,n karuhei.

Manantan bakam supo, maha-
Sie durchschneiden die verehrungswürdige Lanze an der man aufhängt das Sahor (siehe Register), sie durchhaven die Balanga Tingang (heilige Töpfe), sie durchschneiden die Wasserschlange (Kette) der Gong.

Sie durchschneiden alles im Innern des elfenbeinernen Zimmers, sie durchhaven alles was hinter der Türe liegt die wie ein Tambarirang aussieht.

Sie durchschneiden den Vorhang, den weissen, der aussieht wie der Flaum der Nashornvögel, sie durchhauen das Tuch, das mit königlichen Fransen verziert ist.

Sie durchschneiden die weiche königliche Matratze, sie durchhauen das mit Schaum gefüllte Kissen auf dem man schläft.

Sie durchschneiden die rote Kiste, sie durchhauen die königliche Truhe.

Sie durchschneiden das Ringgitsäcklein (ein Säcklein, in dem gewöhnlich ein alter Thaler aufbewahrt wird als Grundlage für den neuen Reichtum, denn die alte Münze zieht die neuen an. Ein Ringgit ist $f 2.50$ ), sie durchhauen das Körbchen in dem man das Gold aufbewahrt.

Sie durchschneiden die Masse mit denen man das Gold wiegt, sie durchhauen die Schalen der Goldwaage.

Sie durchschneiden die zarten Perlen, ja sie durchhauen selbst auch die eingebohrten und ausgefüllten Löcher.

Sie durchschneiden den kleinen Rotankorb in dem aufbewahrt werden die Penjanggürtel der Tingang, sie durchhauen die Hauptkaruhei.

Sie durchschneiden das kleine Oel- 
ris tatamba panjangka. 390

Manantan sambang garantong, maharis hampatong karuhei tatau.

Manantan balanai behas, maharis upak takaran radja.

Manantan bukong sambas, maharis lalang rangkang haramaung.

Manantan pasek puak, maharis kalata gahuri, sumpit simpei.

Manantan njating djadampen kereng, maharis ulai sasumbo radja.

Manantan dinding timpong, maharis pahakumbang benang.

Balo-balon pangalambin ambon barutas matei, panjakatin enon bapilo nihau.

Manantan lepa-lepah paramo,n entang huang parong, maharis lingi-lingis parabea, $n$ tujang medjen siro.

Malik sala lu-Sangiang, mules bambalia lu-Djalajan. krüglein, sie durchhauen die Medizin Panjangka (die sich in diesem Krüglein befindet).

Sie durchschneiden die Trommeln und Gong, sie durchhauen die menschlichen Schnitzbilder der Karuhei des Reichtums.

Sie durchschneiden den grossen Topf in dem der Reis aufbewahrt wird, sie durchhauen die Rinde, das Reismass, das königliche (dieses Reismass wird gewöhnlich von Rinde gemacht).

Sie durchschneiden den grossen Topf von Sambas (ein heiliger Topf der nicht sehr teuer ist und der in der Landschaft Sambas hergestellt wurde), sie durchhauen die heiligen Töpfe, die alten Tiger.

Sie durchschneiden die grossen irdenen Töpfe, sie durchhauen die Kalataund Gahuritöpfe, um deren Oeffnung ein Band läuft (ein Ornament).

Sie durchschneiden das Harz das gesammelt wurde auf den Sandhügeln, sie durchhauen den Docht der Lampe, der königlichen.

Sie durchschneiden die Wände von Tuch und sie durchhauen die Türe von Stoff.

Sie rollen auf die Unheilsursachen der Wolken, der vernichtenden des Todes, die Krankheiten der Tauwolken, der verderblichen des Verlorenen.

Sie durchschneiden restlos alle Dinge der Getragenen im Haus, sie durchhauen ohne etwas übrig zu lassen die Güter der Gewiegten in der Wohnung. Sie wenden ihre Schritte, die Sangiang, sie kehren ihren Gang, die Djalajan. 
Hapintih tambang rawing Es drängen sich dicht zusammen die mananturong labeho,n parong, Füsse der Krokodile und sie schreiten hakangkalo salunga tatau hin zur Wassertiefe des Hauses, es manjahendeng rantau siro.

Manantan labeho,n parong, maharis rantau siro.

Manantan kadjang lu-lalangit bulan, maharis luhing langkau timpong.

Manantan dinding timpong, maharis pahakumbang benang.

Manantan katil garing, sambang bulau, maharis sambang garantong tapadjakan Sangiang.

Manantan paramo,n mangentang, maharis parabea,n saripangku.

Malik sala lu-Sangiang, manantan puket, rengge, haup, hantai, bowo, tali, pangalau, pasat, pisi, taut, harus rawai, maharis gantongan djala. 391

Sama kadjang batalampas dengan ambon barutas matei. Manantan balai rampar buno, stehen dicht zusammen die Beine, die reichen (die reichgeschmückten und tätowierten) und sie begeben sich hin zum Abgrunde der Wohnung.

Und sie durchschneiden die Wassertiefe des Hauses, und sie durchhauen den Abgrund der Wohnung.

Sie durchschneiden die Matten des Himmels der Monde, sie durchhauen die Stützen des Daches von Stoff (das sich über der Wassertiefe des Hauses befindet).

Sie durchschneiden die Wände von Tuch und sie durchhauen die Türe von Stoff.

Sie durchschneiden die elfenbeinerne Bank und die kleinen goldenen Trommeln, sie durchhauen die Gong auf denen die Füsse der Sangiang aufstützen.

Sie durchschneiden alle Dinge die man für die Verrichtung des Hülfswerkes nötig hat, sie durchhauen die Güter, die man braucht für die Vollziehung des auf den Schoss nehmens.

Es wenden ihre Schritte die Sangiang und sie durchschneiden das Netz, das lange Netz, das Hauptnetz, das Hantainetz, die grosse Fischreuse, die Fischschnüre, das Pangalaunetz, das Pasatnetz, die Fischangeln, die Taut, die Harus Rawai, und sie durchhauen die Hänger des Wurfnetzes.

Sie alle waren verhüllt und sie werden nun frei und offen von den Wolken, den vernichtenden des Todes.

Sie durchschneiden den Balai der 
maharis sali tilap lintong talawang.

Manantan atep kanguarin parong, maharis pinto rohong.

Manantan hedjan taletai djela burong dahiang, maharis pakang-pukong kanaherau garing.

Manantan bapatah parong, maharis djihi paka, manantan gahagan tusang, maharis bahat tiling.

Manantan petak sintel eka tadjekan parong entang, lilalilang petak awang kangumpang basial, sarak-saraken liang maing kangambong bakawe.

Nantan manantapei petak awang djiret ringket, awang basial bakawe, awang balasut badarem.

Kalampangan petak awang Djata katontong batuah, timbul liang awang Hatala kadjawan balambit. nebeneinanderliegenden Lanzen, sie durchhauen das Haus der aufeinandergeschichteten Schilde.

Sie durchschneiden die Türe, die Oeffnung des Hauses, sie durchhauen den Eingang der Dolche.

Sie durchschneiden die Treppe, die Treppe mit den Zungen der Vorzeichenvögel (die Treppe besteht aus einem Baumstamm, aus dem Tritte ausgeschlagen werden, diese Tritte nennt man: Zungen der Vorzeichenvögel), sie durchhauen das Geländer, das elfenbeinerne.

Sie durchschneiden den Vorplatz vor der Haustüre (die meist überdachte Veranda), sie durchhauen die Pfosten und Stützen, sie durchschneiden die Tragbalken, die der Länge nach schräg liegenden, sie durchhauen die Querbalken, die der Breite nach schräggerichteten.

Sie durchschneiden die Erde, die harte, über der sich erhebt das Haus der Getragenen, fliehe nun hinweg Erde, die du die Scheide bist für die Unheilsursachen, mache dich fort, fester Stein, der du erfüllt bist von den Unglücksursachen.

Sie durchschneiden und heben auf die Erde, die magere und ausgesogene, die von Unglück und Unheil erfüllte, die von Hitze und Fieber besessene.

Tauche auf o Erde der durch die Djata vermehrt wird das Heil, steige empor o Stein der durch Hatala mit Glück ausgestattet wurde. (D.h. es verschwinde die alte Erde, die von den Ambon Barutas Matei erfüllt ist und es tauche auf die neue Erde, die die 
Nantan pulau peho,n sawang, maharis ruang djumpong bunge.

Manantan lepau parei, maharis bangkat manok, karambang bawoi, manantan djamban tatean.

Manantan lisong kamangkiling Njaring, maharis halo lumpong tabalien.

Manantan pasah ramo, maharis tugal-tundang.

Manantan rasap kaju, maharis sadai karajan.

Manantan bagunan balai, maharis djangkean sali.

Manantan batu lawang paluntaran, maharis liang tapian tingang.

Manantan hedjan rangkang kalingkasan tambon, maharis pakang darehan haur garing njalong panduja.

Manantan batang empas salomon tambon, maharis djamban garing.
Gabe der Djata und des Hatala ist und die erfüllt ist mit Heil und Segen.) Sie durchschneiden die Inseln, die Haufen der Sawang, sie durchhauen alle Abteilungen des Gehölzes der Bunge (anderer Name für Sawang).

Sie durchschneiden die Reisscheuern, sie durchhauen die Hühnerkörbe und die Schweinepferche, sie durchschneiden den hölzernen Brückenweg.

Sie durchschneiden den Stampfblock der aussieht wie ein Njaring, sie durchhauen den Reisstampfer, den kantigen von Eisenholz.

Sie durchschneiden die Hütte in der die Geräte aufbewahrt werden für die Feldarbeiten, sie durchhauen die Reispflanzstöcke.

Sie durchschneiden die Holzhaufen, sie durchhauen das Gestell auf dem der Reis zum Trocknen ausgebreitet wird. Sie durchschneiden das Bauwerk, den Balai, sie durchhauen die Ecken des Hauses.

Sie durchschneiden den Stein an der Türe zum Vorplatz, sie durchhaten den Stein am Anlegeplatz der Boote der Nashornvögel.

Sie durchschneiden die hölzerne Treppe die hinunterführt zu dem Ort wo sich hin- und herwenden die Wasserschlangen, sie durchhauen die Lehne, die von elfenbeinernem Bambus geflochtene, die da herabführt zum Wasser in dem man badet.

Sie durchschneiden das Floss auf dem die Wasserschlangen abwerfen ihre alte Haut (es handelt sich um das Anlegefloss, auf dem man sich nach dem Bade mit Seife einreibt, womit 
Manantan papan bandong lasang, maharis pandong panjandai bulan.

Manantan besei banipis mahadandang tingang, maharis dajong bunter ngaut sara,n bulan.

Manantan lewu ano, maharis rundong ano.

Manantan parong entang hasansila, maharis siro,n tujang hatalumbang.

Manantan bua djambu, nangka, pinang lewu, katilambong njaho.

Manantan pukong pahewan lawang lewu ano, maharis pandong parindjangan dahiang pagerundong ano.

Manantan pataho haga,n mangkalewu, maharis batu mamben gadoh pangkarun- das Abstossen der alten Haut verglichen wird), sie durchhauen das Badehäuschen, das elfenbeinerne (fast auf allen Flossen befindet sich ein Badehäuschen, das auch als W.C. dient).

Sie durchschneiden die Bretter des Bandongbootes (ein weites bauchiges Boot. Möglich dass es ein Frauenboot ist. Der Ausdruck bezieht sich hier aber nicht auf die Balian, die auch bandong lasang genannt werden), sie durchhauen die Bank auf die sich setzen die Monde.

Sie durchschneiden das Ruder, das dünne, das am Griff festgehalten wird durch die Nashornvögel, sie durchhauen das Ruder, das runde, das festgehalten wird durch die Monde.

Sie durchschneiden das Dorf X., sie durchhauen den Ort N.N. (der Name des Ortes wo die Handlungen ausgeführt werden. Im Gesange wird er natürlich genannt).

Sie durchschneiden das Haus der Getragenen auf beiden Seiten, sie durchhauen die Wohnung der Gewiegten nach allen Richtungen.

Sie durchschneiden die Djambubäume, die Nangkabäume, die Betelnusspalmen und die Kokospalmen, die donnernden.

Sie durchschneiden das Gehölz, den heiligen Hain an der Türe zum Dorfe X., sie durchhauen das Gebüsch wo man Rat holt von den Vorzeichen am Eingange zum Orte N.N.

Sie durchschneiden den Pataho, den Wächter des Dorfes, sie durchhauen den harten Stein, den Beschirmer des 
dong.

Manantan pukong tadjahan, maharis hampatong tadjahan.

Manantan lawang labeho,n Djata, maharis rantaı Hatala.

Manantan horong tandjong eka entang mandop mambuang lawang.

Manantan tana lombah, maharis tampoi mirang.

Eka entang manana malan, tau malepau parei, ngarangking pulut.

Manantan bukit gantong, eka mandolang bulau baliat, maharis purok ambo, eka nangkaile rabia leket.

Manantan datah lombah, maharis sungei saka.

Manantan baras lombah, eka bawi mandolang bulau, maharis pambok pahangan tapadjakan djumban nangkaile rabia.

Manantan pulau uei, maharis kabon pambulan.
Ortes.

Sie durchschneiden den heiligen Hain des Tadjahan, sie durchhauen die menschlichen Schnitzbilder des Ahnenheiligtumes.

Sie durchschneiden den Zugang zu der Wassertiefe der Djata, sie durchhauen den Abgrund des Hatala.

Sie durchschneiden die Krümmungen und Buchtungen, den Ort wo die Getragenen auf die Jagd gehen und leer machen die Türe (d.h. das Gebiet vor der Dorfgrenze).

Sie durchschneiden das Reisfeld, das breite, sie durchhauen den Acker, den ausgestreckten.

Den Ort wo die Getragenen das Feld bestellen und dem Reisbau obliegen, von wo sie in die Scheunen einführen können den Reis und ihre Behälter füllen können mit Pulutreis.

Sie durchschneiden den Berg, den hohen, den Ort wo man das zähe Gold gewinnt, sie durchhauen den Felsen, den steil aufragenden, den Platz wo man herausschlägt das festklebende Gold.

Sie durchschneiden die Stufen, die breiten, sie durchhauen die kleinen Wassergräben die vom Flusse nach landeinwärts führen.

Sie durchschneiden die ausgedehnten Sandbänke wo die Frauen Gold waschen, sie durchhauen die aufgerichteten und mit Tuch bespannten Pfähle wo die Frauen das Gold aus dem Flusse waschen.

Sie durchschneiden die Inseln von Rotan, sie durchhauen die Anpflanzıngen und Gärten. 
Manantan palikana, maharis pisang, tewo.

Manantan lepa-lepah, maharis,e lingi-lingis.

Manantan telok lombah eka hababiong bulau telo,n djala.

Malik sala lu-Sangiang, mules bambulia lu-Djalajan.

Manantan hila tumbang danum, eka manotoh bulau pungkal radja, eka maratap bantilon timpong, manetes tambong lamiang.

Nantan djalajan hulu danum eka dohong bapaju dagang.

Manutoh bulau lelak bendang, maningkai rabia puson pandong.

Manuwe riak henda,n bulau, manawing lantin rabia.

Manantan tandjong ambon, maharis luwok enon.

Panantapei ambon barutas matei, panantiup enon bapilo
Sie durchschneiden die Gärten in denen die Küchengemüse gezogen werden, sie durchhauen die Bananen und das Zuckerrohr.

Sie durchschneiden alles restlos, sie durchhauen alles ohne etwas zu vergessen.

Sie durchschneiden die Flussbuchtungen, die grossen, den Ort wo man auswirft die goldenen Hänger des Wurfnetzes.

Es wenden ihre Schritte die Sangiang, es kehren ihren Gang die Djalajan.

Sie durchschneiden die Richtung der Mündung des Flusses, des Ortes wo man kauft das goldene königliche Schmiedewerk, des Ortes wo man zerreisst die Rollen von Tuch (d.h. wo man von den Tuchrollen die bestellte Länge des Tuches abschneidet) und wo man durchschneidet die Trossen von Achatsteinen.

Sie durchschneiden den Oberlauf, den Quellort des Flusses, den Ort wo die Dolche gute Handelsgeschäfte treiben. Wo sie erwerben die goldenen Blumen der Bendangpalme (Goldklümpchen), wo sie abschneiden die goldenen Blütenknospen der jungen Bäumchen. Wo sie mit Betäubungsmitteln einfangen die goldenen Wellen des Goldes, wo sie erwerben die Gelbheit des Goldes.

Sie durchschneiden die Flussbiegungen der Wolken, sie durchhauen die Buchtungen der Tauwolken (d.h. die 33 Wolkenlagen zwischen Welt und Oberwelt).

Durch die man hinaufhebt die Wolken, die vernichtenden des Todes, durch 
nihau.

Manantan bulan tagalan, maharis bintang patendo, $n$ langit.

Manantan pulau pehon sawang huang bukit Kasinta Bungai.

Manantan pulau pehon sawang huang bukit Tundjong Njaho.

Malik sala lu-Sangiang manturong parong mangentang, mules bambulia Djalajan manjahendeng siro saripangku. die man emporstützt die Tauwolken, die verderblichen des Verlorenen.

Sie durchschneiden den Mond des Reispflanzens, sie durchhauen das $\mathrm{Pa}$ tendogestirn am Himmel.

Sie durchschneiden die Inseln, die Haufen der Sawangstauden auf dem Berge Kasinta Bungai.

Sie durchschneiden die Inseln, die Haufen der Sawangstauden auf dem Berge Tundjong Njaho.

Es wenden ihre Schritte die Sangiang und sie kehren zurück zu dem Hause in dem verrichtet wird das Hülfswerk, es kehren ihren Gang die Djalajan und sie schreiten wieder zu der Wohnung in der man vollzieht das auf den Schoss nehmen.

\section{b. Die Sangiang bauen das Lanzenfloss}

Idje Sangiang mamanting Einer der Sangiang verwirft seine tambang,e manjelem parong Beine und er geht hinein in das Haus mangentang.

Manekap baliong rintih batu, manawan pahera bengkoi tolang tingang.

Manting nangkaruan tambang,e tinai bagulong malan balua parong.

Batandjong lawang paluntaran, naturong liang tapian tingang.

Halanggawa,e papan bandong lasang, maut,e besei manipis nahadandang,e tingang. in dem man verrichtet das Hülfswerk. Er ergreift eine Axt, eine geborstene mit dem Stein (in der Spalte steckt das Beil, früher ein Stein), er packt den Schaft, den gebogenen Knochen des Tingang.

Und wieder verwirft er seine Beine und er macht sich rasch auf und tritt wieder heraus aus dem Hause.

Und er schreitet zur Türe des Vorplatzes vor dem Hause, und er geht zum Stein, dem Anlegeplatz der Boote der Tingang.

Er bewegt auf und ab das Brett, das Bandongboot (um dadurch das Wasser aus ihm herauszuschütten), und niun ergreifen sie (es begleiten ihn noch 
Mananturong tandjong pandjang, manjahendeng luwok ambo.

Palus neweng nahadjumbang,e batang banuang taroi tandjong.

Palus netek hatateka,e, belahe njila habalaha.

Palus hantong manansoha nanturong liang tapian ambon.

Djalahan hewang Sangiang sama mangantong djari balemo, panungkup rajong $\mathrm{Dja}-$ lajan manunjong karah,e badjambulei.

Manabasan lanting buno, mantaolah haki renteng.

Bahalap ngasau ranjing buno, badaris kanjapau dandang tingang.

Bahalap marawong samben, badaris malantai Sangiang.

Lenda-lendang lanting buno bahalap kaninding bihing timpong.

Totok tandak lu-Sangiang manabasan lanting buno.

Sambong karunja lu-Djalajan andere Sangiang) die Ruder, die dünnen, die festgehalten werden an den Griffen von den Tingang.

Und sie fahren hinauf die Flussbiegung, die lange, und sie fahren entlang der Buchtung, der grossen.

Und sie fällen und bringen zum Umstürzen die Banuangbäume die ihnen zureicht die Buchtung (die Bäume wachsen schräg am Ufer und sind deshalb günstig zu fällen, sie fallen direkt ins Wasser).

Und sie schlagen weg die Aeste und einige spalten die Stämme.

Und sogleich lassen sie sich wegtreiben vom Wasser und fahren flussabwärts und begeben sich zum Stein, zum Anlegeplatz der Wasserschlangen.

Die Angehörigen der Männer der Sangiang erheben zusammen die Finger, die zarten, die Gemeinschaft der Jünglinge der Djalajan hebt auf die Hände, die schlanken.

Und sie machen das Floss der Lanzen, sie bauen zusammen das Floss der Schwanzfedern.

Schön bedeckt mit Dachsparren von verehrungswürdigen Lanzen, herrlich überdacht mit den Schwanzfedern der Nashornvögel.

Schön geschmückt mit einem Dachfirst von Halsbändern, bedeckt mit einem herrlichen Fussboden, der gelegt wurde durch die Sangiang.

Und es leuchtet das Floss der Lanzen das mit Tüchern schön umwandete.

Beendet ist der Gesang der Sangiang des Bauens des Flosses der Lanzen. Zum Schlusse gekommen ist das Lied 
nantaolah haki renteng.

Lenda-lendang lanting buno, nandai hedjan rangkang kalingkasan tambon.

Linge-lingei haki renteng batujang liang tapian tingang.

Malik sala lu-Sangiang limbah tabasan lanting buno, mules bambulia lu-Djalajan ulek nantaolah hakit renteng. der Djalajan des Herstellens des Flosses der Schwanzfedern.

Es leuchtet das Floss der Lanzen welches sich erhebt an der Treppe, der hölzernen, über dem Orte wo sich hin- und herwenden die Wasserschlangen.

Und es erglänzt das Floss der Schwanzfedern, das sich hin- und herwiegende beim Stein, dem Anlegeplatz der Nashornvögel.

Es wenden ihre Schritte die Sangiang nachdem sie gebaut haben das Floss der Lanzen, es kehren ihren Gang die Djalajan nachdem sie hergestellt haben das Floss der Schwanzfedern.

\section{c. Das Lanzenfloss wird mit den Ambon Barutas Matei beladen}

Surong djandjulana tam- Es treten an ihren Gang die Füsse bang,e sama buli mantang und sie kehren zurück und besteigen parong mangentang.

Sangiang sembang parong mangentang hapintih tambang,e lawah rawing balinga.

Rutang-ritut parong entang nduan telo ruang tapus, hapangasa siro,n tujang notok lambang manansila.

Bahing-bahing tionganto, pahalekas bajang tonggal.

Kadjalahan hewang lu-Sangiang hatawanan ambon barutas matei. das Haus in dem man verrichtet das Hülfswerk.

Und die Sangiang kommen an im Hause in dem man verrichtet das Hülfswerk und es stampfen mit ihren geschmückten Füssen die Krokodile, die schnellen.

Es erbebt das Haus der Getragenen in seinen drei Abteilungen, es erzittert die Wohnung der Gewiegten bis hin zu den beiden Seiten der Schwelle.

Es erschallt ein Laut wie das Rufen des Tiongantovogels, es ertönt ein Gesumme wie von einem Kreisel, dem einzigen.

Die Angehörigen der Männer der Sangiang fangen ein die Wolken, die vernichtenden des Todes.

Panungkup bungai rajong Die Gemeinschaft der Nashornvögel, 
Djalajan nekap manolak enon bapilo nihau.

Balo-balon ambon barutas matei lepah balua parong mangentang, lingis enon bapilo nihau bahandjong siro saripangku.

Dahiang baratus gangguranan ara,e, baja saribu sasabutan biti,e,

Nbalon Sangiang kori-korik nipeng suloh sawang, nantipek Djalajan ringi-ringik manamunan puting simbel.

Palus ohoi bara ohoi imbit,e malan balua parong.

Hajak ehei bara ehei hadjadjita ringkang bahandjong siro.

Palus surong djandjulana mananturong lanting buno bagantong liang tapian tingang.

Manjahendeng hakit renteng batujang nandai hedjan rangkang.

I'ohoi bara ohoi imbit,e nje- der Jünglinge der Djalajan packen und stossen weg die Tauwolken, die verderblichen des Verlorenen.

Sie rollen auf die Wolken, die vernichtenden des Todes, und restlos verlassen sie das Haus in dem man verrichtet das Hülfswerk, ohne dass etwas übrig bleiben würde von ihnen treten heraus die Tauwolken, die verderblichen des Verlorenen, aus der Wohnung in der man vollzieht das auf den Schoss nehmen.

Die Vorzeichen mit hunderten von Namen und Bezeichnungen, die Omen mit tausenden von Benennungen ihrer Personen,

Sie werden ganz klein aufgerollt von den Sangiang, sodass sie einem Schössling einer Sawangstaude gleichen, sie werden ganz eng aufgerollt von den Djalajan, so dass sie aussehen wie die Spitze eines kleinen Schnitzmessers.

Und sogleich erhebt sich das Ohoi und nochmals Ohoigerufe und sie machen sich auf und sie schieben sie hinaus vor das Haus.

Und es erschallt das Ehei und noch einmal ehei und sie ziehen sie, sie schleppen sie heraus aus der Wohnung.

Und sie treten an ihren Gang und sie begeben sich zu dem Flosse der Lanzen, das sich befindet am Stein, dem Anlegeplatz für die Boote der Nashornvögel.

Und sie schreiten $z \mathfrak{u}$ dem Floss von Schwanzfedern das sich hin- und herwiegt bei der Treppe von Holz.

Ohoi und noch einmal ohoi, sie bringen 
lem lanting buno, i'ehei bara ehei imbit,e nantame haki renteng.

Lepah ambon barutas matei tame lanting buno, lingis enon bapilo nihau djakat hakit renteng.

Lepah dahiang baratus gangguranan ara,e, lingis baja baribu sasabutan biti,e.

Hataburan bulau, entang keton, huang parong manuntut rikur baro lepah malan balua parong.

Hatajan rabia bowor tujang manantepet anggan kalambi.

Sangiang pangantau,e ambon rutas panjambilei,e.

Gandang-gandanga parong mangentang, hapanitih siro,n tujang.

Bagarantong dinding pendo, upak kaju djangkang njaho.

Pasang njaho,n badil tambon sie (die Rollen der Wolken und Vorzeichen) und sie gehen hinein in das Floss der Lanzen, ehei und noch einmal ehei, sie führen sie herbei und sie betreten mit ihnen das Floss der Schwanzfedern.

Restlos sind die Wolken, die vernichtenden des Todes, hineingegangen in das Floss der Lanzen, ohne dass etwas übrig geblieben wäre haben die Tauwolken, die verderblichen des Verlorenen, bestiegen das Floss der Schwanzfedern.

Restlos verschwunden sind die Vorzeichen mit den hunderten von Namen und Bezeichnungen, vollständig weggeschafft sind die Omen mit den tausenden Benennungen ihrer Personen.

Streut aus das Gold (Reiskörner), ihr Getragene in Hause, nachfolgend dem Rücken der Oberkleider die alle sich aufmachen und nun herausgehen aus dem Haus.

Säet aus das goldene Streusel, ihr Gewiegte, nachgehend den Kleidern, den Oberkleidern.

Die Sangiang schieben die Unheilswolken weg nach rechts und sie stossen sie fort nach links (sie werden nach allen Seiten hin weggeschoben). Trommelt im Hause, in dem man verrichtet das Hülfswerk, schlaget auf die Trommeln in der Wohnung der Gewiegten.

Und es erschallen die Wände von Pendoholz wie der Schlag der Gong, es erbraust die Rinde von DjangkangNjahoholz.

Wie die aufsteigenden Wellen der 
manjangka enon bapilo nihau. donnernden Kanone der Wasserschlange, die da aufhebt die Tauwolken, die verderblichen des Verlorenen.

Ngabalepan njating djadjamUnd es löscht aus die Harzflamme des pen kereng, ngalabunen ulai sasumbo radja.

Mambelep ambon barutas matei, ngalabunen enon bapilo nihau.

Toh ewen oloh balian idje balian bauntonggang huma sama mendeng hagoet balua huma hajak hamauch hai auch,e, koa,e :

Has tolak lepah kare ambon barutas matei, enon bapilo nihau, njaho,n bulau sangkowak raung, kilat limban basaloh langit, langisan tangis, tantuman tatom.

Dahiang baja, nupi papa, taloh papa handiai.

Upo kabuat bewei hamauch tumon te marak tandjongtandjong intu petak.

Ewen bara huma paham manaburan behas manuntut likut ewen oloh balian ttg. mampidjak laseh mamanto dinding.

Hantelo tingkat mambelep sumbo limbah te imotong,e

Die Balian welche die priesterlichen Handlungen bei der Türe ausgeführt haben, erheben sich nun alle zusammen und treten aus dem Hause heraus und sie singen mit gehobener Stimme:

Wohlan, gehet nun restlos weg, alle ihr Wolken, ihr vernichtenden des Todes, ihr Tauwolken, ihr verderblichen des Verlorenen, Donner der goldenen Späne des Sarges, Blitze des Leichenwassers, das verwandelt wurde in Himmel, Weinen und Schluchzen, Wehklage und Totenlied. Vorzeichen und Omen, schlechte Träume und alle ihr böse Geister.

Der Hauptbalian allein sprach diese Worte aus während seines Herumgehens auf der Erde.

Die Leute aus dem Hause streuen sehr eifrig Reis aus, indem sie hinter den Balian herschreiten, und sie stampfen auf den Fussboden und klopfen an die Wände.

Dreimal löschen sie die Lampe aus und zünden sie darnach wieder an. 
tinai.

Toh belahe ewen mimbit pasok hambaruan, mimbit sangko buang mohon mingkes djete darah upo,n balian idje mondok sara,n tiwing.

Belahe oloh mimbit peteng salentup idje hewoi tampong papas ttg. hampatong uei ttg. bango,n sarangan panginan isut, imbit ewen mohon uras sampai batang.

Ewen mandjakah peteng te akan laut batang hajak malahap hangkudju tingkat.

Limbah ewen djari malahap ewen manjendok danum bara huang djukung idje aton. sara,n batang, imuat,e huang sangko idje buang intu darah oloh balian mondok.

Tinai ewen mangiwak petak idje balemo isut mampaleket,e intu sara,n sangko te kea.
Nun nehmen einige von ihnen das Körbchen mit dem Seelenreis mit sich und die andern bringen einen leeren Sangko mit und sie steigen herunter aus dem Haus und legen sie neben dem Hauptbalian nieder, der am Ufer sitzt.

Einige der Leute bringen den Bündel mit den Knallbambussen mit welchen beigefügt sind : der Büschel des Besens und das Schnitzbild von Rotan und die Kokosschale, die einige Speisen enthält, sie bringen das alles und steigen damit hinunter zum Landungsfloss.

Sie werfen das Bündel vom Anlegefloss aus auf den Fluss hinaus und jauchzen dazu siebenmal.

Nachdem sie ihren Jauchzer beendet haben schöpfen sie Wasser auf aus dem Ruderboote welches sich beim Floss befindet und schütten es in den leeren Sangko den sie neben den Balian auf die Erde gestellt haben.

Ferner brechen sie ein wenig Erde aus welche etwas weich ist und sie kleben sie fest am Rande des Sangko.

\section{d. Das Lanzenfloss wird nach der Oberwelt gebracht}

Toh ewen balian manampara manekap katambong ttg. manandak tumon lago: Manolak ambon rutas.

Koa,n tandak,e :

I'ohoi bara ohoi manolak lanting buno, i'ehei bara ehei manjangka hakit renteng.
Nun beginnen die Balian die kleinen Trommeln zu schlagen und sie singen nach der Weise: Die Wegstossung der Unheilswolken.

Ihr Gesang lautet:

Ohoi und noch einmal ohoi, wir stossen weg das Floss der Lanzen, ehei und noch einmal ehei, wir heben in die Höhe das Floss der Schwanzfedern. 
Manolak lanting buno hajak tolak papan talawang Sangiang, manjangka hakit renteng hajak manjangka bulau dare,n lintong Djalajan.

Papan talawang Sangiang ttg. Sangiang sintong udju, bulau dare,n lintong Djalajan hajak Djalajan lambong hanja.

Engkak bulau manamburak, manansupit teken garing.

Hadjadjita paratar garing hajak ina manjulih.

Tolak papan talawang mampahajak lanting buno, basangka bulau dare, $n$ lintong mambai-mambai hakit renteng.

I'ohoi bara ohoi maliambong lanting buno, i'ehei bara ehei papan talawang Sangiang.

Malan njalombo ambon, ringkang manandjak enon.

Tandak tari djangkangdjarang hasean tandjong ambon tilap telo pulu.

Timang tahitik djantai-djahai luwok enon limebalas hatalamping.

Uras nandjong manangkalau selong, mampan malangkawet.
Wir stossen weg das Floss der Lanzen und wir schieben fort das Schildbrett, wir stützen empor in die Höhe das Floss der Schwanzfedern und wir heben auf das goldene geflochtene Band der Djalajan.

Das Schildbrett der Sangiang gemeinsam mit sieben Sangiang, das goldene geflochtene Band der Djalajan zusammen mit den Djalajan, die da vermehrt sind zu acht.

Löset das goldene zusammengeflochtene Seil, ziehet heraus den Stossbaum, den elfenbeinernen.

Ziehet herein die Treppe, die elfenbeinerne und leget sie nieder zur Abfahrt bereit.

Schiebet weg das Schildbrett, dass es begleite das Floss der Lanzen, stosset $\mathrm{ab}$ das goldene geflochtene Band, dass es Seite an Seite mitfahre mit dem Floss der Schwanzfedern.

Ohoi und noch einmal ohoi, es steigt in die Höhe das Floss der Lanzen, ehei und noch einmal ehei, es fährt aufwärts das Schildbrett der Sangiang. Es macht sich auf und steigt gerade auf durch die Wolken, es macht sich auf und fährt aufwärts durch die Tauwolken.

Und das Lied schwebt empor, wenig Platz einnehmend rudert es empor durch die Flussbiegungen der Wolken, die dreissig übereinanderliegenden.

Das Spruchwort fliegt weg und es hält sich dicht an die Buchtungen der Tauwolken, die fünfzehn doppelt übereinanderliegenden.

Durch alle gehen sie hindurch, an allen fahren sie vorüber, sie, die Machwerke 
Halawo ambon manaputok kilau telon djala bulau.

Halawo ambon barangga sangkabila,n ambon telo pulu hatantilap.

Manjelem tumbang hapandjungan andjong, nantame salohan antang manamuei.

Manangkalau parong randan ain Bulan Indu Samben.

Malangkawet sapamarong iwa ain Bulan Indu Sandoi.

Habasean tandjong Pasang Njaho, nangkajoh luwok Pahadjedjel Kilat.

Habasean Uhat Marau Langit, nandjong mahalau lanting buno.

Habasean tandjong Raho, ngangkajoh luwok Kamintih Tingang.

Ohoi bara ohoi balias nandjong manangkalau selong, mampan manangkawet.

Sembang lewu,n Burong Dahiang.

Ohoi bara ohoi, murik Kahungkong Ambon, djadi nandjong manangkalau tumbang danum Simban Tingang.

Palus ohoi bara ohoi, baba- der Sangiang, überall gehen sie vorbei, überall ziehen sie vorüber.

Und wie ein ausgeworfenes goldenes Wurfnetz fallen sie durch die Wolken, die ausgebreiteten.

Und sie fallen durch die Wolken mit den Strebepfeilern, die Stützen der Wolken, der dreissig übereinanderliegenden.

Und sie fahren hinein in die Mündung von wo die Boote ihre Reise antreten, sie begeben sich an den Ort, von wo aus der Antang wegfliegt.

Und sie gehen vorbei an dem kleinen Hause der Bulan Indu Samben.

Und sie gehen vorüber an der Wohnung, der kleinen, der Bulan Indu Sandoi.

Und sie rudern der Flussbiegung $\mathrm{Pa}-$ sang Njaho entlang und sie fahren hinauf längs der Buchtung Pahadjedjel Kilat.

Sie rudern hinauf die Uhat Marau Langit, sie reisen und fahren vorüber an ihnen mit dem Flosse der Lanzen. Sie rudern entlang der Flussbiegung Raho, sie fahren hinauf die Buchtung Kamintih Tingang.

Ohoi und noch einmal ohoi, schnell reisen sie vorwärts und überall fahren sie vorüber, die Machwerke der Sangiang, an allen Orten gehen sie vorbei.

Sie kommen an in dem Dorfe der Vorzeichenvögel.

Ohoi und noch einmal ohoi, sie fahren hinauf durch den Kahungkong Ambon, sie reisen und sie gehen vorbei an der Mündung des Flusses Simban Tingang.

Und sie rufen ohoi und noch einmal 
lang riak hai manjababalon puron.

Ehei bara ehei, galombang datoh, bahowong tusang.

Palus ngetas ngalapeta tasik Lajang Hanteran Riwut.

Eleh babalang mahi babalang tumbang danum Tingkah Tarong.

I'tokep mananturong, sagila dani manjahendeng,

Tumbang batang danum Rutas, tapadjakan gohong Bapilo.

Babalang bandera pandjang, pupoh tumbang batang danum Rutas.

Batentang rarusir ambo tapudjakan gohong Bapilo.

Eleh sembang lanting buno hajak sembang kea papan talawang,

Tumbang batang danum Rutas, tapadjakan gohong Bapilo.

I'ohoi bara ohoi, mampendeng hampatong rutas.

I'ehei bara ehei maniring sendong badjungan danum.

Hajak bahing bapanting Tinggi Tingang Mama Hanji. Hajak siring bambahinga Sawang Bengkoi Pangganti Balo. ohoi, denn schon sehen sie die Wellen, die grossen, die sich zusammenrollen wie eine Puronmatte.

Ehei und noch einmal ehei, die Wogen, die hohen, erheben sich wie ein schräg stehendes Haus.

Und sie kommen an und nun fahren sie auch ein in das Meer Lajang Hanteran Riwut.

Und schon erscheint- und man sieht immer näher vor sich, die Mündung des Flusses Tingkah Tarong. Und nicht mehr lange dauert die Fahrt, dort drüben schon erreicht man sie,

Die Mündung des Flusses Rutas, den Anfang des Stromes Bapilo.

Und schon sieht man die Fahne, die lange, das Zeichen des Eigentumsrechtes an der Mündung des Flusses Rutas.

Und schon erblickt man die Flagge, die hohe, am Anfang des Flusses Bapilo.

Und schon kommt an das Floss der Lanzen, und schon kommt auch an das Schildbrett,

An der Mündung des Flusses Rutas, am Anfang des Stromes Bapilo.

Ohoi und noch einmal ohoi, sie richten auf das Rutas-Schnitzbild.

Ehei und noch einmal ehei, sie spannen über den Fluss die Absperrung.

Und sie rufen mit lauter Stimme dem Tinggi Tingang Mama Hanji.

Und sie werfen aus ihr Wort und sie rufen dem Sawang Bengkoi Pangganti Balo. 
Handu-handu lanting buno, omba handu papan talawang, huna-hunang haki renteng bara hunang bulau dare,n lintong.

Tende lanting buno maninggang lanting garing, palus tahan hakit renteng manandai bangkar sihong.

Tende papan talawang, tende batoros teken garing.

Tahan bulau dare,n lintong, tahan kanarokan bulau namburak.
Es vermindert die Fahrt das Floss der Lanzen und mit vermindert auch die Schnelligkeit das Schildbrett, es steht im Begriffe still zu stehen das Floss der Schwanzfedern und mit ihm hält auch an das goldene geflochtene Band. Es hält an das Floss der Lanzen dicht bei dem Anlegeplatz, dem elfenbeinernen, es steht still das Floss der Schwanzfedern an der Seite des Anlegeflosses, des elfenbeinernen.

Es hält an das Schildbrett und sie stossen in den Grund den elfenbeinernen Stossbaum.

Es steht still das goldene geflochtene Band, es steht still und es wird festgemacht mit dem goldenen gedrehten Seil das sich am Buge befindet.

\section{e. Das Lanzenfloss ist am Ziele angekommen}

Toh malajan tekap katambong ttg. upo,n balian mangarungut kabuat bewei.

Ie manahiu ampi,n ambon rutas sampai, tapi ewen oloh balian magon melai intu petak sara,n danum.

Koa,n kare bawak auch upo mangarungut :

I'djari sembang pahatewang lewu ambon barutas matei, djadi dinon tewang pangkarundong enon bapilo nihau, djari sembang tewang pangkarundong enon bapilo nihau, sama buli mahapang rangkan panginan simpan, mulang ba-
Nun verstummt das Schlagen der kleinen Trommeln und der Hauptbalian singt nur noch allein.

Er erwähnt, dass die Unheilswolken an ihrem Bestimmungsort angekommen sind, die Balian bleiben aber immer noch auf der Erde am Ufer des Flusses sitzen.

Es lauten die Worte des Hauptbalian, die er singt:

Es sind angekommen an der Buchtung des Dorfes die Wolken, die vernichtenden des Todes, es haben erreicht die Flussbiegung beim Orte die Tauwolken, die verderblichen des Verlorenen, es sind angelangt bei der Krümmung des Dorfes die Tauwolken, die zerstörenden des Verlorenen, ge- 
gentoi uras hakanjatan sukup.

Tinggi Tingang Mama Hanji djari handong hakatawan.

Sawang Bengkoi Pangganti Balo djadi selong batuana. Kadjalahan Sangiang manambang salumpok entang, panungkup bungai rajong $\mathrm{Dja}$ lajan manjangkurong tanterus tujang.

Nambang salumpok entang bara batang danum Rutas, Djalajan manjangkurong tujang bara gohong Bapilo.

Bara hampatong rutas, bara sendong badjungan danum, bara balai rutas, sali bapilo.

Sukup eka Sangiang manambang entang, genep eka Djalajan manjangkurong tujang.

Udju salumpok entang taratambang djari,n Sangiang, hanja tanterus tujang taratakep karah Djalajan.

Kuruk bara kuruk nambawa entang buli, kurei bara kurei nangkiau tujang mulang.

Kuruk hambaruan ewen buli ttg. penjang karuhei tatau, paturong sangkalemo radja, meinsam sind sie wieder zurückgekehrt und sie bringen mit genügende Opfer, umgekehrt sind sie wieder in Booten und sie führen mit hinreichende Speise.

Er der Tinggi Tingang Mama Hanji wird davon Kenntnis haben, er wird es wohl wissen.

Und er der Sawang Bengkoi Pangganti Balo wird bereits davon gehört haben. Und sie die Angehörigen der Sangiang holen nun zurück die Seelen der Getragenen, sie die Gemeinschaft der Nashornvögel, der Jünglinge der Djalajan ergreifen überall die Seelen der Gewiegten.

Und sie holen ab die Seelen der Getragenen vom Flusse Rutas, und die Djalajan holen zurück die Seelen der Gewiegten vom Strome Bapilo.

Vom Schnitzbilde Rutas, von der Sperre die gelegt ist über den Fluss, von dem Balai Rutas und von dem Hause Bapilo.

Von genügenden Orten holen die Sangiang zurück die Getragenen, von allen Plätzen fangen die Djalajan die Gewiegten ein.

Sieben Seelen der Getragenen holen sie, die Sangiang, ein mit ihren Fingern, acht Seelen der Gewiegten holen sie, die Djalajan, zurück mit ihren Händen.

Kuruk und noch einmal kuruk, so rufen sie den Getragenen $z u$, dass sie zurückkehren möchten, kurei und noch einmal kurei, so locken sie die Gewiegten.

Kuruk! ihre Seelen sollen wieder zurückkehren und sie sollen begleitet werden von Penjang und Karuhei des 
name behas mintih, bangkusan timpong.
Reichtums und von Paturong Sangkalemo Radja und sie sollen hineingehen in den Reis, den ausgewählten, und sie sollen sich hineinbegeben in die Bündelchen von Tuch.

\section{f. Das Schildbrett kchrt nach der Welt zurück}

Toh ewen manekap katambong ttg. manandak hapan lago: Talawang mules, koa,e:

I'tingang lalu-Sangiang rata manjelem papan talawang, panungkup bungai lu-Djalajan manantame bulau dare, $n$ lintong.

Engkak bulau manamburak, ibit supit teken garing, nguhas tatambat keket, hadjadjita palatar garing.

I'ngandang langanakatok bahan garing takolok kumpang.

I'nitih ngalapekong bisak garing gadjah baloi.

Badjeleng mendeng nambawa riwut, ganggulong talawang halalian buli.

Basikap manangkiang salatan, pamaruwei dare, $n$ lintong mulang.

I'mules totok riwut, mules papan lu-talawang buli.
Sie schlagen wieder die kleinen Trommeln und singen nach der Weise: Der Schild kehrt wieder um, und ihr Gesang lautet:

Die Tingang, die Sangiang betreten gemeinsam wieder das Schildbrett, die Gemeinschaft der Nashornvögel, die Djalajan schreiten alle zusammen wieder hinein in das goldene geflochtene Band.

Sie lösen das goldene geflochtene Seil und sie zerren und ziehen heraus den Stossbaum, den elfenbeinernen, sie lösen den Strick, den vielgliederigen der sich am Steuerbord befindet, und sie ziehen herein die Treppe, die elfenbeinerne.

Sie trommeln mit den gekrümmten Schultern des elfenbeinernen Kopfes der Scheiden.

Sie klopfen mit der krumm gebogenen gesplissten elfenbeinernen Scheide.

Und rasch stehen sie auf und sie rufen den Winden, damit schnell wieder heimkehren könne der Schild.

Und rasch rufen sie den Winden, damit schleunigst wieder zurückkehren könne das goldene geflochtene Band.

Und es wendet sich die Spitze des Windes und es dreht sich das Schildbrett, das zurückkehrende. 
I'malik djadjak salatan, malik dare,n lintong kamalesan mulang.

I'besei akis-akis, bisa bahan kalialang tambon.

I'besei kundus-kandas, handjaliwan darong mangansilo ganang,e.

I'besei panggok pantar, bawi,n tingang hadandangan pantong,e.

I'besei nentem-nentem, bukei sahep lu-rakaren tambon.

Papan lu-talawang tingang mahalau tasik Lajang Hanteran Riwut.

I'tintu hakalambat manintu tumbang Tarusan Bulan.

I'enjau hatalambat i-lu-manjauh Tarusan Bulan.

Halawo tasik Ambon Bagantong, harende laut Enon Batujang.

Palus njauh langalapeta njanjaroroi djamban Sangi-
Und es wendet sich der losbrechende Sturmwind, und es kehrt sich das geflochtene Band, das wieder umkehrende und zurückfahrende.

Die Ruder, sie stossen heftig zurück und nass werden die Schultern der Schwalben der Wasserschlangen.

Und es reihen sich aneinander die Ruderschläge (sie rudern im Takt) und die Handjaliwan-Darongschlange zischt vor Begierde.

Sie rudern vom Schnabel des Bootes bis zum Pfahl und sie gleichen dem weiblichen Nashornvogel der sein Horn in die Schwanzfedern steckt (d.h. sie rudern in der ganzen Länge des Bootes, von der Vorpflicht bis zum Steuer, und sie drehen bei jedem Schlage ihren Kopf, sodass sie aussehen wie Nashornvögel die nach rückwärts gebeugt den Kopf in die Federn stecken).

Sie rudern und sie tauchen ihre Ruder tief in das Wasser ein und sie schlagen auseinander das Laub, in dem zusammengerollt liegt die Wasserschlange.

Das Schildbrett der Tingang fährt vorbei am Meere Lajang Hanteran Riwut.

Und in vorsichtiger Fahrt steuern sie in der Richtung der Mündung des Tarusan Bulan (Kanal des Mondes). Und in verminderter Fahrt rudert es herunter den Tarusan Bulan.

Und es fährt ein in das Meer Ambon Bagantong, und es kommt an in der See Enon Batujang.

Und mit grosser Schnelligkeit fährt es durch den Weg der Sangiang. 
ang.

Lu-babalang mahi babalang Und schon taucht auf, und schon sieht parong tumbang kapandjungan mandjong.

I'metas langalapeta tandjong ambon tilap telo pulu.

man das Haus an der Mündung des Weges des Gehens, des Schreitens.

Und in gerader Fahrt rudern sie in der Richtung der Buchtungen der Wolken, der dreissig übereinanderliegenden.

I'lu-Sangiang manambang Und die Sangiang holen zurück die entang bara lewu mandereh danum.

Lu-Djalajan njangkurong tujang nasa rundong pamantai tambon.

Lu-manambang salumpok entang ttg. penjang karuhei tatau.

Lu-manakep tanterus tujang hajak paturong sangkalemo radja.

I'tokep la-mananturong riwut bahing panto,n sambang.

I'dani la-manjahendeng salatan bambahingan luhing.

Djadi sembang la-papan talawang dengan karawang tiwing pandjang.

I'tende hando-la-papan talawang, tende ninggang karawang tiwing pandjang.

Manansauh njalong Djata njaloang ruang petak sinta.

Getragenen aus den Dörfern die längs der Flüsse liegen.

Und die Djalajan holen ein die Gewiegten in den Orten die an den Ufern liegen der Wasserschlange.

Sie holen zurück die Seelen der Getragenen zusammen mit den Penjang und den Karuhei des Reichtums.

Sie holen ein die Seelen der Gewiegten und sie bringen auch mit die Paturong Sangkalemo Radja.

Und schon aus der Nähe vernehmen sie den rauschenden Schall der geschlagenen Trommeln.

Und von dort drüben kommt schon der wehende Laut der Trommeln.

Angekommen ist das Schildbrett am abbröckelnden Steilufer, dem langen.

Es hält an, es steht still das Schildbrett, es legt an dicht bei dem abbröckelnden Steilufer, dem langen.

Es fährt herunter durch die Wasser der Djata, es fährt herab durch die Erde der Liebe.

\section{g. Die Seelen werden mit den Körpern vereinigt}

Halalian salumpok entang njelem pasok panangkiling Njaring.
Und es kehren wieder zurück die Seelen der Getragenen, und sie treten wieder ein in das Körblein, das einem Njaring gleicht (das rot ist, so wie 


\section{Manarusan behas mintih, manantame bangkusan tim- pong. \\ Badjamban bunge,n lalu-ham- patong, hatatean mina merang lu-palawi.}

Badjamban manas sambelom peron tambon, manas tasak kanti radja.

Badjamban tambaran erang tali,n tengang, upak langkoang leleng baho.

Hatatean kumis baringen haring nandai luwok lu-Djalajan.

Hajak djadi katotok tandak manolak lanting ambon barutas matei.

Djadi sambong lalu-karunja manjangka bangkar enon bapilo nihau.

Hajak tundjong-la-bahing radja manambawa entang buli.

Siring bambahinga,n kanarohan manangkiau tanterus tujang mulang.

Manambawa i-entang kurok kilau nambawa manok darong tingang. der Njaring rote Haare hat).

Und sie fahren hindurch durch den Reis, den ausgewählten, sie treten ein in die Bündelchen von Tuch.

Hindurchgehend durch den Sawang des Schnitzbildes (der Sawang ist Lebensträger und das Schnitzbild hat als Stellvertreter die gleiche Funktion), hindurchschreitend durch das klappernde Palawibild.

Hindurchgehend durch die Perlen, durch die schmalen blauen Glasperlen aus der Gallenblase der Wasserschlange, durch die Perlen Tasak Kanti Radja.

Hindurchgehend durch den Erangbast der Schnur von Tengang, durch die Langkoangrinde vom Sammelplatz auf dem früheren Felde.

Hindurchschreitend durch den Bast des Waringin, der da gedeiht über der Buchtung des Djalajan.

Und zu Ende gekommen ist das Lied des Wegschiebens der Wolken, der vernichtenden des Todes.

Und abgeschlossen ist nun der Gesang des in die Höhe hebens des Flosses mit den Tauwolken, den verderblichen des Verlorenen.

Und es erhebt sich die Stimme des Königs, und er ruft die Getragenen, dass sie zurückkehren sollen.

Und es wirft aus sein Wort, er der Fürst, und er ruft herbei die Seelen der Gewiegten, dass sie wieder heimkehren sollen.

Und er ruft die Getragenen, und er lockt sie mit dem Laute Kurok, so wie man herbeiruft die Hühner, die Hühner Tingang. 
Nangkiau tujang dje bara Und er ruft die Gewiegten mit dem kurei, tingkah nangkiau bulan bawin riwut burong.

Lockruf Kurei, so wie die Monde, die Frauen, rufen und nachahmen die Stimme des Huhnes.

Lalu sambang la-malik baUnd es ändert die Trommel ihren Laut hing,e, lu-manampong entang buli. um zu sammeln die Getragenen, die da zurückgekehrt sind.

Kruk hambaruan entang bakawan kilau burong tingang.

Toh djadi, ewen palus lepah buli huma.

Metoh,e intu ruar huma upo mantehau bara petak, koa,e:

Oi-ah! lepah ewen djadi buli nah?

Te ewen idje aton huang huma tombah, koa,e:

Endau-endau ikei!

Kruk! Seelen der Getragenen, sammelt euch in Scharen, so wie die Nashornvögel sich vereinigen.

Die Handlung ist nun beendet und sie kehren alle zusammen ins Haus zurück.

Während sie sich noch ausserhalb des Hauses befinden ruft der Hauptbalian von der Erde aus ins Haus hinein, und er erkundigt sich:

Oi-ah! Sind sie (die Seelen) soeben alle zusammen zurückgekehrt?

Und sie, die sich im Hause befinden, antworten und sagen:

Soeben sind wir alle zusammen zurückgekehrt (die zurückgekehrten Seelen geben diese Antwort).

Koa,n upo tinai korik-korik auch,e :

Buli ewen bakandong penjang karuhei tatau, basalungkem

Und es spricht der Hauptbalian wiederum mit gedämpfter Stimme:

Und zurückkehren sollen sie, begleitet von Penjang und Karuhei des Reichpaturong sangkalemo radja, bahaseng batu dia tau una, banjame liang kueh tau rugi.

Batahaseng dohong, bakatekang riwut peres, banjame pulang bakabantus salatan sampar. tums, zusammen mit Paturong Sangkalemo Radja, und mit einem Atem von Stein der nicht mehr vermindert, und mit einem Mund von Fels, der nicht mehr abnimmt.

Mit einem Atem wie Dolche, der abzuwehren vermag die Winde der Krankheiten, mit einem Wunde von Griffen die sich widersetzen können den Stürmen der Seuchen. 


\section{h. Die Bestreichung mit Erde und die Begiessung mit Wasser}

Toh ewen sama lompat akan huang huma malekak sangko sarangan danum ruang, malekak kare pasok hambaruan.

Te palus oloh tempo,n pampatei hakampeleng intu bentok huma ttg. amon olih te genegenep biti,n ewen manjaup danum ruang ttg. oloh balian mohos petak intu usok ewen oloh huma te handiai hajak mangarungut, koa,e :

I'nantemangku petak sintel habalambang tambon, ohosku liang deret habangkalan garantong, petak tapudjakan Djata Sangiang, petak tapudjakan Sahor Parapah, sauh entang kilau randong banama, tampuhak tujang tingkah kamaraun lanting radja.

Karambang entang kilau pulau pehon sawang, hambalat tujang tingkah ruang djumpong bunge.

Mangat entang belom kanuah anak Djata lampang, tau tu-
Nun treten sie alle zusammen in das Haus hinein und sie legen dort nieder den Sangko mit dem Wasser, das aus den Abteilungen des Bootes aufgeschöpft wurde und sie legen auch nieder das Körbchen mit dem Seelenreis.

Und sogleich versammeln sich die Besitzer des Todes in der Mitte des Hauses und wenn es irgendwie möglich ist übergiesst sich jeder einzelne von ihnen mit etwas Wasser das aus den Abteilungen aufgeschöpft ist und die Balian streichen etwas Erde an die Brust der Leute des Hauses und sie singen dazu :

Ich bestreiche dich mit Erde, der festen, die zur Schwelle hat die Wasserschlange, ich bestreiche dich mit dem Stein, dem harten, der als Schwelle besitzt den Gong, mit der Erde, die beschritten worden ist von der Djata und den Sangiang, mit der Erde, die betreten worden ist vom Sahor Parapah, mit der Erde, die da verankert den Getragenen so wie man verankert ein grosses Boot, mit der Erde, die da festbindet den Gewiegten so wie man mit einem geflochtenen Rotanseil festbindet das Floss, das königliche.

Die den Getragenen umzäunt wie eine Insel, wie ein Haufe von Sawangstauden, die den Gewiegten umfriedet wie die Abteilungen eines Gebüsches von Bunge.

Auf dass der Getragene lebe und angerufen werde durch das Kind der Djata, 
jang haring kanjambong das auftauchende, auf dass der Gebusu,n Hatala hadurut. wiegte gedeihe, aufgerufen durch den Jüngsten des Hatala der da herniederfährt.

\section{i. Die Festmachung der Seelen}

Toh belahe mambowor hambaruan intu gagenep takolok ewen oloh huma hajak mangarungut kea, koa,e:

I'buli entang buli hambarua,m lompat batu djundjun karapuron, djakat liang lambaran balau, $m$, nantame batu pariok aseng,m, dumah nambang budjang Sangiang, rampe nakep rajong Djalajan bara batang danum Rutas, gohong Bapilo.

Bakandong njalong kaharingan belom, basangkulem gohong kapaninting tahaseng.
Nun streuen einige die Seelen (d.h. den Seelenreis) auf die Köpfe aller derer die sich im Hause befinden und sie singen dazu:

Kehre zurück Getragener, kehre wieder heim, o Seele, besteige den Stein der Fontanelle, erklimme den Fels auf deinen Haaren und begib dich hinein in den steinernen Mörser des Atems, du die du zurückgeholt worden bist durch die Jünglinge der Sangiang, die du heimgeholt worden bist durch die jungen Burschen der Djalajan vom Flusse Rutas, vom Strome Bapilo.

Begleitet von dem Wasser des Lebens, dem lebenschaffenden, zusammen mit dem Wasser, dem Reiniger des Atems.

\section{k. Die Umbindung von Tambaranschnüren um die Handgelenke}

Toh belahe ewen oloh balian mameteng tambaran intu gagenep lenge, $n$ oloh are hajak kakarungut, koa,e:

I'naharungkangku tambaran erang tali,n tengang, upak langkoang leleng baho, kumis baringen haring manandai luwok lu-Djalajan.

Tisa,n karikar tingang balita,n Rawing Tempon Telon, kalabien sulat 392 Antang Linga
Einige der Balian umbinden nun die Handgelenke aller Leute mit Bastschnüren und sie singen dazu:

Ich umbinde das Handgelenk mit Erangbast, mit der Rinde des Langkoang vom Fundplatz auf dem früheren Feld, mit der Haut des Waringin der da gedeiht über den Buchtungen des Flusses Djalajan.

Den Rest des geflochtenen Gestelles des Tingang des Rawing Tempon Telon, den Ueberfluss des geflochtenen 
Lumba Habaron Bulau.

Akan djamban salumpok
entang gandang halalian buli,
indu tatean tanterus tujang
garantong kamalesan mulang,
buli bakandong njalong kaha-
ringan belom, mulang basang-
kulem gohong kapaninting
tahaseng.

Toh hapus gawi,n tantolak ambon barutas matei.
Bandes des Antang, des geschmückten Krokodiles mit dem goldenen Oberkleide.

Als Weg für die Seele des Getragenen, die wieder zurückkehrt wie der Schall der Trommel, als Brücke für die Seele des Gewiegten, der wieder heimkommt wie der Laut des Gong, begleitet von dem Wasser des Lebens, dem lebenschaffenden, und umkehrt zusammen mit dem Wasser, dem Reiniger des Atems.

Beendet ist nun die Arbeit der Wegschiebung der Wolken, der vernichtenden des Todes.

\section{Die Leitung der Liau nach dem Ort der Balo Indu Rangkang Penjang}

\section{A. Der dualistische Aspekt des Lebenden und Toten}

Der Mensch repräsentiert in seiner Existenz die Totalität des kosmischen und sozialen Dualismus. Er gehört der Unterwelt und Oberwelt an, aber er gehört auch der einen Stammhälfte und der andern Stammhälfte an. Er entsteht durch das Zusammenwirken von Oberwelt und Unterwelt und durch das gemeinsame Handeln der beiden Stammhälften, die sich im Geschlechtsakt vereinigen um neues Leben hervorzubringen. Vater und Mutter sind die Repräsentanten des sozialen Dualismus, der in der Stammesorganisation zum Ausdruck kommt. Diese Stammesorganisation, die wahrscheinlich ein doppeltes System zur Grundlage hatte, ist heute vollständig aufgelöst und lässt sich wohl kaum mehr rekonstruieren, aber dass sie in dieser Form einmal bestanden hat, lässt sich anhand der Texte, der Mythen und der Terminologie mehr als nur wahrscheinlich machen. Vater und Mutter sind die Angehörigen der beiden Stammhälften und es sind also diese, die in diesen beiden Individuen gemeinsam handelnd auftreten und das neue Menschenleben schaffen. Die beiden Stammhälften sind aber auch kosmologisch klassifiziert und die eine Stammhälfte ist mit der Oberwelt und die andere ist mit der Unterwelt assoziiert. So 
treten also auch Oberwelt und Unterwelt gemeinsam handelnd auf und schenken neues Leben. Der Dajak weiss, dass nur durch das $\mathrm{Zu}$ sammenwirken von Mann und Frau ein Mensch geboren werden kann. Bedeutung und Folgen des Geschlechtsaktes sind ihm durchaus bewusst. Aber er weiss auch, dass nicht er der Mächtige und der Schaffende ist, sondern dass sein Tun begleitet werden muss von dem Handeln und der Gabe der Oberwelt und der Unterwelt. Der Mensch kann von sich aus nichts allein tun. Es würde ihm nicht gelingen. Immer müssen Oberwelt und Unterwelt eingreifen und für ihn handeln und dadurch sein eigenes Handeln $z u$ einem göttlichen machen. Was er auch immer unternimmt, es gelingt ihm nur dann wenn die Götter für ihn handeln. Er kann den ersten Schritt tun, aber dieser Schritt bleibt ein vergeblicher, wenn nicht die Götter auf seinen Weg treten und ihn auf ihrem Weg mitnehmen. Nur dadurch erreicht er sein Ziel. Er geht nicht selbst, er wird mitgenommen. Dieses Wissen um das eigene Unvermögen einerseits und die helfende Gabe der Götter andererseits liegt allen Handlungen und allem Tun des Menschen zugrunde. Auch der sogenannten Magie, denn auch in ihr besitzt der Mensch keine Eigenmächtigkeit, sondern was er unternimmt gelingt nur deshalb weil ein Mächtigerer sich seiner Sache annimmt und sie für ihn ausführt. Auch die Magie dürfen wir nicht isolieren, sondern haben sie zu sehen in Verbindung mit dem ganzen religiösen System. Es gibt auch keine automatisch wirkende Macht, die der Mensch in Bewegung setzen könnte, weder im Kultus, noch in der Magie, noch bei der Rezitation der Mythen. Der Mensch kann immer nur bitten und die Götter können ihm helfen, wenn sie wenigstens wollen. Er kann auch den ersten Schritt gehen, aber ob die Götter dann automatisch den zweiten Schritt tun und auf seinen Weg treten und ihn mitnehmen, ist mehr als fraglich, denn die Götter sind frei und jede menschliche Hybris, die sich einbildet über die Götter verfügen zu können, wird von ihnen in der Weise bestraft, dass dem Menschen in Zukunft nichts mehr gelingt was er auch unternimmt. Jede menschliche Hybris führt ins Unheil hinein, weil die Götter nicht mehr hören und nicht mehr antworten. Nie schafft sich der Mensch selber das Heil. Nicht durch eigene Mächtigkeit wird er ein Glücklicher, Friedvoller und Heilvoller. Diese Mächtigkeit besitzt er einfach nicht. Glück (ontong), Friede (kasanang) und Heil (tuah) sind immer Gaben. Er kann sie nicht selbst finden und nicht selbst erwerben. Er kann sie nur empfangen. Und er empfängt sie dann ,wenn die Wasserschlange auftaucht und ihn anruft, wenn Ranjing Mahatala Langit herabfährt und 
ihm zuruft". Dieses Zurufen nennt man manuah und dieses Zurufen schliesst in sich die Gabe des Heiles, das tuah genannt wird. Heil findet man also nicht selbst, erwirbt es nicht durch magische Mittel und löst es nicht durch irgend ein Wort oder eine Handlung automatisch aus. Man muss angerufen werden, erst dann empfängt man es im Anruf selbst, und wird man nicht angerufen, dann helfen alle menschlichen Mittel nichts und man bleibt ausserhalb des Heiles. Heil und Leben, Frieden und Glück hat man immer nur als gleichzeitige Gabe von Oberwelt und Unterwelt beiden. Auch dass man darum bitten kann und dass man den ersten Schritt zu gehen vermag, ist ebenfalls Gabe der Götter und beruht nicht auf Eigenmächtigkeit oder auf machtvollem Wissen. Die Möglichkeit mit den Göttern in Verkehr zu treten hat der Mensch nie aus sich selbst, sondern immer von den Gö̈ttern als ihre gute Gabe. Sie müssen ihm erst den Weg zeigen, der Mensch weiss aus sich selbst den Weg nicht. Den Weg zeigen sie ihm in den Mythen und den religiösen Texten, in denen sich die Götter den Menschen selbst offenbaren. Man besitzt sie aber nie als einen machtvollen Eigenbesitz, mit dem man die Götter nun in den eigenen Dienst zwingen könnte. Götter lassen sich nun einmal nicht zwingen. Der Verkehr mit den Göttern ist nur dem möglich der sich an die damit verbundenen Bedingungen hält. Diese Bedingungen bestehen darin: Unterwerfung unter das Gesetz der Götter das in der Hadat niedergelegt ist. Erst diese Unterwerfung und das Wissen darum, dass die Möglichkeit mit den Göttern in Verkehr treten zu können, ausschliesslich Gabe ist die nicht in menschlicher Hybris missbraucht werden darf und die man auch nie zu einer eigenen Mächtigkeit machen darf, machen es dem Menschen möglich mit den Göttern in Verbindung zu treten.

Jede neue Menschwerdung ist eine Wiederholung der ersten Menschwerdung in der mythischen Vorzeit. Nicht der Mensch wiederholt diese Menschwerdung, denn sie ging in der mythischen Vorzeit ja auch nicht von ihm aus, sondern sie wird wiederholt von denen die den ersten Menschen entstehen liessen, nämlich von Ranjing Mahatala Langit, der in der Oberwelt wohnt und von der Tambon (Wasserschlange) oder wie sie mit ihrem andern Namen genannt wird, von der Bawin Djata Balawang Bulau (der weiblichen Djata mit der goldenen Türe), die im Urwasser haust. Die Tambon oder Djata gibt Fruchtbarkeit und Kindersegen. Man erbittet von ihr Kinder und sie beschirmt auch die Schwangere. Sie schafft den Leib des Menschen, der wie eine zusammengerollte Wasserschlange oder wie ein Fisch in dem mütterlichen Schosse ruht, aber nicht geboren werden könnte, wenn 
nicht Ranjing Mahatala Langit diesem Leib eine Seele geben würde.

Der Leib (bereng) wird verglichen mit der äusseren Hülle eines Baumstammes, mit einer Schwert- oder Dolchscheide (kumpang) oder auch mit dem geflochtenen Rotanring (gantuling) an einem Speerschaft, in den die eiserne Lanzenspitze gesteckt wird. Er wird also verglichen mit einer hölzernen Hülle oder einem Behälter. Wir wissen dass das Holz mit der Tambon assoziiert ist.

Die Seele (hambaruan) ist die Gabe des Ranjing Mahatala Langit. Sie wird in der Basa Sangiang genannt: salumpok. Dieses Wort bedeutet: das innerste Mark eines Baumes. Auf den Abbildungen des Lebensbaumes ist dieses innerste Mark dargestellt als ein eiserner Speer. Der zweite Name für Seele ist in der Basa Sangiang: tanterus. Im gewöhnlichen Ngadju bedeutet tanterus: hell, rein, glänzend, in der Basa Sangiang bedeutet tanterus: eingesteckt sein, das Verbum mananterus: einstecken, in etwas hineinschieben. Die Seele ist also in den Leib eingesteckt. Sie wird auch verglichen mit einem Dolch oder einer Lanze. Bevor ein Sangiang seine Seele in die Balian oder Basir einsenkt, singt man in den Texten:

Mapak bandjang kumpang Und er lässt herunter den Pfahl der tambon kurong labeho,n sa- Scheide der Wasserschlange, er lässt rong. ihn herunter in die Abteilungen der Wassertiefe der Herzgrube.

Scheide wird also hier mit Wasserschlange in Verbindung gebracht und die Seele wird verglichen mit einem Pfahl, der in diese Scheide eingesteckt wird. Die Seele des Sangiang, die in die Balian oder den Sangiang eingefahren ist, nennt sich selbst:

Dohong aku tambon turon, Ich bin der Dolch, ich bin die Wasserbuno sarong mangandawan.

schlange, die herabgefahren ist, ich bin die Lanze der Herzgrube, die heruntergekommen ist.

Lanze, Speer und Dolch, mit denen die Seele verglichen wird, sind deutlich assoziiert mit der Oberwelt. Wir wiederholen: Der Leib als Hülle ist die Gabe der Tambon oder der Djata Balawang Bulau, die Seele, die als innerste Substanz in dieser Hülle steckt, ist die Gabe des Ranjing Mahatala Langit. Nach seinem Leibe gehört also der Mensch zur Tambon, oder zur Stammhälfte die mit ihr assoziiert ist, nach seiner Seele gehört er zur Oberwelt, oder zur Stammhälfte die mit dieser assoziiert ist.

Wenn der Mensch stirbt ist er nicht tot. Durch den Tod wird er ein 
Toter (Liau) und tritt in die Existenzform und Lebensweise des Toten ein. Er verlässt diese Welt und er geht zu den Ahnen in die Totenwelt und führt in ihrer Gemeinschaft als Toter das Leben weiter.

Den Toten nennt man Liau. Das ist nicht der Name der Totenseele, sondern einfach des Toten. Liau apangku: die Liau meines Vaters, bedeutet: mein Vater, der ein Toter geworden ist. Die Seele wird keine Liau und auch der Leib wird keine Liau, aber Seele und Leib zusammen werden die Liau. Sie werden es nicht direkt nach dem Tode, sondern erst beim Tiwah (Totenfest), denn erst beim Tiwah findet die Vereinigung der beiden statt. Nach dem Tode fällt also der Mensch in die $Z$ weiheit auseinander. Es ist gut wenn wir für die nähere Bezeichnung dieser $Z$ weiheit nicht den Terminus Seele gebrauchen, sondern ganz einfach den dajakischen Ausdruck Liau unübersetzt wiedergeben, denn richtig übersetzen können wir ihn doch nicht. Der Mensch fällt also auseinander in zwei Liau und bleibt bis zum Tiwah in dieser $Z$ weiheit bestehen. Die eine Liau wird dann genannt: Salumpok Liau Haring Kaharingan. Schon der Name sagt uns, dass diese Liau mit der Oberwelt assoziiert ist und sie kehrt auch direkt nach dem Tode dorthin zurück, wo sie bis zum Tiwah bleibt. Ob sie wirklich in das Totendorf eingeht, wie Hardeland schreibt, scheint mir fraglich zu sein. Ueber diese Liau lesen wir in HardeLANDS Wörterbuch: „Ueber den Zustand der abgeschiedenen Seelen findet man bei den Dajak nur ganz dunkle, unbestimmte und dazu gar verschiedene und sich widersprechende Vorstellungen und Sagen. [So dunkel und unbestimmt sind die Anschauungen nicht. Hardeland war, trotz seiner grossen Kenntnis, doch zu wenig mit ihnen bekannt weil diese ganze Kenntnis eine umfangreiche und schwierige Spezialuntersuchung für sich darstellt. Sch.] Die meisten stimmen etwa in folgendem überein: gleich von dem Tode des Menschen an lebt dessen eigentliche Liau, auch salumpok liau oder panjalumpok liau genannt, fort, hat indess mehr ein schattenhaftes Dasein. Sie geht zwar gleich in das Lewu liau (Geisterland), hat aber dort noch keine eigentliche, ihr zugehörende Stätte; sie kommt auch oft von dort wieder zurück, durchstreift die Wälder etc. hier auf Erden, und bewacht das Grab, den Sarg, worin ihr Leib liegt. Während dieser Zeit tut die Liau oft Schaden, macht Menschen krank, entweder um frühere Beleidigungen zu rächen, oder weil sie jemand, welchen sie liebt, nachholen will. Um sie zu befriedigen gibt man ihr dann zu essen, opfert ihr Schweine, Hühner etc., auch Bretter mit Häusern, heiligen Töpfen etc. bemalt". Johannes 
Salilah erzählt von dieser Liau, dass sie aufsteige zu Ranjing Mahatala Langit. Beim Tiwah wird sie dann mit dem Leib vereinigt.

Die zweite Liau wird genannt: Liau Balawang Pandjang (die Liau der langen Türe). Sie hält sich nach dem Tode im Leibe auf der im Sarg ruht und ist der Leib selbst. Damit ist sie deutlich assoziiert mit der Tambon und Unterwelt. Hardeland nennt diese Liau: Liau krahang und schreibt von ihr (a.a.O.): „Es ist die mehr materielle, körperliche Seele, oder besser die seelische Substanz des Leibes, welche bis dahin bewusstlos in der Leiche zurückgeblieben war. $\mathrm{Zu}$ ihr gehören auch alle Haare, Nägel und Glieder welche der Verstorbene während seines Lebens verloren hat".

Das Tantolak matei beschäftigt sich mit dieser zweiten Liau und in unserem Abschnitt wird nun dargestellt wie Dohong Mama Tandang die Liau Balawang Pandjang nach dem Ort der Balo Indu Rangkang Penjang bringt wo sie bis zum Tiwah bleibt.

Beim Tiwah wird dann durch den Tempon Telon die Salumpok Haring Kaharingan nach dem Totendorf geführt und wenn das geschehen ist wird am Tage darauf die Liau Balawang Pandjang durch Dohong Mama Tandang nachgebracht. Im Totendorf werden die Liau miteinander wieder vereinigt und es entsteht dadurch der Tote in seiner leib/seelischen Ganzheit, der nun auch als Toter bei den Ahnen und Verwandten weiterlebt. Wir haben bereits auch gesehen, dass Tempon Telon und Dohong Mama Tandang mit den beiden Stammhälften assoziiert sind. Ich verweise dafür auf die ausführliche Einleitung.

\section{B. Die Vorbereitungen für die Leitung der Liau Balawang Pandjang}

Toh oloh manatap ramo hapan magah Anak Liau akan eka Balo Indu Rangkang, palus ih balian hamalem te kea.

Toh oloh manatap ramo, ie te:

Idje randjong imuat behas, hundjun behas te mandak bua
Nun bereiten die Leute alle Dinge vor um die Anak Liau (die weniger wichtige Liau die mit der Unterwelt und der den matrilinealen Aspekt der Gemeinschaft darstellenden Stammhälfte assoziiert ist) nach dem Orte der Balo Indu Rangkang zu leiten, die Balianhandlungen finden noch in der gleichen Nacht statt.

Nun bereiten die Leute alle Dinge vor, die notwendig sind, nämlich:

Einen Korb voll enthülsten Reis, auf dem Reis wird eine Kokosfrucht mit 
enjoh ttg. sawut.

Limbah te oloh mampendeng pakihu atawa rabajang.

Isi,n pakihu te imuno intu bua enjoh, tantahan pakihu impendeng akan ngambo indjarat hapan uei bua-buah mangat dia balihang.

Intu lawi,n tantahan pakihu oloh mangantong atawa mangkoak Balai Lumpang idje djari inampa ttg. sukup kare dawen sawang hajak ingampoh hapan benang babilem.

Tau kea oloh mampendeng batang sawang manjaroi pakihu te, tapi kanateke dia usah.

Karana koa,n belahe: hindai mampendeng sawang, amon oloh maniwah,e atawa tiwah.

Darah upo,n sawang te oloh mingkes idje gantang idje kontep imuat behas, huang,e aton hidjir bendang, aton kea lamiang ttg. ewen mampalua panginan kea iandak hundjun apar.

Kare pasok hambaruan ttg. talo beken hapan, idje djari aton. den Fasern niedergelegt.

Und darnach richten die Leute einen Pakihu oder Rabajang auf (d.h. einen heiligen Speer mit langen Widerhaken).

Das Eisen des Pakihu wird hineingesteckt in die Kokosfrucht, der Schaft des Pakihu wird nach aufwärts gerichtet und gut mit Rotan festgemacht, damit er nicht umfallen kann.

Am Ende des Schaftes des Pakihu hängen die Leute (oder sie befestigen daran) den Balai der Bambusköcher, welcher bereits gemacht und genügend versehen worden ist mit Sawangblättern, und den man verhüllt hat mit einem schwarzen Tuch.

Es kann auch geschehen, dass die Leute eine Sawangstaude längs dem Pakihu aufrichten, aber bisweilen ist das nicht nötig.

Denn es sagen einige der Leute: wir richten noch keine Sawangstaude auf, wir tun das erst wenn wir das Tiwah veranstalten.

Neben der Sawangstauden legen die Leute einen Gantang nieder der gefüllt ist mit enthülstem Reis, darin befinden sich auch Bendangstäbe und auch Achatsteine sind vorhanden und sie bringen auch die Speisen und legen sie auf einen Aparteller (ein Teller von Bronze der auf einem Fuss ruht und mit einem gezackten Rand umgeben ist).

Alle Körbchen die gefüllt sind mit dem Seelenreis (d.h. der Reis in dem sich die Seelen befinden) und alle andern Dinge die man bereits gebraucht hat und die auch vorhanden sind. 
Maka amon djadi te upo,n balian manjoho ewen tempo,n gawi mampalua duit besei teken.

Kare,e dia musti, tau kea idje ringgit akan genep biti,n ewen panombah ttg. due ringgit akan upo, maka duit te indjam handjulo bewei, amon hapus gawi te upo malian duit te akan tempo.

Ampin ewen oloh balian hapan duit te, ie mamangkit,e hajak mahantok intu takolok ai,e ttg. mahantok duit te intu katambong.

Amon djadi mahantok kalote, te ewen mingkes duit te akan huang lawong,e, tau kea huang pakaia,e, tau kea huang pakaia,e beken, asal tatap aton intu ie hamalem te.

Limbah ie manarima duit panombah balian atawa upo manjaki kare ramo te hapan daha,n manok.

Maka marak ramo te aton kea barang pakaian, tinai katune, sundur sarak, kare saramin ranen.
Wenn das geschehen ist, dann gibt der Hauptbalian den Besitzern der Arbeit den Auftrag das Geld für die Ruder und Schiebebäume herauszugeben (d.h. für die Leitung der Liau).

Wieviel es sein muss wird nicht bestimmt, es kann sein einen Ringgit $(f$ 2.50) für jeden Beantworter und zwei Ringgit für den Hauptbalian, dieses Geld wird nur für kurze Zeit geliehen, sind die Arbeiten zu Ende dann gibt der Hauptbalian das Geld den Besitzern wieder zurück.

Die Art und Weise wie die Balian das Geld gebrauchen ist diese: sie beissen in das Geld und sie beklopfen mit ihm ihre Köpfe und sie berühren mit dem Geld auch die kleinen Trommeln.

Wenn sie auf diese Weise mit dem Geld die Köpfe und die Trommeln berührt haben, legen sie das Geld in ihre Kopftücher, es kann auch sein, dass sie es in ihren Kleidern die sie auf dem Leibe tragen oder in solchen die sie abgelegt haben bergen, die Hauptsache ist, dass es bereit liegt und dass sie es bei sich haben während dieser Nacht.

Nachdem sie das Geld empfangen haben bestreichen die Beantworter oder der Hauptbalian alle Gebrauchsgegenstände mit Hühnerblut.

Aber unter diesen Dingen befinden sich auch Kleidungsstücke, ferner Katune zum Schwarzfärben der Zähne, ein enger und ein weiter Kamm, ein Spiegel und andere Dinge mehr. 


\section{Die rituelle Bestreichung der Gebrauchsgegenstände}

Toh upo manjaki,e hajak mangarungut, koa,e :

I'njakiku rangkan panginan simpan, malasku uras hakanjatan sukup, manok darong tingang, katupat namputing bulau, njakiku behas tambak radja, uras akan upah Sangiang Mama Tandang, upah,e antang manamuei mampisik liau haring kaharingan bara bulau sambang raung intu bukit pasahan raung.

Hai pahalendang,m ikau rangkan panginan, pangkor paju,n lingu, $n$ Dohong Mama Tandang, rindang telo karendem Langkah Sawang Mama Bungai Bunge bandong Njaring djahawen.

Palus akan upah,e antang manamuei magahan liau haring kaharingan manjembang Balo Indu Rangkang Penjang.

I'njakiku behas idje gantang radja, kareh Sangiang manjaloh djari baras bulau, bu-
Der Hauptbalian bestreicht sie nun und er singt dazu :

Ich bestreiche alle Esswaren die bereit gemacht worden sind, ich wische ab alle Nahrung die in genügender Zahl vorhanden ist, die Hühner, die Hühner Tingang, die Katupatkuchen mit den goldenen Ecken, ich bestreiche den Reis, den königlich aufgehöhten, alle diese Dinge dienen als Lohn für den Sangiang Mama Tandang, alle diese Sachen werden gegeben als Entschädigung für den reisenden Falken, welcher aufweckt die Liau des Lebens, die lebenschaffende, aus dem goldenen ausgehöhlten Sarg auf dem Berge der Hütten der Särge.

Gross sei euer Glanz, ihr Esswaren, damit aufgeweckt werde im Innern des Dohong Mama Tandang die Lust und das Verlangen, auf dass sich freue und von Begierde ergriffen werde in seinem Herzen der Langkah Sawang Mama Bungai Bunge, der Mann der sechs Njaring.

Und gleichzeitig auch als Lohn für den reisenden Falken der da führt die Liau des Lebens, die lebenschaffende, dass sie ankomme bei der Balo Indu Rangkang Penjang. (Der Name der Liau ist hier unrichtig, insofern aber doch wieder richtig, weil die beiden Liau nur in ihrer Vereinigung eine sinnvolle lebende Ganzheit bilden. Der entscheidende Ausdruck Salumpok fehlt.) Ich bestreiche dich Reis, der du dich in dem königlichen Gantang befindest, später werden die Sangiang ihn ver- 
song hintan, karangan bawak lamiang hapa manimbok djandjihin parong liau ano.

I'njakiku pamantilon bendang bulau, kareh Sangiang manjaloh,e huang lewu,n Balo Indu Rangkang Penjang djadi garing djandjihin parong.

I'njakiku ikau sundur bulau, malasku hajak sarak rabia hapan ngabadjuran pandong lawin balau salumpok liau ano.

I'njakiku katune raho babilem, malasku katiting kendjut bintang hapan liau ano marasih bulau pantar tatah,e.

I'njakiku sambang garantong, malasku pinton djandjingan muat rangkan kapakaian simpan, timpong awang nandjak bantika riak hendan bulau, lamiang omba garing belom.

Pangkur paju,n lingo, rindang telo karendeme panjalumpok liau ano.

I'njakiku pasok panangkiling $\mathrm{Njaring}$, dare, $\mathrm{n}$ djumbang bahandang muat behas parei njangen tingang mangat tau djari baras bulau, busong hintan, injakiku bua katilambong wandeln dass er werde zu goldenem Sand, zu Steinbänken von Edelsteinen und $z u$ Achaten um aufzuhöhen die Pfosten des Hauses der Liau N.N. Ich bestreiche euch ihr goldene Stäbe von Bendangbambus, später werden die Sangiang im Dorfe der Balo Indu Rangkang Penjang sie verwandeln in elfenbeinerne Seitenbalken des Hauses. Ich bestreiche dich, du goldener enger Kamm und ich wische dich ab du goldener weiter Kamm die ihr dienet um in Ordnung zu bringen die Haare der Salumpok Liau des N.N.

Ich bestreiche dich schwarzglänzender Katune, ich wische dich ab Katiting, der du leuchtest wie die Sterne, du dienest zum Gebrauch der Liau des N.N., damit sie mit dir reinigen kann den goldenen Zaun der Zahnstifte.

Ich bestreiche euch, ihr Trommeln und Garantong, ich wische euch ab, ihr Trommeln und Gong, die ihr gefüllt seid mit den Kleidungsstücken und mit Schmuck die in genügender Zahl vorhanden sind, in denen aufgehäuft liegen die Tücher mit den Webeeinschlägen der gelben goldenen Wellen, und mit den Achaten die da gehören zum Lebensbaum.

Sie die die Begierde und das Verlangen des Herzens, die Freude und das Begehren des Innern der Liau des N.N. sind.

Ich bestreiche den Korb der da einem Njaring gleicht, das Geflecht des roten Korbes der gefüllt ist mit dem enthülsten Reis des Reises Njangen Tingang, damit er sich verwandeln könne in goldenen Sand und in Stein- 
njaho, katuen njior bendang, kareh manjaloh,e djadi labeho,n bulan, rantau pahawang, djadi labeho penda tewai sawang, rantau ulek patik ranggan buno, eka hapandujan salumpok liau ano.

I'njakiku ranjing pandereh buno, malasku renteng nanggalong bulau, sama hai ikau palalendang, datoh ikau palalingei.

I'njakiku sawang ringkan tingang, malasku bunge kangkajoh langit, sama hai ikau palalendang,e, rata datoh ikau palalingei.

I'njakiku balai lumpang lalunding liau, malasku sali djajang tingang munuk ambon, kareh Sangiang manjaloh,e huang lewu,n Balo Indu Rangkang djadi balai garantong ajun-ajun bahing,e, sali djandjingan umba-umban djandjahinga, idje tau mamarit rangkan panatau simpan akan salumpok liau ano.

I'njakiku timpong babilem sarong lawang bau,n andau, kareh Sangiang manjaloh,e djadi timpong nandjak ban- bänke von Edelsteinen, ich bestreiche die Kokosfrucht, die reife Frucht der Kokospalme, denn sie soll sich hernach verwandeln in eine Wassertiefe der Frauen, in eine Wassertiefe der Monde, sie soll werden $\mathbf{z u}$ einer Wassertiefe unter den Sawangsträuchern, unter den Büschen von denen man die Speerförmigen Früchte abpflückt (die Blätter), sie soll werden zu einem Badeorte für die Liau des N.N.

Ich bestreiche den verehrungswürdigen Speer, ich wische ab die Schwanzfeder, die das Gold umschliesst, gross soll ihr Leuchten sein, erhaben ihr Glanz.

Ich bestreiche dich, o Sawangstaude von der Ausschau hält der Tingang, ich wische dich $a b$, o Bunge von dem aus man den Himmel sieht, gross sei dein Leuchten, erhaben sei dein Glanz. Ich bestreiche dich, o Balai der Bambusköcher mit dem Reichtum der Liau, ich wische dich ab, o Haus Djajang der Tingang das verhüllt ist mit schwarzen Wolken, hernach, in dem Dorfe der Balo Indu Rangkang, werden die Sangiang es verwandeln in einen Balai von Garantong der seinen Schall hin- und herwiegt, in ein Haus der Gong das seinen Laut hin- und herschwenkt und der da einen Weg macht, auf dem herbeigeführt werden können die für die Liau des N.N. bereitgemachten Reichtümer.

Ich bestreiche das schwarze Tuch, die Hülle der Türe der Wolken, hernach werden die Sangiang es verwandeln, dass es zu einem Stück Tuch werde 
tika.

mit Zeichnungen und gewobenen Streifen, den vielfarbigen.

Toh djadi kare saki,n talo te handiai.

Beendet ist nun die Bestreichung aller dieser Gebrauchsgegenstände.

\section{Die Sangiang werden herbeigerufen um das Schildbrett zu beladen}

Upo,n balian ewen uras mondok intu katil.

Huang palian ewen te ewen mambawa Sangiang bara papan talawang mangat dumah akan huma manduan gana,n ramo idje injaki mimbit,e akan papan talawang.

Toh ewen hapan lago: Nansaran ramo namuei, koa,n bawak tandak,e:

Bahing lu-bapanting maneras bandong i-lasang, siring ibambahinga Djalajan maluhing gentoi burong.

Lalu bahing panganak andau njalumbo parong kurong mangentang, bambahinga, $\mathrm{n}$ panjandai bulan manehos siro saripangku.

Manamuei papan talawang manarindjet tingang Sangiang, mangadja bulau dare,n lintong natugoh bungai $\mathrm{Dja}$ lajan.
Der Hauptbalian und alle andern Balian sitzen auf der Bank.

Bei ihren priesterlichen Handlungen rufen sie nun die Sangiang vom Schildbrette herbei, damit sie hereinkommen in das Haus um die Seelen der Güter welche bestrichen worden sind abzuholen und sie auf das Schildbrett $z u$ bringen.

Sie gebrauchen nun die Weise: $A b$ holung der Güter die für die Reise gebraucht werden und ihr Gesang lautet:

Es erschallt die Stimme aus dem Bandongboote (es sind also die Sangiang die aus den Balian sprechen), es ertönt das Wort der Djalajan die da wie Pfosten stecken in dem Vogelboote.

Es erschallt wie das Summen des Anak Andau und es steigt auf im Hause im Zimmer in dem man ausführt das Hülfswerk, es ertönt wie das Zirpen der Sandai der Monde das da herabfährt in der Wohnung in der man vollzieht das auf den Schoss nehmen.

Es begibt sich hin zum Schildbrett und es schüttelt sanft die Tingang, die Sangiang, es geht hin zum goldenen geflochtenen Band und es stösst vorsichtig an die Nashornvögel, die Djalajan. 
Sama pararindjet hajak Und gemeinsam schütteln sich die Sangiang huang papan talawang, rata pararugoh hindje Djalajan medjen bulau dare,n lintong.

Rawing rata hapantar pinang, busau pinang hakaisek rawei, Djalajan kajal uring manjang, lalu ringkang sarohi tisoi :

Kilen talatai pangentang, apang, balua parong kurong mangentang, isen runtan saripangku, mama, bahandjong siro saripangku?

Kabadjuran talatai pangentang, anak, keton nansaran paramo,n namuei, kabarengan runtan saripangku, aken, keton misat parabean kenjoi mangadja.

Lalu gatang tarahendeng Sangiang sintong udju, hajak tundjong tarahingkat pangandien lambong hanja.

Hatanggar renteng tingang, ngambuah djundjong sampulau dare, mantapei timpong pandjang akan panambai papan talawang.

Nusang renteng tingang malan balua papan talawang, Sangiang im Schildbrett, und es recken und strecken sich die Djalajan im goldenen geflochtenen Band.

Und die Krokodile kauen zusammen Pinang, und trunken sind sie von den Pinang und es forscht ihr Wort, betäubt sind die Djalajan von den Betelnussfrüchten und es erkundigt sich ihre Rede:

Wie steht es in der Sache des Hülfswerkes, o ihr Väter, mit dem Heraustreten aus dem Haus, aus dem Zimmer, in dem $z \mathfrak{u}$ verrichten ist das im Brusttuch tragen, wie steht es mit unserer Handlung des auf den Schoss nehmens, o ihr Onkel, des Herausschreitens aus der Wohnung, in der man vollzieht das auf den Schoss nehmen?

Recht steht es mit der Sache des Hülfswerkes, o ihr Kinder, ihr kommt nun und holt ab die Güter die wir nötig haben für die Reise, gut steht es in der Angelegenheit des auf den Schoss nehmens, o ihr Neffen, ihr ladet nun auf die Sachen die der reisende Falke nötig hat.

Und sogleich erheben sich und stehen auf die Sangiang, sieben zusammen, und es erheben sich und stehen auf die Tiger, die da vermehrt sind zu acht.

Sie bringen in Ordnung die Schwanzfedern der Tingang, sie machen richtig die geflochtene Kopfbedeckung, sie heben auf das Tuch, das lange, das über dem Schildbrett aufgespannt ist. Sie beugen die Schwanzfedern der Tingang und sie machen sich auf um 
maniling pating bungai Djalajan bahandjong bulau dare,n lintong.

Manetei djamban garing lompat balai rampar buno, haratean paratar sihong djakat sali tilap talawang.

Rahun mangasoh buno balua balai rampar buno, manting manganduran renteng,e bahandjong sali tilap talawang.

Kandjan burong tingang tonggal halawo labeho,n parong mangentang, tari,n anak antang sahin njababeroh siro saripangku.

Surong djandjulana Sangiang nanturong paramo,n antang manamuei, rajong $\mathrm{Dja}-$ lajan manjahendeng parabean kenjoi mangadja.

Nekap,e hiring dohong, nawa darah manok darong tingang manjaki paramo,n antang namuei, malas parabean kenjoi mangadja.

Njaki hararaha lepah paramo,n antang namuei, malas herauszutreten aus dem Schildbrett, sie senken die $Z$ weiglein der Nashornvögel und sie kommen hervor aus dem goldenen geflochtenen Band.

Sie beschreiten den Weg, den elfenbeinernen und sie besteigen den Balai der nebeneinanderliegenden Speere, sie begehen die elfenbeinerne Brücke und erklimmen das Haus der aufeinandergeschichteten Schilde.

Wie das Wasser herabfliesst an den Lanzen, so treten sie heraus aus dem Balai der nebeneinander liegenden Speere und sie wiegen und spreizen ihre Schwanzfedern und sie kommen hervor aus dem Hause der aufeinandergeschichteten Schilde.

Schwebend wie ein Tingang lassen sie sich plötzlich herunterfallen in die Wassertiefe des Hauses in dem man verrichtet das Hülfswerk, schwebend wie ein junger Falke stossen sie plötzlich herunter in die Wohnung in der man vollzieht das auf den Schoss nehmen.

Und beendet ist die Reise der Sangiang und sie begeben sich $\mathbf{z u}$ den Gütern des reisenden Antang, und die Jünglinge, die Djalajan, nähern sich den Sachen des hinwegziehenden Falken.

Und sie packen die Schärfe des Dolches und sie fangen auf das Blut des Huhnes, des Huhnes Tingang und sie bestreichen mit ihm die Güter des reisenden Antang, und sie wischen ab die Sachen des hinwegziehenden Falken.

Sie bestreichen alle die nebeneinanderliegenden Güter des reisenden Antang, 
hatataja parabean kenjoi rawen mangadja.

Totok tandak,e lu-Sangiang manjaki paramo,n antang namuei, sambong karunja,e iluDjalajan malas parabean kenjoi lu-mangadja.

Kila-kilat i-isi,n dohong,e Sangiang bentok lu-labeho,n parong.

Manantan paramo,n i-antang namuei djalan Sangiang manandjuri gana,e, maharis parabean kenjoi mangadja, tandohan Djalajan nantekei labata.

Kilat-kilat i-isi,n dohong,e mangandang paramo,n antang namuei, pantja-pantjar la-garing pulang,e manitih parabean kenjoi mangadja.

Sama hajak padjandjuri gana,e kare paramo,n antang namuei, rata humboh panantekei labata parabean kenjoi rawen mangadja. sie wischen restlos ab die ausgebreiteten Sachen des hinwegziehenden Falken.

$\mathrm{Zu}$ Ende ist das Lied der Sangiang, die da bestrichen haben die Güter des reisenden Antang, verstummt ist nun der Gesang der Djalajan, die da abgewischt haben die Sachen des hinwegziehenden Falken.

Und es zucken auf die Blitze des Eisens der Dolche der Sangiang in der Mitte der Wassertiefe des Hauses. Und sie durchschneiden die Güter, die bestimmt sind für den reisenden Antang, und sie machen einen Weg, damit die Sangiang hervorgehen lassen können ihre Seelen, sie durchhauen die Sachen die der hinwegziehende Falke benötigt und sie machen einen Pfad, damit die Djalajan hervortreten lassen können ihre Seelen.

Es zucken die Blitze des Eisens ihrer Dolche und sie beklopfen die Güter des reisenden Antang, es funkeln die elfenbeinernen Griffe und sie schlagen auf die Sachen des hinwegziehenden Falken.

Und gemeinsam treten heraus die Seelen aller Güter des reisenden Antang, und zusammen kommen hervor die Seelen aller Sachen des hinwegziehenden Falken.

\section{E. Das Schildbrett wird beladen}

Toh malik tekap ttg. lago,n manandak tumon lago: $M a$ muat papan talawang. Koa,n tandak,e :

I'ohoi bara ohoi nansaran ramo,n antang namuei, i-ehei
Es ändert sich nun der Trommelschlag und die Weise des Gesanges nach der Melodie: Beladung des Schildbrettes. Der Gesang lautet:

Ohoi und noch einmal ohoi, kommet herzu $z \mathfrak{u}$ den Gütern des reisenden 
bara ehei nampuisat parabean kenjoi mangadja.

I'lepah paramo,n antang namuei taratambang djari,n budjang Sangiang, i-lingis parabean kenjoi mangadja taratekap karah rajong $\mathrm{Dja}$ lajan.

Imbit,e nanturong bauntonggang parong, manjahendeng bambuakan siro.

I'ohoi bara ohoi imbit,e njelem papan talawang.

I'ehei bara ehei, imbite nantame bulau dare,n lintong.

I'lepah paramo,n antang namuei djari imbit,e njelem papan talawang.

I'lingis dje parabean kenjoi mangadja imbit,e nantame bulau dare,n lintong.

I'djadi katotok tandak,e mamuat papan lu-talawang.

I'sambong lu-karunja mameno bulau dare,n lintong.

I'hando manandjulo bahing panto,n sambang, balasang bahing lu-karungut.

I'tahan manalandjat bambahinga,n luhing, bagentoi salatan lukandaju.
Antang, ehei und noch einmal ehei, nahet euch den Sachen des hinwegziehenden Falken.

Restlos haben die Finger der Jünglinge der Sangiang ergriffen die Güter des reisenden Antang, ohne auch nur etwas übrig zu lassen haben die Hände der Burschen, der Djalajan, angepackt die Sachen des hinwegziehenden Falken.

Und sie bringen sie wegschreitend zur Türe des Hauses, sie tragen sie fortgehend zur Oeffnung der Wohnung. Ohoi und noch einmal ohoi, sie werden hineingetragen in das Schildbrett. Ehei und noch einmal ehei, sie betreten mit ihnen das goldene geflochtene Band.

Restlos sind die Güter des reisenden Antang herzugebracht und hereingetragen in das Schildbrett.

Ohne etwas übrig zu lassen sind die Sachen des hinwegziehenden Falken herbeigetragen und man hat mit ihnen beladen das goldene geflochtene Band. $\mathrm{Zu}$ Ende ist nun der Gesang der Beladung des Schildbrettes.

Verstummt ist nun das Lied des Füllens des goldenen geflochtenen Bandes. Schweige nun für kurze Zeit, du Laut des Schlagens der Trommeln, verstumme zusammen mit den in ihren Booten befindlichen Gesängen (d.h. der Sangiang, die sich in den Balian inkorporiert haben und durch ihren Mund singen).

Brich ab für einen Augenblick, o Schall der Trommeln, zusammen mit den Liedern die aus den Fahrzeugen emporsteigen. 


\section{F. Das Schildbrett vor seiner Abfahrt zum Bukit Pasahan Raung}

Toh upo kabuat,e mangarungut manatap Sangiang huang papan talawang teras kaju djambu bahandang lius hagoet akan bukit Pasahan Raung.

I'rinkes-marakesa Sangiang huang papan talawang teras kaju djambu bahandang.

Lalu ringkin-basariang $\mathrm{Dja}-$ lajan medjen bulau dare,n lintong luhing lumpok muntei bulau.

I'rawing rata hapantar pinang, busau pinang hakarangka rawei, kabasewan dje uring manjang ringkang mapak lu-basara.

Gatang tarahendeng Dohong Mama Tandang, tundjong tarahingkat Langkah Sawang Mama Bungai.

Lalu mendeng manambawa riwut, radja hingkat nangkiau salatan.

Mendeng manambawa riwut tingang balua djundjong lunok, manambawa riwut tandang haramaung balua batu kandawa, manambawa riwut pasihai bara kangkelong sambang, riwut bulau bara djalahan hulu danum, riwut timpong bara kalimbahan laut.
Der Hauptbalian singt nun allein und er macht die Sangiang im Schildbrett, im Kernholz des roten Djambuholzes, bereit um wegzufahren nach dem Berge der Hütten der Särge.

Es bringen die Sangiang alles in Ordnung im Schildbrett, dem Kernholze des roten Djambubaumes.

Und es machen alles bereit die Djalajan im goldenen geflochtenen Band. in dem Stamme des Kernholzes des goldenen Munteibaumes (anderer Name für Djambu).

Die Krokodile kauen gemeinsam Pinang, und sie sind trunken von ihren Pinang und sie überlegen ihr Spruchwort, sie sind betäubt von den Früchten der Betelnusspalme und sie beschäftigen sich mit ihrer Angelegenheit.

Es erhebt sich und steht auf der Dohong Mama Taridang, es erhebt sich und steht auf der Langkah Sawang Mama Bungai.

Und er steht da und ruft den Winden, und der König hat sich erhoben und ruft den Winden.

Und er steht da und ruft dem Winde des Nashornvogels, dass er hervortrete aus der Krone des Lunokbaumes, er ruft dem Winde des Tigers, dass er herauskomme aus seiner Höhle, er ruft dem Winde der Pasihai, dass er hervortrete aus der ausgetieften Trommel (handelt sich um einen Gong worin die Pasihai aufbewahrt werden), er ruft dem Winde des Goldes, dass er 
herabkomme vom Oberlauf, vom Quellort des Flusses, und er ruft dem Winde des Tuches, dass er heraufziehe von der Mündung des Stromes an der See.

Manambawa riwut tambon Und er ruft dem Winde der Wasserbalua kalang labeho,n handalem.

Eleh dumah riwut hakampeleng indu ganggulon papan talawang, rampe salatan bahantap akan pamaruwei bulau dare, $n$ lintong.

Manantong sambang bulau putir bawi,n Sangiang, hajak tatap hapantar pinang, palus tingang ie tolak lunok, tambon basangka baras.

Engkak bulau manamburak, idjit nansupit teken garing, nguhas tatambat keket, hadjadjita paratar sihong. schlange, dass er auftauche aus seiner Wohnung in der Wassertiefe, der abgründigen.

Und schon kommen die Winde herbei und sie versammeln sich um vorwärts $z u$ treiben das Schildbrett, es kommen an die Winde um sehr heftig fortzubewegen das goldene geflochtene Band. Und es schlagen ihre goldenen Trommeln die Putir, die Frauen der Sangiang, und beendet ist nun das Kauen der Pinang und nun fliegt weg der Nashornvogel vom Lunok, und es stösst ab die Wasserschlange von der Sandbank.

Löset das goldene geflochtene Seil, ziehet heraus und zerret hervor den elfenbeinernen Stossbaum, machet los den Strick hinten am Boot, holet herein die Treppe, die elfenbeinerne.

\section{G. Die Abreise des Schildbrettes}

Toh ewen oloh balian manekap katambong ttg. manandak lepah biti,e hapan lago: $M a$ nolak papan talawang, koa,e:

I'ohoi dje bara ohoi, ilu-manolak papan talawang, i'ehei dje bara ehei, ilu-manjangka bulau dare,n lintong.

Tolak papan talawang teras kaju djambu bahandang, basangka dje bulau dare,n lin-
Nun schlagen die Balian die kleinen Trommeln und sie alle zusammen singen nach der Weise: Abreise des Schildbrettes, und ihr Gesang lautet:

Ohoi und noch einmal ohoi, wir schieben weg das Schildbrett, ehei und noch einmal $e h e i$, wir stossen ab das goldene geflochtene Band.

Reise weg Schildbrett, Kernholz des Djambubaumes, des roten, stosse ab, goldenes geflochtenes Band, Pfahl vom 
tong luhing lumpok muntei bulau.

Ngaragan awi Dohong Mama Tandang, Langkah Sawang Mama Bungai.

I'tolak papan talawang bara ninggang salanting parong.

Basangka bulau dje dare,n lintong bara tarikajun 393 lubabungan.

I'tolak para-parang kilau bawi,n antang ngamparang tandjong, i-sangka tentetenteng kilau kamaras bau,n djumban bahandang.

I'bahing gandang garantong, pasang njaho,n badil tambon.

Toh oloh mampahiau gandang garantong, tau kea manembak.

I'kilat basangkelang papan talawang, njangkelang pulau pehon sawang, lio dje basampale bulau dare,n lintong, manjarak ruang djumpong bunge.

I'manjangkelang garing batang pantar pandjang, dje manjampale sanggaran dahiang.
Marke des Munteibaumes, des goldenen.

Als Befehlshaber hast du den Dohong Mama Tandang, den Langkah Sawang Mama Bungai.

Reise weg, Schildbrett, aus der Nähe deines Anlegeplatzes im Haus.

Stosse ab, goldenes geflochtenes Band, von der unteren Seite des Daches des Hauses.

Reise weg, querliegend wie die schwebenden weiblichen Antang, querliegend zur Buchtung, stosse ab in gerader Fahrt die da gleicht der Geradheit der Oeffnung des roten Korbes. (Das Boot fährt schräg über den Fluss um gegen die Strömung anzurudern.)

Erschallet, ihr Trommeln und Garantong, und schwelle an, du Donner der Kanone der Wasserschlange.

Die Leute schlagen nun die Trommeln und die Gong und es kann auch sein, dass sie schiessen. (Geschossen wird mit Gewehren oder mit alten Kanonen die noch aus der Compagniezeit stammen und heilig sind. Meistens werden sie beim Pataho aufbewahrt.)

Die Blitze zucken um das Schildbrett und sie vermengen sich mit den Inseln, den Haufen der Sawangstauden, der Regenbogen leuchtet auf über dem goldenen geflochtenen Band und er vermischt seine Farben mit dem Gebüsch der Bunge.

Sie vermengen sich mit dem elfenbeinernen Pfahl, dem langen, sie vermischen sich mit dem Sanggaran der Vorzeichen. 
I'manjangkelang batang pinang lewu, dje manjampale katilambong njaho.

I'papan talawang teras djambu bahandang njaruroi tarusan sawang lewu.

I'bulau dare,n lintong luhing lumpok muntei bulau hapan lapetan bunge rundong.

I'papan talawang dje teras kaju djambu bahandangm habasean tandjong sapapulut lewu.

Panuhan bulau dare,n lintong lumpok muntei bulau, mangkajoh luwok kadjalumpang rundong.

I'papan talawang habasean tandjong nangka lewu, i-bulau dje dare,n lintong mangangkajoh luwok djambu,n rundong.

I'surong besei dje, surong teken papan talawang antang namuei.

I'papan talawang mahalau sara,n dandang Njaring, panuhan dje bulau dare,n lintong malangkawet gahisan penjang.
Sie vermengen sich mit den Pinangpalmen des Dorfes, sie vermischen sich mit den Kokospalmen, den donnernden.

Das Schildbrett, das Kernholz des roten Djambubaumes, geht auf die Fahrt und es rudert weg auf dem Fahrweg der Sawangstaude des Dorfes.

Das goldene geflochtene Band, der Pfahl des innersten Holzes des Munteibaumes, des goldenen, reist weg auf dem Kanale des Bunge des Ortes.

Das Schildbrett, das Kernholz des roten Djambubaumes, rudert entlang der Buchtung Sapapulut des Dorfes.

Das kostbare goldene geflochtene Band, der Pfahl des innersten Markes des goldenen Djambubaumes, fährt längs der Flussbiegung Kadjalumpang des Ortes (mit diesen beiden sogenannten Flussbiegungen sind wahrscheinlich die Palmen gemeint. Das Schildbrett fährt durch das ganze Dorf. Ausserhalb des Dorfes sind die Särge aufgebahrt).

Das Schildbrett rudert entlang der Flussbiegung der Nangkabäume des Dorfes, das goldene geflochtene Band fährt längs der Buchtung der Djambubäume des Ortes.

Schnell schlagt eure Ruder, rasch stosst ein die Stossbäume des Schildbrettes des reisenden Falken.

Das Schildbrett rudert vorbei an den Rändern der ausgestreckten Wohnungen der Njaring, das kostbare goldene geflochtene Band rudert vorüber an den Fundplätzen der Penjang. 
I'ohoi bara ohoi, habasean tandjong karamunting baho, i'ehei bara ehei, i-mangangkajoh luwok kandujong dohong. ${ }^{394}$

I'ohoi dje bara ohoi, habasean tandjong sungkai bungai, ehei bara ehei, mangangkajoh luwok kalipapan a-tandok.

I'eleh tokep dje mananturong bukit lu-pasahan raung, dje dani lu-manjahendeng kereng daharin penda lunok.

I'hando-hando dje manandjulo papan talawang teras kaju djambu bahandang.

I'huna-hunang lalanga dje manalandjat dare,n lintong lumpok muntei bulau.

I'balitan Dohong Mama Tandang mukei pati lu-bahandang, Langkah Sawang dje Mama Bungai badjeleng muap tabala radja.

I'manduan tingang entas, 395 mandino bungai lu-taradjo.

I'hapan mangasene bulau sambong raung ain liau ano.
Ohoi und noch einmal ohoi, es rudert längs der Flussbiegung der Karamuntingsträucher des früheren Feldes, ehei und noch einmal ehei, es fährt vorbei an der Buchtung der Kalandujongsträucher mit den dolchähnlichen Blättern.

Ohoi und noch einmal ohoi, es rudert entlang der Flussbiegung der Sungkaibäume, auf denen die Nashornvögel nisten, ehei und noch einmal ehei, es fährt längs der Buchtung der Erde der Hörner (d.h. längs den Weideplätzen des Hornviehes).

Und schon naht es sich dem Berge der Hütten der Särge, und dort drüben schon werden sie ankommen bei dem Hügel der sich ausstreckt unter den Wohnungen der Lunok (Leichen).

Halte nun an für eine kleine Weile, o Schildbrett von dem Kernholz des roten Djambubaumes.

Bleibe nun still liegen für einen Augenblick, o goldenes geflochtenes Band, Pfahl des innersten Markes des goldenen Munteibaumes.

Und er, der Dohong Mama Tandang, öffnet die Kiste, die rote, und er, der Langkah Sawang Mama Bungai, schliesst rasch auf die Truhe, die königliche.

Er holt heraus den Tingang Entas, er nimmt hervor den Nashornvogel der Goldwaage.

Um erkennen zu können den goldenen ausgehöhlten Sarg der Liau des N.N. (Auf dem Bukit Pasahan Raung werden alle Särge beigesetzt und er muss nun genau wissen um welchen es sich handelt.) 
I'palus lapas,e dje tingang entas, i-malangkusa bungai taradjo.

I'tari dje tatarian u-tingang entas manudjo bulau sambang raung.

I'tingang entas manudjo bulau sambang raung ain liau ano.

I'ijoh bungai taradjo njahendeng runi talangkap njaho.

I'handong dje hakatawan balitan linga Dohong Mama Tandang, u-djadi selong dje batuana Langkah Sawang Mama Bungai.

I'tintu hakalambat papan talawang teras kaju djambu bahandang, i-tingkap habalaun bulau dare,n lintong luhing lumpok muntei bulau.

I'tende handu papan talawang maninggang bukit pasahan raung, i'tahan dje bara hunang bulau dare,n lintong luhing lumpok muntei bulau.

I'tende batoros teken garing, dje tahan naharukan bulau namburak.

I'palus dje njangkabila tatambat keket i-laloha djamban garing.

Manamuei bukit pasahan raung, mangadja kereng da-
Und sogleich lässt er fortfliegen den Tingang Entas, lässt er frei den Nashornvogel der Goldwaage.

Es fliegt weg und schwebt in der Luft der Tingang Entas und begibt sich hin zu den goldenen ausgehöhlten Särgen. Der Tingang Entas fliegt in der Richtung des goldenen ausgehöhlten Sarges der Liau des N.N. Ja, der Nashornvogel der Goldwaage begibt sich zum donnernden Sarge. Und wohl weiss es der schnelle Dohong Mama Tandang, schon ist es ihm gewisslich bekannt, ihm dem Langkah Sawang Mama Bungai (der Tingang Entas hat sich auf dem Sarge niedergelassen und nun weiss Dohong Mama Tandang um welchen es sich handelt). Und vorsichtig fährt weiter das Schildbrett vom Kernholz des roten Djambubaumes, und langsam nähert sich dem Orte seiner Bestimmung das goldene geflochtene Band, der Pfahl des innersten Holzes des goldenen Munteibaumes.

Und nun hält es an und steht still das Schildbrett, in der Nähe des Berges der Hütten der Särge, es hält an und es steht still das goldene geflochtene Band, der Pfahl des innersten Holzes des goldenen Munteibaumes.

Es hält an und eingerammt wird der Stossbaum und festgebunden wird an ihm das goldene geflochtene Seil.

Und sogleich machen sie fest das Seil, das vielgliederige, vom hinteren Teile des Bootes und sie lassen herab die Brücke, die elfenbeinerne.

Und sie gehen $z u$ dem Berge der Hütten der Särge, und sie schreiten 
harin penda lunok.

nach dem Hügel der sich ausstreckt unter den Wohnungen der Lunok.

\section{H. Die Aufweckung der Liau}

Toh malajan tekap katambong, upo hapan karungut manahiu ampi,n mampisik liau, koa,e :

I'djalahan tingang Sangiang rata hapantar bua pinang, panungkup bungai rajong Djalajan tatau uras hataradjo manjang, mantar pinang tatop mandue, hataradjo manjang rempai manelo.

I'sama djadi busau bua pinang Sangiang huang papan talawang, rata kajal uring manjang Djalajan medjen panuhan bulau dare,n lintong.

Metoh Dohong Mama Tandang djari hapantar pinang, ulek Langkah Sawang Mama Bungai luas hataradjo manjang, salenga aton karamahan dumah balitan Sangiang Sahor, eleh karampean nantekas Djalajan Parapah.

Lungang-lingok renteng tingang, pulang-pilik pating bungai.

Mondok hataharep bau dengan kabangkang Dohong Mama Tandang, badjanda
Es hört nun auf das Schlagen der kleinen Trommeln und der Hauptbalian erwähnt in seinem Liede die Aufweckung der Liau, sein Gesang lautet:

Die Angehörigen der Tingang, der Sangiang kauen zusammen Pinang, die Gemeinschaft der Nashornvögel, der Jünglinge der Djalajan, der reichen, sie alle kauen gemeinsam Betelnüsse, sie kauen Pinang, zwei auf einmal, sie kauen Betelnüsse, drei zusammen.

Und sie alle zusammen sind trunken von den Pinang, sie die Sangiang die sich aufhalten im Schildbrett, sie alle zusammen sind betäubt von den Betelnüssen, sie die Djalajan die sich befinden in dem kostbaren goldenen geflochtenen Band.

Und während der Dohong Mama Tandang beendet das Kauen seiner Pinang, und nachdem der Langkah Sawang Mama Bungai fertig geworden ist mit dem Kauen der Betelnüsse, da naht sich plötzlich und kommt herbei der Sangiang Sahor, und mit raschem Gange schreitet herzu der Djalajan Parapah.

Hin und her wehen die Schwanzfedern des Tingang, hin und her schwenken sich die $Z$ weiglein des Nashornvogels.

Und er setzt sich nahe gegenüber der Person des Dohong Mama Tandang, und er nimmt Platz so dass er in die 
hasambewa tandok,e dengan Langkah Sawang Mama Bungai i-Bunge, bandong Njaring djahawen.

Hajak malawo rawei ikau Sangiang Sahor, malekas tisoi Djalajan Parapah.

Rawei tapanjame-njame balitan Sangiang Sahor, tisoi tapadjudju-djuan balitan Djalajan Parapah.

Ijoi nih Dohong Mama Tandang, Langkah Sawang dje Mama Bungai amon aton kasian, tingang, $\mathrm{i}$-asin burong djadjalukan akangku pantar pinang, idje kapantar babarangai.

I'sana naroi pantar bua pinang Sangiang Sahor hapantar pinang, bagulong busau bua pinang.

Djadi busau bua pinang hajak lungang-lingok renteng tingang,e.

Kabasewan uring manjang pulang-pilik pating bungai, randan hakaisek rawei Sangiang Sahor, ringkang basarohi tisoi Djalajan Parapah dengan Dohong Mama Tandang:

Akan kueh bulan djandjulana,m ikau Dohong Mama Tandang?

Dia isek manansekan panamueiku Dohong Mama Tandang, pangadja,n Langkah
Augen des Langkah Sawang Mama Bungai Bunge, des Mannes der sechs Njaring, sehen kann.

Und es wirft aus sein Wort der Sangiang Sahor, und er erhebt seine Stimme, er der Djalajan Parapah.

Das Wort, das flehentlich ausgesprochene des Sangiang Sahor, die Rede, die stürmisch bittende des Djalajan Parapah.

Ja, o Dohong Mama Tandang, Langkah Sawang Mama Bungai, wenn du Gnade kennst, o Tingang, wenn du so gut sein möchtest, o Vogel, dann überreiche mir doch Pinang zum Kauen, gleichgültig ob es nur ein einziges Kausel sei.

Nachdem ihm überreicht worden war ein Kausel von Pinang, kaut der Sangiang Sahor die Betelnuss und rasch ist er schon trunken von der Frucht der Pinang.

Und nachdem er trunken ist von den Früchten der Pinang, wiegt er hin und her die Schwanzfedern des Tingang. Und nachdem er betäubt ist von den Früchten der Betelnusspalme, schwenkt er hin und her die Zweiglein des Nashornvogels und mit sanfter Stimme fragt das Wort des Sangiang Sahor, und mit gedämpfter Rede erkundigt sich der Djalajan Parapah beim Dohong Mama Tandang:

Wohin, o Mond, soll dich deine Reise führen, o Dohong Mama Tandang?

Nicht frage, nicht erkundige dich nach meiner Reise, nach der des Dohong Mama Tandang, nicht forsche nach 
Sawang Mama Bungai, panamueiku badjeleng, pangadjangku basikap.

Mampisik salumpok liau haring kaharingan, manarindjet tanterus pangambon.

Bara bulau sambang raung, bara runi talangkop njaho, bahalap kanangkong tingang.

Palus mangagaha,e akan eka Balo Indu Rangkang Penjang, Sulan Mina Perang Matanandau.

Intu lewu Bukit Kanjaloh Lanting, rundong Kereng Naliwoh Rahan.

Nduan hambekan katon aku mangandang bulau sambang raung, manitih runi talangkop njaho kanangkong tingang.

Ijoi, koa,n rawei Sangiang Sahor, Djalajan Parapah.

Aku djundjun helo mangandang bulau sambang raung, manitih runi talangkop njaho, kanangkong tanggang tingang.

Kareh ikau, njandang rahian, koa,n rawei Sangiang Sahor dengan Dohong Mama Tan- dem Besuche des Langkah Sawang Mama Bungai, meine Reise ist eine rasche, mein Besuch ist ein schneller. Ich will aufwecken die Salumpok Liau, die lebende und lebenschaffende, ich will sanft anstossen die Tanterus Pangambon.

Aus dem goldenen ausgehöhlten Sarg, aus dem donnernden Sarg mit den aufeinanderliegenden Oeffnungen und mit den schönen Längshölzern die geschnitzt sind wie ein Nashornvogel.

Und ich werde sie darnach leiten nach dem Orte der Balo Indu Rangkang Penjang, der Sulan Mina Perang Matanandau.

In dem Dorfe Bukit Kanjaloh Lanting, in dem Orte Kereng Naliwoh Rahan.

Jetzt, in diesem Augenblicke will ich beklopfen den goldenen ausgehöhlten Sarg, will ich schlagen an den donnernden Sarg mit den aufeinanderliegenden Oeffnungen und den Längshölzern die geschnitzt sind wie ein Tingang.

Ja, spricht das Wort des Sangiang Sahor, des Djalajan Parapah.

Ich will mich zuerst erheben und will hingehen um zu beklopfen den goldenen ausgehöhlten Sarg, um anzuschlagen an den donnernden Sarg mit den aufeinanderliegenden Oeffnungen und den Längshölzern die geschnitzt sind wie der Nashornvogel eines Opferbootes. (Der Sarg hat die Form eines Nashornvogelbootes.)

Später kannst du es dann auch tun, hernach soll es durch dich geschehen, so spricht das Wort des Sangiang 
dang.

Bau bitingkuan Sangiang Sahor, metoh,e biti,e melai lewu indjam tingang, rundong nasih nampoi bungai, puna aku karambanga,e kilau pulau pehon sawang, hambalat,e tingkah ruang djumpong bunge, ganggong,e kilau garing batang pantar, sauh,e kilau randong banama, tambuhak,e tingkah kamarau lanting radja.

Awi te, nduan hambekan katon bitingku djundjun helo, biti,m njandang harian.

Nggatang kumin tingang balitan Dohong Mama Tandang, manundjong hirum burong Langkah Sawang Mama Bungai Bunge, bandong Njaring djahawen.

Has, babarangai, koa,n Lumpong Mama Tandang, takan biti,m djundjun helo, balitam totok tambalon djundjun.

Gatang tarahendeng Sangiang Sahor palus hatanggar renteng tingang, tundjong tarahingkat Djalajan Parapah mangambuah djundjong sampulau dare, manangking nantelai dohong, meteng mamba-
Sahor zum Dohong Mama Tandang.

Aber in diesem Augenblicke will ich, der Sangiang Sahor, mich $z \mathfrak{u} \mathrm{ihm}$ hinbegeben, denn zur Zeit als er (der Tote) noch wohnte in dem Dorfe, dem durch die Tingang geliehenen, in dem Orte, der durch die Nashornvögel geliehen worden war, da war wahrlich ich es welcher ihn umzäunte wie eine Insel, wie ein Wäldchen von Sawangstauden, welcher ihn umfriedete wie ein Bunge-Gebüsch, welcher ihn umgab wie mit einem elfenbeinernen Zaun von Stämmen und Pfählen, welcher ihn verankerte, so wie man ein grosses Boot verankert, welcher ihn festband, so wie man mit einem dicken geflochtenen Rotanseil das königliche Floss festbindet.

Aus diesem Grunde geschieht es, dass ich jetzt in diesem Augenblicke mich erhebe und hingehe und dass du das erst später tun wirst.

Er erhebt ein Lächeln, wie das der Tingang, er der Dohong Mama Tandang, er lässt aufsteigen ein Schmunzeln wie das der Vögel, er der Langkah Sawang Mama Bungai Bunge, der Mann der Njaring, der sechsen.

Wohlan, es kann mir gleichgültig sein, so spricht der Lumpong (Dohong) Mama Tandang, wohlauf dann, gehe du zuerst, mache du dich vorher auf. Es erhebt sich und steht auf der Sangiang Sahor und er bringt in Ordnung die Schwanzfedern des Tingang, es erhebt sich und steht auf der Djalajan Parapah und er streicht richtig seinen Kopfschmuck, den geflochtenen, er umgürtet schräg herabhängend seinen 
hulan bulau batu penjang,e.

Palus manting tambang balua papan talawang teras kaju djambu bahandang, nangkaruan salunga bahandjong bulau dare,n lintong luhing lumpok muntei bulau, batandjong petak sintel habalambang tambon, liang deret habangkalan garantong.

Mananturong bukit pasahan rahan raung, mananturong bulau sambang raung.

Surok manenda renteng tingang Sangiang Sahor, Djalajan Parapah, eleh njuro sangan sampok seso, eleh bungkar seso basasampoke, puas sambil mangantau balitan Sangiang Sahor, Djalajan $\mathrm{Pa}$ rapah.

Matei indang buno bili,n banama halalungan laut djahawen!

Leha-lehan kare sampok seso
Dolch und er umbindet und knüpft fest die goldenen Steine seiner Penjang.

Und sogleich spreizt er seine Beine und er tritt heraus aus dem Schildbrett, dem Kernholz des roten Djambubaumes, und er verwirft seine Füsse und schreitet hervor aus den goldenen geflochtenen Bändern, aus dem Pfahl des innersten Holzes des goldenen Munteibaumes, und er schreitet auf der Erde, der harten, die zur Schwelle hat die Wasserschlange, auf dem Stein, dem festen, der als Schwelle hat den Gong.

Und er schreitet hin zum Berge der Hütten, der Versammlungshäuser (rahan sind die Versammlungshäuser der weiblichen Sangiang die in den Genealogien mitgezählt werden, die balai sind die Versammlungshäuser der männlichen Sangiang) der Särge, er begibt sich hin zu den goldenen ausgehöhlten Särgen.

Aber da beginnt etwas $z \mathfrak{u}$ kriechen unter den Schwanzfedern des Tingang des Sangiang Sahor, des Djalajan Parapah, und schon kriechen in grosser Zahl zwischen und über sie hin die roten Ameisen, schon ist er beladen mit einer grossen Menge der roten Ameisen und ganz voll von ihnen ist rechts und links der ganze Körper des Sangiang Sahor, des Djalajan Parapah. (Diese roten Ameisen beissen sehr empfindlich.)

Stirb um gespeert $z u$ werden als Kaufpreis für das grosse Boot das der Meere sechs durchkielt (ein Fluch)! Leha-lehan! welcher Haufe von roten 
lalau, dia panan itah hadjulanan tambang andjo balang.

Sangiang Sahor hakambulat seso huang lawi,n renteng,e, hakambulat kea huang anggan kalambi,e, kontep melai kolok kumpang dohong,e, peno medjen garing lalundjong $\mathrm{pu}$ lang,e hatampulu.

Sangiang Sahor mamanting nangkaruak tambang,e, manggerek kumpal seso.

Amon mepet seso huang rakuren baro,e, ngaramak,e rakuren baro,e.

Amon mepet seso huang bulau pantar tatah,e ngaramak,e bulau pantar tatah,e.

Amon mepet seso huang tambang takep, pidjak-papudjaka tambang Sangiang Sahor, tarahundjeng,e halamantek gawang sahep, leket kilau ngatipei dohong, hadjip tingkah manalepo buno.

Mikau ganggurang kabangkang,e: matei bara matei, koa,n Sangiang Sahor.
Ameisen, zu arg ist es und wir ertragen es nicht mehr unsere Reise zu Fuss fortzusetzen, unser Vorhaben ist vereitelt.

Der Sangiang Sahor ist voller roter Ameisen an den Enden seiner Schwanzfedern, zusammengeballt haben sie sich auch an seinen Kleidern und Oberkleidern, übervoll ist auch der Kopf der Scheide seines Dolches und zusammengeballt haben sie sich auch auf dem elfenbeinernen Knopfe seines Griffes, in grosser Zahl sind sie überall vorhanden.

Der Sangiang Sahor verwirft und spreizt seine Beine und er probiert abzuschütteln die Klumpen der roten Ameisen.

Stechen ihn die roten Ameisen auf dem Rücken seines Oberkleides, dann muss er heftig kratzen auf dem Rücken seines Oberkleides.

Beissen ihn die roten Ameisen in die goldenen Pfähle seiner Zahnstifte, dann muss er heftig kratzen an den goldenen Pfähle seiner Zahnstifte.

Und kneipen ihn die roten Ameisen in seine Füsse und Kniekehlen, dann springen hoch auf die Beine des Sangiang Sahor und er tritt unglücklicherweise auf die Blutegel Gawang Sahep und sie bleiben an ihm kleben wie das Pech an einem Dolch, und sie bleiben an ihm hängen, so wie man verpicht einen Speer.

Er beugt sich und lehnt weit vor mit seinem Oberkörper und er schreit:

Sterben muss ich und nochmals sterben, so ruft er vor Schmerzen, er der Sangiang Sahor. 
Manting nangkaruan tambang,e buli manjelem papan talawang teras kaju djambu bahandang, bulau dare,n lintong luhing lumpok muntei bulau.

Ijoh Dohong Mama Tandang, narai gangguranan ara,e idje leket kilau ngatipei rohong hasansila tambang lawahku balinga?

Nggatang kumin tingang balitan Dohong Mama Tandang Sangiang, ijoh, Sangiang Sahor, Djalajan Parapah, halamantek gawang sahep!

Engkak akangku, Dohong Mama Tandang, engkak!

Ndjidjit Dohong Mama Tandang pamantilon bendang, ngikis,e lamantek gawang sahep, mantap rawo-rawo, balekak lepah-lingis.

Narai gangguranan ara,e talo idje leket huang renteng tingang, hakambulat medjen kolok kumpang dohong, hakatipei babalai garing lalundjong pulang?

Dia isek manansekan, koa,n rawei Dohong Mama Tandang, tisoi Langkah Sawang Mama Bungai, seso, Sangiang Sahor, Djalajan Parapah.
Er wirft aus und spreizt seine Füsse und er eilt rasch zurück und geht wieder hinein in das Schildbrett von dem Kernholz des roten Djambubaumes, in das goldene geflochtene Band, den Pfahl des innersten Holzes des goldenen Munteibaumes.

Ja, o Dohong Mama Tandang, was ist der Name, wie nennt man das das sich festgeklebt hat zu beiden Seiten meiner Beine, meiner Füsse, der schnellen, wie das Pech eines Dolches?

Er erhebt ein Lächeln wie die Tingang, er der Dohong Mama Tandang Sangiang und er spricht: ja, Sangiang Sahor, Djalajan Parapah, Blutegel Gawang Sahep sind es!

Nimm sie weg für mich, o Dohong Mama Tandang, nimm sie doch weg! Es zieht sie hinweg der Dohong Mama Tandang mit einem glattgeschnittenen Stück Bambus, er reibt hinweg die Blutegel Gawang Sahep und sie fallen ab und sie liegen überall herumgestreut, sie alle sind nun weggenommen.

Was ist die Bezeichnung, welcher ist der Name der Dinge die sich da festgeklebt haben an meinen Schwanzfedern des Tingang, die sich zusammengeballt haben auf dem Kopf der Scheide meines Dolches, die sich niedergelassen und angeklebt haben auf dem elfenbeinernen Knopf des Griffes?

Nicht frage, nicht erkundige dich! so spricht das Wort des Dohong Mama Tandang, die Rede des Langkah Sawang Mama Bungai, rote Ameisen sind das, o Sangiang Sahor, Djalajan 


Gerek akangku, Dohong
Mama Tandang Sangiang
mangat gulong bitingku ma-
ngandang bulau sambang
raung, runi talangkop njaho
kanangkong tanggang ti-
ngang.

Mura-narawoh Dohong Mama Tandang djohon pinang, mantap rawo-rawo seso,n baho.

Toh ie! koa,n rawei Sangiang Sahor, bitingku tolak mangandang bulau sambang raung.

Ete-etet bulau pantar tatah,e Sangiang Sahor, giri-gagareten tanteng,e Djalajan $\mathrm{Pa}$ rapah, manting nangkaruan tambang,e batandjong petak sintel habalambang tambon, liang deret habangkalan garantong.

Surok mamenda renteng tingang, njapenda badjakah pimping tingang, eleh bukei palinget babilem.

Mikau haganggurang kabangkang,e Sangiang Sahor, Djalajan Parapah.

Leha-lehan! kare gana,n

\section{Parapah.}

Schüttle sie ab von mir, o Dohong Mama Tandang Sangiang, damit ich mich rasch aufmachen und beklopfen kann den goldenen ausgehöhlten Sarg, den donnernden Sarg mit den aufeinanderliegenden Oeffnungen und den Längshölzern, die da geschnitzt sind wie der Nashornvogel eines Opferbootes.

Der Dohong Mama Tandang spuckt mit weitstreuendem Strahl den Saft der Pinang über sie aus und sogleich fallen herunter und liegen überall herum die roten Ameisen des Busches auf dem früheren Felde.

Geschehen ist es nun und hier liegen sie! so spricht das Wort des Sangiang Sahor, und nun mache ich mich auf um zu beklopfen den goldenen ausgehöhlten Sarg.

Es beisst aufeinander die goldenen Pfähle der Zahnstifte der Sangiang Sahor, es knirscht mit den Zahnstiften der Djalajan Parapah und er wirft auseinander und spreizt seine Beine und er tritt auf die Erde, die feste, die als Schwelle hat die Wasserschlange, auf den Stein, den harten, der zur Schwelle hat den Gong.

Es beugen sich die Schwanzfedern der Tingang und sie kriechen unter den Lianen Pimping Tingang durch, aber da öffnet sich schon der Bau der schwarzen Wespen.

Und weit beugt sich vor und stark lehnt vornüber der Oberkörper des Sangiang Sahor, des Djalajan $\mathrm{Pa}-$ rapah.

Leha-lehan! welche grosse Zahl der 
bukit pasahan raung, labata,n kereng daharin penda lunok.

Njilak njahumpak dohong papan benteng, basariang pulang indu tambing hanji Sangiang Sahor.

Biwis sambil gantau isi,n dohong papan benteng, mahimahi bungkar indu palinget babilem.

Mikau ganggurang kabangkang,e hajak manting nangkaruan tambang,e.

Matei bara matei, nihau bara nihau! halalian papan talawang teras kaju djambu bahandang, mulang bulau dare,n lintong luhing lumpok muntei bulau.

Narai gangguaran ara,e, ijoh Dohong Mama Tandang Sangiang, talo idje bungkar kilau udjan pimping mudjan bitingku, tingkah rihen buno manjamperai balitangku?

Sampai kitik hapangandang bitingku kilau bawi katarunan Sangiang, redjar hapangendjeh rowan habinei katakepan
Seelen des Berges der Hütten der Särge, der Seelen (damit sind gemeint solche die Schaden zufügen, oder auch böse Geister) des Hügels welcher sich ausdehnt unter den Wohnungen der Lunok.

Er zieht heraus und holt hervor seinen Dolch, das Brett der Mitte, er bringt in Ordnung den Griff zur Erhöhung seines Mutes, er der Sangiang Sahor. Und er haut nach links und nach rechts mit dem Fleische des Dolches (d.h. mit dem Eisen), dem Brette der Mitte, aber es nützt nur soviel dass die Wespen noch in grösserer Zahl aus dem Bau hervorbrechen.

Er lehnt weit vor, er beugt stark vorneüber seinen Oberkörper und er verwirft und spreizt seine Beine.

Sterben und nochmals sterben, verloren und nochmals verloren, so schreit er und kehrt zurück zum Schildbrett, dem Kernholz des roten Djambubaumes, und er kehrt wieder um zum goldenen geflochtenen Band, dem Pfahl des innersten Holzes des goldenen Munteibaumes.

Was ist die Bezeichnung, welcher ist der Name, ja Dohong Mama Tandang Sangiang, von den Dingen die da plötzlich herabfallen wie ein Regen von Blaserohrpfeilen und die meinen Körper beregnet haben, die da herunterrieseln wie feiner Staubregen von Lanzenspitzen und die berieselt haben meinen Leib?

Bis dass da erzitterte und erbebte mein Leib, wie der einer Frau in die einfährt der Sangiang, bis dass heftig sich zu schütteln begann mein Körper, 
Djalajan.

Njamah kembang bulau awan tandok, mahabantat panjaran pipingku.

Manggatang takakak Dohong Mama Tandang Sangiang, leha-lehan biti,m Sangiang Sahor lalau mepet palinget babilem.

Mura-narawoh djoho,n pinang Dohong Mama Tandang Sangiang nundjong keleh awan palinget babilem.

Palus manting nangkaruan tambang,e tinai Sangiang Sahor, nanturong bulau sambang raung, manjahendeng runi talangkop njaho bahalap kanampong tanggang tingang.

Eleh hadjadjaka sampok naning 396 gana,n petak bahenda, eleh bungkar indu naning.

Manting nangkaruan tambang,e Sangiang Sahor, halawo bulau sambang raung.

Njilak manjahumpak dohong papan benteng,e, basariang pulang indu tambing hanji.

Eleh nganda-ngandang,e bulau sambang raung, nitinitih,e runi talangkop njaho, wie der einer Frau die besessen wird von einem Djalajan.

Und schon sind geschwollen meine goldenen Augen und es sind dick aufgetrieben die Seiten meiner Wangen. Und es bricht aus in ein schallendes Gelächter der Dohong Mama Tandang Sangiang und er spricht: Leha-lehan! wie ist doch dein Leib, o Sangiang Sahor, so arg zerstochen worden von den schwarzen Wespen.

Und Dohong Mama Tandang Sangiang spuckt weit herumstreuend den Saft der Pinang aus auf die Spuren der Stiche der schwarzen Wespen, damit die Schmerzen gelindert werden sollen.

Und wiederum wirft er auseinander seine Beine und er spreizt seine Füsse und er schreitet hin zu dem goldenen ausgehöhlten Sarg, er begibt sich zu dem donnernden Sarg mit den aufeinandergefügten Deckeln, der geschnitzt ist wie ein Nashornvogel von dem schönen Gestell des Opferbootes. Und schon tritt er hinein in ein Nest der Wespen, der Seelen der gelben Erde, und schon fliegen heraus die Wespen.

Er spreizt und wirft auseinander seine Beine, er der Sangiang Sahor, und er tritt hinzu zum goldenen ausgehöhlten Sarg.

Er zieht heraus und holt hervor den Dolch, das Brett der Mitte, er bringt in Ordnung den Griff welcher vermehrt den Mut.

Und schon klopft er mit ihm vorsichtig an den goldenen ausgehöhlten Sarg, und er schlägt an den donnern- 
eleh dohong habambalon hiring,e.

Matei indang buno bilin banama halalungan laut djahawen!

Mentengku tingang tempo,e, dia menteng dohong papan bentengku, bahanji aku antang Sangiang,e, dia bahanji pulang indu tambing hanji.

Manting tambang Sangiang Sahor, djandjaroman akan Dohong Mama Tandang.

Ijoh Dohong Mama Tandang, djadi bitingku mangandang bulau sambang raung, manitih runi hatalangkop njaho, usang dohongku djari habambalon hiring,e, mentengku tingang tempo,e, dia menteng dohong papan benteng, bahanjiku antang Sangiang,e, dia bahanji pulang indu tambing hanjiku.

Ijoh, koa,n rawei Dohong Mama Tandang, tisoi Langkah Sawang Mama Bungai, ela omba-omba biti,m nahuang mangandang bulau sambang raung, dia olih,m, mbuah amon metoh entang belom, metoh hindai ie lunok den Sarg mit den aufeinandergefügten Oeffnungen, aber schon rollt der Dolch seine Schärfe zusammen (d.h. er zerbricht, oder sein Klopfen bleibt erfolglos).

Stirb um gespeert zu werden als Kaufpreis für das grosse Boot welches durchkielt der Meere sechs!

Mutig bin ich, der Tingang, sein Besitzer, aber nicht mutig ist der Dolch, das Brett der Mitte, tapfer bin ich, der Antang, sein Sangiang (sein Eigentümer), aber nicht tapfer ist der Griff, der da dient zur Vermehrung des Mutes.

Es verwirft seine Beine der Sangiang Sahor um erzählen zu können dem Dohong Mama Tandang was geschehen ist.

Ja, Dohong Mama Tandang, ich habe geklopft an den goldenen ausgehöhlten Sarg, ich habe geschlagen an den donnernden Sarg mit den aufeinanderliegenden Deckeln, aber schon längst hat der Dolch aufgerollt seine Schärfe, wohl bin ich tapfer, ich der Tingang, sein Besitzer, aber nicht tapfer ist mein Dolch, das Brett der Mitte, wohl bin ich mutig, ich Antang, sein Sangiang, aber nicht mutig ist der Griff, der da dient zur Vermehrung meines Mutes.

Ja, spricht das Wort des Dohong Mama Tandang, die Rede des Langkah Sawang Mama Bungai, nicht mache du mit uns mit, nicht wollest du auch beklopfen den goldenen ausgehöhlten Sarg, denn das ist dir ja doch nicht möglich, war es denn nicht so, dass während der Getragene noch lebte, 
batipas pantang,e, manok idje karakop ttg. bulu mahin biti,m djundjun helo hakanana, tapi mangandang bulau sambang raung hatampulu ikau mulang nahabadjin gandang, enteng tendur nahatambit sambang.

Dia olih,m manalawang entang bara riwut peres, nangkahila tujang bara salatan sampar, omba dia olih,m mangandang bulau sambang raung.

Ijoh koa,n rawei Sangiang Sahor, tisoi Djalajan Parapah, djadi aku ngarambang entang kilau pulau pehon sawang, mahambalat tujang tingkah ruang djumpong bunge.

Puna entang ganggarongku kilau garing pantar pandjang, puna djari njauhku kilau randong banama, nambuhak tingkah kamarau lanting radja.

Pea olihku! nambangku riwut peres bara hila tumbang batang danum, dumah riwut während er noch nicht ein Lunok war dem abgebrochen worden sind seine Stützen, dass du eine Hand voll Huhn mit Haut und Haaren verschlungen hast (nämlich die Opfer, die ihm vom Toten dargebracht worden sind), aber jetzt wo es sich darum handelt an den goldenen ausgehöhlten Sarg zu klopfen, da kehrst du rasch wieder um wie der Laut einer Trommel und dein Mut ist erschlafft wie das Fell der Trommel.

Nicht war es dir möglich ein Schild zu sein für den Getragenen gegen die Winde der Krankheiten, nicht war es dir möglich den Gewiegten auf die Seite $z \mathfrak{u}$ schieben, als die Stürme der Seuchen heranbrausten, wie sollte es dir denn jetzt möglich sein mit uns zu kommen und an den goldenen ausgehöhlten Sarg zu klopfen.

Ja, spricht das Wort des Sangiang Sahor, sagt die Rede des Djalajan Parapah, wohl habe ich unzäunt den Getragenen wie man umzäunt die Insel der Sawangstauden, wohl habe ich umfriedet den Gewiegten, wie man umfriedet das dichte Gebüsch der Bungestauden.

Wohl habe ich den Getragenen umwandet wie mit langen elfenbeinernen Pfählen, wahrlich habe ich ihn verankert, so wie man ein grosses Boot verankert und ich habe ihn festgebunden, so wie man das königliche Boot festbindet mit einem grossen geflochtenen Rotanseil.

Aber wie sollte mir noch mehr als dies möglich gewesen sein! erwartete ich den Wind der Krankheiten von 
peres bara djalahan hulu danum, nambangku riwut peres bara djalahan hulu danum, dumah riwut peres bara hila tumbang batang danum.

Nambangku riwut peres kalampangan bara bilon njalong, dumah riwut peres mawi entang bara tandjong ambon.

Nambangku riwut peres bara tandjong ambon salenga dumah riwut peres mawi entang bara bilon njalong, awi te pea olihku ngarambang,e kilau pehon sawang, kueh aku dinon mahambalat tingkah ruang djumpong bunge!

Ijoh, koa,n rawei Dohong Mama Tandang, mulang biti,m Sangiang Sahor buli pahapang pantar pinang, mulang bagentoi puting roko,n tarahan.

Buli pahatewang lewu, mulang pangkarundong,e.

I'palus gatang tarahendeng balitan linga Dohong Mama Tandang, Langkah Sawang Mama Bungai Bunge, ban- der Richtung der Mündung des Flusses, dann wehte der Wind der Krankheiten vom Oberlauf, vom Quellort des Flusses, erwartete ich aber den Wind der Krankheiten vom Oberlauf, vom Quellort des Flusses, dan wehte der Wind der Krankheiten aus der Richtung der Mündung des Flusses.

Erwartete ich, dass der Wind der Krankheiten auftauchen sollte von der Oberfläche des Wassers, dann wehte der Wind der Krankheiten von den Flussbiegungen der Wolken her (von den 33 Wolkenlagen) und fiel über den Getragenen her.

Erwartete ich, dass der Wind der Krankheiten herabstürzen sollte aus der Richtung der Flussbiegungen der Wolken, dann kam der Wind der Krankheiten plötzlich von der Oberfläche des Wassers her und überfiel den Getragenen, wie sollte es mir deshalb möglich gewesen sein ihn zu umzäunen wie man die Sawangstauden umzäunt, wie sollte ich im Stande gewesen sein ihn $z u$ umfrieden wie man ein Bungegebüsch umfriedet!

Ja, spricht das Wort des Dohong Mama Tandang, kehre du nur wieder zurück, Sangiang Sahor, gehe ruhig heim und kaue Pinang, begib dich nach Hause und mache dich zu schaffen mit Rauchwaren der Sklaven.

Kehre heim an die Flussbiegung deines Dorfes, gehe wieder zurück in deinen Ort.

Und sogleich erhebt sich und steht auf er der schöne Dohong Mama Tandang, er der Langkah Sawang Mama Bungai Bunge, der Mann der sechs 
dong bawi,n djahawen, nangking natelai dohong, meteng mambahulan bulau batu,n. penjang palus malan balua papan talawang, bahandjong bulau dare,n lintong.

Palus batandjong ie petak sintel habalambang tambon, manetei ie liang deret habangkalan garantong, mura-manarawoh djoho,n pinang,e nampulilang kare taloh papa, lilang-lilang kare palinget babilem, sara-sarak naning gana,n petak bahenda.

Lila-lilang handipe buno mangantong, sara-sarak padjahe tatikan raung penjang.

Djalan Dohong Mama Tandang nanturong bulau sambang raung.

Palus surong djandjulana nanturong bulau sambang raung, njahendeng runi talangkop njaho, kanangkong tanggang tingang; eleh sembang bulau sambang raung balitan Dohong Mama Tandang.

Njilak manjahumpak dohong lalunding liau, basariang pulang talandjing pangkat.
Frauen, er umgürtet schräg herabhängend seinen Dolch, er umbindet und knüpft fest die goldenen Steine seiner Penjang und dann macht er sich auf um das Schildbrett zu verlassen und herauszutreten aus den goldenen geflochtenen Bändern.

Und sogleich beschreitet er die Erde, die feste, die als Schwelle hat die Wasserschlange, und er betritt den Stein, den harten, der als Schwelle hat den Gong, und er spuckt weit umherstreuend aus den Saft seiner Pinang und er drückt auf die Seite alle schlechten Dinge, und er schiebt hinweg alle schwarzen Wespen, und er stösst auf die Seite die Wespen, die Seelen der gelben Erde.

Und er schiebt hinweg die Schlange Buno Mangantong, und er stösst auf die Seite die Schlange Padjahe Tatikan Raung Penjang.

Sie alle liegen auf dem Wege den er, der Dohong Mama Tandang beschreiten muss um hinzugelangen zum goldenen ausgehöhlten Sarg.

Und nun beginnt er seine Reise und er schreitet hin zum goldenen ausgehöhlten Sarg, er geht hin zum donnernden Sarg mit den aufeinanderliegenden Oeffnungen, die Längshölzer, die da geschnitzt sind wie der Nashornvogel des Opferbootes; und schon ist er angekommen beim goldenen ausgehöhlten Sarg, er der Dohong Mama Tandang.

Und er zieht heraus und holt hervor den Dolch, den Reichtum der Liau, und er bringt in Ordnung den Griff, das Wahrzeichen des Amtes. 
Njaho mangarontong langit njaho,n dohong padjandjuri kumpang,e, kilat handjadjepa hawon kilat pulang bahandjong sangkabang,e, kila-kilat isi,n dohong Sangiang manjanggah bulau sambang raung.

Ie palus nganda-ngandang,e bulau sambang raung hapan totok dohong,e, mantap raworawo uei pakulamba antang.

Omba mantap garing badji,n bulau sambang raung, mengka runi talangkop njaho.

Hindai manjaloh ikau garing badji,n bulau sambang raung amon entang ngentang tiwah tingang, hindai ngadjarian ikau uei pakulamba antang hapan karungut Rawing Tempon Telon amon njaho hai djari namparogoh tungkup.

Diadi buka tutup bulau sam-
Und wie der Donner dröhnt durch die Himmel, so kommt heraus der Donner des Dolches aus seiner Scheide, und wie die Blitze zucken durch die Himmel, so blitzt hervor der Griff aus seiner Scheide, und es blitzt das Eisen des Dolches des Sangiang und es lehnt sich an gegen den goldenen ausgehöhlten Sarg.

Und sogleich klopft er mit dem Ende seines Dolches an den goldenen ausgehöhlten Sarg und es fallen, sich herumstreuend, ab die Rotanbänder die den Falken umschliessen. (Die verstorbenen Ahnen erscheinen, wenn sie aufgerufen werden, in der Gestalt eines Falken, deshalb dieser Ausdruck.)

Und es lösen sich und fallen mit ihnen ab die elfenbeinernen Keile des goldenen ausgehöhlten Sarges, und es öffnet sich der donnernde Sarg mit den aufeinanderliegenden Deckeln.

Noch nicht verwandelt euch ihr elfenbeinerne Keile des goldenen ausgehöhlten Sarges, erst tut es wenn die Getragenen veranstalten das Hülfswerk des Tiwah des Tingang, noch nicht nehmt eine andere Gestalt an ihr Rotanbänder, die den Antang umschliessen, tut es erst dann wenn erschallt das Lied des Rawing Tempon Telon, erst dann wenn der krachende Donner zum Erbeben bringt die ganze Gemeinschaft und Verwandtschaft (bei dem Donner ist nicht nur an die Kanonen zu denken sondern an den wirklichen Domner, denn das Tiwah ist ein kosmisches Ereignis an dem sich die ganze Natur beteiligt).

Es öffnen sich die Deckel des ausge- 
bang raung, djari mengka höhlten goldenen Sarges, es lösen sich bulau hatalangkop njaho, die aufeinanderliegenden goldenen nuntun ampin kahempang,e donnernden Deckel und nun sieht man kilau burong tingang, kilau den Toten wie einen Nashornvogel, tiroh tingang, kantok burong wie einen schlafenden Tingang, wie babalai bulau sambang raung, einen schlummernden Vogel der für basali runi hatalangkop njaho.

Eleh nganda-ngandang naharep hila kabalepan lumpong matanandau belep.

Mambelep hampis limban basaloh langit, mambelep simak hantu matei.

Ngandang manaharep hila ngawa, mangat balawa panuntun liau haring kaharingan.

Ngandang manaharep hila ngadju, ladju tarong,e salumpok liau haring kaharingan.

Ngandang,e manaharep hila kabaloman lumpong matanandau, katundjong lumpong matanandau, katundjong tarong salumpok liau.

Sinde mangandang bulau sambang raung, handue pararindjet salumpok liau, handue manitih runi hatalangkop njaho, hantelo pararugoh tanterus pangambon, hantelo sein Nest auserwählt hat den goldenen ausgehöhlten Sarg, der Wohnung genommen hat in dem donnernden Sarg mit den aufeinanderliegenden Deckeln. Und er tritt von der Seite der untergehenden Ränder der Sonne, der auslöschenden, herzu und klopft langsam an den Sarg.

Auslöschen soll nun der widerliche Gestank des Leichenwassers das in Himmel verwandelt ist, auslöschen soll der Geruch der Leiche des Toten. Und er tritt herzu von der Seite der Richtung flussabwärts und er klopft an den Sarg, damit licht werde das Schauen der Liau des Lebens, der lebenschaffenden.

Und er tritt hinzu von der Seite die nach flussaufwärts liegt und er klopft an den Sarg, damit rasch sich erhebe der Ruhm der Salumpok Liau des Lebens, der lebenschaffenden.

Und er tritt hinzu von der Seite der neuauflebenden Ränder der Sonne und klopft an den Sarg, so wie sich erheben die Ränder der Sonne, so soll auch aufsteigen das Lob der Salumpok Liau.

Zum ersten Mal klopft er an den goldenen ausgehöhlten Sarg, zweimal erzittert die Salumpok Liau, zum zweiten Mal schlägt er an den donnernden Sarg mit den aufeinandergefügten Deckeln, dreimal erbebt die 
mangandang bulau sambang raung, hangkepat palalingak bulau tampak bengkel.

Hangkepat manitih runi hatalangkop njaho, hakalime palalingok bulau awan tandok.

Hangkalime mangandang bulau sambang raung, hangkadjahawen djurang-djuri balengkong tingang.

Hangkadjahawen manitih runi hatalangkop njaho, hangkudju tabanbirep lumpok mata,e.

Hangkaudju mangandang bulau sambang raung, eleh marenang mata salumpok liau haring kaharingan.

I'lalu bahing bapanting Dohong Mama Tandang Sangiang, siring bambahinga,n salatan radja Langkah Sawang Mama Bungai.

Ijoh biti,m keleh ikau tarahondok lambat.

Eleh malawo rawei panjalumpok liau haring kaharingan, palus maninting tisoi panuhan tanterus pangambon:

Eweh gangguranan ara,e namparindjet bitingku metoh aku tiroh tingang, isen sasabutan biti namparogoh balitangku hemben balitangku kantok burong?
Tanterus Pangambon, zum dritten Mal klopft er an den goldenen ausgehöhlten Sarg und viermal wiegen sich die goldenen gleichgeformten $\mathrm{Ohr}$ ringe.

Zum vierten Mal schlägt er an den donnernden Sarg mit den aufeinandergefügten Deckeln, und fünfmal bewegen sich die goldenen Augen.

Zum fünften Mal klopft er an den goldenen ausgehöhlten Sarg und sechsmal bewegt sich die Kehle des Tingang hin und her.

Und zum sechsten $\mathrm{Mal}$ schlägt er an den donnernden Sarg mit den aufeinandergefügten Deckeln und siebenmal blinzeln die Rundungen seiner Augen. Und zum siebenten Male klopft er an den goldenen ausgehöhlten Sarg und nun schlägt die Salumpok Liau, die lebende und lebenschaffende, ihre runden Augen auf.

Und sogleich erhebt seine Stimme der Dohong Mama Tandang Sangiang, und es wirft aus sein Wort, das wehende, er der König Langkah Sawang Mama Bungai.

Und er spricht: Ja, du, möchtest du dich doch vorsichtig aufsetzen.

Und es erhebt ihre Stimme die Panjalumpok Liau, die lebende und lebenschaffende, und es spricht das Wort der herrlichen Tanterus Pangambon:

Wie nennt er sich, wie ist der Name dessen, der mich sanft angestossen hat um mich aufzuwecken während ich ruhte wie ein Nashornvogel, wie heisst er, der meinen Leib geschüttelt hat während ich versunken war in dem 
Metoh aku batambon puron manjapenda djangkut djalembang bulu,n tingang, hemben balitangku bagaling kenter manjalulok kalambu ambon bulu,n burong pahambang bulan bawi,n riwut?

Ela gila,n tingang! koa,n rawei Dohong Mama Tandang, tisoi Langkah Sawang Mama Bungai Bunge, bandong Njaring djahawen.

Andau kueh biti,m tau tiroh tingang?

Puna biti,m djalan matei. Isen balita, $m$ tau kantok burong?

Puna balita,m kanahaman nihau.

Lunok ikau djari batipas pantang,e baringen ikau djari bageto sangkabila!

Amon idje matei te oloh bawi :

Timpong radja ikau djari parariop, bihing mangampoh tandjong ambon, bulau sangkalemo ikau djadi mantap tasala mananggalong petak
Schlummer des Vogels?

Während ich wie eine zusammengerollte Wasserschlange auf der $\mathrm{Pu}$ ronmatte lag unter dem weissen Moskitonetz das dem Gefieder des Nashornvogels gleicht, während ich mich im Schlummer wiegte unter dem Vorhange der aussieht wie Wolken vom Flaume der Vögel die von ihnen aufsteigen wenn sie gegeneinandergestossen werden durch die Monde, durch die Frauen des Windes?

Sei nicht närrisch wie ein Nashornvogel! so entgegnet ihm das Wort des Dohong Mama Tandang, die Rede des Langkah Sawang Mama Bungai Bunge, des Mannes der Njaring, der sechsen.

Wie sollte es denn nur möglich sein, dass du dich im Schlummer der Nashornvögel wiegst?

Denn wahrlich, du bist ja gestorben. Wie sollte es denn nur möglich sein, dass du schläfst wie ein Vogel?

Denn wahrlich du bist ja umgekommen, du bist verloren.

Ein Lunok bist du ja, dem abgeschlagen worden sind seine Aeste, ein Waringin bist du ja, dem zerbrochen worden sind seine Stützen.

Ist die verstorbene Person eine Frau, dann lautet die Fortsetzung der Anrede:

Ein königliches Tuch bist du, das weggeweht wurde, ein gestreiftes und besticktes Stück Stoff bist du, das fortflog nach den Buchtungen der Wolken, ein Goldsplitter bist du, die Stütze der 
sintel, bawi,n tingang ikau djari kanesek lajang, habinei tambon pandjandjahoi kalang labeho handalem.
Schwachheit, der abgesprungen ist vom Amboss und der umschlossen wurde von der Erde, der festen, ein weiblicher Tingang bist du, der hinwegflog und sich verirrt hat, eine weibliche Wasserschlange bist $\mathrm{du}$, die ihren Weg verlor und nicht mehr zurückkehren kann nach ihrer Wassertiefe, der abgründigen.

Amon idje matei te oloh hatue:

Buno baletup ikau djari ngandang kanarean dare, talawang batesei manarana tapaku lujang bulan, hatuen tingang ikau kanesek lajang, rajong tambon pandjandjahoi baras.

Awi tapakalong riak penjang Pantoh Ganan Kaju Hai, tapugenggem ringkin paturong Embak Ganan Bua Bakas.

Mintan djadi nahalanting lewu indjam tingang, halantingan rundong nasih nampoi bungai.

Nahalatingan kilau piring buang, halantingan tingkah djarah sandong.

Awi aseng,m bahetep njam-
Ist die verstorbene Person ein Mann, dann lautet die Fortsetzung der Anrede :

Ein zerbrochener Speer bist du, den man eingehüllt hat in zahlreiches Geflecht (um ihn aufzubewahren), ein gesprungener Schild bist du, den man umbunden hat mit Bändern die aussehen wie die Armringe der Monde, ein männlicher Tingang bist du, der wegflog und sich verirrte, ein Jüngling der Wasserschlangen bist du, der seinen Weg verloren hat auf der Sandbank.

Weil du umzingelt worden bist von den Wellen der Penjang des Pantoh Ganan Kaju Hai, weil du eingeschlossen wurdest von den Wogen der Paturong des Embak Ganan Bua Bakas. Und nun hast du von dir weggestossen das Dorf, das geliehene, der Tingang, und du hast von dir weggeschoben den Ort, den geliehenen, wo sich aufhalten die Nashornvögel.

Weggeschleudert hast du es wie einen leeren Teller, fortgeworfen hast du es wie die Natter abstösst ihre alte Haut.

Weil dein Atem unter den überein- 
penda hinting, $m$ bawak lamiang, nganatelan kaju,n sanggalang garing, nganahaman bulus lampesong kereng.

Magon sua-sual tatah,e salumpok liau haring kaharingan, djawa-djawap tanteng,e tanterus pangambon.

Puna dia bitingku djari lunok batipas pantang,e isen balitangku baringen bageto sangkabila,e, puna metoh bitingku melai karong garing, medjen lawang tambarirang.

Melai parong mahawangku, medjen siro matendo,e.

Ela gila,n tingang! koa,n rawei Dohong Mama Tandang, puna biti,m djari djalan matei, tingang ikau djadi kanesek lajang, awi ikau tarahondok lambat, tarahekeng lowah.

Palus tarahondok lambat panjalumpok liau, tarahekeng lowah tanterus pangambon.

Ijoh, Dohong Mama Tandang, Langkah Sawang Mama Bungai Bunge, bandong Njaring djahawen: te andau kueh bitingku djadi djalan matei, lungang-lingok rantunan tandoka liau haring andergefädelten Achaten (also im Hals) zerschnitten worden ist, weil er niedergedrückt wurde durch den Baum, den hohen, weil er getötet wurde durch das Langholz vom Sandhügel.

Noch immer widersetzen sich die goldenen Stifte der Salumpok Liau, der lebenden und lebenschaffenden, noch immer widersprechen die Zahnstifte der Tanterus Pangambon.

Wahrlich, ich bin nicht ein Lunok dem abgeschlagen worden sind die Aeste, sicherlich, ich bin nicht ein Waringin dem zerbrochen worden sind seine Stützen, gewiss, ich blieb in meinem Zimmer, dem elfenbeinernen, wahrlich, ich hielt mich auf in der Türe die einem Tambarirang gleichsieht.

Ich blieb im Hause meines Wohnens, ich hielt mich auf im Hause meines Bleibens.

Gebärde dich nicht wie ein närrischer Nashornvogel! so spricht das Wort des Dohong Mama Tandang, denn wahrlich du bist gestorben, du bist ein Nashornvogel welcher weggeflogen ist und sich verirrt hat, sitze nun vorsichtig auf, erhebe dich nun langsam. Und sogleich setzt sich vorsichtig auf die Panjalumpok Liau, und es erhebt sich langsam die Tanterus Pangambon.

Ja, o Dohong Mama Tandang, Langkah Sawang Mama Bungai Bunge, Mann der Njaring, der sechsen: wann soll es denn geschehen sein, dass ich gestorben bin? und es wiegt sich hin und her auf ihrem Sitze die Liau, die lebende und lebenschaffende. 
kaharingan.

Ijoh, koa,n rawei Dohong Mama Tandang Sangiang, hemben nduan hambekan katon bitingku maningkes biti,m, balitangku manalamba balita, $m$ :

Hila kueh djalajan hulu danum, hila kueh tumbang batang danum?

Awi ikau manggatang bulau pating djari,m, manjangkat rabia tenong lenge, $m$ !

Djandjaroman akangku tumbang danum, hila kueh djalajan hulu danum!

Palus panjalumpok liau haring kaharingan manggatang bulau pating djari,e, tanterus pangambon njariangkat rabia tenong lenge,e, nindjok hila tumbang batang danum: kanih hila djalajan hulu danum, nindjok djalajan hulu danum; kanih hila tumbang danum.

Ela gila,n tingang! koa,n rawei Dohong Mama Tandang, hila tumbang danum leka njewut,m djalajan hulu danum, hila djalajan hulu danum salenga njewut,m tumbang batang danum.
Ja, spricht das Wort des Dohong Mama Tandang Sangiang, so steht es in unserer Sache, so ist es mit unserer Angelegenheit, ich will dich nun auf die Probe stellen, ich will dich jetzt prüfen :

Nach welcher Richting liegt der Oberlauf, der Quellort des Flusses, nach welcher Richtung liegt die Mündung des Stromes?

Erhebe nun die goldenen $Z$ weiglein deiner Finger, halte in die Höhe die goldgeschmückten Finger deiner Hand!

Weise mir nun die Mündung des Stromes und zeige mir die Richtung des Oberlaufes, des Quellortes des Flusses!

Und sogleich erhebt die Panjalumpok Liau, die lebende und lebenschaffende, die goldenen $Z_{w e i g l e i n}$ ihrer Finger, die Tanterus Pangambon streckt in die Höhe die goldgeschmückten Finger ihrer Hand und sie weist nach der Mündung des Flusses und spricht: dont liegt der Oberlauf, der Quellort des Wassers, und sie zeigt nach dem Oberlauf, dem Quellort des Stromes und sagt: dort liegt die Mündung des Flusses. (Für die Liau ist alles verkehrt 397.)

Gebärde dich nicht närrisch wie ein Nashornvogel! so spricht das Wort des Dohong Mama Tandang, die Richtung der Mündung des Wassers nennst du plötzlich den Oberlauf des Flusses und die Richtung des Oberlaufes, des Quellortes des Flusses, bezeichnest du auf einmal als Mündung des Stromes. 
Magon sua-sual tatah,e panjalumpok liau haring kaharingan.

Awi tinai aku maningkes biti,m, manalamba balita,m.

Hila kueh kabaloman lumpong matanandau belom ttg. hila kueh kabalepan lumpong matanandau?

Awi biti,m djandjaroman akangku, koa,n rawei Dohong Mama Tandang.

Palus nggatang bulau pating djari,e salumpok liau haring kaharingan, nundjok hila kabaloman lumpong matanandau belom: kanih hila kabalepan lumpong matanandau, nindjok hila kabalepan lumpong matanandau: kananggare hila kabaloman lumpong matanandau belom.

Te andau kueh bitingku djari lunok batipas pantang,e, pea aku tau baringen djadi bageto sangkabila,e!

Magon sua-sual tatah salumpok liau haring kaharingan.

Ijoh, koa,n rawei Dohong Mama Tandang, salatan tisoi Langkah Sawang Mama Bu-
Aber immer noch widersetzen sich die goldenen Stifte der Zähne der Panjalumpok Liau, der lebenden und lebenschaffenden.

Wohlan denn, ich werde dich nochmals auf die Probe stellen, ich werde dich nochmals prüfen.

In welcher Richtung befindet sich dann das Aufleben der Ränder der Sonne, der aufgehenden, und nach welcher Seite hin liegt das Auslöschen der Ränder der Sonne?

Wohlan nun, erzähle es mir doch, so spricht das Wort des Dohong Mama Tandang.

Und sogleich erhebt die goldenen Zweiglein ihrer Finger die Salumpok Liau, die lebende und lebenschaffende, und sie weist nach der Richtung des Aufganges der Ränder der Sonne und sie spricht : dort drüben liegt die Richtung des Auslöschens der Ränder der Sonne, und sie weist hin nach der Seite des Auslöschens der Ränder der Sonne und sagt: dort ist der Ort des Auflebens der Ränder der Sonne, der aufgehenden.

Wie sollte es nun wahr sein, dass ich ein Lunok bin dem abgeschlagen wurden seine Aeste, wie sollte es nun möglich sein, dass ich ein Waringin bin dem zerbrochen worden sind seine Stützen!

Und immer noch widersetzen sich die goldenen Zahnstifte der Salumpok Liau, der lebenden und lebenschaffenden.

Ja, so spricht das Wort des Dohong Mama Tandang, so sagt die wehende Rede des Langkah Sawang Mama 
ngai Bunge, bandong Njaring djahawen, awi aku mukei akan mangat ikau manuntu ie.

Palus Dohong Mama Tandang mukei batu kangkalingei liau, liang saramin tanterus pangambon, palus hadjaluka hasambewa tandok liau haring kaharingan.

Santah rantunan tandok liau haring kaharingan manuntun batu kangkalingei liau, manureng liang saramin pangambon, tuneng njababeneng tandok liau haring kaharingan.

Eleh taratuntu tunding 398 handang djarenang nduan talenda-lendang huang bulau awan tandok.

Eleh gatang tangis tingang liau haring kaharingan, nundjong tangungos burong tanterus pangambon:

I'kai bitingku puna toto aku lunok djari batipas pantang,e, kueh balang aku baringen djadi bageto sangkabila,e.

Puas sambil mangantau bulau rantunan tandok liau haring kaharingan.

Aku ih! manggare bitingku
Bungai Bunge, des Mannes der Njaring, der sechsen, wohlan denn, ich will es dir eröffnen, damit du es selbst anschauen kannst.

Und alsogleich öffnet der Dohong Mama Tandang den Stein des Schattenbildes der Liau, den Stein des Spiegels der Tanterus Pangambon und er hält ihn hin, dicht unter die Augen der Liau, der lebenden und lebenschaffenden.

Und langsam senkt sie ihre Augen hernieder, sie, die Liau, die lebende und lebenschaffende, und sie schaut auf den Stein des Schattenbildes der Liau, und sie besieht den Stein des Spiegels der Pangambon und sie betrachtet ihn scharf mit hellen Augen, sie die Liau, die lebende und lebenschaffende.

Und nun sieht sie Leichenbemalung der Stirne mit der roten Farbe des Drachenblutes, die da leuchtet und glänzt in ihren goldenen Augen.

Und die Liau, die lebende und lebenschaffende, beginnt $\mathrm{zu}$ weinen wie ein Nashornvogel weint und die Tanterus Pangambon bricht aus in ein Schluchzen wie ein Vogel schluchzt und sie spricht mit klagender Stimme:

$\mathrm{O}$ weh, wahr ist nun, dass ich ein Lunok bin dem abgebrochen worden sind seine Aeste, offenbar ist es nun geworden, dass ich ein Waringin bin dem zerschlagen worden sind seine Stützen.

Und sie wischt links und rechts ab ihre goldenen Augen, sie, die Liau, die lebende und lebenschaffende.

Oh weh, was habe ich nun getan! ich 
tiroh tingang, nansuwa balitangku kantok burong; kai bitingku djadi nahalantingangku lewu indjam tingang, halantingangku rundong nasih nampoi bungai, nahalantingangku parong mahawangku, halantingangku rundong matendo,e.

Ijoh, koa,n rawei Dohong Mama Tandang Sangiang, hemben nduan hambekan katon, aku hapandujan biti,m, nampuenan balita, $m$, awi ikau gatang tarahendeng, tundjong tarahingkat, ijoh liau haring kaharingan.

Palus balitan Dohong Mama Tandang Sangiang hapandujan liau haring kaharingan huang njalong bahiring, te batetes simak hantu matei, bageto kilat limban basaloh langit.

Hapanduja tinai huang labeho,n ulek tangkong banama, bakepak like mandjan habalita liau.

Hapanduja tinai huang labeho,n bulan, rantau pahawang, labeho penda tewai sawang, rantau ulek patik rangga,n buno, pali mandoi baka hobah kabangkang, endus ha- beschaute mich selbst als einen schlafenden Tingang, ich bezeichnete mich selbst als einen schlummernden Vogel, aber o weh, was ist nun geschehen, weggeschoben habe ich das Dorf, das geliehene der Tingang, weggeworfen habe ich den Ort, den geliehenen, in dem sich aufhalten die Nashornvögel, von mir weggeschoben habe ich mein Haus, von mir fortgestossen habe ich meine Wohnung.

Ja, so spricht das Wort des Dohong Mama Tandang Sangiang, so ist es nun in dieser Sache und so steht es in unserer Angelegenheit und das will ich nun vollziehen: ich werde dich baden, ich werde dich abwaschen, wohlan, erhebe dich nun und stehe auf, o Liau, du lebende und lebenschaffende.

Und sogleich badet Dohong Mama Tandang Sangiang die Liau, die lebende und lebenschaffende, in dem Wasser, dem scharfen, und alsobald ist weggeschnitten der widerliche Geruch der Leiche des Toten und ist zerrissen der Blitz des Leichenwassers das da verwandelt ist in Himmel.

Und darnach badet er sie in der Wassertiefe, in dem Wirbel, in dem Teile des Bootes aus dem man das eingedrungene Wasser ausschöpft und es fällt $a b$ von ihr aller Schmutz und er läuft herab am Leibe der Liau.

Und darnach badet er sie in der Wassertiefe des Mondes, in der Wassertiefe der Frauen, in der Wassertiefe, die unter den Sawangstauden liegt, in der Wassertiefe die gelegen ist unter den Lanzen, von 
pandujan baka hisat katentang.

Eleh liau haring kaharingan hobah kabangkang,e kilau garing kanumpah budjang, palus balitan Dohong Mama Tandang mangkepan rangkan pakajan simpan, mamasang iran panjambungan sukup.

Timpong awang nandjak bantika, bulau maing timbul manalaga henda.

Ijoh, djadi katotok tandak,e mangkepan rangkan pakajan, simpan iran panjambungan sukup.

Tapi liau kaharingan magon tolang,e balemo, manunjang uhat badjambulei, mangantong tahaseng tapas, saheroi korang.

Palus balitan Dohong Mama Tandang mukei pati bahandang, muap tabala radja, mukei supu garing, nandjuri denen man abpflückt die Früchte (gemeint sind damit auch die Sawang, die lanzenförmige Blätter haben; die Früchte sind die Blätter, die man für die rituellen Handlungen braucht), in der es pali ist zu baden, weil sonst der Körper verwandelt wird, in der es verboten ist sich $\mathbf{z u}$ waschen, weil sich sonst die Gestalt verändern würde.399 Und alsogleich verwandelt die Liau, die lebende und lebenschaffende, ihre Gestalt und sie wird $z \mathfrak{u}$ einem Elfenbein, das in der Mitte seiner Jünglingszeit steht (der Tote wird verjüngt, das gilt natürlich auch für die weiblichen Toten) und der Dohong Mama Tandang zieht ihr die Kleider an, die in genügender $Z$ ahl vorhanden sind und er schmückt sie mit allen Geschmeiden.

Mit dem Tuche, dem bestickten und mit schönen Motiven geschmückten, mit dem Golde, dem kräftigen, das aufgetaucht ist aus dem Teiche der Gelbheit.

Ja, beendet ist nun der Gesang der Bekleidung der Liau mit den Kleidern, die in genügender Anzahl vorhanden sind, der Schmückung der Liau mit den Geschmeiden die in ausreichender Menge bereitliegen.

Aber die Liau, die lebende und lebenschaffende, hat immer noch zu schwache Knochen, besitzt immer noch zu kraftlose Muskeln und leidet immer noch an ungenügendem Atem.

Und sogleich öffnet der Dohong Mama Tandang die rote Kiste, die königliche Truhe, und er nimmt heraus das elfenbeinerne Töpfchen, und er öffnet 
njalong kaharingan belom, manantekei gohong kapaninting tahaseng akan liau haring kaharingan, nduan telo takar lamiang garing belom, epat hanjang pating perang bahandang.

Eleh batekang tolang kilau tabalien lantang penjang, haduring uhat,e njakatan uei rantihen tingang, mirang darah,e kilau laut lombah, manjurong isi,e tingkah tandjong karangan penjang, bakandong njalong kaharingan belom hapan manimbok isi tapas, nambang tolang,e lu-baritih, nontong uhat,e lubageto, njalong kaharingan belom njandik njimpei kampongan atei, djiret njandik tantowong tonggal, njalong kaharingan belom manjauh sapurapar isi, mansuhan gantongan tolang, manjauh ontong gandalin djantong,e.

Te liau haring kaharingan barendeng pinding,e, baterus tampajah,e.

Djadi katotok tandak,e Dohong Mama Tandang Sangi- es und giesst aus das Lebenswasser, und er lässt aus ihm ausströmen das Wasser, den Reiniger des Atems für die Liau, die lebende und lebenschaffende, und er entnimmt ihr drei Masse Achatsteine die da wachsen am Lebensbaum, er entnimmt ihr vier Masse der $Z_{\text {weiglein, der rotleuch- }}$ tenden.

Und sogleich werden fest ihre Knochen, wie das Eisenholz das Penjang ausspriessen lässt und das weit herum ausbreitet ihre starken Wurzeln, und sie werden zäh wie Rantihen Tingang-Rotan der sich nach allen Seiten verbreitet wie ein weites Meer, und es vermehrt sich ihr Fleisch, so wie anwächst die Buchtung eines Flusses, so wie sich ausbreitet eine Sandbank von Penjang, so füllt das Wasser des Lebens aus das Fleisch und vermehrt das noch fehlende und es fügt wieder zusammen die Knochen, die sich gelöst haben, und es verbindet die Muskeln, die zerrissen waren, und das Wasser des Lebens fügt zusammen und vereinigt die Abteilungen des Dorfes der Leber 400 und es verbindet das Herz, das einzige, und das Wasser des Lebens verankert die verschiedenen Teile des Fleisches das da liegt über seinen Aufhängern, über den Knochen, und es verankert den heilvollen Zaun des Herzens.

Und nun besitzt die Liau, die lebende und lebenschaffende, wieder aufgeschlossene Ohren und sie verfügt über hellschauende Augen.

Beendet ist nun der Gesang des Dohong Mama Tandang Sangiang der 
ang nandjuri njalong kaharingan belom.

Te Dohong Mama Tandang manaroi rangkan panginan simpan palus liau haring kaharingan njurong mangantihan mambouras hakanjatan sukup, djadi nundjong kabesoh,e, mangangkat kabasoha liau haring kaharingan.

Djadi katotok tandak,e njurong mangantihan.

Te Dohong Mama Tandang Sangiang manaroi aka,e njalong tantahidjau bulau, gohong taranjekan karangan hapan liau haring kaharingan manandang ambon rahusan aseng,e, manehang enon rantaran njama,e.

Te djadi katotok tandak,e manaroi aka,e njalong ambon.

Balitan Dohong Mama Tandang Sangiang manaroi aka,e pantar bua pinang, liau haring kaharingan hapantar bua pinang.

Te djadi katotok tandak,e hapantar pinang palus tarantang Sangiang pekas Penjang nandak mindah guranan ara,e, mangarunja misat sasabutan über der Liau ausgoss das Wasser des Lebens, das lebenschaffende.

Und nun reicht ihr der Dohong Mama Tandang die Speisen, die in genügender Menge vorhanden sind und sogleich macht sich die Liau, die lebende und lebenschaffende, über sie her und sie rafft zusammen und sie verzehrt die reichlichen Speisen und es steigt auf in ihr das Gefühl der Sattheit und es erhebt sich in der Liau, der lebenden und lebenschaffenden, die Befriedigung ihres gestillten Hungers.

Beendet ist nun der Gesang des Hinreichens und des Verzehrens der Speisen.

Und nun überreicht ihr Dohong Mama Tandang Sangiang das grünliche schimmernde Wasser, das golden leuchtende, das Wasser das aufgeschöpft wurde von den Steinbänken, und er gibt es der Liau, der lebenden und lebenschaffenden, damit sie mit ihm die Wolken vertreibe, die sich lagern über dem Fahrweg des Atems, damit sie befreie den Weg des Mundes von allen Tauwolken.

Beendet ist nun das Spruchwort des Hinreichens des Wassers zur Vertreibung der Wolken.

Und nun überreicht er, der Dohong Mama Tandang Sangiang, der Liau ein Betelnusskausel und die Liau, die lebende und lebenschaffende, kaut nun die Frucht der Pinangpalme.

Beendet ist nun das Spruchwort des Kauens der Betelnüsse und sogleich beginnen die Kinder der Sangiang, sie die geliehenen Penjang (d.h. die Sangiang die in die Balian eingefahren sind), 
biti,e mukong ie sambang garantong, lapik hapan timpong piara radja.

I'gananggare ano.

Ijoi djadi buah gangguranan ara,e, hinut sasabutan biti,e.

Te koa, $\mathrm{n}$ rawei Dohong Mama Tandang, tisoi Langkah Sawang Mama Bungai: aku antang manamuei mangagahen biti,m akan lewu Bukit Kanjaloh Lanting, rundong Kereng Naliwoh Rahan.

I'sana-sana liau haring kaharingan djadi huang papan talawang teras kaju djambu bahandang, medjen dare,n lintong luhing lumpok muntei bulau, usang,e liau bulau sambang raung paliambong bagantong bukit pasahan raung huang batang danum Rutas, awa balai rutas, sali bapilo.

Hemben nduan, hambekan katon ringkes-marangkesa hajak tingang handak tolak den Gesang der Aenderung der Benennung, des Namens, und sie singen und sie verwandeln den Namen des Toten und sie setzen ihn auf Trommeln und sie setzen ihn auf einen Gong, auf den gelegt ist das königliche Tuch von Seide, das weiche.

Er soll nun fortan heissen.... N.N. (Der neue Name, der dem Toten gegeben wird, wird nun von den Priestern ausgesprochen.)

Ja, zutreffend ist nun die Benennung, gut ist nun der Name, in Ordnung ist nun die neue Bezeichnung des Toten. Und nun spricht das Wort des Dohong Mama Tandang, sagt die Rede des Langkah Sawang Mama Bungai: ich bin der reisende Falke, ich werde dich nun leiten nach dem Dorfe Bukit Kanjaloh Lanting, nach dem Orte Kereng Naliwoh Rahan.

Und kaum befand sich die Liau, die lebende und lebenschaffende, im Schildbrett, dem Kernholz des roten Djambubaumes, in dem geflochtenen Band, dem Pfahl des innersten Holzes des goldenen Munteibaumes, da war es bereits geschehen, dass die Liau aus dem goldenen ausgehöhlten Sarg nach aufwärts fortgeweht wurde und dass sie aufgestellt wurde auf dem Berge der Hütten der Särge am Flusse Rutas, unterhalb des Balai Rutas, des Hauses Bapilo (es handelt sich hier wahrscheinlich um die Seele: gana, des Sarges, aber nicht um den Toten selbst).

Und jetzt in diesem Augenblicke, jetzt zu dieser Zeit wird nun auch alles in Ordnung gebracht und der Nashorn- 
lunok bara bukit pasahan raung, tambon lius basangka baras.

Ijoi koa,n rawei liau haring kaharingan idje djadi sarikumpang hajak basalungkem hindje kaharati, tolang uhat,e, isi,e daha,e, upak bulu, lumpok mata,e:

Narai bulan kahunga, penjang aku mandjah simpei,e, paturong santi tilong tamburak, antang kurong tadjahan lingongku, kenjoi makang bantilong karendemku.

Ijoi, Dohong Mana Tandang Sangiang, koa,n liau haring kaharingan, tanterus pangambon balawang pandjang, bitingku nahuang nanturana lingongku, nantaregah karendemku, nahuang mangalingo lewu mahawangku, mangarendem rundong matendo,e metoh bitingku melai lewu indjam tingang, hemben balitangku medjen rundong nasih nampoi bungai.

Ijoi, koa,n rawei Dohong Mama Tandang Sangiang, kareh biti,m ngalingo hapan vogel will wegfliegen vom Baume, will fortgehen vom Berge der Hütten der Särge, und die Wasserschlange will abstossen von der Sandbank.

Ja, so spricht das Wort der Liau, der lebenden und lebenschaffenden, welche wieder vereinigt wurde mit dem Verstande, mit den Knochen und Muskeln, mit dem Fleisch und dem Blut, mit der Haut und den Hauthaaren und mit der Rundheit der Augen : 401

Was, o Monde, sollte ich dagegen einzuwenden haben! ich bin doch ein Penjang der eingefügt wird in sein Bündel, ich bin doch ein wohlriechender Paturong, ein glattgeschnittener, der zusammengeflochten wird, ich bin ein Antang, dessen Innerstes umzäunt wird, ich bin ein Falke, dessen Herz umwandet wird mit glattgeschnittenen Pfählen.

Ja, o Dohong Mama Tandang Sangiang, so spricht die Liau, die lebende und lebenschaffende, so sagt die Tanterus Pangambon Balawang Pandjang, ich möchte wohl noch Ausdruck geben dem Gefühle meines Innern, ich möchte wohl noch aussprechen das Verlangen meines Herzens, ich möchte gerne mein Innerstes ausschütten, ich möchte Ausdruck geben dem Leid meines Herzens, dass ich Abschied nehmen muss von dem Dorfe, in dem ich mich einst aufhielt, weinend möchte ich mich trennen von dem Orte, dem geliehenen, in dem ich mich während langer Zeit aufgehalten habe. Ja, so spricht das Wort des Dohong Mama Tandang Sangiang, hernach wirst du dein Herz ausschütten und 
bahing karungut,m gantogantong huang kabantengan njalong riwut, menda-menda ambon hapantar.

Mangat babalang bahing karungut, $m$ bewei, hindai biti,m hapan lasang riwut panangka dje andau, gentoi salatan panalandjat pandang kalaman.

Amon djadi ngentang tiwah tingang, tujang mangko haoi burong.

Ringkes-marangkesa, ringkinbasariang, engkak bulau manamburak, ndjidjit nasupit teken garing, nguhas tatambat keket, ndjidjit hadjadjita djamban garing.

Mendeng manambawa riwut, palus riwut dumah hakampehes akan ganggulon papan talawang teras kaju djambu bahandang, salatan pamaruwei bulau dare, $n$ lintong luhing lumpok muntei bulau.

Malik bahing panto,n sambang kadjalahan pulau rewan bawi, mules salintik luhing deine Klage wird aufsteigen im Liede, dann wenn wir angekommen sein werden in der Höhe, in der Mitte des Wassers der Winde und unter den aufgestützten Wolken.

Aber dann wird nur aufsteigen der Laut deines Liedes, aber noch nicht wirst du benützen das Boot des Windes, nur kurze Zeit wird deine Klage dauern, noch nicht wirst du Gebrauch machen von dem Fahrzeug des Sturmes, denn nur einen Augenblick wirst du dem Leide deines Herzens Ausdruck geben.

Denn erst dann wirst du es richtig ausführen, wenn man sich rüstet für das Tragwerk des Tiwah des Tingang, wenn man sich bereit macht für das auf den Schoss nehmen des Totenfestes des Vogels.

Und sie bringen alles in Ordnung und sie machen alles bereit, sie lösen das goldene zusammengeflochtene Seil, sie ziehen und zerren heraus den Stossbaum, den elfenbeinernen, sie lösen das Seil, das vielgliederige, am hinteren Teile des Bootes, sie ziehen herein den elfenbeinernen Steg.

Und sie erheben sich und rufen den Winden und sogleich kommen die Winde herbei mit heftiger Kraft um zu beschleunigen die Fahrt des Schildbrettes vom Kernholz des roten Djambubaumes, wehen die Winde herzu um fortzutreiben das goldene geflochtene Band, den Pfahl des innersten Holzes des goldenen Munteibaumes.

Und nun wechselt der Schall des Schlages der Trommeln der Angehörigen, des Haufens der Frauen, und 
djumpong tambon haruwei bungai. es ändert der Laut der Trommeln der Schar der Wasserschlangen die verzwillingt sind mit den Nashornvögeln.

\section{Das Schildbrett reist mit der Liau nach dem Bukit Kanjaloh Lanting}

Toh hobah tekap katambong ttg. hobah lago,n tandak. Ewen manandak lepah biti,e, koa,e :

I'ohoi bara ohoi, ilu-manolak papan talawang, i'ehei bara ehei, ilu-manjangka bulau dare,n lintong.

I'tolak dje papan talawang bara bukit pasahan raung, i-sangka bulau dare,n lintong dje bara kereng daharin penda lunok.

I'tolak dje para-parang kilau bawi,n antang mangamparang tandjong, i'sangka tente-tenteng kamaras bau,n djumban bahandang.

Njalumbo tandjong ambon limebalas hatantilap, njanjapenda tandjong ambon hapantar kilau bulau pantar sanggar.

I'lu-bagantong manandjulo papan talawang huang njalong riwut ganto-gantong.
Es ändert sich nun der Schlag der Trommeln und es wechselt auch die Melodie des Liedes und sie alle zusammen singen nun und ihr Gesang lautet:

Ohoi und noch einmal ohoi, es fährt nun weg das Schildbrett, ehei und noch einmal ehei, es stösst nun ab das goldene geflochtene Band.

Es reist weg das Schildbrett vom Berge der Hütten der Särge, es stösst ab das goldene geflochtene Band von dem Hügel der sich ausdehnt unter den Wohnungen der Lunok.

Und es reist weg, schrägliegend, so wie ein weiblicher Falke in schrägem Fluge schwebend in der Luft kreist, es stösst $a b$, so wie man abschneidet mit einem Schlag ein langes Stück Holz und seine Fahrt gleicht der geraden Oeffnung eines roten Korbes.

Es steigt in gerader Fahrt aufwärts durch die Buchtungen der Wolken, die fünfzehn doppelt übereinanderliegenden, und es fährt auf den Flussbiegungen bis hin zu den Wolken die gestützt werden durch einen Pfahl, der da aussieht wie ein goldener geschmückter Mast (handelt sich wahrscheinlich um einen Sanggaran).

Und das Schildbrett hält an für einen Augenblick droben in der Höhe und es schwebt über den Wassern der Winde. 
Bulau dare,n lintong tuja-tujang tahan medjen gohong lu-salatan.

I'malik bahing panto,n sambang djalahan pulau rewan bawi, lalu mules salintik luhing djumpong tambon haruei bungai.

Manjaroroi gandang apang liau kaharingan mangalingo, manantepet towong mama pangambon mangarendem.
Das goldene geflochtene Band bleibt stehen und es wiegt sich über den Fluten der Stürme.

Und es ändert der Laut des Schlagens der Trommeln der Angehörigen, des Haufens der Frauen, und es wechselt der Schall der Trommeln der Menge der Wasserschlangen die da verzwillingt sind mit den Nashornvögeln.

Und sie befolgen die Weise der Vatertrommel, die da spielt wie die Liau, die lebenschaffende, ausschüttet ihr Inneres, und es begleitet die Onkeltrommel das Lied der Pangambon, in dem sie offenbar macht ihr Herz.

\section{K. Die Liau nimmt weinend Abschied von der Welt und sie ermahnt die zurückgebliebenen Angehörigen}

Ein Höhepunkt in der ganzen Handlung des Tantolak matei ist, wenn der Tote sich noch einmal zu seinen Angehörigen wendet und von ihnen, und auch von seinem Dorf und Fluss, den Feldern und dem Wald für immer Abschied nimmt. Die Worte werden mit schwermütig klagender Stimme vorgetragen. Tiefe Bewegung ergreift die Zurückbleibenden, wenn sie noch einmal die bekannte Stimme hören, die für immer Abschied nimmt von allem was ihm lieb war. Während des Mangalingo (Abschied nehmen) bleibt man zu Hause. Es ist Pali ins Freie $z u$ gehen, weil dieser Gang mit manchen Gefahren verbunden wäre, denn das Abschiednehmen des Toten ist ein kosmisches Ereignis. Der ganze Kosmos kommt in Bewegung und äussert auf mannigfache Art und Weise seine Teilnahme am Hinscheiden eines Gliedes das zu ihm gehört hat. Die ganze kosmische Ordnung ist gestört und man muss mit allen Möglichkeiten Rechnung halten. Die Sonne verfinstert sich, die Tier- und Pflanzenwelt trauert. Krachende Donner und zuckende Blitze lassen die Welt erzittern, schwere Unwetter brechen plötzlich los. Die ganze Natur ist in Aufruhr und Trauer um den Einen mit dem sie unlöslich verbunden war und der sich nun auch von ihr losreisst und Abschied nimmt für immer.

Toh hobah lago,n tekap ttg. Es ändert sich nun das Schlagen der lago,n tandak,e manumon Trommel und die Melodie des Ge- 
lago,n tekap: Lian ngalingo, koa,e :

I'kakalingo liau haring kaharingan, kakarendem pangambon balawang pandjang.

Babalang bahing karungut,e bewei bara njalong riwut, batentang salatan kandaju bara gohong salatan.

I'kakalingo-lingo ikau batang danum are bara bambai, bakarende-rendem gohong kutoh basakati.

Male-maleh hemben horan metoh aku melai lewu indjam tingang, pesangku medjen rundong nasih nampoi bungai,

Bei Männern lauten nun die Abschiedsworte:

Ekaku dohong manganjum hiring buno, mangumban rangga, ekaku dohong bapaju dagang, buno batolak bungkal.

Hadjualan bantilan timpong nangkaria,e dengan kilat bulau pungkal radja, tampong lamiang hatalimbas omba rabia tisik tambon. sanges und sie werden vorgetragen nach der Weise: Die Lian nimmt $A b$ schied. Der Gesang lautet:

Klagend schüttet ihr Inneres aus die Liau, die lebende und lebenschaffende, weinend giesst ihr Herz aus die Pangambon Balawang Pandjang.

Und es erhebt sich der Schall des Liedes aus der Richtung der Wasser der Winde, und es steigt auf der Laut des Gesanges von der Seite der Fluten der Stürme.

Ich nehme nun Abschied von euch, ihr Flüsse, ihr zahlreich nebeneinanderliegende, ich verlasse euch für immer, ihr Ströme, ihr zahlreich aneinandergrenzende.

Damals in früheren Zeiten, als ich noch lebte in dem Dorfe, dem geliehenen der Tingang, in den Tagen, als ich mich noch aufhielt in dem Orte, in dem weit verstreut leben die Nashornvögel.
Da warst du der Ort, wo ich, der Dolch, hin- und herwiegte die Schärfe der Lanze, wo ich schwang meinen Speer (gedacht ist hier wahrscheinlich an die Waage), da warst du der Ort, wo ich, der Dolch, mühelos verkaufen konnte meine Handelsgüter, wo ich, der Speer, ausgemessen habe das Schmiedewerk.

Da warst du der Ort wo ich verkauft habe die Rollen des Tuches und wo ich sie austauschte gegen das blitzende Gold, das königlich geschmiedete, wo ich auswechselte die Achatbündel gegen die goldenen Schuppen der 
Wasserschlange.

Kakalingo-lingo hila djalajan hulu danum, kakarende-rendem hila tandjong ringkin karangan.

Male-maleh hemben horan metoh aku melai huang lewu indjam tingang dinon totok tambalon tambon, pesangku medjen rundong nasih nampoi bungai,

Ekaku manotoh bulau lelak bendang, maningkai rabia puson pandong, ekaku manuwe riak henda,n bulau, manawing lanti,n rabia.

Ich nehme Abschied von dir, o Oberlauf und Quellort des Flusses, ich grüsse dich nochmals, o Buchtung, wo über die Steinbänke hüpfen die Wellchen.

Damals in früheren Zeiten, als ich noch lebte in dem Dorfe, dem geliehenen der Tingang, und in dem Munde der zusammengerollten Wasserschlange, in den vergangenen Tagen, als ich mich noch aufhielt in dem Orte, in dem weit herumverstreut wohnen die Nashornvögel.

Da warst du der Ort, wo ich in Menge einsammelte die goldenen Blüten der Bendangpalme, wo ich herunterriss die goldenen Herzblätter der Pandong, da warst du der Ort, wo ich mit betäubenden Mitteln einfing die Wellen der Gelbheit des Goldes, wo ich auffing die goldenen Wogen (es handelt sich hier um Gold das am Oberlauf der Flüsse gewonnen wird).

Kakalingo-lingo hila pai,n Ich nehme nun Abschied von dem Fuss bukit gantong, kakarendem djaka purok ambo.

des hohen Berges, ich grüsse dich noch einmal, du steilaufragender Fels.

Male-maleh hemben horan, ekaku mandolang bulau baliat, manawing rabia leket.

Njamah hapelek aku kanderang tingang, basakati uak kalawet.

Maleh nduan, hambekan kaDamals in früheren Zeiten warst du der Ort wo ich ausgewaschen habe das Gold, das zähe, wo ich gesammelt habe das Gold, das klebende.

Wo ich wetteiferte mit dem Gerufe der Nashornvögel, wo ich $u a k$ schrie zusammen mit dem roten Bergaffen. (Gedacht ist bei dieser Beschreibung wahrscheinlich an den Gunong Mas bei Tewah am oberen Kahaian wo von sehr vielen Dajak Gold gesammelt wird.)

So war es früher, aber nun steht es 
ton djadi nahalanting lewu indjam tingang kilau piring buang, halantingangku rundong nasih nampoi bungai tingkah djarah sandong.

Panting batu aku, dia tapalulang-luli, djakah liang, dia tapamalik-mules.

Kakalingo-lingo tana lombah, kakarende-rendem tampoi mirang.

Male-maleh metoh aku melai lewu indjam tingang, pesang$\mathrm{ku}$ medjen rundong nasih nampoi bungai,

Ekaku mandolang bulau kambang ambon, nangkaileku rabia leket.

Bakalingo-lingo ikau tandjong pandjang, bakarenderendem ikau luwok ambo ttg. telok lombah.

Male-maleh hemben horan ekaku hababiong bulau telon djala, mangumban ontai rabia sampo,e.

Mandjala kalawau bewau andau mandjohan batihi,n bulau, dinon undang salintik gandang, sapan djalan kara- ja so: weggeworfen habe ich das Dorf, das geliehene der Tingang, so wie man wegwirft einen leeren Teller, von mir weggeschoben habe ich den Ort, in dem weit herum verstreut die Nashornvögel leben, fortgeschleudert habe ich es, wie man fortschleudert einen unbrauchbaren Teller.

Und nun bin ich selbst ein weggeworfener Stein, der nie mehr zurückkehren wird, und nun bin ich selbst ein weggeschleudertes Stück Erde, das nie mehr heimkommt.

Ich nehme Abschied von dir, du breites Reisfeld, ich grüsse dich nochmals, du ausgestreckter Acker.

Damals in früheren Zeiten, als ich noch lebte in dem Dorfe, dem geliehenen der Tingang, in den vergangenen Tagen, als ich mich noch aufhielt in dem Orte der bewohnt wird von den weit herum verstreut lebenden Nashornvögeln,

Da warst du der Ort wo ich einsammelte die goldenen Blumen der Wolken, wo ich mir erwarb das festklebende Gold.

Ich nehme nun Abschied von dir, du lange Flussbiegung, ich grüsse dich nochmals, du grosse Buchtung, und dich, du weit ausgestrecktes Ufer.

Damals in früheren Zeiten waret ihr der Ort wo ich auswarf die goldenen Hängsel meines Wurfnetzes, wo ich hin- und herwiegte das goldene Seil an dem man aufhängt das Netz.

Ich fing in dem Netze die Behau, und ich fing die Mandjohan zur Zeit als sie voller Eier waren, ich fing die Krebse Salintik Gandang, und ich 
ngan.

Bakalingo-lingo ikau datah lombah.

Male-maleh hemben horan ekaku mandop mambuang lawang, ekaku mengan tingang, manjelek ampong kalawet ajun baputi, negahku bandan Njaring, nitihku pahen Sahakong.

Dia ijen kakira,n lingongku hemben nduan hambekan katon, isen bintang kakira,n djarah karendemkı matok dinon hambekan katon.

Djadi nahalantingku lewu indjam tingang kilau pring buang, halantingangku rundong nasih nampoi bungai tingkah djarah sandong.

Bakalingo-lingo ikau pukong pahewan antang, bakarenderendem pandong parindjangan dahiang.

Male-maleh hemben horan metohku melai lewu indjam tingang, pesangku medjen rundong nasih nampoi bungai, ekaku hataburan behas parei njangen tingang, mandjakah roko,n tarahan balaku karambang kilau pulau pehon sa- schöpfte auch die Fische auf den Wegen zwischen den Sandbänken.

Ich nehme Abschied von euch, ihr Sprossen, ihr breiten.

Damals in früheren Zeiten warst du der Ort wohin ich auf die Jagd auszog und wo ich leermachte den Platz vor der Türe des Dorfes, warst du der Ort wo ich aus meinem Blaserohr die Pfeile abschoss auf die Vögel, wo ich beschlich den Zufluchtsort des Kalawet Ajun Baputi (Affen), wo ich klopfte an das Gestell der Njaring, wo ich schlug an das Gerüst des Sahakong. Nicht kann ich jetzt zu dieser Zeit in genügender Weise aussprechen die Gedanken meines Innern, nicht, o Sterne, ist es mir jetzt in diesem Augenblicke möglich Ausdruck zu geben an dem was mein Herz bewegt. Denn weggeworfen habe ich ja das Dorf, das geliehene der Tingang, so wie man wegwirft einen leeren Teller, fortgestossen habe ich ja den Ort, wo die Nashornvögel weit herum verstreut wohnen, fortgestossen habe ich es wie man von sich wegstösst ein unbrauchbar gewordenes Gefäss.

Ich nehme Abschied von dir, o Gehölz, du heiliger Hain des Falken, ich grüsse dich noch einmal, o Wald wo man Vorzeichen erbittet.

Damals in früheren Zeiten, als ich noch lebte in dem Dorf, dem geliehenen der Tingang, in den vergangenen Tagen, als ich mich noch aufhielt in dem Orte, in dem weit herum verstreut wohnen die Nashornvögel, da warst du der Ort wo ich ausstreute den enthülsten Reis von den Reiskörnern 
wang, hambalat tingkah ruang djumpong bunge, amon bitingku dohong manarikan hiring,e, buno tandjan djalajan hila hulu batang danum.

Bakalingo-lingo ikau lawang labeho,n Djata.

Male-maleh hemben horan ekaku hataburan bulau urai, hatatajan rabia bowor metoh bitingku tolak buno badjamban laut, dohong tandjak pasang hariran.

Bakalingo-lingo ikau lewu mahawangku, bakarenderendem ikau rundong matendoku.

Bakalingo-lingo ikau lanting garing, bakarende-rendem bangkar sihong.

Male-maleh hemben horan ekaku manambang tambon tamuei bungai, manambang emban pandjang.
Njangen Tingang, wo ich niederlegte die Rauchwaren der Sklaven, und wo ich die Bitte aussprach umzäunt zu werden, so wie man umzäunt die Insel der Sawangstauden, umfriedet zu werden wie ein Bungegebüsch während der Zeit in der ich, der Dolch, flussaufwärtsreiste mit meiner Schärfe, während der Dauer meiner Fahrt nach dem Oberlauf, dem Quellort des Stromes.

Ich nehme Abschied von dir, du Türe zu der Wassertiefe der Djata.

Damals in früheren Zeiten warst du der Ort wo ich ausstreute die goldene Saat, wo ich auswarf das goldene Streusel (der Reis, der für die Djata ausgestreut wird färbt man mit Curcuma gelb. Die gelbe Farbe ist assoziiert mit der Unterwelt. Für die Oberwelt streut man weissen Reis aus, denn weiss ist die Farbe der Oberwelt), wenn ich, der Speer, mich aufmachte um auf die Reise zu gehen auf den Wegen über die See, wenn ich, der Dolch, auszog über die Flut des Meeres.

Ich nehme nun Abschied von dir, du Dorf in dem ich einst wohnte, ich grüsse dich noch einmal, du Ort in dem ich einst lebte.

Ich nehme nun Abschied von dir, du Landungsfloss, ich grüsse dich noch einmal, du Anlegeplatz von Elfenbein. Damals in früheren Zeiten warst du der Ort wo ich erwartete die Wasserschlangen und die reisenden Nashornvögel und wo ich empfing das lange Festboot (es handelt sich hier um den ganzen Stamm, dessen eine Hälfte mit 
der Wasserschlange und Unterwelt und dessen andere Hälfte mit dem Nashornvogel und der Oberwelt assoziiert ist, und der in den Festbooten angereist kommt um sich anlässlich wichtiger religiöser Handlungen $z u$ vereinigen. Siehe auch die Einleitung).

Bakalingo-lingo ikau njalong kapandujan tingang.

Male-maleh hemben horan metoh aku melai lewu indjam tingang, pesangku medjen rundong nasih nampoi bungai hatampulu lalalangangku hapandujan kabangkangku.

Maleh nduan, hambekan katon nahalantingku kilau piring buang, halantingangku tingkah djarah sandong.

Bakalingo-lingo ikau papan bandong lasang, bakarenderendem pandong panjandai bulan, besei manipis nahadandang tingang, dajong bunter namunan sara, $n$ bulan.

Male-maleh hemben horan metoh aku melai lewu indjam tingang, pesangku medjen rundong nasih nampoi bungai hapaku habeseian tandjong pandjang, mangangkajoh luwok ambo, mananturong tana lombah, manjahendeng tam-
Ich nehme nun Abschied von dir, du Wasser in dem sich die Nashornvögel badeten.

Damals in den früheren Zeiten, als ich noch lebte in dem Dorfe, dem geliehenen der Tingang, als ich mich noch aufhielt in dem Orte, in dem weit herum verstreut leben die Nashornvögel, wie oft geschah es da doch nicht dass ich dort meinen Leib badete.

So war es früher, aber nun steht es ja so: weggeworfen habe ich es, so wie man wegwirft einen leeren Teller, fortgeschleudert habe ich es, wie man fortschleudert ein unbrauchbar gewordenes Gefäss.

Ich nehme nun Abschied von dir, o mein Boot, ich grüsse dich noch einmal, du Sitzplatz, von dem aufstieg das Gezwitscher der Monde, und dich, du dünnes Ruder, das festgehalten wird durch die Tingang, und dich du rundes Ruder, das dem Rande des Mondes gleicht.

Damals in den früheren Zeiten, als ich noch lebte in dem Dorfe, dem geliehenen der Tingang, in den vergangenen Tagen, als ich mich noch aufhielt in dem Orte, in dem weit herum verstreut leben die Nashornvögel, da gebrauchte ich euch um den langen Buchtungen entlang $z u$ rudern, da be- 
poi mirang.

Dia ijen kakira,n lingongku, hemben nduan hambekan katon nahalantingku ikau kilau piring buang, halantingangku tingkah djarah sandong.

Bakalingo-lingo ikau hedjan rangkang, kalingkasan tambon.

Male-maleh hemben horan hatampulu ikau hadjadjakan tambang lawah rawingku balinga metoh bitingku namuei lanting garing.

Bakalingo-lingo ikau batu lawang paruntaran tingang, bakarende-rendem liang panapian tambon.

Male-maleh hemben horan ekaku mampong garing tarantangku.

Bakalingo-lingo ikau batang pinang lewu, bakarenderendem ikau bulus upo,n katilambong njaho.

Male-maleh hemben horan metoh aku melai lewu indjam tingang, pesangku medjen rundong nasih nampoi bungai, nutzte ich euch um auf den grossen Flussbiegungen $z \mathfrak{u}$ fahren, um mich auf das breite Feld zu begeben, um nach dem ausgestreckten Acker zu reisen.

Es ist mir nicht möglich auszusprechen die Gedanken meines Innern, denn jetzt ist es ja so, dass ich es weggeworfen habe, wie man wegwirft einen leeren Teller, dass ich es fortgeschleudert habe, so wie man wegschleudert ein unbrauchbar gewordenes Gefäss.

Ich nehme nun Abschied von dir, du Treppe, die du hinführst zur Tiefe in der sich hin- und herwenden die Wasserschlangen.

Wie oft haben dich damals in den früheren Zeiten nicht betreten meine Füsse, die geschmückten, die des raschen Krokodiles, dann wenn ich mich zum Landungsfloss begab, dem elfenbeinernen.

Ich nehme nun Abschied von dir, du Stein an der Türe zum Vorplatz des Hauses, ich grüsse dich noch einmal, du Stein am Anlegeplatz der Wasserschlangen.

Damals in den vergangenen Zeiten warst du der Ort wo ich mich so oft unterhielt mit den Elfenbeinen, mit meinen Kindern.

Ich nehme nun Abschied von euch, ihr Stämme der Pinangpalmen des Dorfes, ich grüsse euch noch einmal, ihr zarten Herzblätter der donnernden Kokospalmen.

Damals in früheren Zeiten, als ich noch lebte in dem Dorfe, dem geliehenen der Tingang, in den vergangenen Tagen, als ich mich noch 
kindjap bitingku hatalandjong, balitangku njangkiat. ${ }^{402}$

Dia ijen kakira,n lingongku, hemben nduan hambekan katon, isen bintang djarah karendem, matok dinon djaretan etoh djadi nahalantingangku kilau piring buang, halantingangku tingkah djarah sandong.

Bakalingo-lingo ikau bua djambu, nangka.

Male-maleh hemben horan eka bitingku babalai.

Bakalingo-lingo ikau parong kola awang manansila.

Male-maleh hemben horan ekaku batantang kadja, basawong rusik.

Dia ijen kakira,n lingongku hemben nduan hambekan katon, djadi nahalantingang$\mathrm{ku}$ lewu indjam tingang, halantingangku rundong nasih nampoi bungai.

Bakalingo-lingo ikau mangaliling parong mahawang, bakarende-rendem manalumbang siro matendoku. aufhielt in dem Orte, der bewohnt wird von den weit herum verstreut lebenden Nashornvögeln, da habe ich euch oft bestiegen, da habe ich euch manchmal erklettert.

Ach, es ist mir ja nicht möglich auszusprechen die Gedanken meines Innern, denn jetzt ist es ja so, ach, es ist mir ja unmöglich zu äussern die Gefühle meines Herzens, denn so ist es nun ja in dieser Angelegenheit: weggeworfen habe ich euch ja, wie man wegwirft einen leeren Teller, fortgeschleudert habe ich euch ja, wie man wegschleudert ein unbrauchbar gewordenes Gefäss.

Ich nehme nun Abschied von euch, ihr Djambu- und Nangkabäume.

Damals in den früheren Zeiten, da umgabet ihr den Ort wo ich meine Wohnung hatte.

Ich nehme nun Abschied von euch, ihr Häuser meiner Verwandten, welche sich erheben $z u$ beiden Seiten meiner eigenen Wohnung.

Damals in früheren Zeiten, da war ich so oft geneigt sie $\mathrm{zu}$ besuchen, da freute ich mich so manchmal sie zu betreten.

Nicht vermag ich ja auszusprechen die Gedanken meines Innern, denn jetzt steht es ja so, dass ich weggeworfen habe das Dorf, das geliehene der Tingang, dass ich fortgestossen habe den Ort, in dem weit herum verstreut wohnen die Nashornvögel.

Ich nehme nun Abschied von dir, du Umgebung des Hauses in dem ich einst wohnte, ich grüsse dich noch einmal, du Nachbarschaft meiner Wohnung in 
Bakalingo-lingo bangunan balai, bakarende-rendem djakean sali.

Male-maleh hemben horan ekaku mangarak riwut bakahut, ekaku manguhas salatan hapungkal, ekaku manambang totok riwut lawo manakep djadjak salatan rampe.

Bakalingo-lingo lepau parei, bakarende-rendem pasah lisong, bakalingo-lingo lisong kamangkiling Njaring, bakarende-rendem halo lumpong tabalien.

Male-maleh hemben horan ekaku nepe marewoh parei njangen tingang, nampuras pulut lumpong penjang.

Bakalingo-lingo ikau talai.

Male-maleh hemben horan hapaku mangiap behas parei njangen tingang, hapaku nahalanting salumo kilau tambon belom, halantingan kahempang,e kilau burong tingang.

Bakalingo-lingo ikau penda lepau balai, bakalingo-lingo der ich einst lebte.

Ich nehme nun Abschied von dir, du Bauwerk des Balai, ich grüsse dich noch einmal, du aufgerichtetes Haus. Damals in früheren Zeiten warst du der Ort, wo ich auseinanderbrach den umwundenen Wind (den Blasebalg), der Ort, wo ich löste den Wind zum Schmieden, der Ort, wo ich erwartete den Ausbruch des Sturmes, des herniederfallenden, der Ort, wo ich empfing den losbrechenden Wind. (Unter dem Balai befindet sich der Schmiedeplatz. Hier wird die Bedienung des Blasebalges beschrieben.)

Ich nehme nun Abschied von dir, du Reisscheuer, ich grüsse dich noch einmal, du Bergplatz für die Stampfblöcke, ich nehme Abschied von dir, du Stampfblock, der du aussiehst wie ein Njaring, ich grüsse dich noch einmal, du kantiger Reisstampfer von Eisenholz.

Damals in früheren Zeiten, da waret ihr ja der Ort wo ich stampfte und feinrieb den Reis Njangen Tingang und wo ich scheuerte den Klebereis Lumpong Penjang.

Ich nehme nun Abschied von dir, du Reisworfelmatte.

Damals in früheren Zeiten gebrauchte ich dich um zu worfeln den enthülsten Reis des Reises Njangen Tingang, ich gebrauchte dich um den Reis $\mathbf{z u}$ reinigen, so wie die Wasserschlange abstösst ihre alte Haut, um dich zu säubern, so wie ein Nashornvogel säubert sein Gefieder.

Ich nehme nun Abschied von dir, du Platz unter der Reisscheuer, dem 
ikau baputan njarong njiang kewus ${ }^{403}$ kining tambarirang, bakarende-rendem ikau tahanapusu lajang, pasiong 404 totok tingang, apui lowang rawan.

Male-maleh hemben horan ekaku mantaolang tangkuranan tasalku, manabasan dohong papan benteng, nantaolah ranjing buno.

Bakalingo-lingo ikau karambang bawoi samben, bakarende-rendem karongan manok darong tingang.

Male-maleh hemben horan sana andau kasibahan aku manjurong rangkan pangina, $m$.

Bakalingo-lingo ikau hedjan taletai djela burong dahiang, bakarende-rendem ikau pakang-pukong, kanaherau garing.

Male-maleh hemben horan metoh aku melai lewu indjam
Balai (unter der Reisscheuer, die auf Pfählen steht, befindet sich oft ein Raum der als Aufenthaltsort für die reisenden oder besuchenden Fremdlinge dient. Verwandte werden ins Haus genommen), ich grüsse dich noch einmal, du Blasebalg mit den eingeschlossenen Stosshölzern, den Augen wie ein Tambarirang (die Spitze dieser Hölzer ist breit und mit Flaum umgeben, sodass sie aussehen können wie grosse Augen), ich nehme Abschied von dir, du Zurückhalter des Windes, des verirrten, und auch dich Pasiong, Schnabel des Tingang und auch dich, du Feuer aus der durchscheinenden Höhle.

Damals in früheren Zeiten, da warst du der Ort wo ich schuf die verschiedensten Sorten meines Schmiedewerkes, wo ich herstellte die Dolche, die Bretter der Mitte, wo ich schmiedete die verehrungswürdigen Speere.

Ich nehme nun Abschied von dir, du Pferch der Schweine mit den Halsbändern, ich grüsse euch noch einmal, ihr Körbe der Hühner, der Hühner Tingang.

Damals in früheren Zeiten, dann wenn sich der Tag geneigt hatte, bewirtete ich euch immer mit Futterwaren.

Ich nehme nun Abschied von dir, du Treppe, du Treppe mit den Zungen der Vorzeichenvögel, ich grüsse dich noch einmal, du Geländer mit den schützenden Stäben, du Lehne von Elfenbein.

Damals in früheren Zeiten, als ich mich noch aufhielt im Dorfe, dem ge- 
tingang, pesangku medjen rundong nasih nampoi bungai, hatampulu bitingku hadjadjakan biti,m.

Dia ijen kakira,n lingongku, hemben nduan hambekan katon, isen bintang kakira,n djarah karendem matok dinon djaretan etoh, djadi nahalantingku ikau kilau piring buang, nalantingangku tingkah djarah sandong.

Bakalingo-lingo ikau parong mahawang, bakarende-rendem ikau siro matendoku, bakalingo-lingo betok labeho,n parong, bakarenderendem pahor rantau siro.

Bakalingo-lingo ikau ranjing pandereh buno.

Male-maleh hemben horan hatampulu bitingku hadjadjitan bitim hapaku mandop mambuang lawang.

Bakalingo-lingo ikau bentok labeho,n parong.

Male-maleh hemben horan ekaku hasarongan lasang pinang manambang kadja,n rohong.

Bakalingo-lingo huang karong garing, bakarenderendem lawang tambarirang. liehenen der Tingang, in den vergangenen Tagen, als ich noch lebte in dem Orte, wo weit herum verstreut wohnen die Nashornvögel, wie oft habe ich dich doch damals betreten.

Nicht vermag ich ja auszusprechen die Gedanken meines Innern, denn so steht es jetzt ja, nicht ist es mir möglich genügend $z u$ äussern die Gefühle meines Herzens, denn so ist nun ja die Sache: weggeworfen habe ich euch, wie man wegwirft einen leeren Teller, fortgeschleudert habe ich euch, wie man fortschleudert ein unbrauchbar gewordenes Gefäss.

Ich nehme nun Abschied von dir, du Haus in dem ich einst wohnte, ich grüsse dich noch einmal, du Wohnung in der ich einst lebte, ich nehme nun Abschied von dir, du Wassertiefe in der Mitte des Hauses, ich grüsse dich noch einmal, du Abgrund in der Mitte der Wohnung.

Ich nehme nun Abschied von dir, du verehrungswürdiger Speer.

Damals in früheren Zeiten, da geschah es, dass ich dich so manchmal hervorholte und dich gebrauchte für die Jagd um zu entleeren die Wälder vor der Türe des Dorfes.

Ich nehme nun Abschied von dir, du Wassertiefe in der Mitte des Hauses. Damals in früheren Zeiten, da warst du der Ort wo ich empfing mit einem Fahrzeug (Gefäss) voller Pinang den zu erwartenden Besuch der Dolche.

Ich nehme nun Abschied von dir, dem Innern des Zimmers, des elfenbeinernen, ich grüsse dich noch einmal, du Türe, die du geschmückt bist mit ei- 
Bakalingo-lingo djangkut djalembang bulu, $\mathrm{n}$ tingang, benang lalapai radja.

Bakalingo-lingo tilam pahara radja, bantal putak kalihulon batiroh, amak djarenang.

Male-maleh hemben horan ekaku bagaling kenter batambon puron.

Dia ijen kakira,n lingo, hemben nduan hambekan katon, isen bintang pahulawang huang,e, matok dinon kadjaretan etoh djadi nahalanting$\mathrm{ku}$ lewu indjam tingang, halantingangku rundong nasih nampoi bungai.

Amon aton anak sawa:

Kakalingo lunok pakungangku, kakarendem labeho kandawangku, garing tarantang, ijoi sihong lalundong.

Sama tarahondok lambat keton mangat manahingan nem Tambarirang.

Ich nehme nun Abschied von dir, du Vorhang, der du die Weissheit besitzest des Flaumes der Nashornvögel, du Tuch mit den königlichen Fransen.

Ich nehme nun Abschied von dir, du Schlafmatratze, du weiche, du königliche, und von dir, du Kissen das gefüllt ist mit Schaum und auf dem man sich niederlegt zum Schlafe, und von dir du rote Matte.

Damals in früheren Zeiten, da waren sie der Ort wo ich zusammengerollt lag wie eine Wasserschlange zwischen den Puronsträuchern.

Nicht vermag ich genügend auszusprechen die Gedanken meines Innern, denn so steht es jetzt ja, nicht ist es mir möglich zu äussern die eingeschlossenen Gefühle meines Herzens, denn so ist ja nun die Sache: weggeworfen habe ich ja das Dorf, das geliehene der Tingang, fortgestossen habe ich den Ort, wo weit herum verstreut wohnen die Nashornvögel.

Wenn der Tote Frau und Kinder zurückgelassen hat, lautet die Fortsetzung des Gesanges:

Ich nehme nun Abschied von dir, du Lunok mit dem ich zusammenlebte, ich grüsse dich noch einmal du Wassertiefe bei der ich mich aufhielt, und euch meine elfenbeinernen Kinder, meine elfenbeinernen Nachkommen.

Setzet euch vorsichtig auf damit ihr hören könnt mein wehendes Wort, 
riwut raweiku, keleh keton taraheken lowah njalanean salatan tisoiku.

Djaka keton tiroh tingang te pararindjet keton tiroh tingang, amon keton pararindjet tiroh tingang keleh keton tarahondok lambat mandokan bumbong dare, $n$ puron.

Amon keton djadi mandokan bumbong dare,n puron keleh sarak-saraken pandong lawi,n balau pandjang, mikeh are manandjala anting kanahan danum djalan keton manahingan riwut raweiku gantogantong kabantengan njalong riwut.

Ijoh nih bulan bandong toh aku malawo rawei, malekas salatan tisoiku akan keton.

Nantuadjar batu piring lingo,n keton, nantahurok liang djarah karendem.

Tau-tau keton hatalatai riwut lingon keton, pandai-pandai keton malempang djarah karendem.

Ela keton ngantong lingo sadingen kilau bari kahalalangan alem, ela manunjang möchtet ihr euch doch langsam erheben und Platz nehmen damit ihr vernehmen könnt meine brausende Rede. Und solltet ihr in Schlaf gefallen sein wie ein Tingang, dann stosse ich euch sanft an in euerem Schlaf der der eines Tingang ist (d.h. ein leichter Schlummer), und wenn ihr erwacht seid aus euerem Schlaf des Nashornvogels, dann erhebet euch vorsichtig und setzet euch auf die Matte, das Geflecht von Puron.

Und wenn ihr Platz genommen habt auf der Matte, dem Geflechte von Puron, dann kämmet eure Haare und streichet zurück die langen Enden euerer Haare, vielleicht dass sonst vieles eingefangen würde im Netz und manches zurückgehalten würde wie die Wassertropfen an den Ohrringen, während ihr hört nach meinem wehenden Wort aus der Höhe, von der Mitte der Wasser des Windes.

Ja, du Mond, du meine Gemahlin, nun lasse ich herunterfallen mein Wort, nun spreche ich für euch aus meine wehende Rede.

Nun lehre ich den steinernen Teller eneres Innern, nun unterrichte ich das irdene Gefäss eueres Herzens (die Herzgrube wird mit einem Teller oder Gefäss verglichen, das nun mit guten Ratschlägen gefüllt wird).

Wohl ist es euch möglich in euerem Innern selbst einen Rat $z \mathfrak{u}$ ersinnen, wohl vermöget ihr in euerem Herzen selbst gute Gedanken zu denken.

Nicht sei nun euer Inneres kalt wie der gekochte Reis, den man während eine Nacht aufbewahrt hat, nicht sei 
karendem basanggengem kilau danum sahai hulu sungei. Ela ngantong lingon keton napang mangalakoang, isen nunjang karendem lanas malampuke.

Keton hatalatai riwut lingon keton, malempang djarah karendem.

Keleh ngantong lingon keton lasut-lasut mindjam bahen kalapapan tandok, manunjang karendem keton pulok-pulok nasih sahewan tamiang randau bulau.

Mikeh tarong keton leteng nahariak rawing, salatan tinting keton lilap tingkah ringkin lombah.

Keton tahandjungan tarong bulau indu ampong lingo, njariangkat salatan kilat tinting liang hawar karendem.

Ela maku tarong keton leteng njangkelang kola,n keton garing idje beken, ela suka tinting keton lilap njampale hamputan due lain.

Ela biti,m manandjuri rawei badjangkang mangandjang penjang keton hindje simpei,e. nun euer Herz kühl wie das trübe Wasser des Oberlaufes eines Flusses. Nicht sei nun euer Inneres flach, nicht sei nun euer Herz wie etwas das im Wachstum zurückgeblieben ist.

Erdenket nun selbst ein Wort eueres Innern, ersinnet nun selbst einen Gedanken eueres Herzens.

Möchte euer Inneres nun warm sein wie die Hitze der glühenden Kohle von Kalapapan Tandok-Holz, möchte euer Herz nun heiss sein wie die Hitze der Fackel von Tamiang, dem dünnen und goldenen.

Vielleicht dass nun euer Ruhm wieder versinkt, überwellt von den Krokodilen, vielleicht dass euer Lobpreis wieder in sich zusammenstürzt wie die breite Welle.

Erhebet nun den Ruhm, den goldenen, zum Troste eueres Innern, lasset nun aufsteigen den Lobpreis, den wehenden und blitzenden, zur Stärkung eueres Herzens.

Nicht darf es geschehen, dass euer Ruhm untergehe zwischen eueren Verwandten, nicht darf euer Lobpreis verschwinden weil er vermengt wurde durch den von zwei andern Geschlechtern.

Nicht lasset aus euch hervorgehen ein viel Raum einnehmendes Wort, das einen Schatten werfen würde auf die Penjang die mit euch zu einem Bündel vereinigt sind. (Um den Frieden in der Verwandtschaft nicht $\mathbf{z u}$ zerstören dürfen keine beleidigenden oder grosssprecherischen Worte ausgesprochen werden. Man hüte seine Zunge, weil 
Ela manantekei tisoi,m badjawo manjarak hamputam paturong homba tamburak,e.

Mikeh penjang keton pangangkarak simpei, paturong keton bakuhas tamburak,c.

Amon penjang keton pangangkarak simpei,e, narai bulan kadjarian lingo, amon paturong keton bakuhas tamburak,e, isen bintang kakira,n djarah karendem?

Tau keton akan gandang tatah djalajan garing idje beken, pandai keton indu garantong djela,n sihong due lain.

Keleh keton ngantong tolang batekang, manunjang uhat hatamiang, maniring sara,n tana lombah, hatabasan tampoi mirang.

Hatindih keton manampong bulau kambang ambon, hatipeng manundun rabia kekah enon. man für die Aufrechterhaltung dieses Friedens mitverantwortlich ist.)

Nicht bringet hervor aus euch eine Rede, eine dick ausstehende, die auf die Seite schieben würde einen aus euerem Geschlecht, einen Paturong der mit euch zusammengeflochten ist.

Denn sonst wäre es möglich, dass das Bündel euerer Penjang auseinanderbrechen würde und es könnte sein, dass das Geflecht, das euere Paturong zusammenhält, zerrisse.

Und wenn es geschehen würde, dass das Bündel euerer Penjang auseinanderbrechen würde, was, o Monde, wäre dann das Ergebnis für euer Inneres, und wenn das Geflecht, das euere Paturong zusammenhält, zerrisse, was, o Sterne, wäre dann das Resultat für euer Herz?

Dann würdet ihr nur werden zu Trommeln der Zahnstifte der Angehörigen der andern Elfenbeine, dann würdet ihr nur dienen als Gong der Zungen, der Elfenbeine, der zwei andern. (Würden sie durch lose Worte Uneinigkeit in die Verwandtschaft hereintragen, dann würden sie nur zum Geschwätz und Gespött.)

Gebrauchet fleissig euere harten Knochen, spannet kräftig an euere geschmeidigen Muskeln und bearbeitet gründlich das grosse Feld bis hin zu seinen Rändern und versorget fleissig den grossen Acker, den ausgestreckten. Damit ihr miteinander vergleichen könnt die aufgehäuften goldenen Blumen der Wolken, damit ihr euch messen könnt mit den goldenen Blüten der Tauwolken (sie sollen zum min- 
Mangat kalabien bulau kambang ambon hapan keton manuwe kilat bulau pungkal radja, kalambungan rabia kekah enon hapan keton manawing rabia tisik tambon.

Kalabien bulau pungkal radja hapan keton mamidjang baner tapang, kalambungan rabia tisik tambon hapan keton manawing manetes rantai garantong.

Mundah-mandahan tarong keton lampang aju-ajun mangumbang lewu mandereh danum, salatan tinting keton umba-umban manasa rundong hapamantai tambon.

Tarong simbel tau habambang batu, tinting kumpit rabia pandai hatikap liang. desten ebensoviel arbeiten und ebenso grosse Ernten erzielen wie ihre Verwandten).

Damit ihr den Ueberfluss der goldenen Blumen gebrauchen könnt um euch mit ihm zu erwerben den Blitz des goldenen königlich geschmiedeten Schmukkes, damit ihr mit dem Ueberschuss der goldenen Blüten der Tauwolken eintauschen könnt die goldenen Schuppen der Wasserschlange.

Und den Ueberfluss des goldenen königlich geschmiedeten Schmuckes gebraucht ihr um euch $z u$ erwerben die Brettwurzeln des Stammes (es ist hier gedacht an den Lebensbaum dessen Brettwurzeln von Gong bestehen. Die Erwerbung von Reichtum, wie sie hier geschildert wird, wird verglichen mit der Aufrichtung eines Lebensbaumes), und den Ueberschuss der goldenen Schuppen der Wasserschlange verwendet ihr um durchschneiden zu können die Ketten der Gong.

Dann wird sich ausbreiten euer Ruhm und er wird auftauchen und er wird in wiegendem Schritte herumgehen durch die Dörfer an den nebeneinanderliegenden Flüssen, und euer wehender Lobpreis wird ausgehen nach den Dörfern an den Ufern der Wasserschlange.

Und der Ruhm des kleinen und unbeachteten Schnitzmessers vermag auszuhauen den Stein und der Lobpreis des goldenen kleinen Messerchens vermag Späne herauszuschlagen aus dem Stein. (Der Reichtum ist noch klein und unbedeutend aber er beginnt doch 
Tau nansaran suloh batu, nampaisat taladjok liau hapan manuwe tanteloh tingang.

Mandahan keton nansaran tanteloh tingang hapan manuwe bukit batu sarakumpang rawing, nawing paisat kereng liang kalihulon amban.

Nansaran keton bukit batu sarakumpang rawing hapan manusaran radja hatanggoi tingang, nampuindah keton kereng liang kalihulon amban hapan nampuindah andin habungai lamiang.

Radja hatanggoi tingang hapa keton nansaran bukit batu petak kalabien bulan.

Andin habungai lamiang hapan keton nampuisat kereng kalambungan lumpong matanandau. bereits Einfluss $z u$ haben.)

Und es ist ihm möglich sich zu nähern den Schösslingen der Steine, er vermag heranzutreten zu den aussprossenden Blättern der Liau und er kann sich nun erwerben die Eier der Tingang. (Es handelt sich bei diesen Namen um billige heilige Töpfe, denn bei diesen beginnt man und schreitet dann weiter bis man sich auch die teuersten Töpfe erwerben kann, die einen Wert von 2000-3000 Fl., und mehr, haben.)

Und weitergehend könnt ihr gebrauchen die Eier der Tingang um mit ihnen zu erwerben die Steinberge, die mit Krokodilen umgeben sind (heilige Töpfe mit Drachenmotiven am Hals), und um in eueren Besitz zu bringen die Steinhügel die man aufreiht auf dem Gestell (die heiligen Töpfe, die man auf ein besonderes Gestell stellt).

Und ihr gebraucht die Steinberge, die von Krokodilen umgeben sind, um euch mit ihnen zu nähern dem König mit dem Hute des Tingang, und ihr vertauscht die Steinhügel auf den Gestellen um sie auszuwechseln gegen den Wassergott mit dem Tingang von Achaten (es handelt sich auch hier um Namen von heiligen Töpfen).

Und mit dem König der einen Tinganghut trägt nähert ihr euch dem Steinberg von Erde, die man genommen hat von dem Ueberfluss des Mondes. ${ }^{405}$

Und den Wassergott mit dem Tingang von Achaten gebraucht ihr um ihn zu vertauschen gegen den Hügel, der gemacht wurde von den überschüssigen 
Mandahan tarong keton tarantang nole tau kanuah anak Djata lampang, kanjambong busu,n Hatala hadurut, tau hatalatai lunok njawak pamua, njaripangko baras bulau lampang njurut paneah,e limbah nole keton nupi penjang, ulek siren mangampa paturong.

Tau-tau keton tarantang nole hatalatai riwut kalingon keton, ela keton kalapean banama baputi bagantong bukit pasahan raung, batujang kereng daharin penda lunok.

Djeleng ngantong keton lingo,e, hariak hatalatai lunok mamua undan, njaripangku baras hapasang darahm njaho hai namparugoh tungkup, kilat pandjang namparindjet ruang mangat bitingku gulong sembang lewu tatau idje dia rumpang tolang, medjen rundong radja isen pamalu
Rändern der Sonne.

Und ausbreiten wird sich dann euer Ruhm, ihr Kinder, ihr Waisen, und ihr werdet angerufen werden von dem Kinde der Djata, dem auftauchenden, und ihr werdet angerufen werden von dem Jüngsten des Hatala, dem herniederfahrenden und dann werdet ihr im Stande sein einen Rat $z u$ ersinnen über den Lunok welcher ausgiebig Früchte trägt, und ihr werdet nachdenken können über den Sand, den goldenen, der sichtbar wird wenn die Wasser im Flusse abnehmen, das wird euch möglich sein nachdem ihr Waisen von Penjang träumtet, nachdem ihr verlassene Kinder im Schlafe gesprochen habt von Paturong.

Und dann ihr Kinder, ihr Waisen, dann könnt ihr bedenken einen wehenden Rat in euerem Innern: nicht vergesset das weisse Boot, welches aufgestellt ist auf dem Berge der Hütten der Särge, das sich wiegt auf dem Hügel der sich ausstreckt unter den Wohnungen der Lunok. (Das weisse Boot ist der Sarg der bis zum Tiwah aufgebahrt bleibt, im Tantolak matei aber an den Fluss Rutas gebracht worden ist.)

Und rasch erhebt ihr euer Inneres und ihr lasset rauschen die Wogen der Ueberlegung und ihr sinnet nach wie der Lunokbaum Undanfrüchte tragen soll (d.h. wie die Kopfjagd ausgeführt werden soll) und ihr beratet was zu tun sei damit der Sand auftauche mit Blut vermischt (d.h. wie die Kopfjagd ausgeführt oder das Menschenopfer dargebracht werden soll), was alles zu 
uhat.

tun sei, dass der grosse Donner zum Erbeben bringe die ganze Gemeinschaft, dass die zuckenden Blitze erzittern machen alle Abteilungen des Hauses, damit ich rasch ankomme in dem Dorfe, dem reichen (es handelt sich um das Tiwah, bei dem die Liau nach dem Totendorf gebracht wird) in welchem man nicht mehr kennt Ermüdung der Knochen, damit ich bald erreiche den Ort, den königlichen, wo man nichts mehr weiss von Erschlaffung der Muskeln.

Toh sandik simpei karuhei tatau, paturong sangkalemo radja akam, ijoi tarantang nole.

Akam belom hatontong kanuah anak Djata, haring hatinggang kanjambong busu,n Hatala hadurut.

Penjang tuwe,n peres baratus gangguaran ara,e, paturong tawing sampar baribu sasabutan biti,e.

Djeleng! koa,n rawei Dohong Mama Tandang, gulong! koa,n Langkah Sawang Mama Bungai.

Kareh helo, liau haring kaharingan, hindai aku hapantar pinang.

Koa,n liau manontong auch,e :

Ijoi-ijoi, bulan bandong ha-
Hier überreiche ich dir nun die Bündel, die Bänder der Karuhei des Reichtums, der Paturong Sangkalemo Radja, für euch sind sie bestimmt, für euch, ihr Kinder, ihr Waisen.

Auf dass du lebest und dir zu Teil werde, dass dich anrufe das auftauchende Kind der Djata, dass dir zurufe der herunterfahrende Jüngste des Hatala.

Die Penjang, die da betäuben die Krankheiten mit hunderten von Namen und Bezeichnungen, die Paturong, die da kraftlos machen die Seuchen mit tausenden ihrer Benennungen.

Beeile dich! so lautet das Wort des Dohong Mama Tandang, spute dich! so spricht die Rede des Langkah Sawang Mama Bungai.

Einen Augenblick verweile noch, Liau, lebende und lebenschaffende, denn noch nicht habe ich Pinang gekaut.

Es spricht die Liau, indem sie ihre Rede wieder fortsetzt :

Ja-ja, o Mond, meine Gemahlin, reiche 
djakan akangku pantar pinang idje kapantar, sundur bulau, sarak rabia, hakadjahan akangku katunei raho babilem, nantujak bangkang hanselan tingang akangku huang njalong riwut.

Toh panamueiku panting batu, aku dia tapalulang-luli, djakah liang, isen aku tapamalik-mules, djadi nahalantingku lewu indjam tingang, halantingangku rundong nasih nampoi bungai.

Dia ijen kakira,n riwut lingongku, ijoi bulan bandong, pakarok nambeleng riwut penjang Pantoh Ganan Kaju Hai, mintan asengku bahetep njampenda hinting bawak lamiang.

Toh bitingku tolak manjembang Balo Indu Rangkang Penjang, Sulan Mina Perang Matanandau, ela keton tandjong kalapean, luwok talingau. mir Pinang zum Kauen, ein Kausel nur, gib mir den goldenen engen Kamm, reiche mir den goldenen weiten Kamm, gib mir den Katunei von dunkler Schwärze, den Katiting, der da leuchtet wie die Sterne, reiche mir einen Strahl von dem wirklichen Oele, das alles habe ich nötig, der ich mich aufhalte in den Wassern des Windes.

Und nun reise ich weiter, und ich gleiche einem weggeworfenen Stein der nie mehr zurückkehrt, einem fortgeschleuderten Stein der nie mehr heimkommt, denn ich werde nie mehr umkehren, ich habe doch weggeworfen das Dorf, das geliehene der Tingang, ich habe doch fortgeschoben den Ort, in dem weit herum verstreut wohnen die Nashornvögel.

Nicht vermag ich genügend Ausdruck zu geben den Gefühlen meines Innern, ja mein Mond, meine Gemahlin, zu gross ist mein Schmerz, dass ich gepackt worden bin durch den Sturmwind der Penjang des Pantoh Ganan Kaju Hai und dass mir abgerissen wurde mein Atem unter der Treppe der Achatsteine (der an Schnüren übereinander aufgereihten Achate, die man um den Hals trägt).

Und nun reise ich weg um anzukommen bei der Balo Indu Rangkang Penjang, der Sulan Mina Perang Matanandau, vergesset mich nicht, ihr Flussbiegungen, fühlt euch nicht verlassen, ihr Buchtungen. 


\section{Das Schildbrett setat die Reise fort}

Toh oloh huma mandjakah sipa balua huma.

Toh hobah tekap katambong awi papan talawang hagoet bara Njalong Riwut manjalumbo ambon magah liau haring kaharingan akan eka Balo Indu Rangkang Penjang ttg. hobah kea lago,n manandak, koa,n bawak auch,e :

I'ohoi bara ohoi, manolak papan talawang bara Njalong Riwut.

I'ehei bara ehei, manjangka bulau dare,n lintong bahandjong gohong lu-salatan.

Njalumbo Ambon Hapantar, Ambon Kamarisai, njalumbo Ambon Marakeran.

Manjalumbo Ambon Dadahukong, halawo Ambon Renteng-Renteng.

Nangkalau Ambon LingkaLingkat, halawo Ambon BihiBihing.

Halawo Ambon Maruang, sampai Ambon Babarohor.

Manjalumbo Ambon Handi-
Die Leute des Hauses werfen nun Betelkausel zum Hause hinaus (die für die Liau bestimmt sind).

Es wechselt nun das Schlagen der Trommeln, weil das Schildbrett die Reise fortsetzt und weiterfährt von den Wassern der Winde und aufsteigt durch die Wolkenlagen um zu leiten die Liau, die lebende und lebenschaffende, nach dem Ort der Balo Indu Rangkang Penjang, und es ändert sich auch die Melodie des Liedes und der Gesang lautet:

Ohoi und noch einmal ohoi, das Schildbrett setzt seine Reise fort und fährt weg von den Wassern der Winde.

Ehei und noch einmal ehei, es stösst ab das goldene geflochtene Band und es geht weiter von den Fluten des Sturmes.

Es steigt auf durch die Ambon Hapantar, durch die Ambon Kamarisai, es steigt auf durch die Ambon Marakeran. (Es handelt sich bei dieser Aufzählung wieder um die 33 Wolkenlagen. Zwischen der 12. und 13. Lage befand sich das Njalong Riwut.)

Es steigt auf durch die Ambon Dadahukong und es fällt ein in die Ambon Renteng-Renteng.

Es fährt vorüber an den Ambon Lingka-Lingkat und es fällt ein in die Ambon Bihi-Bihing.

Und es fährt ein in die Ambon Maruang, und es kommt an in den Ambon Babarohor.

Und es steigt auf durch die Ambon 
kong, halawo Ambon Budjur.

Manangkalau Ambon Hapintih, halawo Ambon Hatangkanjang, habeseian Ambon Muak, halawo Ambon Kakanderang.

Manangkalau Ambon Mangariak, halawo Ambon NgiakNgansilon.

Nangkalau Ambon Nangkahak, halawo Ambon Sasakungkong.

Balias liaran papan talawang halawo Ambon Hasansawong.

Halawo Ambon Manampusok kilau telon djala bulau.

Halawo Ambon Barangga sangkabila,n ambon telo pulu.

I'nandjong manangkalau garing Tandok Raho Bajoh Langit.

I'ohoi bara ohoi, manjelem tumbang Kapandjungan Mandjong.

Manangkalau tandjong $\mathrm{Pa}-$ sang Njaho, malangkawet luwok Pahadjedjel Kilat.

Dimpah sira-sirang mananturong tandjong Uhat Marau Langit.

Surong besei, surong dajong, surong teken, surong lajar.

Murik danum lu-badehes,
Ambon Budjur.
Amdikong, und es fält ein in die Es fährt vorüber an den Ambon Hapintih und es fällt ein in die Ambon Hatangkanjang, es rudert weiter durch die Ambon Muak und es fällt ein in die Ambon Kakanderang.

Es fährt vorbei an den Ambon Mangariak und es fällt ein in die Ambon Ngiak-Ngansilon.

Es fährt vorüber an den Ambon Nangkahak und es fällt ein in die Ambon Sasakungkong.

In rascher Fahrt segelt weiter das Schildbrett und es fährt ein in die Ambon Hasansawong.

Und es fährt nun ein in die Ambon Manampusok, die den Hängern des goldenen Wurfnetzes gleichen.

Und es fährt ein in die Ambon Barangga, die Stützen der Wolkenlagen, der dreissig.

Und es reist weiter und fährt vorbei an dem Baume Tandok Raho Bajoh Langit.

Ohoi und noch einmal ohoi, nun rudern sie hinein in die Mündung Kapandjungan Mandjong.

Sie fahren vorüber an der Flussbiegung Pasang Njaho, sie rudern vorbei an der Buchtung Pahadjedjel Kilat. Und in schräg liegender Fahrt fahren sie hinüber über den Fluss und rudern nach der Flussbiegung Uhat Marau Langit.

Tüchtig schlagt die Ruder, kräftig zieht an die langen Ruder, stark stösst ein die Stossbäume, mächtig schwellt die Segel.

Rudert aufwärts auf dem stark 
manandjak gohong lu-batiki.

Manangkalau bukit Gagas Tingang, malangkawet kereng Gahumot Bungai.

Manangkalau tandjong Tandjak Raho, malangkawet luwok Kamintih Tingang.

Palus nandjong manangkalau lewu,n bawi,n Ambon are hatantilap.

I'nandjong manangkalau Selong Mampan, malangkawet batang danum Simban Tingang mupoh lunok ranggau 406 rohong.

Eka liau Talawang njampirang njaho, Panuhan Lintong pamatas kilat.

Bahing bapanting randan hakaisek rawei, ringkang basarohi tisoi:

Akan kueh bulan djandjulanan balitan Dohong Mama Tandang?

Dia isek,m manansekan, hagagahan liau haring kaharingan.

I'surong djandjulana papan talawang djadi murik Kahungkong Ambon.

I'tintu-tintu haloan papan talawang ngitar njanjanbilei.

Hasambau tasik Lajang Hanteran Riwut. strömenden Fluss, fahrt flussaufwärts auf dem reissenden Strom.

Und sie fahren vorbei an dem Berge Gagas Tingang und sie rudern vorüber an dem Sandhügel Gahumot Bungai. Und sie fahren vorbei an der Flussbiegung Tandjak Raho, und sie rudern vorüber an der Buchtung Kamintih Tingang.

Und sie fahren weiter und sie rudern vorbei an den Dörfern der Frauen Ambon, den zahlreich aufeinanderfolgenden.

Und sie fahren weiter und sie rudern vorüber am Selong Mampan, und sie fahren vorbei am Flusse Simban Tingang, der als Wahrzeigen besitzt den Baum welcher Dolche als Blätter abwirft.

Der Ort wo die Liau Talawang mit schrägem Schlage durchhaut den Donner, der Platz wo der Panuhan Lintong abwendet die Blitze.

Und er erhebt seine Stimme und er fragt mit gedämpftem Worte und er erkundigt sich mit sanfter Stimme:

Wohin, o Mond, führt dich deine Reise, wohin begibst du dich doch, o Dohong Mama Tandang?

Nicht frage, nicht erkundige dich, ich leite die Liau, die lebende und lebenschaffende.

Und das Schildbrett setzt wieder fort seine Reise und es fährt flussaufwärts den Kahungkong Ambon.

Und es richtet sich aus der Bug des Schildbrettes und dreht sich um nach der linken Seite.

Und vor ihrem Angesicht liegt nun das Meer Lajang Hanteran Riwut. 
I'ohoi bara ohoi, malungkah tasik Lajang Hanteran Riwut.

I'ehei bara ehei, mahantas laut Ahoi Nganggahan Sala$\tan$.

Babalang bandera pandjang tumbang batang danum Rutas.

I'tintu hakalambat tumbang tarusan Pangkoh Lunok.

I'ohoi bara ohoi, murik tarusan Pangkoh Lunok.

I'surong besei, surong dajong, surung teken, surong lajar.

Papan talawang teras kaju djambu bahandang halawo batang danum Baras Bulau. I'ohoi bara ohoi, nanturong lewu Bukit Kanjaloh Lanting.

I'ehei bara ehei, manjahendeng rundong Kereng Naliwoh Rahan.

Onbet babedjau papan talawang teras kaju djambu bahandang, dare, n lintong luhing lumpok muntei bulau,

Palus bahing bapanting randan hakaisek rawei :

Eweh gangguaran ara,e maria-aran papan talawang teras kaju djambu bahandang?
Ohoi und noch einmal ohoi, sie fahren nun auf ihr Ziel los, sie rudern zum Meere Lajang Hanteran Riwut.

Ehei und noch einmal ehei, sie schlagen den kürzesten Weg ein und fahren nach der See Ahoi Nganggahan Sala$\tan$.

Und schon sieht man die Fahne, die lange, die sich erhebt an der Mündung des Flusses Rutas.

Und in vorsichtiger langsamer Fahrt rudern sie nach der Mündung des Kanales Pangkoh Lunok.

Ohoi und noch einmal ohoi, sie fahren nun flussaufwärts auf der Durchfahrt Pangkoh Lunok.

Tüchtig schlagt ein die Ruder, kräftig zieht an die langen Ruder, stark stösst ein die Stossbäume, mächtig schwellt die Segel.

Das Schildbrett, das Kernholz des roten Djambubaumes fährt nun hinein in den Fluss Baras Bulau.

Ohoi und noch einmal ohoi, sie fahren hinzu zum Dorfe Bukit Kanjaloh Lanting.

Ehei und noch einmal ehei, sie nähern sich schon dem Orte Kereng Naliwoh Rahan.

Nur noch wenig entfernt von ihm ist nun das Schildbrett, das Kernholz des roten Djambubaumes, das geflochtene Band, der Pfahl des innersten Holzes vom goldenen Munteibaum,

Und schon wirft man aus das Wort und man erkundigt sich mit gedämpfter freundlicher Stimme:

Wer ist es, wie lautet der Name dessen der da segelt mit dem Schildbrett, dem Kernholz des roten Djambu- 
Koa,n Balo Indu Rangkang Penjang, Mina Perang Matanandau.

Dia isek manansekan, koa,n rawei Dohong Mama Tandang.

Panamueiku aku Dohong Mama Tandang Sangiang.

Mangagahan liau haring kaharingan, nanturong biti, $\mathrm{m}$ Balo Indu Rangkang Penjang.

I'kipai malambai tingang, tende lunok.

Tende handu papan talawang teras kaju djambu bahandang.

Tahan hunang bulau dare,n lintong luhing lumpok muntei bulau.

Tende, toros teken garing, tahan, naharukan bulau namburak, njangkabilan tatambat keket.

Halaloha djamban garing, namuei lewu Bukit Kanjaloh Lanting. Mangadja rundong Kereng dje Manaliwoh Rahan. baumes?

So rief fragend herüber die Balo Indu Rangkang Penjang, die Mina Perang Matanandau.

Nicht frage, nicht erkundige dich, so antwortet ihr das Wort des Dohong Mama Tandang.

Ich bin es der da reist, ich der Dohong Mama Tandang Sangiang.

Ich leite die Liau, die lebende und lebenschaffende, ich führe sie her zu dir, o Balo Indu Rangkang Penjang.

Sie winkt und sie ruft dem Nashornvogel herbei, dass er sich niederlasse auf dem Lunok.

Und es hält an und steht still das Schildbrett, das Kernholz des roten Djambubaumes.

Es hält an und steht still das geflochtene Band, der Pfahl des innersten Holzes des goldenen Munteibaumes.

Haltet an, stecket ein die Stossbäume, die elfenbeinernen, beendet die Fahrt und bindet fest das goldene geflochtene Seil, verknüpfet den hinten am Boot sich befindlichen Strick, den vielgliederigen.

Lasset herunter den Steg, den elfenbeinernen, damit wir eintreten können in das Dorf Bukit Kanjaloh Lanting. Damit wir besuchen können den Ort Kereng Naliwoh Rahan.

\section{Die Ankunft der Liau im Dorfe Bukit Kanjaloh Lanting}

Toh malajan manekap katambong ttg. panombah manandak, baja upo kabuat bewei hapan karungut, koa,e :
Beendet wird nun das Schlagen der kleinen Trommeln und es verstummt auch der Gesang der Hülfsbalian, nur der Hauptbalian singt noch allein 
weiter und sein Spruchwort lautet:

I'gatang tarahendeng linga Es erhebt sich und steht auf der Dohong Mama Tandang, schnelle Dohong Mama Tandang, der Langkah Sawang Mama Bungai Bunge, bandong Njaring djahawen.

Djandjaroman akan Balo rasche Langkah Sawang Mama Bungai Bunge, er der Mann der Njaring, der sechsen.

Indu Rangkang Penjang, kang Penjang, er berichtet der Sulan Sulan Mina Perang Mata- Mina Perang Matanandau: nandau:

Kai talatai kilau bulan mating manalatai dare, katong pamalempange tingkah budjang laut lajang mapan banama.

Bau bitingku manamuei hambekan katon, balitangku mangadja matok dinon djaretan etoh mangagahan liau haring kaharingan, liau ano, anak eso,n liau ano, lunok ie djadi batipas pantang,e, baringen ie djadi bageto sangkabila,e.

Awi tapakalong riak penjang Pantoh Ganan Kaju Hai, tapugenggem ringkin paturong Embak Ganan Bua Bakas.

Bitingku mangagahan biti,c mangat bagantong lewu Bukit

So ist unsere Ueberlegung, so wie die Monde vor sich ausbreiten das Flechtwerk $u m$ es $z \mathfrak{u}$ überdenken, so ist unsere Beratung, so wie der Jüngling vom Meere her, der verirrte, sich baut ein grosses Boot.

Denn so steht es nun, ich bin hieher gereist, jetzt zu dieser Zeit, ich bringe dir jetzt in diesem Augenblick meinen Besuch um herzuführen die Liau, die lebende und lebenschaffende, die Liau des N.N., das Kind und der Enkel der Liau N.N. (die Namen werden zur Legitimation genannt, denn eine Liau, die keinen Anspruch erheben kann auf die Hülfe der Balo Indu Rankang, wird auch nicht in ihrem Dorfe aufgenommen), ein Lunok ist er, dem abgeschlagen worden sind seine Aeste, ein Waringin ist er geworden, dem man zerbrochen hat seine Stützen.

Weil er umringt worden ist von den Wellen der Penjang des Pantoh Ganan Kaju Hai, weil er umzingelt worden ist von den Wogen der Paturong des Embak Ganan Bua Bakas.

Und nun führe ich ihn hieher, damit er hier in dem Dorfe Bukit Kanjaloh 
Kanjaloh Lanting, badjanda manalandjat batujang Kereng Naliwoh Rahan.

Hindai biti,e manjembang lewu tatau idje dia rumpang tolang, manasa rundong radja idje dia malu uhat.

Amon entang ngentang tiwah tingang, tujang mangkut haui burong,

Amon djadi Lunok mamua undan, baras bulau lampany hapasang darah,

Manapang karungut Telon Mama Tambon Buno, bagentoi kandaju,n Hamparong Mama Kandajun Lanting, Amon djadi murik batang danum Tijawo Bulau, manandjak gohong Sating Manelak Hintan,

Te Telon manduan biti,e huang lewu,m Balo Indu Rangkang Penjang.

I'narai bulan kahunga! koa,n rawei Balo Indu Rangkang Penjang, isen bintang kabuku, tisoi Sulan Mina Perang Matanandau.

Nduan hambekan katon djalahan tingang Sangiang, pa-
Lanting sich vorläufig aufhalte, damit er sich hier niederlasse und sich hier wiege, hier in dem Orte Kereng Naliwoh Rahan.

Denn noch nicht geht er ein in das reiche Dorf (Totendorf) in dem man nicht kennt Ermüdung der Knochen, noch nicht betritt er den königlichen Ort wo man nicht weiss um erschlaffte Muskeln.

Dann, wenn die Getragenen sich rüsten zur Veranstaltung des Tiwah für den Tingang, wenn die Gewiegten sich vorbereiten für das Haui (Tiwah) des Vogels,

Dann, wenn der Lunokbaum Undanfrüchte zu tragen beginnt, dann wenn der Goldsand mit Blut vermischt auftaucht,

Begleitet von dem Liede des Telon Mama Tambon Bungai, zusammen mit dem Gesange des Hamparong Mama Kandajun Lanting,

Wenn es geschehen ist, dass man auf dem Flusse Tijawo Bulau aufwärts fuhr, dass man hinaufreiste den Strom Sating Manelak Hintan (nämlich um Tempon Telon zu holen, der die Liau nach dem Totendorf $z u$ leiten hat), Dann wird er von dem Telon abgeholt werden in deinem Dorf, o Balo Indu Rangkang Penjang.

Was sollte ich dagegen einzuwenden haben, o Mond! so spricht das Wort der Balo Indu Rangkang Penjang, weshalb sollte ich mich dem widersetzen, o Stern, so lautet die Rede der Sulan Mina Perang Matanandau.

Aber jetzt zu dieser Zeit, o Angehörige der Tingang, der Sangiang, der 
nungkup bungai Djalajan, djalahan tukang kamasan 407 panungkup kawan tingang,

Manabasan parong taheta batundjong, nantaolah siro nambahua sarigatang bentok lewu,n Balo Indu Rangkang Penjang, njababeroh rundong Sulan Mina Perang Matanandau.

Dia balandong tahi djadi tabasan parong,e, isen bahunang nantaolah siro ain liau haring kaharingan.

Parong hai palalendang,e kilau parong Djata telok Rahan Banama.

Siro datoh palalingei kilau siro,n kanarohan Kereng Tonggal Nungkang Hadjaran.

Parong nalumbang pagar lamiang, siro nimbok baras bulau akan liau haring kaharingan.

Parong tatap karong bilit,e, dampohan pahe, tatap rindjing landai, piring mangkok, karuir sendok, kandarah danum, palundu, n bulo garumbang bawoi, pasok kusak, kadjang sirip, lontong palundu, tanggoi butah.
Gemeinschaft der Nashornvögel der Djalajan, ihr Angehörige der Meister der Feinschmiede, der Gemeinschaft der Schar der Tingang,

Aber jetzt richtet auf ein neues Haus, das sich hoch erhebe, jetzt bauet eine neue Wohnung, die da stehe in der Mitte des Dorfes der Balo Indu Rangkang Penjang, in der Mitte des Ortes der Sulan Mina Perang Matanandau.

Und nicht lange Zeit dauerte es, da war schon aufgerichtet das Haus, nicht lange ging es, da war bereits gebaut die Wohnung für die Liau, die lebende und lebenschaffende.

Und es war ein Haus von grossem Glanze, gleich wie das Haus der Djata an der Flussbiegung Rahan Banama. Und es war eine Wohnung, die weithin leuchtete, gleichwie die Wohnung des Fürsten auf dem Kereng Tonggal Nungkang Hadjaran.

Und das Haus war umgeben von einem Zaun von Achatsteinen, und der Boden auf dem sich die Wohnung erhob war aufgehöht worden mit goldenem Sand für die Liau, die lebende und lebenschaffende.

Und in dem Haus war alles bereit: die abgeteilten Zimmer, der Feuerplatz und das Gestell für das Brennholz, und bereit waren auch: die Pfannen und Kochtöpfe, die Teller und Tassen, die Schöpflöffel und Esslöffel, die Wassergefässe, die Reiskörbe und die Schweinetröge, die Pasok und Kusak (kleine Körbe), die Kadjang und Sirip (die kleinen und grossen Matten), die Lontong und Palundu (grosse Körbe), 
I'tatap sadia amak lampit balantak paku, djangkut kahowut, amak bantal akan liau haring kaharingan.

Balanai behas,e, supak takara,e, lusok parei, karangking pulut, pisau langgei, djudjok panuhok,e, manas munik, rambo pilus,e, puket rengge, haup hantai, bowo tali, pasat pangalau, pisi taut, harus rawai, gantongan djala.

I'uras aton akan paramo,n liau haring kaharingan, batang talian, arut palius,e, besei teken, djamban tatean.

Ijoi mangaliling parong liau haring kaharingan, manalumbang siro,n liau balawang pandjang aton bangkat manok, karambang bawoi, baputan tasal tasalan, lepau parei, pasah lisong, halo lumpang, tantali raran. die Frauenhüte und die Tragkörbe. Und bereit sind auch in genügender Zahl die den Boden des Hauses bedeckenden Matten, die mit Nägeln festgemachten, der Bettvorhang und die Decke, die Schlafmatratze und das Kissen für die Liau, die lebende und lebenschaffende.

Und bereit sind für sie auch: die Töpfe, die mit enthülstem Reis gefüllten, die Schalen zum Messen (des abzukochenden Reises), die Behälter für den Reis, die Bergplätze für den Klebereis, die Buschmesser und Schnitzmesser, die Bohrer zum Bohren, die zarten Perlen, das Garn und die dazugehörenden Nadeln, die Netze und Renggenetze, die Haupnetze und Hantainetze, die Fischreusen und Angelschnüre, die Pasat- und Pangalaunetze, die grossen und die kleinen Fischangeln, die Stricke, die mit vielen Angeln besetzten, die Aufhänger und Wurfnetze.

Alles ist restlos vorhanden, und alle diese Güter sind bestimmt für die Liau, die lebende und lebenschaffende, und bereit ist auch bereits das Anlegefloss und das Boot zum Ausfahren, die Ruder und die Stossbäume, das Badehäuschen und der Brückenweg. $\mathrm{Ja}$, auch um das Haus herum, das der Liau, der lebenden und lebenschaffenden gehört, in der Nähe der Wohnung der Liau Balawang Pandjang befinden sich die Körbe für die Hühner (in denen sie sich während der Nacht aufhalten), die Schweinepferche, der Blasebalg und der Hammer zum Schmieden, die Reisscheuer, das Ge- 
I'tatap aso pusa, sapi radja, randin tandang, kambing batumpang bintang, itik, djapon, burong dara radja.

I'sakaren kabon pambulan, tatak palikana, enjoh pinang,e, sirih djarenang bahandang tolang,e, kare kabon djagong, henda parahang antang, sahang djandjanang matan tingang, lai suna, uwi gambili, saretak lempang, kudjang rimbang.

Sukup ramo,n palikanan ain liau haring kaharingan.

I'palus Dohong Mama Tandang Sangiang manjaloh balai lumpang, lalunding liau, sali djajang tingang mumok ambon, djadi balai garantong ajun-ajun bahing, sali pinton djandjingan umba-umba bambahingan idje tau mamarit rangkan panatau akan liau haring kaharingan. stell für den Stampfblock und die kantigen Reisstampfer und das Gestell zum Trocknen der Wäsche.

Und bereit sind auch schon die Hunde und Katzen, die königlichen Kühe und die Wasserbüffel, die sternig gefleckten Ziegen, die Enten und die türkischen Enten und die königlichen Tauben.

Und in ausreichender Menge sind vorhanden die Gärten und Anpflanzungen, die sauber gekappten, die Kokos- und Betelnusspalmen, der Sirih Djarenang mit den roten Adern, die Maisanpflanzungen, die Gelbwurz Parahang Antang, der rote Pfeffer, der schräg in die Höhe steht wie die Augen des Nashornvogels, der Ingwer und Schnittlauch, die Uwiknollen und Gambiliknollen, die Bohnen und Lempang, die Süsskartoffeln (kladi) und Rimbang.

Hinreichend sind die Produkte des Gemüsegartens und der Anpflanzung für die Liau, die lebende und lebenschaffende.

Und alsogleich verwandelt der Dohong Mama Tandang Sangiang den Balai der Bambusköcher, den Reichtum der Liau, das Haus Djajang Tingang, das verhüllt ist mit den schwarzen Wolken, und er wird $z \mathfrak{u}$ einem Balai der Garantong, die ihren Laut hin- und herwiegen, $\mathrm{zu}$ einem Haus der Trommeln und Gong, die ihren Schall überall herumgehen lassen um anzulocken die Dinge des Reichtums der Liau, der lebenden und lebenschaffenden (wohl so dass die Bambusköcher sich in Gefässe verwandeln die immer neu gefüllt werden mit den Opfergaben, die 
Balai garantong manalumbang talaga udju hatalumbang.

Idje talaga,n bangkang hanselan tingang, idje talaga,n lauk saratus gangguaran ara,e, saribu sasabutan biti,e, idje talaga eka njalong kapanduja, idje talaga,n batu bangkalan tuwe, idje talaga,n njalong arak radja.

Talaga udju hatalumbang, lapekong hanja basakati.

Palus balitan Dohong Mama Tandang mimbul sawang ringkan tingang.

Manjaloh bunge,n hampatong, marentar mina merang palawi, saloh djadi oloh mangalunen akan tarahan liau haring kaharingan, akan puja kalinti,n pangambon.

Akan soho rentah,e barapi mandjoho, malaik mambilis, manetek kaju lawas, masip tempe, manana malan, panatau tarahan liau haring kaharingan.

Palus ndua,e timpong babilem die Opfernden nicht von ihrem Eigentum nehmen sondern von dem der Liau).

Und der Balai der Gong wird umgeben von sieben Teichen, die nach allen seinen Seiten hin liegen.

Ein Teich ist gefüllt mit dem wirklichen Oele des Nashornvogels, und in einem Teich leben Fische mit hunderten von Bezeichnungen und Namen und mit tausenden ihrer Benennungen, ein Teich ist gefüllt mit Badewasser, und ein Teich ist gefüllt mit Reisbier, und ein Teich ist gefüllt mit dem königlichen Reisbranntwein.

Diese sieben Teiche sind es, die ihn auf allen Seiten umgeben, diese acht Teiche umschliessen ihn überall.

Und sogleich pflanzt der Dohong Mama Tandang auch die Sawangstaude Ringkan Tingang.

Und er verwandelt das Schnitzbild von Bunge (Sawangstaude), und er verändert die Gestalt des klappernden Palawi, und er gibt ihm die Gestalt eines Menschen der die Erde bewohnt, eines Sklaven für die Liau, die lebende und lebenschaffende, in einen Knecht und Diener der Pangambon.

Der ihrem Auftrag und ihrem Befehl untersteht, der für sie den Reis kocht und die Gemüse zubereitet, der für sie das Holz hackt und die Köcher schneidet in die man das Wasser aufschöpft, der für sie Wasser holt und den Reis stampft, der für sie arbeitet und das Feld bestellt, das tut alles er, der köstliche Sklave der Liau, der lebenden und lebenschaffenden.

Und er nimmt das Tuch, das schwarze, 
maliambong mangadjang pantai danum kalunen, manjanggah parong tarantang nole, djadi sarong baun andau, mangat salumpok liau haring kaharingan dia mite tarantang nole.

Djadi ambon njarakokop parong, rahasan ngentang manangkadje.

Kaput bakati alem gita,n liau matei, gita,n dahiang baja, gita,n taloh papa.

Balawa pela-pelau gita,n $\mathrm{Dja}$ ta, Sangiang, Sahor Parapah, gita,n Sangumang Sangkanak, gita,n Antang Tadjahan, Pampahilep Tandok, awang manggau mahaga.

I'djadi katotok tandak manjaloh balai lumpang, sambong karunja marentar sali djajang tingang.

Palus balitan linga Dohong Mama Tandang, Langkah und er spannt es auf in der Höhe und er verhüllt mit ihm die Ufer des Flusses der Welt, und er lehnt es an gegen das Haus der Kinder, der Waisen, und verhängt ist nun die Türe zu den Wolken (d.h. der Eingang zu den 33 Wolkenlagen und damit auch zu der Oberwelt), sodass die Salumpok Liau, die lebende und lebenschaffende, nicht mehr die Kinder, die zurückgelassenen Waisen zu sehen vermag.

Und wie eine Wolke verhüllt es das Haus und der Wohnort der Getragenen ist gereinigt.

In Dunkelheit und doppelte Finsternis gehüllt sieht die Liau des Toten das Haus, und sie sieht nur Vorzeichen und Omen, und sie gewahrt nur böse Geister*.

In Licht getaucht und freistehend wie ein hoher Baum sehen das Haus die Djata, die Sangiang und der Sahor Parapah, sieht es der Sangumang Sangkanak, sieht es der Falke des Ahnenheiligtumes und der Pampahilep Tandok, so sehen sie alle das Haus, sie, die den Menschen beschützen und beschirmen.

$\mathrm{Zu}$ Ende ist nun der Gesang der Verwandlung des Balai Lumpang, verstummt ist nun das Lied der Veränderung des Hauses Djajang Tingang.

Und sogleich beginnt er, der schnelle Dohong Mama Tandang, er, der Lang-

* Schwarz ist die Farbe der bösen Geister; da das Haus mit einem schwarzen Tuche verhüllt wird, sieht die Liau die Farbe der bösen Geister und glaubt dass die Bewohner nun von ihnen verfolgt würden, denn sie selbst gehört bis zum Tiwah auch noch auf die Seite der bösen Geister und sie fügt den Verwandten Schaden zu. 
Sawang Mama Bungai Bunge, bandong Njaring djahawen,

Ewen due Balo Indu Rangkang Penjang, Sulan Mina Perang Matanandau, Mampendeng kata,n parong ain liau haring kaharingan, mikeh Rawing Tempon Telon sala mandua,e amon lunok djadi mamua undan.

Nampendeng rangkang lamiang, pupoh parong,e mahawang liau haring kaharingan, akan patendo,n siro,n pangambon.

Djadi hakatotok tandak,e manabasan parong batundjong, sambong karunja nantaolah siro sarigatang.

Palus balitan Dohong Mama Tandang nanturong papan talawang teras kaju djambu bahandang, manjahendeng bulau dare,n lintong luhing lumpok muntei bulau.

Djandjaroman akan liau haring kaharingan.

Ijoi, koa,n rawei Dohong Mama Tandang, nduan hambekan katon aku mangagahan biti,m liau haring kaharingan lompat parong batundjong, manantame siro sarigatang. kah Sawang Mama Bungai Bunge, der Mann der Njaring, der sechsen,

Zusammen mit der Balo Indu Rangkang Penjang, der Sulan Mina Perang Matanandau,

Aufzurichten ein Zeichen des Hauses der Liau, der lebenden und lebenschaffenden, denn es könnte sonst vielleicht geschehen, dass Rawing Tempon Telon die unrichtige Liau abholen würde, wenn der Lunokbaum Undanfrüchte getragen hat.

Und sie richten auf ein Boot von Achatsteinen und dieses dient als Eigentumszeichen des Hauses der Liau, der lebenden und lebenschaffenden, als Kennzeichen der Wohnung der Pangambon.

Und zu Ende ist nun der Gesang des Aufrichtens des Hauses, des hoch sich erhebenden, verstummt ist nun das Lied des Bauens der Wohnung. Und sogleich begibt sich der Dohong Mama Tandang zum Schildbrette, zum Kernholz des roten Djambubaumes, und er schreitet zum goldenen geflochtenen Band, zum Pfahl des innersten Holzes des goldenen Munteibaumes.

Und er erzählt was getan worden ist der Liau, der lebenden und lebenschaffenden.

Ja, so spricht das Wort des Dohong Mama Tandang, jetzt ist der Augenblick gekommen dass ich dich führe, o Liau, lebende und lebenschaffende, und dich hereinbringe in das Haus, das hoch sich erhebende, und dich leite nach der Wohnung, die für dich auf- 
Narai bulan kahunga, koa,n rawei liau haring kaharingan.

Puna antang kurong tadjahan lingo, kenjoi makang bantilong karendem, palus gatang tarahendeng liau haring kaharingan balua papan talawang, bahandjong bulau dare, n lintong, manetei djamban garing, haratean paratar sihong, lompat lewu Bukit Kanjaloh Lanting, rundong Kereng Manaliwoh Rahan.

I'palus gatang tarahendeng Balo Indu Rangkang Penjang Sulan Mina Perang Matanandau, mimbing bulau tampong papas, rabia tundon kalingking, dawen sawang gagar, danum karak, danum njanjah mamapas liau haring kaharingan lompat lewu,n Balo Indu Rangkang Penjang, mamapas pali endus, dahiang baja, nupi papa. gerichtet ist.

Was, o Mond, sollte ich dagegen einzuwenden haben, so spricht das Wort der Liau, der lebenden und lebenschaffenden.

Es ist ja doch mein Inneres ein Antang, ein umschlossener des Ahnenheiligtumes, und mein Herz ist ein Falke der umzäunt wird von glattgehauenen Pfählen, und nun erhebt sich und steht auf die Liau, die lebende und lebenschaffende, und sie tritt heraus aus dem Schildbrett, und sie verlässt das goldene geflochtene Band, und sie schreitet über die Brücke, die elfenbeinerne, und sie steigt herunter die Treppe, die elfenbeinerne, und sie betritt das Dorf Bukit Kanjaloh Lanting, den Ort Kereng Manaliwoh Rahan.

Und sogleich erhebt sich und steht auf die Balo Indu Rangkang Penjang, die Sulan Mina Perang Matanandau, und sie hält in der Hand den goldenen Bündel des Besens, den goldenen Tross des Wischers, die Blätter von der Sawang Gagarstaude, das lösende Wasser, das kräftig wirkende Wasser (d.h. der Besen ist in dieses Wasser getaucht) um mit ihm abzuwischen die Liau, die lebende und lebenschaffende, welche nun eintritt in das Dorf der Balo Indu Rangkang Penjang, und sie $\mathrm{zu}$ reinigen von den Pali und Verboten, von den Vorzeichen und Omen und von allen schlechten Träumen. *

\footnotetext{
* Mit der Liau findet die gleiche Handlung statt wie mit jedem Fremdling der ein Dorf betritt und zuerst von dem Dorfältesten gereinigt wird bevor er es wirklich betreten darf.
} 
Mamusit tanteloh manok darong tingang upo,n hedjan taletai djela burong dahiang bau,n parong taheta batundjong.

I'palus liau haring kaharingan lompat parong batundjong, nantame siro sarigatang.

Aton taraha puja kalinti akan soho rentah,e mampatei manok darong tingang, palus Balo Indu Rangkang Penjang manjaki liau haring kaharingan hapan darah manok darong tingang, naharukan manas sambelon peron tambon, manas tasak lentup njahe, 408 mambowor behas parei njangen tingang, manantisan bangkang,e hanselan tingang, mananteman petak sintel habalambang tambon huang bulau repang samben liau haring kaharingan.

Palus bahing bapanting balitan Dohong Mama Tandang, randan ie hapeteh rawei dengan Balo Indu Rangkang:

Ijoi, Balo Indu Rangkang Penjang, amon tarantang nole djadi kanuah anak Djata lampang, kanjambong busu,n Hatala hadurut, amon nole djadi nupi penjang, lalundong
Und sie zerbricht ein Ei des Huhnes, des Huhnes Tingang, am Fuss der Treppe mit den ausgekerbten Zungen der Vorzeichenvögel, die hineinführt in das Haus, das neu sich erhebende. Und sogleich steigt die Liau, die lebende und lebenschaffende, ein in das neu sich erhebende Haus, und sie betritt die Wohnung, die erst kürzlich aufgerichtete.

Einer der Sklaven, der Knechte und Diener, einer dem man befiehlt und Aufträge gibt, tötet ein Huhn, ein Huhn Tingang, und sogleich bestreicht die Balo Indu Rangkang Penjang die Liau, die lebende und lebenschaffende, mit dem Blute des Huhnes, des Huhnes Tingang, und sie umbindet ihr Perlen, die länglichen Glasperlen aus der Gallenblase der Wasserschlange und auch die Perlen Tasak Lentup Njahe, und sie streut über sie aus den enthülsten Reis vom Reise Njangen Tingang, und sie giesst über sie aus das wirkliche Oel des Nashornvogels, und sie bestreicht mit der harten Erde, die zur Schwelle hat die Wasserschlange, die goldene Kette des Halsbandes der Liau, der lebenden und lebenschaffenden.

Und sogleich wirft aus seine Rede, er der Dohong Mama Tandang, und mit gedämpfter Stimme gibt er der Balo Indu Rangkang den Auftrag:

Ja, o Balo Indu Rangkang Penjang, dann wenn es geschehen ist, dass die Kinder, die Waisen angerufen worden sind durch das auftauchende Kind der Djata, dann wenn sie aufgefordert worden sind durch den herunterfahren- 
siren mangampa paturong, hatalatai lunok mamua, malempang baras hapasang darah bakurangan penjang,

Hatandjungan riwut tarong liau haring kaharingan mahapang karungut Rawing Tempon Telon mangagahan biti,e lompat lewu tatau idje dia rumpang tolang, rundong radja idje dia malu uhat,e.

Te biti,m Balo Indu Rangkang hadjalukan liau haring kaharingan akan Rawing Tempon Telon.

I'djadi hakatotok tandak,e ie hapeteh rawei hadjandji dengan Balo Indu Rangkang Penjang.

Palus Dohong Mama Tandang manaroi bua endjong kalapean, 409 idje kabawak akan liau haring kaharingan, mangat ie kalapean bulan bandong,e, garing tarantang,e, ngalapean lewu huma,e huang lewu indjam tingang, mangat ie dia manjaranta entang pantai kalunen. den Jüngsten des Hatala, dann wenn die Waisen geträumt haben von Penjang, und wenn die Kinder, die verlassenen, im Schlafe gesprochen haben von Paturong, dann wenn der Lunokbaum im Begriffe steht Undanfrüchte zu tragen, und wenn aufzutauchen beginnt der Sand vermischt mit Blut und erfüllt von Penjang,

Dann wird aufsteigen der schallende Ruhm der Liau, der lebenden und lebenschaffenden, Gebrauch machend von dem Liede des Rawing Tempon Telon welcher sie leiten wird und hereinführen wird durch die Türe des reichen Dorfes, in dem man nichts weiss von ermïdenden Knochen, in den königlichen Ort, in dem nichts bekannt ist von erschlaffenden Muskeln.

Und dann, o Balo Indu Rangkang, wirst du die Liau, die lebende und lebenschaffende, ihm, dem Rawing Tempon Telon, überreichen.

$\mathrm{Zu}$ Ende ist nun der Gesang des Befehles und des Auftrages an die Balo Indu Rangkang Penjang.

Und alsogleich überreicht der Dohong Mama Tandang von den Endjongfrüchten des Vergessens eine Frucht der Liau, der lebenden und lebenschaffenden, damit sie vergesse den Mond, ihre Gattin, und die elfenbeinernen Kinder, damit sie nicht mehr gedenke ihres Wohnortes und ihres Hauses in dem Dorfe, der geliehenen der Tingang, und damit sie nicht mehr krank mache die Getragenen an den Ufern des Flusses der Welt. 
I'palus tinai balitan Dohong Mama Tandang habarikan djamban tiring idje dia kanuntun tandok, mangantjang paratar gigi, idje dia kanureng kining,

Manjembang sara,n lewu tatau idje dia rumpang tolang, habaras bulau, habusong hintan,

Akan djalan liau haring kaharingan madja sara,n dandang lewu tatau mangat biti,e tau manuntun lewu tatau idje habaras bulau.

I'djadi katotok tandak maniring djamban liau, palus linga Dohong Mama Tandang Sangiang manambang salumpok entang, mikeh aton tandang lajar, manjangkurong tanterus tujang, mikeh ajun kariunan.

Udju salumpok entang taratambang djari,n Sangiang Dohong Mama Tandang, hanja tanterus tujang taratakep karah Djalajan Langkah Sawang Mama Bungai.

Salumpok entang buli hatampong kilau bua sanggalang garing, tanterus tujang mulang hatundun tingkah langa-
Und alsogleich lässt der Dohong Mama Tandang hernieder die Brücke, die straff gespannte, welche nicht gesehen werden kann mit den Augen, und eifrig richtet er auf die Treppe der Zähne (Leitersprossen), die man nicht wahrzunehmen vermag mit den Hellen (den Augen),

Welche hinüberreicht bis zum Rande des reichen Dorfes, in dem man nichts weiss von ermüdenden Knochen, und in dem sich befinden die Sandbänke von Gold, und in der aufgehäuft liegen die Steinbänke von Edelsteinen, Und welche als Weg dient für die Liau, die lebende und lebenschaffende, damit sie $z u$ besuchen vermag den Rand, den hellen, des reichen Dorfes, damit sie anzuschauen vermag das Dorf, das reiche, das bedeckt ist mit feinem goldenem Sand.

$\mathrm{Zu}$ Ende ist nun der Gesang der Herstellung des Weges für die Liau, und alsogleich beginnt der Dohong Mama Tandang zurückzuholen die Seelen der Getragenen, denn es könnte sein, dass sich von den Tigern einige verirrt hätten, und er holt heim die Tanterus der Gewiegten, denn es wäre möglich dass sie sich wiegten im Fluge.

Sieben Seelen der Getragenen werden zurückgeholt von den Fingern des Sangiang Dohong Mama Tandang, acht Seelen der Gewiegten werden aufgepackt von den Händen des Djalajan Langkah Sawang Mama Bungai.

Und die Seelen der Getragenen kehren zurück, zusammengebüschelt wie die Früchte der Bäume die man an den $Z$ weigen, $z \mathfrak{u}$ einem $B$ üschel vereinigt, 
djah tarong, buli bakandong bulau ontong pandjang, basalungkem rabia njame ambo.

Sangiang nambawa entang: kuruk, kilau manambawa manok darong tingang, $\mathrm{Dja}$ lajan nangkiau tujang: kurei, tingkah nangkiau bulan bawi,n riwut burong.

Toh upa mambawa hambaruan, koa,e :

Kurk hambaruan ewen buli bakandong njalong kaharingan belom, basangkulem gohong tapaninting tahaseng.

Toh upo kabuat,e hapan karungut, koa,e:

I'djadi hakatotok tandak,e mangagahan liau haring kaharingan akan lewu,n Balo Indu Rangkang Penjang.

Hemben nduan hambekan katon, matok dinon kadjaretan etoh, koa,n rawei Dohong Mama Tandang Sangiang: aku mambang penjang,e karuhei tatau, manekap paturong sangkalemo radja akan lalundong siren.

Palus ringkes marangkesa hajak ringkin basariang, bawa nach Hause trägt), und die Seelen der Gewiegten kehren wieder heim, zu Trossen vereinigt wie die Früchte der Bäume, und sie kehren zurück, begleitet von dem Golde des langen Heiles, zusammen mit dem goldenen Atem, dem dauerhaften.

Und die Sangiang rufen die Getragenen: Kuruk! so wie man ruft die Hühner, die Hühner Tingang, und die Djalajan locken die Gewiegten : Kurei! so wie die Monde, die Frauen des Windes, herbeilocken die Viögel.

Nun ruft der Hauptbalian die Seelen und sein Wort lautet:

Kurk! ihr Seelen, kehrt doch wieder zurück, begleitet vom Wasser des Lebens, dem lebenschaffenden, zusammen mit dem Wasser, dem Reiniger des Atems.

Der Hauptbalian singt nun allein weiter und sein Gesang lautet:

Beendet nun der Gesang des Leitens der Liau, der lebenden und lebenschaffenden, nach dem Dorfe der Balo Indu Rangkang Penjang.

So steht es nun in diesem Augenblicke, so ist es nun mit unserer Sache zu dieser Zeit, so spricht das Wort des Dohong Mama Tandang Sangiang: ich werde nun holen die Penjang und die Karuhei des Reichtums, und ich sammle nun ein die Paturong Sangkalemo Radja für die Kinder, die Waisen.

Und sogleich bringt er alles in Ordnung und macht er alles bereit und 
hatangkiau ewen manjelem papan talawang teras kaju djambu bahandang, manantame bulau dare,n lintong luhing lumpok muntei bulau.

Rawing rata hapantar pinang, Djalajan tatau hataradjo manjang.

Sama busau bua pinang, Djalajan kabahasen manjang palus mendeng manambawa riwut, hingkat manangkiau salatan akan ganggulon papan talawang, indu pamaruwei bulau dare,n lintong.

Dumah riwut hapungkal kilau kamungkal rohong, rampe salatan habangkalan tingkah mangkalan buno.

Engkak bulau manamburak, idjit supit teken garing, nguhas tatambat keket, hadjadjita djamban garing, ina,e manjulih,e papan talawang teras kaju djambu bahandang. dann ruft er und fordert sie auf (die andern Sangiang) einzutreten in das Schildbrett, das Kernholz des roten Djambubaumes, hereinzukommen in das goldene geflochtene Band, den Pfahl des innersten Holzes des goldenen Munteibaumes.

Zusammen kauen die Krokodile Pinang, gemeinsam kauen die Djalajan, die reichen, die Betelnüsse.

Und zusammen werden sie trunken von den Früchten der Pinang, und die Djalajan sind betäubt von den Betelnüssen und sogleich stehen sie auf und sie rufen den Winden, und alsobald erheben sie sich und sie fordern auf herbeizukommen die Stürme zur Beschleunigung der Fahrt des Schildbrettes, um anzutreiben das goldene geflochtene Band.

Und es kommen die Winde in raschem Fluge, so wie vom Amboss wegschleudert der Dolch, und es kommen die Stürme in brausendem Wiegen, so wie man schleift einen Speer.

Löset das goldene geflochtene Seil, ziehet heraus die Stossbäume, die elfenbeinernen, löset den vielgliederigen Strick hinten im Boote, ziehet herein die elfenbeinerne Brücke und leget sie nieder im Schildbrett, dem Kernholze des roten Djambubaumes.

\section{N. Das Schildbrett reist vom Dorfe Bukit Kanjaloh Lanting weg und fährt zum Sangiang Saloh Simpei}

Toh ewen balian uras manandak hajak tekap katambong manumon lago: Manolak papan talawang, koa, n bawak tandak:
Nun singen die Balian alle zusammen und sie schlagen die Trommeln nach der Weise: Abreise des Schildbrettes, und es lautet das Lied: 
I'ohoi bara ohoi, manolak papan lu-talawang, teras kaju djambu bahandang.

I'ehei bara ehei, manjangka bulau dare,n lintong luhing lumpok muntei bulau.

Batolak papan talawang bara lewu,n Balo Indu Rangkang Penjang.

Basangka bulau dare,n lintong luhing lumpok muntei bulau, bahandjong rundong Sulan Mina Perang Matanandau.

I'tolak papan talawang manjauh batang Baras Bulau.

I'tapok papan talawang tasik Lumpong Matanandau.

I'Dohong Mama Tandang Sangiang nanturong eka Sangiang Saloh Simpei.

Bara hila likut kaleka Batu Nindan Tarong, Liang Angkar Bantilong Njaring.

I'papan talawang njanjambilei kaleka nanindan tingang.

I'harus bentok papan talawang babalang parong pandjang idje dia kanuntun tandok, likut kaleka Batu Nindan Tarong, siro ambo nahuang mangimai lumpong matanandau, eka radja HawoHawong Ambon, kanarohan
Ohoi und noch einmal ohoi, es reist weg das Schildbrett, das Kernholz des roten Djambubaumes.

Ehei und noch einmal ehei, es stösst ab das goldene geflochtene Band, der Pfahl des innersten Holzes des goldenen Munteibaumes.

Es reist weg das Schildbrett aus dem Dorfe der Balo Indu Rangkang Penjang.

Es stösst ab das goldene geflochtene Band, der Pfahl des innersten Holzes des goldenen Munteibaumes, es verlässt nun den Ort der Sulan Mina Perang Matanandau.

Es reist weg das Schildbrett und es fährt abwärts auf dem Flusse Baras Bulau.

Es schlagen die Ruder an das Schildbrett und sie treiben es fort durch das Meer Lumpong Matanandau.

Und Dohong Mama Tandang reist nun hin nach dem Orte des Sangiang Saloh Simpei.

Und er naht ihm von der hinteren Seite her des früheren Dorfes Batu Nindan Tarong, Liang Angkar Bantilong Njaring.

Und das Schildbrett fährt auf der linken Seite vorüber an dem verlassenen Dorfe, dem steilaufsteigenden der Nashornvögel.

Und schon sieht man von der Mitte des Fahrwassers aus, in dem das Schildbrett treibt, das Haus, das lange, das man nicht wahrzunehmen vermag mit den Augen, auf der Rückseite des früheren Dorfes Batu Nindan Tarong, die Wohnung, die hohe, die beinahe die Ränder der Sonne berührt, den 
Buntat Dia Batuntur Pulu.

Kareh malawo rawei amon hadjalukan kaju,n penjang karuhei tatau.

Palus tende handu papan talawang teras kaju djambu bahandang, tahan hunang bulau dare,n lintong hajak batoros teken garing, naharukan bulau namburak.

Toh malajan tekap katambong, upo kabuat hapa karungut, koa,e :

I'palus gatang tarahendeng linga Dohong Mama Tandang, hajak tundjong tarahingkat Langkah Sawaing Mama Bungai Bunge, bandong Njaring djahawen hajak batontong garo bulan idje bakalinda tingang, mamasang hampis simak santi ngeket pahawang idje bakalampang tambon.

Hajak manantiang behas tambak radja bahalap ngarambang giling pinang, hambalat roko,n tarahan.

Hajak mimbit rangkan pa- Und er bringt die Esswaren, die be-
Ort des Königs Hawo-Hawong Ambon, die Wohnung des Fürsten Buntat Dia Batuntur Pulu.

Erst hernach werfen sie aus ihre Rede, erst dann wenn ihnen überreicht worden ist das Holz der Penjang und der Karuhei des Reichtums.

Es hält an und es steht still das Schildbrett, das Kernholz des roten Djambubaumes, es hält an und es steht still das goldene geflochtene Band und eingestossen in das Flussbett wird der Stossbaum, der elfenbeinerne, und festgemacht wird an ihm das goldene geflochtene Seil.

Es hört nun auf das Schlagen der kleinen Trommeln und der Hauptbalian singt nun allein, und sein Lied lautet:

Und sogleich erhebt sich und steht auf der schnelle Dohong Mama Tandang, und es erhebt sich und steht auf der Langkah Sawang Mama Bungai Bunge, der Mann der Njaring, der sechsen, und er entzündet den Weihrauch der Monde, welcher anzulocken vermag die Nashornvögel, und er baut auf den Geruch, den herrlichen Duft, welcher ausgeht von den Monden und der zum Auftauchen bringt die Wasserschlangen.

Und er trägt auf seiner flachen Hand den aufgehöhten enthülsten Reis, den königlichen, den schön umzäunten mit den Reihen von Pinang, den umfriedeten mit den Rauchwaren der Sklaven. 
nginan simpan mananturong parong radja tunggo,n upo,n kaju,n karuhei tatau.

Palus surong djandjulana manaroi rangkan panginan, mandjulok behas tambak radja,

Hapa hadjawi kaju,n penjang karuhei tatau, hapan hapekat sandik paturong sangkalemo radja.

I'palus nggatang kumi,n tingang hajak balitan Sangiang Saloh Simpei manambang rangkan panginan, manakep behas tambak radja, palus njimpei penjang karuhei tatau idje kasimpei, njandik,e paturong sangkalemo radja due kasandik.

Te hajak bahing kakarungut radja manaroi simpei karuhei tatau, manadjoh paturong pasihan rundjan akan tarantang nole mangat hatontong ie kanuah anak Djata lampang, hatinggang kanjambong busu,n Hatala hadurut.

Ijoi nih, koa,n rawei radja, kareh ikau manaroi,e akan entang pantai kalunen, naroi intu djari,n Dohong Mama Tandang, Langkah Sawang Mama Bungai Bunge, ban- reitgemachten, und er schreitet mit ihnen zum Hause des Königs, dem Wächter am Fuss des Holzes der Karuhei des Reichtums.

Und er hat das Ziel seiner Reise erreicht und er übergibt die Esswaren, und er überreicht den aufgehöhten Reis, den königlichen,

Um mit ihnen einzutauschen die Hölzer der Penjang und der Karuhei des Reichtums, um mit ihnen einzuhandeln die Bündel der Paturong Sangkalemo Radja.

Und sogleich bricht aus in ein Lächeln der Tingang, er, der Sangiang Saloh Simpei, und er nimmt in Empfang die Esswaren und er ergreift den aufgehöhten Reis, den königlichen, und alsogleich büschelt er Penjang und Karuhei des Reichtums zu einem Büschel und er bündelt Paturong Sangkalemo Radja zu zwei Bündeln. Und mit den Worten des wohllautenden Gesanges überreicht der König die Bündel der Karuhei des Reichtums, übergibt er die Paturong und Pasihan der heiligen Töpfe (mit deren Hülfe man sich mühelos heilige Töpfe erwerben kann) für die Kinder, die verlassenen Waisen, damit sie angerufen werden sollen durch das auftauchende Kind der Djata, damit sie aufgefordert werden sollen durch den herabfahrenden Jüngsten des Hatala. Ja, wohlan, nimm sie $z u$ dir, so spricht das Wort des Königs, und hernach wirst du sie überreichen den Getragenen am Ufer des Flusses der Welt, und damit legte er sie in die Hände des Dohong Mama Tandang, des 
dong Njaring djahawen.

Kareh Dohong Mama Tandang manaroi akan tarantang nole amon sembang pantai danum kalunen, amon sembang parong,e mangentang.

Malik sala Sangiang nanturong papan talawang teras kaju djambu bahandang, manjahendeng bulau dare,n lintong luhing lumpok muntei bulau.

Engkak,e bulau manamburak, idjit,e nansupit teken garing, nguhas tatambat keket, hadjadjita djamban garing, ina,e njulih papan talawang.
Langkah Sawang Mama Bungai Bunge, des Mannes der Njaring, der sechsen.

Und hernach wird sie der Dohong Mama Tandang überreichen den Kindern, den verlassenen Waisen, dann, wenn er angekommen sein wird an den Ufern des Flusses der Welt, dann, wenn er zurückgekehrt sein wird in das Haus, in dem man verrichtet das Hülfswerk.

Und nun kehren sie wieder um, die Sangiang, und sie begeben sich zum Schildbrett, dem Kernholz des roten Djambubaumes, und sie schreiten zurück zum goldenen geflochtenen Band, zum Pfahl des innersten Holzes des goldenen Munteibaumes.

Und sie machen los das goldene geflochtene Seil, und sie ziehen heraus den Stossbaum, den elfenbeinernen, und sie knüpfen auf den Strick, den vielgliederigen, am hinteren Ende des Bootes, und sie ziehen herein die Brücke, die elfenbeinerne, und sie legen sie wieder zurück ins Schildbrett.

\section{O. Das Schildbrett setzt seine Reise fort und kommt wieder in der Welt an}

Toh ewen manekap katam- Nun schlagen sie die kleinen Trombong ttg. uras manandak meln und sie alle singen nach der hapan lago: Mandurut papan Weise: Die Herabfahrt des Schildtalawang teras kaju djambu bahandang, koa,n bawak tandak,e : brettes vom Kernholz des roten Djambubaumes, und es lauten die Worte des Gesanges :

Tolak papan talawang, sangka dare,n lintong.

Reise weg Schildbrett, stosse ab geflochtenes Band.

Njauh manahandar kaleka Fahre flussabwärts und lege an beim 
manindan tingang.

Tintu hakalambat papan lutalawang.

Manintu tumbang Djaka Baras Bulau.

Ngetas ngalapeta batang Baras Bulau.

Tintu hakalambat papan lutalawang tumbang lu-tarusan Bulau Pangkoh Lunok.

Njauh hakalambat tarusan Bulau Pangkoh Lunok.

Hasambau tasik Ambon Baragantong.

Manangkalau pulau telo luhatontong.

Eleh duru-durut papan lutalawang.

Manjauh rahasan antang $l \mathfrak{u}-$ namuei.

Lu-masohan djalan kenjoi mangadja.

Eleh njauh-njauh tandjong Tandjak Njaho.

Lu-mansohan luwok lu-Kamintih Tingang.

Njauh-njauh tandjong $\mathrm{Pa}$ ngarontong Njaho.

Lu-mansohan luwok Pahadjedjel Kilat.

Lu-halawo tandjong Uhat Marau.

Balias hadurut papan lutalawang.

Eleh njauh tandjong djaka Pasang Njaho. verlassenen Dorfe, dem steil ansteigenden der Nashornvögel.

Steuere dorthin in langsamer Fahrt, Schildbrett.

Und es steuert nach der Mündung des Flusses Djaka Baras Bulau.

Und in schrägliegender Fahrt lässt es sich abtreiben nach dem Flusse Baras Bulau.

Und es steuert in vorsichtiger Fahrt das Schildbrett nach der Mündung des Kanales Bulau Pangkoh Lunok.

Und in langsamer Fahrt fährt es hinunter durch die Durchfahrt Bulau Pangkoh Lunok.

Und vor ihren Augen sehen sie schon sich ausbreiten das Meer Ambon Baragantong.

Und sie fahren vorüber an den drei Inseln die nebeneinander liegen.

Und schon fährt herunter das Schildbrett.

Es fährt flussabwärts auf dem Wege des reisenden Antang.

Und es fährt flussabwärts auf dem Pfade des herumschweifenden Falken. Und schon fährt es langsam vorbei an der Flussbiegung Tandjak Njaho.

Und es fährt herab längs der Buchtung Kamintih Tingang.

Und es fährt vorüber an der Flussbiegung Pangarontong Njaho.

Und es fährt flussabwärts längs der Buchtung Pahadjedjel Kilat.

Und es fällt ein in die Flussbiegung Uhat Marau.

Und in rascher Fahrt stösst herunter das Schildbrett.

Und schon fährt es herunter längs der Flussbiegung Pasang Njaho. 
Lu-mansohan luwok Pahadjedjel Kilat.

Eleh njauh-njauh tumbang Kapandjongan Mandjong.

Mansohan Salohan Antang manamuei.

Eleh njauh ambon tilap telo pulu.

Pandak djangkau-djarang hasean tandjong ambon.

Timang tahitik djantai-djahai luwok enon limebalas hatalamping.

Halawo ambon sawak, halawo ambon turong.

Eleh lu-babalang bahing riwut sambang.

Djadi lu-batentang salatan bambahingan luhing.

Eleh duru-durut papan lutalawang, djadi rentu-rentut bulau dare,n lintong njandar tulalanga lawi,n tambon palangka,n pantar.

Njanjangkelang dawen katilambong njaho, malangkawet bumbong djaka pinang lewu.

Tende handu-handu papan lutalawang.

Tahan huna-hunang bulau
Und es fährt vorüber an der Buchtung Pahadjedjel Kilat.

Und schon fährt es flussabwärts durch die Mündung Kapandjongan Mandjong.

Und es fährt vorüber an dem Salohan Antang, dem reisenden.

Und schon stosst es herunter durch die Wolkenlagen, die dreissig übereinanderliegenden.

Kurz, und nicht weit auseinander stehend ist der $Z$ wischenraum der Wolkenlagen.

Enge, und nicht weit voneinander entfernt ist der Abstand zwischen den einzelnen Buchtungen der Tauwolken, der fünfzehn doppelt übereinanderliegenden.

Und es lässt sich fallen durch die Wolken in heftiger Fahrt, und es kommt herab durch die Wolken in rascher Reise.

Und schon hört man den aufsteigenden wehenden Schall der Trommeln.

Und schon vernimmt man den brausenden Laut der Trommeln.

Und es fährt herunter das Schildbrett und in schräg abwärts gerichteter Fahrt kommt an das goldene geflochtene Band und es lehnt sich an und es berührt das Ende der Wasserschlange an dem Gestell des Mastes (des Sanggaran).

Es vermischt sich mit den Blättern der Kokospalme, der donnernden, es fährt hindurch zwischen den Herzblättern der Pinang des Dorfes.

Und nun hält an und steht still das Schildbrett.

Und nun hält an und steht still das 
dare,n lintong.

Djadi tende ninggang panjalanting parong.

Tende lu-batoros djaka teken garing.

Tahan naharukan bulau manamburak.

Njangkabila lu-tatambat keket.

Djadi halaloha djaka djamban garing.

Manamuei i'balai i'rampar buno, lu-mangadja siro tilap lu-talawang. goldene geflochtene Band.

Es hat angehalten dicht beim Anlegeplatz des Hauses.

Stehet nun still und stecket ein den Stossbaum, den elfenbeinernen, im Flussbett.

Leget nun an und bindet an ihm fest das goldene geflochtene Seil.

Verknüpfet das Seil, das vielgliederige, am hinteren Ende des Bootes.

Lasset herunter die Brücke, die elfenbeinerne.

Betretet nun den Balai der nebeneinanderliegenden Speere, klimmet herauf in das Haus der aufeinandergeschichteten Schilde.

\section{P. Die Befestigung der Seelen der Getragenen}

Toh papan talawang djari tende, Sangiang dumah manamuei, ewen manandak malajan helo, oloh balian simpa ranen.

Toh ewen manampara manandak tinai ttg. manekap katambong hapan lago: Ngentang mandehen, koa,e:

Ludja liau matei randan are manandjong ambon, tohi pangambon nihau mampan Raho manawan Bulan.

Teneng gandang Njaring menteng randan are babalai Lunok, rintoh towong ihing batujang hapamontong kalang labeho handalem.
Das Schildbrett hat nun seine Fahrt beendet, die Sangiang kommen zurück von ihrer Reise, sie hören vorläufig auf mit Singen und die Balian kauen Betel usw.

Sie beginnen nun wieder $z \mathfrak{u}$ singen und sie schlagen die kleinen Trommeln nach der Weise: Verrichtung des Hülfswerkes bei der Befestigung, und ihr Lied lautet :

Fliehet, ihr Liau der Verstorbenen, und beschreitet die Wolken (die 33 Wolkenlagen), machet euch weg, ihr Pangambon der Verlorenen, nach der Seite des Raho, welcher den Mond einfängt.

Schweiget, ihr Trommeln der Njaring, der tapferen, welche in Scharen bewohnen die Lunok, verstummet, ihr Trommeln (die Stimmen) der Ihing (Wasserschlangen, anderer Name für 
Ela harantong bahing sambang Sangiang huang papan talawang, isen njampelek bambahingan luhing Djalajan medjen bulau dare,n lintong.

Ngentang lu-mandehen peteng dawen tapaura-urai, mangko lu-mandjiret kanihen tandjong djaka leoh-lembai.

Nduroh karewo, $n$ garing balitan Dohong Mama Tandang balua papan talawang, lubahandjong bulau dare,n lintong.

Djari ambon njarakukop, njarakukop parong mangentang.

Kaput bakati alem gita, $n$ ambon barutas matei.

Balawa pela-pelau gita,n Djata lu-Sangiang.

Batentang linge-lingei nureng Sahor ilu-Parapah.
Tambon), die ihr euch wiegt zu beiden Seiten der Wassertiefe, der abgründigen.

Nicht versperret den Weg dem Laute der Trommeln der Sangiang, die sich befinden im Schildbrett, nicht zerbrechet den Schall der Trommeln der Djalajan, die sich aufhalten im goldenen geflochtenen Band.

Denn wir verrichten nun das Hülfswerk der Befestigung der Bündel der Blätter, der in aufgelöstem Zustande herunterhängenden, wir stellen wieder her die schwach gewordenen Flussbiegungen und die Buchtungen von denen die Erde abgebröckelt ist. Und er, der Dohong Mama Tandang streut elfenbeinerne Asche aus während er heraustritt aus dem Schildbrett, während er herausschreitet aus dem goldenen geflochtenen Band.

Und zu Wolken verwandelt sich die Asche und sie verhüllen und bedecken das Haus in dem man verrichtet das Hülfswerk.

Und Dunkelheit von doppelter Nacht erblicken die Wolken, die vernichtenden des Todes wenn sie herabschauen auf das Haus.*

Und in hell leuchtendem Glanze, und frei sich erhebend, so wird das Haus gesehen von der Djata und von den Sangiang.

In glänzendem Scheine erstrahlend und offen stehend, so sieht die Wohnung der Sahor Parapah.

* Die Farbe der Asche ist, wie die des schwarzen Tuches, assoziiert mit den bösen Geistern. Schauen nun solche auf das Haus herab, dann sehen sie die schwarzen Wolken und wissen, dass es bereits von bösen Mächten heimgesucht worden ist. 
Lila-lilang dahiang baratus Und es machen sich auf die Flucht die gangguaran ara,e, endau Vorzeichen mit den hunderten von Bedjadi kedjau baja baribu zeichnungen und Namen, und schon sasabutan biti,e. sind weit weg und nicht mehr zu sehen die Omen mit den tausenden ihrer Benennungen.

Dahiang Pantis Tantingai Die Vorzeichenvögel Pantis Tantingai Rohong sama merem uson Rohong (die Pantis mit den Dolchen pandong, handipe Buno Ma- die mit goldenen Stiften beschlagen ngantong rata merem sahep sind), sie alle ziehen sich zurück ins lu-rakera.

Gehölz, die Schlangen Buno Mangantong (erhobener Speer) kriechen hinein in den Haufen zusammengewehten Laubes.

Lepah merem lu-dahiang baratus gangguaran ara,e.

Lingis baja medjen baribu sasabutan biti,e.

Parong lu-mangentang ngarambang penjang lu-Sangiang, hinut siro,n tujang luhambalat paturong Djalajan.
Und vollständig haben sich zurückgezogen die Vorzeichen mit den hunderten von Namen und Bezeichnungen. Und restlos haben sich geflüchtet die Omen mit den tausenden ihrer Benennungen.

Und das Haus in dem man verrichtet das Hülfswerk wird umzäunt mit den Penjang der Sangiang, und die Wohnung der Gewiegten wird gut umfriedet mit den Paturong der Djalajan.

\section{Q. Die Sangiang verlassen nach beendeter Arbeit die Körper der Balian}

Toh beken tekap ttg. lago,n tandak tumon lago: Pabuli Sangiang, karana Sangiang idje aton huang genep biti,n ewen oloh balian balua bara biti,n ewen ttg. buli akan papan talawang idje aton huang ruar huma.

I'buli tambon tamuei lu- Kehret wieder zurück, ihr Wasser-
Es ändert sich nun der Schlag der Trommeln und die Melodie des Liedes nach der Weise: Rückkehr der Sangiang, denn die Sangiang, welche sich noch in jeder Person der Balian befinden, treten nun aus ihren Körpern heraus und sie kehren zurück zum Schildbrett welches sich ausserhalb des Hauses befindet. 
Sangiang, buli djalajan dohong indu teras bandong lasang.

I'mulang ihing pangadja,n luDjalajan, mulang panungkup pulang idje luhing gentoi burong.

Limbah Dohong tantan ambon barutas matei, limbah magah liau haring kaharingan.

Buli mengkak rakeran tambang balinga hajak kilau anak darong handjaliwan.

Mulang manguhas salunga bapilik hindje njakatan busu,n randin talampe.

Buli nantan anak tambon randan djadi djala balua bihing,e.

Mulang marandit busu,n tingang pasihai djadi tandoha bahandjong tandaung.

Barapandjong dje lu-sampulau dare hajak panjansirai rangka bahandang.

Lu-bahasut dje luhing angkol timpong, njambarirang dje bulau awan tandok.

Palalinggang bulau tampak bengkel, njababintir bulau pantar tatah. schlangen, ihr reisenden Sangiang, kehret wieder um, ihr Angehörige, ihr Dolche, die ihr gedient habt als innerstes Kernholz des Bandongbootes.

Kehret nun wieder um, ihr Ihing (Wasserschlangen), ihr besuchende Djalajan, kehret wieder um, ihr zu einem Geschlechte vereinigte, ihr Griffe, die ihr waret die innerste Substanz der Vogelboote.

Nachdem nun der Dohong durchschnitten hat die Wolken, die vernichtenden des Todes, nachdem er geführt hat die Liau, die lebende und lebenschaffende.

Kehret zurück und entspannet wieder euere zusammengebogenen Beine, die schnellen, entfaltet euch wieder wie das Junge einer Darong Handjaliwanschlange.

Kehret zurück und löset die verschlungenen Füsse, die raschen, gleich wie sich auseinanderlöst das Jüngste der Randin Talampe Schlange.

Kehret zurück, ihr Kinder der Wasserschlange, und zerreisset das Netz und tretet aus ihm heraus.

Kehret zurück und streifet $a b$, o ihr Jüngsten der Tingang, eure Hüllen, denn geebnet ist der Weg eueres Gehens.

Und schon erscheint der geflochtene Kopfschmuck, und schon sieht man auftauchen die Haarlocken, die roten. Und es fähnt heraus der geknüpfte Zipfel des Kopftuches, und man sieht schon leuchten die goldenen Augen.

Und es wiegen sich hin und her die gleichgeformten Ohrringe, und es blitzen die goldenen Pfähle der Zahnn- 
stifte.

Baragantong hinting santagi Und es kommt zum Vorschein die randan, tujang-tajun dje pu- Treppe der Santagi, der feinen, und sok-njawong samben.

Sangiang buli nundjong panantapei baro hajak.

Hagangganang i-ranak lu-dahiang.

Panantuhang garing kanjambang pulang, njariantang sarukan kumpang pasihai.

Gagarising bulau batu,n penjang halendjut anak naga randan.

Bahasut lawah lamiang hatangkenja paho pandang bulan.

Baragantong tambang lawah rawing balinga manidjak helang bulau tantan sarong.

Baratujang salunga bapilik hindje mulang-mekeng rabia randit tiwong.

Ampin burong tangkasiang tarong buli mandolang bulau ulek telok langit.

Tingkah busu,n Tangkabajoh malem mulang marikan tumbang ulang hagandang. wie erfasst von einem Wirbelwind schüttelt sich die Halskette.

Und die Sangiang kehren zurück und sie heben auf, sie heben in die Höhe ihre Oberkleider.

Und sie erscheinen wie weissgefleckte Vorzeichen.

Und darunter sieht man bereits die eingesteckten elfenbeinernen Griffe, die unter ihnen verborgenen Scheiden und Hüllen.

Und es ertönen die goldenen Steine der Penjang, die den Körper des Kindes der kleinen Naga zum Zusammenziehen bringen.

Und es kommen zum Vorschein die Beinringe von Achat, die sich anschmiegen an die volle Wärme der Monde (der mondförmigen Tätowierungen an den Beinen).

Und es erheben sich die Beine, die beringten, der Krokodile, die raschen, und sie betreten die goldenen $Z$ wischenräume der Herzgrube.

Und es wiegen sich die Füsse, die schnellen, und sie beschreiten die goldenen Abteilungen der Herzgrube. Und nun gleicht er dem Vogel der in seinem Neste steht auf dem Wipfel des Baumes und der zurückgekehrt ist vom Einsammeln des Goldes unter den Buchtungen des Himmels.

Und er gleicht dem Jüngsten des Tangkabajoh (die Bedeutung ist mir nicht bekannt), der gestern von der Mündung her flussaufwärts fuhr und zurückkehrte und wieder heimkam. 
Kilau matanandau basarentar pandang,e manjalungka ka$\mathrm{ju}, \mathrm{n}$ lu-sanggalang garing.

Tingkah bulan nundjong kabantera bahandjong tengak Raho Bajoh Langit.

Toh salenga hobah tekap ttg. lago,n tandak,e manahiu: Sangiang sewn bara hundjun takolok akan laseh bentok huma, koa,e:

Lu-nangkero dje lu-mangentas tambang,e hanjaring bumbong riak dare,n puron.

Lu-mangumban salunga bapilik hindje harende pandong lu-hakanjau dare.

Hadjadjakan dje bukit baras bulau, haratean i-luhing busong hintan.

Lu-mananggar i-tingang lukalangkang garo, i-nampahinot bungai hampatong santi.

Lu-manusang dje djari randan hajak lu-manekap rangkan panginan.

Lu-maninding i-karah lu-Djalajan hindje lu-manekap behas tambak radja.
Und er gleicht der Sonne, die zum Bersten brachte die Stämme der Bäume, der grossen, in die sie eingedrungen ist mit ihrer Hitze.

Und er gleicht dem Monde, der sich erhebt in seiner Rundheit und hervortritt hinter dem zurückgebogenen Kopfe des Raho Bajoh Langit.

Nun ändert sich plötzlich der Schlag und die Melodie des Gesanges und er erwähnt nun, dass die Sangiang herabspringen vom Kopfe auf dem Fussboden in der Mitte des Hauses, und das Lied lautet:

Sie springen herunter und sie lassen herabfallen ihre Füsse auf die rote Matte, das wellende Geflecht von Puron.

Und sie wiegen ihre Beine, die schnellen, und sie lassen sich herunterfallen auf die Matte, die kreuzweise geflochtene.

Und sie beschreiten den Berg von goldenem Sand und sie steigen herab auf die aufgehöhten Steinbänke von Edelsteinen.

Und sie bringen in Ordnung den Tingang vom Gestelle des Weihrauches, und sie setzen wieder richtig den Nashornvogel des wohlriechenden Schnitzbildes.

Und sie strecken aus ihre Finger, die zarten, und sie ergreifen die bereitliegenden Esswaren.

Und sie strecken geradeaus ihre Hände, sie die Djalajan, und sie nehmen den aufgehöhten Reis, den königlichen. 
Sama njamie luhing pantar bua pinang Sangiang buli manalandjong buno.

Rata nupai dje roko,n lutarahan Djalajan mulang manangkedjat renteng,e.

Baragantong dje tambang lubalinga hajak lompat balai puna lampar buno.

Baratujang salunga lu-bapilik hindje djakat sali tilap lutalawang.

Lu-manetei dje puna djamban garing mananturong papan talawang teras kaju djambu bahandang.

Haratean paratar sihong njahendeng bulau dare,n lintong luhing lumpok muntei bulau.

Lu-mantapei dje timpong pandjang akan panambai papan lu-talawang.

Manantiup dje lu-pahangan ambo salabumbon bulau dare,n lintong.

Lu-manusang dje renteng tingang lu-Sangiang hajak lumanjelem papan talawang.

Lu-maniling dje pating bungai Djalajan hindje manantame bulau dare, n lintong.

Buli puron dje panduka mon-
Und gemeinsam ergreifen sie die aufgehöhten Kausel der Früchte der Pinang und die Sangiang kehren für kurze Zeit wieder zurück auf ihre Speere.

Und sie alle zusammen packen die Rauchwaren der Sklaven und die Djalajan begeben sich wieder für einen Augenblick auf die Schwanzfedern (d.h. auf die Speere).

Und sie erheben ihre Beine, die schnellen, und sie besteigen den Balai der nebeneinanderliegenden Lanzen.

Und sie wiegen ihre Füsse, die raschen, und sie erklimmen das Haus der aufeinandergeschichteten Schilde. Und sie beschreiten die Brücke, die elfenbeinerne, und sie begeben sich in das Schildbrett, das Kernholz des roten Djambubaumes.

Und sie gehen über den Brückenweg, den elfenbeinernen, und sie steigen ein in das goldene geflochtene Band, den Pfahl des innersten Holzes des goldenen Munteibaumes.

Sie heben auf das Tuch, das lange, das herabhängt auf den Seiten des Schildbrettes.

Sie heben hoch in die Höhe das grosse Tuch, das ausgebreitet ist über das goldene geflochtene Band.

Und sie senken die Schwanzfedern der Tingang, sie die Sangiang, und sie gehen zusammen hinein in das Schildbrett.

Sie senken die Zweiglein der Nashornvögel, sie die Djalajan, und gemeinsam betreten sie das goldene geflochtene Band.

Sie kehren zurück auf die Puronmatte, 
dok, lalian ringkin tampudjene badjanda.

Buli garantong dje lapik baru, halian rundjan sandar balita,e, sama naharep dje lasang pinang, mantar pinang, hataradjo manjang.

Djari busau dje puna bua pinang, hajak randan hakaisek rawei,

Kabaseian dje puna uring manjang, i'lalu ringkan basarohi tisoi :

Kilen talatai dje puna lupangentang keton dohong dumah tambon turon?

Isen runtan dje saripangku djalahan pulang rampe sarong ngandawan?

Kabadjuran talatai pangentang hemben nduan hambekan katon.

Kabarengan runtan saripang$\mathrm{ku}$ matok dinon djaretan etoh. ihren Sitzplatz, sie kehren wieder zurück auf das gewellte Geflecht, auf dem sie sich niederzulassen pflegen. Und sie kehren zurück auf die Gong, die die Unterlage ihrer Oberkleider sind (d.h. auf die sie sich setzen), sie kehren wieder um $z u$ den heiligen Töpfen, ihren Rückenlehnen, und gemeinsam nähern sie sich dem Gefäss mit den Pinang um Pinang $z u$ kauen, um Betelnüsse zu kauen.

Und schon sind sie trunken von den Früchten der Pinang und mit gedämpfter Stimme fragt ihr Wort, Bereits sind sie betäubt worden von den Früchten, den Betelnüssen und sie erkundigen sich mit freundlicher Rede :

Wie denkt ihr nun über das Hülfswerk das wir verrichtet haben, wir Dolche, wir angekommenen und eingefahrenen (in die Balian) Wasserschlangen.

Wie ist nun euere Ueberlegung über unsere Arbeit, unser euch auf den Schoss nehmen, die wir, die Angehörigen der Griffe, ausgeführt haben nachdem wir eingefahren waren?

Gut sind unsere Gedanken über das Hülfswerk, das ihr jetzt zu dieser Zeit ausgeführt habt (d.h. sie sind mit dem, was die Sangiang taten, sehr zufrieden).

Rechtschaffen denken wir über das auf den Schoss nehmen, das ihr nun in diesem Augenblicke vollzogen habt. 410

Die Sangiang setzen ihr Gespräch fort:

Limbah natolak ikei ambon Nachdem wir nun weggeschoben haben barutas matei, ulek manjang- die Wolken, die vernichtenden des 
ka enon bapilo nihau,

Limbah antang ikei manamuei ngagahan liau haring kaharingan,

Ulek kenjoi rawen mangadja manjembang lewu,n Balo Indu Rangkang Penjang,

Hemben nduan hambekan katon, sama malajan itah tolang rumpang.

Matok dinon djaretan etoh sama maleleng itah uhat leso.

Djewu nontong,e tandak,e hinai, omba andau djadi lubabandang.

Djeha nambing karunja luDjalajan, tatepen enon djari lu-badandang.

Mangkang Sangiang dohong tambon turon, ngendjong Djalajan buno sarong mangandawan.

Indu teras dje puna bandong lasang, lu-mangahem papan bandong lasang.

Akan luhing dje puna gentoi burong, lu-marimpar pandong sandai bulan.
Todes, nachdem wir nun aufgehoben haben die Tauwolken, die zerstörenden des Verlorenen,

Nachdem wir nun, wir Antang, gereist sind und geleitet haben die Liau, die lebende und lebenschaffende,

Nachdem wir Falken ausgezogen sind und sie geführt haben, sodass sie ankommen konnte im Dorfe der Balo Indu Rangkang Penjang,

Steht es jetzt nun so, ist es auf diese Weise : wir beenden nun unsere Arbeit und wir ruhen unsere ermüdeten Knochen aus.

Steht es in diesem Augenblicke nun so, dass wir uns erholen von unseren erschlafften Muskeln.

Morgen erst setzen wir wieder fort unseren Gesang, am kommenden Tage wenn es hell geworden ist.

Hernach nehmen wir wieder auf das Lied der Djalajan, dann wenn die Wolken licht geworden sind.

Und dann werden wir wieder $z u$ sich selbst bringen die Sangiang, die Dolche, die herunterfahrenden Wasserschlangen, dann werden wir wieder aufwecken die Djalajan, die Speere, die in die Balian eingehenden.

Als Kernholz für die Bandongboote (gemeint sind damit die Balian) um zum Versinken zu bringen die Bretter der Bandongboote (es handelt sich um die rituelle Kenterung der Boote und das Untertauchen der Menschen im Fluss).

Als innerster Stamm der Vogelboote, um eben zu machen die Haare der zirpenden Monde (d.h. sie werden ins Wasser untergetaucht, sodass ihre 
Tende bahing panto,n sambang kaju,n lembai bakabuang ambon rutas.

Lalu tahan bambahingan luhing, luhing paturong bakasangkan bapilo nihau.

Tende tamberang tingang ngarambang Sangiang penjang, tahan kariak antang bapager paturong Djalajan.

Toh ewen oloh balian sama malajan, sama mado tiroh,e ttg. oloh beken.
Haare eben sind mit dem Wasser). Schweige nun, Laut des Schlagens der Trommeln, der biegsamen Hölzer, die da vertreiben die Wolken, die vernichtenden.

Verstumme nun, Schall der Trommeln, der Stützen der Paturong, die da aufheben die Tauwolken, die vernichtenden des Verlorenen.

Verstumme nun, Gerufe der Tingang, der Sangiang, die da umzäunen (das Haus und die ganze Verwandtschaft des Toten) mit Penjang, schweige, Geschrei der Falken, der Djalajan, die da umfrieden mit Paturong.

Die Balian hören nun auf und sie wollen sich zur Ruhe begeben, und mit ihnen auch die andern Leute des Hauses.

\section{Abschliessende Handlungen}

Bei den abschliesssenden Handlungen wird dem Menschen, der dem Tod angehörte, und der nun durch die Sangiang und durch die Mitwirkung der Oberwelt (Ranjing Mahatala Langit) und der Unterwelt (Tambon), von seinem Unheil befreit worden ist, aus dem er sich nicht selbst $z u$ erlösen vermochte, das neue Leben geschenkt als Gabe der Oberwelt und der Unterwelt beiden. Um aber das Leben empfangen zu können wird er in den Tod gegeben, und aus dem Tode ersteht er als neugewordener Mensch zu einem neuen Leben in einer neugewordenen Welt. Das ist mit wenig Worten gesagt die Bedeutung des Untertauchens im Fluss die nicht eine Reinigungshandlung darstellt sondern die neue Welt- und Menschwerdung. Das zeigen uns vor allem die umfassenden Handlungen am Schlusse des Tiwah, die hier beim Tantolak matei in sehr gekürzter Form ausgeführt werden.

Wie haben wir uns die Kenterung der Boote zu erklären, die bei allen Initiationshandlungen und sogenannten Krisisriten vorgenommen wird? Wir bringen sie in Verbindung mit der Welt- und Menschwerdung. Der Mensch wird an den Anfang der Dinge in der mythischen 
Vorzeit zurückversetzt und die Boote werden identifiziert mit den ersten beiden Booten, in denen sich die ersten Menschen befanden, die auf dem Urwasser herumtrieben. Zurückversetzt an den Anfang sind sie nun auch die ersten Menschen, die das Leben aus dem Urwasser und aus der Oberwelt beiden empfangen haben. Die Boote werden gekentert, denn der Mensch gehört durch den eingetretenen Tod der Todesseite an und wird erst dann von ihr ganz erlöst, wenn ihm Oberwelt und Unterwelt beide das neue Leben geschenkt haben, das heisst: wenn aus dem alten Menschen ein neuer Mensch geworden ist. Und weil er der Todesseite angehört und weil der alte Mensch vergehen muss ehe der neue werden kann, wird der alte Mensch an den Anfang der Welt- und Menschwerdung zurückversetzt und hier am Anfange aller Dinge in den Tod gegeben. Der alte Mensch geht in den Tod, aber er sinkt im Urwasser unter in das Leben und er taucht wieder auf als neugewordener Mensch, an dem durch Ranjing Mahatala Langit und durch die Tambon die Menschwerdung der mythischen Vorzeit wiederholt worden ist.

Nicht der Mensch wiederholt dieses Geschehen, wie könnte er auch! Nicht das Wasser besitzt diese Mächtigkeit und Heiligkeit an sich. Flusswasser ist nun einmal Wasser das aus den Bergen hervorquillt und sich in die See ergiesst. Jeden Tag badet man sich in diesem gewöhnlichen Wasser, ohne dass man dadurch nun ein neuer Mensch würde. Das Wasser an sich ist nichts und hat keine Bedeutung. Aber es empfängt dann eine andere Bedeutung, es wird dann zu einem heiligen Wasser, wenn es durch Oberwelt und Unterwelt geheiligt wird. Dann badet der Mensch nicht mehr im gewöhnlichen Wasser. Er taucht dann unter in das heilige Wasser, in das sich die Quellen der Oberwelt und Unterwelt ergossen haben. Er taucht dann unter in Ranjing Mahatala Langit und die Tambon, nicht weil er will, sondern weil er darf, weil sie ihm diese Gabe und Gnade schenken, weil sie ihm in voller Freiheit und Unabhängigkeit vom Menschen, die Gabe des neuen Lebens schenken. Es handelt sich hier nur um das neue Leben des Menschen, noch nicht aber um das der Pflanzen und Tiere und auch noch nicht um die neue Welt. Das geschieht erst beim Tiwah. Die ausführlichen Texte und Beschreibungen werden im IV. Bande dieses Werkes gegeben. Von dort aus haben wir aber auch diese Handlung, die beim Tantolak matei nun vollzogen wird, $z u$ sehen und $z u$ interpretieren. 


\section{A. Die Aufweckung der Sangiang am Morgen des angebrochenen Tages}

Maka amon andau djadi sawah oloh balian limbah kuman, limbah simpa maroko ranen, toh ewen balian namparindjet Sangiang, koa,n tandak,e :

Siring bambahinga labata,n karunja,n tambon haruei ibungai.

Omba andau kasibahan, tatepen enon lu-ba-i-dandang.

Manamuei papan talawang teras kaju djambu bahandang.

Mangadja bulau dare,n lintong luhing lumpok muntei bulau.

Manarindjet tingang Sangiang keton huang papan talawang.

Manantugoh bungai tatau medjen dare,n lintong.

Sama pararindjet hajak Sangiang misik tiroh tingang.

Rata pararugoh hindje Djalajan luas kantok burong.

Sama akis hagagia bantal putak kalihulon batiroh.

Lalu birik habarika timpong bangkuran njaho.
Nachdem die Morgendämmerung angebrochen ist, und nachdem die Balian gegessen, Betel gekaut und geraucht haben usw., dann wecken die Balian die Sangiang auf und ihr Gesang lautet:

Es erhebt sich der Schall der Seele des Liedes der Wasserschlangen die verzwillingt sind mit den Nashornvögeln.

Der Tag ist nun wieder angebrochen, die Wolken der Nacht sind hell geworden.

Und wegreisen soll nun auch das Schildbrett, das Kernholz des roten Djambubaumes.

Und wegfahren soll nun das goldene geflochtene Band, der Pfahl des innersten Holzes des goldenen Munteibaumes.

Reckt und streckt vorsichtig euere Glieder, ihr Tingang, ihr Sangiang im Schildbrett.

Wachet auf, ihr Nashornvögel, die ihr euch befindet im geflochtenen Band.

Und gemeinsam recken und strecken ihre Glieder die Sangiang, die aufgewacht sind vom Schlafe der Tingang. Und zusammen schütteln sie ihre Glieder, sie, die Djalajan, die erwacht sind aus dem Schlummer der Vögel.

Und gemeinsam stossen sie weg und schieben sie fort die schaumgefüllten Kissen, auf die man sich niederlegt zum Schlaf.

Und sie schütteln ab und werfen von sich weg das Tuch der Decke, der 
donnernden.

Tarahondok lambat hajak Und langsam setzen sie sich auf und mandokan bumbong dare,n sie lassen sich nieder auf die Matte puron.

Tarahekeng lowah hindje bavon geflochtenem Puron.

Und sie setzen sich vorsichtig auf und sie nehmen Platz auf der Matte von Irit Bungai, und aufgelöst wie ein ausgeworfenes Wurfnetz hängen her$\mathrm{ab}$ ihre Haare, die langen.

Balita kende-kendet mangendet bumbong dare, $\mathrm{n} \mathrm{pu}-$ ron.

Sandara,e pantok-pantok mantok lasang sinau Sangiang.

Nduan idje gawang tingang njarantar bumbong dare,n puron.

Ngitar garing pandoka mondok manaharep sambang garantong, misat sihong tampudjena badjanda manjambau pinton djandjingan.

Eka talaga,n njalong ambon, lapekong gohong enon.

Mangusau pandong lawi,n balau pandjang sarak-saraken.

Sarabian bagundai ambo, manggurang bulau pantar tatah,e, misut rabia sadurin guntong.

Mangambuah pandong lawi,n balau, mantahinot bagundai ambo, manantipek tingang tempo,e, pakun djampalulangzu Locken, so wie geflochten wird die Matte, das Geflecht von Puron.

Und sie ziehen an, sie schmücken sich mit den verzierten Armringen der Männer, der Sangiang.

Und sie kriechen ein Stück weit fort das die Länge hat einer Spanne eines Nashornvogels, sie kriechen fort auf der Matte, dem Geflechte von Puron. Und sie drehen sich auf ihren elfenbeinernen Plätzen, ihren Sitzen, und sie nähern sich den Trommeln und Gong und sie wenden sich auf ihren elfenbeinernen Sitzplätzen und sie drehen ihr Gesicht nach den Trommeln und Gong.

Den Teichen des Wassers der Wolken, den Orten die gefüllt sind mit dem Wasser der Tauwolken.

Und sie plätschern in dem Wasser mit den Enden des Haares, des langen und des weit auseinanderstehenden.

Und sie kämmen das Haar, das lange, und sie reinigen die goldenen Pfähle der Zahnstifte, und sie scheuern den Zahn des Mundes.

Und sie bringen in Ordnung die Haare, die Enden der Haare, und sie machen tadellos zurecht die Haare, die langen, die drehen sie, sie die Tingang, 
luli.

Njarokan antang lu-Sangiange suloh hawok, habaranger ampi,n tandok musai ambon pakalentang parei njangen tingang.

Dohong Mama Tandang radja mangun parentah, Langkah Sawang Mama Bungai kanarohan mapak basara akan Sangiang garing tabela belom mandjawet rangkan panginan simpan, panungkup puja kalinti hababian uras kahanjatan sukup. Totok djadi rangkan panginan ewen huang papan talawang, sambong uras hakanjatan sukup Djalajan medjen bulau dare,n lintong.

Sangiang bapiring pandjang napus huang papan talawang, Djalajan badjaran ambo manggenep patas bulau dare,n lintong.

Sama nundjong kabesoh, hajak injip upo,n pambulu mendeng.

Djalajan mangkat kabesoha,e hindje marinap pandong lawi,n balau pandjang.

Misut njalumbong bulau pating djari,e, nahalanting,e ihre Besitzer, sie wiegen sie hin und her und sie machen sie fest und rollen sie auf zu einem Knäuel.

Und sie werden festgemacht durch den Antang, ihren Sangiang, und sie werden festgemacht, gleichwie die Augen Musai auf dem Reise Njangen Tingang (die Bedeutung dieser Augen Musai ist mir nicht bekannt).

Und er, der Dohong Mama Tandang, der König, gibt nun einen Befehl, und er, der Langkah Sawang Mama Bungai, der Fürst, erteilt einen Auftrag den Sangiang, den junglebenden Elfenbeinen, dass sie bereit machen die Esswaren in genügender Menge, dass sie, die Gemeinschaft der Sklaven, die Speisen rüsten in hinreichender Zahl. Und bereit sind schon die Esswaren im Schildbrett, und zugerüstet sind schon die Speisen in hinreichender Menge und sie sind bestimmt für die Djalajan, die sich aufhalten im goldenen geflochtenen Band.

Und die Sangiang ergreifen ihre Teller, die langen, die verstreut liegen im ganzen Schildbrett, und die Djalajan nehmen ihre Schüsseln, die grossen, die sich in allen Abteilungen des goldenen geflochtenen Bandes befinden.

Und gemeinsam sättigen sie sich und sie saugen ein die Wurzeln der aufrechtstehenden Haare (d.h. des Reises).

Die Djalajan stillen zusammen ihren Hunger und sie ziehen ein die Haare, die Enden der Haare, der langen (damit ist ebenfalls der Reis gemeint). Und sie reinigen die überzogenen goldenen $Z_{\text {weiglein }}$ ihrer Finger (die 
piring buang.

Manggurang bulau pantar tatah,e, halantinga djarah sandong.

Manantengok njalong ambon, manandang ambon rahusan aseng.

Hajak minjip gohong enon, manehang enon rantaran njama,e.

Badandang ambon idje katahusan Sangiang limbah hapumpong puseh, batehang enon due kabarengan Djalajan luas ngampungan pating balawan randan.

Djalahan kawan tarahan marasih piring buang.

Imbing,e papas bulau kamalangkang, kilau puso,n pinang lewu, marasih huang papan talawang, mangkehes patas bulau dare,n lintong.

Mamapas bari bowor limbah Sangiang bapumpong puseh.

Mamapas tantaujas pinang, Und sie fegen aus ihnen weg die Reste vom Reise beschmutzt worden sind, denn der Dajak isst den Reis mit den Fingern), und sie schieben von sich weg die Teller, die leeren.

Und sie scheuern die goldenen Pfähle ihrer Zahnstifte, und sie stossen von sich fort die Teller, die gebrauchten.

Und sie trinken das Wasser der Wolken um wieder frei zu machen die Wolkenlagen auf dem Wege des Atems.

Und langsam ziehen sie ein das Wasser der Tauwolken um licht zu machen den Vorplatz ihres Mundes (d.h. die Mundhöhle).

Und hell sind nun die Wolkenlagen der Flussbiegungen der Tauwolken der Sangiang, nachdem sie zu sich genommen haben die Speisen, licht sind nun die zwei Krümmungen der Tauwolken der Djalajan, nachdem sie genossen haben die kleinen $Z$ weiglein des Reisstampfers.

Und die Angehörigen, die Schar der Sklaven, reinigt nun die Teller, die leeren.

Und sie ergreifen den Besen, den goldenen, das Bündel, das am einen Ende dicker ist als am andern und das aussieht wie die Blütenknospen der Pinang des Dorfes (also wie ein Blumentross), und sie reinigen mit ihm das Innere des Schildbrettes, und sie säubern alle Abteilungen des goldenen geflochtenen Bandes.

Sie reinigen sie von den zerstreut herumliegenden Resten des Reises der Sangiang, die zu sich genommen haben die Speisen. 
marasih puting roko,n tarahan.

Idje tingang manok Sangiang ewen huang papan talawang, due ranjing ajam Djalajan medjen bulau dare,n lintong.

Miring sangko radja bahalap mangarawang bulau, manantiang saparanggon dalam badaris kangatil bawak lamiang eka lasang pantar pinang lutambako lumpok tampike.

Sangiang bairing pinang napus huang papan talawang, Djalajan badjarah manjang manggenep patas bulau dare,n lintong, mantar pinang tatop mandue, hataradjo manjang rempai manelo.

Sama njipa ulang manantali tanteng,e, ngendas pulau pulu batandjong henda.

Ludja malik baputi kilau gita,n Lunok Tarong.

Ludja malik bahenda manamunan riak hendan bulau.

Ludja malik bahandang manjakatan darah burong tingang.

Rangkang Dohong Mama Tandang, Langkah Sawang Mama Bungai Bunge, bandong Njaring djahawen, der Pinang, und sie reinigen es von den Enden der Rauchwaren der Sklaven.

Einer der Tingang von ihnen (einer der Sklaven), eines der Hühner der Sangiang befindet sich noch im Schildbrett, zwei grosse Hühner der Djalajan halten sich immer noch auf in dem goldenen geflochtenen Band.

Und er reicht herum den königlichen Sangko, den schön verzierten mit goldener durchbrochener Arbeit, er bedient mit dem Gefäss des Palastes, dem zierlich eingelegten mit Stücken von Achat, dem Ort in dem sich befinden Betelkausel und Tabak den man abgepflückt hat vom Bündel.

Und die Sangiang reichen herum die Pinang in ganzen Innern des Schildbrettes, und die Djalajan geben herum die Betelnüsse in allen Abteilungen des goldenen geflochtenen Bandes, und sie kauen Pinang, zwei auf einmal, und sie kauen Betelnüsse, drei zugleich.

Und sie kauen und mahlen sie und sie bewegen ihre Zahnstifte und von den Inseln, den zahlreichen, fliesst es gelb herab.

Und ihr Speichel verändert sich in Weissheit und er gleicht dem Gummi des Lunok Tarong.

Und ihr Speichel wird gelb, gleichwie die Wellen der Gelbheit des Goldes.

Und ihr Speichel verändert sich in Röte und er gleicht dem Blute des Nashornvogels.

Und er, der Alte, er, der Dohong Mama Tandang, der Langkah Sawang Mama Bungai Bunge, der Mann der Njaring, der sechsen, 
Minjup parutan garing, manamunan kabali bulau.

Asep lu-malenteh balua langkau papan talawang.

Ampi,n asep sapunang notong tumbang danum lu-Djalajan.

Tingkah ambon lu-baduroh tumbang danum lime puluh.

Djalajan Sangiang awang hapantar pinang, Djalajan. maing hataradjo manjang,

Lu-balita ti-puntang-pintik papan talawang sintong udju. Mintik djoho,n pinang luSangiang tarantang Dohong Mama Tandang.

Olih putak karenteng-renteng manjauh kamburi,n papan lutalawang.

Putak djoho,n pinang luSangiang lalundong santi,n Mama Bungai.

Djari busau dje bua pinang Sangiang huang papan lutalawang.

Tabasewan uring manjang Djalajan medjen bulau dare,n lintong.

Palus randan hakaisek rawei, ringkang basarohi tisoi :

Kilen talatai pangentang, Wie denkt ihr über das Hülfswerk, o
Er raucht eine elfenbeinerne Tabakpfeife, die die Grösse besitzt eines goldenen Reiskochtopfes.

Und der Rauch fällt hernieder und er schwebt hervor unter dem Dache des Schildbrettes.

Und die Art des Rauches ist wie der einer abgefetuerten Kanone an der Mündung des Flusses Djalajan.

Und er ist gleichwie die Wolken, die sich heruntersenken von den Mündungen der fünfzig Flüsse (in der Oberwelt).

Und die Angehörigen der Sangiang, die da kauen die Pinang, sie die Djalajan, die kräftigen, die da kauen die Betelnüsse,

Sie schaukeln hin und her die Schildbretter, die sieben zusammen.

Und sie machen Zeichen mit dem Safte der Pinang, sie, die Sangiang, die Kinder des Dohong Mama Tandang.

Und der Schaum, der gestreifte, fliesst herunter auf der Steuerseite des Schildbrettes.

Der Schaum des Saftes der Pinang der Sangiang, der wohlduftenden Kinder des Mama Bungai.

Und trunken sind sie von den Früchten der Pinang, sie die Sangiang, die sich aufhalten im Schildbrett.

Und betäubt sind von den Früchten der Betelnusspalme die Djalajan, die sich befinden im goldenen geflochtenen Band.

Und sie fragen mit gedämpfter Stimme, und sie erkundigen sich mit kleinem Wort: 
apang, balua parong kurong lu-mangentang.

Isen runtan saripangku, mama, bahandjong siro saripangku?

Hemben nduan hambekan katon, anak, keton padjandjuri kumpang.

Matok dinon djaretan etoh, aken, keton buno panantekei gantuling,e.

Buno sarong dje mangandawan akan luhing gentoi burong.

Indu teras dje bandong lasang mangahem papan bandong lasang burong.

Akan luhing dje gentoi burong marimpar pandong sandai bulan.

Mangahem palepah ambon barutas matei, mampalingis enon bapilo nihau.

Narai bulan kahunga, apang, penjang garo manadjah simpei.

Isen bintang kabuku, mama, paturong santi tilong tamburak,e.

Pire bandong lasang buang bagantong bindang katil garing?

Isen hasean gentoi burong
Väter, über das Heraustreten aus dem eingeschlossenen Hause in dem verrichtet wird das Hülfswerk?

Wie ist euer Sinnen wegen des Tragens auf dem Schoss, o Onkel, des Verlassens des Hauses in dem vollzogen wird das Tragen auf dem Schoss?

So steht es nun, so ist es jetzt, o ihr Kinder, die Dolche können hervorgehen aus ihren Scheiden.

So steht es nun, so ist es jetzt in dieser Sache, o Neffen, die Speere können sich lösen aus ihren Ringen.

Die Lanzen der Sarong fahren nun herunter als Stamm für das Innerste des Vogelbootes.

Als Kernholz der Bandongboote (der Balian), damit sie zum Sinken bringen können die Bandongboote der Vögel. Als Stamm des Innersten des Vogelbootes (Balian), damit sie eben machen können die Haare der zirpenden Monde (die im Wasser untertauchen). Um restlos zu ertränken die Wolken, die vernichtenden des Todes, um vollständig auf die Seite zu schaffen die Tauwolken, die zerstörenden des Verlorenen.

Was sollten wir dagegen einzuwenden haben, o Väter, die duftenden Penjang wollen aufsuchen ihre Bündel.

Was sollten wir $z \mathfrak{u}$ erwidern haben, o Onkel, die wohlriechenden Paturong wollen zusammengeflochten werden zu einem Bande.

Wieviele leere Bandongboote sind vorhanden auf dem Brett der elfenbeinernen Bank?

Wie gross ist die Zahl der Vogel- 
sandong batujang ulai sansuro radja?

Telo bandong lasang buang, telo dohong tambon turon, epat gentoi burong sandong, epat buno panantekei gantuling.

Sama mangkang barangkap rohong ampi,n kanjoka,h kumpang.

$\mathrm{Njapo}$ bario,n balita,e, rowan kanjahungker rohong.

Ampi,n panamuei Pataho menteng manendjang luhing karambang sawang.

Lu-pangadja,n Batu Mamben bahanji hadjadjakan ranggan buno.

Hajak nangking manantelai dohong, meteng mambahulan bulau batu,n penjang.

Hatanggar renteng tingang, ngambuah djundjong sampulau dare. boote, die sich wiegen auf dem zierlich gedrehten Gestell, dem königlichen? (Die Sangiang erkundigen sich nach der Zahl der Balian in die sie einfahren wollen.)

Drei Bandongboote sind leer, drei Dolche der Wasserschlangen können in sie einfahren, vier Vogelboote sind ledig, vier Speere können sich lösen aus ihren Ringen.

Und sie alle bringen nun in Ordnung und machen fest die Dolche, die Stützen der Scheiden.

Und sie bestreichen sich den Körper und nun gleichen sie der Stütze des Dolches.

Und sie gleichen dem sich auf die Reise begebenden Pataho, dem tapferen, der heraustritt aus den Pfählen des Zaunes die die Sawangstauden umgeben.

Und sie gleichen dem besuchenden Batu Mamben (anderer Name für Pataho), dem mutigen, der daherschreitet mit dem gezackten Speer.

Und sie umbinden schrägabstehend ihre Dolche, und sie umgürten und knüpfen fest die goldenen Steine ihrer Penjang.

Und sie bringen in Ordnung die Schwanzfedern der Tingang, und sie machen zurecht den Aufbau des geflochtenen Kopfschmuckes.

\section{B. Die Sangiang fahren in die Balian ein}

Toh Sangiang hagoet turon bara papan talawang manetei djamban tame akan huang balai rampar buno, sewu bara balai rampar buno akan ben-
Die Sangiang begeben sich nun zum Herunterfahren aus dem Schildbrett heraus und sie beschreiten die Brücke und gehen hinein in den Balai der nebeneinanderliegenden Speere, sie 
tok huma palus manalih oloh balian.

Sama ih auch dengan ,mangkang Sangiang", uras sama auch,e sampai hapus ,paturon Sangiang“, baja isut kabeke,e solak nampara "paturon Sangiang", koa,e : springen herunter vom Balai der nebeneinanderliegenden Speere in die Mitte des Hauses und sie begeben sich zu den Balian.

Die Worte lauten gleich wie das Mangkang Sangiang (Von Seite 594, C.: Die Sangiang kommen im Hause an, bis und mit Seite 597 ff. D. : Die Sangiang fahren in die Balian ein), alle Worte sind gleich bis zur Beendigung des Paturon Sangiang (Seite 597 ff.), nur am Anfang des Paturon Sangiang sind einige kleine Verschiedenheiten, und der Anfang lautet nun (Nur diese kleinen Abweichungen werden hier wiederholt, für den ganzen Text wird auf die Seiten $594 \mathrm{ff}$. verwiesen) :

I'dumah tambon mangasoh balua papan talawang, rampe ihing manganduran bahandjong bulau dare,n lintong, tambarirang saroi hadurut basingah lumpong matanandau, Busun Unar Djala malentur basampalak matan pangalantin langit...
Es kommen die Wasserschlangen und steigen herunter und sie treten heraus aus dem Schildbrett, es kommen und steigen herab die Ihing (Wasserschlangen) und sie schreiten heraus aus dem goldenen geflochtenen Band, der Tambarirang fährt mit Heftigkeit herab, beleuchtet von der Rundheit der Sonne, der Busun Unar Djala steigt herunter, beschienen von dem Auge, dem gelben, des Himmels.... (Vgl. Seite 599 ff.).

Der Unterschied (die neugebrauchten Wörter sind unterstrichen) besteht darin, dass die Handlungen, die früher vollzogen und besungen wurden, nachts stattfanden während sie hier nun am frühen Morgen vorgenommen werden. Dort kommt deshalb der Tambarirang Saroi „beleuchtet von dem Lichte der Rundheit des Mondes“ herab, hier wird er von der aufgehenden Sonne beleuchtet.

Tinai huang lawi,n auch ,paturon Sangiang" mansanan djalana,e turon akan ,Kang-
Und am Fnde des Spruchwortes der Einfahrt der Sangiang wird mitgeteilt dass es sich diesmal beim Einfahren 
kahem".

Tinai,uras mandjulok sipa roko ttg. tuak arak akan ewen oloh balian. darum handelt, dass die Sangiang das Kangkahem (untersinken, ertrinken im Wasser, hier auch: die Kenterung der Boote) zu vollziehen haben.

Und weiter: alle überreichen den Balian nun Kausel und Zigaretten, Reisbier und Reisbranntwein.

\section{Die Kenterung der Boote}

\section{a. Die Vorbereitungen}

(Im gewöhnlichen Ngadju mitgeteilt)

Ewen oloh huma manatap kare ramo hapan kangkahem, $\mathbf{4 1 1}$ ie te:

1. Manatap idje, due sampai telo djukung buang, andak,e intu sare batang.

2. Pusu,n pinang idje haru burai ttg. dawen sawang, dawen kaju kilau ramon tampong papas.

3. Mantokan apui intu sara,n danum ttg. udju katetek humbang akan salentup.

4. Idje pakihu atawa rabajang atawa rando, uras tau asal ttg. tantaha,e.

5. Idje kongan manok pehok belom, andak,e huang karonga,e, karonga,e ingkes intu saran karatak, manok te injewut: manok
Die Leute im Hause bereiten nun alle Dinge vor die man nötig hat für die Kenterung der Boote im Fluss, nämlich diese :

1. Man macht eines, zwei oder drei leere Boote bereit und bringt sie zum Anlegefloss.

2. Blütenknospen der Pinang, die sich erst kürzlich geöffnet haben, Sawangblätter, und Blätter von verschiedenen Baumsorten, wie man sie auch gebraucht für das Bündel des Besens.

3. Feuerbrände, die man an den Rand des Flussufers bringt, und sieben Stück Bambus zum Knallen.

4. Ein Pakihu oder ein Rabajang oder ein Rando (heilige Speere), alle drei können gebraucht werden, aber es müssen Schaft und Eisen vorhanden sein.

5. Ein Huhn, das heisst eine lebende Henne, sie wird in einen Korb gelegt und den Korb legt man an den Rand des Flussufers, dieses Huhn nennt man: Huhn für das An- 
tatukan ambon barutas matei.

6. Tepong behas ingkes huang pontong bua enjoh, enjoh te ttg. isi,e.

7. Lepah oloh balian ttg. katambong akan sara,n danum.

8. Pasok hambaruan ttg. hampatong huang,e, sukup ramo,e kilau djadi injadia helo.

9. Idje behas tambak, huang,e aton mangkok terois tatap roko sipa.

10. Pisau kupit,e akan genep biti,n oloh balian.

11. Idje sahewan tamiang ttg. tunek njating huang bangu,n enjoh.

Toh bawi balo mohon hajak kare oloh huma melai lompat intu sare djadjukung intu sare batang.

Are biti,n ewen, amon djukung dia muat,e te tau belahe melai intu sara,n petak, kareh ie maneser hajak djukung ingahem.

Toh ewen djadi aton huang djukung, te palus oloh balian manampara manekap katambong ttg. manandak, tapi zünden der Wolken, der vernichtenden des Todes.

6. Reismehl, das man gelegt hat in ein Stück einer Kokosnussfrucht, diese Kokosnuss, zusammen mit dem Fruchtfleisch.

7. Alle Balian begeben sich mit den kleinen Trommeln zum Rande des Flussufers.

8. Das Körblein mit den Seelen (d.h. mit dem Seelenreis) und darin auch das menschliche Schnitzbild und alle dazugehörigen Dinge, die bereits vorher bereit gemacht worden sind.

9. Ein Gefäss mit aufgehöhtem Reis, auf ihm befindet sich eine Teroistasse in der bereitliegen: Zigaretten und Betelkausel.

10. Ein altes beschädigtes Buschmesser für jeden der Balian.

11. Eine Tamiangfackel und Harzmehl in einer Kokosnusschale.

Die Witwe steigt nun zum Fluss herunter und mit ihr alle Leute die sich im Hause befanden, sie besteigen den Rand des Ruderbootes, das sich beim Anlegefloss befindet.

Es sind ihrer viele, wenn das Ruderboot sie nicht alle zu tragen vermag, dann können sie sich am Rande des Flussufers aufstellen und sie tauchen dann ins Wasser unter wenn das Ruderboot zum Kentern gebracht wird.

Sie befinden sich nun im Ruderboot und alsobald beginnen nun die Balian die kleinen Trommeln $\mathrm{zu}$ schlagen und zu singen, aber die Balian bleiben 
ewen balian melai intu sara,n petak dia intu hundjun batang, kareh intu hundjun batang amon kangkahem lawi,n gawi,n tiwah. am Rande des Flussufers stehen und steigen nicht herunter zum Anlegefloss, erst später stellen sie sich auf dem Anlegefloss auf, nämlich wenn sie am Schlusse der Handlungen des Tiwah die Kenterung der Boote ausführen.

\section{b. Das Schildbrett fährt zum Fluss}

Toh ewen balian manahiu Die Balian erwähnen nun die Abreise manolak papan talawang ha- des Schildbrettes, das von der Seite goet bara darah huma akan des Hauses wegfährt und sich nun sara, $n$ danum kea.

ebenfalls zum Flussufer begibt.

Koa,n bawak tandak ewen, Es lauten die Worte des Liedes, das manandak lepah biti,e: alle zusammen singen:

I'bahing lu-bapanting Sangiang maneras bandong lasang.

Lalu siring bambahinga Djalajan maluhing gentoi burong.

Bahing panganak anak andau manamuei papan lu-talawang.

Bambahingan panjandai bulan mangadja bulau dare,n lintong.

Manamuei papan talawang manarindjet tingang Sangiang.

Mangadja bulau dare,n lintong mamparugoh bungai Djalajan.

Sama pararindjet hajak rawing rata hapantar pinang.

Busau bua pinang randan Und nachdem sie trunken sind von 
ewen hakaisek rawei :

Kabasewan uring manjang lalu ringkan basarohi tisoi:

Kilen talatai pangentang hemben nduan hambekan ikaton?

Isen runtan saripangku matok dinon djaretan etoh?

Katon talatai pangentang keton mangitar papan lu-talawang.

Mananturong bau,n tiwing pandjang, manjahendeng liang tapian i-tingang.

Mangat mangahem papan bandong lasang, mangahem ambon barutas matei.

Mangat marimpar pandong panjandai bulan, marimpir palingis enon bapilo nihau.

I'gatang tarahendeng Sangiang huang papan talawang. I'lalu tundjong tarahingkat Djalajan medjen bulau dare, $n$ lintong.

Engkak bulau namburak, idjit supit teken i-garing.

Tolak papan talawang bara ninggang salanting parong. den Früchten der Pinang, fragen sie mit gedämpfter Stimme:

Und nachdem sie betäubt sind von den Früchten der Betelnusspalme, erkundigen sie sich mit freundlichem Worte:

Wie steht es nun mit dem zu verrichtenden Hülfswerk jetzt zu dieser Zeit?

Wie denkt ihr nun über die Sache des auf den Schoss nehmens jetzt in diesem Augenblick?

So denken wir über das Hülfswerk: wenden sollt ihr nun das Schildbrett.

Und begeben sollt ihr euch zum Steilufer, dem langen, und hinfahren sollt ihr nun zum Stein des Anlegeplatzes der Nashornvögel.

Damit ihr zum Kentern bringen könnt die Bandongboote, damit ihr im Wasser versinken lassen könnt die Wolken, die vernichtenden des Todes.

Damit ihr eben machen könnt (mit dem Wasserspiegel) die Haare der zirpenden Monde, damit ihr flach machen könnt (wie oben) die Tauwolken, die zerstörenden des Verlorenen.

Es erheben sich und stehen auf die Sangiang im Schildbrett.

Und sogleich stehen auf und erheben sich die Djalajan im goldenen geflochtenen Band.

Und sie lösen das goldene geflochtene Seil, und sie ziehen heraus den Stossbaum, den elfenbeinernen.

Und sie reisen weg mit dem Schildbrett vom Rande des Anlegeflosses unter der Dachtraufe über der Haustüre. 
Tintu hakalambat manintu Und sie steuern vorsichtig und sie karawang bau,n tiwing i- fahren in der Richtung des Zaunes am pandjang.

Bulau dare,n lintong njahendang liang panapian $\mathrm{i}$ tingang.

Tende batoros teken garing naharukan bulau namburak.

Njangkabila tatambat keket, halaloha djamban i-garing.

Manamuei lanting garing, ilumangadja bangkar sihong.

Djalan tamuei Sangiang nalampas bawi,n tingang, tatekai langkai,e. Steilufer, dem langen.

Das goldene geflochtene Band rudert zum Steine beim Anlegeplatz der Nashornvögel.

Und sie halten an und sie stecken den Stossbaum ein und sie binden an ihm fest das goldene geflochtene Seil.

Und sie machen fest das Seil, das vielgliederige, vom hinteren Ende des Bootes, und sie lassen herunter die elfenbeinerne Brücke.

Und sie begeben sich zum Anlegefloss, dem elfenbeinernen, und sie schreiten hin zum Halteplatz, dem hölzernen.

Der $Z$ weck der Reise der Sangiang ist : frei zu machen den weiblichen Tingang (d.h. die Witwe), auf- und niederhüpfen zu machen die gebogenen Schwanzfedern der Hähne (d.h. des Kopfschmuckes).

Akan tandohan rajong DjaUnd der Sinn des Besuches der Djalajan njampelau habinei tambon, kamaras tandok,e.

lajan ist: offen zu stellen (d.h. zu befreien von allem was sie noch umgibt) die weibliche Tambon, damit sie ihre Augen wieder geradeaus richten kann.

\section{c. Die Handlungen der Sangiang beim Fluss}

Toh upo,n balian malajan manandak ttg. katambong, baja upo mahapan karungut bewei metoh toh, koa,e:

I'gatang tarahendeng Sangiang huang papan talawang teras kaju djambu bahandang, bulau dare,n lintong luhing lumpok muntei bulau.
Der Hauptbalian hört nun auf mit Singen und es verstummen auch die kleinen Trommeln, nur der Hauptbalian singt nun wieder allein weiter und sein Spruchwort lautet:

Es erheben sich und stehen auf die Sangiang im Schildbrett, dem Kernholz des roten Djambubaumes, im goldenen geflochtenen Band, dem Pfahle des innersten Holzes des golde- 
Manetei djamban garing lalu batandjong lanting garing, haratean bangkar sihong.

Manjun bulau tampong papas, mangumban rabia tundon kalingking, mamukul elang salentup, mangahem papan bandong lasang, marimpar pandong panjandai bulan.

Akan pambelep mambelep palepah ambon barutas matei, mampalingis enon bapilo nihau.

Mamapui tunek njating, hajak nampulilang njalong awang kangumpang basial, gohong maing kanjambong bakawe.

Lila-lilang njalong kapandujan rawing basiak.

Lila-lilang njalong kapandujan taloh papa.

Kareh kalampangan njalong kapandujan Djata, amon djadi mangahem papan bandong lasang manaharep matanandau belom.

Hemben nduan hambekan katon Sangiang manandjuri njalong Djata, manantekei gohong Hatala, manandjuri njalong pandujan Sahor $\mathrm{Pa}$ rapah. nen Munteibaumes.

Und sie beschreiten die elfenbeinerne Brücke, und sie betreten das elfenbeinerne Anlegefloss, den hölzernen Halteplatz.

Und sie wiegen hin und her den goldenen Tross des Besens, und sie schwenken hin und her den goldenen Büschel des Besens, und sie schlagen mit den Bambusstöcken zum Knallen, und sie bringen zum Kentern die Bandongboote und sie machen eben (mit dem Wasserspiegel) die Haare der zirpenden Monde.

Um auszulöschen und auzublasen die Wolken, die vernichtenden des Todes, um restlos $\mathbf{z u}$ vertreiben die Tauwolken, die zerstörenden des Verlorenen.

Und sie verbrennen das feingestampfte Harz um auf die Seite zu stossen das Wasser, das von Unheil besessene, das Wasser, das kräftige, das von Unglück erfüllte.

Mache dich hinweg, Wasser in dem sich baden die wilden Krokodile.

Fliehe hinweg, Wasser in dem sich die schlechten Geister baden.

Und hernach wird zum Vorschein kommen das Wasser des Badens der Djata, dann wenn stattgefunden hat das Kentern der Bretter, der Bandongboote, in der Richtung der aufgehenden Sonne.

Aber jetzt zu dieser Zeit, und jetzt in diesem Angenblicke lassen die Sangiang hervorfliessen das Wasser der Djata, herausströmen das Wasser des Hatala, hervorsprudeln das Badewasser des Sahor Parapah. 


\section{d. Ranjing Mahatala Langit und Djata schenken neues Wasser}

Toh ewen manekap katambong ttg. manandak hapan lago,n karunja, koa,e:

I'lalu bahing ilu-bapanting Sangiang nandjuri pahu njalong Djata.

Dje hajak siring i-puna bambahinga Djalajan nantekei dje gohong lu-Hatala.

I'padjandjuri dje njalong laDjata dje lu-katontong tuah.

I'panantekei sapula gohong lu-Hatala awang Hatala kadjawan lu-balambit.

I'padjandjuri ikau njalong la-Djata hila tumbang danum.

I'panantekei ikau gohong luHatala ila-bahandjong dje tapudjakan gohong.

I'padjandjuri dje puna njalong la-Djata huang labeho i-hila hulu danum.

I'panantekei dje puna gohong ila-Hatala bahandjong rantau hila tandjong ringkin karangan.

I'padjandjuri dje puna njalong la-Djata bara tumbang danum are barabambai.

I'panantekei dje puna gohong ilu-Hatala bahandjong tapa-
Sie schlagen nun die kleinen Trommeln und singen nach der gewöhnlichen Melodie des Gesanges, und ihr Lied lautet:

Und alsobald werfen die Sangiang aus ihr Wort und sie lassen hervorfliessen das reife (d.h. das gute) Wasser der Djata.

Und die Djalajan lassen ausgehen den Schall ihres Wortes und sie lassen herausströmen das Wasser des Hatala. Sie lassen heraussprudeln das Wasser der Djata, welches verlängert das von ihr geschenkte Heil.

Und sie lassen herausfliessen das Wasser des Hatala, mit welchem Hatala vermehrt das von ihm gegebene Glück.

Fliesse nun hervor, du Wasser der Djata, von der Richtung der Mündung des Flusses.

Sprudle heraus, du Wasser des Hatala, und gehe hervor von der Mündung des Stromes.

Fliesse nun hervor, du wirkliches Wasser der Djata, aus der Wassertiefe im Quellgebiet des Flusses.

Sprudle heraus, du wirkliches Wasser des Hatala, und gehe hervor aus der Wassertiefe, die in der Richtung liegt wo die Wellen über die Steinbänke hüpfen.

Fliesse nun hervor, du wirkliches Wasser der Djata, aus den Mündungen der Flüsse, der zahlreich nebeneinanderliegenden.

Sprudle heraus, du wirkliches Wasser des Hatala, und gehe hervor von den 
djakan gohong dje are hataretei.

I'padjandjuri dje puna njalong la-Djata labeho udju dje puna bara latontong.

I'panantekei dje puna gohong ilu-Hatala bahandjong rantau dje hanja baratinggang.

Sama padjandjuri ikau njalong la-Djata, njalong Djata awang katontong lu-batuah.

Dje panantekei ikau gohong ilu-Hatala, dje maing, Hatala kadjawan lu-balambit.

I'padjandjuri ikau njalong kapandujan Djata ain Sahor Parapah Idjin mànggau mahaga.

I'panantekei i-gohong lu-Hatala dje ain Antang, ain Pampahilep Tandok.

Kareh kalampangan njalong Djata katontong batuah amon mangahem papan bandong lasang naharep pambelom andau.

Mangat entang dje sama hapandujan tau belom ilakanuah Djata.

Mangat tujang dje puna nampuena hatinggang Hatala kadjawan lu-balambit.

Toh salenga malik tekap ttg.
Mündungen der zahlreich aufeinanderfolgenden Ströme.

Fliesse nun hervor, du wirkliches Wasser der Djata, aus den sieben nebeneinanderliegenden Wassertiefen. Sprudle heraus, du wirkliches Wasser des Hatala, und gehe hervor aus den acht Wassertiefen, die sich dicht aufeinanderfolgen.

Und gemeinsam fliesset hervor, ihr Wasser der Djata, ihr Wasser der Djata, welche vermehren das durch sie geschenkte Heil.

Sprudelt heraus, ihr Wasser des Hatala, ihr kräftigen Wasser des Hatala, die da verlängern das von ihm gegebene Glück.

Fliesse hervor, du Wasser des Badens der Djata des Sahor Parapah Idjin, welcher beschirmt und beschützt.

Sprudelt hervor, ihr Wasser des Hatala, des Antang und des Pampahilep Tandok.

Und hernach werden aufsprudeln die Wasser der Djata, welche vermehren das von ihr geschenkte Glück, dann wenn man zum Kentern bringen wird die Bretter, die Bandongboote, in der Richtung des Lebens des Tages (der aufgehenden Sonne).

Damit die Getragenen, die gemeinsam baden, leben können, angerufen durch die Djata (die ihnen neues Leben und neues Heil schenkt).

Damit die Gewiegten sich setzen können ganz in die Nähe des Hatala, welcher ihnen verlängert das Glück. Nun verändert sich plötzlich das 
lago.

Lalu djadi dje hakatotok tandak,e manandjuri dje puna njalong Djata.

Hemben nduan dje lu-hambekan katon i-lila-lilang anggan badjai Mama Sawang Bungai.

Palus djalahan hewang Sangiang mamasang penjang garo rangkang.

Djari bandjang dje garing hatalumbang laut liang panapian tingang.

Sama djadi dje hakatotok tandak,e mangkepan bandjang garing, kareh ie bakarak habarasan biti,e amon djadi totok talatai pangentang.
Schlagen der kleinen Trommeln und es wechselt der Gesang.

$\mathrm{Zu}$ Ende ist nun der Gesang des Hervorsprudeln-lassens der Wasser der Djata.

Und jetzt in diesem Augenblicke, jetzt zu dieser Zeit legt ab das Oberkleid des Krokodiles, er der Mama Sawang Bungai. 412

Und sogleich legen die Angehörigen der Männer der Sangiang in Paare zusammen die wohlriechenden Penjang, die hölzernen.

Und sie verwandeln sich in elfenbeinerne Pfähle mit denen man die Flüsse absperrt und schliessen mit ihnen nun ab die Flusstelle ausserhalb des Steines am Anlegeplatz der Nashornvögel (d.h. sie schliessen ab die Stelle wo die Kenterung der Boote und das Untertauchen stattfinden soll). Und $z \mathfrak{u}$ Ende ist nun der Gesang des Aufrichtens der Pfähle, der elfenbeinernen, mit denen man die Flussstelle abschliesst, hernach werden sie wieder niedergerissen und eben gemacht, dann nämlich wenn beendet ist die Handlung des Hülfswerkes.

\section{e. Das Knallen mit den Bambusstöcken und die Abwischung mit dem Besen}

Toh ewen malajan helo manekap katambong ewen oloh balian.

Belahe manjalentup, belahe manjun papas, amon hapus dje manjalentup mamapas te salentup ttg. papas te indjakah akan danum mangana,e ttg. auch njalentup
Sie hören nun vorläufig auf die kleinen Trommeln zu schlagen, sie die Balian.

Einige von ihnen bringen nun die Bambusstöcke zum Knallen und andere schwingen den Besen, und wenn beendigt ist das Knallen und das Reinfegen, dann werden die Knallbambusstöcke und der Besen ins Wasser hin- 
mamapas te sama ih kilau helo.

Toh idje biti mamapas hapan puso,n pinang, koa,e: ausgeschleudert und fortgeworfen, und das Spruchwort das beim Knallen und beim Reinfegen gesungen wird ist das gleiche, das früher bereits mitgeteilt wurde. (Vgl. pag. $628 \mathrm{ff}$. und $632 \mathrm{ff}$. Die Texte werden hier nicht wiederholt.)

Einer der Balian fegt nun rein mit dem Blütentross der Pinangpalme, indem er dazu singt:

I'ajun-ajun bulau tampong papas puso,n pinang lewu, umba-umban rabia tundon kalalingking bumbong manggulau rundong.

Hapa mamapas mampalingis ambon barutas matei mangat entang batalampas kilau bulus kumpang malem, mangat tujang basampelau tingkah kaju,n sanggalang garing.

Toh puso,n pinang te inedjep ganto-gantong hundjun takolok oloh huang djukung hajak manandak, koa,e:

I'nantesangku ambon barutas matei, netesku enon bapilo nihau.

Mangat sama bageto paju,e kilau paju,n timpong, batetes
Ich schwinge den goldenen Tross des Besens von den Blütenknospen der Pinang des Dorfes, ich wiege den goldenen Büschel des Besens der miteinander vertraulich plaudernden Herzblätter der Betelnusspalme des Ortes (sie rauschen durch den Wind bewegt und dieses Rauschen wird als Plaudern angedeutet).

Um wegzufegen und zu vertreiben die Wolken, die vernichtenden des Todes, auf dass der Getragene wieder frei dastehe und hoch sich erhebe wie die grossen Bäume, damit der Gewiegte wieder offen dastehe wie der hohe Baum auf dem Sandhügel.

Die Blütenknospen der Pinangpalme werden nun mit einem Schlag durchschnitten ziemlich hoch über den Köpfen derer, die sich im Boote befinden, und die Balian singen dabei :

Ich durchschneide die Wolken, die vernichtenden des Todes, ich durchhaue die Tauwolken, die zerstörenden des Verlorenen.

Damit verrissen sei ihre Anziehungskraft, wie zerrissen ist die der Tücher, 
bambalia tingkah riak henda,n bulau. die niemand mehr kaufen will, damit zerschnitten sei das Verlangen um sie zu kaufen, wie das nach den Wellen der Gelbheit des Goldes.

\section{f. Die Kenterung der Boote in der Richtung nach Sonnenuntergang}

Toh djadi ie mamapas, palus upo manduan pakihu atawa rabajang atawa rando mamuno sara,n timbau bua-buah manenjek mangahem akan hila pambelep andau hajak karungut, kaa,e :

Ingahemku papan bandong lasang, marimparku pandong sandai bulan akan hila pambelep, mangahem mambelep mampalepah ambon barutas matei.

Toh ewen intu huang djukung omba maniling djukung te mangat bagulong kahem.

Ewen awang beken idje mondok lakau sara,n petak rata sewu akan danum hajak mampateser takolok,e.

Maka metoh ewen magon hong danum te upo,n balian mantadjok sahewan tamiang idje sadia apui intu lawi,e hajak ie manduan bango sarangan tunek njating idje halus, ie manduroh tunek nja-
Das Reinfegen ist nun beendigt und der Hauptbalian ergreift jetzt den Pakihu, oder den Rabajang, oder den Rando (heiliger Speer) und er sticht ihn in den oberen Rand der Bretter des Bootes ein und er bringt das Boot zum Kentern in der Richtung nach Sonnenuntergang, indem er dazu singt:

Ich bringe nun zum Kentern das Brett des Bandongbootes, ich mache eben (mit dem Wasserspiegel) die Haare der zirpenden Monde in der Richtung nach Sonnenuntergang, ich tauche nun unter, ich lösche aus und ich bringe gänzlich zum Verschwinden die Wolken, die vernichtenden des Todes.

Sie, die sich im Boot befinden, helfen durch hin- und herwiegen mit, das Boot in eine schräge Stellung $z \mathfrak{u}$ bringen, damit er rascher umschlägt.

Die andern aber, die sich am Flussufer gesetzt haben, erheben sich nun und sie alle zusammen springen num in das Wasser und tauchen ihre Köpfe unter.

Aber während sie sich noch im Wasser befinden streckt der Hauptbalian die Tamiangfackel aus welche an ihrer Spitze entzündet worden ist und er ergreift die Kokosschale, das Gefäss in dem sich das gestampfte Harz befindet, das sehr fein ist, und er streut 
ting te intu njalan apui idje dieses feingestampfte Harz in die aton intu lawi,n sahewan.

Flamme des Feuers an der Spitze der Fackel.

Maka metoh ie manduroh Während er das feingestampfte Harz tunek njating te ttg. metoh njala,n apui idje hai awi tunek njating, te ewen idje huang danum te maneser karana amon takolok ewen lampang puna tau bakeho awi njala,n apui te.

Maka metoh te upo,n balian kakarungut, koa,e :

I'njaherauku ambon barutas matei hapan tunek njating sahewan tamiang randau bulau hapa mampalingis kare ambon barutas matei, dahiang baja, nupi papa, kasingen kahiri, pali endus, uras bengkak handiai.

Maka amon hapus auch,e ie mambelep sahewan te hapan danum ttg. ie balaku buring sahewan te ttg. buring sahewan iupit,e hewoi dengan tepong behas idje djadi injadia huang pontong bua enjoh, djete ilekak,e handjulo hundjun batang. ausstreut und während die Flamme des Feuers hoch aufschlägt durch das feingestampfte Harz, tauchen die die sich im Wasser befinden unter, denn wenn ihre Köpfe sich über dem Wasser befinden würden, könnten sie Brandwunden erleiden durch die Flamme des Feuers.

Aber während dieser Handlung singt der Hauptbalian und sein Lied lautet:

Ich vertreibe die Wolken, die vernichtenden des Todes, mit dem feingestampften Harz und mit der Fackel von Tamiang Randau Bulau, um gänzlich aufzuheben die Wolken, die vernichtenden des Todes, die Vorzeichen und Omina, die schlechten Träume, die Schaden zufügenden Zauber und die Feindschaft, die Pali und die Verbote, sie alle zusammen seien nun weggenommen.

Wenn er dieses sein Spruchwort beendet hat, dann löscht er die Fackel mit Wasser aus und er nimmt ein wenig von den Holzkohlen der Fackel und er zerstösst die verkohlten Fackelstücke und vermengt sie mit dem Reismehl welches sich am Ende der Kokosnuss befindet, und er legt alles für einen Augenblick nieder auf das Anlegefloss.

\section{g. Die Kenterung der Boote in der Richtung nach Sonnenaufgang}

Maka amon djadi djete, limbah ewen djadi manimba
Wenn das beendet ist, und wenn die Leute, die soeben untertauchten, das 
djukung te ewen haluli tinai lompat djukung te.

Amon djadi mondok kilau helo ie mangahem tumon helo kea, tapi sinde toh ewen manaharep akan hila matanandau belom.

Upo mangarungut, koa,e:

I'ngahemku papan bandong lasang, marimparku pandong panjandai bulan akan hila matanandau belom, katundjong lumpong matanandau belom, katundjong aseng entang, katarik luhing kanur hawon, katarik njama,n tujang, mangat hapandujan nialong Djata, awang Djata katontong batuah.

Toh ie palus manenjek timbau djukung te hajak ewen huang,e maniling mangahem djukung kea.

Toh ewen uras huang danum ttg. hundjun petak sahewu sama uras radjin mandoi danum idje batuah te.
Wasser wieder aus dem Boot ausgeschöpft haben, dann besteigen sie wiederum das Boot.

Und nachdem sie sich wiederum gesetzt haben, so wie sie früher sassen, bringt der Hauptbalian das Boot wiederum auf die gleiche Weise zum Kentern, so wie er es bereits vorher tat, aber diesmal in der Richtung der aufgehenden Sonne.

Der Hauptbalian singt und sein Lied lautet:

Ich bringe zum Kentern das Brett des Bandongbootes, ich mache eben die Haare der zirpenden Monde in der Richtung des auflebenden Tages, und so wie sich erhebt die Rundheit der Sonne, der lebenden, so soll sich auch erheben der Atem der Getragenen, und so wie aufsteigt die Wärme, die Hitze der Wolken (das Flimmern der Wärme beim höchsten Stande der Sonne), so soll auch aufsteigen der Atem der Gewiegten, damit sie gebadet werden mögen in dem Wasser der Djata, der Djata welche vermehrt das von ihr geschenkte Heil.

Er drückt nun mit dem heiligen Speer hernieder den oberen Rand der Bretter des Bootes, und sie, die sich im Boote befinden, bringen es in eine schräge Haltung und helfen mit, dass es rascher kentert.

Sie alle nun, die sich im Wasser befinden (im Boot), und sie, die am Ufer sind, springen nun in das Wasser und sie freuen sich alle $\mathrm{zu}$ baden in Wasser welches mit Heil erfüllt ist. 
Maka metoh ewen magon huang danum te upo,n balian mambisa isi,n rando huang danum, ie mahantis danum te intu gene-genep takolok ewen idje huang danum.

Ewen uras manokep ie.

Ie mahantis danum intu genep takolok ewen hapan isi,n rabajang atawa rando hajak kakarungut, koa,e :

I'nantesangku njalong Djata, gohong Hatala badjamba ranjing pandereh buno, hatatean renteng nanggalong bulau.

Maka amon rata biti,n ewen iawi,e tumon te, te ewen manimba djukung ttg. uras lompat manangkiri pakajan, balo kea manangkiri pakaja,e, tapi magon hapan benang baputi, djaton tau idje habintik bahandang, karana awi hindai kangkahem salawi,n tiwah.

Während sie sich immer noch im Wasser befinden, benetzt der Hauptbalian die eiserne Spitze des heiligen Speeres mit Wasser und er lässt das Wasser, der Reihe nach, auf alle Köpfe tröpfeln, derer, die sich noch im Wasser befinden.

Sie alle nähern sich ihm.

Von der Spitze des heiligen Speeres lässt er nun, der Reihe nach, das Wasser auf alle Köpfe tröpfeln und er singt dazu und sein Gesang lautet:

Ich besprenge euch mit dem Wasser der Djata und mit dem Wasser des Hatala, und ich gebrauche dazu diesen heiligen Speer, ich verwende dafür diese Schwanzfeder (Speer), die das Gold umschliesst.

Aber wenn an allen Personen auf diese Weise gehandelt worden ist, dann schöpfen sie wieder das Wasser aus dem Boot heraus und dann steigen sie ins Haus hinauf und wechseln ihre Kleider (sie sind neue Menschen geworden und bekleiden sich deshalb mit neuen Kleidern), auch die Witwe wechselt ihre Kleider, aber sie benützt dazı immer noch weisses Tuch, denn sie darf noch keine gestreiften oder roten Kleider tragen, weil noch nicht stattgefunden hat die Kenterung der Boote am Ende des Tiwah.

\section{Die Rückkehr der Seelen der Getragenen}

Maka amon ewen uras djadi sadia hapan pakajan idje keang te ewen manunggo intu karatak.
Wenn sie nun alle trockene Kleider angezogen haben, dann warten sie auf dem freien Platz zwischen den Häusern und dem Fluss. 
Maka metoh te ewen oloh balian nampara manekap katambong ttg. manandak intu sara,n danum hajak manaharep pasok hambaruan.

Toh ewen manekap katambong ttg. manandak, koa,e:

I'ohoi bara ohoi, maliambong ambon barutas matei, i'ehei bara ehei, manantiup enon bapilo nihau, malan manjalumbo ambon tilap telo puluh, mangadja luwok enon lime balas hatalamping.

Tandak tari,e djangkau-djarang maliambong ambon barutas matei.

Timang tahitik djantau-djahai manantiup enon bapilo nihau.

I'lenjoh hatanggalong ambon barutas matei kabantengan tasik Lajang Hanteran Riwut.

I'lentar hagagumpa enon bapilo nihau huang laut Ahoi Manggagahan Salatan.

Toh hobah tekap ttg. lago,n Nun ändert sich der Schlag der kleinen

Inzwischen beginnen nun die Balian die kleinen Trommeln zu schlagen und sie beginnen auch $z u$ singen und sie nähern sich dem Körblein mit den Seelen (d.h. dem Körblein in dem sich in einen Fetzen eingewickelt Reiskörner befinden in die die Seelen zurückkehren).

Sie schlagen nun die kleinen Trommeln und sie singen, und ihr Gesang lautet:

Ohoi und noch einmal ohoi, in die Höhe gestiegen sind nun die Wolken, die vernichtenden des Todes, ehei und noch einmal ehei, in die Höhe gehoben sind die Tauwolken, die zerstörenden des Verlorenen, sie haben sich aufgemacht um aufzusteigen die Wolkenlagen, die dreiunddreissig, sie haben sich aufwärts begeben auf den Buchtungen der Tauwolken, der zweimal fünfzehn übereinanderliegenden.

Und das Lied schwebt aufwärts und es drängt zusammen und hebt auf die Wolken, die vernichtenden des Todes. Und das Spruchwort ballt zusammen und hebt in die Höhe die Tauwolken, die zerstörenden des Verlorenen.

Und aufgelöst und in Ballen aufgehäuft sind die Wolken, die vernichtenden des Todes, und sie befinden sich schon in der Mitte des Meeres Lajang Hanteran Riwut.

Und geborsten und in aufgedunsenem Zustande befinden sich die Tauwolken, die zerstörenden des Verlorenen, oben in der See Ahoi Manggagahan Salatan. 
tandak,e, ewen uras manandak kea, koa,e :

I'lu-Sangiang manambang entang bara lewu mandereh danum.

I'lu-Sangiang manambang entang bara telok tasik Sampang Haringan.

Sangiang manambang salumpok entang bara desa,n Bawin Djata Balawang Bulau.

Baratus gangguaran ara,e rajat, baribu sasabutan biti,e.

Djari udju salumpok entang taratambang djari,n Sangiang.

Hanja pananterus tujang taratakep kareh bungai Djalajan.

Nampong,e salumpok entang kilau bua sanggalang garing.

Manundon tanterus tujang tingkah lu-langadjah tarong,e.

Buli bakandong njalong kaharingan belom, basangkulem gohong kapaninting tahaseng. Hajak djari hakatotok tan-
Trommeln und es wechselt die Melodie des Gesanges und sie alle zusammen singen nun, und ihr Lied lautet:

Und die Sangiang holen nun zurück die Getragenen aus den Dörfern die längs den Flüssen liegen.

Und die Sangiang holen ab die Getragenen von der Buchtung des Meeres Sampang Haringan (Weg des Lebens, wahrscheinlich ist damit der Badeplatz gemeint, wo die Kenterung der Boote stattgefunden hat).

Und die Sangiang holen zurück die Seelen der Getragenen von den Untertanen der Bawin Djata Balawang Bulau (die weibliche Djata mit der goldenen Türe).

Hunderte von Bezeichnungen und Namen tragen ihre Untertanen, tausende von Benennungen ihre Diener.

Sieben Seelen der Getragenen sind es die zurückgeholt wurden von den Fingern der Sangiang.

Acht Seelen der Gewiegten sind es die aufgepackt haben die Hände der Nashornvögel der Djalajan.

Und sie bündeln die Seelen der Getragenen, so wie man bündelt die Früchte der Bäume (die man an den Zweigen, zu einem Bündel vereinigt, nach Hause trägt).

Und sie büscheln in Trossen die Seelen der Gewiegten, so wie man büschelt die Fruchtzweiglein der Bäume.

Und sie kehren zurück, zusammen mit dem Wasser des Lebens, begleitet von dem Wasser, dem Reiniger des Atems. Und beendet ist nun das Lied der 
dak,e mangahem papan bandong lasang.

Djari sambon lalu-karunja marimpar pandong panjandai bulan.

Palus hewang lalu-Sangiang halalian salumpok entang buli.

Panungkup rajong lalu-Djalajan mangagahan tanterus tujang mulang.

Manjelem pasok panangkiling Njaring, bahalap dare,n djumban bahandang.

Udja-udjan salumpok entang manjelem behas mintih bangkusan timpong.

Sama djadi katotok tandak,e halalian salumpok entang buli, manjelem pasok panangkiling Njaring.

Mangitar papan lalu-talawang bara karawang bau,n tiwing pandjang.

Mampamules bulau dare, $n$ lalintong bara liang panupian Tingang.

Mananturong parong lalumangentang, manjahendeng siro saripangku.

Tende papan lalu-talawang, tende ninggang panjalanting parong.
Kenterung des Brettes, des Bandongbootes.

Und abgeschlossen ist nun der Gesang des Ebenmachens der Haare der zirpenden Monde.

Und sogleich geben zurück die Männer, die Sangiang, die Seelen der Getragenen, die wieder umgekehrt sind. Und die Gemeinschaft der Jünglinge der Djalajan führt herbei die Seelen der Gewiegten, die wieder heimgekehrt sind.

Und sie schütten sie hinein in das Körblein, das einem Njaring gleich sieht, in den schönen geflochtenen Korb, den roten.

Und wie rieselnder Regen fallen hinein die Seelen der Getragenen in den Reis, den ausgewählten, der sich in den Bündelchen von Tuch befindet.

$\mathrm{Zu}$ Ende ist nun das Lied der Rückkehr der Seelen der Getragenen, die da heimgekehrt und eingegangen sind in das Körblein das einem Njaring gleicht.

Und sie drehen nun weg das Schildbrett vom Zaune am Ufer des Flusses, dem langen.

Sie wenden das goldene geflochtene Band vom Steine, dem Anlegeplatz der Nashornvögel.

Und sie wenden es nach dem Hause, in dem verrichtet wird das Hülfswerk, und sie drehen es nach der Wohnung, in der vollzogen wird das auf den Schoss nehmen.

Halte an, Schildbrett, und beende nun deine Fahrt dicht beim Anlegeplatz über der Türe, dem Eingang zum Haus. 
Tahan bulau la-dare,n lintong, tahan manandai siro saripangku.

Batoros la-teken garing, tahan naharukan bulau namburak.

Njangkabila tatambat keket, i'halaloha la-djamban garing.

Namuei balai rampar buno, mangadja sali tilap lu-talawang.

Sama rawing hapantar lapinang, Sangiang malajan tolang rumpang.

Djalajan hataradjo manjang, rata maleleng uhat leso.

Lalu sambang la-malik bahing manampong salumpok entang buli.

Luhing mules la-bambahinga manundun tanterus tujang mulang.

Toh palus upo,n balian hamauch, koa,e :

Kuruk! hambaruan ewen buli uras bara ambon barutas matei, bara desa,n Bawin Djata Balawang Bulau, bara dahiang baja, bara taloh papa handiai.
Stehe still, goldenes geflochtenes Band, und beende deine Reise dicht beim Hause, in dem man vollzieht das auf den Schoss nehmen.

Stecket ein den Stossbaum, den elfenbeinernen, und machet an ihm fest das goldene geflochtene Seil.

Verknüpfet das Seil, das vielgliederige, vom hinteren Ende des Bootes, lasset herunter die Brücke, die elfenbeinerne. Begebet euch zum Balai der nebeneinanderliegenden Lanzen, betretet das Haus der aufeinandergeschichteten Schilde.

Und gemeinsam kauen die Krokodile Pinang, und die Sangiang ruhen aus ihre ermüdeten Knochen.

Und die Djalajan kauen Betelnüsse und sie alle erholen sich von den erschlafften Muskeln.

Und die Trommeln ändern ihren Laut des Büschelns der Seelen der Getragenen, der zurückgekehrten.

Und die Trommeln wechseln ihren Schall des in Trossen Bindens der Seelen der Gewiegten, der wieder heimgekommenen.

Und nun spricht der Hauptbalian, und sein Wort lautet:

Kuruk! kehret wieder zurück, alle ihr Seelen, von den Wolken, den vernichtenden des Todes, von den Untertanen der Bawin Djata Balawang Bulau, von den Vorzeichen und Omina, und von allen schlechten Geistern zusammen. 


\section{E. Auf die Brust wird mit Mehl ein Kreuz gezeichnet}

Toh ewen oloh balian mohos tunek tepong idje hewoi dengan buring sahewan tamiang, iohos tjatjak burong intu usok kare ewen idje mondok manunggo intu karatak.

Hajak kakarungut, koa,e :

I'nantemangku djulen tepong hasambalut buring sahewan tamiang randau bulau, hasambalut darah manok darong tingang, mananteman njalong kaharingan belom, gohong kapaninting tahaseng.

Hajak bulau ontong pandjang, humboh rabia njame ambo.

Karana tepong te nah iewoi dengan daha,n anak manok idje korik haliai, anak manok te rapak intu njama,e hapan mampatei ttg. mampalua daha,e palus iewoi dengan tunek tepong te nah.

Maka hantu,n manok korik te palus indjakah ingana,e.
Die Balian bestreichen nun mit dem Mehl, das vermischt ist mit der gestampften Holzkohle der Tamiangfackel, die Brust aller derer die sich wartend gesetzt haben auf dem Platz zwischen Fluss und Haus und sie zeichnen damit ein Kreuz auf die Brust.

Und sie singen dazu und ihr Lied lautet:

Ich bestreiche dich mit der Weissheit des Mehles, die da vermengt ist mit den Holzkohlen der Fackel von Tamiang Randau Bulau, das vermischt ist mit dem Blute des Huhnes, des Huhnes Tingang, ich bestreiche dich mit dem Wasser des Lebens, dem lebenschaffenden, mit dem Wasser, dem Reiniger des Atems.

Zusammen mit dem Golde des langanhaltenden Glückes, gemeinsam mit dem Golde des langdauernden Atems.

Denn das Mehl wurde auch vermischt mit dem Blute eines jungen Huhnes das noch sehr klein war, dieses junge Huhn wurde mit dem Munde zerrissen (von einem der Balian) um es zu töten und um das Blut herausfliessen zu lassen, das dann mit dem Mehle vermischt wurde.

Die Leiche dieses jungen Huhnes wurde sogleich weggeworfen.

\section{F. Ausgiessung von Oel über den Köpfen und Kämmung}

Maka amon djadi djete, te Wenn das stattgefunden hat, dann oloh balian manitis undus giessen die Balian Oel aus auf den hundjun takolok gagenep Kopf eines jeden einzelnen der Leute ewen ttg. manjarak ma- und sie kämmen mit einem weiten und 
njundur balau gagenep takolok ewen, hajak kakarungut, koa,e :

I'nantisangku bangkang hanselan tingang, runting padjahun burong, minjak uring katilambong njaho idje belom ganto-gantong akan indu tihang lewu pulu, haring tujatujang rajar rundong djalatien, hatampulu nambeleng bulan bawi,n riwut dia santah dawe,e, hangkahanja namputer habinei salatan dia sundong bumbong,e.

Hapaku manjalangkah pandong lawi,n balau pandjang, manandjaho salabian bagundai ambo, mangat aku nanteman sarak tamba tolang tingang, sundur barawar tambon.

Manjarak mampalingis panganduang ambon barutas matei, manjarak mampalingis sial kawe, manjarak mampalingis pali endus ,manjarak mampalingis peres badi, haban kapehe. einem engen Kamm die Haare auf dem Kopf aller Verwandten, indem sie dazu singen :

Ich giesse aus über dir das wirkliche Oel des Tingang, das Oel des Vogels, das Oel der Frucht der Kokospalme, der donnernden, welche aufsteigt in die Höhe wie ein Flaggenstock (Wahrzeichen) der zehn Dörfer, welche sich wiegt wie ein Mast in den Dörfern, den neunen - wie oft doch ist er schon angefallen worden von den Monden, den Frauen des Windes, und nicht beugten sich seine Herzblätter, wie manchmal schon wurde er angepackt von den Frauen des Sturmes, aber nie beugten sich seine zarten Blütenknospen.

Um nach zwei Seiten auseinander zu kämmen die Haare, die Enden der Haare, der langen, um mit Oel einzureiben die Haare, die langen, damit ich mit ihm bestreiche den weiten Kamm von den Knochen des Nashornvogels, den engen Kamm von den Rippen der Wasserschlange.

Um restlos wegzukämmen die Unheilsursachen der Wolken, der vernichtenden des Todes, um restlos wegzukämmen das Unheil und das Unglück, um restlos wegzukämmen die Pali und die Verbote, um restlos wegzukämmen die Krankheiten, die hitzigen, die Leiden und die Schmerzen.

\section{G. Ueber einem Huhn zeird Oel ausgegossen und darnach wird es gekämmt}

Toh djadi manjarak balau Beendet ist nun das Kämmen ihrer ewen te. Haare. 
Toh upo,n balian manduan manok pehok idje djari inatap akan gawi te, palus ie manitis undus ttg. manjundur manjarak likut manok te, hajak ie mangarungut, koa,e :

I'natisangku bangkang hanselan tingang hajak nantemangku sarak tamba tolang tingang, sundur barawar tambon, manjalangkah tundu lawi,n balau,m, marasih salabia,n bagundai ambo hajak indahku gangguaran ara,m, isatku sasabutan biti,m.
Der Hauptbalian nimmt nun eine Henne, die bereit gemacht worden ist für diese Handlung die er nun auszuführen hat, und er giesst über ihr Oel aus und kämmt ihren Rücken mit einem engen und einem weiten Kamm, indem er dazu singt:

Ich giesse aus über dir das wirkliche Oel des Tingang und ich bestreiche mit ihm auch den weiten Kamm von den Knochen des Nashornvogels und den engen Kamm von den Rippen der Wasserschlange, ich kämme damit die Bündel der Enden deiner Haare, ich bringe mit ihnen in Ordnung die Enden deiner langen Haare, und ich verändere deinen Namen, deine $\mathrm{Be}$ zeichnung, ich wechsle deine Benennung.

Er, der Hauptbalian ändert nun den Namen des Huhnes, übereinstimmend mit dem Uebernamen des Hauptbalian, denn jeder Hauptbalian hat einen Uebernamen mit welchem er durch alle andern Balian angesprochen und genannt wird, es ist der Name der Seele seines Armringes (mit Armring ist hier wahrscheinlich der Körper gemeint in den der Sangiang einfähnt, den er anzieht wie man einen Ring anzieht), zum Beispiel: wenn sein rechter Name A. ist, dann ist der Name seines Armringes, der den Sangiang bekannt ist, dann, wenn er als Hauptbalian auftreten kann, z.B. Bapa Lambong (Vater des Lambong), und es geziemt sich nun, dass er den Namen des Huhnes verändert in Indu 
Djaka gana,n lujang,e Bapa Mating, te ie patut mobah ara,n manok te: Indu Mating.

Matja-matjam kare ara,n gana,n lujang oloh balian.

Djaka upo,n balian te oloh bawi, amon ara,n gana,n lujang,e: Indu Lambong, te patut oloh manatap manok djagau ttg. ie patut mobah ara,n djagau te: Bapa Lambong.

Maka paribasa enah djari iobah ara,n manok te: Indu Lambong, toh ie manetek ikoh manok te hapan pisau hajak kakarungut koa,e :

I'natekangku pandong lawi,n balau,m pandjang, marasku salabian bagundai, $m$ ambo, njewutku gangguaran ara,m: Indu Lambong.

Natekangku kea ambon barutas matei, enon bapilo nihau.

Eweh manjewut gangguaran ara,m manok darong tingang, punei rungkoi ambon te, mimbul tewo saloh djadi taberau bungai, mimbul pisang bulau, basaloh djadi pisang awai.413
Lambong (Mutter des Lambong).

Heisst die Seele seines Armringes aber z.B. Bapa Mating, dann muss er den Namen des Huhnes verändern in Indu Mating.

Sehr verschieden und zahlreich sind die Namen der Armringe der Balian. Wenn der Hauptbalian aber eine Frau ist und wenn der Name der Seele ihres Armringes lautet: Indu Lambong, dann geziemt es sich, dass die Leute einen Hahn für diese Handlung bereit machen und dass sie den Namen des Hahnes ändern in: Bapa Lambong. Wenn aber zum Beispiel der Name des Huhnes abgeändert worden ist in Indu Lambong, dann ergreift der Hauptbalian ein Buschmesser und schlägt ihm die Schwanzfedern ab, und er singt dazu:

Ich schlage ab den Büschel der Enden deiner Haare, der langen, ich schneide weg die Enden der Haare, der langen, ich nenne dich mit der Bezeichnung und deinem Namen: Indu Lambong. Ich schneide auch durch die Wolken, die vernichtenden des Todes, die Tauwolken, die zerstörenden des Verlorenen.

Wer auch immer deinen Namen, deine Benennung aussprechen wird, du Huhn, du Huhn der Tingang, du Hahn, du Hahn der Wolken, der vernichtenden des Todes, der wird Zukkerrohr pflanzen, aber es wird sich verwandeln in Taberau Bungai (ein Schilfgewächs, das dem Zuckerrohr sehr ähnlich ist aber keinen Wert hat), der wird Goldbananen pflanzen, aber 
sie werden sich verwandeln in Pisang Awai (die ebenfalls ungeniessbar sind. Er kann also vornehmen was er will, nichts wird ihm mehr gelingen).

H. Das Streuen von Reis auf die Köpfe und das Aufpicken des Reises durch das gekämmte Huhn

Toh idje biti bara oloh balian panombah mambowor behas gene-genep hundjun takolok kare ewen idje mondok intu karatak.

Ie mambowor behas te sunisuni ih.

Toh upo,n balian mimbit manok idje imbing endau manaharep takolok gene-genep ewen mangat manok te manotok-manotok behas isu-isut bara gagenep takolok ewen hajak kakarungut, koa,e :

Ikau Indu Lambong manatokan ambon barutas matei, manotok mampalingis enon bapilo nihau, dahiang baja, natokan sial kawe, natokan peres badi.

Toh djadi kalote.
Einer der Balian, nämlich ein Beantworter (ein Hülfsbalian), streut nun enthülsten Reis auf die Köpfe aller derer welche auf dem Platze zwischen Haus und Fluss sitzen.

Er streut den enthülsten Reis nur stillschweigend aus.

Der Hauptbalian kommt nun mit dem Huhn, das er soeben in seinen Händen hielt und nähert sich mit ihm dem Kopf eines jeden einzelnen, damit das Huhn ein klein wenig Reis aufpicke von jedem Kopf, und er singt dazu und sein Lied lautet:

Du, o Indu Lambong, sollst aufpicken die Wolken, die vernichtenden des Todes, du sollst aufpicken und vollständig zum Verschwinden bringen die Tauwolken, die zerstörenden des Verlorenen, die Vorzeichen und Omina, du sollst aufpicken das Unheil und Unglück, du sollst aufpicken die Krankheiten und das hitzige Fieber.

$\mathrm{Zu}$ Ende ist nun diese Handlung.

\section{Die Reinigung der Verwandten mit dem gekämmten Huhn}

\section{a. In der Richtung nach Sonnenuntergang}

Ewen oloh are uras injoho Alle Leute erhalten nun den Auftrag mondok manaharep hila sich in der Richtung nach Sonnen- 
pambelep.

Maka amon uras mondok akan hila pambelep te upo,n balian manjun manok te nah huang ambo takolok balo ttg. ewen handiai, hajak kakarungut, koa,e :

I'mapasku manaharep hila pambelep, mampelep mampalepah rutas kapali, dahiang baja, taloh papa handiai. untergang zu setzen.

Nachdem sich nun alle gesetzt haben in der Richtung nach Sonnenuntergang, dann schwingt der Hauptbalian das soeben genannte Huhn über dem Kopf der Witwe und den Köpfen aller andern Leute und er singt dazu:

Ich wische euch ab, mich wendend nach der Richtung des Auslöschens des Tages, auslöschen und gänzlich verschwinden sollen nun die Rutas und die Pali, die Vorzeichen und Omina und alle bösen Geister.

\section{b. In der Richtung nach flussabrërts}

Toh ewen handiai mondok manaharep hila ngawa, amon ewen uras djadi naharep hila ngawa te upo manjun manok te tinai hajak kakarungut, koa,e :

I'mapasku manaharep hila ngawa, balawa ambon paduran tahaseng entang bakawan, sama hatontong kanuah anak Djata lampang, hatinggang kanjambong busu,n Hatala hadurut.
Nun setzen sich alle in der Richtung nach flussabwärts, und wenn sie sich gesetzt haben in der Richtung nach flussabwärts, dann schwingt der Hauptbalian wiederum das Huhn über ihren Köpfen und singt :

Ich wische euch $a b$, mich wendend nach der Richtung von flussabwärts, hell sollen nun werden die Wolkenlagen der Wege des Atems der in Scharen versammelten Getragenen, vermehrt soll nun werden das Angerufenwerden durch das auftauchende Kind der Djata, möglich soll nun wieder sein das Aufgerufenwerden durch den herabfahrenden Jüngsten des Hatala.

\section{c. In der Richtung nach flussaufwärts}

Toh ewen injoho naharep Es wird ihnen nun befohlen sich in hila ngadju, maka amon uras der Richtung nach flussaufwärts zu ewen djadi manaharep akan setzen, und wenn sich alle gesetzt 
hila ngadju, te upo manjun haben in der Richtung nach flussaufmanok hajak kakarungut, wärts, dann schwingt der Hauptbalian koa,e : wiederum das Huhn über ihren Köpfen und singt dazu:

I'mapasku manaharep hila Ich wische euch ab, mich wendend ngadju, ladju tarong keton nach der Richtung von flussaufwärts, lampang babalang hatontong rasch steige nun auf und erscheine kanuah anak Djata lampang, wiederum euer Ruhm, begleitet von hatinggang kanjambong bu- dem Angerufenwerden durch das Kind su,n Hatala hadurut.

der Djata, das aufsteigende, zusammen mit dem Aufgefordertwerden durch den Jüngsten des Hatala, den herabfahrenden.

\section{d. In der Richtung nach Sonnenaufgang}

Toh ewen injoho mondok Es wird ihnen nun befohlen sich in manaharep akan hila pambelom andau, maka amon uras djadi manaharep pambelom andau te upo manjun manok te hajak kakarungut, koa,e : der Richtung nach Sonnenaufgang $z \mathfrak{u}$ setzen, und wenn sich alle gesetzt haben in der Richtung nach Somnenaufgang, dann schwingt der Hauptbalian wiederum das Huhn über ihren Köpfen und singt dazu :

I'mapasku manaharep matanandau belom, katundjong lumpong matanandau belom, katundjong tahaseng entang bakawan belom bahaseng pandjang mandepe langit, haring banjame ambo manggawang hawon.

Ich wische euch ab, mich nun wendend nach der Richtung der aufgehenden Sonne, so wie sich erheben die Ränder der auflebenden Sonne, so soll sich auch erheben der Atem der in Scharen versanmelten Getragenen, damit sie einen Atem haben, dessen Länge bis an die Wolken reicht, damit sie einen Mund (Atem) besitzen, der hinaufgreift bis zum Himmel.

\section{e. Das Huhn wird in der Richtung der aufgehenden Sonne weggeworfen}

Toh ewen uras mendeng, Nun erheben sich alle und der Hauptupo,n balian mandjakah ma- balian schleudert weg und lässt fort- 
narawang manok te manaharep matanandau belom hajak hamauch, koa,e:

Katundjong lumpong matanandau belom, katundjong tahaseng keton entang, katarik luhing kanur hawon, katarik njama,n tujang haring. fliegen das Huhn in der Richtung der aufgehenden Sonne, und er singt dazu :

So wie sich erheben die Ränder der Sonne, der lebenden, so soll sich auch erheben der Atem der Getragenen, so wie aufsteigt die Wärme und Hitze am Himmel, so soll aufsteigen der Mund (Atem) der Gewiegten, der lebenden.

\section{K. Die Seelen werden ihren Besitzern wieder zurückgegeben}

\section{a. Die Verwandten des Toten begeben sich ins Haus}

Toh ewen oloh are handiai uras lepah buli akan huma, belahe mimbit kare pasok hambaruan, uras ewen handiai injoho helo akan huma.

Amon ewen uras aton huang huma, te ewen oloh balian manandjong akan huma, metoh ewen oloh balian magon intu petak upo,n tangga, te upo mantehau, koa,e:

Eleh ewen nah, eleh ewen nah, eleh ewen nah?

Te ewen huang huma tombah, koa,e :

Usang-usang ikei djari helo!

Te upo hamauch, kota-kotak:
Alle Leute zusammen kehren nun ins Haus zurück, einige bringen das Körblein der Seelen (in dem sich der Seelenreis, gewickelt in Tuchfetzen, befindet) mit sich, aber allen wird befohlen, dass sie nun ins Haus zurückkehren sollen.

Wenn sie sich alle im Hause befinden, dann begeben sich die Balian auch zum Hause, während sich aber die Balian immer noch auf der Erde, am Fuss der Haustreppe, befinden, ruft der Hauptbalian und spricht:

Sind die von soeben angekommen, sind die von soeben angekommen, sind die von soeben angekommen? (Die Leute, die vor ihnen das Haus betreten haben.)

Und nun antworten sie, die sich im Hause befinden:

Schon eine ganze Weile ist es her seit wir ins Haus zurückgekehrt sind!

Der Hauptbalian spricht nun die Worte aus: 
Buli ewen tatau sanang, ureh Zurückgekehrt sind sie und sie sollen ngalawan, dia haban pehe, Frieden haben und fröhlich sein, nicht dia balasut badarem. sollen sie mehr angefallen werden von Krankheiten und Leiden und von hitzigem Fieber.

\section{b. Der Seelenreis wird mit Oel bestrichen und die Seelen werden in den Körper zurückgebracht.}

Toh ewen oloh balian uras aton kempeleng intu huma, ewen mukei behas hambaruan, mundus,e, mingkes,e huang mangkok korik, ewen oloh are uras mondok bentok huma, toh oloh balian mambowor behas mambuli hambaruan, koa,e :

I'buli entang, buli hambaruan, lompat batu djundjong karapuron, djakat liang pariok njama,m, lompat batu ganggelem ontong, $m$, djakat liang pariok sangkurama,m ambo, buli bakandong njalong kaharingan belom, humba gohong kapaninting tahaseng.
Die Balian sind nun alle versammelt im Haus, sie öffnen die Bündel die den Seelenreis enthalten, sie bestreichen ihn mit Oel und legen ihn dann in ein kleines Gefäss, die Leute setzen sich alle in der Mitte des Hauses auf den Fussboden und die Balian streuen nun den Reis aus um die Seelen zurückkehren $z \mathfrak{u}$ lassen, indem sie sprechen :

Kehret zurück, ihr Getragenen, kehret zurück, ihr Seelen, besteiget den Stein, der sich über der Fontanelle erhebt, erklimmet den Stein, den Mörser des Mundes (des Atems), besteiget das steinerne Gefäss des Glückes, erklimmet den steinernen Mörser des lange dauernden Heiles, kehret zurück, begleitet von dem Wasser des Lebens, dem lebenschaffenden, zusammen mit dem Wasser, dem Reiniger des Atems.

\section{c. Die Berührung der Köpfe mit dem Schnitzbild}

Toh belahe mahantok hampatong palawi, koa,e:

I'hantok ikau bunge,n hampatong mina-merang palawi
Einige der Balian berühren nun mit dem menschlichen Schnitzbild von Palawiholz die Köpfe der Leute, indem sie sprechen:

Ich berühre mit dir, du Sawang des menschlichen Schnitzbildes vom klap- 
akan djamban salumpok pernden Palawiholz (Sawang bedeutet: entang gandang halalian buli, in dem das Leben ist, klappernd: der indu tatean tanterus tujang garantong kamalesan mulang.

Buli bakandong bulau ontong pandjang, mulang basangkulem rabia njame ambo. lebt), dass du dienst als Steg für die Seelen der Getragenen, die zurückkehren wie der Schall der Trommel, dass du gebraucht wirst als Brücke für die Seelen der Gewiegten, die wieder heimkehren wie der Laut der Gong.

Die da zurückkehren begleitet von dem Golde des langdauernden Heiles, die da heimkommen zusammen mit dem goldenen Mund (Atem), dem grossen.

\section{d. Die Handgelenke werden mit Bändern von Glasperlen umbunden}

Toh balian mameteng manas intu lenge,n balo, koa,e:

I'naharukangku manas sambelom pero,n tambon, manas tasak lentup njaho, omba roho-rohong kakupeh bawi petak sila, kakusok habinei tanah Djawa akan djamban salumpok entang gandang halalian buli, indu tatean tanterus tujang garantong kamalesan mulang homba sapunggut belom, sapamaling tahaseng.

Toh djadi mameteng manas.
Die Handgelenke der Witwe werden nun von den Balian mit Glasperlen umbunden, indem sie sagen:

Ich umbinde dir die Perlen, die länglichen Glasperlen aus der Gallenblase der Wasserschlange, die Perlen Tasak Lentup $\mathrm{Njaho}$ (der übereinander aufgereihte rollende Donner), die in Menge zwischen den Fingern gedreht wurden von den Frauen, deren eine Körperhälfte von der Erde genommen wurde (Bawi Petak Sila, die andere Körperhälfte stammt aus der Oberwelt. Es handelt sich wahrscheinlich um Priesterinnen, die die kosmische Totalität darstellen), die zwischen den Fingern gerieben wurden von den Frauen aus dem Lande Djawa (Java), damit sie dienen als Steg für die Seelen der Getragenen, die da zurückkehren, damit sie gebraucht werden als Brücke für die Seelen der Gewiegten, die wieder heimkommen.

Beendet ist nun das Umbinden der Bänder von Glasperlen. 


\section{Die Sangiang kehren wieder in ihr Dorf zurück und empfangen für ihre Hülfe den Lohn}

\section{a. Die Vorbereitungen und die Ueberreichung des Lohnes}

Palus oloh manatap toh Und sogleich machen nun die Leute ramo,n pabuli Sangiang, ie te: die Dinge bereit für die Verabschiedung der Sangiang, nämlich diese :

1. Tambak behas huang 1. Aufgehöhten enthülsten Reis in der mangkok genep biti,n oloh balian.

2. Kupit pisau akan gagenep biti,n ewen oloh balian.

3. Panginan, kare manok, takupat ranen huang apar.

4. Idje pakiho, idje palundo muat behas, idje bua enjoh, idje ketetek benang babilem kampoh lumpang, idje lamiang pandak, satali bulau, duit atawa barang due kiping. Uras akan upo,n balian.

5. Telo rupiah akan genep biti,n panggapit,e.

Toh, amon djadi tatap te upo mangarungut kabuat, koa,e :

I'bahing bapanting Sangiang maneras bandong lasang, siring bambahinga Djalajan maluhing gentoi burong, manjewut upah bambang penjang,e natolak ambon barutas matei, mandinon pekat Tasse eines jeden der Balian.

2. Ein altes, unbrauchbares Buschmesser für jeden der Balian.

3. Speisen, nämlich Hühner, Kuchen usw. in einem Aparteller.

4. Einen Pakiho (heiliger Speer mit Widerhaken), einen Korb gefüllt mit enthülstem Reis, eine Kokosnuss, das Stück schwarze Tuch, das als Decke über den Balai Lumpang gebraucht wurde, ein kurzer Achat, Gold im Gewichte eines Tali (eines 25 Cent Stückes), Geld oder Waren im Betrage von zwei Kiping (vier Gulden). Das alles ist für den Hauptbalian bestimmt.

5. Drei Gulden für jeden der Beantworter des Hauptbalian (also für jeden Hülfsbalian).

Wenn nun alles bereit ist dann singt der Hauptbalian und sein Lied lautet:

Es wirft aus den Schall seines Wortes, er, der Sangiang, der als Kernholz dient des Bandongbootes, es lässt ausgehen den Laut seiner Rede, er, der Djalajan, der der innerste Stamm ist des Vogelbootes, er nennt den Lohn für die Stücke der Penjang, die da 
paturong manjangka enon weggestossen haben die Wolken, die bapilo nihau. vernichtenden des Todes, er zählt auf die Entschädigung für die Paturong, die da aufgehoben haben die Tauwolken, die zerstörenden des Verlorenen.

Toh ie kota-kotak upo,n balian manjewut upah Sangiangku: telo kiping, pisau, behas tambak, lamiang, manas, bulau, behas ttg. palundu, bua enjoh, benang babilem, rabajang ttg. tantaha,e, djete uras akan Dohong Mama Tandang, koa,n upo.

Tinai koa,n upo, kota-kotak: ain Sangiang panggapitku duit sama tangah telo kiping, pisau, behas tambak ttg. huang,e sipa roko, djete akan Sangiang tarantang garo, koa,n upo.

Es spricht nun der Hauptbalian und er nennt den Lohn seines Sangiang: drei Kiping (sechs Gulden), ein Buschmesser, aufgehöhten Reis, Achate, Perlen, Gold, Reis zusammen mit dem Korb, eine Kokosnuss, schwarzes Tuch, einen Speer mit dem Schaft, das alles ist bestimmt für den Dohong Mama Tandang, so spricht der Hauptbalian.

Und weiter spricht der Hauptbalian: für die Sangiang meiner Helfer sind bestimmt: für jeden die Hälfte von drei Kiping (also für jeden 3 Gulden), ein Buschmesser, aufgehöhter enthülster Reis in dem sich Betelkausel und Zigaretten befinden, das alles ist bestimmt für die Sangiang, die Kinder des Weihrauches, so lautet die Rede des Hauptbalian.

Toh ewen tempo,n gawi Die Besitzer der Arbeit (die Verwandtombah :

Ijoh Sangiangku, uras,e njanggup ikei ih. ten des Verstorbenen) antworten nun: Ja, unser Sangiang, wir sind mit allem einverstanden.

Te ewen tempo,n gawi maDie Besitzer der Arbeit weisen nun, nundjok, barangai tundjok gleichgültig immer auf welche der bedengan ramo idje kueh-kueh kea. reitgemachten Dinge sie weisen (um zu zeigen, dass der Lohn bereits vorhanden ist, und dass sie gewillt sind ihn zu überreichen).

Toh upo kakarungut tinai, Der Hauptbalian singt nun wieder und koa,e : sein Lied lautet: 
I'keton Sangiang sama tarima djawi,n bambang penjang, dinon pekat paturong,e, kare tambon repang garantong, bulau pungkal radja, baras bulau, busong hintan, bantilan timpong, tampong lamiang, darehan garing, dohong maing bahiring sara,e.

Sukup djawi,n bambang penjang,e Sangiang, genep pekat paturong batu, n Djalajan.
Wohlan, ihr Sangiang, empfanget nun gemeinsam den Lohn für die Stücke euerer Penjang, nehmet nun die Entschädigung für euere Paturong (damit ist die Zugehörigkeit zu der andern Stammhälfte gemeint, denn Penjang und Bündel, Paturong und Geflecht gehören zusammen. Bündel und $\mathrm{Ge}-$ flecht aber, die hier nicht genannt, aber vorausgesetzt werden, bezieht sich auf die Verwandten des Toten), nämlich: die Wasserschlangen (Ketten) mit den Reihen der Gong, königlich geschmiedetes Gold, Sandbänke von Gold und Steinbänke von Edelsteinen, Rollen von Tuch, Trossen von Achaten, elfenbeinerne Geflechte und den kräftigen Dolch, der auf seinen Seiten scharf ist. Vollzählig ist der Lohn für die Stücke der Penjang der Sangiang, vollkommen ist die Entschädigung für die Paturong der Steine der Djalajan.

\section{b. Die Sangiang kehren in ihr Dorf zurück}

Toh ewen balian manekap Die Balian schlagen nun die kleinen katambong hajak manandak Trommeln und sie singen nach der tumon lago: Pabuli Sangiang, Weise: Die Rückkehr der Sangiang, idje kilau tekap karunja, die gleich ist wie die Melodie der hajak ewen tempo,n gawi Lieder (im Unterschied zu dem manitis undus intu genep ta- rhythmisch gesprochenen Sprichwort) kolok oloh balian.

Maka auch bawak tandak,e sama kilau djadi insanan helo.

Maka amon Sangiang djari und die Besitzer der Arbeit giessen Oel aus auf die Köpfe der Balian.

Der Text des Liedes ist aber der gleiche, der bereits genannt wurde. (Es handelt sich hier um den gleichen Text der auf den Seiten 779 bis 788 mitgeteilt wurde und der hier nicht mehr wiederholt wird.)

buli bara biti,n ewen, Sangi- kehrt sind aus ihren Körpern (aus 
ang palus manduan kare ramo denen der Balian), dann holen die idje djari inukas aka,e ttg. Sangiang sogleich alle Waren ab, die idje aton hong bentok huma. Sangiang mibit,e balua huma mamuat,e intu papan talawang.

Sangiang buli, sama djalan kilau djalan hadurut. für sie bestimmt sind, und die sich in der Mitte des Hauses befinden.

Die Sangiang bringen sie zum Haus hinaus und beladen mit ihnen die Schildbretter.

Die Sangiang kehren wieder zurück und der Weg, den sie zurücklegen, ist der gleiche wie der der Herunterfahrt. (Der Text wird durch die Balian gesungen aber hier nun nicht wiederholt.)

\section{Die Balian empfangen ihren Lohn und kehren nach Hause zurück}

Maka amon Sangiang djari buli sampai lewu huma,e, te oloh balian manarima laloh,e ttg. oloh magah ie buli eka,e kea.

Toh ewen huang huma te mamali.

Telo bulan dia tau kuman badjang.

Idje bulan dia tau kuman bawoi.

Telo bulan dia tau kuman palandok ttg. karahau.

Idje mambatang mamali, ie te:

Balo ttg. kola,n oloh idje matei te.

Katelo ie dia tau mahapan djukung idje hapan hangkakahem.

Katelo dia oloh tau managih manampah, mamputang ma-
Wenn die Sangiang zurückgekehrt und in ihrem Dorf und in ihren Häusern angekommen sind, dann empfangen die Balian ihre Entschädigung und werden von den Veranstaltern der Handlung nach Hause zurückgebracht.

Die Leute des Hauses werden aber nun für einige Zeit für Pali erklärt.

Während drei Monaten dürfen sie kein Hirschfleisch essen.

Während einem Monat dürfen sie kein Schweinefleisch essen.

Während drei Monaten dürfen sie kein Fleisch der $Z$ werghirsche und der Rehe essen.

Die Hauptsache ist, dass diese in den Palizustand versetzt werden, nämlich: Die Witwe und die nächsten Verwandten des Verstorbenen.

Während drei Tagen dürfen sie nicht gebrauchen die Ruderboote, die für die Kenterung verwendet worden sind. Während drei Tagen dürfen die Leute nicht Schulden eintreiben und nichts 
njinger huang huma te, amon halau bara telo andau te tau amon aton hal en-en.

Balo dia tau mangkajan benang bahandang amon dia djadi tiwah bana,e. auf Kredit geben und keine Bussen verhängen in diesem Hause, wenn diese drei Tage verstrichen sind, dann kann das alles wieder ausgefühnt werden, wenn dazu eine Veranlassung besteht.

Die Witwe darf sich nicht mit Tüchern von roter Farbe bekleiden, solange das Tiwah für ihren Gatte noch nicht stattgefunden hat. (Es bestehen noch mehr Pali, die aber hier nicht alle aufgezählt werden. Die wichtigsten sind aber genannt worden.) 
Hans Schärer - 978-90-04-28681-8 Downloaded from Brill.com๑4/26/2023 11:12: ๑5AM 


\section{ERKLAERUNGEN}

1, S. 30.

Mangko Amat ist ein Sohn des Ratu Basar und ein Bruder des Tantaolang Bulau, der der Stammvater der Sangianggeschlechter in der Oberwelt ist. Mit seinem Bruder zusammen wohnte er in Batu Nindan Tarong, Liang Angkar Bantilong Njaring, dem Ursprungsdorfe in der Oberwelt aus dem sich die Sangiang über die ganze Oberwelt verbreiteten. Ein Sangiangstamm, nämlich der des Maharadja Bunu stieg auf die Welt (pantai danum kalunen: das Ufer am Flusse der Welt) herab und von ihm stammen die Menschen ab. Unter Menschen verstehen wir nur die Freien, die durch ihren Stammbaum nachweisen können, dass sie von Maharadja Bunu abstammen, nicht aber die Sklaven (djipen) oder die Hexen (hantuen). Diese Freien werden von den Unfreien oder Sklaven angesprochen: Tempongku, Sangiangku (mein Herr und mein Sangiang). Siehe auch die Ursprungsmythe von Batu Nindan Tarong und die ausführlichen Geslechterlisten im II. Band dieses Werkes. Mangko Amat war verheiratet mit $\mathrm{Njai}$ Djaja, die eine Priesterin war. Njai nennt man die Frauen reicher, angesehener Leute. Djaja, ein Wort aus der Basa Sangiang (Sangiangsprache oder Priestersprache) bedeutet: scharf, kräftig im religiös/kultischen Sinne. Das davon abgeleitete Verb badjaja ist synoniem mit balian : die priesterlichen Handlungen ausführen, durch die man die Sangiang in der Oberwelt um ihre Hülfe und ihren Beistand bittet, was durch die Priesterinnen (balian) oder durch die mit Frauenkleidern bekleideten Priester (basir), die in die gleiche Kategorie wie die Balian gehören, geschieht.

2, S. 30.

Pahuni ist eine besondere Art religiöser Verbote von denen man sehr viele unter verschiedenen Namen kennt. Jeder Name bezeichnet ein besonderes Gebiet auf das sich diese religiöse Verbote erstrecken. Pahuni nennt man sowohl das Verbot als auch die Folgen, die durch die Uebertretung dieses Verbotes entstehen. Durch pahuni, d.h. durch die Uebertretung dieser bestimmten Verbotsbestimmung wird man 
pahuni, d.h. man kommt in einen Unheilszustand der durch die Uebertretung dieses Verbotes entsteht. Pahuni ist: wenn man sich vorgenommen hat etwas zu kochen, zu backen oder Sirih bereit zu machen aber dann diesen Entschluss, aus welchen Gründen auch immer, nicht ausführt. Pahuni ist ferner: wenn man bereit gestelltes Essen nicht zu sich nimmt, oder die Speisen, die man auf das Feld oder zur Arbeit im Wald, zur Jagd oder auf den Fischfang mitgenommen hat, nicht isst, ferner wenn man angebotenes Essen, Tabak, Zigarren, Cigaretten oder Sirih usw. abschlägt ohne vorher mit den Fingerspitzen der rechten Hand sie berührt zu haben. Pahuni ist auch wenn ein Festgeber ein bereits angesagtes Fest, zu dem auch die Gäste schon eingeladen worden waren, absagen oder verschieben muss. Die Gäste können den Festgeber rechtlich verfolgen und er muss für sie ein Opfertier schlachten und sie, um sie aus dem Unheilszustand der durch das Pahuni entstanden ist, zu befreien mit dem Blute des Tieres bestreichen. Die Folgen des Pahuni, die ebenfalls Pahuni genannt werden, sind: Seitenstechen und Milzvergrösserung die verursacht werden durch einen Geist der unsichtbar seinen Speer auf diese Menschen abgeschleudert hat die ihm, wegen der Uebertretung dieser Verbotsbestimmung, verfallen waren.

$H$. Sundermann erzählt uns eine solche Pahunigeschichte wie man sie unter allen Dajakstämmen sehr viel findet. Ich teile sie hier zur Illustration des Gesagten mit:

Lempan und sein Vater hatten nichts mehr zu essen, da machten sie sich auf, um Waldprodukte $z u$ suchen. Was sollten sie aber zu essen mitnehmen auf den Weg? Sie wickelten etwas Abfall vom Reisstampfen ein. Als sie aber weggingen, vergassen sie es, es blieb in einem Körbchen liegen. Im Walde fanden sie vielerlei. Sie erlegten Wildschweine, Hirsche und Affen. Das Fleisch trockneten sie in der Sonne und über dem Feuer. Der Vater ging jagen, Lempan aber bewachte die Hütte, die sie sich gemacht hatten. Plötzlich hörte er einen Geist kommen der vor sich her sprach: „In diesen kurzen Bambus wird das Blut des Lempan getan, in den langen das seines Vaters". Als Lempan das hörte, fürchtete er sich sehr, floh und versteckte sich, indem er in den Wipfel eines Baumes kletterte. Der Geist ging in die Hütte und ass alles getrocknete Fleisch auf, darauf entfernte er sich wieder.

Am Abend kam der Vater des Lempan zurück von der Jagd und brachte neuen Vorrat. „Wer hat unser Fleisch aufgegessen“, fragte er. „Das hat ein Geist getan“, antwortete Lempan. „Wart nur", erwiderte sein Vater, „morgen werde ich ihn schiessen mit vergifteten Pfeilen". 
Am andern Tage lauerte er dem Geist auf. Es dauerte auch nicht lange, da kam er wieder. Sofort schoss er ihm mit seinem Blaserohr alle Pfeile in den Leib. Aber kein Gedanke daran, dass er ihn töten konnte. Nachdem der Geist alles Fleisch wieder verzehrt hatte, machte er sich fort.

„Hier ist es nicht auszuhalten“, sagte der Vater des Lempan, „lass uns nur nach Hause gehen". Darauf gingen die Beiden heim. Als sie zu Hause ankamen, sahen sie, dass ihr Essen, welches sie hatten mitnehmen wollen, und welches noch immer eingewickelt in dem Körbchen lag, voll Pfeile steckte (nämlich die Pfeile, welche sie im Walde auf den Geist geschossen hatten). „O“, sagte der Vater des Lempan, „also dies ist der Geist gewesen, der uns verfolgte weil wir es vergessen hatten mitzunehmen. (Dajakkische Fabeln und Erzählungen. Bijdragen tot de Taal-, Land- en Volkenkunde van Nederl. Indië. Deel 66. Den Haag 1912).

\section{3, S. 30 .}

Das Substantiv gawi (Arbeit) und das Verbum bagawi (arbeiten) bezieht sich ursprünglich auf die Ausführung einer kultischen Handlung oder die Darbringung von Opfern. Das Ganze nennt man gawi während man die Vorbereitungen und die Handlungen bagawi nennt. Die Darbringung von Opfern und die damit verbundenen sakralen Mahlzeiten (die Mahlzeiten bei Kult- und Opferhandlungen haben ja immer und in erster Linie sakrale Bedeutung) würde man also besser mit Arbeit als mit Fest bezeichnen. In Anlehnung an den europäischen Sprachgebrauch der sich mit der Zeit eingebürgert hat nennt der Dajak diese Arbeit auch pesta (Fest), doch ist dieser Sprachgebrauch noch keineswegs zu einem allgemeinen geworden. Gawi oder bagawi, die früher in erster Linie auf diese religiösen Handlungen angewandt wurden, bekamen mit der Zeit auch einen mehr profanen Sinn. Man versteht heute darunter auch die Ausübung irgend einer andern Arbeit, oder braucht es im Sinne von: machen, tun, etwas ausführen. Jede Arbeit besitzt aber ihre eigene Bezeichnung und bagawi kann eigent lich nie allein stehen sondern erfordert die nähere Bezeichnung durch dieses spezielle, nur für diese und keine andere Arbeit gebrauchte Wort, damit deutlich wird welche Arbeit man überhaupt meint. Malauk (fischen) sagt aus, dass man Fische fängt, aber es sagt nicht aus auf welche Weise und mit welchen Hülfsmitteln das geschieht. Der Ngadju Dajak kennt mehr als dreissig verschiedene Arten des Fischfangs für die eigene Bezeichnungen bestehen von denen wieder eigene Verba 
abgeleitet sind. Das gleiche gilt für beinahe alle andern Arbeitsgebiete auch.

4, S. 31 .

Pali bedeutet: heilig, verboten, tabu. Man unterscheidet verschiedene Gruppen heiliger Verbotsbestimmungen. Diese Gruppen besitzen eigene Namen. Pali ist ein zusammenfassender Name. Will man ein Verbot genauer bezeichnen dann nennt man den Namen der ganzen Gruppe unter die dieses Verbot fällt, z.B. pahuni (Siehe Erklärung 2). Ueber die Innehaltung aller Pali wachen die Njaro (Donnergötter). Unter ihnen steht der Radja Pali (der König der Pali) der verschiedene Diener hat die über die verschiedenen Paligruppen verteilt sind und über ihre Befolgung zu wachen haben. Wer die Pali übertreten hat kommt dadurch in den Palizustand und ist als Schuldiger den Njaro oder dem Radja Pali und seinen Dienern ausgeliefert die den Ungehorsamen strafen. Er wird nun buah pali, d.h. durch die Pali angefallen oder durch sie krank gemacht oder durch sie ins Unheil versetzt. Bei den schwersten Paliübertretungen kann der plötzliche Tod (matei manta: unreifer Tod) eintreten, oder sie hat die Versteinung (basaloh) und den Untergang des Schuldigen, sowie seiner ganzen Verwandtschaft und seines ganzen Dorfes zur Folge. Durch den plötzlichen Tod und durch die Versteinung (unheilvoller Tod) wird man aber auch aus der Gemeinschaft der Toten und der überweltlichen Ahnen ausgeschlossen und man muss als Geist (taloh) ruhelos in dieser Welt und in den Wäldern herumschweifen, sich selbst und den Menschen zur Plage. Diese Taloh, d.h. diese unheilvollen Toten, leben z.T. auch in Geisterdörfern (lezwn taloh) die aber nicht in der Oberwelt, nicht in der Gemeinschaft der überweltlichen Ahnen, sondern getrennt von ihnen in dieser Welt liegen.

5, S. 31.

Akui ist ein Ausruf des Schreckens oder des Erstaunens.

6, S. 31 .

Wind ist gleichbedeutend mit Atem. Von der Erschaffung der ersten Menschen wird erzählt (siehe die Geschichte von Ranjing Pahatara) : Eines Tages ging Ranjing Pahatara segeln. Er fand sieben Eier von Erde, nahm sie zu sich und zerschlug sie und formte aus ihnen eine weibliche und eine männliche Gestalt. Aber diese Gestalten besassen keine Knochen und hatten keinen Atem und waren deshalb schwach 
und leblos. Er brachte sie heim und eines Tages begab er sich wieder auf die Reise um für die Menschen Steinatem und Steinknochen zu holen. Während er sich auf der Reise befand kam Peres. Er erkundigte sich bei Andin Bamban (Frau des Ranjing Pahatara): „Wo ist dein Mann?" Sie antwortete ihm: „Er hat sich auf die Reise begeben um für diese beiden menschlichen Gestalten da Steinatem und Steinknochen zu holen“. „So“, sagte Peres, „das ist nicht gut was Ranjing Pahatara da unternehmen will. Es ist besser, wenn wir diese Menschen da beleben, denn siehst du, wenn ihre Knochen und ihr Atem von Stein genommen sind, dann haben diese Menschen ewiges Leben, sie können nicht sterben und bald wird deshalb die Welt für sie zu klein sein. Es ist besser wenn sie nur kurze Zeit in der Welt leben und dann sterben und später wieder für kurze Zeit auf sie zurückkommen". Erstaunt fragte Andin Bamban: „Wie soll das aber möglich sein?“ Peres antwortete: „Der Leib ist von Erde, den Atem nehmen wir vom Wind, die Knochen schnitzen wir aus Holz und das Blut nehmen wir vom Wasser". „Es ist gut so“, sagte Andin Bamban. Sie fing nun etwas Wind ein für den Atem und schöpfte etwas Wasser für das Blut.

Nach dem Tode kehrt der Atem wieder zum Wind, das Blut wieder zum Wasser, die Knochen zum Holz und der Leib zur Erde zurück.

7, S. 32.

Has geht einer Aufforderung oder Anfeuerung voran und bedeutet: wohl, wohlan, schnell, geschwind, lasst uns tun. Z.B. Has itah kuman: lasst uns essen, oder: itah batolak: wir reisen ab, worauf die Angesprochenen antworten: has: Wohlan!

\section{8, S. 32.}

In den Pubertätsjahren werden die Zähne der Mädchen und Knaben abgefeilt und darauf schwarz gefärbt. Zur Gewinnung des Farbstoffes gebraucht man das Katiting oder Kandaliholz. Hardeland (siehe unter katiting) schreibt: „Katiting oder Katune, ein Baum; wenn man das Holz desselben verbrennt, fliesst ein schwarzer, klebriger, scharfer Stoff heraus, welcher auch katiting oder katune genannt, und zum schwarz färben der Zähne gebraucht wird. Schwarze Zähne hält der Dajak für schön. Reibt man die Zähne zehn Tage nacheinander damit ein, so sind sie dadurch für Lebenszeit schwarz gefärbt. Auch soll der Katiting gegen Zahnschmerz gut sein“. Dieser Stoff, der aus dem Holz herausfliesst, fängt man in einem dulang katune (Trog für den Katune) auf. Diese dulang katune sind etwa $10-20 \mathrm{~cm}$ lang und haben die Form 
eines gewöhnlichen Ruderbootes das leicht ausgehöhlt ist. Andere dulang stellen eine Wasserschlange oder ein Opfertier dar (Büffel, Huhn). Sie werden von Eisen geschmiedet. Siehe der Abbildungen 2, 4 und 5 in: Georg Tillmann, De metalen bakken van Zuid-Sumatra en de dierenvoorstellingen op de z.g. Kroë-doeken. Cultureel Indië. 1ste jaargang 1939, pag. 16. Die dajakischen (Ngadju) dulang katune haben mit den dort aigebildeten „metalen bakken“ grosse Uebereinstimmung. Die Erklärungen, die der Verfasser gibt, scheinen mir nicht befriedigend zu sein. Ueber das Feilen und Schwarzfärben der Zähne siehe: Mallinckrodt: Ethnographische mededeelingen over de Dajaks in de Afdeeling Kualakapuas. Bijdragen, Deel 81, pag. 76. Die Bedeutung dieser Sitte haben wir zu suchen in dem ganzen Komplex der Initiationszeremonien durch die die Knaben und Mädchen zu einem religiös und sozial vollwertigen Glied des Stammes werden. Durch diese Initiationsriten werden sie in den Tod geführt und darnach neu geschaffen und sie beginnen als neue Menschen ein neues Leben. Die besonderen Formen der dulang katune, vor allem Boot und Naga, weisen direkt hin auf die Mythe der Welt- und Menschwerdung, die durch die Initiationszeremonien wiederholt werden. Auch die Tätowierungen, die ebenfalls $\mathfrak{z u}$ den Initiationsriten gehören, und die verschiedenen Tätowierungsmuster können nur gedeutet werden von der Mythe der Welt- und Menschwerdung her.

\section{9, S. 32.}

Maharadja und Umang (katinganisch, im Ngadju wird Umang genannt: Sangumang) sind die beiden Helden der Eulenspiegelgeschichten (Sansana Umang) die eine überaus reichhaltige und umfangreiche Literaturgattung ausmachen. Das Thema der meisten Sansana Umang ist dieses: Umang, der Schwiegersohn des Maharadja (siehe die Mythe von Umang und dem Hirsch), ist jung aber sehr listig und verschlagen. Maharadja ist alt und meint dass er in allen Dingen viel weiser und verständiger sei als Umang. Erzählt ihm Umang von einem Streich den er wieder ausgeführt hat, oder von einer Arbeit die er vollbrachte, dann lässt ihn Maharadja gewöhnlich nicht aussprechen, sondern er antwortet, seine Erzählung unterbrechend: es ist nicht nötig, dass du weiter erzählst, ich weiss schon was du sagen willst, denn ich bin älter und viel verständiger als du. Er geht dann hin und will den gleichen Streich auch ausführen oder die gleiche Arbeit auch vollbringen und es misslingt ihm und er trägt nur Schaden und Spott davon weil er nicht auf Umang gehört hat. Will er Umang überlisten, 
auch ein sehr häufig vorkommendes Thema in diesen Erzählungen, dann geht Umang scheinbar auf seine List ein und tut wie wenn er Maharadja nicht durchschaut hätte aber das Resultat ist, dass er von Umang noch auf viel raffiniertere Weise überlistet wird.

Die Sansana Umang illustrierten uns in ausgezeichneter Weise die Eifersucht und den verborgenen und offenen Kampf der beiden Stammhälften, die im Streit auseinanderfallen sich aber doch immer wieder finden weil sie aufeinander angewiesen sind wenn sie eine wichtige Handlung oder Arbeit zu einem, für den ganzen Stamm guten Abschluss führen wollen.

Es gilt auch hier was Dr. W. H. Rassers über die javanische Wajangaufführung sagt: „In de verhouding der beide stamhelften komen overal precies deze zelfde ambivalente gevoelens aan den dag; ook de phratries zijn elkaars gelijken en aan elkaar gelijkwaardig; in hooge mate is in beide een gevoel van verwantschap en hoogere eenheid aanwezig; zij zijn onmisbaar voor elkaar; en toch leeft onder deze eenheid onmiskenbaar en voortdurend, zooals Howitt het uitdrukt, een sterk gevoel van ,vermomde vijandschap" ". (Over den zin van het Javaansche drama. Bijdragen. Deel 81, pag. 378).

Umang, aber nicht Maharadja, ist auch einer der wichtigsten und am meisten angerufenen Ahnen. Hardeland schreibt von ihm: „Ausser den bereits genannten Sangiang steht unter den Dajacken noch ein mächtiger Sangiang, der Sangumang und seine Genossen Pa Paloi und Sakanak in grossem Ansehen. Man weiss viele Heldenstaten von ihm zu erzählen. Man begibt sich gern in den Schutz des Sangumang, wofür man ihm dann natürlich Opfer bringt. Oft übergibt man Kinder dem Schutze des Sangiang Sangumang, und verspricht ihm dafür ein parapah sandehen bereng (ein Opfer für Befestigung des Leibes), welches gewöhnlich in einem Büffel besteht, und gebracht wird wenn das Kind gesund und wohl etwa sein zwanzigstes Lebensjahr erreicht hat" (Wörterbuch, siehe Sangiang, pag. 506).

Er ist Wohltäter und Heilbringer (siehe die Mythe vom Ursprung des Eisenholzes als auch die Mythe von Umang und dem Hirsch), aber er ist auch der listige Betrüger und man kann auch von ihm aussagen: „Hij is, meer dan eenig ander god, de vertrouwde en populaire weldoener der menschen, die hij gaarne bezoekt en met zijn goddelijke hulp en gaven verblijdt. Maar hij is ook de listige bedrieger, de amoureuze dvonturier en de clown onder de goden. Hij staat in zeer nauwe betrekking tot de machten van leven en dood, de goden van boven- en 
onderwereld“. (Prof. Dr. J. P. B. de Josselin de Jong: De oorsprong van den goddelijken bedrieger. Amsterdam 1929).

Die Sansana Umang haben für den Dajak auch pädagogischen Wert. Sie werden den Kindern viel erzählt mit der Nutzanwendung: werde ein Umang aber nicht ein Maharadja.

10, S. 34.

Tengang ist eine dicke Schlingpflanze. Sie wird so dick wie das Bein eines Mannes. Von dem sehr dick übereinandersitzenden faserigen Baste derselben macht man Schnüre, die man meistens für Netze und Angelschnüre verwendet und für diesen $Z$ weck auch in den Tauschhandel bringt.

11, S. 34.

Sapundu sind geschnitzte Opferpfähle die für das tiwah (Totenfest) aufgerichtet werden. An ihnen werden die Opfer (früher Menschenopfer, heute Wasserbüffel oder Kühe) angebunden und langsam zu Tode gespeert. Beschreibungen mit Bildmaterial geben: C. T. BertuING : „Hampatongs” of „tempatongs” van Borneo. Nederlandsch Indië Oud en Nieuw, 12e jaargang. 1927. W. C. TEN Cate: De doodenpalen in de onderafd. Melawi der afdeeling Sintang v. d. Residentie Westerafdeeling van Borneo. T.B.G. LXI. 1922. Pag. 201 ff. H. F. Tillema: Doodenpalen, Tiwah en Lijkverbranding op Borneo. Nederlandsch Indië Oud en Nieuw. 1931/32. Pag. 131 ff.

Die pantar sind hohe Eisenholzmasten $(10-20 \mathrm{~m}$. hoch) die beim tiwah (Totenfest) für jeden Verstorbenen aufgerichtet werden. Auf der Vorderseite dieser Pantar sehen wir zwei- bis fünfmal je sieben Kerbe. Der oberste Teil ist meistens gegabelt. Auf der einen dieser Gabelungen befindet sich ein aus Eisenholz geschnitzter Nashornvogel, auf die andere wurde früher ein Menschenschädel gesteckt. Am oberen Katingan laufen die, meist bedeutend kürzeren (5-10 m.) Pantar in ein kugelförmiges Ende aus das den geschnellten Kopf darstellen muss. Beim Tiwah werden sie mit Tellern und verzierten Bambusköchern behängt die die Opfergaben für die Liau enthalten. Man nennt die Pantar djamban liau (Weg oder Brücke des Toten). Ueber die Pantar hinweg steigt die Liau (der Tote) in die Totenstadt, die in der Oberwelt liegt.

Vgl. über die Pantar: H. Schaerer: Das Menschenopfer bei den Katinganern. T.B.G. LXXVIII. 1938. Pag. $553 \mathrm{f}$. Eine genaue Beschreibung der Sapundu und Pantar, versehen mit Zeichnungen, soll 
im II. Band dieses Werkes gegeben werden. Aus ihr kann dann auch die richtige Bedeutung abgeleitet werden über die man in den verschiedenen Darstellungen noch im Dunkeln tastet.

\section{2, S. 35 .}

Radja Peres (König der Krankheiten) herrscht über die Krankheiten, die alle personifiziert gedacht werden. Die Krankheiten sind seine Diener die auf die Menschen losgelassen werden. Vgl. auch: Manolak Peres und die Mythe vom Ursprung des Peres unter D, 2, $\mathrm{c}$ in diesem Werk.

\section{3, S. 36.}

Der balai ist das Versammlungshaus in dem die Männer ihre Rechtssitzungen abhalten und in dem auch die Waffen und Schilde aufbewahrt wurden. Im Balai schliefen nachts auch, unter Aufsicht eines alten Mannes, die jungen, unverheirateten Männer des Dorfes und wurden durch ihn in die Arbeiten und Rechte und Pflichten des Mannes eingeführt.

Im Balai wurden auch die Fremdlinge empfangen. Sie schliefen aber nicht hier sondern im Fremdenbalai, ein Raum der unter der Reisscheuer für diesen $Z$ weck eingerichtet wurde.

14, S. 36.

Kajah, oder in der Reduplikation kaja-kajah, ist ein Ausruf des Schmerzes, des Schreckens, des Erstaunens oder der Bestürzung.

\section{5, S. 37.}

Welt. Die Welt, die von den Menschen bewohnt wird, nennt man in der religiösen Terminologie: pantai danum kalunen (die Ufer am Flusse der Welt). Sie liegt zwischen den lewun Sangiang (Dörfer der Sangiang) die die Oberwelt darstellen und dem Dorfe der Djata das die Unterwelt darstellt.

\section{6, S. 38.}

Der Ausdruck pehe atei, der mit Herzeleid übersetzt wird, bedeutet eigentlich: Leid in der Leber (atei ist die Leber), denn in der Leber empfindet der Dajak Freude und Schmerz, Leid und Wonne. Einige Beispiele: Angat atei (die Meinung des Herzens) bedeutet: die Ansicht. die Meinung. Ie dia atei (er hat kein Herz) bedeutet: er ist hart, herzlos, 
er schämt sich nicht, er hat kein Gefühl und kein Gemüt. Ela manduan atei tagal auche (nimm nicht Herz wegen seiner Worte) bedeutet: nimm seine Worte nicht zu Herzen, werde nicht betrübt oder zornig. Ie hakotak tumon ateiku (er spricht nach meinem Herzen) das heisst: er spricht freundlich, herzlich. Ikau bara atei botong, bara daha danum, hapinding lilin (du hast ein Herz als botong: schlechte schmacklose Sorte Melone die ungeniessbar ist, Blut als Wasser, Ohren von Wachs), das sagt man zu trägen und widerspenstigen Menschen. Handjak atei (freudiges Herz), das heisst: erfreut sein, beglückt sein. Baatei (von bara atei : ein Herz haben) bedeutet: Mut haben, Tapferkeit zeigen.

17, S. 38 .

Hau, oder in der Reduplikation hau-hau die eine Verstärkung bedeutet, ist ein Ausruf der fragenden Verwunderung, sowohl der Freude als der Bestürzung.

18 , S. 38.

Lehan, Reduplikation leha-lehan, oder zusammengezogen zu lalehan, ist ein Ausruf des Zornes oder der Verwunderung. Kalehan oder kalalehan bedeutet : gross, ungemein, ausserordentlich, so dass man sich darüber wundern muss.

19, S. 39.

Ajo geht wie has einer Aufforderung oder Anfeuerung voran und bedeutet ebenfalls: wohl, wohlan, schnell, geschwind.

Z.B. Ajo, itah hagoet: wohlan, lasst uns gehen.

20, S. 39 .

Tuwe ist der Name einer Schlingpflanze von der es verschiedene Sorten gibt. Die bekanntesten sind: tuwe apoh mit breiten und die tuwe rurok mit schmalen Blättern. Die gestampften Tuwewurzeln legt man in einen Topf der gefüllt ist mit Wasser und lässt sie einige Zeit darin liegen. Das Wasser giesst man in kleinen Flüssen aus deren Mündung mit starken Palisaden verschlossen wurde. Die Fische erscheinen nach einiger Zeit betäubt auf der Oberfläche und können dann mühelos eingesammelt werden. Die auf diese Weise gefangenen Fische sind durchaus geniessbar, ein grosser Teil von ihnen wird getrocknet und als Vorrat aufbewahrt. Der auf diese Weise ausgeführte Fischfang kann durch Einzelne geschehen wird aber in vielen Fällen auch durch 
den ganzen Stamm ausgeführt. Die Männer und Frauen nehmen teil, sodass meistens hunderte von Menschen zusammenströmen. Die Männer erscheinen mit, für diesen $Z$ weck schön geschmückten und bemalten Speeren, mit denen die grösseren Fische aufgespeert werden. Dieser Raubfang ist heute durch die Regierung verboten, er wird aber in den mehr abgelegenen Teilen von Zentralborneo doch noch ausgeführt.

Mit Tuwe vergifteten sich in früheren Zeiten oft auch Mädchen die von ihren Liebhabern verlassen worden waren.

Das Verbum manuze bedeutet: Fische fangen mit Tuwe, aber auch: Güter und Reichtum erwerben (manuwe panatau: Reichtum erwerben).

\section{1, S. 40 .}

Diese Mythe ist den Stammythen der Ot Danum, den sogenannten Auch Tatom Tambon Bungai (das Wort der Erzählung von Tambon und Bungai) entnommen. Diese Mythen sind sehr umfangreich und bis heute in der Literatur noch unbekannt. Sie sind von grosser poetischer Schönheit und ihre Rezitation (sie werden gesungen) ist auch für den Europäer ein Genuss.

Tambon und Bungai, die Helden dieser Mythen, sind zwei Brüder die zwei verschiedene Stammhälften repräsentieren. Tambon (Wasserschlange) ist das Attribut der Unterwelt und auch der Name der einen Stammhälfte. Bungai (Nashornvogel) ist das Attribut der Oberwelt und auch der Name der andern Stammhälfte. Heldentaten und wichtige Arbeiten und Handlungen, die das Heil des ganzen Stammes verbürgen, können nicht durch eine Stammhälfte allein ausgeführt werden, sondern erfordern den ganzen Stamm, sowie bei der Weltwerdung auch Unterwelt und Oberwelt zusammenarbeiten mussten damit sie wirklich gelingen konnte. Bei allen wichtigen Handlungen treten deshalb Unterwelt (Tambon) und Oberwelt (Bungai) gemeinsam auf, weil ohne ihr gemeinsames Auftreten die ganze Handlung misslingen müsste. Wir sehen hier die kosmische Bedeutung des Stammes der in seinen beiden Hälften mit Unterwelt und Oberwelt assoziiert wird und der nur in seiner Ganzheit auftretend „schöpferisch" und zum Heil des ganzen Kosmos und Stammes wirken kann. Auch heute noch nennt man, auch bei den Ngadju Dajak, die Teilnehmer an einer wichtigen Handlung oder einem Fest (z.B. Totenfest): Tambon haruwei Bungai (die Wasserschlangen die vermischt sind mit den Nashornvögeln) und damit bringt man zum Ausdruck, dass der ganze Stamm an diesem Geschehen teilnimmt weil es ohne diese totale Teilnahme überhaupt 
unmöglich wäre und misslingen müsste. (Vgl. für die Bezeichnung Tambon haruwei Bungai auch den zweiten Teil dieses Bandes).

22, S. 40.

Vgl. die ausführliche Genealogie im II. Band dieses Werkes und auch: Weltwerdung und Ursprung der Sangiang nach Bapa Haastert (IV. Religion, A, h).

23, S. 41.

Die lian ist die Totenseele. Man würde den Ausdruck zwar besser übersetzen mit Toter, denn der Verstorbene lebt nicht als Seele weiter sondern als Toter der Leib und Seele besitzt. Nach dem tiwah (Totenfest) werden die eigentliche Seele (salumpok liau) und die Leibseele (liau balawang pandjang) wieder vereinigt und dadurch entsteht der Tote der in seiner leib/seelischen Einheit nicht verschieden ist vom Mensch, sondern nur an einem andern Ort, nämlich in der lewu liau (Dorf der Toten in der Oberwelt), und in einer andern Gemeinschaft, nämlich der der Liau, lebt. Tote und Lebende sind nicht streng und nicht für immer voneinander geschieden. Man bringt den Toten Opfer und sie nehmen auch an allen wichtigen Handlungen und Arbeiten der Lebenden teil wozu sie als Masken erscheinen.

H. Tн. Fischer sagt in seiner Inleiding tot de Volkenkunde van Nederlandsch-Indië. V.U.B. 1940, pag. 177: „Het volksgeloof zegt, dat... de hambaruan een gana wordt". Das ist unrichtig, sowohl sachlich als inhaltlich. Die Gana ist die Seele von leblosen Dingen und Pflanzen und hat mit der Seele des Menschen nichts zu tun. Man kann auch nicht sagen, dass die hambaruan (Lebensseele) eine liau (Totenseele) werde. Diese Transformation vollzieht sich nicht. Die Seele eines Lebenden nennt man hambaruan, den Toten aber (nicht die Seele des Toten und auch nicht die Totenseele) nennt man liau. (Liau apangku wird immer übersetzt mit: die Totenseele meines Vaters, diese Uebersetzung ist unrichtig, ist zu europäisch gedacht und ausgedrückt. Es müsste heissen: mein Vater, der ein Toter geworden ist, womit ausgedrückt wird, dass er sich nicht mehr als Lebender in der engen Gemeinschaft der Lebenden aufhält, sondern dass er als Toter eingegangen ist in die Gemeinschaft der Toten. Auch bei den Tieren unterscheidet man hambaruan und liau). Vgl. dazu auch den zweiten Teil dieses Bandes und die weiteren Bände dieses ganzen Werkes. 


\section{4, S. 41.}

Das Schwein durchschweifte das ganze Wohngebiet der Ot Danum. Das Mantikeieisen ist sehr berühmt. Bis vor etwa sechzig Jahren wurde von der Bevölkerung dort Erz geschmolzen und verarbeitet. Die Ueberreste der primitiven Schmelzöfen habe ich am Mantikei noch selbst gesehen. Vgl. darüber auch die Beschreibung von C. A. L. M. Schwaner: Borneo, Deel II. Pag. 145. Durch die Einfuhr von billigeren Eisenwaren durch Händler von der Küste ist die Eisenproduktion und Verarbeitung am Mantikei vollständig verschwunden.

Früher wurde mit diesen Produkten ein reicher Handel getrieben und fast alle alten Waffen, die man noch heute in Süd-Borneo findet, sind von Mantikeieisen geschmiedet. Es gilt heute als Zeichen der Echtheit und des Alters einer Waffe.

\section{5, S. 42.}

Sempong, der Onkel des Bungai, ist ebenfalls ein vielgenannter Held der Auch Tatom Tambon Bungai.

\section{6, S. 42.}

Njaring sind böse Geister von der Gestalt und Grösse eines Menschen. Sie haben feurige Haare und sie bewohnen in dem hinter dem Dorf gelegen Wald die Lunok- (Waringin-) und andere gummihaltigen Bäume. Sie sind sehr böse, den Menschen feindlich gesinnte Wesen, die sie krank und unklug machen. Manche Dajak getrauen sich auch heute noch nicht Gummipflanzungen anzulegen weil sie Angst haben damit die Njaring anzulocken und ihnen in den Gummibäumen Wohnungen zur Verfügung zu stellen. Als der Pambakal von Buntut Bali (Katingan) eine solche Pflanzung anlegen wollte, wurde sein Plan durch die ganze Dorfbevölkerung abgewiesen weil sie Angst hatten damit durch die Njaring bedroht zu werden. Siehe weiter unten auch: Das Mantumbal (D. Mythen zum Totenkult, 2, b) und im zweiten Teil dieses Bandes die Texte zum Manganjau Kaju.

Kalue sind weibliche Geister von menschlicher Gestalt und Grösse. Sie haben aber nur eine Brust mitten auf dem Leibe die weit herabhängt (Kalue, die einbrüstige!). Sie wohnen unter der Erde, wo sie grosse Dörfer besitzen. Sie haben die Macht das Gebären zu verhindern. Schwangere Frauen streuen ihnen als Opfergabe Reis auf die Erde. Der Frosch ist das heilige Tier der Kalue. Wer ihn ausspottet bringt den Untergang über sich und die ganze Verwandtschaft und das ganze Dorf herbei (Vgl. die Basaloh Mythen). Wer ihn verwundet oder tötet 
wird durch die Kalue ebenfalls verwundet oder getötet (Vgl. das oben genannte Mantumbal).

27, S. 42.

Vgl. die umfangreiche Mythe von der Welt- und Menschwerdung im II. Band dieses Werkes wo diese Mythe ebenfalls, und dann im richtigen Zusammenhang, mitgeteilt wird.

28, S. 43.

Das schwimmende Eisen ist nach dieser Mythe im Besitze des Maharadja Sangen. Das ist unrichtig, denn das schwimmende Eisen gehört Maharadja Sangiang. Vgl. auch die Mythen über die Welt- und Menschwerdung. Die Einteilung der Sangiangstämme in der Oberwelt stimmt überein mit der Einteilung des Stammes und der Benennung der Stammhälften und von hier kann es kommen, dass sich jede Stammhälfte im Besitze des sinkenden Eisens wissen will und der andern Stammhälfte das schwimmende Eisen zuschreibt. Die Differenzen, die wir in den verschiedenen Mitteilungen dieser Mythen antreffen, erklären sich dann aus einer bewussten Bearbeitung und Interpretation durch und für den eigenen Stammteil, aber nicht, wie das auch oft gesagt wird, aus einem nicht mehr genau wissen der Ueberlieferungen. So vergesslich ist der Dajak sonst nicht, vor allem dann nicht wenn es sich um wichtige Mythen handelt.

29, S. 43.

Das sinkende Eisen, das nicht nur verwundet sondern tötet, ist im Besitze des Maharadja Bunu. (Vgl. : Der Ursprung der Sangiang nach Hardeland). Für die verschiedenen Differenzen zwischen den einzelnen Mythen gilt was oben gesagt wurde. Vgl. dazu die ausführlichen Mythen in den Texten des II. Bandes dieses Werkes.

30, S. 44.

Tjeh ist ein Ausruf des Abscheues, des Zornes, der Verwunderung und bedeutet: Ei, Oh, Pfui. Z.B. Tjeh karajapm, djaton mahamen (Pfui, deine Schurkereien, schämst du dich denn nicht). Tjeh kahai humam (Ei, wie gross ist doch dein Haus).

31, S. 45.

Schwester (betau) bedeutet die wirkliche Schwester oder auch die Gemahlin, die man ebenfalls mit Schwester anspricht, oder von der man die Benennung Schwester gebraucht wenn man von ihr spricht. 
32, S. 46.

Diese Mythe erzählt auch weshalb der Orang Utan sterben muss und weshalb das Eichhorn das Recht hat die Waldfrüchte zuerst zu sammeln.

\section{3, S. 46.}

Der Vogel heisst auch: Kangkaput Tampa Bua, Ranggang Tutup (tampa bua: der Fruchtmacher, ranggang: offen sein, nicht dicht zusammenschliessen, tutup: der Deckel). Die Bedeutung ist: der Kangkaput schafft soviel Reis, dass die Reisbehälter übervoll werden und die Deckel nicht mehr geschlossen werden können. Der Kangkaput ist eine Art Schwalbe, der etwa drei bis viermal so gross ist als die gewöhnliche Schwalbe. Seine Farbe ist lichtgrau, dunkelbraun oder schwarz getüpfelt. (Hardeland, W. B.).

\section{4, S. 48.}

Die Sonne stellt man sich vor als ein grosses Dorf das von zahlreichen Menschen bewohnt wird. Ihr Aeltester (er wird in den Mythen König genannt) ist Djangkarang. Die Mythe findet ihren Hintergrund in der Stammeinteilung. Ein Stammteil wird in Verbindung gebracht mit der Sonne, der andere mit dem Mond (bulan). Beide wirken bei wichtigen Handlungen und Arbeiten zusammen mit und deshalb finden wir auf manchen Abbildungen auch immer Sonne und Mond dargestellt, z.B. bei der Abbildung des Lebensbaumes. Auf der einen Seite des speerförmigen Wipfels sehen wir die Sonne, auf der andern den Mond. Wir finden sie aber nie allein dargestellt. Die beiden zusammen stellen die Vollkommenheit und Ganzheit des Stammes dar. Sagt ein Jüngling zu seinem Mädchen das er liebt: „Ikau bulan matanandauku“ (du bist mein Mond und meine Sonne), dann hat das nichts zu tun mit einem romantischen Natur- und Liebesgefühl, sondern mit der Vollkommenheit des Stammes, der in der Vereinigung seiner, auf einander angewiesenen Hälften, gute und vollkommene Taten vollbringt zum Heil des ganzen Stammes und auch des ganzen Kosmos.

35, S. 54.

Damit ein Individuum ein vollkommener oder guter Mensch (oloh bahalap), oder ein berühmter Mensch (oloh basewut) werden kann müssen verschiedene Bedingungen bereits erfüllt sein oder noch erfüllt werden.

a.) Das Individuum (Mann oder Frau) muss bautus sein (utus: die 
Verwandtschaft, der Stamm, der Stand), d.h.: es muss zu einer Verwandtschaft oder einem Stamm gehören die ihren Ursprung von den Sangiang herleiten können und die ferner im Stande sind nachzuweisen, dass dieses genealogische Band nie verbrochen worden ist. Es muss mit dieser Verwandtschaft oder diesem Stamm ein Fleisch und ein Blut sein (isi idje, daha idje). Nur durch diese genealogische Abstammung von den Sangiang gehört das Individuum zum utus bahalap (zum guten, zum vollkommenen Stamm und Stand) und es besitzt durch die Geburt das daha bahalap (das gute und vollkommene Blut). Nur in dieser Gemeinschaft, aber nie ausser ihr, ist es möglich ein vollkommener und berühmter Mensch zu werden.

b.) Nebst dieser Grundlage, die gegeben sein muss durch die Geburt oder die geschaffen werden kann indem man sich in diese Gemeinschaft aufnehmen lässt, was sehr kompliziert und teuer ist, ist es auch notwendig, dass das Individuum durch die verschiedenen Initiationsriten zu einem religiös und sozial vollwertigen Gliede des Stammes gemacht worden ist. Diese Riten beginnen vor der Geburt und sie finden beim Manne im vollen Mannesalter (40-45 Jahre), mit den letzten und vollkommensten Tätowierungen (Lebensbaum auf der Brust) ihren Abschluss.

c.) Vollkommen kann das Individuum nur dann genannt werden wenn es sich immer im vollen Gehorsam unterworfen hat unter das religiös/ soziale Lebensgesetz (hadat), das durch die Ahnen aufgestellt worden ist und das für jedes Glied des Stammes bindende und verpflichtende Gültigkeit hat. Es muss sich ferner stets leiten lassen von dem Willen und Rat der Ahnen und es darf nichts unternehmen ohne ihre $\mathrm{Zu}$ stimmung und nichts ausführen ohne ihre Leitung. Es ist im ganzen Leben und in seinem ganzen Handeln an diese Bindungen gebunden und darf sie nie lösen und verbrechen. Es ist ferner seine Pflicht mit allen Kräften mitzuarbeiten, und zwar auch wieder in Verbindung mit den Ahnen, an der sozialen, oekonomischen und religiösen Wohlfahrt des ganzen Stammes und damit auch des ganzen Kosmos. Es darf sich nie und nirgends dieser Mitarbeit entziehen und nichts unternehmen was die Wohlfahrt des Stammes und des ganzen Kosmos benachteiligen würde. In Erfülling dieser Pflichten arbeitet der Dajak nicht nur an der Förderung seines materiellen und diesseitigen Heiles, so diesseitig ist der Dajak trotz aller Darstellungen dann doch nicht, er arbeitet damit auch an der Erreichung des zukünftigen und jenseitigen Heiles, denn nur dann wenn er diese, ihm von den Ahnen auferlegten Pflichten erfüllt hat, wird er nach seinem Tode auch eingehen in ihre überwelt- 
liche Gemeinschaft und Teil haben an ihrem ewigen Heil. Sonst aber nicht.

Nur dann, wenn das Individuum (Mann oder Frau) diese Bedingungen erfüllt und sich im ganzen Gehorsam dem Willen der Ahnen unterwirft und sich von ihnen führen und leiten lässt, nur dann ist er ein oloh bahadat (ein Mensch der nach dem religiös/sozialen Lebensgesetz lebt und handelt und sich in allen Lagen bewusst bleibt, dass es für ihn bindende Gültigkeit hat) und nur dann kann er auch ein vollkommener Mensch genannt werden, sonst aber nicht.

d.) Ein solcher Mensch ist sanang und salamat (er hat den Frieden und das Heil). Sein Reichtum mehrt sich, seine Felder tragen reiche Frucht, sein Tauschhandel blüht, er ist gesegnet mit guten Kindern und alles was er unternimmt gelingt ihm, weil ihn die Ahnen, deren Willen er sich gehorsam unterworfen hat, mit ihren guten Gaben beschenken und ihrem weisen Rat leiten. Diese Gaben der Ahnen bestehen in guten Träumen (nupi bahalap), in guten Vorzeichen (dahiang bahalap), in Gesundheit (karigas), in Tapferkeit (kamenteng), in gut aufgesetzter und überzeugender Rede. Sie bestehen in karuhei (glückbringende Mittel), die ihm im oekonomischen Leben Reichtum, Gewinn und Glück verschaffen, ferner in penjang (glückbringende Mittel), die ihn auf Kriegszügen, bei der Kopfjagd und bei der Rechtssprechung beschirmen und ihn immer als Sieger aus dem Kampf heimkehren lassen. Schliesslich bestehen die grössten Gaben auch in der Freundschaft von bestimmten Ahnen die sich dem Menschen, sei es im Traum oder bei einer persönlichen Begegnung, offenbaren und mit ihm Blutsbruderschaft (hurai, hampahari) schliessen.

e.) Ein Mensch der Heil und Frieden (salamat und kasanang) besitzt ist berühmt. Man spricht überall von seinem Reichtum, seiner Tapferkeit, seiner Weisheit, seiner gut durchdachten und vorgetragenen Rede und seinem Wohlergehen. Er wird überall gelobt (batarong) und sein Lob verbreitet sich in allen Dörfern und an allen Flüssen. Der ganze Kosmos wird von seinem Lob erfüllt, die Tiere horchen auf wenn sein Lob verkündet wird und die Bäume und Sträucher beugen sich wenn sein Ruhm erschallt.

R. BRANDSTETter untersucht in seinem Aufsatz: Die Hymnen der dajakischen Tiwah-Feier (Festschrift für P. W. Schmidt. Wien 1928) auch die Ethik der Tiwahlieder und schreibt: „Es herrscht eine fröstelnde ethische Gestimmtheit. Da, wo wir erwarten, dass die sittlichen Verdienste des Verstorbenen hervorgehoben würden, vernehmen wir bloss, er sei ein berühmter Mann gewesen, so berühmt, dass ,Blitz 
und Donner' zu schwache Bilder seien, um seinen Ruhm zu charakterisieren". Er spricht auch noch über die Seelenkälte der Tiwahlieder. Ganz abgesehen davon, dass Brandstetter nur wenige Texte für die Untersuchung zur Verfügung standen, nämlich die von Aug. Hardeland, die nicht ein abgerundetes Bild ergeben, hätte doch untersucht werden müssen was eigentlich berühmt bedeutet. Das Resultat wäre dann ein anderes gewesen. Blitz und Donner sind Zeichen, dass beim Tode dieses Menschen der ganze Kosmos getrauert hat und wenn sie zu schwache Bilder sind, dann sagt uns das, dass der Verstorbene ein sehr berühmter Mensch war.

Ein unvollkommener oder ein schlechter Mensch (oloh papa) ist ein Mensch der durch seine Geburt ausserhalb der Stammesgemeinschaft steht und der mit ihr nicht gleiches Fleisch und gleiches Blut hat, sondern schlechtes Blut (daha papa). Dieser Mensch gehört entweder zu den Sklaven, oder zu den Hexen (hantuen) oder zu den, durch eigene Schuld aus der Stammesgemeinschaft ausgeschlossenen und verfluchten Gliedern, die kein Heil und keinen Frieden mehr haben und denen keine guten Gaben der Ahnen zuteil werden.

Ein solcher Mensch ist im umfassenden Sinne heillos und heimatlos, denn er ist nicht nur ausgeschlossen aus der Gemeinschaft der Lebenden, sondern auch aus der der Toten.

\section{6, S. 54.}

Siehe Mallinckrodt: Het Adatrecht van Borneo. Leiden 1928. Band I. Pag. $126 \mathrm{ff}$.

\section{7, S. 55.}

Vgl. auch die Mythen der Welt- und Menschwerdung und die Genealogien im II. Band dieses Werkes, sowie die Mythen von Tumbang Lahang die weiter unten mitgeteilt werden.

\section{8, S. 55.}

Man unterscheidet zwei Arten Sklaven. 1. Die djipen. Man wird djipen wenn man seine Schulden nicht bezahlen konnte. Man hat nun für den Schuldiger zu arbeiten bis die Schuld abbezahlt ist. Man kann auch einen anderen Herrn wählen wenn dieser bereit ist die Schuld zu übernehmen. Auf alle Fälle besteht die Möglichkeit aus diesem Verhältnis wieder frei zu werden. 2. Die rewar sind die eigentlichen Sklaven die turon manuron (von Geschlecht auf Geschlecht) Sklaven bleiben und nie die Möglichkeit haben frei zu werden. Ihr Ursprung wird von 
der Menschwerdung her abgeleitet. Die Freien sind an goldenen Seilen auf diese Welt heruntergelassen worden, die rewar aber stiegen nur an langen Stangen aus der Oberwelt herab. Die Anzahl der rewar wurde vermehrt durch Mörder, durch Brandstifter und durch Kriegsgefangene. Die Sklaverei ist in Borneo in jeder Form seit dem Jahre 1892 theoretisch aufgehoben, praktisch aber besteht sie in Zentral-Borneo immer noch, wenn auch in schwächerem Masse und Umfange als früher. Vgl. auch Mallinckrodt: Het Adatrecht van Borneo. Band I.

\section{9, S. 55.}

Die Mythe von Antang Taui, ein weiteres Beispiel für den Ursprung der Sklaven, gebe ich wieder nach der Uebersetzung von R. KühnleDegeler. Sie findet sich in : Evangelisches Missionsmagazin. Basel 1932. Den Schluss dieser Mythe habe ich nach einem fast gleichlautenden Text, den ich am Katingan aufgeschrieben habe, ergänzt. Die Mythe erzählt auch den Ursprung der Hexen und des Giftes mit dem die Hexen arbeiten. Es handelt sich bei diesem Gift um sogen. ramon oloh (Dinge der Menschen), d.h. um verderbliche Mittel derer sich die Hexen bedienen um den Mitmenschen Schaden zuzufügen und sie zu töten. Will man sich dieser ramon oloh bedienen, dann kann man sie selbst nicht herstellen sondern muss sie von Hexen kaufen oder man muss den Hexen den Auftrag geben einen Feind mit diesen Mitteln $z \mathfrak{u}$ vernichten. Wirksam sind sie nur unter Mitwirkung der Hexen. Hier sehen wir auch deutlich, dass die ramon oloh in die Ake/Tahumanlinie gehören.

40, S. 55 .

Tangkahen ist ein Dorf am oberen Kahaian. Baras Manjang ist ein Dorf am Rongan, einem Nebenfluss des Kahaian. Vgl. auch die Mythen von Tumbang Lahang, einem stammverwandten Dorf am mittleren Katingan, wohin die Mythe von Antang Taui eigentlich auch gehört.

41, S. 58.

Boh ist ein Ausruf der Verwunderung.

42, S. 59.

Der Rasen ist ein Nebenflüsslein des Rongan.

43, S. 60.

Wenn die Hexen nachts das Haus verlassen um anderen Menschen 
Schaden zuzufügen oder Leichen aufzuessen, begibt sich nur der Kopf mit den daranhängenden Eingeweiden auf die Reise. Der Körper bleibt als eine leere Hülle zurück. Vor der Morgendämmerung müssen sich Kopf und Körper wieder vereinigen. Wird das verhindert, z.B. dadurch, dass man einen Stock in die Halsöffnung des Körpers steckt, dann stirbt die Hexe. Eine fliegende Hexe nennt man nicht hantuen sondern hantimang. Man erkennt sie daran, dass sie als ein bläuliches Licht langsam über das Dorf fliegt, in einer Höhe von etwa dreissig bis vierzig Metern. Ich habe auf meinen Reisen dieses Licht oft gesehen, Schrecken überfiel dann immer meine Begleiter und leise flüsterten sie einander zu: „Hantimang“. Ich weiss nicht wie wir uns dieses Licht zu erklären haben. Es ist möglich, dass es sich um Erdgase handelt, denn man sieht das gleiche Licht auch oft über frisch aufgeworfenen Gräbern und sagt dann, dass sich die Hexen eingestellt hätten um die Leiche aufzuessen. Die Erklärung, die Hardeland (W. B.) gibt befriedigt in keiner Weise. Er sagt: „Hantimang, das in Deutschland fliegender Drache genannte Meteor. Die Dajaken glauben, der Hantimang sei der König der Hantuen (das ist unrichtig, Sch.), und sie fürchten Unglück werde kommen, wenn ein solches Meteor erscheint". Um einen Meteor kann es sich in keinem Falle handeln, die Lichter die ich sah glichen langsam schwebenden Gasen.

44, S. 61.

Das Gegengift stammt ebenfalls von den Hexen. Krankheiten und Leiden, die durch Hexen verursacht wurden können nur durch Hexen wieder geheilt werden. Weiss man gewiss, dass man eine Krankheit der Wirksamkeit einer Hexe zuzuschreiben hat dann kauft man von einer andern Hexe Gegengift oder man bittet sie die Handlungen zur Erlangung der Gesundheit vorzunehmen. Man bringt den Hexen auch Opfer und legt ihnen Gelübde ab. Vor allem opfert man dem König der Hexen, dem Radja Haramaung Batolang Buno, der über allen Hexen steht und auch vor allen Hexen beschützen kann.

\section{5, S. 62.}

Auch heute noch sind die Bewohner des Oberen Serujan berüchtigt und sehr gefürchtet und man reist nicht gern dorthin aus Angst vergiftet oder durch die ramon oloh der Hexen vernichtet zu werden. Wer die Reise doch aus irgendwelchen Gründen zu machen hat beobachtet sehr viele Vorsichtsmassregeln und rüstet sich aus mit 
Gegengift und Gegenmagie um die vernichtende Wirksamkeit der Bewohner dieses Gebietes zu vereiteln.

\section{6, S. 62.}

Vergleiche auch die ausführliche Welt- und Menschwerdungsmythen im II. Bande dieses Werkes, wo auch unbekanntes Material, das im Zusammenhang mit dem Totenkult durch den Priester rezitiert wird, mitgeteilt werden muss. Eine Zusammenfassung und Vergleichung des heute bekannten und in der Literatur vorliegenden Materiales gibt W. Münsterberger in seiner Dissertation: Ethnologische Studien an Indonesischen Schöpfungsmythen. Den Haag 1939.

Zum Inhalt der ersten Mythe, die hier mitgeteilt wird, ist noch zu sagen: obgleich wir sehr vorsichtig sein müssen gewisse Bestandteile einer Welt- und Menschwerdungsmythe dem Einfluss der missionarischen Verkündigung zuzuschreiben, so glaube ich doch, dass wir von dieser Mythe behaupten können dass sie in ihrer Bearbeitung diesem Einfluss ausgesetzt war. Die ältesten Mythen, die wir im II. Bande dieses Werkes finden, enthalten die Version, dass Mahatala aus einem Knochen des ersten Mannes die Frau geschaffen habe, nicht. Sie ist der christlichen Verkündigung zuzuschreiben. Auch zahlreiche andere Texte, die bei wichtigen Handlungen durch die Priester rezitiert werden müssen, enthalten Materialien aus der christlichen Verkündigung. Die Auswanderung der verschiedenen Sangiangstämme aus dem Ursprungsdorf Batu Nindan Tarong wird in Verbindung gebracht mit dem Turmbau von Babel, manche Basaloh-Mythen (Versteinungsmythen) kombiniert man mit der Sündflut, Tempon Telon der die Liau nach der Lewu Liau (Dorf der Toten) führt vergleicht man mit Jesus Christus usw. Das ist keine Degenerationserscheinung sondern sie zeigt uns die religiöse Auseinandersetzung des dajakischen Priesters mit der christlichen Verkündigung und die Eliminierung ihrer wichtigsten Bestandteile indem sie in das religiöse System eingeordnet werden und hier ihren sinnvollen Platz bekommen. Der Dajak setzt sich nicht nur auseinander mit der ganzen Erscheinungswelt die ihn früher umgeben hat, er setzt sich auch systematisch klassifizierend mit allen neuen und fremden Erscheinungen auseinander und gibt ihnen den richtigen Platz in seinem, so vollkommenen und bewundernswert aufgebauten religiösen und sozialen System, das erst dann befriedigend dargestellt werden kann wenn uns einmal die ganze Mythologie und die Beschreibungen der Ober- und Unterwelt vorliegen. Jedenfalls ist das sicher, dass nicht nur der Europäer, oder der Araber, oder der Chinese einen Platz 
bekommt in diesem System und in den Beschreibungen der Oberwelt, wo auch diese fremden Welten harmonisch eingereiht wurden, sondern auch die kulturellen und religiösen Aeusserungen dieser Fremden, soweit sie für die dajakische Auseinandersetzung und Klassifizierung irgend wie erfassbar und auch wichtig und nötig geworden waren.

47, S. 64.

Vgl. Aug. Hardeland: Wörterbuch, unter Sangiang.

48, S. 64.

Hardeland irrt sich. Die Sangiang lebten vor alten Zeiten nicht auf dieser Welt, sondern die Menschen, die auch vom Geschlecht der Sangiang abstammen, lebten vor alten Zeiten in der Oberwelt, in Batu Nindan Tarong, und sie sind von dort, weil Maharadja Bunu im Besitze des tötenden Eisens (sinkendes Eisen) war, auf diese Welt heruntergestiegen.

49, S. 65.

Auch hier irrt sich Hardeland. Die Stammväter der Sangiang sind noch keineswegs emeritiert sondern nehmen sehr aktiv Teil am Ergehen der Menschen und sie helfen mit, dass die Liau nach der Lewu Liau geleitet werden können. Vgl. die Ursprungsmythen im II. Bande dieses Werkes und dann auch die weiteren Texte die dort, und in den andern Bändern mitgeteilt werden.

50, S. 66.

Vgl. C. A. L. M. Schwaner: Borneo. Band I. Pag. 175. Die Beschreibung ist ziemlich undeutlich und verwirrt. Die Anmerkungen (pag. $232 \mathrm{ff}$ ), bearbeitet durch Pijnappel, sind durchaus unbrauchbar.

\section{1, S. 71.}

In : Tijdschrift voor Neêrland's Indië. Achtste Jaargang. Derde deel. Batavia 1846.

52, S. 73.

In : Bijdragen tot de Taal-, Land- en Volkenkunde van NederlandschIndië. Deel 66. 1912.

53, S. 74.

In: Bijdragen tot de Taal-, Land- en Volkenkunde van NederlandschIndië. Deel 80. 1924. 
54, S. 79.

In: Wörterbuch. Siehe unter Djata.

55, S. 80.

Bapa Haastert wohnt in Mengkatip am Barito. Er stammt aus einem sehr angesehenen Dajakgeschlecht und ist ein guter Kenner der Kultur seines Volkes. Er hat Missionar Göttin wertvolles Text- und Bildmaterial geliefert und auch diese Mythe stammt aus dieser Sammlung. Bapa (Vater), Haastert (der Name des ältesten Sohnes). Verheiratete Dajak, die Kinder haben, werden nicht mehr mit ihrem eigenen Namen, sondern nach dem des ältesten Kindes (Sohn oder Tochter) genannt, wobei dem Namen die Bezeichnung Vater (bapa) oder Mutter (indu) vorgesetzt wird. [Vgl. die Lebensbeschreibung von Bapa Haastert durch R. Kühnle-Degeler; holländische Uebersetzung von K. J. Brouwer. Culemborg 1935.]

56, S. 80.

Die Mythe wird mit dem ursprünglichen Text mitgeteilt weil dieser für die Vergleichung mit dem Text der vollständigen Mythe im II. Band dieses Werkes notwendig ist. Die Sprache ist das gewöhnliche Ngadju, nicht aber die Basa Sangiang (Sangiangsprache oder Priestersprache). Manche Elemente der Basa Sangiang werden hier allerdings mit dem Ngadju vermengt.

57 , S. 81.

Tuntang (und), im Original abgekürzt : ttg.

58 , S. 84.

Die dajakische Stammesorganisation kennt kein Königtum. Der malaiische Term radja (König) bedeutet im dajakischen Sprachgebrauch : der Dorfälteste, der Wichtigste, der Berühmteste. Ie radja,n oloh dagang (er ist der König der Handelsleute) bedeutet: er ist der berühmteste aller Händler. Ie radja,n anak sekolah (er ist der König der Schulkinder) bedeutet: er ist von allen Schülern der gescheiteste.

59, S. 85.

Betan (Schwester) bedeutet auch hier wahrscheinlich nicht die Schwester, sondern die Frau des Tantaolang Bulau. 
60, S. 86.

Der butah ist ein von feinem Rotan geflochtener Rückenkorb in dem die Traglasten getragen werden.

61, S. 87.

Wozu dieser Dolch eigentlich dient ist mir noch nicht bekannt.

62, S. 87.

Minjak ajar mata dujung. Nach R. J. WiLkinson: A Malay-English Dictionary. 2 Bände. Mytilene. 1932 bedeutet minyak tangis duyong: „dugong tears" believed to be a most potent love philtre.

Nach H. von DE WALL: Maleisch-Nederlandsch Woordenboek. Uitgegeven door $\mathrm{H}$. N. Van der Tuuk. Batavia 1880 bedeutet dujung: de zeekoe; ajer mata $d$. zeekoe-tranen, een vocht, dat (zegt men) der gewonde en stervende zeekoe, wanneer hare jongen voor hare oogen gedood worden, uit de oogen vloeit en zorgvuldig met boomwol afgedroogd wordt. Deze met zeekoe-tranen bevochtigde boomwol is een beroemd toovermiddel, om tegenliefde te verwekken.

Diese Tränen werden offenbar vermischt mit minjak (Oel), das im magischen Gebrauch eine sehr grosse Rolle spielt. Dieses Oel wird auf irgend eine Weise dem Menschen, dessen Liebe man erwerben will, beigebracht, sei es vermischt mit den Speisen oder auf die Kleider geschmiert.

\section{3, S. 87.}

Minjak saputar balik. Putar ist nach HaRdeland, W. B. ein Zaubermittel, durch welches man jemand tötet. Hier handelt es sich um ein Mittel um erkaltete oder verlorene Liebe wieder zurückzugewinnen und das Herz, dessen den (die) man liebt wieder $z \mathfrak{u}$ verändern. Hardeland schreibt: Gau karohei intu tabit hapa mambalik atei,e, mangat ie mangilak ikan tinai: such ein Zaubermittel bei einem Zauberdoktor, um sein Herz zu verändern, auf dass er dich wieder liebe. Balik: das gewechselt, verändert werden (Kleider, Worte); das umgedreht, umgekehrt werden. (W. B. unter balik).

\section{4, S. 87.}

Guna (Sanskrit). R. J. Wilkinson schreibt: The virtue in anything. In two senses: (i) magical potency; (ii) usefulness. For (i) (und dieses interessiert uns hier allein), the older and more specific meaning, cf : g.-gana (philtres of all sorts); g.-pěngaseh (love philtre), Ht. Koris ; 
ubat $g$. (philtre); kena $g$. (to be under the influence of a philtre and not in one's right mind).

H. A. van Hren: De Javaansche Geestenwereld. Semarang 1896, schreibt im II. Band seines vierbändigen Werkes, Seite $30 \mathrm{f}$ : De gunaguna beteekent iets vereenigen of bij elkander brengen; de geheime middelen, die daarbij in het geheim worden toegediend, maken iemand gedachteloos (bruwet), van welken toestand men gebruik maakt om van hem of haar te verkrijgen, wat men wil.

Ten einde de lezer goed te doen begrijpen, hoe men daarbij te werk gaat, volgt hieronder een voorbeeld, waarbij wij tevens de toe te dienen middelen zullen beschrijven.

Iemand is verliefd op een meisje, doch zij wil van den verliefde niets weten. $\mathrm{Nu}$ gaat de man naar een dukun guna-guna; gewoonlijk zijn dit vrouwen. Men betitelt ze wel eens met den naam van Ungah-ungahi, d.i. koppelaarster. Zulk een dukun tracht dan met het meisje in aanraking te komen en haar langs geheimen weg, gewoonlijk door middel van vrouwelijke bedienden of huisgenooten, een poeder toe te dienen van de Djaka-tuwa, een kleine tor, die alvorens gedood, gedroogd en fijngestampt te worden, met ketjubung-bladeren gevoed is. Is dit gelukt, dan plaatst de dukun den eerstvolgenden Maandag- of Donderdagavond een Guna-guna voor de deur van de woning, waarin zich het meisje bevindt; deze Guna-guna bestaat uit twee uitgeknipte poppen, voorstellende het meisje en den man, die haar verlangt, welke poppen in den grond begraven worden. Op dien dag heeft zij door tusschenkomst van een bediende of huisgenoot eenig hoofdhaar van het meisje weten machtig te worden, dat gezamenlijk met de hoofdharen van den verliefden man, bewierookt met Stanggi en omwonden met Kanangabloemen in het hoofdkussen van het meisje verborgen wordt.

Door de toediening van den Djaka-tuwa is het meisje in een toestand gebracht, waarin zij weinig meer beseft (bruwet) ofschoon haar wezen niets veranderd is en zij is dan genegen alles te doen, wat men van haar verlangt. De dukun heeft nu niets meer te doen dan te trachten haar toe te spreken, bij welke gelegenheid zij ongemerkt een der ontbloote deelen van het lichaam aanraakt met minjak dujung, d.i. de tranen van de zeemeermin, en haar verzoekt bij den verliefden man te komen, waarbij zij haar geleide aanbiedt. Meestal gelukt dit en wordt het meisje door de dukun in de armen van den verliefden man gevoerd.

Indien het de dukun volstrekt onmogelijk is door tusschenkomst van bedienden of huisgenooten in aanraking met het meisje te komen, dan wordt de waschvrouw te hulp geroepen en verlangt de dukun van haar 
een kleedingstuk in leen, dat door het verlangde meisje gedragen is, welk kleedingstuk alsdan door tooverformulieren betooverd wordt, zoodat het meisje even gewillig wordt, ja zonder verdere middelen soms van zelf naar den verliefden man komt. Dit tooveren bestaat in het bewierooken van het kleedingstuk met Stanggi en in het uitspreken van tooverformulieren, die onmogelijk opgeschreven kunnen worden.

Ter bereiking van zijn doel maakt de man ook gebruik van den Tjoblong, een boomgeest in de gedaante van een tjupu of doosje. Daartoe moet hij, na de standplaats van den Tjoblong te hebben gevonden, aan den voet van den boom een offerande aanbieden, terwijl hij gedurende drie dagen moet vasten, onder het aanroepen van dien geest om hem behulpzaam te zijn om zijn doel te bereiken. Wordt die bede verhoord, dan ontvangt hij op den derden dag een weinig olie, die minjak Tjoblong wordt genoemd en de eigenschap heeft om het verlangde meisje of de gewenschte vrouw lijdzaam en gedwee te maken, wanneer zij slechts even er mede in aanraking wordt gebracht.

Den gleichen Gebrauch der guna oder guna-guna finden wir auch in Borneo. Die Mittel stammen wahrscheinlich von den Malaien oder aus Java und sind nicht typisch dajakisch. Echte und ursprüngliche dajakische Mittel sind die karuhei von denen wir unten zu sprechen haben.

\section{5 , S. 87.}

Lingo, ein Wort aus der Basa Sangiang (Sangiangsprache oder Priestersprache) bedeutet im gewöhnlichen Ngadju: das Innere, die Begierde (huang). Das davon abgeleitete Verbum mangalingo bedeutet: seinem Schmerz, seiner Sehnsucht, seinem Heimweh Ausdruck geben. Peres lingo: die Krankheit des Innern, Liebeskummer, unerfüllte Sehnsucht, ungestilltes Heimweh. Hier in diesem Zusammenhang ist es Liebeskummer oder die unerfüllte Sehnsucht nach der Geliebten.

\section{6, S. 87.}

Minjak Sri Gunong Ali. Darüber ist mir nichts bekannt. Wahrscheinlich ist es auch eine Liebesmedizin wie die bereits genannten. R. J. Wilkinson schreibt unter Ali: A proper name. Often met with among Malays; borne by the Prophet's son-in-law the Caliph Ali (baginda Ali), the "lion" or "tiger" of God (asad Allah, hariman Allah), regarded by Malays as the perfect husband of the ideal wife (Fatimah) and as such often mentioned in love charms, e.g. the pokok payong Ali. 
67 , S. 87.

Hardeland schreibt über die karuhei (W. B.).: Karohei, krohei (Schreibweise von Hardeland, heute schreibt man statt eines $o$ ein $u$ ), Zaubermittel um Glück, Vorteil zu erlangen. Man hat verschiedene Arten Karohei.

Karohei (ohne ein anderes Wort dabei) besteht aus einer Art Oel und Stückchen Baumwurzeln darin, soll Männern die Gunst der Frauen, et vice versa, erwerben; man bestreicht mit den Stücken ins Oel getauchtem Holze die Kleider der begehrten Person, oder die Sirihblätter, welche sie kauen wird. Auch kann man ein durch Mohamedanen gemachtes Zauberbriefchen zu dem $Z$ wecke gebrauchen, welches man im Kopftuche trägt; dann muss man Sorge tragen den Schatten des Kopftuches auf die begehrte Person fallen zu lassen.

Karohei badagang (Karohei zum Handel treiben) besteht zus 3, 4, 5 oder sieben Stücken Holz verschiedener Holzsorten, oder aus so viel verschiedenen Steinen, welche durch ein simpei (Band) zusammengeflochten sind. (Das manjimpei, hasimpei dengan: zusammenbinden oder flechten, geschieht mit viel Feierlichkeit; es werden Opfer dabei gebracht). Man nimmt dies Karohei mit auf Handelsreisen, um Glück zu haben. Das Holz dazu muss durch einen dewa (Geist), oder durch einen Traum angezeigt werden; man darf die Holzsorten dann nie zu etwas anderem, zu Bauen, Kochen etc. gebrauchen. Man muss das Karohei jeden Monat manjaki (mit Blut bestreichen), dann behält es seine Glück bringende Kraft bis auf die fernste Nachkommenschaft; aber nur auf die Nachkommen des ersten Herrn, verkauft darf es nicht werden.

Karohei tatau (Karohei des Reichtums), ebenfalls Holzstückchen oder Steine, welche durch einen Dewa oder einen Traum angewiesen sind, und welche innerhalb dreier Tage nach einer Mondfinsternis geholt werden müssen. Man schneidt dann gewöhnlich hampatong (Püppchen) aus dem Holze, welche man sorgfältig im Hause bewahrt. Man hofft durch sie Glück, Gesundheit, gute Ernten etc. zu erlangen. Sie werden jährlich einmal manjaki (mit Blut bestrichen).

Karohei mandjawet (Karohei für die Flechterei) nennt man verschiedene Gräser oder Baumblätter, welche man gebraucht, um jemand geschickt im Verfertigen von Flechtwerk zu machen. Man kaut sie und speit das Gekaute kleinen Kindern auf den Kopf; den grössern Kindern reibt man die Finger damit ein. Die verschiedenen Familien gebrauchen verschiedene Gräser und Blätter zu diesem Zwecke, die, welche von den Vorfahren her dazu bei ihnen im Gebrauche waren. 
Karohei djazet (Karohei der Flechtarbeiten), Stückchen Holz, welche man in ein Flechtwerk einflicht, um es gut und teuer verkaufbar zu machen; auch dazu gebraucht jede Familie eine andere Sorte Holz, welche? das muss Geheimnis bleiben.

Karohei mamisi (Karohei für den Fischfang), Stückchen Holz welche man an Angelschnüren festbindet um glücklich beim Fischen zu sein; das Holz muss durch einen Traum angezeigt, und bei einer Mondfinsternis geholt sein; man kann dann so viel holen als man will, und auch andern davon verkaufen. Einige Sorten von Glück bringende Zaubermitteln haben nicht den Namen Karohei, sondern andere Namen; z.B. sangkalemo, emo, panjuka, bestehen in Zauberbriefen, oder in einigen arabischen Wörtern, welche man leise vor sich herspricht; sie sollen Männern die Gunst von Männern, vorzüglich den geringern die der reicheren, vornehmeren, erwerben; dieses Mittel kauft man von Mohamedanen.

Sampun parei, sampun behas sind kleine hölzerne Püppchen, welche man auf einen Reishaufen steckt, damit Segen darauf ruhe; das Holz dazu muss durch einen Traum angezeigt werden. Wir sehen, dass die Karuhei, die besser nicht mit Zaubermitteln übersetzt werden, wie das seit Hardeland immer wieder geschieht, weil sie eben keine Zaubermittel sind, gute Gaben der Ahnen sind. Der Mensch hat sie nicht aus sich selbst, er kann sie nicht selbst anfertigen und kann sie auch nicht selbst auffinden. Die Hölzer oder Steine, die für die Karuhei verwendet werden, müssen ihm durch die Ahnen im Traum angezeigt und ihr Fundplatz muss ihm auch dann mitgeteilt werden, sonst vermag er sie nicht $\mathrm{zu}$ finden.

Karuhei geben auch die Urai (die Ahnen mit denen man Bruderschaft geschlossen hat), sei es im Traum, sei es bei einer persönlichen Begegnung. Ein wichtiger Fundplatz für die Karuhei ist der Bukit Raja, die höchste Erhebung des Schwanergebirges. Er ist der Götterberg. Aber auch dort kann man die Karuhei auch nicht einfach so holen und mit ihnen wieder weglaufen. Bevor man sich zu diesem Zwecke nach dem Bukit Raja begibt muss man sich während einiger Zeit aus der Gemeinschaft und von Familie und Frau absondern und in einer einsamen Hütte, unter Beachtung von Askese, alle religiösen Handlungen erfüllen um von den Ahnen nicht nur die Zustimmung zur Reise, sondern auch ihren Schutz während der Reise und ihre Mithülfe beim Suchen der Karuhei zu bekommen. Wenn man erfolgreich von seiner Reise zurückgekehrt ist mit diesen guten Gaben der Ahnen, dann wird ein grosses Opferfest gehalten um den Ahnen zu danken. Eine der 
wichtigsten Bitten an die Ahnen, die wir in allen Texten immer wieder finden, ist nebst der Bitte um gute Träume und gute Vorzeichen, die dem Menschen auf allen seinen Wegen und in allen seinen Entscheidungen Leitung geben, auch die um gute Karuhei, d. h. um gute Gaben der Ahnen die soziales und oekonomisches Glück und Wohlfahrt versichern und mehren.

Die günstigste Zeit zum Aufsuchen der Karuhei ist die der Mondfinsternis. Nicht die Finsternis ist an sich günstig, sondern die Vereinigung von Sonne und Mond der ein Kampf vorangeht. Diese Vereinigung, vor allem dann der Kampf, erweckt bei den Menschen nicht nur Besorgnis, sondern sie vermittelt kosmisches Heil und Frieden. Das gleiche sehen wir ja auch bei der Vereinigung des Stammes bei wichtigen Arbeiten und Handlungen die durch den ganzen Stamm ausgeführt werden müssen. Auch dieser Vereinigung geht immer ein erbitterter Scheinkampf voraus. Aber nach diesem Kampf erfolgt die Vereinigung zum gemeinsamen Handeln das für den ganzen Stamm und darüberhinaus auch für den ganzen Kosmos heilvoll ist. Vgl. für die Sonnen- und Mondfinsternis die Mythe: Die Ursache der Sonnenund Mondfinsternis. Für die heilvolle Vereinigung des Stammes verweise ich auf die Texte des II. Bandes dieses Werkes.

68, S. 88.

Zwischen der Oberwelt (lewe Sangiang: Dörfer der Sangiang) und der Welt die von den Menschen bewohnt wird (pantai danum kalunen: die Ufer am Flusse der Welt) herrscht keine strenge Scheidung. Die Ahnen steigen auf die Welt herunter und die Menschen steigen in die Oberwelt hinauf (Siehe die Mythen von Panjat und von der Ursache der Sonnen- und Mondfinsternis unter I. und IV.). Als Weg dient hier der dereh batu pandjang... (die steinerne Säule).

69, S. 88.

Wird der Reis an der Sonne getrocknet dann bewacht man ihn vor den Hühnern die sich ihm immer wieder nahen. Meistens geschieht das durch die Franen die sich mit einem Stock in der Hand unter die Haustüre setzen und die Hühner verscheuchen. In einzelnen Fällen gebraucht man dazu auch einen Falken dem man die Flügel gestutzt hat. Die Hühner wagen sich nicht diesem Raubvogel zu nahen.

70, S. 88.

Pantar pandjang. Vgl. auch Erklärung 11. Dort ist der pantar 
beschrieben als djamban liau (Steg, Brücke für den Toten), hier sehen wir dass der gleiche pantar, der in diesem Falle nicht aus Eisenholz sondern aus Stein besteht, dem Tato Garagasi als Brücke zwischen Oberwelt und der Welt der Menschen dient, und also den gleichen Nutzen hat wie der pantar als djamban liau.

\section{1, S. 89.}

Der Pangirak ist der Aufrufer der die Aufträge des Pambakal (Dorfhaupt) überbringt und bei Rechtssitzungen oder $z u$ verpflichteten Arbeiten (Heerendienst) die Männer des Dorfes zusammenruft.

\section{2, S. 91.}

Hanggulan apui ist ein Stück Holz welches man des Abends glimmend unter die Asche legt, damit man am Morgen noch Feuer finde.

\section{3, S. 91.}

Pondok apui ist ein brennendes Stück Holz, ein Feuerbrand; Holz welches gebrannt hat oder angebrannt ist. Sihong bedeutet im gewöhnlichen Ngadju Elfenbein, in der Basa Sangiang aber Holz. Hier hat es die letztere Bedeutung.

74, S. 91.

Pulut ist eine Art Reis. Die Pflanze ist länger als die des gewöhnlichen Reises, die Körner sind dicker, mehr rundlich, und kochen sich breiiger als der rechte Reis. Man kocht den Pulut zusammen mit Kokosnuss und bekommt dann den sogenannten Klebreis der bei Festen gegessen wird und auch als Opfergabe dient.

\section{5 , S. 91.}

Tato Seso. Die seso sind grosse rote Ameisen die sehr empfindlich beissen. Tato (Ahne) ist der Vorvater von dem die Seso abstammen. Dass er die Grösse hat eines Ziegenbockes ist keine Uebertreibung, denn nach dajakischer Vorstellung zeichnen sich die Ahnen der Tiere und auch der Menschen durch riesenhafte Grösse aus. Darstellungen sehen wir auf den sapundu (geschnitzte Opferpfähle).

76, S. 91.

Die saragate sind kleine, rate Ameisen die sehr schmerzhafte Bissstellen zurücklassen. Diese, wie auch die seso halten sich meistens bei den genannten Bäumen auf und haben dort ihre Nester. 
77, S. 93.

Laut (die Richtung nach dem Meere, nach der Mündung zu) und djalajan (die Richtung nach dem Oberlauf, dem Quellgebiet des Flusses) drücken nicht nur eine gewisse geographische Lage aus, sondern auch die Lage der Stammhälften. Das Gebiet der einen Stammhälfte wird mit Djalajan oder mit ngadju (stromaufwärts) bezeichnet, das Gebiet der andern Stammhälfte mit laut oder ngawa (stromabwärts). Die vier Windrichtungen, die auch mit der Stammesorganisation zusammenhängen sind: Hila matanandau belom (die Richtung der aufgehenden Sonne), hila matanandau belep (die Richtung der untergehenden oder auslöschenden Sonne), hila ngadju (die Richtung nach stromaufwärts) und hila ngazwa (die Richtung nach stromabwärts). Dieser Einteilung werden wir in den Texten immer wieder begegnen. Mit dieser Einteilung in Laut und Hulu, oder ngawa und ngadju, hängt auch die Sitte der Aufbahrung der Leichen zusammen. Die Leichen der Frauen werden aufgebahrt mit den Füssen nach stromaufwärts, die Leichen der Männer mit den Füssen nach stromabwärts. Das hat durchaus nichts zu tun damit, dass die Männer vom Meere her eingewandert sein sollten. Diese Annahme entbehrt jeder Unterlage und ihre Unrichtigkeit ist für die Ngadju- und Katingandajak sehr einfach zu beweisen, es hat aber zu tun mit der Stammorganisation und Stamm. verteilung und ihrer kosmischen Auswirkung die in der Einteilung der Windrichtungen ihren Niederschlag findet. Dem Ausdruck budjang laut und laut begegnen wir noch sehr oft in den Mythen und Texten und dürfen dabei nie an Fremdlinge und fremde Gebiete denken, die ausserhalb des Stammgebietes liegen würden, wir müssen immer die Stammeinteilung und -verteilung im Auge behalten. Das gilt vor allem auch für die oft vermeldeten Heiraten zwischen budjang laut und budjang hulu, wobei der erstere ein Jüngling, der letztere aber eine Jungfrau ist.

\section{8, S. 93.}

Lasang ist ein Wort aus der Basa Sangiang und bedeutet im gewöhnlichen Ngadju djukung: ein, aus einem Baumstamme gemachtes Boot. Banama ist ein grosses Handelsboot mit dem man auch über See segelt. Kalulus ist ein langes, schmales, schönes Boot, welches man nur bei Besuchen etc. gebraucht, vor allem auch bei religiösen Festen und Handlungen bei denen der ganze Stamm teilnimmt und wobei eine Stammhälfte die andere besucht. 
79, S. 94.

Djihi sind die hohen Eisenholzbalken die das ganze Haus tragen. Jeder dieser djihi hat seinen eigenen Namen. Tongket sind die Eisenholzbalken auf denen der Fussboden ruht.

80, S. 94.

Ambon Rutas. In der Basa Sangiang lautet der vollständige Name: Ambon barutas matei, enon bapilo nihau (die Nebel, die zerstörenden des Toten, der Tau, der vernichtende des Verlorenen).

HardeLand (W. B.) schreibt unter rutas: das pali, verunreinigt sein durch eine Leiche. Katahin rutas djaton tau tapas katelo, idje toto ombet kudju, tapi aton kea idje sampai telo bulan, hapan huang,e: dass man sich, wenn jemand im Hause gestorben ist, als unrein hält (man hält sich nicht als unrein, sondern man wird durch den Toten unrein, man wird durch ihn in den Tod hineingezogen, Sch.), mag nicht unter drei Tagen sein, seine gehörige Dauer ist sieben Tage, aber es sind auch Menschen welche es bis drei Monate lang tun, jeder macht das nach seinem Belieben (das stimmt auch wieder nicht ganz, denn wahr-scheinlich gelten für die verschiedenen Familien verschiedene Rutaszeiten, was zusammenhängt mit der Bestattung und dem manolak rutas: dem Wegschieben des rutas, Sch.).

Barutas: durch einen Sterbefall unrein sein. Aku djaton tau ombo mihop, barutas amaku matei (ich kann nicht mit zum Trinkgelage gehen, ich bin unrein dadurch, dass mein Oheim gestorben ist).

Marutas: etwas (Häuser, Flüsse, Menschen) für unrein erklären und absperren, wegen eines stattgefundenen Sterbefalles. Auch beim Tiwah (Totenfest) marutas (sperrt) man den Fluss (ab) da wo das Haus, in welchem das Fest gegeben wird, steht, sieben Tage lang. Es darf dann niemand dort vorbeirudern, - zu Pulopetak (die Dörfer am Murong zwischen Kuala-Kapuas und dem Barito) jedoch lässt man gegen ein kleines Geschenk dann doch Boote passieren.

Nach den Priesterkarten und Priestertexten gibt es in der Oberwelt einen batang danum rutas (Rutasfluss) wo sich ein Dorf befindet das von taloh (Geistern) bewohnt wird. Bevor man dieses Dorf betritt kommt man zum hampatong rutas (dem Schnitzbild rutas). Nach der dajakischen Glaubensvorstellung und der Erzählung verhält es sich damit so: jedesmal wenn ein Mensch auf dieser Welt (pantai danum kalunen) stirbt wird ein solches Schnitzbild durch Tinggi-Tingang für jeden Toten aufgerichtet, als Zeichen für diesen Menschen der gestorben ist. Aber auch für Tinggi-Tingang ist dieser Hampatong ein 
Zeichen zu seiner Erinnerung das er aufgerichtet hat nach dem Befehl des Radja Balawang Bulau der seinen Wohnort hat auf dem Berg Bulau Manjampaga Bulan am Oberlauf des Flusses Baras Bulau. Wenn die Menschen das Tiwah feiern werden die Hampatong rutas weggeschlagen und fortgeworfen.

Ueber den Fluss Rutas hat Tinggi-Tingang einen sendong badjungan danum gespannt. Sendong ist ein Verbotszeichen das durch ein Rotanoder Badjunganseil (badjungan: eine Sorte Rotan, wird daumendick; wertlos; kann nicht gesplissen und für Flechtarbeiten verwendet werden; man bindet Büffel damit fest etc.) gebildet wird mit dem man einen Fluss absperrt, indem man es über den Fluss spannt, zum Zeichen, dass niemand dort vorbeifahren darf weil der Platz pali (rituell verboten, heilig) ist. Danum (der Fluss, das Wasser). Sendong badjungan danum bedeutet: das Verbotszeichen das in einem $\mathrm{Ba}$ djungan besteht der über den Fluss gespannt worden ist.

Sendong ist gleichbedeutend mit talutok (siehe Hardeland, W. B.). Das Wort bedeutet: das abgesperrt sein eines Weges oder Flusses, dadurch dass man ein Rotanseil mit einer hölzernen Lanze oder einem hölzernen Messer daran quer darüber herzieht. Es geschieht dies z.B. dann wenn irgendwo gefährliche Krankheiten herrschen oder eine Leiche aufgebahrt liegt, auch dann wenn man andern verbieten will auf einem Waldstück, das man für sich in Besitz genommen hat, Rotan zu schneiden etc.

Der durch Tinggi-Tingang über den Fluss gespannte sendong $b a-$ djungan danum (für jeden Toten einen eigenen) dient jedem Toten als Zeichen, dass er hier nicht vorbeigehen dürfe um sich nach der Totenstadt zu begeben, bevor für ihn das Tiwah gefeiert worden ist. Beim Tiwah werden die sendong badjungan danum durchgeschnitten und weggeworfen durch Tempon Telon oder durch Dohong Mama Tandang die die Liau (Toter) nach dem Totendorf leiten.

An der Mündung des Rutasflusses befinden sich verschiedene treibende Pflanzeninseln, nämlich eine Bakonginsel (bakong ist eine Wasserpflanze, wahrscheinlich die Wasserlilie. Sie wächst an den Ufern der Flüsse, oft weit in den Fluss hinein, und es werden dann bei starker Flut oft ganze Inseln davon weggespült. Der Stengel wird gegessen, die langen breiten Blätter gebraucht man als talusong, als die äussere Umhüllung der Harzlichter) und eine Kadjanginsel (kadjany werden die Matten genannt die von den Blättern der Ipahpalme geflochten werden. Man gebraucht diese Matten für Hauswände und für sehr viele andere $Z$ wecke im täglichen Leben und in der Arbeit. Es 
handelt sich wahrscheinlich hier um eine Insel von Ipahpalmen). Diese Inseln können sich fortbewegen und ihren Liegeplatz in Meer Lajang Hanteran Riwut verändern. Mit diesen Inseln verhält es sich folgendermassen : Nach der religiösen Vorstellung der Dajak gibt es nicht nur eine Liau, sondern zwei hauptsächliche Liau. Die eine wird genannt Salumpok Liau, die andere nennt man Liau Balaziang Pandjang. Die Salumpok Liau, oder wie sie mit dem ganzen Namen heisst: die Salumpok Liau Haring Kaharingan wird durch Tempon Telon nacl dem Totendorf geleitet. Die Liau Balawang Pandjang aber wird durch Dohong Mama Tandang nach dem Totendorf geleitet. Tempon Telon leitet die Salumpok Liau eine Nacht bevor Dohong Mama Tandang die Liau Balawang Pandjang leitet. Wenn Tempon Telon bei der Mündung des Flusses Rutas ankommt und in diese eingefahren ist, dann verschiebt er diese Pflanzeninseln und versperrt mit ihnen die Mündung des Flusses Rutas um Dohong Mama Tandang zu necken. In der nächsten Nacht kommt Dohong Mama Tandang mit der Liau Balawang Pandjang dort an und er kann die Mündung des Flusses Rutas nicht finden. Er spricht: „Hau, das hat gewiss Tempon Telon getan um mich zu necken und auf die Probe zu stellen". Er schiebt die Inseln auseinander und kann dann die Reise nach dem Fluss Rutas und nach dem Totendorf fortsetzen.

Am Flusse Rutas liegt das Dorf des Tinggi-Tingang. Im Dorf ist ein hoher Flaggenstock mit einer Fahne aufgerichtet als Eigentumszeichen des Dorfes und Flusses (die Fahne trägt die Farben des Tinggi-Tingang). Im Dorf befindet sich auch ein Balai (Versammlungshaus) der den Namen Balai Rutas trägt. Oft wird er auch Balai Hamparang (der quer liegende, den Weg verschliessende Balai) genannt. Am Ende des Dorfes liegt der Bestattungsort für die Leichen, der Bukit Pasahan Raung (der Berg mit den Hütten für die Särge. Die Särge werden auf Gestellen über der Erde beigesetzt und mit einem Dach versehen). Nach der religiösen Vorstellungswelt der Dajak und nach den Erzählungen verhält es sich damit so: Alle Särge, die in dieser Welt (pantai danum kahunen, also in der Welt der Menschen) beigesetzt werden, haben eine gana (Seele, d.h. die Seele von leblosen Dingen, der Bäume und Pflanzen). Die Särge, die im Dorfe des Tinggi-Tingang beigesetzt werden sind die Gana der Särge, die die Menschen auf der Welt beigesetzt haben.

Tinggi-Tingang kennt alle Liau (Toten) die in sein Dorf kommen. Er hat auch die Macht alle Speisen (Opfer) in Empfang zu nehmen, die die Menschen ihm senden und sie unter seinen Untergebenen zu 
verteilen. Er selbst aber steht unter der Macht des Njaho Erang Matan Kilat Pandjang Dimpah Ruang Langit und des Radja Balawang Bulau. (Nach den Erklärungen des Johannes Salilah zu den Karten der Oberwelt. Eine gründliche und befriedigende Erklärung des Rutas-flusses und des Tinggi-Tingang kann erst dann gegeben werden wenn wir die ganze Oberwelt und damit auch das ganze religiöse System der Dajak gründlich kennen).

Vgl. auch die pali, $n$ rutas im II. Teil dieses Bandes. Zum manolak rutas (Wegschieben des rutas) werden, ebenfalls im II. Teil dieses Bandes, die ausführlichen Texte mitgeteilt.

\section{1, S. 94.}

Tingang ist der Nashornvogel. Es handelt sich hier wahrscheinlich um längliche Blätter die die Form der Schwanzfedern des Nashornvogels haben. Dawen marau (Maraublätter. Marau ist eine Art Rotan, wird so dick als wenn man die fünf Finger zusammenhält, die einzelnen Glieder sind aber kaum eine Spanne lang. Es wird gebraucht um Flösse etc. damit anzubinden). Manjamei ist der Wächter an der Türe des Himmels, das heisst beim Eingang in die Oberwelt. Vgl. auch die Texte im II. Teil dieses Bandes, in denen der Zugang zur Oberwelt und die Reise dorthin näher beschrieben wird.

\section{2, S. 95.}

Die penjang bestehen meistens, wie auch die karuhei aus Hölzern, Steinen und aus diesen Hölzern geschnitzten hampatong (kleine menschliche Figuren, oder auch Tigerfiguren), sowie aus Tiger- und Krokodilzähnen. Auch die Penjang kann man nicht selbst machen oder finden, sie sind wie die Karuhei die Gabe der Ahnen. Man erwirbt sie von ihnen durch das batapa (Askese, vgl. den Anhang: Aus der Mythologie eines Dajakdorfes wo das Batapa ausführlich beschrieben wird), man erhält sie von ihnen als freie Gabe bei einer persönlichen Begegnung, oder ihr Fundplatz und ihre Beschaffenheit wird im Traume mitgeteilt. Man kann auch von den Penjang nicht von Zaubermitteln sprechen, weil es Gaben von Ahnen sind, die, im täglichen Leben, und hier speziell bei Krieg und Kopfjagd und Gerichtssitzungen verwendet, Schutz und Hülfe der Ahnen selbst verleihen. Die Penjang dienen hauptsächlich zur Abwehr von nahenden Feinden, zur eigenen Stärkung und Lähmung der Feinde im Krieg und auf der Kopfjagd und zum dumm machen oder versöhnlich stimmen der Gegner bei Gerichtssitzungen. Die gefundenen Hölzer oder Steine, oder solche die 
man direkt von den Ahnen empfangen hat, legt man in verzierte Bambusköcher die man mit einem kleinen Deckel oder Zapfen der meistens zu einer menschlichen Figur oder einer Tigerfigur ausgeschnitzt ist, schliesst. Diese Köcher werden in einem Gestell über der Haustüre aufbewahrt. Der Sammelname der dort niedergelegten Penjang heisst Penjang Pas. Die Hölzer und Steine legt man auch in Tiger- und Krokodilzähne die man mit Schnüren umflicht und mit dem gleichen Material zu Gürteln zusammenflicht die um die Hüfte getragen werden.

Auch die Bitte um Penjang gehört, nebst der um gute Träume, gute Vorzeichen und Karuhei, zu den am häufigsten ausgesprochenen in den Priestertexten. Weil wir den Penjang und der Macht der Penjang in den Texten sehr oft begegnen müssen wir hier eine nähere Beschreibung geben. Die wichtigsten Penjang sind die folgenden:

a.) Penjang panggering bulu (der Penjang, der die Haare zu Berge steigen lässt). Begibt man sich in den Krieg, oder will man eine Schlacht liefern (es handelt sich nicht um Kopfjagd), dann räuchert man die Penjang panggering bulu mit Weihrauch und bestreicht sie mit Opferblut. Die Macht des Penjang teilt sich nicht nur seinem Besitzer mit, sie nimmt selbst teil am Kampf und sie lähmt den Mut des Feindes, auch wenn er noch so gefürchtet und stark ist. In seinem Herzen steigt die Furcht auf, sodass ihm die Haare zu Berge stehen und er kann vom Besitzer des Penjang panggering bulu mühelos überwunden werden.

b.) Penjang pangitau (der zerstreuende, irreführende Penjang). Er besteht ebenfalls aus Hölzern die man in Bambusköchern aufbewahrt. Hatte man gegen einen andern Stamm oder gegen ein feindliches Dorf eine Schlacht geliefert und dabei Menschen umgebracht, dann nahm der Vorkämpfer, nachdem er mit seiner Truppe wieder nach Hause zurückgekehrt war, einige Hölzer aus dem Penjang pangitau, räucherte ihnen und bestrich sie mit Opferblut und legte sie in einen andern Köcher. Dieser wurde auf der Ueberseite des Flusses, oder hinter dem Dorf im Walde eingesteckt. Nahten sie nun die Feinde um am Dorfe für ihre erschlagenen Angehörigen Rache zu nehmen, dann führte sie die Macht dieses Penjang pangitau irre und machte das Dorf für sie unsichtbar, sodass sie an ihm vorbeiruderten und in ihrer Verwirrung und Zerstreuung die Bewohner eines Nachbardorfes überfielen. Auf die gleiche Weise handelte man auch wenn sich das Gerücht verbreitete, dass Kopfjäger im Anzuge seien.

c.) Penjang pangahat (der verdunkelnde, verwischende Penjang). Er besteht ebenfalls aus Hölzern die in Bambusköchern aufbewahrt 
werden. Wollte man auf die Kopfjagd ausziehen, sei es um Rache zu nehmen oder für irgend eine Opferhandlung Köpfe zu erbeuten, dann entnahm man den Penjang pangahat ein wenig Holz. Nachdem es mit Weihrauch geräuchert und mit Opferblut bestrichen worden war, steckte man es in ein kleines Köcherchen, oder in einen Tigeroder Krokodilzahn des Penjang mangajau. Man konnte aber das Holz auch fein stampfen und mit Sirih vermengen und kauen. Der Penjang pangahat verbarg vor den Augen der Feinde die Kopfjäger und weil sie unsichtbar waren konnten sie ihre Feinde mühelos überfallen und ihre Köpfe mitnehmen.

d.) Penjang mangajau (die Penjang der Kopfjagd). Bevor man eine Kopfjagd antrat erbat man von den Ahnen Penjang die den Bittenden beim batapa, durch die Ahnen direkt oder im Traum übergeben wurden. Von den auf diese Weise erhaltenen Hölzern oder Steinen nahm man ein wenig und füllte mit ihnen die Oeffnungen von ein bis drei Tigeroder Krokodilzähnen aus, die man darauf mit $\mathrm{Holz}$ und Draht gut verschloss oder mit Harz verklebte. Am Tage des Antritts der Kopfjagd hing man diese Penjang mangajau an die Schwertscheide oder an den Gürtel und ihr Nutzen bestand für den Träger darin, dass er stich- und schussfest war und dass die Feinde durch die Kraft des Penjang schwach wurden, sodass sie die Arme und Beine nur mühsam gebrauchen konnten, ferner vermittelte der Penjang seinem Besitzer Mut, sodass er sich unerschrocken und furchtlos mit tapferem Mute in den Kampf stürzte.

Musste ein Mann die Notdurft verrichten, dann hatte er zuvor den Penjang abzulegen und ebenso wenn er im Boote die Stelle passierte (das Mittelstück) wo das hereindringende Wasser mit einem Schöpfer herausgeschöpft wird.

e.) Penjang taring haramaung (der Tigerzahn-penjang). Ein reicher und berühmter Kopfjäger, vor allem aber der Vorkämpfer (pangkalima), musste im Besitze eines Gürtels von Tigerzähnen sein der um die Hüfte geschnallt wurde. Die Zähne erwarb man sich von Jägern oder nahm sie von selbsterlegten Tieren. Zog man auf die Kopfjagd, dann bekleidete sich der Besitzer des Penjang taring haramaung mit einem Panzer, der von kleinen Muscheln angefertigt oder von Schnüren geflochten war. Seinen Kopf schmückte er mit den Schwanzfedern des Nashornvogels, um seine Hüfte band er den Penjang taring haramaung und den Dolch, und in die eine Hand nahm er den Schild und in die andere das Blaserohr. 
Der Penjang, dessen Zähne mit Hölzern und Steinen (ebenfalls penjang) gefüllt waren, verlieh ihm nicht nur die Stärke und den Mut eines Tigers, sondern auch den Schutz seiner Ahnen die zum Tigerclan gehörten. (Bei der Beschreibung der sapandu die mit Tigerfiguren geschmückt sind haben wir näher auf diese ihre Bedeutung einzugehen. Die Beschreibung findet sich im II. Band dieses Werkes). Der Penjang taring haramaung schützte den Träger vor allen Gefahren. Blies ein Feind einen Pfeil auf ihn ab, dann kehrte der Pfeil zurück und traf den Schützen. Blies aber der Träger des Penjang einen Pfeil ab, dann tötete dieser nicht nur einen Feind, sondern er sprang von einem auf den andern über bis seine Kraft erschöpft war.

Die Penjang taring haramaung werden auch beim Tiwah von denjenigen getragen die früher die Sklaven und heute die Wasserbüffel (hadangan) zu töten haben.

f.) Penjang panawah (der schwächende, lähmende penjang). $\mathrm{Er}$ besteht ebenfalls aus Hölzern die in Bambusköchern aufbewahrt werden. Diesen Penjang brauchte man bei der Rechtssprechung. Hatte man irgendwo einen Mord begangen, einen Feind getötet oder den Kopf eines Sklaven geholt, dann hatte man den Angehörigen, bezw. dem Besitzer des Sklaven eine Busse zu bezahlen, den Blutpreis. Die Dorfältesten reisten ins Dorf des Mörders um dort die Rechtssache zu besprechen und den Blutpreis zu fordern. Hatte man gehört, dass sie im Anzuge seien, dann öffnete man den Penjang panawah und entnahm ihm ein wenig Holz und stampfte es fein und mischte es unter den Reis. Nachdem die Kläger im Dorfe angekommen waren bewirtete man sie freundlich und gab ihnen verschiedene Lebensmittel und andere Gaben zum Geschenk und unter ihnen befand sich auch der Reis den man mit dem feingestampften Penjang panawah vermischt hatte. Kochten sie diesen Reis, dann wurde nach dem Essen ihr zorniges Herz plötzlich freundlich gestimmt, sie stellten keine grossen Forderungen und sie überliessen die Schlichtung des Prozesses ihren Feinden, die auf diese Weise recht günstig wegkamen.

Der Penjang panawah hielt auch nahende Kopfjäger vom Dorfe fern oder er stimmte ihr Herz gegen das Dorf so freundlich, dass sie, nachdem sie bei ihm angekommen waren, alle Gedanken an einen Ueberfall und die Kopfjagd aufgaben.

g.) Die warnende Stimme der Penjang. Wird ein Dorf im Stammgebiet durch Feinde überfallen oder geschieht irgendwo im Stammgebiet ein Mord, dann geben alle Penjang in allen Dörfern und allen 
Häusern des ganzen Gebietes einen leisen pfeifenden Warnungslaut von sich, der sich von Zeit zu Zeit wiederholt. Man weiss dann, dass etwas Furchtbares geschieht und dass man auf der Hut sein muss oder dem bedrohten Dorf oder gefährdeten Angehörigen des Stammes zur Hilfe eilen muss.

h.) Der Kampf zwischen den Penjang. Auch die Feinde sind natürlich im Besitz von Penjang die sie schützen, ihnen Mut und Kraft verleihen und für sie streiten. Der Streit vollzieht sich nie nur zwischen Menschen, sondern auch zwischen den Ahnen der beiden Parteien und auch zwischen ihren Penjang. Ein solcher Streit wird ausführlich beschrieben im II. Teile dieses Bandes unter dem Manganjau kaju (der Rachezug gegen die Baumgeister).

i.) Palivorschriften beim Gebrauch der Penjang. Während die Penjang für den einen oder andern $Z$ weck gebraucht werden haben die Menschen verschiedene rituelle Verbotsbestimmungen $\mathrm{zu}$ beachten von denen die folgenden die wichtigsten sind. Im Dorf oder beim Haus dürfen keine Ruder in die Erde gesteckt werden. Im Dorf darf kein Reis gestampft werden. Bricht die Dunkelheit herein, dann darf man auch ausserhalb des Dorfes keinen Reis mehr stampfen. Reisstampfer dürfen nicht aufgestellt werden, man muss sie auf die Erde oder auf die Gestelle legen. Sirih- und Kambaungblätter dürfen nicht gekaut werden. Rimbangfrüchte dürfen nicht gegessen werden. Bambanrohr (eine Art Bambus) darf nicht ins Haus gebracht werden.

Die Nichtbeachtung dieser Pali hätte den Tod zur Folge der mit der Art und Weise der Uebertretung übereinstimmen würde. Man würde von Feinden erstochen, so wie man ein Ruder in die Erde gestochen hat. Man würde zerschmettern, so wie die Reishüllen vom Reisstampfer zerschmettert werden. Das Ende wäre ein bitteres, wie die Bitterkeit der Rimbang, es wäre ein stinkendes wie der Geruch der Kambaungblätter.

Der Penjang Pas muss ehrerbietig behandelt und darf nicht anders als nur mit ehrfurchtsvollen Blicken angeschaut werden. Es ist pali ihn zu beliebiger Zeit zu öffnen, zu berühren, mit dem Finger auf ihn zu zeigen, oder ihn gar zu belächeln.

Vor dem Gebrauch der Penjang Pas werden die Penjang, die man den Köchern entnommen hat mit Weihrauch beräuchert und mit dem Blute eines Opferhuhnes mit kurzen Schwanzfedern bestrichen.

Nach vollendeter Kopfjagd wurden die Penjang, die man gebraucht hatte, mit dem Blute grosser Opfertiere (Wasserbüffel oder Kühe), 
oder mit dem Blute von Opfersklaven bestrichen. Bei jedem grossen Tiwah (Totenfest) öffnet man den Penjang Pas, legt alle seine Bestandteile in einen grossen Gong und bestreicht sie mit dem Blut der grossen Opfertiere. Früher aber mussten sie mit Menschenblut bestrichen werden.

\section{3, S. 95.}

Tandang haramaung (tandang ist das Wort für haramaung: Tiger in der Basa Sangiang). Der Tiger kommt in Borneo nicht vor, wohl aber die Tigerkatze deren Zähne man für die penjang verwendet. Eine Abbildung findet sich in: Dr. H. H. Juynboll: Catalogus van 's Rijks Ethnographisch Museum. Borneo I. Leiden 1910. Plaat III, 7. Die Beschreibung, die dazu gegeben wird, stimmt nicht ganz, denn es handelt sich hier nicht um ein ,halssieraad", sondern um einen penjang taring haramaung in kleinerem Masse, der um die Hüfte getragen wird, sodass die Zähne auf dem Rücken aufliegen.

84 , S. 95.

Tupai ist ein Eichhörnchen. Wahrscheinlich handelt es sich hier um eine besondere Art eines Nashornvogels. Das Horn des Nashornvogels gehört zum Schmuck des Kopfjägers.

85, S. 95.

Tapas-tapas ist ein mit Watte (Kapok) gefütterter Panzer.

86, S. 95.

Durch die weiblichen Tambon (Wasserschlangen) werden die Urwasser bewohnt, während der Tingang, oder Bungai (Basa Sangiang) die Oberwelt bewohnt. Damit werden aber auch die Angehörigen der beiden Stammhälften bezeichnet, die, wenn sie zu einem Fest oder einer wichtigen Handlung und Arbeit zusammenkommen und sich vereinigen, genannt werden: Tambon haruwei Tingang (die Wasserschlangen die mit den Nashornvögeln vermischt sind).

87, S. 97.

Penjang idje hindje simpei,e, paturong hindje sandik,e (Penjang die an einem Bande aufgereiht sind, Paturong die sich in einem Bündel befinden), damit wird der starke und unzerreissbare Zuzammenhang des Stammes ausgedrückt. Die Kraft der Penjang (Paturong ist das Wort aus der Basa Sangiang) liegt in ihrer unzerreissbaren und unzer- 
störbaren Vereinigung. Sie zu zerreissen oder zu zerstören würde Unheil zur Folge haben. Das gleiche gilt auch für die Stammesgemeinschaft die so fest und dauerhaft sein muss wie die zusammengeflochtenen und zusammengeschnürten Penjang. Würde sie zerrissen und auseinanderfallen dann käme der ganze Stamm in einen Unheilszustand. Die scheidende Liau gibt ihren noch lebenden Stammesgenossen die Mahnung: haltet fest zusammen, seid wie die Penjang, die an einem Bande aufgereiht sind, wie die Paturong, die sich in einem Bündel befinden. In dieser Einheit liegt nicht nur die Kraft des Stammes sondern auch sein Heil.

Früher waren die Menschen auf dieser Welt so stark verbunden mit den Sangiang in der Oberwelt wie die einzelnen Penjang untereinander verbunden sind. Durch die Trennung der Menschen von den Sangiang wurde dieses Band gelockert. Diese Lockerung ist aber nur relativ, wie die Lockerung zwischen den beiden Stammhälften auch nur eine relative ist, denn bei wichtigen Handlungen und Arbeiten und vor allem beim Tiwah kommen nicht nur die beiden Stammhälften, sondern auch dic sangiang und Menschen wieder zusammen und bilden eine unverbrüchliche Einheit die die Wohlfahrt und das Heil des ganzen Stammes entweder fördert oder neu herbeiführt. Vgl. für die Zusammenarbeit der Sangiang und Menschen den II. und III. Band dieses Werkes.

88, S. 97.

Tempon Telon wird von den Menschen, seinen Verwandten, nicht nur freundlich, sondern mit besonderer Auszeichnung empfangen. Er erhält das beste Bier und am meisten Sirih.

89, S. 97.

Seit der Beschreibung von Djata durch Hardeland (W. B.) ist es Sitte geworden Djata als männlich zu beschauen. Das ist unrichtig. Djata ist die weibliche Göttin der Unterwelt die mit Ranjing Mahatala Langit zusammen die Welt und die Menschen geschaffen hat. Djata schenkt Kindersegen und fruchtbare, gute Ernten. Der Name Djata, der anstelle des ursprünglichen Wortes Tambon (Wasserschlange) getreten ist (Vgl. die Mythe im II. Band dieses Werkes), ist wahrscheinlich zur Zeit als die Dajak mit der hindu/javanischen Kultur und Religion in Berührung kamen, übernommen worden von dem Sanskritwort deva oder devatā. (Vgl. auch: G. A. Wilken: Verspreide geschriften. Deel III. Pag. 186).

Heute unterscheidet man sehr viele Djata und Tambon. Fast jedes 
Dorf kennt einen Ahnen, der in eine Tambon oder Djata verwandelt (basaloh) wurde. Diese Djata und Tambon stehen aber alle unter der Ur-Djata und Ur-Tambon und wir müssen die beiden Kategorien gut auseinanderhalten. Bei der Welt- und Menschwerdung haben nicht die verschiedenen Djata und Tambon der verschiedenen Dörfer mitgewirkt, sondern die Ur-Djata und Ur-Tambon. Von diesen erzählt ausführlich die umfangreiche Mythe der Welt- und Menschwerdung im II. Bande dieses Werkes.

90, S. 98.

Lunok. In der Basa Sangiang ist Lunok der Fruchtbaum und hat nichts zu tun mit dem andern Lunok, dem Waringin, der in dem Mantumbal Lunok beschrieben wird.

91, S. 98.

Der Dolch wird hier karis genannt. Der karis ist der javanische Dolch. Der dajakische Dolch heisst dohong (Basa Sangiang: rohong). Seine religiöse (nicht magische!) Bedeutung liegt darin, dass er mit der Weltwerdung und dem Lebensbaum zusammenhängt. Bei der Wiederholung der Weltwerdung, dem sogenannten balaku ontong (Gewinn, Glück erbitten. Siehe die Beschreibung und die Texte im IV. Band dieses Werkes), und bei andern wichtigen religiösen Handlungen spielt der Dolch ein grosse Rolle. Er wird auch mit dem Lebensbaum identifiziert. Die Wurzelausläufer des Lebensbaumes werden durch Dolche gebildet (batundjang dohong, siehe die Zeichnungen im IV. Bande dieses Werkes). Im Griffe des Dolches befindet sich eine Oeffnung (lalundjong). Der Dajak bewahrt darin Seelengold (bulau hambaruan), karuhei oder penjang auf. Bei religiösen Handlungen findet sich in dieser Oeffnung auch Lebenswasser (danum kaharingan belom).

Das Beissen auf Eisen bei religiösen Handlungen und bei Rechtssitzungen muss von hier aus gesehen werden. Man nimmt nicht die Härte des Eisens, sondern die schöpferischen Kräfte des Lebensbaumes, von dem alles Leben stammt, in sich auf.

92, S. 98.

Hardeland (W. B.) schreibt zu Tambarirang: eine Feuerkugel, das in Deutschland unter dem Namen ,fliegender Drache" bekannte Meteor. Den Dajacken ist es ein sehr gefürchteter böser Geist, dessen Erscheinungen ihnen ein Vorzeichen grosser Dürre ist. Ob diese Erklärung von Hardeland richtig ist müssen die späteren Untersuchungen zum II. 
Band dieses Werkes darlegen. Ich vermute, dass Tambarirang, der auch noch in anderem Zusammenhange genannt wird, eine andere Bedeutung hat als nur die eines fliegenden Meteors.

93, S. 99.

Tunggul hadjunan danum (der Baumstumpf, der gefüllt ist mit Wasser).

94, S. 99.

Die Boote werden nebeneinander gelegt und mit starken Holzstangen miteinander verbunden. Das Boot ist ein Abbild des Hauses.

95, S. 100.

Eine Art Palmbaum, fast wie die Kokospalme, aber mit Dornen besetzt; von dem untern Teile der Blätterstiele macht man Kämme und Pfeile. Von dem Holz macht man Latten mit denen die Fussböden der Häuser hergestellt werden.

96, S. 101.

Halo,n puseh oder kusok: ein Gerät um Feuer zu machen. Es besteht in einem kleinen Brette voller Löcher, lisong genannt, und dünnen langen Hölzchen. Man quirlt einen halo so lange in einem der Löcher des lisong umher, bis er $z \mathfrak{u}$ brennen beginnt, wozu man etwa eine Minute nötig hat; natürlich kann man jedes Loch der lisong nur einmal gebrauchen. Man nimmt $\mathrm{zu}$ den lisong und halo am liebsten Holz von den Bäumen Nonang, Rahandjang und Sungkai. Heute ist dieses Gerät bei den Ngadju Dajak verschwunden und durch eingeführte Zündhölzer ersetzt.

97, S. 102.

Sang Paukur misst das Leben des Menschen. Nach der Länge und Dauer, die er bestimmt hat, bleibt der Mensch leben. Ist das Mass voll, dann stirbt der Mensch. Weil er über dem Leben des Menschen steht kann man ihn auch bitten das Leben zu verlängern oder einen Toten wieder lebend zu machen.

98, S. 102.

Der dohong (Dolch) ist die ursprüngliche Waffe des Dajak. Das Schwert (mandau), das in den alten Mythen nie genannt wird muss erst später von Zentral-Borneo her eingeführt worden sein. 
99, S. 102.

Ranjing Pandereh Buno. Vgl. die Mythen im Anhang: Aus der Mythologie eines Dajakdorfes.

100, S. 104.

Die Erzählung folgt der biblischen. Hier ist der Einfluss der christlich/missionarischen Verkündigung auf die moderne Bearbeitung und Anpassung der Mythen an- und die Auseinandersetzung mit dem christlichen Stoff deutlich.

101, S. 104.

Tambalik angin, oder kaju sambalik angin (den Wind kehrendes oder gegen den Wind gerichtetes Holz). Name eines im Innern der Insel Borneo wachsenden Holzes. Man bestreicht damit die Nase der Hunde um sie zu guten Jagdhunden zu machen.

102, S. 104.

Dass es heute viele Djata gibt hängt zusanmmen mit der Stammesorganisation. Jeder Stammteil und jeder Clan hat seine eigenen Djata und heute besitzt auch jedes Dorf eine eigene Djata. Man kann sich mit den Djata verbrüdern (hurai, hampahari, basahabat), was sehr oft geschieht. Die Djata geben den Menschen Karuhei um Kindersegen und reiche Ernten zu erhalten.

103, S. 107.

Die Olon Tamuan (tamuan soll abgeleitet sein von tamuei: Fremdlinge, Herumreisende) bewohnen in der Onderafdeeling Sampit der Z.O. Afdeeling van Borneo den unteren Mentaja (auch Sampitrivier genannt) und dessen Seitenflüsse. Sie sind kulturell mit den Katinganern verwandt. Die Sprache und die Stammythen der Olon Tamuan und Katinganer stimmen weithin überein. Eine Verstärkung sollen die Olon Tamuan erhalten haben durch zahlreiche Sklavenfamilien die nach der Aufhebung der Sklaverei vom Katingan an den Mentaja übersiedelten. Es ist möglich, dass die hier mitgeteilte Mythe eine solche Umsiedelung ehemaliger Sklaven als Grundlage hat.

104, S. 108.

Die Olon Sembuluh bewohnen in der Onderafdeeling Sampit den unteren Serujan und dessen Seitenflüsse sowie die Ufer des SembuluhSees. 
105 , S. 109 .

Weitere Mythen über die Mächte sind auch die Basaloh- und Gaipmythen, sowie die Mythen zur Abwendung des vorausgewussten Todes und die im Anhang: Aus der Mythologie eines Dajakdorfes (S. 233260).

106, S. 109.

Hantuen (Hexe) ist abgeleitet von dem Wort hantu (Leiche, böser Geist). Vgl. auch die Erklärungen 39-45.

107 , S. 110.

Oberland (hulu) bezeichnet hier das Gebiet des oberen Kahaian, Kapuas, Katingan, Serujan und deren Seitenflüsse, sowie das Gebiet des oberen Kapuas Bohang (der bei Pontianak in die Javasee einmündet) mit seinen Seitenflüssen. Es handelt sich also um das Gebiet in dem die Ot Danum wohnhaft sind.

108, S. 110.

Die Ot sind schweifende Stämme der sogenannten Ur- oder Primitivmalaien, die sich in den zentralbornesischen Wäldern aufhalten. Man unterscheidet verschiedene Stämme. Sie sind sehr scheu und kommen wenig mit der Aussenwelt in Berührung. Handel treiben sie mit Zwischenhändlern, d.h. mit Ot-Männern die sich mit einer Frau eines sesshaften Stammes verheiratet haben und in einem Dorf niederliessen. Ueber die Kultur der Ot wissen wir so gut wie nichts.

109, S. 111.

Am Katingan lautet der Sammelname für die Tiere nicht meto (Tier), sondern lauk (Fisch). Lauk korik mata,e (der Fisch mit den kleinen Augen) ist die Umschreibung für balawau (Maus), deren Name nicht ausgesprochen werden darf so lange der Reis noch auf den Feldern steht.

110, S. 112.

Der Sualapilz ist heilig. Bei Tod und Totenfesten erscheinen nachts Masken die mit diesen Pilzen bekleidet sind. Das in der Dunkelheit matt leuchtende Licht gewährt einen merkwürdigen Anblick.

111, S. 113.

Die Schweine durchschweifen in der Früchtezeit in grossen Herden die Wälder und durchschwimmen bei hunderten die Flüsse, meistens 
jedes Jahr an der gleichen Stelle. Die Dajak machen, sei es in kleinen Gruppen, sei es in sehr grossen Verbänden Jagd auf die Tiere. Oft strömen die Männer eines ganzen Stammes zusammen um während einiger Tage den über den Fluss schwimmenden Schweinen aufzulauern und auf sie Jagd $z \mathfrak{u}$ machen. Sie bringen $z u$ diesem $Z$ wecke reich verzierte und bemalte Speere mit. Nebst dem oekononischen Wert den die Jagd unzweifelhaft hat (Gewinnung von Fleisch und Fett) trägt sie auch den Charakter eines Stammvergnügens.

\section{2, S. 114.}

Das gilt natürlich nicht allgemein, sondern nur für verschiedene Stämme oder Stammteile oder Clan am Kahaian oder am Katingan, für andere aber (z.B. für die Leute aus Tumbang Lahang) ist die gegenseitige Heirat durchaus erlaubt.

\section{3, S. 115 .}

Bevor man ein Haus betritt räuspert man sich zuerst und ruft: aton oloh? (Befinden sich Leute im Haus?) Erhält man die Antwort: djaton oloh! (Nein, es sind keine Leute im Haus), dann weiss man, dass sich in ihm nur Frauen befinden und es durch einen Mann nicht betreten werden darf. Ein Gespräch unter der offenen Haustüre, sodass man jedermann sichtbar bleibt, verstösst nicht gegen die gute Sitte (hadat).

\section{4 , S. 117.}

Die dajakische Wiege besteht aus einem Stück Tuch an dessen beiden Zipfeln je ein Seil festgemacht wird. Mit diesen Seilen wird sie an einem Querbalken des Hauses festgemacht. Das Kind schläft darin liegend oder sitzend. Im letzteren Falle bindet man unter dem Kinn des Kindes ein Stück Tuches das man um die Zipfel der Wiege schlingt wodurch der Kopf des Kindes festgehalten wird.

\section{5, S. 120 .}

Antang (Haliastur intermedius) tritt hier nicht in der Bedeutung als Omenvogel auf. Er ist die gana,n tadjahan (die Seele des Ahnenplatzes). Sie erscheint, aufgerufen durch den Priester, in der Gestalt eines Antang. Vgl. die Mythen über den Ursprung des Antang und die Erklärung 137. 
116, S. 125.

Eine der viel genannten Ursachen weshalb sich die Ahnen aus der Welt der Menschen in die Oberwelt zurückgezogen haben ist die, dass es in der Welt zu stinken begann. Die Dajak sagen: seit die Händler zu uns gekommen sind und uns blasan (getrocknete und dann zusammengestampfte Garnale: kleine Seekrebse, eine der gewöhnlichen Zuspeisen zum Reis. Ihr Geruch ist sehr widerlich) gebracht haben fühlten sich die Ahnen und Geister nicht mehr wohl auf dieser Welt und haben sich für immer zurückgezogen. In dieser einfachen Erklärung liegt die tiefere Wahrheit, dass durch den Einfluss der Fremden, seien es Malaien, Chinesen oder Europäer, manche alten Ordnungen und Institutionen angetastet und viele Neuerungen eingeführt wurden mit denen sich die Ahnen nie und nimmer einverstanden erklären konnten und sich deshalb aus dieser Welt zurückzogen. Als die Regierung die Dajakgebiete unter ihre Oberherrschaft stellte war eine der häufigsten Klagen, die man zu hören bekam: unser Reis gedeiht nicht mehr, unsere Ernten misslingen seit die Fremden hier sind und es kehrt bei uns Hunger und Armut ein. Das alles war die Folge weil Fremde herrschten und Fremde die Ahnen auf die Seite schoben und ohne nach ihrem Willen und Rat $z \mathfrak{u}$ fragen umwälzende Veränderungen einführten sodass auf allen Lebensgebieten ein Gefühl der Unsicherheit und der Ungewissheit entstand das schliesslich kulminierte in dem resignierten Ausspruch : die Ahnen haben uns verlassen. Es ist deshalb nicht verwunderlich, dass der religiös/romantisch gefärbte Nationalismus der letzten Jahre die Devise führt: zurück zu den Ahnen.

\section{7 , S. 126.}

Hardeland (W. B.) schreibt: Silai ist eine fabelhafte Person. Er ist der Sohn der Putir Radja,n Madja Pait und dem Kadjanggan Hatue,: Bulan. Er soll der Stammvater der oloh baputi (der weissen Menschen) sein.

\section{8, S. 126.}

Djangga oder Kadjangga ist der Herr, oder der Dorfälteste des Mondes. Die Dajak meinen, dass der Mond ein grosses Land sei, mit vielen Dörfern etc. Kadjangga ist der König. Bei Mondfinsternissen wird Kadjangga mit seinen Untergebenen durch Djangkarang Matanandau gefangen genommen. Hardeland (W.B.) teilt noch mit: bei Mondfinsternissen bringen die, welche seit kurzem verheiratet sind, welche ein neues Haus bezogen haben, oder die eine wichtige Arbeit 
oder eine Reise verrichten wollen dem Kadjangga ein Schwein zum Opfer, damit die Mondfinsternis ihnen nicht schädlich sei. Vgl. auch Erklärung 34.

119, S. 126.

Vgl. die Erklärung 34.

120, S. 128.

Der saloang ist ein kleiner wohlschmeckender Fisch. Er wird etwas länger als ein Finger. Man unterscheidet zwei Arten, nämlich den saloang toto (weisslich) und den saloang karing (rötlich). Er spielt in den religiösen Vorstellungen der Dajak eine bedeutende Rolle. In manchen Mythen tritt er als der listige Widersacher auf. Vgl. die Mythe vom Tod der Naga Andoh. Man gebraucht den Saloang auch um Feinde blind $\mathrm{zu}$ machen. $\mathrm{Zu}$ diesem $\mathrm{Z}$ wecke sticht man einem Saloang die Augen aus und lässt ihn in der Richtung des Feindes wegschwimmen indem man Verfluchungen ausspricht. Der Feind soll dadurch blind werden.

\section{1, S. 135.}

Ein Mensch der diese Gaben besitzt ist vollkommen. Er kommt erst in ihren Besitz nachdem er alle Initiationshandlungen vollbracht hat. Die Mythe von Silai ist eine Initiationsmythe. Vgl. auch die Erklärung 35.

\section{2, S. 135.}

Weisse Menschen sind hier nicht Europäer sondern Dajak die einem bestimmten Stammteil angehören, nämlich dem patrilinealen. Die Farben nehmen im ganzen System des Dajak ihren bestimmten Platz ein. Die drei Grundfarben sind: rot, weiss und schwarz. Rot wird immer genannt in Verbindung mit der Unterwelt und der Tambon oder Djata. $\mathrm{Zu}$ Rot gehören aber auch: grün (Pflanzen, Perlen), gelb (Gold) und blau (Perlen); Weiss wird genannt in Verbindung mit der Oberwelt, Schwarz wird genannt in Verbindung mit den bösen Mächten und dem Tod. Nach diesen Farben werden auch die Menschen eingeteilt. Die gleiche Einteilung finden wir auch in zahlreichen religiösen Vorstellungen. Kameloh Lumot Garing, die erste Frau, setzt sich auf der Weltsee in ein banama bulau (ein goldenes Boot). Manjamei Bulau Onggon Tingang, der erste Mann, setzt sich in ein banama hintan (Edelsteinboot, die Edelsteine gehören zur Oberwelt, das Gold zur 
Unterwelt. Vgl. die Mythe ïber den Ursprung der Welt und der Sangiang nach Bapa Haastert). Die Opferhühner und der Opferreis wird ebenfalls nach diesen Farben eingeteilt und die gleiche Einteilung finden wir auch für die Antang (Haliastur intermedius) durchgeführt. (Vgl. den Text zum Manganjau kaju im II. Teil dieses Bandes). Ebenso findet diese Einteilung auch Anwendung auf die Erde die durch Schwangere gegessen wird wodurch sie die Kräfte der Unterwelt oder Oberwelt in sich aufnehmen.

\section{3, S. 137.}

Lilang ist nach Hardeland (W. B.) der Name eines Sangiang, nämlich des Bruders des Tempon Telon. Er wird angerufen wenn man auf dem Wasser in Gefahr ist durch Sturm und Wellen, dass er die Wellen malilang (auseinanderschiebe) und einen Weg hindurchbahne. Kommt man glücklich durch die Gefahr, dann opfert man ihm sieben Zigarren und sieben Sirihkausel welche man daheim angekommen vor die Haustüre hinauswirft.

\section{4, S. 138.}

Raho. Wilken: Verspreide geschriften, III, 281 ff. sagt: Naar de voorstelling van de Indiërs worden (zon- en maaneclipsen) veroorzaakt door den boozen geest Râhu. Toen de goden - aldus luidt de mythe na de voltooiing des hemels vergaderden on de amrta, het water des levens, te drinken, vermomde zich Râhu als een hunner, en dronk ijlings een weinig van den nektar. Maar de zon en de maan, die dit opgemerkt hadden, waarschuwden Vishṇu. Deze mikte nu met zijn vernielenden cakra of werpschijf op Râhu en trof hem juist aan den hals, zoodat het hoofd van het lichaam werd afgescheiden. Door den nektar, dien hij reeds binnen had, was Râhu echter onsterfelijk geworden. Het hoofd verhief zich dan ook in de lucht en tracht zich sedert op zon en maan te wreken, door ze nu en dan te verslinden. Vandaar de eclipsen.

Deze voorstelling dat zons- en maansverduisteringen ontstaan door booze geesten, die de beide hemellichamen verzwelgen, komt ook bij de Maleisch-Polynesische stammen voor. $\mathrm{Zij}$ moet zich bij hen wel spontaan gevormd hebben, buiten vreemden, dat is dan hier bepaaldelijk Hindûschen, invloed, want men vindt haar zelfs bij de volken, die de eilanden van de Zuidzee bewonen... Ook bij de volken van den Indischen Archipel moet deze voorstelling zeer zeker inheemsch zijn geweest, hoewel aan den anderen kant sporen van Hindûschen invloed 
daarin duidelijk merkbaar zijn. Dit is onder andere het geval bij de Javanen. In het hierboven genoemde mythologisch en cosmogonisch werk Manik-Måjå, vindt men bijvoorbeeld de Indische mythe omtrent râhu, of karawu zooals de naam hier gespeld wordt, bijna onveranderd terug, en nog heden ten dage bestaat het geloof, dat eclipsen aan dezen demon moeten worden toegeschreven. Het is daarom dat er bij een dergelijk natuurverschijnsel op rijstblokken en andere werktuigen zoo hard mogelijk geslagen wordt, om door het geraas Râhu te verdrijven en de beide hemellichamen van zijne aanvallen te bevrijden... Bij de Dajaks, bepaaldelijk bij de Olo Ngadjoe's, bestaat eveneens de voorstelling dat bij eene eclips, zooals de inlander zich uitdrukt, „bulan nawan talo", dat is: de maan door een boozen geest gegrepen wordt. Het Sanskritsche râhu ontmoeten wij hier, onder den vorm raho, als benaming voor de gestalte van de maan bij een eclips.

\section{5, S. 139.}

Umang, die Eulenspiegelfigur. Vgl. Erklärung 9. Einige Eulenspiegelerzählungen von Umang (oder auch Sangumang) und Maharadja finden sich in H. Sundermann: Dajakkische Fabeln und Erzählungen. Bijdragen tot de Taal-, Land- en Volkenkunde van Nederl.Indië. Deel 66. Den Haag 1912.

126, S. 140.

Rotes Huhn. Vergl. Erklärung 122. Bei den Opferhühnern, die den verschiedenen Ahnen dargebracht werden unterschiedet man die Farben der Hühner. Es ist nie gleichgültig welche Farbe ein Opferhuhn besitzt weil die Farben kosmisch und religiös klassifiziert sind. Schwarze Hühner (d.h. Hühner mit schwärzlichem Fleisch) bringt man den hantuen (Hexen) und bösen Geistern als Opfer dar.

127, S. 142.

Nach Missionar Becker: Von dem Gottesdienste auf Borneo. Achtzehnter Jahresbericht der Rheinischen Missionsgesellschaft. Barmen 1847. Pag. 157 ff.

128, S. 144.

Nach Missionar C. Hupe: Korte verhandeling over de godsdienst, zeden enz. der Dajakkers. Tijdschrift voor Neêrland's Indië. Achtste Jaargang. Derde Deel. Batavia 1846. Pag. 131. 
129 , S. 147.

Der Bukit Raja ist die höchste Erhebung (2280 m. über Meer) des Schwanergebirges. Hardeland (W. B.) schreibt: Bukit Raja ist der Name eines hohen Berges im obern Katingan. Die Dajacken sagen, man habe sieben Tage nöthig um bis oben zu kommen, und habe dann alle Wolken etc. tief unter sich. Die Putir Santang, die Töchter Mahataras, haben ein Bad oben auf dem Gipfel (es ist dort also wohl ein kleiner See), wenn sie dorthin herabkommen um zu baden, wird eine glänzend weisse Matte für sie ausgebreitet. (Der Gipfel wird also zu Zeiten mit Schnee bedeckt sein. [Das ist fraglich. Wohl fällt auf dem Bukit Raja Hagel und es kann auch sein, dass sich nach kalten Nächten Reif bildet, Sch.].) Auf diesem heiligen Berge wächst das Holz, Moos, etc. welches $\mathrm{zu}$ karohei, glückbringenden Zaubermitteln, zu tatamba (Arzneien) gebraucht wird.

\section{0, S. 148.}

Zur Belebung von Toten gebraucht man immer ein siebenfach gefaltetes Tuch. Akah Ihang Iho bringt ihren Mann Patih Teteh in der Form eines Nashornvogeleies aus dem Totendorf in die Welt zurück. Sie muss das Ei auf ein siebenfach gefaltetes Tuch legen und giesst Lebenswasser über ihm aus. Patih Teteh wird durch diese Handlung wieder ein lebender Mensch. Vergl. die Mythe.

\section{1, S. 150.}

Drei, fünf und sieben sind die Zahlen der Vollkommenheit. Abbildungen dieser hampatong (menschliche Figuren) finden sich in F. Grabowsky: Ueber verschiedene weniger bekannte Opfergebräuche bei den Oloh Ngadju in Borneo. Internationales Archiv für Ethnographie. Band I. Pag. $130 \mathrm{ff}$ und Tafel X.

\section{2, S. 167.}

Vgl. die Erklärung 26.

\section{3, S. 168.}

Verwandte von den Njaring sind Menschen mit roten Haaren. Die $\mathrm{Njaring}$ haben selbst auch rote Kopf- und Körperhaare. Wird ein Kind mit roten Haaren geboren dann beschaut man es als eine Gabe der $\mathrm{Njaring}$. $\mathrm{Zu}$ den Verwandten der $\mathrm{Njaring}$ gehören weiter die Hantuen (Hexen). 
134, S. 169.

Kudjang (Colocasia antiquorum). Ein rübenartiges, in der Erde wachsendes Knollengewächs. Die Malaien nennen es keladi.

135, S. 170.

Seelenreis (behas hambaruan). Vgl. die Beschreibung im II. Teile dieses Bandes wo sich auch Abbildungen finden.

\section{6, S. 171.}

Pisau pepet (das Buschmesser in das man beisst). Man beisst in ein Messer bei Verwundungen, Rechtshandlungen, Krankheiten, bei der Ausführung religiöser Handlungen usw. Die dynamistische/magische Bedeutung womit diese Handlung erklärt wird scheint mir nicht ganz zutreffend zu sein und erklärt jedenfalls die Sitte nicht in befriedigender Weise. Das Messer, überhaupt das Eisen, haben wir immer in Verbindung mit dem Lebensbaum zu sehen durch den die Welt und die Menschen entstanden sind. Das Beissen auf Eisen und der Gebrauch des Eisens für Kranke usw. übermittelt m.E. den Menschen die schöpferischen Kräfte des Lebensbaumes und ist eine teilweise Wiederholung der Menschwerdung.

\section{7, S. 172.}

Rika Bulau Hatuen Antang Ganan Tadjahan ist der Name des Falken vom Ahnenheiligtum. Ruft der Priester (tukang tazur) die Ahnen vom Dorfheiligtum (tadjahan) auf, dann erscheinen sie in der Gestalt eines Falken der nicht verwechselt werden darf mit dem gewöhnlichen Falken (Haliastur intermedius). Dieser Antang Ganan Tadjahan ist ein mythischer Vogel. Er erscheint nur dann wenn er durch den Priester aufgerufen wird und verschwindet nach der Handlung sofort wieder in der Richtung des Tadjahan. Jeder Stamm oder Clan, heute auch jedes Dorf, ruft seinen eigenen Antang Ganan Tadjahan auf. Stammen die Leute des Dorfes ursprünglich aus einem andern Gebiet oder von einem andern Fluss, dann rufen sie den Antang ihres verlassenen Dorfes auf.

Der Antang gibt direkten Rat (siehe die Mythe vom Ursprung der Hexen am unteren Katingan), er ist aber auch der Mittler zwischen dem Priester und den andern Ahnen. Der Antang begleitet auch die Kopfjäger auf ihren Zügen und nimmt aktiv am Kampfe teil, wahrscheinlich gegen den Antang der Feinde. Man kennt Antang die bei diesen Kämpfen einen Flügel verloren haben und die man, wenn man 
sie aufruft, sofort wieder erkannt weil sie nur einen Flügel besitzen. Diese Antang sind sehr angesehen.

Tadjahan abgeleitet von tadjah: Vorzeichen oder Rat vom Antang Ganan Tadjahan fragen. Das Verbum manadjah bedeutet: den Antang um Vorzeichen oder um Rat fragen.

Der Tadjahan ist das Dorf-Ahnenheiligtum, das sich entweder oberhalb des Dorfes oder gegenüber dem Dorf (am andern Flussufer) im Wald befindet, oft auch auf einer Insel oder dann im früheren Dorf (kaleka) aus dem man ausgewandert ist, er besteht aus einer Reihe von hölzernen Ahnenbildern die etwa $80 \mathrm{~cm}$. hoch sind und aus einer kleinen Opferhütte. Beim Tiwah (Totenfest) wird für jeden Verstorbenen ein Ahnenbild aufgerichtet. Bei den Ngadju findet man die Tadjahan nicht mehr, wohl aber noch bei den Ot Danum. Hardeland (W. B. unter tadjah) schreibt: Tadjahan; wenn der Antang Glück verkündet hat, haut man einen kleinen Platz von Buschwerk und Gras rein, und stellt dort sieben hölzerne Püppchen auf, deren Gana (Seelen) zu Sklaven des Antang werden. Solch ein Platz heisst Tadjahan. Diese Erklärung von Hardeland trifft aber die richtige Bedeutung des Tadjahan nicht. Vgl. auch H. Schaerer: Das Menschenopfer bei den Katinganern. Tijdschrift voor Ind. Taal-, Land- en Volkenkunde. Deel LXXVIII. 1938. Pag. 556. Vgl. auch die Mythen über den Ursprung der Antang unter: Der Verkehr mit der übersinnlichen Welt.

\section{8, S. 175.}

Das ursprüngliche Kochgerät in den der Reis abgekocht wurde ist der Bambusköcher, den wir auch in Zentral-Borneo noch finden. Man schüttet Reis und Wasser in den Köcher und dreht ihn dann langsam über dem Feuer damit der Reis regelmässig kocht und der Köcher nicht verbrannt wird. Man braucht den Köcher nur einmal. Der Reis, auf diese Weise gekocht, soll sehr schmackhaft sein. Heute kocht man bei den Ngadju den Reis nur noch bei Opferfesten und vor allem beim Tiwah in Bambusköchern. Vgl. die Beschreibung und die Abbildungen im II. Bande dieses Werkes.

\section{9 , S. 182.}

Wahnsinn ist hier ein Zeichen, dass die Brüder des Anak Luting Geister geworden sind. In diesem Falle ist der Wahnsinnige nicht nur von Geistern besessen, sondern selbst ein Geist geworden. Er hat eine andere Existenz und Ausdrucksweise erhalten die dem Menschen als Wahnsinn erscheint aber nicht als Krankheit beschaut wird sondern 
als andere Ausdrucksform eines Menschen der ein Geist geworden ist. Die Balian und Basir (Priesterinnen und Priester) müssen, bevor sie diesen Beruf wählen können und dazu geschickt sind Erscheinungen von leichtem Wahnsinn gezeigt haben, die nicht mit einem psychischen Defekt $z u$ tun haben sondern die man damit erklärt, dass ein Sangiang von ihnen Besitz ergriffen hat und damit zu verstehen gibt, dass er sich dieses Menschen bedienen wolle im Verkehr mit den Menschen. Während der priesterlichen Funktionen ist der Priester (basir) und die Priesterin (balian) nicht sich selbst, sondern der Sangiang, der in sie eingefahren ist. Die Seele des Priesters oder der Priesterin wird mit der des Sangiang ausgetauscht. Die Seele des Sangiang kommt für diese Zeit in den Körper des Priesters oder der Priesterin und die Seele der letzteren geht in die Oberwelt bis die priesterlichen Funktionen beendet sind. Erst darnach findet der Austausch der Seelen wieder statt und wird der Priester oder die Priesterin wieder ein gewöhnlicher Mensch. Vgl. dazu die ausführlichen Beschreibungen im II. Teil dieses Bandes.

140, S. 182.

Auch die geifernden Zungen, die lang aus dem Mund heraus hängen und die aus den Höhlen tretenden Augen sind ein Zeichen, dass ein Mensch ein Geist (taloh) geworden ist. Auf den Opferpfählen (sapundu) werden die Ahnen auf die gleiche Weise dargestellt.

\section{1, S. 199.}

Das Haus besitzt einen sakralen und profanen Teil. Die Teilung geschieht durch die erhöhte Schwelle die sich durch das ganze Haus zieht. Diese Schwelle wird genannt: tambon ganan lungko (die Wasserschlange, die Seele der Schwelle). Diese Einteilung hängt mythologisch zusammen mit dem Bau des ersten Hauses durch die Djata (oder Tambon) und Ranjing Mahatala Langit. Vgl. die Mythe im II. Band dieses Werkes. Das Haus ist ein Abbild des Kosmos nach seinem religiösen und sozialen Aspekt. Religiös ist das Haus eingeteilt in Oberwelt (Dach) und Unterwelt (Fussboden), sozial ist es eingeteilt in die Hälfte für die Bewohner (innerhalb der Schwelle) und für die Gäste die von auswärts, aus dem andern Stammteil (Tambon oder Bungai), kommen (zwischen Schwelle und Türe).

142, S. 210.

In Verbindung mit dem Term saloh oder basaloh braucht man auch 
das Wort badjea (durch den Blitz getötet werden), oder badjea basaloh batu (durch den Blitz getötet- und in Stein verwandelt werden).

\section{3, S. 213.}

Die rituelle Fingeramputation als Sühnopfer oder Selbstopfer ist nach dieser Mythe also auch für Borneo bezeugt. Heute kommt sie nicht mehr vor aber ist ersetzt durch das Blutopfer. Tritt ein furchtbares Unwetter auf, sodass man befürchten muss, dass das Dorf untergeht und in Stein verwandelt wird (basaloh) dann erkundigt man sich wer sich einer schweren Sarok- oder Tulahübertretung bewusst sei. Meldet sich ein Schuldiger dann sticht man in seinen kleinen Finger, fängt das Blut auf und spritzt gegen den Himmel und fordert Njaro auf es als Opfer anzunehmen und das Unwetter ohne schwere Folgen für das Dorf vorbeigehen zu lassen. Vergl. für die Fingeramputation J. C. van Eerde: Vingermutilatie in Centraal Nieuw-Guinea. Tijdschrift van het Koninklijk Aardrijkskundig Genootschap. Tweede Serie. Deel XXVIII. 1911. Pag. 49 ff. und J. Söderström: Die rituellen Fingerverstümmelungen in der Südsee und in Australien. Zeitschrift für Ethnologie. Siebzigster Jahrgang. 1938. Pag. 24. In diesem Aufsatz finden sich Abbildungen und eine ausführliche Literaturliste zu diesem Thema.

\section{4, S. 213.}

Hardeland (W. B.) schreibt: „Kowo, das eingesperrt sein. In Pulopetak (die Ngadjubevölkerung zwischen dem heutigen KualaKapuas und dem Barito) nur noch seltener, mehr im Innern noch ziemlich häufig, thun Eltern das Gelübde ihre Töchter eine bestimmte Zeit, gewöhnlich bis zur Heirath, einzusperren; auch Frauen übernehmen solche Gelübde, wenn ihre Männer auf Krieg etc. auszogen; sie schliessen sich dann in eine kleine Kammer ein, wohin ihnen eine alte Frau täglich zweimal Essen bringt".

Das Bakowo findet auch heute noch bei verschiedenen Ot Danumstämmen von Zentral-Borneo statt. Es ist eine Initiationshandlung und hat nichts zu tun mit einem Gelübde. Das Mädchen wird während einiger Zeit (bis zu drei Jahren) in einem kleinen Zimmer des Hauses (meistens wird dieses Gemach über dem Schlafplatz der Eltern hergerichtet) eingeschlossen und verborgen. Eine alte Frau oder auch eine Sklavin bedient sie in ihrem Gemach, das sie während dieser Zeit nicht verlassen durfte und führte sie auch in die komplizierten Flechtarbeiten ein. Beim Abschluss des Kowo wurden die Wände des Gemaches durch 
Aelteste des eigenen und der umliegenden Dörfern abgebrochen und das Mädchen wurde von einem Aeltesten zum Flusse hinuntergetragen und dort rituell gebadet auf die gleiche Weise wie man das für ein neugeborenes Kind tat. Verschiedene Opferhandlungen schlossen das Abbrechen der Kowozeit ab. Vgl. dazu auch: E. L. M. KüHR: Schetsen uit Borneo's Westerafdeeling. I. Beroemboeng. In: Bijdragen tot de Taal-, Land- en Volkenkunde van Nederlandsch-Indie. Deel XLVI. 1896. Pag. 63. und J. Mallinckrodt: Het Adatrecht van Borneo. Deel I. Pag. 413, 424 und 429.

\section{5 , S. 216.}

HaRdeland (W.B.) schreibt unter tulah: "Unerlaubt zu heirathen, Blutschande; nicht gerade aufeinander, nicht passend, nicht symmetrisch, nicht ebenmässig. Beispiel: Was das Heirathen betrifft: wenn die Eltern ihre Kinder heirathen, oder wenn sich leibliche Geschwister unter einander oder mit den Stiefkindern ihrer Eltern verheirathen, ferner wenn Tanten und Oheime sich mit ihren Neffen und Nichten verheirathen, alles das ist Blutschande. Wenn Menschen Blutschande begehen, so wird das ganze Land verunreinigt, dann müssen wir beide versteinen", sagen die Dajak (d.h. das schuldige Paar wird in einen mit Steinen beschwerten Korb gesetzt und ertränkt. Es wird versteint damit das Dorf nicht versteint- und die Bevölkerung nicht in taloh (Geister) verwandelt wird).

146, S. 218.

Bei Tulahübertretungen werden als Rächer nicht Njaro und seine sieben Brüder genannt, sondern Radja Pali (der König der Pali, der rituellen Verbotsbestimmungen). Dieser Radja Pali ist aber identisch mit Njaro. Radja Pali verursacht die Naturkatastrophen und ihm werden die stellvertretenden Sühnopfer dargebracht.

\section{7 , S. 221.}

In kangkamiak verwandeln sich die verstorbenen Hantuen (Hexen). Sie haben menschliche Gestalt und wohnen in Dörfern zusammen. Sie versuchen die Menschen zu töten oder zu manggaip. Die weiblichen Kangkamiak versuchen die Schwangeren und ihr Kind zu töten indem sie in sie fahren. Sie locken auch junge Männer an indem sie ihnen als sehr schöne Jungfrauen erscheinen. Entweder entrücken sie sie und nehmen sie in ihre Gemeinschaft auf oder sie saugen ihnen im Schlafe das Blut aus und töten sie auf diese Weise. 
148 , S. 227.

Die Treppe (hedjan) besteht aus einem Stamm der ausgekerbt ist. Sie liegt schräg gegen das Haus an. Unten läuft die Treppe in einen Holzzapfen aus der in einer Höhlung ruht die aus einem Stück Eisenholz herausgeschnitzt wurde. Nachts, oder auch tagsüber um den Hunden den Zugang zum Haus zu wehren, wird die Treppe umgedreht. Das gleiche geschieht auch wenn man das Haus verlässt.

149, S. 230.

Nach einer unveröffentlichten Mitteilung von R. Kühnle-Degeler in : Erklärungen zu den Gegenständen zum dajakischen Totenfest aus der Sammlung von Dr. M. Vischer, Kuala-Kapuas, ausgestellt im Missionsmuseum Basel.

150, S. 231.

Der balai sanggaran ist eine Opferhütte die beim Tiwah in der Nähe des Sangkaraja (Schädelpfahl) aufgerichtet wird. Man bringt in ihr den herumirrenden Liau (Toten), für die das Tiwah noch nicht gehalten wurde, Opfer dar.

151, S. 231.

Hardeland (W. B. unter ärang) schreibt: kaju ärang, ein Baum im Sangianglande; sein Holz ist ein Zaubermittel (d.h. es wird wahrscheinlich für Karuhei verwendet, Sch.) um reich zu werden.

\section{2, S. 235.}

Wassertiefe (labeho) ist der Zugang zu der Unterwelt, zum Reiche der Djata, der Tambon, der Naga oder Ihing (mythische Wasserschlangen). In diesen labeho, die sich meistens an der Stelle finden wo ein Nebenfluss in den Hauptfluss einmündet, halten sich zahlreiche Krokodile auf die als die Diener der Djata beschaut werden. Steigen diese Diener im Auftrag der Djata an die Wasseroberfläche herauf, dann nehmen sie die Gestalt von Krokodilen an.

Labeho,n huma (Wassertiefe des Hauses) nenr.t man den mit Tuch umzäunten Platz im Haus auf dem die religiösen Handlungen vollzogen werden. Er ist der Zugang zur Unterwelt und hier erscheinen auch die Abgesandten der Unterwelt, oder von hier aus begibt sich der Priester oder die Priesterin (basir oder balian) nach der Unterwelt. 
153, S. 245.

Der Aufenthaltsort der in taloh (Geister) verwandelten Brüder der Bulau liegt an den Grenzen des ganzen Stammgebietes der TumbangLahanger.

154, S. 250.

Diese Speere nennt man rowajang oder dere bunu. Der Speer dient nicht als Waffe, sondern wird bei allen heiligen Handlungen durch den Priester getragen. Bei der Hochzeit wird er, dann wenn das Brautpaar durch den Priester und die Aeltesten rituell mit Opferblut bestrichen wird, von der Braut und dem Bräutigam umfasst. Während dieser Handlung ruhte die Spitze des Speeres früher in einem Menschenschädel, heute in einer Kokosnuss, die den Schädel vertritt. Der Rowajang ist identisch mit dem Lebensbaum. Vgl. die Mythe: der Speer des Maharadja. Der Speer darf nur von Menschen geschmiedet werden die schon einen Kopf erbeutet oder einen Opfersklaven getötet haben.

155 , S. 255.

Die Mythe stammt von Penda-Hara (ein Dorf am mittleren Katingan). Sie zeigt uns die religiöse Bedeutung des heiligen Speeres.

156, S. 255.

Sambong Maut ist verheiratet mit Putir Gimai, der Tochter des Ranjing Mahatala Langit. Er wohnt am Flusse Hintan in der Oberwelt. Er ist der Herr des Lebens. Ihm gibt Ranjing Mahatala Langit den Auftrag den Lebensfaden eines Menschen abzubrechen. Unter Sambong Maut stehen seine drei Diener: Sapanipas tahaseng (der Wegnehmer des Atems), Sapaukur (der Messer der Länge des Atems), Sapanende (der Beendiger des Lebens). Sapaukur misst die Länge des Lebens, Sapanende sagt wenn das Leben abgelaufen ist, Sapanipas tahaseng führt den Auftrag des Sambong Maut aus und bricht den Atem oder Lebensfaden eines Menschen ab.

157, S. 255.

Teras bedeutet: das Kernholz, die innersten und härtesten Teile eines Baumes. Es hat aber auch die Bedeutung von: fest, entschieden, standfest, etwas oder jemand worauf man sich verlassen kann. Vgl. auch HardeLAND, W. B. 
158, S. 256.

In dieser Mythe wird der König der Schweine Katungau genannt, aber in der Mythe vom Ursprung des Eisens wird das Reich der wilden Schweine Katungau genannt. Wahrscheinlich ist, dass der Name des Wildschweines Katungau lautet, denn so wird es auch in den übrigen katinganischen Mythen genannt.

159, S. 259.

Die Verbrüderung nennt man unter den Ngadju hampahari (pahari: der Bruder, hampahari: verbrüdert sein, Brüder sein). Die Verbrüderung durch gegenseitiges Bluttrinken nennt man: hatundi daha: gegenseitig der eine das Blut des andern essen. Es werden dadurch unter den Dajacken die engsten Freundschaften geschlossen; man betrachtet einander dann als Verwandte. Auch besiegelt dies Blutessen oft auch stattgefundene Versöhnung. Es werden bei dieser Ceremonie jedem einige Blutstropfen aus der Schulter genommen, welche mit Tuak (Art Arak) vermischt getrunken werden. (HardeLAND, W. B.)

Die Verbrüderung geschieht $\mathbf{z w i s c h e n}$ Personen die einander viel zu verdanken haben, sie geschieht auch auf Veranlassung eines Traumes oder nach der Aufforderung durch die Ahnen. Oft kommt Verbrüderung vor zwischen fremden Händlern die sich in fremdem Gebiet niedergelassen haben und den Bewohnern dieser Gebiete. Durch die Verbrüderung wird man ein Fleisch und ein Blut und tritt in die Rechte und Pflichten eines Verwandten ein. Blut wird auch getrunken zwischen Adoptiveltern und Adoptivkind, wodurch das Kind ein Fleisch und ein Blut mit seinen neuen Eltern wird und durchaus in die Kindesrechte und Kindespflichten eintritt. Die Verbrüderung findet auch statt zwischen Menschen und Ahnen. Man nennt bei den Ngadju diese Verbrüderung ebenfalls hampahari, noch mehr aber wird der Ausdruck gebraucht: basahabat, vom malaiischen Wort sahabat: der Freund, d.h. also zum Freund machen. Am Katingan lautet diese Verbrüderung zwischen Menschen und Ahnen hurai, abgeleitet von urai: der Bruder. Eine solche Verbrüderung geschieht durch eine Aufforderung im Traum oder bei einer persönlichen Eegegnung mit einem Ahnen oder Geist. Sehr oft kommt die Verbrüderung vor zwischen Menschen und Umang oder auch Djata. Die Ahnen und Geister geben dem Bruder Glück, Kindersegen, reiche Ernten und Heil, erwarten aber vom Menschen auch jährliche Opfer.

J. Mallinckrodt nennt die urai aardgeesten. Ethnographische mededeelingen over de Dajaks in de Afdeeling Koealakapoeas. Bijdragen tot 
de Taal-, Land- en Volkenkunde van Nederlandsch-Indië. Deel 81. Pag. 188. In seiner Dissertation: Het Adatrecht van Borneo. Deel I. Pag. 150 schreibt er: „We komen daarmede op het punt hoe het den enkeling mogelijk is zich in den stam te dringen. In de eerste plaats kan dat geschieden door huwelijk, doch de moeilijkheden daaraan verbonden zagen we vroeger reeds. De tweede manier is die van het sluiten van bloedvriendschap met een der leden van den stam, in welke men wenscht opgenomen te worden, of met welke men in vriendschappelijk verkeer wil treden. Door het drinken van elkanders bloed en de daarbij gebruikelijke ceremoniën wordt men magisch geschikt gemaakt de gevaren van de andere omgeving te trotseeren; men gaat daardoor deel uitmaken van het andere verband. De animistische bewoners van de Katingan, die de magische kracht van een streek verpersoonlijkt achten in de oerai of grondgeesten noemen zulke bloedvrienden dan ook haoerai, één-oerai-hebbend". Diese Beschreibung von Mallinckrodt ist durchaus unrichtig. Erdgeister oder Bodengeister nennt man am Katingan nicht urai, solche Geister, die diesen Namen als Eigennamen tragen würden, bestehen überhaupt nicht. Urai ist der Bruder, der Blutsbruder, der Freund und wie bereits gesagt wurde kann auch ein Ahne oder ein Geist Bruder oder Freund werden, wenn er mit einem Menschen in dieses mehr intime Verhältnis treten will. Der Mensch nennt dann diesen Ahnen oder Geist im Gespräch mein urai: mein Bruder. Die Form haoerai ist ebenfalls unrichtig und wahrscheinlich verwechselt mit dem Verbum hurai: sich verbrüdern. Die Katinganer nennen Blutfreunde nie haoerai sondern immer urai.

Auf Seite 345 des gleichen Werkes schreibt Mallinckrodt nochmals über die urai in Verbindung mit den Handlungen die vollzogen werden müssen bei der Inbesitznahme eines Grundstückes für die Anlage eines Reisfeldes. Er schreibt von diesen Handlungen: „Deze handelingen gaan gepaard met het brengen van offers aan de grondgeesten oerai“. Auch hier ist der Ausdruck urai durch Mallinckrodt unrichtig verstanden und gebraucht.

160, S. 261.

Matei manak, Tod bei der Geburt; darunter versteht man in der Literatur von Borneo meistens der Tod der Mutter bei der Geburt oder im Wochenbett. Das ist nicht ganz richtig. Man hat darunter zu verstehen den Tod der Schwangeren während der Schwangerschaft, während der Geburt und des Wochenbettes und bis zu vierzig Tagen nach der Geburt. Tritt der Tod während dieser Zeit, durch welche 
Ursache dann auch immer, ein, dann ist der Mann der Schuldige. Er hat bewusst, oder unbewusst, auch das ändert daran nichts, die Schwangerschaftspali, die er zu beobachten hat, übertreten und zufolge dieser Uebertretung hat seine Frau den Tod gefunden. Es kann auch sein, dass er während dieser Zeit ein Verhältnis mit einer andern Frau oder einem andern Mädchen angeknüpft hat und dass diese aus Eifersucht die rechte Frau mit ramon oloh (Mittel aus dem Gebiete der schwarzen Magie) ums Leben gebracht hat. Auf alle Fälle ist immer der Mann der Schuldige. Die nächsten Angehörigen der verstorbenen Frau bringen den Fall vor die Dorfältesten und der Mann hat für den Tod den er verursacht hat eine Busse zu bezahlen. Man nennt diese Busse singer pangarai und sie besteht in der Bezahlung von djipen hanja (acht Sklaven, d.h. 360 Gulden), ferner in der Bezahlung der pakajan hantu (Leichenkleider) die ebenfalls djipen idje sampai due (ein bis zwei Sklaven, also 40-80 Gulden) betragen. Zudem hinzu hat der Mann seiner Frau noch das Totenfest zu veranstalten und die Kosten ebenfalls auf seine Rechnung zu nehmen.

161, S. 263.

Lampinak ist eine bohnenartige Schlingpflanze. In den runden Früchten, die etwa so gross wie eine Haselnuss sind, sitzen vier essbare Kerne; aussen an den Früchten sitzen vier Dornen, welche kreuzweise übereinanderstehen. Lampinak nennt man auch das einfache Kreuz $(+)$, das man auf Sawangblätter, auf Medizinflaschen, auf die Brust von Kranken etc. mit Kalk schmiert. Das Kreuz bedeutet wahrscheinlich die vier Windrichtungen und damit auch die kosmische Ganzheit und Vollkommenheit. Wir begegnen ihm auch mehrfach bei den priesterlichen Reinigungshandlungen.

162, S. 265.

Anstelle von Darahen Radja,n Antang liest man in den Priestertexten auch oft: Antang Darahen, oder Darahen Antang oder auch nur Darahen. Die Bedeutung ist aber immer die gleiche.

\section{3, S. 266.}

Djarenang (Malaiisch: djernang, Lat. Daemonorops Draco. Bl. fam. Palmae). Een rotansoort, die vooral op Borneo voorkomt en zich onderscheidt door de vruchten, die aan de buitenzijde een roode hars afscheiden, het z.g. Drakenbloed. Dit wordt gewonnen door de vruchten in een bak met water te stampen. De hars wordt dan door het water 
opgenomen, en verzamelt zich, nadat de resten van de vruchten verwijderd zijn, op den bodem van de bak. Het water wordt dan afgegoten en de hars in mandjes gedaan, waarin hij na een dag of tien hard wordt. (Enc. van Nederl.-Indië. Tweede druk. Eerste Deel. Pag. 554.)

Dieser Farbstoff wird nicht nur für den eigenen Gebrauch (Färben von Kleiderstoffen, Rindenstoffen und Rotan den man zu Flechten braucht) hergestellt, sondern auch für den Export. Heute wird statt Drachenblut auch ein Farbstoff gebraucht den man einführt. Die Uebersetzung dieser Stelle: eine Djarenangmatte mit schönen Verzierungen geschmückt, sollte eigentlich heissen: eine Rotanmatte die mit Drachenblutt rot gefärbt wurde.

164, S. 269.

Bevor die Frauen eine komplizierte Flechterei, die nach alten Mustern ausgeführt wird die Familienbesitz sind, beginnen, legen sie diese Muster neben dem Material, das sie zum Flechten brauchen, nieder und überdenken zuerst die Flechttechnik und die einzelnen Motive und dann beginnen sie die Arbeit, die oft einen Monat dauert oder selbst auch noch länger. Und so wie die Frauen handeln. bevor sie diese wichtige Arbeit beginnen, so überlegen auch die Männer und Aeltesten ihre Angelegenheit, so auch die Reisseelen, die vor den Antang Darahen hintreten um ihm ihren Auftrag zu unterbreiten und mit ihm einen Rat zu suchen.

165, S. 269.

Der hülflose Mensch, der durch seine Mittler (die Priester oder Priesterinnen) die Ahnen um Hülfe aufruft, wird mit einem kleinen Kinde verglichen, das die Mutter im Schultertıch trägt. Entang oder sindjang entang: ein langes Tuch, worin man, das Tuch über die Schulter schlingend, ein kleines Kind an der Brust trägt. Entang ist auch Verbum und bedeutet: ein kleines Kind im Schultertuch an der Brust tragen. Der Mittler (Priester oder Priesterin) nimmt den hülflosen Menschen wie ein kleines Kind an seine Brust und vertritt seine Sache wie eine Mutter für ihr Kind sorgt.

166, S. 269.

Die Zusammengehörigkeit und Verbundenheit des Stammes oder des Clan wird ausgedrückt mit: Penjang idje hindje simpei,e: die Penjang, die unlöslich und unverbrüchlich an einem Bande aufgereiht sind und nur dadurch ihren Sinn und ihre Macht haben. Das Indivi- 
duum wird verglichen mit einem tarantang penjang: einem Kinde, oder einem Gliede des Penjang. Vgl. die Erklärung 87.

167, S. 269.

Mit dem Ausdruck salotih paturong wird ebenfalls das Individuum bezeichnet. Vgl. die Erklärung 87.

168, S. 269.

Lunok (Waringin) bedeutet: der Mann, der männliche Mensch.

169, S. 271.

Der Santagi ist ein Schmuckstück, das bei den priesterlichen Handlungen von den Priesterinnen auf der Brust getragen wird, bei Festen wird es auch von den vornehmen Frauen getragen und bei wichtigen Handlungen ziert er auch die Brust der Aeltesten oder der Dorfhäupter.

Eine Abbildung eines solchen Santagi findet sich im Catalogus van 's Rijks Ethnographisch Museum. Borneo. Deel I. Plaat IV, Abbildung 4. Die Beschreibung dazu lautet (Seite 40 des gleichen Bandes): „Borstsieraden (Daj. santagi) bestaande uit drie of vier halvemaanvormige platen van geel koper [ursprünglich wurden sie von Gold geschmiedet], die boven elkander met de punten aan een koord zijn verbonden. De bovenste plaat is aan het midden van het concave gedeelte van een convexe verbreeding voorzien. Aan het koord zijn tusschen de drie bovenste platen blauwe cylindrische kralen en bladvormige stukken plaatkoper met ingeprikte stippen geregen en bovendien boven de punten der bovenste plaat een vogel of ook een naga [Wasserschlange] van geel plaatkoper, eenige blauwe kralen enz."

Hardeland, W. B. schreibt: Santagi: Gold- oder Silberblech, in der Gestalt von Halbmonden, welche man an die Halsbänder von Agaatsteinen gebunden auf der Brust trägt.

Ueber die Stellung und Bedeutung der Santagi in der dajakischen Kultur wissen wir so gut wie nichts. Soviel steht aber fest, dass sie in dem totemistisch/kosmologischen System der Dajak in Verbindung stehen mit der Unterwelt die von der Tambon oder Naga bewohnt wird. Zur Unterwelt gehören auch : Mond, Perlen, Gold, Silber, Kupfer und Achate. Damit gehören die Santagi auch in die matrilineale Stammhälfte und es ist anzunehmen, dass sie hier geschmiedet und auch von hier aus in den Tauschhandel gebracht werden. Ihre Stellung und Bedeutung in der Kultur wird erst dann zu bestimmen sein wenn einmal 
die Kultur, und vor allem auch die Mythen, gründlicher untersucht worden sind.

170, S. 273.

Das Haus ist ein Abbild des Kosmos. Es setzt sich zusammen aus Unterwelt und Oberwelt. Die Unterwelt ist der Fussboden. Die Mitte des Hauses, die durch die Schwelle in zwei Teile geschieden wird, nennt man labeho,n huma: die Wassertiefe des Hauses. Die Wassertiefe ist der Zugang zur Unterwelt, die durch die Tambon oder die Djata bewohnt wird. Die Schwelle selbst heisst, wie wir in Erklärung 141 sahen, tambon gana,n lungko: die Wasserschlange, die Seele der Schwelle (oder auch einfach: die Wasserschlange, die Schwelle). In der Mitte des Hauses finden die priesterlichen Handlungen statt und hier erscheint auch die Tambon. Wichtige Handlungen (Hochzeit) finden hier über der Unterwelt statt, weil aus ihr Segen und neues Leben geschenkt werden. Die Leiche wird hier aufgebahrt (d.h. in der Unterwelt), weil hier der Ort ist wo sie neues Leben empfängt.

171, S. 273.

Das Bier wird genannt: batu bangkulan tuze oder auch gohong pandih Njaring (zwei Bezeichnungen die nur in der Basa Sangiang vorkommen). Tuze (Vgl. die Erklärung 20), in Wasser aufgelöst, ergibt eine weisse, milchige Flüssigkeit. Gohong pandih Njaring: die Wasser die abgesperrt sind durch die Njaring. Gedacht ist an die Njaring, die die Lunokbäume als ihre Häuser bewohnen. Sie sperren den Saft der Bäume ab, denn die Bäume dürfen durch die Menschen nicht verletzt werden. Der Saft der Lunok ist ebenfalls milchig und klebrig. Auch das Bier ist etwas klebrig und hat eine weissliche Farbe und aus diesem Grunde wird es in der poetischen Sprache der Basa Sangiang verglichen mit Tuwe und dem Saft der Lunok.

\section{2, S. 274.}

Djilau bulan kapanaho matei biti,e ist ein Fluch oder eiin Ausdruck der bedeutet: nichts, gar nichts, überhaupt nichts.

\section{3, S. 274.}

Garing tabela belom: Elfenbein, junges, lebendes, bedeutet eigentlich junges $\mathrm{Holz}$ (Elfenbein ist gleichbedeutend mit Holz) oder unerwachsene Knaben. Die Erwachsenen nennt man Lunok: der Baum. 
174 , S. 276.

Die Ahnen offenbaren den Menschen nicht nur im Traum oder bei einer persönlichen Begegnung den Fundplatz von Karuhei tatau die in dieser Welt zu finden sind, sie besitzen auch in der Oberwelt Fundplätze mit Karuhei tatau und Penjang und reisen die Reisseelen in die Oberwelt dann bringen sie auch immer von diesen guten Gaben der Ahnen mit und übergeben sie den Menschen oder man verlangt sie von Geistern die einem Menschen Schaden zugefügt haben als Entschädigung und die Reisseelen bringen sie dann auf ihrer Rückreise aus der Oberwelt mit.

\section{5, S. 276.}

Paturong sangkalemo radja: ein anderer Name für Karuhei tatau. Hardeland, W. B. schreibt über sangkalemo, emo, panjuka: sie bestehen in Zauberbriefen, oder in einigen arabischen Wörtern, welche man leise vor sich spricht; sie sollen Männern die Gunst von Männern, vorzüglich den geringern die der reichen, vornehmen, erwerben; dies Mittel kauft man von Mahomedanen.

176, S. 276.

Mait und djaja bedeuten stark und kräftig im religiös/magischen Sinne.

\section{7 , S. 277.}

Lintong talazerang sind die feingeflochtenen Rotanbänder die nicht nur als Verzierung, sondern auch als Verstärkung am oberen und unteren Ende um den Schild gebunden werden. Die Schilde werden bei der Haustüre gegen ein Gestell gelehnt.

\section{8, S. 278.}

Wenn der Fluss hoch anschwillt, dann treiben auf dem Wasser eine Unzahl von grossen, grau/gelben Schaumflocken die vom Quellgebiet herkommen. Mit diesem goldenen Schaum wird der Kapok, der flockige, mit dem man die Kissen füllt, verglichen.

179, S. 285.

Batuah: glücklich sein, Gewinn- oder Vorteil haben. Der Mensch erwirbt sich diese Güter nicht mit eigenen Kräften und Mitteln, sie sind eine Gabe der Djata, die sie den Menschen, denen sie wohlgesinnt 
ist, schenkt. In der Erde verborgene oder vergrabene Schätze rufen (manuah) die Menschen an, d.h. sie machen mit einem feinen Laute, den sie von sich geben, die Menschen auf sich aufmerksam. Das ist auch der Fall mit Erde, die eine besondere Kraft besitzt und die meistens von den Schwangeren gegessen wird. Auch sie ruft (manuah) den Menschen herbei als Gabe, die durch die Djata geschenkt wird.

Batuah (glücklich) ist der Mensch der unter diesem Segen der Djata steht und ihre Gaben empfängt, aber immer ist Glück und Heil, das umschrieben wird mit dem Terminus tuah, abhängig von ihr und ihre freie Gabe.

180, S. 286.

Pulang, der Schwertgriff, werden die unerwachsenen Knaben genannt. Die erwachsenen Männer nennt man Dohong: Dolch; der Griff an diesem Dolch sind die Knaben. Vgl. auch Erklärung 173.

181, S. 287.

Njating (Harz) wird von den Frauen auf den Sandbänken der Flüsse gesammelt. Das Harz wird dort vom Flusse angespült. Dieses Harz gebraucht man auch meistens für die Harzlichter. $\mathrm{Zu}$ diesem Zwecke wird das Harz feingestampft und in Blätter gerollt und diese Rollen werden in ein, meist schön geschnitztes Gestell von Eisenholz, neuerdings auch von Eisen, gesteckt.

182, S. 287.

Tangis tingang oder tangungoi burong wird der schluchzende Laut der Vögel genannt. Es gibt auch Vögel von denen man aussagt, dass sie weinen.

183, S. 289.

Bari ist gekochter Reis, behas ist enthülster Reis, parei (in der Basa Sangiang: parei njangen tingang) ist der gewöhnliche, noch nicht enthülste Reis.

184, S. 290.

Die Abstände, die man auf einem Fluss zurückzulegen hat, bezeichnet man nach den Flussbiegungen, die alle ihre eigenen Namen besitzen. Einem Dajak, der viel reist, sind diese Namen bekannt. Fragt man wie weit es noch bis zum nächsten Dorfe sei, dann erhält man die 
Antwort: so und so viel Flussbiegungen und man weiss dann auch wie lange man noch $z u$ rudern hat. Für eine lange Flussbiegung rudert man eine Stunde, für eine kurze eine halbe Stunde. In einem Tag rudert man ungefähr acht bis zwölf Flussbiegungen. Am Oberlauf der Flüsse verschwinden die Flussbiegungen und man nennt die Abstände nach den Steinbänken (karangan) und man weiss ebenfalls wie lange man von der einen zur andern Steinbank zu rudern hat. Auch die Steinbänke tragen Namen wie die Flussbiegungen.

185, S. 293.

Die Dörfer des Sangumang liegen in der Oberwelt. Sangumang ist Heilbringer, der in der Gestalt des kleinen Dolches (ein Antang: Falke) auftritt. Vgl. auch die Erklärungen 9 und 125 und die Ursprungsmythe und Genealogie im II. Band dieses Werkes.

\section{6, S. 296.}

Hamputut (feingestampfter Baumbast) wird zusammengebunden zu einem Strick, so lang und dick als ein Arm, und wird dann angezündet, um durch den dadurch verursachten starken Rauch die Moskitos zu vertreiben. Ein Hamputut genügt für die ganze Nacht. (Hardeland, W. B.) Am glimmenden Hamputut entzündet man auch Feuer und diese Eigenschaft des Hamputut ist in dieser Stelle gemeint.

\section{7, S. 297.}

Manangkadje andau. Andau: der Tag, die Witterung, die Hitze. Manangkadje ist gleichbedeutend mit irek: reinigen. HaRdeLAND, W. B. schreibt darüber (seine Darstellung ist natürlich nicht vollständig): Irek, das gereinigt sein (Fische von den Schuppen etc. reinigen); das in gute Ordnung gebracht sein. Mirek, hirek dengan, reinigen, in gute Ordnung, guten Stand bringen. Hirek, (neutrum) oder mirek oloh, Menschen von Krankheiten reinigen, geschieht wenn man Arzneimittel bei einem Kranken vergeblich angewandt hatte. Die Krankheiten hält der Dajack für Individua, Personen, Knechte des Radja Hantuen, welche die hambarua (anima) des Menschen gefangen fortführen, sie quälen, und an Stelle der Seele dann im Körper des Menschen wohnen. Das hirek geschieht durch Balian, ein, drei, fünf oder sieben, gewöhnlich ihrer drei. Es besteht im Hersingen von Zaubergesängen, wodurch man die Sangiang (Luftgötter) bewegt bei dem Radja hantuen es zu vermitteln, dass er die Hambarua zurückgibt, und die Krankheit fort- 
gehen heisst. Man opfert dabei dann auch dem Radja hantuen ein Schwein oder ein Huhn, von dem er aber nur die Seele und den Geruch erhält, das Fleisch isst man selbst; zu Zeiten wird auch ein Hund geopfert, der aber wird nicht gegessen. Dabei mangumul oder malin, mangalin, mangkawan die Balian dann auch den Kranken, d.h. sie bespeien die Stelle wo der Schmerz sitzt, kneifen und kneten den Leib, wobei sie vorgeben kleine Steine, Fischgräten, Holzstückchen, Ameisen etc. aus dem Körper des Kranken zu holen, welche durch die Krankheit hineingesteckt seien. Auch wehen sie mit Sawang-, Talengkap-, oder Kakambat-Blättern rund um den Kranken her, vorgebend, dass sie dadurch die Krankheit wegfegen. Zum Schlusse des hirek wird der Kranke injaki, mit Blut bestrichen.

Es gibt verschiedene Arten des hirek: manjunggoh, wobei ein Schwein geschlachtet und das Opfer ins Haus oder dicht bei dem Hause des Kranken gesetzt wird; basungka, wobei man zu Gräbern geht, und dort opfert; baramanja: wobei drei Hühner geopfert werden; manangkadje, nangkadje, mangarakau, ngarakau, wobei nur ein Huhi geopfert wird; manumbal, wobei man nur Eier und Reis als Opfer bringt. Je nachdem die Krankheit gefährlich ist, wird die Art des Hirek gewählt.

\section{8, S. 297.}

Hardeland, W. B. beschreibt diese rituelle Handlung folgendermassen : Manjaki, hasaki dengan, mit Blut bestreichen, eine abgöttische Feierlichkeit welche unter den Dajacken sehr häufig im Gebrauch ist. Viele Eltern manjaki ihre Kinder jeden Monat bis sie zehn bis zwölf Jahre alt sind, um alle Krankheiten etc. von ihnen abzuhalten. Reiche Leute schlachten zu dem $Z$ wecke jedesmal ein Huhn; Arme nehmen dazu nur ein wenig Blut aus dem Kamme eines Hahns; dies nennt man auch: mandjunggul [djunggul: der Kamm auf dem Kopfe der Hühner und der Vögel; mandjunggul: Blut aus dem Kamme entnehmen für das manjaki]; auch nimmt man statt Blut wohl auch den Dotter eines Eies zum manjaki. Ist ein Kind gestraft worden, so muss man es manjaki „bele hambarua,e manjalo palus manganan arep,e: damit seine Seele nicht traurig werde, und sich selbst wegwerfe", damit es nicht sterbe. Haben zwei Menschen miteinander Streit gehabt, so werden beide bei der Wiederversöhnung injaki [mit Blut bestrichen]. Nach jedem Götzenfeste, nach jedem Opfer, müssen die, welche es veranstaltet haben, injaki werden um sie $z \mathbf{u}$ reinigen. Hat man einen glücklichen Traum gehabt, manjaki man denselben, d.h. man be- 
streicht sich selbst mit Blut, damit der Traum desto gewisser eintreffe. Alle Kranken werden injaki, damit die Krankheit weiche. Brautleute werden bei der Hochzeit injaki. Auch Sachen manjaki man, z.B. ein neues Haus, wenn man es bezieht, desgleichen die Häuser, in welchen Todesfälle stattgefunden haben. Wenn man mit dem Pflanzen des Reises beginnt, manjaki man das Feld, man sprengt etwas Blut darauf umher mit den Worten: aku manjaki ikau, petak, mangat basiwoh, aloh tanangku idje karabit olih manjuang lepau: ich besprenge dich mit Blut, o Erde, damit du fruchtbar werdest, ist auch mein Feld nur ein kleines Stück, es möge füllen eine ganze Reisscheuer. Balanga (heilige Töpfe), Gold etc. werden injaki, damit sie nicht verloren gehen, damit Segen dabei sei. Alle Karuhei und andere Zaubermittel muss man oft manjaki, damit sie kräftig bleiben. Man darf zum manjaki nur Blut von Büffeln, Schweinen und Hühnern gebrauchen; auch wohl Eidotter. Soll ein Mensch injaki werden, so muss dies durch drei oder sieben Personen verrichtet werden, eine muss eine Balian (Priesterin) oder ein Basir (ein Priester in Frauenkleidern) sein, die andern so viel möglich reiche, angesehene Leute. Man taucht einen spanischen Dollar [dazu werden auch heute noch alte Münzen, seien es spanische, portugiesische oder holländische verwendet. Die meisten dieser Münzen stammen aus dem 17. und 18. Jahrhundert], oder auch ein Stück Eisen in Blut, und bestreicht damit zuerst die linke Fussohle, dessen der injaki werden soll, mit den Worten: nalatap kare talo papa (es seien ausgehauen alle bösen Dinge), wobei man die talo papa (die bösen Dinge) einzeln hernennt, z.B. Krankheiten, Gespenster etc. Dann wird die rechte Fussohle bestrichen mit den Worten: uka mahundjeng petak kasambujan (damit du auf fruchtbare Erde tretest). Dann bestreicht man die beiden Fussgelenke mit den Worten: uka maling kare sial peres (damit verdorren mögen alle Unglücksursachen und Krankheitsgeister). Dann kommt die Reihe des Bestrichen werdens an die beiden Kniee, wobei der Bestreichende sagt: mangat manuntut balanga halamaung (auf dass du nachgehest, d.h. erreichest, erhaltest, einen Balanga, einen Halamaung, das sind heilige Töpfe von grossem Wert). Dann wird die linke Hand mit den Worten bestrichen: uka makis kare talo papa (damit du wegstossest alle bösen Dinge). Dann die rechte Hand mit den Worten: mambet balanga halamaung (ziehe her zu dir Balanga und Halamaung). Dann werden beide Handgelenke bestrichen, wobei gesagt wird: mukot kare talo bahalap (ziehet herbei alle guten Dinge). Dann beide Ellenbogen mit den Worten: manjiko kare sial peres (stosset alle Unglücksursachen und alle Krankheitsgeister weg). Dar- 
auf bestreicht man die Herzgrube, sagend : mangat matei kutoh panatan bulau (auf dass du viel Reichtum und Gold erwerbest). Dann beide Schultern, zuerst auf ihrer Vorderseite: mangat manjangka kare ampin talo papa idje kapenda langit (damit ihr in die Höhe forthebt alle Arten böser Dinge, welche unter dem Himmel sind). Dann beide Schultern auf der Hinterseite: mangat tariup kare sial peres, palahan (damit weggeblasen werden alle Arten von Unglücksursachen, Krankheiten und heimlichen Nachstellungen). Darauf wird die Stirne bestrichen mit den Worten: injakiku lingkau,m, mangat ikau baserent, tatau, hai (es wird bestrichen durch mich deine Stirne, auf dass du werdest berühmt, reich, angesehen). Dann die Scheitel: mangat mahalau kare kapapan talo hai korik (damit an dir vorbeigehen alle bösen Dinge, die grossen und die kleinen). Darauf wird dem Menschen etwas enthülster Reis auf den Kopf gestreut, mit den Worten: kakare te anak, $m$, panatau, $m$ (alsoviel mögen deiner Kinder und Reichtümer werden). Darauf lässt man dem Menschen etwas Wasser auf den Kopf tröpfeln, und sagt: kambo batangdanum kambo tahaseng,m, kasadingen danum kasadingen tahaseng, $m$ (so lang ein grosser Strom ist, so lang sei auch dein Atem, wie die Kühle des Wassers sei auch die Kühle deines Atems). Dann schmiert man etwas nasse Erde unter die Fussohlen und auf die Herzgrube des Menschen, und sagt: kare petak kare panatau,m; petak djaton tau una, dia kea una panatau,m dapit (wie die Menge der Erde ist, so sei die Menge deines Reichtums, die Erde kann nicht vermindern, noch alle werden, so möge auch dein Reichtum später nie abnehmen). Endlich bindet man dann dem Menschen eine Schnur Perlen um das Handgelenk des rechten Armes, zum Zeichen, dass er injaki ist. Die Perlenschnur soll zugleich alle die über ihm ausgesprochenen Wünsche an ihm festbinden. Er muss die Schnur sieben Tage lang tragen, sollte sie während dieser Zeit reissen, dann wird das saki (die Bestreichung mit Blut) kraftlos.

Verwiesen sei auch auf die manjaki-Handlungen in den Texten zum Tantolak matei, die sich in diesem Bande finden und auf die Texte in den weiteren Bänden dieses Werkes. Es ist hier nicht der Ort eine ethnologische Auseinandersetzung über das manjaki zu geben, doch glaube ich, dass man sich hüten muss diese Handlung nur als eine magisch/dynamistische zu sehen, etwa in dem Sinne, dass durch die Bestreichung mit Blut automatisch Macht ausgelöst und übertragen werde zur Abwehr von Unheil und zur Erlangung von Heil. Es geschieht auch in der primitiven Religion nichts automatisch. Von den Opfertieren, deren Blut für die Bestreichung gebraucht wird, wissen 
wir, dass sie mit den Menschen verwandt sind und dass sie mit ihnen die gleichen Ahnen haben. Siehe die Welt- und Menschwerdungsmythe im II. Band dieses Werkes. Auch diese Handlung wird nur gesehen werden können von dem totemistisch/kosmologischen Hintergrund der dajakischen Kultur und sie wird m.E. auch nur von hier aus gedeutet werden können.

189, S. 297.

Mali, das Verbum von pali, bedeutet: etwas als verboten beschauen und behandeln.

190, S. 297.

Bawoi samben: das Schwein mit dem Halsband. Damit ist das gezüchtete Schwein, im Gegensatz zum Wildschwein gemeint. Das Schwein hat einen schwarzen Streifen um seinen Hals, der wie ein Halsband aussieht und deshalb trägt es in der Basa Sangiang auch diesen Namen.

191, S. 301.

Gana,n Apui: die Seele des Feuers. Die Gana ist die Seele der leblosen Dinge, der Pflanzen und Tiere. In diesem Falle übersetzen wir den Term besser nicht oder wir übersetzen einfach: das Feuer, weil es personifiziert gedacht wird. Die Uebersetzung mit Seele, Lebenskraft und Seelenstoff befriedigt deshalb nicht weil es immer um die Ganzheit geht, aber nicht um ihre eine oder andere Seite. Statt Gana,n Apui (und das gilt überall wo man den Term gana braucht) kann man auch sagen: radja,n Apui (der König des Feuers) oder hatue,n Apui (der Herr des Feuers), wobei man sich in diesem Fall das Feuer als König oder Herr vorstellt. Den wechselseitigen Gebrauch dieser Terminologie finden wir in allen Texten.

192, S. 302.

Apam kembong rizent, lipat djela tandang und njiring-njababiring kilat sind verschiedene Arten von Kleingebäck, das nach seiner Form so bezeichnet wird.

Behas tambak radja: königlich aufgehöhter Reis, ist enthülster Reis den man in einem Gefäss aufgehöht hat zu der Form eines Berges. Die Seelen der Veranstalter und Teilnehmer von und bei priesterlichen Handlungen können sich verirren, sie können mit den Reisseelen oder dem Antang Ganan Tadjahan (dem Falken vom Ahnenheiligtum) nach der Oberwelt und Unterwelt reisen und sie können sich dort verirren 
oder zurückgehalten werden. Nach Abschluss der Handlungen ruft deshalb der Priester die Seelen zurück. Sie kehren nicht direkt in den Körper zurück, sondern halten sich auf dem behas tambak radja auf und von dort führt der Priester die Seelen wieder in ihre Körper ein, indem er den Reis auf die Köpfe der Veranstalter und Teilnehmer streut. Durch die Fontanelle treten sie wieder in den Körper ein und werden dort wieder "festgemacht".

193, S. 306.

Panjangka (der oft stützt, von sangka: der Pfeiler, die Stütze) ist eine Medizin, ein Oel das durch einen Tabit (ein Priester der sich mohammedanischer Mittel bedient) besprochen wurde (indem er darüber Korantexte aussprach). Man bestreicht sich mit diesem Oel wenn man Fieber oder Kopfweh hat.

Salatutup oder salantutup sind Holzstückchen, Zaubersprüche oder Zettel. Man kann sich mit ihnen unsichtbar machen für alle bösen Geister und Gespenster, auch für alle Krankheitsgeister. Die Salatutup werden in der Form von kleinen Hampatong (Schnitzbilder mit einem menschlichen Angesicht) den kleinen Kinder als Schutzmittel um den Hals gebunden.

Parapat ist eine kleine Pflanze, hat kleine runde und mit Härchen bewachsene Blätter, etwa so gross wie der Nagel an einem Finger. Man quetscht sie und legt sie auf Wunden, welche dadurch schnell heilen.

Panamar ist eine Schlingpflanze. Sie wird etwa so dick wie ein Daumen. Von innen ist die Pflanze gelblich und schmeckt sehr bitter. Man gibt das Holz denen als Gegengift zu essen, welche durch Schlangen gebissen worden sind.

Die Bedeutung von salapandom ist mir nicht bekannt.

194, S. 308.

Der djoho ist eine Gemüsesuppe die zum Reis gegessen wird. Er erhält seinen Namen meistens vom Hauptgemüse das dafür gebraucht wird. Hat man Fleisch (Schweine, Hühner, Hirsche usw.), dann kocht man einen Teil des Fleisches im Djoho mit. Der Festdjoho, der besonders schmackhaft ist, ist der djoho,n singkah enjoh (die Gemüsesuppe, zubereitet von dem zarten Fleisch der Herzblätter der Kokospalme). Man fällt $\mathfrak{z u}$ diesem $Z$ wecke eine oder mehrere Palmen und vermischt dann diesen $D$ joho auch noch mit Schweinefett und Schweinefleisch.

Paria ist eine Pflanze, die den Bohnen ähnlich ist. Die sehr bittere 
Frucht hat Aehnlichkeit mit kleinen Gurken, Sie wird zum Reis gegessen oder im Djoho mitgekocht.

195, S. 308.

R. Brandstetter: Die Hymnen der dajakischen Tiwah-Feier, 1928, schreibt über sial: „Das sial oder Siyal existiert in verschiedenen indonesischen Sprachen. Im Malaiischen bedeutet es ,unheilverkündend", im Toba „Pechvogel“. Die Wurzel ist yal, die auch im Karo kiyal ,beim Spiel verlieren" auftritt."

Hardeland, W. B. schreibt: Sial, (kawe, das Wort für Sial in der Basa Sangiang, wird oft zur Verstärkung hinter sial gesetzt) alle bösen, Unglück verursachenden Wesen, z.B. auch alle Krankheiten, welche der Dajak personifiziert. Sie wohnen oben in der Oberwelt über dem Lande der Sangiang, am Batangdanum baderep (dem einstürzen machenden Flusse). Sie stehen unter einem König, dem Radja Sial. Sie tun Böses, so viel sie können, auch ohne dass sie beleidigt werden.

Sial nennt man auch alles durch Sial verursachte Unglück, hauptsächlich alles das was nur eine Person unter vielen trifft, z.B. wenn bei einer allgemein guten Ernte, einer oder einige doch eine schlechte Ernte hatten, wenn zur Zeit in der keine Seuchen auftreten, jemand doch krank wird (z.B. an Cholera oder Pocken).

Basial, auf den die Sial es abgesehen haben, unglücklich.

Wir können hier nicht den ganzen Komplex des Sial beschreiben, weil es zu weit führen würde. Immer ist aber das Sial, das zu verschiedenen Zeiten und bei verschiedenen Gelegenheiten und auch unter verschiedenen Namen über die Menschen hereingebracht wird, mit dem Radja Sial und seinen Untertanen verbunden. Heute wird der Ausdruck auch im profanen Sinne von: Unglück haben, Pech haben, gebraucht. Nicht jeder, der heute aussagt, dass er basial sei (dass er Pech oder Unglück habe) ist auch wirklich ein von den Sial Verfolgter. Bei ethnographischen Beschreibungen muss man diesen doppelten Sprachgebrauch vor Augen halten und auch daran denken, dass der Ausdruck Sial oft sehr nachlässig und auch unzutreffend verwendet wird. Davon hat sich Mallinckrodt in seinen Beschreibungen zu wenig Rechenschaft gegeben und die Beispiele, die J. J. Fahrenfort (Dynamisme en logies denken bij natuurvolken, Groningen 1933. Pag. 141-142) aus Mallinckrodt gibt, haben streng genommen mit Sial nichts zu tun, auch der unheilvolle Zustand in den die Menschen zeitlich gekommen sind kann nicht als Sialzustand bezeichnet werden. 
196, S. 309.

Das balaku ontong ist eine der wichtigsten Handlungen bei den Dajak, die immer nach grossen Reinigungshandlungen oder nach schweren Krankheiten vorgenommen wird.

Hardeland, W. B. schreibt: Ontong, Vorteil, Gewinn, Glück. Radja Ontong, der König des Glückes, oder auch radja balawang bulau, der König der goldenen Türe, ist der König alles Glückes und Vorteils. Sein Wohnplatz liegt über den Dörfern der Sangiang in der Oberwelt, dicht bei dem Orte, wo Mahatara, der höchste Gott, wohnt. Wer Unglück hat, oder wer sein Glück noch zu vermehren wünscht, muss von ihm „balaku ontong“, Glück erbitten.

Sieben Balian (weibliche Priesterinnen) haben zwei Nächte lang damit $\mathrm{zu}$ tun. Die erste Nacht wird durch Zaubersprüche etc. alles Sial (Unglück, Unheil) vertrieben. In der zweiten Nacht bringt man dann Opfer, und zwar sieben Hühner, ein Ei, sieben Blätter voll Reis, sieben Bambusköcher voll Reis, ferner Backwerk, Früchte, Zuckerrohr. Man lässt die Gana (Seele) davon durch einen Sangiang dem Radja Ontong überbringen, welcher dem Sangiang dafür ein wenig Gold gibt, was dieser den Balian überbringt, welche damit dann drei Gantang (ein Gantang ist ein Reismass) enthülsten Reis, ein wenig Gold, und einen eine Klafter, eine Elle, eine Spanne und drei Zoll langen Rotan bestreichen. Alles das wird dann vor die Balian hingelegt, welche nun ihre Zaubergesänge weitersingen. Hat sich dann später der Reis oder das Gold um etwas vermehrt, und ist der Rotan etwas länger geworden, so ist das ein Zeichen, dass wirklich durch den Radja Ontong Glück mit jenen Dingen verbunden worden ist. Der, welcher um Glück bitten lässt, isst den Reis dann auf, schmiedet das Gold an seine Ohrringe, und legt den Rotan unter sein Kopfkissen, und meint dann zuversichtlich auf Glück rechnen zu dürfen.

Mit diesen, durch Hardeland beschriebenen Handlungen wird eine einfachere Form des Balaku Ontong beschrieben. Das eigentliche Balaku Ontong aber, das nach dem Tiwah vorgenommen wird ist viel komplizierter. Die vollständigen Texte, Bilder und Beschreibungen davon werden im IV. Band dieses Werkes gegeben. Sie werden dort ungefähr 400 Seiten beanspruchen.

197, S. 309.

Tantolak Sial Apui. Man kann das Sial Apui auch verabschieden wenn man andere Sial verabschiedet. Man unterscheidet verschiedene 
Sorten der Sial, die alle als Diener unter der Herrschaft des Radja Sial stehen.

198, S. 309.

Tingen ist der Name einer Grasart, die wie der Reis aussieht, wo es wächst lässt es nichts anderes aufkommen, und es ist sehr mühsam auszurotten. Man gebraucht das Gras für die Dachbedeckung meist provisorisch oder zeitlich aufgerichteter Hütten (Feldhütten, Festhütten).

199, S. 310.

Baloh: Kürbis. Die baloh asip ist rund, sie wird nicht gegessen sondern ausgehöhlt und statt der Bambusköcher zum Wasserschöpfen verwendet.

200, S. 311.

Mit tambon haruei bungai (die Wasserschlangen, die gemeinsam auftreten mit den Nashornvögeln) sind hier die Balian (Priesterinnen) und Basir (männliche Priester, die Frauenkleider tragen) gemeint. Als Hintergrund der ganzen Handlung haben wir aber den ganzen Stamm zu sehen, der in seinen Vertretern bei wichtigen Handlungen teilnimmt. Die eine Stammhälfte wird Tambon (Wasserschlange) genannt und ist verbunden mit der Unterwelt, die andere Stammhälfte wird Bungai oder Tingang (Nashornvogel) genannt und ist verbunden mit der Oberwelt. Tritt der Stamm in seiner Ganzheit zu einer wichtigen Handlung zusammen, dann kann man ebenfalls sprechen, und es wird auch so gesprochen, von tambon haruei (oder haruwei) tingang.

201, S. 311.

Njarang Tingang Hatuen Apui bedeutet: Njarang, der Nashorn. vogel, der Herr des Feuers. Nashornvogel bedeutet ebensoviel wie Herr. An anderer Stelle wird das Feuer einfach genannt: Gana,n Apui : die Seele des Feuers, oder das Feuer. Vgl. die Erklärung 191.

202, S. 312 .

Upo,n Balian. Upo bedeutet: der Ursprung, der Anfang, die Ursache, der Stamm, das Vorzüglichste. Der Upo,n Balian ist der (oder die) Hauptbalian. Der (die) Upo,n Balian singt die Texte, die andern Balian oder Basir, die ihn (sie) begleiten und die man panombah (Beantworter) oder panggapit (abgeleitet von gapit: Baumstämme oder 
Holzstücke, welche man an die Seiten eines aufs Land gezogenen Bootes legt, damit das Boot feststehe. Manggapit bedeutet: solches Holz an ein Boot legen; jemandem im Range der Nächste sein. Panggapit: eine Stütze, jemand der im Range der Nächste ist) nennt, wiederholen diesen Text.

203, S. 313.

Njarakumpang, abgeleitet von kumpang: die Scheide, der Ueberzug, die Fassung, bedeutet hier, dass das Spruchwort des Njarang Tingang Hatuen Apui eingehe in den Gesang, wie das Schwert eintritt in die Scheide.

204, S. 314.

Der Sinn dieser ganzen Stelle ist: Der Njarang Tingang Hatuen Apui fährt nun in den Upo,n Balian ein und während den weiteren Handlungen tritt er persönlich in der Gestalt des Upo,n Balian auf. Die Seelen werden dabei ausgetauscht. Die Seele des Upo,n Balian tritt aus dem Körper und begibt sich in die Oberwelt in den Körper des Njarang Tingang Hatuen Apui und die Seele des Njarang Tingang Hatuen Apui kommt in den Körper des Upo,n Balian. Dieser Austausch der beiden Seelen wird mit einem batu bangkalan oder liang kantihan (Schleifstein) verglichen, der hin- und herfährt. Der Upo,n Balian aber wird verglichen mit einem Lunok, einem Baum, der goldene Früchte trägt, oder mit dem Goldsand der aus dem Fluss auftaucht, der bei den Sandbänken oder Steinbänken angeschwemmt wird und dort von den Frauen herausgewaschen wird. Die goldenen Früchte und der goldene Sand ist das Spruchwort des Upo,n Balian, oder auch sein Gesang. Auch in der Oberwelt kommen diese Bäume vor, die als Früchte Stammythen tragen. Wer von diesen Früchten isst, der wird ein berühmter Sänger und Kenner der Stammythen werden.

205, S. 327

Die Eidesablegung nach Aufhebung einer Fehde. Wurde nach einer Kopfjagd oder nach einem Kriege die Fehde zwischen zwei Stämmen aufgehoben, dann versammelten sich die Parteien zum Vergleich an einem vereinbarten Ort. Nachdem der Vergleich, und damit auch der Friede, zustande gekommen war, vollzog der Priester die ausführlichen Eideshandlungen, an denen beide Parteien teilnahmen. Zuerst rief er die Ahnen aus der Ober-, Mittel- und Unterwelt herbei um bei dieser 
Handlung teilzunehmen und Zeugen der Eidesablegung zu sein. Wer jemals den Eid bricht, den soll der Fluch dieser Zeugen treffen.

Zuerst streut der Priester Salz und Asche aus und spricht: der Atem des Eidesbrüchigen fliege fort wie die Asche, und sein Leben schmelze hin wie das Salz.

Dann nimmt der Priester einen ausgehöhlten Kürbis (baloh) und die beiden Parteien zerschlagen ihn mit den Worten: Wer den Eid bricht, dessen Leben soll zerbrechen, wie dieser Kürbis zerbrochen wird. Von Geschlecht auf Geschlecht soll das Leben seiner Nachkommen zerbrochen werden.

Darauf lässt er sich den Schaft eines Beiles (idjang pahera) geben und die Parteien zerbrechen ihn, indem sie dazu sprechen: Wie der Schaft des Beiles zerbrochen wird, so soll auch das Kinn (idjang) dessen zerbrochen werden, der den Eid bricht. Zerbrochen werden sollen seine Arme und Beine.

Darnach halten die beiden Parteien ein Stïck Rotan fest (an jedem Ende steht eine Partei). Der Priester durchschneidet es, indem er spricht: Wie dieses Stück Rotan durchschnitten wird, so soll auch der Atem des Eidesbrüchigen durchschnitten und abgebrochen werden. Wenn das geschehen ist, dann übergibt der Priester den beiden Parteien ein Huhn. Während sie es festhalten schlägt er dem Huhn den Kopf ab mit den Worten: Wie dieser Kopf hier ahgeschlagen wird, so soll auch der Kopf des Eidesbrüchigen abgeschlagen werden; so wie das Blut dieses Huhnes auf die Erde fliesst, so soll auch das Blut des Eidesbrüchigen vergossen werden und die Erde rot färben.

Schliesslich treten die Parteien zum Fluss. Jede Partei wirft einen Stein ins Wasser und der Priester spricht dazu: Wie diese Steine im Wasser versinken und nicht mehr auftauchen, so soll auch das Leben des Eidesbrüchigen und seiner Nachkommen von Geschlecht auf Geschlecht versinken und nicht mehr auftauchen.

Nach dieser Handlung kehrt man wieder auf den alten Platz zurück und dort angekommen bittet der Priester die Parteien trockenes Holz herbeizutragen und ein Feuer anzufachen. Brennt das Holz, dann giessen die beiden Parteien darüber Wasser aus und der Priester spricht dazu: Lösche aus Feuer! So wie das Wasser dich auslöscht, so sollen auch alle Gedanken an Rache und Vergeltung in den Herzen der beiden Parteien ausgelöscht werden. So wie aus diesem Holzhaufen kein Feuer mehr aufsteigt, so sollen auch sie nie mehr in ihren Herzen aufkommen.

Zum Abschluss der Eideshandlung begibt sich der Priester mit den 
Parteien zu einem Durianbaum. Der Priester fordert sie auf, einen langen Eisenholznagel in den Stamm des Baumes zu schlagen. Wenn das geschehen ist, dann spricht der Priester zu den Parteien: Seht diesen Nagel, den ihr in den Baum geschlagen habt! Er hält fest und man kann ihn nicht mehr herausziehen. So fest seien nun auch die Eide, die wir gemeinsam abgelegt haben. Wer diese Eide aber zerstört und bricht, über dessen Leben mögen alle Verfluchungen hereinbrechen, die wir ausgesprochen haben. So fest, wie der Nagel in den Stamm des Durianbaumes eingeschlagen worden ist, so fest soll auch der Fluch an dem Eidesbrüchigen und an allen seinen Nachkommen von Geschlecht auf Geschlecht haften bleiben. So wie der Nagel nicht mehr herausgezogen werden kann, so kann ihn auch niemand mehr freimachen von den Verfluchungen die sich an ihm und an seinen Nachkommen auswirken sollen.

206, S. 332.

Es handelt sich um Blätter, die durch das Feuer verwelkt und vertrocknet sind.

207, S. 332 .

Ein Boot wird festgemacht indem man eine Stange oder den Speer in den Flussboden steckt. Daran bindet man das Boot mit dem Rotanseil das am Kiel befestigt ist fest. Ist das Wasser zu tief, dann bindet man das Boot an einem Baume am Ufer fest oder steckt die Stange oder den Speer in das Ufer und befestigt es dort. Anker werden sehr selten gebraucht. Ich persönlich habe nie einen gesehen. Als Anker braucht man schwere, auseinanderstrebende Baumwurzeln oder einen schweren Stein.

208, S. 333.

Der sampulau dare ist ein kronenförmiges Rotangeflecht oder ein um den Kopf gelegtes, von Rotan geflochtenes Band mit einigen, über den Kopf hinübergebogenen Stäben, in welchen Nashornvogel- oder Pfauenfedern, oder auch die Federn des Argusfasanen stecken. Der Sampulau dare wird im Krieg und bei Festen getragen.

209, S. 333.

Der andoh njaho: der donnernde Strafblock, ist gleichbedeutend mit andoh buno (basa Sangiang) oder panga (Ng.) : ein Block worin man die Uebeltäter mit den Füssen einschliesst. Das Wurfnetz wird mit einem solchen Strafblock verglichen. 
210, S. 333.

Damit das Wurfnetz gleichmässig fällt und sinkt, wird es mit einem Gewicht beschwert in der Form einer leichten Kette die sich um den ganzen Rand des Wurfnetzes zieht. Das Wurfnetz des Dohong Mama Tandang ist beschwert mit grossen Gong, mit kleinen Gong und mit grossen Trommeln.

\section{1, S. 334 .}

Die liau karahang tolang gehört zu der liau balawang pandjang. Vgl. die Erklärungen 23 und 80.

\section{2, S. 334.}

Pangambon rahandjang uhat ist ein anderer Name für liau karahang tolang. Pangambon: die nebelgleiche, rahandjang: ein Baum, das Holz ist sehr weich und leicht (damit wird der Leib verglichen), uhat: die Wurzeln (damit werden die Knochen verglichen).

\section{3, S. 335 .}

Sampu oder sampu,n tujang nennt man hölzerne, durch Basir gemachte Püppchen, welche man in einen tujang, ein als Wiege aufgehangenes Stück Tuch legt, oder über ihr an einer Schnur befestigt. Es soll das Kind vor allen Krankheiten und bösen Geistern beschützen. Nebst diesem Püppchen findet man noch eine ganze Anzahl anderer Dinge, wie Hölzer, Steine, Muscheln, Zähne, Schneckenhäuschen mit diesem sampu,n tujang zu einem Bündel vereinigt. Auch dieses ganze Bündel nennt man sampu,n tujang.

\section{4 , S. 335 .}

Mangarangkep ist das Verbum von rangkep: eine Falle um Affen zu fangen. Sie hat die Gestalt einer grossen Kiste. Man stellt sie auf und legt eine Lockspeise so darunter, dass die Falle zufällt, sobald der Affe die Lockspeise berührt. Marangkep (oder Basa Sangiang: mangarang. $k e p)$ : Affen in einer solchen Falle fangen.

\section{5 , S. 336.}

Die Armknochen werden genannt lazeas penang. Lawas: das Glied, was zwischen zwei Gelenken oder Knöcheln liegt. Z.B. die einzelnen Glieder der Finger, die einzelnen Abteilungen des Zuckerrohrs, des Bambus, des Rotan usw. Penang: der Arm von der Schulter bis zur Hand. 
216, S. 337.

Supu: ein kleines Töpfchen von Porzellan mit einem Deckel. Man gebraucht es zur Aufbewahrung von wohlriechendem oder heilkräftigem Oel.

217, S. 339.

Es handelt sich auch hier um die gleiche Eideshandlung wie sie in Erklärung 205 beschrieben wurde.

218, S. 339.

Die Liau Balawang Pandjang oder auch Salumpok Liau Balawang Pandjang ist die Hauptsubstanz des menslichen Körpers mit seinen Knochen und Weichteilen. Es ist besser wenn man nicht von Seele spricht, sondern von dem Toten in seiner leiblichen Erscheinungsform. Diese wurde geraubt von dem Njarang Tingang Hatuen Apui. Die Liau Karahang Tolang hat sich in das Ei eines Nashornvogels verwandelt. Diese Verwandlung finden wir auch in der Mythe von Patih Teteh und Akah Ihang Iho und wir werden ihr auch in den späteren Texten wieder begegnen.

219, S. 340 .

Mangalingo wird das Abschiednehmen der Liau von dieser Welt genannt. Vgl. die Texte im Tantolak matei und im III. Bande dieses Werkes. Zu lingo (die Sehnsucht, das Heimweh) vgl. die Erklärung 65.

220, S. 341.

Kalangkang: ein Gestell wie ein grosser Korb, wird gebraucht um Kleider darauf zu räuchern. Man entzündet Weihrauch darin und hängt dann die Kleider darüber (Hardeland). Es handelt sich hier also um ein einfaches Opfergestell.

221, S. 343.

Die Kokosnuss ist der Repräsentant des menschlichen Schädels. Wir finden sie heute bei allen Handlungen gebraucht für die früher ein Menschenschädel notwendig war. Dass die Kokosnuss diesen Platz einnehmen kann, erklärt sich aus der dajakischen Mythologie selbst. Die Köpfe des Mangko Amat und der Njai Djaja verwandelten sich nach ihrem Tod in Kokosnüsse oder Kokospalmen. Vgl. die erste Mythe in diesem Werk über den Ursprung der Nutzpflanzen.

Bei der Bezahlung des Blutpreises für einen Ermordeten oder fahr- 
lässig Getöteten muss unter anderem mehr für den Kopf des Toten eine Kokosnuss an die Verwandten gegeben werden.

222, S. 347.

Das Durchschlagen dieses pantan nennt man miap pantan. Miap bedeutet eigentlich verwünschen, das auf folgende Weise geschieht: Wenn jüngere Menschen alte Leute verspotten, erzählt der Alte von seiner früheren Kraft, seinem Reichtum, seinen Gefahren, nennt die durch ihn erlegten Menschen etc. und fügt dann hinzu: wenn du nicht auch alles das erreichst oder erlebst, sollst du nie glücklich sein. Solch ein Fluch wird sehr gefürchtet. Ein Pantan wird immer dann aufgerichtet wenn die Kopfjäger erfolgreich von der Kopfjagd zurückgekehrt sind und sich mit dem erbeuteten Schädel dem Dorfe nahen. Er wird aber auch dann vor allem aufgerichtet, wenn die andere Stammhälfte zur Teilnahme an wichtigen Handlungen oder Arbeiten (Reisbau, Hochzeit, Tiwah) sich dem Dorfe naht. Auch die Kopfjagd haben wir schliesslich in diesem Zusammenhange zu sehen, denn sie kann nie allein durch ein Dorf ausgeführt werden sondern ist, nach den Mythen zu urteilen, immer eine Angelegenheit des ganzen Stammes. Beim Pantan entspinnt sich zuerst ein Scheingefecht und hernach wird er durchhauen, indem die ankommenden Gäste alle Reichtümer und Heldentaten aufzählen und die Hälfte derselben dem Geber des Festes, oder beim Tiwah den Toten, zum Geschenke anbieten.

Ueber die Pantan und die Bedeutung der Pantan werden im II. Bande dieses Werkes die ausführlichen Texte veröffentlicht.

\section{3, S. 349.}

Karamunting balo: ein Strauchgewächs, trägt kleine, schwarze, essbare Beeren; die gestampften Blätter legt man als Heilmittel auf Wunden; mit den Blüten bestreut man den Reis, den man als Opfer darbringt.

\section{4, S. 349.}

Kalapapa tandok: ein Baum. Das sehr zähe Holz verarbeitet man gerne zu Messergriffen, Rudern etc. Die sehr lange Feuer haltenden Kohlen dieses Holzes gebraucht man zum Schmelzen des Goldes und die jungen Blätter verwendet man als Medizin gegen Augenentzündungen. 
225, S. 349.

Sungkai ist der Name eines Baumes. Er hat hartes, dauerhaftes Holz. Die von den Blättern gekochte Brühe wird als Arznei gegen Leberleiden gebraucht. Das Holz soll im Wasser bald versteinern und dieses versteinerte Sungkaiholz gibt gute Schleifsteine.

226, S. 349.

Embak ist ein Baum der im Innern Borneo's gedeiht. Seine Früchte sind sehr schmackhaft. Njaring Gana,n Bua Bakas: Die Njaring sind Baumgeister, die den Menschen Schaden zufügen, Gana: die Seele der Bäume, Bua Bakas: der alte Fruchtbaum. Auch hier kann man den Namen nicht übersetzen: Embak, der Njaring, die Seele des alten Fruchtbaumes, sondern eher mit: Njaring, der Bewohner des alten Fruchtbaumes, den man sich auch als Person und nicht als Seele, oder als Seelenstoff oder Lebenskraft denkt. Vgl. über die Njaring die Erklärungen 26 und 133.

227, S. 350 .

Pantoh ist nach Hardeland (W. B.) ein Waldgeist, hat menschliche, aber doch ungeheuerliche Gestalt; er hat nur ein Auge welches mitten auf der Stirne sitzt. Kommen Menschen in die Nähe seines Wohnplatzes, dann lässt er sie geisteskrank werden. Ueber den Ausdruck Gana,n Kaju Hai: die Seele des hohen Baumes, gilt was oben gesagt wurde.

228, S. 350 .

Undan pamalunok bungai, kamban lumpong manduroi rohong ist der gebräuchliche Ausdruck für den erbeuteten Schädel oder den abgeschlagenen Kopf eines Opfersklaven, den man auf den Sanggaran aufgepflanzt hat.

Der Sanggaran ist ein hoher Eisenholzmast. Der untere Teil ist mit geflochtenen Bändern umziert, die in Fransen auslaufen. Dieser untere Teil wird abgeschlossen mit einem heiligen Topf, dem man den Boden ausschlug um ihn dadurch auf den Mast aufsetzen zu können. Ueber diesem heiligen Topf erhebt sich in liegender Stellung eine Wasserschlange. Ueber dem Körper der Wasserschlange sind in schräger Richtung auf jeder Seite des Pfahles je drei hölzerne Speere aufgerichtet. Etwas über der Mitte der Speere ist, ebenfalls in liegender Haltung, ein Nashornvogel angebracht. Am Ende des, etwa 5 bis $8 \mathrm{~m}$. 
hohen Sanggaran ist ein Menschenschädel aufgepflanzt. Statt des Menschenschädels finden wir heute auch einen Nashornvogel.

Diese Sanggaran werden von den Ngadju Dajak bei den Tiwah aufgerichtet.

Hardeland (W. B.) schreibt: Sanggaran, ein etwa 18 Fuss langer Eisenholzmast; mitten daran sitzt ein grosser irdener Topf, welchem der Boden ausgeschlagen ist, sodass der Mast durchhin geht. Am Ende des Mastes ist ein Querholz befestigt, auf welchem sechs hölzerne Spiesse stehen, drei an jeder Seite des Mastes. Auf der Spitze des Mastes ist ein hölzerner Vogel befestigt [ein Nashornvogel]. Man macht solche Sanggaran für ein Tiwah und pflanzt sie dann dicht bei dem Sandong auf [d.h. beim Häuschen in dem die Knochen derer aufbewahrt werden für die man das Tiwah gefeiert hat]. Man glaubt, dass die Gana, Seele des Sanggaran, im Geisterlande [gemeint ist die lewu liau: Totendorf] zu allerlei Schätzen für den Verstorbenen werde.

Abbildungen von solchen Sanggaran finden sich in: Catalogus van 's Rijks Ethnographisch Museum. Borneo. Tweede Gedeelte. Plaat XXIV. Abbildung 1. Vgl. auch die Beschreibungen auf Seite 346 des gleichen Bandes.

Texte, Erklärungen und Bilder zum Sanggaran finden sich im II. Bande dieses Werkes.

229, S. 350 .

Dohong papan benteng: der Dolch, das Brett der Mitte; die Dolchscheide wird verglichen mit einem Brett, das aus der Mitte (der Scheide) herausgezogen wird. Die Scheide wird gebildet von zwei kunstvoll bearbeiteten und geschnitzten (oder auch einfachen) Brettchen, die aufeinandergelegt und mit feingesplisstem Rotan sehr schön umflochten und zusammengefügt werden.

230, S. 351.

Talampe: eine grosse, fabelhafte Schlange. Sie lebt unter der Erde, wie die Naga unter der See.

231, S. 353.

Merap Ganan Sahep. Merap ist der Name. Sahep: abgefallenes Laub, sowohl frisch als trocken, wie auch das schon verfaulte, zur Erde gewordene. 
232, S. 353.

Kadjang Edan ist ein Schmarotzerpflanze mit breiten Blättern, die auf den grossen Aesten der Bäume wuchert. Der Njaring Ganan Kadjang Edan wird sehr gefürchtet. Er verursacht vor allem Kinderkrankheiten.

\section{3, S. 354.}

Kaju Sanggalang Garing und Bulus Lampesong Kereng ist in der Basa Sangiang die Bezeichnung für den hohen, ausgewachsenen Baum, der über die andern Bäume hinausragt.

234, S. 355.

Von dem Antang (Haliastur intermedius) gibt es verschiedene Arten. Die ersten Antang, die ausgesandt werden, gehören zu diesem Antanggeschlecht. Sie stehen ebenfalls unter dem Darahen Radjan Antang, sind aber von ihm und dem Antang Ganan Tadjahan streng zu unterscheiden, denn sie spielen eine sehr untergeordnete Rolle und können nur bedingt als Omenvögel betrachtet werden. Die Mythe sagt von diesen Antang aus, dass sie ihren Ursprung finden in den Federn die dem Darahen Radjan Antang aus dem Gefieder fallen und auf die Erde geweht werden. Die strenge Scheidung zwischen diesen Antang und dem Darahen Radjan Antang oder dem Antang Ganan Tadjahan wird in der Literatur nicht beachtet. Wenn der Priester den Reis streut und den Antang herbeiruft, dann ruft er nie den Haliastur intermedius herbei sondern immer die Ahnen vom Ahnenheiligtum, die in der Gestalt eines Antang (Antang Ganan Tadjahan) erscheinen. Vgl. auch Erklärungen 115 und 137.

Dieses Missverständnis wurde schon durch die ersten Darsteller von Borneo gemacht und seit dieser Zeit immer wiederholt. Vor allem stützt man sich auch auf die Mitteilungen von Hardeland, W. B., wo er schreibt: Antang, Raubvogel, zum Falkengeschlechte gehörig. Es gibt viele Arten, z.B. Antang salia: der wahre Antang (gewöhnlich schlechthin Antang genannt), so gross als ein Hahn, gelblich mit schwarzen Streifen, unter den Flügeln weiss. Der Antang bahandang: der rote Antang, etwas kleiner als der vorige, rot mit weissem Halse. Der Antang badjang: der Hirsch-Antang, so gross als eine kleine Gans, schwarz, unter den Flügeln weiss. Der Antang tandjaung: grösser als eine Gans, schwarz, Beine und Schwanz weisslich. Antang tabunau: so gross als der Antang badjang, die Farbe wie die des Antang tandjaung. Antang Salampipit: so gross als eine Taube, gelblich mit 
schwarzen Streifen. Die Dajacken suchen von den Antang (vor allem von dem Antang salia und tabunau) bei allen wichtigen Gelegenheiten dahiang (Vorzeichen) zu erhalten, z.B. wenn man auf die Reise gehen will, bei Krankheiten, bei Kriegsgerüchten etc. Man glaubt, dass die Antang mit den Sangiang (Luftgöttern) im Verkehr stehen. Man meint, dass jeder Antang seinen besonderen Bezirk habe; je nachdem dann die Vorzeichen häufiger erfüllt werden, wird der eine Antang berühmter als der andere; so hatten wir zu Pulopetak zu meiner Zeit als sehr angesehene Antang, den Antang Baguntan, mitten im TrusanKanale; den Antang Katapang, etwas unterhalb des Trusans etc. Den Antang fragen wollend pflanzt man 100 bis 1000 Fuss voneinander zwei Pfähle (rahasan) auf und bestimmt, dass der eine (gewöhnlich der rechts) Glück, der andere Unglück, oder der eine Ja, der andere Nein etc. bedeuten soll. Dan ruft man den Antang, wartet auf sein Kommen, und gibt acht, welchem jener Pfähle gegenüber er erscheint. Fliegt der Antang über beide Pfähle hin, dann bedeutet das Unglück; konmt er von hinten, oder den Pfählen gar nicht gegenüber, so bedeutet das nichts; kommt er überhaupt gar nicht (pungut), so ist das ein Unglück verkündendes Zeichen. Man wartet bis drei Tage lang auf sein Kommen. Man verspricht ihm, wenn er Glück verkünden, und die Verkündigung eingetroffen sein wird, Opfer zu bringen, Hühner, Schweine etc.

\section{5, S. 356.}

Singkah sind die auf dem Stamme selbst neu herauskommenden Sprosse, die udjau sind die Sprosse die aus dem Wurzelstock aufsprossen. Die Gemüsesuppe, die davon zubereitet wird ohne dass man noch andere Beigemüse gebraucht, schmeckt fade.

\section{6, S. 357.}

Das Trommelfell ist auf der Trommel mit Keilen festgemacht. Beim Trommeln löst es sich, worauf die Keile wieder fester angezogen werden müssen.

237, S. 359.

Halaloh, abgeleitet von laloh: Lohn, welchen man den Balian (Priesterinnen), den Tabit (Priestern) oder den Bidan (Hebammen) gibt.

Lalohan: Geschenke, welche Verwandte an solchen geben, die ein Tiwah feiern wollen. Sie bestehen gewöhnlich in einem Schwein oder 
in Geld (10 Fl.), in Arak und einem Hampatong (einem geschnitzten Bilde, es handelt sich hier nicht um einen Hampatong, sondern um einen Sapundu).

Malalohan oder lalohan: solche Geschenke überbringen, geschieht in schön geschmückten, mit Flaggen verzierten Booten, mit Musik und Lahap (Jauchzen) am fünften Tage des Totenfestes. Der sechste Tag ist nämlich der Haupt-Fest- und Fresstag.

Lalohan nennt man auch diese Verwandten, die diese Geschenke überbringen und die mit allen Ahnen, die sie als Masken verkleidet begleiten, am Tiwah teilnehmen. Es handelt sich hier um die andere Stammhälfte. Die beiden Stammhälften vereinigt nennt man dann: Tambon haruei Tingang (die Wasserschlangen in Gemeinschaft mit den Nashornvögeln). Wir haben bereits nachgewiesen, dass diese Namen die der beiden Stammhälften sind. Tambon ist der Name für die matrilineale Stammhälfte, Tingang ist der Name für die patrilineale Hälfte. Die Geschenke, die auf zeremonielle Weise übergeben werden, müssen natürlich dann wieder in der gleichen Form, in der gleichen Anzahl und zum gleichen Werte wieder zurückgegeben werden wenn die andere Stammhälfte ein Tiwah feient.

Die vollständigen Texte und Handlungen, die sehr umfangreich sind, werden im II. Bande dieses Werkes mitgeteilt. Sie finden sich in den Texten von A. HaRdeland (Anhang zum Versuch einer Grammatik der Dajackischen Sprache) nicht.

238, S. 359.

Salahawo: eine dreizackige Lanze, mit welcher man Fische sticht. Mit einer solchen Lanze werden die Krallen des Antang verglichen, diese sind seine Penjang oder Paturong.

239, S. 361.

Napugenggem (Basa Sangiang), abgeleitet vom Ngadjuwort: sagenggem (Verbum: mangenggem) : was man mit vier Fingern, zwei von jeder Hand, umspannen kann.

240, S. 363.

Der Antang Pipit ist gleichbedeutend mit dem Antang Salampipit in Erklärung 234.

241, S. 367.

Darong handjaliwan. Der Name lautet eigentlich: handjaliwang darong (die Brillenschlange, coluber naja). 
242, S. 368.

Pakarok, abgeleitet vom Ngadjuwort karok: das ausgehöhlt, ausgeweitet, ausgetieft sein.

243 , S. 370.

Siren: die Waise; sire-siren: betrübt sein wie eine Waise betrübt ist, die ihren Vater oder ihre Mutter verloren hat.

\section{4, S. 371.}

Der Sanggaran (siehe Erklärung 228) dient auch als Steg nach der Oberwelt. Reisen die Balian nach der Oberwelt, dann steigen sie am Sanggaran auf. Kommen die Ahnen aus der Oberwelt herunter, dann gebrauchen sie als Steg ebenfalls den Sanggaran. Die Elfenbeine, die stummen, sind die Köpfe die auf dem Sanggaran aufgepflanzt werden.

\section{5 , S. 371 .}

Kasambuti (Ngadju: sambuti) bedeutet: ein Mass, von der Spitze des ausgestreckten Daumens bis zur andern Seite der Hand, also etwa $2 / 3$ einer Spanne lang.

\section{6, S. 371.}

Ranjing pandereh buno ist ein heiliger Speer der ganz aus Eisen besteht. Er wird ausführlich beschrieben in den Mythen von TumbangLahang.

\section{7, S. 372.}

Hagalanggang ist ein Gottesgericht, zur Entscheidung solcher Klagen, für die hinreichende Beweise oder Zeugen fehlen. Die Streitenden müssen 40-50 Fuss voneinander in ein enges, bis an die Brust reichendes Gitter eingeschlossen, zugespitzte Bambu gegeneinander schleudern, bis einer von ihnen gefährlich verwundet ist. (Hardeland, W. B.).

\section{8 , S. 374.}

Mikau, von kau: das Rufen der Hirsche. Wird aber auch von Menschen gesagt, welche mit heller, hoher Stimme rufen oder schreien.

249, S. 378 .

Tujang ist die dajakische Wiege, die aus einem Stück Tuch besteht, das an seinen beiden Zipfeln am Balken einer Wohnung aufgehängt wird. Hier bedeutet tujang: das in die Wiege gelegte Kind und mit 
diesem wird der hülflose Mensch verglichen, der während aller priesterlichen Handlungen seinen Mittlern (den Priestern oder Priesterinnen) anvertraut ist, die für ihn sorgen wie die Mutter für das in die Wiege gelegte Kind sorgt und es vor allen Gefahren beschützt. (Vgl. auch die Erklärung 165.)

Die Entang und Tujang (die Getragenen und Gewiegten) sind mit den Reisseelen zusammen nach der Oberwelt gereist. Sie könnten sich dort verirrt haben und deshalb ruft sie der Priester oder die Priesterin wieder zurück. Aber sie kehren nicht mit leeren Händen zurück sondern beschenkt mit den guten Gaben der Ahnen, die ihnen das Heil, im umfassenden Sinne des Wortes, verbürgen. Vgl. auch die Erklärung 192.

250, S. 378 .

Sapalinda, abgeleitet von linda: zahm, vertraulich, gewöhnt, anhänglich, sind Mittel die die Besitzer von heiligen Töpfen geneigt machen diese zu einem vorteilhaften und billigen Preis dem Besitzer der Sapalinda abzustehen.

251, S. 378.

Njalong Bukit Batu (Wasser aus dem Steinherg) sind heilige Töpfe von ziemlich hohem Wert.

252, S. 378 .

Lunok belom mamua bulau dje bahalap babasong rundjan: lebender Lunokbaum, der goldene Früchte trägt und der schön aufspriesst aus dem heiligen Topf, bedeutet: nach dem Todesfall müssen die Hinterlassenen Güter und Reichtümer erwerben um das Tiwah veranstalten zu können. Besitzt man alle diese Güter und Reichtümer, dann besitzt man den vollkommenen Reichtum und nennt diesen: ein lebender Lunokbaum, der goldene Früchte trägt. Er ist in gewissem Sinne ein Abbild des Lebenbaumes, der eine viel umfassendere Bedeutung besitzt, und wie dieser spriesst er hervor aus einem heiligen Topf. (Vgl. dazu den IV. Band dieses Werkes mit den Texten und Zeichnungen.) Welche Güter notwendig sind und in welcher Reihenfolge sie erworben werden, zeigen noch ausführlicher die Texte zum Tantolak matei.

\section{3, S. 378 .}

Napatok ist abgeleitet von patok: das Beissen, das Picken der Hähne die einander anfallen. Mamatok: zwei Hähne in die Hände nehmen, 
und sie sich einander beissen lassen. Man tut das mit Hähnen, die man miteinander fechten lassen will. Hier in der Basa Sangiang bedeutet das Wort: sammeln, auflesen, sich aneignen.

254, S. 378.

Baras bulau lampang dje njahumpak njalong bukit batu: das an der Wasseroberfläche erscheinende Gold, das hervorsprudelt aus den Quellen der Berge, hat die gleiche Bedeutıng wie Erklärung 252.

\section{5 , S. 378 .}

Zur Erwerbung von Reichtum, der für die Veranstaltung des Tiwah nötig ist, brauchen die Hinterlassenen des Verstorbenen Penjang und Paturong, deren Fundplätze die Ahnen ihnen im Traume anweisen. Ohne die Mitarbeit der Ahnen und ohne ihre guten Gaben wäre es dem Menschen nie möglich sich Reichtum und Heil zu erwerben, nur mit diesen Gaben gewinnt er sie und deshalb sind sie für die Hinterlassenen unmissbar und man wünscht ihnen, oder wünscht auch für sie, dass sie davon träumen und dass sie ihre Namen im Schlafe aussprechen.

\section{6, S. 380 .}

Manundon abgeleitet von tundon: der Tross (z.B. gesagt von einem Tross Bananen oder einem Tross Pinang).

257, S. 380 .

Der Lockruf der Hühner wird verschieden geschrieben weil er auch verschieden ausgesprochen wird. In den Texten begegnen wir den Formen: kuruk, kurei oder kruk.

\section{8, S. 381 .}

Batu djundjun karipurun, liang pariok njama: die Fontanelle, durch die die Seele (hambaruan) den Körper verlässt oder in ihn eintritt, wird verglichen mit einem Fels oder mit einem Schmelztiegel in dem man Edelmetalle schmilzt.

259, S. 381.

Buno niwong panantaha,e: das Eisen des Speeres wird hineingeschoben in das geflochtene Band. Es gibt Speere deren Eisen mit einem festen Seil verbunden sind mit dem Schaft. Das Eisen wird in das Band, mit dem der oberste Teil des Schaftes gut umflochten ist, 
hineingesteckt. Wird der Speer geschleudert, dann rollt sich das Seil ab. Das Schlachtopfer wird verfolgt, das Eisen, das meistens mit Widerhaken versehen ist, wird aus der Wunde genommen und wieder in das Band des Schaftes geschoben.

260, S. 385.

Halaluan nennt man das Aufbahren der Lieche in der Mitte des Hauses längs der Schwelle. Die Leichen der Frauen werden mit den Füssen nach flussaufwärts, die Leichen der Männer mit den Füssen nach flussabwärts aufgebahrt. Vgl. auch die Erklärungen 77 und 170.

261, S. 388.

Nicht nur der Verwundete wird gefährdet, sondern auch der Witwer oder die Witwe und deshalb müssen auch sie mit Blut bestrichen werden.

262, S. 390.

Der Reis, der in seinem ganzen Wachstum ganz mit dem Menschen verglichen wird, ist die einzige Pflanze von der man sagt, dass sie eine gana (Seele der leblosen Dinge, der Tiere und Pflanzen) oder eine hambaruan (Seele des Menschen) besitze.

263, S. 391.

Der Reis findet seinen Ursprung im Kaju Erang Tingang (im Erang Tingang-Baum). Die Mythen dieses Baumes sind mir nicht bekannt. Er wächst in der Oberwelt und von ihm erbittet man immer wieder Segen für das Gelingen der Ernte.

264, S. 392.

Die Taloh papa (böse Geister) die sich zum Orte begeben wo der Sarg hergestellt wird nennt man Kambe Rawit (das zerreissende Gespenst). Nachdem der Sarg gemacht wurde, richtet man auf dem Platz ein Kambe Rawit auf, das man von Stöcken und Blättern macht. Das Gesicht wird durch eine Maske dargestellt. Die Höhe des Kambe Rawit beträgt 1-1,50 m. Menschen, die sich dem Platze nahen, werden während der Palizeit vom Kambe Rawit zerrissen.

265, S. 394.

Die Pali Hinau beginnen mit dem Todestage und endigen nach den vollzogenen Reinigungshandlungen beim Tantolak matei, also am sieben- 
ten oder achten Tag. Das Paligebiet (das heisst das ganze Gebiet, das zum Dorf gehört) wird abgesperrt mit einem Rotanseil (djanang- oder djantar pali), an dem Sawangblätter aufgehängt werden, die mit einem Kalkkreuz versehen sind. Diese Seile werden ober- und unterhalb des Dorfes auch über den Fluss gespannt und da wo sie auf den Ufern befestigt werden richtet man einen Flaggenstock mit einer weissen Fahne auf. Das Passieren dieser Versperrung war früher bei Todesstrafe verboten, heute kann das geschehen wenn man dafür eine Kleinigkeit bezahlt (10 Cent bis 50 Cent). In das Dorf oberhalb der Versperrung und in das Dorf unterhalb der Versperrung schickt das Dorf, das diese Versperrungen aufgerichtet hat, durch seine Abgesandten den Totok Bakaka (den Schnabel des Bakaka. Der Bakaka ist ein von Fischen lebender Raubvogel, etwas kleiner als eine Taube, mit grünem Rücken, gelber Brust, roten Füssen und Schnabel und einem kurzen Schwanz). Die Bedeutung dieses sogenannten Totok Bakaka, der aus einem kleinen Geschenk besteht, ist diese: die Leute dieser beiden Dörfer haben die vorbeifahrenden Fremdlinge auf die Versperrung aufmerksam zu machen und ihnen zu verbieten an ihr vorbeizufahren.

266, S. 395.

Mamanjong (Verbum von Pajong): das Schlagen der Garantong (Gong) wenn jemand gestorben ist. Es geschieht gleich nach dem Tode. Es werden vier verschiedene Garantong dazu gebraucht, und je vier Schläge, einer auf jedem Garantong, getan. Der erste Schlag geschieht auf einem Garantong, welcher einen ziemlich tiefen Ton hat, dann folgt je ein Schlag auf zwei Garantong mit höheren Tönen, darauf der vierte Schlag auf dem Garantong der den tiefsten Ton hat.

Nebst dem mamanjong wird auch das manitih ausgeübt. Der Name kommt hier selbst nicht vor, aber es ist doch notwendig darauf hinzuweisen, weil die beiden Handlungen oft miteinander verwechselt werden. Das Verbum manitih ist abgeleitet von dem Subtantivum titih: der Totenschlag. Er erschallt sobald jemand gestorben ist, etwa drei Minuten lang, und zwar das erste Mal wenn die Leiche gekleidet, das zweite Mal wenn sie in den Sarg gelegt, das dritte Mal wenn sie zum Sterbehaus hinausgetragen und das vierte Mal wenn sie ins Grab gelegt wird. Man tut je vier Schläge zusammen nacheinander auf vier Garantong von verschiedener Grösse. Manitih, hatitih dengan: für jemand auf den Gong den Totenschlag schlagen. Für Menschen, welche an den Pocken sterben, schlägt man den Totenschlag nicht, damit die Pocken nicht noch ärger wüten (Nach Hardeland, W. B.). 
267 , S. 396.

Ontong: Glück, Vorteil, Gewinn, Heil. Der Mensch hat dieses Glück oder Heil nicht aus sich selbst und erwirbt es auch nicht selbst, es ist immer Gabe der Ahnen oder der Götter. Vergl. auch Erklärung 196.

268, S. 396.

Die Bezahlung dieser Busse dient zur Vollziehung der Reinigung. Die andern Bussen, die aus diesem Rechtsbruch fortfliessen, müssen, wenn er gerichtlich verfolgt wird, nach den feststehenden Rechten ebenfalls bezahlt werden.

269, S. 401.

Die Grenze dieses Macht- oder Paligebietes wird gebildet durch die Versperrungen die in Erklärung 265 beschrieben worden sind.

270, S. 403.

Nach andern Versionen verwandeln sich nicht die Stücke der übrig gebliebenen Knochen in Hirsche, $Z_{\text {werghirsche, Wildschweine und }}$ Rehe, sondern die Toten selbst, sei es für immer oder meistens nur für die Zeit von drei Monaten. Nach dieser Zeit gehen sie dann erst definitiv in das Totendorf ein. In andern Gebieten verwandeln sich die Toten während dieser Zeit in verschiedene Pflanzen und Gemüse, die dann nicht gegessen oder beschädigt werden dürfen.

\section{1, S. 406.}

Witwenkleider. Hardeland schreibt über die Witwen in seinem Wörterbuch: „Balo: Witwe. Die Witwen müssen ihr Haar bis auf die Schulter abschneiden, oder sich von dieser Pflicht mit zwei Gulden loskaufen. Sie müssen weisse, und nachdem der erste weisse Anzug aufgebraucht ist, schwarze Kleider tragen, und mögen sich nicht wieder verheiraten, bis das Tiwah für ihren verstorbenen Mann gehalten ist. (Das gilt natürlich auch durchaus für die Witwer.)

Mambalo: zur Witwe machen, das heisst einer Witwe die Haare abschneiden und ihr weisse Kleider kaufen. Beispiel: Ikau kea mambalo ie, basa ie sawan liau paharim: du musst sie zur Witwe machen, weil sie die Frau deines verstorbenen Bruders ist.

Mambalo arepe: sich selbst als Witwe kleiden. Geschieht auch zu Zeiten wenn der Mann noch lebt, um ihn zu ärgern, zugleich in der Hoffnung, dass er dann bald sterben werde".

Witwen und Witwer dürfen keinen Schmuck mehr tragen. Aller 
Schmuck wird mit Rotan ersetzt. Statt den goldenen Ohrringen trägt man solche von Rotan, statt der Armringe trägt man um die Arme Rotanbänder usw.

272, S. 408.

Mamanggar ist das Verbum vom Subst. panggar: womit man etwas aneinander festhält, z.B. die über einem Floss hinliegenden, auf den einzelnen Stämmen des Flosses festgekeilten Querhölzer, die quer durch ein Boot hin liegenden Hölzer, welche die Seiten des Bootes zugleich fest, und auseinander halten. (Hardeland, W. B.).

\section{3, S. 408.}

Palanggaran Raung oder auch Panangkalau Raung runi wird die Busse genannt, die bezahlt werden muss, wenn der Witwer oder die Witwe Ehebruch getrieben hat. Die Busse beträgt dann:

1. Singer dosa: die Busse für den Ehebruch, nämlich: djipen hanja (acht Sklaven oder 320 Gulden).

2. Die Verwandten der Witwe oder des Witwers verlangen dazu hinzu noch eine zweite Busse, die genannt wird: panangkalau raung runi (die Ueberschreitung des Sarges). Sie beträgt: djipen epat sampai hanja (vier bis acht Sklaven oder 160 bis 320 Gulden).

3. De Schuldigen haben in jedem Fall auch noch Opfertiere zu schlachten (meistens ein Huhn und ein Schwein).

Die gleichen Rechtssätze gelten (die Summen werden auf die Hälfte heruntergesetzt) auch für die Verlobten falls eines der beiden Verlobten stirbt.

\section{4, S. 409.}

Baho nennt man ein Reisfeld vom zweiten bis zum sechsten Jahr (länger wird es nicht gebraucht. Meistens braucht man ein Feld nur zwei bis drei Jahre und legt dann anderswo wieder ein neues Feld an). Im ersten Jahre heisst das Feld himba: Urwald, wohl weil zuerst der Wald niedergelegt werden musste, bevor es dort angelegt werden konnte. Sprichwort: Hindai aton baho,e dapit, amon dia ikau mahimba,e helo: es wird später kein baho entstehen, wenn du nicht zuerst ein himba machst, das heisst: mühsamer Anfang, gutes Ende, und man sagt das zu jemandem den man zu einer mühsamen Arbeit ermuntern will, denn aus einem Stück Urwald ein Feld zu machen ist eine sehr mühsame, wenn auch lohnende Arbeit. 
275, S. 410.

Palas: eine Art Palmbaum. Der Stamm wird nur so dick als ein Bein. Der Baum aber wird bis zu dreissig Fuss lang. Die Frucht ähnelt den Körnern des Maises. Die Blätter ringelt man zu Locken, etc., trocknet sie dann, und gebraucht sie als Schmuck und Zierrath der Häuser bei Festen. Solche geringelte Blätter nennt man sangkai. (Hardeland, W. B.)

Die Bulu sind mir nicht bekannt.

276, S. 410.

Bandera: Flagge oder Fahne, hängt zusammen mit dem Lebensbaum, dessen Stamm von einem Speer gebildet wird und dessen Blätter aus goldenen Tücher bestehen. Als Hintergrund haben wir das totemistisch/ kosmologische System zu sehen, in dem auch die Farben der Flaggen ihre Einteilung finden. Jedes Dorf in der Oberwelt und auch in der Unterwelt besitzt seine Flagge mit der ihr zubehörenden Farbe und an ihr erkennt man auch unter wessen Macht dieses Gebiet steht. Die drei wichtigen Farben sind: weiss, rot und schwarz, die mit verschiedenen andern Farben (z.B. blau, grün, gelb, grau), die alle auch nach diesem System eingeteilt sind, noch vermehrt worden sind.

Wenn Mallinckrodt (Ethnographische mededeeling over de Dajaks in de Afdeeling Koealakapoeas) die Bedeutung der Holländischen Fahne bei den Reisbaufeierlichkeiten beschreibt, als ob dies ein mächtiges Symbol sei unter dem der Reis besser gedeihe, dann vergisst er, dass die Dajak Fahnen hatten bevor sie die Holländische Fahne kennen lernten und dass die Farben der Holl. Fahne gesehen werden müssen von ihrer Bedeutung aus die sie im dajakischen System immer hatten und noch haben. So schreibt Mallinckrodt (Bijdragen Kon. Inst. Deel 81. 1925. S. 196) : ... ten slotte wordt de Nederlandsche vlag geheschen, nadat de stok gemanjakied (mit Blut bestrichen) is en met toewak (Reisbier) begoten. Het dient gezegd, deze vlag is een machtig symbool in het oog dezer primitieven. Ze achten deze de vertegenwoordiger van de kracht der Blanda's (Holländer), zij rekenen hem te zijn de hambaruan Blanda (de ziel der Hollanders) en het is een beproefd middel om sial af te wenden, die vlag te hijschen. Eine solche Erklärung gibt man einem Regierungsbeambten, aber merkwürdig ist es, dass er sich mit ihr zufrieden gibt. Ueber die Bedeutung der Flagge siehe auch den II. Band dieses Werkes. 
277, S. 416.

Hardeland : Das „Augh oloh balian hapan tiwah“. In: Versuch einer Grammatik der Dajackischen Sprache. Pag. 207-374. Mallincrrodt : Het magah liau, een Dajaksche priesterzang. T.B.G. LXVIII. 1928.

278, S. 417.

Sangiang. Wilken (Verspreide Geschriften III. Pag. 184/85) gibt folgende Erklärung: „Onder dezen vorm, sanghjang, komt het woord voor bij de Javanen als benaming van geesten en ook ter aanduiding van de zielen der afgestorvenen".

R. Brandstetter (Die Kunst des Erzählens bei den Dayaken. 1930. Pag. 8) sagt: „Sangiang ist das Alt-Jav. sang hyang „die Götter”. Die Bedeutung von sang hyang ist also im Dayakischen eingeengt, gerade wie die des Lehnwortes dewa".

279, S. 417.

Die Seelen des Streureises (ganan tawur) denkt man sich personifiziert. Die Balian oder Basir verwandeln den Reis in sieben schöne Jungfrauen (bawin tawur) die nach der Oberwelt reisen und die Aufträge überbringen. Die gleiche Funktion hat auch die Seele des Gesanges (ganan oder labatan karunja). Auch sie denkt man sich personifiziert.

280, S. 418.

Diesen kosmischen Dualismus findet man ausnahmslos in den wichtigsten Welt- und Menschwerdungsmythen, und auf sie muss auch bei allen priesterlichen Handlungen, durch die man neues Leben, Heil und Frieden erlangen will, zurückgegangen werden. Auf sie greift man natürlich auch dann zurück wenn die Welt- und Menschwerdung wiederholt wird, sei es im Zusammenhang mit dem Tiwah (vgl. den IV. Band dieses Werkes) oder im Zusammenhang mit einem der grossen Sühnopfer (z.B. bei der Sühnung der Blutschande) oder der Reinigung des Dorfes (mamapas lewn) die in einem Turnus von einigen Jahren stattfindet und wobei Welt- und Menschwerdung ebenfalls wiederholt werden müssen. Von einem Urmonotheismus besteht im religiösen System der Dajak keine Spur.

281, S. 418.

Salutup ist die Kopfbedeckung des Mannes. Sie wird in den meisten Fällen geflochten, aber der Rotan wird nicht gefärbt sondern bleibt 
weiss. Damit ist die männliche Kopfbedeckung auch der Farbe nach assoziiert mit der Oberwelt, während der rote Frauenhut, der von den Männern nicht getragen werden darf der Farbe nach assoziiert ist mit der Unterwelt. Die Kopfbedeckung des Tukang Hanteran (Leiter des Toten nach dem Totendorf) und die der Sangiang stimmt überein mit der des Ranjing Mahatala Langit. Sie stellt den Lebensbaum dar.

282, S. 421.

Durch die Weltwerdung, die nur durch die Mitarbeit von Oberwelt und Unterwelt möglich ist, entsteht keine kosmische Dreiteilung, denn die Welt (pantai danum kalunen) ist Oberwelt und auch Unterwelt und sie repräsentiert in dieser ihrer Vereinigung die kosmische Totalität. Auch die Weiterexistenz der Welt oder ihre Neuschaffung durch die Wiederholung der Welt- und Menschwerdung, ist nur möglich durch die Zusammenarbeit von Ranjing Mahatala Langit (Oberwelt) und die Tambon oder Bawin Djata Balawang Bulau (Unterwelt).

$Z$ wischen der Welt der Sangiang, die wir in unserer Arbeit wiederholt Oberwelt nannten, und der Welt der Menschen darf nicht streng geschieden werden. Sie gehören zusammen und man unterscheidet in unseren Texten diese beiden Teile durch die Namen: Lewun Sangiang (die Dörfer der Sangiang, d.h. das Gebiet über den 33 Wolkenlagen, das wir mit Oberwelt bezeichnet haben. Dieser Term findet sich aber in den Texten nicht. Die Reise nach den Dörfern der Sangiang wird ausgedrückt mit: manjalumbo, in die Höhe auffahren, oder mit: manarikan, flussaufwärts reisen) und Pantai danum kalunen: die Ufer des Flusses der Welt. Diese Unterscheidung ist aber nicht nur eine geographische, sondern auch eine kosmologisch und sozial klassifizierende. Merkwürdig ist nur, dass in diesem System eine Umdrehung der Klassifikation stattfindet, indem das obere Gebiet nun von der Stammhälfte bewohnt wird die den matrilinealen Aspekt der Gemeinschaft repräsentiert, während das untere Gebiet (Pantai danum kalunen) bewohnt wird von der Stammhälfte die den patrilinealen Aspekt der Gemeinschaft repräsentiert. Das wird uns auch deutlich gemacht aus den Mythen. Die Frauen steigen aus der Oberwelt herunter und verheiraten sich in der Welt mit den Männern aus dem Gebiet der Pantai danum kalunen. Beim Tod findet wieder eine Orientierung nach diesen zwei Gebieten statt. Die Leichen der Frauen werden aufgebahrt mit den Füssen in der Richtung nach flussaufwärts (also nach den Dörfern der Sangiang), die Leichen der Männer 
werden aufgebahrt mit den Füssen nach flussabwärts (also nach Pantai danum kalunen). Die soziale Organisation, die sich nicht mehr an diese der mythischen Urzeit anlehnt, ist aber heute umgekehrt. Das obere Gebiet des Flusses oder des Dorfes wird bewohnt van der Stammhälfte die den patrilinealen Aspekt der Gemeinschaft repräsentiert, das untere Gebiet des Flusses oder des Dorfes wird bewohnt von der Stammhälfte die den matrilinealen Aspekt der Gemeinschaft repräsentiert. Wann und wie diese Umkehrung stattgefunden hat können wir heute noch nicht aussagen, weil für den Nachweis und die Beschreibung die Einsicht in die umfassende Stammesmythologie notwendig ist, die wir heute noch nicht besitzen.

\section{3, S. 423.}

Dieser lokalen Organisation des Dorfes in zwei, bezw. drei Teile, entspricht auch die Organisation des heutigen Dajakdorfes. Als Beispiel wählen wir das Dorf Tumbang-Lahang am oberen Katingan. Die lokale Organisation zeigt uns zwei Dorfteile. Der obere Teil des Dorfes wird bewohnt von dem Utus gantong (hohe Bevölkerung, man nennt sie auch oft: die Freien, oder der Adel). Diese Dorfhälfte wird bewohnt von den Familien die den patrilinealen Aspekt der Gemeinschaft repräsentieren. Der untere Teil des Dorfes wird bewohnt von dem Utus randah (dem niederen Volk, die Sklaven). Diese Dorfhälfte wird bewohnt von den Familien, die den matrilinealen Aspekt der Gemeinschaft repräsentieren, in einer dienenden Stellung stehen und sich hauptsächlich mit dem Landbau beschäftigen.

Daneben unterscheidet man aber auch das Dorf das oberhalb des eigenen Dorfes liegt und das Dorf, das unterhalb liegt. Das Dorf oberhalb repräsentiert dann den patrilinealen Aspekt und das Dorf unterhalb den matrilinealen. Das eigene Dorf aber, das in der Mitte liegt bildet die Totalität und höhere Einheit dieser beiden Dörfer.

\section{4, S. 424.}

R. Brandstetter (Die Kunst des Erzählens bei den Dayaken. Pag. 10) sagt zu Sangen: sangen sind ,altüberlieferte Geschichten, besonders von Göttern". Im Javanischen ist angěn "Gedanke“, im Maduresischen „an Vergangenes denken“. In Maduresisch angěn liegt ein Bedeutungsübergang zum Dayakischen sangen vor, denn die Sangen sind Geschichten aus der Vergangenheit. Eine merkwürdige Parallele zu angěn „denken“ und sangen „erzählen“, eine Parallele der 
Form und der Bedeutung nach, ist Karo ingět „sich erinnern" neben

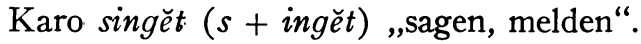

285, S. 424.

Sahor bedeutet: ein Gelübde ablegen wobei man sein Leben, oder das Leben eines Angehörigen in die Hand der Sangiang, der Geister, der Djata oder des Ranjing Mahatala Langit legt. Diese Gelübde werden abgelegt für kleine Kinder, für die man langes Leben und Heil erbittet. In diesem Falle bezahlt man das Gelübde (mambajar sahor) meistens in der Pubertätszeit. Gelübde legt man auch ab wenn man krank ist, oder man legt sie ab für ein krankes Familienglied, und bezahlt sie nach der Genesung. Gleiche Gelübde legt man auch ab wenn man auf eine Reise geht oder in den Krieg zieht, die Bezahlung geschieht nach der Rückkehr.

Die Ablegung dieses Gelübdes nennt man basahor. Es geschieht folgendermassen: man füllt eine kleines Gefäss (Tasse, Becher oder Teller) mit enthülstem Reis. In diesen Reis legt man ein Tuchbündelchen von schwarzem und gelbem Stoff in dem sich sieben Körber Seelenreis befinden .In einem zweiten Bündel von schwerzem Tuch befinden sich: Kausel und Rauchwaren, ein silberner oder goldener Ring und ein munong (kurzer Achat) oder auch ein länglicher Achat. Das ganze Gefäss wird mit einem schwerzen Tuch verhüllt. Die Bedeutung dieses schwarzen Tuches (siehe auch die Texte bei der Beschreibung des Balai Lumpang) ist die folgende: die bösen Geister, die einen Menschen anfallen wollen oder ihn bereits krank gemacht haben, sehen nun das Sahor in dem die Seele verwahrt wird (sieben Körner Seelenreis) von Finsternis und unheilvollen Nebeln umlagert und sie nehmen an, dass sich Unheil und Unfrieden auf sie herabgesenkt hätten. Die guten Geister aber sehen das Sahor in leuchtenden Farben und nehmen an, dass es sich um einen Heilvollen handle, dem sie das Heil nicht entziehen sondern im Gegenteil noch vermehren.

Das Sahor dient also als Aufenthaltsort der Seele des Menschen, die nun unter den Schutz des Sangiang Sahor (siehe die Texte) gestellt wird. Er hat den Menschen zu beschützen. Man erwartet von ihm, ,dass er ein Schild sei für den Menschen gegen die Winde der Krankheiten, und dass er ihn auf die Seite schiebe, dann wenn die Stürme der Seuchen heranbrausen, sodass er von ihnen nicht getroffen wird". 
Und der Sangiang Sahor beschreibt seine Aufgabe bei der Abholung des Toten, an der er auch teilnehmen will, folgendermassen: „Zur Zeit als er (der Tote) noch wohnte in dem Dorfe, dem durch die Tingang (Menschen) geliehenen, in dem Orte, der durch die Nashornvögel geliehen worden war, da war wahrlich ich es der ihn umzäunte wie eine Insel, wie ein Wäldchen von Sawangstauden, welcher ihn umfriedete wie ein Bungegebüsch (Sawang), welcher ihn umgab wie mit einem elfenbeinernen Zaun von Stämmen und Pfählen, welcher ihn verankerte, so wie man ein grosses Boot verankert, welcher ihn festband, so wie man mit einem dicken geflochtenen Rotanseil das königliche Floss festbindet".

Das Sahor wird mit Tengangbambus umflochten. Dieser Bambus muss gefunden sein als alle Vorzeichen günstig lauteten (tengang idje bahalap dahiange). Es wird, meistens im Schlafgemach über dem Platz aufgehängt auf dem der, für den das Sahor dargebracht wurde, schläft. Das Aufhängen geschieht an einem Blaserohr. Die religiöse Bedeutung des Blaserohres liegt darin, dass sich in seiner Höhlung die Seele des Menschen bergen und verbergen kann. Dajak die im Walde übernachten müssen schlafen mit einem Blaserohre zwischen ihren Beinen. Während dem Schlafe birgt sich die Seele im Blaserohr und kann nicht durch böse Geister angefallen und weggeschleppt werden.

Nachdem das Sahor auf diese Weise aufgehängt worden ist, hängt man an das Geflecht noch ein Sawangblatt, ein Sambelomblatt, eine Schwanzfeder eines Nashornvogels und ein Kadjundjungblatt.

Nachdem es aufgehängt ist, bestreicht man das Ganze mit Hühnerblut und auch bei jeder Opferhandlung muss diese Bestreichung wiederholt werden, nicht zur Stärkung, sondern zur Wiederholung, denn jedes Opfer bedeutet einen Neuanfang und eine neue Periode.

Die Bezahlung geschieht nach der Abmachung.

286, S. 425.

Grabowsky, Der Tod, das Begräbnis, das Tiwah oder Todtenfest. Pag. 186. Er hat diese Aussage von Hardeland übernommen, W.B. unter Liau (308/2).

\section{7, S. 428.}

Die Rahan sind die Versammlungshäuser der wichtigsten weiblichen Sangiang, die in den Genealogien genannt werden, im Unterschied zu den Balai, die die Versammlungshäuser der männlichen Sangiang sind. Diese Unterscheidung der beiden Versammlungshäuser scheint mir ein 
Beweis zu sein für das doppelte System der Ngadju Dajak. Der Rahan wäre dann das Versammlungshaus der Stammhälfte, die mit der Unterwelt und dem matrilinealen Aspekt der Gemeinschaft assoziiert ist, und der Balai wäre das Versammlungshaus der Stammhälfte, die mit der Oberwelt und dem patrilinealen Aspekt der Gemeinschaft assoziiert ist. Auch die architektonische Form der beiden Bauwerke zeigt diesen doppelten Aspekt, der im gewöhnlichen Wohnhaus nicht mehr auseinandergehalten wird, sondern verschmolzen ist (in der religiösen Darstellung des Hauses aus den Priesterzeichnungen werden auch die beiden Wohnhäuser getrennt aufgeführt).
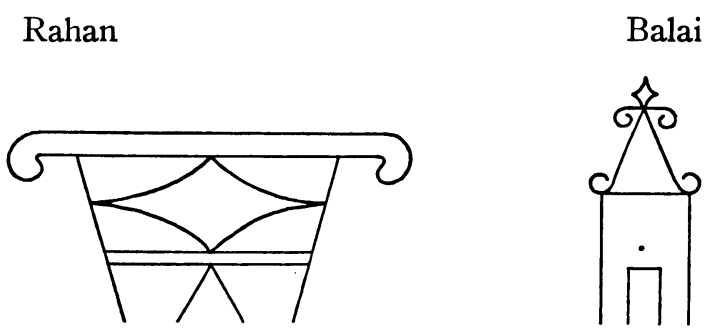

288, S. 432.

Das gilt z.B. für das heutige Dorf Kuala-Kapuas, das an der Mündung des Kapuas in den Murong (in der Nähe von Bandjermasin) liegt. Dieses Dorf zerfällt in zwei Dorfteile: Barimba und Hampatong. Barimba liegt in der Richtung nach flussaufwärts und wird von dem Utus randah (niederes Volk, frühere Sklaven) bewohnt. Hampatong liegt in der Richtung nach flussabwärts und wird von dem Utus gantong bewohnt. Der alte Antagonismus zwischen diesen beiden Gruppen besteht auch heute noch, trotzdem sie schon seit langem der christlichen Gemeinde angehören.

Kuala-Kapuas ist ein neues Dorf. Früher wohnten die Freien in Dörfern, die mehr nach flussaufwärts gelegen waren. Nach dem Aufstand von 1859 befahl die Regierung diesen Dörfern, sich auf einem neuen Platz, näher bei der Küste, zusammenzulegen. Und so entstand etwas nach 1860 Kuala-Kapuas. Die Unfreien, die ursprünglich flussabwärts wohnten, behielten bei der Zusammenlegung der Dörfer ihre eigenen Niederlassungen und die Freien siedelten sich unterhalb derselben an, sodass wir heute eine Dorfeinteilung haben, die mit der ursprünglichen nicht mehr übereinstimmt.

289, S. 434.

W. H. Rassers, Over den zin van het Javaansche drama, Pag. 378 unten bis 379 mit Zitat von Durkheim. Beim dajakischen Totenfest 
vereinigt sich ebenfalls der ganze Stamm, oder heute die Gruppen, die die alte Stammesorganisation repräsentieren. Da sich die Stammhälfte, die von dem Unheil getroffen wurde, nicht selbst daraus befreien kann wird diese Befreiung durch die andere Stammhälfte vorgenommen wobei es notwendig ist, dass durch die Rezitation der Texte und Mythen das schöpferische Geschehen der Urzeit wiederholt wird, was nur durch die besuchende Stammhälfte geschehen kann. Es ist anzunehmen, dass das auch bei den Initiationsriten bei andern Völkern geschieht.

\section{1, S. 439.}

Die früheren Badju, die heute nur noch bei festlichen Gelegenheiten getragen werden, oder die man auch bei den alten Frauen unter den Ot Danum noch oft sieht, sind lang und reichen bis über die Kniee. Sie sind geschlossen. Der etwas erweiterte Halsausschnitt wird mit einer goldenen oder silbernen Schnalle geschlossen. Die neuen Badju sind offen und man zieht sie wie eine Jacke an und schliesst sie auf der Vorderseite mit goldenen Nadeln. Aermere verwenden statt goldenen Nadeln heute auch die importierten Sicherheitsnadeln.

\section{2, S. 440.}

Der Sarong ist ein Umschlagtuch dessen Enden zusammengenäht sind. Bei festlichen Gelegenheiten trägt man sehr teure seidene Sarong. Früher wurden die Stoffe aus Rindenbast hergestellt und bestickt, oder sie wurden auch gewoben, heute werden sie importiert und die alte Technik ist bei den Ngadju gänzlich verschwunden und findet sich auch bei den Ot Danum nicht mehr. Ein kümmerlicher Ueberrest ist bei den letzteren noch das rohe Bast-Lendentuch, das keine Verzierungen und auch keine Stickereien mehr aufweist.

\section{3, S. 444.}

Tampulak humbang und bukit batu. Die Erklärung des Priesters ist unrichtig. Die Bedeutung ist keine magische, sondern eine durchaus religiöse. Vor dem Hause, das durch den Tod einer seiner Bewohner ebenfalls auf die Todesseite gehört und dem Untergange verfallen ist (es liegen über ihm die alles vernichtenden Ambon Barutas Matei), wird der Zustand hergestellt, der vor der Welt- und Menschwerdung bestanden hat. Der Stein stellt den Urberg dar, auf dem Ranjing Mahatala Langit wohnt, und der mit Wasser gefüllte tampulak humbang stellt das Urwasser vor, in der die Tambon oder Bawin 
Djata Balawang Bulau haust. Gegenüber dem Tod und der Vernichtung stehen die Zeichen des Anfangs aller Welt- und Menschwerdung, die beim Tantolak Matei teilweise, beim Tiwah aber vollständig wiederholt werden. Diese Wiederholung geschieht nicht durch die Menschen, auch nicht durch die Aufrichtung dieser Zeichen, sie geschieht durch Ranjing Mahatala Langit und die Tambon selbst, die absolut frei handelnd auftreten und nicht in einen, durch Mythe und Ritus in Bewegung gebrachten, automatisch sich abwickelnden Prozess hineingezogen werden. Der Mensch besitzt dazu weder die Macht noch die Möglichkeit, denn er kann sich aus dem Unheil und Tod nicht selbst befreien, er kann sie nur als Tatsachen anerkennen und sich unter diese Tatsachen stellen und in dieser Haltung kann er die Zeichen der neuen Welt- und Menschwerdung aufrichten und im Glauben ihre Realisierung von Ranjing Mahatala Langit und der Tambon erwarten, die ihn dadurch aus Unheil und Tod erlösen und ihm das neue Leben in einer neuen Welt schenken.

294, S. 445.

Auch diese Erklärung ist unrichtig. Die bösen Geister fürchten das Zeichen des Kreuzes nicht weil es nun ein Kreuz ist. Dieses Zeichen bedeutet die vier Weltrichtungen: Sonnenaufgang, Sonnenuntergang, Quellort des Stromes und Mündung des Flusses. Es stellt die kosmische Totalität dar, die in ihrer ungebrochenen Einheit das Heil und den Frieden für Kosmos, Stamm und Individuum verbürgt. Durch dieses Zeichen stellt man sich unter diese Totalität, die durch den Tod gestört ist, durch Ranjing Mahatala Langit und die Tambon aber wieder hergestellt wird.

295, S. 445.

Isi bedeutet das Fleisch oder die wichtigste Substanz. Hier bedeutet es die eiserne Speerspitze, die am Schafte festgemacht ist, denn die Hauptsache am Speer ist nicht der Schaft sondern das Eisen.

\section{6, S. 445.}

Tambaran. Wir lesen (W.B.) unter Njamo: „ein Baum, von Gestalt fast als der Nangkabaum, wird aber nur so dick als eine Kokospalme. Der unter der Borke liegende etwa $1 / 2$ Zoll dicke Bast lässt sich, nachdem er in Wasser gelegt ist, breit auseinanderschlagen $z \mathfrak{u}$ einem Stoffe, aus welchem man Kleidung macht; auch dieser Stoff wird Njamo genannt. Die dünnen, erst armdicken Njamobäumchen nennt 
man Tambaran; es werden Stricke vom Baste derselben gemacht".

297, S. 445.

Puron. Name eines Schilfgewächses, so dick als junger Rotan, und wird etwa 5-6 Fuss lang; es trägt sehr kleine Früchte. Es wird viel zu Flechtwerk gebraucht; besonders macht man Schlafmatten davon, da solche Puronmatten weicher als Rotanmatten sind. Auch diese Matten werden puron oder amak puron genannt.

298, S. 446.

In dem kosmologisch/totemistisch klassifizierenden System der Dajak gehören Nacht und Mond zur Unterwelt und sind damit auch assoziiert mit der Stammhälfte die den matrilinealen Aspekt der Gemeinschaft repräsentiert, Tag und Sonne gehören zur Oberwelt und damit auch zur Stammhälfte die den patrilinealen Aspekt der Gemeinschaft repräsentiert.

299, S. 446.

Tangaring: ein Fruchtbaum, eine Art des Baumes, welchen die Malaien Rambutan nennen; doch sind die Früchte des Tangaring kleiner als die des Rambutan (W.B.). Dawen pilang, die Bedeutung, bezw. die Art dieses Baumes oder Strauches ist mir nicht bekannt. Taberau: ein Schilfgewächs, dem Zuckerrohr sehr ähnlich. Hadjandjalau: ebenfalls unbekannt. Sawang gagar: eine Sawangstaude mit langen, schmalen gelbroten Blättern die herunterhängen.

300, S. 446.

Kaliong ist das Wort aus der Mantangaisprache für das Ngadjuwort kaliling: etwas umgeben, um etwas herumgehen, die Umgebung. Manas telo kaliong lenge: Perlen, drei Stränge, deren jede einmal rund um das Handgelenk geht.

301, S. 446.

Sambelom, eine Art länglicher dünner, blauer Glasperlen die man um das Handgelenk trägt.

302, S. 447.

Die tempon pampatei (Besitzer des Todes) sind die Verwandten des Toten. Der tempon pampatei ist die Person, die das Tantolak matei oder auch das Tiwah veranstaltet und leitet und für den Gang desselben 
und die wichtigsten Funktionen verantwortlich ist. Es ist der Bruder oder Onkel, die Schwester oder Tante des (der) Verstorbenen.

303, S. 449.

Mamedak, abgeleitet von $d a k$, ahmt das klirrende Geräusch der auf den Boden aufschlagenden und zerbrechenden Tasse nach. Statt dak sagt man auch oft $b a k$.

304, S. 451.

Garo, Räucherwerk. Es gibt viele Arten desselben, gewöhnlich werden mehrere Sorten durcheinander gemengt; in Pulopetak gebraucht man nur Holz und Harz als Weihrauch, z.B. von den Bäumen ramas, pilau, von den Schlingpflanzen kalanis, sawang kelep, gusar. Der Weihrauch ist aber durchaus wirkungs- und machtlos wenn er bei den priesterlichen Handlungen nicht vermengt wird mit den Hölzern, die die Sangiang aus ihren Dörfern mitbringen. Es sind also die Sangiang, die die Handlung vornehmen, denn der Mensch kann aus sich selbst und mit seinen eigenen Mitteln nichts tun. Manjan ist ein wohlriechendes Harz, das ebenfalls als Räucherwerk verbrannt wird.

305, S. 452.

Die Wirksamkeit dieser Bestreichung liegt nicht in der „magischen Kraft des Blutes", denn an sich besitzt das Blut diese Eigenschaft nicht. Die Wirksamkeit liegt in der kosmologisch/totemistisch klassifizierenden Stellung des Huhnes, das mit dem Menschen verwandt ist. Das Huhn, und alle andern Haustiere, wurde von der Urmutter geboren bevor sie menschlichen Kindern das Leben schenkte. Es ist also der Bruder oder die Schwester des Menschen. Aus diesem Grunde besitzt sein Blut stellvertretenden Charakter (panggirih), weil es das gleiche ist wie das des Menschen. In diesem Opfer gibt sich der Mensch selbst hin, oder opfert sich selbst in seinem Stellvertreter, und nur durch diese Selbsthingabe und durch die Anerkennung des Unheiles und Todes, dem er verfallen ist, kann er sich in die Hände der Geister oder des Ranjing Mahatala Langit und der Tambon geben und von ihnen das neue Leben empfangen.

306, S. 453.

Supak ist ein von der Schale einer Kokosnuss gemachtes Mass (die Kokosnuss wird in der Mitte durchschnitten). Acht supak ergeben einen gantang. 
307, S. 453.

Der gantang ist ein Mass von Eisenholz mit dem der Reis ausgemessen wird. Er enthält etwa 3 Kilogramm Reis.

308, S. 453.

Siam ist ein grosser, schwarzer Wassertopf, etwas grösser und bauchiger als die heiligen Töpfe.

309, S. 453.

Bateran (Kahaian: blanai) ist ein grosser, irdener Wassertopf.

310, S. 453.

Bukong ist ein grosser gelber Topf mit stark umgebogenem Rand. Die Bezeichnung Sambas weist daraufhin dass er aus dem Gebiete Sambas, wo man diese, und auch heilige Töpfe, fabrizierte, eingeführt wurde.

311, S. 459.

Kalawet ist ein Affe, eine Art des Orang Utan, aber kleiner als der gewöhnliche, der Leib schwärtzlich, der Hals weisz (Hardeland, W.B.).

312, S. 460.

Pamalusong ist abgeleitet von talusong oder katalusong, der Name für ein Harzlicht das aus feingestampftem Njating (Harz) besteht der in trockene Blätter gewickelt wurde. Pamalusong bedeutet dann: das mehrere Male Umwickeln, so wie man mit Blättern das feine Harz umwickelt.

313, S. 461.

Pasok ist ein kleiner viereckiger, von Rotan geflochtener Korb.

314, S. 461.

Salipi, ein von Rotan geflochtener Korb, der was wie ein Buta (Rückenkorb) aussieht. Ipoh ist ein Rankengewächs.

315 , S. 461.

Tamiang ist der Name einer Art Bambus, der ziemlich dünn bleibt und sehr lange Glieder hat. Die Farbe ist schwarz-grau. Er ist sehr rauh und scharf, sodass die Dajak ihn gebrauchen um Holzwerk zu feilen. 
316, S. 462.

Pimping tingang ist eine Schlingpflanze. Es ist möglich, dass man von ihr die pimping macht, d.h. die kleinen Trichter von sehr leichtem Holze, welche man an Ende der Pfeile befestigt, die man durch die Blaserohre bläst, damit man besser blasen kann und damit sie ruhiger fliegen.

317, S. 464.

Der upon binji ist die Reismutter, die bei der Aussaat des Reises in der Mitte des Feldes aufgerichtet wird.

318, S. 465.

Manjawar: das Einwerfen der Reiskörner (meistens etwa fünf zusammen) in die tundang (die in die Erde gestochenen Löcher).

319, S. 465.

Panalatak, abgeleitet von dem Ngadjuwort talatak: der Federkiel in dem der feine Goldsand aufbewahrt wird.

320 , S. 468.

Taladjok, oder taludjok, oder talusok: die eben ausspriessenden Blätter der Palmen, Pisang etc., solange sie sich noch nicht recht entfaltet haben, sondern noch halb zusammengerollt in die Höhe stehen.

321, S. 470.

Mandong, bandong, habandong, marantep bedeutet: sich einen Frau nähern um mit ihr den Geschlechtsverkehr auszuüben. Sinau: der Gatte oder die Gattin, manjinau oder mahadjip hat die gleiche Bedeutung wie oben.

322, S. 470.

Rungon oder rungun, Name eines Baumes. Die Rinde wird in Ermangelung von Sirih statt des Sirih gekaut. Offenbar werden aus der Rinde oder aus dem $\mathrm{Holz}$ auch Flöten gemacht.

323, S. 470.

Patendo oder salampatei: der Gürtel des Orion (der sogenannte Jakobsstab). Wenn dieses Sternbild beim Dunkelwerden vertical, recht über dem Haupte steht, fängt man mit dem Reispflanzen an. Siehe auch die Arbeit von M. C. SchadÉE: De tijdrekening bij de Landak- 
Dajaks in de Westerafdeeling van Borneo. Bijdragen, Deel 69, 1913.

324, S. 471.

Gento ist ein kleines Messer, welches beim Ernten gebraucht wird; das Messer sitzt auf einem kleinen Holze, über welches quer der Stock hinläuft, an dem man es fasst, und zwar so fasst, dass das Messer quer von den Fingern her steht. Gute Abbildungen des Messers und auch der Handhaltung finden sich im dem Werke von Van Helsdingen : Daar werd wat groots verricht. Amsterdam 1941. Pag. 140 und 141.

\section{5 , S. 472.}

Karangking, ein von $\mathrm{Holz}$ und Blättermatten gemachter grosser Behälter, in dem der grösste Teil des geernteten Reises aufbewahrt wird. Diese Reisbehälter befinden sich da, wo man keine eigene Reisscheuer besitzt, im Haus. Gegenwärtig sieht man die Reisscheuern nur noch selten und in den meisten Dörfern wird der Reis im Hause aufbewahrt.

\section{6, S. 472.}

Kalalusong ist das B.S. Wort für lusok: der runde Reisbehälter, der von Blättermatten gemacht wird und bedeutend kleiner ist als der karangking.

327, S. 472.

Karawang oder kahempang ist die Leiche, das Aas, die abgeworfene Haut einer Schlange. Hier wird der Ausdruck gebraucht für die leeren Reiskörner oder die Spreu des Reises.

328, S. 479.

Djangkau: Blumen oder feingeschnittene wohlriechende Blätter, die man zwischen die Haare legt und in sie einflicht. Timang: das schöne, zärtliche Namen geben; das zärtlich genannt werden. Hieher gehört auch der Ausdruck kambang: die Blume, die Blüte. Kambang oder kambangan bedeutet auch: der Anfang des Sprechens oder einer Rede (welcher bei den Dajacken zugleich gewöhnlich scherzend, noch nicht recht auf den Gegenstand kommend, ist: captatio benevolentiae). Mit allen diesen Termen bezeichnet man auch die poetischen Redewer1dungen und Bilder in den Gesängen und Mythen. Sie kommen nur in der Basa Sangiang vor. 
329, S. 489.

Entas ist „eine von dem äusseren Baste gereinigte, und genau so mitten durchgehauene Kokos- oder Pinangnuss, dass die untere Hälfte den einen, die obere den andern Teil bildet. Sie werden gebraucht um zu mentas: um von den Götzen Antworten auf Fragen zu erhalten. Nachdem man die Frage getan, wirft man die an einander gehaltene, durchhauene Nuss auf die Erde. Fällt die obere Hälfte auf ihre platte, durchhauene Seite, dann bezeichnet das ,ja“, fällt aber die untere Hälfte auf die platte Seite dann bedeutet das „nein“. Fallen beide Hälften auf die platten oder auf die runden Seiten, dann sagt man: taloh mureh aku: die Geister spotten meiner und wirft weiter bis ein ja oder ein nein erfolgt". (Hardeland, W. B.).

Hier handelt es sich um zwei solche Schalen die als Waagschalen gebraucht werden und die wahrscheinlich mit Schnüren an einem Waagenarm befestigt sind, der die Form eines Nashornvogels besitzt.

330, S. 489.

Taradjo ist eine kleine Goldwaage. Das Wort bedeutet auch: die Erwägung, die Ueberlegung.

\section{1, S. 489.}

Kangkalingei abgeleitet von kangkalingen: der Schatten, das Schattenbild eines Gegenstandes oder einer Person, das Bildnis im Spiegel oder im Wasser.

\section{2, S. 492.}

Kalumit oder kakudang ist ein Gürtel von kleinen kupfernen oder messingenen Ringen, mit welchem die Frauen ihre Sarong um die I.enden festbinden. Bei den Ngadju sieht man diesen, etwa $20-30 \mathrm{~cm}$. breiten Gürtel nicht mehr, bei den Ot Danum noch sehr wenig, höchstens etwa bei Festen.

\section{3, S. 496.}

Der Sarg wird hier genannt: Boot des Tingang, weil er wie ein Nashornvogel geschnitzt ist. Er stellt auch das Banama Tingang (Nashornvogelboot) vor, das gleichbedeutend ist mit dem Banama Hintan (Edelsteinboot). Dieser Sarg ist also assoziiert mit der Oberwelt und mit der Stammhälfte, die den patrilinealen Aspekt der Gemeinschaft darstellt. Nebst dieser Sargform kennt man auch die der 
Wasserschlange und wir haben darin wahrscheinlich eine Gleichsetzung mit dem Banama Bulau (Goldboot) zu sehen. Dieser Sarg ist assoziiert mit der Unterwelt und auch mit der Stammhälfte, die den matrilinealen Aspekt der Gemeinschaft repräsentiert. Es ist anzunehmen, dass die Stammhälfte, die mit dem Nashornvogel (bungai) und der Oberwelt assoziiert war, den ersten Sarg brauchte, und die Stammhälfte, die mit der Wasserschlange (tambon) assoziiert war den zweiten Sarg verwendete. Damit wird der Tote an den Anfang der Welt- und Menschwerdung in der mythischen Vorzeit zurückversetzt, die an ihm wiederholt wird, denn er wird identifiziert, sei es mit dem Urvater (Manjamei Limut Garing Balua Unggom Tingang) oder mit der Urmutter (Putir Kahukup Bungking Garing). Siehe auch die Abbildung des Sarges, der die Wasserschlange darstellt. Leider fehlt der Kopf. Ich verweise aber auch auf die Illustrationen in meinem Werk: Der Totenkult der Ngadju Dajak.

334, S. 498.

Biro ist ein Palmitgewächs von dessen Blättern Matten geflochten werden.

335, S. 499.

Taberau bungai ist ein Schilfgewächs das dem Zuckerrohr ähnlich sieht. Vergl. auch Erklärung 299.

336, S. 500 .

Pisih oder pikis sind kleine chinesische Geldmünzen mit einem Loch in der Mitte. Sie werden in Borneo nicht als Münzen gebraucht, aber z.B. als Oesen bei den Schlafgardinen, um die Bindfaden, mit denen man die Gardinen auf- und ausspannt, hindurch zu ziehen. Vornämlich gebraucht man diese Pikis als Tenong, d.h. um die Götter um Rat zu fragen, und zum salampikis oder salampisih, zur Entscheidung einer Rechtssache, wenn die Aussagen der Zeugen nicht hinreichend sind. Man nimmt dann zwei solcher Pikis, lässt den einen im Feuer schwarz anlaufen, während man den andern scheuert bis er blinkt; beide werden dann in einen Topf voll wasser getan, welches durch Asche ganz trübe und undurchsichtig gemacht ist. Dann muss jeder der beiden Streitenden einen Pikis herausnehmen. Wer den schwarzen herausnahm, hat verloren, wer den weissen ergriff, hat gewonnen (W.B.). 
337, S. 500 .

Njampiang, abgeleitet von sampiang: die kleinen dreieckigen Wände, womit das Dach an beiden Seiten geschlossen wird. Siehe die Zeichnung des Hauses.

338, S. 500 .

Piak bedeutet in der Pataisprache: das Huhn. Piak lian: Name eines Vogels, eine Art Eule, ist etwas kleiner als eine Taube (W.B.). Man spricht auch von burong piak liau: der Vogel, das Huhn der Liau; manok piak liau: das Huhn der Liau und von tingang piak liau: so wird der Nashornvogel genannt der das Lanzengestell des Sanggaran bildet. Siehe die Zeichnung. Auch in der Oberwelt finden sich die burong piak liau. Johannes Salilah erzählt von ihnen: Auf dem Bukit Bunter gedeiht der Lunok Tangkadje (der Baum, der zur Reinigung dient). Hier hält auf ihrer Fahrt nach dem Totendorf die Lanting Samben an (das Halsbandfloss mit dem Tempon Telon, die Salumpok Liau Haring Kaharingan nach dem Totendorf führt). Auf dem Lunok Tangkadje haben sich Scharen von Burong piak liau niedergelassen. Tempon Telon entnimmt diesen Vögeln etwas Blut um damit die Liau $\mathrm{zu}$ bestreichen.

In unserer Stelle befinden sich die Burong piak liau auf dem Dach des Hauses der Liau in dem Totendorf. Was ist nun die Bedeutung dieser Burong piak liau? In der Beschreibung des Hauses haben wir seine religiöse Darstellung. Das Haus ist der Lebensbaum (Batang Garing Belom), der aus der Kopfbedeckung des Ranjing Mahatala Langit entstanden ist. Wir haben gesehen, dass von diesem Baum zwei mythische Vögel (Bawin Tingang und Tambarirang) die Früchte aufgepickt haben und dabei in Streit gerieten. Durch diesen Streit ist ein Teil der Welt und sind auch die ersten Menschen entstanden. Die Burong piak liau repräsentieren diese beiden mythischen Vögel. Die Erhöhungen auf dem Hausdach, auf denen sie stehen sind die Früchte des Baumes. Auf andern Zeichnungen sehen wir das deutlicher. Sie sind dort als Früchte dargestellt, auf die die Vögel, von zwei Seiten herfliegend, mit offenem Schnabel einpicken. Dass die Liau mit diesen Vögeln in Verbindung gebracht werden, hat wahrscheinlich die Bedeutung, dass sie in die mythische Urzeit zurückversetzt und direkt mit der Welt- und Menschwerdung in Verbindung gebracht werden, in dem Sinne, dass an ihnen die neue Menschwerdung vollzogen wird.

339, S. 506.

Sarajong ist ein Teil eines Saling Lamiang (Halsband von Achat- 
steinen), welcher hinten auf den Nacken kommt. Der vorn auf dem Hals und der Brust anliegende Teil besteht aus drei übereinanderliegenden Schnüren, der Sarajong aber nur aus einer Schnur. Die Pinangtrossen werden also mit einem Halsband verglichen.

340, S. 506.

Batiwong, abgeleitet von tizvong: ein Band von Rotan, welches man um die Griffe der Messer etc. flicht, damit sie nicht spleissen.

341, S. 507.

Kadjang sind von den Blättern der Ipahpalme geflochtene Matten, von denen man die Wände in den Häusern, die Dächer auf den Booten etc. macht. Das Wort steht hier für Ipah.

342, S. 507.

Tingkap sind kleine, sehr primitiv gebaute Hüttchen, die man meistens aufrichtet wenn man gezwungen ist im Walde zu übernachten. Man steckt ein paar Stäbe in die Erde und legt darüber einige kadjang (Matten). Auf der Erde breitet man Blätter aus und Hütte und Lager sind fertig.

343, S. 509.

Bungo wird das kleine runde Käppchen genannt das in die grossen Sonnenhüte eingeflochten wird, damit man sie richtig tragen kann.

344, S. 509.

Der tanggoi hentap ist ein grosser Hut, oben mit weissen Litzen besetzt. Er wird von den Witwen zum Zeichen ihrer Witwenschaft bis zum abgeschlossenen Tiwah getragen.

345, S. 510 .

Kambungan ist ein Geflecht von Blättern das die Form einer grossen Düte hat. Es ist mit Flechtwerk verziert. Man hängt diese Kambungan um die Opfer her, die den Djata dargebracht werden.

346, S. 511.

Uei andong (Andongrotan) ist eine besondere Art Rotan, die sehr zäh ist und zu Lanzenschäften gebraucht wird. 
347 , S. 511.

Maruang bedeutet: auf der einen Seite ausstehend, auf der andern Seite vertieft sein (convex und concav).

348, S. 511.

Lamiang selong sind durch einen Sangiang aus Blut verfertigte Achatsteine. Sie werden als glückbringend angesehen und in grossem Werte gehalten. Manjelong: solche Achatsteine machen. Beispiel: Balian te mait Sangiange, tau manjelong: die Balian wird besessen durch einen mächtigen Sangiang, sodass sie Selong machen kann. Die echten Achate sind also immer eine Gabe der Sangiang.

349, S. 515.

Bulan Indu Samben, Kalawet Baputi Batenong Garing. Die beiden wohnen, zusammen mit der Indu Sandoi, im Dorfe Tumbang Kapandjungan Mandjong, das am Eingang zu der ganzen Sangiangwelt liegt. Es sind auch Sangiang und sie begleiten den Mantir Mama Luhing auf seinen Reisen nach und von der Welt und nach und von den Dörfern der Sangiang. Der Kalawet Baputi Batenong Garing = der weisse Kalawet, der den Garing bedient, das heisst das Segel auf dem Boote des Mantir Mama Luhing. Der Segelmast wird Garing genannt und mit dem Lebensbaum gleichgestellt. Er wird auch als Lebensbaum dargestellt (Batang Garing Belom. Auf manchen Zeichnungen sieht man dann auch den weissen Kalawet auf dem Segelmast herumklettern). Die Bulan Indu Samben und die Indu Sandoi reisen ebenfalls im gleichen Boote mit um die Balianhandlungen auszuführen. In dem gleichen Ort liegt auch der talaga bangkan hanselan tingang (der Teich mit dem wahrhaftigen Oele des Nashornvogels). Von hier wird das Oel erbeten, das man bei den priesterlichen Handlungen nötig hat, und es wird vermischt mit dem Oel, das der Priester braucht und für die Handlungen mitbringt. Sein eigenes Oel wäre aber wirkungsund machtlos ohne das von hier erbetene Oel, denn der Mensch kann nichts tun, und seine Mittel helfen ihm nichts, sie werden ihm denn von den Sangiang selbst in die Hände gelegt. Das Nashornvogeloel ist assoziiert mit Ranjing Mahatala Langit und mit der Stammhälfte, die den patrilinealen Aspekt der Gemeinschaft repräsentiert. Ranjing Mahatala Langit gibt also dem Menschen selbst das Mittel in die Hand, das ihm Heil und Leben schenkt.

350, S. 519.

Rahasan nennt man die Pfähle, die man aufrichtet wenn man den 
Antang aufruft. Meistens werden zwei oder drei solchen Pfähle aufgerichtet. Jeder dieser Pfähle hat seine besondere Bedeutung. Der eine bedeutet z.B. Glück, der andere Unglück. Der Antang Ganan Tadjahan schwebt über einem dieser Pfähle und gibt dadurch die Antwort auf die an ihn gerichtete Frage. Mit diesen wichtigen Rahasan wird also auch der Stamm, oder ein Stammteil, oder ein Clan verglichen.

\section{1, S. 519.}

Ruang werden die verschiedenen Abteilungen des Hauses, die zwischen zwei Pfählen liegen, und auch die Kammern genannt. Die verschiedenen Abteilungen werden meistens von je einer Familie bewohnt.

\section{2, S. 523.}

Die in Erklärung 338 Burong piak liau genannten Vögel werden hier Tingang und Antang genannt. Die Bedeutung ist die gleiche wie sie in der genannten Erklärung bereits beschrieben wurde, nur werden die Vögel dort mit der Liau in Verbindung gebracht.

\section{3, S. 526.}

Tantamau ist der Name einer Wasserpflanze. Die roten Blätter, den Blättern der Kudjang ähnlich, stehen nur just mit der Spitze aus dem Wasser hervor; in den 3-4 grünen Früchten, von Gestalt und Grösse wie ein Hühnerei, sitzt ein dem Mohnsamen ähnlicher Same, welcher gern gegessen wird (W.B.).

\section{4, S. 530.}

Der pajong bulau: der goldene Schirm, wird bei den priesterlichen Handlungen gebraucht. Man stellt ihn auch als stilisierter Lebensbaum dar und wahrscheinlich wird er, nach den Zeichnungen zu urteilen, mit ihm in Verbindung gebracht. Mit dem Schirm (heute mit einem gewöhnlichen Sonnen- oder Regenschirm) bedeckt man z.B. auch den aufgebahrten Sarg. Unter dem Schirm trägt man beim Tiwah die Knochen des Verstorbenen. Unter einem Schirm gehen bei einer Hochzeit auch Bräutigam und Braut, eine Sitte die auch in der christlichen Gemeinde üblich ist.

355 , S. 530 .

Tumbak gandjur: eine Lanze. Das Eisen ist nicht sehr breit aber dick, bayonetartig (W.B.). 
356, S. 533.

Sababulun werden Staketen von Bambus genannt, der gelockt wurde, sodass die feinen, etwas zusammengerollten Fäden als Schmuck von den Stäben herunterhängen.

\section{7, S. 535.}

Bohol: der Knoten, der Knopf. Man spricht auch von dem bohol tahaseng: Knoten des Atems, bohol tahaseng bageto: der Knoten des Atems ist zerrissen, d.h. gestorben sein. Mombohol ist eine priesterliche Handlung für einen Kranken, um dessen Seele festzuknoten, damit er nicht sterbe. Die Balian oder Basir machen, unter dem Absingen von Texten, verschiedene Knöpfe in eine Schnur, die dann dem Kranken um die Handgelenke gebunden wird. Die Sangiang halten so seine Seele zurück.

\section{8, S. 536.}

Sandah ist nach Hardeland (W.B.) eine Sklavin des Tempon Telon, die unter den Sangiang die Rolle des Bajazzo und Eulenspiegels spielt. Nach mündlichen Mitteilungen ist es eine etwas linkische, $z u$ allen Streichen aufgelegte Sangiang, die auch bei der Geburt mithilft und über dem Leben des Säuglings wacht.

359, S. 537.

Lambong bulau, abgeleitet von malambong: ein grosses, schönes Staatsboot, in welchem vornehme Herren ausrudern. Es wird durch mehrere kleine davor gespannte Boote gezogen. Wahrscheinlich ist es das Prunkboot von Clanhäuptern, das übereinstimmt mit dem Banama Bulau.

360 , S. 537.

Tilai ist der Name eines Baumes der lange Schotenfrüchte trägt, die bis $1 \frac{1}{2}$ Fuss lang werden (W.B.).

361, S. 541.

Der loang ist der Botschafter, der im Auftrag eines Clan- oder Stammhauptes auftritt. Sandte früher ein solches Haupt einen Botschafter in ein anderes Dorf, dann übergab er ihm ein Beweisstück, 
aus dem man ersehen konnte in wessen Auftrag er auftrat. Dieses Beweisstück bestand meistens in dem Dolch, dem Schwert, dem Speer oder dem Kopftuch des Auftraggebers. Nachdem der Loang das Beweisstück vorgelegt hatte, teilte er seinen Auftrag mit. Das am meisten gebräuchliche Beweisstück, das man einem Loang mitgab war aber der salugi, ein Stück Bambus von etwa $40 \mathrm{~cm}$. Länge. Auf der einen Seite war es zugespitzt, auf der andern Seite war es mit einer Schnur versehen. In den Salugi schnitt man, übereinstimmend mit dem Auftrag, Kerbe ein. Ein Kerb bedeutete: besucht unser Dorf, wir haben wichtige Angelegenheiten zu besprechen, drei Kerbe bedeuteten: zieht für mich die Schulden ein, usw. Der Loang musste den Salugi immer vor Augen haben und überall wo er ging musste er ihn an seinen Auftrag erinnern. War man im Dorfe angekommen, wohin man gesandt worden war, dann wies man den Salugi vor und legitimierte sich damit als Loang. Bei der Mitteilung des Auftrages sprach man für den Salugi, nämlich : der Salugi spricht zu euch, der Salugi beauftragt euch usw.

\section{2 , S. 547.}

Apak ist ein dünne aber breite Leiste von $\mathrm{Holz}$ oder gesplisstem Bambus. Mapak: dünn und breit spleissen.

$362^{a}$, S. 547.

Gilit-ginting: immer dicht bei jemandem sein, ihm überall nachlaufen.

\section{3, S. 558.}

Balai lampar buno wird das Gestell genannt, das sich in jedem Hause über der Haustüre befindet und auf dem die Lanzen, Speere und Blaserohre aufbewahrt werden. Es dient also als zeitlicher Aufenthaltsort für die Sangiang.

\section{4, S. 568 .}

Ranggau sind Bäume welche alle Blätter verloren haben, sei es dass sie diese abgeworfen haben, oder dass sie vertrocknet und abgestorben sind. Rohong bedeutet dann in diesem Zusammenhang: der blätterlose Stamm. Auf den hohen Bergen gedeihen keine hohen Bäume und kein Laubholz mehr. Der Hochwald verschwindet und man findet nur noch Sträucher oder kurzes Nadelholz. 
365, S. 569.

Badjoko ist eine Seeschildkröte, 1-11/2 Fuss lang, schwärzlich mit gelber Brust. Sie wird gegessen.

366, S. 569.

Kelep, eine Schildkröte, eine Spanne lang und breit, fast rund. Der Rücken schwärzlich, die Brust gelblich. Lässt sich eine Kelep auf einem neuen Reisfelde sehen, so ist das ein böses Vorzeichen, welches anzeigt, dass der Besitzer des Feldes bald sterben, oder arm werden wird.

367, S. 571.

Pudjut menteng sind eine Art kambe (Gespenster). Sie haben menschliche Gestalt aber einen sehr platten Kopf. Sie sind sehr böse und pflegen die Menschen, welche sie im Walde treffen, zu verschlingen. In den Dörfern haben sie keine Macht Menschen zu töten, wohl aber sie krank zu machen. Die Krämpfe in der Brust, Asthma etc. kommt von ihnen.

368 , S. 571 .

Kariau bulau sind Gespenster, die die Grösse eines etwa sechsjährigen Kindes haben. Sie sind Untertanen des Pampahilep und leben im Walde. Sie stehlen den Jägern und denen die im Walde arbeiten oder Waldprodukte suchen, die Speisen und Gerätschaften, oder sie begegnen ihnen in der Gestalt eines Bekannten, bringen sie auf Irrwege und verschwinden dann plötzlich. Sie verbergen das Wild vor den Augen der Jäger, den Rotan und Bambus vor den Augen derer, welche Rotan schneiden wollen. Ist man nun beim Rotansuchen oder auf der Jagd nicht glücklich, so bringt man den Kariau Opfer, gewöhnlich Eier, auch Reis und Hühner, auf einem Antjak (flacher Opferkorb).

\section{9, S. 571.}

Kambe nennt man alle Arten von Gespenstern. Ihre eigentliche Gestalt ist die menschliche, aber hässlich und schrecklich gross, so dass sie über die Wipfel der Bäume hinausragen, sie können aber auch kleinere Gestalt, auch ganz andere Gestalt annehmen, z.B. die eines Tieres, besonders eines Hundes. Die Kambe djadin (oder wie sie auch genannt werden: die $D j i n$ ), mit sehr langen Händen und Füssen, leben im Wasser. Die andern Kambe leben auf der Erde, gewöhnlich in 
Zaubergebüschen (pahewan), oder an kleinen Flüssen. Hantuen (Hexen) und Zauberer werden nach ihrem Tode zu Kambe. Die Kambe haben keinen König, sie leben nur paarweise, Mann und Weib, beieinander. Sie fressen gern Menschenleichen und halten sich deshalb gern bei Gräbern auf. Lebende Menschen erschrecken sie gerne, werfen z.B. nach ihnen, doch ohne sie treffen zu wollen, tun ihnen aber sonst kein Leid, wenn man sie nämlich nicht beleidigt. Eine Beleidigung ist es z.B. wenn man Bäume in der Nähe ihres Wohnplatzes fällt, oder dort des Abends Fisch brät, dann rächen sie sich und verursachen die gajap kambe: Gürtelrose, erbarmen sich aber wieder wenn man ihnen Opfer bringt (besonders Hunde, aber auch Schweine und Hühner). Beim Reispflanzen verspricht man ihnen Opfer, wenn sie die Ratten etc. vom Felde abhalten wollen, so dass man gute Ernten hat.

Kambe Lemba Halawong Djela: Lemba Kambe, das seine Zunge als Kopftuch gebraucht.

\section{0, S. 571.}

Kamiak tandjong, abgeleitet von kangkamiak: böse Gespenster. Alle weiblichen Hantuen welche über dem Gebähren sterben, werden Kangkamiak. Als solche erscheinen sie entweder in der Gestalt eines Huhnes oder einer schönen Frau, aber mit sehr langen Nägeln, immer in Schwarz gekleidet. Sie sprechen dann auch, aber der Laut ihrer Stimme ist sonst der eines Huhnes oder eines jungen Hundes. Sie suchen in schwangere Frauen $z u$ fahren, und deren Gebähren zu hindern, man bringt ihnen in solchen Fällen Hühner zum Opfer. Auch suchen sie Männer an sich $z u$ locken welche sie dann töten (W.B.).

\section{1, S. 571.}

Das kalabawai oder kalawawai luwok ist ein in den Wäldern hausendes Gespenst, lässt sich nicht sehen, aber oft seine weinende Stimme hören (mambareai: weinen, davon auch der Name). Es ist bösartig, verursacht oft Krankheiten, besonders Tollheit (Geisteskrankheit).

\section{2, S. 572.}

Es werden hier die Namen verschiedener Wasserschlangen genannt. Wahrscheinlich handelt es sich immer um die gleiche Tambon in ihren verschiedenen Erscheinungsformen. Tambon lio: die RegenbogenTambon. Man sagt vom Regenbogen: der Regenbogen ist der Widerschein der Naga oder Tambon, wenn sie aus dem Meere auftaucht. 


\section{3, S. 572 .}

Tambon parukat: die Wasserschlange der Wurzeln. Die Wurzeln der Bäume ruhen in dem Leibe der Wasserschlange, ebenso wie man von einem Menschen sagt, dass er sich im Schnabel der Wasserschlange befinde, weil er auf der Erde lebt.

\section{4, S. 572 .}

Tambon pentet. Pentet ist der Name eines Fisches, welcher etwa so dick als ein Arm und zwei Fuss lang wird; er ist schwarz mit roten Flecken, die Brust gelb (W.B.). Wahrscheinlich handelt es sich um eine Wasserschlange die die gleichen Farben trägt, denn die Wasserschlange stellt man sich verschiedenfarbig vor, sie trägt die Farben, die mit ihr assoziiert sind (blau, grün, gelb, rot).

\section{6, S. 572.}

Die Bedeutung der beiden letzten Namen und ihre Beziehungen zu der Wasserschlange ist mir nicht deutlich.

\section{7, S. 574.}

Der Hauptbalian nimmt vor Beginn der Handlungen die Reiskörner, die den Seelenreis darstellen, und bindet sie in den Zipfel seines Kopftuches. Sobald der Sangiang in ihn eingefahren ist, ist er aber nicht mehr sich selbst, sondern es ist nun der Dohong Mama Tandang, der an seiner Stelle handelt. Dieser sammelt die Seelen der Getragenen, die gebüschelt herbeigebracht werden, ebenfalls in sein Kopftuch und vereinigt sie dort mit dem Seelenreis.

\section{8, S. 574.}

HaRdeLAND (W.B.) schreibt über hariten: ,geborsten (nur von Reiskörnern gebraucht). Bei einer Krankheit, welche nach der Meinung der Dajacken dadurch entsteht, dass böse Geister die hambarua, Seele des Kranken entführt haben, bindet man, wenn der Beschwörer die Seele des Kranken zurückholen will, sieben ganze Reiskörner in ein Tuch. Sind nach vollbrachter Beschwörung die Körner sämtlich oder doch teilweise hariten, so ist das ein Zeichen, dass die Seele zurückgekehrt ist, und der Kranke gesund werden wird".

Die Körner bersten nicht nur deshalb weil die Seele des Getragenen zurückgekehrt ist, die bei allen priesterlichen Handlungen zurückgeholt werden muss, sie bersten vor allem auch deshalb weil er beladen mit Penjang und Karuhei des Reichtums und dem Lebens- 
wasser zurückkehrt. Man unterscheidet verschiedene Formen des hariten, denn die Reiskörner werden nach der Rückkehr der Seelen genau untersucht.

Hariten:
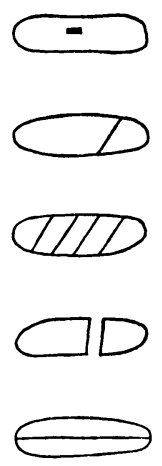

Name :

nanteloh (Eiform)

hariten (geborsten)

hariten are (oft geborsten)

hapontong (zerbrochen)

hariten hambudjur (der Länge nach geborsten)
Bedeutung :

gut

gut

ungünstig

schlecht

sehr schlecht

379, S. 597.

Tiwong ist ein Band von Rotan, welches man um die Griffe der Messer etc. flicht, damit sie nicht spleissen. Mit diesem Bande wird hier die Herzgrube verglichen.

380 , S. 598.

Maner: eingeschlafen sein (Arme oder Beine), dann auch überhaupt ein Gefühl, welches dem Gefühle eingeschlafener Glieder ähnlich ist, kein eigentlicher Schmerz, aber ein dumpfes, gelähmtes Gefühl.

381, S. 602 .

Gumi: Bart, Haare, Fühlfäden am Maule der Katzen, etc. (auch der Fische), Fühlhörner (der Insekten), die Endchen Bindfaden etc., welche noch über einen Knoten ausstehen.

382, S. 605.

Kungkong: ein Halsband, nur aus drei bis fünf lamiang (Achaten) bestehend. Ein vollständiges Halsband wird saling genannt.

383, S. 608.

Die Beschreibung gibt wahrscheinlich eine Darstellung des Ge- 
schlechtsverkehres zwischen dem Sangiang und der Balian, die dem Einfahren des Sangiang in die Balian vorangeht. Pasang danum njaho und lawang ganggerang bedeutet den weiblichen Schamteil. Marantep und mahadjip bedeutet: das sich zärtlich nähern und liebkosend anschmiegen an den Geschlechtspartner zur Ausübung des Geschlechtsverkehres. Saramin sina: der chinesische Spiegel. Diese Spiegel sind meistens bemalt mit einem verlockend aussehenden jungen Mädchen, das in sehr fragwürdiger Bekleidung und Haltung dargestellt wird. Kaju hewang bedeutet wahrscheinlich den männlichen Geschlechtsteil. Manjimpei penjang: die Ausübung des Geschlechtsaktes. Tuwe langit : der Samenerguss.

384, S. 609.

Der Palast des Fürsten wird mansigit genannt. Das Wort ist abgeleitet von mesigit: die Moschee. Auf den Zeichnungen werden die Wohnungen der höchsten Götter auch dargestellt wie eine Moschee. Der Name zeigt uns, dass der Ngadju dem mohammedanischen Sultanspalast (Karaton), den er natürlich von Martapura her kannte, die religiöse Stellung gegeben hat, die auch sein eigenes Haus besitzt.

385, S. 619.

Diese Perlen, die um das Handgelenk getragen werden, werden mit ihrem Namen direkt assoziiert mit der Tambon und Unterwelt, und sind also auch assoziiert mit der Stammhälfte, die den matrilinealen Aspekt der Gemeinschaft darstellt.

386, S. 619.

Die Reinigung der Verwandten des Toten ist keine magische Handlung die der machterfüllte Priester mit machterfüllten Mitteln vornimmt. Die Reinigung geschieht durch die Sangiang selbst mit Mitteln, die sie aus ihren Dörfern mitgebracht haben und die ihre Bedeutung darin finden, dass sie kosmologisch/totemistisch klassifiziert sind und entweder Stellvertreter oder die Gaben der Tambon oder des Ranjing Mahatala Langit sind zur Erlösung des Menschen, der sich aus seinem Unheil nicht mehr selbst zu befreien vermag. Bei der Aufzählung des Ruhmes und des Reichtums die dem Gereinigten zuteil werden sollen, handelt es sich natürlich nicht um eine egoistische Haltung und Selbstbehauptung des Menschen, die rein materiell/diesseitig orientiert wäre (eine Interpretation des Heiden, die wir oft hören). Der Reichtum, den man sich erwirbt, hat keinen Selbstzweck und dient nicht in erster 
Linie dazu, dass man berühmt und machtvoll werde, der Ruhm dient dazu, dass man sich leicht Reichtum erwerben könne und der Reichtum dient ausschliesslich dazu, dass man rasch das Tiwah (Totenfest) veranstalten könne um so das Heil und den Frieden des Kosmos, des Stammes und damit auch des Individuums, aufzurichten, die, wie der Reichtum selbst, Gabe und Tat der Oberwelt und Unterwelt beiden, durch Vermittlung der Sangiang, sind. Die Erwerbung des Reichtums hat also einen religiösen Hintergrund und dient ausschliesslich zur Erfüllung der religiösen Pflichten.

387, S. 631.

Tadjor: der Zwirn in einer Nadel, das eingefädelt werden.

388, S. 634.

Tingak liau: die Ermahnung, Erinnerung durch eine Liau. Es ist pali von einer Liau zu sprechen, spricht man doch von ihr, dann wird man von der Liau ermahnt und diese Ermahnung besteht in sehr heftigen Kopfschmerzen.

389, S. 639.

Tambok oder sumbol ist ein kleiner viereckiger Rotankorb mit einem Deckel in dem vor allem Pusaka (heilige Erbstücke), Penjang, Karuhei, Achate und dergleichen aufbewahrt werden.

390, S. 652.

Bakam supo (oder supu) wird ein kleines porzellanes Töpfchen genannt, in dem wohlriechendes Oel, oder auch heilbringendes Oel, das man von den Sangiang empfangen hat, aufbewahrt wird.

Tatamba panjangka: die stützende Medizin. Ein Oel, das von einem Tabit (Priester der sich hauptsächlich mohammedanischen Mittel bedient) besprochen worden ist. Man bestreicht sich mit diesem Oel bei Kopfschmerzen, Fieber und andern leichteren Erkrankungen.

391, S. 653.

Rengge: ein ungefähr hundert Fuss langes aber nur etwa drei Fuss breites Netz mit sehr grossen Maschen. Man sperrt kleinere Flüsse damit ab, und jagt dann von oberhalb die Fische gegen dieses Netz an, welche in den Maschen desselben hängen bleiben.

Haup: ein sackartiges Fischnetz, fünf bis sieben Fuss breit und etwa fünf Fuss lang. An der Oeffnung befinden sich zwei Hölzer, mittelst 
welcher man das Haup öffnen und schliessen kann. In einem kleinen Boot des Nachts langsam den Fluss abtreibend, hält man das Haup geöffnet ins Wasser, sobald man fühlt, dass ein Fisch darin sitzt, schliesst man es.

Hantai oder auch humbing: ein Fischnetz, etwa acht Fuss lang. An der etwa fünf Fuss breiten Oeffnung wird es durch ein Holz auseinandergehalten. Man gebraucht es des Nachts und stellt es in einem Flüsslein auf. Sobald man merkt, dass Fische hineingeraten sind, zieht man es in die Höhe.

Bowo ist eine von Rotan geflochtene Fischreuse. Man kennt kleine Bowo, die etwa $80 \mathrm{~cm}$. bis einen Meter lang sind, aber man hat auch die grossen Bowo die bis zu drei Meter lang sind und einen Durchmesser von etwa $1,80 \mathrm{~m}$ besitzen.

Pasat: ein grosses viereckiges Fischnetz. Mitten in dem Netz ist ein Stück Blei befestigt, welches das Netz niederzieht. Von den vier Ecken gehen Stricke nach einer Stange, mittelst welcher man das Pasat ins Wasser lässt und wieder herauszieht.

Pisi: Angel, Fischangel (pisi nennt man sowohl die eigentliche Fischangel, als auch die ganze Angelrute (tantahan: Stock, tali: die Schnur und pisi: die Angel). Es gibt verschiedene Arten von Pisi, z.B. bandjur, rawai, sakang, tadjua, taut.

Taut, oder pisi taut: eine grosse Angel, wird gebraucht um grosse Fische $\mathrm{zu}$ fangen.

Harus: ein Strick, an welchen man viele Fischangeln mit Ködern bindet, und ihn dann im Fluss wirft. Der Strick mit den Angeln daran heisst rawai, der Strick allein heisst harus rawai. (Nach W.B.).

\section{2, S. 677.}

Karikar, von rikar: ein von Rotan geflochtener Korb, worin man Teller etc. birgt.

Sulat oder saloang: ein von Rotan geflochtenes, oder auch ein eisernes oder kupfernes Band, welches um etwas gelegt oder geflochten wird (z.B. um den Schnabel eines Bootes, um einen Messergriff, um das Ende eines Lanzenschaftes etc.) um das Spleissen zu verhindern. Auch an der Türe befinden sich solche Saloang, um das Querholz, mit welchem man die Türe verschliesst, hindurch zu stecken.

\section{3, S. 696.}

Tarikajun wird die untere Seite des Daches, zwischen Dach und Haustüre (an der äusseren Seite des Hauses) genannt. Dort befindet 
sich der Anlegeplatz für das Schildbrett. Dort werden auch die Abwehrmittel aufgehängt um den bösen Geistern das Anlegen beim Haus und das Betreten des Hauses zu verunmöglichen.

394, S. 698.

Karamunting: ein Strauchgewächs, trägt kleine, schwarze, essbare Beeren. Die gestampften Blätter legt man als Heilmittel auf die Wunden. Mit den Blüten bestreut man den Reis, den man den Geistern opfert.

Kandujong oder kalandujong: ein Strauchgewächs. Man kaut den Bast in Ermangelung von Tabak oder Sirih.

395, S. 698.

Entas: die beiden kleinen Kokosschalen der Goldwaage. Siehe auch Erklärung 329.

396, S. 709.

Naning: eine Art Wespe, etwas grösser als eine Biene, kurz aber dick von Gestalt, hellgelb von Farbe.

397, S. 720.

Für die Liau ist ailes verkehrt. HardeLAND (W.B.) schreibt: „Die Liau sprechen im lewu liau dieselbe Sprache wie hier, jedoch so, dass die Bedeutung der einzelnen Wörter sich dort gerade in das Gegenteil verkehrt, dass z.B. süss dort bitter, und bitter dort süss bedeutet. Mendeng (stehen) bedeutet dort menter (liegen), und umgekehrt. Davon kommt das Wort haliau: heuchlerisch, anders sprechen als man es meint. Kaliau: die Heuchelei".

398, S. 722.

Tunding: das bemalt sein (einer Leiche). Manunding, hatunding dengan: eine Leiche bemalen. Allen Leichen werden sieben rote Punkte in einer Reihe auf die Stirne, und je ein roter Punkt auf alle Nägel an Händen und Füssen gemalt. Statt der Bemalung legen Reiche auch Goldplättchen auf diese Stellen der Leiche. (Nach W.B.).
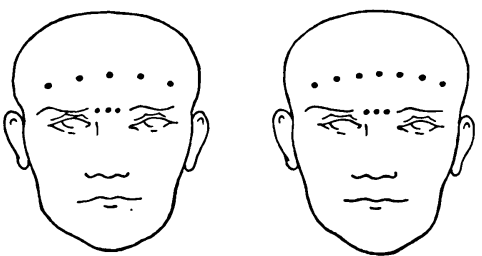

Am Katingan ist die Bemalung etwas anders. Siehe die Abbildung. 
399, S. 724.

Die Wassertiefe des Mondes. Die Kokosschale repräsentiert die Wassertiefe des Mondes, oder die Wassertiefe der Frauen. Sie scheint den weiblichen Geschlechtsteil darzustellen und findet sich in dieser Form auch mehr. Die weiblichen Masken binden sich z.B. bei ihrem Auftreten Kokosschalen um den Unterleib, die ihren Geschlechtsteil vergrössert darstellen soll. Unter dem Sawang: dort befinden sich nach den Zeichnungen des Dorfes, das dem Toten mitgegeben wird, nicht nur die Wassertiefe des Mondes, sondern unter die Sawang des Dorfheiligtumes (Pataho) legt man auch die Kokosnüsse bis sie ausgesprossen sind und dann verpflanzt werden können. Die Wassertiefe selbst stellt wahrscheinlich das Urwasser dar.

400, S. 725.

Die Leber der Opfertiere, die von dem Priester genau untersucht wird, stellt die verschiedenen Abteilungen des Dorfes dar, dann wenn das Opfer von der ganzen Gemeinschaft dargebracht wird. Wird ein Opfer aber von einer Hausgemeinschaft dargebracht, dann stellt die Leber das Haus mit seinen verschiedenen Abteilungen, die von den einzelnen Familien bewohnt werden, dar. Die Leberschau ist eine Wissenschaft für sich, die wir hier nicht darstellen können.

401, S. 728.

Man spricht meistens von sieben Seelen des Menschen, aber man unterscheidet streng genommen nur zwischen dem Geist des Menschen und dem Leib. Die andern fünf Seelen, die meistens mit Körperteilen oder mit Eigenschaften assoziiert sind, gehören nicht zum Geist, sondern zum Leib.

402, S. 739.

Njangkiat, abgeleitet von sangkiat: der Strick, den man um die Füsse legt als Hülfsmittel beim Erklettern der Bäume.

403, S. 741.

Kereus: unten mit Federn umbundene Hölzer, womit man im Baputan (Blasebalg) Wind hervorbringt. Mangewus: die Kewus im Baputan auf- und niederstossen (also Wind machen). Kakewus: sanft wehen (der Wind), langsam, säuselnd aufsteigen (der Rauch). (W.B.) 
404, S. 741.

Pasiong oder basiong: ein Stück Bambus mit dem man das Feuer anbläst.

\section{5, S. 748.}

Die teuersten heiligen Töpfe sind von dem Ueberrest der Erde hergestellt mit dem der Mond gemacht wurde. Hardeland (W.B. unter radja) teilt davon ein Mythenfragment mit, das wir hier wiedergeben. Er schreibt: „Radjapait (der König von Madjapait). Madjapait war bekanntlich ein grosses Reich im Osten von Java. Die Dajacken wissen aber nur von einem Radjapait, von welchem sie gar viel zu erzählen wissen. Eine dieser Erzählungen lautet: Einst hatte Radjapait im Spiele alle seine Schätze und Länder verloren. Da erbarmt sich Mahatara (Ranjing Mahatala Langit) seiner und sendet den Kadjangga Bulan (den Herrn des Mondes) zu ihm. Dieser verspricht ihm Hülfe unter der Bedingung, dass er ihm seine Tochter zur Frau gebe. Nachdem er sieben Tage mit ihr gelebt, geht der Kadjangga bulan dann mitten auf Java auf einen hohen Berg, welcher von sechs andern kleineren Bergen umgeben ist. Er hatte eine Portion Erde mitgenommen, den Ueberrest der Erde, von welcher Mahatara früher den Mond gemacht hatte. Von dieser Erde machte Kadjangga sieben Tage lang Blanga und andere heilige Töpfe, Karis (Dolche) etc., bis alle die umherstehenden sechs Berge voll davon standen. Den Ueberrest der Erde säte er auf den siebenten Berg und rund um alle sieben Berge her; dieselbe wuchs auf zu herrlichem Reis und köstlichen Früchten. Kadjangga zu seiner Frau zurückkehrend erzählte ihr, was er getan hatte, und befahl ihr mit ihrem Vater und vielen Arbeitern dorthin zu gehen und einen Zaun um die sieben Berge her zu machen; sie müssten aber die grösste Stille beobachten, bis der Zaun vollendet sei. Darauf kehrte der Kadjangga zum Monde zurück. Früh am andern Morgen ging Radjapait mit einer Menge Volks nun auch dorthin [d.h. zu den sieben Bergen], und man fing an den Zaun zu machen. Als es aber warm geworden war, wollte ein Teil der Arbeiter sich an den köstlichen Früchten erquicken, andere wollten das nicht zugeben, und so entstand ein lauter heftiger Zank. Augenblicklich sprangen alle die Blanga etc. in die Höhe, und eilten davon; und obwohl man sich nun aufs äusserste beeilte um den Zaun zu vollenden, waren doch nur drei Berge voll von den heiligen Sachen zurückgeblieben, die andern drei Berge voll waren schon fort. Jedoch war auch der Rest hinreichend, um den Radjapait wieder unermesslich reich zu machen. Die wegge- 
laufenen sind nun eben die heiligen Töpfe, welche man jetzt noch unter den Dajacken hat".

Wir verweisen hier auch auf die Mythe von der Entstehung der Sonnen- und Mondfinsternis.

406, S. 754.

Ranggau: ein Baum, der seine Blätter abgeworfen hat und kahl dasteht.

407, S. 759.

Kamasan (Bandjaresisch) : ein Feinschmied, der Gold, Silber und Kupfer zu feinem Schmuck und schönen Geräten zu verarbeiten versteht.

408, S. 766.

Manas tasak lentup njahe. Manas: Perlen, tasak: Name einer Eidechse, njahe: der Bruder, die Schwester nennt ihren Bruder so. Es handelt sich also um Perlen, die ebenfalls totemistisch klassifiziert und mit der Eidechse assoziiert sind. Die Eidechse ist assoziiert mit der Lnterwelt und auch mit dem Stammteil, der den matrilinealen Aspekt der Gemeinschaft darstellt.

409, S. 767.

Bua endjong kalapean. Endjong bedeutet nach dem W.B.: „Früchte welche in der Geisterwelt wachsen und gegessen werden".

410, S. 784.

Der Dajak ist in der Aeusserung seiner Gefühle sehr zurückhaltend (die Aeusserung der innersten Gefühle und Bewegung betrachtet er als weichlich und weibisch!) und kennt vor allem nicht eine Dankbarkeit, die er in wortreicher Sprache zum Ausdruck bringen würde. In diesem, beinahe geschäftlichen Gespräche, ist aber jedes Wort von Bedeutung und drückt die ganze Dankbarkeit aus. Man hat von dem Dajak oft gesagt, dass er keine Dankbarkeit kenne, weil sein Sprachschatz kein Wort für Dank besitze, sondern dafür ein Lehnwort aus dem Malaiischen (tarimakasih) gebraucht werden müsse. Das ist natürlich absolut unrichtig. Der Dajak kennt die Dankbarkeit wie jeder andere Mensch auch, aber er äussert sie nicht in vielen Worten, sondern durch die Tat und durch seine ganze Haltung, die mehr Wert ist als viele Worte, die rasch ausgesprochen sind und womit man seine Pflicht getan zu haben glaubt. 
411, S. 797.

Kangkahem. HaRdeland schreibt unter kahem: Bakakahem oder kakahem: wenn man geheiratet, oder ein Totenfest gegeben, oder Gefahr drohende Dahiang (Vorzeichen) gehabt hat, setzt man sich in ein Boot, welches eine Balian dreimal mit dem darin sitzenden unter das Wasser taucht, während andere Balian mit Sawangblättern über dem Kopfe des im Boote sitzenden wehen, und gepulverten Damar (Harz) über seinem Kopfe verbrennen. Diese Prozedur nennt man: bakakahem. Nachdem die also gebadeten aus dem Wasser gestiegen sind, wird ihnen Reis auf den Kopf gestreut, welchen man durch Hühner abfressen lässt. Man hofft dadurch alles Unglück von dem Menschen zu verscheuchen".

Ein prinzipieller Unterschied zwischen dem Kangkahem und dem rituellen Bad (pampandoi), das mit kleinen Kindern oder auch mit Jungfrauen und Jünglingen nach dem Abschluss der Initiationszeremonien vorgenommen wird, besteht m.E. nicht. HardeLAND beschreibt das Bad der kleinen Kinder folgendermassen (die Beschreibung trifft auch zu auf das Bad nach dem Abschluss der Initiationszeremonien): Mampandoi anak: Kinder baden, ist eine abgöttische Ceremonie, welche nicht bei allen Dajacken, aber doch bei vielen Familien seit undenklichen Zeiten im Gebrauch ist, vielleicht also ein Ueberbleibsel der Wirksamheit katholischer Missionare, welche vor etwa 200 Jahren in Südborneo gearbeitet haben. [Hardeland irrt sich darin und kommt $z u$ dieser Feststellung wegen der grossen phänomenologischen Uebereinstimmung zwischen dem rituellen Bad der Dajak und der Tauf in der christlichen Gemeinde]. Es geschieht wenn das Kind $1 \frac{1}{2}$ bis 6 Jahre, oder auch noch älter ist. Des Abends zuvor schöpft man sieben Fässer voll Wasser in einen Topf, und stellt daneben drei Mass Reis, nebst einem Rotan, welcher ein Klafter, eine Elle, eine Spanne und drei Fingerbreiten lang sein muss. Die Angehörigen des Kindes bewachen diese Sachen, während die Balian während der ganzen Nacht die Sangiang bitten, dass sie Danum kaharingan (Lebenswasser) von der Djata herbeiholen. Ist dann am Morgen das Wasser und der Reis um etwas vermehrt, und der Rotan etwas länger geworden, so ist das ein Zeichen, dass das Lebenswasser gebracht ist. Dann wird das Wasser in einen Gong getan, und mit Schweinsblut vermengt. Das Kind wird damit besprengt, und darauf auf dem Gong liegend nebst demselben in den Fluss untergetaucht. Ins Haus zurückkehrend muss das Kind auf ein getötetes Schwein treten, und sich dann von einem Huhne etwas Reis vom Kopfe picken lassen. Darauf wird 
das Kind mit Blut bestrichen, und es wird ihm ein Halsband umgebunden, welches es nicht wieder ablegen darf. Dann geht man ans Essen und Trinken. Man glaubt durch diese Taufe alles Unglück vom Kinde zu wehren, und ihm Glück zu bringen.

412, S. 805.

Oberkleid des Krokodiles. Wahrscheinlich hat Dohong Mama Tandang die Gestalt eines Krokodiles angenommen um für diese Handlung die Wasser der Djata aus den unterirdischen Quellen hervorsprudeln zu lassen. Nachdem er diese Arbeit vollendet hat legt er diese Hülle wieder ab. Hardeland schreibt über das Krokodil: „Die badjai (Krokodile) sind Sklaven der Djata. Sie haben menschliche Gestalt, und erscheinen als Krokodil verkleidet nur an der Oberwelt. Man bringt ihnen Opfer, und wagt sie durch Zauberer (pangareran) nur dann töten $z \mathfrak{u}$ lassen, wenn die Blutrache es fordert, wenn ein naher Verwandter durch sie getötet ist".

\section{3, S. 818.}

Taberau bungai (Erklärung 299) und pisang awai (awai: eine Pflanze, fast als eine Pisang, aber die Frucht ist bitter, nicht essbar. Die Kerne der Frucht trägt man als Perlen um den Hals) werden hier als zwei Beispiele genannt, dass dem Menschen nichts mehr gelingen wird, was er auch immer unternimmt. Alles was er gepflanzt hat, gleicht durchaus dem was er pflanzte, aber es ist wertlos und ungeniessbar. 


\section{Angeführte Literatur}

Adriani, N.: Verzamelde Geschriften. Drie deelen. Haarlem 1932.

Becker, J. F.: Von dem Gottesdienste auf Borneo. J.Rh.M. 18. 1847. S. 157-170.

Bertling, C. T. : „Hampatongs“ of „tempatongs“ van Borneo. I.O.N. XII. 1927/28. S. 131-141, 179-192, 223-236, 249-254.

Brandstetter, R.: Die Hymnen der dajakischen Tiwah-Feier. In Festschrift für P. W. Schmidt. Wien 1928.

- Die Kunst des Erzählens bei den Dayaken. Luzern 1930. (Nicht im Handel).

Cate, W. C. ten: De doodenpalen in de onderafdeeling Melawi. T.B.G. LXI. 1922. S. 201-222.

Eerde, J. C. van: Vingermutilatie in Centraal Nieuw-Guinea. T.K.A.G. Tweede Serie. Deel XXVIII. 1911. S. 49-65.

Encyclopaedie van Nederlandsch Oost-Indië. Tweede druk. 's-Gravenhage en Leiden 1917.

Fahrenfort, J. J.: Dynamisme en logies denken bij Natuurvolken. Groningen, Den Haag, Batavia 1933.

Fischer, H. Th.: Inleiding tot de Volkenkunde van Nederlands Indie. Haarlem 1940.

Grabowsky, F.: Ueber verschiedene weniger bekannte Opfergebräuche bei den Oloh Ngadju in Borneo. I.A.E. I. 1888.

- Der Tod, das Begräbnis, das Tiwah oder Todtenfest bei den Dajaken. I.A.E. II. 1889. S. 177-204.

Hardeland, A.: Versuch einer Grammatik der Dajackschen Sprache. Amsterdam 1858.

- Dajacksch-Deutsches Wörterbuch. Amsterdam 1859.

Helsdingen, W. H. van: Daar werd wat groots verricht. Amsterdam 1941.

Hien, H. A. van: De Javaansche geestenwereld. 4 Bände. Semarang 1896.

Hupe, C.: Over de godsdienst, zeden enz. der Dajakkers. T.N.I. VIII, 3. 1846. S. $127-172,245-280$.

Josselin de Jong, J. P. B. de: De oorsprong van den goddelijken bedrieger. Mededeelingen. Bd. 68. S. 1-29.

Juynboll, H. H.: Catalogus van 's Rijks Ethnographisch Museum. Borneo I./II. Leiden 1910.

Kruyt, A.: De West-Toradjas op Midden-Celebes. 4 Bände. Amsterdam 1938.

Kühnle-Degeler, R.: Aus der Mythologie eines Dajakstammes. E.M.M. Basel 1932. S. 247-251, 275-282, 307-314.

Kühr, E. L. M.: Schetsen uit Borneo's Westerafdeeling. Bijdragen. Deel XLVI. 1896. S. 63-88, 214-239; Deel XLVII. 1897. S. 57-82.

Leeuw. G. van der: Phänomenologie der Religion. Tübingen 1933.

Mallinckrodt, J.: Ethnografische mededeelingen over de Dajaks in de Onder- 
afdeeling Kapoeas. Bijdragen. Deel LXXX. S. 397-466, 521-600; Deel LXXXI. S. $61-115,165-310$.

- und L. Mallinckrodt-Djata: Het magah liau, een Dajaksche priesterzang. T.B.G. LXVIII. 1928. S. 292-346.

Mallinckrodt, J.: Het Adatrecht van Borneo. 2 Bände. Leiden 1928.

Münsterberger, W.: Ethnologische Studien an Indonesischen Schöpfungsmythen. Den Haag 1939.

Perelaer, M. T. H.: Ethnographische beschrijving der Dajaks. Zaltbommel 1870.

Rassers, W. H.: Over den zin van het Javaansche drama. Bijdragen. Deel LXXXI. 1925. S. 311-381.

Schadée, M. C. : De tijdrekening bij de Landak-Dajaks in de Westerafdeeling van Borneo. Bijdragen. Deel LXIX. 1914. S. 130-139.

Schärer, H.: Das Menschenopfer bei den Katinganern. T.B.G. LXXVIII. 1938. S. 536-578.

- Die Bedeutung des Menschenopfers im Dajakischen Totenkult. M.D.G.V. Nr. 10. Hamburg 1940. S. 3-30.

- Die Vorstellungen der Ober- und Unterwelt bei den Ngadju-Dajak von SüdBorneo. C.I. IV. 1942. S. 73-81.

Schwaner, C. A. L. M.: Borneo. 2 Bände. Amsterdam 1853.

Söderström, J.: Die rituellen Fingerverstümmelungen in der Südsee und in Australien. Z.E. LXX. 1938. S. 24-47.

Sundermann, H.: Dajakkische Fabeln und Erzählungen. Bijdragen. Deel LXVI. S. $169-214$.

Tillema, H. F.: Doodenpalen, Tiwah en lijkverbranding op Borneo. I.O.N. XVI. 1931/32. S. 131-157.

Tillmann, G.: De metalen bakken van Zuid-Sumatra en de dierenvoorstellingen op de z.g. Kroë-doeken. C.I. I. 1939. S. 16-19.

Veen, J. M. van: Nathan Söderblom. Proefschrift. Amsterdam 1940.

Wall, H. von de: Maleisch-Nederlandsch Woordenboek. Uitgegeven door H.N. van der Tuuk. Batavia 1880.

Wilken, G. A.: Het shamanisme bij de volken van den Indischen Archipel. Verspreide Geschriften, deel III. Semarang, Soerabaja, 's-Gravenhage 1912.

Wilkinson, R. J.: A Malay-English Dictionary. 2 Bände. Mythilene 1932.

Wirz, P.: Die Krankenbehandlung bei den Dajak des Siang-Landes. T.B.G. Deel LXVI. 1926. S. 240-258. 


\section{Abkürzungen}

Bijdragen: Bijdragen tot de Taal-, Land- en Volkenkunde van NederlandschIndië.

C.I. : Cultureel Indië.

Catalogus Borneo: Catalogus van 's Rijks Ethnographisch Museum. Borneo. Twee deelen. Leiden 1910.

E.M.M.: Evangelisches Missions Magazin.

E.N.O.I.: Encyclopaedie van Nederlandsch Oost-Indië. Tweede druk.

M.D.G.V.: Mitteilungsblatt der Deutschen Gesellschaft für Völkerkunde, Hamburg.

Mededeelingen: Mededeelingen der Koninklijke Akademie van Wetenschappen, Afdeeling Letterkunde, Serie B.

I.A.E.: Internationales Archiv für Ethnographie.

I.O.N.: Nederlandsch-Indië Oud en Nieuw.

J.Rh.M.: Jahresberichte der Rheinischen Mission.

T.B.G.: Tijdschrift voor Indische Taal-, Land- en Volkenkunde. Uitgegeven door het Bataviaasch Genootschap van Kunsten en Wetenschappen.

T.K.A.G.: Tijdschrift van het Koninklijk Nederlandsch Aardrijkskundig Genootschap.

T.N.I.: Tijdschrift voor Neerland's Indië. Batavia.

W.B.: Hardeland, A.: Dajacksch-Deutsches Wörterbuch. Amsterdam 1859.

Z.E. : Zeitschrift für Ethnologie. 


\section{N D E X}

\section{der in den Erklärungen (S. 831-958) erläuterten Dajak Wörter}

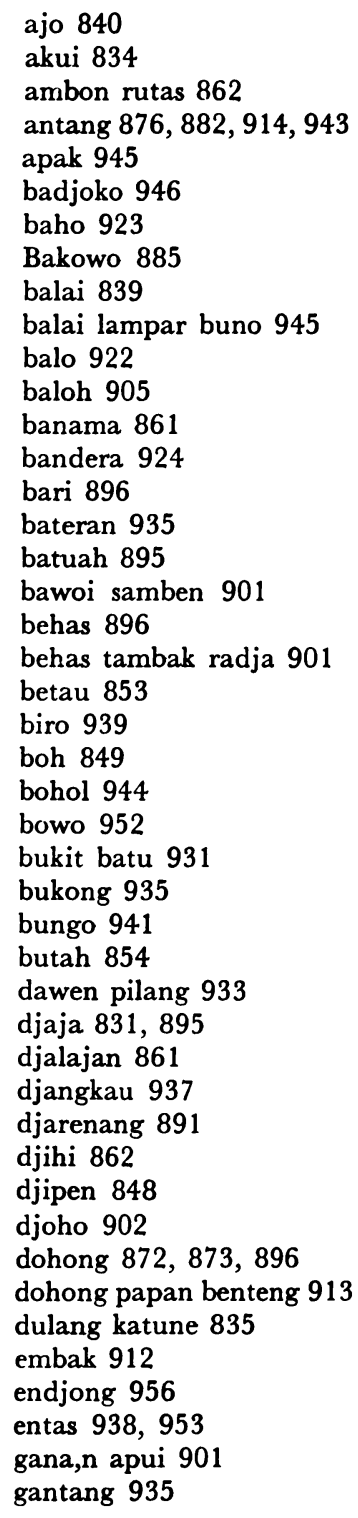

garo 934

gawi 833

gento 937

gilit-ginting 945

gumi 949

hadjandjalau 933

Hagalanggang 917

Halaluan 920

Halo,n puseh 873

hambaruan 842

hampahari 889

hamputut 897

hanggulan apui 860

hantai 952

hantimang 850

hantuen 850, 875, 947

hariten 948, 949

harus 952

has 835

hau 840

haup 951

hedjan 887

hirek 898

isi 932

kadjang 941

kadjang edan 914

kahempang 937

kajah 839

kakudang 938

kalabawai 947

kalalusong 937

kalapapa tandok 911

kalawet 935

kaliong 933

kalulus 861

kalumit 938

kamasan 956

kambang 937

kambe 946

kambe rawit 920

kambungan 941

kamiak tandjong 947

kandujong 953

kangkahem 957

kangkalingei 938 kangkamiak 886

kangkaput 845

karamunting 953

karamunting balo 911

karangking 937

karawang 937

kariau bulau 946

karikar 952

karis 872

karuhei 857

kasambuti 917

katiting 835

kelep 946

kewus 954

kudjang 882

kungkong 949

kuruk 919

labeho 887,894

laloh 915

lalohan 916

lambong bulau 944

lamiang selong 942

lampinak 891

lasang 861

laut 861

lawas 909

lehan 840

liau 842

lingo 856

lintong talawang 895

loang 944

lunok 872, 893, 894, 918

mait 895

mamanggar 923

mamanjong 921

mamedak 934

manangkadje andau 897

mandong 936

maner 949

mangalingo 910

mangarangkep 909

manitih 921

manjaki 898

manjawar 936

manundon 919 
marau 865

maruang 942

matei manak 890

miap pantan 911

mikau 917

naning 953

napatok 918

napugenggem 916

ngadju 861

ngawa 861

njalong bukit batu 918

njampiang 940

njarakumpang 906

njaring 843

njating 896

ontong 904, 922

pahuni 831

pajong bulau 943

pakarok 917

palas 924

pali 834,901

pali hinau 920

pamalusong 935

pambakal 860

panalatak 936

panamar 902

pangirak 860

panjangka 902

pantar 838

pantar pandjang 859

pantoh 912

parapat 902

parei 896

paria 902

pasat 952

pasiong 955

pasok 935

patendo 936

pehe atei 839

penang 909

penjang 865,870

piak 940

pikis 939

pimping tingang 936

pisau pepet 882

pisi 952

pisih 939

pondok apui 860

pudjut menteng 946 pulang 896

pulut 860

puron 933

radja 853

Radjapait 955

Radja Peres 839

rahasan 942

raho 879

ranggau 945, 956

ranjing pandereh buno 917

rengge 951

rewar 848

rohong 872,945

rowajang 888

ruang 943

rungon 936

rutas 862

sababulun 944

Sahor 928

salahawo 916

salampatei 936

salapandom 902

salatutup 902

salipi 935

saloang 878

salugi 945

salutup 925

sambelom 933

sampu 909

sandah 944

sangen 927

sanggaran 913, 917

sangiang 925

sangkalemo 895

sangkiat 954

santagi 893

sapalinda 918

sapundu 838

saragate 860

sarajong 940

sawang gagar 933

sendong 863

seso 860

sial 903

siam 935

singkah 915

siren 917

sulat 952

sumbol 951 sungkai 912

supak 934

supu 910,951

taberau 933

taberau bungai 939, 958

tadjahan 883

tadjor 951

taladjok 936

talampe 913

taludjok 936

talusok 936

tambalik angin 874

tambaran 932

tambarirang 872

tambok 951

tambon lio 947

tambon parukat 948

tambon pentet 948

tamiang 935

tampulak humbang 931

tandang 870

tangaring 933

tanggoi hentap 941

tantamau 943

tapas-tapas 870

taradjo 938

tarikajun 952

taut 952

tempon pampatei 933

tengang 838

teras 888

tilai 944

timang 937

tingang 865, 943

tingen 905

tingkap 941

tiwong 941, 949

tjeh 844

tujang 917

tulah 886

tumbak gandjur 943

tunding 953

tupai $\mathbf{8 7 0}$

tuwe 840,894

udjau 915

uei andong 941

Umang 836, 880

upo 905

upon binji 936

urai 889 


\section{KONINKLIJK INSTITUUT \\ VOOR TAAL, LAND- EN VOLKENKUNDE}

\section{VERHANDELINGEN}

34. H. Myron Bromley, The Phonology of Lower Grand Valley Dani. 1961.

35. J. C. Anceaux, The linguistic situation in the Islands of Yapen, Kurudu, Nau and Miosnum, New Guinea. 1961.

36. G. W. J. Drewes, De Biografie van een Minangkabausen Peperhandelaar in de Lampongs. 1961.

37. J. P. K. van Eechoud, Etnografie van de Kaowerawédj (Centraal Nieuw-Guinea). 1962.

38. Tapan Raychaudhuri, Jan Company in Coromandel, 1605-1960. 1962.

39. H. J. de Graaf, De regering van Sunan Mangku-Rat I Tegal-Wangi, Vorst van Mataram, 1646-1677. II Opstanding en ondergang. 1962.

40. C. Skinner, Sja'ir Perang Mengkasar (The Rhymed Chronicle of the Macassar War) by Entji' Amin. 1963.

41. Silvia $W$. de Groot, Van isolatie naar integratie. De Surinaamse Marrons en hun afstammelingen. Officiële documenten betreffende de Djoeka's (1845-1863). 1963.

42. P. Drabbe, Drie Asmat-dialecten. 1963.

43. S. J. Esser, De Uma-taal (West Midden-Celebes). Spraakkunstige schets en teksten. 1964.

44. J. C. Anceaux, The Nimboran Language. Phonology and Morphology. 1965.

45. H. van der Veen, The Merok Feast of the Sa'dan Toradja. 1965.

46. C. L. Voorhoeve, The Flamingo Bay Dialect of the Asmat Language. 1965.

47. H. K. J. Cowan, Grammar of the Sentani Language. 1965.

48. P. A. M. van der Stap, Outline of Dani Morphology. 1966.

49. H. van der Veen, The Sa'dan Toradja Chant for the Deceased. 1966.

50. Sartono Kartodirdjo, The Peasants' Revolt of Banten in 1888. 1966. 